B

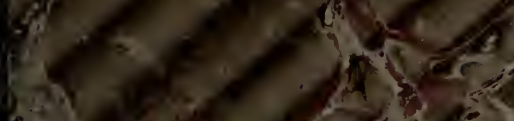

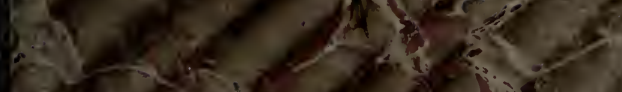

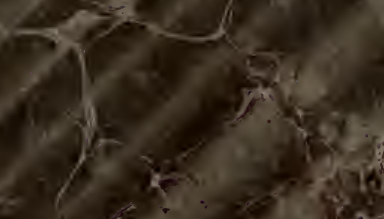

1

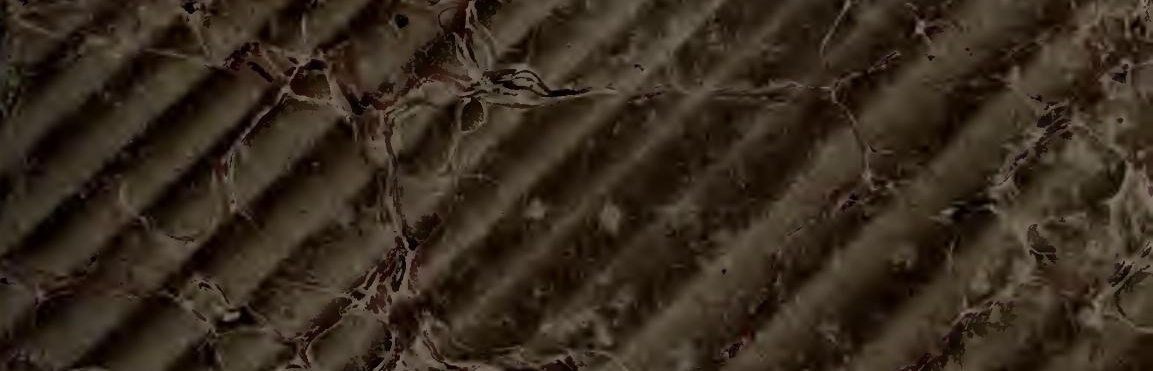

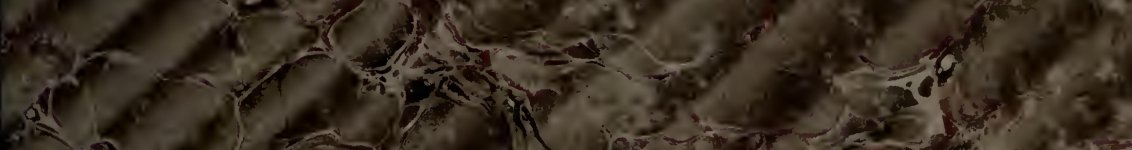

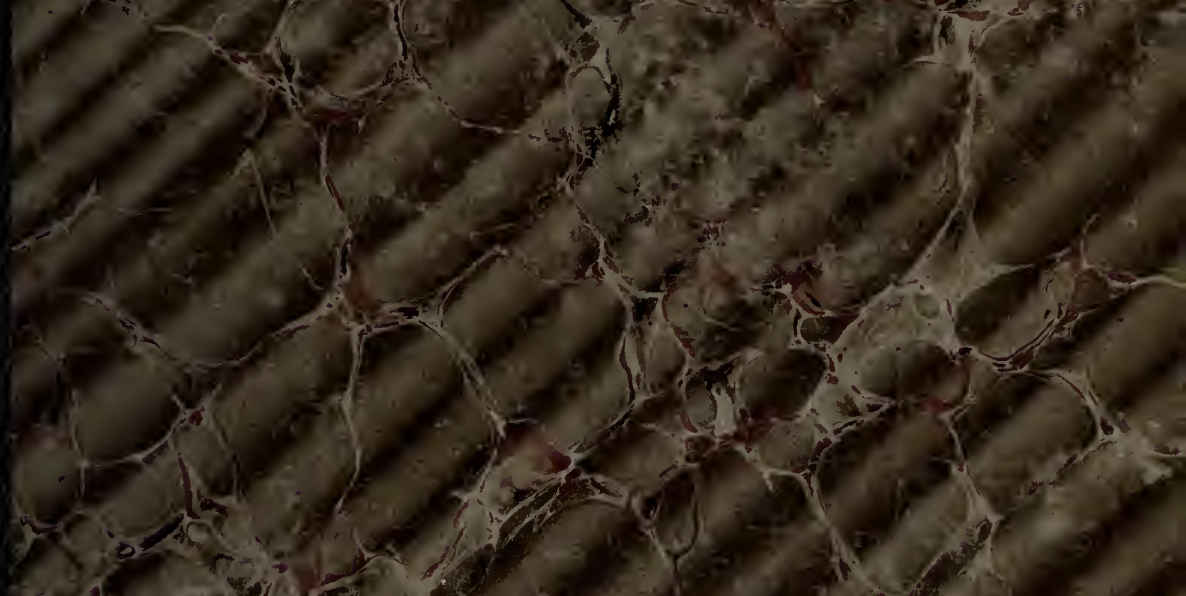
$\therefore$ (1)
(50.
(50.

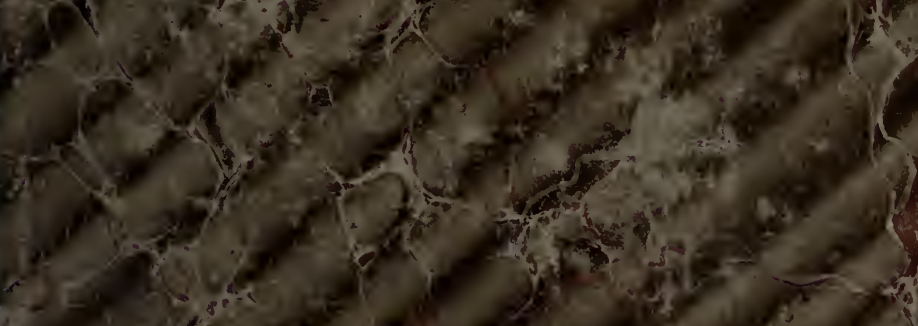

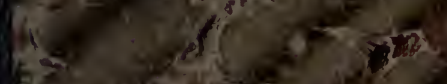

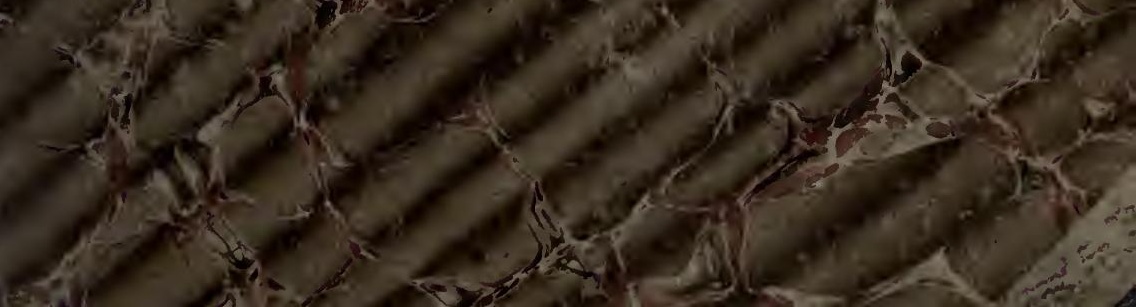



. 



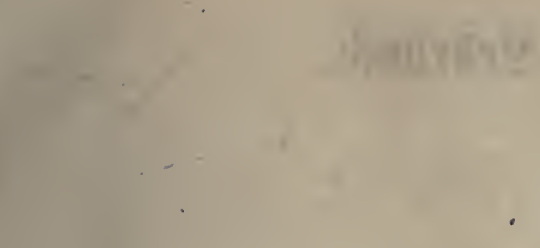

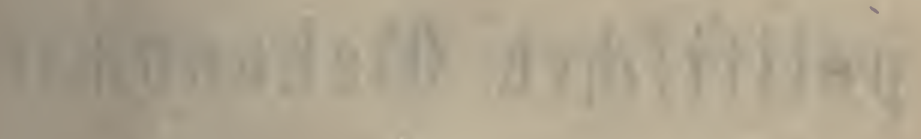

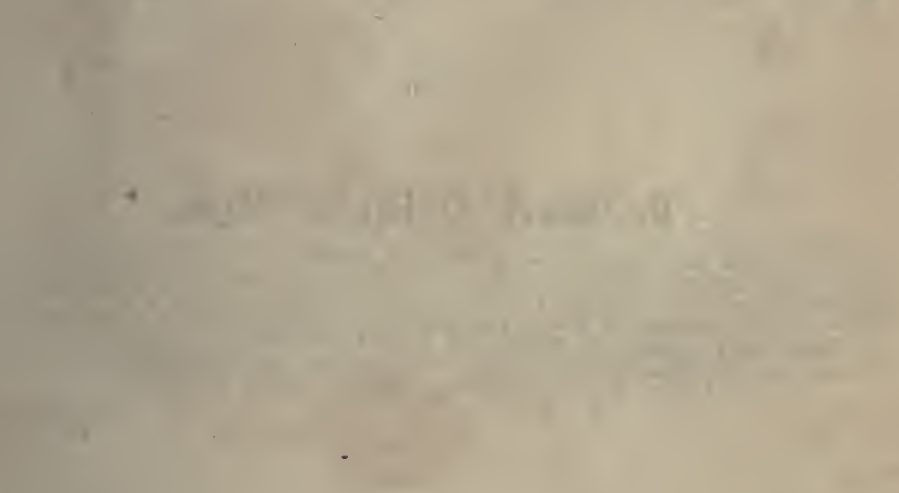

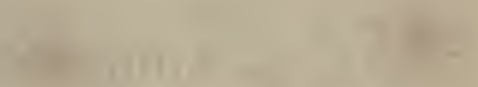

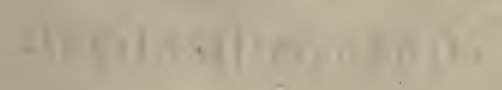

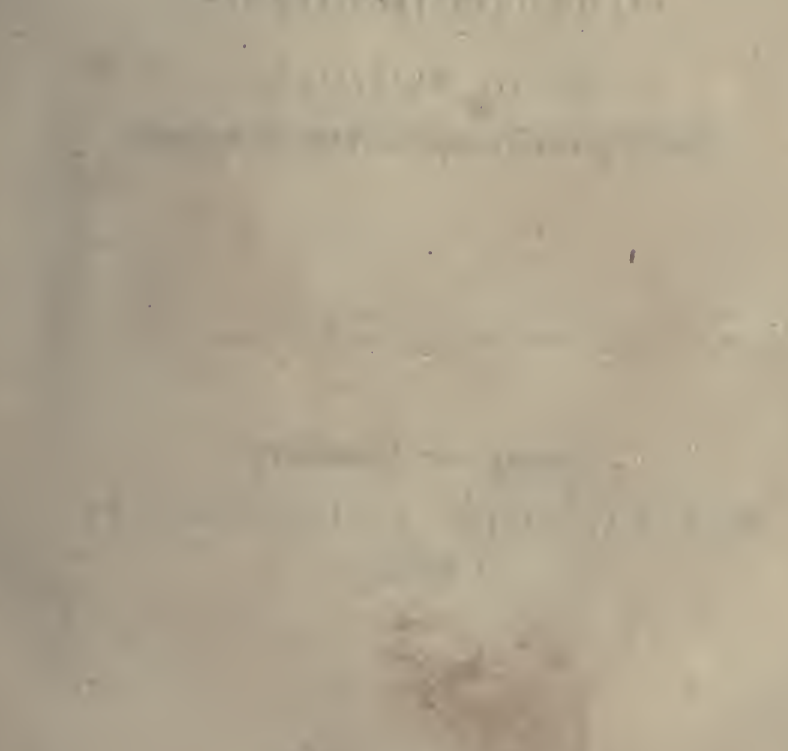




\section{Qeflytultid}

\section{"xr \\ politilden (1)ekonomite \\ von}

\section{Dr. Raxl Scciurich Pau,}

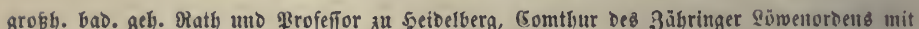

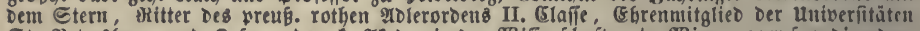

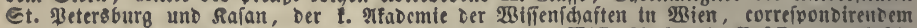

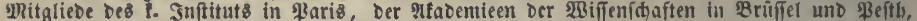

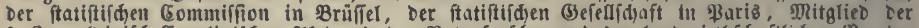

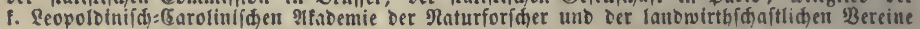

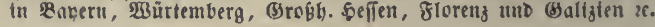

\section{Dritter $B$ and. \\ Sinanjmiffenfdjaft.}

3 weite 2 btheilung.

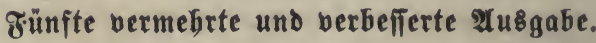

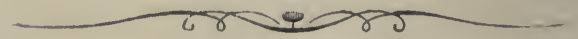

Lcipzig unb פeibelterg.

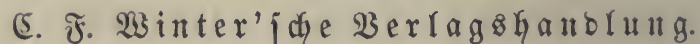




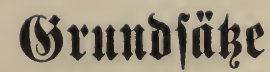

\section{ver

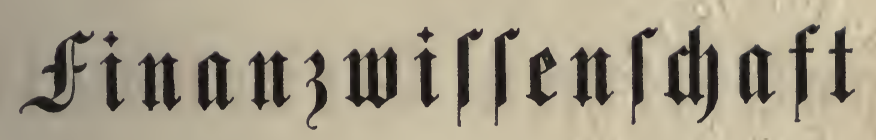

yon

\section{Dr. Raxl Sciurich Mau,}

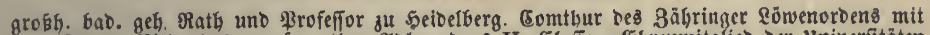

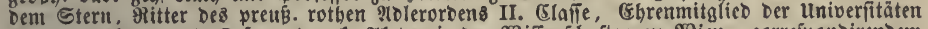

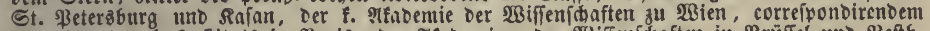

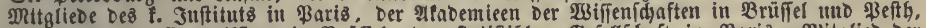

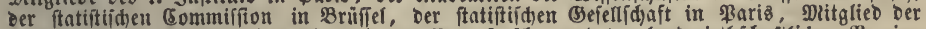

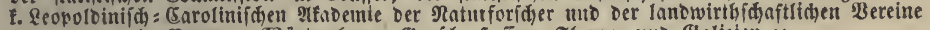
in Bayert, Wütemberg, (Sroßh. Selfen, Florettz und Balizten zc.

3 weite abtheilung.

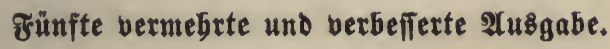

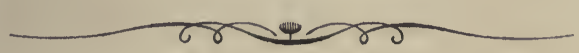

Seipzig utto seibelberg.

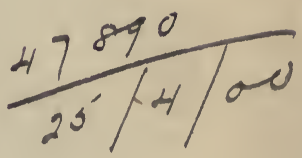

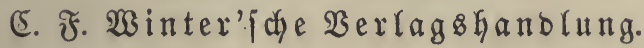

$$
1865 .
$$




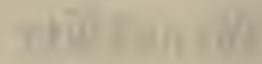

$+1$

$-1+1+2$

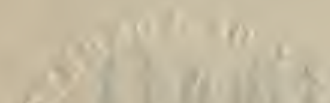

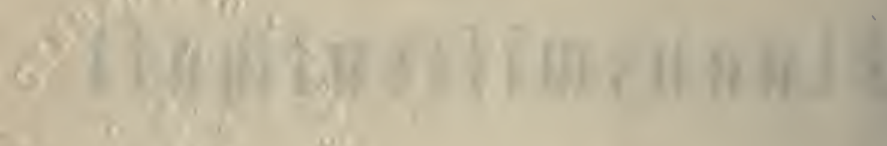

nom

s.

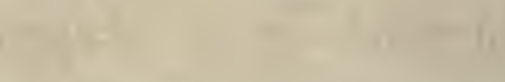

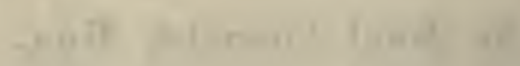$$
=
$$ 


\section{Đormort 3ut 5. Ausgande.}

2lud) in ber Bearbeitung biejer 2. Arftheifung hat jowohl

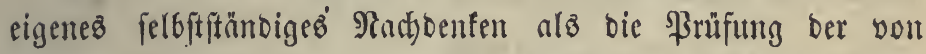
amberen Sdriftiftellern aufgeftellten Sehriäb̧e zu vielen $\mathfrak{B e r}=$ änberungen, bie id) für $\mathfrak{B e r b e f f e r u n g e n ~ h a l t e n ~ b a r f , ~ n a m e n t l i d ) ~}$

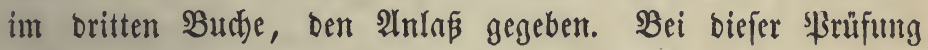
neuer $2 \mathfrak{n}$ nftchten war es mein Beftreben, jeben Fortictritt bes Biffents bereitwillig anzuerfenten und zu benuben, bem aber, was mir unbefriebigent fđjien, nur Esửnde entgegenzulę̧en. Manct)e Reuere Gaben eine 2lat ber \$olemif angenommen, bie weber gered)t, nod) für bie 2 Bifferifdaft frudtbringeno ift. - Die bald zur Ërläuterung, Gald zutr Beftätigung all=

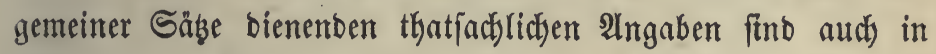

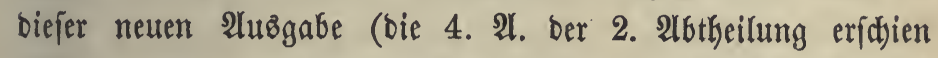
1860) vermefyrt uno fortgeführt worben, wobei id abermals für mandje fdjäbbare Mittheilung zu banfen babe. Bei ber

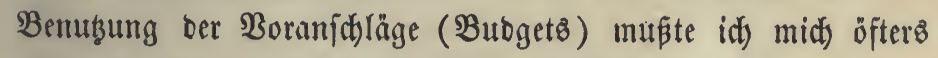
mit ben an bie ftänbifdjen Berfammlungen gebradten (Ent= würfen begnůgen, weil fie leidfter zu haben fint, alz bie genefmigten Bubgets, bie audh meiftens yon ienen nidjt viel abrweidyen. 
Rad) bent lę̧ten 2Ingaben foll bie Sd)uld ber norbamerica=

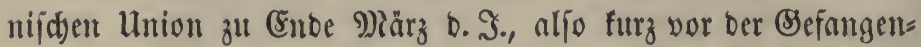
nehmung von \&ee, 2366.955000 D. getwejen fein, 3ins in Bold 64 Mitl., in \$sapiergelo 38.820000 Dodr.

Eime polnifate Ueberfę̧ung ber finangwifienfdaft von Dr. v. Dczapows $i$ ift unter ber Preffe.

Bei biefer (E) fung binzu. Wer in ber Rage ift, viele ftatiftifite 3ahlenangabent jul gebraudjen, ber wirb ben $\mathfrak{B} u$ unj) mit mir theilen, baß unfere Statiftifer burd)gehentos bei großen 3ahlen bie Milfionen umb Taujente im Druf femutlid) madjen mödten. 3ahlen you ficter umo adyt. Biffern okne eine Ibtheilung greifen nidyt

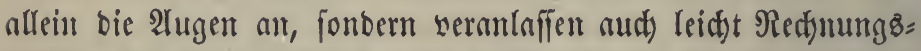
fehler bcim 3 ufammenzäblen uno 2tbzichen.

Secibelberg 27. April 1865 .

$\Re$. 


\section{$\mathfrak{I} \mathfrak{i} \mathfrak{h} \mathfrak{a} \mathfrak{l} \mathfrak{t}$.}

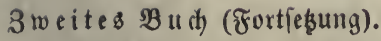

2. Abtheilung. Die einzelmen Arten von Steuern.

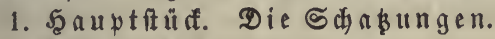
rinteitung, \&. 297-300

1. Atbfab. Brumbfteuer.

A. Allgemeine (Srunbfäk̨e, \$. 301-315 . . . 9

B. Inlegung ber Gruntftetter, \$. 316-338 . . 34

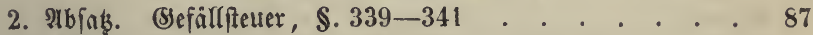

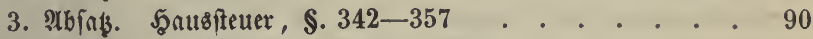

4. 26̧ą̧. Gewerbfteuer, \&. 358-376 . . . . . . 114

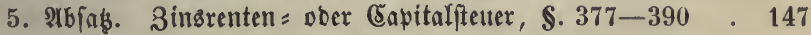

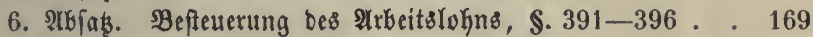

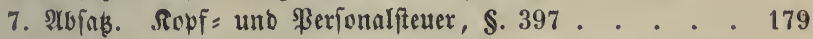

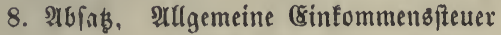

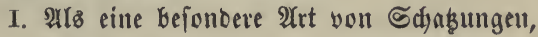

§. $398-400$ b . . . . . . . . . 183

II. शा's Inbegriff ber einzelnen Sdją̧ungen,

§. $401.401 \mathrm{~b}$. . . . . . . . . . 197

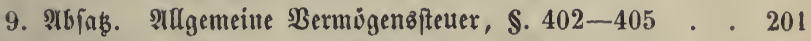

2. Sรa

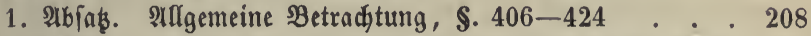

2. 2⿰亻

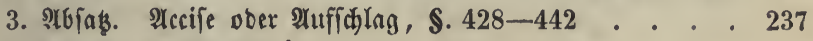

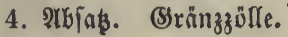

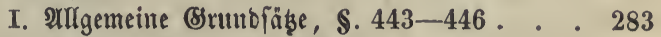

II. Ginzelne arten ber Bölle.
A. Einfuhrzölle, §. 447-453 . . . . 290
B. श्tusfuhrzölle, \$. 454-456 . . . . 300
C. Durdjgangżzille, S. 457 . . . . 303

III. Esinridgtung bes 3olfwejens, \$. 458-462 . 304 


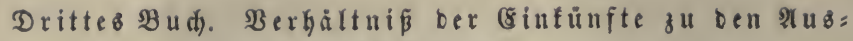
gaben bes Stantb.

I. Rb §. $463-170$

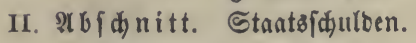

1. Abtheilung. Weien unb Wirfungen ber Staatbidulben, §. $471-484$

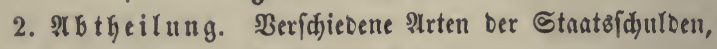

§. $485-506$. 354

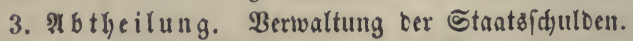

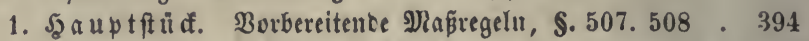

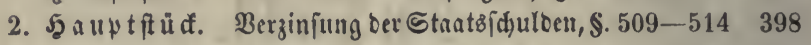

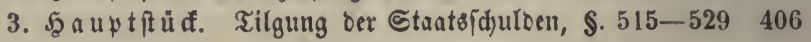

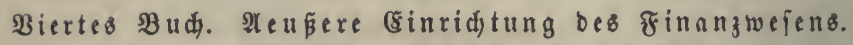

I. AB b a nitt. Behorben unb Remter im finanzweien, \$.530-537 443

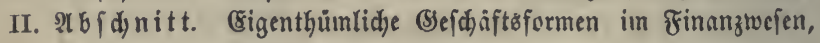
Einleitung, \$. 538 . . . . . .

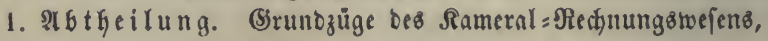
452 §. $539-560$ 453

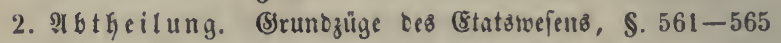

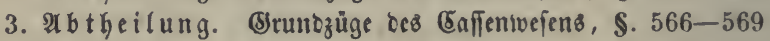
482 491 शnkang . 497

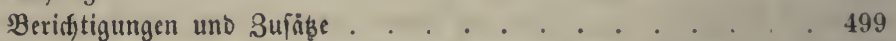
Regifter . . . . . . . . . . . . . 503 


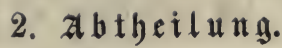

\section{Die einzelnen Arten von Steutu.}

1. Şa $\mathfrak{u}$ tffü

Die

Einleitung.

§. 297.

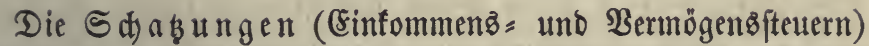
mad)en es ben Steuerbefjöroen nothwenbig, die Bermögenz= umftänoe ber eirizelnen,, Bürger foweit zu erforidyen, baß man die Steuerfähigfeit berfelben ermeffen und hiernad) ifre jährlidue Steuerfouldigfeit fefteken famn $(a)$. Die an jeben Einzelnen geridstete Steuterforberung ift baher unbebingt unb für ben, ber nicht feine 3ablungsunfähigfeit barzutthun vermag,

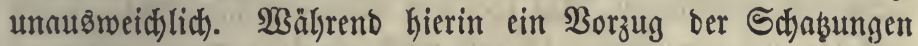
in $\mathfrak{B}$ ezug auf bie frefere (sinnahme bes Stants liegt, ift $b a=$ gegen bie 2lnlegung berjelben mit großen Sdywierigfeiten ver= bunben, bie aus ber verwidelten uno veränberlichen Bejđjaffen= heit ber Einfünfte unb aus ber Abneigung oer Steuerpflid)tigen entfpringen, igren Beftis und Erwerb funb werben zu lafien.

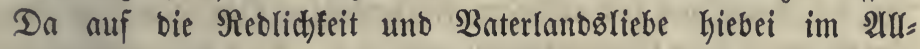
gemeinen nicht gemug zu bauen ift $(b)$, fo mus man fid) be jeber Schaşung nad) ben fitjerften äuferen, offenfunbigen Rennzeidien ber fteuerbaren (Sinfünfte ımfehen, auf bie Dutellen berfelben zurüfgeken unb bas Einfommen jeber Serfon, wenn es zufammengejebst ift, in feine Beftanbtheile auflöfen.

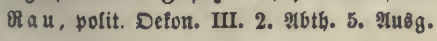


(a) Die birecten Steuern in Defterreich und ihre Reform, mit einem ab= gefonberten Şep̂te ftatiftifder Tafeln. Sgerausgegeben bom t. f. Finanz= minifterium. 203ie! 1860 for.

(b) Der Einzelne beforgt oft, Daß́, wenn er genaue Angaben madyen würbe,

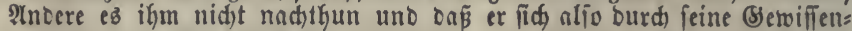
haftigfeit eine ftârfere Belaftung zuziehen werbe; Das Beifpiel ber un= reolidifeit ift anfecfeno uno es biloet fid leidst eine Prt ftillidymeigenter

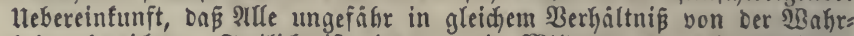
heit abweid)en. Freilid ift bies nur ein Milloerungs =, Eein (Entict)ul=

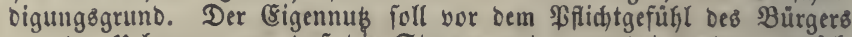
uno Der ueberzeugung, Dá bie Steuern gut verwendet werben, zurưf: weidben.

\section{§. 298.}

Wenn man berfudyen wollte, bic Sdjab̧ungen genau nadh ben Cinfünften anzulegen, bie jeber einzelne Bürger in jeoem 3eitabjchnitt (\$afr) wirflic) bezogen hat, fo würbe bics für Die Steuerpflicttigen überaus läftig, für bie Regierung mühfam und foftbar fein und bennod) nidjt gelingen, weil baz (Sin= fommen ber Steuerpflichtigen fehr beränberlich ift uno von vielen Umftänten abbängt, bie unmöglid) ganz erforfdyt werben fönnen. Dian mús fich) folglid) ber Bereinfadung willen mit einer foldyen 2 mnäherung an bie $\mathfrak{W a h r k e i t ~ b e g n u ̈ g e n , ~ d a ß ~ b i e ~}$ शbweid)ungen von biefer theilz fid) in nid)t langer 3cit aubs gleidjen, theils wenigftens mur eine unbebeutente Wirfung auf bie Steueriduldoigfeit ber Sinzelnen äupern, wozu bie Feft=

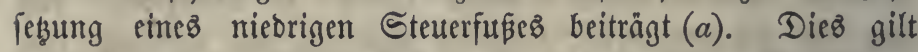

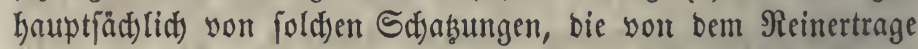
bleibenber $\mathfrak{B e r m o ̈ g e n z t h e i l e ~ e r b o b e n ~ u n o ~ n a d ) ~ b e r ~ B e j c h a f f e n t h e i t ~}$ ber leb̧teren angelegt werben, wie \&änbereien, Şäufer und (Sewerbieinridtungen. Da bier ber Steueranjd)lag auf längere 3eit hinaus unveränbert bleiben muß́, fo faun man weber auf ben burch sorzüglidyen fleiß uno (Eifer getwonnenen bökeren

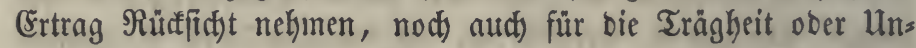
geididflidfeit ber jezigen Beftier cine Sdjonung eintreten laffen, weil beibe umftänbe vorïbergeheno fino, man muß vielmehr

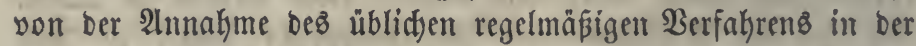

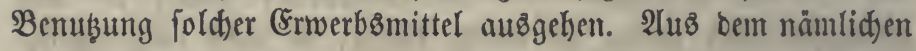
Srunbe fann aud) ber von äußeren Ereigniffen herribrenbe Wed) jel im Betrage Der Cinfünte von Эahr zu Sahr nidjt genau verfolgt werben, vielmehr muß man einem Durd)/dyitt berfelben annefmen uno von ber Bergangenbeit auf bie $3 \mathfrak{Z}=$ 
funft idsließen. Bei ben burd) Arbeit erlangten (Einfünften ift eళ fermer unthunlid), bie inbivibueflen Berjojebenkeiten im Unterkaltzbebarfe ber in einer gewiffen 2lrt ber Erwerbstbätig= feit bejchätigten einzelnen Familien zu bead)ten uno man muß vielmefr eine mittlere (Srößje für jebe (Elaffe von Bürgern und jebe Stufe bes rohen Einfommens fuchen.

2uf biefe 2 Beife tritt an bie Stelle ber unerforfalicten wirfliden Cinnahme ein mittlerer Betrag berfelben (b).

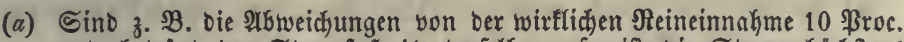

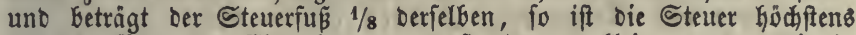
Itm 11/4 \$roc. Der Esinnahme zu groś sber zu flein, was wenig in Betradt fommt.

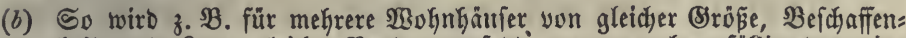
heit und Rage gleidye Fente angeiebt, wenn aud zufällig Das eine etwas höher als bas andere vermiethet worden ift. - Murhard nennt biefen mittleren voer "ibealen" Betrag bes reinen Ëinfommens

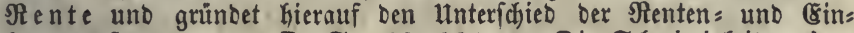
fommenbffeuer, ๙. a. D. S. 199, 267. - Die Edbierigfeiten einer yollfänoigen uno genauen Beftenerung aller reinen Eoinfünfte haben

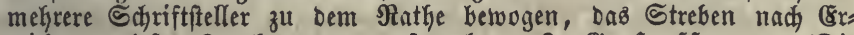

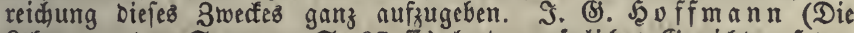
\&efire von ben Steuern, S. 37 fi.) legt vorzúgliches (sienvidft nuf Den

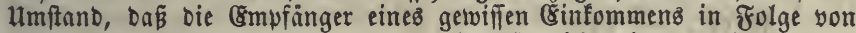

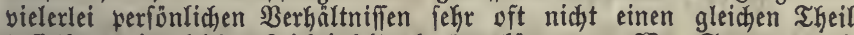
Deffelben mit gleidjer \&eidjtigfeit abgeben fönnen. "Wer Gteuern nad) Dem Einfommen vertheilt, Der unternimmt zu beftimmen, weldyer Theil

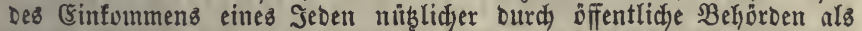
Durch ifn felbft verwendet twerde ... Bei Den \&ebenzuerhältniffen, weldye fich unter gefitteten $\mathfrak{B o b l f e r n}$ in oer Reige von Sahrhunterten ausgebildet haben, beruhen alle SBerfutche zur Begrünoung eines folden Itrtheils auf einer wohlgemeinten Selbftåuidung", ङ. 40. - 2 ber man fann nidjt auf bie Schab̧ungen gänzlid verziduten uno ber bei ifnen mögliche fegler ift body befto fleiner, je forgfältiger man in ber :inlegung zu Werfe geht.

§. 299.

Bei Den Sdhaksungen wirb für jeben Steuterpflidtigen uno fuir jebe. Art von Einfünten beffelben eine gewiffe Sabress ictulbigfeit ber Steuer feifgejest. Dazu ift erforberlich

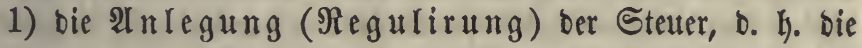
Berfertigung ber Steuerbüder, Steuerbefdreibungen ober Ratafter $(a)$. Shierunter verfteht man bie Berzeidjniffe aller bie Steuerfähigfeit begründenben Sautlen ber Einfünfte

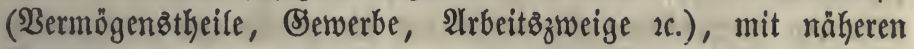
Bejatreibungen und 3ahlen(b). Da ber jälyrlidje Steuerfuß je

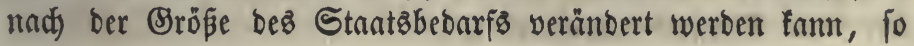


wirb er gewöhnlid) nidjt in bie Ratafter aufgenommen und bieje zeigen baker bie jährlidje Steuerjajulbigfeit jebes Einzelnen nidjt an, weld)e aber leidjt baraus zu bered)nen ift. Şiez̆ bient ber Steueranjdlag ( $\mathfrak{A}$ taftergröße, allivrement), D. h. bie eine Belofumme ausbrüdente 3 ahl, weld)e für jeben fteuerbaren Begenftand neben Der Befdreibung Der Scauptmerf= male beffelben in Ratafter fteht. (58 giebt mehrere Arten ben Eteuteranjallag anzuję̧en. Derjelbe fann nämlid)

a) unmittelbar bos mutbmaflidje fteuerbare (Einfommen

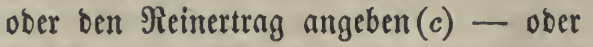

b) Die fteuerbare $\mathfrak{B e r m o g g e n s m a f f e ~ o b e r ~ b a s ~ f o g . ~ S t e u e r = ~}$ capital, ben mittleren \$reis (Berfefrsinerth) einer Einnahmsqquelle, welder ie nadt ben angenommenen

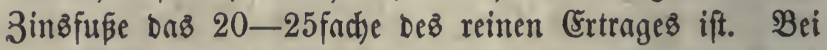

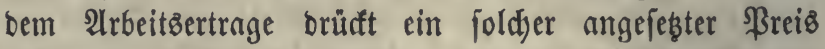
nidjt ein wirflides, fonbern nur ein in Bebanfen an= genommenes (fingirtes) $\mathfrak{B}$ ermögen aus, weld)ez man burd) Bervielfad)ung (Eapitalifitung) Des Reinertrages finbet, - ober

c) einen gemiffen fleinen Theil bes ermittelten Eintommens ober Steuercapitals, dab fog. Steuerfimplum ( $\mathfrak{A} \mathfrak{n}=$ id) lagstheil, Steucreinkeit). Die Anję̧ung fordyer Simpla bient bie $\mathfrak{B} e r e d)$ mung ber jährlident Steuerbeträge zu erleidftern, inbem man mur anzugeben braudst, wiesiel Eimpla in einem Jahke zu entrict)ten feien $(d)$.

Nad) ber Beftimmung einez Ratafterz follten bie Steuers

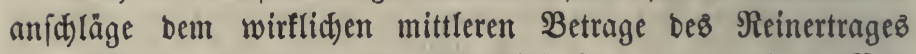
ober $\mathfrak{B e r m o ̈ g e n z ~ e n t i p r e d j e n ~ u n d ~ b i e ́ p ~ j u d j t ~ m a n ~ b e i ~ b e r ~} \mathfrak{B e r}=$ fertigung bes seatafters ž erreichen. Wenn in Folge fpäterer

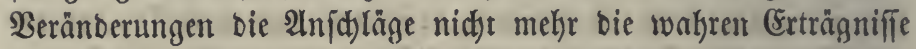
anzeigen, fo fann bodt bas Sintafter braud)bar bleiben, woferne bie in bemfelben aufgeführten 2Injalchge burd)gängig in gleid)em Berbältnís zu Den wirflichen 3ahlen ftehen $(e)$.

2) Die Entwerfung ber iährliden Errhebung zliften (Şeberollen), welde zu Etande gebradit werben, intem man ben bejdlofienen Steuerfús auf bie im Satafter enthaltenen Injidläge anwenbet und hieraus bie jebesmalige Steuteriduuldig: feit jebes Bürgers ausmittelt $(f)$. 
(a) Der Uriprung bes Wortes Ratafter ift bon Sac. Bothofredus (Cod. Theodos.) zuerît ridjtig erflärt worben aแร einer 3ินfammenziehung yon capitationis registrum ober wohl capitum registrum, was ourch bie alt = franzijifiche Schreibart capdastre beftätigt wirt. Capitatio war fowohl (S)und = als Sopfiteuer, caput bas einzelne feuerbare Dbject. Cabafter, Cadastre, ift alfo unridjtig. Du Fresne du Cange,

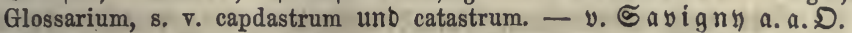
(\$. 247.) - $\mathfrak{D a c}$ a $i$ a velfi (Istorie Fiorentine, 4. PBud) berichtet, Das 20 ort fei zuerft für eine Bermoggensfteuer in Florenz gebraucht worben, wegen Des शैbmeffens bes SBermigens, accatastare, weldjes eigentlid, aufflaftern, auffdichten bebeutet, wie catasta Fुolzitố. Diefé

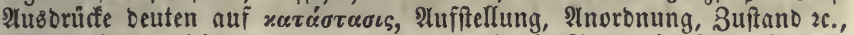
uno es fonnte leidjt catasto, welches zuerft bie Steuer felbft bezeidynete, audy in Dem Sinne genommen werben, wie unier "Ratafter". Diefé lestere 2rbleitung läpt fich fo benfen, ba oben angegebene Weife fid gebilbet hatte, feine Berbreitung burd bie Eriunerung an ein anderes âhnlid lautenbes, fđon vorhanbenes $230 r t$ bon griechifdyer शrbfammung beförbert worben ift.

(b) Die Erhaltung uno Fortfübrung Der Ratafter erforbert eine befondere Fürorge, vgl. \$. 338. - Redeifen, Das Stetter= und Ratafter=

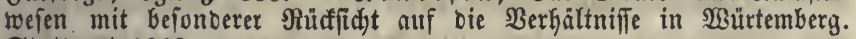
Stuttgart 1848.

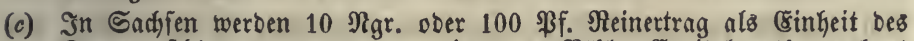
Steueranid)lages angenommen, bie zu $10 \Re$ thlr. (Sapitalwerth gerechnet wirb (30fad)), uno man giebt jährlich bie 3ahl ber zu erhebenden Pfennige ober Procente an.

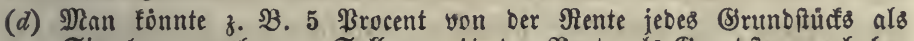
Simplum annehnen. Soll mun $1 / 5$ ber Rente als (S)tunditeuer erfoben werben, fo werben 4 Simula geforbert. In Naffal $z$. $\mathfrak{B}$. ift bas

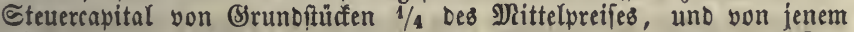
wirD $1 / 240$ ( $1 / 4$ Ir. vom (SulDen) als Simplum angeiest. - Das heutige Gimplum ift fichon in Dem simplex tributum Der romifden

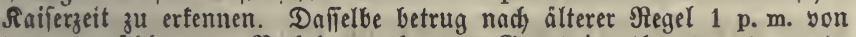

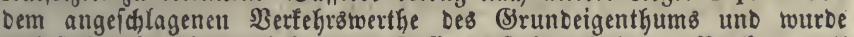
mehrfach, in einem befaunten Falle 10 fad erhoben. B Beffer unb Darquarot, Şanbbud ber rỏmifden Alterthủmer, III, 2, ऽ. 177. Ituch Die im 13. Iafrhuncert entfandene florentinif be Bermógensfteuer (estimo) bon $1 / 2-1$ \$roc. Des \$ermögens Gatte biefe Einrichtung, Da

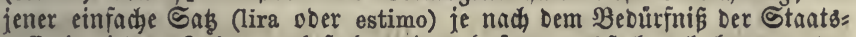
cafle in jebem Jahre mefriach, einmal fogar 12 fach erkoben wurbe. Dafielbe fand bei ber ipáteren Bermỏgenşfteuer (catasto) fitatt. De Parieu, Hist. des impôts généraux sur la propriété et le revenu, ๙. $30-41$.

(e) \$8 fönnten 3. B. in Folge einer Beränberung in Den \$reifen Des

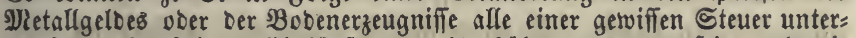
worfenen fataptrirten Ginfünfte um $1 / 3$ böher geworben jein, als bie

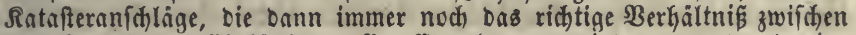
Den feuerbaren Einfünten aller Einzelnen anzeigten uno burd eine

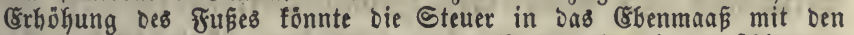
anberen Shabungen gebradt werben. WHenn aber in verfhiebenen Fâllen die Steueranichläge balo um $1 / 4$, balo um $1 / 3$ ober mehr yon

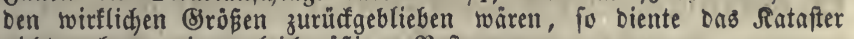

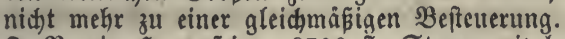

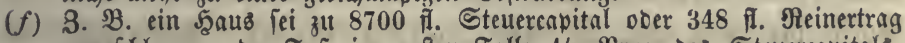
angefdlagen, ter Fuß im erften Falle $1 / 3$ Proc. Des Steuercapitals, im zweiten Falle $1 / 12$ Des angef(blagenen Seinertrages, fo ift bie Steuer: 


\section{$-6$}

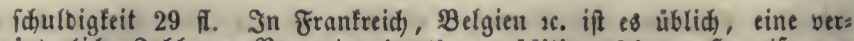
ánberliche 3ahl von \$rocenten (centimes additionnels) zur \$̧auptfumme einer Steuer zu fólagen.

\section{§. 299 a.}

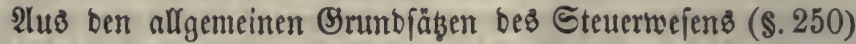

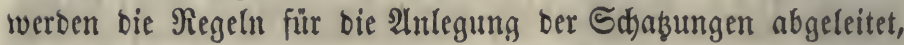
inbem man Das $2 B e f e n$ unb bie (sigenthümlidfeit jeber 2rt ber leksteren in Betrad)t zief)t. (Es giebt jebod) einige allgemeine

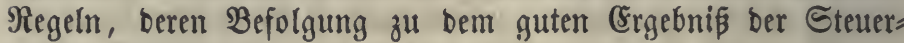
anlegung beiträgt.

1) Für bie zur genauen शusిmittelung ber Steuergegenftänoe

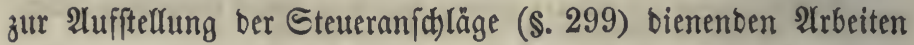

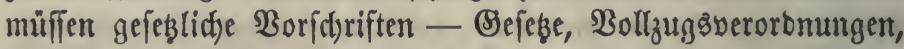
(Befd)äftzanmeifungen (Inftructionen) - gegeben werben, um jede $\mathfrak{B i l l f u ̈ r}$ zu verhüten unb bie nöthige (Sleidförmigfeit bes Berfakrens zu bewirfen. Sn einem gropen Staate und bei

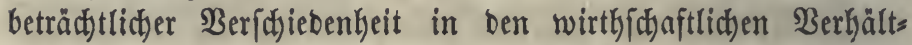
niffen ber größeren \&anbesttheile (\$rovinzen zc.) fann es rath= fam werben, für biefelben bejonbere Borfdriften aufäuftelfen $(a)$.

2) 3 u ben in 1) erwälynten Arbeiten wurben ehemals bloß Staatzbeamte gebraudjt, bie bödffens bann, wenn fie einer 2luşfunft über örtliç) Umftänbe beburften, zuberläffige Ein= wohner ber Drte ober Bezirfe zu Şülfe nahmen. Die von

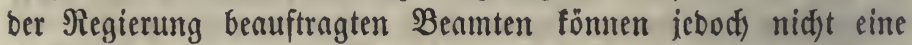
fo vollftänbige Renntniß von bem Umfange, ber $\mathfrak{B e f d j a f f e n k e i t ~}$ unb ber Benuķunģweife ber Erwerbs̊quelfen in iebem Theile

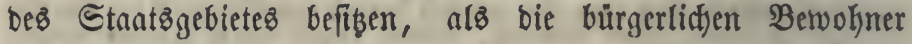
beffelben. Man hat baher neuterlid) mehr uno mehr erfannt, Daß̧ aนt ben verfdiebenen Claffen ber Steuerpflidtigen (Steuter= trāger) beizuziehen. Dießs gewährt zugleid, abgefehen von ber

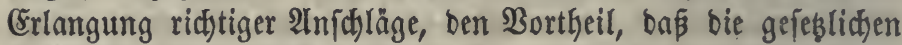
Borfdriften im $\mathfrak{B o l f e}$ mehr befannt werben und bie Heber= zeugung von ber Eereçtigfeit und 3wecfmäßigfeit besి ganzen bie Berfertigung ber Ratafter beztwedenben Serfalyrens fid vers breitet. Se mefyr überfaupt (Sinftat unb Bemeinfun in einem Bolfe herridjen uno je mehr baffelbe in Der Theilnabme an offentlid)en Âtngelegenteiten geübt ift, ein befto gröserer Antheil 
fann benifelben audh an ben Sataftergeichäften anvertraut wer= ben. Freilich tritt hiebei bie Beporgníp ein, baß̄ bei ben aus einem fleineren $\mathfrak{B}$ ezirfe genommenen bürgerlicjen Bertretern $\mathfrak{B a r}=$ teilid)feit uno (Sigennus nad)theiligen Einflü gewoinnen fönnen

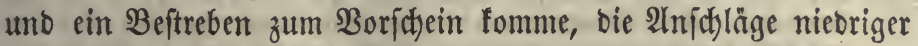

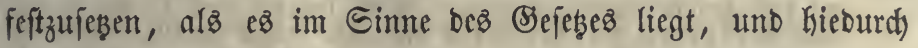
fitr bie einzelne (Segent eine ungerechte Begünftigung zu er= langen. Dieß̉ ift bei ben fog. Suotitätżftenern (\$. 295) nod) eher zu beforgen, als bei ben von oben herab vertheilten, Den Repartitionşfteuern, und eş fann leidjter ftattfinben, wenn bie beigezogenen Bürger eine entfdeibende Stimme erbalten, alṡ wenn fie bloß zum Beirathe berufen find (b). 3ur פerbủtung foldjer Ungered)tigfeiten bient

a) bie Mitwirfung von Stratß̧beamten. (Ein foldher erbält

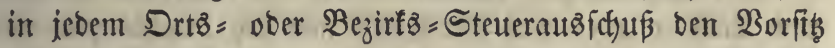
unb hat bie 2ufgabe, bei jeber Belegenteit auf bie $\mathfrak{B} e=$ ftimmungen ber Steutergefebe hinzuweijen;

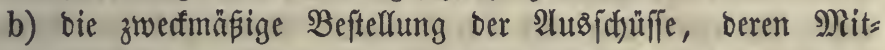
glieber zum Theil von einer Stantzbeföroe, zum Theil you ber Eemeinbebeförbe, bon einzelnen Elnffen ber Steuerpflidytigen ober von ben Sertretern eines größeren Bezirfes zu ermennen fint $(c)$;

c) eine 2lbftufung mefrerer über einanber ftehenber Arten

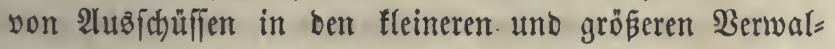
tungşbezirfen bes Ranbes,, fo baß bie Irbeiten ber unteren von bell höheren geprüft, verglichen uno nöthigenfalls beridftigt werben.

3) Seber Befteuerte muf yon bem ifn betreffenden $\mathfrak{a}$ =

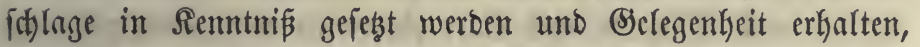
gegen benfelben bei einer bökeren Stelfe Berufung einzulegen, weld)e bann einer forgfältigen \$rüfung unterworfen wirb $(d)$.

(a) Dié́ fommt mefr bei ber Sefteuerung Der Brunbrente als bei anderen Edakungen vor.

(b) Dic a. Schrift: Die Directen Steuern in Defterreich, 1860, ङ. 37,

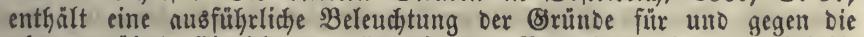

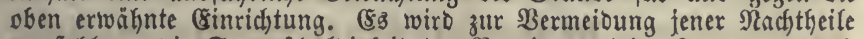
empfoklen, die Steuerfhuldigfeit Der Sruvinzen (Die "Eandesquvten")

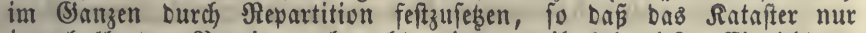

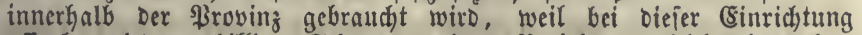
offentar jeoe unbillige Sdjonung eines Bezirfes zugleid Die ueber:

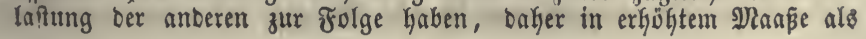


verwerflidy erfofeinen würte. Die im \$. angegebenen shittel laffen jeboch erwarten, baj auch bei Duotitåtofteuern bie befurchteten Uebel= fiande befeitigt merben fỏnnen.

(c) Raikeres bei ber Srumbiteuer \$. 336.

(d) Das bab. Gefes v. 8. Iuli 1848 enthält nidjt blós neue seftimmungen über ben in jeder (Semeinbe beftehenden 5 d) a sungs rath, ber aus oen verffiebenen Stainben von ber Semeinbebehorbe getwählt joirb unb nit Dem Ratnfterbeamten zufammen wirft, fonbern aud bie शnorbnung eines Steuerid) wargeridte \& für feben Bezirf von $30-60000$ (ङ zur Entidheibung freitiger Steuerfragen. Diefe Sdyurgeridte follten nad) Seję v. 12. Februar 1849 von ben Rreisveriammlungen getoảhlt werben. Da jebod bicie, eine Frt von Steisfänben, nicht zur शlus: fiffrung famen, fo unterblieb audi bie Berufung ber Steueridiwur:

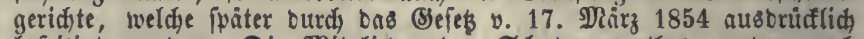

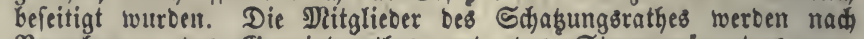
Bernefmung bes Semeinberathes uno Des Steuerperäquators bom Bezirfsamte ernannt. Die Berufung geht an bie Steuerbirection.

\section{\$. 300 .}

Dic Sdłab̧ungen entftanben in ben einzelnen Ränbern nad) unb nad), wie eళి Dazి Bebürfniß mit fid) bradfte unt wie man

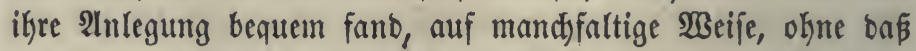
man von allgemeinen Begriffen aubiging und cime wiffenfdjaft= licke Unterickeibung ber veridhiebenen (Sattungen zu Srumbe egte. Dod) laffen fid) alle wirflid) vorfommenoen S(t)ab̧ungen in folgenbe abtheilungen bringen:

I. Steuern bon bem Einfommen, unb zwar

A. von ben einzelnen 3weigen beffelben.

1) Die Srumbrente famn belegt werben

a) bei ben Eigenthumern, in ber (s) runofteuer (i. ben folg. 1. 2lbjab);

b) bei benienigen, welde vermöge eines Real= redtes einen Theil bayon beziehen, burdy bie

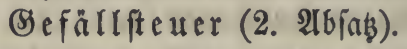

2) Diefelbe mit einer Zinsిrente verbunben zeigt fid in ber Şausrente unb bilbet ben Segenftant ber

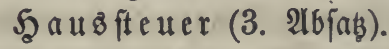

3) Die (Enpitalrente finbet fith

a) in Berbinoung mit Betwerbserbient in bem Einfommen Der (Sewerbsiunternchmer, weldyes ber (B) ewerbfteuer unterliegt (4. 2)faßz);

b) abgefonbert in bem 3infe nuzgelehener (Sapitale, für welde bie 3 ins $B$ uno (5apitalfteuer beftimnt ift (5. 2) 


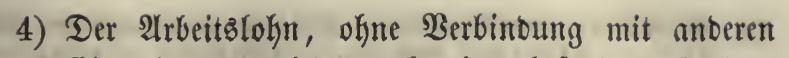
Einnakmen, wirb burd eine bejonbere gohn= fite uer getroffen (6. 2 (bfaks).

B. $\mathfrak{B o n}$ bem gejanmten Einfommen iebes Steuerpflidy= tigen im Samzen;

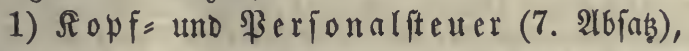

2) allgemeine (Einfommeng fteuer (8. 2tbaa);

II. Stettern yon bem gefammten $\mathfrak{B e r m o ̈ g e n , ~} \mathfrak{B}$ erm g̈ gen $B=$ fteuer (9. 2tofab).

\section{1. $\mathfrak{A} \mathfrak{b}\{\mathfrak{a b .}$ \\ (5) $\mathfrak{r} \mathfrak{u} \mathfrak{u} \mathfrak{d}$ it $\mathfrak{e} \mathfrak{u} \mathfrak{e} \mathfrak{r}$.}

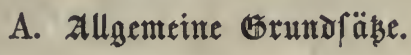

\$. 301.

Die Er un b fteuer $(a)$ ift beftimmt, einen Theil ber Brunbs rente, D. $i$. Des reinen Errtragez, weldyen bas Esrunbeigenthum gewährt $(I, 207)$, für bie Stantşcaffe in $2 \mathfrak{n}$;prud) zu nefmen (b). Die Srunbrente fann aus fehr verichiebenen Bentbunģånten einer gerwiffen $\mathfrak{B}$ odenflädhe Kerrülfen, inbem eine foldje bald zum Bergbau, balo zum Lanbbau, zu einem Bewerfb̈ = ober Dienftgejdät, zum Ueberbauen 2 . angerwendet wirb uno in allen biejen Făllen bem (Eigenthümer einen Reinertrag zu ges währen vermag. In ben meiften Stanten ift bie Srumbrente Der gröfte Beftanttheil bes reinen $\mathfrak{B o l f s e i n f o m m e n s , ~ u n t ~ b i e ~}$ Srunbfteter nimmt baker unter ben Sdjabangen in Scinftd)t auf Ergiebigfeit bie erfte Etelle ein, fowie fie zugleid) ber Staatşaffe ein fidjeres, wenig wanbelbares Cinfommen ge= währt $(c)$. Dá fie früler entftand als bie anderen Sdjaksungen, erflärt fich) leidyt aus ber am Tange liegenden Stenerfäbigfeit

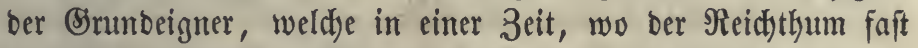
blop in Ränbereien beftano, mehr hervorteat, als jeit ber $\mathfrak{B} e r m e \mathfrak{k}=$

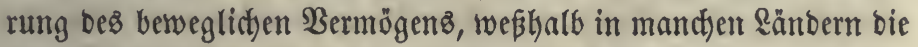

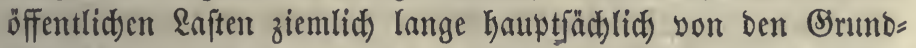
eigenthümern getragen werben musten $(d)$. 2(ud) giebt andere Cteutr, beren 2 tnlegung fo vieles Nadjoenfen unt fo grope Borarbeiten veranla fit hätte als bieje. 


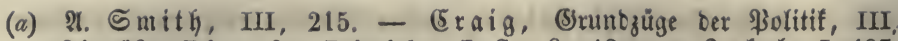
24-66. Ricardo, Principles, I, Cap. 9-12.- v. J a fob, I, 487.

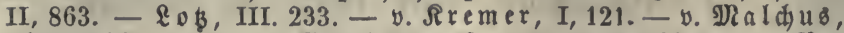
Finanzivifi. I, 186. - Nurharo, 5. 263. - Sh of fmann, Bon Den Steuern, S. 94. - y. \$rittwib, Theorie ber Steuern und Sülle, ऽ. 132. - de Parieu, Traité I, 167. - v. Jgof́, Itbgaben ธ. 129. - Benzenberg, Heber ons Sentafter, Bomn 1818, 2 Boe. 3weite 2urgabe 1824. - Eväth, Heber oie (Stuntifeuer nad bem

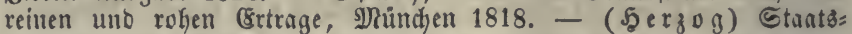

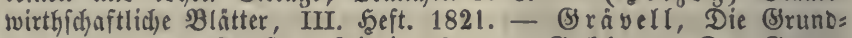

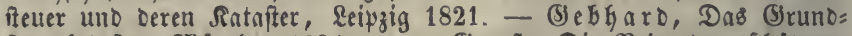

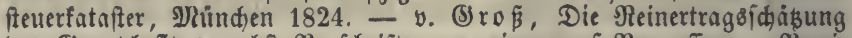

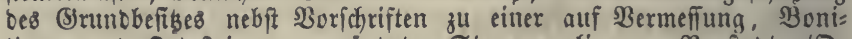
tirumg unD Sataftrirung gegrünoeten Steuerregulirung, Neuftaot a/D. 1828. - Selß̈, Errundfäke zur 2lufnafime und Erfhaltung von Srundfatafer in ben Deutichen Stanten, MBefel uno Reipzig 1840. Rle mm, Staatswirthichaftlide Blätter, Stuttg. 1842, Şeft II-IV. -

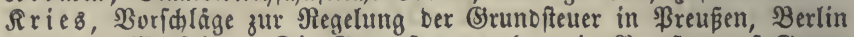
1855. - Niafher, Die Brrundfteuerregelung in \$reußen auf Bruno

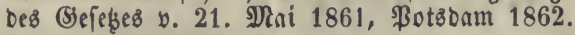

(b) Daher folägt Safob ben Namen (S) runbrentenfteuer yor.

(c) Die Grumbfteuer betrigt

\begin{tabular}{|c|c|c|c|c|}
\hline & $\begin{array}{l}\text { von } \\
\text { Eteutern }\end{array}$ & Dent & & 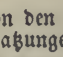 \\
\hline Spa & 40 & \$roc. & 16 & $\mathfrak{3 r o}$ \\
\hline & 29 & " & & $"$ \\
\hline & 29 & " & & \\
\hline & 28 & " & & \\
\hline $\mathbb{B}_{e}$ & 25 & " & & \\
\hline mberg & 25 & " & & \\
\hline & 18 & $"$ & & \\
\hline Baden & 16 & & 4 & \\
\hline
\end{tabular}

"wobei in Franfreid und Belgien bie Stausfteuer eingered)net ift. Der

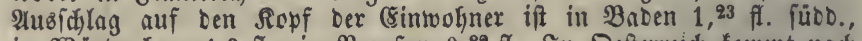
in 20 ürtemberg 1,2 fl., in \$reußen 0,82 fl. Sn Defterreich foumt nach

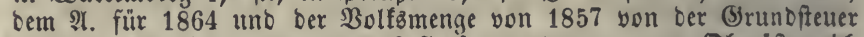

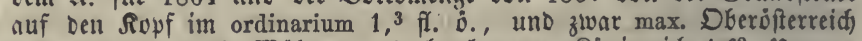

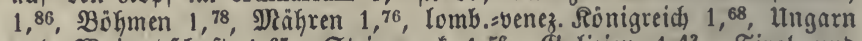
uno $\mathfrak{M}_{\text {somoof }}$ aft 1,67 , Steiermarf 1,56 , Salizien 1,43 , Tirol und Borarlberg 0,76, Siebenburrgen 0,66, Dalmátien 0, 53, Bufowina 0,47 min.,

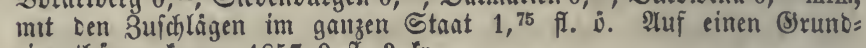
eigenthümer famen 18579 fi. 3 fr.

(d) In GGina befteht nod, jebt neben ber Srunbfteter feime mbere Sdjaķung. Natalis Jiondot bei Parieu S. 219.

\section{§. 302.}

Dic Erunbrente, als ein Einfommen, von weldyem bie Soften ber Bobenbenubutung idjon abgezogen finb $(a)$, faum ber Erfalyrung gemäß ofne Radjtheil für bie bauernbe Boben=

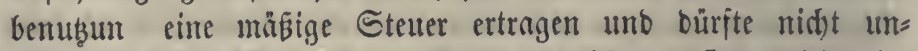
befteuertg bleiben $(b)$. Die Brunbeigenthümer fint nid)t im Stande, iene Steuer auf eime anbere Claffe von Bürgern zu 
wålzen unb müffen fie folglid) aus ifrer Sorumbrente beftreiten. Dieş läpt fith fo nadjweifen:

1) Der Sreis ber Bobenerzetugniffe läß̈t fíd nidjt ber Steuer willen erkjöken, fo baß bieje yon ben Săufern getragen wửbe, weil biezu eine Bermintentng Dez 2 ngebotez in Folge einer idjwäd)eren (Erzeugung erforberlid) wäre, zu ber bie Entunbeigner

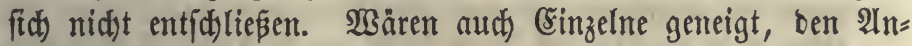
bau bez \&anbez einzufdhränfen, fo würbe bod) eine gleidfförmige

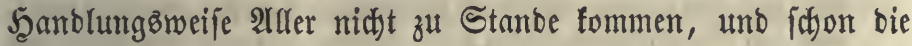
Reidtigfeit ber Einfuhr yom 2lublanbe würbe einen foldten Berfuci) vereiteln: Die (Srunbfteter ermuntert vielmelgr zum

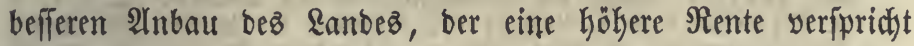
unt baburd) iene Slbgabe, to lange fie unveränbert bleibt, weniger läftig madht. Nur eine foldye fehlerhafte Erundfeteter,

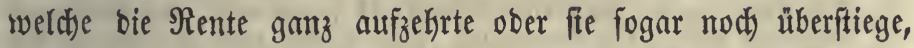

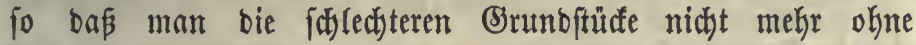
Schaben bauen fönnte, wutrbe bie Folge haben, baj ein Theil

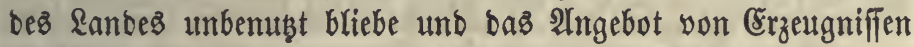
abnähme $(d)$.

2) (Eben fo wenig läß̈t fich bie Steuer auf bie \$adter wälzen, Denn biefe fönnten bei einem um ben Steuerbetrag ergöhten \$adjtzins nidft beftefen, fie werben nidft mekr geben, als wozu fie oknefin burdh bas Mitwerben genöthigt werben, und wenn ifnen bie Steuerentridjtung auferlegt wirb, befto weniger Sładtzinz bieten. Ałth wiffen bie Srunbeigenthümer, baß fie bie Steuer unfehlbar auf fiét) nehmen müžten, wenn fie ifre sänbereien felbjt bewirthfdhafteten.

(a) Die Ertraysfähigfeit ift zwar zum Theil bie Folge eines frủheren Eapitalaufroandes für urbarmad)ung uno Srrunbverbefierungen, allein in foldjen Fällen ift bas Eavital als foldjes nidjt mehr vorfanoen, bie 2 irfung beffelben if Dauernd uno unzertrennlich mit Dem \&ande

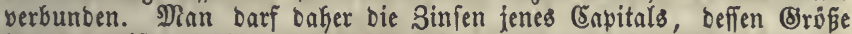
in ben meiften Fårlen nidht mef̧r befannt uno aud bei Lánbereien von gleicher jebsiger Befdaffenheit ohne 3tweifel Godylt veridjieben geweien ift, nidht unter bie Roften rechnen, benn fie bilben ein reines, mit ber Srunbrente veridjmolzenes Einfommen. - In ber \$adjtrente von dänbereien find neben ber wahren (reinen) Grunbrente nod foldye unterhaltungsfuften yon Dinuern, Dämmen u. Dgl. enthalten, Die ber Eigenthümer zu beftreiten Gat. - Die neuern Mleinungsyeridjiébenkeiten liber $\mathfrak{B e f e n}_{\text {uno }}$ Beftimmgrůnbe ber Srunbrente haben auf bie Steuer=

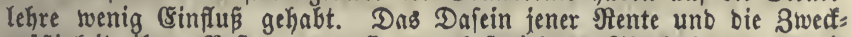
mäpigfeit ifrer Befteuerung fino unbefreitbare Thatfadjen uno bie 


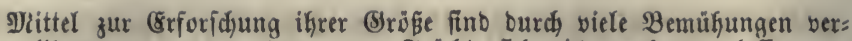
vollfommuet worben, beren gute Früdte fich nidt berfermen laffen.

(b) Mac Culloch (Treatise $\mathbb{S}$. 43) verwirft Die SSrunofteuer. Derjenige Theil ber Sstunbrente, meld)er von einem auf Sebåube, Esinfrieoigung, Gutwäilerung $2 c$. vertwendeten Bapitale herrübre, laffe fid bon Dem anteren nidyt leidst fdeibent. Befteuere man jenen ebenfalls, fo Galte Dies von weiteren Bobenverbefferungen ab; gelinge aber bie Trennung beiber Theile, io fei boch eine Steuer, bie nur ein eingelnes Einfom: men treffe, ungeredst. Diejer leşte Sabs hätte nur (Servid)t, wenn es neben ber Srunofteuer feine anberen Sdjabungen gäbe, gegen Den erften if zu erinnern, Das bie Binsrente vou Meliorationen ofne Rach: theil beftetert werben fann, weil biefe mit Dem $B$ oden feft verbunden fino (bgl. $(a)$ ), ferner baj feine (Strunofteuer fogleid), etwa alliälyrlid, nach Den Ileliorationen ergoht wiro, fondern nur nad, langen 3wifijen,

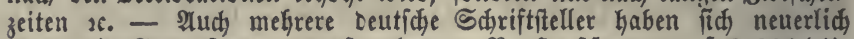

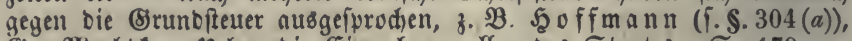
(Sr. Il oltfe, Heber Die Einnahmequellen bes Staates, ङ. 179. v. Beffe Dorf in $y$. Eengerfe, Anmalen ber Lanbw. VII. Jahrg.

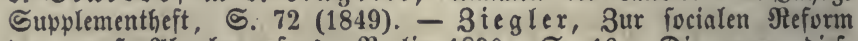
Des preußi. Abgabenweiens, Berlin 1830, S. 19 . Die gegen diefe Steuer gemadjten (Einwürfe fommen in $\$$. 311 fi. zur unterfudjung. Die Neinung ber genannten Berfafier ift jeood nidat, Daß̧ bie Bruno: rente gar nidjt belegt werben foll, benn fie fino einer allgemeinen Ein= fommenfteuer nicht entgegen.

(c) 2. S $\mathrm{mith}, \mathrm{III}, 216,232$.

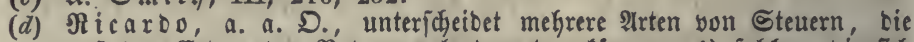
auf ben (Értrag tes Bobens gelegt merben fonnen: 1) folche, die fich nad) Der Menge von Erzeugniffen (Nolyertrag) richten uno folglid) wic irgeno eine Bergröp̈erung ber Şervorbringungstoften anzujeken fino, (Sap. $9 ; 2$ ) fuldhe, Die genau im Berkältnis ber Srundrente fiehen. Bon biefen gilt tas im $\$$. Befagte; 3) folde, bie auf alle Rảndereien, aud auf bie fdjedsteften, rentelofen gelegt fino, uno beşhalb, ba fie

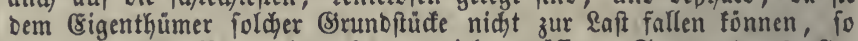
wie bie unter Nr. 1 betrahteten wirfen müfen, S. $_{2} 11$ ber 2. A.,

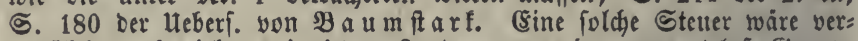
werflid, Dod giebt es in jebem \&anbe nur toenig ganz rentelofe (S) runo= ftude, Deren Debebleiben idswerlid, Das Angebot yon Bobenerzeugniffen in füGlbarem Daaße verminbern fỏnnte.

\section{§. 303.}

Die Srunbfteuer foll benjenigen Theil bes Reinertrags bon Sruntitüuen treffen, Der bem Eigenthümer als fold)em zufällt. Die Einfünte find jebod) in ber $\mathfrak{W i r f l i d}$ feit nid)t immer fo von einanter gejdieben, wie fie im Begriffe gejonbert werben mủifen.

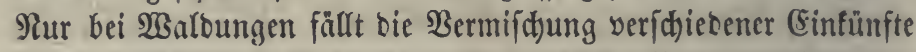
faft ganz hinweg. Bei anberen Srunbftủfen ift ju unterfaceiben:

1) wenn fie bon bem (Eigenthümer felbit bewirthid)aftet wer= ben uno. folglid) Beftantbtheile eines \&anogutes bilben, fo făllt mit ber Sirunbrente zujammen

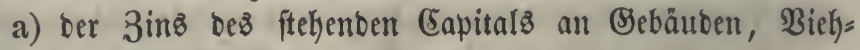
fano uno Beräthidjaften, 
b) ber 3inz bes umlaufenten Capitals, weldjes in Belb und $\mathfrak{B}$ orräthen beftelgt,

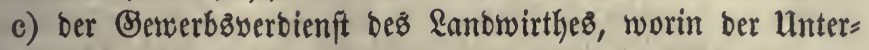
Galtzbedarf bez leşteren unb oft nod) ein reiner Berwinn ent= Galten ift.

Diefer Serwerbszerbienft ift bei verjdiebenen Graben yon Fleí, Runft unb Capitalbefits bes Sanbwirthez fehr ungleid), währent bie Erunbrente, Der Antheil beż Eigenthümers alz foldsen, von jenen perfönlidjen Utmftänben unabjängig ift unb (id) nad) ber üblidjen Behandlungämeife ridłtet, I, \$. 208.

2) Bei \$̧adjtungen ganzer Lanbgüter begreift ber \$adtżinz wenigftens bie unter a) aufgefüfrten. Binjen und eine $\mathfrak{B e r}=$ gửtung für bie 2lbmüb̨ung yon Denjènigen Begenftänben, bie bem \$adter yon bem Esigenthümer überliefert werben. Nur bei einzelnen Barten = und Felbftüffen fällt bießs hinweg und

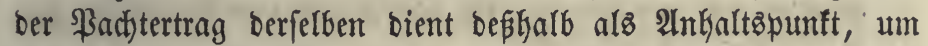
audi bei anderen Srundftüfen gleidjer $2 \mathfrak{r t}$, Befdjaffenteit und

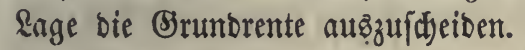

\section{§. 304.}

Bei ber Srrunbftetter zeigt fid fogleid) bie oben (\$. 298)

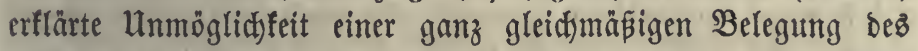
reinen (Sinfomments fehr bettlid). CEin unt baffelbe Sintmbftüf

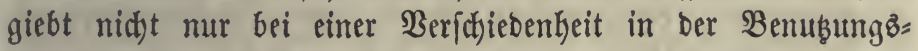
weife, 子. B. als 2lder, Earten, Bimmer=, Trofenplał 26 ., fon= bern aud wegen ber Ungleid)beit in ben Ernten und in ben \$reifen Der (Erzeugniffe von Sahr zu Sahr nicht bie nämlidfe Fente (a). Die genaute Erforidjung ber je besimaligen wirf=

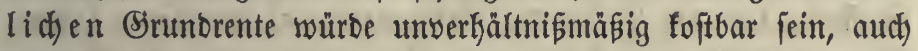
würbe bieje unermepliche und endloje 2 lrbeit unfehlbar nadt)= läffig betrieben werben und baburd) wieber viele Fehler ver= anlaffen. Man muß fith bes̆alb mit ber mittleren \&rund= rente begnügen, weldye man yon jebem Srunbftüfe nad) gettauter Beruidfict)tigung aller (Eigenichaften befielben ermarten fann. Die Brunbfteterbefdreibung fann wegen ifrer Sdywies rigfeit und $\Omega_{0}$ ftbarfeit nidft oft ernetert werben, fie mus aljo foldje Umftänoe, bie einem bäufigen $\mathfrak{B}_{\text {ed }}$ jel unterworfen finb,

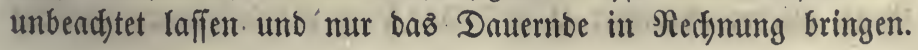




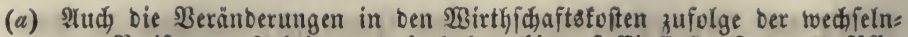
ben \$reife oer Arbeit u. ogl. Gaben Gierauf Einfús, ferner unfälle, bie ben Esinzelnen faber treffen unb fị nur in längeren Seiträumen gegen bie günftigen Infire wieber ausgleidjen. Dieje unvermeibliḑen

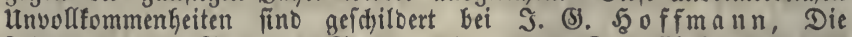
\&efre von ben Steuern, S. 40 uno 106: "Das Einfommen aus

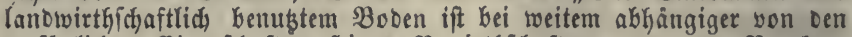
perfönlidjen Eigenfduaften feines Bewirthfdafters uno von Begeben= Geiten, tweld)e die 2 irthfdaftsfoften unt Die Frudtpreife beftimmen,

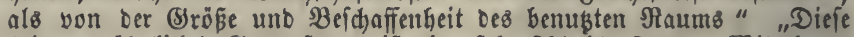
(bie gewobnlidie) (brunditeuer ift eine fehr idjledste form, Nittel zur

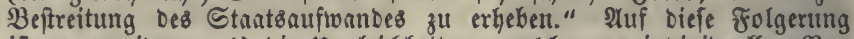
ift zu ervibern: 1) bie Ungleich heiten, weldye aus indivibuellen Bers Galtniffen Des andwirthes entftehen, betreffen nicht fowohl bie Brund:

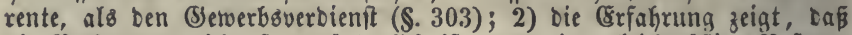

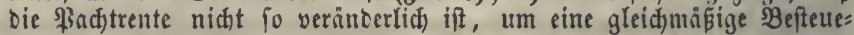
rung unzuläfifig zu maḑen; 3) wollte man auf cie in Der Ertrags:= fäfigfeit liegende Stïbe Der Befteuerung verzidjten, fo würbe biefe nod) weit weniger geredyt uno viel fdywieriger auszufüfren fein. -

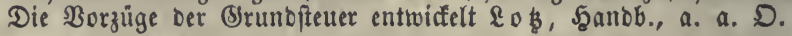

§. 305 .

(Sewöhnlid) benutzen bie Menfduen iffr Bermögen fo gut, als fie es fönnen und veriteken, und in jeber (S)egend läßjt fiț

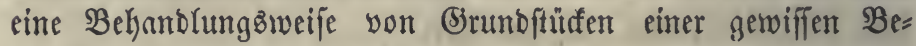
id)affentheit erfemen, weldje als Regel anzunebumen ift unb nad) weldyer bie mittlere (Sirumbrente gejudd werben fann, §. 303. Şiebei bleibt es außer Betradtung, wenn 1) mit

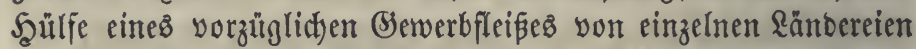

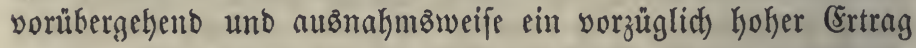
gewonnen wirb, es fei mun burth eine autgegezeichnete lanowirth= idfaftlid)e Behanblung ober burdh Benukung zu einem anberen 3wecfe $(a) ; 2$ ) wenn (Erunbftüfe eine 3eit lang, 8 . B. in ber Şand eines bürftigen ober nadyläfítgen Ranowirthes, weniger abwerfen, als esి gewöhnlid) geidhieht. Şieher gefjört aud) ber

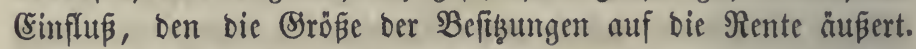
Benn Der Morgen eines großßen Ranoguttez weniger einträgt, als ber eines mittleren uno fleineren, fo hat ber Eigenthüuner

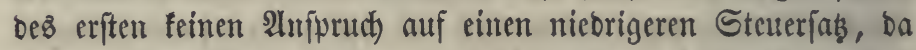
es in jeiner $\mathfrak{B a h l}$ fteht, biejen Umptand zu änbern $(b)$. Da= gegen fann aud) ber Beftzer weniger Morgen, bie vielleidjt

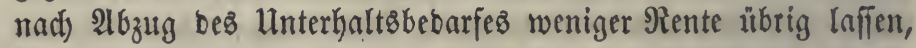
feine Steuererleidterung verlangen, weil ber $\mathfrak{B e f i t g i t a n b}$ zu vers änberlid) ift, weil eine übermäpige 3erftüdfelung, bei ber bie Rente wieber abnimmt (I, \$.373), feine Begünfigung verbient 
unb weil bie freie 3eit zu einem Nebenerwerbe benutbet werben fann; 3) wenn fie yorübergehend auf eine nicht twerbente 2 Beife

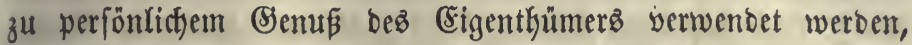
wie Ruftgärten $(c)$, Spielpläge u. Dgl. Şier verzichtet berjelbe eine 3eit lang freimillig ouf bie Rente, weil er einen nidjt werbenten (Bebrautd) höher anfdylägt; bie Steuer wanbelt fita während beffelben in eine शlufwanbzffteuer (\$. 292) um, weldhe audi) zuläfifig ift, inbem berienige, weldyer eine foldye fidjere Einnakme aufgiebt, wahridteinlid) aus anberen Dueflen ein reidjliches (sinfommen bezieht $(d)$.

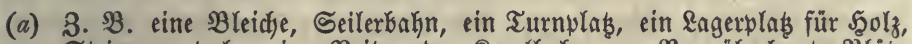

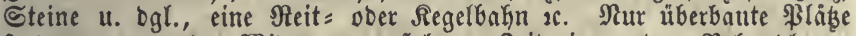
forbern wegen ber $\mathfrak{B}$ Bibmung auf lange Beit eine antere Bef̧andlung.

(b) शtnoers verhält es fich freilidy $b a$, wo bie Theilung gefestich verfinbert

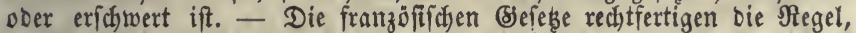
Den Durchidfnitt vom Ertrage beider Beivirthidhaftutrgen, in groß̈en und fleinen (Bütern, zu nehmen, wobei bie Befiţer ber erferen etwas zu furz fumment, mit bem Sałze: Le but, qu'on se propose dans l'évaluation d'une commune, est d'atteindre le taux moyen du produit des terres, et la loi dit positivement qu'on n'aura aucun égard au plus ou moins d'industrie des propriétaires; c'est une industrie que de diviser son domaine en petite tenue. Recueil méthodique etc. शrrt. 563.

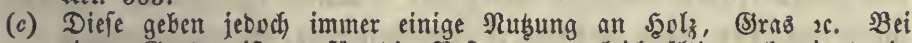
einem Sarten ift eB für bie Befteuterung gleidhgültig, ob Die Darin

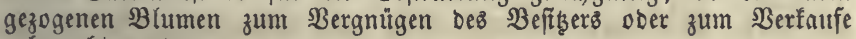
gebraudst werden.

(d) Die pofitiven Gteuergeiebe ftimmen hiermit überein. - Diefer Fafl giebt ein Beifpiel Davon, Dñ Dutrd Steuern aud veríchiebene nidjt finanzielle 3tweffe Des (Semeintwohles befördert werben fónnen, wie hier bie Begünftigung ber probuctiven Bobenbenubung, obidjon aud $a b=$ geféfen von Dieferm bejonderen Srrmbe die in \$. 304 entrwiffelten Säbe fu jener Folge füfrem. Meonthion in ber angef. Sd)rift hat fid yorzüglich mit biefen sebenztwecten uno Rebentwirfungen ber Gteuern beidnäfiget. Sie bürên jebod) nicht mit ber Şauptbeftimmung in ssiberftreit ftegen.

\section{\$. 306 .}

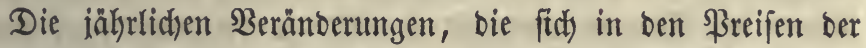
Erzeugniffe, uno mit 2hünahme ber Waaloungen auth im Raturalertrag ereignen, erftrefen fith auf viele in einer Begeno

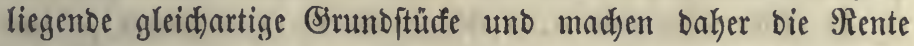
Des felbftwirthichaftenden (Eigenthümerz ungleid), fowie fie audt) auf bie \$adtzinje bei ben neuten \$adtungen einwirfen. Die

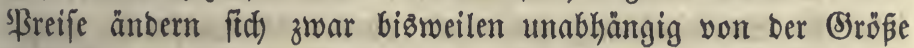
Des Erzeugniffes burd) 3umahme ober 2(bnahme bes Begehrs,

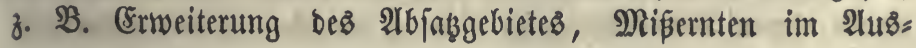


lanbe u. Dgl., öfter jebod) nad) ber größeren ober geringeren Ergiebigfeit ber einzelnen Sakre. Daher getwinnen bie Lanb= wirtlye nad) fdjlect)ten Rorn $=$ D $b$ it $=$, $\mathfrak{B e i n}=$ Şeut $=2 c$. (Ernten

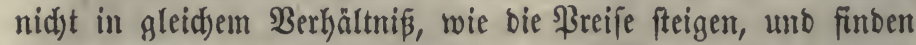
bagegen bei grofer $\mathfrak{B}$ ohlfeilfeit in ber Fülle bes Ernteertrages einige, obfdyon feine ganz zurcidyente Entiduäbigung, I, \$. 160. Nimmt man bie (Ertragsీfäbe unb \$reife nad) Dem Durd)fanitte einer längeren Sahresircifye in bas Ratafter auf $(a)$, jo gleidyen fich) geringere $\mathfrak{B e r n ̈ n b e r u n g e n ~ v o n ~}$ fönnen unbead)tet bleiben. In Mifiajahren bilft man burd)

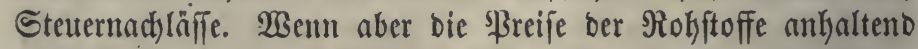

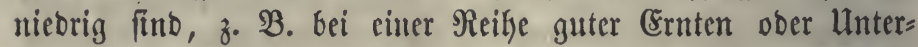
brechung Der bizhkerigen 2lbfablwege, - ober anbalteno hod, 3. $\mathfrak{B}$. in Folge einer 3unahme ber Bebölferung ober ber $\mathfrak{A} u b=$ fufbr, fo verliert ber Durdsidynitt einer früferen \$eriobe feine Inwenbbarfeit auf bie gegentwärtige unb esิ wirb eine $\mathfrak{B}$ erid) = tigung nöthig, bie entweber in einer einftweiligen 2 lenberung ber fataftrirten $2 \mathfrak{n}$ jhläge, Doer wenigftens in ciner Berästberung Des Steuerfußes beftehen fann (b). Aud) bie Sdwantungen im \$reife bes (Beloes tönnen eine ăhnlidje Wirfung haben.

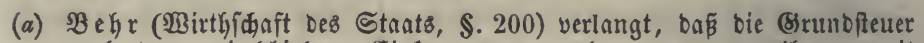
nad) bem wirflid)en (Einfommen umgelegt werde, weil nur mit Diefem bie Steuerfähigfeit gleid)en Sdyritt halte.

(b) Şiernady hat man in ben meiften Staaten bei ber 930 Glfeilffeit ber 1820 S Sahre gehanbelt, indem Die Ratafter aus Der theureren 3eit her: ftammten. \&8 fann nirgenos an ber Renntnis berjenigen ftatiftifchen Thatiadjen feflen, nach Denen biefe Beridytigung vorzumehmen ift.

\section{§. 307.}

Der Borfdlag, die (Srumbiteuer im Ratafter in Boben= erzeugniffen (in natura) anzufesen und nad) ben sjereifen jebes Sahres bie Steuerichuldigfeit in Beld zu beftimmen $(a)$, bamit ber Innbbauenben Elafie cine (Erleid)terung veridafft werbe; hat Folgenbes gegen fids:

1) Die roke unb reine (Simnalyme ber Ranbwirthe ift atts Der in \$. 306, angegebenen Urjadje feintesิwegs fo verfdjicben,

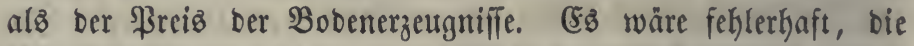
jährlidbe Steuerzahlung nur nad) biefem Berfaufछ̈preife abzu= meffen, ofne babei audh bie erzeugte Dienge in Betrod)t zu ziehen, beren Berïffifdtigung aber zu umfttindlid) fein würbe $(b)$. 
2) Man hătte vielerlei Felo = uno sartengewåd)je zu bead)=

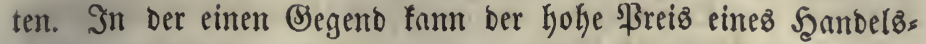

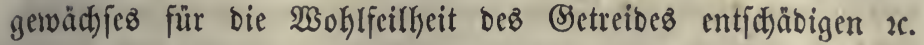

3) Da fhon ein Theil ber Steuern, namentlich bie 2 luf $=$ wanbsfteuern, unftintig ift, fo wäre ę für bie Dromung im

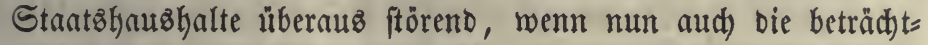
licffte unter ben Echnķungen jährlid) einen veränocrlid)en (Es= trag bătte. Woolte man Dagegen ben Sejammtbetrag ber Srund = fteuer gleid) bleiben laffen uno mur nart, ben jebesimaligen Preifen Der Erzengniffe die 2lbgabe Der veridjiedenen Arten bon \&änbereien neu beftimmen, fo würbe jebe (Erleidterung eine Befdwerbe auf einer anderen Seite herborbringen, z. B. ein fehr wohlfeilez Betreidejalyr würbe den Steuerantheil ber $\mathfrak{W}$ ein=

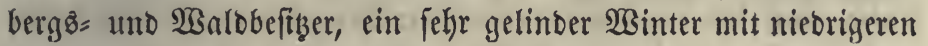
Şolzureifen ben ber Aderbefizer erfiöhen (c).

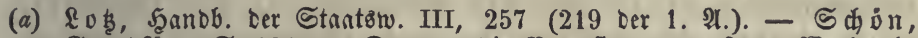

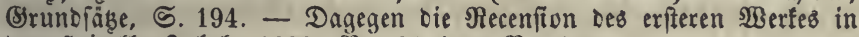

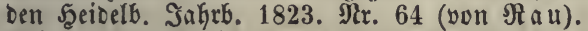

(b) Bei weldhem \$reife Der lanowirthjdaftlichen Erzengniffe Die Brumb=

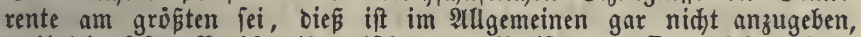

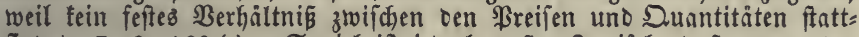
fincet, I, \&. $160(e)$. Subiel ift jebod aufer 3weifel, Daś, twenn Der

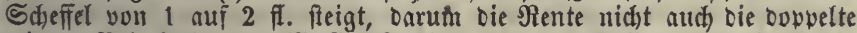

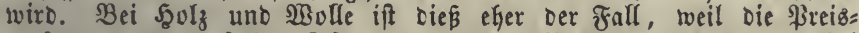
veränoerungell Derfelben faft mur von Dem Begehre nużgefen. - Bei beridjiedener Frudtbarfeit und veríchiebenen \$reifen Gleiben auch Die Ruften Des Ranowirthes nicht ganz gleid, aber wenn man biejen um= fand ebellfalls beaditen wollte, fo würbe die Berwidflung vollends unlöslich.

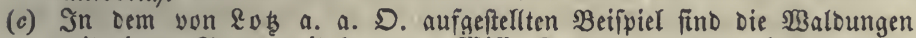
mit einem Steuercapitale von 2 SAill. Rlaftern Seolz angelegt, wovon

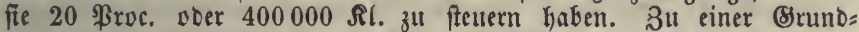

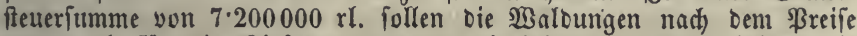
bon 3 rl. für die Rlafter 1.200000 rl. beitragen. Nun fteigen Die

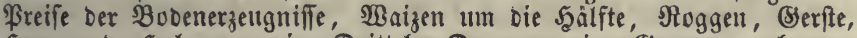
Şeu und Şolz um ein Drittel. Da man im (Sanzen audi) nur $7 \cdot 200000 \mathrm{rl}$. aufbringen will, fo bertheilt man die $\mathfrak{L} a f t$ fo, Das bie

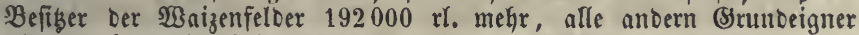
aber reniger alz bisher bezallen, währeno vielleicht die Steuerfähigfeit Der $\mathfrak{B a l o b e f i z e r ~ a m ~ a l l e r m e i f t e n ~ z u g e n o m m e n ~ b a t . ~ S ̧ i e z u ~ f o m m t , ~ D a ́ ̧ ~}$

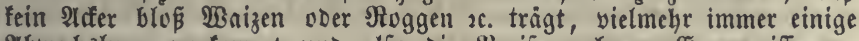
Abrochslung vorfommt und alfo bie \$reife mebrerer Erzeugniffe zu= fammengefaßst werben mußsten.

\section{\$. 308.}

Die Beffibungen bes Bauernftandes waren frïkerfin ings gemein mit ertheblicten bäuerlid)en \&ajten belegt. Da ein foldtes

ช aน, polit. Deton. III. 2. થbth. 5. ฆนริg. 
RenIrecht auf Dienjte unt शlggaben einen Theil Des Rein= ertragez bem $\mathfrak{B}$ erectigten zuwentet, fo fann bie Steuerpflidt Des belafteten (Eigenthümerz fich mur auf ben bempelben bleiben= ben Ueberreft ber (B) nunbrente erfitrefen. Derienige Theil bes Reinẹtrages abcr, weldjen ber belaftete Eigentfümer wieber $a b=$ geben muß̧, bilbet in ben Şänben bes Bered)tigten eine Befäll= rente, für meldje berfelbe ebenfalla befteuert werben mus, ba fein 2Intheil nad) 2lbzug ber Erthebungafoften ebenfalls reines Einfoumen ift. So wie ez bie Bsleid)heit verleben würbe, wenn man bie Befällbered)tigten fteuerfrei ließße (\$. 338), fo wäre frohn= 2 . pflidtiger Srumbitüfe ebenio zu behanbeln, wie ben, befien Beftigungen ganz unbelaftet finto $(a)$, und biefer Unter=

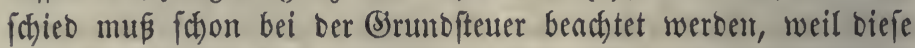
verichicbenen bäuerlidten Raften mit ber 2 rt bez (S)unbbefízez zufammenhängen $(b)$. Bon ben Dienftbarfeiten gilt Dafielbe $(c)$.

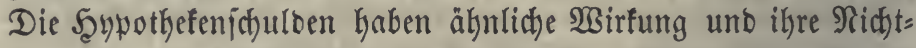
beact)tung bei ber Steuerbelegung ber Orrunbeigenthüner ift eine

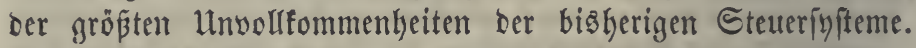

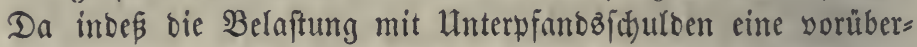
gekenbe und veränberlidje ift, aud) nur eine cinzelne 2 (rt ber Berfofuldung biloet, fo fann fie an einer anteren Stelle $a b=$ gehandelt werben, \$. $401 \mathrm{a}$.

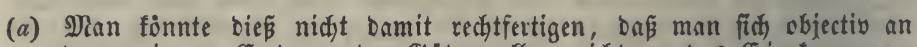
Den reinen Ertrag ber Silterquelle, nicht an cas Einfommen Der \$erfonen halten wolle, Denn jenes wäe eben in folder \$eife un= zuläfíig, vgl. \$. 262.

(b) In Defterreich wurbe bei ber Therefianifden Srunofteuerregulirung $(1750-1756)$ Den (Sefällberechtigten eine Dominicalfteuex aufgelegt, eine Erleidterung ber belafteten (Sigentfuumer fojeint aber nicht vor: gefommen zu fein, ba man in Nieberofterreich bie Nuftical= (bäuerlichent) unt Deminical = (gutbherrlichen) Befibungen alff gleidse Weife nads

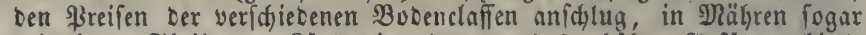
bei einem Theife Der \&änbereien ons rusticale höhere शnfäbe erfielt, als Das dominicale yon gleidyer Bobengüte; Linden, Sruntiteuer:

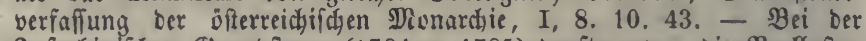
Sofexhintiden Srunbfteuer (1784 u. 1785) Durften zwar sie Reallaften bei ber \&usిmittelung Des (5rtrages nidjt abgezogen wercen, es wurbe ifnen aber ein getwifies Nianß gejęt, incem bie Steuern uno Srumb: laften zujammengenommen nicht über 30 \$roc. Des Nohertrages betragen follen, und ba fene im Durd)ínitt auf 12 fi. $13 \frac{1}{8}$ fr. gefest wurben, fo blieben für bieje 17 fi. $46 \% / 3$ fr. von 100 fl. übrig; v. Rremer, II, 60. Li inven, I, 72. Diefe Bermincerumg Der (S)runtgefälle, eine für bie Bereditigten Garte Maß̈regel, trat vom 1. November 1789 an ein uno tourbe fidon 1790 mit bem ganzen jofephinifden Brundfeucr- 
fyfteme von \&eopolo II. wieber aufgethoben, Dodh follten twenigitens von jest 'an bie Gerrifyaftlichen (Srunditüfe eben fo hod als bie unter= thänigen (bäuerliden) befteuert werden, worats für bieje cine 2tbgaben= verminoerung entfand. \&inoen, I, 76. Durch Das Steuerproviforium yom 8. Februar 1819 für einen Theil Der \$rovinzen, in Denen nach

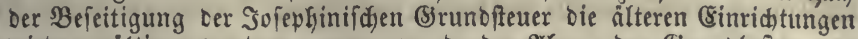
wieder gültig getworben waren, wourbe Der ABzug Der Brundlaften ver= oronet. Die virecten Stettern 2c. S. 5. - Das \$atent pon 1817

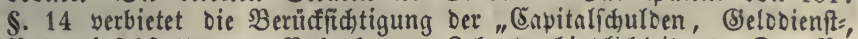

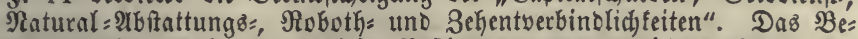
oủrfuís einer ABbảnderung Diefer $\mathfrak{B}$ eftimmung wurbe nidbt verfannt. In

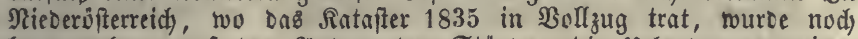
furz vorber, auf Den Antrag Der Stände, Die Hlebertragung eines Theiles Der (Srunofteuer bon belaftetem \&ande auf Die Beredhtigten ver=

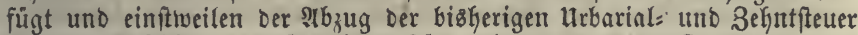
yon Dem An 1834. Während unbelaftetes Esigentfum von 100 fi. Seinertrag 16 ff. $55^{3} / 4 \mathrm{fr}$. giebt, io tragt ber belnftete Esigentfyumer nur $13 \mathrm{fl} .13 \frac{1}{2} \mathrm{fr}$. uno Der $\mathfrak{B}$ erechtigte Die übrigen 3 fi. $12 \mathrm{i} / 4 \mathrm{fr}$. \&i in Den, I, 555. II, 14

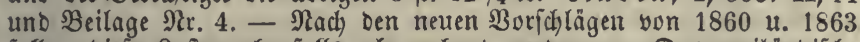
follen bieje saften ebenfalls abgeredjnet werben. - Das mailäntijhe Ratafter trifft Den (Srundeigentfümer nad) Naaß̧gabe feines feften ober

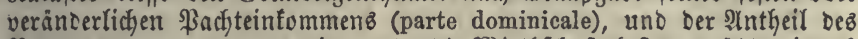

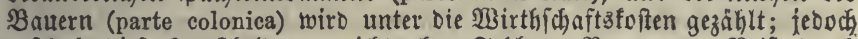

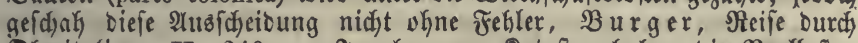

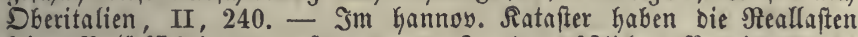
feine Berüffichtigung gefumben. - In Den siftichen \$rovinzen oes preusifichen Stantes gab ezs viele Banuern, weldye Befälle in Beld ober Früchten an Die Domanencafie entridfteten und Dafür von cer (Sirund: feuer frei geblieben waren. Naan muß̈te baher bei ben (S)efälnblöfungen einen Der länblichen (8rumbiteter entiprechenden Theil ausidueioen uno als Eteuer fiefen lafien. Um Die Befizer hiezu geneigter zu madjen,

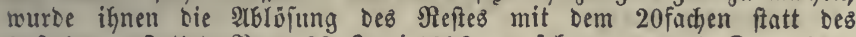
25 fachen geftattet, $\mathfrak{3}$. ๒. 23. Juni 1836, zuriaffgenonmen 1. Dec. 1843. S屯immelpfennig, Die prenßi. Directe Steuer, I, 42.

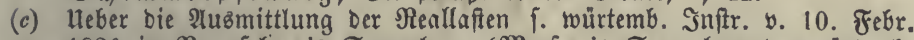

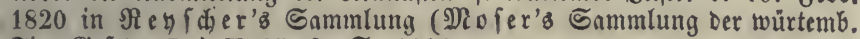
Fin.=(S)efę̧e, II.) XVII, 2. ङ. 1104.

§. 309.

um biejer Forberung Der Seredtigfeit zu genthen, hat man in Den meiften beutichen Stanten bei ber Rataftrirung jebez (Sirunbftücfes aud) Die Sirunolaften forgfältig erforfdyt, ifren mittleren Betrag in Belo berestyet uno von Dem Reinertrage

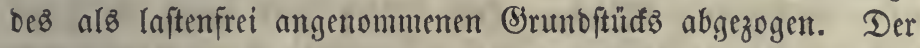
Uleberreft bilbet ben fteuerbaren Ertrag bes belafteten Eigen= thưmerz; zugleid) wirb aber von bem Berechtigten eine bejonbere (B)efälufeuer erkoben $(a)$. Dießß Berfahren gewährt ben Eigen= thümern bolle Sicherkeit unb $\mathfrak{B}$ equemlichfeit, nur wirb baburd) bie Rataftrirung viel umftänblictser uno foftbarer. C\&8 wäre

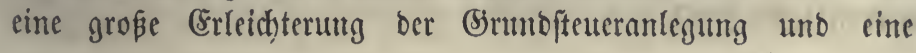


Bercinfadjung ber jäbrlidjen Steutererbebung, wenn man bie

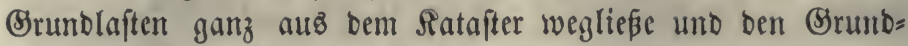
eigentlyümer ermädbtigte, bem Bered)tigten bei Der Entrid)tung

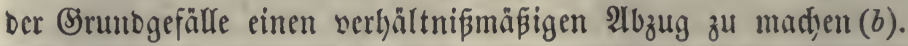

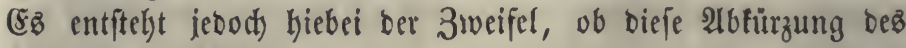

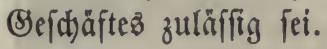

(a) 3. B. bab. Brunbiteueroronung v. 1810 , §. 4 : 3efnten, Beeten,

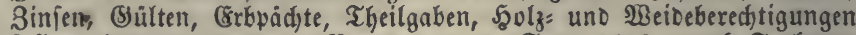
follen abgezogen werben: Beroron. v. 6. Sept. 1813: aud Frohnen, Die auf einem Eruntfüfe haften (Dagegen ift nad) Beroron. v. 4. När 1811 Der 26zug Des Şanblohns unb Sterbfalls nidyt geftattet, weil fie nicht jährlid eintreten; ein unbefriebigenber (Sruno). - E Ebenio würtemb. (Sef. v. 15. Iuli 1821, §.21.22. - İm Siroßj. S2efien

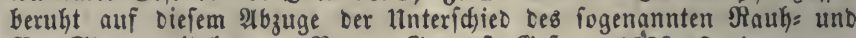
Pur= Steuercapitalez. - Bayer. Sirundit.: (Se). v. 1828, S. 4.

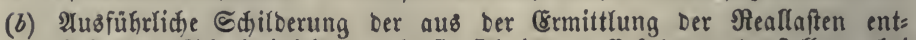
ftehenden Schrierigfeiten, wie fie fich in ber Erfahrung barfelfen, bei

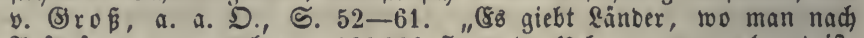
शैufopfering von mefreren 100000 fi. zu Der Heberzeugung gelangt ift,

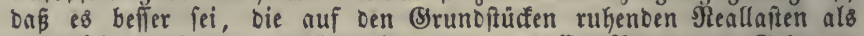
gar nidgt vorkancen zu betradjten unb Deml Cmpfänger umb (S)ber zu

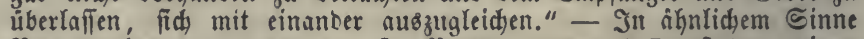
Benzenberg, II, 283. - In Babern wurbe 1677 geitattet, einen entiprechenden 2 ibug an Den Grundaften wegen ber Brunofteuer zu

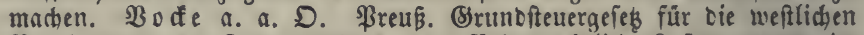

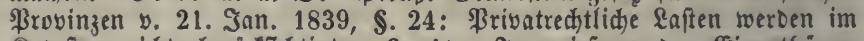
Rataffer nicht berüffiðtigt. §. 41: In wieferme Der Eigenthümer yon einem Berechtigten Entijhádigung verlangen fann, beftimmen bie beftehenden Sejeģe.

\section{§. 310 .}

(Segen biefer żweite einfadjere Berfahren laffen fith folgende Bebenten erbeben:

a) Bei verwidfelten bäuerlid)en Berbältniffen entîtehen oft zwifden ben Beredtigten und \$flidytigen Streitigfeiten über

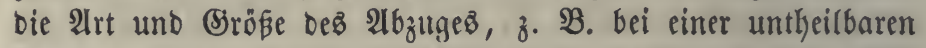
Reiftung, bie in Selo angeid)lagen werben muß, weil bie $\mathfrak{B}_{e}=$ red)mung fdywierig ift und bie beiten Betheiligten über bie= felbe verfdiebener Mleimung fint. Dieß wirb burd) bie forg=

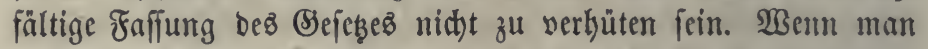
aud) eine (eid)te, unfoftipielige Sd)lid)tung fold)er Streitigfeiten, etroa burd) ein Sdjiebrgeridt, anoronet uno für baffelbe cine Inleitung (Inftruction) auffellt, fo bleiben Dod) Beftswerlid)= feiten, yon benen bie Steuerpflidytigfeiten lieber frei erhalten werben follten $(a)$. 
b) Der Sefälrberectigte wirb hiebei mittelbar (inbirect)

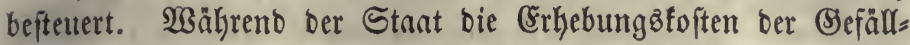
fteuer eripart, ift eş für ben Srumbeigenthủmer läftig, baß̧ er bieje Stetter yoridjießen mußs. Bei ben mur von 3eit zu 3eit

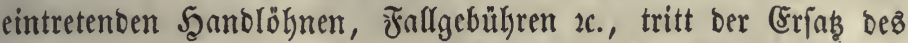

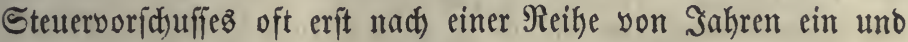
fommt erft bem Erben oder Räufer zu Bute $(b)$.

c) Bei manḑen Befällen, vorzüglid) bei 3ehnten, hat ber Berechtigte verfchiebene Einfammlungs $=$ Tramb̋ortfoften, $\mathfrak{B e r}=$ lufte u. ogl. zu tragen, auch ruken auf bem 3ebnten bäufig $\mathfrak{B a u =}$ uno anbere Raften (II, \$. 70 a). Dem (Sefällpflictigen muß bie ganze (Entrichtung in 2 lbug fommen, Dem Berechtigten aber barf nur ber nad) Beftreitung jener Roften übrigbleibende Theil alsె fteuerbares Einfommen angefebt werben, feine Steuter= iđ)ulbigfeit ift folglid) geringer alz bie bem Srunbeigenthümer zu geroährende Erleidterung. Dhne Rataftrirung ber Sefälle läßjt fith Diefe Forberung ber (Serechtigfeit nid)t nuşfüfyren.

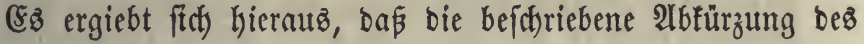
Ratajtergefdäftes mur on zu empfeblen ift, wo bie Srundaften meiftenz fđjon abgelöft ober wenigitens in eine einfactse form umgerwandelt finb, wie bieß alferbings in neuefter 3 eit in ben meiften Ränoern gefdehen ift; ferner in bem Falfe, wo ber Bereç)tigte 2luălänoer ift $(c)$.

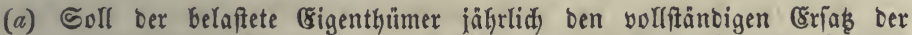

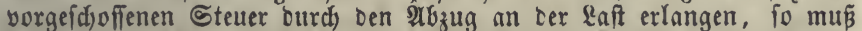
es befannt fein, Den wievielifen Theil der ganzen アiente Des Grund:

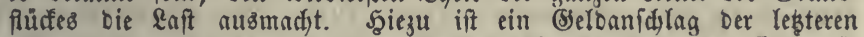
exforberlich uno wenn mehrere (Sefallberedstigte vorhanoen fint, fo

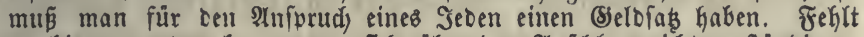
es Gieran, oder fann man fid liber ben P(nid)lag nicht berftindigen, fo fonnte nur etwa angeoronet werben, Dá̧ von jeoer \&eiftung an bie Bered)tigten Der ebenjovielfte Theil zurúdbefalten werbe, als bie Steuer

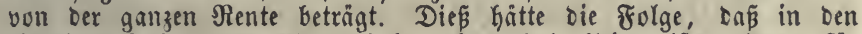
einzelnen Jahiren Der 2 tbzug balo gröper balo fleiner iff, als ber für

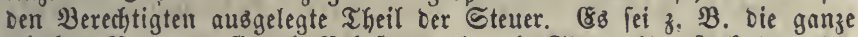
mittlere Siente 18 fl., Die Belaftung $1 / 3$, Die Stetter $1 / 6$, fo fat an Der Steuer von 3 fl. Der Eigenthumer 2 fi., Der Bered)tigte 1 fi. zu tragen.

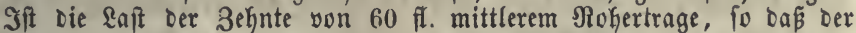
2rbag von 1 fl. $=1 / 6$ bes Sefinten ift, uno finft in einem einzelnen Sakre Derielbe auf 48 fl., Der 3ehnte auf 4,8 fl., fo wáre ber Abzug bon $1 / 6$ mur 0,8 f., wákrend Der Belafete ohnefin yon ber Brund:

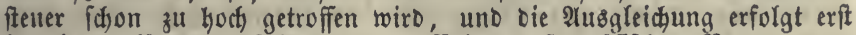
in einem längeren Seitraum. - Bei ber franzöfifdien Beroronung: Il (le propriétaire) est autorisé à retenir la contribution de la portion du revenu, dont il ne jouit pas, Rec. Art. 329, bleibt eş unbeftimmt, 


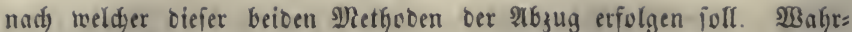
(d)einlid) geidhiefst es nad, ber ztweiten und zwar fo, Daf ber (Sigen-

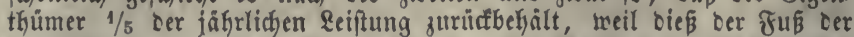
Srundfteuer fein follte. So veroronet auds bas angef. bayerifdse (Sefess

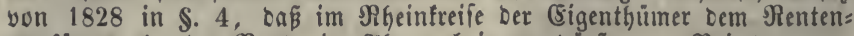

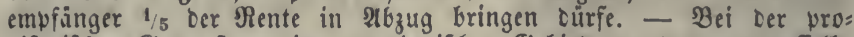
viforifien (Sruntfeuer in venezianifden (S)biete wurbe 1815 daffelbe vorgefdrieben. \&inden, I, 193.

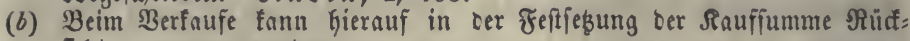
fid)t genommen werben.

(c) In Bayern wurbe in Şinfidt auf oas Brunbentlaftungsegefęs v. 4. Iuni

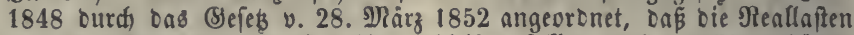
aus sem (Sirundifeuerfatafter hinwegbleiben follen, ba $\tilde{\beta}$ ber Eigenthümer bie volle Eteuer bezafilt uno für bie nod) nidjt abgeloften (Srunogefälle von Dem Berechtigten $1 / 15$ beß Betrages als (Erfas anipredien Darf. -

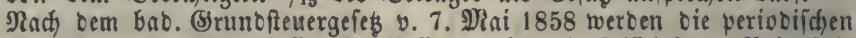

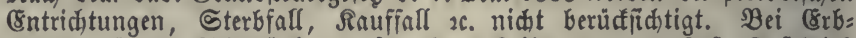
beftanosigütern, Squpfleken auf mekrere Leiber uno ber Laft, Fafelvieh zu halten, wirb bem Grunobefizer bie $\mathfrak{a n f t}$ an feinem Eteueranfilage abgejogen, bei anberen (Sefällen geichieht bießs nicht, ongegen wirb ifhm bie von bem Sins =, Bsult =, 3ehnt = und sibeideberedytigten entriditete (Sefälliteuter ausbezablt. Diefe Pnorbnung berubt wahricheinlich auf

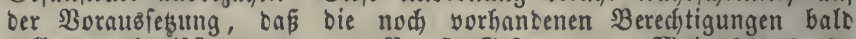

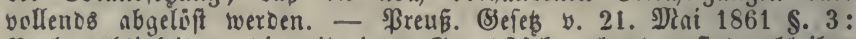
Realgerechtigfeiten, Die mit einem Srunoptud verbunben fino, bleiben ebenio außer Betracht alz Reallaften uno Servituten. - Nach bem

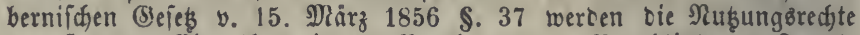

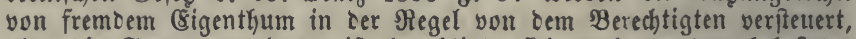
aber bie Eteuerverwaltung if bereditigt, fid aud an ben belafteten Brunbeigenthumer zu halten, $D$. h. Die Sruntente ohne 2abzug für \&aften zu beiteuern uno Dem Esigenthümer zu überlaffen, Daß $\mathrm{er}$ oem Berechtigten ben 2 bुug madbe.

\section{§. 311 .}

Es ift ftreitig, ob uno wieweit Die Brunofteuter in eirtem Ranbe nady ifrer anfünglidyen Feftegung ofne Ungerect)tigfeit uno Radytheile verïnoert werben bürfe. 3ur Entidyeibung bier= über ift es notfwendig, bie $\mathfrak{W}$ irfungen einer gleidb blei= benben (5) rundefer auf bie Şreife ber Eänoereien zu unterfudjen, weil bie $\mathfrak{B e r t b e i b i g e r ~ b e r ~ U n v e r a ̈ n o e r l i d f e i t ~ a u s ~}$

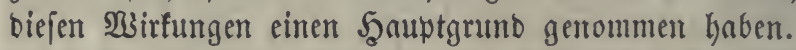

Benn in einem Ranbe feine anbere Canabung befteft, alв Die (Srunoftèter, uno biefe unveränberlict) ift, fo wiro fie wie eine Brunblaft oder eine Berringerung ber Frudftbarfeit bei Der Erwerbung ber (5runbftüfe in Anjalag gebrad)t werben. (Sine folct)e fefte Sirunoftener bemirft aljo unter übrigeng gleidfen

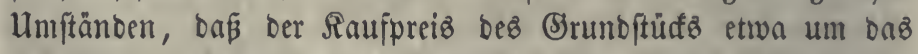
20,25 ober 33 factje iffres Betrages nicbriger ift, als wenn fie nidft vorkanben wäre, uno ber Säufer wirb yon ifgr nidyt 
befdywert, weil er nur ben nath Ilfautg ber Steuter itbrig blei= benben Reinertrag bezahlt hat. Dagegen leibet Derienige, weldjer bas (Srunbftüf nad) ber Einführung ber Steuer zum erften Miale verfauft, ben vollen Berluit, und ber Staat erjueint ifym gegenüber wie ein (Sefärubered)tigter, benu ber $\mathfrak{W e r t h}$ bez immer: währenben 2lniprutbs nuf bie Stetter wirb gerabe burd) iene Summe aubigeorüaft, um weldje fith) ber Wreiz ber Länbereien erniebrigt. $\mathfrak{W e r}$ nidjt verfauft, feht wenigftens feinen $\mathfrak{B e r m o ̈ g e n s}=$ anjd)lag uno feinen Crebit verringert. Sebe Steuererböhung bringt eine ähnliche 2 Birfung herbor.

\section{§. 312 .}

Diefe Wirfung ift nidyt einer foldyen Srumbiteuer allein eigen, fonbern fann bei jeber Sdjaķung vorfommen, bie alf einen verfäuflid)en Begenftand von verünberlid)em Sfreife gelegt wird uno baker jeben Eigenthümer beffelben trifft, woferne fie nur vereingelt fteht, z. $\mathfrak{B}$. bei ber Steuer von Scäujern, realen

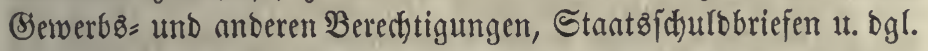

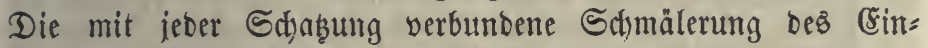
fommens brüt fid) in fold)en Fällen in einer Preiberniebrigung Der befteuerten $\mathfrak{B e r m o ̈ g e n z i t h e i l e ~ a u s , ~ w a ̈ h r e n d ~ a n d e r e ~} 2$ rten ber

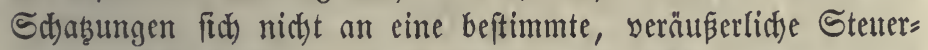

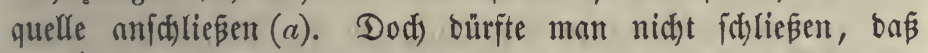
eine foldye ältere (sruntofteuter, weldye bie einzige Schabung wäre, von ben $\mathfrak{B}$ efteuerten gar nidft alB $\mathfrak{B} e$ fdjwerbe empfunden würbe. Denn 1) zeigt fith Der (Sinflup ciner foldhen (Sinub= fteuter auf Den \$reis ber Riegenichaften feimesiwegs in allen Fällen. Sin Theil ber \&ändereien befindet fith in fefter Şand

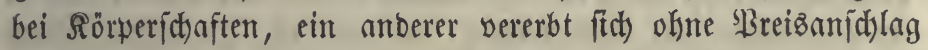
an Rachfolger in Fibeicommiffe, an einzige ober bevorzugte Rinber unb Teftamentzeerben, unb bei Erbtheilungen unter (B)efdwiftern pflegt ein niebriger 2ufhlag zu Sirunbe gelegt zu werben. In allen biefen Fällen wirb fein von ber Steuer erniebrigter Jjeiz bezablt, uno ein foldyer zeigt fith nur etron bei einem $\mathfrak{B}$ ermögenbuüberid)lage, 子. $\mathfrak{B}$. für eine $\mathfrak{B e r p f a ̈ n b u n g . ~}$ 2) Der SHeis ber Srundftücte ift wechjelno, theils wegen ber Beränberlidjfeit oer Srunbrente (\$. 306), theils aud) bei einerlei Sröße Derjelben wegen ber Beränderungen im Begefre unb 
Ingebot fowie im 3inşuß̧e, I, §. 119. Reben biejen häufigen

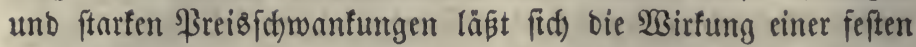
(B)unbfteuter nid)t hernusfintoen, bieje erfd)eint bem (Figenthümer

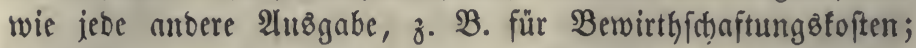

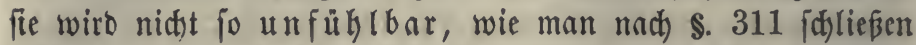
follte, weil man ons beutlidje Bewufptjein nidjt hat, baß́ man ifretwegen befto wohlfeiler gefauft habe (b).

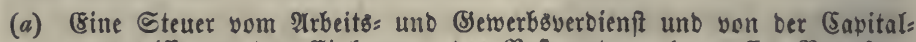
rente trifft nur Das Einfommen Des Befteuerten, ohne Deffen Bermogen Dem Berfehroberthe uno Streife nad zu erniebrigen. Benn ein Lant= gut yon 10000 fi. Sreisanif)lag uno 400 fi. Siente mit 80 fi. befteuert wirb, fo bleiben nur nod 320 fl. labrig, uno ber Preis wirb vielleidst auf 8000 ff. finfen, es gehen alfo an ber शnfaufbfumme 2000 fิ. ver: lorel1. Eiu Raufmann, Der von 10000 ff. Sapital 800 fl. Sins und (S)twerbsgetwinn bezóge und bavon 80 fi. Steuer gäbe, hätte in feinen Sinfinften gleiche Esinbure, uno fein Capital trüge ihm $4 / 5$ Broc.

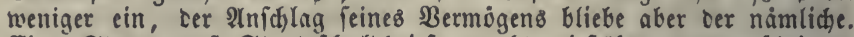

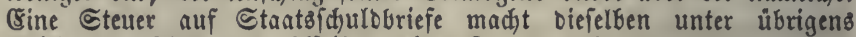
gleidhen Umptänen wohlfeiler, eine Steuer auf Unterpfandsbarleken fann eine foldje folge nidht Gaben.

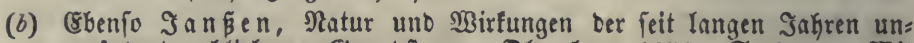
verindert gebliebenen (Srundfteuer, Droenburg 1851, ङ. 35. - शRit ten Reallapten berbält es fíd barum anbers, meil bieje oft einen viel färferen Thzil bes Seinertrages hinwegnełmen, auch Das (Sepräge ter

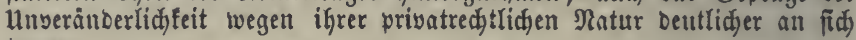
tragen.

§. 313 .

In ben vorftekenten Betradftungen (\$. 311. 312.) wurbe borausige fteuer. Wenn bagegen alle Cinfünfte, alfo aud) alle Arten, Bermoggen werbend anjulegen, gleidfmäpig befteuert fino, fo fällt jene Wirfung ber Srunofteuer auf bie \$reife ber Srund= ftüfe ganz binweg, weil ber Beftzer eitter Belofumme, bie zu einer einträglict)en 2 Inwentung beftimmt ift, in allen Fällen yon bem baraus fließ̧enben Ertrage eine 2lbgabe geben muß und folglid) feinen 2bhaltungżgrumb mehr hat, (5runbeigenthum

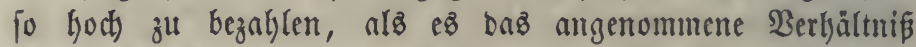
z'vifd)en 3inz unt Stammbermögen mit fid) bringt. Wurbe ein Srunbftüa, weld)es borker 100 fl. gegolten und 4 fl. Rente getragen hatte, mit $1 / 8$ ber leksteren befteuert, fo fanf ber Spreis auf $87 \frac{1}{2}$ fl. Gerab. Werben aber päter alfe $\Re$ enten in gleidjem Maape in bie Eteuer gelegt, fo taß übernll von 4 ßroc. nur $3^{1 / 2}$ ober 1 fl. von $28^{4} / 7$ fl. Stammbermögen übrig bleiben, 


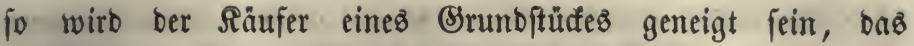
$284 / 7$ fache ber nummehrigen freibleibenben Rente, D. h. wieber wie borker 100 fl. bafür zu bezahlen, benn er fteht fith bei biefem ßreije ebenjo gut alz bei einer anberen 2lnlegung feines Bermögens. Waren, fo lange bie Srunbfteuer allein beftand, bie Shüterpreife niebriger geworben, fo müffen fie bei bem Şin= zufommen anberer $\subseteq$ d)abungen wieber in bie Şöhe gehen, weil fo lange, alsె man aus Ränbereien eine Gökere Rente erhält, ein ftärferer Begehr nad) benfelben eintritt. Se vollfommener

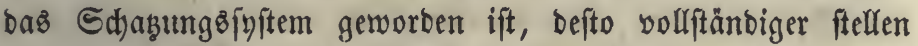
(tid) biejenigen \$reife Desి (Srunbeigentfums wieber her, weldye ohne alle Stjaksungen ftattfinden würben, und nur etwa barum, weil biefe gewöhnlich ftärfer auf bas liegenfidaftlidye (sigenthum fallen, als auf bas berweglidye Bermögen, bleibt vielleidyt uod) einige Erniebrigung ber Ränbereipreije in Folge ber Erunb= fteuer übrig $(a)$.

(a) Unter Der Boraubิ

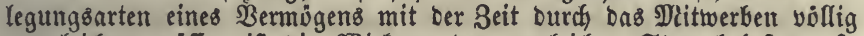

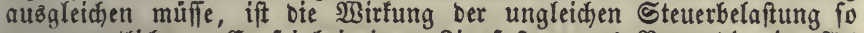

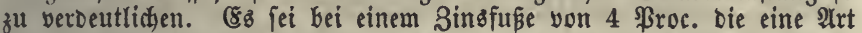
bes Bermögens mit $1 / 2$ Froc. ober $1 / 8$ ber $\Re$ iente befteuert $(z$. $\Re$. länbereien und Şüu(er), eine andere Art mit $1 / 4$ \$roc. ober $1 / 16$ Der Rente (3. 2B. Die vom Eigenthumer zum Bemerbsbetriebe gebraud)ten (Capitale), eine britte 2 (rt gar nicht belegt ( (Eapitale), fo läßst bie Steuer ben 3 (Elaffen von Bermogensbefizern $31 / 2-3^{3} / 4$ unb 4 \$roc. Der Fente übrig. Diés fann nicht fortbauern. Die abnefimenoe Nadjfrage nady Riegenfdjaften wirb ben Sireis ber: felben erniebrigen, zugleich wirb man mefr auszuleiken fudjen und ber 3inzfü wirb berabgehen. Sinft Derfelbe auf $3^{3} / 4$ ßroc. uno ber \$reis Der Riegenfichaften auf $93 \frac{3}{4}$ Broc., fo fieken alle Drei Berwendungen

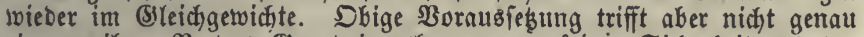
ein, weil z. B. Das Brunbeigenthum twegen feiner Sidjerkeit und ber

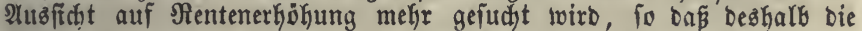

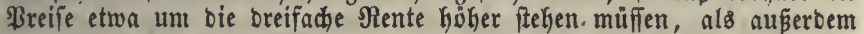
(etwa $281 / 2$ fad fatt 25 fad), - weil bas wechfelnde scitwerben und

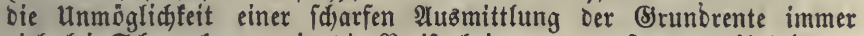
vielerlei Shwonfungen in bie \$reife bringen, - ferner weil bei Dem Aubleiken viel auf ben Brab von Sidjerheit uno Bequemlidfeit bes (5) läbigers anfommt, uno weil ein geringer unterfhieb nidjt zureicht, um viele Capitaliften zu Setwerbsuntertehmungen, ober biskerige unter: nefimer zum शtubleiken zu betwegen 2 .

\section{§. 314 .}

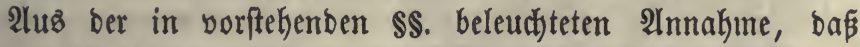
eine burch lange 3eit gleid)gebliebene Brumbfteuer für ben ieşigen Befţer ganz unfüklbar geworben fei, hat man gefolgert, 
biefe Steuer folle butrdyaus unseräntert bleiben, inbem fie bam einem Theile besి Srunbeigenthums entipprest)e, ben bie früberen Berfäufer ohme Eriana abgegeben hätten uno ber gleidjam bem Stante antheimgefalfen jei, wäkreno iebe Berminberung ber

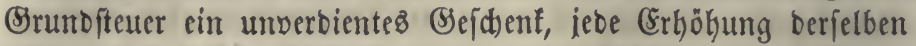

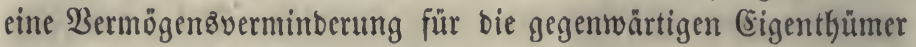

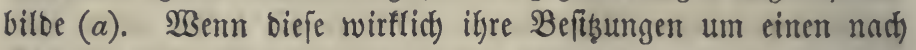
Berbältniß ber Steuer verminberten \$reis erworben bätten, to wäre bie nad) Abzug ber Steuer übrig bleibente Rente alb

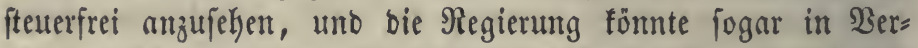
futt)ung fommen, biefe Eigenthümer als Ermpfänger eines un= belafteten reinen (Einfommenz gleid) anberen Stänben, bie cin fold)ez geniefen, nod) ciner weiteren Sd)ab̧ung zu unterwerfen (b). ItUein faft in alfen Stanten ift burd) bab Şingufommen anberer St)ab̧ungen iene Preizernicbrigung Der befteuerten Brumbitüce größstentheils wieber aufgelyoben worben (\$. 313) unb felbft ba, wo bieß nidft geidechen wäre, müpte bodi bie behauptete $\mathfrak{u n}_{\mathfrak{n}}=$ füh)lbarfeit aus ben in \$. 312 angegebenen Esủnben bejweifelt werben. Wird endlich bie (Srunbfteuter nid)t gejeslid) für un= veränberlid) erflärt, werben vielmefre 2 bänberungen vorbehalten

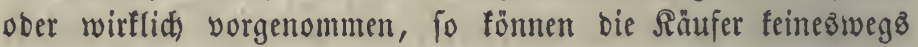
auf bas Fortbeftehen ber gegenwärtigen Steuerfäß̨e bauen $(c)$.

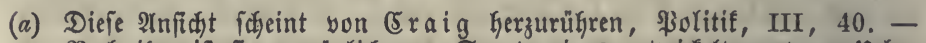
Nach ifm ift fie vorzuglich von Sartoriub entwidfelt worben, lleber

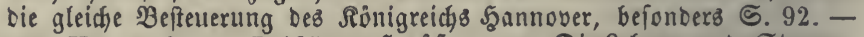

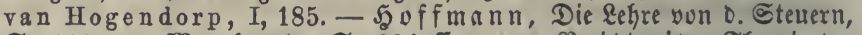
ธ. 110 . - Murhard, ธ. 294 ff. - v. Prittwib. Theorie Der Steutern uno 3olle, $\mathfrak{S}$. 132 . - Over de belastingen der vereenigde

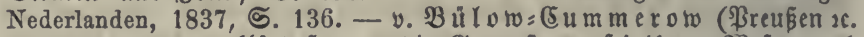
II, 181, 1843) erflät jogar, die (Srunofteuer fet ifrem 23 ejen nach feine Steuer, fondern eine Sirunorente, uno glaubt, Der Stant fei nicht zur neuell 2inlegung einer foldjen berechtigt, soeil Dieß eine (Snpitalsberwubung ober eine Sd)mälerung bes (S)runovermỏgens fei. -

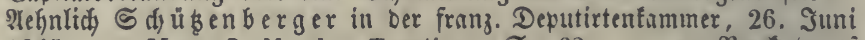
1845. - Mac Culloch, Taxation, ฐ. 62. - v. SBeffeodri

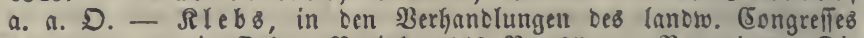
bon 1848 uno in Defon. Neuigf. 1849 Nr. 95. - Bergiub, Die

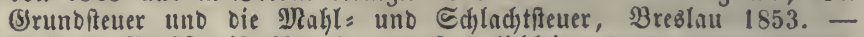

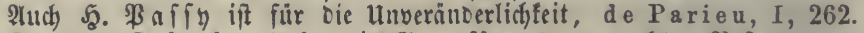
Dagegen Rrón ffe, Heber Die Srunofäbe einer geredaten Bejteuerung, 5. Abhanolung, S. 276. - B̊enzenberg, Heber bab Satapter, I,

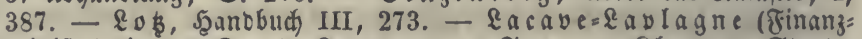
minifter) in cer Deput. Siammer a. a. Tage. - Sle mm, Stants: wirtfídaftlide Blätter, III, 5. - Sgarfort, Bemerfungen über bie (5)runopteuerausgleidung, Berlin 1849. - v. \$a to ro a.a.D. S.5.- 
Sañ̄en a. a. D. - ๖. Struenfee, Die Brundfetuer mit bef. Beziefung auf Das Sỉnigreich \$reußen, 1850, \$. 81.

(b) शR urharo baut jo feft auf bie unfühlbarfeit alterer (Srundftettern fitr

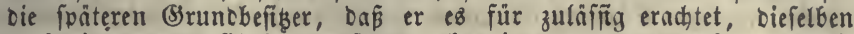
noch einer neuen (Sinfommenfteuer neben jenen zu unterwerfen, weil fie ionit gar nidgt mit ifrem eigenen (8infommen in 21njprud) aenommen

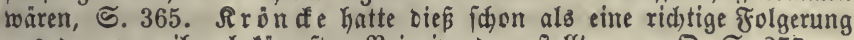
aus Dem youl ifm befämpiten Principe Dargeffellt, a. a. D. S. 277. Ebenbahin zielt ber Dloenburgijde Einfummenfenerentwurf von 1850.

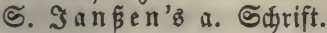

(c) v. $\mathfrak{B}$ a to w a. a. D. zeigt, baf́ bie preupifide Sirunofteuer viele Ber= änoerungen erlitten hat und baß bie neueren (S)efez̧e wieberfjolt eine

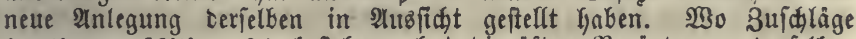
(centimes additionnels) beftehen, Gat bie oftere Beränberung berfelben obige $\mathfrak{B}$ irfung.

\section{§. 315 .}

Die Forberung ber Berechtigfeit fowie Der Staatsflug= Keit, Daß bie gegenwärtige mittlere Sirunbrente fowohl burch)=

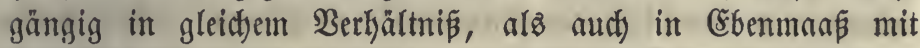
ben anberen 3weigen bes reinen Einfommens befteuert werben folle, baß folglid) wahrgenommene Mipoerhältniffe in beiben Simfitten zu bejeitigen feien, fülyrt zu Seränoerungen in ber Srunofteuer, aud) wenn gleidyzeitige und gleid)uääige 2lenbe=

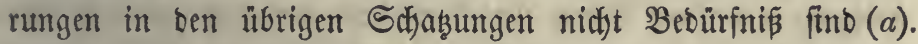
Finbet man bie (Srunbfteuer in 2(rfgemeinen zu hod) ober zu niebrig, fo läpt fich leid)t burch) A(bönderung bes Steuer= fǘses helfen. Die Urjadse hievon fann fowohl in einer von 2lnfang an feblerbaften Anlegung ber (Srunbiteuer alz in ipäteren $\mathfrak{B e r a ̈ n b e r u n g e n ~ b e r ~ v e r f d h i e b e n e n ~ C s i n f u ̈ n f t e ~ l i e g e n , ~ i n = ~}$ Dem die Srunbrente mit ben Fortfdritten bes 2lnbautes, ber Bebolferung uno bes $\mathfrak{W o b l f t a n b e s}$ angewachjen ober aud bei verminbertem aušwärtigem 21b fake unb gejunfenem ßreije ber Bobenerzeugniffe wenigftens vorübergehent niebriger geworben ift. WBas Den angeregten 3weifel über bie rechtlid) 3uläffigfeit einer foldyen Steuerberänbenung betrifft, fo ift offenbar berienige,

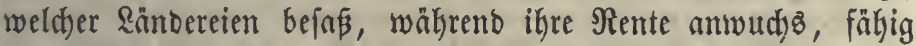
uno berpflidstet, eine Steuererböhung zu ertragen, und wer feine

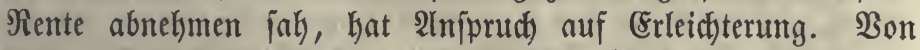
foldsen Erwerbern, weld)e bie Srundfüte um einen geminderten Anid)lag an fich brachten, gilt (Sleidjes, \$. 312 Nr. 1. Nur biejenigen (Erwerber fönnen in Nadbtheil fommen, weldye erft fürzlid) nad) Der erfolgten 3unahme ber Rente \&ano für einen 
berfelbent entiprectentent \$reis gefauft haben, ohne babei auf

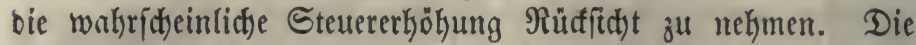

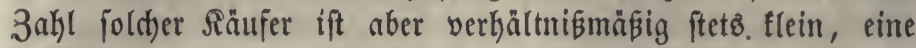

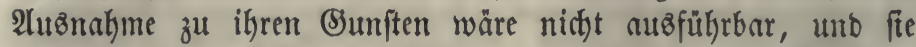
haben auf ithre Befaht hì gefauft. Şätte bagegen eine Ulebers bürbung Der (Srunbeigenthümer in $\mathfrak{B}$ ergleid) mit anberen Stetter= pflițtigen lange gebauert, fo würben alferbingż viefleicht viele Srunbftüfe um niebrigere \$reife an bie jeşigen Befizber gelangt fein, bie beß̧̧alb von einer Steuerermäßigung einen unverfyoften Bortheil zögen unb bei ben von ieß̧t an erfolgenben \&ano= veräußerungen größere Sreife erlangten. Man fönte burd) bieje Betradtung bewogen werben, bie Srumbfteuer nur um

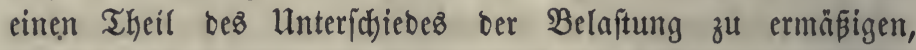
zugleich) aber bie anderen Sdjakzungen zu erhöhen, um fith ber allgemeinen (Sleid)lyeit bes Steuerfüez zu nähern. Sndę́ finten auti) für biejen $F a l l$ bie in $\$$. 312 entbaltenen Bemerfungen ifre Antwentung, insbejonbere ift zu bebenfen, baß sänbereien

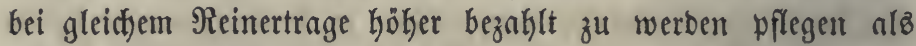

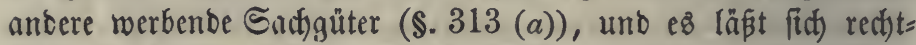
fertigen, wenn ber Stant fid überhaupt lebiglid) autf bas $\mathfrak{B} e r=$ hältníß ber Steuer zu ber Rente hălt, ohne bie Bebingungen zu beacten, unter benen bie leştere von bem Srunbbefízer erworben worben ift, wenn er aljo blopi barauf bebadyt ift, von ber Brunbrente eime eben fo große Duote zu erheben, als von anberen Einfünften $(b)$.

(a) Die englifaje Brunbfteuer, auf bie man fiđ oft als auf ein Beifipiel ber Unveränberlichteit bernft, ift von eigenthümlicher Art. In Englnno

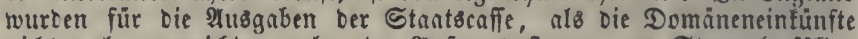
nidat mekr nušreiditen, neben ben Alufwanosfteuern uno Stempelgefällen lange 3eit Ginourch periobifhe Steuern bom (S)runbeigenthum, Die

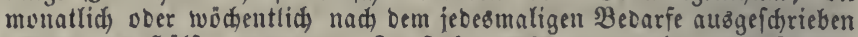
twurten, zu Shtilfe genommen. Im Sahre 1693 rource eine neue Grund= fitterbefdreibung verfertigt, welde cinen (Sefammtanichlag von 10 \$rill. \&. St. ergab. Şievon twurben feitbem balo 1, balo 2, 3 unb in ter Saälfte Des ganzen 3eitraums 4 Sdilling vom \&. St., D. K. $1 / 20-1 / 5$ als Steuer erhoben, ver Durchidnitt war 3 Sd. 3 ஒ. vom \&. St.

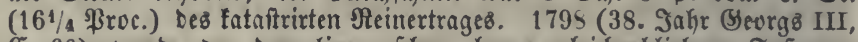
(5. 60) wurbe Der Damalige, fajon lange gleidjgeblietiene $\widetilde{F}$ 4 Sh. vom \&. Der शnichläge von 1693 als immerwährent erflät. Die Gumme war 2.037627 \&. Sugleid rourbe auf \$itt's Intrag in bem nämlichen (Sefes bie unveränberliche Srunofteuer für a 6 f it u f lid erflärt, fo Daßj Der Şigenthümer gegen .Singabe einer getwiffen Gumme in Staalspapieren fid von Diefer Steuer befrcien fonme. Jebes \&. St. (Srundfeuer foll Durd lleberweifung bon 1 \&. 2 Sd. Doer 
$11 / 10$ \&. Sins in 3procentigen Sdulbideinen, aljo mit $362 / 3$ \&. Nominals betrag berfelben abgelöit werben. Diefe Sbligationen ftanden Damals zu 50 , Die $36 \% / 3$ \&. Lwaren folglich mit $181 / 3$ \&. zu faufen und wer fie um dicien ßreis erwarb, bezng 6 Proc. Sinfen, wåhreno er nur 5,45 ßroc. Srunditeuer bamit tilgen fonnte, Der abloffende Srundetgner muste alfo Den $\mathfrak{B}$ ortheil Der Anlegung auf ficheres unbervegliches $\mathfrak{B}_{\text {er: }}$ mỏgen und bie Sidherheit gegen eine füntige Steuererhöhung mit Der 2ufopferung von 0,55 ßroc. Binfen erfnufen. Bei einem \$reife Der 3 proc. Shuldbriefe bon 75 if Die शbfaufşfumme Der $271 / 2$ fadje 2 etrag ber Steuer, bei einem \$reife bon 92 if fie bas 33,73 fache. \$ it

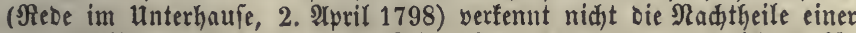

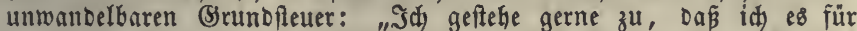
einen urfwrüngliduen Dlangel (an original defect) Der jesigen Berthei=

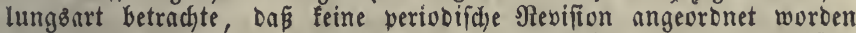

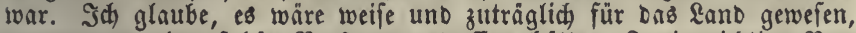
wenn man eine fuldje Boriurge getroffen hätte. 3wei widhtige Bor: fefrrungen (guards) wären nöthig, nämlid, z" verhinbern, Dấ bie $\mathfrak{H} n=$ gleidheit zu grof́ twüroe, uno zugleidjo Berbefferungen nicht zu ent:

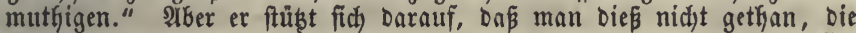
Steuer fhon lange ungeändert gelafien habe und bie Ranofäufe fïh Giernach gerichtet hätten. Das (S)efes ๖. 15. Auguit 1853 (16. 17. Bict. (5. 74) berfügt, Daß̧ man ftatt 10 \$roc. mełr, füuftig $71 / 2$ \$roc. weniger an Sinfen zum शrbfauf zu überweifen habe, alfo für $1 \mathfrak{L}$. Stetter mur 0,925 \&. oder 30,86 \&. 3 proc. Sđulobriefe im Nennbetrage. Nach Dem (Sefes yon 1798 Durften aud andere Berionen bie Srund =

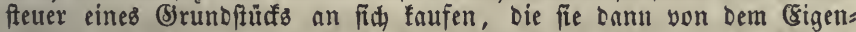

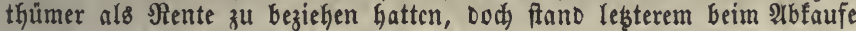
Der Borzug zu. Nach Dem Sefes von 1853 ift Der शrbfauf nur Den Esigenthumern oder Den Errbberechtigten geftattet. Frembe Berjonen Gatten von Der (5rlanbnís oes Anfaufes wenig (Sebrauch gemacht, es waren nur 2073 foldje Räufe borgefommen. Die Rblöfungen bauern noch fort. Die nicht abgelofite (S)rundifteuer belief fich 1858/59 auf 1.135677 \&. mit Einfdhlú von 35596 \&. für Sdjottland, 3. report of ... inland revenue, 1859. - Hendriks in Journ. of the Statist. soc. London, September 1857. Die Beränberungen in Der Srunbrente Gaben bie Steuer im Laufe ber 3eit fo ungleid gemađt, Daß̧ fie in ben ant meiften aufgeblüften (Siegenden nur $3 / 4$, in Lancafhire fogar

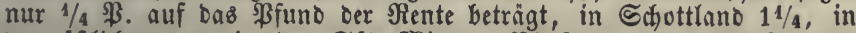
Den offlichen uno in Den GüD= Mittelgraffinaften aud nur 6 \$. ober $1 / 10$ (max.). The Scots Magazine. LX, 275. Rees, Cyclopaed. XX. Artifel Land-Tax. Eine neue tmlegung würde jeboch fhon Darum unauвfülis: bar fein, weil Sdjottlano Durch Die Unionsurfunde Dagegen gefdübt ift. Uebrigens if Dod nur Der Steuerbetrag jeder Drtidaft oer

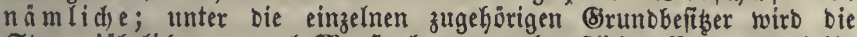

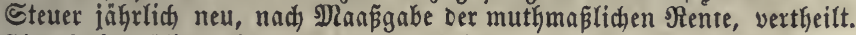
Sinclair, Hist. of the Revenue, II, 340. - Bailly, I, 567-584. Wenn Gieraus bermuthet werben fönnte, Die Srunorente fei in (Sropis= britanien ungebührlich niebrig belaftet, fo ift Dagegen zu bebenfen, bấ

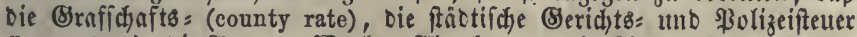
(borough r.), Die Armen=, NBegbau=2Rbgabe und Die Rirchenabgabe Gaupt:

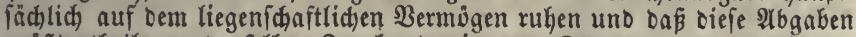
gröstentheils zu Denfelben Swedfen Der inneren Staatzberwaltung Dienen, für welche in anderen \&änbern Steuern in bie Stantseaffe bezahlt wer: ben. Der Belauf Derjelben war um 1850 gegen $91-93$ פlill. fi. (S) neift, Dns englif̧e Srunofteuerfuftem, Berliu 1859. - In an= beren Gtanten hat man nad) fehr veridjiedenen Srundfäzen gehandelt. In ben bereinigten Nieberlanden wurde Der Fuß ber Srunbfteuer (ver- 
ponding) oft verainbert uno oft auf eine orücfenbe Şöhe gebradt, $3 . \mathfrak{B}$. in Doertile auf 42 \$roc. Der Nente. In Seelano twurbe unteriagt, Daß́ ver (Sigenthümer ber Cteuer tvillen fein Lano aufgebe. Over de belastingen .. staande de republick de vereenigte Nederlanden. Amst. 1837. ङ. 125. - Im Rirchenftaat frieg Der Єteuerfuß bis auf $1 / 3$. De Parieu in Journ. des Econ. 2. Ser. XXI. 34.

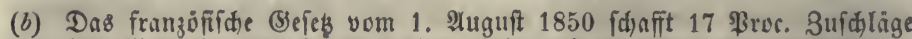
für allgemeine 3werfe $a b$, weldje bisher mit ber (Srunofteuer verbunben waren. Bei anderen Eteuern beftegen fie nod).

\section{§. 316 .}

Fin anderes $\mathfrak{B e r f a h r e n ~ i f t ~ n o ̈ t h i g , ~ w e n n ~ f i d ) ~ e i n e ~ v e r b a ̈ l t = ~}$

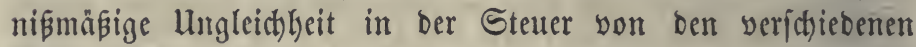

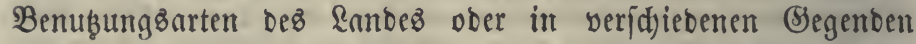
ober bei einzelnen Srunbftiden zeigt. In biejen Fällen ift bie Feeritellung einer gleithförmigen Belaftung nur burd) eine $\mathfrak{B e r}=$ änberung in ben Steueranfd lägen zu berwirfen, weldhe gleid)falls nidht unterlaffen werben foll, benn

1) nuan entbedt bisిweilen Fehler in ben Sdjähungen, bie cine 2 bänberung erforbern $(a)$.

2) Die Sirumbrente einzelner Stủue ober Bezinfe wirb bigz= weilen, iebod) nicht bäufig, burdh) natürlidfe $\mathfrak{B}$ erichlect)terung,

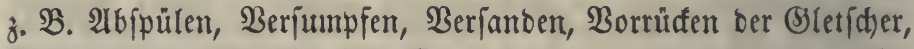
Berfdütten 2c., erniebrigt; fie fteigt aber oft aus foldjen $\mathfrak{u r}_{\mathrm{r}}=$ jadjen, bie von ber Şanblungşweife ber Brunbeigenthünter un=

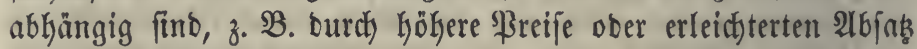
oer Bobenerzeugniffe (b).

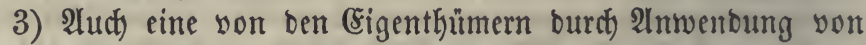
Funft und Fleiß bewirfte Dauernde $\mathfrak{B}$ ermetyrung Desి Fieinertrages begrünoet eine größere Steuerfähigfeit Der erfterent.

Die Bejorgniá, Daß̄ bie Steuererhöhung bei einem vermefyr= ten Bobenertrage von ferneren $\mathfrak{B e r b e f f e r u n g e n ~ b e r ~ R a ̈ n b e r e i e n ~}$ abhalten und ben Sewerbfleís entmuthigen möd)te, ift nicht begrünbet $(c)$, weil cine in ridtigem $\mathfrak{B e r h a ̈ l t n i \beta}$ crböbte Eteuer immer nod) ben größten Theil bes erzielten Mehrertrages übrig läßjt, aud) ofnehin biefe Maafregel immer mur nad) längeren 3wifhenzeiten erfolgt, weil ber Nieinertrag von anderen werben=

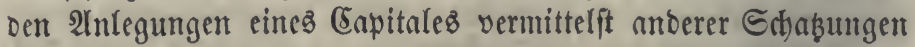
ebenfalls befteuert wird, uno bie vorzüglich einträglid)e Betwirth= id)aftung burd) einen einzelnen Sanbwirth von ber Ertunbfeuer gar nidjt getroffen wiro, \$. 298. Nur eine willürlidje, bns 


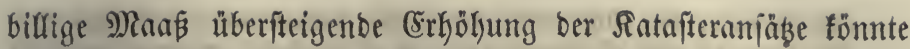
iener Befürdstung Raum geben $(d)$.

2lutb) bei biefem Falle ift ber 3weifel erhoben worben, ob nicht bie zu hohe ober zut niebrige Belnftung einzelner Branto=

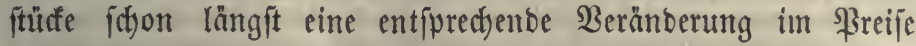
Derjelben bewirft habe, fo baß bie jestigen Beftzer weder einen Injprudf auf eine Steuerer(eid)terung haben, nod auth gered)ter Weife böher belegt werben bürften. Sciernuf ift auper ben

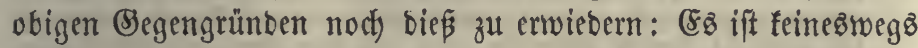

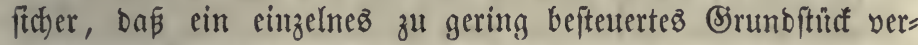
hältnifmäfig höher verfauft wiro, benn ba mant niddt fo leidjt

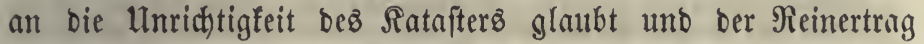
idjwer zu erforid)en ift, fo famn leicht ber Räufer fein \$reiz= gebot gerabe nach bem Steueranjhlage abmeffen. Dauert baz Steigen ober Sinfen ber Srunbrente fort, fo hat ber gröfte Theil ber jeşigen Beftzer von biejer $\mathfrak{B i r f u n g}$ felbet nod) Nutzen . ober Echaben gehabt, und es ift alfo billig, bap bie Steuter= fäz̧e veränbert werben. Die Errfahrung lefrt, Dá bie Eteuer=

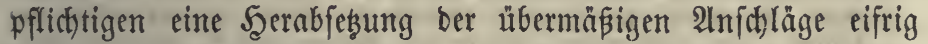
begehren und DanfGar erfennen, eine Erfjöhung ber zu niebrigen

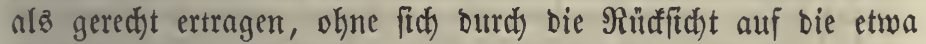
voraużgegangenten Saufpreife hieson abbalten zu lafifen.

Uebrigens ift es wegen ber Srößpe uno Softbarfeit bes

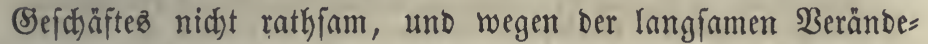
rung im Durdjidnittabetrage Der Eirunbrente nidyt nöthig, bie

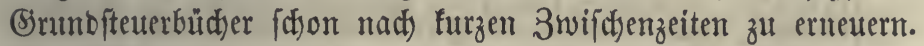
Diefe Maaßregel wirb yon 3eit zu 3eit zum Bebürfnißß, wenn

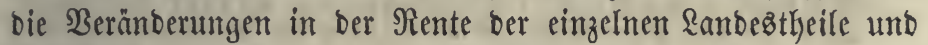
Bobenbenubungåarten fo beträcttlid) geworben finb, baj fie eine empfindliche Ungleidheit im Betrage ber Steter ver= urjadien $(e)$.

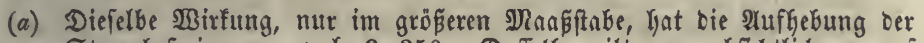
Steuerbefreiungen, ygl. \$. 250. Daffelbe gilt von abfictlichen, auf Begünftigungen gewifiter Ștänce berufenben ungleidheiten. In biefem

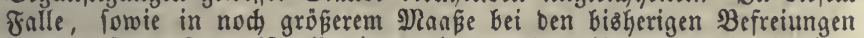
vou ter (s)runbfteuer ift alferdings nicht zu bezweifeln, Dan bie niebriger

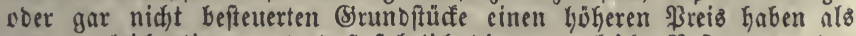

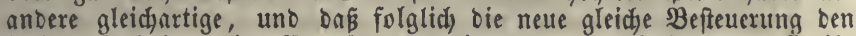
jeşigen Jnhabern eine SBermögenserminberung verurfadyt, wenn fie ifr

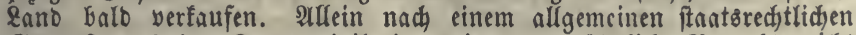

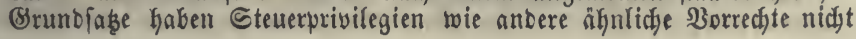


Das Bepräge oer Unwiderruflichfeit wie ßrivatrechte, uno ifgre Bei= befaltung ift um fo weniger mit Der Serechtigfeit zu vereinigen, als Die efemaligen (S)genleiftungen Der Steuerfreien zur Staatsbertheibigung

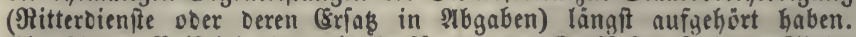

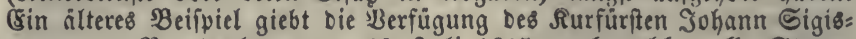
mund yon Brambenburg yom 13. Sull 1615, nach welcher alle ๔teuer= befreiungen, zu Deren Betwilligung er Durd) allerlei Borftellungen ("subet obreptitio und zum Shaben und Berberb unierer \&ande uno \&eute") bewogen war, wieber aufgehoben werben. Subem pflegen foldhe (Stüter weniger oft an Nidtwerwanbte berfauft zu werben und nach läneren Swifichenzeiten hat gewóhnlid, fijon Das allgemeine Steigen ber Srunb: rente die von Der eintretenoen Steuerpflicht zu ertwartenbe \$reizernies

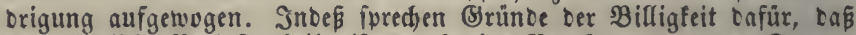
Der plöbliche Berluft theiltweife burch eine Bergütung aub ber Ctants=

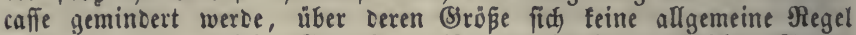
auffinden läst. Diefer Segenfand if neuerlich im preubifden Stante vielfady befprodjen worben. Nadjoem fhon bas (5oict vom 27. Sept. 1810 Den Srunbias ber allgemeinen gleichen Befteterung vertindigt Gatte, war bie Fortbauer Der Befreiung ber Stäbte uno Nittergüter von ber Brunbfteuter nur als einftweilig anzufehen. Das Sefes vom 24. Februar 1850 verorbnet Die 2ufhebung aller Srundfteterbefreiungen,

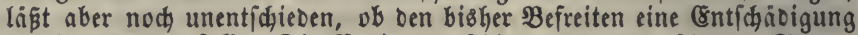
gegeben werden folle. Die Regierung fidlug 1853 vor, $2 / 3$ Des ๔teuer= betrages mit bem 20 fachen (Sapitale zu vergüten, Dießs wurbe aber von Den Stänben nidht angenommen. Der Borfalag von 1859, bei nach)=

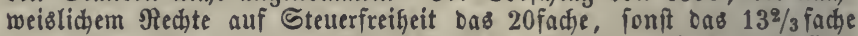
fu bergüten, fam nicht zur Errlebigung, Der 1860 vorgelegte neue Ent= wurf aber wurbe angenommen und am 21. Nai 1861 als Sefes ver= fündet. Die Befreiungen hören von Anfang Deßి $\$ .1862$ all auf. Srumbeigner, Denen ein.privatrechtlicher Titel zur Seite fteht, erhalten Das 20 fadie, andere ons $13 \% / 3$ fadje Der \$lefrbelaftung, Die fie nad Der in jebem \&anbestheile beftehenden Steuerverfaffung zu übernehmen haben würben; ein anberes Sefes vom nämliden Tage oronet zugleidh eine

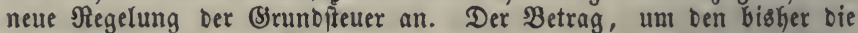
Bstunditeuer zufolge Der $\mathfrak{B}$ efreiungen verminbert war, ift auf 719000 Thlr. berchnet worben. Ausfüfrlid Gierüber $\mathfrak{D}$ a $\{$ der a. a. D. - Die Bergütung twar in Braunidyeig (1821) vollfandig, in Wreimar ift (1821) $1 / 2$, in Sadjien (1834) 3/5, Neiningen (1846) 1/3, Saannover (1826) $1 / 4$ gegeben worben, v. \$atow a. a. D. S. 60 . - Segen bie Centidabigung v. Strueniee a. a. D. S. 106. Şoffmann

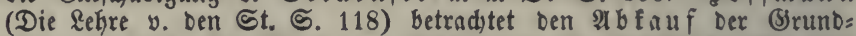
feuer alళ Das beite Nittel zur Befeitigung ber Steuerfreikeiten unD Begunitigungen. Aber würbe mall fpäter umbin fonnen, bic Srunbs rente in einer anderen form zu befdaben uno wurben bie Steuer=

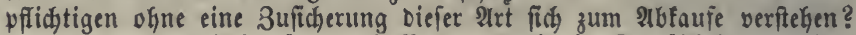

(b) In Dex Lombarbei beträgt nads $\mathfrak{B}$ urger bie in Semäbjeit bes alten Ratafters erfoberte Srunditeuer in Den ebenen Segenoen, bic fchon lange beroaifert uno gut angebaut fino, $26-27$ ßroc. 'Des jeşigen \$ad)tertrages, in Den nidht bewifferten bergigen (Segenben, Die nad Der Rataftrirung zu cinem viel befferen Anbalu gebradjt morben find,

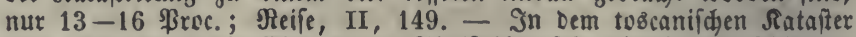
yon 1496 waren bie (8benen uno Thalfohlen feljr niebrig angeldhlagen, weil fie Gäufigen Heberidwemmungen uno Bermüfungen Durd reip̈ende Bäche außgefest waren, Die Şügelyegenden bagegen Kod. Später, als jene Begenden vor Befdjäbigungen gefdügt waren und viel eintrugen,

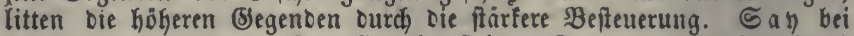
Parieu, I, 266. - In allen fataftrirten Segenden yon Frantreid 
gab es einzelne Srunbeigenthümer, bie vorfer $1 / 4,1 / 3$, felbft $1 / z, D a=$ gegen aud andere, bie nur $1 / 10-1 / 50$ iftes Seinertrages feuerten. Nads

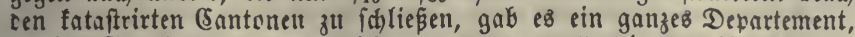
welche ftatt $1 / 5$ mut $1 / 13$ entridtete, Imb Derell 5 , bie nur $1 / 2$ abgaben. Gaudin, Mémoires II, 261. 297. - Benzenterg, Heber Das Ratafter I, 355, auch $\mathfrak{Q}_{0}$ s III, 276. - शluch bei bein keutigen fran= zófichen Rataffer fint bie Departements ungleid belegt, von $3,{ }^{74}-9$ Proc. Der (Srunorente, Der Durchfdnitt if 6 \$roc. Die 1850 befdolofiene

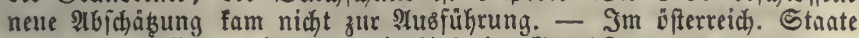
Gat fich neuerlich gezeigt, Daß̉ bie bisherige (Srunofteuer yon bem genau ermittelten SReinertrage in ๔alzburg nur $82 / 3$ Sroc., Defterreid unter

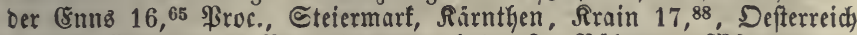

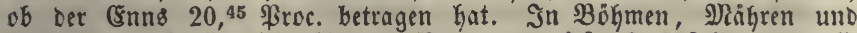
Schlefien madht fie nicht über 16 ßroc. und biefer Fup follte mun alls gemein eingeführt werben, Salzburg jeooch anfangs nur 12 łroc. be= zaflen. Nlinift. Bortrag zu Dem $\mathfrak{B}$. für 1849. \$atent v. 10. Det. 1849. গach fpäteren शngaben fullten bie einzelnen Frovinzen bon $11^{2 / 3}-43$ \$roc. zu tragen Gaben. Die tirecten @teuern in Defterreid

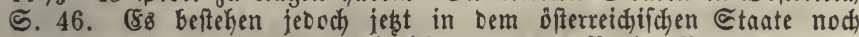
neun verfhiebene Srumbfteuereinrichtungen, z. B. in Borarlberg Das Gaberifde \$roviforium von 1808. - Jn ber Dftgålfte Des preusifichen

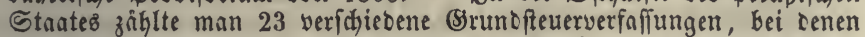

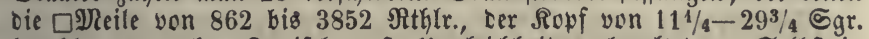
bezahlte uno ofue 3meifel grope ntngleidyeiten obwalteten. Selbit in ganzen \$rovinzen fanten folche, nur in geringerem Mlaaße, ftatt, indem (nad) Şinzuredinung Der befreiten (Sirundeftide, Der Domänen uno geift= lichen (S)üter) auf 100 Nitglr. (Srundrente trafen in ben vier norboft= liden \$rovinzen 5 , in ben weftidyen 8 , in Sachien 8,5 , in Sdylefien

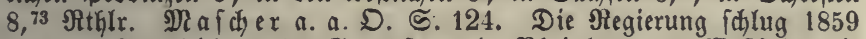

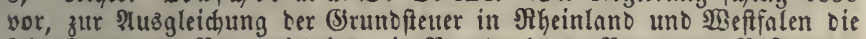
2bigabe um 20 Froc. niebriger, in Brandenburg, \$ommern, Fofen und Sreusen um 10 ßroc. Göber anzufezen, toch follte in ben fects obftichen

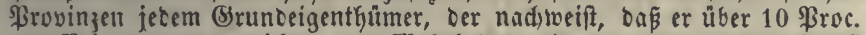

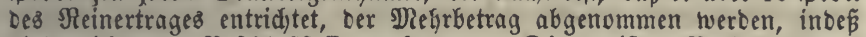
Dié̃ nidjt zur Befdluffáfilung fam. - Die meiften Beränberungen

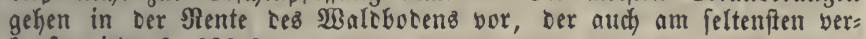
tauft toirt, $\$ .333 \mathrm{~b}$.

(c) Şiemit übereinftimment N. Smith, III, 216 fi. - Monthion,

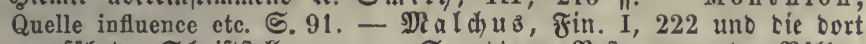
angeführten Sdyriftifeller, - v. Seutter, Befteuerung oer Borfer, ธ. 111. - Burger, Neife burch Dber= Stalien, II, 255. - de Parieu, Traité, I, 262.

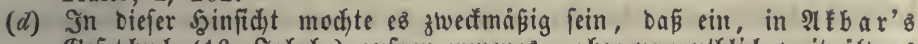
(Sefebbud) (16 Jahrh.) aufgenommenes, aber vermuthlidy weit álteres uno nod geltentes perfifd)es (Sefeb berbot, die Stcuern unter Dem Borlwanbe ciner burch Berbefierungen betvirften Ertragserfobung zu bergrö́fern. Reynier, Ec. publique et rurale des Perses et des Phénic. G. 264. - Wer ein (Eapital auf Brunbverbefferungen wenbet, fann Dafür feine Steuerbefreiung anfpredyen, wenn zugleid) bie in Sémerben angelegten und Die ausgeliehenten Eapitale einer Eteuer unterliegen. Die im \$. angedeutete Bejurgnís wird Kinreidend befeitigt, wem die perio=

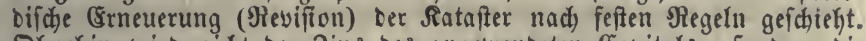
Dhnefin wirb nicht ber Sins bes angetwenbetent Eapitals, fonbern bie

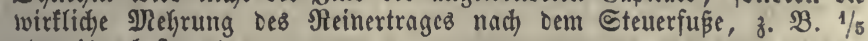
ober $1 / 8$, beftewert.

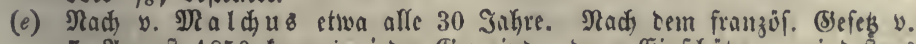

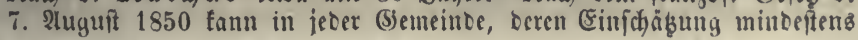

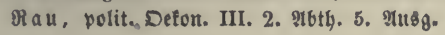


30 Saffre alt ift, eine (Erneuerung (révision) beßs Sataifers beid)lofín wercen. - Smith (III, 224) räth, cem (Srundeigenthümer, Der $\mathfrak{B} e r=$ befierungen vornchmen will, bie Niditerföhung ber Eteuer auf eine

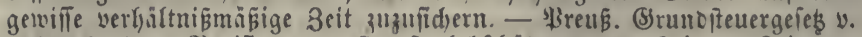
1831 \$. 26: Neviñon Der Rataftralabichäzung von 3eit zu 3eit. -

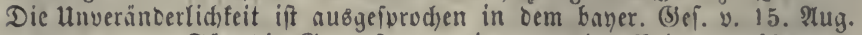
$1 \$ 29$ \$. 3: "F̂ur die (Stunoiteuer wiro nur eine Beitragsgroje aus= gemittelt, uno es bleibt Dieielbe unveräncert, fo lange ber Beiteuerungo gegenitano Dauert." Dennod) fino nadh \$. 76 glinderungen unc Meh= rumgen Durd, (ETementars ober fonftige Şufalle uno unfille zulaifig. In Franfreich hat man, fo oit man unriditigfeiten wafhrnahm, ons (S)leidhgewidat nur burd) Erniebrigung ber zu hohen Eontingente her= zuitellen gefudft, woourd ber ganje Betrag ber (Srunciteuer fid bon Seit zu 3eit verringerte. Die in Jafjr 1848 angeffellte Unteriudung zeigte, Dá̧ bie einzelnen Departementż von $1 / 6-1 / 18$ Der Rente ent= richteten, es rurben oaker 52 Departements erleichtert, fo dá ibre Steuer $1 / 8-1 / 10$ betrug.

\section{B. Anlegung rer Brundfteuer.}

§. 316.

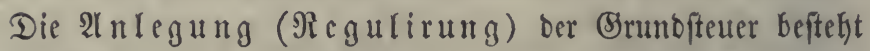
in oer Berfertigung cines Ratafterz (B) runbiteuterbucbeo, (S)runo= fteuterbeidgreibung), weldyes bei jetem Grunofitüfe orer ganzen \&anogute eine zur Feftiebzung ber jebesimaligen Etcueriduldigfeit zu bentsente, in einer Selofumme ausigebrüte 3abl, einen Steueramid)lag angiebt, §. 299. In ben für bie Serfertigung Des Ratafters vorgefdriebenen Regeln unb Dem babei angewen=

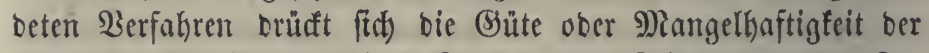

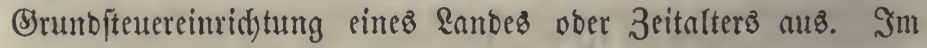

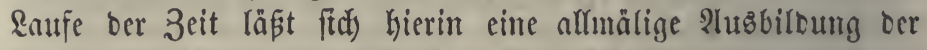
Befteucrungafunft wabrnefymen. Эin alterthume focint man

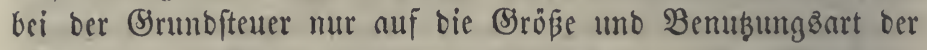

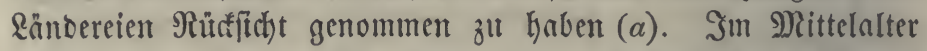
beftand neben ben vielen grunb = unb lefulferrlicten 2lbgaben lange 3eit feine allgemeine Sirunditeuer $(b)$, in ben beutidyen Sänbern erfdjien cine foldye zuerft als cime 2 rt ber auf verfdsic=

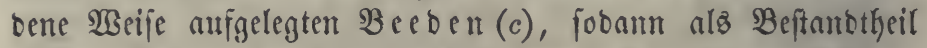

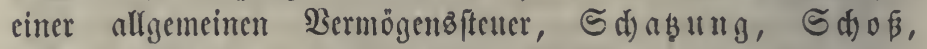
Sontribution 2c. $(d)$, ats ber fie fid) fobann als eine be= fonbere Steuergattung hervorhob, inbem bie Befteuerung anterer Bermögenştheile, namentlict) ber betweglid)en Saabe, unterblieb (e). Dieje Steuern wurben früherhin meiftens nicht fortbauerno, jonbern nur je nad) Beburfuiß̧ crlyoben. Dic Befthreibungen 
ber fteuervflidtigen Ränbercien $(f)$ waren lange 3eit himburd noc) fefre untyolffommen. Bei bem Mlangel alfgemeiner leiten=

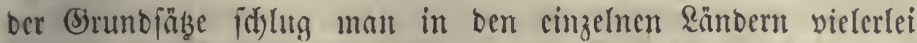
STege ein, um eint billige uno zugleidg einträglidye Eteuer zu Stanbe zu bringen, fültrte auch ftatt einer einjigen (5) runbifteter häuffig mehrere, nadh veridbiebcren Begenftänben angelegte $\mathfrak{B}_{e=}$ laftungent ber (Srunbrente cin; aud) gehört ber Name (Bruno= fteuer erft ber neueften 3eit an. Bei ber fefre ungenauen

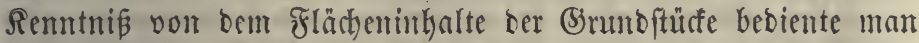

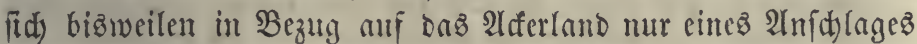
nach) Der 2 tı

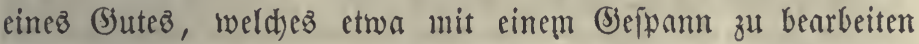

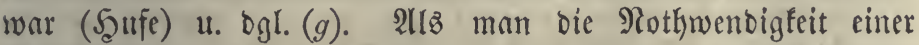

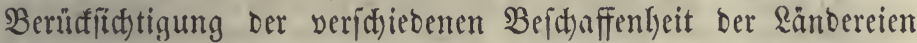
erfannte, fing man an, einige (grwöhnlid) brei) 2(bftufungen

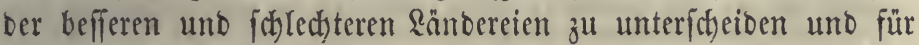
fie ohne genaute Ermittlung des Ertragşverhältniffes allgemeine Injäß̧e auf̧uftellen $(h)$. Diefe Mängel wutroen bei bem niebrigen Betrage ber ganzen (5rundfteuer wenig empfunben, boch war nran yon 3eit zu 3eit nuf Berbefferungen bebadtt, fowie bie Steuer erhöht werben mußste. Sn neuerer 3eit fühlte man ftärfer das Bebürfnis einer befferen 2 Inlegung berfelben, weil

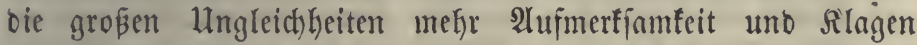
erregten unto einer ftärferen Belaftung bez Sorunbeigenthumb in Wege ftanben. (Es wurben baher bie beiben Sgaupttheile

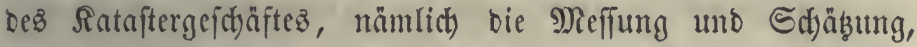
fehr verbolfommet, woju fit)on bie 2lufbebung ber bizkerigen Steuerfreil)eiten cinen 2Intrieb gab unt bie 2lubsiloung ber

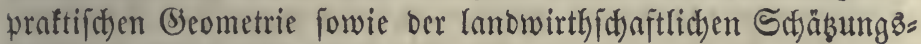
funft bie Mittel lieferte $(i)$.

(a) In Fegypten wurbe fhon früh, angeblich von Sefoitris, um bie Ropten Der Ennalbanten zu beffen, onz Der Rriegerfafte zugewiefene Drittheil bes \&nnoes einer Steuer unterworfen, nur mit susnahme Les von bell Esigentfyumern felbit gebauten शntheils. 3ur 3eit ber

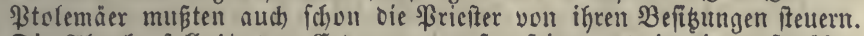
Die Abgabe foll $1 / 5$ Des Ertrages getweien fein, uno in einem fo übers

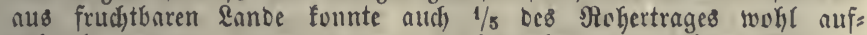
gebradjt werben. (Reynier bermuthet efger yom reinen 8rtrage.) Die 2lubochnung ber Heberichmemmungen beitimmte jöhrlich, weldhe Läntereien befteuert werben fönnten, uno ba feife Gsänzen bes Esigens thums unter biefen Umpänden unmü gewefen wären, fo muste jährlich 
ourd) eine Bermeffung jebem (Srunbbefizer ein gleid)es Stuid bes bom Ril befruditeten Eantes zugetheilt tvercen. Co erflärt fïh oer $3 u=$

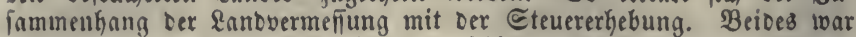

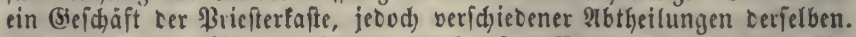
Reynier, De l'écon. publ. et rurale des Egypt. et des Carthagin.

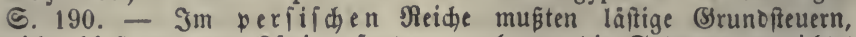
nid)t bloj an ben Rönig, fonbern aud) an bie Satrapen entrichtet werben, wobei viele Erprefijungen yorfummen fonnten; es waren (S) fettern uno Raturallieferungen. Bei ben Streitigfeiten ber griediichen

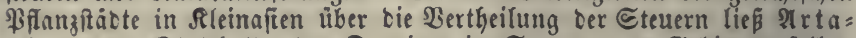
Whernes, Etatthalter des Darills in Sardes, Das (Sebiet Derílben vermeffen uno bie Steuer nach \$arafangen (zu 30 Etabien) um=

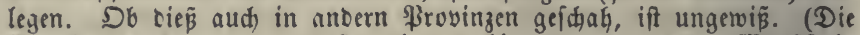

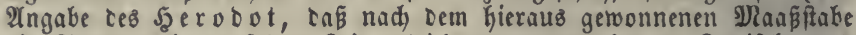
bie 巨teutern bis zu feiner Seit entridytet wurben, hat zu Sweifeln und veridjiebenen शluslegungen Anlaß̄ gegeben.) Herodot VI, 42. -

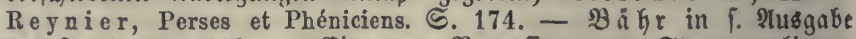
Des Şerob. III, 809. - Esine neue Bermefiung uno @teuerregulirung in ßerfien foll unter RObaD I. (rei]. Feit 491) begonnen und von soşru I. (Feit 531) beendigt worben fein; Sartleben, Suftiz=, Rameral:, uno ßolizeifama, 1822, Nr. 33, uno Den cort citirten Silv. de Sacy. - In Bezug auf Sparta rügt शriftoteles, Dá̧

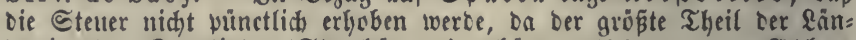
Dereien ben Eyartiaten (ङtabtburgern) gehore, Politic. II. 7. - A then hatte feine befondere (Srunbiteuer, aber cer (Srunbbefis wourbe in oer ie nad) ten Bebürniffen Des Ctants eingeforberten Bermogensfteuer vorzüglid mitgetroffen. Edon bie Bezeidynungen ter Solonijaen

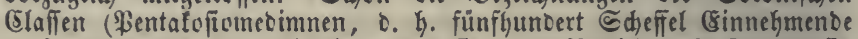

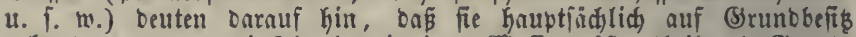
gebaut waren und bie \$lggaben in jeber Elaffe gróstentheils als (Srund: feuer gelten fönnen. Reynier Grecs. S. 284 fi. Die Saz̧e bes Ranbertrags, twelde bie शufnakune in cine (5laffe bebingten, waren bei Den Drei vberen (Slaffen $500-300-200$ \$iedimnen (zu' $15 / 16$ preuß́. ๔dyeffel $=0,51$ Jeftul. $=0,34 \mathrm{BaD}$. Malter) (Setreite, ober nach Dem angenommenen ßreife von 1 Dradjme (26 Rr.) für ben $\mathfrak{N})$., ebenfoviel Draçmen. Scieraus tourbe turd) Bervielfadung mit 12,10 und 5 Das fteuerbare Bermögen auf $6000-3000$ und 1000 Dr. geiest, aber

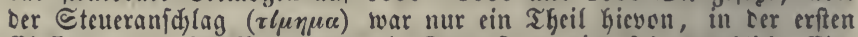
(Slaffe $1 / 5$. - In sto om tor tie Srmuteteuer eine fehr erheblidse Ein= nafmzquelle. Sie geforte, powie die Ropfiteluer, zur capitatio uno hiés tributum soli oder agri. In Itolien war nod) zur 3eit bes Frei= fanats alles sand fetterfrei geworten, felbft in ben \$roviuzen genofien viele Ctãote in bem jus Italicum aud Diefen $\mathfrak{B o r z u g}$, allem biefe $\mathfrak{B}_{e}=$ freiung Stuliens ging unter Diocletion bei ber Esinführung ber indictio

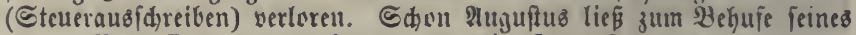
census Bermeffungen vornelymen, um bic Brrubfteucr gewalter anzu= legen, tod) twurben nicht tie einjeluen (Srunoftüfe, fonbern nur Bezirfe gemefíen. Man gab an, wie viel Cteuereingeiten (caput ober jugum) tiefelben enthielten, 子. VO. tie Statmarfung von Turus in Gyrien 60000 juga. Savigny überiebt caput Durd Steuerhufe. SIan weí̄, oaß̧ 1 jugum alif 100000 Sefterzen (gegen 11666 f.) angeid)lagen war, wovon cer einfache Steuerfaz̧ ocer ons ję̧t fog. Simplum (simplex tributum) 1 p. m. betrug. Die räumliche (Srof̧e tes jugum ift nidjt befunnt uno aus einigen aufgezeidneten Ingaben bsu \$reifen Des Ranoes nidjt abzunefymen. Spriterhin ideint jugum nidat mekr ein

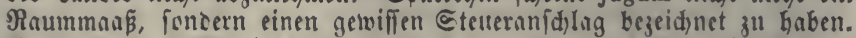
Nad) Den von ulpian (L. 4. D. de censibus, L. 15.) mitgetheilten 


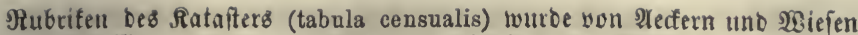

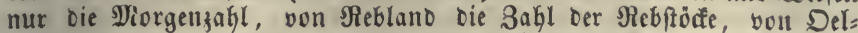
gärten Baum = uno Diorgenzahl, von NBeibe und Wald oie ungefähre SRorgenzahl (quot jugerum esse videantur), alles nach ber eigenen $2(n=$ gabe Des (Srunbberizers, eingetragen. (8\$ bleibt ungewiós, wie man ein foldhes caput berednnete, wie viel 2 seinftöffe 3. $\mathfrak{B}$. einem Norgen 2lfer gleidggefest wurben; bođ müffen wohl folde Berbältnifie beftan= Den haben. Goict ber $\mathfrak{R}$. Şonorius uno Theodofius (L. 2. Cod. de immunitate nemini conc. $\mathbf{X}, 15$ ): Possessores ... pro jugerum numero

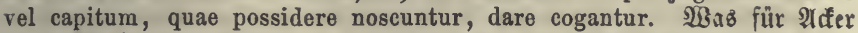
oder $2 B i e f e$ zu nehmen fei, Darüber entidjec bie Benubung in oen

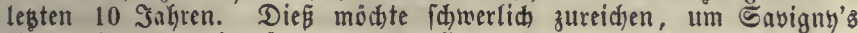
Bermuthung zu begrủnoen, Dás alle 10 Jahre Das Ratafter emeuert worben fei. Hnter Trajan murben in \$annonien 2 Elafien bes Adfer:

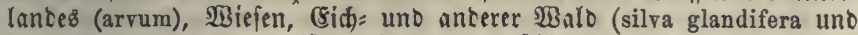
s. communis pascua), aljo 5 arten unteridjieben. Die Eteuer wurbe

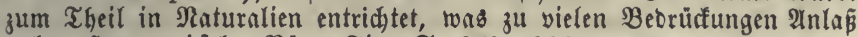

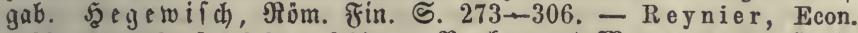
publ. et rurale des Celtes, 274. - Beffer uno $\mathfrak{D a r q u a r o t , ~} 5 a n o=$ bud III, 2. S. 163. Die romifde (Srunoftetter hat fid) wie im oft= gotfifichen Feidje, fo aud) in (Sallien unter ben fränfichen Rönigen erhalten (Reynier, Celtes, 277), fie wurce fortwährend nach Dem

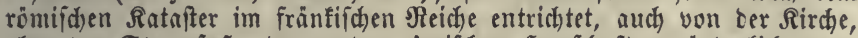

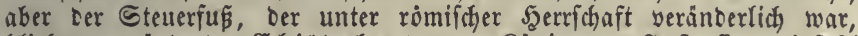
blieb unberïnbert. (5 bilbebert II., Rönig bon Auftrafien, befahl im 5.590 , bas unter feinem Bater Siegebert verfertigte Ratafer

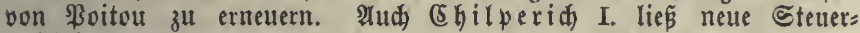
anid)lage madell (descriptiones novas et graves in omni regno suo fieri jussit, Gregor. Turon.), fano jeouch gropen Wiberfand. (Nach

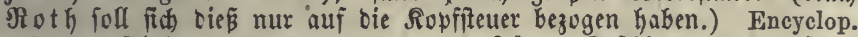
méthod., «bth. Finances I, 152. - v. \&ủw, (Sefwidte ter benticher

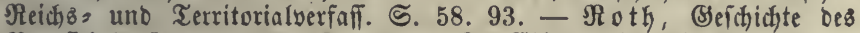

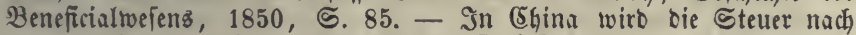
Dem angebauten flächenraum erfoben, fie foll $1 / 5-1 / 3$ bes Ruhertrages

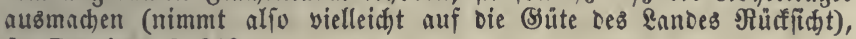
de Parieu I, 219.

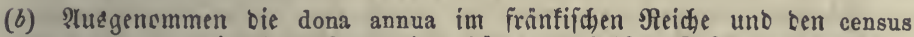
regalis bon einzelnen (Srunbeigenthümern. Slie, (Sefd). Des Deutfich

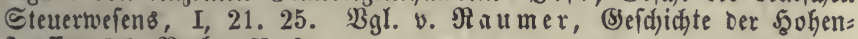
ใิauffen IX. B̈ud, IV, 3.

(c) Die Beede (petitio, precaria exactio) war nad) (5iđhorn uriprüng= lid eine Abgabe, ourd bie man fich bon bem Rriegsoiente lobfaufte

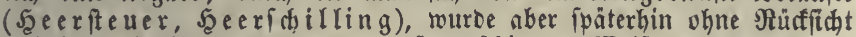
auf jene Entfehungsart unt auf veridiebene 2Beife erhoben, nach Röpfen, nad) Şaufern, nad) bem SBiehitanoe, nach \&anohuten. (sigen=

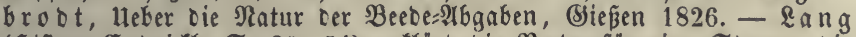
(Şiftor. Entwviafl. S. 20. 54) erflärt die Beebe für eine Steuer, die Der \&efinkerr yon feinen $\mathfrak{B a f a l l e n}$ erhob. - Dié̃ fibeint audb uriprüng= lich Das BBefen ber franzöfifchen taille gewefen zu fein, bie fihon 1185 vorfam. Unter Sarl VII. wutrbe fie eine Gleibente Steuer, um bie erften ftehenden Truppen (9000 sieiter) zu erhalten, weldye an bie Stelle Der zügellofen Refenmiliz traten. Die taille war eine fehr flüchtig,

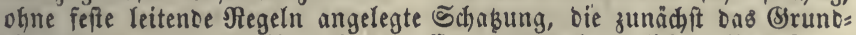
eigenthum, zum Theil aud ben (Srtrag bes betwegliden Sermỏgens traf. In einigen \$robinzen beftand die taille réelle, bei weldjer das unbelvegliche Bermögen ohne Siủffibt auf ben Stano ber Eigenthümer 
befteuert werbe. In tiefen Ranbestheilen beftanden Satafter. B̉ei cer t. personnelle fam oer Stund Deß Befibers in Betradt und ber ADef war befreit. Saier wurbe aud bas (Sinfomment aus (S)ewerben und anzogeliehenem (Belte beigezogen. do Pariou I, 221 verglidsen mit Encyclopédie neéthodique, 2ిbtf. Finances, 2irt. Taille. (\$3 if bei Dicfer Stelier Mandies nid)t aennu befannt.) Die taille war eine Wer= theifungeftetuer $(\$$. 295). Sie betrug mit ben 3uidhligen unter Sgein= rich III. i. D. 3.064000 \&iv., Froumenteau G. 10. Meben ifr beftano bis zur Revolution eine (Sruncfteuer von 10\% \$roc. DCB SRein= ertragezz (deux vingtièmes et 4 sols par livre), wozu feıt 1782 nod́)

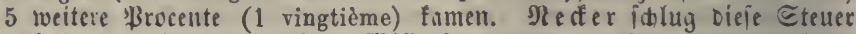
auf $76^{1 / 2}$, cie taille auf 91 Dill. $\mathfrak{\&}$ an uno glaubte, ons von jener wegen veridhiecener nutberer nebenbei getroffener CEinfünfte 74 פill., bon ter taille etwa 81 Difl. auf Das (Sirundeigenthum fielen, Administr. des fin. I, 4 u. 110 (1785). - Biefleicht entfand bie Beere nus Den früberen donis annuis, $\mathfrak{J l f e}$ 5.54 . Heber bie Beeden in SBurtemberg 1. Il vier, Gumml. Der Wütemb. Finanzgefeze II, 2. S. VII.

(d) \&aıq a. a. D. S. 97. - Borzüglid lefyrreid) für bie (Befdichte Der (s)runtfetler ift $\delta$ dimmelfennig, Die preufifiden birecten

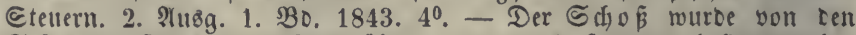
Etîten auf oab vlatte \&anb übertragen uno traf Dort aud) Sanowerfer, Taglöfuer, ben Biefftano $x$. In Diefer Bermögensiteler begnügte man fid oft mit ber eiblid erhärteten eigenen 2lngabe bes 厄telier: pfichtigen und beptimmte nur ben Steuerfü̧, z. B. Roburg. Beroron. v. 15. Tpril 1589 bei $\mathfrak{S a r l}$, Sambb II, 152: bon 1 ff. (Stüterwerth 1 Bf., nadh Dem jebsigen $\mathfrak{W e r t h}$ ber (Stuter "ober wie fie ein jeber geben wollte", bei Esiden uno \$rlichten. - Furifl. Gell. $\mathfrak{B}$. v. 19. Dec. 1576, zur Türfenfteuer vou 100 fl. Sauptgero jährl. 1 Śdyredfenberger $(1 / 7$ î.), aud von Bief uns verfäuflichen Borrathen. Steuer=S. einer bayer.

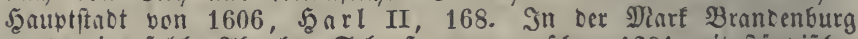

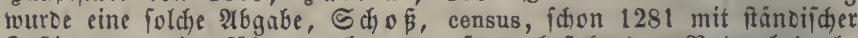
Suftimmung eingefiigrt, neben ber fion beftehenden Natmalabgabe

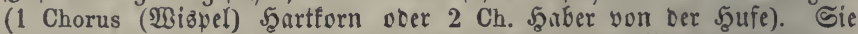
betrug 2 ङchill. von Der Jaufe ober 2 \$f. vom \$fund (talentum).

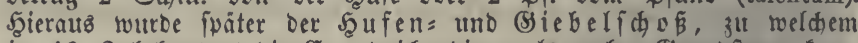
im 16. Sabrfundert bie (5ontribution als wahre Brunofteuer fam. Shimmelfennig I, 335. - In Sachien fincet fich ichon 1481

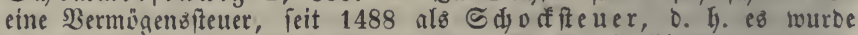

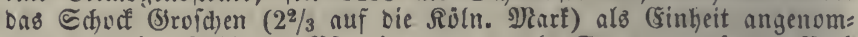
men und eine 3ahl von \$fennigen Davon als @teuer angcięzt. Nad́ ber Regulirung von 1660 (wo die fafrende Sabe bon oer Steuer befreit wurbe) erfielt ein Idfer Feld 3 Sdjudf, शieie 5, (S)arten 6 ic. S d) immelfennig I, 390. Bgl. Bergiub, Nag. VIII, 217. Shlefiliche Schabung von 1527, auf bie eigene Angabe (Incicticui) yon

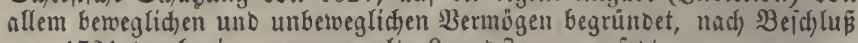
von 1721 curd) eine neu geregelte $\mathfrak{L} a$ no fite uer eriegt.

(e) Dodh war in England fdjon Das won Ethelred feit 991 erfyobene und anfangs zur Reiffung Des Tributes an Die bänifchen Rönige be= ftimmte Dânengelo (danagild) cine Srunbitetter, 1 Schilling von ber hide Ennbes, Daher ber fpatere Name hidagiun. Die hide, hyde oer Angelfachfen war, wie bie Şufe in Deutid)land, eine IIfernakrung, mit einem \$flttge zแt beftellen, ifre (Sröbe twar aber nidjt gleidfourmig angenommen. Evaterhin rechnete man fie zu 100 , zu $\$ 6$ ober 120 acres (fíchfifich hyde, Sूütte). General introduction fum Domesdaybook,

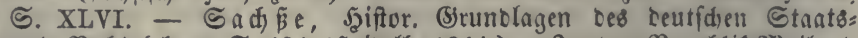

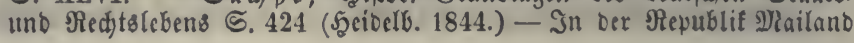


marb 1208 eine Rataftrirung Des $\mathfrak{B}$ ermögens (stima e catastro de' beni) begonnen uno 1248 beendet. Niemano war frei. Whan bezaflte an= fangs 10 soldi 5 den. von 100 lire (etwas tỉber 1/2 Proc.). Die

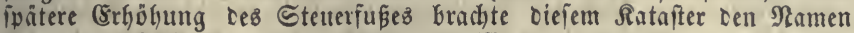
Sdymerzensbuth) (libro del dolore) zu 2 iege; Carli, Del censimento ธ. 185 Der Classici mod. XIV. - Die decima in Flurenz von 1494 war eine (5runo = und Scaubiteuer yon 10 \$roc. Des Nieinertrages. Daв Berzeidnís enthielt bei jeoem (Stunofüaf ben Esigentfümer, Die Bemeinbe, Den Flächenraum, bie Begränzung, Den Eertrag uno Den \$reis̊nfd lag. Daffelbe murbe 1532, 1618 uno 1714 erneuert. Della decima e di varie altre gravezze imposte dal comune di Firenze, Lisbona e Lucea $1765, \mathrm{I}, 37$.

(f) Bei ben älteren Ranobühern war Die Befteuerung nur ein Nebenzwed, Şauntiache Die Beftimmung Der Esigenthumbెverhältniffe, Der grunoferr: lichen (Seredtfame u. Ogl. Das Domesdaybook (domus dei, ineil in ver Rirde verwahrt), aud liber judiciarius, censualis etc. genannt, wurbe unter 23 ifhelm I. yon England, wahridseinlid, 1086, zu

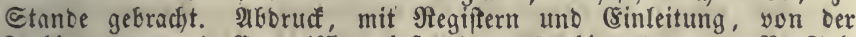
शrrebib $=$ (record) Commiffion bejorgt, 1783 bis 1816, IV $\mathfrak{B}$. Foll. Moreau de Jonnès in Journ. des Econ. 2. Ser. IV, 205. - Aefyn= (id) Das im S. 1375 unter Rarl IV. verfante $\&$ anbbud Der Rurmarf Branbenburg, Geraugigegeben 1781 von Minifier v. Sgerzberg, uno

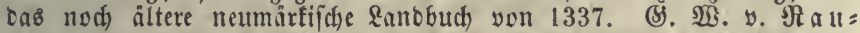
mer, Die Neumarf Br. im $\$$. 1337, Berl. 1837. - Ratafter Der Probence yon 1471 , auf weldhes man nod fiảer zuriadfam, um bie

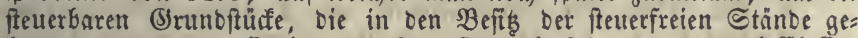
fommen waren, aušfinoig zu mad)en, ferner in शlençon, wo brei Claffen yon \&änoereiet unterfdieden murben, Bodinus, De republica, L. VI.

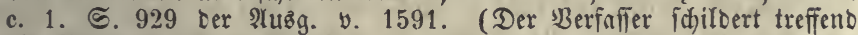

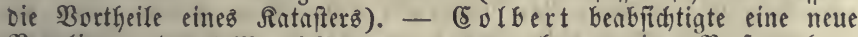
Siegulirung Der taille réelle, es murbe aud bon einer Berfammlung Der Intendanten in Den Froviuzen, wo tene beftand, eine Beroronung entworfen, Deren Senefmigung aber Eolberts Too werfinberte,

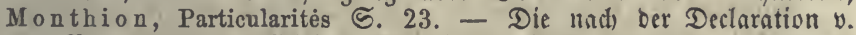
21. Nov. 1763 beabjidbtigte Rufiftellung eines allgemeinen Sistafters

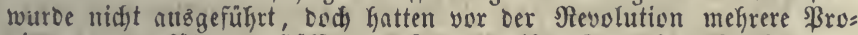

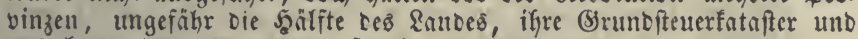
unterlagen oer taille réelle, f. (c). Encycl. meth. Fin. I, 1853.

(g) Ueber \$̧ufen f. II, \$. $76(f)$. Die Shäb̨ung nad) Scufen, nad) ganzen, halben uno SiertelBhofen, nach şflugen u. Dgl. war nothwentig fefir oberfiäblidy. Bommerifde Stevern nady Şufen, 1653. - Senernl= Sूufendi)o

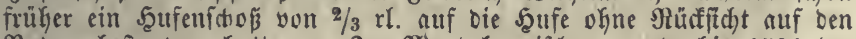
Boben beftanden hatte. - Im IIagoeburgifiden wurbe bis 1531 ber zefinte sfennig ( 10 \$roc. bes angeid)lagenen Sohertings), feit jenem Snlyre ber 50fite, yon 1534 an Der 70 fte erhoben; 1 Seufe Rand ober

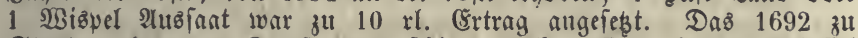

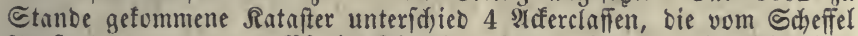

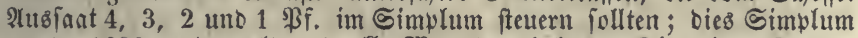
wurbe 1693 verboupelt uno alle \$lonate erfoben. Rlewis, Steuer= verf. im Sgerz. Magoeburg, II, 9. (1797) - In Sdyeden wirb nod

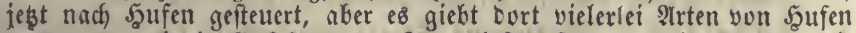
(hemman), Die in Infefung ber Stantslnften fefr yon einander abwei= den; f. aud Forfelf, Stat. v. Sdtw. (1835), S. 82. - In Defterreid) murben bei Der Thereftanifhen Steuerregulirung (1748-54)

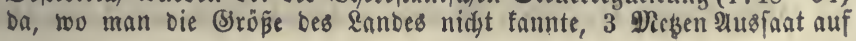


1 Jodh angentommen. \&inden, (5)runofteuerverfafiung $D$. Difterreid. Monarit)ie, I, 8 (1840). - In Böbmen wurbe 1654 ein gemiffer

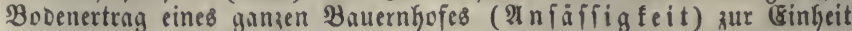

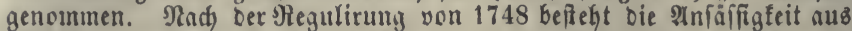
180 fi., von tenen 60 fi. Die Steuer bilten. \&i noen, I, 117. In (Salizien (B. v. 1774) wurbe $1 / 3$ Des Adferlandes für bie Bradje

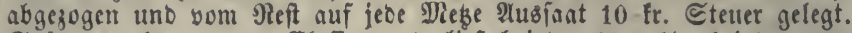
¿päter madite man 3 Elaffen uno liés bei ber 2 ten $1 / 5$, bei ber 3 ten

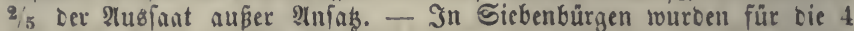
Bobendafien vom Rubel Rusfaat ober vom Jod Bicie 20, 16, 12, $8 \mathrm{fr}$. Etetter beftimmt. Tafeln zur Etatiftif ces @teuerwefens im jifterr. Raijerfanat. 1858. ๔. XV. XVI.

(h) In Danemarf if in Dem unter (5 hriftian V. 1681-1688 zu Stande gebradjten Ratufter Das \&and nady Tounen 5aatfurn angefitauen, worunter man fich feinen gewiffen frlädyentaum, fonbern einen gewifiten Bobenertring Denfen mú̈. Bom beiten Boben gehen $28000 \square$ Esllen (2 Tonnen $\mathfrak{R}$ กnd) nuf eine Tonne Şartforn, vom fdylechteften in Süt=

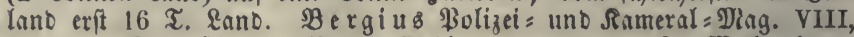

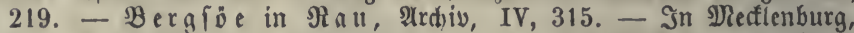

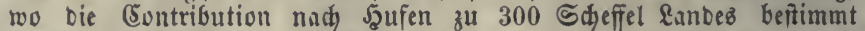
wurbe, verorbnete man in (srbvergleid) bon 1751, twie viel \&and nach

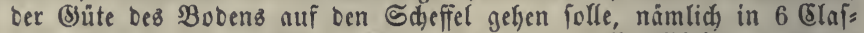

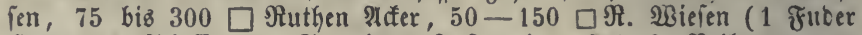

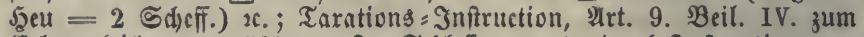
Erbvergleidje von 1760. - In Sdylefien wurbe burdy Initruction vom 8. Dec. 1746 eine Unteridjeioung von 4 Adferclaffen, in Denen bie 2urfant $6=5=, 4=$ und 3 fach geerntet würbe, ferner von 4 veridhiece= nen Jittelpreifen ber Frủchte aufaeftellt. Bon bem nusgemittelten Ertrage zafilten feit 1744 geiftliche Etiftżūter 50, ritterliche (Sommen=

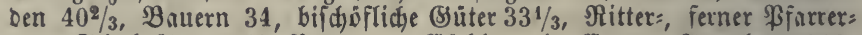

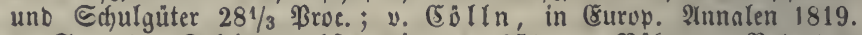
V. S. 183. Shimmelfennig, I, 251. - Bubmen, ßatent y.

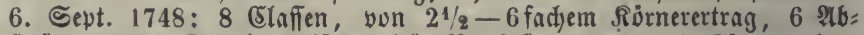
ftufungen Des (Setreidepreifes. Für Baufoften twurben 2 Rörner abges zogen, vom lleberreft wurbe $1 / 3$ als @teuer angefést. \&inden, I, 117. - Bamberg, B. v. 1716, Schäbungsinftuction v. 1731: Jebes

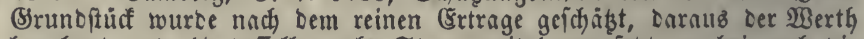
berednet und $1 / 3$ Deffelben als Steuercapital angefést, wobei nudy Die

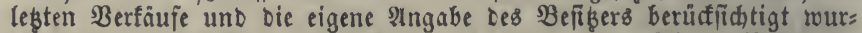

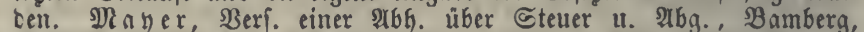

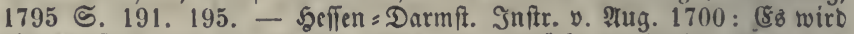

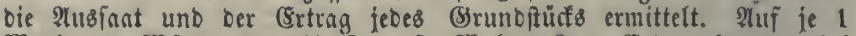
Marburger Muitte oder $3^{1 / 2}$ Darmft. Malter Rorn Errtrag fommen bei zehntpfiditigen (Ssumbfücfen 15, 10 ober 5 fi. Eteuercapital je nad) Der (Entfernung unb Frudhtbarfeit. 3ugleich finbet eine Bermeffung

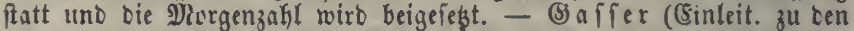
sfon. polit. u. Eameralwifi. 1729, ङ. 312) glaubt, es fei billig, von

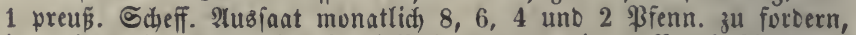
je nachoem bie Gant eben fo vielfadh geerntet wirb. Bergl. überkaupt v. $\mathfrak{B}$ offe, Darftelf. Des faratsivirtfich. 3uftandes in Den D. Straten, ธ. 305. - Die (Srunoptetter zeigte bei Dieien (Einrichtungen nod) auf: falleno groß̈e, Die Beredytigfeit verlebenbe Ungleidheiten.

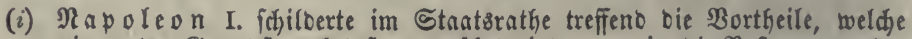
ein gutes (Srundfteuerfatafter gewährt, incem es in bie Befteuerung ber Srumbrente Feftigfeit bringt unb bie WBilleur befeitigt, Bresson,

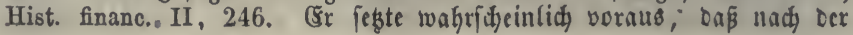




\section{- 41}

Bollenoung bes Ratafters bie Srumbfteuer in eine Quotitätsfteuer um= gemandelt werben wurbe, was jebod in Franfreich nod nicht ges ifieken ift.

\section{§. 317 .}

3ur gerectent unlegung biejer Steuer auf jebez einzelne (S)unbftü mus man vor Aflem ben Fläd)eninhalt beffelben genau fennen. Die bloß̧e Schäzung ber (Sröße nad) bem Altgen=

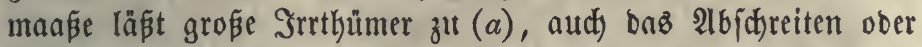
bie flüchtige, funftlofe Meffung giebt feine genügende Sienauig= feit $(b)$. Diefe ift nur von einer forgfältigen, mit affen Şülfz= mitteIn ber Runft berwirften Bermeffung zu erwarten (c). Die

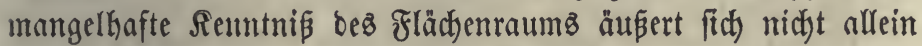

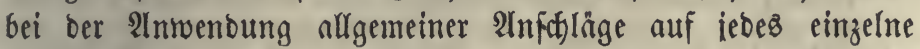
(Brunoftüf nachtheilig, fontern madbt nuch biefe alnfd)läge für ganze Elnffen uno Bobenbenubungasnten felbft fehlerbaft, wenn

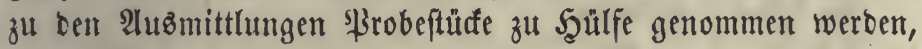
beren (Brößje man nidyt genau fennt. Eine gute Bermeffung ift zwar foftbar (\$. 329), leiftet nber nicht blop zur guten Umlegung ber (Srunbfteter, fonbern auth in anberen Şinftuten wejentlicbe Dienfte. Sie bilbet eine nothwenbige (Sirunblage

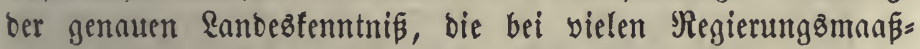
regelu benubst wirb, fte berhütet Brönzitreitigfeiten, weil bie (S)änzen babei nelt berichtiget uno feftgeitellt weroen, uno giebt Dem Srunbeigenthum eine volffommene $\mathfrak{B}$ eftimmtheit, bie aud bem Unterpfanoşgläubiger viel mükst uno z" neuen Darleiken mefr Ermunterung giebt $(d)$, 一 fie erleidtert bie 3ertheilung you Ränbereien, 子. $\mathfrak{B}$. von Semeinberweiben, bie 2lustaufdung

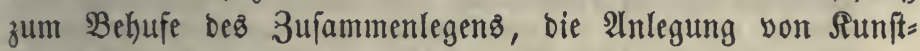

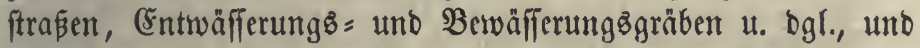
eripart in allen foldben Fällen bie viel foftbarere Mefiung ein= zelner Stüde. Frü ben Befteuterungsిzwed allein if lebod) basి

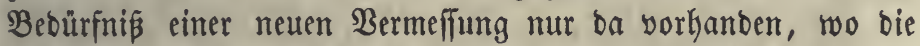

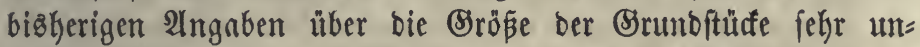
genau find und wo bie Srunorente fowie bie Brumbiteuer fith fo hod) beläuft, baßj bie feblerbafte Befteuerung empfindlide Birfungen åuß̉ert.

(a) Bei groben Flächen, beionbers bei NBalbungen ift bas शugenmaa

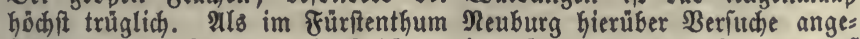

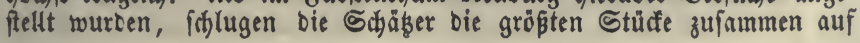


385 Morgen an, oie twirflidje (S)röße war aber 1103 D2. und ber Fefler idyanfte biebei zwifthen 84 und 43 \$roc. bes wahren Betrages, Bei=

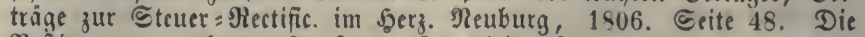
Beftimmung nad, Der 2tublant wübe teine fo grefen Feller gegebn haben, Dod ift fie ebenfalls unzuverläfing, weil bie Stirte der Eadt bei Den einzelnen Enntwirthen ungleids if unb fid auds ie nach Der (3) üte bes Bubens abảnbert.

(b) Bei Der Durd Snifer So feph II. 1785 angeoroneten Sataiftrinng ge: (chal) bie शleffung mit शlusnahme ber aflzu unregelmisigen friguren burd) Die Sidjter uno (Seidywornen jeDes Dorfes, mit Retten oder Etriffen. Inftruction zur $\mathfrak{B}$, v. 20. F̂ril 1785 in 28 ergiuz, Gamm= lung beuticher ennoesgeiebe, X. 326 fi. Bei शrbhängen, forwie bei

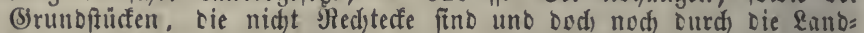
leute gemeffen werden ourften, fonnten grobe Fehler vor fid gehen. Sn 4 Jabren war Die Arbeit in Den Deutiden Enncen ber Mlonardjie und in Salizien beentigt, aber 1790 unter \&eopolD II. wourben bie früberen Steueriäke wieber eingeführt, was freilid) mefor wegen ber Âtrt ber Ertragbidjabung geidah. Statiftifche Ergebnifle Der Jofephi=

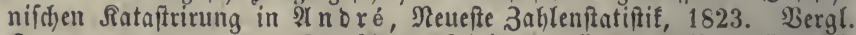
Sremer, II, 48. - Sm âlteren Theil Dez Eantonz Bern fino die

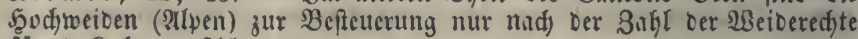
für 1 Suly angeid)lagen.

(c) Bermefiungen zur Anlegung ber (Srumbiteuer fint ficon alt, $\$ 316(a)$. Die Benezianer natimen in Doren eine foldhe Bermeffung vor, $\mathfrak{i}$ a n $\mathrm{k} e$, Jiftor, polit. Seitidyrift, III, 444. In Wütemberg und SBeimar ge=

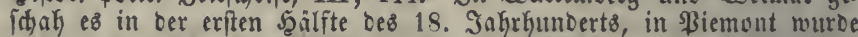
1661 uno 1675 eine Siefiung aller Srunofitude uno eine Shäßung nad) 3 Wertfabfufungen feber Benubungsaat verorbnet, abex bie 2us = führung war mangelfaft, es entifancen viele Beidwerten uno bie In=

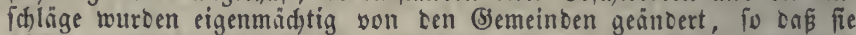
hỏ hit ungleichmäpig twurben. Plebano \& Musso, Des finances du

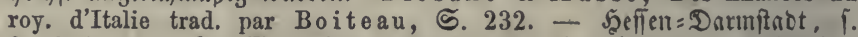
§. $316(h)$. In Nagbeburg wurbe 1720 eine Mefinng benbfictiget ( $\Re$ Tewibs, II, 61.), in SBeftpreunen fand man bei der Gteueran=

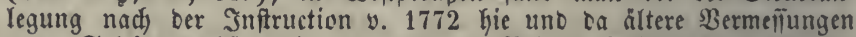
vor, Shimmelfennig, I, 163. - Bei ber in Breupen 1 S61 an= georoneten neuen Ŝnlegung Der (Sirumbiteuer fwll man fid) two móglid

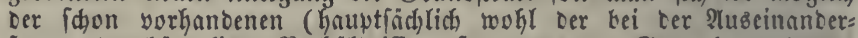

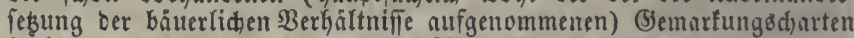
bebienen und nur in bringenden fällen neue Rufmahmen verampalten,

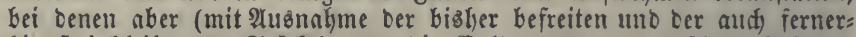

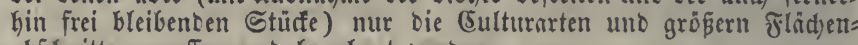
abjdyitte gemeffen uno beredynet werbert.

(d) Dieie Seite bes segenfandes ift befonbers Gervorgethoken in Noizet, Etude sur le cadastre, P. 1857. Der BerwaltungBrathy Leß Crédit foncier in Franfreid flagt (Beriat v. 30. Fpril 1856) über Die un=

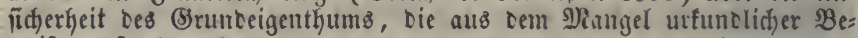
weife entifand. Nous pourrions citer telles communes où l'on ne possède que par tradition; on ne peut $\mathrm{y}$ acheter ou $\mathrm{y}$ prêter que de confiance. - Hebrigens bezieft fith oie ourd ein Satafter zu erlangenoe Sidjerbeit melyr nuf Das (Srundituif, als auf Das Recht ses Esigen: thumers, Denn bei ber Aufuahme oes Ratafters twiro ber Sefiber als Gigenthümer angenommen, wenn feine (simipradje erfolgt ober bas (s): gentbeil offentunoig ift, twie bei ßadjtftüfen. 


\section{3}

\section{§. 318 .}

Soll eine Bermeffung leoiglich zur Steueranlegung Dienen, fo genủgt $c B$, Dab (S)biet (bie Bemarfung) jeder Semeinde abgeionoert für fict) aufzunefmen und in eine (Sharte zu bringen. Dieß $\mathfrak{B}$ erfahren ift aber nicht jureidjeno, tm eine genaue \&an= Deģđ)arte zu geben, weil bei bem Alneinanderfügen ber einzelnen Flurdarten in fleinerem Manßjtabe viele Fehler unvermeiblid fint. Wilf man Daker zugleid) auth bie anderen erwäknten 3weffe erreidyen, fo inuß Der Alfmahme Der Fluren bie Dreiect= meffung (Triangulirung) vorauşgehen. (5: wir nảmlich burd) höct)ft forgfältige 9) Jeffung einer großen Standinie, 2ufnakme Der $\mathfrak{B}$ infel ber Seblinien und trigonometrifac Berectuntung bie Rage einer Menge you SHuncten beftimmt uno fo ein gropes Neks von Dreiedfen entworfen, weld)es Der Bermeffung einzelner Stücfe zur feften Stütze bient. Scieraus laffen ftd) bann zu= verläifitge Sharten in fleimeren Maaßłtäben für bie Ranbeştheile unt für baż ganze Staatågebiet erlangen. Der Mehraufwand, Den Dieje 2rbeit verurfadyt, wirb burd) ben Nuben guter (5har= ten vergưtet und

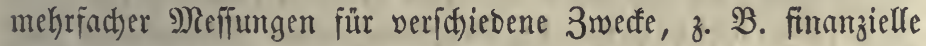
und militärif(t)e, fich) zutr Seranftaltung einer vollfommenen Sanbespermeffung vereinigen $(a)$. (sz ift nid)t ungered)t, ben (S)runbeigenthủmern für ben $\mathfrak{B}$ ortheil, ben ifnen bie Alufnahme

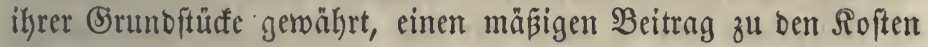
aufzuerlegen, weil fie auf biefem $\mathfrak{B}_{e g e}$ bie genaue Renntnif́ von Der Bröß̈e, Seftalt uno \&age ifress (Sigentfums mit einem geringen 2 utwande erlangen $(b)$.

Bei einer foldyen Ranbesivermeffung wirb das Rand in Bes banfen in eine großße 2nzahl von Duabraten zerid)nitten und jebez berjelben zufolge ber (Simzelmeffung Durth eine Charte bargeftellt, wobei $e z$ nicht zu vermeiben ift, baß bie Marfung einer Semeinde oft in zwei ober mefrere foldhe fogenannte Detailcţarten fällt.

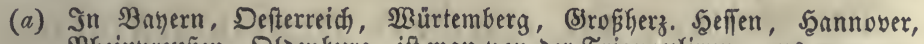
SRkeinpreuß̃en, DlDenburg, ift man von ber Triangulirung ausigegangen, in oer sombarbei und in Franfreid, fo wie in Sienf (1841) unb

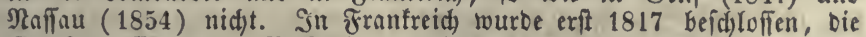
sataftermeflung zur Berfertigung eimer neuen Charte fintt ber alten Gaffini'fhen zu benubsen. In. Sachfen ging bie Dermeffung Durd 
tas Ingenieur = Sorps voraus uno Die Rataftermeffung lefnte fidh an bie nod fenntliden trigonometrifaen \$uncte an, "wiewohl zur Eriva= rung ber Seit und ber soften feine eigentlide (Shartinung benbfidtigt wirb." - Bei Dem \$angel Der allgemeine॥ Triangulirung mús man in jeber Flur eine beionbere Standrinie meflen uno Dreiefispuncte bes fimmen, was ebenfalls umfänolid ift uno Die (Sefalyr zu fehlen ber:

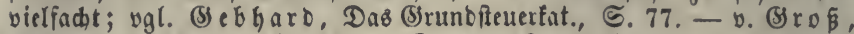

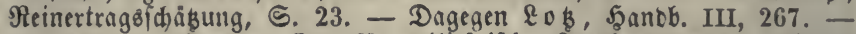
In mefhreren Etaaten find für militixifhe S3wedfe unter ber leitung ces Beneralftabes Sleffungen veranitaltet worben, bie ber (Sivilverwal tung fremb blieben, z. $\mathfrak{B}$. in Bayern uno Baben. In lebterem $\mathbb{E} a n t e$ leitese Das militirifh = topographifde Burenu eine auf ein Dreiectenes

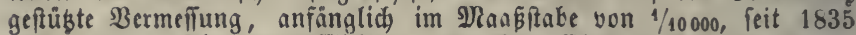
yon $1 / 25000$. Die (bortreffliden) gebrudten (Sharten find im $1 / 50000$. Beibe Slaapitäbe fino für anbere Berwaltungszmecte zu fleit. Diefe Unternchmung foftete $1819-40289000$ fl., romit vie Triangulirung beentet und tie Rufuahme von $153 \square$ Di. bewirft murbe. Berh. Der 2. Л. 1841. Beil. IV, 94. 1842, Beil. V, 120 (yon $\mathfrak{B} \circ$ gelmann). 1848 wurbe eine neue Bermefiung zur Rataftrirung beabfiditigt, welche jecod Damals nod nidjt zur Ptusführung fam. Der im \$. 1851 aber: mals vorgelegte Entwurf führte zu oem (S)í. v. 26. Wiäz 1852.

(b) Bab. (Sef. v. 1852 §. 5: (Srund = uno Şausbefiber haben 15 fr. nom Deorgen und baneben $5 \mathrm{fr}$. von jebem Stücf beizutragen. Jür ein

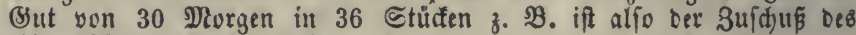
Eigenthümers 10 fi. $30 \mathrm{fr}$.

\section{§. 319 .}

Ueberfidft ber Beffäfte bei einer \&anbeşvermefiutung $(a)$ :

I. Borarbeiten. 1) Beftellung einer Dberbehörte zur Reitung ber ganzen 2 rbeit (b). 2) Entwerfung von Dienft= anweifungen (Injtructionen) für bie vorfommenben Sejdäfte, mit ben nöthigen Formularen, Eharten = Duffern u. bgl. (c). 3) Anftellung Des in zwei ober brei $2 b$ fufuntungen eingetheilten Meffungşperfonals $(d)$, für befien Unterweifung man erforber= lichert Fallez Sorge tragen mußs. Für ifre Bejahlung wiro cin Bebührentarif aufgeftelut $(e)$. 4) Anjd)affung ber Inftru= mente. 5) Befetzlidye Borfdriften, um bie fidjere Bezeidynung

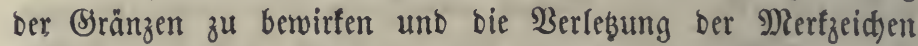
(Signale, Steine, \$fäble 2x.) mit Strafe zu belegen $(f)$.

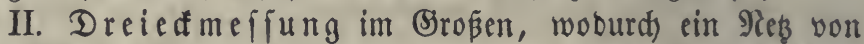
Dreieffen eriter und zweiter ober audi nod) britter Dronung entworfen wirb $(g)$.

III. Meffung ber einzelnen Semeinde= Fluren, worủber für ben gegentwärtigen 3wed mur Folgentez ju bemer= fen ift: 1) Den $2 \mathfrak{n}$ fang madjt bie Beftimmung ber \&age vieler einzelner \$uncte (Dreicfe vierter Dromung, Detnilneß̧) $(h)$. 
2) Die Erånzen ber Flur uno ber einzelnen Stüđe werben mit 3uzichung ber Drtaborfteher uno ber an jeber Etelfe betheiligten Srunoeigenthümer befichtigt, berid)tigt uno bezeidhnet (berfteint). Ergeben fid) lïber bie Sränzen bez Eigenthumz Streitigfeiten, fo müffert biefe nuf geridftlichem $\mathfrak{B e g e}$ entiffieden werben (i). 3) Der Felomeffer hat hiernad) bef(t)reibende Berzeidfniffe ber

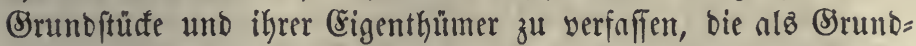

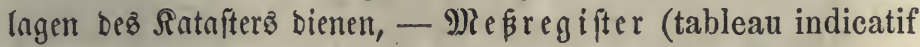
des propriétaires et des propriètés). 4) Die Meffung ter größeren Flurtheile (Felolagen, - Serwanne) ober ber auf gleiche Weife bemuksten Flächen (Eulturarten) ohne 2ufnakme alfer einzelnen Stüde ift zwar weit leichter, aber ungenügent, weil man Kiebei die Srößße ber einzelnen fteuerbaren Srundftüfe nur nach einer Muthunafung findet uno alfo erbebliche Unrid)= tigfeiten borfommen, wef̧halb die Meflung aller einzelnen Stüde ( $\$$ arcellen = ober Stü ofmeffung) ungeachtet ifyer Un= fiändidffeit Den Borzug verbient $(k)$. 5) Da bie Meffung $a b=$ Gängiger Brumbftücfe nicht bie wahre Srö̈ße, fonoern nur bie mageredte Srumbflädie (Gorizontale \$rojection) Darftellt, io

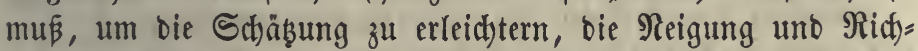
tung Der 2tbbänge erforid)t und angemerft werben $(l)$. 6) Die Bermeffungen werben forgfältig geprüft $(m)$.

IV. 3eidnung oer (5harten uno Beredyung bes Flächeninfaltes jebes Stücfes $(n)$. Der Maap̧ftab ber Charten

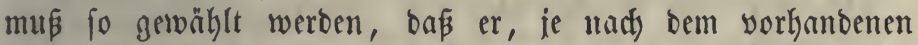

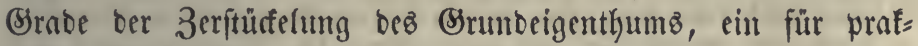
tij(t)en (Sebraud) genügende Benauigfeit gewälyrt $(o)$.

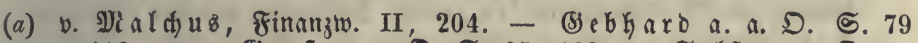

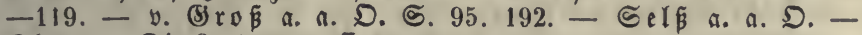
Slemm, Die Ranbesvermefitung, 1842.

(b) Errichtung einer unter Das Finanzminifferium geffellten Direction ber Rataftervermefiung, bad. B. v. 19. Zebr. 1855. Diefe Bef̧öbe giebt ein eigenes Beroronungselatt heraus.

(c) Beifpiele: Franfreidy. Shauptinftruction v. 5. Nov. 1805. Bufammen= ftellung aller Borfhriften im Recueil méthodique etc. Tit. IV. Bayer. Sntftuction für Die allg. \&andesvermefitung v. 12. April 1808,

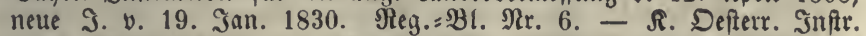
y. 28. Nlärz 1818, neue $\mathfrak{A} .28$. Febr. 1824, \&inden I, 273. Inftruct. über Das Berfahren bei ber Bermefiung Des Srunbeigenthums

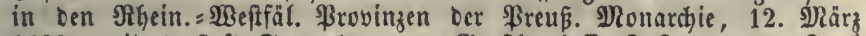

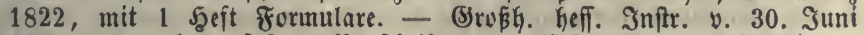

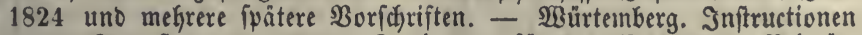
v. 20. Pluguft 1825 uno 28. Suni 1830 für Das, Bureau Der \$rimär: 


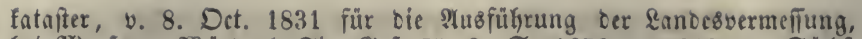
bet Ilvier, פBurtemb. Fin.:(Sei. II, 2. S. 1670 u. 1802. - Eädj.

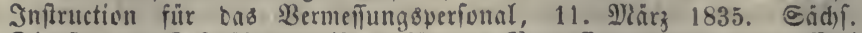

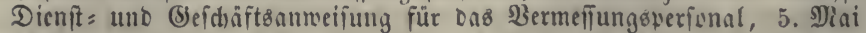
1837. - Dibenb. Inftruction für Das Berfaliren bei ber Bermefilung

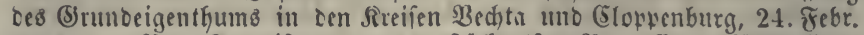

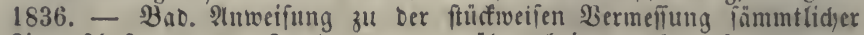
Riegenidhaften v. 22. Juni 1855, neu literarbeitet 9. शuguit 1862 . -

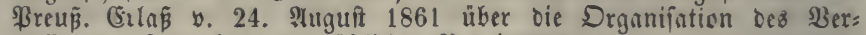
mefiungarwefens (in den 6 viflid)en \$rovinzen).

(d) Bayern uno 2 irtemberg: Trigonemeter, Dber=(Seumeter, Seumeter; 3 Clafiell yon (Seometern, jeoe mit einem beftimmten Sinnß̧e onn $20 x=$

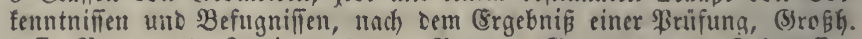

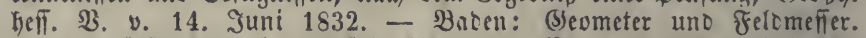
Eeģtere bürfen nux (S)runoftüife biz zu 50 Nivorgen flächengehalt ver= mefien. Beite haben eine \$rüfung ju beftehen, bao. Beroron. vom 2. Dlai 1857. - Den Felomefiern ift if Sreusen Die Annahme von (5) füllfen geftattet.

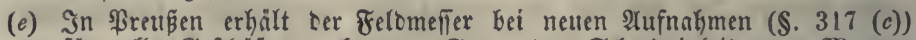

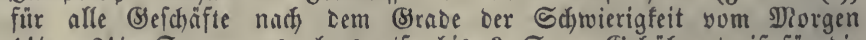

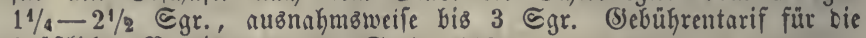
6 siftliden \$rovinzen y. 21. Sept. 1862.

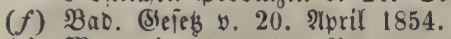

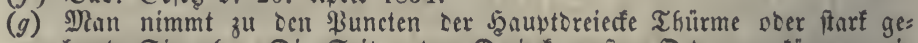
baute Gignale. Die Eeiten Der Dreiecfe erfer Dronung fonmen, ie nady ber lage Der \$uncte, mefrere Neilen lang fein, in Nheimpreuben haben fie renigitens 6000 Ruthen, Die Der 2ten Dronung 3 bis 6000, ber 3 ten $1-3000 \Re$. Der झूeffungeffeflex Darf bei Der 2ten Dronung nicht $1 / 3000$, bei Der 3 ten nicht $1 / 2000$ betragen, Inftr. \$. 20. 32.

(h) Sraphifiche Triangulirung in Defterreich.

(i) Sr. heff. Inftr. Giezu yom 30. Juni 1824. (ङef. ๖. 23. Detbr. 1836. Bab. SB. über die Bervflichtungen Der Steinfeber v. 7. Уiärz 1856. Die Srundeigenthumer werden bei diefem Sefhoffte mit ifren (sintwen= bungen gegen bie vorgefdlagene Begränzung vernommen. Jit ihre 3uftimmung erlangt ooer ein gerichtlidjes Erfenntnip belvirft worben,

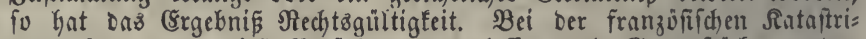
rung hatte man Dieß Berfahren unterlaffen, Lie Srundfücfe routben nur nad) ifyer Benubung (jouissance) im 2(ugenbliaf ber Bermefiung aufgenommen uno nidht verfeint, wef̧alb bie (Sränzen oft fidson nad furzer Beit wieber veränbert worroen. शtuch bei ber abermaligen Ratas ftrirung in 1790 Semeinden in ben $\$$. $1842-50$ wurben Dieje Fefler

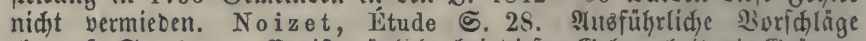

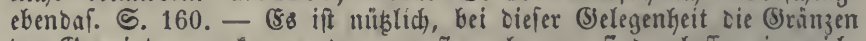
Der (B) emeinbegematfungen $D a$, wo fie unbequem fino, befier einjuridy= ten, - audy fönnen cie Felomefier zugleid) währeno ifjes (S)eichätes zu einer befleren (Eimrichtung Der Felowege fowie zur 3ufammenlegung Der Srunoftüfe (II, \$. 98) einen jefyr roirffamen beiftand leipten und $e^{b}$ ift bienlich, Diés gleichjeitig zu thum, bamit fogleich bie neutere befiere (Sintheilung Der Bsemarfung in Das Satafter aufgenommen wirb.

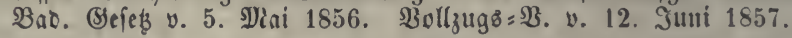

(k) In Franfreids Gatte zwar bie conftituirenoe Berfammlung 1791 cine Barcellarmefiung befchlofien, ba biefe aber nidjt augigeführt worben war, fo fdjeute man fid), als unter Bonaparte bie Gache roiecer nufs genomment tourbe, anfänglich yor Dem gropen sufwante ser Ctüct: mefifungen. 1802 befd)lós man, Blós 1800 (Semeintefiuren mefien uno

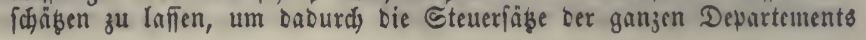


zu beridytigen. 1803 murbe bie Mefiung aller Bemeinben unt aller Eulturmafien in Denielben angeurtuet. Die Srundeigentfümer folften

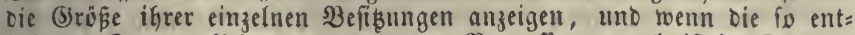

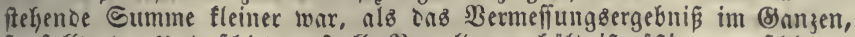

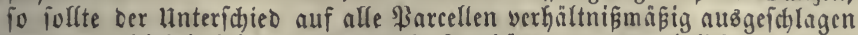
werben. Şiebei blieben aber viele Irrthümer unvermeiolid, weil die

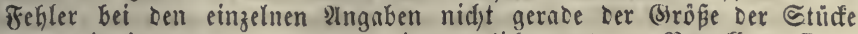
proportionirt waren, uno man ging enolid 1808 zur \$arcelfarmeñung über, Benzen berg I, 81-89. - Eifrige Bertheibigung biefer voll=

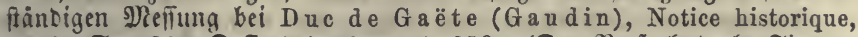
1818, 5. 195: Deff. Mémoires II, 259. (Der Berf. hat als Finanz= minifter bie $\mathfrak{B S}_{\text {ahl }}$ Diefes Berfạrens vorzüglich entiffieden.) (Segen vie \$3arcellarmeflung v. Se utter, Befteurung ber Bölfer S. 128-33.--

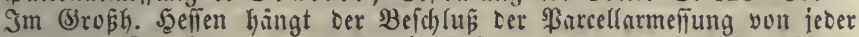
einzelnen (S)emeinde $a b$, welche Die Roiten zut tragen hat. Der Etant zahlt Dazu bie Roften Der Bewannenmefiung. Steuergef. v. 13. Alpril 1524 शrt. 34. Bef. y. 11. J̃an. 1831. Befanntm. y. 20. J̄uni 1831.

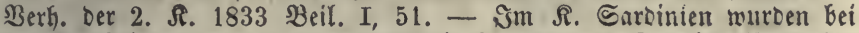
Der Rataftrixung von 1840 an nur Die Staatz= und (S) im Sinzelnen vermeīen, die \$riwatbefïhungen nur mañentweife.

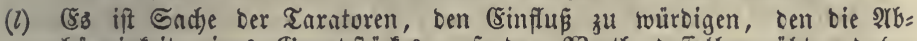
hângigfeit cines (Srunditücfes auf bell $\mathfrak{B}$ erth Deflfelben übt; Daher Braudjt bei ber Meffung nur ber (S)rab Der Neigung ermittelt zu wer=

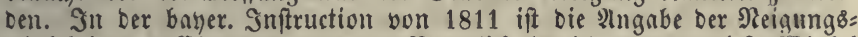
winfel in Der Sharte veroronet. Netrerlid, bezeidnet man viefe 2Binfel

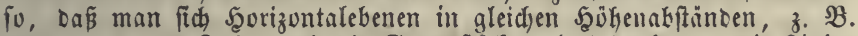
von 20 zu 20 Fu⿰ Durch Die (SrumDftüffe gelegt benft und Die Rinicn einträgt, in weldhen jene fflächen die abgängige Dberfläche fdhneiden würben. Heber Den $\mathfrak{B}$ erth abGringiger Flächen $\mathfrak{a} a$ in $\mathfrak{A}$ nor é, Def.

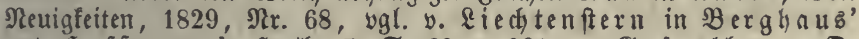

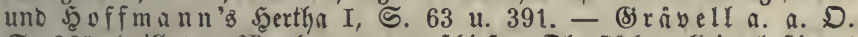

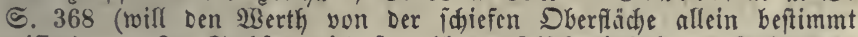

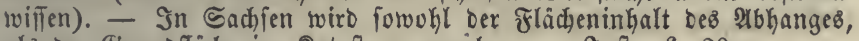
als oer (Sirunofliche im Ratafter angegeben, a. Inftr. \$. 29.

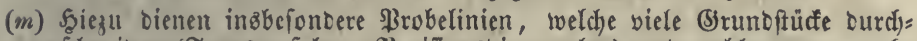

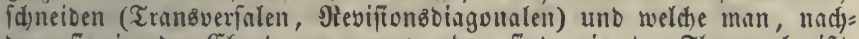
Dem fie in ber Eharte gezogen worben fint, in ber Flur nachmişt.

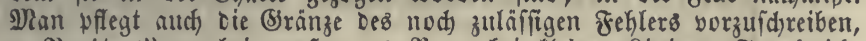
3. B. $1 / 2$ Hroc. bei groß̈en, 1 \$roc. bei fleinen \&inien, Frantreich, Rec. 21rt. 261.262, - 1/2 Proc. bes Flächenraums Defterreich, - 1 Broc.

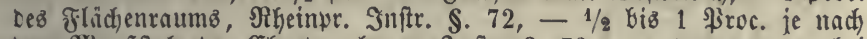

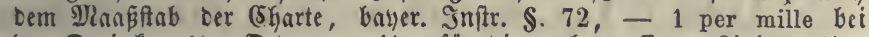
ben Dreiecfen 4 ter Dromung, $1 / 300$ für Die nachgemeifenen Linien, 1/150 für bie flächen oer \$inrcellen, Dloenburg. Inftr. \$ 112, - 1/2 \$rve.

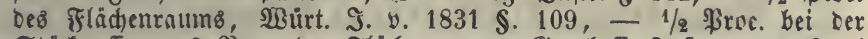

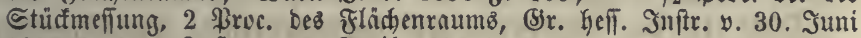
1824 §. 15. Juftr. y. 4. April 1831 §. 8.

(n) 3ur abfürzung hat man Red)enmaidjinen erfunten; 3 obel uno

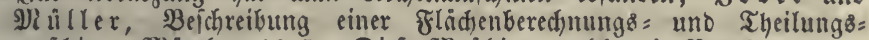

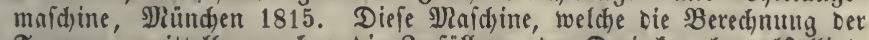
Trapeze unmittelbar, vhne die 3crfällung Der Drciecfe, belwerfftelligt, foll bie Sañlfte ber Seit erfparen, ifr (bebraud if aber wieber auf = gegeben worten. In Bern wurbe 1830 eime anbere Erfinbung für gleidjen 3med angefünbigt. (Sine neuere \$lafdine (\$lanimeter) von

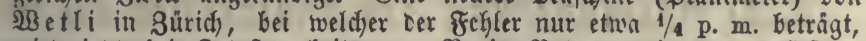
wiro jebt bei Satafterarbeiten, 3. 2. in Baben, mit gutem Srfolgé 
benubt. Stampfer in Dingler, Polnt. Journ. CXVI, 424 (1850). In \$reupen if ber \$olarplanimeter von $2 \mathrm{~m}$ s ler empfohlen tworben, f. ßreuß. (Sircular ๖. 13. Drt. 1862 über Die Ermittlung Des Fläđen= infalts.

(o) Nailano: $1 / 2000$ Der natürlidjen (S) röß̈e, rebucirte (Sharte jeber flur bon

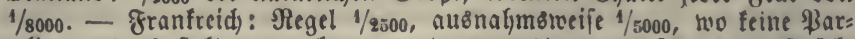
cellen unter 2 Şeftaren vorfommen, Dagegen $1 / 1250$, wo über 4-j Etứfe auf 1 Sgett. - Defterreid: : Regel 1 Sull gleid 40 Rlaftern oter 1,2880 , bei griseren Nafien Galbes YRǻ ober $1 / 5760$. - Würtemberg $1 / 2500$, bei geringer 3erfiủcelung nur $1 / 5000$, bei @täoten 1/2500. - Nhein= preupen $1 / 5000,1 / 2500,1 / 1250$, ie nadjoem Die verfommenoen \$arcellen über 4 , ober $1-4$, ober nur 1 D2. Uno carunter enthalten. - Bayern $1 / 5000$ Fegel, ausinahmsweife 1/2500 für Drtidaften und andere (Segenden, bei beren jener \$lanßftab nidjt genau genug ift, mad (Sutbefinden ber Ratafteritelle. \$. 11 ces (\$e). v. 1828. - (Sr. Şeflen, für Bsewann= djarten 1 p. m., (Semarfungsdjarten 1/5000. - Sadjien 1/2730. - Diten= burg $1 / 3000$ Regel für Flurcharten, bei geringer Serftüfelung $1 / 4000$ bis 1/5000, bei gripserer $1 / 2000$ bis zu $1 / 500$ (für Dörfer uno Etäote). $\mathfrak{B a D}$. Bermelīungrantweifung: Negel $1 / 1500$, bei größerer Serftüfelung $1 / 1000$ Doer $1 / 500$, bei gröperen (Srunoftüđen $1 / 2000$ ober $1 / 1000$. - Breúfen 1861: bei neuen 2 ufnahmen 1/2500 bis 1/5000. - Die Bervielfältigung ber Egharten burd Den Steinbruaf getwäht ben einzelnen Butsbefikern,

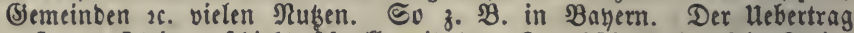
auf ben Stein geidieft idnell mit bem Stordfdynabel. Die Eteine werben aufbewahrt, um 2(enberungen einzeid)nen zu fönnen.

\section{\$. 320 .}

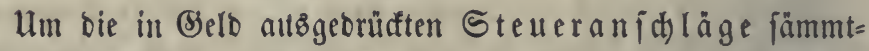
lidjer Srumbftưde zu erkalten, fint in neuerer 3eit verichiebente Bege eingeid)lagen worben, weldye fich unter folgenbe Scaupts abtheilungen bringen laffen:

A. Bemub̨ung einez einfadyen Thatumftanbez, aแż bem man nuf ben fteuerbaren Ertrng (4)lieft, und zwar 1) bes

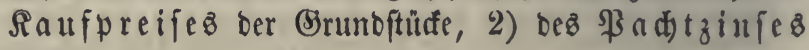
Derjelben;

B. Bered)nung Des muthmaß̧idyen mittleren Bobenertrages, 1) Dez rohel, yon bem man leitte Bewirthid)aftungs? loften ober bod) nur einen fleimen Theil berfelben in Ilfüly bringt, 2) beż reinen Ertrages.

Diefe in ben folgenden $\$ S$. Darjuiftelfenden Şauptmethoden

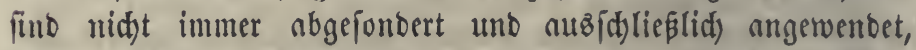
jonbern es find ofters mebrere berfelben mit einnuber in $\mathfrak{B e r}$ binbung gefest worben, waz autch alz zwefmäßig anjulehen ift.

\$. 321 .

A. 1) Inlegung nad) Den Raufpreifen ber $\mathbb{L} a ̈ n=$

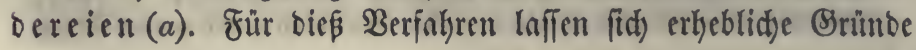


angeben. Diefe Sreife iteben im Sanzen genommen beiläufig

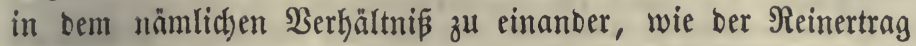
Der Sirunbitüfe (I, \$. 219), und brüffen Daв Urtheil ber land: bauenten Elaffe über Den ungefähren $\mathfrak{B e r f e h r z a m e r t h ~ D e r ~ B r u n d ~ = ~}$

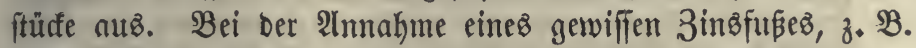

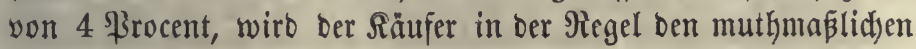
Reinertrag nidjt wohl böker als mit bem 25 fadjen beffelben erfaufen und zugleich ift ber Berfäufer abgeneigt, unter bie= fem B̧etrage einen Berfauf einzugehen. Dbgleid) beibe Theile in vielen Fällen ben zu erwartenden গieinertrag ie nad) ifren befonderen $\mathfrak{B e r h a ̈ l t n i f f e n ~ u n g l e i d ) ~ b e u r t h e i l e n , ~ f o ~ m a d h t ~ f i d ~ b o d ) ~}$ ourd) Das beiberjeitige Mitwerben ein getwiffer örtlicjer Mittel=

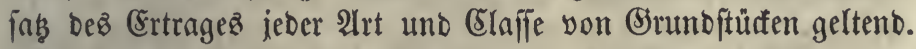
Bollte man fíd) bei ber Feftiebung ber Steueramidläge mur an bie in eimen gewiffen Zeitraum bezahlten Sreife ber ein= zelnen Srumbitüffe Galten, fo würbe man fogar bie Bermeflung erpparen (\$. 317). Die Berfäufe von Riegenfidnften werben \{4) on Der Beglaubigung wegen bei ben (Sicrid)ten aufgezeidnet (regiftrirt) und bie Steuerbebörbe fann fid) leicht bie Angaben über bieje Sintragungen wäfrent eines feftgefezten Zeitraums

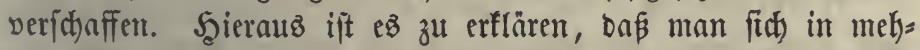

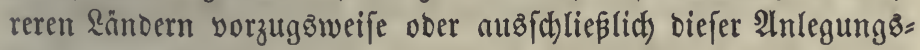
art zugewendet hat $(b)$.

(a) Frü Die Anlegung nach bem "gemeinen $B e r f e f r z w e r t f$ " Die Schrift:

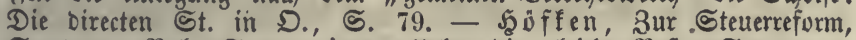
ธ. 177. Bgl. Sartoriub, ueber bie gleide Beft. S. 73. -

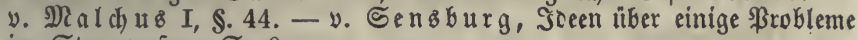
im Eteuerwejen, S. 9.

(b) Beifpiele in ben folg. \$\$. - Sn Tirol wurbe, madjoem man (Esbict

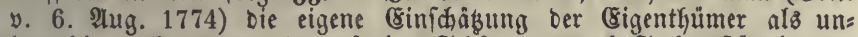
braudbar erfannt und barauf eine Edhäkung Durd Eadjuerfänbige an=

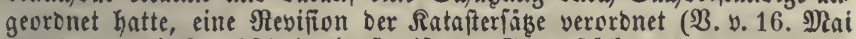
1780), Der Die Durdfidnittsfinufpreife Der Sruntefüdfe yon 1760-80 zur

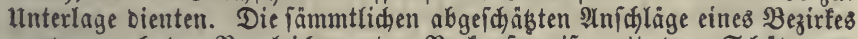

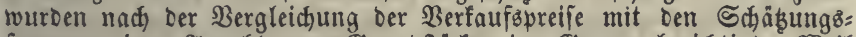

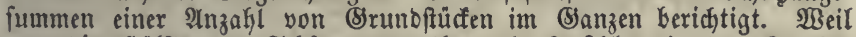

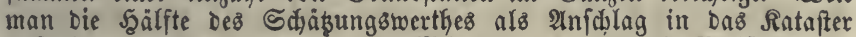
aufnefmen wollte (\$atent ๖. 26. Mairz 1777), uno bie \$reife Der er= mähnten Sahresreike als ungetoöhnlid hoch erfannte, fo wurben yon bem fog. (Surrentwerthe mur $3 / 8$ zum Ratafteranidilage genommen. Das gamze fo erhaltene Steuercapital betrug 46,6 MRidionen. Da num von

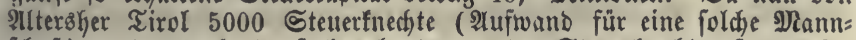
fidaft) zu tragen Katte, fo berechnete man Den Steuterfnedyt auf 9000 fl., wovon 54 fl. Steuer $=0,{ }^{6}$ p. mille zu entridjten waren. Sirehl, Beiträge, ๔. 157. Rremer, II, 40. Einden, I, 130. Tafeln zur

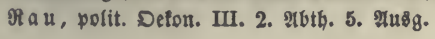


Statifitif tes Steuerweiens im i. Raiferifante S. XXVIr. - Bei bem

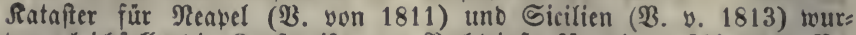
ben gleidfalls bie Rnufpreife und \$adjtzinje für tie veridjiebenen $\mathfrak{B}_{e}=$ nubutugsarten und Bobenclafien zu Srunbe gelegt. Plebano et M asso, Fin. du roy. d'Italie. S. 211. - D'A u d iffret, (I, 31) (đ)lägt vor, bie (S)runbitetter uno bab enregistrement ben namlid)en

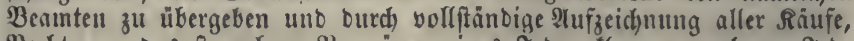
ßadhte 2c. Das fteuerbare Bermögen einez Jeben tlar zu madjen. Jebe andere $\mathfrak{A r t}$, bie Srunofteteranialáge zu erhaltelt, eradjtet er für weni= ger genau.

\section{§. 322 .}

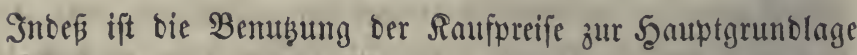

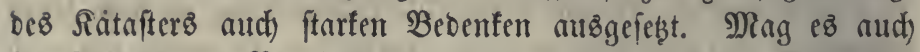
im Sanzen als Regel angentommen werben, baß̄ bie Raufpreife unter einnober in bem nämlidłen $\mathfrak{B e r b a ̈ l t n i \beta}$ ftehen, wie bie

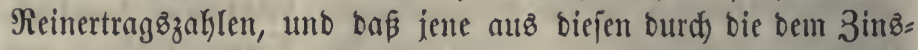
fü entipred)ende Bervielfacjung gefunben werben fönnen, fo trifft biés bod) weber bei ben einzelnen srumbftüfen, nod bei allen

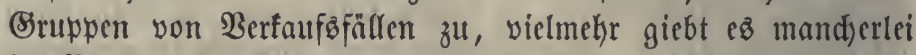
im $\mathfrak{B}$ egehr ober 2 ngebot liegende Umifände, weldye ftöreno ein =

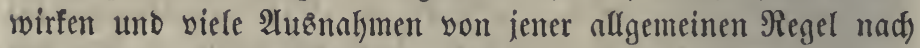
fidf zielyen. Soldje Umftänte fint $(a)$ :

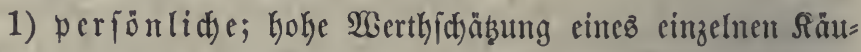

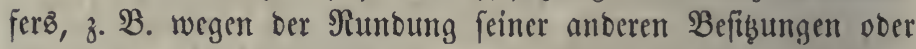
wegen einer beabfidtigten befonberen Bemubungzart, - Noth

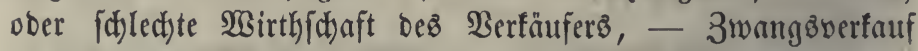
11. Dgl. Der niebrige \$reis, um weldten einem Sintoe Das älterlidje Sut zufolge einer $\mathfrak{B}$ egünftigung ủberlaffen miro, fann zut Befteuerumg gar nidft bemub̧t werben;

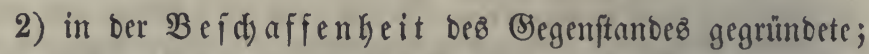
namentlid) werben gebuntene Bauerngüter unter übrigen gleidsen

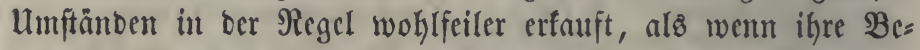
ftanttheile außserthalb bes Berbantes (walzend) wären (b), audc) ift ber Saufpreis ganzer (süter gewöhnlich) niebriger alø Die Summe der Preife ber einzeln verfauften Stïde (c);

3) örtlid)e; geringe Menge yon verfäuflidjen Ränbereien in eimer Drtidjaft ober (begent im Bergleid) mit ber (5imwoly)= nerzahl, z. B. in Escbirgågegenten $(d)$, ober wo viele Befibungen in fefter Şano fint, wie bei Domanials, Eorporations:, Stamm=

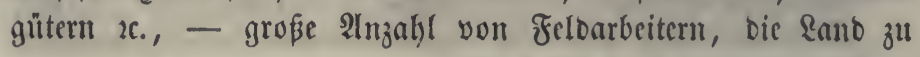




\section{1}

padten ober zu faufen fuctjen, z. $\mathfrak{B}$. in ftarf besölferten $\Re(b=$

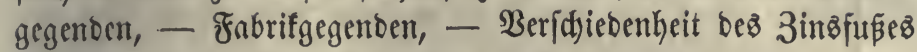
in reidjent und armen Siegenden, I, $\$$. $232-(e)$;

4) zeitlid)e, bie jwar in einem einzelnen 3eitpuncte bie \$reife vorübergekent erhöken ober erniebrigen, aber auf bie 2lufdalăge in einem für längere Dauter beftimmten Ratafter

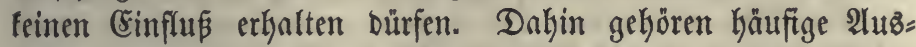
wanberungen, - eine vorübergekente Theurung ober $\mathfrak{B O H}_{\mathrm{K}}=$ feillyeit grwiffer (anbwirthfibaftlidjer Erzeugniffe, - Sriegżnoth

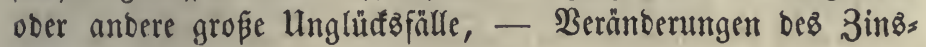
ศирев $(f)$.

2luserbem fommt in Betradit, Das in mandjen (d)wad) bes völferten Eegenten wenig Beräuperungen vorfommen unt ein Theil ber Raufpreife wegen ber beigefügten Rebenbebingungen ober Begenteiftungen 2 . nidjt bemught werben fann $(g)$.

(a) Beiträge Giezu in Dieterici, Nittheilungen, 1853, ๙. 212.

(b) Daher wurbe in Bayern ein 3ujdylag zu Dem Eteuerjaze ber gebunbenen (Suter angeoronet, bei tell grösten (S) itern bis an 40 Sroc. Wieber

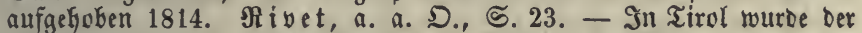
Durchidnitt aus ben Raufpreifen ber Muftergrunoftücfe in jeber (Se: meinde etwas ermäsigt, wenn barunter fleine Stücfe waenn. Bei Räufen unter 100 fi. zog mant $2 / 5$ ab, bei $2000-2500$ nod $3 / 20$, von 3500 fi. an aber nidjts mehr. \&inben, I, 140. - Sergl. \$. 307 (b). (S)bunbene (S)üter gefien oft lange fort mit einem niebrigen väterliḑen Inichlage auf bie Erben über.

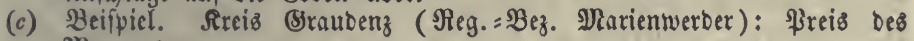
Diorgenв :

\begin{tabular}{|c|c|c|c|}
\hline$i$ & & & \\
\hline & von 1 & & \\
\hline & $\begin{array}{l}600- \\
300-\end{array}$ & & \\
\hline $\begin{array}{l}\text { i Bautern } \\
\text { i Răthne }\end{array}$ & $\begin{array}{cc}30-300 \\
n & 1-30\end{array}$ & & \\
\hline
\end{tabular}

wobei ber niebrige \$reis ber Bauerngüter eine befondere urfache haben nuน⿰.
Sireis ๔djwet:

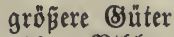
Bauterngüter Rand ber Nieberung . . . 46 Sitglr. sobike - $23^{1 / 2}$

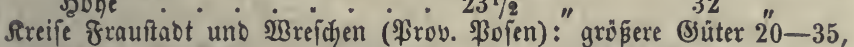

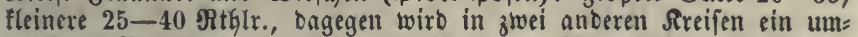
gefefyrtes $\mathfrak{B}$ erhältni you 1860 follten nidht \$reife von einzelnen Stüfen, fonbern yon ganzen (S)utøfäufent genonumen werben, Die bir. St. S. 80.

(d) Deßbalb ift in Sayern eine bejonbere 2tusgleidung ber Steuerfäbe zrwifhen ebenen und Bebirgögegenden angeoronet worben, um reştere

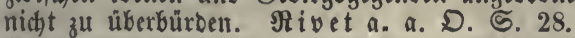

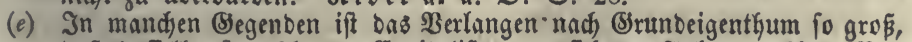
Das baffelbe fowohl von Capitaliften zur fidjeren Inlegung ihres $\mathfrak{B e r}^{2}$

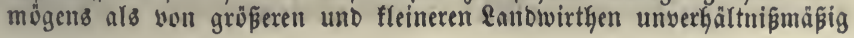


Gud bezaflt wiro, befonders in fleinen Ethofen. Der Befiber eines

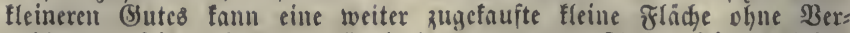

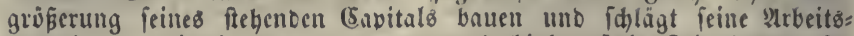
vermelyrung nicorig an, wemn er nud bisfer fieie 3eit hatte. In Belgien waren die mittleren \$ad)tzinfe in ben Safren 1830, 35, 40

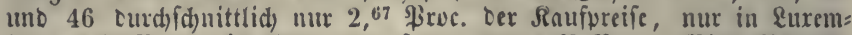
burg 4,38 \$roc., in J̧ennegau fogar nur 2,38 \$roc. Biele Betrad)= tungen hierüber in Agric. Recensement gén, de 1846 ङ. 186. In

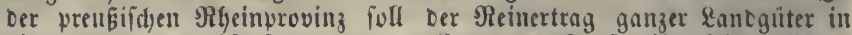
viclen (Segenden huddentens $2 \frac{1}{2}-3$ ßroc. Des Raupreijes fein. Räufe zur (5ifenbahn ober zu Baupläzen fino ohnehin zu hod) für ben 3weff DCE Ratafters.

(f) In Franfreici) Gat man Die Rauforeife von 1790 an für unbraudjbar angeichen, was fid wegen Der aus ocm Sevolutionzzufance herftam: menden Berwirrungen leidht erflären läpt. Deß̧halb follen nad) Der

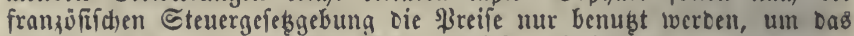

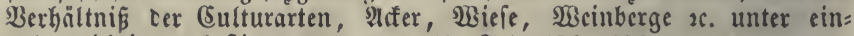
anber richtig zแ beftimmen, $\mathrm{Recueil}$, Irt. 426.598 .

(g) Bei Selegentheit Der ueuen preusifichen Rataftritung ift von Den Gads= verfändigen überall auछgefprudjen wurben, oaß bie Raufpreife nidjt genügten. Denfichrift Des (Seneralcommifínrs für Die RGeinproving

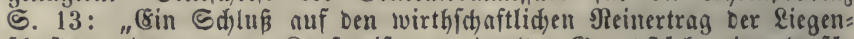

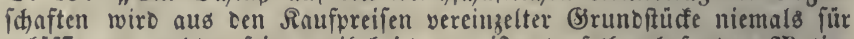
zuläfity zu eradten fein, weil bei ben meiften berfelben befoncere Dlotive Der \$reisfteigerung zu erfennen fein werben." 21ehulid) Denffdrift bes

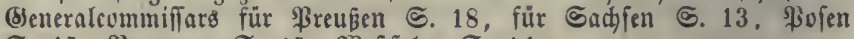

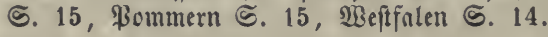

\section{\$. 323.}

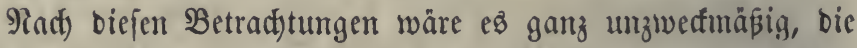

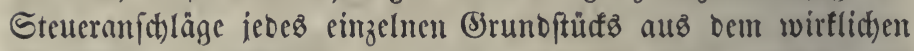

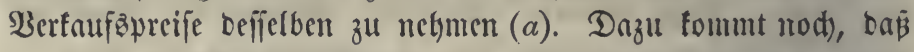
ein Theil ber (S)rundftüde gar nid)t, ein anderer Theil wenigitens in bem angenommenen 3eitraum, bejonbers wenn Derjelbe furz ift, nid)t mit freien 9Ritwerben veräußert wirb, währento in cinem längeren 3eitabid)nitt Ränbereien von gleid)er (Einträglich)feit bald höhere, bald niebrigere \$reije erbalten mo baher veridsie= ben angejchlagen werben müpten. WO man verfud)t hat, bie wirtlid)en Raufpreije ber einzelnen Stüde ju Srrunde ju legen, on hat man fid) genöthiget géfehen, zur ßermeioung grö̈er $\mathfrak{H}_{1}=$ gleidhbeiten Berid)tigungen zu Şülfe ju uekmen, weld)e bic gerübmte Einfadheit biefer Eteueranlegungsont aufbeben und bentod) feinen fideren (Erfolg erwarten laffen, weil die $2 \mathrm{ab}=$

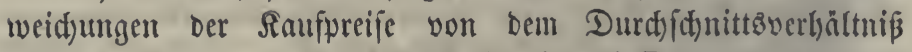
zwifhen Rente und Sreis aud in cinerlei Drt uno Zeitpunct in teiner Şinfit)t gleidförmig fint. In Bayern futo und)= ftehende Beridtigungommittel angewendet worben: 


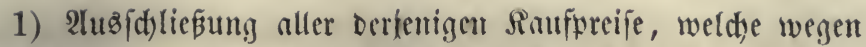
eines ber genannten inbivibuellen $\mathfrak{M}$ mítänbe (\$. 322) nid)t bem

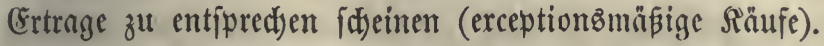

2) Ergänzung fowohl ber ganz fehlenten, als ber unan=

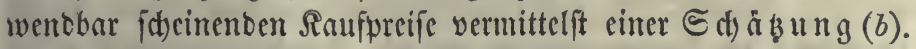
Diefe ift hier fahweriger als in anberen Fällen, weil fie nid)t für bie Biegenwart, fonbern für einen verfloffenen 3eitraum vor= genoumen werben umí.

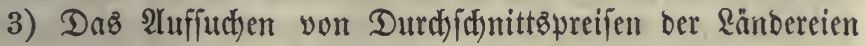
von mittlerer (S)ite in jeber Benutzungänrt (Mittelwerthe), um

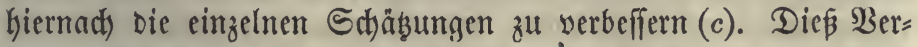
fahren jeł̧ voraus, baß̧ bie Echäbungen innerbalb eines jeben

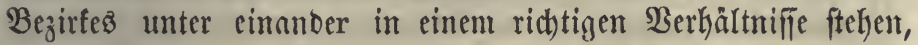
twas icood) nidft fither anzumelymen ift; auth) liegt in ber als

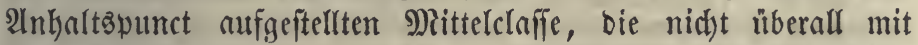
Befftimmtheit zu erfenten ift, eine Urjacte von Ungleid)heiten.

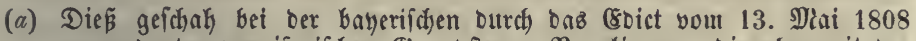
angeoroneten proviforifhen (Srundfteter $=$ Regulirung, Die aber mit Der Sinführung oes Definitivum wieber aufgehoben warb. Dieß́ \$roviforium if in $111.1 \square$ Meilen von Bayern aubigefügrt worben uno bat mur

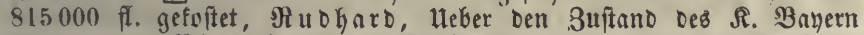

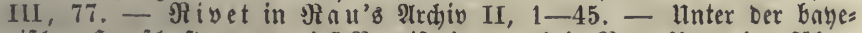

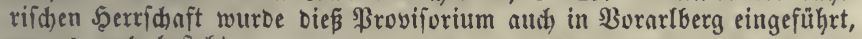
wo ez noch befteht.

(b) Die Werthangabe Durdh Den Eigenthümer felbft wurbe in Bayern als untauglich beieitigt, ongegen aber eine Cdäbung Durdh vereibete Tarn=

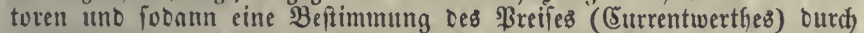

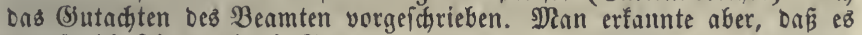
unmöglid) fei, ourch bie Taxntoren ben wahren Dittelpreiz zu erhalten, und iuchte föaterfin biefelben nur bazu anzuhalten, onś fie alle Stïffe in ifrem Bezirfe gleichmäß̈ig befancelten.

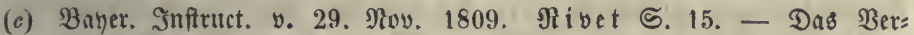
fahren war folgendes: 1) Nan fucfite in 6-8 Diftricten eines 2 imtes

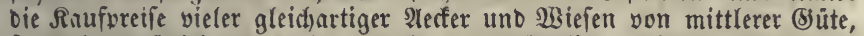
forwohl ber freieigenen, als oer mit rer gewöhnlidhen mittleren Belaftung verbuntenell, bieraus ergab fich, mit Berïdifichtigung Der Dorgenzahl, Der Durchichnittsureiz eines Morgens. 2) Die fämmtlichen Stetter: bezirfe eines 2(mts murben nach Der Bodengüte (Bonität) clafifficirt, unD für biejentigen, in welchen jene Nittelwerthe nidht ielbit gefunben waren,

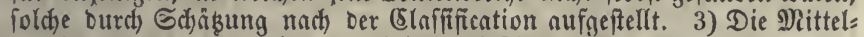
werthe wurben nun mit ben, bei ben frifheren SRegulirumasarbeiten ers

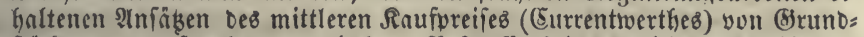
itüffen cer entiprechenten mittleren $\mathfrak{B}$ efdafifengeit verglichen uno hieraus Die Regel abgeleitet, ob uno um wieviel bie biskerigen Säbe in Dem ganzen Bezirfe erföht oder erniebrigt werben follten. 


\section{§. 324.}

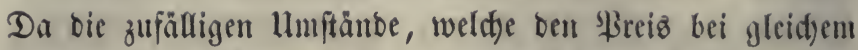
Reinertrage bald böher, balb niebriger ftellen, fich bei einer

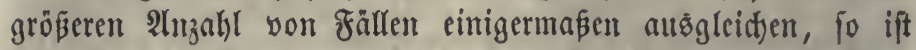

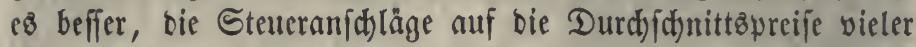
Brunbftücfe żu bauen, bie einanber im $\mathfrak{B}$ erthe ungefähr gleid) ftehen. Es wiro alfo hiebei eine Eintheilung ber Räntoreien

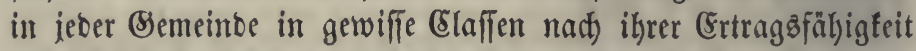
孔u Şülfe genommen, bie Seaufpreife werben für bie zu jeber Slaffe gehörenben Srunbftủfe zufammengefitellt unt es wirb aus

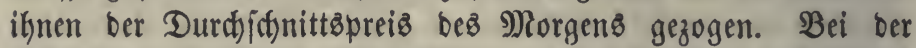
2luffitellung ber Elaffen braudjt man feine 3ahlen bes Ertrages

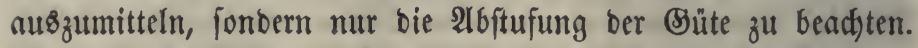
Der gute Erfolg biefes in $\Re a f f a u(a)$ und 'Baben (b)

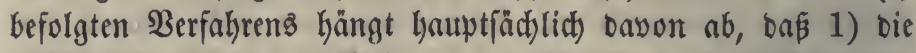
Elaffeneintheilung forgfältig, mit vollftänbiger Berüuffidstiguntg

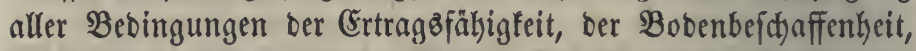
ber Eage 2 . vorgenommen werbe. Ez ift baker nöthig, ben

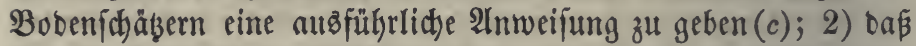
für bie 2luffiuct)ung ber Saufpreife eine \$eriobe getwählt werbe, beren Errgebniffe ale mañgebend für bie 3ufunft angejehen werben fönnen, - aljo ein 3eitabfannitt, in bem bie mentigften Störungen Der \$robuction uno bes $\mathfrak{B} e r f e h$ raz ftattgefunten haben unb in weldsen feine bebentente unb fortbauernbe $\mathfrak{B}$ eränterung fällt $(d) ; 3)$ baß man alle biejenigen \$reife, bie aus cinem ber angegebenen Srünte (\$. 322) muthmaplid) nidjt in ridftigem

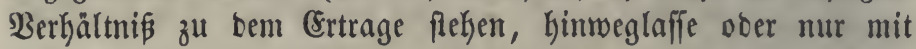

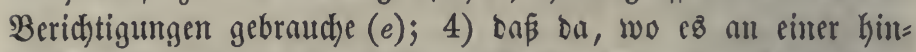

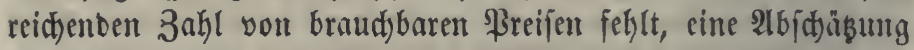

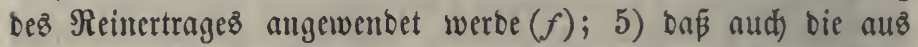
fehlerfreien Saufpreifen abgeleiteten (Slaffenjäbe nod) einer \$irü= fung nad) SBadtzinjen uno (Ertragäbered)nungen unterworfen unto mit ben für benadybarte $\mathfrak{B}$ ezirfe gefunbenen verglidjen wer= ben, woburd) bieje Ratajtrinungsant fid) ber in \$. 328 bar= geftellten nähert $(g)$. - Unter biefen Bebingungen vermag baß bejdrriebene Berfahren, sweld)es fich) zugleid) burd) feine Siürze compfieblt, ziemlid) viel zu leiften, obgleid) ez immer fel)r idjwer 
ift, bie ben Sinufpreifen als Şauptgrunblage anflebenten $\mathfrak{U n}_{\mathfrak{n}=}$ volfommenkeiten (\$. 322) zu befeitigen (h).

(a) Nafifau: Steuergé. v. 10. u. 14. Febr. 1809, in ber Sanmulung ber Inuseshetrl. (5)icte, 2 iesb. 1817, I, 362.

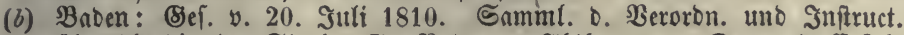
über Die birecten St. im Br. Baben. I. Âbth. 1817. Der gute Erfolg

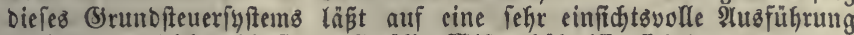

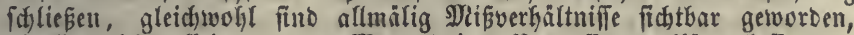
bie fidh nidjt allein aus bem Inangel einer Bermeffung erflären laffen. Bemerfungen gegen biefe Niethode in $\Re$ rehl, Beitrïge S. 177. Das Seies v. 7. Yna 1858 veroronet eine Ermeuerung ves Ratafter auf ber nämlidben (Srunblage, jebod) mit mandben Berbefferungen.

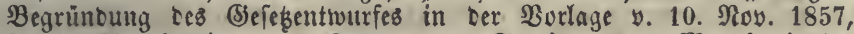
Fusfdusberidgte in Der 2. Rammer von Steiner uno $\mathbb{D}$ uth, in ber 1. von Frh. v. (S) oler. Für Die Beibehaltung Des 1810 eingefüfrten

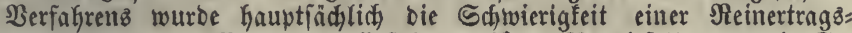
berechnung, Der Dangel an Erfahrungsiäben für biefelbe uno bie \&ee= wobnung an bas beftehende Syftem angeführt.

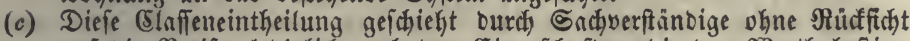

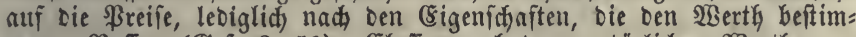

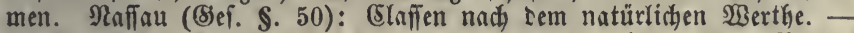
Baben (Neues (Sef. \$. 7): nad) Der mefr ober minoer guten Boden= beidjaffenkeit uno nach oer für bie \&anowirthidaft mehr oder minoer günftigen Rage. Die Slafien follen nidht im Boraus entworfen werben, fondern fid bei Der Betraditung aller fflurtheile von felbit ergeben uno

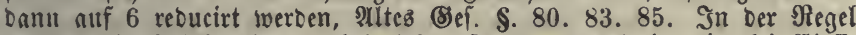
werben bie Stülfe cines Felobezirfs (Bewannes) in einerlei (Elafie

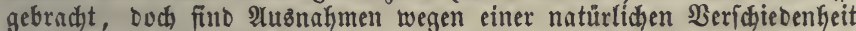
geftattet, §. 81. Man hat in beiben Rïnoern unterlaffen, Hähere $\mathfrak{A}=$ leitung über biefe claffeneintheilung zu geben.

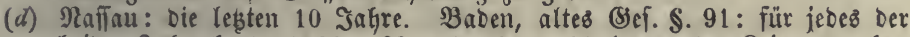
beioen Ialjrzebenoe 1780-89 und 1800-09 (wegen Der Rriegżturuken

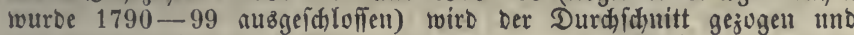
aus beiben wieber bas Mittel genummen. - Die \$reife bes erferen Jahrzehenos funnten ben lanbwirthfdyaftliden Serfältniffen einer foviel ponteren 3eit nidht mefre gut entiprechen! ygl. Arefl 5.179 . -

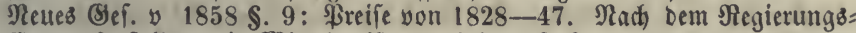
Ëntwurfe follten bie Mittelpreife Der beiden Salizzefente 1835-45 und 1846-55 gefudjt und aus ifnen follte vieber Der Durchidjnitt gezogen wersen. - Der \$langel einer Bermefiung mad)t idfon bie Durd) f(d)nitts = preife jeber Benubungsont uno Elaffe ungenau, \$. 317.

(e) So in Baden, neues Ser. \$. 11. - WBenn ber erbaltene Durdjfdnitt you Dem mittleren "saufwerth" Der ßeriode bebeutend abweidht, io if

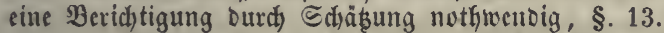

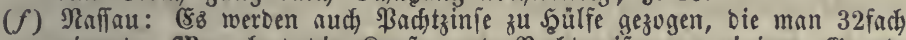
nimmt. Nan legt Die Rnuf= und ßadjtpreife von cinigen (Srund=

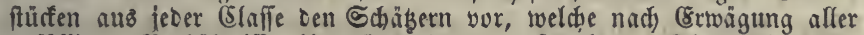
zufälligen Berkältniffe ify (Sutad)ten aubipreshen. Dieß wiro Dell Steuerpflidytigen befaunt gemadyt, Deren Einwenbungen man wieber Den Sdjäbern zur Beantwortung mittfeilt. \$.50-61. Baben, n. Ber. §. 13-16: feglt eछ für eite (Slaffe oder für eine Culturart voer für eime ganze (Senteinde an einer finreichenden 3ahl von Snufureifen, fo

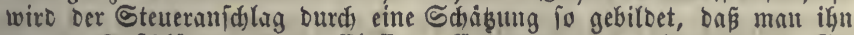

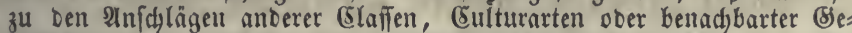

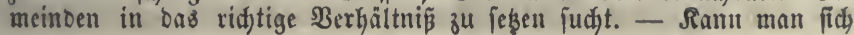


nidgt nadh einer Radbbargemarfung riduten, fo twirb ber 25 fadje mittlere

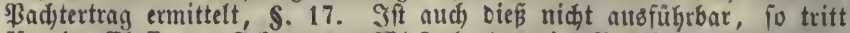

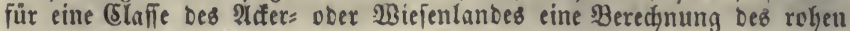
und reinen Ertrages ein, f. 18. - Shion Das (S)eieb v. 1810 foutte in

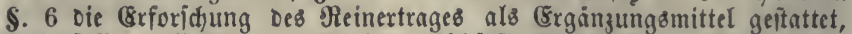
ood) follte baffelbe nur als lezte शibhülfe gebraudyt werben, wo bie

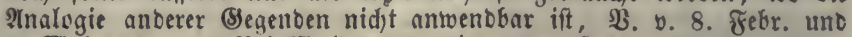
4. Wiai 1811. - Bei Waaldungen wird Der 15 fache nadjhaltige $520 l 3=$ ertrag nad) bem \$reife auf Dem Stamme genommen, ofne (5inretbnutig

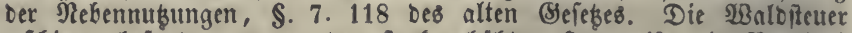
eridfien, bejonders wegen Der ftart erböhten Şolzpreife, in Bergleidh

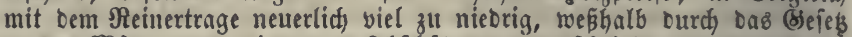

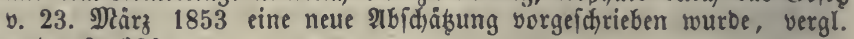
unten \$. 332 .

(g) Bab. altes (Sef. \$.96. 97: Die mittlexen Saufpreife Der Elaffen werben Den Taxatoren borgelegt, beren Shägung, wenn fie von jenen Durd)=

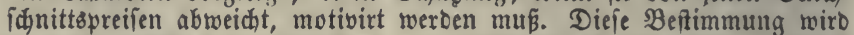
im neuen (Seies Durd, Den oben $(e)$ angeführten $\$ .13$ erfeb̧t. - Nad́)

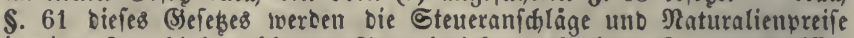

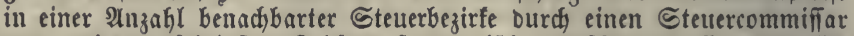

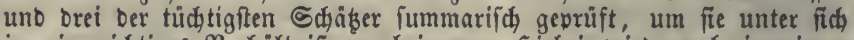
in ein richtiges Berhältniß̄ zu bringen. Şiebei wiro aud in einem ober mefjreren Der Steuerbezirfe je für eine Elaffe ber Şauptculturarten

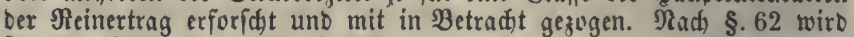

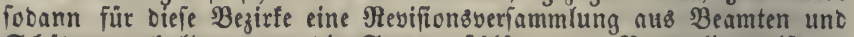
Ģäbern gehalten, um bie Steueranifjläge uno Naturalienpreife zu begutachten. Die Feffftellung Derielben geidjieft von ser unter Dem Frinanzminifterium ftekenden (5ommiffion. Pud Das naffauifose uno

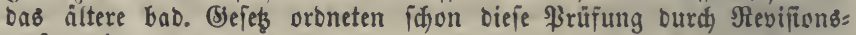
veriammlungen an.

(h) Begen Die nach Dem Sefés von 1810 aufgeftellten Stenteranidsläge fino

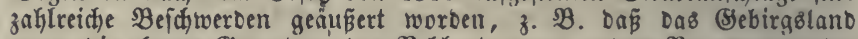

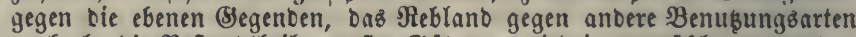
zu hoh, bie Beftanotheile grofer (Suter zu niebrig angefd)lagen worben ieien. $\Re$. Beridt von Steiner.

\section{§. 325 .}

A. 2) Anlegung nad) ben ßadtzinien(a). Diefe pflegen bem Reinertrage zwar genauer verkältniß̈mäfig zu fein, als bie Raufpreife, fteken aber bod) aud) unter bem (simfluffe

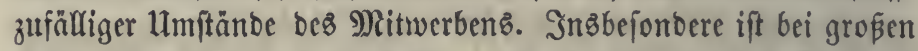
\$achtgütern ber 3inz iebes Morgens gewölgnlid) unter übrigens gleid)en Umftänben bebeutend niebriger alz bei fleinen Stüffen, um bie fich bürtige \&anbbewohner betwerben. Anbere Sd)wierig=

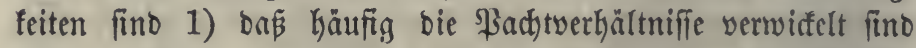
uno mandjerlei gegenjeitige Reiftungen vorfommen, bie erft müh= fam zu Belb angejekst werben müffen; 2) baß in vielen (Begen= ben ober Drtidsaften mur eine geringe 3 ahl von ßadjtfälen vorfommt (b), von benen nod) ein Theil wegen zufälliger Urjad)en yon ber mittleren Rente abweid)t, cin anberer Theil unridtig 


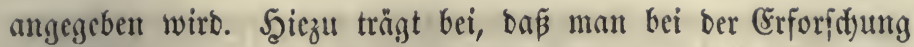
ber Şact)tzinje auf feinen fo langen 3eitraum zurüafgehen fann,

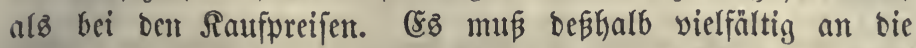

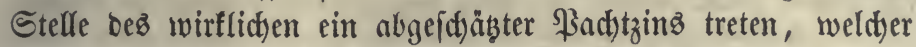

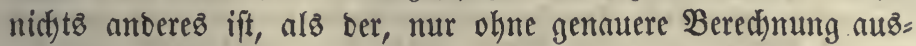

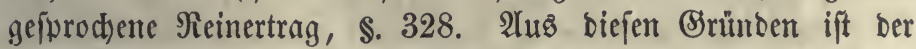
Panchtzinz nid)t geeignet, Die Şauptgrunblage einez Rataptersె

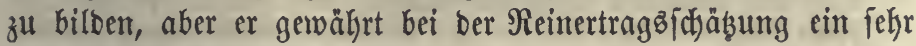

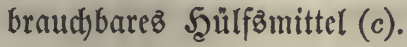

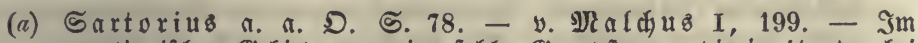
venetianifhen (Sebiete war eine foldhe Brundfeuer, Die in $1 / 10$ ber bei Dem Steuerbeamten regiftrirten \$adjtzinie beftano. Der felbftwirth=

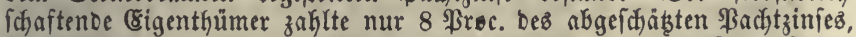
2. S mith III, 218. - Aefnlidy fonft bas verponding (Srunofteuer) in mehreren झrovinzen Der vereinigten Rieberlanoe. MRögel. 2nnal. II, 166. Over de Belastingen etc. $\mathfrak{5}$. 125. In Szolland murbe bie Steuter 1627 auf $1 / 5$ Der Badjtrente geiebt, in Sroningen war fie $1 / 4 .-2 u d 4$ bie britifden (Brafichaftz = und QTrmenabgaben werben nad) ben \$adjt: zinfen aufgelegt. Rries a. a. D. S. 96.

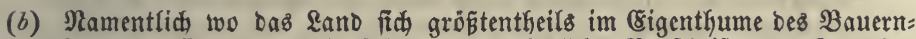
fandes befindet und Die (Siüter nad gefeblicher Borjdrift ober (Sewokn= Geit meiftens unzertheilt auf einen Erben „ibergehen. In Brobbritannien, Irland, Dberitalien, Franfreid, Belgien 2c. if Das Berpadyten vor: herridjent.

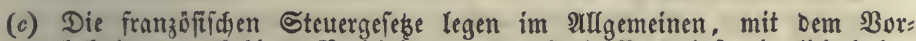

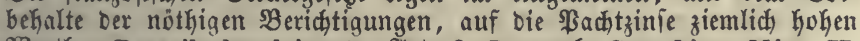
Werth. Recueil des lois etc. 2Trt. $\$$. 7 ; пuゆ $G$ a udin, Mém. II, 315. - Daffelbe gilt von ber olbenburgifiden Rataftrirung.

§. 326.

B. 1) arnlegung nad) bem rohen Ertrage, entweder ill feutem sollen Betrage ober wenigftens nur mit foldyen $216=$

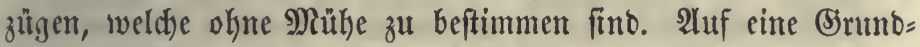
fteuer nad) bem roken Ertrage fonnte f(t)on bas Beifpiel bez 3ehnten fübren $(a)$. 3u ihrer (Empfehlung gereiçte vorzüglid) Der Umftano, baßi ber roke (Ertrag weit leidfter zu ermitteln ift,

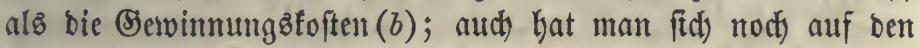
(5)und geftübt, Daß ber rohe Ertrag ober bie aub Demfelben abgeleitete natürliçe Ertragşfähigfeit $(c)$ gerabe bas anzeige, wละ bie (Srunbftetter belegen folfe, nämlid) bie unveränberlidłe ) Nitwirfung

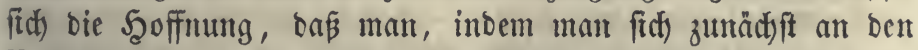
Saturalertrag halte und bie ivechfelnden Belopreife befeitige, 


\section{eine auf alle 3eiten hintaus braudbbare Sataftrinung zu Stanbe bringe.}

(a) Şiefjer gehöt aud ber Boridhlag eines als einzige Steuer zu erkeben=

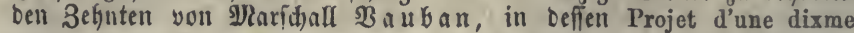
royale, Paris 1707. (8\$ follte von allen (sinfunnften, auch aus (S)ewerfen

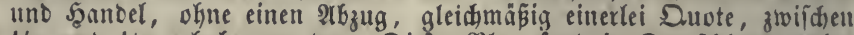
$1 / 10$ und $1 / 20$ erfoben werben. Diejer Plan fand in Deutidhlano emige Bertheidiger (b) unding, ßefderin, $\mathfrak{R a r l}$ ), wurbe aber burd von Der \&ith uno v. Sufti befimpft, $B$ ergius, Solizei= uno Ram.= Mag. IX, 196-210. - In Dalmatien beiteht nod ber 3efinte als Srunditeuer. (8r wirb in (beld erfoben, nad) einer jäfrlidon (Er:

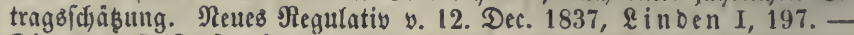
Die von $\Omega$. Jofeph (20. Ipril 1785) angeoronete Brunofteuerregu= lixuty (bas Sofephinum, f. oben $\$ .317(b)$ ) beruft auf ber 2lngabe Des rohen Ertrages burch bie Eigenthümer, nut nadjolgenber amtridjer Frifung. Der Raifer hatte fid felbft in S

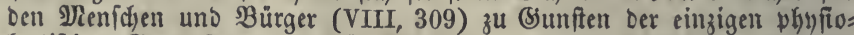

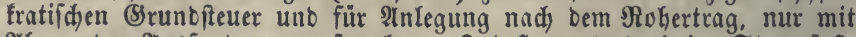

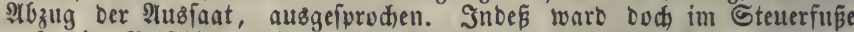

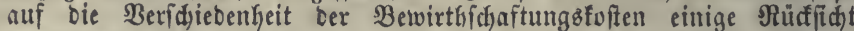
genommen, inoem man von je 100 กี. Rokertrag bei Recfern, $\mathfrak{B}_{\text {ein }}$ bergen, Teiduen $10 \mathrm{fl} .371 / 2 \mathrm{fr}$., bei 2 biefen uno (Särten $17 \mathrm{fl} .55 \mathrm{fr}$.,

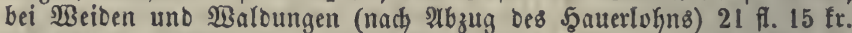
als Steuer anjekte. Im Durdifhnitt follte bie Steuer $12 \mathrm{fl} .13^{1 / 3} \mathrm{fr}$.

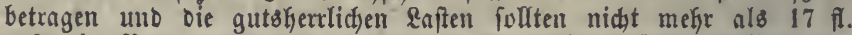

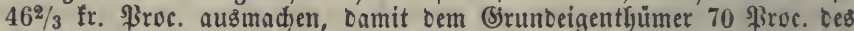
Nokertrages fider blieben. Sremer II, 43 fi. Linden I, 59 fi. Diefe Rataftrirung, alв auf einem unriditigen (Srunbfabe rufeno, funnte fein gutes Ergebnís liefern. Bielleid)t war es bie Folge ber

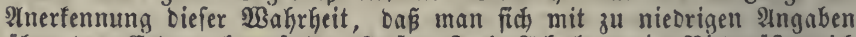

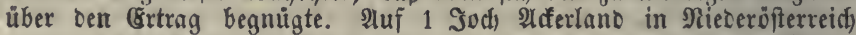

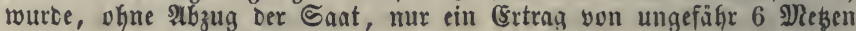
beredinet (=11/2 Malter yom bab. $=3$ Sirfeffel yom preuß. II.), und bei 2Biejen nur gegen 10 (5tr. 5eut $(=7$ (5tr. bab. $=5,3$ (5tr.

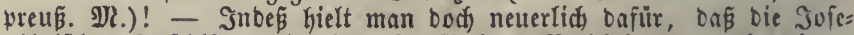
phinifden Anfalnge mit einer forgfaltigen Beridytigung now minoer unridhtig feien, alB oie biskerigen âlteren Anfäße, man legte alfo jene Dem proviforifhen Satafter, bis zur Bollenoung Des Definitiven, zu (S)runbe, in Nieberöfterreich, Defterreid ob ber (Snnz, Steiermarf,

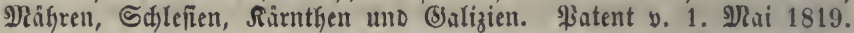
Rinden I, 79. 263. - In Banern wurbe, nadjbem 1808 Die Defini= tive Grunbfeueriebung befolvfien worben war, 1809 bie fataptrirung

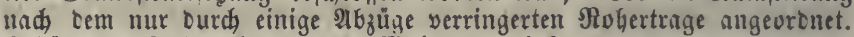

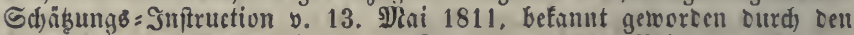
शboruf in Den Berkandr. Der 2. Sammer, 1822, Beil. V, 442. Nach einiger unterbredung twurbe in Dem Sefes v. 15. 2tug. 152S Die Fortiegung Der Rataftrirung nad) Dem nämliden Şauptyedaufen aus= gefprodien. Bonitirungs = Smptruction und Infruction fü bie \&iquidi= rung, Rataftrirung unb umidyreibung ber befinitiven Sruncfteuer, beide

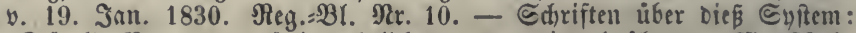

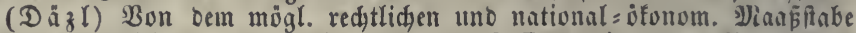

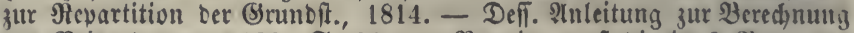

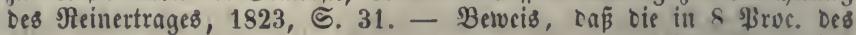

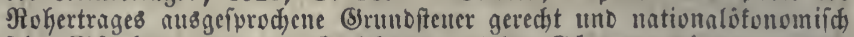

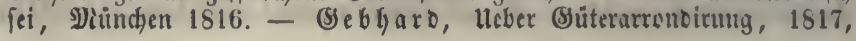


5. 95 (gegen bas Syftem, worauf fid eine literarifdye zebbe zwifden

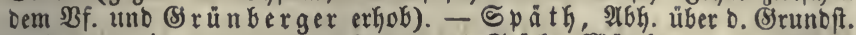
nad) Dem reinen uno roben Ertrag Der Stüfe, Diünden 1818. (Ëben= falls gegen bas Syftem.) - v. (S) rünberger, Rurzgefapte (Scididyte uno Darfellung ber Rataftercommiffionsarbeiten, Meundben 1820. -

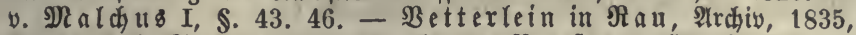

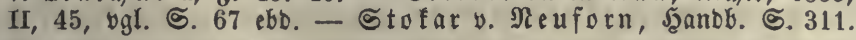

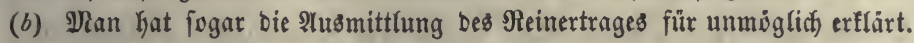

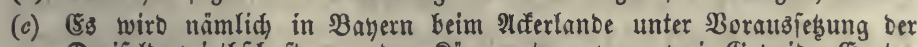
Dreifelberwirthidaft nur Der Rỉrnerertrag von ztwei BetreiDe $=$ Ernten

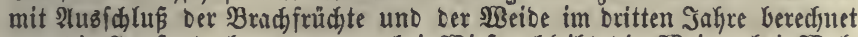

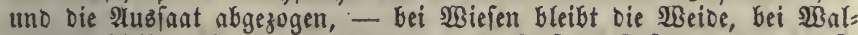

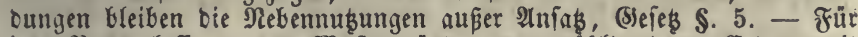
jebe Bobenclafie werben Muftergrünoe nusgewáflt, beren Ertrag mit Benuł̧ung Der eiolichen 2Ingaben bes (sigenthümers ober ßadjters forg= fåltig abgefđảz̧t witro, §. 23.

\section{§. 327.}

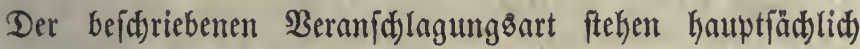
folgende Brutnde entgegen:

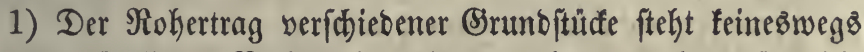
in bem nämlidsen $\mathfrak{B e r b a ̈ l t m i ́ s ~ w i e ~ b e r ~ r e i n e , ~}$ woent bie Steuer fidh an ienen anjhliest, eine gleidförmige $\mathfrak{B}$ efteuerung Der (Sinmorente nidjt erreidyt werben. Dies zeigt fid

a) bei ber Bergleidung verfdiebener 2Trten von mubaren Ränbereien, $b a$ z. $\mathfrak{B}$. gleid)er Rokertrag von $\mathfrak{B i e j e n ~ n i d j t ~ f o ~}$ viele Roften verurjadt, alş von Affer = ober bejonbers bon (Sarten = und গebland $(a)$;

b) bei verfatiedenen Elafien ber Bitte. Unergiebigere ober entlegenere Brunbfüde ftehen binter ben frudbtbaren ober günftig gelegenen im reinen Ertrage weiter zurüd als im roken, eż tweroen baher, wenn biefer entidjeibet, bie idhled)teren Räubereien unverbältuißßmäßig ftarf in 2nfprud) genonmen. Bei einem fehr unfutdtbaren 2lder fönnen bie Roften leidyt 80 ober 85 Froc. Des gefammten (srzeugniffes binwegnebmen, währent fie bei ben beften Feldern vielleidyt 60 ober nod) weniger ßrocent aus? madjen. Csine Steuer von $1 / 20$ Des $\Re$ okertrages nimmt aljo von Dem beften Alferlande ungefähr nur $1 / 8$, von bem (d)lect)= teften Dagegen $1 / 4$ ober $1 / 3$ Der Rente binweg. Wirb yon bem Rohertrage eit Theil abgezogen, um ben Steueranidlag zu bilden, fo wirb fieburd) Der Fefler um fo mekr berichtigt, ie meל̧r bie 2lbzüge ben fämmtliçen Roften proportionirt fino $(b)$; 
c) bei verifdicocuer Bewirthjdaftungåweife; boun ein mit größerem Eapitale erzielter Ertrag läß̈t wentiger Ueberidfuß itber Die Soften, als cin leidft erlangter, bei weldyen man bem

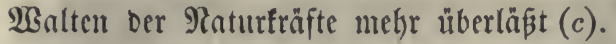

2) Sm Ertrage bes Bobens, wenigftens bei ben fünftlidjeren

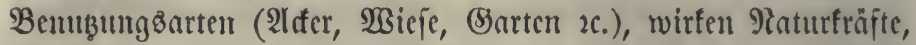

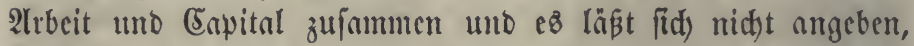
was ohne bie beiben lekgteren Bebingungen ber Boben für fid) alfein hervorbringen würde. Daher ift bei ber 2tnnahme eintes

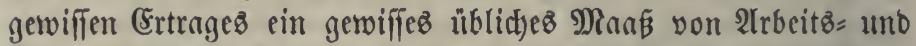

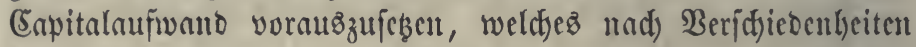
ocs Drtes uno ber 3eit ungleidt) ift uno nact) oen SBreifent ber Trrbeit, ber ভtoffe, Beräthe 26 . in feinem Belobetrage wed) jelt. Der rohe Ertrag ift feincöwegs ber 2 tubortud ber fog. natür=

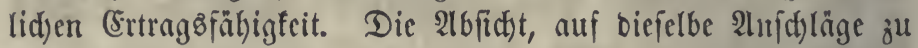
grünoen, weld)e für alle fpäteren 3eiten brautboar bleiben

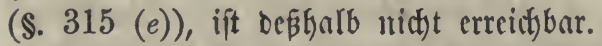

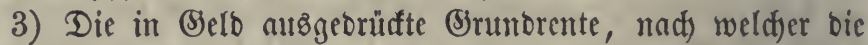
Steuerfiduldigfeit bemeffen wirb, hängt zum Theil you ben

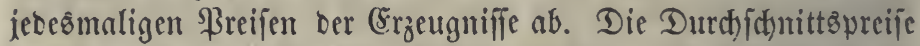

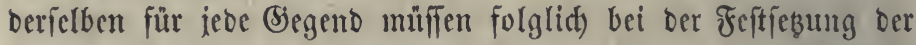
Steucranidhläge mit in Betracht gezogen werben. Die 2lmahme gleidyer Betreibenreife in einem ganzen \&anbe würoc für bic Betwohuer ber Begenten, in benen fortonuerno niebrige siscife

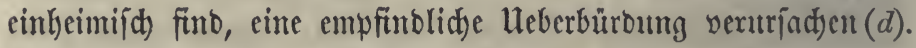

(a) Bei guten $\mathfrak{B i e j e n ~ f a n n ~ D e r ~ \Re e i n e r t r a g ~} 80$ ßroc. Deß rofen fein. -

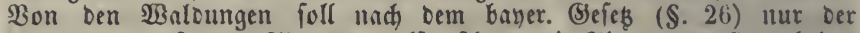

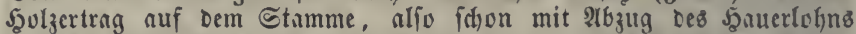
angered)net werben. Da num bie nidjt mit berüdifiditigten Neben= mubungen mekr betragen fönnen, als die Benufî̉,htigungs = unb bie anberen allgemeinen Belvirthichaftungzfoften, fo it in bieien fällen ber fataftirte (8xtrag logar nod) niebriger alo oer reine; Betterlein a. a. D. S. 61. - Rtad) Dem ifterreichifden Ratafter betragen z. B.. Dic Roften in Srocenten bes sohertrages bei

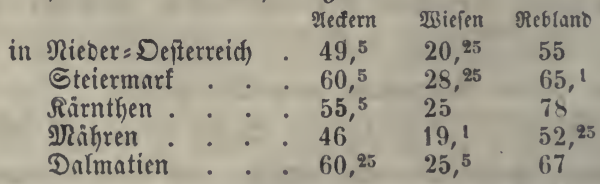

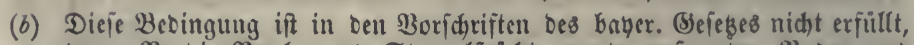
Da 3 . B. Die Brads = und Stevpelfruidste gerabe auf gutem Boben und

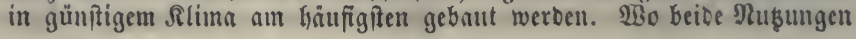




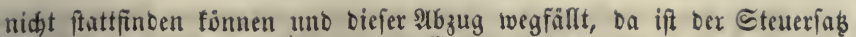
ein weit höherer Theil Des ganzen Ertrages.

(c) Uebereinftimmeno $\mathscr{L}$ inden $\mathrm{I}, 264$.

(d) In Defterreid) wurDen Die Mittelpreife ber Marfturte von $1772-81$ angenoumen, mit $\mathfrak{A b z u ̈ g e n ~ f u ̈ r ~ e n t l e g e n e r e ~ D r t i d a f t e n . ~ - ~ I n ~} \mathfrak{B}$ ayern

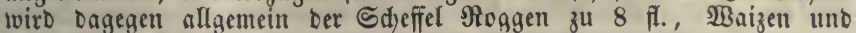
Riern zu 12 , Serfte zu 6, Şaber zu 4 fi. angelegt, Der Centner Şeu

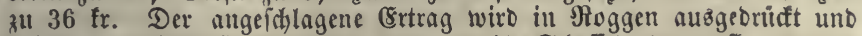
fleigt yon eitrer Elañe zur andern um $1 / 3$ Sd)effel voer 1 fi., wovou Das Simplum $1 \mathrm{fr}$. betrâgt. - Die Miängel diefes Syftems find wahr=

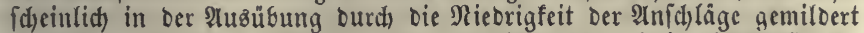
worden, oa felbit Das (Sartenlano nicht leidht hujher alö in bie 24. Slaffe, alfo zu 24 fl. Shohertrag auf Das bayer. Tagetwerf, gefebt worden ift.

\section{§. 328 .}

B. 2) Erforfdung Des Reinertrages (a). Diejes Berfahren ift unmittelbar auf Das Biel gerichtet, welthes bie anberem Methoden nur burch) Umwege zu erreichen bermögen,

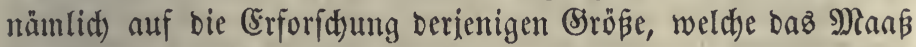
ber Steuerfähigfeit bilbet (\$. 302), und zwar auf eine gründ= liche Beife. Daker ift biefe Rataftrirumggaart in ber neuteren 3eit am häufigften getwählt worben, uno ba fie, wie eŝ für einen guten Erfolg nothwendig ift, mit einer Bermeffung it Berbinbung gejebt mutrbe, fo pflegt man beide als wejentlict) zufammentyängende (Sefdyäfte anzulehen, was jeboch nidjt ridjtig ift, weil bie Bermefifung aud) bei nnoeren 2lrten Der $\mathfrak{B} e r a n=$ fichlngung vorfommt. Nach mandhen früheren Ünternefymungen Diejer Art (b) gab Die öfterreidyifche Niegierung iul Şerzogthum ) Xailant das erfte Beifpiel ciner foldben forgfältig eingerid)teten (3)unofteuerregulirung $(c)$. Im 19. Inhikunbert wurben in

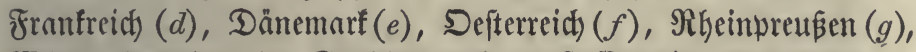
Woürtemberg $(h)$, im Sroß̧herzogthum Şeffen $(i)$, F̧amnover $(k)$, Sadjen $(l)$, Tożcana $(m)$, Sarbinien, Feftland uno ber Snjel $(n)$, Brounfdrweig $(o)$, Dldenburg $(p)$, im ganzen preupifden State $(q)$ 2c. äfnliche 2 rbeiten ins 2 erf geję̧t.

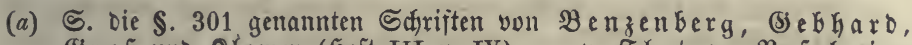

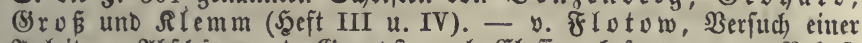

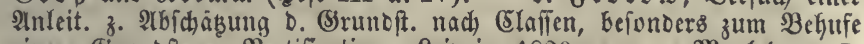

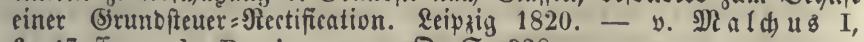
§. 47 กि. - de Parieu a. a. D. ङ. 328.

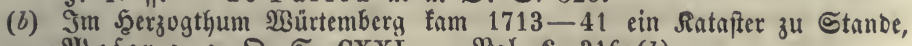
)ivier a. a. D. ङ. CXXI. - Bgl. \$. $316(h)$.

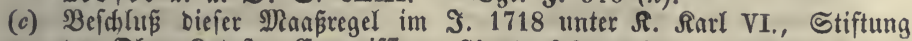
Der Dber = Ratafer = Commifítun, Giunta del censimento generale. 1719 Beginn Der Burarbeiten, Pufforberung an bie Brunt= unb Şauseigen: thyümer, genaute 2ingaben zu liefern. 1721-23 Miefiung. 1726 Been, 
oung Der Sdäb̧ungen. 1732 war bie wieberfolte \$rüfung berfelben ebenfalls beenbet, 1733 unterbrad, ber strieg bie Sadse, 1749 ward fie wieber aufgenvinmen, 1759 vollenoet, 1760 traten bie Єteueriäß̧e von 1732 in शnwentung. Carli, Relazione del censimento dello stato di Milano, a. a. D. (\$. $316(d))$. Deutffy: Wiailands Eteuerberf., uีberf. von 23 if of ber mailänoifiden Steuerregulirung, aus bem Ṡtal. Iena 1821. 40. v. Aremer II, 68. - B urger, Reife Durd Dberitalien, 1832, II, 227. - Morandini, Del censimento Milanese, Mil. 1832. III. $\mathfrak{~}$. - $\mathfrak{E}$ inden I, 412. - Das mailändifde Ratafter (censo milanese) ift von ber ofterreidifiden Regierung eine Seitlang beibehalten worben.

(d) $\mathfrak{B g l}$ I. §. $320(d)$. O y o n, Collection des loix, décrets, instructions et circulaires relatifs au Cadastre de la France, Paris 1804 ரि. 5 Foe. Recueil méthodique des lois, décrets, réglemens, instructions et décisions sur le cadastre de la France, 1811. 40. mit 1 Şeft fol. - Thum,

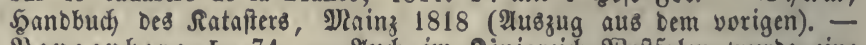
Benzenberg I, 74. - Auch im Ronigreid) Beftralcn wurbe eine folde Rataftrirung beabifatiget (Sefeb v. 21. Nuguft 1808), fie fam

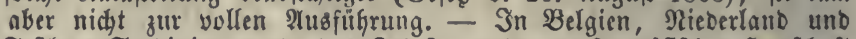
Feftland: Sarbinien wurbe Das Ratafter unter ber franzoficicen Ferridhaft angefangen und fpäter yollenbet, Dod nahm man nadher mandje Ber: befierungen bor. In ben Nieberlanden wurbe 1826 eine 8rneuerung beidlofien uno fobann in bem 1830 abgetrennten Belgien 1835 Das Ratafter zur ltmlegung Der Brunbfteuer angewentet. - In Den \$ro= vinzen Rimburg und \&uremburg warbe Dafielbe erit 1844 vollenbet.

(e) $\mathfrak{3}$. ๒. 1. Dct. 1802 ; aber Das neue Satafter if noch nicht eingefügrt; Bergioe in $\Re a u$, Irdjiv IV, 318.

(f) \$atent v. 23. Dec. 1817. Sdäbungginftruction von 1826 und 1828. v. Sremer II, 89. - 2usfübrlid \&inben I, 269-411. - In ten

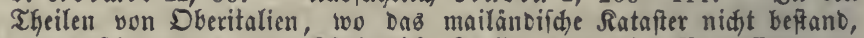
wurbe fdjon unter Dem Sonigreidje Stalien 1805 eine Bermefiung an: gefangen, weldje 1816 bollendet war, ferner wurbe eine proviforifde

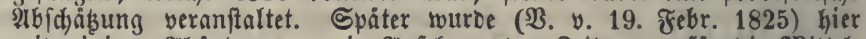

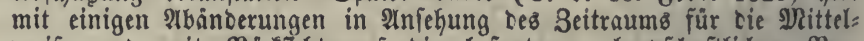

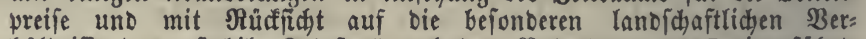
Gáltniffe bas "ftabile Ratafter" nach Dem \$atent yon 1817 eingefiigrt. Für ungarn, Eroatien, Slayonien, die 20 jwodiđaft und Eiebenbürgen murbe (Patent v. 4. Nårz 1850) eine auf ben Seinertrag geftủbte proviforifoce Steuerregulirung vorgenommen, bie Bermeffung if aber im Sange. Aufer ben leştgenannten Ränoern ift aud) in (Salizien, Bufowina, Tirol unD Borarlberg Das fabile Ratafter niđt eingefürt worben. Die (Stundfteter betrigt Da, wo Daffelbe befteht, in 16 \$roc.

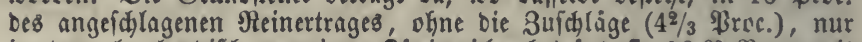
in Dem lombarbifíd = benezian. Ŕonigreiche betrảgt fie 26,86 ßroc. mit

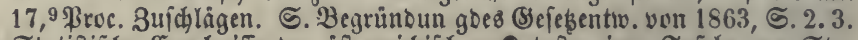

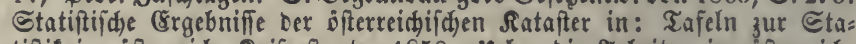
tiftif im offerreid. Saiferfaate, 1858. Ueber oie Arbeiten im sfterreich. Dberitalien, Maggi, Sul nuovo catasto, 1845. - Rezzonico in Giorn. del Inst. Lombardo. 1845.

(g) R. Cabinetsorbre, 26. Suli 1820. - 2ulg. Inftruction uีber Das $\mathfrak{B e r}$

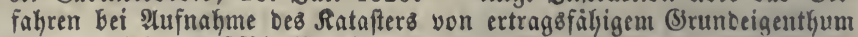
in ben thein.= meffiar. Brovinzen, 11. Februar 1822 mit 1 folisheft Formulare. - Inftruction riber Das Berfahren vei Der 8 rmittlung bes Sieinertrags von Brunbeigentfum, 3. Suni 1822. - Nehrere Berord: unngen gefammelt in: Beroronungen uno Inftructionen über bie $\mathfrak{B e r}$ 
waltung Der birecten Stcuern für Den $\Re e g .=2 B e z$. Düffcloorf. 1833. $4^{0}$.

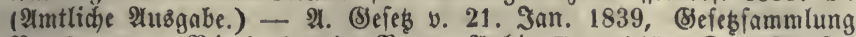

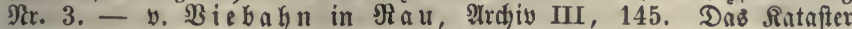
wutrbe 1834 foweit bollenbet, Daßs bie Steuter 1835 nad ifm erfoben werben fonnte, bod) blieben noch einige (Seichäfse für bie folgenben Jahre übrig. Der Steuerfuß beträgt, Da bie Steueriumme im (Sanzen nicht erfibgt werben follte, (ohne die 3uldyläge) 11,918 \$roc. Des fata=

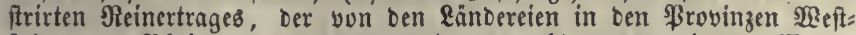

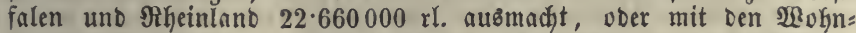
Gäufern $27 \cdot 253000$ rl., woraus fich Die Steuerfumme von $3 \cdot 248000 \mathrm{rl}$. ergiebt. In ber öftlichen Şälffte bes preufifhen Staates beftanden nod bie alten, fefje verfohiedenartigen Brunofteuern, f. (q).

(h) Das (Seí. ๖. 25. Inti 1821 oronete die Şerftellung eines proviforifhen

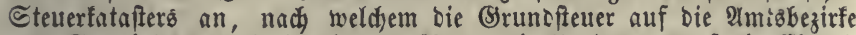
uno Bemeinoen vertheilt wiro, währeno die Hmlegung auf bie Einzel= uen Durd) Die Semeinden nach irtlichen älteren Plormen gefdieft. Infructionen für bie DberamtB $=$ Steuer $=$ Sommiffarien, 6. Sept. 1821. Furtf. Februar 1822. Die 2lużmittlung. Deछ̉ rofen uno reinen Ertragę geichah nur für ganze fluren unb Flurftücfe (Bservente, (Sewanne). Diefe Irbeit wurbe 1823 vollenoet, Dod twurben fpäter noch mandie Beridytigungen vorgenommen. Heberficht Der fatiftifben Ergebniffe in

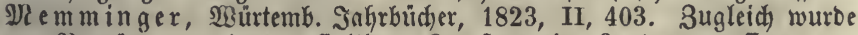
zur Begrünoung cines befinitiven Ratafters eine \&andesvermefing ver anftaltet $(\$ .319(b))$, biв zu berm Beendigung Die Sçäbung ber einzelnen 巨tüafe verichoben wurbe. Diefe $\mathfrak{B}_{\text {ermeffung if }}$ unterbeffen vollendet worben. Die Srundfeuer iviro fortwährent zu 17/24 Der

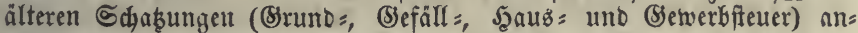
genommen (\$. 295), welde für 1858/61 im (Sanzen auf 3 Nifll. fl. beftimmt worben find $(1855 / 583.300000$ fi. $)$. Der im Ratafter an=

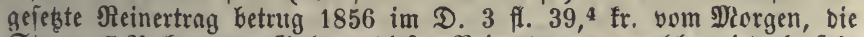
Gteuter 7,24 fr. vom Bulden Diefes Peinertrages, weldher jeood fefr wafricheinlich weit unter bem wirflichen fteht. SD. Siokl, lanoft. Bericht v. 14. Det. 1858.

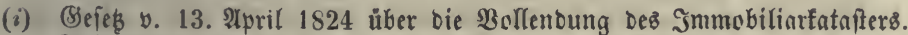

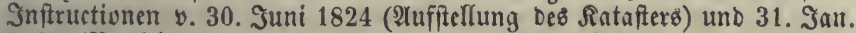
1825 (Bontitung). - Seoffmann, Beitrảge S. 67.

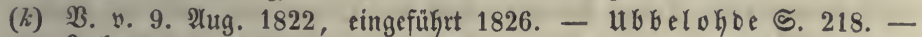
Ee hren I, 340.

(l) Angeoronet im Lanbtagsabfjued v. 30. Det. 1834. Ueber Die Mefiung

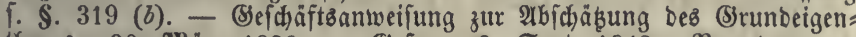
thumb , 30. פläz 1838. - Sef. v. 9. Gept. 1843. Seroron. vom 26. Det. 1843.

(m) જ. ๖. 7. Detbr. 1817. Dą న. wurbe 1834 im ganzen \&ande ein= gefüfrt.

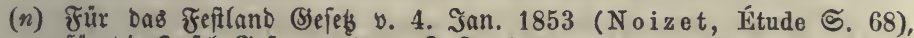
für Die కnjel (5é. v. 1839, Inftruct. v. 1840. Benvenuti e Meneghini, Manuale del cittadino degli Stati Sardi I, 169. Diés uro= viforif̧ye Ratafter wurbe 1840-55 auzgefübrt. Bon 2020 (S)ememoen Gaben 1500 Satafter mit 2Hngabe Dez Flädbengehaltz, 910 aud Flur: dyarten Die 2lnlegung eines neten Definitiven Ratafters wurbe 9. Suni 1858 verorbnet.

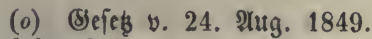

(p) 1852.

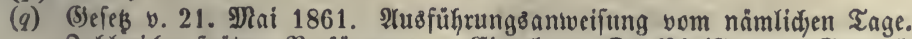
3afilreidje fpätere Berfügungen, Eirculare, Denffidriften Der (Senerals 
commiffare $x$. yon $1861-63$. शిafder a. Bud S. 209. - Die

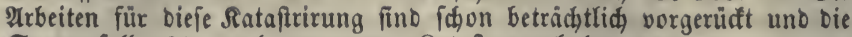
Steuer foll 1865 nach ben neuen Rataftern erfoben werben.

\section{§. 329 .}

Man hat neuerlid) beridhiebene Cinnenbungen erhoben, weldse entweber bieje Methode liberhaupt als verwerflict) Darftellen, ober wenigitenz zeigen follten, onß̧ ifhr Erfolg im Berbältnís zu Den mit ifr verbundenen $\mathfrak{B e f d}$ werlid)feiten unvolftommen fei. Şiebei fint bejonbers folgende Umftänbe herborgehoben worben $(a)$ :

1) Die gropen Sioften eimes folden Setafters, weldye leidyt ben ein= ober zweijährigen Errtrag ber ganzen (S)runbfteuer hinwegnehmen fönnen $(b)$.

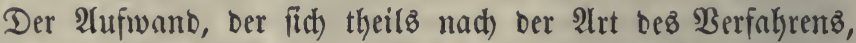
theils nad) Der 3erftủdelung bes Erumbeigenthums ridjtet $(c)$, ift allerbing bei ben bişherigen Ratniterarbeiten groß gewefen, modyte er mun auz der Stantżcaffe, ober von ben Srunbiteuer= pflicftigen, ober theilweije auf beiben $\mathfrak{B B g}_{\text {en }}$ getragen werben $(d)$. 2trein er bertheilt fith nid)t alfein auf cine jiemlid) lange ßeriobe, jonbern ber grökere Theil ber Roften fommt auf bie Meffung uno bie zugehörigen $\mathfrak{B e r r i c h t u n g e n ~}(e)$, uno hieourd) wirb, wenn zugleich) für bie 2 lufzeid)nung aller eintretenoen 2lenberungen ge= forgt ift, ein erkeblicher, onuernber Bortheil für verichiebene 3roefe erreid)t (\$. 317), ber biejen 2ufwand wohl bergütet. Die 2 lb= (đ)äbzung ift leichter unb mit viel geringeren Roften nušzufülyren, und befonders ift bei ben neueften Rataftrirungen eine bie foften anjehnlid) bermindernbe Bereinfact)ung angewendet worben. (ङฐz ift jeboch in jebem \&anbe nady ben in $\$ .317$ gennnnten Um=

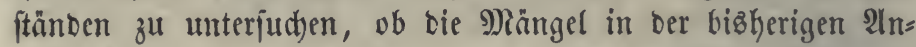
legungşweife ber (Srunbfteuer cine neue forgfältige Anlegutug Derfelben zum Beoürnís madyen.

(a) 3. B. Sartorius, Ueber bie gleide Befteuerung 2c. S. 61 ரீ. -

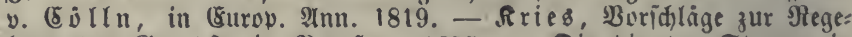
lung Der Grunoft. in \$rellen, 1855. - Die Directen Eteuern in Depterreid ธ. 62.

(b) Uleber Die Satafterfoften. 1) In Franfreid) foftete ((S) onin's Bubget8berichte für 1837)

1 Szeltar

$\begin{array}{ll}\text { bis } 1822 & 4,42 \\ 1822-35 & 2,32 \\ \text { yon } 1836 \text { an } & 2,34 "\end{array}$

1 geogr. $\square$ Mieile

11439 กิ.

6004

6056 
alfo neuterlid gegen 6000 fl. für Die $\square$ Meile $=16^{3} / 4$ fr. für Den pr. $=23,62 \mathrm{fr}$. für Den $\mathrm{BaD}$. Norgen. Biz 1822 waren 11 Nill., von 1822-35 an 30 Inill. S2eft. Eataftrirt worden uno (5) ou in ver= muthete, Daß́ Daz Ratafter im (Sanzen 145 SItill. Fr. foften werde, wofür neuerlid, 200 Nill. angenommen worben find. Nach frükeren (5rforidyungen in Franfreidh beredynete $B$ enzenberg (I, 403) Die bortigen Roften auf 3898 rl. (6870 f.) für Die $\square$ ग) eile. - 2) In $\mathfrak{B}$ ayern war ber Roftenanfhlag für bie \$eriode 1831-37 6312 fi. auf Die $\square$ Neile. Der Umftano, Daß̧ in Bayern nicht Der reine (8r:

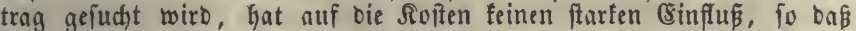
Diefe füglich Gier mit anoeren verglichen twerben fönnen. গach Den Ergebnifien voll 1839-41 find bie befonderen Supten (nebft 60000 fl. jährlichen allgemeinen) a) alif bie $\square$ Meile für bie Triangulirung (ohne Die Roften Der fhon früher beendigten Şauptorcieffe) 187 f., Silefung 3516 ff., Bunitirung 135 ff., Elafifificirung 1262 f., Blamarbeiten 94 fi., zแfammen 5194 fi.; b) auf jedes Blatt für Steincrud 74 fl., Berechung 47 fl., Ratnftervorarbeit 29 fl., zufammen 150 fl., oder auf Die $\square$ Deile (3แ 10 Blättern, welches baz Minimum ift) 1500 f̂., mit a) zufammen mindeftenz 6694 f.; c) nuf die Bsemeinbe $(5-6$ auf

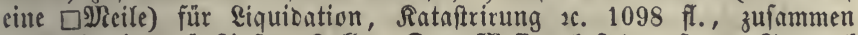
7792 fi. im güutigften Falle. Das Mellen foftet auf Das Tagwerf $13 \frac{1}{8} \mathrm{fr}$. $=9,8 \mathrm{fr}$. auf Den $0 \mathrm{r}$. $=13,86 \mathrm{fr}$. auf Dell bad. $\mathfrak{D}$. Der ganze Rufwand für Das Ratafter biz Ende 1841 war 12.855000 fl.,

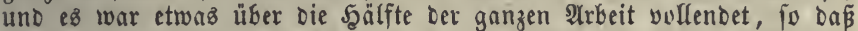
noch gegen 9 Nilf. fi. nothig waren. Aber im Siartreife muste ein Theil ber (Seidbifte nod eimmal vorgenommen werben. Berhanbl. Der Rammer Der 2 logeuroneten 1840 , Beil. XXII. K (von Trautner), 1843. Beil. LII. (BB. Friebriđ.) - 3) Die Roftell Dez Ratafterz in Weftrálen und Rleberrbein twurben auf 4.712688 rl. angefdlagen,

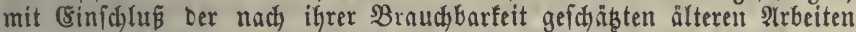
und Der nod zu beendigenden (Befdäfte (Denfichrift vom 10. Detober 1835); auf jebe $\square$ Meile fommen 5583 rl. ober 9770 fl., auf ben Norgen 26,2 fr. In Diefen orei \&ältoen ift übrigens die Şäuferftenter

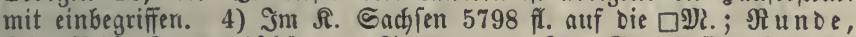

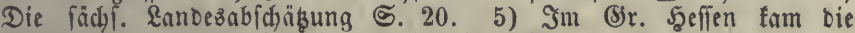
Neffung mit (Elaffeneintheilung für bie $\square$ Meile auf 7600 fl. 6) In Den beutifhen \$rovinzen Des Dfterreidjifdyen Stants obue Tirol, aber mit Dalmatien, einer Fläche von 2314 jifterr. $\square$ N2., war Der Rufwand füt bie $\square$ II.: : Triangulirung 186 fl., (Sinzelmefiung 2983 f., Stein= zeidunung 170 fi., Śdhäbung 812 fi., Unterfudung ber Befdyerben 905 f̂., 3ufammenftelfung oes Ratafters 127 fi., zufammen 5183 fl.

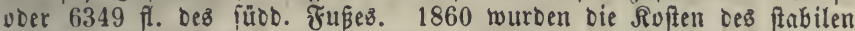

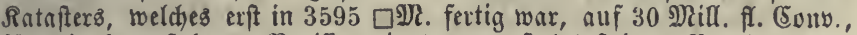
für bie bevoritckende झevifion in Den zuerft fataftrirten \$rovinzen auf 6 Mill. angeidslagetr. Die proviforifde Shäbung in ungarn uno Siebenburgen fam nuf 1548 f. $=1896$ f. fïtod. fïr Die $\square \mathbb{2}$. 7) शuf $571 \square \mathfrak{N}$. Des nidht unter oen Censo milanese fallenoen offer= reichifhen Dberitaliens foftete bie Shäbung 8202, bie unterfudung Der Befdwerben 3880 , bie 3ufammenftellung 2811 fi., alfo biefe trei Arbeiten zแammen 14894 fi. $=18275$ ff. fübo.! - 8) Das hanno=

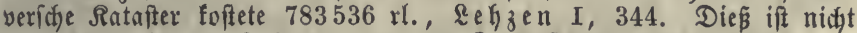
ganz $2 / 3\left(0,{ }^{64}\right)$ Des Safresertrages ber Srunbfteuer $(1.223000 \mathrm{rl}$.)

Die (Srunbiteuer trägt auf bie $\square \mathbb{M}$.:

9397 fi. Sadjien 1861-63.

6115 " Baben 1864. Im Sahre 1850 war Der Srundteuerbetrag

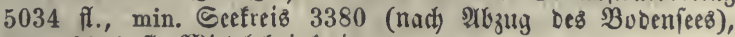
max. 6000 fI. Wittelrheinfreis. 
6002 ศf. Würtemberg 1859.

4544 "Defterreidy ordinarium von 1564, max. 10536 lounbard.=benez. Rönigreid), 10317 f. Böhmell, 7452 (8rzh. Depterreid), 4827 Ungarm, 2415 Eiebenburgen, 1423 Tirol und Borarlberg.

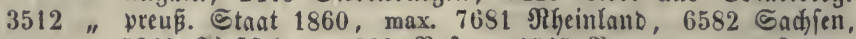
5843 weftfalen, 1662 ßofen, 1515 \$onmern, $1410 \mathrm{~min}$. ßreūenen.

3468 " Baayern 1861-67.

3088 " Şannover $1859 / 60$.

Dieje Berfhiebenkeiten rübren nidyt affein von ber ungleidyen Saghe Der Srumbrente und Des Stcuerfües jedes ๔tantes, fonbern zum Theile auch yon ber grỏereren ober geringeren ungenauigfeit ber Eteuer: anjólalige her.

(c) v. (S) fataftriren will, Die Roften für jebe auf 8000 fl. (I, 404, vgh. II, 164,410) nimmt Die Roften nad) Dem franjōifiden Berfahren auf bie $\square \mathfrak{M}$. im Durchjobnitt zu 7000 fl. $(4000$ rl.) an,

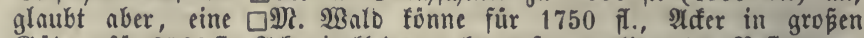

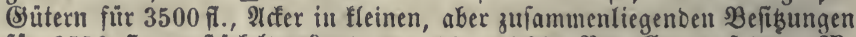
für 2550 fl., zerfituffeltes \&ano von $10-16000$ Parcellen auf ber $\square \mathfrak{I}$. ( $2-3$ per Şeftar) für 7000 , von $33-49000$ \$arcellen $(6-9$ per \$.) fogar nur für $10500-12225$ f. fataftrirt werten. - In Bayern if die 3ahl ber \$arcellen auf Der $\square$ Deile zmifhen 985 (Berhtesgaben, श्रlpengegeno) und ungefähr 45000 (Begenden in Unterfranfen), im D. Des ganzen \&anbes 12259 , in Dberbabern 8041 , in Unterfranten 29330 ; a. Beticht von Trautner; in Eadjen 7366.

(d) In Den wefłtidyen Frovinzen Dez prensifichen Stantes werben die Soften ourch einen Suichlag zur (Srunditeuer aufgebracht. In Jranfreid twur= ben fie bis 1822 ebenfalls größtentheils auj bie (S)undfeuer bez ganzen

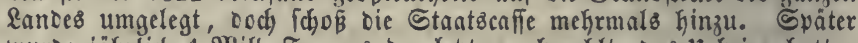
wurbe jährlich 1 Nill. Fr. aus ber lebteren bezahlt, Ias Hebrige hatten Die einzeluen Departements Durdh facultative Steuerzulyläge $(\$ .54)$ zแ Deffen, bie 1832 und 1833 gegen 4.600000 Jr. betrugen. 1859: 50000 Fr. aแs der Staatscaffe uno 25000 Fr. aus den Steuer= zufd)lägen ber Departentents. 1865: 200000 Fr. (Gauptfächlich für Eorfica uno bie neuen Departement8) uno 100000 fr. - Bergl.

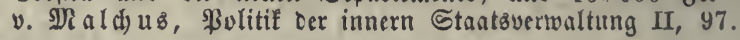

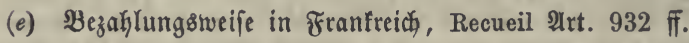
vout beftar

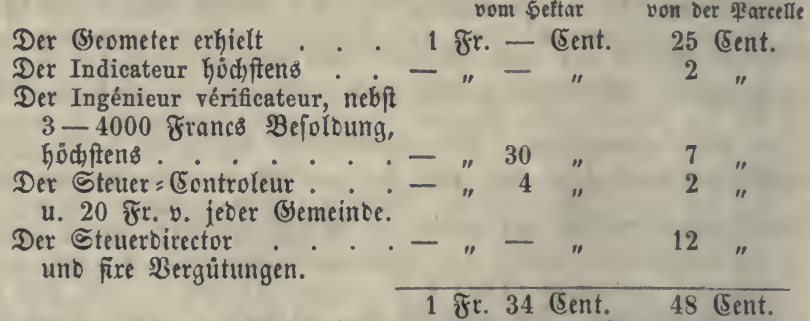

थuperbem erfält ver ๔t. = Snipector 100 Fr. vom (Eanton und 20 Fr. von feder (Sicmeinde. Die Taxaturen werben tagmeife bezahlt. Sabon

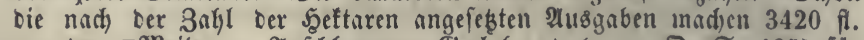
yon ber $\square$ Neile. - Pmidhlag von \&eb haro (a. a. D. ङ. 125) für Die $\square$ Micile bei bem Maapitabe von $1 / 2500$ uno $1 / 5000$, Triangulirung $500-650$ f.., Detailmefilmg $1600-2100$ f.., Nevifion $350-500$ f.., 


\section{$-67$}

Beredyung uno Entwerfung Der Srumbbücher 450-550 fi., \&itho= graphirung 300-400 fl., alfo im Sanzen refp. 3300-4200 fi.

\section{§. 330 .}

2) Die lange Dauer ber Ârbeit, als Üract)e von Ungleid)=

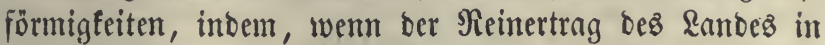
einzelnen Begenden ober Bobenbenubungen fortwährend Berånberungen erleitet, bie in berichicbenen 3eiten fata=

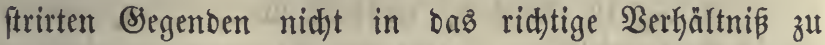
cinanber gejęst werben uno bie fpäter bernmidlagten Begenten zu hoch belegt werben $(a)$.

Die Rachtheile biejez langiamen Fortganges find in mehreren Ränoern umberfennbar zum $\mathfrak{B o r j}$ dein -gefommen. Bei ber $\mathfrak{B e r}=$ meffung ift eine fdnelle Beenoigung nidt möglid), fidon weil

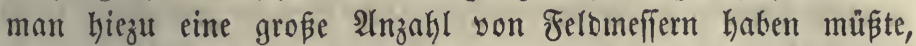

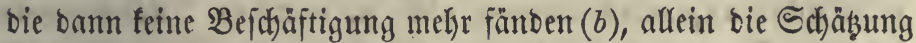

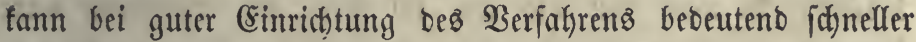
auşgefüfrt werben. Die Serzögerung, welcte in ber Fataftri= rung mefrerer Ränoer ftattfand, war nidyt in bem Wefen bes (B)ejchäftez gegrünoet, fonbern rüfrte zum Theil von ben Unter= brechungen Ker, an Detten äuß̧ere Ereigniffe ober Beränderungen

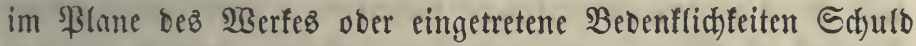
waren. Wo feine folden llmftinte eintreten, ift bie erforber= liche 3eit nidjt fo lang, baß fie einen 26haltunggigruno abgeten fömte (c). Ferner. Laffen fich 9) Mittel zur $\mathfrak{B e r m e i b u n g ~ b e g ~ e r = ~}$ wäknten llebelftanbes anwenden. Man fann in ben zuerft fntaftrirten \&anbestheilen cinzelne Bemeinben ober Bezirfe auf=

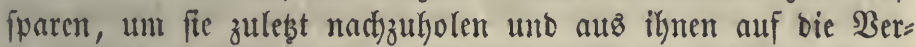
änberungen in ben anberen gleid)artigen Segenten einen Sdlut zu madyen. Die Bergleidung ber Ergebniffe nad) ber Beenbi= gung aller einzelnen Sdäkzungen bient ebenfallz bazu, bie \&ans

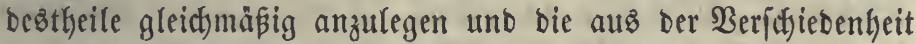
ber Sdjåkzungåzeit entfitambenen Folgen zu bejeitigen.

(a) In Rieberofferreid, weld)es um 1833 fataftrirt wurbe, fint bie jegigen Sadjt= unt Raufureife 2,7 uno 2,4 mal fo hod als bie Eteueranichläge, in anberen fpäter abgefdäabten $\mathfrak{B r o v i n z e n ~ n u r ~} 1,7-1,8 \mathrm{mal}$.

(b) Sur Neefiung ift warme Jahreszeit uno gute $\mathfrak{B g i t t e r u n g}$ nüthig, bie übrige Seit wird zum Beidnnen und Bered)nen benübt.

(c) In Franfreid wurbe in 9 Safren $1 / 4$ bes \&andes volfendet, jährlidg

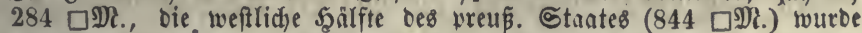

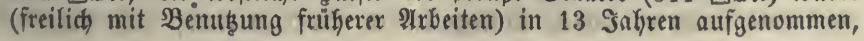


aljo jährlid, an $65 \square$ Di. - Das Şerzogth. Dlailano, gegen $220 \square$ D. großs, aus 2387 (Semeinden befteheno, wurbe in etwas mehr als 3 Jahren gemefifen uno gezeidnet. - In Sadhfen ift in funf Summern, 1838

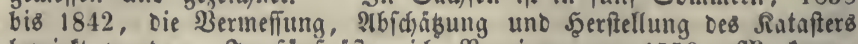
bewirft worben. In fün ojterreid). ßrovinzen von $1556 \square$ SI. famen

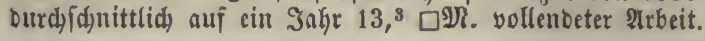

\section{§. 331 .}

3) Die Unmoglidfeit, auf biefem $\mathfrak{B e g e}$ einen befriebigenben (Erfolg zu crreid)en, web̧halb man, mit Şinblia auf bie Siatafterarbeiten in einzelmen \&änbern, bezweifelt hat, Daß die gropen Ruften wolyl angerwenbet feien $(a)$.

Şierauf lăfit fid erwiebern: a) Sine mathematifate (Senauig=

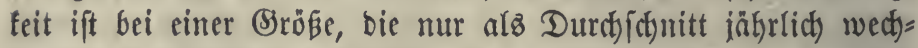
felnoer Grgebniffe bei üblicter Bewirth)f(t)aftungäweife ermittelt werben fann und bie ber einfithtżvolle Srunbeigenthümer felbft nidjt fidjer anzugeben vermag, nid)t zu erreichen. Sönnte mant inbes 3. $\mathfrak{B}$. nud nur bis auf 10 Jroc. Der Babrkeit nake

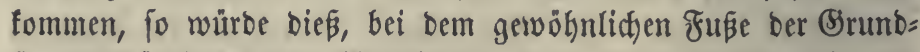
fteuer, Gödjtens eine Abweidung von $1 \frac{1}{2}-2$ ßroc. in ber

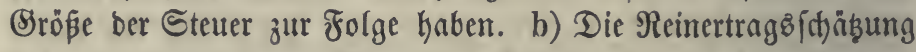
hat yor ben anberen Arten ber Steueranlegung ben $\mathfrak{B o r}$ ug, baß fie bie gejuchte mittlere Srunbrente auts ben einzelnen Thatfachen ableitet, von benen fie beftimmt wirb, unb baj

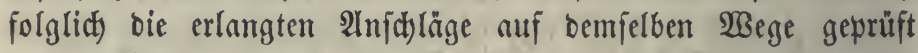
werben fönmen, was bei ber Rataftrirung nact Raufpreifen ober ßactzinfen nicht ber Fall ift. c) Die Benutbung biefer beiben Anfaltzpuncte ift bei bem crwähnten Berfabren nidjt ausz= geidylofien und vielmekr fehr zu empfehlen. (5ฐ fönuen alfo bie brei Mittel zur Errlangung guter Anfoläge mit einunber in Berbinbung gejest werben, fo baj jebes berfelben bazu bient, bie aแs ben anberen gewomenen 3nhlen zu priffen uno zu beridtigen. Wirb Dieß angeorbnet, fo vercinigt ons Berfabren bie Borgüge aller befannten unb biskger in 2mwenbung gefom= menen Methoden und eridheint hieburd) als oas volffommenfte. d) Die Beredjung Des Reinertrages feşt gründidje lano= uno volfomwirthidaftlid)e Renntniffe, (Sefdyidfidfeit, Sorgfalt unb vollfommene Reblidfeit voraus unb es ift biernus leid)t zu er=

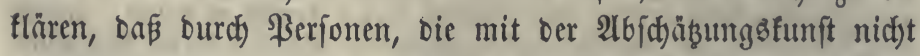
vertraut waren, burd) mangelfafte Boridyriften, eilfertiges $\mathfrak{B e r}=$ 
fahren zc. ungenaute Ilnf̧̧läge aufgeftellt worben fino. e) In einem großjen \&anbe liegt in ber Menge ber mitarbeitenben ßerfonen uno in ber größeren Berfchiebenheit ber lanbwirth=

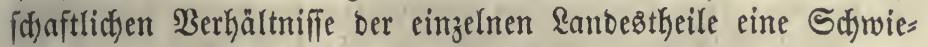
rigfeit ber gleichförmigen Beranid)lagung, bie in Staaten von geringerem IImfange in weit forwäd)erem Brabe yorfommt. Saat man jebod) bie genannten limfände als erfatwerento er= fannt, fo ift man aud im Stanto ifrem Cinfluffe burd) ztwerf: mäßige $\mathfrak{B e r m}$ ftaltungen zul begegnen $(b)$. Die $\mathfrak{W a h l}$ diefer Berfahrens bietet baher im Allgemeinen nod) nidht bie $\mathfrak{B}$ ürg= fijaft Des bollfommenen Selingens bar, fonbern erft bunn, wenn zugleid) fữ bie genannten $\mathfrak{B}$ orbebingungen geforgt wirb.

4) Die Beränderungen im (Eigenthum, in ber Bemuşunģ̨= weife uno bem (Ertrage ber \&ändereien, woburch) aud) ein anfangs fehlerfreies Ratafter mit ber 3eit unbrauchbar werben mußs.

WBas bie (Sigenthumbaverkältniffe betrifft, fo mußs, auf wers d)em $\mathfrak{B}$ ege aud) bnz Ratafter zu Stande gebract, worben fein mag, jeber Wectyel in ber fierjon bez Eigenthümers, fowie jebe Theilung unter utehrere Scerren aufgezeidhet und fo ber

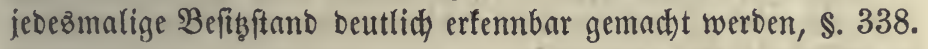
Daffelbe gilt von Den Culturberänberungen, $\mathfrak{z}$. $\mathfrak{B}$. Der Robung bon $\mathfrak{W a l b u n g e n ~} 2 c$. Fenderungen im Reinertrage, went fie nidjt auf einzelne Stüffe befdränft bleiben, erforbern von 3eit

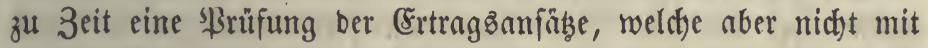
gropen Edwierigfeiten verfnuppft ift uno bei oen oben betrad)= teten anderen Methoden ebenfalrs nidyt aubbleiben follte, $\$ .316$.

(a) 3. B. D'A u diffret, Syst. fin. de la France, I, 31: Toute évaluation spéculative d'une richesse aussi variable que la propriété immobilière, toute classification des bien-fonds reposant sur les probabilités qui naissent du rapprochement d'un grand nombre de faits, lorsqu'elles sont soumises au jugement si divers de l'intelligence humaine, sont exposées à des graves erreurs et aux contestations des intérêts froissés.

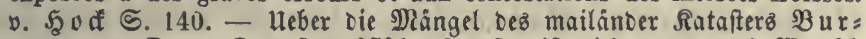

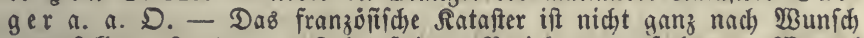
ausgefallen. In ben zuerft fataftrirten Bezirfen verurfadite oer Dlangel

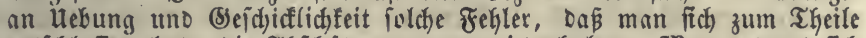
entichlofien hat, bie शुbidäbungen zu wieberkolen. IRan getraut fids Daker nod nicht, Die Brundfeuer nach Den Ratafterergebnifien auf bie Ranbertheile umzulegen, vergl. \&. $337(c)$ - Das 1835 vollendete romifde sintafter zeigte fid) ebenfalls fehlerhaft uno es wurbe 1845 eine (5ommiffiton zur Berid)tigung Deffelben ernannt. - 2 ud an Dem rbein= länbif 
Aries a. a. D. S. 65. Die Erfahrungen in Sadfen füD oagegen für bas neue Ratafter fehr günftig, incem man bei Räufen, Berpfän= Dungen, Rblofungen 4 . Dergl. fid ber Rataptereinheiten o bebienen

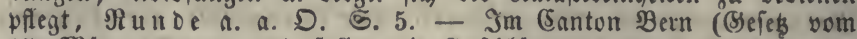

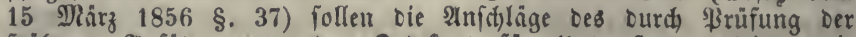

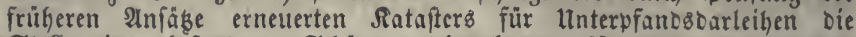
Stelle einer befonberen Sdäk̨ung einnefmen, für Erbtheilungen und 3 wangsabtretungen aber nidjt gebraudit worben. - In Nordoeutidyland hat man fïh überhaupt wegen ber zahlreidjen, von funoigen \&anowirthen verwalteten gröseren (Süter iel mit ber (Erforfd)ung Der lanowirth)=

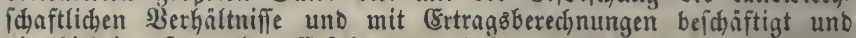
bic hiebei gefammelten Erfafrungen leiften zur Anlegung ber હteuer guten Beiftand.

(c) Mefrere Shriftifteller ( \$o uffielgue) finb Der Dieinung, cin (Srunbiteuerfatafter leifte Gaupt= (åd)lid) zur guten umlegung Der Steuer intrerkalb einer Semeinde

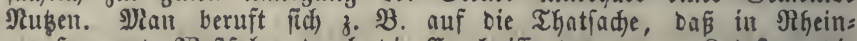
preupen uno 2Beftfalen Durd Die Ergebniffe Des neuen Ratafters Die frủhere Bertheilung oer Eteuer auf Die beiden \$rovinzen und bie ndyt Negierunģbezirfe im \$anzen nur wenig, aber für oie fleineren Bezirfe, (5)emeinden und einzelnen (S)runoftüfe viel, bis zu $40-50$ अroc. ab= geändert worben ift, Iries 5.47 . Sene gerinize Abineidyung ber

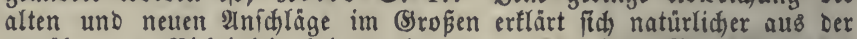
annäherncen Nichtiafeit beiber als etwa aus einer Mangelgaftigfeit

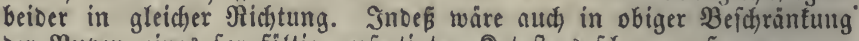
Der Nuß̧en eines forgfältig verfertigten Ratafters ichon grofi genug. -

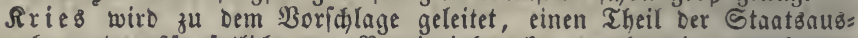
gaben, ber für ortlide uno ßrovinzialzwedfe gemad)t wirb, nadh Dem

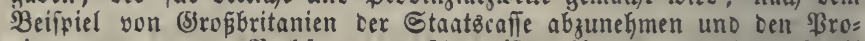
vinzen uno engeren Berbäncen zu überweifen, hiezu ben gröseren Theil

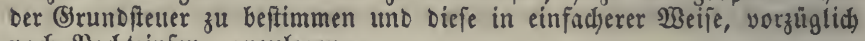
nach \$adtzinien, anzulegen.

\section{§. 332 .}

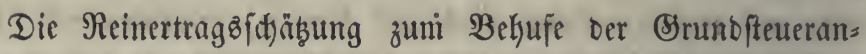
legung hat mit ber Berfertigung von ßachtanfdylägen für Do= mänen (\$. 121 ff.) Bieles̃ gemein, weid)t jebod) audh in manchen \$uncten von berjelben $a b$, befonders weil für bie Befteuerung weniger nuf vorïbergebenoe llmftänoc Rüfifit)t genommen werben barf unb weil nicht blö ein einzelnes \&ano=

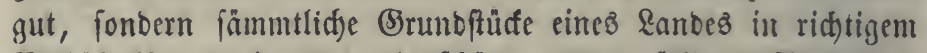

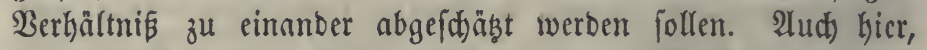
wie zum Befufe der ßad)tanidläge, find gewiffe $\mathfrak{B}$ orarbeiten

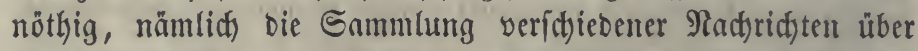

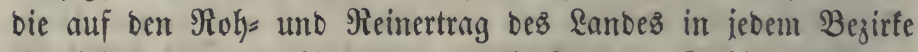
einwirfenden oder Kindeutenden Umitüne. Dahin gehören: Beftaltung Der Dberflädbe, - geognoftifdye Berbältuiffe, -

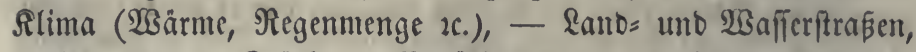
2lbfaşwege, - Stärfe ber Bewölferung, - betriebente Sicwerbb = 
zweige, - Bertheilung bes Erunbeigenthums in größere ober fleinere Beftßzungen, - Erzeugniffe bes Sanbbaues, - Stärfe Des Biehftanbes nad) ben 2Irten ber Thiere, - Semeinbes länbereien, - Berbăltniffe ber Dienfitboten uno Taglöhner, Raufpreife, ßadtzinje u. Dergl. (a). Für bie Beranid)lagung jelbft gelten nachftekende Sgauptregeln (b):

1) Der inittlere rohe (Ertrag eines Srumbftủfes, bie zur

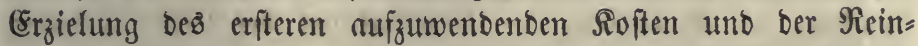
ertrag, folglich bie in biefem enthaltene (Srunbrente, werben, abgejehen von ben Reallaften; vorzüglid) beftimmt:

a) von ben förperlidyen (Sigenfdyaften ber einzelnen Srumb=

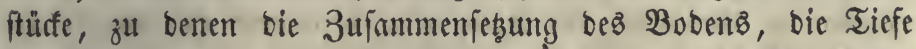
Der Rrume, Die Befchaffenkeit bes Untergrundes, Daş Slima Der Begend, bie koke ober tiefe, wagrechte ober geneigte \&age, Der (Srab Der Befeudfung 2c. gefjören (\$. 127. 1));

b) von ber Rage. Der Srumbitücfe gegen bie Sirthf(h)aftz=

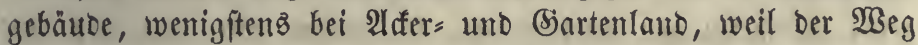
von Demfelben zu bem Sूofe von Menichen uno (Sejpannen oft zurüafgelegt weroen muß. Diefer Umftand hat on ben größsten

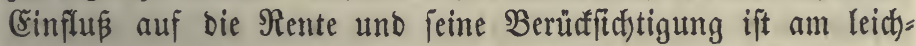
teften auşzufübren, wo bie zu einem Bemeindebezirf (Semar= fung, Bann) gebörenden 5 gुfe in einem Dorfe beifammentiegen uno bie Semarfung gropi ift $(c)$;

c) von ber in Der Segend üblid\}en Bemirthfa)aftungşweife, namentlid) ber Fruidtfolge uno Feldeintheilung, \$. 128. 1);

d) bon ben bajelbit beftehenben mittleren ßreifen, bie fo= twohl bei ben Erzettgniffen als bei ben (seldaubagaben in Betrad)t fommen. Für jene werben bie Durd) jdynittzopreife ber nädjiten Narftorte aub einem gewiffen 3eitabfidnitte zu Srunbe gelegt $(d)$ und es wird je nach) ber (sntfermung von bem Martte und ber

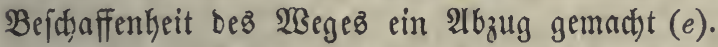

2) Für (Sewädjle, Deren (Ernteertrag von Jahr zu Jalyr berfchieben ift, wirb eilt Mitteljabs aus längerer (Erfakrung an=

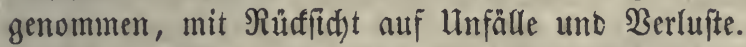

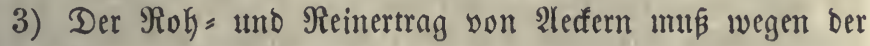

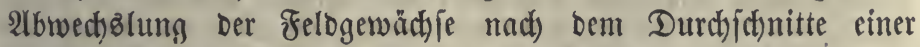
ganzen łeriobe, aljo z. B. nach ber üblidfften Frudftolge für 3 ooer 6 Jakre berechnet merben $(f)$. 
4) 3u Den vom Rokertrage abzuziehenden Roften gehören 2luşant, — Infauf von Düngemitteln, bie man nidht felbft erzengt, z. B. (Sips, - Arbeitzlokn (fowohl (S)lolohn als Befoffigung oer 2lrbeiter unb Bekerbergung bes (Sefinber), เvo= bei aud) ber linterhalt bes \&anowirthes eingered)net werben follte, - Futter, WBartung, Stallung und 21bmïbung Des

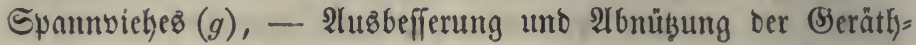
ichaften, - Baufoften, - Unterbaltung ber Ufer, Dämme,

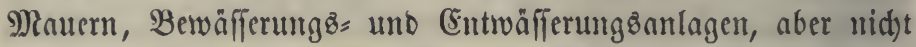

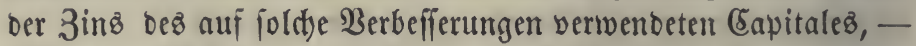
Binfen oes ftehenoen uno unlaufenten Eapitales $(h)$, - ferner

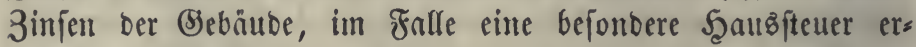
hoben wirb (i).

5) Da bie Sebunbenteit ber Ranogüter in ben meiften Sänbern fđon aufgehoben, in ben anberen aber ifje Fortbouer zweifellyaft ift uno immer freie (walzenbe) Srumbftüfe uno ein= zelne Zertheilungen vorfommen, fo müffen alle einzelnen $\mathfrak{B}_{e}=$ ftandtheile eines (Sites abgefonbert gefdäbst werben. (Sleid)= wohl werben bie Rojten nidjt fo bered)net, wie fie fids bei oer

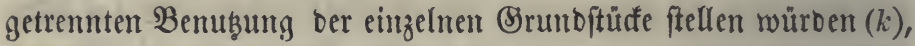
jonbern unter 2(mnahme eines Ranogutes son gewiffer mittlerer (Sröße in jeder Begend.

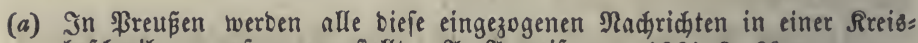
befdreibung zufammengeftellt. A. Anweif. von 1861 \$. 23.

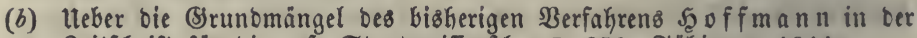
Beitjdjrift für bie gef. Etaatzivifienif., I, 350. Tübingen 1844.

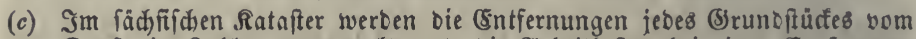
Dorfe in 3ahlen angemerft und bie 2rrbeitfoften bei einer (8ntfernung

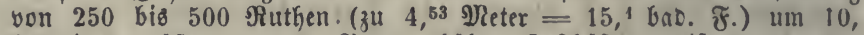

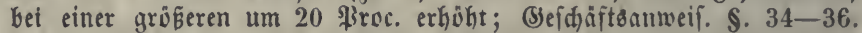
Berednungen Gierüber bei $\mathfrak{B} \mathfrak{L}_{\mathcal{D}}$ f́, Mittheilungen III, 380. miro in feber \&egend nusgemittelt werben fönnen, um wie viele Srocent

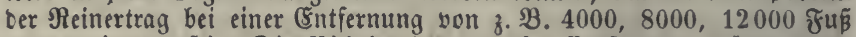
zu verminbern jei. Die Nidjtbeadhtung Diefer Entfernung würoe einen Theil ber (Srunceigenthümer zu hodh belaften. In mandjen (Semar= fungen giebt es abgeionderte entlegene flädien, 3. B. auf einem Berg=

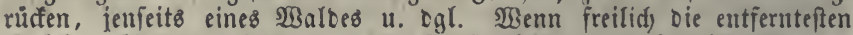
Stüffe näher an einem anteren Dorfe liegen und folglidg yon ten Bemohnern Deffelben gepadjtet ober erfauft werben fömnen, fo dürfte

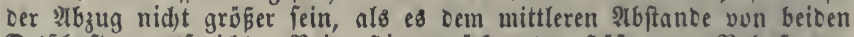

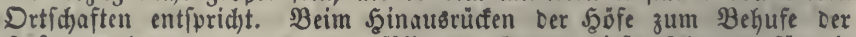
Sufammenlegung (II, \$. 99) făllt ber (3)rund Diefes शtbzugez für bie entlegenen Etücfe hinweg uno wenn eine Bemarfung größstentheils aus

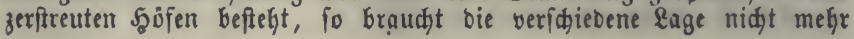


berüdifd)tigt zu werben. Die Serftreutheit Der cinem (sigenthưmer gehörenben Stücfe fann wegen bes häufigen (Sigenthumstwechiels nicht in Betradjt fommen, wie es aud bie a. preup. Pnweifung y. 21. Dai 1861 \$. 3 vorfdreibt. Nady Dem offerreich. Sefescentwurfe von 1863

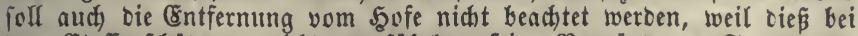

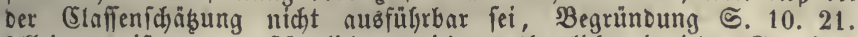
Arlein $e^{3}$ ift nur umftänblider, nidht unthunlid, in jeber Stemeinbe

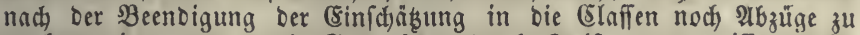
machen, indem man bie Semarfung surd Sxeife von gewifien Salb= meffern in mefyrere Theile zerlegt, bie som Dorfe nach außien auf ein= an ber folgen.

(d) Die hiezu gewählte \$eriobe muß im ganzen Lanbe bie nämliche fein. Franfreich: Marftpreife aแz Dem Durdhidnitt ber Sakre 1783-1790 und 1797-1803. In Belgien nahm man bafür neuerlich Den Durch)= idnitt you 1812-26. - (Sr. Şeffen: D. 1818-23. - In Defter= reidh wourden bic Marftpreife von 1824, als bie niebrigiten, z" Srunde gelegt. In Sadhfen theilte man 46 Bezirfe Des \&anbes ab und nahm für jeden einen gewifien Roggenpreis an, yon 2 rl. 12 ggr. $-3 \mathrm{rl}$.

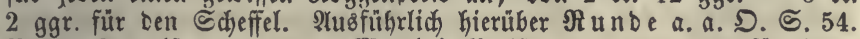
\$reus. Antveif. von 1861: Niartini = \$reife von 1837-60 fur jeben sreis, mit Şinweglaffung Der zwei höhften und zwei niebrigften.

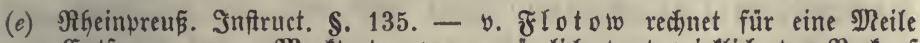
Contfermung yom \$arftorte, wenn nảmlich bort wirflich ber Berfauf gefdieft, 2 ßroc. ab, S. 37.

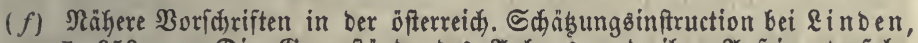

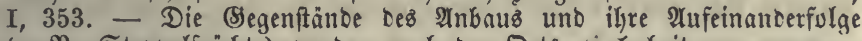
(3. B. Stuwwelfruthte) werben nad) Der Drtsgewohnheit angenommen,

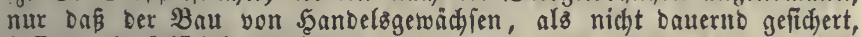
befler unberüffichtigt bleibt.

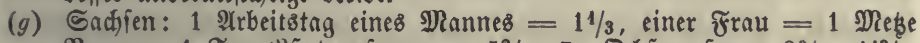

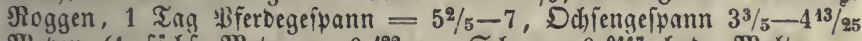

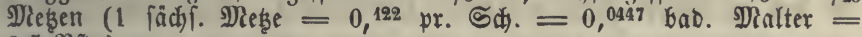
9,5 PFD.).

(h) Daż umlaufente Capital gefört im Falle ber Berpachtung Dem ßaçter, uno Der Berpachter hat Darum feine Bergütung Dafür zu erwarten. Die 3infen Dez ftehenden Eavitales fallen, wenn ein ganzes Ranogut verpachtet twiro, Dem Eigenthümer neben ber Srunorente zu, und brauditen in foldsen Fällen nidht abgezegen zu werben, wenn nidjt aud ofter einzelne (Srunditüfe in \$adyt gegeben würben. y. (S) ro s., S. 32, ift gegen biefen $216 z u g$, weil bie Binfen fein Theil Der \$roouctions: foften feien. Beifpiel ber Berechnung bei $v$. Flo to wo, Anleitung zur

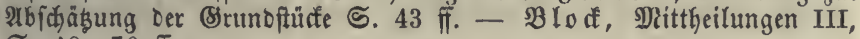
ธ. $48-70 \mathrm{fi}$.

(i) Das åltere Berfahren, nach Dem man, um bie Berechnung ber Roften zu exparen, Diefe alz ein Bielfades ber (Setreibeauzfaat betrad)tete (\$. 128. 2)), if auch bei Cteueranichlägen vorgefommen, z. $\mathfrak{B}$. in bem preusifiden uno branbenburgifduen Şufenido ó̉, bei ber hannoveridhen

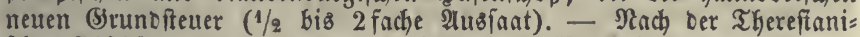

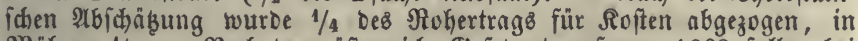
Niährell $1 / 3$. - Nad) Dem sfterreich. (Seiebentwurf von 1863 follen bei

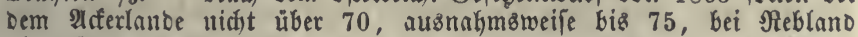

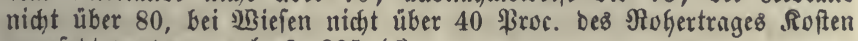
angeiest werben, vgl. \&. $335(d)$.

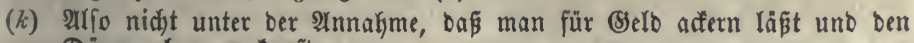
Dünger baar anfauft. 


\section{§. 333.}

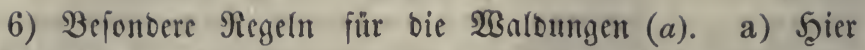
werben bie in ber Forfitwerwaltung, befonders ber Stantz=, (5) meinbe= unt Corporationzwaloungen gemadt)en (Erfahrungen

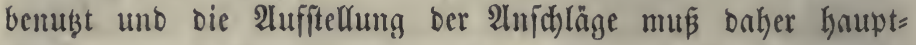
(äc)lid) von Foritmännern bewirft werben. b) (EB ift zunächjt ber nadjhaltige Şolzertrag zul erforiden, ber von Boben, \&age uno Altima, Şolzart unt Betriebsిweife bebingt ift, ferner bon oem Dafein eincs Borrathes yon ftehentem Şolze, I, \$. $390-(b)$. c) Şier ergiebt fidt) aber bie Sdywierigfeit, Dá̈ biäweilen ber Şolzbeftano eines $\mathfrak{B a l b e s}$ zufolge einer fehlerhaften Behand= lung geringer ift, als or bei einer guten $\mathfrak{B}$ ewirthiddaftung fein muitroe, baß folglid) auth ber jährliche Scolzertrag unter bem regelmaäßigen (normalen) ftefyt uno baß eine geraume 3eit verftreichen fann, biz bie $\mathfrak{B i r f u n g e n ~ e i m e r ~ u n b o r t h e i l l y a f t e n ~} \mathfrak{B} e=$ hanblung gänzlid bejeitigt fint. Würbe man fid lebiglid) an ben

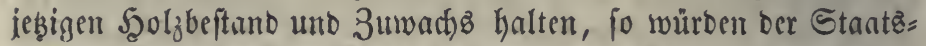
caffe bie Früdte einer fünftigen befferen $B$ ewirthfdhaftung entgehen; wollte man aber ben auf einem gewiffen Etanborte mögliden normalen Ertrag zu Srunde legen, fo würben bie Eigenthủmer in ber nächften 3cit offenbar überbürbet. Der einfad)fte 2 lü = weg beftefl barin, baß man für jeben Standort einen mittel=

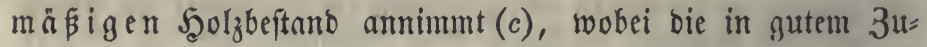
ftanbe befindlictyen $\mathfrak{W a l}$ aldungen nicoriger angejeşt werben, alz

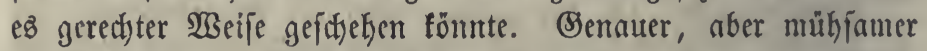

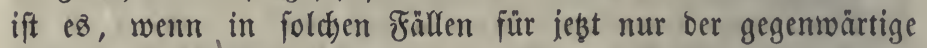
Ertrag in 2(mid)lag gebradt, iebod) eine ßriffung unt allen=

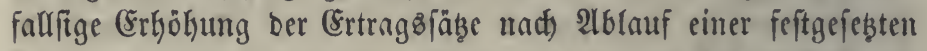
Frift vorbehalten wirb $(d)$. Man hat alfo zu unterfucten, ob Die veridjicbenen Alterżclaffen biz zur Umtriebżzeit jümmtlid) in ridtigem $\mathfrak{B e r h a ̈ l t n i}$ s vorhanben, und wic yolfrtänbig ober

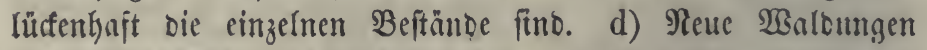

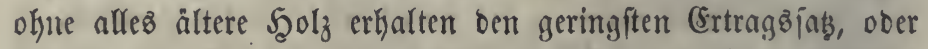
werben eine 3eit lang freigelaffen, weil bie won ifnen erfybene Steuer vorgefhoffen weroen mus. e) Die Beftantbtheile eintez

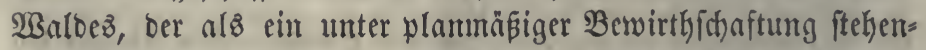
Des Branzes anzujehen ift, werben nidjt einzeln behandelt, mo= 
ferme nidft einzelne Theile von beträthtlicter 2htsobhnung in Anjehung bes Bobens jehr yon ber Saautmafie abreidten. f) Bei fleinen $\mathfrak{W}$ aldungen, bie feinen iährlicten Şieb zullaffen,

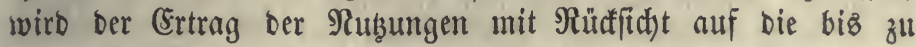

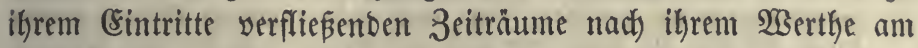
Sd)luffe Der Untriebzperiode aubgemittelt uno bie jährlide Szolzrente berectinet, weldye in gleidjer 3eit zu ienem Betrage

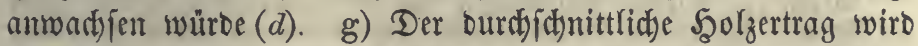
nad) ben veridjiebenen Scolzforten und ben örtliden Mittel= preifen einez längeren 3eitabid)nittes auf bem Stamm zu Selo angejd)lagen, fobann werben bie Roften, mit Sinjd)lup bes

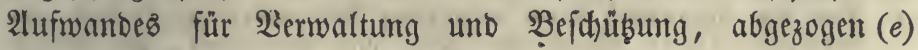
uno bie Nebenmutzungen beigefügt $(f)$.

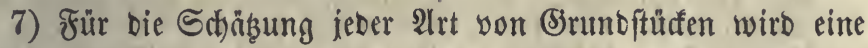
au\&führliche 2Inweifung (Inftruction) aufgeftellt, aljo auper ben

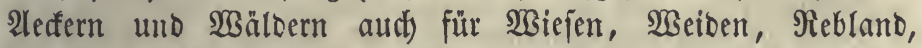
(S)ärten verfdyiedener 2 rtt, Şeiden, Teidje, Torfftiche, Stein= brüche, Rekmgruben 11. Dgl. Der Ertrag bes Rubviekes, als

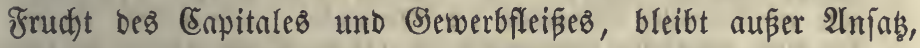

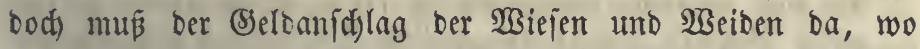

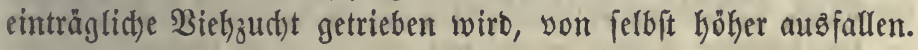

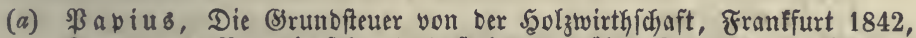

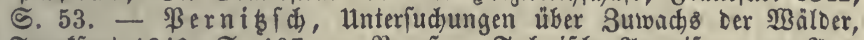

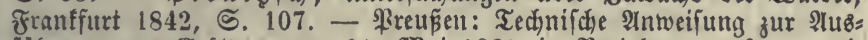
führung tes (8eiéses yom 21. Mai 1861 in Beziefung auf ... Die

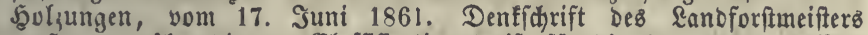
y. Şagen ûber bie ... Elafifificationstarife für bie Şolzungen, 1. Mai

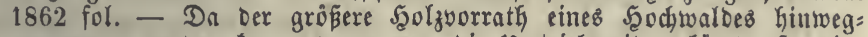
genommen wercen tann, wenn man bie $\mathfrak{u}$ mtriebszeit verfürzt, fo wiro

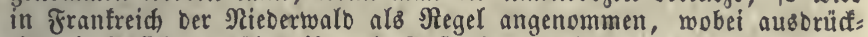

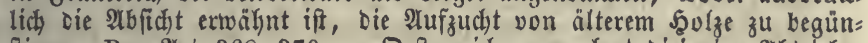
figen. Rec. Atrt. 368. 370. - Defterreid): man Yegt Diejenige Albtrieb:= periode zu Srunde, welche die befferen Forftmirthe der Bemeinde oder oer Begend befolgen. - Sadjien: man ridjtet fid nady Der in jebem SGalde beifelyenden Betriebsart. Der Ertrag wiro theils nad Den fünf Bobenclaifen, theils nach ben fünf 2reftufungen Des 2 Bud fes beurtheilt uno es find hiezu für jebe (Elafie gemifife EErtragsfäze fihon in Der

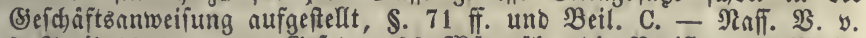

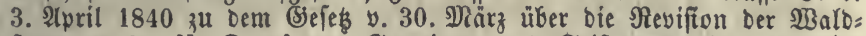
fteter, \$. 8: für Domånen=, Semeinde= und Stiftungżvaldungen wirt Der Fohertrag nad Dem beftehenden 233 irthidhaftzolan und ben jüugiten perivoifden (Ertragstabeflen, bei ftanbeskerrlidjen und (anderen) \$rivat= waloungen nad) einem von ber श्abidikgungscommifition angenommenen

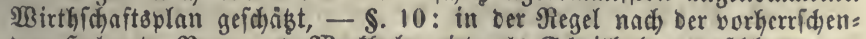

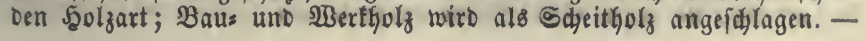




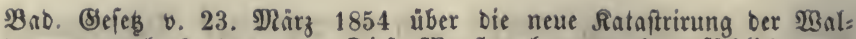

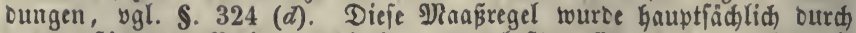

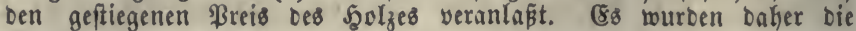
Dittelpreife von 1845-47 uno 1850-52 ftatt ber älteren zu Brunbe gelegt, zugleid wurbe aber aud, Der Saturalertrag nad bem jesigen Suitumbe neu abgeidäst. Der Injolag wirb aus bem normalen

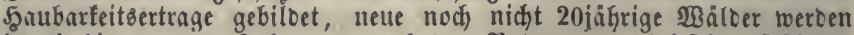
jeovd bis zum 20. Inhre nur nach Dem Bobenertrage bei feiner frügeren Benubungsiweife angeiest. Roffen werben nidyt abgezogen, oer Ertrag wirb aber, wie nad) oem älteren (Srundfteuergefes, nur 15 fad) (ftatt 25fad) zu (Eapital angeichlagen und Nebennubungen bleiben auser

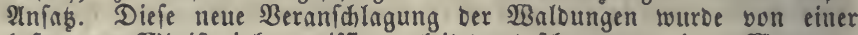
Befonocren Itinifterialcommiffion geleitet uno facon 1855, in 17 Dlonaten,

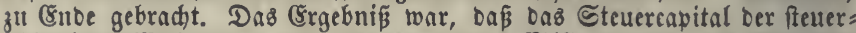
pflichtigen $\mathfrak{B a}$ aloungen yon $291 / 2$ auf 73,9 Dill . fi. ober bes \$lorgens von 26,3 alf 66 fi. erhögt wurbe.

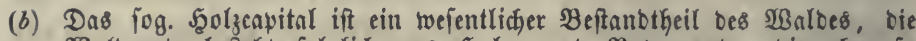

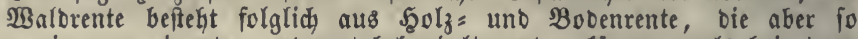
wenig von einanter getrennt behanbelt werben fönnen, als bei einem

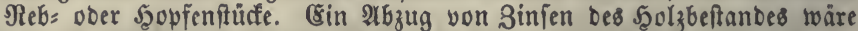
aljo unzuläfifg, Demn jene gehören zu Dem ftetterbaren $\mathfrak{k a l b e r t r a g e . ~ - ~}$

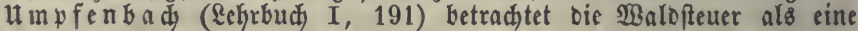
Eapitalfteuer.

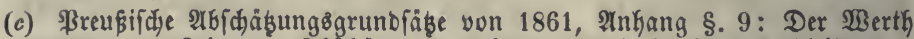
Des zur Seit ber 2ibfhảzung vorkantenen Syolzbeftandes bleibt un= berufifidtigt. Diejer Sas if in Der a. tednifden Intweifung $\mathfrak{S} .11$ genauer beftimmt worben. \&\$ foll cin mittelmäsiger Şolzbeftano,

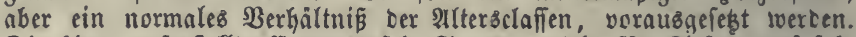
Die hiezu autfgeftellte Ertragstnfel (ธ.17) ergiebt für Riefern auf fẹr gutem Standorte nur 32 uno 24 (5ub. Fuß Derbfolz vom INorgen. Şievon twerben "für Die gewöhnlidgen unvollfommenfeiten uno moglidgen ünglủớsfälle" je nach ben gröperen ober geringeren (sefabren nod $1 / 5$ bis $1 / 2$ abgezogen.

(d) Bierfad in Den Reuen Jahrbüchern Der Forfffunde VI, 81.

(e) Şauer = und Fufrrlofn werben nidft berechnet, weil ber Berfauföpreiø Des fiehenden \$zolzes zu Srunde gelegt twird. - Sachien, §. 84. 85: Für Unfälle zieht man beim Nabelwald 16, beim Şochtwald Des \&aub=

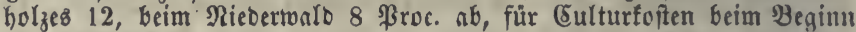

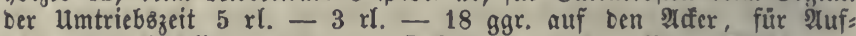

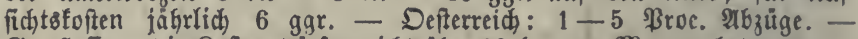
(Sr. Szeffen: Die Roften ourfen nicht über $13 \mathrm{fr}$. vom Norgen betragen. Bab. Sef. v. 1854 \&. 8: Der Naturalertrag wirb nad Der tibliden Art Der 2 uffbereitung unter bie veridhiebenen (Sattungen (Sortimente),

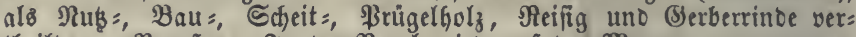

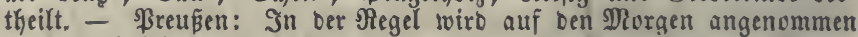

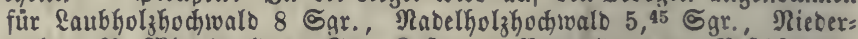

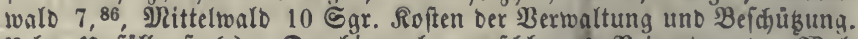

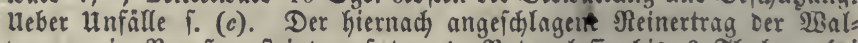
Dungen in \$reupen fieigt auf Der 1. Bobenclaffe bis 6 Thaler, bei Beibenpflanzungen fogar bis 8 Thaler, er finft in Der 8 . Bobenclatie hie und ba bis auf 1 Sgr. Gerab.

(f) Dod mur foldhe, weldje ofye Schmalerung bes Şolyertrages fattfinten

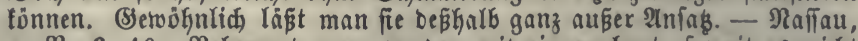
a. SB. \&. 10: Nebennubungen werben mit eingerednet, foweit es nidit angeft, fie gegen Culturfoiten auszugleidyen. 
§. 334 .

(sine grope $\mathfrak{B e r e i n f a d j u n g ~ g e w a ̈ h r t ~ a u t h ) ~ b e t ~ b i e f e r ~ M e t h o b e ~}$ ber $\mathfrak{B e r a n i d j l a g u n g ~ b i e ~ E i n t h e i l u n g ~ b e r ~ R a ̈ n b e r e i e n ~ j e b e r ~} \mathfrak{B}_{e}=$

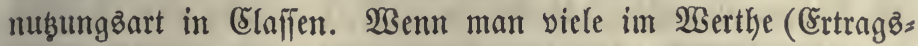
fähigfeit) einander ungefähr gleidffommente Stüăe in eine Elaffe mit einem gewiffen Ertragbafaze zufammenftellt, fo bleiben allerbingz fleine $\mathfrak{B}$ eridfiebenbeiten unbead)tet uno ez ift biz= weilen in Fällen, wo ein Sorunbftưf gerabe in ber Mitte

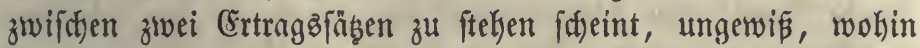
baffelthe zu feşen fei. Dagegen ift bie 2tbfürzung ber 2lrbeit

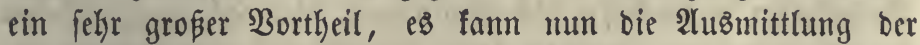
Elaffenfäke befto jorgfältiger und grünolicher geithefen uno ber möglidje Fehler ift gering, wenn bie iebe Claffie bezeid)nenden 3aklen nicht weit yon einanber entfernt find. WBenn man feine Elaffen z̆ Şülfe nälnute, fo würbe unvermeiblich bei ber un= geheuren Menge yon einzelmen Schäbungägegenftånten eine Hebereilung einreißen, in ber weit größere Fehler begangen werben fönnten.

\section{\$. 335 .}

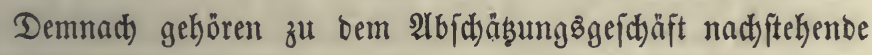
Berrichtungen:

1) Elaffeneintheilung (Elaffification), b. h. 2ufs ftellung einer gewiffen 3 aht you Elaffen bes einer jeben $\mathfrak{B} e=$ muşung von ber höchften biz zu ber geringiten (Ertragsfähigfeit herab,

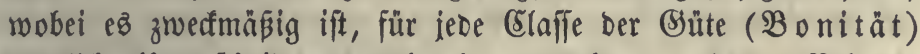
beutlid)e Unteridjeibungšmertmale anżugeben, \$. 127. Bei ben Beranfdjlagungäarbeiten ber meiften Ränber gejđjah bieß für jebe einzelne Semeinde bejonderz, wobei man ber leidten Heber= fits)t wegen überall nur eine fleine 3 ahl yon Elaffen geftattete $(a)$.

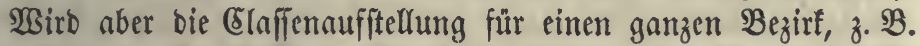
yon einer $2 \mathfrak{n} z a h l^{\circ}$ von Duabratmeilen, in weldyem ähulidye Boben = uno überhaupt lanbwirth/d)aftliche Berhältniffe obwalten, vorgenommen, fo wirb nidjt blop fehr viele Mähe uno 3eit erfpart, jonbern eine größere (Sleichartigfeit ber Elaffen uno ber ganzen 2tbichäķung bewirft. Nur ift großpe Sorgfalt nöthig, bamit bie örtlidjen Berjdiebenkeiten bei biejer überfítytlidjen 


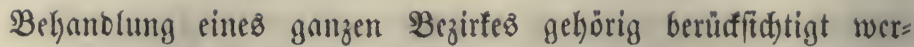
Den $(b)$. (Es ift überlyaupt fdjwer, neben ber förperlidjen $\mathfrak{B}_{e}=$ idjaffentyeit bes \&anbes mandje anbere auf ben Rokertrag unt

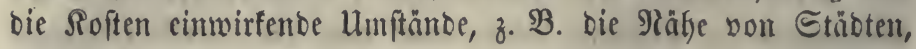
Die Entlegenteit, Die leidte Errangung von Düngemitteln, (B) faht von Ueberfd)wemmungen u. Dgl. bei ber CElaffenftufung in rict)tigem Mlanße in Betrad)t zu zieben, fo Daß bie Frud)t= barfeit bes Bobents nid)t alfein entidjeibet. In einem fleineren Lanbe fönnte eine Elaffeneintheilung, wenn fie ben \&ehriäßzen ber Bobenfunbe fowie alfen vorbanoenen $\mathfrak{B}$ erifjicoenteiten oer

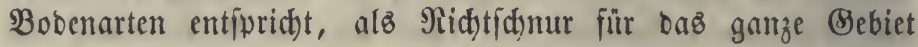
aufgeftellt werben, nöthigenfalls mit 3ulailung von 3wifhen= und Unterclaffen. Ein foldyes allgemeines Syftem ber Boben=

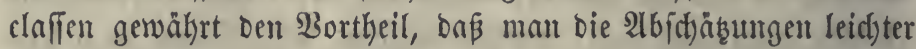
prüfen uno in Uebereinftimmung bringen fann, wälyreno jonft möglid ift, Daß̧ z. B. einte gewwiffe Bobenart hier bie zweite, Dort bie vierte ober fünfte (Elaffe billoet unb nid)t als

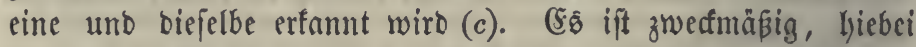
für jebe Claffe cinen gewiffen Rohertrag anz̧ugeben, ieooch mur als ungefähren 2inhaltżpunct. Sntoeß buitfte man fich an eine foldye Reikenfolge ber Bobenarten wegen ber erwähnten anter= weitigen lumftänoe nidit unbebingt halten, vielmegr wirb eime gemifife Bobenbefthaffentheit nad) anberen Müffidten balo ciner böheren, balo einer niebrigeren wirthjd)aftlidben (öfonomijoben) (Éafie zugetheilt merben mủifen.

2) Beftimmung Des roken uno reinen Errtrageż jecer Êaffe in jeber (Semeinbe burd) Sdjäbzung ober Berect)nurg. Şiebei fann man fich an beftimmte, bas (Sepräge jeber (Elafife beutlid) an fict) tragende $\mathfrak{M} u$ ft erftü ce (types, étalons) baltert, bei benen bie wirflidten Ergebniffe ber Bewirthfdyaftung, ferner bie Saufpreife uno \$adytzinfe, foweit fie fids erfahren laffen, zu Şülfe genommen werbett. In einer \$rovitz ober einem fleineren Staate, wo feine große Berfchiebentheit ber lanbwirtbidjaftlicten Berhältniffe vorfommt, famu man die Roftenbered)nung für iebe

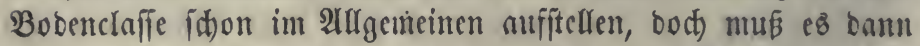
noch) imumer geftattet fein, bie örtlich) nöthigen näheren Beftim= Imungen uno Beridbtigungen hinzuzufügen, weil bie angetrou= mene Regel bişweilen unanwenbbar ift $(d)$. Die Feffieb̧ung 


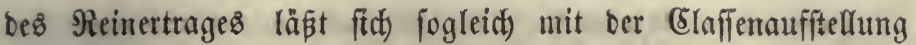
verbinben $(e)$.

3) Einreihung afler Stüfé ber Bemeinbemarfung in bie

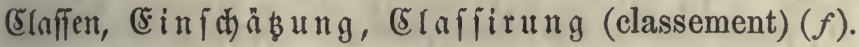

(a) In Iiailano waren nur 4 Elaffen exlaubt, in Franfreich fino beim 2dferlanbe 5, bei anberem nur 3 vorgefdrieben, bod mit 2ubznafmen, Rec. 2. 510. - Э̌m (Sr. Şefien (Inftr. v. 13. April 1824 §. 6) uno

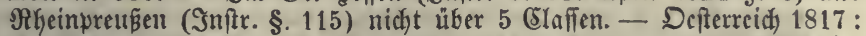
Die 3aht Der Elaffen foll nicht ohne Ginlänglichen Srumb vervielfältigt werben. - Bgl. v. Flo tow S. 18.

(b) In ßreußen gefdyiegt Die ČIaffification nach Den Borfdariften won 1861

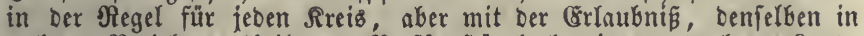
mehrere $\mathfrak{B}$ ezirfe zu theilen, 3 . $\mathfrak{B}$. für Şügel, bergiges uno ebenes \&ano,

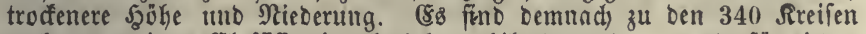
nodf 56 weitere Elaffifientionsbezirfe gebiloet moroen, unb für jeoen

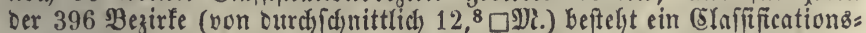

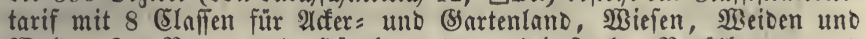
2Balb. In Berg= uno Şügelgegenten, bei farfer Bevölferung uno intenfivem 2ubau foinmen melyr, fowohyl natürliche als fünftliche $\mathfrak{B e r}=$

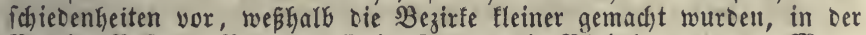

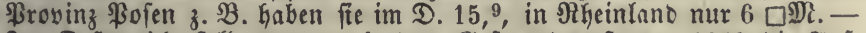
In Defterreidy foll zwar nach bem (Séésentwurf von 1863 bie 2uf=

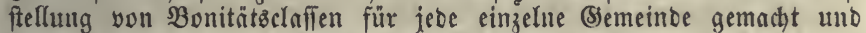
für jebe CInffie ein Die Rennzeichen Derfelben seutlich an fich tragendes Siufterfituif bezeichnet werben, aber nachber follen in einem ganzen

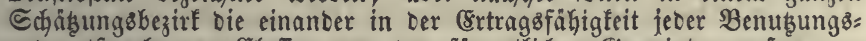

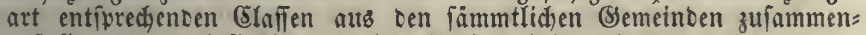
gefiellt uno es foll hiedurch eine Stufentabelle gebilbet werden, wqzu

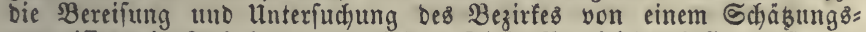

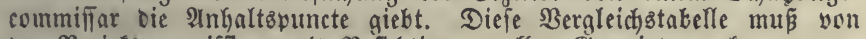
Der $\mathfrak{B}$ ezirfócommiffíton mit $\mathfrak{B}$ efichtigung aller Biemeinbemarfungen ge= prüft mersen. (ङ8 icheint einfacher, Die Claffification Diefer Eommiffion felbft zu überlaffen, wie in \$reupen, f. im $\mathbb{S}$. Nr. 1).

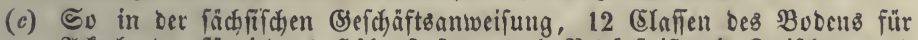

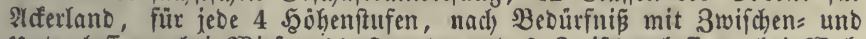
unterclafien; bei SBiefen 11 Sgmupt= uno 9 3wiftenclafien; bei $2 B a l=$ Dungen 5 Elafien, vgl. $\$ .128(a)$ uno $(e)$. - Entwurf eines ähnliçen (Elafienfyftems für थltenburg bei $\Re$ un be, Beil. S. 80.

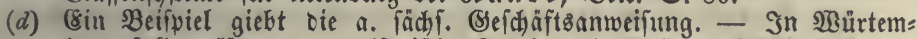
berg follen für bas proviforifche Satafter bie Roften bei 2lderland auf

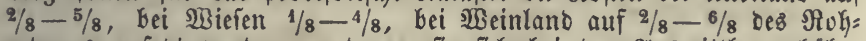
ertrages gejest werben, uno wo fie fich bei ber 2tusmittlung hober

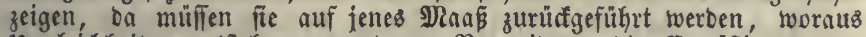
ungleichkeiten entifeken, zu beren Bermeibung bie Srmäsigung Der Roftenfäbe von anderen Răndereien nötrig wiro, Befes vom 15. Juli 1821 §. 21. Inftr. §. $71-73$. - In Defterreich (1817) Durften Die Roften

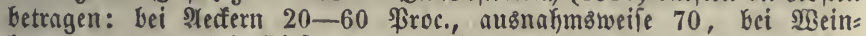
bergen 30-80, bei SBiefen 10-30 \$roc. Soldye Buriduriften erregen Bebenten, weil bie Roften bismeilen wirflid) ein foldhes Naar über= fteigen. Slan trifft Brundfunde an, Die fo unergiebig ober entlegen

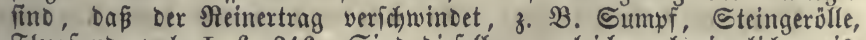

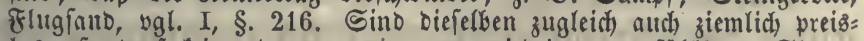
los, fo Darf fein ober nur ein ganz nicoriger, unfühlbarer Stetter: anficlag gemadyt werben. Nadh Dem Srumbiteuergefes für die NBeft= 
provinzen son Preußen §. 19 Darf für \&and, weldhes nod irgent cine Benubung geptattet, Der Neinertrag nidht unter $1 \frac{1}{2}$ Sgr. $\left(5 \frac{1}{4} \mathrm{fr}\right.$.) vom Dorgen angefebt merben. In Sadjen ift in jeber Blaffe uno Stufe ber geringite zuläfifge sReinertragsfabs oer gemeine $2 B$ eicetverth, welder in ber unteriten (Slafle und ber hödjten (fälteiten) Eage nuf

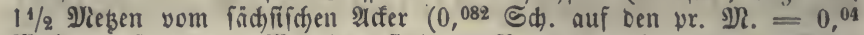

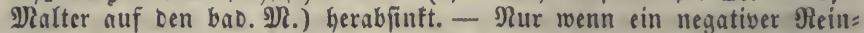
ertrag zum Borídein fäme, Dürite man eine unrid)tige Beredumang vermuthen. - Bgl. Rec. 21rt. 515. - Die Bornusfę̧ung oer rhein=

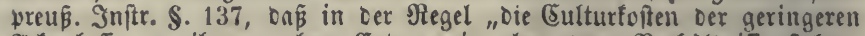
Adferclaffe zu ihrem rohen Ertrage in eben Dent Berhâltniffe ftehen,

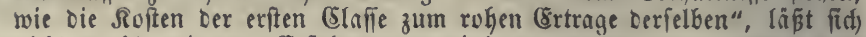
nidyt wohl mit ber Erfahrung vereinigen, auser etwa, wenn bas

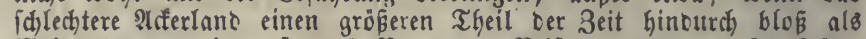

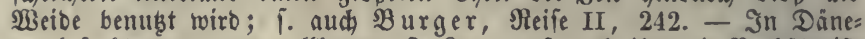
marf fudte man bas vollfommenfte \&and auf, gab ifm bie Berfáltníp:

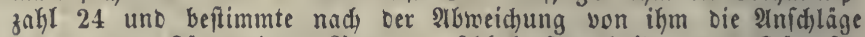
ber anberen Räncereien. Bon Den idjlechteften Seeiben uno Gümpfen famen exft etwa 400 Raumtheile einent Theil Normalboden gleid. $\mathfrak{B}$ ergföe a. a. $\mathfrak{D}$.

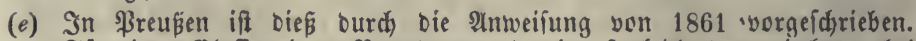
Für jeoe (Elafie einer Benubunganart wirb fogleid) ber mittlere, bei gemeinbegewöhnlidjer Bewirthidjaftungsart zu erwartence Reinertrag feftgeftellt. Rommt bei ciner Maffe von Srunoftuden ein befoncerer, zur Erhaltung ocr Errtragzfähigfeit erforcerlid)er Alufwano vor, io if́t für fie ein entiprechender Blaffentarifbiaz anzunehmen. Nan foll cie beften uno bie fdledteften (Srunbftüe gegeneimanoer abwägen uno bie in Dent Rreife vorfommenden Ertragsverichiebentheiten aufufafien fudjen.

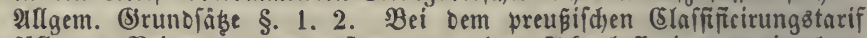

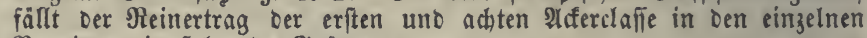
Provinzen in folgende Srinzen:

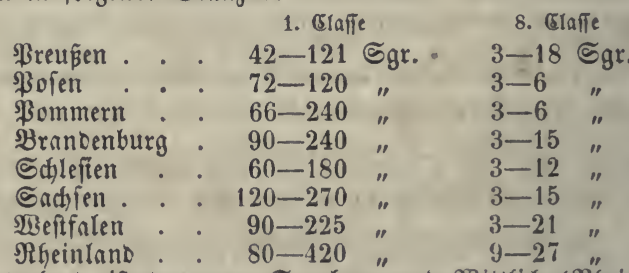

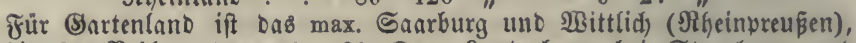

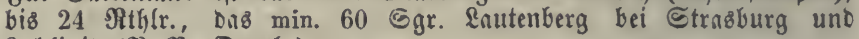

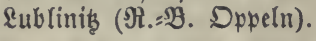

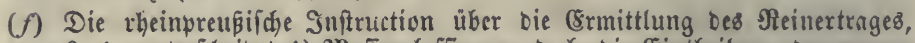
§. 4, unterfideidet 1) Maffenclaffirung, D. h. Die Eintheilung ter ganzen (S)emeinbeflur in grösere, Den veríchiebenen (Slafien entiprechende शib: theilungen, 2) tie befondere (Slnffirung, wobei nämlid) einzeluc (Srund:

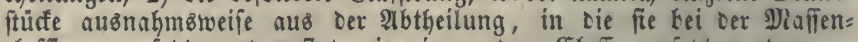
clafifrung gefest worben find, in eine andere Elafie veriebst werben.

\section{§. 336 .}

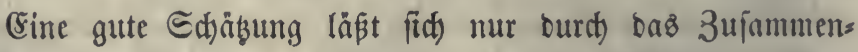
wirfen bon ßerfonen verfhiebener 2rrt berwerfitelligen. Man

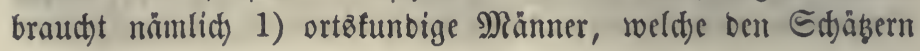




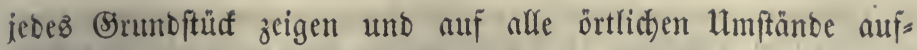
merffam madyen fömnen, Feloanzeiger (indicateurs); 2) Sad) $f u n b i g e$, bie aus eigener längerer (Erfahrung eine gründliche Renntmí ber Eanowirthichaft im IIffgemeinen fowie

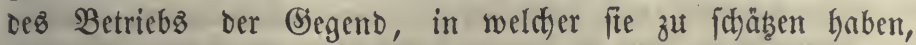

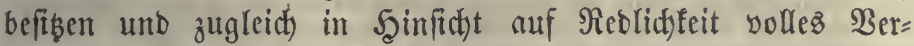

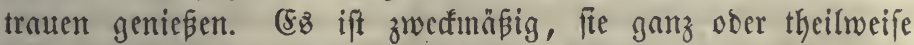
yon ben (S)undeigenthümern wählen zu lafien, §. 299.2. Sie

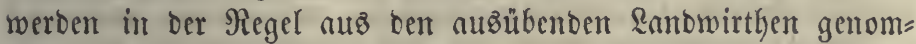
men. 3) Seitende Beamte, bie mit bem Steutrgejese jo= wie mit ben Srunofäten ber politifífen Defonomie uno ber Ranbwirthidaft vertraut fint. Shre Mitwirfung bient bazu, Die vorbereitenten Erforidjungen mzufteflen, Nad)richten zu

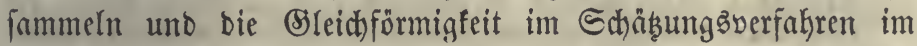
Sinne ber aufgeftellten gejeglidjen Boridsiften zu erbalten, bie fonft aud bei aller (Befdedflid)feit uno Bewiffentaftigfeit ber in 2) genannten Eacjuerftänbigen nidyt zu erreid)en wäre. (58 ift

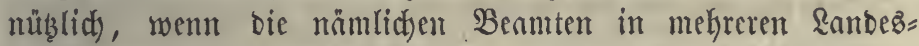

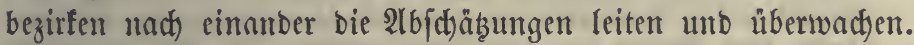
Damit bieß von Mehreren gleichzeitig in veriftiebenen Begen= ben in gleichem Simme geichehe, ift $e$ b rathjam, fie burd) müno=

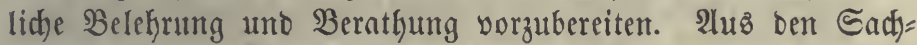
funbigen (2.) und Beamten (3.) werben Commiffitonen für fleinere uno größere 2lbidjnitte bez ভtantżgebietez, endlid) für Dab ganze \&ant gebilbet, bamit bic Schäkungąergebniffe flufens weije für cine größere §läd)e mit cinander verglidjen, mit Bemuţung anderer Thatjadyen geprüft umo nad) übereinftimmen= Den Regeln beridytigt werden fömen $(a)$.

(a) Die Einridutungen in Den einzelnen Ctanten weidben unter anberen

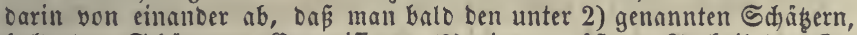

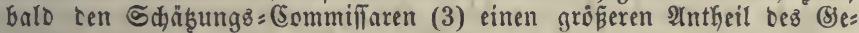
ichäfts übertragen hat. Bei oer Bahbl Der 2moronung if Darauf zu achten, wie bie Biloung unter ben \&anoleuten fid) verkält uno über welde $2 n z a h l$ von (5ommiffaren man verfügen fann. Franfreid): Die Steuercontroleure des Departements werden vom fräfecten in vie zu

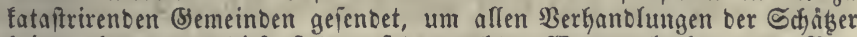

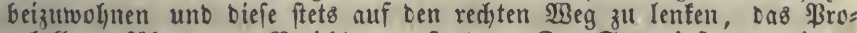
tofoll zu fübren und Beridyt zu erftatten. Der Steuerinjpector nimmt

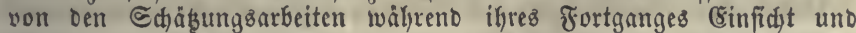

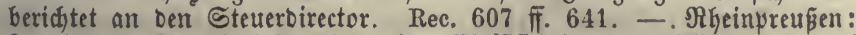

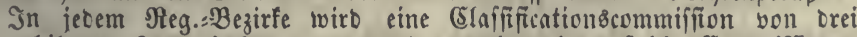
gebilicten Eanowirthen, ober merben aud) mekrere joldbe (Sommiffionen

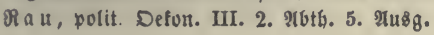


errid)tet, แแ1 zux Befurgung aller Rataftergefdäfte eines Berbante (Bezirfeछ) beauitragt. (Ein Eteuerbeamter fülyrt Das \$rotofoll, mehrere Sontreleure fino beigegeben. Die Commiffen theilt ben Berbano in Diftrite und fellt für jeben die (Slafien auf. (sin Mlitglied beLorgt in

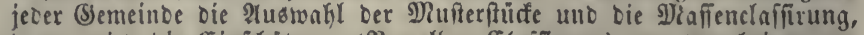

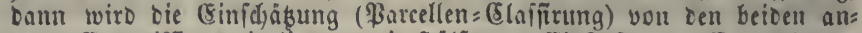

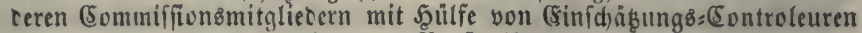
vorgenoumen (nach) oer früheren Borfdrift in Der aflgem. Inftuction von brei Taxatoren). Die (Ertragberechnung gefdjefht fpäter von ber obengenannten (Sommifíton fưr alle (Semeinden. - Sads fen: In jedem Bezirfe ein Dbercommiffar, Der mehrere (Sehülfen (Epecialcommifiare) unter fich hat. Sener fegt bie (Slafien feft und wählt bie Mlufterfitüe;

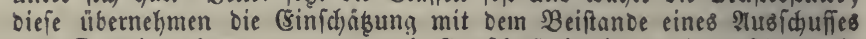

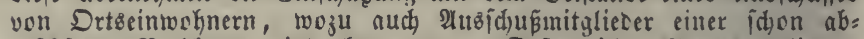
geichäbten Nahbargemeinde fommen. - Depterreid), Steuerregulirung

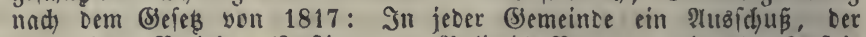

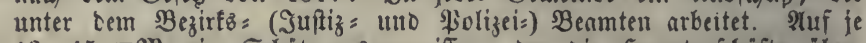

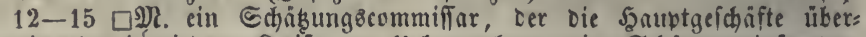
nimmt: ill jebem Rreije zur Uebermadyung ein Śdjigungsinipector. Linden I, 317. Afeljnlich in cen mod nicht fataftrirten Theilen ber lombarbifalen uno in Den venezianifden \$rovinzen. In jeder Bemeinde ift eine delegazione von brei \$litgliebern zur Sdảjung beftellt. \&in= Den I, 421. Sintrurif von 1863: In jeder (Semeinde cine Drtbs=

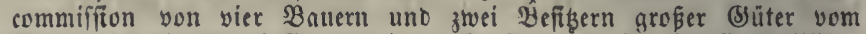

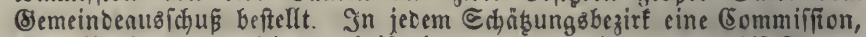
Deren Boriand yom Finanzminififerium exnaunt wiro, uno zwölf Steuer: träger (\$)rumbiteuerpliditige), tooju orei Bauern bon cen Bsemeinden

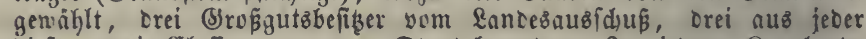
Diefer zrei (Slnffen von den Staatzbenmten. In jebem Rronlande (Wrovinz) eine Rnubescommifition, zur Şälite yon Dem Randange, ges wählt. Bei Dem Finallzminifterium ein Beirath yon 10-12 $\mathfrak{B e r}_{\mathrm{e}}$ trauenżmännern. Şiezu fommen reifende Eentral= uno Dberinfpectoren.ßreú̧en 1861: In jeoem lanträtglidien Rreife eill von Dem finanz= minifter ernannter Beranlagungžcommiffar; Dem zur \&usführung oer

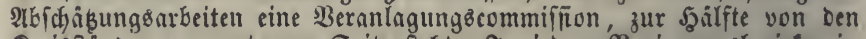
Rreib̂fänden ernannt, zur Gcite fieht. In jebem Siegicrungobezirfe ein $\mathfrak{B e z i r f z e c o m m i f f a r ~ m i t ~ e i n e r ~ z u r ~ S ̧ a ̂ l f ̈ t e ~ y o u ~ c e m ~ P r o v i n c i a l l a n d a n g e ~ g e = ~}$ wảhlten $\mathfrak{B}$ ezirföcommiffion. Bier Seneralcummifinare, für je zmei \$ro: vinzen eimer. Sine Centralcommiffion unter Dem Sorfis Des Finnz= minifters, beftehend auz den vier Seneralcommiffaren, viet yom finanz: minifterium bertfenen Sadjerftänoigen uno 16 anderen Ditgliebern,

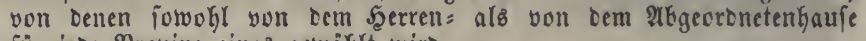
für jede \$rovinz einezి gemảhlt wirb.

\section{§. 337.}

3ur Bolfenoung bes Satafers gehört eine mehrmalige forgs fältige \$runfung ber auşgemittelten 3ahlen. Seber Brunbeigen=

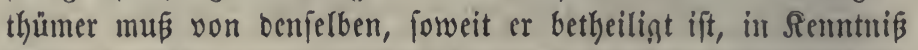
gejeşt werben $(a)$, um innerhalb einer getwiffen Frift allenfallz Bejdjwerben vorbringen zu föınen, zu weldjen vorzủglid) bie (Einjdjäb̨ung 2unlaß geben fann. 3ur Unterfudjung foldjer Befdjerben ( Reclamationen) bienen bie in $\$ .336$ 
erwähuten Commifitonen bohkerer Etufen, weldye audy, wo

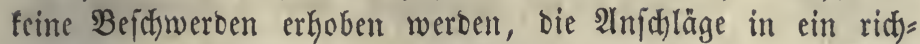

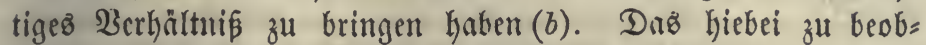
ad)tende $\mathfrak{B e r f a b r e n , ~ i e ~ n a c h ) ~ D e n ~ u ̈ b e r b a u p t ~ z u l a ̈ i f i g e n ~ B e g e n = ~}$ ftrinden einer $\mathfrak{B} e f(d w e r b e, ~ m u \tilde{p}$ ourdh eine $\mathfrak{B}$ eroromung genau geregelt werben $(c)$. Die Sirtragş/äze ber einzelnen \&anbez= theile müffen überfaupt gegeneinanber gekalten uno mit anderen Erfakrungen über ben Bobenertrag verglicten werben, um $\mathfrak{u n}_{n}=$

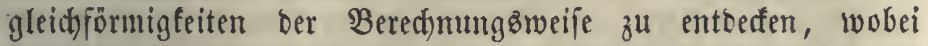

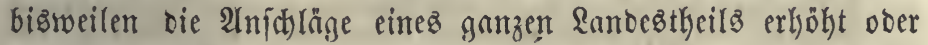
ernieorigt werben müffen. CSin gutes Şülfs̈mittel hiezu ift bie Bergleiduung ber 2Infäßze für bie an ben Bränzen zweier Bezirfe liegenoen (B)runoftüfe von ziemlict, gleid)er Ertragz̧ähigfeit $(d)$. গach Diefen $\mathfrak{B e r b e f f e r u n g e n ~ f a n n ~ o a s ~ R a t a f t e r ~ b u r d ) ~ B e j c h l u ß ~}$

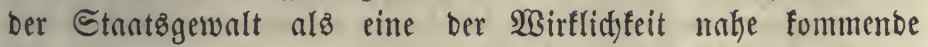
Darftellung Der Srunorente in einem sanoe anerfannt uno zu Der Bertheilung ber (Erundfteuer allf Frovinzen, Bezirfe 2 . biz auf bie einzelnen (Srunbeigentfümer benutst werben (e). Dod) bervirfen ict)on die Berânoerungen, bie fid) in Den \$reifen Der Erzeugniffe 2c. ereiguen, balo, Daßj bie Satafterjäßze nidyt mehr genau bie wirfliche (S)unbrente auborüden, fonbern nur alsz

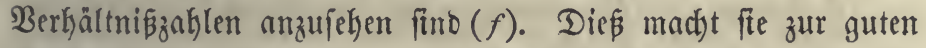
umlegung ber Srunofteuer nid)t weniger braudbor, weil man ourch) 2bänberung Des Steuerfußes leid)t bas benbfitctigte $\mathfrak{B e r}=$ hältniß ber Steuer zu bem wahren Betrage oer Eruntorente Gerftellen faun $(g)$. Welchen Theil ber ganzen Srumbrente ber

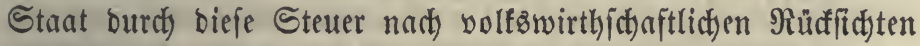
in Injpruch nefymen bürfe, bießs läßjt fith nicht alfgemein bes

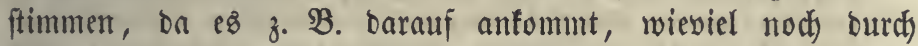

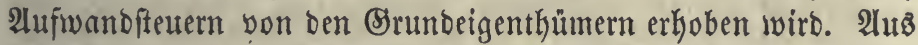
Bergleidungen ber Steutern in mekreren Staaten ift anzuneh= men, buß́ 20 \$roc. ein hober, 10 ein mäßiger Fuß fei $(h)$; nur ift ber Befammtbetrag Der Srumbrente im Verbältnißß zu Den anderen fteuerbaren (Einfünften nid)t mefyr aus Dem Rntafter

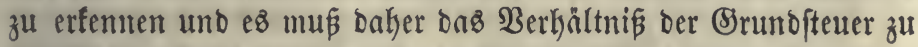
ben übrigen Sthakungen aus anberen Thatfachen beftimmt werben.

(a) Franfreidh: Jebem Srunbeigner wiro fdriftliđ angezeigt, wie feber Theil feines Befizes eingeldyät, uno wie ber Ertrag jeder Elaffe an: 
genommen worben ift. Bugleid werten alle biefe Riften auf bem SRath= haule zur Einficht aufgelegt, Rec. 684 ff. Iefgnlich sibeinpreus. allg. Inftr. \$. 158. 159.

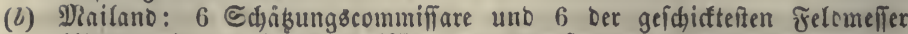
bildeten eine einzige Sommifíton zur unteriuchung aller Befdwerben. Franfreid: Der Steuercontroleur uno Der ङdjäker unterjudjen in jeder

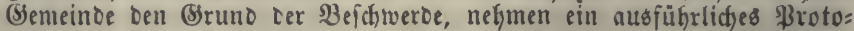

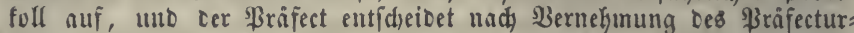
rathes; Rec. 734-45. - In Defterreid, werben die B̈efdwerden von

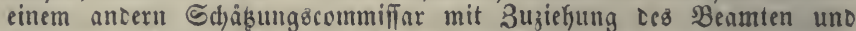

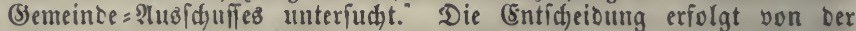

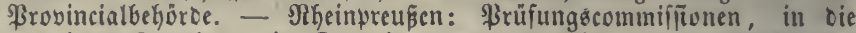
aus jeder Bemeinde ein Deputirter ernannt roird, unter SBorfïb Des Eanoraths und Theiluahme Des Steuerbeamten $2 c$. Die Bezirforegierung entfdeidet über Die Boridaln̈ge diefer Sommifĩon. Rulg. Inftr. \$. 170 bis 180. - Bayern: Eompromígeridfte aus 1 Dbertarator und

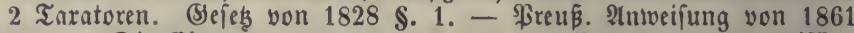
§. 45: Die Eimwentungen werben von Der Beranlagungscommifition (\$. $336(a))$ geprüft.

(c) Sireús. Amweifung über ons Berfahren bei Befanclung Der Reclamas tionen ... v. 15. Suni 1863. Sinzelne Steuerpflidtige Düren nid.t Den ganzen SInffificationstarif Des Rreifez anfechten, wohl aber ift Dié̈ von Eeite ber Bertreter befielben zuliffĩg.

(d) Franfreid: (Enntonsuerfammlungen, aus jeber Semeinde ein bum (Se= meincerath gewaiblter Srunceigenthümer, um bie Gdjabungen ser ein=

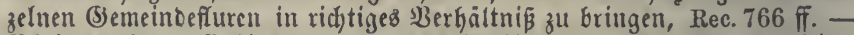

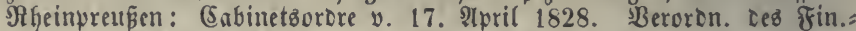

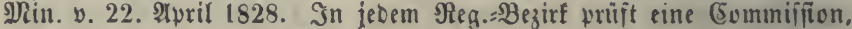

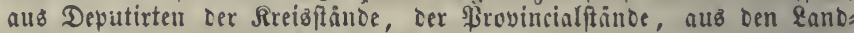

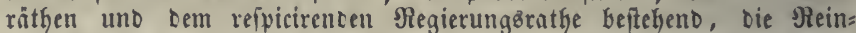
ertragsiäbe aller Diftricte, แad) Dem Bortrag eines (Seneralinfpector

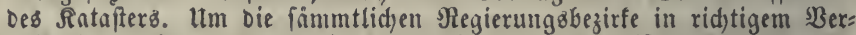
Gältnís anzulegen, wurce eine (Sommiffiton aแż fändifd)en Rbgeoroneten uno Den Siegierungöpräfioenten gebiloet. - In Dem CSlaifiñcationstarif

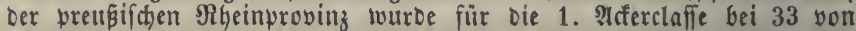

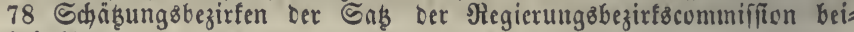
behalten.

(e) Die Bertbeilung Der Brunofteuer unter Die eimzeluen Departementz ge= fdieht in Franfreich nuch immer mach älteren BerbaltniBzahlen, in

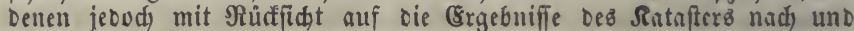
nad) manche Berñnderungen vorgenommen worben find, tum Diejenigen Defartements, weldue überbübet foienen, zuerleidstern. Diefe Jiethode

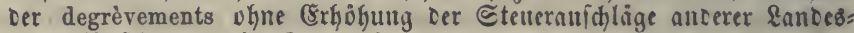
theile iff peit 1819 in (Sebraud, Rapport au roi, 1828, ङ. 32. Der

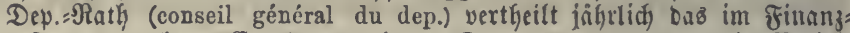
geies angegebene Contingent jeoes Departements unter Die Bezirfe (arrondisscments), Der Bezirfornth beptimmt Gierauf Den Beitrang jeder eimzelnen Bemeinoe zur Steuerjumme tes शrrontiñement uno uur in Dicfer wird bic Ulunlegung nad) Dent Satniter vorgensmmen. Dieie Esinridytung wurbe 1821 getroffen, als Der grösere Theil bes sandes nod) nidyt fataftrixt war, und feitcem beibehalten, vgl. \$. 331 (a).

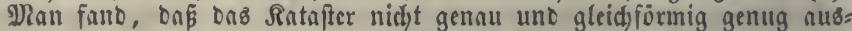
geführt worben war, wie bieß̧ bei ben Ylangel ber in ben netreren Ratafterarbeiten augewenceten Diethooen leidgt zu erflicen ift. Die ફ̧auptiumme (principal) touroe 1791 von oer assemblée constituante auf 240 Ilill. Geptimmt, 1821 war es bis 154 Ilill. Kernbgefęt wor= Den, 1864 war es $167 \cdot 850000$ Fr. 


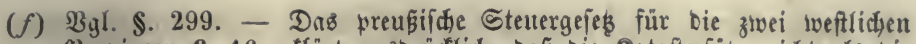
Frovinzen \$. 16 erflärt ausorủdflid, Daß Die Ratafterfäze nicht ale die wirflichen wirthidjaftlichen Reinerträge geltend gemadjt werben tönnen.

(g) 2Benn $z$. B. Die Steuter $1 / 6$ Der Sirunorente fein foll unb Der fataftrirte Ertrag um $1 / 4$ unter Dem gegeltwärtigen fteht, fo wuirbe Der Steuerfús $2 / 9$ ober 22,2 Brocent Des angefdlagenen Eitrages fein müfien In Belgien wiro angenummen, Dấ 1859 Die Errund = unD Şaubrente um 30 Siroc. gröper ift als bie auf \$reife von $1812-26$ geftügten $\mathfrak{A n}_{n}$

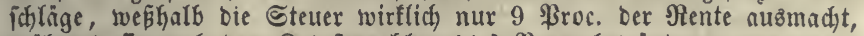
wäkreno fie nach Den Ratafterzaklen 11, \$ \$roc. betrảgt.

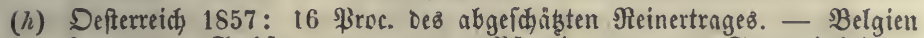
f. $(g)$. - Gadien 1858-60: 9 \$fennige von Der Steuereinkeit =

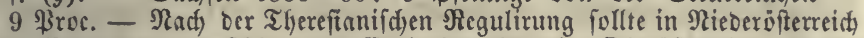

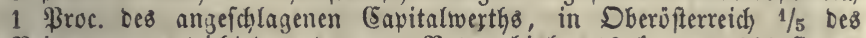

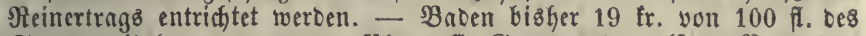
Steuercapitals ober von ungefähr 4 fi. Srumbrente, alfo 8 ßroc. Der= felben, allein bie wirflidje Fente if ofyne 3weifel beträdytlich höher. In Franfreich follten gefeglich (Feit 1790) 20 \$roc. erhoben twerden, man glaubt aber, Die Steuer fei nur 8 \$roc. Der wirfliden (j)rund= und Sausrente uno mandye (Semeinden feien Dem Fupe nady $10 \mathrm{mal}$ io

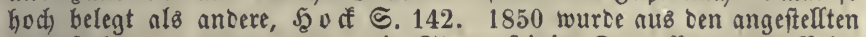

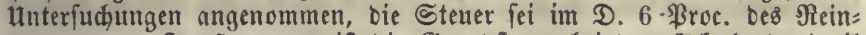
crtragez. - In Şannover ift bie Srundfteter bei bem Alferlande (weil

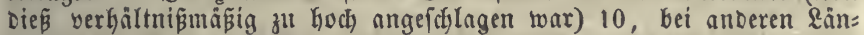
Deteien 11 ßroc. Des Steueranfdhlages ("Steutercapitals"), viefer fiteht aber, mie man annimmt, wenigftens um $1 / 3-1 / 4$, bei ben Forften aber

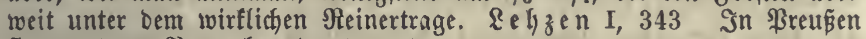
fino 18608 ßroc. Beantragt worben.

\section{§. 338 .}

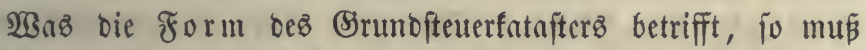
Daffelbe in tabellariftyer 2 norbnung alfe Thatfactben, weldye auf

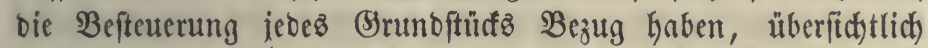
barftellen. Sebe Siemeinde erbält ifyr eigenes Satafter. Um nuz Demfelben leidt)t die Şebeliften für jebes Jahr verfertigen zu fönen, hat man burdygehendos vorgezogen, bie einem jeben Eigenthümer gehörenoen Begenftänoe zllammen zu fitllen, o. i. baż Ratniter nad ben Berionen zu oronen, wobei jedoch audh)

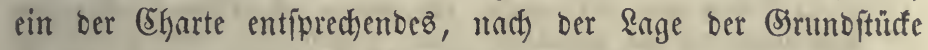
in ber Flur georbnetez $\mathfrak{B e r}_{\mathrm{z}}$ eidjuiß berjelben nidjt z" entbehren ift (a). Das eigentlicke Ratafter (Mutterrolle, matrice du

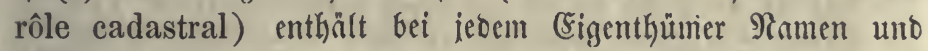

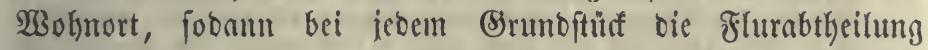
(Section) uno Nummer ber Eharte, - bie Eröße, - bie Art ber Benubung, - die Bobenclaffe, - ben barauz fitt) ergebens

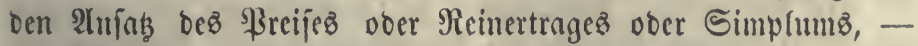
die Reallaften (fallz oieje ebenfallz fataftrirt werben), - uno 
bent nad) 2 bzug berfefben übrig bleibenten Eteueranjd) (ag (b).

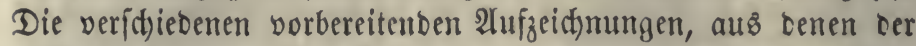
angegebene Sulfalt bes Satafterz herborgeht, werben zum $B_{e}=$ hufe ppäterer słrüfung ebenfaltz aufberwahrt.

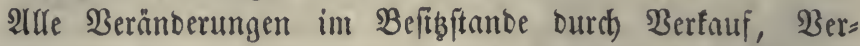
erbung, Theilung 2 ., forwie in ber Bemub̧ungarart ober im Steueramidtlage, o. B. bei natürlidjen Berichlect)terungen, beim

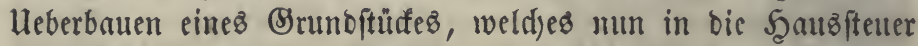
übergeht $2 c$, werben entweder in bejonteren $\mathbb{l} m i$ it reibe= bủd)ern $(c)$, oder im Ratafter felbit, weldes zu biefen Rad)= trägen leeren Maum enthalten mú, aufgezeidjnet $(d)$, aud wer=

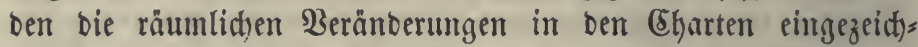
net (e). Dieje jährlidje Fortführung Der Srunofteuerbüd)er muß forgfältig geichehen, Durd) Berorbnungen geregelt und genau überwadyt werben, §. 331.4). Sie wiro am beften befonderen Beamten übertragen, bie mit ber Steuererhebung nid)ts zu thun Gaben $(f)$. Die Betheiligten werben aufgefordert, alle Beränberungen, weldje eine 2 at feidjnung erforbern, bem $\mathfrak{B}$ eamten an bem für eine Bemeinbe beftimmten Tage anzuzeigen unt bie Urfunden vorzulegen, weldje zum Beweife Deż Borganges

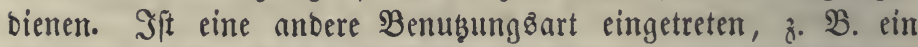
Bald ober eine Weibe in 2 Afer ober $\mathfrak{B}$ Bieje umgerwanbelt wor= ben, fo wiro eine neue 2 bidjägung nöthig, weldhe nad) ben bei Der uripruinglicten Ânlegung Des Ratafterz augewendeten

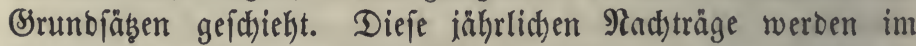
Enttwurfe von höheren Beamten geprifft uno fooann befitätigt.

(a) $\mathfrak{B}$ enzen berg (II, 184) zieft ein Flurbuch Dem nad) Den (Sigentfyumern georometen Ratafter vor, ohne jedod) Daneben ein Bud ber Eigenthumer,

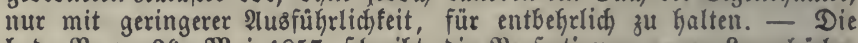
bab. $\mathfrak{B}$. v. 26. Nai 1857 ídreibt bie Berfertigung neuer Eagerbuider in jeber Semeinde vor, wozu Das bei ber Bermeffung entfandene (S)üterberzeid)níß als (Srunblage bient, zugleidh aber eine genaue $\mathfrak{B}_{e}=$

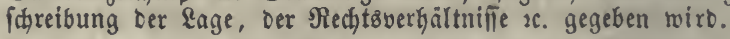

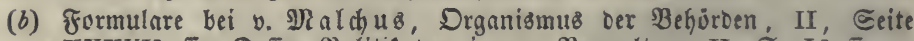
XXXVII ff. Deîen \$olitif oer innern Berwaltung II, ๙่. Li Ta a n t ola, \$raft. Darftellung Der Mail. Steuerregulirung $\mathfrak{B}_{\text {eil. }}$ VI. Das mailander Ratafter enthallt bie Benubungsart nidit, Die man Daher

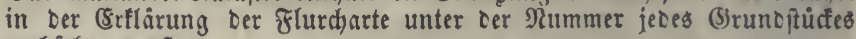
nad̆feken mú̃.

(c) Franfreidh: Arle (Eigenthumbveränoerungen werben in einem Tagebuch nach Der Seitfolge aufgezcidnet. In Der Yiutterrolle twit' oer ganze

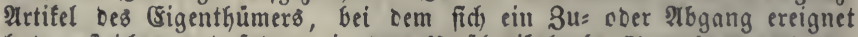
hat, geftriden und pobann in Den Unidreibebuche (livre de mutations), 
meldhes als eine Fortiebung ber Diutterrolle anzuieken if, neu einge: fhrieben, Rec. 862.876. Diefe Eimrichtung if befwwerlich, Benzen= berg I, 493. - Belg. $\mathfrak{B}$. über tie fortführung bes Rat., 22. Siärz 1845. - BBayern: Das tmidjreibefatafter nimmt nur Die $34=$ unD 216gänge uno Die nach Denielben abgeñnberte jebesmalige Steueridjuloigs feit bes Befizers auf, Inftuction für bie Riquidirung oer (S)runbfteuer, 19. Ian. 1830 §. 83 . Neverlid hat man in Unterfranfen eine anoere Form bet Ratafter eingeführt, wobei bie Betheiligten fogleich ihre $\mathfrak{A n}_{n}=$ erfenmung einzeidnen unb für $\mathfrak{B}$ efibveränberungen einiger Siaum frei

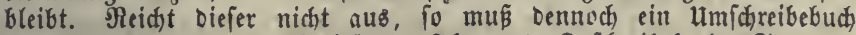
beigezogen werben. - Minilänoer $2 \mathrm{Ab}=$ uno 3ufareibebud, Taran= to la, Beil. VII.

(d) Boridilag yon Benzenberg II, 184, im Ratafter bei jecem Brund:

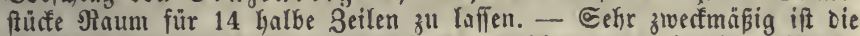
Binrichtung Des babiid)en Intafters, - weldhes aus cinzelnen Bogen (Steuerzetteln) befteht und in weld)en alle Berïnoerungen nachgetragen werben, ohne Daf man eines Umidreibebudbs bebürfe. Nur if ein Foldjes Satafter nidyt mit gleidger Bequemlidyfeit zu gebraudien, wie ein eingebuntoenes.

(e) Dié̃ war in Franfreid unterblieben.

$(f)$ In $B$ aben find Giezu Die 55 Bezirfs= Steuerperäquatoren beftimmt, bie

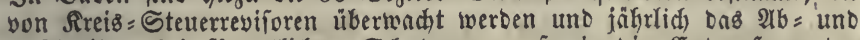
3uid)reiben bei fämmtlichen Sdabungen, fowie bie Entwerfung ber Steterliften beforgen; Sammlung Der auf Errbaltung Des Ratafters ber Directen Steuern in $\mathfrak{B}$. Bezüylichen $\mathfrak{B}$ eroron. 1t. Inftructionen, 1838. -

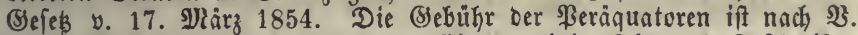
v. 12. Dec. $18531 \mathrm{fr}$. für jeben Eintrag beim $916=$ und Suidreiben Der (5)runofteuer. Die sofien bes $216=$ und 3ujd)reibens merben (wie fdon bisker) von ber Staatscafie getragen. Der 2 . für 1860 enthält

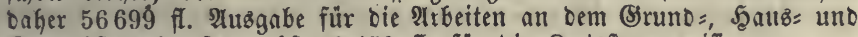
(s) werbfteuerfatafter nebft 12459 fl. für bie Reteffteuerrevifionen.

\section{2. $\mathfrak{A} b \mathfrak{a}$.}

\section{(5) e f äl $\mathfrak{l}$ it $\mathfrak{e}$ u $\mathfrak{e}$.}

§. 339 .

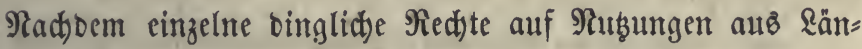
Dereien fith von Dem Eigenthumbirechte gejonbert uno eine Befdränfung beffelben gebilbet haben, zerfällt bie ganze Sruno=

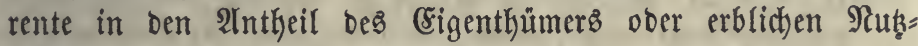
nießers (B) runorente im engeren Sinne), uno ben ber anderen Berechtigten, \$. 308. Diejer Intheil enthält bie (5) runogefälle. Die Steuerpflidyt ber Befällherren im ark= gemeinen fanm feinem 3weifel unterliegen, weil dicjelben im (S) fteuer fann jebod) nur da ftattfinten, wo die (Sefälle bei Der 2us̊mittlung ber Srumbrente berüafifitigt worben fino uno bie

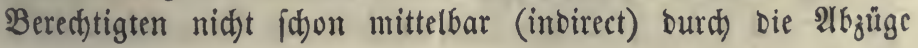


Der gefälluflidstigen (S)rutbeigenthümer getroffen werben, \$. 309. Die (B) efäll= (Dominicals) Steuer imus gleidseitig mit ber (S)runtfteuer angelegt werben, weil hiedurd) bie Arbeit jehr erleidftert wirb, fie ift and) in 2tufefyung ber zu befolgenoen Sruntofäke nidft fdjwierig, wohl aber wegen der Unterjuctumg

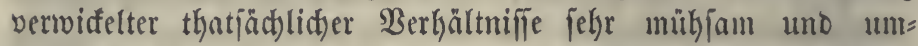
ftäno(id), wofern nidyt alle biefe bäuerlidjen Reiftungen id)on

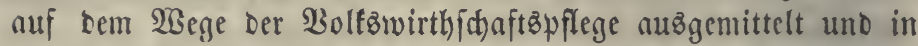
eine einfacte Entrictung unigewantelt find $(a)$. Die Begen= ftänbe Diefer Stcuer find 1) jährliche (Entrid)tungen auz bem Ertrage der \&änoercien, 3ehnten, - Srunozinie in Bjeld ober Raturalien, unter veridjiedenen Namen, - Şolzberedtigungen;

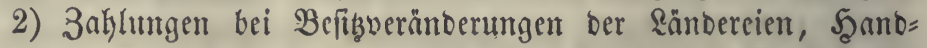
lohn $x$.; 3) Frohndienfte, bie jebud) meiftenz fidon feit längerer 3eit umgewantelt ooer abgelöft find. - Redjte auf gewiffe Benub̧ungzarten frember \&änbereien, wie bie SiBeibe=, JagD=, Fifchereiberedtigutngen, fallen nidft in ben $\mathfrak{B}$ egriff yon (S) $e=$ fällen, fonmen aber in $\mathfrak{B} e \mathfrak{j u g}$ auf bie Eteuerpflid)t mit jenten übercin uno fönnen nuf gleiche 2 seije befteuert werben. WSie bie 2 blöjung ber Şrundgefälle fortíh)reitet, verjd)winbet allmälig

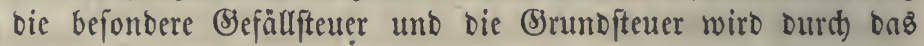
Wegfallen bez 2 lbzugez erhöht $(b)$. Die Befällfteuer ift in Den Boranid)lägen unt Staatżred)mungen gewöhnlid) unit ber eigent=

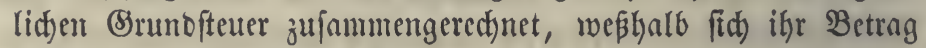

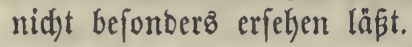

(a) BaD. (5rundfteuer $=\$$. \$. 68. - Bayer. Brumbfteuergeíg v. 15. Aug.

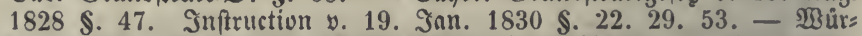
temb. Intr. fưr vie Dber =Amt $=$ Steuer = Sommiffarien, 6. Sept. 1821

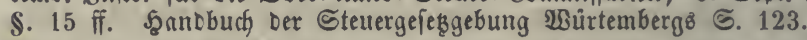

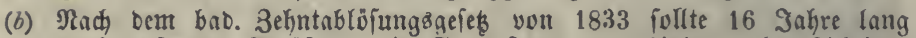
nach eriolgter श्रblöung Die Sirunofteuer ber bißher zehntpflichtigen \&ánbereien niđat erhöht twerben. Nach $\mathfrak{B}$. v. 5. Mlai 1856 wird Der für die erworbene 3ehntfreifeit z"l machende 3uid)lag jur (Srunditeuer burdh eine neue Sdją̧ung beftimmt. Im Boranidhlage für 1855-59 wurde bie hieraus zu ertwartende Bermehrung des (S)undfteuer=(5apitalo auf 50 Dill. fl. angefblagen, währent cas bisherige Srund= uno

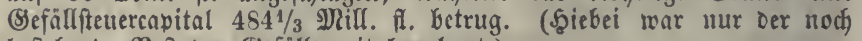
beftehende গieft ber (Sefälle mit beredynet.)

\section{§. 340 .}

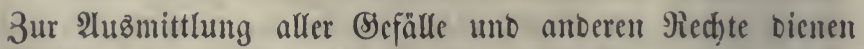
bie 21ngaben ber belafteten Eigenthümer als Sonmolage, ob fie 
fifon für fith alfein nidjt zureidjen, weil bei ifnen fowohl in

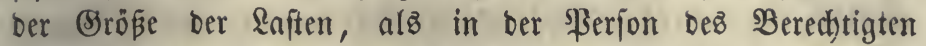
inandbe Fefler begangen werben fönnen. Man verbindet bounit bie von ben Berechtigten jelbft zu erkebenden 2 (ngaben über Umfang und Mian werben mit Şülfe von urfunden, z. B. Flurbüdjern, geridt) licken (Enticheibungen u. Dgl. aufgeflärt, und bie Bered)tigten ober beren Etellyertreter mưffen bei ber Feffftellung aller biefer Berechtigungen gehört werben. Der Betrag ber feften Reiftungen wirb nach) Den Durdjidnittspereifen ber Begend zu Beld an= geid)lagen. Für verichiebene, mur in geringer Menge vorfom= imente (Entrid)tungen, z. B. Eeflügel, pflegt man für baв ganze

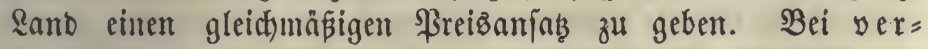

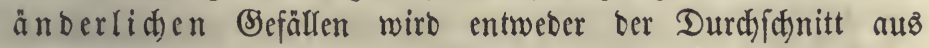
cinem beftimmten 3eitraum, forouhl in 2 nfehung ber Bröße ber Naturalnuţung als in Betreff Dez Bjelbpreifez, ober eine Schäbung zu Erunbe gelegt. Der 3ehntertrag insbefonbere fau aนร bem bei ber Erundfteuerregulirung gefunbenen $\Re$ ok= ertrage abgenommen werben. Bei ben Befikgeränderungåabgaben

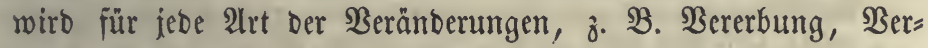
fauf, eine gewiffe SBeriode feftgejest, imnerhalb beren man einen joldjen Fall annimunt. Dem Beredtigten ift

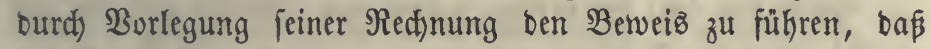
Der Errtrag fleiner gerwejen jei, als man ifn angenommen hatte.

\section{§. 341.}

Bon bem Rohertrage ber Befälle fint abzuziełen:

1) bic auf benfelben ruhenben $\mathfrak{L} a f t e n$ und Begenleiftungen, 8. B. Die Beföftigung ber Frohnnrbeiter, bie für bas $\mathfrak{B}$ ered tigungžłolz zu bezahlende $\mathfrak{B} e r g u ̈ t u n g, ~ b i e ~ \mathfrak{u n t e r h a l t u n g ~ e i n e z ~}$

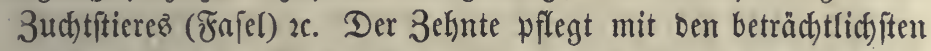
Eaften belegt zu fein, II, \$. 70, Nr. 4. Dą̧ Berfahren bei ber 2lusimittlung fold)er Eaften fam nach ben zur Umwandlung

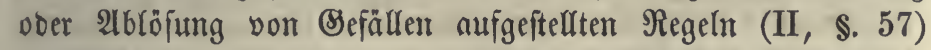
cingerichtet werben, mur baß man für ben 3weê ber Befiteuerung einen minber umftänolichen $\mathfrak{B}$ eg wählen barf $(a)$;

2) bie mit ber Einzichung verbunbenen Soften, Berlufie unt Befd)werben. Şier fann man fid allgemeiner 2Infäß̧e für 
Die Unberveglidfeit ber Bebäube iffre beliebige Benuţung bes iftränft uno ber Lage einen großen Cinflus auf ben Ertrag

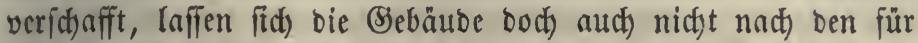

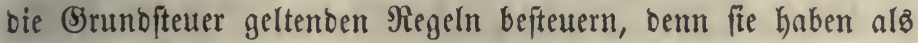
Sunfterzengniffe eine bejtyräntte Dauer, unterliegen einer $\mathfrak{B e r}=$ ichlecterung und werben auf ganz anbere Weife bemubgt als bie Erunbitüffe. Die getrennte Befteuerung dez überbauten

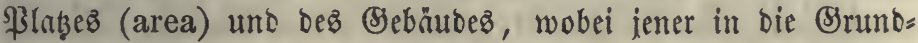
fteuer, biefes aber in eine anbere Sd)abung gezogen wirb (b), verbient feine Radjahmung, weil hierbiurd bas wejentlich uno innig Berbundene willfürlich) geidjieden wiro und ber Bauplak mur beiträgt, ben Eertrag eineż ङebäubeż zu bewirfen. Die

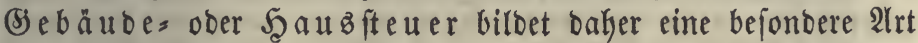

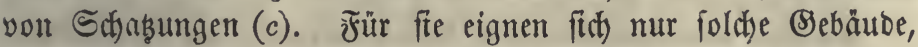
D. h. Durdh Uumfdhließung und Bebadung für Den 2lufenthalt ober bie Sefchäfte ber Menifjen tauglidje Baumerfe, weldye einen Ertrag geben, Doẹr Deren Nuken wenigitens einem Er = trage gleid) zu act)ten ift. Man barf indeßs nid)t bie zufällige

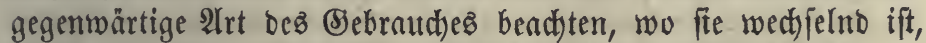
fonbern mur bie aus ber Bejhaffentyeit bez Bebäubez als

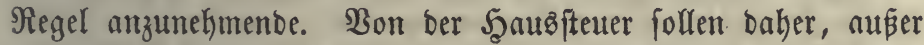
ben žum Stantżeigenthum gehörenden (B) bäuben, bie auz .einem allgentcincren Brunde (\$. 265) nidts belegt werben, aud) alle biejenigen Sebäute befreit bleiben, Die iffrer ganzen Einridftung ober ifrer bauernoen Beftimmung nad) nicht als (Erwerbsimittel

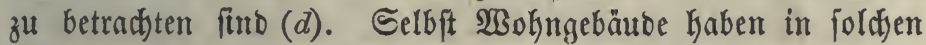

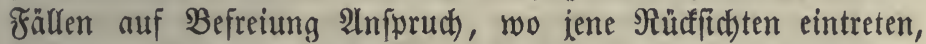
weld)e bie Schomung Dez Corporations: und Stiftungävermögenz gebieten, \$. 263. 264.

(a) Sine allgemeine Şaubiteuer in ifrer heutigen geregelten Einridtung ift von ziemlid) netrem uriprung. S̃n alten Seiten, als bie Şäujer now feinen \$reis Gatten uno feinetr Dietfyzins trugen, alio nut bas eigene Familienbebürfniß̄ befriedigten, fonnte man an teine Beffetterung berfelben

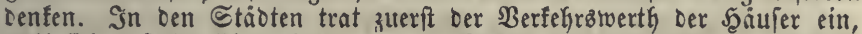
weil fich Dafelbft Sinwohner, bie zur Diethe wohnen musten, zahlecich einfanben. Die Sुaubfteuer twar in Den alten Beeben, Eanbifeuern,

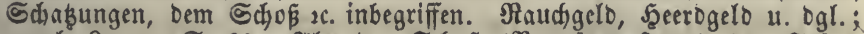

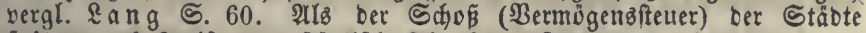

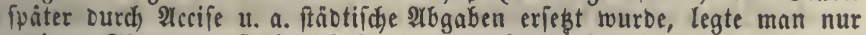
geringe Cteuern auf bie \$̧äufer, unb auf Dem \&anbe wurben biefelben

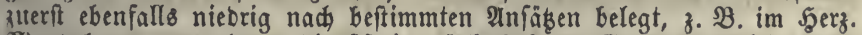
Diagoeburg von einem bienffreien Iderkof 16 Sgr. monatlic, von 


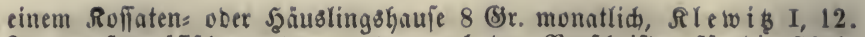
In Der franzoififhen taille wurben nah Den Boriduriften für bie Généralité von \$aris bon 1775 2Bohnhajujer in Stäbten zu $1 / 20$, alf cem Eance zu 1/40 Des Niethertrages befteuert. - Die Diferreidifdue Theres fianifae Steuerrectification (1750 fi.) gab oaв Beifpiel einer Befteue= rung Der Jäujer nad) ifrem Ertrage. v. Rremer II, 22. Linben I, 11. 2üd Die Jofephinifde Steuerberfafitung enthielt eine befontere

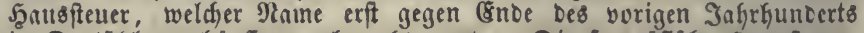
in Deutichlanc häufiger gebraudgt murbe. Die franziñiche Szatisfteuer, gleidszeitig mit oer (S)runoftetter angelegt, trug bei, zur Einführung jener शluflage aufzumuntern. - Der preusifde Etant hatte bisfer nod) feine allgemeine Şausfteuer. Die beiben weftlid)en \$rovinzen Gatten eine mit oer (Srunbiteuer verbunbene 5 ausfifterer, \$. $328(\mathrm{~g})$. In anderen Frovinzen beftanden veridjiedene stbgaben von ben Gebăuben. In

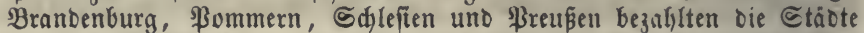
Den fog. Servis, D. i. eine urjprunglich. zur Bergutung oer Ein= quartierungslaft beftimmte 9 bgabe, Die aber aud yon Sänbereien, ge= wiffen (S)ewerben uno Beioloungen entrid)tet werben muste. (Er betrug (B. von 1810) in 3 Elaffen ber Str̈bte $25-18^{3} / 4$ unb $121 / 2$ Sgr. nuf ben Ropf ber (Sinwohner, bgl. \$. $358(d)$. Der gatze Belauf mit

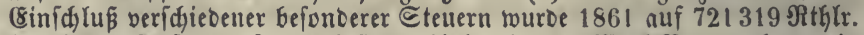
beredynet. Tuf Dem Lanbe beftano bisker in Der Darf Brandenburg ein

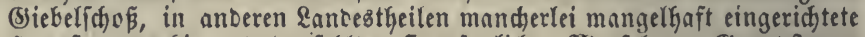

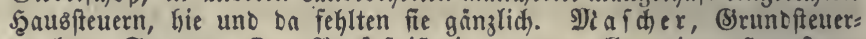

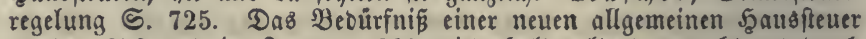
wurbe 1859 und im Jamuar 1860 wiederholt gelteno gemadst uno turdh Das Bejes vom 21. Daai 1861 if Dieje Gteuer angeorbnet worben. -

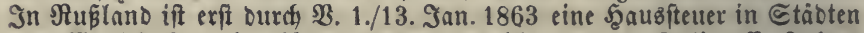

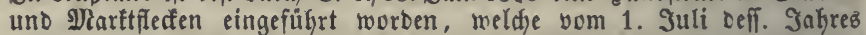
anfing. (S) leidyzeitig trat Die Ruffebung Der fäbtifdyen Ropfiteuer ein.

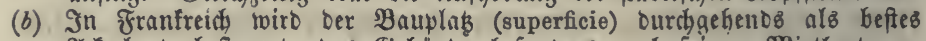
Piderland befteuert, Das Bebaube befonoers nad feinem Niethertrage,

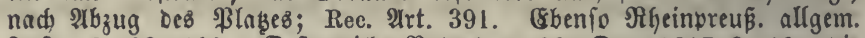
Inftr. §. 98. 100. Defterreid). Batent v. 23. Dec. 1817 \$. 13: Die

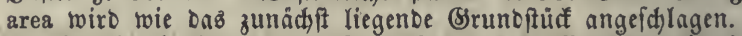

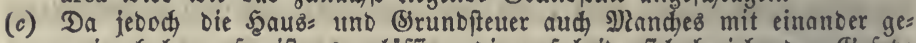
mein haben, fo ift es zulâfig, Die auf beibe fid) beziehenten (Sefę̧e uno Beroronungen zufammenzufügen, wie dieß̄ nach cem Borgange von Mailand in Franfreid), SRGeinpreupen, Sadhien 2c. geideken ift.

(d) Rirdjen, Shulbäujer, Armen=, Rrantentäufer, offentliche Sebäube für

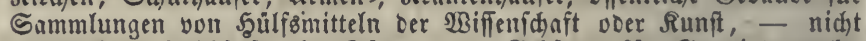

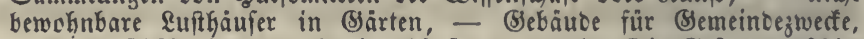

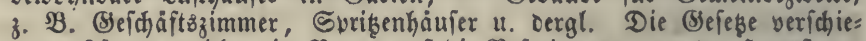

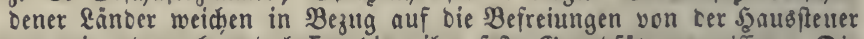
von einander ab unt lafien bismeilen fepte (S)rundäaze vermiñen. Die

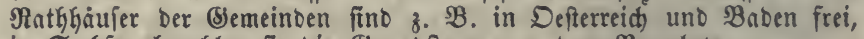
in Sadjen bezahlen fie die (S)runbiteuer von bem Bauplabe.

\section{§. 343.}

Bei Den fteuerpflidytigen Şäujern fino zunäd)ft bie $2 B \circ b n=$ unb (s) toerb gebäube zu unterfdeiben.

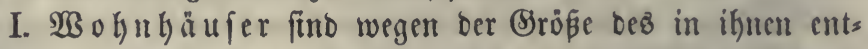
Galtenen rentetragenocn Bermögens cin einträglicher Gteuer= gegenftano, ben unan früher belegt bat, als man hierüber tiefer 
gehende Unterfuchungen anftellte. Die 3uläjfitgfeit biejer Steuer ift in bem Falle am einleuthtentften, wo cin Şaus ver= miethet wirb, beñn bann wirft eŝ einen Seldertrag $a b$, wel= d)er nad) 2 lbzug einiger Roften ein reines Einfommen übrig läpt. Dbid)on num im volfżwirthfichaftlichen Sinne mur bie Wohnungen herworbringender Arbeiter ein wahres Capital fint, welches zu ben Unterbaltämitteln gehört (I, \$. 126) uno fich) vor ben anderen Arten berjelben lebiglith ourch feine Dauer

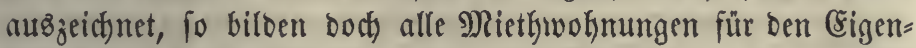
thümer ein werbendes Bermögen, aljo (Eapitale im privatwirth)= idfaftlicten Simne (I, \$. 223), beren Rente in Der Beitteuerung ber wabren Eapitalente völlig gleid) zu feben ift, \$. 261.

\section{§. 344 .}

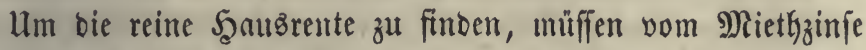
abgezogen werben (I, §. 224):

1) Die größeren 2lub̧befferungen, weldhe üblicher Weife oer Şauseigenthümer übernimmt und weldye nur im Ueberblicfe eines längeren 3eitraums beiläufig angeiđdlagen werben fönnen;

2) Die Berfitherungşfoften gegen Feuerżgefahr;

3) Die $\mathfrak{B e r g u ̈ t u n g ~ f u ̈ r ~ . ~ D i e ~ e n b l i c t e ~} \mathfrak{B e r t f g z z e r f t o ̈ r u n g ~}(a)$, beren (Sintreten je nact) bem 2llter bez (Sebäubes uno feiner Bauart früber ober fpäter zu erwarten ift.

Der (Sebrauch $b=$ unb aud) Der Berfehrsinerth eines (Sebäubes nimmt unter $\mathfrak{t}$ brigens gleiçen Umftänben jährlid $a b$, fowie Der Beitpunct näker rüdt, wo bafielbe ganz unbrautboar wirb. Dod) wirfen bie 3unahute bes $\mathfrak{B}$ egefrs und bas Steigen ber Baufoften, hauptfächlid) burd) Bertheuerung ber Bauftoffe uno

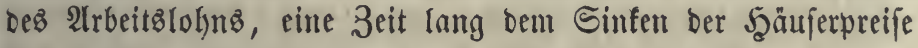
fo mädtig eutgegen, oaß̧ biefe anfangż anjefnlich zu fteigen pflegen, bis ber ftärfere Berfall eines Şaufes uno bie bayon

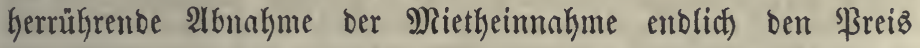
unaufbaltfam verringert $(b)$. Wrivatperionen madben fid zwar beim Raufen und Bermiethen von Şäufern biefe Zahlenverbält= niffe oft nidft genug beutlid) und legen nud) feine Summe für oen fünftigen Reubau zurüd $(c)$, bie Berechtigfeit forbert jebod) bie Berüdfidftigung biefer bejdräntten Dauer, wie aud) in ber

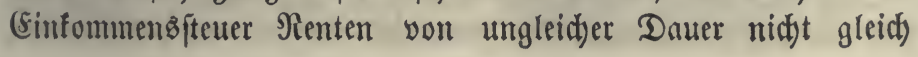


befteutert werben. In ber Mietheinnahme bes (Sigenthümers mus neben bem (Erjab ber unter 1) uno 2) angefüḩrten Roften unb bem eigentliden Binfe auth) einiger Eapitalerfaks (Tilgungszs betrag) angenontmen werben, ber nidjt wahres (Einfommen ift. Defiglb burfen neue uno alte, mafítive und leidter gebaute Şäufer, auth wenn fie gleidje Miethe eintragen, bodt in ber Befteuerung einanber nidjt gleid) geicht werben. Um bie bie= Durd) begrünbete (Ermäßigung zu bered)nen, famm man ben nad)

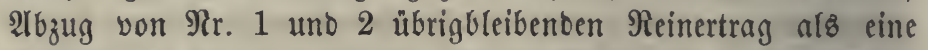
3eitrente anjeken uno beren iesigen 2 Serth im 3eitpuncte ber meuen Anlegung biefer Stcuer zum Steueranidhlage nethen, ober, was zu bem nämliçen (Ergebni die Reubaurente (Reäbificationsbetrag) abzieken, ๖. h. Die jährlidłe Znhlung, die mit Zins und Zinfeszins wăhreno ber ganzen Dauerzeit einez gewiffen Sebäubez zu Dem Betrage ber Ertbaumtgeffoften anwäctjt, II, \$. 70 a (c). Da bie Erneuerung ober mejentlidje Beränberung eines̊ gauzen Şaujes obnethin eine neue Beftimmung bes 2lnifthlages erforbert, fo

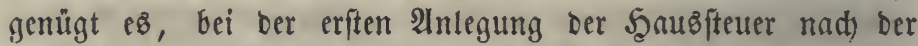
jekzigen Bejdyaffenteit uno ber mutthmaflidjen Dauer ber (Se)= bảube etwa orei, 子. B. furze bis angefähr 50 jährige, längere $50=$ bis 100jährige, und nod) längere Dauer, zu unterid)ciben, unb für jebe einen beftimmten, von ber Miethe abzuziet)enden Reäbiffcationsbetrag anzunefymen $(d)$. Rad) ber 2lnleitung eines beigezogenen Baumeifters wirb es ben Schäbern nidjt fdher fallen, bie vorhanbenen Bebäube in bieje brei Claffen einzu= reiken $(e)$. Sngogentein hat man für alle Şäufer einen gleid)=

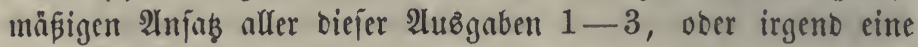
gleiche Berůdfictitigung berfelben angerwentet $(f)$;

4) bie auf einem Scmufe ruthenten Reallaften $(g)$.

(a) Defterreid. ßutent y. 23. Dec. 1817 §. 6: Bom Niethertrage foll ein Abfhlag vorgenommen werden für bie unterkaltungsfoften und für ben im Berlaufe einer beftimmten Beit ganz ober zum Theil zu (S)runde gehenden Capitalwerth.

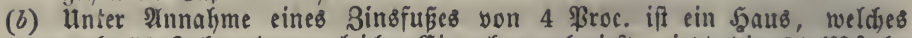

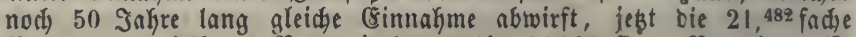

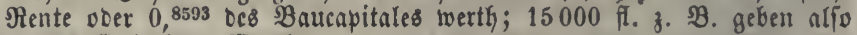
12889 fl. jebigen $\mathfrak{W}_{\mathrm{B}} \mathrm{erth}$.

(c) Der Räufer bietet für ein fefter gebautes Şaus fdjon Darum mefor, als für ein minber bauerhaftes, weil jenes mefir פliethe eintrigt unb geringere Unterkaltungsfoften verurjadyt, aber er follte audy bedenfen, 
Daß́ von bem vergänglidjeren Bebåube bei gleichem arter ichon ein

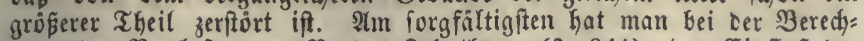
nung ber $\mathfrak{B a u l a f t e n , ~ z . ~} \mathfrak{B}$. Des 3ehntherrn (\$. 341), ben Einflús ber

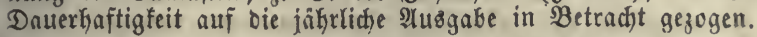

(d) Die 3eitrente, welche nit 3ins und Binleszins ons exforterliche Reu=

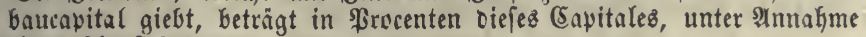
cines 3inв

\begin{tabular}{|c|c|c|c|c|c|c|c|}
\hline & \multicolumn{2}{|c|}{2 Broc. } & \\
\hline 12 & fâlyriger & Dauex & 3 & $\Re r$ & 2,6 & Broc & $2,^{3}$ Proc. \\
\hline & ( & & 1,1 & . & 0,86 & $"$ & $0,63 \quad$ " \\
\hline 75 & $n$ & & 0,7 & 5 & 0,35 & $"$ & 0,21 \\
\hline 100 & & & 0,3 & & 0,16 & $"$ & 0,07 \\
\hline
\end{tabular}

Wollte mau, "mit v. ร̈af ob (I, §. 625), feine "3injen einrectynen, io

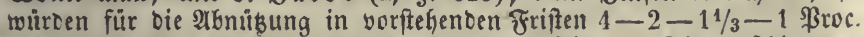
Des (Sapitales vom Siethertrage abzuziefien fein. - Die verfoiedenen

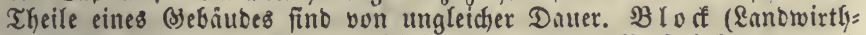

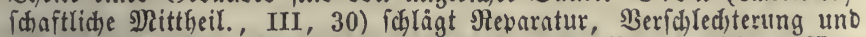

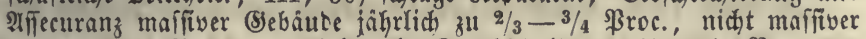
fu $12 / 3-21 / 3$ \$roc., uno beicer im Durdyfdutt fu $1 \frac{1}{6}-11 / 2$ \$roc. an.

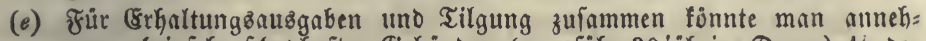
men: bei fehr fdyobaften Bebäuben (ungefähr 30 jährige Dauer) $1 / 2$ Der Ditethe, bei beffer erhaltenen (ungefähr 75 jährige Dauer) $1 / 5$ Der פiethe, bei gutbeichaffenen $1 / 10-1 / 12$ berfelben.

(f) In Der florentiniftueu decima yon 1494 (\$. 402) wutrben 10 \$roc. Des Diethertrages abgezogen, Della decima I, 37. - In Franfreich (Rec. 2irt. 392) wird yon ber Mitetfe $1 / 4$ abgezogen, wie fifon feit 1775 in oer taille personnelle, - nach Dem preup. Srunbftettergefes für bie

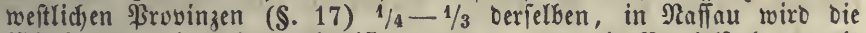
Stiethe nur mit $14^{2} / 7$ capitalifirt, twas, gegen bie Bervielfadjung mit 20 gehalten, einem $\mathfrak{A b}$ zuge von 28 ßroe. gleidfommt. - Nach Dem toefter̂l. (S)efés ertrages abgezogen werbent. - In Miailano $30 \mathrm{~g}$ man $1 / 8 a b$, aber zu= gleid Darum, weil Die Scâluer fpater fataftrirt wurben uno fonft gegen bie Rambereien zu how gejdäbt worben wärell. - In Defterreich ift

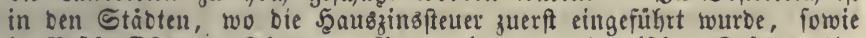

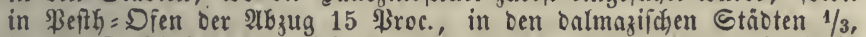
in ben Drtfijaften, wo biefe Steuer 1849 angeoronet wurbe, fowie in ungarn und Giebenbürgen nach ben (Befesen bon 1850 , beträgt ber 2HEjug 30 ßroc., in Salzburg fällt ex hinweg. Tafeln 2 . 1858, S. XXXIV. - Reues ("ftabiles") Ratafter Der lombarbifi = venezia= niijden Srovinzell, wo oas alte censimento nidht beftefit: in ben Stäbten werden 20-30 IBroc. bes \$Niethertragez abgezogen, und zwar Defto mehr, je geringer bas Ertrōgnís nach Der Lage ift, in Flecfen uno gröseren Dơrfern $30-35$, in fleinen Dỏrfern uno bei zerftreuten

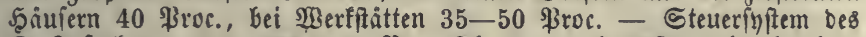

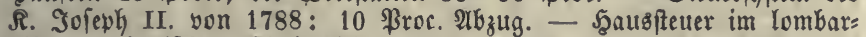

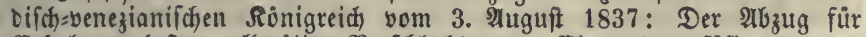
E\&rfaltungefoften, allmálige Berfdhled)terung, Elementarunfälle und aus

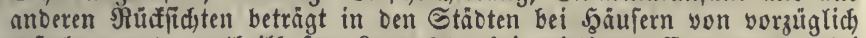
gefudyter uno vortheilhafter Rage 20, bei mittlereul Ertrage 25, bei geringerem 30 \$roc. Des abgeidiąten Niethertrages, in Flecfen unb Dorfern 30, 35 und 40 ßroc., bet $\mathfrak{W e r f i t a t t e n ~} 35-50$ ßruc. - Ent= wourf von 1863: in 3 Slañen ber Drtfdaften, je nachoem oie burds= id)nittliche DRiethe eines (Sebaubebefandtheils is fi. ober mehr, über 5 fi. bis an 15 f., utiter 5 ff. betriggt, 20, 25 und 30 Proc. ber

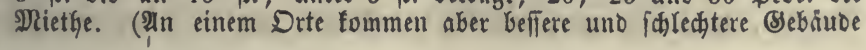


vor, worauf bei biefer Beftimmung nidjt gendtet werten fann.) -

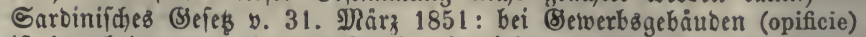
ift $1 / 3$, bei anberen $1 / 4$ ber Dlietge abzuziefyen. - Sadjen: ber शbzug für Unterfyaltung uno aflmálige Beridblechterung beträgt in 18 शื = ftufungen von $1-300 \mathrm{rl}$., in feinem Falle aber über Die Şálfte cer

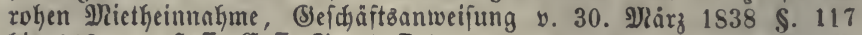

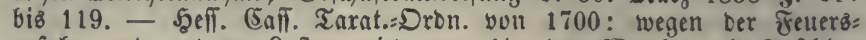

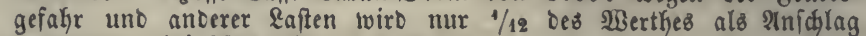
genommen, bei \&änbereien $1 / 4$ befielben.

(g) Die bab. Şñuferfeueroron. \$. 7 verbot ben शbzug von Gülten, Sinien

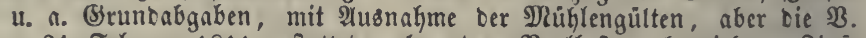
v. 21. Februar 1811 geftattet aud andere Reallaften abzuziefen. Sinie werben mit bem 20:, Erbpadstrabgaben mit bem 25 fadjen setrage vom Gteuercavitale abgezogen.

\section{ร. 345 .}

Sn ber nad) biefen 2) rente fino ztwei Theile zu unterjdeiben $(a)$, nämlid) 1) ber 3inzి Des auf Den $\mathfrak{B} a$ uerwenbeten (5apitals ober Des bei eincm älteren, verid)led)terten Şaufe nod) vorhanbenen Theiles Deffelben,

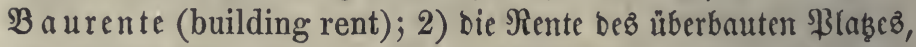
eine wahre (5) runbrente, die aub ben Preijen ber nod) Iceren Baupläßze.zu erfennen ift $(b)$. 3wifden biefen beiben Beftand $=$ theilen findet eine erfyeblicke $\mathfrak{B e r f d j e b e n b e i t ~ f t a t t . ~ D i e ~ B a u t = ~}$ rente ift gleidförmiger, weil man fid) zul neuen Bauten nur Dann entidyließst, wenn ber Miethertrag nad) 2lbug ber Rente

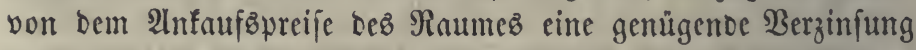
veripricht. Die Srunbrente ift veränberlicher, weil ber von ber

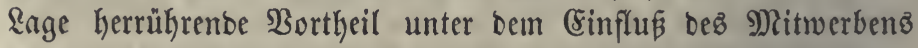
höher ober nicbriger bezahlt wirb. Bei zerftreuten $\mathfrak{W}$ ohnungen ift bie Rage insigemein nidyt von foldyer $\mathfrak{B}$ idftigfeit, baß ein

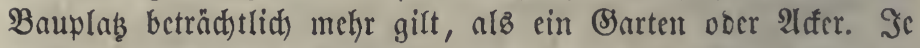

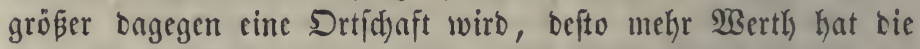
Lage eines SHabes im đdönften ober lebhafteften Theile; Die Miethe 1:no ber \$rciz ber Scäufer fönnen hier fehr fteigen uno Diefer Miehrbetrag (I, \$. $329($ a) ) brütt ftd) in eimer hohen

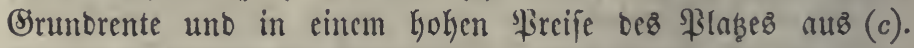
Ein verringerter $\mathfrak{B e g e h r}$ ober cin übergroßę 2lngebot von Bohmungen erniebrigt ben Sreis ber Şäufer, aber aud ber Baupläkse. Céne 3eit lang fönnten jovar Die Rauppreife und Miethen ber Şäujer fo nicbrig fein, Daß̧ fie aud) bie Baurente nid)t mekr vollftändig vergüten, aflein bieß wärbe von neuen Bauten, ja jogar von ber Bieberkerftellung bcjecäbigter Şäufer 
abłalten, und es gejören außerorbentlidje Uumfänbe bazu, menn Diefer Stant ber \$reife yon längerer Dauer fein foll $(d)$.

(a) 2. Smith III, 239 (IV, 189 Baf.). Ricardo, (5ap. 14, folgt Smith in tiefem Begenfande. - Sn England fint oft Srundeigner und Baukerr zweierlei Perionen, und bas Şaus fălnt naw getwiffer 3eit bem Srumbeigner ankeim.

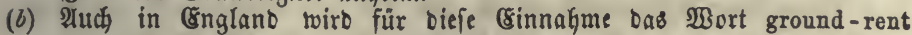

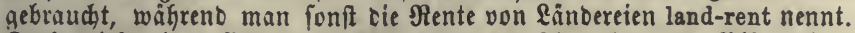

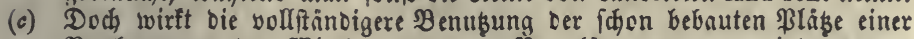
Bertheuerung ber Niethen uno ber Siaupläbe entgegen, inbem man

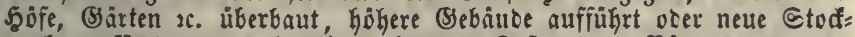
werfe auffest, woourd mit geringeren Soften neue Raume getwonnen werben, oa man \$lą̧fauf, Fumbament, Seller und Bebacjung $x$. exipart.

(d) Sn alten, feh̆r gejunfenen Stäbten, z. B. Benebig, finb foldhe Bets hẩttnifie möglida.

§. 346.

Eine neue auf bie Şausieigentfümer gelegte Steuer $(a)$ muß zunñafft aus ber Şausirente beftritten werben, weil bas Angebot von $\mathfrak{W}$ ohnungen nicft verringert und aljo bie 2luflnge nidft auf bie Miethberwohner überwälzt werben faun. Die Rente uno Der ßreiz ber Baupläze werben bieburd) herabgebrůdt. So lange aber biefe noch fo viel eintragen, als etwa 2lder = ober (5)artenland gleidjer 2Irt, und bas Baucapital baneben fid ver= zinjet, fo fann man nod) ohne Berluft neue Bauten vornchmen, um bem jeocżmaligen Begehr von 2 Bohnungen zu entipred)en.

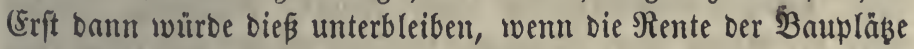
unter jenes Maá̉ Gerabjänte uno bie Baurente fo gering würbe, oaßs man bie Euft berlöre, Eapitale nuf foftbare Ausbefferungen,

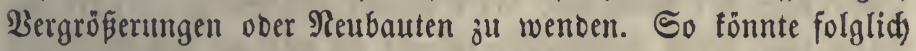
eine fehr hohe Şausffteuer bie Ueberwälzung auf bie Miethleute bewirfen, ieboch erif nad) langer 3eit, unt wenn nidst in ber

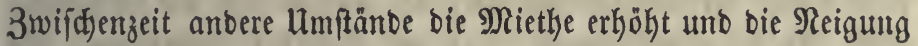
zum Bauen wieber belebt haben. 2luf bem \&nnbe, wo bie

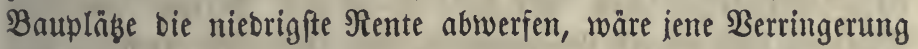
Derfelben unter bie Rente von Bartenland am leidjteften mög= lid, bier aber fommen überhaupt wenige Miethen vor, benn

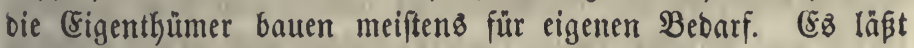

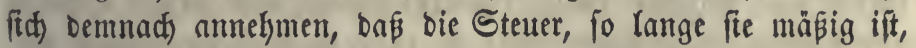
von ben Şauвeigenthưmern getragen werben เmuß

(a) Die englifde Şausftuer, von weldyer Smith unt $\Re$ icarb o fpredien, wurbe yon ben 5ausbewnhnern entridtet. Bee ifgr if eine Meberwálzung

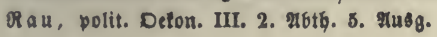


nur in foferne moglid, als ein Theil ber शRiether, um nidgt mefr im

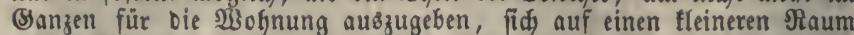
befdjränfen, fowie auds Die Eigenthümer aus bemfelben (Srunte mehr Sgutstheile zu vermiethen fudjen und auf biefe Weife ein Sinfen Der

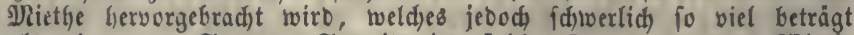
als bie ganze Stetter. Sotweit eine foldhe Steuer won Den Nieth= bewoknerit getragen wirb, hat fie, wie $\mathbf{S}$ mith ridgtig bemerft, bie Ratur eituer Stufwanosfteuer, $\$ .426$.

\section{§. 347.}

Ein vom Cigenthumer felbit bewohntes Sุa (\$. 343) giebt fein Csinfommen, fonbern eripart mur eine 2 tubs= gabe und zeigt einen (Sebraudbrwerth $(a)$. Es ift baher ber 3weifel entftanden, ob in biefem Falle eine Sdyaß̧ung gerecht= fertigt fei (b), ober ob nidyt mit gleidjem Rect)te aud anbere

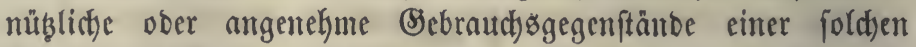
Steuer unterworfen werben bürften. Man fann zwar nidft jeben Theil Dez Beftzez barum, weil er bem Eigenthüner eine 9)ieth= auछggabe erfpart, einer (sinnafme gleid) adten, allein bei Scău= jern ift bieß̧ zuläfifig. Denn 1) ift 2 oljnung ein allgemeineb,

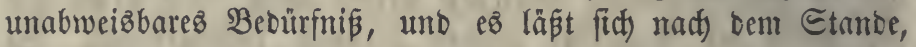
(5)ẹdäfte uno Familienverbältniffe eincs Seben ein gewiffes

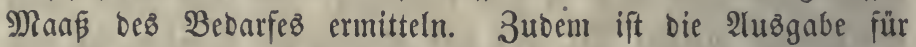
Die Mietfyohnung fehr beträd)tlid), Da fie nady ben umftänoen oft ben adten, fedfiten und felbit eitren nod) größeren Theil vom Durd)fdnittseinfommen einer Familie auszmadt. Daber wirb ber Senuß einer $\mathfrak{W}$ olynung üblidyer Weije in verjdiebenen Fällen einem gewiffen (Einfommen gleid)gefebzt, z. B̉. bei Dienft: wohmungen ber Beamten, bei Siewerbägehülfen 2c. 2) In ber

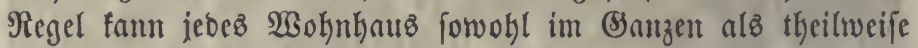
zum Bermiethen benubst werben. Bei ber eigenen Bewofunng

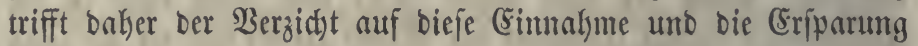

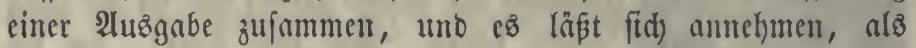
jeien $\mathfrak{B e r m i e t h e r ~ u n o ~ M i e t h e r ~ i n ~ c i n e r ~ ß e r j o n ~ v e r e i n i g t . ~}$ Dagegen finto andere Senußmittel, wie Semälde, foptbare (Be= räthe 1t. Dglo, entbehrlich), fo baß fein Beoarf oerjelben angegeben werben fann, fie fint meiftenz nidjt leid)t vermiethbar, größten= theils von firzzerer Dauer, minoer foftbar und zubem nicht fo

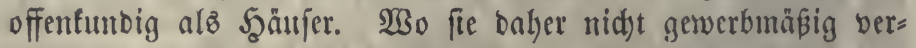
miethet werben, weldjez bann unter bie Serwerbfteler fällt, oa

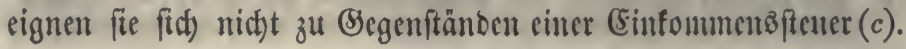


(a) Nur Dann fönnte man bas Segentheil befaupten, wenn man aud ben perfönlidjen Bortheil Des (s)ütergebrauches zu bem (sinfommen rechnen

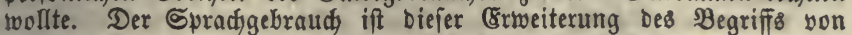
Sinfummen, revenu, reditus, nidt güntig; aber felbft wenn man ihn

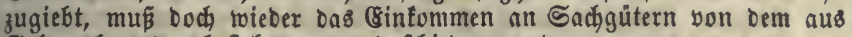
(sebraudisnuben beftekencen unterjdjieben werben.

(b) Diefer Anficht ift $\mathbb{L}_{\mathbb{B}} \mathrm{g}$ III, 315 , welder bie vom Eigenthümer benubsten

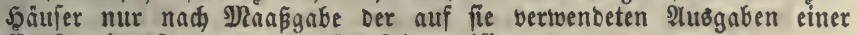
(Sonjumtionsifteuer unterworfen jeken will.

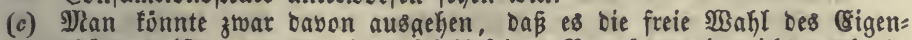
thümers iff, wenn er einen Theil feines Sermögens in nidht werbenbe (S)iter (bauernbe Benusmittel) verwendet unb auf Den Errtrag berzichtet, ten fonft biefe (s)ittermenge abtoerfen würbe, unb Diés würbe zu einer allgemeinen $\mathfrak{B e r m o ̈ g e n s f t e u e r ~ f u ̈ b r e n ~}(\$ .402)$, allein gegen Diefe furechen erkeblidge Erründe, \$. 403.

\section{§. 348 .}

Die von ben Eigenthümern benüksten $\mathfrak{W}$ ohnungen Dürfen jeboch nicht in allen Fällen ganz fo wie bie vermietheten behan= oelt werben, weil ber (Sigenthümer nicht überall uno bei jebem Theile feines Şaufez bie freie $\mathfrak{B a h l}$ hat, ihn zu vermiethen ober felbft zu gebrauchen. Bei zerftreuten Şöfen fällt bie (5)elegenkeit zum Bermiethen meiftens hinweg. In Dörfern

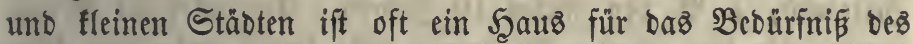
Befitzers zu großß, faun aber nidjt bermiethet werben, weil es an ßerfonen fehlt, bie eine Miethwohnung yon ber gegebenen Befd)affenkeit fuchen und bein Eigentfümer in Şinftcht auf bie nöthige Sidherkeit uno Sdjonung bes Bebåubes zujagen. Dießs tritt z. B. bei ๔allöfīern, Bfarrbăujern u. bgl. hăufig ein, aud ift bas Beburnfnis einer fhonenben Belegung foldher 2 ohn=

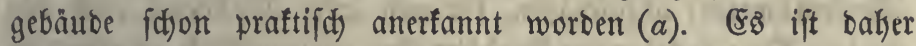

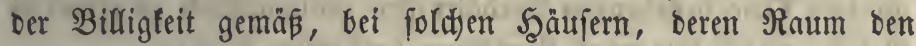
mittleren WofnungBbebarf einer Familie übertrifft, ben Steuer= anjhlag verbåltnißmåkig zu verringern, woferne ber Crigen= thumer barauf Amprud madt. Die Sdwierigfeit ber 2 La: $=$

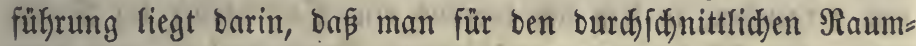
beonrf einer Familie feinen feften Maaßfitab befigt und baker

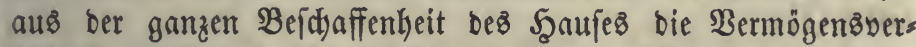

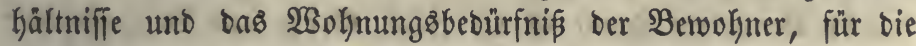
esీ fitc) eignet, abnehmen mus.

(a) Nailand: Wobkngebäube auf bem Lanbe, bie ber đigenthümer felbft benukgt, fino nur nach Dem Bauplake zu beffeuern, ber wie bas benach=

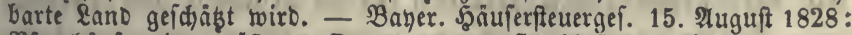
Pfarrhāufer in grökeren Drten, wenn fie bloß̉ zur 230 hnung bes 
Sfarrers verwenbet werben, follen nur nad, Dem Rußen bemeffen wer: Den, Den fie in Diefer Şinfidt geben, \$. 17. \$farrbăujer und nidt vermiethete Sdbloffer auf Dem Lanbe gehoren unter Die (Sebäube, toeldye

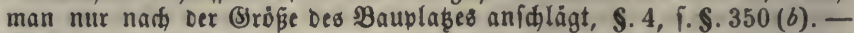

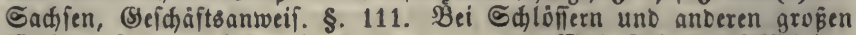
Wohngebảuben auf bem \&ante werben nur 10 S3ohnfuben berúdfidgtigt, falls nidgt zur Bermiethung ober anberweitigen $\mathfrak{B}$ enusung ber übrigen

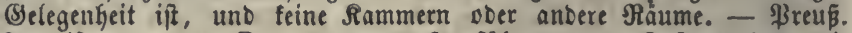

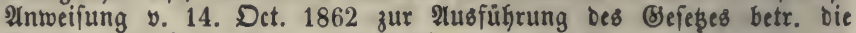
(Sinfükrung einer allgem. (Sebaubefteuer v. 21. \$lai 1861 \$. 46: fưr

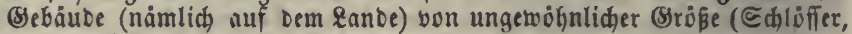

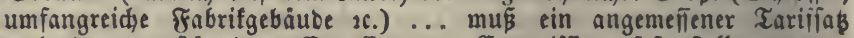
nach bem verftänoigen (Ermefien ber Commiffion feftgeftelft werben, wobei auf bie gröpere ober geringere Pusbehnung, in meldjer cas

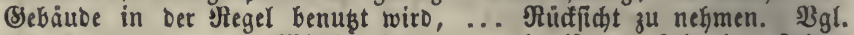

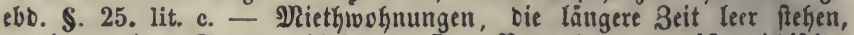

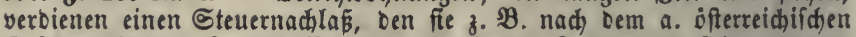
(5efeßse erbalten, f. aud Berbandl. Der bayer. Rammer ber \&bgeoroneten 1834 X, 359. Beil. V, 259. - Unbewshnte Ruitgebrube follten bló̧ nach bem Bauplabe befteuert werten.

\section{§. 349 .}

Unter bie äuferen Şůlfömittel zur 2Inlegung ber Şaub̧fteuer gehören bor allen bie Mitethzinfe aus eitrem nicht langen 3eitraum, z. B. Den leşten 10 Jahren. Die wirflicte Mieth= fumme für iebe einzelue $\mathfrak{W}$ ohnung fteht jeboch) unter bem (Ein= fluß zแfälliger Umfände bes 2Nitwerbenz, ift oft nid)t genau 孔u ermitteln, z. $\mathfrak{B}$. wegen verwifelter $\mathfrak{B}$ ertraggbebingungen, uno ein groper Theil ber $\mathfrak{B o h n u n g e n ~ i f t ~ n i d f t ~ v e r m i e t h e t . ~ ( E ) ~ i f t ~}$ Daker beffer, auf bem (Srunbe einer Ginreid)enden $2(u z a k l$ ficherer Angaben über virflicte $\mathfrak{B e r m i e t h u n g e n ~ o e n ~ m i t t l e r e n ~ S r e i s ~}$ (Berfehrswerth) abzujdäzen, ber von jeoer $\mathfrak{B o h m u n g ~ n a d ) ~ b e n ~}$ an bem Drte beftehenden $\mathfrak{B e r h a ̈ l t n i f f e n ~ m u t h m a ß ̧ l i c h ~ z u ~ e r w a r t e n ~}$ ift (a), wobei folgendes Berfahren beobadjtet wirb:

1) Die an jebem Drte in einem gewiffen 3eitraume wirf: (id) entridteten Miethzinje vieler $\mathfrak{B o h n u n g e n ~ m e r b e n ~ e r f u n b e t ~}$ und vergliden, fo Daß firty hieraus eine Etufenleiter ber פieth= preife für $\mathfrak{B o h m u n g e n ~ v e r i d b i e b e n e r ~ B e f d a f f e n t e i t ~ u n d ~ \& a g e ~}$ billoet $(b)$.

2) Bei jebem Şauje ift bie 3ahl, Srröße uno Bejđaffenkeit forobyl ber bewohnbaren, als Der anberen zugeförigen Räume, 8. B. Reller, Stall, ferner Die Rage in Bezug auf Innchmlid)= feit ober gewerblid)en Bortheil (c) zu beachten und barnach ber jener Stufenleiter entiprechenbe mittlere Miethertrag ju bemeffen. 
Der 3uftand berienigen Theile, welde bald verid)ledtert werben (Tapeten, 2inftrid) 2c.), ferner Berzierungen und Beftanotheile von inbivibuelfem 2 erth fommen nid)t in Betradt.

3) Sodann ift für jebes (Sebäube ober jebe Claffe ber

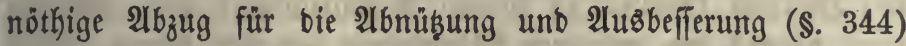
forwie für bie Sthwierigfeit bes Bermiethens (\$. 348) vor= zunehmen.

(a) Nał ber Thereftanifhen Steuerregulirung (1748-56 ausgeführt) wurben

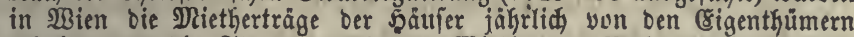
erhoben und bie Eteuer war $1 / 7$ ber Diethe. - Nad Dem \$atent bes Saifers \ofeph von 1788 wurben burchgängig bie Mietfzinfe zu Brunbe gelegt, auch bie mailänbifase 5 gaubffeuter folgt bem wirflichen Mieth= ertrage. Derfelbe (Srunofab ift für bie Difterreichifdje Definitive (S) runb: fleter, weldhe die (Sebảube mit umfant (Eoist von 1817 \&. 5. 13) auf=

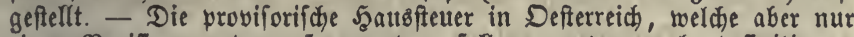
einer शevifisn unterworfen werben foll, um Dann als befinitio zu gelten (angef. Sefebs v. 1. Märs 1820, Inftruct. v. 26. Suni 1820), wiro in ben größeren Stäbten nach ber vom Eigenthümer ganz aus = führlich angegebenen, yon ben Niethleuten beftätigten unb amtlia

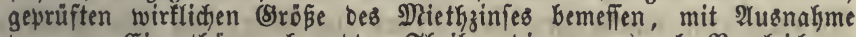
ber vom Ëigenthümer benubten Theile, bie man burd Bergleidjung

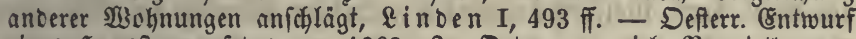
eines 5̧ausfeuergefeses von 1863: In Drten, two viele Bermiethungen vorfonmen, wirt alfe orei Jahre ber vom Eigenthümer anzugebende Iniethertrag bes vorausgegangenen Iahyes zu Srunbe gelegt. - In Franfreidy Dagegen wirb bie mittlere Diethe (valeur locative) zu (Srunbe

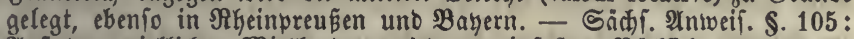
Tuf ben wirfliden Miethertrag twirb nur infofern SRüfifidt genommen, als er einiges श̂nfyalten für bie wirfliche ober mögliche Mliethertrags: fáfigfeit giebt uno Daraus ber mittlere sliethertrag ober Der Durd, idnitt aus ben wirflich bezogenen Niethen Kervorgeht. - Sarbinifhes

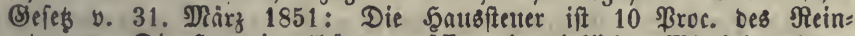
ertrages. Die Şaubigenthümer müffen bie wirffichen \$ietheinnahmen mit Borlegung Der Diiethyerträge ober bie nath ber Inalogie ber ver:

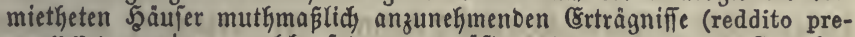
sumibile) anzeigen, welde fobann geprüft werben. Ungenaue Angaben ber Driethfumme ziehen Strafe nad) fid, und felbft bei bem Inichlag

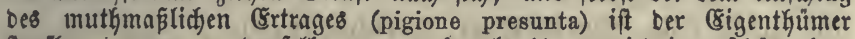
frafbar, wenn er benfelben um mefir alb $1 / 4$ zu niebrig gefdäbt bat,

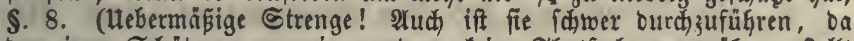
ber einen Sdbagung nur eine anbere, feine Thatfadje gegenüber geftellt merden fann.)

(b) Franfreich, Rec. भ(rt. 536. - Banern, angef. (Sef. v. 15. 2ug. 1828,

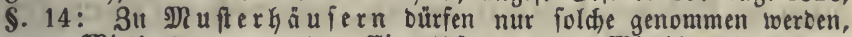
Deren Diethertrag von ben Eigenthümern uno Miethbewofnern an= gegeben und von ben Shäbern allerfannt, auch yon ben fämmtliden Saubeigenthümern nidat befritten worben ift.

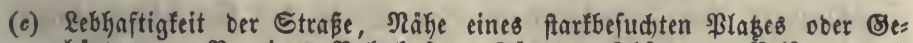

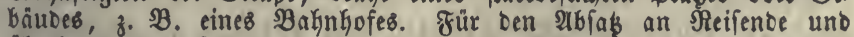
liberfaupt yon \&uxusgegenfänben Gat bie Rage in einer Sauptifrafse einen groß̈en $\mathfrak{B o r}$ ug. 
S. 350 .

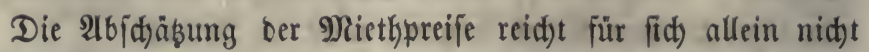
bin, benn an fleinen Drten uno bejonbers bei zerftreut liegen= Den Şäufern fommen zu wenige Bermiethungen vor, nlä onß man Daraut ben mittleren Mietkertrag bemefîen tönnte. Will man aljo einen zur Befteuerung bienenben 2lnjfhlag von bem

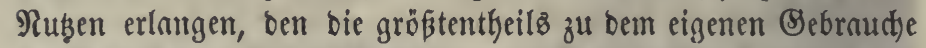

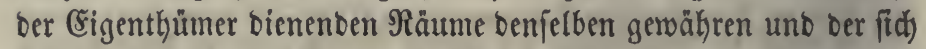

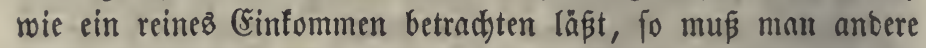
Bege einjajlagen. Man hat mehrere berielben verfuctit, um für

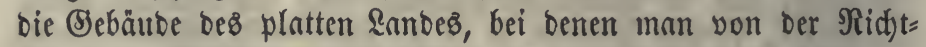

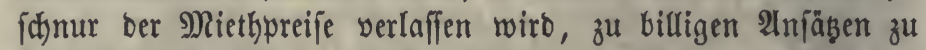
gelangen. Beifpiele foldjer Rataftrirungsిmittel, benen allen jebod) nidjt unerkeblidfe Bebenfen entgegenftethen, fint:

1) Eine Claffeneinttyeilung nad) ber $\mathfrak{2} \mathfrak{n} z$ ahl ber benusten

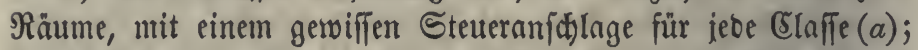
ein $\mathfrak{B} e r f a h r e n$, weldjez bei einem niebrigen $\mathfrak{B} e t r n g e$ ber Sdjaķungen fid) wenigftens burd) feine (Einfadbeit empfiehlt;

2) bie Beranidhlagung nach bem blopen Bauplakge, alfo

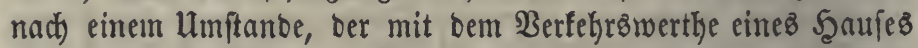

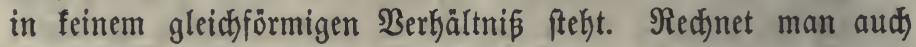

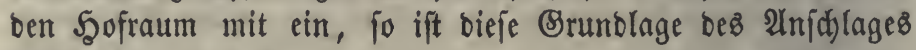
vollenbos zufällig (b).

3) 2lud) bie Auffetllung eines nad) bem Bauplak̨e bemefife: nen Minimum fann Gieker geredynet werben, inbem fie eine

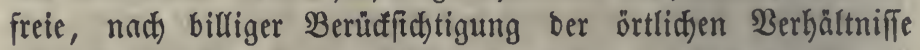
verfakrende Sdäß̨ung yorauş fę̧t uno berjelben nur eine Sdjranfe, uno zwar eine fehr niebrige, yoridjreibt (c).

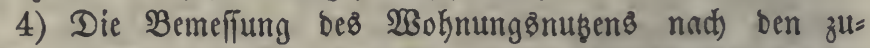

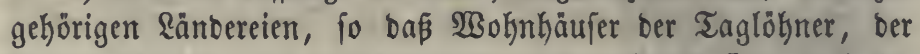
fleinen Bauern, ber mittleren und großen (S)utaberiber nach bes fitimmten $2 \mathfrak{n}$ [äß̨en befteuert werben, bod) nod) mit einem gerwiffen Spielraum nach Sröpe uno Beictaffenheit. (58 ift unvermeibs

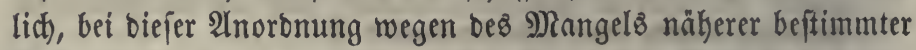
Stüłpuncte ben Taratoren in ber $\mathfrak{B a h l}$ ber 2 nnjoläge inner= halb ber vorgezeidjneten Sränzen viel Freiłheit zu geftatten, wos bei eine sprüfung unt Beridftigung idjwer ift $(d)$. 


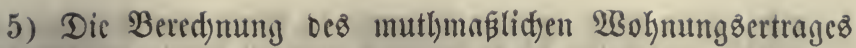
Der Şäufer nad) verichiebenen (Elaffen ber Srtidyaften und nad) Der 3 ahl uno Beichaffenkeit ber zugehörigen $\mathfrak{B}$ ohnräume (Зim= mer, Rammern), in Semäßheit gewiffer Stufenfätze (e).

2lu beften wirb bie Unzulänglidffeit ober ber gänzlid)e Mautgel ber Mietherträge ergänzt, wemu man zugleich bie Rauf= preije in Betradyt zieht (\$.351), wobutrd) aud) für bie nöthigen 2lbzüge (\$.344) ein guter Stübpunct gewonmen 1viro.

(a) Deferreid. Snftruction yon 1820, bei \&iи oen I, 524, y. Sxemer II, 138, de Tegoborski I, 176. In ben altüfterreidjif

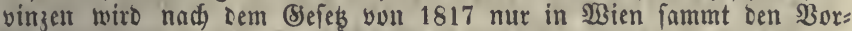
fitoten und umliegenden Ditfáaften und in 16 anderen Stäbten Die

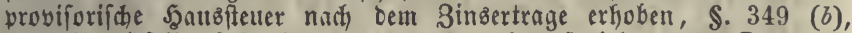
bodh if biefelbe fpäterfin (1849.50) aud) auf viele anbere Drte aus= gebefint worben. Für bie übrigen Drte find 12 Claffen mit einem Eteuerbetrage von $40 \mathrm{fr}$. biz $60 \mathrm{fl}$. (anfänglid) nur halb fo hoch)

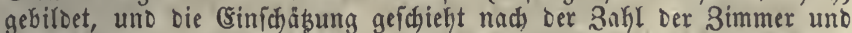

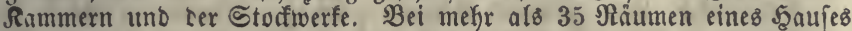
mird für ie 5 berfelben ein 3uffhlag yon 2 ober 1 fl. zu bem Sabe ber 1. Crafife gemacht, je nadjoem bas Jaaus ein Stoffwerf bat ooer niđłt. Sn ben vier grốzeren Stäoten yon Dalmatien findet eine 5jährige Sinsfatirung ftatt. Sm ganzen Difterreid. Staate mit 2usznafme von Tirol, Der Rombarbei uno Benedig trug 1857 die gefammte Steuer nad) bem

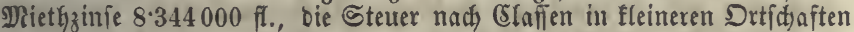
3.353000 fl. Die Sausfteuer madyt auf Den Sippf ber (Sinwohner in Siebenbürgen $53 / 4$, Der $\mathfrak{B}$ diwobichaft $6^{3} / 4$, Ungarn $10^{1} / 4$, Dalmatien 12,

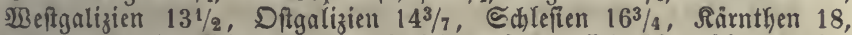

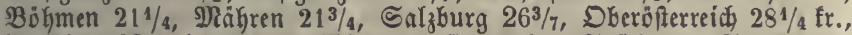

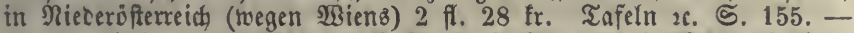
Da in mittleren uno fleineren Stãoten bie lage bes Saaujes nody einen

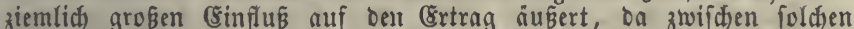
Drten uno Dörfern nod ein merflicher unterfichieo frattfindet, auch oie

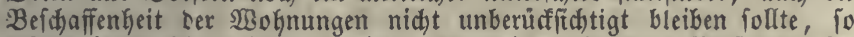

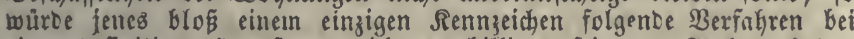
einer befinitiven Şausfteuer nidjt zu billigen fein. - 2ud nady ben franzöfifichen und rheimpreusifchen Steuergejesen foll $b a$, wo man nidht

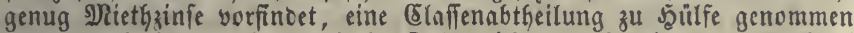
werben, Die jebod nidjt, wie in Defterreid, an ein einzelnes Nierfmal fid anlefint.

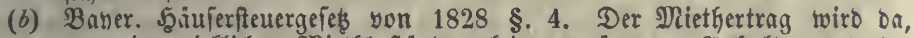

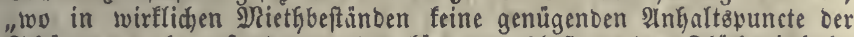
"Ed)äkung mehr gefunden werben tỏnnen", bloß aus bem Flädeningalte

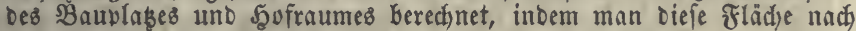
ber 30. Bobenclaffe anjchlägt. Dieß̃ gäbe fủr Den \$lorgen einen Ërtrag yon $30 / 8$ Sdheffel $\Re$ oggen ober 30 fi., alio ein Simplum von $30 \mathrm{fr}$. Die beioen Flädjen zufammen follen aber nidjt unter $1 / 10$ uno nidht über $3 / 4$ शlorgen angeiebt werbert, $D$. K. Das Simplum foll zwifhen 3 uno $22 \frac{1}{2} \mathrm{fr}$. Fallen. (5ुiecurch) wirb eine Sd)ägung exforderlich), für

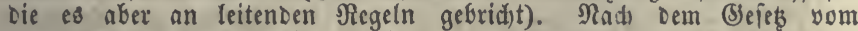

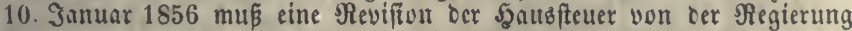
angeurbnet twerden, 1) went in einer nach ben NRiethen befteuerten Eemeinde biefelben fid um $1 / 4$ veränbert Gaben, 2) wenn bie Serbält= 
niffe, unter benen in einer Semeinbe bie Dieth= ober Nrealfteuer ein= geführt worben ift, fị由 fo wejentlich verảnbert haben, baß cine biefer Ssattungen an bie Stelle ber anberen treten muß́. Beftanb bisker bie Arenlfteuer, fo werben Diethfaffionen eingeforcert und es toirb geprift, ob fie zur Esinidsizung zureiden. Im entgegengefesten falle muß Die unzulänglid)feit ber vorkanbenen Nietfuntifer Dargethan werben, wenn bie beantragte llmwanblung in bie Arealfeuer erfolgen foll. S to fo

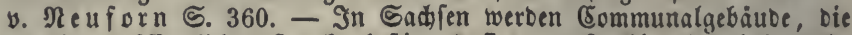
fu einem iffentliduen 3werfe beftimmt finb, auf obige 2urt bekanbelt, Befकäftsantweifung §. 122.

(e) Eranfreich, Rec. \$. 393. Das \$Ninimum Des für ein \$2aus anzuneh= menben (Ertrages if 1) ber Ertrag bes $\$$ Bauplaşes, ben man als beftes

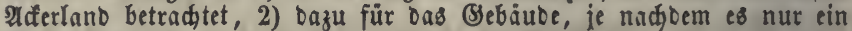
Grogejhó ober aud ein ober mehrere Stodiverfe Gat, Der $2=3=$ ober 4 fadhe Ertrag ber area. Das Dad twirb nicht als Stodwerf angeichen. -

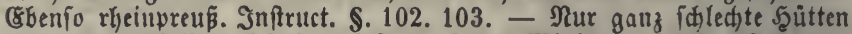
ober fefir verfallene Şnufer büren auf bas Dinimum felbft gejest wers Den, Rec. 543.

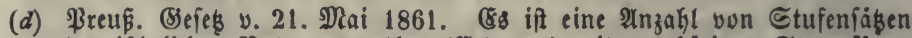
bes jührlichen Nubungswerthes (\&rtrages) mit zugehorigen Steueriäben angegeben. (Seringe Wohngebäube, zu benen feine ober nur fleine Brunoftude von geringem Ertrage gehören, fommen in bie 1. Stufe bis zu 4 Thlr. Nuşungswerth uno 4 Sgr. Steuer $(1 / 30)$. TBohn= Gåufer folder Eigenthumer, zu beren unterkalt ber Ertrag länblidher

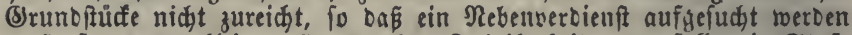
mús, ferner ber fleinen Şanbwerfer, Fabrifarbeiter sc., fallen in Stufe $1-6$ (lebtere mit 12 Thlrn. Ertrag ober 12 Sgr. Steuer). Flir

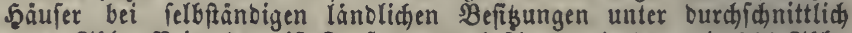

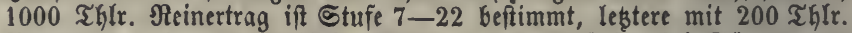
Nukungswerth ober 8 ThIr. Steuer $(1 / 25)$. Şäufer bei Siutern von 1000 Thlrn. Feinertrag ober Daruber fallen in Stufe $17-37$, mit

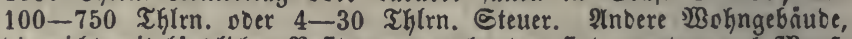

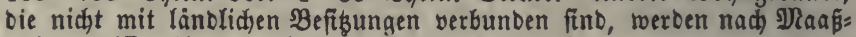
gabe gewiffer hiezu bezeidneter Stribte behanbelt.

(o) Defterreiđ. Sntwurf von 1863. Allle Drte, an benen weniger vers miethete als von ben Eigenthümern benuste' 3 oknungen fino, werben in 3 claffen getheilt, 1) über 2000 (Einwohner, 2) reniger (Sinwohner,

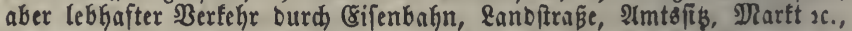
3) anbere Drtfifaften. Für jebe Diefer CElaffen 9 शrbftufungen ber Nubung von jedem Bimmer uno bem halben Betrage fứ jebe Nammer. शuf Der unterften Stufe toiro ein Simmer ber 3 Claffen zu $9-8-6$ fi., auf ber 9. zu $31-27-21$ fl. angefest. (s8 twirbe bemnach) 3. 38 . ein fleines நnus von 1 Simmer und 2 Ranmern angefdlagen werben in Drten über 2000 Sinwohner auf 18-62 f., in Drten ber 2. Blaffe auf $16-54$, ber 3 . auf $12-42$ fl. Sievon gefien überall 30 झुroc. Erfhaltungs = uno Tilgungsfoften ab, alfo bleiben 1) $12,6-43,4$ fi., 2) $11,2-37,8$, 3) $8,4-29,4$ fi. Steueranidlag. - Die Unterideibung mefrerer Claffen bon Drten ift zmedmápig, ood bleibt ber 3roeifel übrig, ob bie aufgeftellten 3ahlenjäß̨e wirtlid auf oie Erfabrung ge: grünot find und bie Beranidglagung inmerbalb Diefer Sirinzen allen vorfommenden Fallen entipriat. \$8 cridsien fabon nothig, fur bie

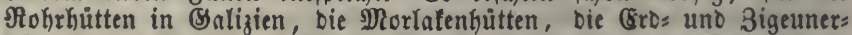
Gutten in Ungarn und Siebenburgen Den Tariffas Der Rammern in fleinen Drten anzuwenben. - Gahjen: Wenn bei Wokngebäuten auf bem Lanbe fein anberer Bergleidungmanfitab anwenobar, fo follen

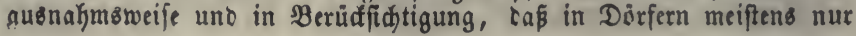


einzelne Stuben vermiethet werben und babei auf bie Räumlidfeit

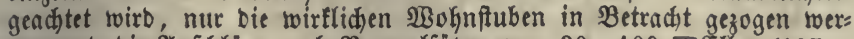

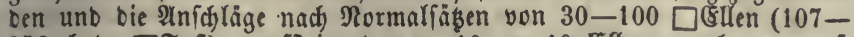
356 bab. $\square$ Fußs), aufiteigent von 10 ztl 10 EIllen, nad Dem aufs gefunbenen sliettywerthe für Stuben einer gemiffen SOröß̈ße, gebirbet werber. Antweif. \$. 108.

\section{§. 351 .}

Legt man bie Şausfteuer nad) ben Raufpreifen an, fo ift ein $2 b_{z}$ tg für 2 lusbefferungen $u$. bgl. unnöthig, weil ber ßreiŝ fitc) von felbit neben bem Miethertrage zugleid) im Banzen genommen nach) ber Feftigfeit uno muttymąlid)en Dauer eines (Sebäubes ridftet. SSleidjwohl ftehen einer Befteuerung nad ben wirflichen Şäujerpreifen auz einem gewiffen Zeitraume nod) erheblichere Bebenflichfeiten im $\mathfrak{W}$ ege als bei \&änbereien (\$.322), benn bie Şäuferpreife ftehen nod) mehr unter bem (Einflute zu=

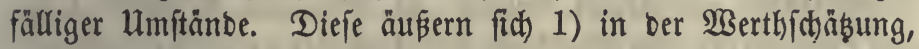
weil jebes Şaus eine Bejonberkeit hat, weldhe von ben Rauf=

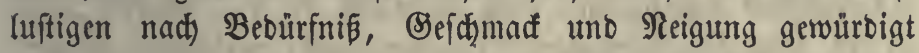
wirb, währeno ber $\mathfrak{B}$ erth eineż lanbwirthjid)aftlid benuşten (8runbftüfes eher eine allgemeine 2lnerfennung erhält; 2) in Dem Nitwerben, weil bie meiften Menfidjen, oer mühjamen Berwaltung willen, fid yor ber (Erwerbung mehrerer Şäufer, befonberz yor bem Beftis eines Sagufes in einem Drte, an bem fie nidjt wohnen, zu idjeuen pflegen. Daker fitt bie \$reife

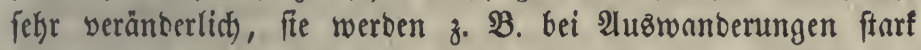
erniebrigt, bei raider $\mathfrak{B e r m e k r u n g}$ ber Einnokner, wie in Babes orten u. ogl., anieknlic) erföht. IIm meiften zufällig ift ber \$reis ganz vereinzelter ober foldjer Bsebäube, bie an ifrem Drte bie cinzigen ifrer $2 \mathfrak{n t}$ fino. Mandje Şäujer haben foftbare Einridtungen und foldje 3ubejörungen, weldje nicht gerabe

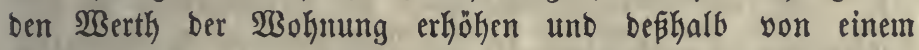
Miether nidjt leidst vergưtet merben mürben, bennod) aber zu bem $\mathfrak{B e r t h e}$ bes Şaufes geredynt swerden müffen und hin unb wieber ober theilweife auth von einem Räufer bezahlt werben.

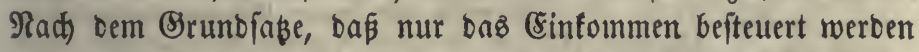

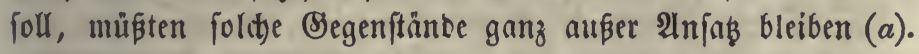

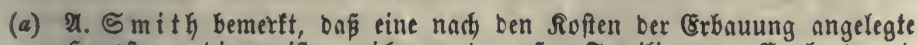
Shauళfetter bie meiften reidjen unb grofen Familien yon Englanb unb vielleiöt bon allen \&änbern zu Erunbe ridten würbe. Die ganze reine 
Nente ifyrer (B)üter betrågt beinake nidjt megr als $6 \frac{1}{2}$ ober 7 Broc. Der Erbauungsfoften ifyrer Şäufer, an benen mebrere (Senerationen gearbeitet Kaben, III, 244 (IV, 195 Bạ.). - Eanbgräflich heff. Inftr. vom Juni $165 \$$ '\$. 9: Die İofubauler uno Sofraithen follen nidt nach Der Roftbarfeit.Der Bebrim, fonbern nadjoem fich Der Befizer Der= felbigen entweder vor fid felbfen ober burd) Berlenflung ber logia-

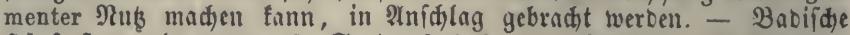

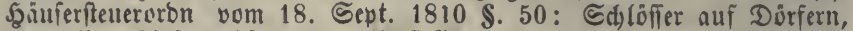
ehemalige Rloftergebiube u. ogl. follen, "wenn fie aud grof und foft:

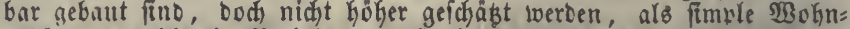
gebrube, weldse in Beziehung auf bie \$erion bes Esigenthümers bie

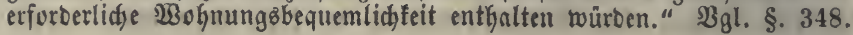

\section{§. 352 .}

Demnach müffen, wenn man bie Ranfpreife zu Srunbe legen will, bie wegen zufälliger Störungen zu hohen ober zu niebrigen Breife berictitigt uno Mittelpreife für jebe (Srößße, Rage und Befd)affenkeit aufgejucht werben, fo Daj man an jebem Drte eine Stufenleiter bon Durchifhnittžpreifen ber berfdiebenen 2 rten von Scäujern erlangt uno nad) benfelben bie viel größere 3ahl ber it Dem angenommenen 3eitraume nid)t verfauften Şäujer burct) Schäbung einzureihen im Stande ift $(a)$. Cine Claffens eintkeilung ber Bebäube ift wegen ber gropen Berfchiebenartigs

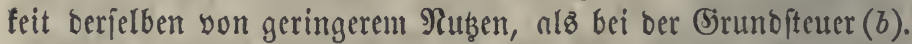
3ur ßrüfung, richtigen 2lnmenoung uno Ergänzung ber Sinuf=

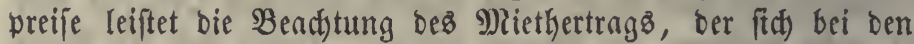
Taratoren unvermeiolid) und felbft unwillfürlid) gelteno madst, gute Dienfte. Es zeigt fid) baker aud) bout biefer Seite, Daßj

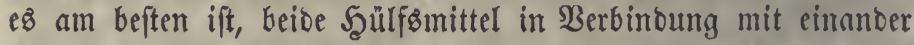
zu benubsen. Die Ânfdhläge werben am meiften Bertrauen ver= bienen, wenn fie zugleid) ben mittleren Rauf= uno Miettpreifen (wo leştere zalylreid) genug vorkanden fint) entipredyen, fo baß̃, nach) ben nötbigen 2lbzügen, die Mietherträge zu ben

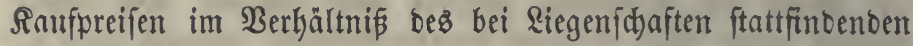
3ingิfües fiteken (c).

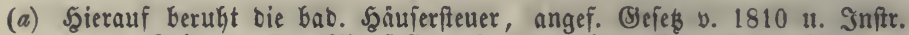
y. 16. Febr. 1812. Sie joll nach Dem reinen Ertrage angelegt twer= Den (\$. 1), bet aber aus bem mittleren Rocalmerthe erfichlofien wird (\$. 6). Die trirflidjen Raufureife von 1800-1809 werben, nadj ben nöthigen Modificationen, zum Manäitabe genommen, um cie anderen

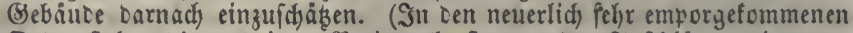
Drten fiehen Die aus jener ßeriode herftammenden Ptnídläge weit unter

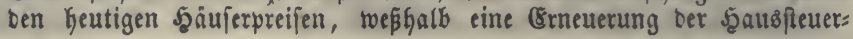




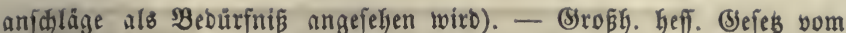
13. April 1824 und కnftruction yom nämlichen Tage §. 31. 32: 4 ßroc. Des "mittleren localen Raufpreifes" gelten als reiner Ertrag, bei Meuhlen uno Şammetwerfen 1/30. - Therefianifje Steuer in Defterreia: in Stäbten und Därften naw bem Eapitalwertf, Steuer 6-50 fl. - Die neue ruffifde Satubfteuer (\$. $342(a)$ ) wiro Durd) ein (Seies nuf Die \$rovinzen (Boubernement8) vertfeilt (max. 176690

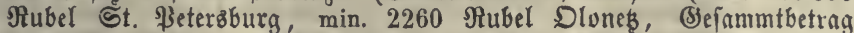

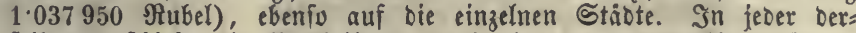
felben gefdieht bie Bertfeilung burch einen yon ben (Eigenthumern

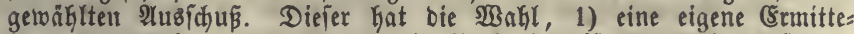
lung vorzunefimen, $100 z$ er bie Berfaufopreife uno bie IInichláge bei unterpfanbsbarleifen benubt unb eigene Befidtigung anfellt, ober 2) bie, vorhandenen 2njolảge zum sehuje ber Stabt= uno Duartier= fteuern zu (Srunbe zu legen, in benelt er aber Nenberungen zu madjen befugt ift. Infruction Des Finanzminift. v. 20. Febr. 1863.

(b) Sie ift in 23 ürtemberg eingeführt. Inftruction yon 1821 unb 5ूanb= buch 5. 67. Fin jede Claffe, in bie ein Bebäude fällt, wird bns arithmetiface Neittel zum Infichlage genommen, z. $\mathfrak{B}$. 7750 fl. für bie Elaffe bon $7501-8000$ fl. - Theref. Steuer in Defterreid für bas platte \&ano: 6 Slaffen, Steuer $11 / 2-20$ ff.

(c) SBenn man die Einwohnerzahl cines Drtes in oas gefammte Şaus: fteuercapital bivibirt uno bie auf jeben Rovf treffende Summe für ver: fhiebene Drte vergleicht, fo zeigt fich eine Stufenfolge, bie einigermaßen

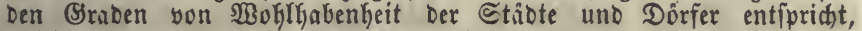
obiçon fein foldyez einzelnes Rennzeichen untrüglich ift. Freilich wiro Giebei vorausgefebt, Daś die Steuter in allen \&antestheilen gleidymåzig angelegt fei. Die Şausftettercapitale in $\mathfrak{B a b e n}$ Betrugen im $\$ .1829$

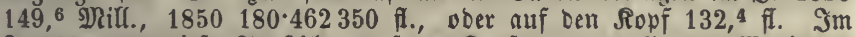

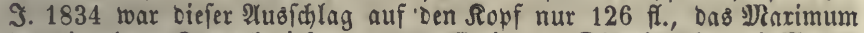
Der einzelnen Steuerbezirfe war 222 fl. in ber Dbereinnehmerei शann= heim, worauf Die Dbereinnehmerei Rarlbruhe mit 207 fl., Şeidelberg mit 172 กี. folgten. Das \$inimum twar 51 fl., Dbereinnefmerei St. BIafien im Sđjwarzmalb, zunảdht baran 69 fl. Thiengen, 86 fl. B̈udjen (DDen= wald), 90 fl. Bonndorf (Shwarzmald). Fưr 1860 find bie Steuer= cavitale $1941 / 3$ IRill. Doer 141,8 fi. auf ben Ropf. Mlerfwüroig ift Die ziemlich âfnliche Stufenfolge ber Bebölferung unb ber Scauptfeuer= capitale jedes Roufes. In Baben war:

\begin{tabular}{|c|c|c|c|c|c|}
\hline 1830. & $\begin{array}{c}\text { Bevöffe: } \\
\text { rung }\end{array}$ & $\begin{array}{l}\text { 5. St. } \\
\text { Capital }\end{array}$ & 1850. & $\begin{array}{c}\text { Bevölfes } \\
\text { rung }\end{array}$ & $\begin{array}{l}\text { 5. St. } \\
\text { (Eapital }\end{array}$ \\
\hline ne & & 151 fi. & unt & 5365 & 142,6 fi. \\
\hline & & $149 "$ & ei் & & \\
\hline Rinzig= & 4 & 130 & (S)anzes Sand. & 4904 & 132,4 \\
\hline Dreifams. & 4487 & $118 "$ & Dberrbeinfreiz . & 4815 & 121,4 \\
\hline Rain=... & 3670 & 106 " & Seefreis. . . & 3087 & 115,3 \\
\hline & 278 & 103 & & & \\
\hline
\end{tabular}

Berfandl. Der 1. Rammer von 1833 Beil. IV, 432 (Beridjt über bie

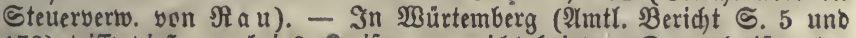
173) trifft diế nur bei 3 Sireifen zu, niळht bei Dem Donaufreife, Der bei 3566 6sinw. auf ber $\square$ Dieile foviel Sansfteuer nuf oen Ropf giebt, als Der boppelt io farf bevölferte Rectarfreiz. - Sm öfterreiditiden

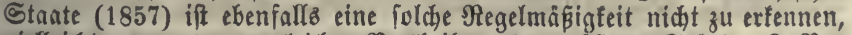

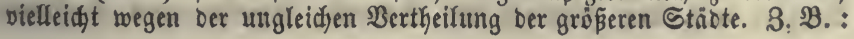




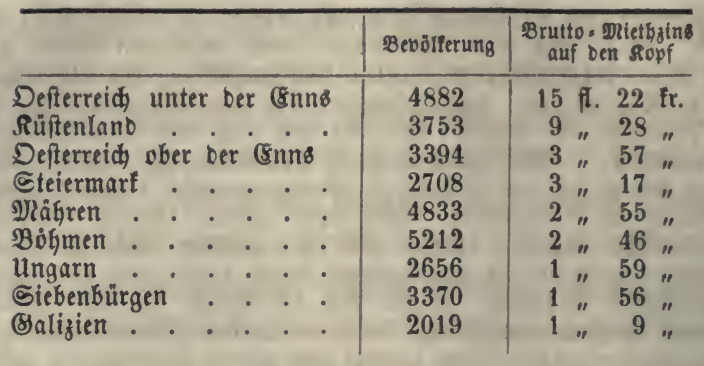

§. 353.

In bem regelmäßigen 3 uftanbe, wo ein Baucapital fid genügent verzinjet, fönnen zur ßrüfung oer Steueranidläge aud) bie Erbauungstoften benuģt merben, foferne fie zmect=

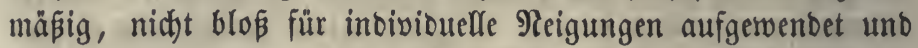
niçt zuffällig vergrößert worben fino. Dieje Bauloften mit

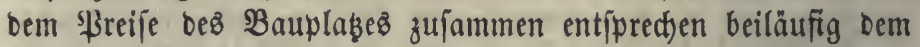
mittleren Saufpreife eines yolfommen gut erhaltenen \&ebäubes, für ein ältereż můffen fie aber nacd Maajgabe ber erfolgten Berjdjlectlerung geminbert werben. Dagegen eignen fid) bie

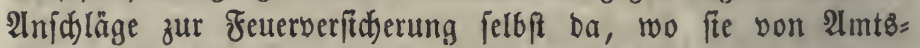
wegen feftgeiegt werben, nidyt für bie Rataftrinung, weil ein Theil bes Werthez und Softenjaz̧ez als unberbrennlidi unb nidjt gefähroet auszgejd)loffen bleibt.

\section{\$. 354 .}

II. Bebäube und Theile berfelben, die zur $\mathfrak{B} e=$ treibung eines sewerbez bienen uno baker für ben Unternefmer ein Theil bes ftehenden Capitals find (\$. 342), laffen fid wieber in zwei 2lbtheilungen bringen.

1) Einige fint fo bejdaffen unt gelegen, one fie von vielen Beswerbsleuten bentţ̨t werben föunen uno hăufigen Begehr finben, weßkhalb oer Unternehmer fie nid)t eigen zu befizen brautht, fonbern fie miethen fann. Dießs gilt vorzüglidy von joldten Räumen, bie ebenfogut zu veridjiebenen Bewerbszmeden, alz zur Bewoknung braudbbar fint, wie bie $\mathfrak{B e r f f t u b e n}$ vieler Şanbwerfer (Sdyneiber, Sdjulfmadjer, $\mathfrak{B e b e r , ~ B u d b b i n b e r , ~}$ Dredszler, Budjoruder, Stcinoruder, Blajer, Strumpfwirter, Sattler 2c.), bie Bimmer ber Sdjents, Speifes und Saffeerwirtly= 
idjaften u. bergl. Bebåabe, bie für ein einzenes Senverbe befonbers eingeridjtet find, wie Siramlabon, Etälle unb Sdjeu=

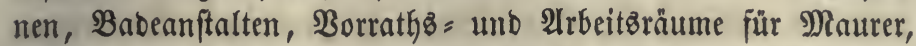
Bimmerleute, Erophänder, Sd)reiner, Wagner, Sdymiebe, Ed)loffer, Bewerbbeinridtungen für Bäđer, Bierbrauer, (sa) wirthe, Bleidyer $2 c$., Iaffen fid an Drten, wo bas betreffentbe Sewerbe bảufig betrieben wirb, leidjt vermiethen unb auch an fleineren Drten gefdieht bieß́ oft bei 2lpothefen, Mủhlen, Brauteien u. bgl. Sewwerbsgebäute biefer 2 rt geben itrem Eigenthủmer einen Miethertrag uno fönnen baher wie $\mathfrak{W o h n}=$ gebåube befandelt werben, mögen fie nun wirflid vermiethet ober von bem Eigenthümer felbft benukgt werben. Es verftegt (iid), Daf bagegen bei ber Befteuerung Des Becwerbsunternehmers

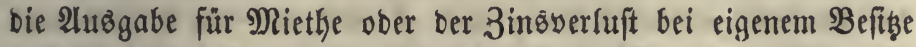

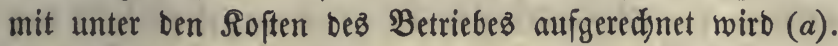

(a) v. Jatob I, S. 643.

\section{\$. 355 .}

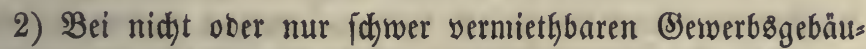
Den, wie viele Fabrifeinridtungen, Berbereien, 3iegel= uno

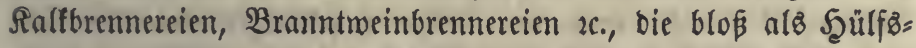
mittel zur Errlangung einte senverbzertragez mitwirfen, giebt eళి zwei Beftenerungämethoden.

a) (5z wirb eine befonbere Şausfteuer crhobell, bie man nach ben wirflicten ober abgef(t)äbten Raupreifen uno ben Bautoften anjeģt, wobei man vurauşę̧t, $D_{a \beta}$ bas in foldjen Sebäuben enthaltene Canital einen 3inz abwerfen můffe, ber in bem Bewerbsertrage enthalten ift. Dagegen wiro basienige Cinfoumen, weld)es mit Şülfe ber Ssebäube entfteht, bei feiner Befteuerung to angefdilagen, alछ̄ befäße ber Empfänger teine eigenen Sebäube; man nimmt aljo nidbt bló bie Unterbaltungz: toften uno bie Serfoflect)terung, fonbern auth ben Capitalzing ber Bebäube unter bie abzuzielyenden Betriebsfoften einer lands wirthidjaftlidsen, serwerfs =, Şanbels= voer Dienftunternekmung auf (a). Bei ber Brunbifteuer ift biefer $2 \mathfrak{l}_{z} u g$ bann unnōthig, wenn biefelbe nadf Saufpreifen angelegt wirb.

b) Man behanbelt bie Bebäube wie andere Theile bes fteken= ben Capitaleछิ, beren Binzి, objhon er ben Begriffe nad) immer 
als ein bejonberes Einfommen anzujehen ift, bod) in ber (5r=

- fojeinung mit ber Ssrunbrente ober bem Setwerbbeinfommen verfnüpft vorfomunt, z. B. bei Brumen, Nafdjinen, $\mathfrak{B}$ erfzeugen. Der Srrunbeigenthümer (bei lanbwirthid)nftlid)en Bebäubent) unt Der (S)ewerfżs ober Şanbelämternebmer wirb baun zugleid) als Befízer bes Sebäutbecapitales betrad)tet uno bei ber Berect)mung Des fteterbaren (Einfoumens wirb unter ben vom Rohertrage abzuziekenten $\mathfrak{B}$ etriebsfoften nur bie 2 Aużgabe für Unterhalt uno Sidjerkeit Der Bebäube, fowie beren 2tonübung abgezogen; io baßß bie wahre Şatbrente bei \&änbereien mit ber Brunbrente,

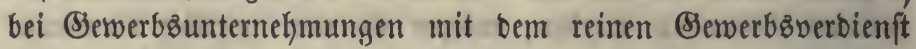
unb bem 3inz bes Betriebzacapitals verbunben in 2njidjlag gebrad)t wirb (b). (Es fällt bemnart) eine bejonbere Şausfteuer

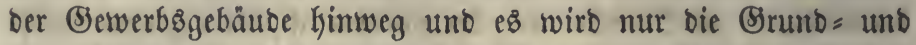
Eerwerbfteuer ber Cigentthümer befto höher angefest, wie biés bei ben anberen Theilen bez ftehenten Capitals in ber Bemerb=

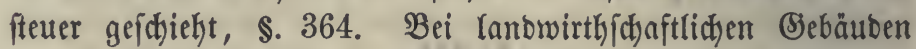
hat man augzumitteln, weldjer (Eapitalmerth und 3ins von Stallungen, Echeunen u. bgl. in jeber Begeno auf einen Mors gen Adfer ober SBieje trifft, unb barnadt foldye Erumbeigen= thümer, bie micht auch im Befţ̧̦e zugehöriger Siebäube finto, verbältmifmäßig nicbriger in bie Srunbfteuer zu legen, wie

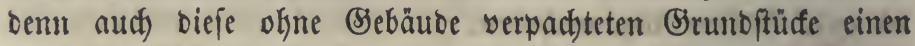
geringeren \$adjtzins abwerfen würben.

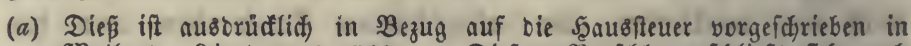

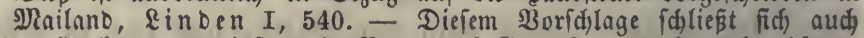

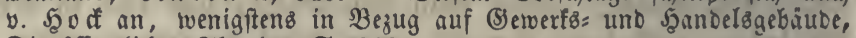
Die öffentlichen 2 bagaben S. 202.

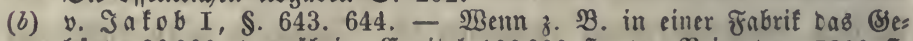
Gåude 30000 , Das übrige Capital 100000 กี., Der Reinertrag 7200 f. betriagt uno von jenem Bermógen 4 ßroc. Bins angenommen twerben, fo it Das fteuerbare Einfommen 1200 ค.. 5 aus $=, 4000$ fi. anbere Capital= rente uno 2000 f. reiner Setwerbsverbienft. Sads Der obigen Sethobe a) wäbe bie Sausfeuer von ben 1200 fi. erhoben unb bas (sinfommen aus Dem Fabrifgeidáfte fo autsgemittelt, (Sebäube mit Den anberen Roften vom Rohertrage abgeft. Nach Der Nethoce b) werben bie vollen 7200 fl. als fteterbares Betwerbsein= fommen angefest.

\section{§. 356 .}

Das erftgenannte Berfahren ift bas üblide, leidtere. Man hat an bemielben ber (servokntheit wegen unb sermutblid) nud barum feftgekalten, weil man bie bisherige fidjere uno fortbauernbe 


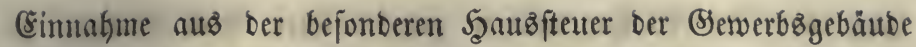
erhalten wollte und befürdytete, fte bei bem zweiten Berfahren in ber (Selverbfteuer nid)t vollfänoig erfebst zu finden. Das zweite, objhon nidht bon Schwierigfeiten frei, empfiehlt fidh aber bur(t) mehrere Bruntoe.

1) (5z ift ber viel häufigere Fall, Daß̧ bie Betverbzిgebäube Dem Sirunbeigenthümer ober Setwerbsిunternehmer gehören. Deß $\beta=$ halb verurfad)t es weniger 9üke, für foldte Steuerpflidytige Diejer Elaffen, weldse feine eigenen (Sebäube haben, einen $\mathfrak{a b}=$ zug zu berechnen, als wenn man überall bei ber 2lnfebung ber

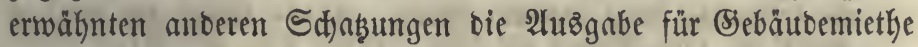
zu Den Betriebsfoften zu id)lagen uno eine bejondere Saaubifteuer anzujesen hat. Dhnekin fann man bei einer forgfältigen (Srund= fteuerfesung nidht umbin, nad) Den Erfahrungen jeber Begeno

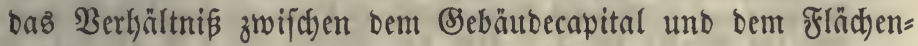
raum und wohl aud) ber Fruchtbarfeit ber Felogüter zu er= forfdien $(\alpha)$.

2) Der Nuben, ben bie (Sebäube in einem Serwerbe leiften, ridjtet fich) feinesinegs immer nad) ilyrer (s)ößje unb Befdaffen= heit und läßst fith) weber aus ben Roften iffer (Erbauung, nod) aud) on, wo fie nicht bermiethbar fino, atto cinem Miethzinje erfennen. 9) Tanche Unternekmer vermögen mit fleinen uno wohl= feilen Gebäuben einen anfehnliden Betrieb zu unterhalten (b). Bei mandyen Anberen find bieje unmöthig großj und foftbar, bald weil ber Umfang ber Unternehmung fid berminoert hat (c), bald zufolge eineż übelberectneten Bauaufwandes, wie benn Die befannte Reigung Der Bewerbolleute, ifre Bebäube zu vers größerl ober ju vervolffommnen, vielfältig eine Urjache von Sinşverluften geworben ift. Diejenige Şauzrente, weldhe man aus ber abgefonberten Betradtung ber vorfandenen Sebäube ermittelt, ift baker yon ber in bem Serwerbsertrage wirflid) enthaltenen oft beridjieben, und offenbar follte nur bie leştere, nicht bie erftere, befteuert werben. Die (Se)werbfteuer läpt fid nad) bem iebermaligen 3uftanoe ber Unternehmungen leidhter von Sabr zu Sabr abänbern, bie Şauß̨fteuer ift wie bie (S) runt: fteuer nuf längere unberänberte Fortbauer eingerichtet uno wiro folglid) in obigen Fällen leid)t unrichtig. Bei Innowirthjad)afts licken Sebriuben hat man zuerift bemert, baß sine Şaubfleuer 
nad) Den bei Wokngebäuben gewöhnlid)en (Einridtungen zu Unbilligfeiten füfren würbe unb bieje Betrnd)tung Kat zu einer đdjonenoen Behanblung ber erfteren \&lnlaß̧ gegeben, aber ähn=

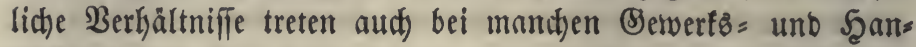
Delögebäuben ein $(d)$.

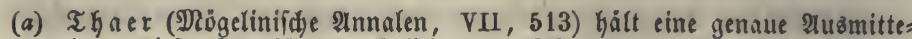

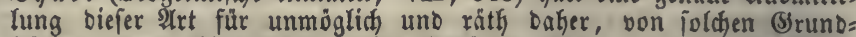

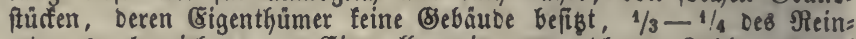
ertrages abzuziefen. - Ein allgemein anwenbbarer Sablenausorud läpt fid alferbing nidyt twofl finben, Da aud bie Betwirthfdhaftungs = weife, Die Roften Der $\mathfrak{B}$ aumaterialien uno ber 2 rbeit, Die (SröBe Der \&anogüter $x$. mit eintwirfen, Dod twirb man in gegebenen fällen bie

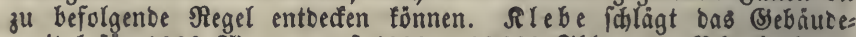
capital für 1000 Slorgen auf $4000-10000$ Thlr. an. $B$ lo df (Eano=

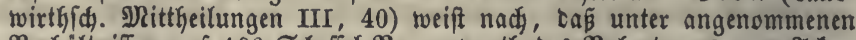

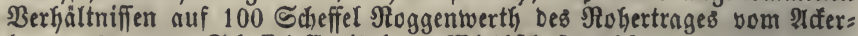
lanoe 120-136 Sheffel Capital an \$Bitthidaftsgebảuben tommt, ofne

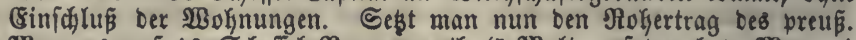
פlorgens auf 10 Sheffel Noggenwerth (5 Nalt. auf Den bao. Norgen) unb ben Sheffel auf 3 fl. (bas bab. Malter auf 8 fi. 12 fr.), fo finbet man auf ben pr. Mlorgen 40 fl. $48 \mathrm{fr}$. Saluzicapital $(57,5$ fi. bao. Dlorgen), woyon Der Sing zu 4 Froc. 1,63 fi. $(2,3$ fl. bad.) für ben Dlorgen beträgt. Soviel wäre alfo von bem feuerbaren Reinertrage

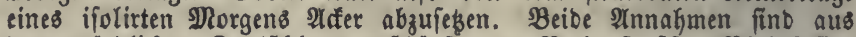

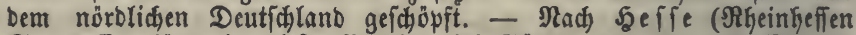

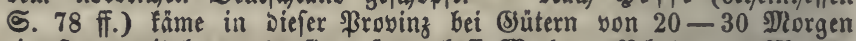

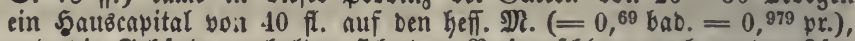

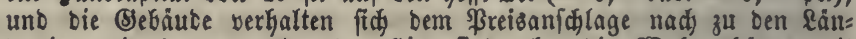

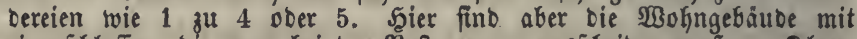
eingefilofien, bie man bei ber झefteucrung ausidjeiben mus. - Slee= ma nn (Encyflop. Ianowo. Berbảltn. S. 316) reçnet bei guten, nidit

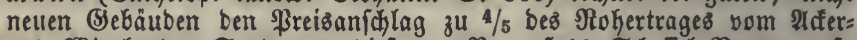

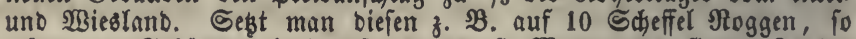
wäre Das (Sebäubecapital auf ben preuß́. Morgen 24 fl. - In ber

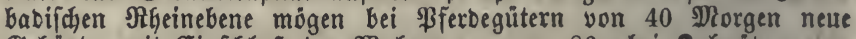

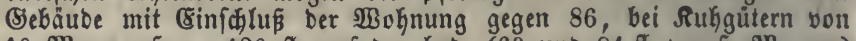
10 Dorgen pogar 120 fl. allf ben kao. (60 uno 84 fl. preus. Morgen) foften.

(b) Die meiften englifकen Lanogüter Gaben z. $\mathfrak{B}$. Hleine Sheunen, weil Das ungebroịdene Betreite und Das Şeu in Feimen (stacks) auf: betwagrt iviro.

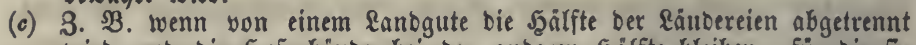
mirb tmb bie Sgofgebåube bei ber anberen \$ălfte bleiben, für bie fie liberfiuffig grofi fino, - wenn eine (Saft = ober Babeanfalt in Berfall geräth, eine Fabrif wegen Nangel an शlbfas fdwad betrieben wiro.

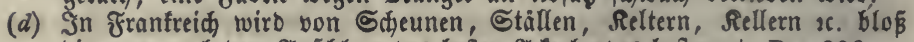
bie 'area nach cem 2tnichlage Des beften 2lferlandes beftettert, Rec. 396. -

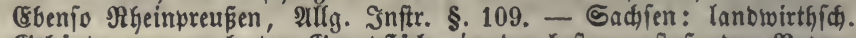

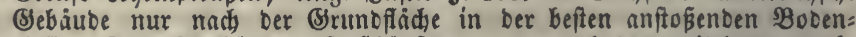
claffe, Betwerfiggebäube, Bafthäufer sc. nur nach bem mittleren muth= máslidjen Diethertrage, uno wenn biefer nicht zu ermitteln ift, nach Dem Ertrage Des Raums, wenn man benfelben als 20 ofyung vermiethen würbe, mit 2lbzug von 50 \$roc., bei Schuppen, Ralfufen 2c. bis 70 ßroc. \$. 127. - Bon Der farbinifiden 5yausfeuer (1851) find bie 


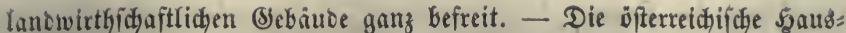
îner trifft nur Die 30 hngebaube, Daffelbe ift in Dem Entwurf von 1563 angenommen. - \$reuß. (S)efes von 1861 §. 3: Befreit von Der Sebåttoeftuer find ... 7) Diejenigen unbewohnten Bebäube, weldje nur zum Betriebe ber Ranbwirthidaft beftimmt find, nidit minber foldje zu gewerblichen Anlagen gehorige (Sebäube, welche nur zur Auf= betwahrung von Brenmmaterialien und Sohftoffen, fowie als @tallungen für Das lebiglich zum (setwerbobetriebe beftimmte 3ugvieh Dienen. Die anceren der Steuer unterworfenen Betwerbigebäude, z. $\mathfrak{B}$. Fabrifen, Brauereien, Ylühlen, Burratygggebäube 2 . werben nur mit 2 \$iroc. Deś

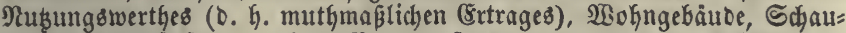
fpicl=, 3Babehäufer 2 . ntit 4 Froc. befteutert, \$. 5 Des a. Bejézes. -

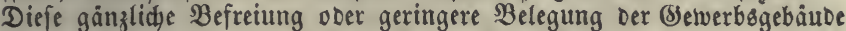

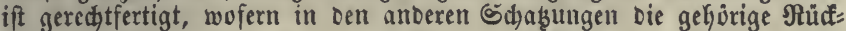
fỉht Darnuf genommen wirb. In Bezug auf Sdheumen, Stâlle $x$. Bei Eamogütern läßt fich gegen Daż oben vorgefdjlagene Berfahren Folgen= Des einwenden: Derjenige Sirundeigentfumer, welder ungewöhnlide foftbare Bebrude jener art aufführt uno fich biedurch cine Arbeits:

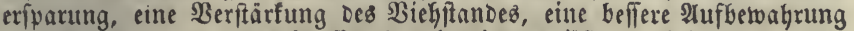

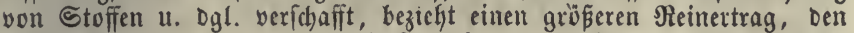
Die Srrunofteuer nicht trifft, weil fie auf Dauernde Berbåltniffe gegründet

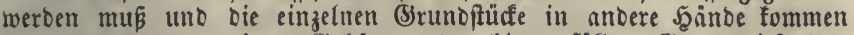
fönnen, two Dann jener (Siebäubenuben Gintwegfällt. SSegen Dieje un= gleich heit Der Belaftung fam nur eine landwirthichaftlide Betwerbfteuer (\$. 363) Abhülfe gewăhren, in ber ein ungewöhnlich grof̧es uno wirf:

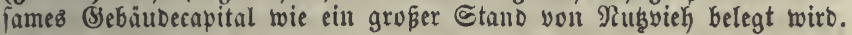

\section{§. 357.}

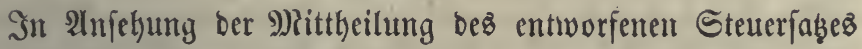
an ben Eigenthümer, ber ßrüfung erfobener Befdwerben, ber

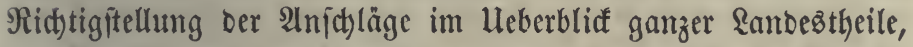

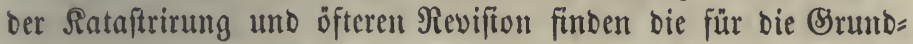
fteter aufgefteflten Regeln (\$.337.338) aud) hier ifyre Anwen= bung. Bauveränoerungen, Dic Den Werth und Ertrag erböljen, und neue Banten erforbern eine neue Scjäkung, weldye aber

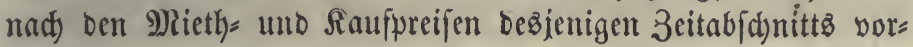
genommen weroen mußs, ber bei ben älteren Sebäuben zu Srunde

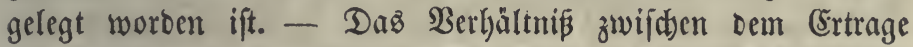
Der Şaus = unb Srunofteuer ift in Den einzelnen \&ändern unb Sanoesttheilen böd)ft ungleich, zunäd) ft wegen ber fehr verichie= Denen Srumbfäßze, nach. Denen die Şaubrente in ber Befteuerung beljambelt wirb, jobann regen ber fekr beridjiebenen Menge yon Sebäntoen auf glciçem Flächentaume, z. B. einer $\square$ Mleile. Bei gleicher Steuercinrid)tung muß bic Şauz̧fteuer in größeren Stäbten und Fabrifgegenden an meiften, in Segenten mit vor= herrichendem Rndobau weniger, in $\mathfrak{W a l}$ gegenten am wenigiten betragen $(a)$.

R a , polit. Deton. III. 2. श6tน. 5. 2uвg. 


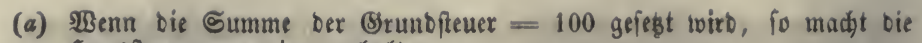
5ausfteuer gegen jene gehalten

35,8 ßroc. in Baben (1864), früher 40 ßroc., und zwar 45,5 \$rittel= rhein $=, 44$ unterrhein $=, 35$ Dberrhein = uno Seefreis;

33,2 "Deferreid 1864, aber 1857 nur 25,2, whne Rombardei und

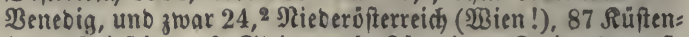
lanb (Trieft!) 24,8 Śteiermarf, Rärnthen, Rrain, 33 meft= liches, 23 sftlides Esalizien, 17,4 MRăhen, 16,8 3 obmen, $16,{ }^{1}$ Oberifferreid, 12,9 Ungarm, 4,4280 jilwobidaft ;

$23,5 \quad$ " $(4 / 17)$ in $\mathfrak{B}$ üttemberg, feftes Berfältní; ;

22,8 " Sammover, 1858. 59;

14,9 " Bayern $1861-67$, Dagegen nur $10,21855-61$, und zlwar 14,2 Dberbayern (max.), 14 शNittelfranfen, 8,5 Sdjwaben, 6,5 Niederbayern (min.).

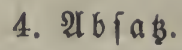

\section{(5) $\mathfrak{e} \mathfrak{w} \mathfrak{e} \mathfrak{r} \mathfrak{b}$ it $\mathfrak{e} \mathfrak{u} \in \mathfrak{r}$.}

\section{§. 358 .}

Die Sdjaķungen founten bei iffer erften Cinführung nidft

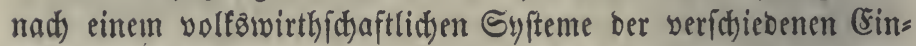
fünfte, fonoern mur nad) gewiffen leidft femttliden 2(rten uno Sruppen berfelfen angelegt werben. Man behanbelte onker

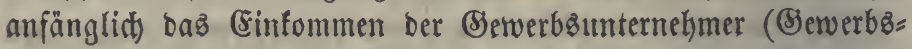
leute) als ein Banzes. Daffelbe nurbe hin und wieber fijon

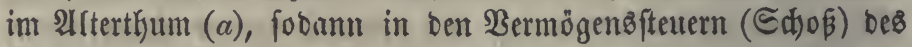
Mittelalters nad) bem in einem Setwerbe enthaltenen Eapitale angelegt $(b)$. Sleinere Bewerbsleute und blope Rohnarbeiter

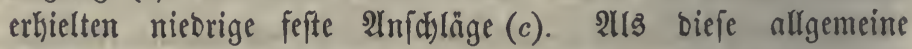
Sdyatung auper (Sebrautd) fam uno burd) mefrere befondere Ed)aşungen, in ben Etäbten auth) zum Theil butrd) bie शlccife erfest wurbe, begnügte man fidt) meiftens in Bejug auf bie Bewerbe mit geringen feften 2 najäß̨en, außer bei einigen (B)e werben, bie einen leidytfentlicten Mlanß̧itab barboten $(d)$. Die Geutige forgfältig abgeftufte, alle Sewwerbe umfafienbe Serwerb= fteuer gefjört aber bem 19. Jahrhunbert an $(e)$.

Unter Beswerbe verfteft man im weiteren Sinme lebe $\mathfrak{B} e=$ fdäftigung, Deren 3wed in Ërlangung von Ead)gütern befteht, im Begenfab̧e folcher Berridjtungen, bei benent bie Bergütuts (Şonorar, Befoldung 2 c.) einer höheren Beftinumung wegen nidft zum Şauptbetweggruno gemad)t werben barf. In einem engeren Sinne werben blope Rohmarbeiten aug̈gejd)lofien uno 
nur biejenigen Ěrwerbsgefdjäfte Senwerbe genannt, bie mit Şülfe eines Capitals betrieben werben, alio Unternebmungen fino unb ein zum Theil yon bem angewenbeten Capitale abhängen= Des (Sinfommen abwerfen $(f)$. Die Bewerbftetter nad) biejer engeren $\mathfrak{B}$ ebeutung ift folglid) bie ben Unternet)mern (Betwerbs: leuten) aufgelegte Sdjaß̧ung.

(a) Unter ben exfen römifhen Raifern fam f̧on eine Steuer yon Rauf=

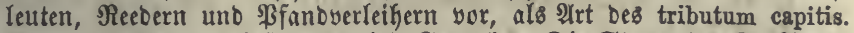
Alexanber Severts befteuerte viele (Setverbe: Die Steuter ber Raufleute, Sanowerfer uno Fabrifferren heift feit Eonftantin lustralis collatio, weil fie immer auf je neun Iahre bezahlt wurbe. Ilufgehoben von

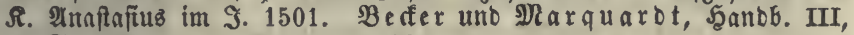
2. ๙. 188. - de Parieu I, 281.

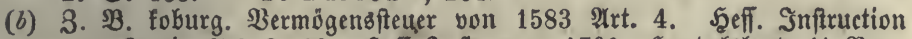

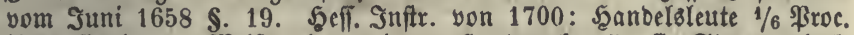
ifres (5apitals, Meifter in geringen Scanbwerfen 50 fl. Steuercapital, für jeben Bejeflen 25 fr. mehr. - Magdeb. Inftruction von 1689 \$. 3 (bei Rle wib II, 7): von jebem Thaler "profitirter Nubung" 4 Ggr. als simplum. - In Der franzoffichen taille personnelle war Das Ge: werbseinfommen wie jebes andere befteuert.

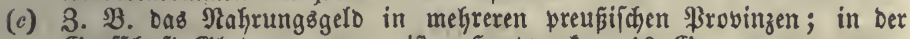
(S)afid)aft (J)

(d) 3. B. Shúklen, Brauereien, Baider, wo man auf ben Utmfang bes

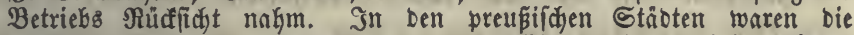

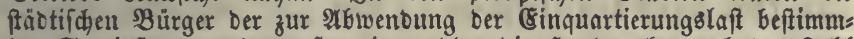
ten Gerviafteuer unterworfen, in weldyer bie Sganbroerfer nach ber 3ahl ihrer Befellen, Stügle 2 ., Raufleute nach ifrem Befdäftsumfang, ferner jene fog. (5onfumtionsgewerbe nad ifrer \&usbehnung belegt tourben. Der Gervis twar eine fábtifdse Semeinbeabgabe uno bie Semeinde fonnte ifn beliebig aufbringen, theils von \&anbereien und (Sebaiben (\&) runofervis), theils von Bewerbsleuten, Befoldeten, Lohnarbeitern $2 c$. (Na hrungs = unb (Sehalts fervis). Das Befés v. 30 Inai 1820 verorbnet, Daß̧ Der Servis in bie Staatscaffe gezogen toiro unb ermähtigt bie (Semeinben, ifn auf bie Riegenjagften umzu= legen (bgl. \$. $342(a)$ ). - Die bamberg. Sdjäzungsinftruction yon 1731 geht in ber Berúdfichtigung gewerblider Berbältniffe fdon ziem:

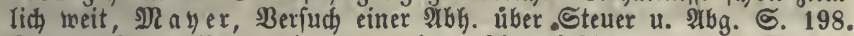

(e) Sam aud ber Name hin und wieber fdon fruiher vor (nad) Ni a bex

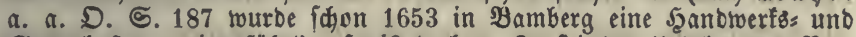

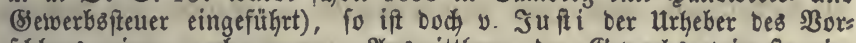

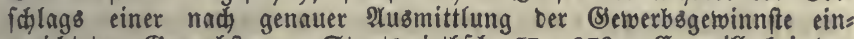
geridteten Betwerbfteuer, Staatsoirthid. II, 373. Gr will bei ben 3tweigen bes \$ambels einen (setwerbsgetwinn von 10-13 \$roc. anneh)=

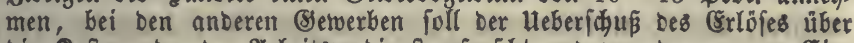
Die soften ober ber Arbeitzberbienft erforfat uno von bem ganzen Gin= fommen Des Gelverbsmantes follen $2 / 3$ für ben Unterfalt abgezogen

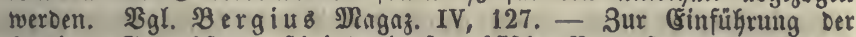

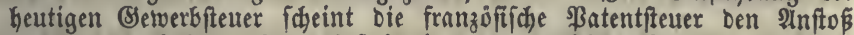
gegeben zu Gaben. Sene beftegt in Den beuticjen Staaten unb un:

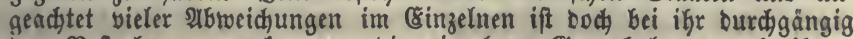
Das seftreben zu erfennen, bie cinzelnen Setwerbsleute nadi ihrem

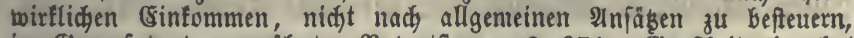
im Segenfą̧e ber erwähnten ßatentfeuer, \$. 374. Eroßjbritanien Gat 
Dem Ramen nach feine (S) werbfteuer, allein bie Rbtheilung (Schedule) D ber britifhen Einfommenfteuer nimmt bie Stelle jener Steuer ein, §. 400. - Heber Die Serwerbfteuer v. \$acob I, \$. 663 II. II, §. 1063 fi. - y. Maldu\& I, \$. 53-55 und dic tort angeführten Sdyriften. - Späth, शbh. über Die Rufnahme der Sewerbiteuer, Sulzbach 1822. - Szoff mann, Die Rehre von Den Gteuern S.189. ๖. Brittmib, Theorie Der Steuern uno Bolle $\widetilde{\sigma} .157$ (verwirft cie (Selverbfteuer, weil fie mit ber 3eit auf Die 3efrer falle und weil oer Berf. überkautut bie Steuerpfliçtigfeit für ein "wefenlofez \$̧Gantum" hảlt uno bloß́ bie Steuerfähigfeit anerfennt). "Shon ๔artorius (lleber bie gleidye Befteuerung $\widetilde{S}$. 310) Gatte fid gegen bie (Sewerb= fteuer erflärt.

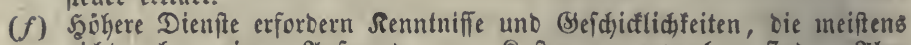
nidit ohne einen Aufwano ond Roften zu erwerben find. Aber biefes nur in einem uneigentlid)n Einue fogenannte (Sapital verbält fid in vielen feimfidsten anders als Das wahre (Sapital eines (B)etwerbes, feine (Sirobe fann bei verfdiebenen \$erfonen von gleid)em (Sinfommen felyr ungleich fein, fein wirthfdaftlid)er Erfolg hängt von bem \&eben,

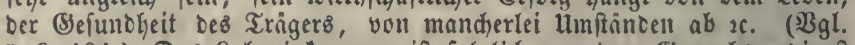
I, \$.194.) Das \&ukneinfummen ift folglid) von bem (Setwerbsberbiemft wejentlidh verídjeben, bießs verhinbert jcood nid,t, bie Steuern beiber unter einem gemeinidaftlidsen গamen zufammenzufaffen, wie in ber ifterreid). Erwerbfteuer. Bgl. v. Scoff, Die iffentl. Plogaben 5.214.

§. 359.

Sn bem von ben Eemerbsitunternehmern bejogenen Einfom= men (Gewerbseinfomment) fint zmei wejentlid) veridsiebene Theile enthalten:

1) Bewerbayerbienft, Bewerbsprofit, sou weldem ber Unternefmer feinen unt feiner Familie nothwentigen Unter= Galt zu beftreiten und bie bei feinem sefechäfte vorfommente Bagni位 zu tragen hat, I, \$. 237. Dicfe 2lubgaben nehmen bizweilen ben ganzen Eewerbžverbienft himweg, meiftens bleibt

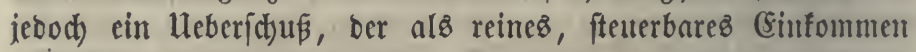
anzufchen ift, I, \$. 242. 3war ift für ben nothwentigen Unter=

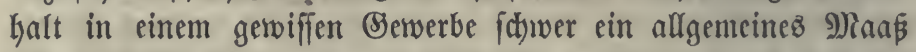
zu beftimmen unt man hat beß̧halb meiftenż nut bas ganze (rohe) Sinfommen bes Uluternchners in Betrad)t gezogen, allein man barf nie vergeffen, Laß hievon Sioften beftritten werben

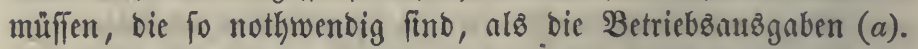

2) 3in 8 bes angerwenteten (Eapitals. Er befteht, ba bie Errhaltungsfoften 2 . F(t)on unter ben Betriebzantsogaben bered)net werben, alts reinem Einfommen. Sat ber Utnternehmer einen Theil bes capitales geborgt, fo muß er ben 3 ins bafür an feinen Släubiger abgeben. Diefe fehr hrufige Theilung ber Sinien zwifd)en ben Unternehmer uno (Eapitaliften ift bei bent 


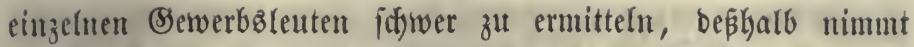

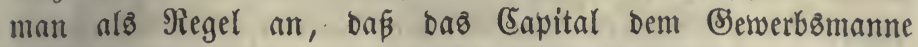
geföre unb folglid) beide (Einfünfte in einer Şand vereinigt fint, boch follte in ber 2Inlegung ber Steuer immer auf bie Fälle iener Theilung siüfficht genommen werben, fo weit fie offentundig fint, ober wenn ein Berverbzిmann feine $\mathfrak{B e r} j$ duls. Dung auf glaubhafte Weife anzeigt und bie Zinbrentenfeuter zur Beftätigung Der 2lngabe bient, $\$ 384$.

Im fleinen Berverbäbetriebe, z. $\mathfrak{B}$. bei ben mehriten Seanb= werfżmeiftern, ift Der (S) nehmung nid)t genug befdäftigt uno alfo ber Bewerbseberbienft zum Unterhalte unzulänglidh, ber Unternefmer nimmt baher aud an ben einzelnen (Sewerbseverridytungen Antheil, fo Daß

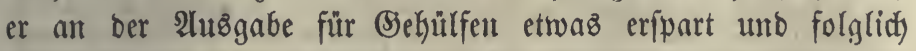
auth einigen \&ofn bezieft, I, \$. 187. Der mit \&ohn ver= bunbene Semerbsyerbient fann ebenfo wie ber unvermifate behanbelt werben, ift aber niebriger alb biejer zu belegen, weil

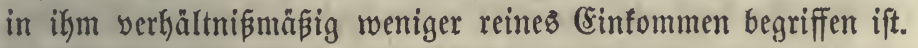

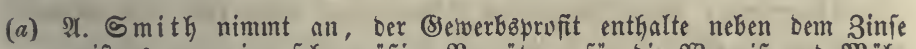

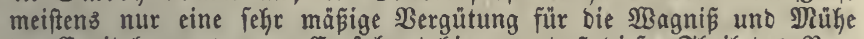

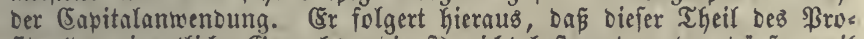
fits (Der eigentlid)e (Bewerbsueroienft) nidyt befteuert werben bürfe, weil fonft cer Semerbsimann Die Steter auf bie Räufer ber $\mathfrak{B s a a r e n ~ v o e r ~}$

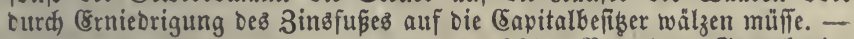
J. St. Mill, Princ. of polit. econ. II; 361: $\mathfrak{B o n}$ Dem Bewerbsein=

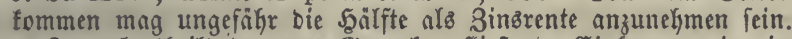

(b) y. Jacob theilt Das aus Gewerben fließ̄ende Ginfommen in eine per=

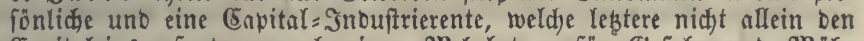
Capitalzins, fonbern aud) einen Miehrbetrag für Befahr und Mä̉he enthalten foll (Staatsfinanzwifi. I, §. 676). Nach obiger Darfellumg ift Diefer Diefrbetrag Beftanotheil bes Bemerbsgewinnes.

\section{§. 360 .}

Die (5ewerbe find fdwerer nad) ifrem Reinertrage genau

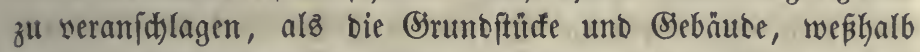
auth bie Bewerbfteuter weniger einzutragen pflegt, als ntan nad)

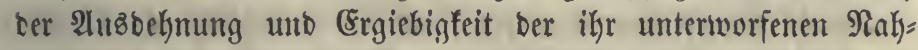
rungaz weige erwarten bürte $(a)$. Die Sd)wierigfeiten entfpringen 1) aนเ Der Berjhiebenartigfeit ber vielen (Sewerbe, beren jebes feine eigenthümlid)en Berbältniffe bes (Enpitalez,, ber foften

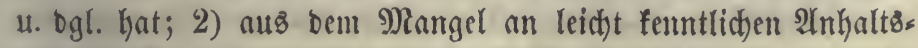
puncten für mandje (Sewerbe, z. B. Banfgefdäfte; 3) aนธ Dem 


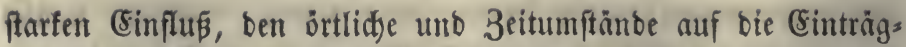

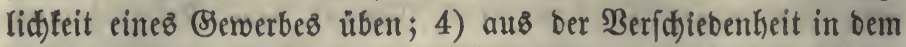
Ertrage, ben ein uno Daffelbe Sewwerbe ben einzelnen Unter= nehmern gewährt, weil ihre Făhigfeiten, iłhr Eapital, ihr Fleiß unb mand)e anbere $\mathfrak{u m p t a ̈ n b e}$ bei ifnen ungleid) fint.

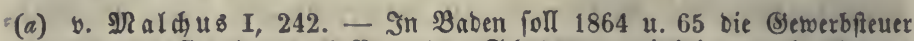
789978 fl. ober 21,4 \$roc. Der Sdjabungen einbringen, in Bantern $1861-671.284000$ ober 13,7 \$roc. ber Ghasungen, in Defterreich ohne ungarn und Giebenbürgen 18574.646821 fi., 18646.868000 fl., wozu aber bie \$erjonalerwerbfteter in ben ungariftyen \&änbern, Die entiprechenten Taxen in Siebenbürgen uno die Einfommenfteter 1. Glafie fommen, zufammen alfo 21.755919 fl. $=15,4$ Proc. - In \$rütem=

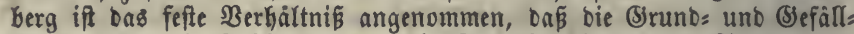
freuer 17/24, Die Bebáube $4 / 24$, bie Bewerbe $3 / 24$ zu ber Summe von 3 Mill. fl. tragen follen. Dieß́ betraigt 1861-63 375000 f. ober

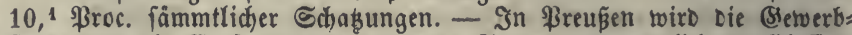
fteuer nur als đorgảnzung ber anberen Steuern, namentlid, ber Elaffen: fteuer, angeiehen. Sie trifft bie 5ुandwerfömeifter nur, wenn fie mehr als einen ermadjenen (Sehülfen haben (Sefés v. 30. SDai 1820), die SBebereien und Birfereien bei mehr als vier Stühlen, bas getwerb:

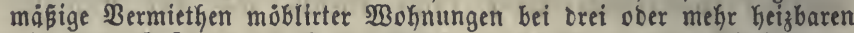
Simmern, Seleb v. 19. Juli 1861 §. 18. So of $m$ an $n$, Die \&ehre 2 . ङ. 195. அ. für $18613 \cdot 286000$ Thlr. $=12$ \$roc. Der Śchaßungen. Sannover 1859-60 $219600 \mathrm{rl}$. $=7,8$ ßroc. Der Shaßgungen. - Im Rirdenftante twurbe Durd Das EDoict v. 14. Det. 1850 eine (S) werb=

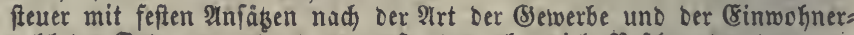
zahl ber, Drte angeoronet, es entftanden aber viele Bef hrwerben Dagegen, Die Anfábe twurben 1854 vereinfadt und fefr verringert, aber Dennod unterblieb bie 2Aubführung.

\section{ฐ. 361 .}

Die setwerbfteuer ift zunäc)jt als bie von ber fogenannten

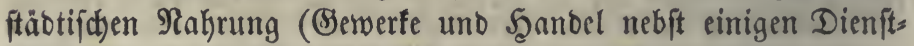
gewerben) zu entridtenbe Sdjakzung betradjtet worben. (E) ht man inbeß von bem Begriffe einer Beswerbsunternchimung auz, fo finbet man einen weiteren Sreiz yon Steuerpflidtigen, uno

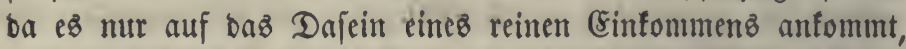
fo madjt ez feinen Unterfajieb, ob ein Benerbe gütererzengent (productiv) ift ober nicjt. Die Sränzen, bei benen bie Genverbos unternebmungen einerfeits bon ben höheren uno nieberen \&ohns arbeiten, antererfeits bon einer blopen Integung eines zinb= tragenton Capitales fict) unterfd)eiben $(a)$, müfîn burd) bie

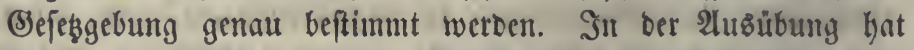
man meifens bie niebrigeren 3weige ber Roknarbeit wit zu ber Bewerbfteuer gezogen, weil biefelben mand)en mit ganlz geringem Eapitale betriebenen Eetwerben nahe felyent. Die fämmtlidjen 
Unternefymungen, weldye einer foldjen Steuer unterworfen wet ben fömten, Inffen fich fo überbliffen (I, S. 97 ff.)

1) Eroarbeit; Serwinnung von Mineralftoffen, \&anto=

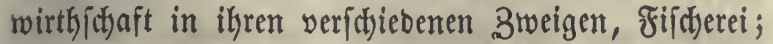

2) Seswerfe; Şanbwerfe, Enabrifen, Bauunternetyungen, Speife= und Sipithäujer;

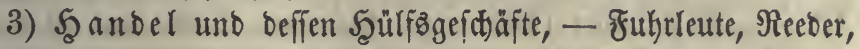

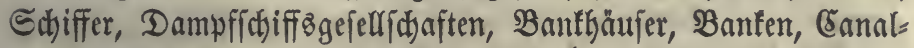
unb Cifienbahngejellidiaften $(b)$;

4) Dienftgewerbe unb folde, bie ben (sebrauch von Sachen betreffen, z. B. Unternehmer von Sohnfutidjen, Stell= wägen (Dmmibub), Theatern, Menagerien, Babeamftalten, Sumft= reitergejerfichaften, Muficanten, Frifeure ut. Dgl.

5) (Semifd te (Sewerbe, o. B. Schents und (Saftwirth= id)aften, bie auts शr. 2) 3) uno 4) zufammengefét fino, 2lpos thefer aus 2) uno 3) 2 .

6) Serwerbe, bei benen aus ber Uebernahme einer $23 a g n i \beta$

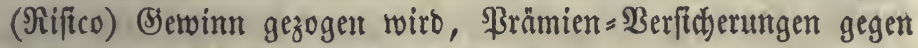
Feuter = unt Seegefahr, Rebenşuerficterutngen $2 c$.

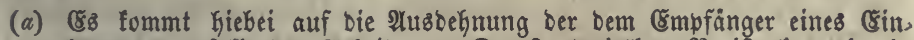
fommens zufallenben 2 trbeit an. Der \&anbwirth $z$. $\mathfrak{B}$. if eher wie ein

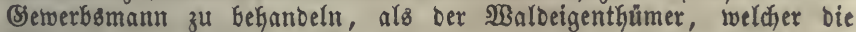

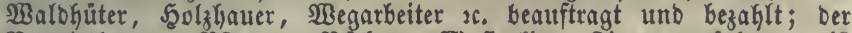
Bermietfer von SPferben, Bübern, \$luficalien, Simmergeräthen 2c. if

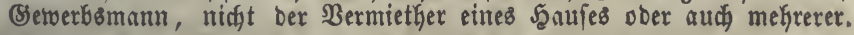

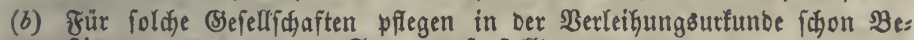
ftimmungen wegen ber Steuer aufgeftellt zu rerben.

\section{§. 362 .}

Unter biefen 6 2tbtheilungen ber Serwerbe ift mur bei ber erften bie 3uläfftgfeit einer Beiziefung zur Eetwerbfteuter nidft auser 3weifel.

Bei Der Serwinnung ber Mineralftoffe fint bie Bergs werfsunternehmungen gemöhnlid) barum yon biejer Steuer frei geblieben, weil man ifnen vermöge bes̊ $\mathfrak{B}$ ergwerfäregales eine eigene höbere 2lbgabe auferlegt hatte, beren Ërmäßjigung nach bem Fupe ber Setwerbfetter jebod) rathjam uno in einigen ¿änbern icton auşgefübrt ift, \$. 181. Steinbrüd)e, Torfftidje,

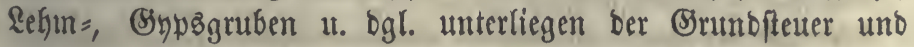
bringen als Berwerbsumternefymungen in ber Regel neben ber 
Srrunbrente nur einen geringen fteuerbaren Sewwerbsertrag. $2 \mathbb{B}_{0}$ jebod) biefer beträdtlich) unb als vorïbergehend in ber (Srunos=

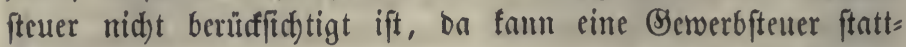
finter.

3u ber $\mathfrak{L} a$ nowirthid a ft gehören: Sambirthe im enge= ren Sinne, weldye Felbbaut uno Bichzudst mit einanber verbin=

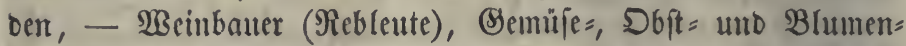

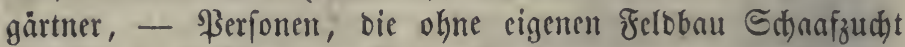
betreiben ober Rühe zur Mrildfwirthjd)aft miethen (Şollänberei= \$adjter) $(a)$, - Teid) = uno Fluffifif $)$ u. Dergl. Şiebei ift

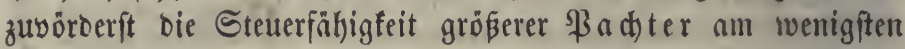
zu beftreiten, ba bieje in Bezug auf Eapitalzinz und Senerbz= werbienft anderen Unternehmern gleidfftchen, wermittelft ihrez anjelynlidjen Enpitalez zwijhen veridjiedenen Beidjäftigungen ober wenigftenz zwifhen veridjiebenen Begenoen uno Ränbern wăhlen fönnen unt ein reines (Eintommen erwerben, weldjes

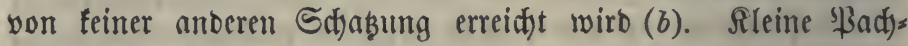
tungen bagegen, bie mur ein geringez Enpital erforbern,

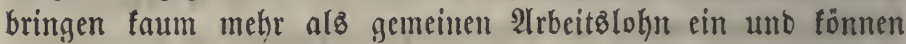
füglidh wie bie Rohnarbeit behandelt merber, weil baş ftarfe Mitwerben unbegniterter Inowirthidjaftzfunbiger ßBerionen ge=

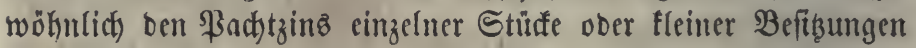

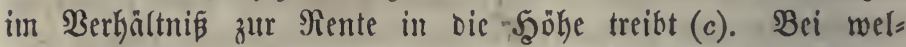

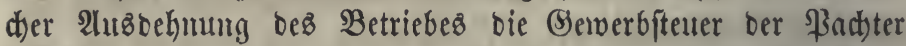
anfangen und nad) weldter Niegel fie fteigen foll, bié̈ fann

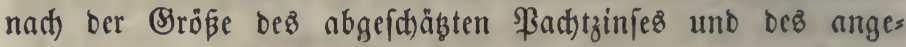

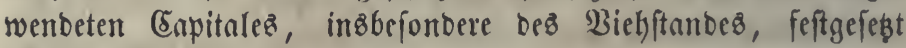
werben $(d)$.

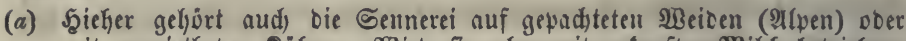
mit gemietheten Silfen. SBirb fie aber mit gefunfter Dild betrieben, To ift fie ein (Semerf, nämlid) Berartheitung ber פlita.

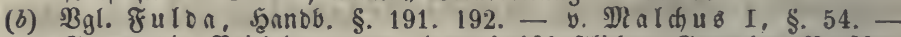

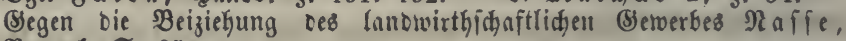
Bemerf. ธ. 95.

(c) Bei ftarfer Bertheilung oes (Srumbeigentlyums fönuen fid Eleine ßachter, menn fie gar fein eigenes \&and Gaben, nur fdywer belyaupten.

(d) Die franzôfifdue taille personnelle trấ auth bie ßaditer. Encyclop. a. a. D. S. 654. Rach Dem Steuer= Megulativ Des (S)eneralgouverne:

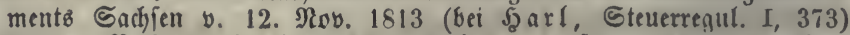
murben ßadter mit einem Steuercapitale angéfebt, weldjes $5 / 3$ ifrez Fachtziufes betrug. In 2 eimar verfteuern Pachter ganzer Eanogüter $1 / 4$ Des Sadtzinfes, in Sadjen (Sefes v. 24. Dec. 1845 \&. 37) zahlent 


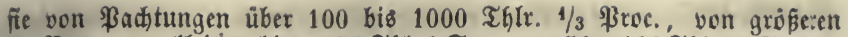
2/3 \$roc., von fleiven biв zu 50 Thl. 8 Sgr., von 50-100 Tht. 15 Ggr.Bei ber britifden Einfommenteuer giebt ber \$adyter in England halb poviel, als ber (Sirunbeigner, in Sduttland uno Srlano ungefâfr $1 / 3$ $(\$ .400(a))$, es ift alfo angenommen, oas fein (Sinfommen in (8nglano bem Galben \$adtzinie gleidfommt. Bei fleinen Buttern, z. B. von

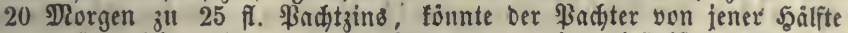
(250 fi.) nicht beftehen, er beziegt melyr, aber oiés ift gropentheils

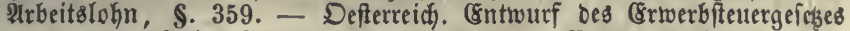
von 1863: Sleine Pachtungen, bei Denen 5 \$roc. Des Ertrages Das Cteuerfimplum von 2-8 fi. nidut erreidjen, Bleiben frei. - Nad Dem

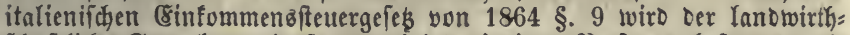
(4)aftridhe (5etwerbsverbienft nur bei benjenigen \$erionen befteuert, Die nidht Die Srunbeigenthumer find. - In bem franzöfichen (Sinfommens: feuerentwuri bon (S) oud d a $u x$ war eine Beiziehung bez Ianbwirth=

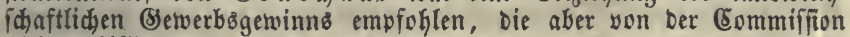
nicht gebilligt wurbe, $\$ .374(d)$.

\section{§. 363 .}

Für die Steuträhigfeit bez felbftwirthfdaftenden

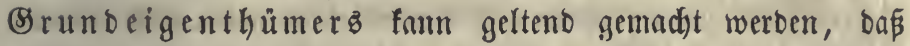
berjelbe neben ber Brumbrente zugleich einen Bewerbäberbienft unb Capitalzins wie ber ßađter $(a)$, bei fleineren Beftz̧ungen auch) Arbeitzlobn bezieben muß uno onß bieje (sinfünte von ber Srrunbfteuer nicjt getroffen werben. Daker find in mebreren \&ånbern auch wirflich alfe \&anbwirthe, fowohl \$achter alo (5igenthủmer, unter bie (Setwerbftetterpflid)tigen eingeredynet wor= Den (b). Coldye Ranbwirthe, bie ifyren Sänbereien burch befondern (S) ewerbfleís unb größeres (Capital beträchtlid) mehr (5rtrag $a b=$ gewinnen, alz man bei ber 2lnfeķung ber Srunbfteuer auf längere Dauer und uad) ber üblid)en Bewirthidjaftung anneh)= men burfte, \&. $\mathfrak{B}$. Durch) eine ftarfe $\mathfrak{B i e h n u k u n g ~ ( \$ . ~ 3 3 3 , ~ \Re r . ~ 6 ) ~}$ ober ftarfen 2 nbau bou Scanbelsgewächfen, foftbare arbeit= parente Mafdimen, vorgüglidh gute Sebäube u. bgl., fönmen offenbar leid)t eine Setwerbfteuer tragen. Sebod ftelfen fid) einer allgemeinen Bewerbfteuer von ben ihre eigenen $\mathfrak{B}$ efizungen verwaltenden \&nnbwirthen mehrere (Srünbe entgegen. 1) Bei

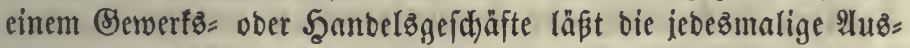
behnung bes (sewerbzిbetriebes auf eine gewiffe Esinträglidfeit

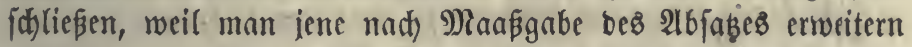
ober werengern fann. Dagegen beftimmt fid) ber llmfang eiuer

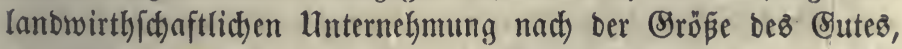
bie als ein gegebener Umitand anzufehen ift, Denn eine $\mathfrak{B e r}=$ gröperung ift in ber Pehrzahl ber Falle nid)t autfinlyrbar unt 


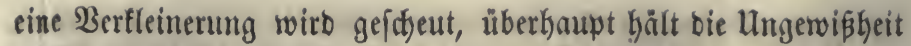

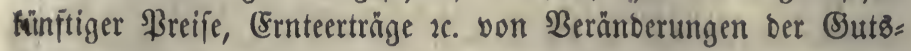
flidc) ab. Der Eigenthümer ift an fein \&ano gebunben, er ımis saffelbe auch) unter ungünítigen Uumfänben fortbauen uno if in ber Berwirthfdyaftung burd) Rage uno Beidjaffenteit mehr beidgränft als viele anbere Berwerbtreibenbe. Raturereigniffe und unbortheillyafte Sreife idjmälern biszweilen fein (Einfommen, okne Daß er ein anberes (Erwerbsimittel zu Şülfe nehmen fonnte, unb er hat bann ichon Mähe, yon Sabr zu Sahr eine gleid)e (Snunb= fteuer aufzubringen. 2) Die Ornubrente wirb zum Theil von Den Bimfen ber Unterpfanbsiduldoen aufgezehrt. So lange ber ftarf veridjuldete Sirundeigenthỉmer feine Steuererleidfterung

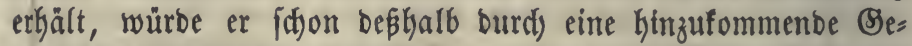
werbiteuer zu fdjwer getroffen werben. 3) Waährend grofe Unternełgmungen in anberen Betwerben nidjt nur einen größeren . Conpitalzinb, fonbern aud) cinen höheren ßrocentfak bez (B)e

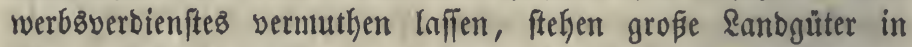
Der leģteren Şinfitst oft ben mittleren nad), wenn fie nidjt vorzüglid) gut bewirthfdaftet werben, uno haben aud) gewöhn=

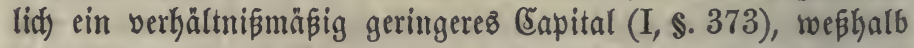
ihre Eigentfyumer idjon yon ber (Srunbfteuer mehr bejdyert werben, \$. 305. 'Mittelgüter zeigen allerbings in biejer Şin= fidyt einen günftigeren 3uftanb, bod) finb bei innen fowie bei ben Eleinen uno ben Sătern ohne befonderes Epannvieh bie

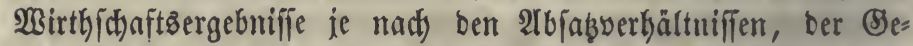
iofidflid)teit, Thätigfeit uno bem Canital ber Eigenthümer fefhr ungleit). Bei einem Theile berfelben beat ber SeetwerbByerbienft

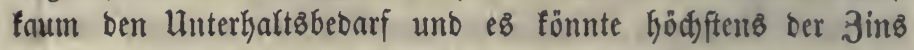
bes angewendeten Erpitals als fteuterbares Einfommen gelten. 4) Bei metreeren anberen Sdjabangen fowie bei ben anberen Seiverben erfennt man bie großen Sdjwierigfeiten einer volls

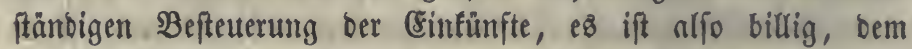
lanbwirthf(d)aftlidjen (Eewerbe, weldjes fid ber Sdjäß̨ung weniger entziefen fann, eine Sthonung zu geftatten. Demnad) würbe

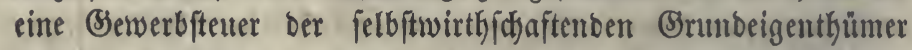

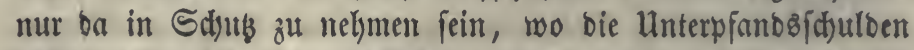
bei ber Srrumbftener beruffictitigt werben und wo ber Betrieb eines \&anogutes befonbers einträglid) ift, \&. B. wegen vorzŭglich 
bortheilhaft eingeridteter Sebäube (\$.356 (d)), neuer (S)runb= verbefierungrn, bie in ber Srunbfteuer erft bei einer Erneuerung beadjtet werben fönnen, eines beträd)tlidłen 2 ufroandes an

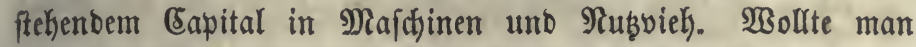
aber bie Stenter mur in foldjen Fällen auflegen, fo würbe bie Rataftrinung fefre verwidelt, in Erfolge ungleid) uno feinez: roegs beloknent fein $(d)$.

(a) Thaer, Eanowirthid). Eewerbslehre $\$ \cdot 75$. - Dá̃ ber Sins won bem ftehenben und umlaufenden Sapitale ein neben ber Sirunbrente feken= bes Crinfommen ift, Gat man audy bei ben Berechmungen ber legteren anerfannt, indem man 3 . $\mathfrak{B}$. Den 3 ins Des Biekitanbes unter bie Eul= turfoften redinet, §. 333. 8. - \$. of $\mathrm{fmann}$ (ङtaatstwifienid). 3eit=

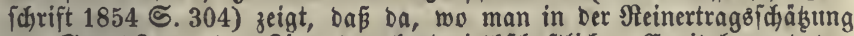

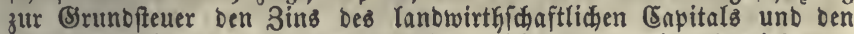
Setwerbsverbienft ber \&anbwirthichaften nicht unter bie abzuziehenden Soften aufnimmt, Die (Srunbfteuer zugleid eine Setwerbsfteuer in fid) id)lieft. Sene ift bann bei verpaditeten Brunbitúden zu hod.

(b) Nach bem naffauifichen Betwerbfteuergefes von 1841 erfilt ein \&ano= wirth für eine volle Fubr (1 \$ferd ober 2 Dhjen) 100 ff., für $1 / 2$ fuhr (1 ßf. unter 3 S. ober 1 Ddfe ober 2 Rủhe) 57 fl., ofne Spann= vieh 50 fl. Steuercapital, ein $\mathbb{W B}_{\text {eingärtner unter } 11 / 2} \mathfrak{D}$. 50 fl., von $1 \frac{1 / 2}{-3}$ IR. 100 fl., yon $3-6$ IR. 200 fl. unb für je 3 IR. weiter

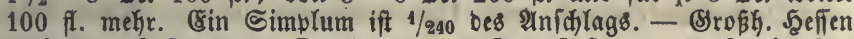
nad Dem Seres v. 2. Detober 1813. Das Sefes v. 16. Suni 1826

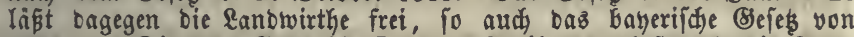
1856. - Die Bab. Setwerbft. SD. v. 6. April 1815 befteute bie RnD $=$ wirthe, aber nidjt hojker als Taglöhner. Das Bef. ๖. 23. Tpril 1854 unteridueibet aber 3 Glaffen, mit einem Srumbfeuercapital unter 10000 fl., von 10-20000 fr. unb über 20000 fl., es wirb jeopd für bieje brei Claffen nur ein Steuercapital bes periónlichen Berbienftes von 500, 875 unb 1750 f. angerebt, aljo (zu $5 \%$ ) ein fteuerbares Betwerbsein= fommen won $25,-42,75$ uno 87,5 fi. voraugefest, tovon bie jesige Steuer 1 fr. $55 \mathrm{fr},,-3$ f. 21 fr. unb 6 fr. 42 fr. ausmadit. -

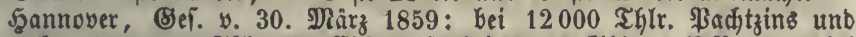
mehr 140-156 Thlr. (1. (El.), alfo bei 12000 Thlr. 1,16 \$rocent, bei 6-8000 Thlr. $65-80$ Tlr. Steuer $=1,08$ \$roc., bei $80-120$ Thlr. nux $151 / 2$ Sr. = $1 / 2$ \$roc., \$adter unter 80 Thlr. find frei. - Sn $\mathfrak{W e i m a r}$ wird ber felbftwirthif aftende (Srunbeigenthumer fo behanbelt, als wenn er frembes \&and baute.

(c) Die Biehfteuer fann als eine nach einem Theile bes Eapitals angelegte landwirthfijaftlidje Setwerbftewer angejehen werben. Sie fam fojon im 13. Jakrh. vor, Lang ธ. 102. In ben alten Bermögensifteuern wurbe Das Bieh mit angefest. Im R. \$reusen beftand neben Dem

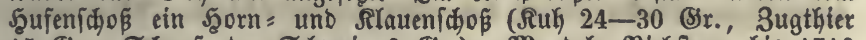
15 (3r., Sdaaf voer Sdwein 3 (Sr.). Siagbeb. Biehfteuter bis 1716 (\$ferb 4 ober 8 (Sr., Dhie 3, Suh 2 Gr. 26.), Rle wib I, 59. Die alte Gdjodfteuer traf aud ben Biekfano. - Das ang. Keff. Sef.

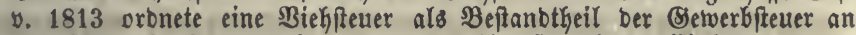
unb feste als Steutecapital (worunter hier fteuerbares Einfommen ver= ftanden ift) von 1 \$ferbe 2 f. $30 \mathrm{fr}$., von 1 3ugochen ober frarren

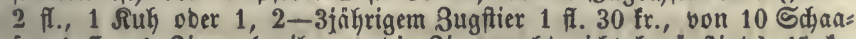
fen 1 fl., 1 Siege (tweil man bie 3iegenzudit nidht begunftigte) $45 \mathrm{fr}$. Daneben erfielten alle Eanbwirthe cin Steuercapital bon $18 \mathrm{fl},-$ Bine 
Befteuerung bes Biehifantes fann zwar aus bem in Rste $(a)$ bemertten (Srunbe vertheidiget werben, hat jeodd wenigftens bei bem ir beits:

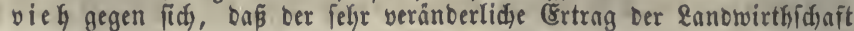
(oben NR. 1) genaue Beredinungen verhindert und es fehr ztweifelhait madat, of bicier unentbegrliche Theil bes (Sapitales fid aud wirflich

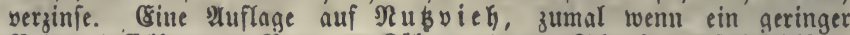
Betrag befielten, z. 2. 1-2 Suthe, 10-20 Sthaafe 2 . frei bleiben, wurbe fich nod, am erften vertheidigen laffen, wenigftens in 3eiten, wo Die wirflichen \$reife Der landwirthichaftlidjen (ËrzeugnifTe in Bergleids mit ben bei Der Srunoftetter angenommenen vortheilhaft erífteinen. Die

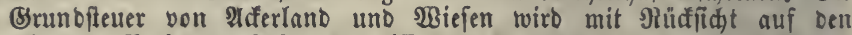
mittleren Preis Der श्रfererzeugnifie uno bes Syeues angelegt, es wiro

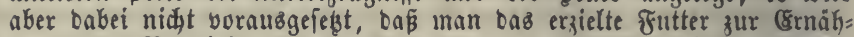
rung von Nurbieh verwendet unb baraus mit Şülfe eines gröperen Sapitales einen ftäfferen (Bewinn exlangt. Die श̂̉usführung if feood) wegen ber zu Beruidfidtigenden Berífiebenkeiten fatwierig; 3. $\mathfrak{B}$. in

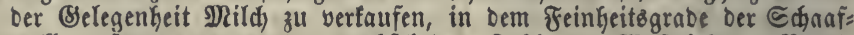

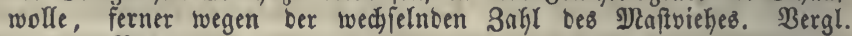
§. $333, \mathfrak{N r} .6$.

(d) Şiemit ftimmt Bierfad überein, Heber Beft. S. 152. - Naffe

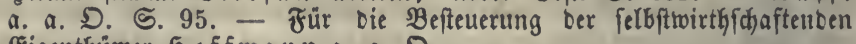
Eigentbumer $\mathfrak{S}$ offmann a. a. D.

\section{§. 364 .}

Das Csinfommen bes Unternehmers ift ein Theil besి ge= fammten Berwerbbertrages uno muß in einer unb berfelben 2 rt bon Unternebmungen mit biefem $a b=$ unb zunehmen. Bergleid)t man aber mefrere (Serverbs z weige, fo wiro ber Intheil bes Unternehmers einen febr ungleichen Theil bes ganzen Ertrages

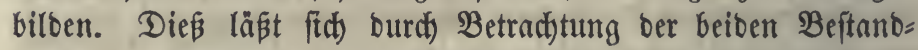
theile bes \$sewerbseinfommens (\$. 359) erläutern.

1) Der (5apitalzing muß verbältnißmäßjig befto melyr betragen, ie foftbarere ftehenbe (Eimridytungen in einem Semerbe zu Şülfe genommen werben und je langfamer bas umlaufente (Eapital fid erfebst, 8. B. wenn Borräthe längere Zeit hinourd) liegen bleiben müfien (a). Die gewöhnlidje $\mathfrak{W}_{0}$ hlhabentyeit bei einigen Elaffen von Betwerbbleuten (z. B. Bäđfern, Brauern,

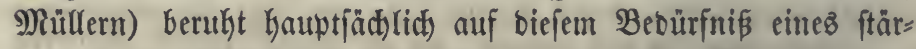
feren Capitalbefizes unb bem baburd befdränften शitwerben (b). Der 3ins vom umlaufenben Eapital ift am geringften, wenn ber Serwanblungaftoff nidyt bom Unternebmer angefd)afft zu werben braudyt, wie bei ben meiften Sdjneibern, Bubjbinbern, vielen $\mathfrak{M a h l} l=$, Dels, Sdhneibemüllern (nämlid) ben fog. Runts werfen), bei $\mathfrak{W e b e r n , ~ B l e i d b e r n , ~ F a ̈ r b e r n ~ 2 c . ~ i n ~ b e r ~ \Re i e g e l ; ~}$ ferner bei Commiffions: unb Spebitionsagefdäften. 
(a) Wenn in bem einen Betwerbe 120 , in Dem anceren 400 fi. Péfendes uno umlaufendes Capital Dazu gehören, um für 100 f. Erzeugniffe zแ liefern, fo find in Diejem (Erlje in bem einen falle 6 , in Dem andern 20 \$roc. Sins (zu 5 \$roc.) enthalten. - Serber, Schreiner, Siein=, Rorn=, Şolzhänoler 3 . $\mathfrak{B}$. Gaben beträdtlidae Sorräthe nothig. Benn ein SSewerbsmann, z. $\mathfrak{B}$. ein Rrämer, fein Capital $4 \mathrm{mal}$ im Jagre umegt, fo braucht er zu Dem Sahreberlöfe von 12000 fl. nur 3000 fl., welde 150 fl. Sins tragen, bei einjäfrigem Utmlaupe wirb er 12000 fi. (Sapital haben uno 600 fi. Sins erhalten müfen.

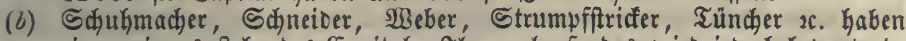
ein geriuges ftekendes (Eapital. Shr umlaufentes wird jedod bedeutend, wenn fie viele SSefülfen beidaitigen.

\section{§. 365 .}

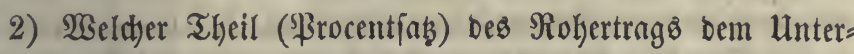
nehmer als \&ewerbsoproienft zufalle, dieß woird bebingt theils ebenfallz bon bem erforberlichen (Sapitale, weil mit bie= fem bie Şöhe ber Wagní, bie Sd)wierigfeit ber Srünbung unt Reitung Des Sewerbes und bie geringere Stärfe Des Mit= werbenz einigermaßen zujamment)ängt, - theils von ber Menge uno Sdywerigfeit ber 2lrbeit, z. B. Dem Maaße von Rennt= niffen, Sefdyidflidfeit, Erfohrung u. Dgl. Daher müffen cinem

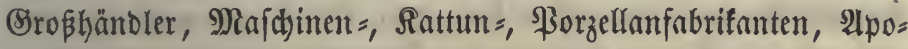
thefer, Bauuternebmer, Budbänoler, d)emifacen Fabrifanten, Uhrmadher, Sumelier 2 . mehr \$rocente beż (Erlöfes alb (B)e= werbz̄verbienft zufallen, als̄ einem Blajer, Topper, Seiler,

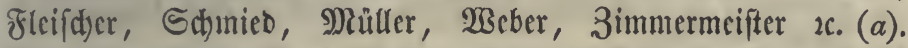
Wentn ber fleine Unternebmer aud) gemeinen alrbeitblohn be= zielyt (\$. 359), to famm biejer mur nađ) Dem für bie Sefhủlfen jeber Art bon Serwerbe beftehenben Saze angejthlagen werben. Dieje beiben (sinfünte mad)en zufammen einen befto gröferen Theil bez (Ertrages aแts, ie mehr überbaupt ber Unternefmer zur (Erzielung beffelben burd) geiftige ober förperlide Thätigfeit mitwirft.

(a) Sin 2abfak von 100 fl. exforbert vielleidgt in bem eiten Setwerbe 10 Arbeitstage Des unternefmers zu 2 fl., in Dem andern nur 1 Tag zu 5 fi., alfo refp. 20 und 5 \$roc.

\section{§. 366 .}

Bon bem ganjen Serwerbsిverbienit ift nur ber über ben Unterhaltäbebarf hinauzgehenbe Theil als reines, fteuerbares (Sinfommen anzuleken. (Er giebt fidf) burdy reidjlidten 2ufwand für 20 blleben und burd) Erfparniffe zur Bermefrung Des 
Eapitales funt. Diefer Betwerbs geminn madt) teineswegs immer einen gleidjen Theil bes gejaumten Bewerbserberdenftes aus. Bei vielen im Rleinen betriebenen funftlofen Bewerben fteht fid) ber Unternefmer wenig befier als feine Soknarbeiter, b. h. nimmt nur ungefähr foviel ein, als ber nöthige Unterbalt feiner Eamilie erforbert $(a)$. Wirb bagegen ein Bewerbe in grö́perem Uumfange, mit Şülfe bon wirffamen Rumftmitteln, mit Brelegen= beit zu Betrieb8̇verbefferungen unb Softenerparungen, mit einem

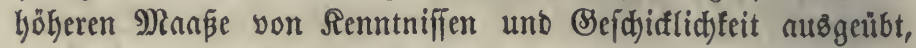
fo pflegt ber reine Bewwerbsuerbienft nidjt allein gleidymääig mit bem ganzen Berbientt zu fteigen (\$. 365), fonbern aud) eine größere Duote beffelben zu bilden, weil unter fo gümftigen Umftänoen ein bas mittlere Manß überfteigender $\mathfrak{B e r b i e n f t ~ e i n , ~}$ tritt. (Es ift zwar idfwer, genau anzugeben, wie weit ber Unterkaltsbebarf gehe und wo bagegen Der entbehrlide, Dem Wohlleben angehörente Theil des 2lufwanbes anfange, bod

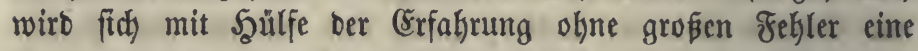
Stufenleiter ber ungefähren Unterbalt\&loften in ben veridjiebenen Bewerbsazweigen für jeben Drt oder Bezirf $(b)$ aufftellen unb eine mittlere Dutote Des reinen Semerbönerbienftę bezeidnen laffer $(c)$.

(a) Ștaatseinridjtungen, weldje ben 3utritt zu einer $\mathscr{A r t}$ yon (B)etwerben

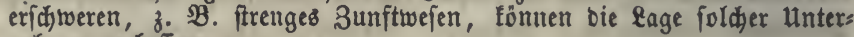
nelymer verbefiern.

(b) SBegen ber ungleidjen Soften ber WBoknung, Des Şolzes, felbft ber Rebenzmittel $2 c$.

(e) Fănbe man $z . \mathfrak{B}$. in 4 Sewerben ben mittleren $\mathfrak{B} e$ barf einer Familie

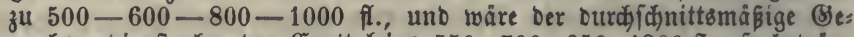

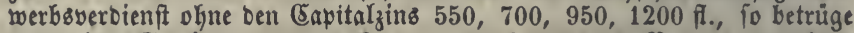
Der reine Berwinn $9,-14^{2} / 7,-15,79$ uno 20 Proc.. Des ruhen. Gdjlägt man aber bie Gapitalzinjen bazu, fo werben Die Qutoten tes

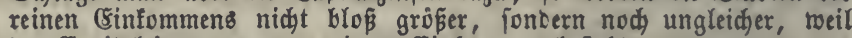
ber Eapitalzins ganz aus reinem Einfommen beftegt.

\section{\$. 367.}

Die verfdiebenen Rennzeiden, aus benen man bie wirthjdaftlidjen Berbältniffe ciner Bewerbsunternehmung und insbejonbere bas aus ihr fliefente rohe unt reine Einfommen bemefien fann, müffen bei ber 2 nnlegung ber serwerbfteter forg= fältig beadjtet werben. Sebez beriélben bient bazu, in getwiffen

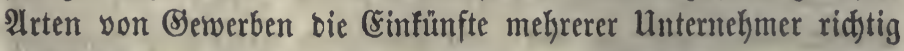
zu bemeffen, allein bie Bergleidjung von Unternehmungen ver= 
fdjiebener Irt fann mur aus ber Sejammtheit alfer Umftäno mit Sidjerkeit angeftellt werben. Bei berfdjiebenen Bewerben tritt bald Daş eine, bald Das ambere Rennzeidjen beutlicher her= vor. Şieher gehören:

1) Die \&rö́pe des ftehenden Capitales, woraus

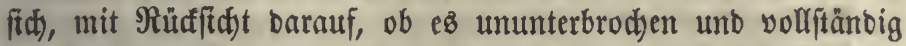

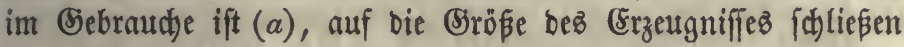
läpt. Bei mand)en (Sewerfen ift biefez Merfmal vorzüglid) bezeidjuent, z. B. Die 2 nzakl von 23 ebftülen $(b)$, Spinteln in Spinnereien, Sdyeermafhinen, Drehbänten, Druferpreffen, Sdjopfmajchinen, Bütten in ber \$apiermüfle, Reffeln in ber Färberei, Drudtifichen ober $\mathfrak{B a l z e n ~ i n ~ D e r ~ R a t t u m f a b r i f , ~ D e j e n ~}$

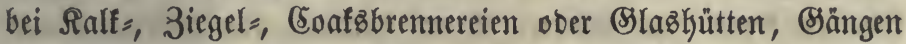

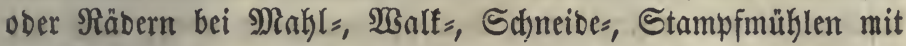

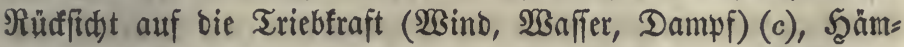
mern unb Sceerbfeuern bei Şüttentwerfen, Drahtzügen, Majchinen verfobiebener ant $(d)$. Daffelbe gilt von einigen anderen (S) werben, 子. B. 3ahl unb Befdaffenteit ber 3immer in einem (5)afthofe (e), ber Sfferbe eineż Fuhrmannes unb Rutichers, ber Rühe einesి Mildtyerarbeiters, Tonnenzahl eines Segel = ober Dampfichiffes $(f)$. Meiftens giebt aud) bie 2 (ubbefymung ber

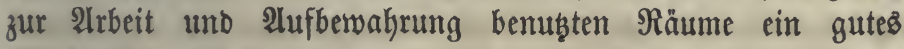
9)ierfmal.

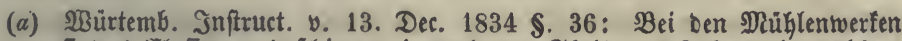
find 4 (5laffen unterfacieon, je nad bem Theile Des Safyres, in meldyem fie in Sebrauch fint. Szantb. G. 91. Das গaff. Sef. v. 1841 theilt zu Diefem Befufe bas Jafre bei veridjiebenen Belwerben in 2,3 unb 4 श्रb

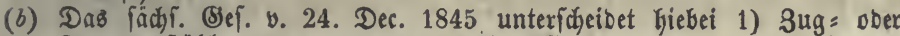
Jacquarbitulyle, a) von 3 ober mehr (Ellen Breite, b) von geringerer SBreite, 2) getwögnlidbe Stůhle.

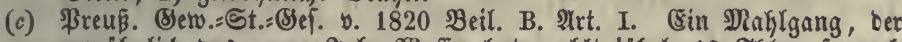
getwỏnnlich bas ganze Jahy Waffer Kat, zahlt jährl. 12 Thlr., fo aud 1 Sraupengang, 1 Delpreffe, 1 Gágegatter an einer Mä́fle, bie mekr als eine Sảge hat (jonft gilt bie einzige nur als halber șahl= gang), 6 (E)rubenlöber eines Stampfwerfes. - Sächf. Bef. v. 1845:

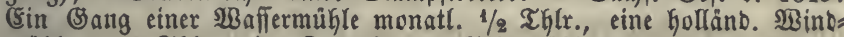
mühle 2-6 Thlt., eine Dampf: ober Thiermühle 20-40 Sgr. für Die

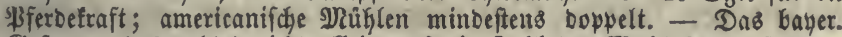

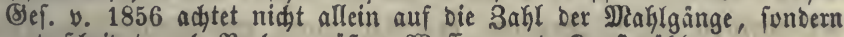

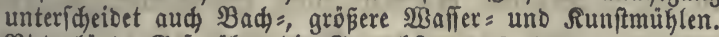

(d) Nieberlänb. Biê. über bie (sewerbfteuer (droit de patente) ๖. 21. Nai 1819 u. 6. 2Tpril 1823: 2uß̈er Dem Durch Die 2rbeiterzaf)l beftimmten (Slaffenfaze zahlt ein faarber von jesem Refiel 2,60 fl., cin Tudprefier von jeber Tuchpreffe $4 \mathrm{fl}$., cin Sattunfabrifant von jeber Drudtwalze 
8 f., ein (Serber von jeber Sufe voer (Srube $0,55-1,10$ fl., - IRahl= müfletl (Tab. 3) $2-4$ Proc. Des Inietfzinies (valeur locative). Biele

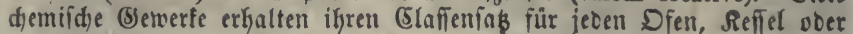
jebe Feutertätte, 3. B. ein 5odyufen El. 1-8, 1 Baar Walzen bei

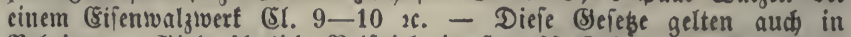
Belgien. - Biele åhnlidbe Beifpiele im franzơf. Bef. ๖. 18. Nai 1850.

(e) R. Nieberläno. (Sef. Tab. 13, aud bie 3afil ber Babetwannen in Bäbern, ber Billarbe.

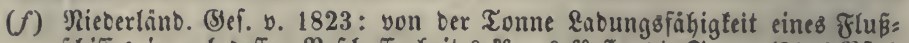

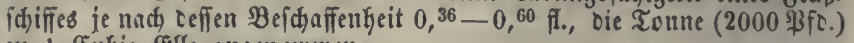
ju 1 Cubic= Elle angenommen.

\section{§. 368 .}

2) Sröpe bes umlaufenden Eapitalbs, a) Bistweilen ergicbt fidh eine gute Selegenteit, bie Menge verbrauthter Stoffe fennen ju lernet, twenn nämlid) von benjelben eine Alufiwandzffeucr (3oll ober Ilecife) entrictet wirb, wie bei Fleipct)ern, Brautereien, Branntweinbremereien $(a)$, Nühlen, wo cime Mahlifeuer befteht, Weinhanblungen, Edjentwirthfdaften, Rübenzucferfabrifen, Fabrifen, weldbe bloß zollpflichtige ein= geführte Stoffe verarbeiten. b) Sn anberen Nakrungżzmeigen ift bie Menge ber bereit gehaltenen $\mathfrak{B}$ orräthe bon berfäuf= liałen Dingen in bie Altgen fallent: Alpothefen, Raufläben, Şol $=$ unt Rolylentandlungen 2c. c) Bon vorzüglidjer $2 B i d=$ tigfeit aber und zugleids leidft wahrzunelymen ift bie $3 \mathfrak{a h l}$ Der SSehülfen. Se mehr bic anderen Betriebsiaugagaben im Berbältniß zum 2lufivano für die 2Irbeit betragen, ie mebr namentlid 9) anjuinen unt Stoffe foften, in Defto ftärferem (S)abe wiro burt), Das Şinzutreten einer gewiffen 2(uzah) neuter Arbeiter Der gamze (Ertrag und Der Antheil bez Unternehmerz vermefrt (b). Daß es übrigens hiebei nicht allein auf bie $3 a \mathfrak{l}$ ber bejdäftigten 2Irbeiter, fonbern zugleid) auf bie fiunft= lidfeit ober (Sinfactheit iffer Berridytungen und ben barnach abgemeffenen Lofyn anfoumt, erfenut man beutlid), wenn man fid) 子. B. Die 2lbftufung yon ben Comptoirbebienten eimes gropen Banflyaufe herab bis zu ben $23 e i b e r n$ unb finbern, bie in einer Tabafछ̈=, \$apierfabrif 2 . arbeiten, vergegenwärtigt.

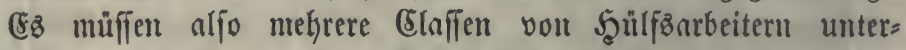
fásieden werben. Mit geböriger Beactutung aller in cinem Sewerbe obivaltenden Berbältniffe läßt fich von bem gennnnten Merfunal ein febr müb̧licher (Sebraudj matjen $(c)$. 


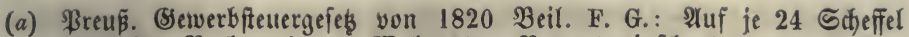
jährlidjen Berbraudy an פlalz ober Branntweinidjrot werben 8 (Sr. (S) werbfteuer angefebt. - Nieberlanbe: Bierbrauer unb gifigfieder bon 14000 uno mekg Sgeftol. Nalzberbraud) fommen in bie 1. Elaffe, von $10-14000 \mathrm{5g}$. in bie 2... unter $250 \mathrm{Sg}$. in bie 14. Cl. Bayern: Brauereien itber 75 Sdjeffel Darlzberbraudy geben für jeben weiteren Sdjeffel yon 1-225 Sđ. $4 \mathrm{fr}$., Darüber $6 \mathrm{fr}$.

(b) 88 fei bei 3 Setwerben A, B, C bie Bertheilung bes ganzen Erlojes nadi) \$rocenten folgenbe:
1) शrbeitalofir
A B $\quad$ C
2) Berbraud) von Stoffen . . . . 25
3) Sins .
4) Betwerbsyerdient

\begin{tabular}{rrr}
25 & 40 & 50 \\
$-\quad 7$ & 10 & 15 \\
$-\quad 8$ & 10 & 15 \\
\hline 100 & 100 & 100
\end{tabular}

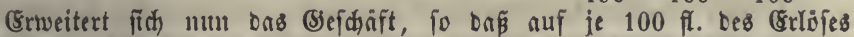
10 fi. mehr für Arbeiter nusgegebent twerben, fo wähft ber \&oknaufwand bei A von 60 auf 70 ober um $1 / 6$, bei B um $1 / 4$, bei C um $1 / 2$, unb Da bie anderen 2antheile fowie ber ganze (erlös ungefifye in gleidjem Berbåltnifis ausgebehnt werben, fo fteigen bie ben unternefymern zufallen= bell Esinfünfte $\mathfrak{N r}$. 3 ınD 4 bei A yon 15 auf $172 / 3$, bei B yon 20 nuf 25 , bei $C$ yon 30 auf 45 fi. - 10 शrbeiter in einer Sdyefelfäure:

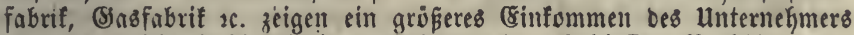

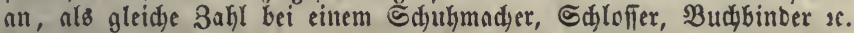
Die Sahl Der (Sefhullfen follte Demund nur in Berbindung mit anberen befannten Berballtniffen zur Biloung yon Stewerfäben in verfhiebenen (S)ewerben gebraudit werben.

(c) 3. B. Nieberlänb. Seféce von 1819 unt 1823. In Tab. I bes erften (5efebes if eine झlenge von Bewerben gennmt, bei benen bie Steuer

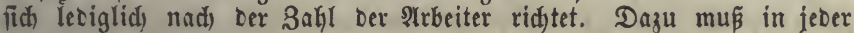

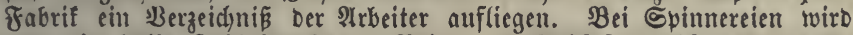
nur bie halbe 3ahl bered)net. Bei $1-3$ Befuilfen gehỏt ber unter: nefymer ber 1. 2tbth. Der Semerbe in bie 13., bei ber 2 . 2tbth. in bie 15. Elaffe, bei 3-6 Sehülfen refp. in die 12. und 14. El. u. F. f., bei $300-400$ Sielyülfen refip. in die 1. unb 3. Elaffe. B̉ei mandjen ber zugeforigen (Setwerbe finden nod) 3ujäze nadh Dem fiehenben (5api= tale fintt (\$. 367), unb bei einer शtuzafil von Sandwerfern zugleid

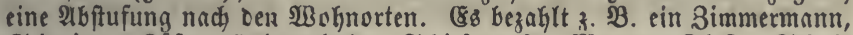

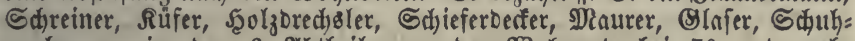

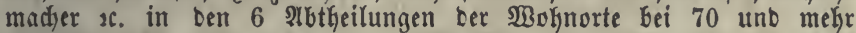

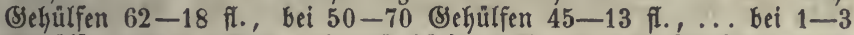

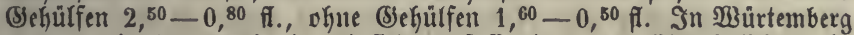

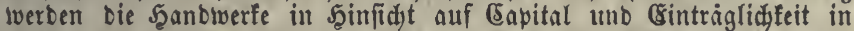
4 2ibtheilumgen gebradst, beren jebe 9 (Slaffen in fing begreift, 1) bei nicht vollem, 2) bei vollem Betriebe burdy 1 Menficen, 3) mit 1 (Ses bưlfen, 4) mit 2-3 Gehülfen, ... 9) mit 10-24 (sehülfen. Sebe Elafie hat wieber Itbftufungen, bie bazu bientu, nady inbiviouellen,

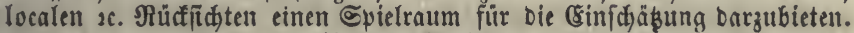

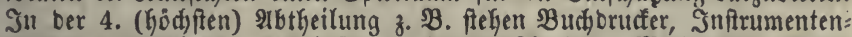

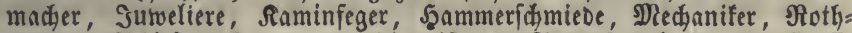
gerber, Sdjeferbeder u. a. Shier iff Der Steuerfas in ber 1. Elaffe $42 \mathrm{fr}$. bis 2 fl. $24 \mathrm{fr}$., in ber 2.2 fl. $12 \mathrm{fr}$. $-7 \mathrm{fr} .12 \mathrm{fr}$., in ber 3.2 fl. $48 \mathrm{fr} .-9$ fi., ... in ber 9.23 fi. $48 \mathrm{fr} .-56$ fi. $18 \mathrm{fr}$.

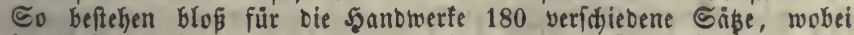
jebod ofters eine $3 a$ hl $3-4$ mal borfommt, twas fdjon eine umbothige

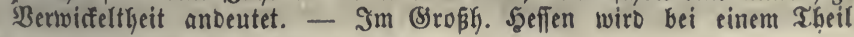
or a u, polit. Deton. III. 2. 96เ5. 5. शusg. 
Der Serwerbe für teben (Selyullfen $1 / 3$ Des Normalfteuercavitals zugefest. Gadjen: für jeoen (sefellen ober tedjnif(h) ausigebiloeten männfidgen Selyulffer $1 / 2$ bes Tariffabes mekr, für (S)hülfen ohne foldhe BitDung, ferner für weiblide uno für \&efrlinge $1 / 4$, ood if e in \&egrling frei. Das bayer. Sewerbftettergeies vom 1. Suli 1856 §. 12 unterideibet geid)äftsfundige (Sekülfen und 2irbeiter für untergeurduete (Sefdäfte. $\mathrm{B}_{\mathrm{ei}}$ biefen wiro nur ber Sag ber 1 . Steuerclaffe $(20 \mathrm{fr}$. Bis 1 fi. nads cer (Sinwohnerzahl Des Drts) angetwendet, bei jenen für ben erften Sehuilfen bie balbe, für jeben weiteren bie gamue Rormalanlage binzu: gefugt. Shur bei fabrifen findet feine unterideioung jener 2 Slaffen von (S)hullien tratt und es wirb für feben ein beftimmter Saks, in ber

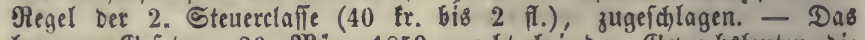

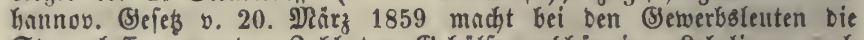
Stenerclaffe you ber $3 a h l$ ber (behülfen abhängig. Lehrlinge nad

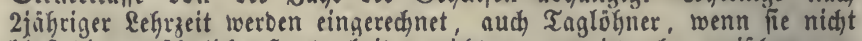
blos bie gelwobnlidje Şanbarbeit verridten, es wirb aber zwifden ver: fdiebenen Arten von (Sehülfen fein unterichied gemadt. Baidfer mit 7 uno mehr Sehülfen zahlen 子. 2 . 27-45 Thlr. (5. (5l.), mit $3-4$ (S)hülfar 3 Thlr. 18 Sr. bis 10 Thlr., ohne Bsehullfen, wenn fie mehr als zweimal wödsentlid baden, 1 זglt. (10. (5l.). - 2lud in Frantreich iit neuerlich bei einer 2 nzahl von (Setwerben angeoronet, laß́ fü jeben Arbeiter uber 5 ober 10 nod) 3 Fr. weiter zu entridften iino. - Baben F. \$. 373.

\section{§. 369 .}

3) (5) Eeiftungen, o. $\mathfrak{B}$. Menge ber berfenbeten Wanten, ber beher= bergten ßerfonen, ber Zabl bon Babffammen einer Beleuth)= tungघgefellictaft $(a)$. Bei mand)en Semerben ift es nidjt idfwer, Dieje Nenge zul erfatiren, auto ber man bann ben ganjen (Se= werbsertrag ermitteln fann (b). Sn mehreren Stanten hat man

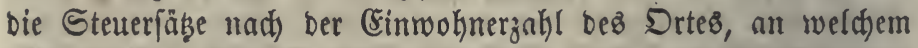
eit (Bewerbe betrieben wirb, abgeftuft, weil man antabm, baß

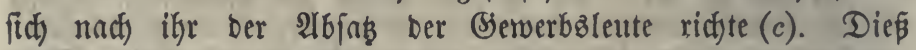

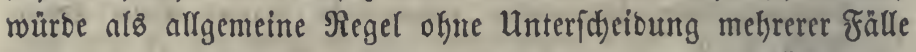
nid)t zu billigen fein unb ez muß baher bie Berủdficdtigung biefes Umftanbes mit Behutjamteit gefdeken. a) Bei (Sewerben, beren Erzeugniffe eine weite beriendung ertragen ober beren

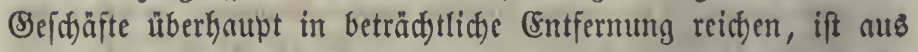

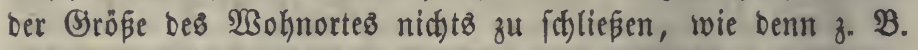
viele Fabrifen wegen bes wohlfeilen Şeizftoffes, ber Waffer=

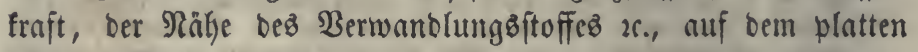
Lanbe angelegt worben fint, ohne barum weniger zu ertragen.

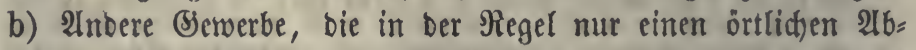
fas Gaben, fönnen bod) in benad)barten Drtfdaften zahtreidje 2bnefiner finten, 子. B. Dorffanbwerfer in ber Säfye von 
Stäbten, ober auß̊nahmbiweife für einen weiteren UMmtreis

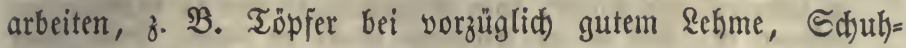

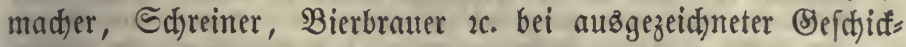
lictfeit. c) $\mathfrak{W}$ enn bagegen ein Bewerbe in einem gegebenen Falle für rein örtlid) erfannt wiro, fo fann man aus ber yon Den (Eimwohnern verbrautiten uno nicht etwa auf andere $\mathfrak{B s e i f e}$

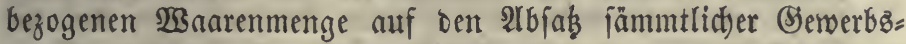
genofien bes Drtes falliepen uno hieraus einen Mittelfas bes auf ieben Unternetymer fommenten Ertrages uno Selverbzein= tomments ableiten, an bem freilid bie einzelnen Betwerbsleute in fehr ungleidjem Maaße Theil nehmen fönnen (d). d) Mandje Şanbwerfe arbeiten zlwar nifft allein für bie Drtß̧berwohner, finteen jebod) an einem volfreidjeren 130 hnfitige wegen ber Reid $=$ tigfeit Der Beftellungen uno bes $\mathfrak{B e r f a u f s}$ erheblidye $\mathfrak{B}$ ortheile, unt ein Theil ber zugehörigen $\mathfrak{B}$ erridtumgen, z. B. bie Atts= befferungen älterer Bsemertşwaren, ift. Faft ganj auf ben Drt befd)räntt. Bei foldjen Bemerbsizweigen ift $e B$ angenerfien, zwar im 2trgemeinen ben Stetterbetrag nach ber Soröpe bes 230 hnortes ftcigen zu laffen, Dod) nidft fo ftarf, wie im vorigen

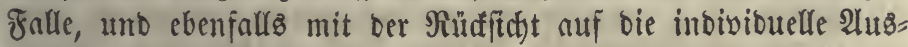
Defhung Deß Betriebez.

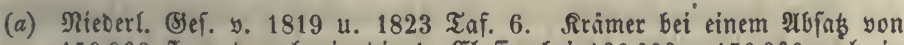
150000 fi. und mehr in bie 1. Slaffe, bei $100000-150000$ excl. in bie 2., bei $75000-100000$ in bie $3 . .$. unter $1000 \mathrm{fl}$. in bie 17. ฮร. - Taf. 15. Theater unb andere Belttfigungen im Shaufpiel= Gaule bezahlen 1 ßroc. Des Esintrittse geldes jeber Borftellung, Das Szaus als voll angenommen. - Die शlbgabe von Miethfutichen $(\S .212(a))$,

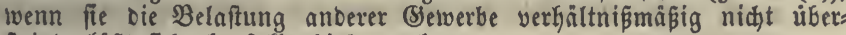
fiteigt, läít fid ebenfalls hieher redhnen.

(b) 3. B. Naffau: Bietbrnuer unter $50 \mathrm{Dhm}$ jährliø in bie 1. Elaffe, unter 75 in bie 2., tunter 100 in bie 3. und für je 50 Ohm weiter um eine Slaffe Göher. - Bayern (1856): ủber 150 (Simer Bier be= arünoen is 75 erimer weiter einen Sufaz von 1 fi. für Bierfdenten. Branntweinbeenner für jeben (simer über 10 eituelt Steuterzuidhlay von 3 fr. - In Jannuver (1859) werben Bierbrauer nad) Der 3ahl Der gebrauten Dhume angeiegt, Branntweinbrenuer bezahlen $11 / 2$ \$roc. Der SRaifdfteuer, wenn Diefe über 100 Thlr. ift.

(c) So z. 3 . Die franzoffiche Cteuerpatentabgabe §. 374, Doch nidgt für

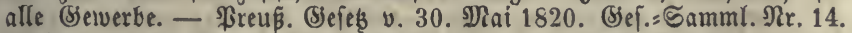
(SinnholD) Die Bemerbfleuerverfafiung Des preus. Stants, Riegnibs 1831. 40. Şier twerben unterfuieben 1) bie 10 grossten Striote, 2) Die 133 (iegt 121) mittleren, 3) Die übrigen Drte über 1500 Einwohner, 4) Die fleinerent. - Das Bab. SSejes v. 23. Nairz 1854 nimmt für einen Theil Der Serverbe viererlei Drte, nämliđ Dörfer - Stảdte unD פlärfte bis 4000 (Sinw., - foldje yon 4-10000 uno über 10000

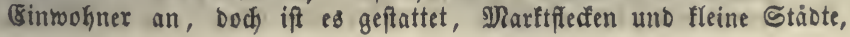


Die auf einer nieberen @tufe bes (s) werbsbetriebes ftehen, wie Dỏrfer zu beftetern, unb Stäbte, Deren Einwohnerzahl liber bie Claffengrảnze geftiegen ift, nod) in ber bizherigen Glaffe zul Iafien, fermer fleine Nebenorte nid)t zum Saaptorte zu redinen. - Naffau: nur Stabte und Rant. - Bayer. (Sefeb bon 1856: 4 Abtheilungen, von meniger als 1000 , von $1000-4000,4000-20000 \mathrm{Gw}$. uno Darúber. Diefe

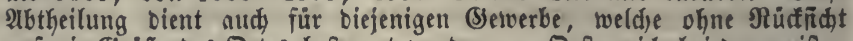
auf oie Bripipe bes Drtes befteuert werben. - Defterreid) bei ben meiften Semerben: 1) WBien uno $11 \mathrm{mgegent}$ bis zmei Ileilen Entfernung, 2) Szauptifatte ber ßrovinzen, 3) anbere Drte von 4000 (8iv. an, 4) von $1-4000$, 5) unter 1000 (8w. Batent v. 31. Dec. 1842. (S) fegentwurf yon 1863: Bemeinben unter 2000, yon 2-10000, von $10-50000$ (sw., über 50000 und enolid) Sieu.

(d) Das preus. Sejess fellt für jebes SSewerbe in jeber ber 4 ibtgeilungen eimen Ilittel= und einen niebrigften Gab auf. Sener mit ber 3ahl cer (Sewerbtreibenben Der Stabt soer (in Der 4. 2Abtheilung) Des Sreifes vervielfad,t, zeigt die von benfelben im Sanzen aufzubringente Summe.

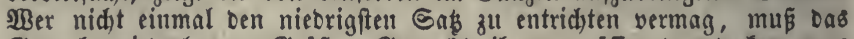

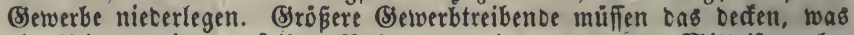

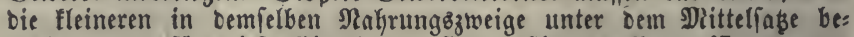
zaklen, und für biefe Esinteifung find befimmte \$rogreffionen vor= gefdriében. So z. B. für Şantwerfer

शำ 2.2 3. u. 4.

Mittelfak . . . . . 8 Thlr. 6 Thlt. 4 Thlt.

Riebrigfter Sab: : : 4 " 2 " 2 "

Dic Steigerung if $4-6-8-12-18-24-30-36-48$ " 60 Thlr.

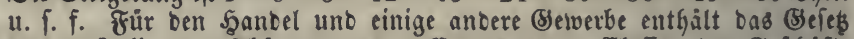
v. 19. Suli 1861 Abảnberungen 88 merben 3 (Elafien Der (Sefhajte gebilbet. A. I. anfehnlidje Şanbels: uno Fabrifunternehmungen, Spe:

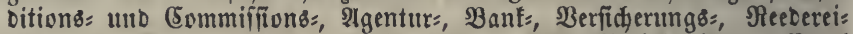

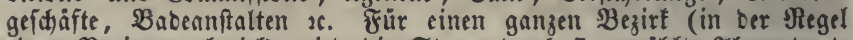
einen Régierungsbezirf) wiro bie Steuer burd) 7 gewählte RGgeorbnete auf bie Einzelnen umgelegt; 13 Regierunggbegirfe bilben bie 1., Die ủbrigen 12 bie 2 . Abtheilung.

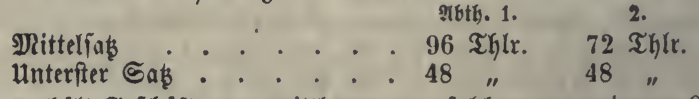

A. II. enthält Befabifte vou mittlerem, B. foldje von geringent Sapital uno umfange.

$$
\text { श6th. } 1 .
$$

A. II. Mittelfą̣ . $24 \mathfrak{T h l r}$. unterfter ऽaß . 12 "

B. Dittelfaßs

unterfter ธas

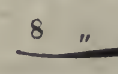

2. 3.

$-\frac{4 .}{10 \text { Thlr. }}$

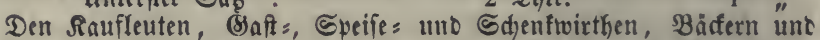
ङdläditern ift es geftattet, Die Steuer unter fid burch Mbgeorbnete umlegen zu lafien. Den übrigen Bewerben tann bießs, wo tie Dert: lid)feit es ausfübrbar madt, ebenfalls betwilliat mercen. Sede folde (Sefellidaft wählt jährlich aus ifrer Ylitte 5 शibgeoronete, und zwar 1 aus ben grösten, 1 aus ben geringiten, 2 aแs ben mittleren ltnter= nehmern, ben fünften beliebig, (Sei. v. 1820, §.26-59. Bei Baäfern unD

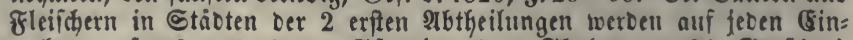
wohner refp. 8 und 3-6 Bfennige (ben Thaler zu 24 (Srofden) gerechnet, um Darnus bie Gteuerid)uldigfeit aller Deteifer in jetem viejer

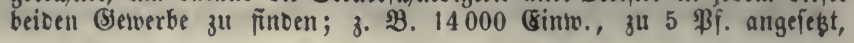




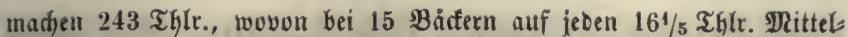
fał fommen. Bemerfungen gegen diefes Befes v. Эa to b I, \$. 1099.

\section{§. 370 .}

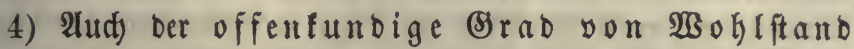
einer (Elaffe von Setwerbtreibenden, forwie (Einzelner unter ifnen, fann berüafiftiget werben, mur ift im lesteren falle zu er= forjden, ob ber Serverbzmann nidjt zugleid) anbere Eimnafymb = quellen habe. Die Şöhe bes sohnez ber Séhülfen verbient ebenfalla Bendytung, weil hierin bie Untergränze für ben 2 Intheil Des Unternefuners liegt, \$. 355. Wie weit Das wirflidje Ein= fommen ber Serverbtreibenden biejen unterften Betrag überfteigt,

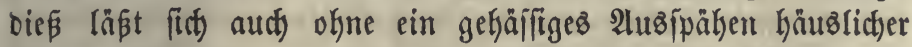
Dinge aแz Der ganzen leitft erfennbaren Rebens?weife Der Familien uno aus ber fidftbaren $3 \mathfrak{s}=$ ober 2lbnahme ifres Bermögetts abnehmen $(a)$. Şat man für ein gemifiez Siewerbe

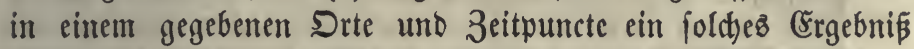
getwonuen, fo fann wieber Der Einzelne mit ber Mehrzahl feiner Sentoffen bergliden werden, und hiebei wird bon felbft ber mit frembem (Enpital Wirthja)aftende (\$. 359.2)) ben Cinbrud einer geritgeren $\mathfrak{B e r m o ̈ g l i d j e i t ~ h e r b o r b r i n g e n . ~ S f t ~ e i n ~ B e t r i e b ~}$

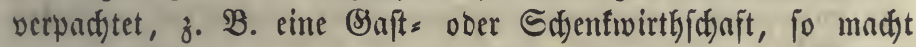
dieß im Steuerfab̧e feinen Unteridfied und ez wirb ben $\mathfrak{B}$ ethei= ligten überlaffer, zu verabreden, wer bie Steuer tragen folle.

(a) Späth, angef. Abhanolung, will oie Regulirung nur vorgenommen jegen nad) Dem शlujwande bes Unternefmers uno nad) Dem Raufpreife,

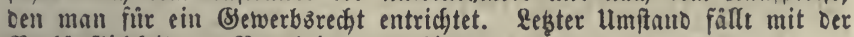
Berfäuflidhteit oer Bered)tigungen Giuneg.

\section{§. 371 .}

Die groß̧e Berjhiebenartigfeit ber bizher betrad)teten $\mathfrak{U m}=$ ftänbe fönnte zu Dem (Entid)luffe fïlyren, bei Der Entwerfung

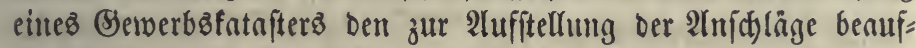
tragten fact) = uno ortzłuntigen Sdjäz̨ern ganj freie Şand zu geben (a). Daum toürbe fith Die Sorge Der Regierung nur

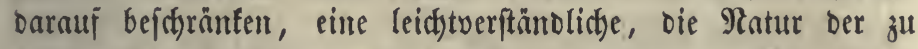
befteuernoen Sinfünfte uno bie Bebingungen und Sentzeichen

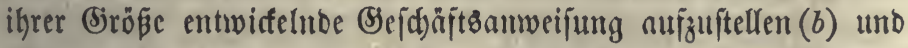
fobann fähige unto zuverläffitge Taratoren aแb ben Bürgern iedes Drtes oder Bezirfes zu wählen, die unter ber \&eitung 
eines $\mathfrak{B}$ eamten arbeiteten. Diés Berfahren würbe zwar bie Bead)tung aller gegebenen $\mathfrak{B e r b a ̈ l t n i f f e ~ e r l e i d t e r n , ~ a l l e i n ~ e s ~ h a t ~}$ aud) erheblidje Sdfatterfeiten, benn ber Mangel thatfadjlidjer 2nleknumgs̊puncte giebt ber zufälligen intoibibuellen 2luffafiung, ber $\mathfrak{B}$ illür uno bem İrthum zu meiten Spielraum uno

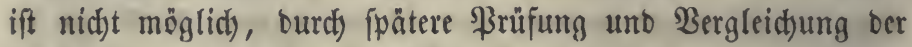
Innid)läge bie nöthige (Sleidfförmigfeit im ganzen Ranbe žl er= reidjen. (Es ift beß̧halb fidjerer, burd) allgemeine $230 r i d$ riften einige Begränzung bes yor Den Schäkęern liegenden Felbes zu geben. In mandfen Staaten if man fogar in ber Aurfferfung allgemeiner Siegeln zu weit gegangen, to baß für bas Ermeffen bez einzelnen Falfes zu wenig Frciheit blieb.

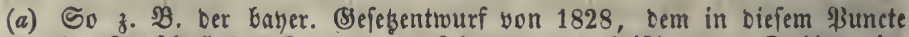

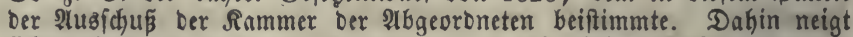
fid aud $\mathfrak{v}$. Ia fo b, II, §. 1092, Dod mit einigen Befdiranfungen, §. 1095. - Das farbin. (E)efes v. 16. Juli 1861 grünbet Die Betwerb=

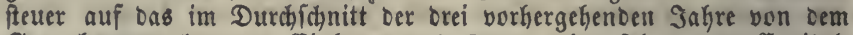
(S)enerbimann bezogerte Einfommen (reddito), ohne शlbug von Capital: zins. Daffelbe wird von bem Eteuerpflichtigen angegeben, yon bem verificatore gepruft unb berichtigt, ber Entwurf wirb offentlich auf= gelegt unb über bie (sinwendungen wird, won einem शैusfd) Drte entidieben. Dießs gefhieht jährlich. Das Beies enthâlt nicht die geringite Sorfdrift für bie Beranjalagung.

(b) Die bisherigen Bsefę̧e und Inftructionen laffen Gierin viel zu wünfकen übrig.

\section{§. 372 .}

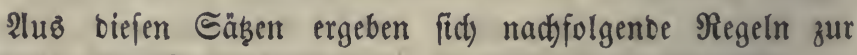
Anlegung ber Bsenerbfteuer:

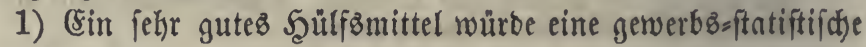
Borarbeit geben, nämlid) bie (Erforfdung ber wirthfdaftliden Berbältniffe aller (S)cmerbe, namentlid) ber zu einem getwiffen Erzeugnif und Belbertrage erforberliden Menge von 2lrbeit uno Enpital uno ber Theile bez leksteren, ber Art wie fith ber ganze Erlöz vertheilt $\mathfrak{u}$. ogl. Man fann bei jebem Esewerbe yon einem gerviffen Soknfabe als Minimum bes Csinfommens augigeken uno unterjudjen, wieviel jeber einwirfento Umftant zur (Erhöhung beffelben beitrïgt.

2) Seber Unternebmer fann gefeglich verpflichtet werben, über feinen $\mathfrak{B e t r i e b}$ gerwiffe 2 ngaben żu madjen, unb bie Er: flärung über foldhe $\mathfrak{u m f t a ̈ n b e , ~ b i e ~ f i d ) ~ g a r ~ n i d j t ~ v e r h e i m l i c h e n ~}$

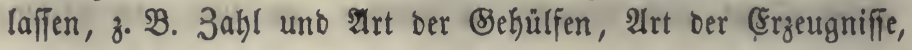


3aht uno Bejd)affentheit ber Mafdinen und anberen ftehenoen Borridtungen fann unbebenflid) von Sebem verlangt werden.

3) Da ftd nidft bei allen fteuerpflidftigen (Semerben bie

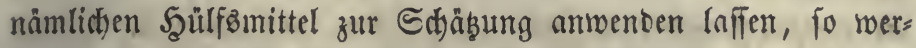
ben iene zu biefem Behufe in mekrere 2(btheilungen gebradt. So fönnen bie Şantwerfe mit fleinem und bagegen mit bes trädtllichem Enapitale, - Jabrifen, - Eerwerfe, weldye bie

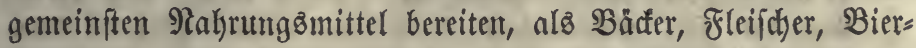
brauer, - Der Erobhanbel nebft bem Banfgefdaäfte, - Der

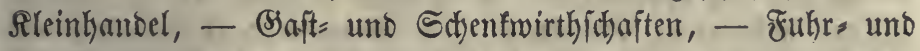
Schiffergewerbe, - Dienftgenverbe 2 . in ebemioniele Erappen getrennt werben $(a)$. Für jebe berjelben werben bie bei iffr vor= züglich brautdbaren Sennzeidfen ber CEinträglidffeit (\$. 367-70) bezeid)net.

4) Bei jeder 2rbtkeilung von Bewerben ift insbejontere eine Regel anzugeben, wic ber Steueranjelalng nad) Der 3ahl unt

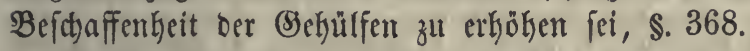

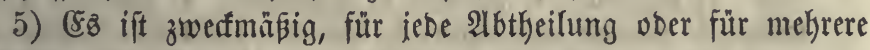
berfelben eine $\mathfrak{A n}_{z} a h l$ yon elaffen aufzuftellen, beren jeder ein

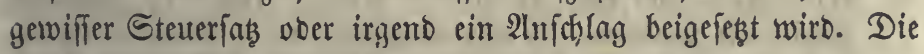

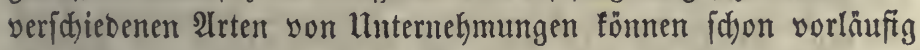
im Alffgemeinen in bieje (Elafien eingereifyt werben, und zwar bei Serwerben, anf weldye bie Einwohnerzahl bes Drtes ftarfen

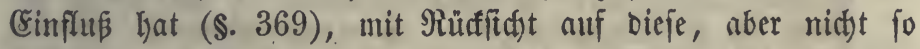

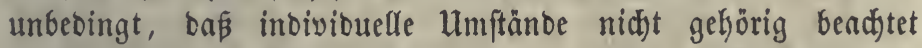

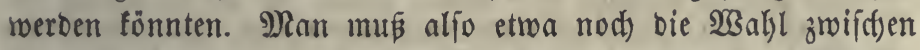
mehreren Şaupt $=$ und Unterclafien freigeben, ober eine 2lbänbes

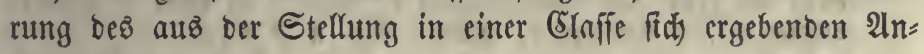
idjlages geftatten (b).

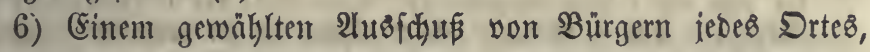
zum Theil aus ben Setwerbtreibenben, wirb unter Mitwirfung

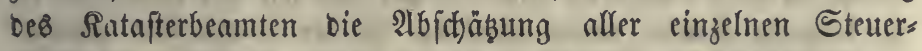

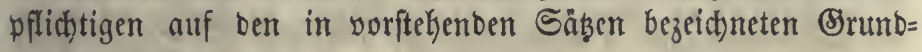
lagen übertragen.

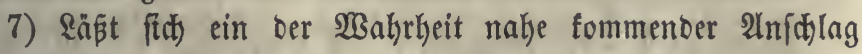
für fämntlicje Unternekgmer eines Berwerbes an einem Drte im Sanzen erlangen, fo fann bie Bertkeilung ber Eumme unter

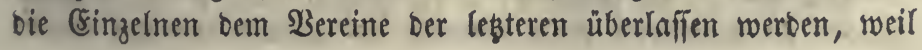




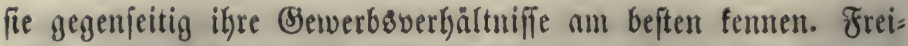
(id) entftefen Giebei leidft Streitigfeiten, zu beren $\mathfrak{B e r m i t t l u n g}$ ber Beiftand eines Steuterbenumten nöthig wirb $(c)$.

(a) Defterr. Errwerbsffetter, \$atent v. 31. Dec. 1812, Decret v. 11. Eept. 1822. 1) Ranbesfabriten in 8 (Elaffent von $40-1500$ fl. Stetur, 2) (Srokhandlungen in vbigen Abtheilungen von Drten (\$. 369 (c)), für jeble mit 3-8 (Claffen, 3) Rünfte, gewoifnnliçe Fabrifen, Srämer, Şanbwerter, nad, Den Drten, in $\mathfrak{B B i e n}_{\text {mit }} 12$ Slaffien, yon $1-300$ fi. 4) Dienftgetwerbe ebenfo, liberall mit mefreren (Slaffen nad int bes

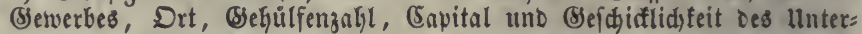
nelymers. (8ntwurf von 1863: 14 शtgtheilungen, 3. $\mathfrak{~}$. (Se)erbe für Nietalle unt Netallwaren, für d)emifdse Sroducte, jür Berarbeitung yon Fajerftoffen, Berfenbung 2c. - Furtemberg: 1) Şandwerfer uno Sleitränbler (unter 200 fi. (Setverborcapital), 2) Şandlungen umb

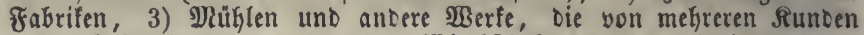

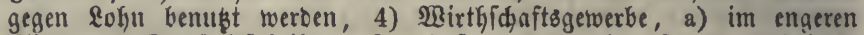
Simue, b) Esetränfefabrifen. 3u 1) ケ. \$. 368 (d). '3u 2) muв jeder (Setwerbsmann fid nad) feinem ganzen Bsemerbscapital in eine von 15 Şatptclaffen einreihen, woriber bann eine \$rüfung angefteflt wirb. S5ieraut beftimmen bie Sdbizer, in welde von ben 3 unterclaffen jeoer Sauptclaffe ber Unternefgmer zu fez̧en fei. 2uch für 3) uno 4) beftehen

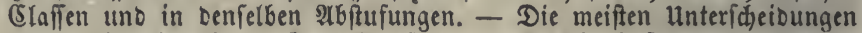

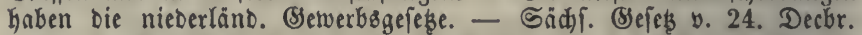
1845: 1) Raufleute, 2) Şältbler, 3) Fabrifanten, 4) (E)aft: uno Epeifes

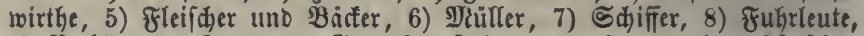
9) Padter yon \&ano ober Selverfsamitalten, 10) Şanblverfer, Rünftler, 11) Unmerziekende (Sietwerbsfeute. - Bayern, 1856: 1) medanifde

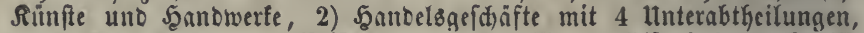

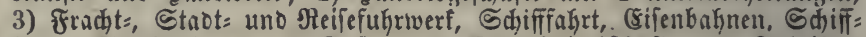
bau, Strá̧enbau, 4) (Saft = uno Sdjenfwirthichaft, 5) Fabrifen, 6) Bratereient und Brauntweinbrennereien. - Franfreid, für die

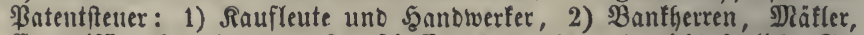

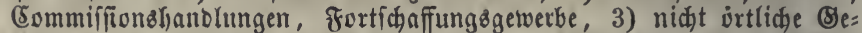
werbe wie Reibrentengéfellidjaften, Canalunternefmungen, Eabrifen,

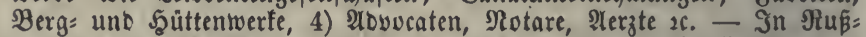
Iano find bie saufleute in 3 Bsilden getheilt, für Die ein Eavital yon 15000,6000 und 2400 Rubel angenommen wird. Die beioen erften

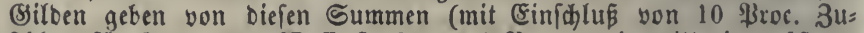

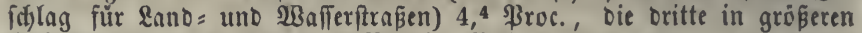
Stäoten 66, in fleineren 43 Stubel. SBgl. \$. $374(d)$.

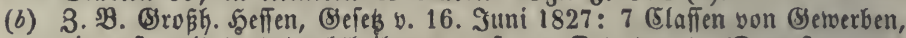
Die erfte mit 2 utnterabtheilumgen; ferner Drte bes 1. (Darmftaot uno

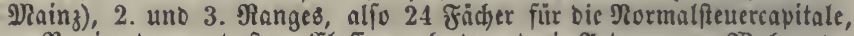
8. B. in Der unterften (5lafie nads Den brei Itrten von Sgohnorten

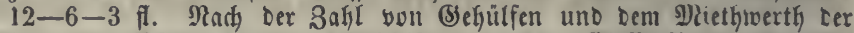

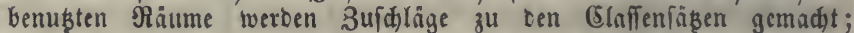

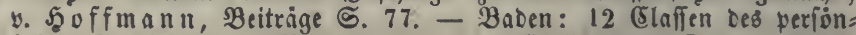
liden SBeroienftes in Berbindung mit 4 (Elafien yon Drten. Biele,

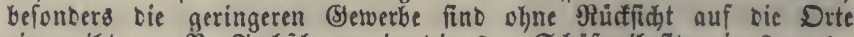

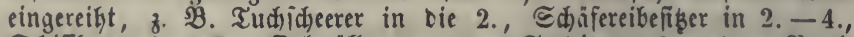
Sdifffbauer 2.-7., Delmullter 2.-6., Spediteure 6.-10., Bant= herren 9. -12 ; andere foumen an verfdictenen Drten in veridietene

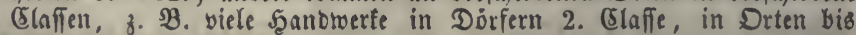
4000 (Éw. 3., bi⿱ 10000 4., in ben grésten Drten 5, uno 6. Slaffe. Bei 20 Şanbirerten ift in mittleren uno grỏßeren Śtäbten erlaubt, 
fatt ber angegebenen bie näh fitniebrigere vber höhere Claffe zu nehmen,

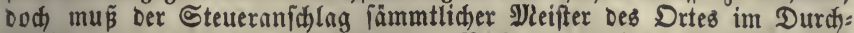
idnitt Dem tarifmäsigen entiprechen. Nad ber $3 a$ hl ber Behülfen wiro ein 3uidlag gemad)t, \$. $373(a)$. - Naffau: 22 Elaffen mit einem Steuercapitale von 20-30000 fi. Die meiften (S)ewerbe find, ie nach) bem fie in einer Stabt ober auf bem \&ande betrieben werben, feft in eine getwiffe (Slaffe gebradyt, anbere werben ofne Ruidfidt auf ben Drt

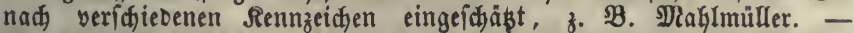

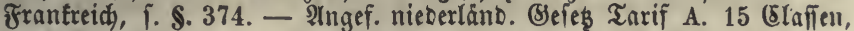
Deren Steueriäbe von 180 fi. Bis 0,8 fl. Kernbyehen. Tarif B. 14 Elafien unb 6 Abtheilungen Der $\mathfrak{B}$ ohnorte, z. 2 . Elaffe 1. $100-50$ fl., 14. Elafie $1,60-0,5$ f. - Şamnoyer: 12 Elaffen, in ber 1. mit $140-156$ Thlr. in Der 6 . mit $27-45 \mathfrak{T h l r}$, in Der 11. und 12. mit $15 \frac{1}{2}$ Sr. Steuer. Bei Den meiften Bewerben ift nur angegeben,

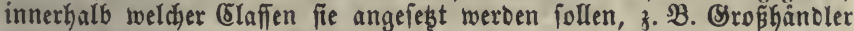

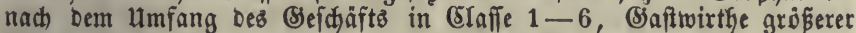
Gtáde in (Elaffe $1-9$.

(c) $\mathfrak{B g l}$ \$. 369 c) uno (d). In Sahien werben in gropen uno \$littel fầten 26, 16 ober 10 Thlr. auf jeden Broßßhänbler angenvinmen uno

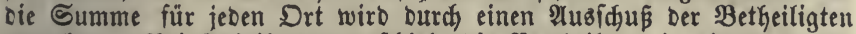
umgelegt. Bei Fabrifanten geidhieht bie Bertheilung in einem ganzen Steuerbezirf. - Nach Dem ófterreich. Ontwurf yon 1863 wirb im (S)ês nur ein Minimum Der Steuer für 8 Şauptelafien ber Betverbe und 5 Abtheilungen Der Drte aufgeftellt, z. $\mathfrak{B}$. für Die meiften fleineren Unternefmungen mit Einichluß ber Şanowerfe $8-6-5-4-2$ fi. Die $B$ ezirfż = oder Stadtcommiffiton ftellt für jeden Einzelnen einen Infidlag auf. Die Dagegen erfobenen Befdwerben werben unterfudht. Sobann wiro Der bisherige Befammtertrag Der Bewerbfteuer auf Die

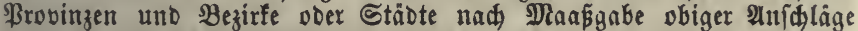
vertheilt, in jeber Semeinde if aber ber auf fie treffende Steuerbetrag von Dem Bemeindeborftande felbftändig mit Dem Beiftande von Ber: trauensmännern auf bie Setwerbsleute Des Srtes zu vertheilen, ohne

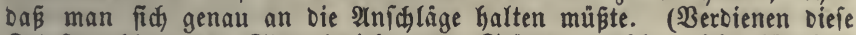
Ratafterzablen Dex Steuerbezirfe uno Stäbte, weldie nidht für jebe ßrovinz und wieder für den ganzen Staat verglicjen unb geprüft wers Den, foviel Bertrauen, Daß̃ fie zur (Srundlage Der Repartition genom= men werben fonnen?) - Das ipanifiche Sejes won 1850 hat einen Tarif nach ber Einwohnerzahl und nah Elafien Der Bemerbe. Die Einfdäzung gefdiefgt burd) Sdjäzer, Die Den aufgeftellten Claffen= anihlag für bie einzelnen Semerbsleute bis auf Das 5 fache erhöhen oder bis auf $1 / 5$ ernieorigen Düren, de Parieu I, 350.

\section{§. 373 .}

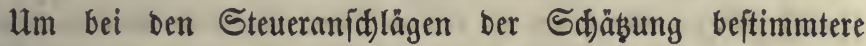
Ridjtpuncte zu geben und biefelben genauer nad) ben gegebenen Umftänoen iebes einzelnen Serverbsimannes einzuridyten, bat man in einigen Sandern Die Bewerbfteuer in zroei Theile zer= legt, weldye abgefonbert ermittelt reerben. Dahin gehört

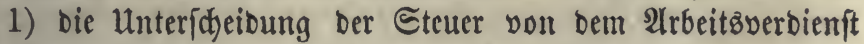
Deß Unternefymers mit Beifalägen für bie gegebene Zahl von (B)hülfen, und Der Steuer von Dem Ertrage beż Capitales,, meldyes man in 3ahlen zu ermitteln fudft $(a)$. Diefe Theilung 


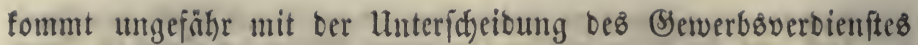
unb Capitalzinfes (\$. 359) überein, nur baß jener ebenfalls einigermasen unter bem (Einfluffe Des Crapitales fiteht uno mit ifm fteigt ober finft (\$. 365), uno baß ber Stẹuerzuid)lag nach) Der $3 a h l$ und 2 rtt ber (Bef)ülfen, aljo nach) ber Altżgabe für 2rbeitzlohn, feinem $\mathfrak{B e j e n ~ n a d ) ~ z u ~ b e m ~ B e t r i e b z e c a p i t a l e ~ g e f o ̈ r e n ~}$ würbe; bie Sctwierigfeit einer 2 tusిmittlung bes in (Selo bes ftelyenden Conpitales hat indes bie 3uredynung jener Summe fu bem perionlidyen Berbienfe empfohlen. Die Steuer vom Betriebsecapitale wirb, wenn fith Beränberungen jugetragen Gaben, net ermittelt. (Segen bieje (sinrid)tung läßt fich) vorzüg=

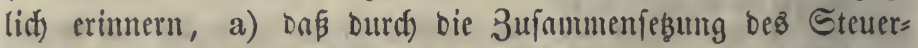
anidylages aแs zwei Theilen ber Ueberblia einer Unternehmung im (Banzen, nad) iffrem (Sefammteinorud und im Bergleid)e mit bem 3uftande anderer Unternehmer erfawert wirb; esి fönnte jeboch) angeortnet werben, daß bas anf biefem $\mathfrak{B}$ ege erbaltene 3ahlenergebniz fït jeben Steuerpflichtigen nod) mit ber (Be= fammtheit ber Erffheimungen uno ben Steuerfäß̨en 2lnberer ber= glicfen virb und Damach abgeänbert werben barf $(b)$; b) oaß manthe andere gute Rennzeichen unbenuz̧t bleiben, c) Daß̧ bie

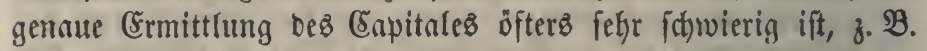
wenn bie $\mathfrak{B o r r a ̈ t}$ the in verichiedenen 3eitpuncten bes Sabres fid fefgr veränbern, ober wenn ein Theil des umlaufenden Capitales nidjt in bie Alugen fälnt, wie im aubiwärtigen Şanbel, über=

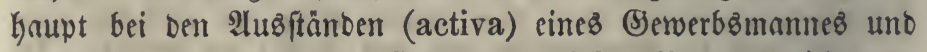
bergl. (c). Dod) ift bie Erfahrung biefer Methode nictit un= günftig. Sie ift einer meiteren Bervolutommnung fäbig, z. B. burch) (Finflyaltung mebrerer Sennzeict)en, wobei fie freilich auds fünftlicter und fdwerer auszufülyren werben würbe. Bei bem

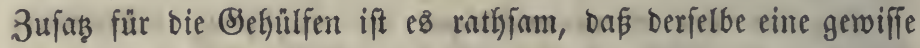

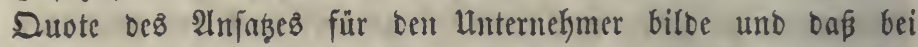

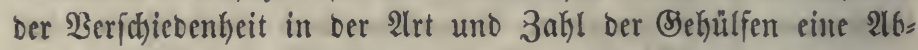
fufung obne ftarfe Eprünge gewählt werbe. Für bie 21nfeģut

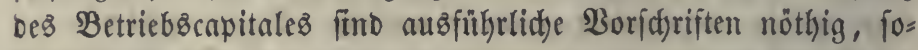

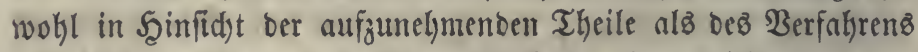
uno oer 3uziefung bes befteuterten Mnternehmerz $(d)$.

2) Die Trennung eines unveränoerlichen, für alle

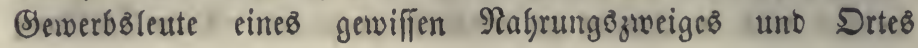


gleidmääigen, uno eines̊ nach ben bejonberen Umftänben jebes Unternefmers eingeridteten, aud) von 3eit zu 3eit wechfelnoen veränberlichen Theilez der Bewerbftetter. Für ben leģteren werben bie veríchiebenen Remuzeichen bes Umfanges und Ertrages oer Bewerbe benukst. Diefe (sinrictung unteridbeibet fich yon ber vorigen hauptfäd)lid) baburd), Dap fie feine (Erforfdung bes Betriebşcapitalez in einer (S) lozahl verlangt $(e)$.

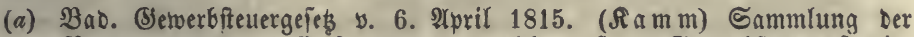
Beroronungen und Erläterungen, welche auf onzి (Sewerbiteuergefé im

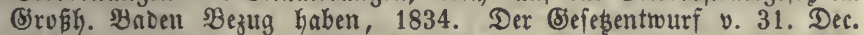

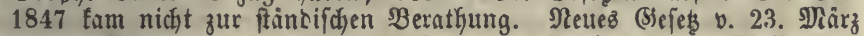
1854. Regenauer, Staatsh. S. 422. E8 find I. 12 (Elafien bes perfónlichen $\mathfrak{B}$ eróien ite so von 500-8000 fi. Steutercavital, worin Die $\mathfrak{B o r a u s ̧ e b u n g ~ e i n e s ̧ ~ r e i n e n ~ B e r b i e n f t e z ~ v o n ~ 2 5 - 4 0 0 ~ f i . ~ l i e g t ~ ( z u ~}$ 5 Proc.). Die Steuer betrảgt, nadh dem jeşigen fuß̧e von $23 \mathrm{fr}$. auf 100 fl., 1 fl. $55 \mathrm{fr} .-30$ ff. 24 fr., vgl. \$. $372(b)$. SBei ben (S) hưlfen werben 2 (Slaffen unterichieben: 1) getwerbsfundige mảnnliøe 5ुulfşarbeiter biż zu 10 an ber 3ahl; Gier sviro für jesen bem \&ohn= herrn $1 / 5$ feines Steuercapitals zugéebt; 2) männliche (Selverbsarbeiter über 10 , Inedyte, Şanblanger, Fabrifarbeiter für gemeine Şanbarbeit,

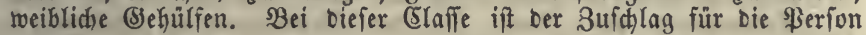

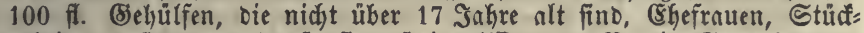

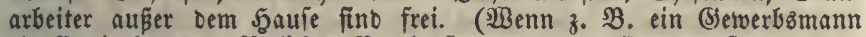
ein Capital Des berfönlidjen \$erbienftes von 5000 fi. zu verffettern hat, fo werden ifm für jeden ber 10 eriten (Sehülfen 1000 ff. ober 3 fl. $50 \mathrm{fr}$. Steuer, für Den 11. u. ff. nur 100 fl. ober $23 \mathrm{fr}$. Steuer hingugefügt.) II. Sum Betriebscapitale werben gezählt Nafferfräfte, - Na=

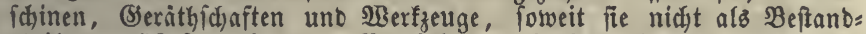
theile ber Şäufer gelten, - Borräthe von fertigen $\mathfrak{B}_{\text {aaren, }}$ Bertwano:

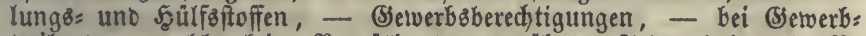
treibenden, weld)e feine Borräthe ber erwähnten Arten haben (子. B. sBanquierb), bie "Fonos, mit benen fie ifre (Befduåt betreiben". (Bei Anberen twerben alfo Forberungen und Schulben fowie bie Belovorratthe nidht beachtet.) Das lanowirthfdaftlide Eapital bleibt aujer 21niab. Für diejes sectriebscapital find 20 Elafien gemadgt uno jebe hat einen getwiffen Anfas, Der bie untere Branze oer Elaffe bildet, uno bei ben 3 erften Elaffen fogar nod niebriger ift:
1) (ฮIaffengränze
2) 6- 800
3) $800-1000$ "
4) $1000-1500 "$
5) $1500-2000$
शีกโล
300
500
700
1000
1500 น. f. f.

Betriebscapitale bis zu 400 fl. fowie bie im Puslanbe befinolichen (Eapitale find frei. Der (S)emerbżmann gat fein Betriebscapital felbft anzugeben, Die Angabe wiro geprüft uno wenn feine Berfändigung erfolgt, eine Befichtigutig aller Begenftände im Szaufe ces Betwerbo: mannes verantaltet, - bei fehr veräncerlichen Theilen bes Eñitals freilich ungenügeno. - İn Würtemberg (๙. Inftr. v. 13. Dec. 1834) ift bei Fabrifen uno Sandolungen mit jeber (Elafie bes Capitales ein beftimmter Steuerfab ber "2Arbeitsrente" Des Unternegmers und jeces

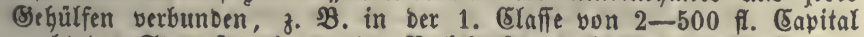
madyt ber Steuerją̧ a) von ber Berfekrofumme in 3 unterabtheilungen 


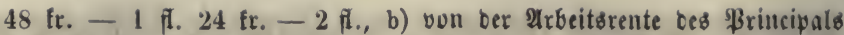
2 ก. $24 \mathrm{fr}$, ledes Sehülfen 1. Blaffe $36 \mathrm{fr}$, 2. (Slaffe $1 \mathrm{ff} .12 \mathrm{fr}$. In ber 15. (Göchften) (Slaîle, yun 125001 bis 160000 u. \%. tw., wiro entridytet a) yon Der BerfeGrøfumme $540-580-640$ fl. b) yon ber 2rbeitorente bes Srincibals 15' f., cimes Behülien in 1. (Elafie 5,

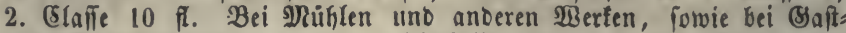
unb Sduenfmirthidjaften wird gleidyfalls eine befonoere Steuer ber Mrbeitserente von Dem Ertrage bes (Sanges oder jeber \$lafdine uno ein Beif́lag für die Befgülfen angejegst.

(b) Bayer. Eefę̧ von 1856 §. 25 a). Eine \&rmäpigung ber Durch Bes redonung ermittelten @teuerfumme wegen befonterer örtlidger Berfehrs:

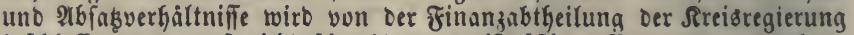

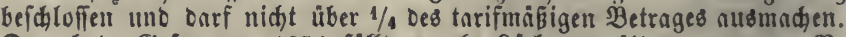

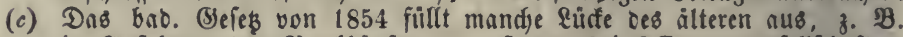
in शnfefung ber BanfGäufer $(a)$, jerner bei थfifecuranzgefellichaften, beren Betriebscapital bem mittleren Betrage Der im Inlande bezogenen \$rámien gleidgeadtet wiro (\$. 40). - Bei Brob̧änblern if oas Şin= weglafien oer (freilid nidyt erfennbaren) Alusftäne cine groß̧e @d)onung.

(d) Das ๔teuercabital ber Setwerbe in Baben war 1829139.295000 ff.,

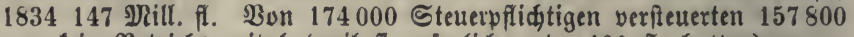
gar fein Betriebscapital (weil fie nainlid) unter 400 fi. Gatten), wor= unter 87650 Landivirthe und 10950 Taglogner, 12000 ftanden in

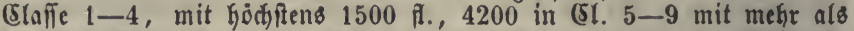
1500 f. Betriebrenpital. Bei fait allen Bewerbell ift ein Theil ber IInternefimer ofye 2tnjas fur bas Betriebscavital geblieben, z. B.

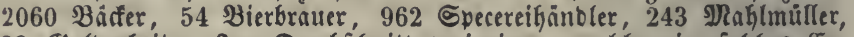

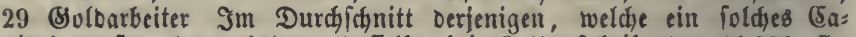
pital verfteuerten, betruy baffelbe bei Rattunfabrifanten 31929 fi., Banquiers 30460 fi., \$avierfabrifnnten 11450 fl., Tabafgfabrifanten 9700 fl., Bijouteriefabrifanten 8940 fl., BHuhänolern 5200 fl., 2lpo= thetern 3880 , Butiorudern 2660, IRablmüllern 1900, Şolzhánblern 1890, Brauern 1730, Nothgerbern 1490, Specereibänolern 1050, Snit= twirthen 920 , Bärfern 420 fi.; Dieje Sảze fino vermuthlid, alle zu niebrig. - Neuerer Betrag bes ganzen Semerbiteuercapitals

$$
1847
$$$$
1850
$$

1863

(5a⿱. Des perí. Berd. 132.855125 fl. $127 \cdot 748225$ f. 135.960875 fl.

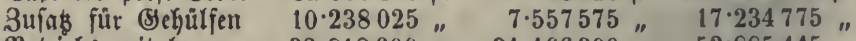
Betrieborcapitale

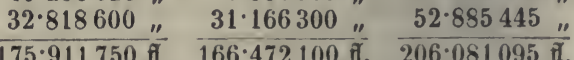

zนศаmmen $175 \cdot 911750$ ศิ. 166.472100 กิ. 206.081095 กิ.

Bei einer Berzinfung von $5 \%$ if oemnad ber reine perfonlide Bers bienft mit ber (sehúlfenzulage auf $72 / 3$ शRill. fl. zu idjoigen, Der (Sapitals zins auf 2,64 शillf., allein bas gefammte Capital auch ofne (Sebảube ift weit größer und feeigt ficherlid, über bas Doppelte, weil Eleine Betråge uno mekrere erfeblidbe Theile befielben nicht eingeredonet uno bie in Betrndt gezugenen nisht vollftindig befannt werben. Die fiarfe

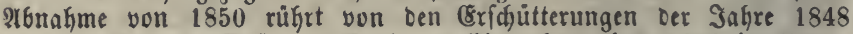
uno 49 her. - Fuf Den Ropf Der Sinwohner fam 1856 im lnter: rheinfreife (max.) 132 fl., im Dberrheinfreife (min.) 112 fl., im ganzen Eanbe 122 ff. Die 3afl ber Steuerpffichtigen twar 1859215000 (100: von 105000 \&anbwirthe uno 15000 Taglöhner), es traf folglich auf jeden ein Berdienfterpital von 596 fi. und mit rem 3 ufalag für (Se: Gůlfen von 666 fi., D. i. ein muthmaß̧lidjer mittlerer reiner Berdienft yon $33 \frac{1}{3}$ ff. (ofne 3tweifel betrádtlid) unter bem wafren (sintommen), und Da 95000 feuerpflichtige Betwerfs = und \$nndeloleute vorhanden waren, fo belief fid́) Das abgefdabste Betriebscapital für jeoen berfelben im D. nuf 504,8 fl. oder Die Sinseinnahme auf $25 \frac{1}{4}$ ff. 


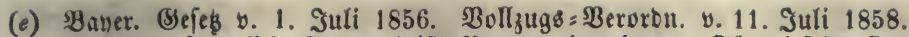
Die unverinberlide Steuer Geifst $\mathfrak{R}$ ormalanlage. Für Dief́lbe find 33 Elaffen gebildet, beren jebe 4 2tbftufungen nad ber Eintwohnerzahl Der Drte $(\$ .369(c))$ hat. Die Srämen fino für bie fleinften Drte

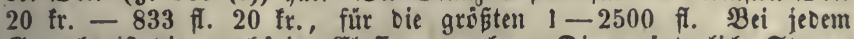
(B)ewerbe ift Die zugehorige (Elafie angegeben. Die verảnberlidue Steuer,

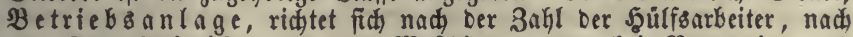
ben Setwerbseinridatingen uno Nafdjinen, uno bei Brauereien uno Branntweinbrennereien nad) bem Erzeltgníf. Bei \$zanbwerfen wirt tie Betriebsanlage in Der Regel mur nađ ber 3ahl Der Sehullfen beptimmt, bei Şanbelsgeidaften wirb für fie einer aus einer gewiñen 2 mzahl

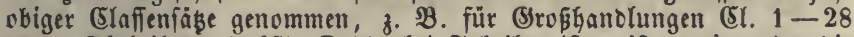
Der 4. 2tbtheilung (grispte Drte), bei Fabrifen if meiftens cime ober bie anbere biefer beiben Nethoden verorbuet, für einen Theil terfelben finb Rennzeidjen anderer Frt angemenbet.

\section{§. 374 .}

Die \$ateutfteuer (contribution ober droit de patentes) in Franfreid) (a) Gat baz (Eigenthünlidłe, Daß̧ auf bie $\mathfrak{B e r =}$ idjiebenkeiten in ber \&nge Der einzelnen Unternehmer nur wenig Rücffitht genommen wirb. Sebes Sewerbe erbält einen einzigen, ober mefrere nach ber Sinmoknerzagl bes Srtes abgeftufte Stenterä̉ze, unb alle Selverbzleute in eimerlei (Sefdäft unb Drt entrid)ten gleiduviel, wephalb aud bie Steuer fogleid) bei ber

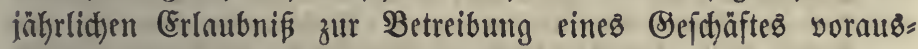
bezablt wirb unt fict) einer (sebüly näbert, §. 245 . Reben biefer feften Steuter (droit fixe) beftegt cine veränberlidye (droit proportionnel), bie fid) blop unit) Dem Miethbetrage ber be= muşten (Serverborräume ridbtet, wobei fid) nicht verfennen läpt,

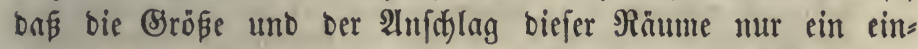
zelnes unb oft nidjt genau zutreffenoes Rennzeidjen bes $\mathfrak{U m}=$ fanges uno ber (sinträglid)feit eines Sewverböbetriebes ift (b). (Ein $\mathfrak{B o r z}$ ug biefer ßatentfteuer ift $e$, Daß fie nach einer feften

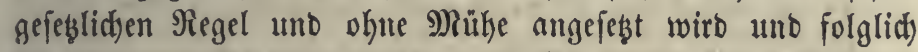
jebe mit ber Sdjäß̧ung verbunbene Befahr eines nแเ Srrthum ober \$arteilidfeit entftehenben unrid)tigen 2 nfallages himwegs fällt $(c)$. Wenn man aber von ihr rülymt, Daßj fte zur Errvei= terung ber Bewerbsigejdäfte ermuntere, weil fie bann immer weniger fithlbar werbe, fo ift bies ein zweibeutiger Borzug, Denn biejenigen Betwerbolleute, Die ifren Betrieb nid)t aus̆zu= behnen sermögen, werben babei auf unbillige $\mathfrak{B e}_{\mathrm{e}} \mathrm{je}_{\mathrm{f}}$ färerer ge= troffen. (sos ift weber gered)t nod) volfzivirtbidyaftlid) zroed: mäpig, ben gropen $\mathfrak{B e t r i e b}$ in ber Beftetterung zu begünftigen, 
unb hierin liegt einte größere Ungleidheit, als in ben Fehlern, bie man bei ber (sinfd)äbutung ber (5ewerbsileute nad) ihren

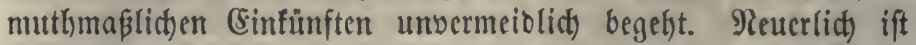
jedoch in Franfreid) bei vielen (5attungen ber Serverbe bie fefte Steuer nad) verichicbenen auf ben Umfang ber Unternebmungen binbeutenton Merfmalen cingerictet worben uno aud) bie ver= änberliche hat nicht mehse einerlei ₹uß̈, fo bañ bie Steuer oer im \$. 373. 2) bezeichneten äbntid ift $(d)$.

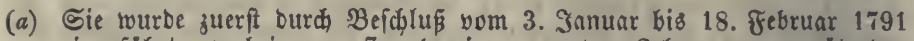
eingeführt, wobei man fie als einen von ben Belyern zu vergütenden

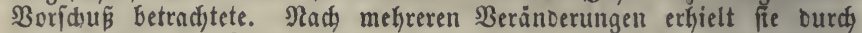
Das Befes v. 1. Brum. VII die Esinnidftung, welde fie lange behielt;

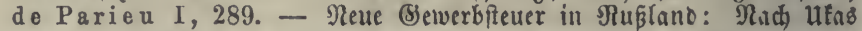

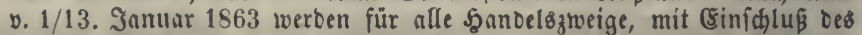

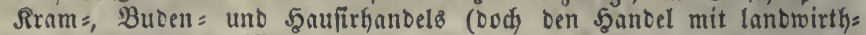
ihaftlidien (Erzengnifien, Biegeln, Brettern, Salf $x$. ausgenommen),

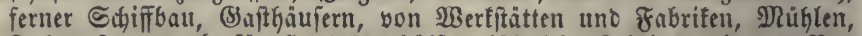
Fuhrwefen, aud für Şanbelsgehülfen jährlide Echeine mit ber Ber= binblidfeit zur (Entridjtung einer fogleid, yorauzzubezahlenden Stetter eingefübrt. Man unteridheibet faufmännifdje Sdyeine nach ten zivei

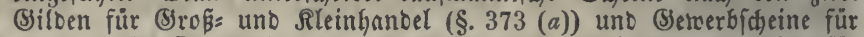
Rram:, Şaufirhanbel uno anbere (Semerbe. Die Steuer wirb für

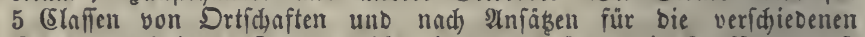
Bewerbe erhoben. Dagegen hört in Den Stäbten bie Ropfifeuer auf. Die Bilbenfteuer war für 1862 孔 5,2 झRill. angeīhlagen, Die neue Stetter für 1863 zu 71/2 Milll, wowon aber bie aufgehobene ftäbtifhe

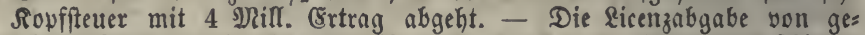

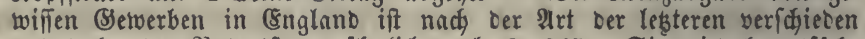

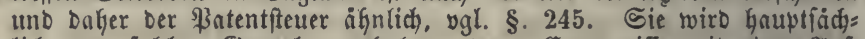

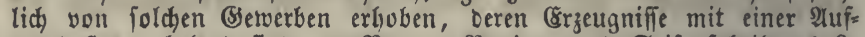
wanosfteter belegt find, 8. B. von \$apier: uno Geifenfabriten 4 \&. 7 Sd., Banfferren 30 \&., \$f Sanbverteigern $7 \frac{1}{2}$ uno 15 \&.., Berfäufern

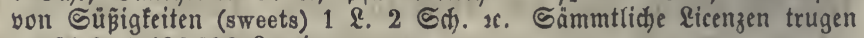
1858/59 1.436826 \&. ein.

(b) Diéß droit proportionnel war lange 3eit 10 Froc. von bem muth=

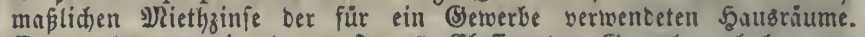
Es twurde nur in ben erfen 5 Elafien ber Bewerbe erhoben. -

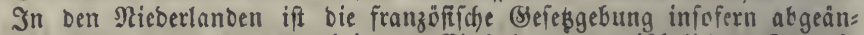
bert tworden, als man bei ber Ginholung bes jährlidjen (Bseverb= ideines (\$atente8) nur eine aeringe (Sebühr bezahlt uno bagegen ber

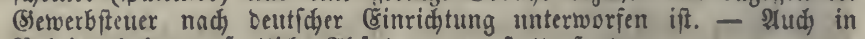

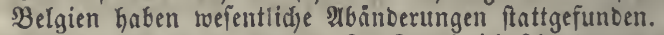

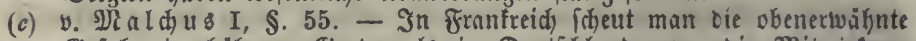

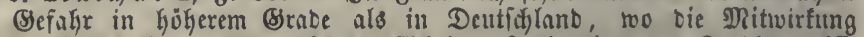
gewählter Bertreter Der Eteuerpflidftigen fowie bie guten Eachfenntuifie

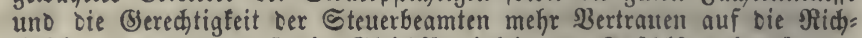
tigfeit ober Dody auf bie Sleidförmigfeit ber Injidläge begrinden. Ici, comme sur plusieurs autres points de nos recherches, il faut observer, que la nature des taxes, étant en rapport avec les moeurs et la politique des divers pays où elles peuvent être établies, ne saurait être approuvée ou condamnée partout en rertu de règles absolument uniformes. De Parieu I, 391. 


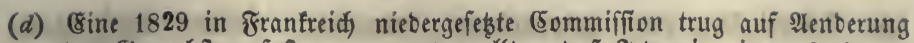
Des Senerbfteuterigftems an uno lovilte, Daj Seber in einem droit variable neben bem droit fixe unto proportionnel nach oen Rennzeichen

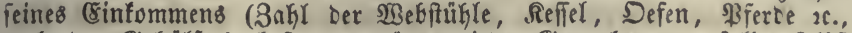

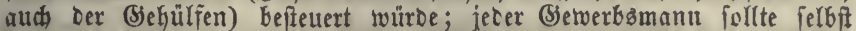

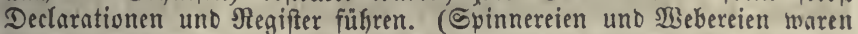
fdjon feit 1817 uno 18 auf biefe $\mathfrak{B}$ eife befteuert worben.) Diés verwarf

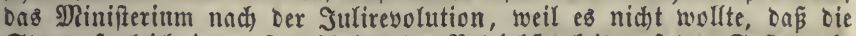

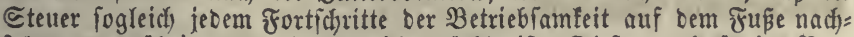
folae, was übrigens auch gar nidjt nötgig iff. Diejer merfwüroige Bor= fchlag, ber nidht yollftänbig befannt wurbe uno neuerlich in Frantreid) fapt in SBergeffenteit gefommen war (d e Parie a I, 293), ift nun yon \$arieu (V, 182) veröffentlicht 'worben. Neute Brefeke v. 25. 2April 1844 und

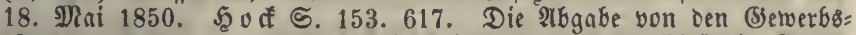
räumen (droit proportionnel) fällt bei ber 7. und 8. Claffie in Drten, Die nicht über 20000 (sinw. Gaben, fintog unb hat fontt eine $216=$ flufung von $1 / 5-1 / 50$. Die fefte Śteuer hat für bie \$iehrzaht ber

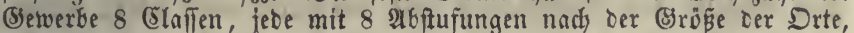
yon Bisemeinben bis zu 2000 bis zu Stäbten mit 100000 und mekr (Eimmoknern. Die Sä̧̉e Der 8 Claffen gehen in ber erfent von 12300 fr., in oer 2. von $10-270$, in ber 8 . von $2-35$ frr. Bei (S)ewerben, für weld)e bie (sinwohnerzahl nicht in Betracht fommt, ift entweder ein beftimmter Eteuerfag, oder es fino gewifie Mierfmale zur Bemeñung angegeben, Bahl ber Stü̈hle, Defen, EpindeIn, Refiel ut. ogl. unt überall cine Unter= und Dbergränze, z. B. Spinnereien, $2 B e b e r e i e n$, Brautereien $10-400$ Fr. 2. für 1863 Scauttpeter $49 \cdot 864000$ Fr. uno mit ben 3ufdjlïgen für aflgemeine 3weffe 55.717000 ₹rr., ohne Die 3uf́chläge für die Departementz und Bsemeinden. Die 3afgl ber Steuerzahlenden mar $1844 \quad 1 \cdot 511000,18451 \cdot 352930,18551.664329$. Im S. 1857 maren 270 Sewerbsleute, Die 2500 Fr. und Darüber bezakilten. - Das piemuntefifase Befers y. 7. Juli 1853 ift Dem fran= zöjifichen von 1841 verwandt. Das droit proportionnel finoet mur bei

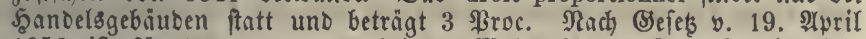

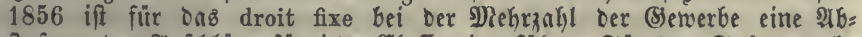

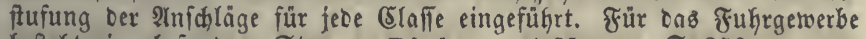
beftegt eine bejontere Stetter. Plebano et $\mathrm{Musso} \subseteq .258$.

\section{§. 375 .}

\section{Weitere Bemerfungen zu Berwerbfteuer.}

1) Die berjelben unterliegenden Bewerbe müffen im Sefeşe einerfeitş gegen die höheren Dienfte; andererjeitż gegen die Einnahme aus Renten ofne (Sewerbsbetrieb uno gegen bie einfacbe Rohnarbeit genaul abgegränzt werben (\$. 358), ins: befondere find nähere Beftimmungen oarüber erforterlid), weldje Şanbelöunternebmungen zur Serverbfteuer. Der Şanbelsleute zu zieken fint $(a)$.

2) Berwerbaleute, die ifr (seid)äft ganz im Sileinen, mit einem geringen Capitale, ohne Sehülfen betreiben, behanbelt man am beften wie Lohnarbeiter, und unter llmftänben, weldhe. 
bie Düftigfeit ber Unternehmer berweifen, follten bieje ganz befreit werben (b).

3) Reue 2rten yon Unternelymungen, weldte nad) ber $216=$ fafiung bes Bewerbfteuerge é(Bez auffommen, werben burd) nad)=

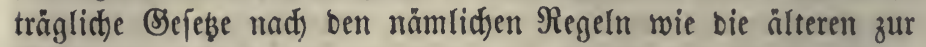
Befteutung beigezogen.

4) $\mathfrak{B e n n}$ cin Unternelymer in cinem Drte mehrere Bewerbe zugleid) betreibt, fo fint zwoi frälfe zu unteridseiben: a) Eteken bie Bewerbe in einem inneren 3 ufanmentange, fo ba anber gegenfeitig unteritüben unb bebingen, fo fino fie zufammen=

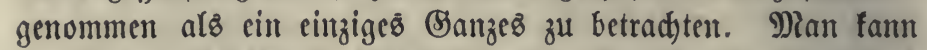

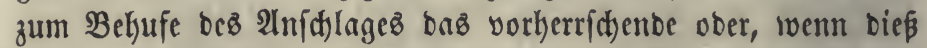

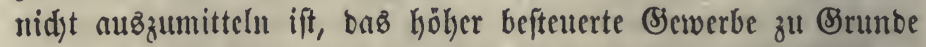

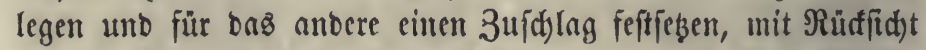
auf bie Summe ber Eapitale, Irbeiter 2 . - b) Sint fie cin= anber fremb, io fteht ber Forberung ber vollen Bewerbfteuer

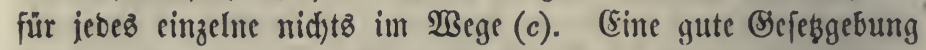
über 3unftwejen ober Serwerbsbered)tigung mú bazu bienen, nake verwante Setverbe in Beziekung auf bie Befugni备 zu itrem Betriebe zufammenzumerfen.

5) Eine Bejellfdjaft, bie ein Beswerbe betreibt, wirb wie ein einzelner Unternefymer befteuert, bie au ber Beifdäftzführung neben bem Scautstworfteher theilnelymenten Mitglieber werben

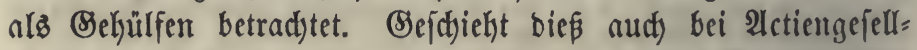
idjaften uno Commanbiten, fo barf ber an bie 2etieninlaber und ftillen Befellfthafter einer Commantite gelangente Rein=

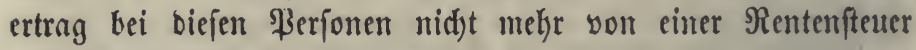
getroffen werben $(d)$.

(a) Şierüber entfdeiben getwojgulid fđion bie Boridriften über bie zu einer

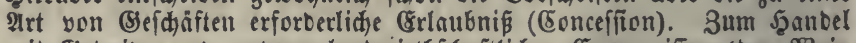
mit (setreise uno anbern lanbwirthfid)aftlidjen (Erzeugnifien (ben $\mathfrak{B}_{3}$ in

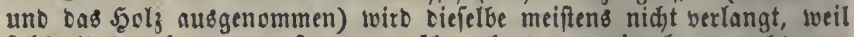
folde Unternehmungen vit nur yoribergeheno uno einzeln gemadt wer: Den; fo aud Der Seanbel mit Staatspapieren uno 2etien bei \$erfonen, Die nidit förmlid) SRuf = ober Banfherrn finb. - Şiefler getiont bie Beftimmung, in welden Fällen bie ben Banffäujern geförenden Ber=

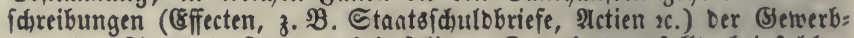
ober ber Singrentenfteter angeimfallen. Das legktere follte bei folden

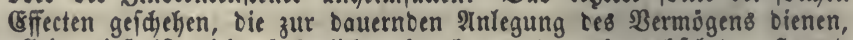

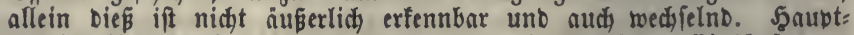
fädlid if Darauf zu feken, baß meber ein Theil ber Eeinfunfte un: beffeuert bleibe nod aud toppelt belafet loerbe. - Der Berfauf eigener 
Erzeugniffe ift fein befonderes Sandelzgetwerbe, wenu er nur burdh Feilbieten zu Şauje ober Durd) Befuchen eines 28 odenmartes betwirft wirb. Der Berfauf von eingefanften $\mathfrak{B}$ ancen gilt bagegen als Şandel

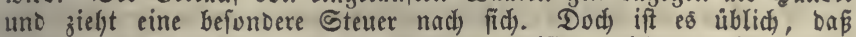
mandien Şanbwerfern aud ber Serfauf getwifier, nidst won ifgen ver= fertigter 23anen geftattet wiro, okne oaj fie bafür eine Steuter yoin

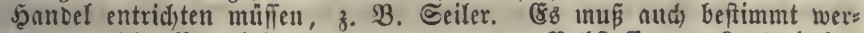
Den, weldse SBerarbeitung Der getwonnenen Stokftoffe Dell Ranbwirthen ohne (sntrichtung einer (s)ewerbiteuer erlaubt ift.

(b) Sn Baben (Sefes v. 1854 §. 30) find befreit von ber Befteuerung bes

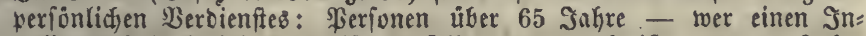
valibengefjalt beziegt voer für Denjelben vorgemerft ift, ober 15 Safre im Militir gebient uno onbei eiten Felozug mitgemadht hat, boch nut in ben unteren 6 Elafien, - wer aus offentlichen Sitteln unterftube wirb, ober wegen notorificher Armuth Dazu geeigenichaftet iff; ferner

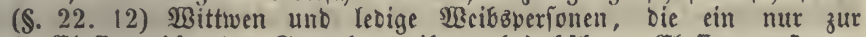
1. Elaffe gehorendes Setwerbe treiben; bei Göheren (SIallen verfteuern fie nur $4 / 5$ Des Elaffenịabes. - In \$reuken find foldhe Scanowerter

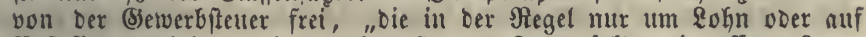
Beftellung arbeiten, ofne auch nußer ben Sahrmärtten ein offenes \&nger von fertigen 2 sanren zu Galten, fo lange fie Dab (Sewerbe nur für igre Berion ober mit cinem ertwadjenen Siefulffen unb mit einem \&efyrling betreiben." A. (Sefeş \$. 12 , vgl. \$. $360(a)$. - Gndien: Sुnno= werfer ohme Belyülfen gebelt nut $3 / 5$ Des Tariffabes, und wenn fie mur

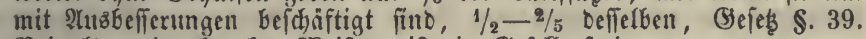
Bei alten ober tranfen Meiftern if ein (seielle frei.

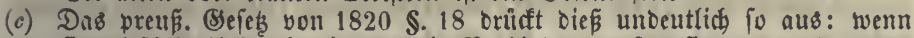
fie a b fichtlich mit cinanber in Berbinbung geiebt find" - uno "wenn fie zufälig wou einer Berion betricben twerben". Im erfen Falle follen fie nad) Dem gemeinjódtliden umfange nur eimmal befteuert

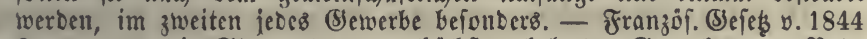
§. 7: nur Die Steucr $D C B$ am Göhften belegten (Sewerbes. - Bab. Siefes v. 1854 \$. 10 : Die Steuer Des periönlichen Berdienftes wirb nur von Demjenigen (Sewerbe entrichtet, weldes brn hökeren Sag hat, Das Betriebzcapital wird von ben verbunbenen (Setwerben zujammen=

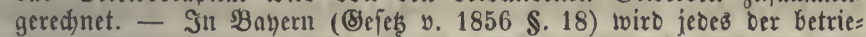
benen Setwerbe befonders verfteuert, auser wenn biefelben in einer engen ober naturlichen ober tedfnificen Berbinoung ftehen; in biefem

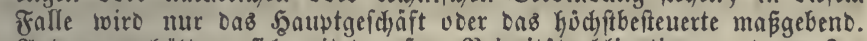

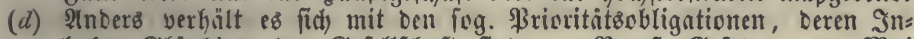

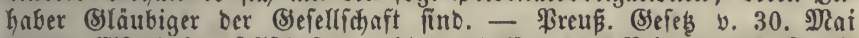

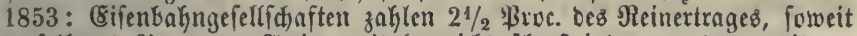
Derfelbe 4 \$roc. Dez Pletiencapitals nicht liberfteigt, von Dem weiteren

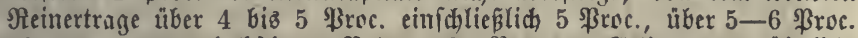

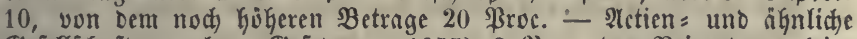

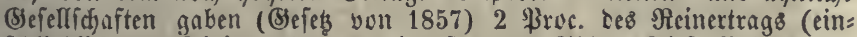
(c)lieflich ber Divioende) uno minceftens 36 Thlr. Diefe Befteuerung

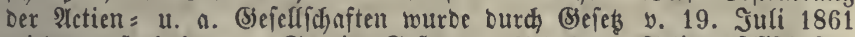
wiecer aufgehuben. - Garbin. Sefes v. 1851 \$. 8: Petiengefellfhaften geben 2 ßroc. von Sins, Dividende und Envitalvermefyrung.

\section{§. 376.}

6) Die eigene 2lngabe oes Steuerpflidtigen, zumal wenn er, ofne cine beftimunte Summe auşupprect)en, ftd) nur in eine

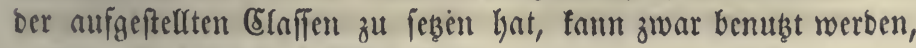


barf aber nidft yon ber forgfältigen Unterfudjung burd) oie Sct)ăker abhalten.

7) 2tuf bie Beriftuloung ber Betwerbsteute (\$. 359. 2)) ift bişher bei oer Bewerbfteuer fo wenig als bei ber Brrunt = uno

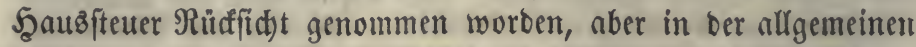
Einfommensffeuter geidjieht biefes (\$. 398) unt bie (Einführung Der fog. Capitalfteuer erleidfert iene Edjonung ber Edjulbner autd) bei ben erwähnten einzeluten Sdjab̧ungen, \&. 401 a.

8) $3 \mathfrak{u}$ ber Anlegung ber Steuter fowie zu ber \$runfung umb Entidjeibung ber gegen bie vorläufigen 2lnidhläge erhobenen

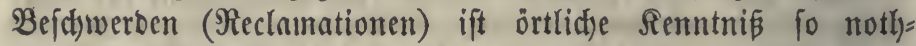
wenbig, one wenigftenz in jeber mittleren und gröperen Stabt

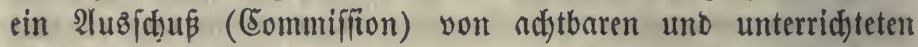
Bürgern สแล ben verichiebenen Battungen von Bewerbtreiben= Den gebildet werben mús $(a)$. Für Dörjer uno fleine Stäbte

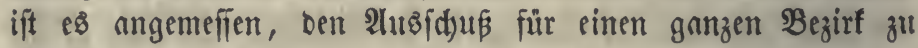
wählen.

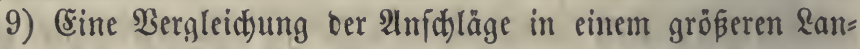
beştheil in Şinficht auf (s)leidfor rmigfeit, obgleid) idjwieriger

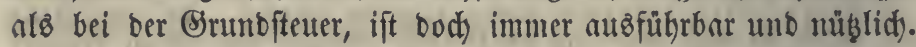

10) Die Semerbfteuerfatafter behalten ihre Braudbbarfeit

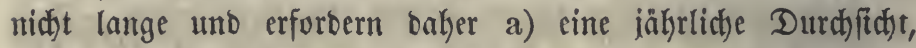
nobei bie $\mathfrak{B} e r a ̈ n b e r u n g e n$ in ben 'Berionen uno ber 3 ahl ber

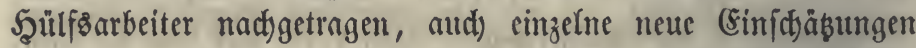
vorgentomment werben, wenn ein Bjetwerbämann auf Şerabfę̧ung antrågt, ober eine Eัrłjöhumg ben Beauten angemeffen fojeint, b) eine allgemeine Revifion nad) nidft langen 3wifdenzeiten.

(a) Baten, Befęs y. 17. Ilärz 1854: 2n jeocm Drte befteht fowohl zur

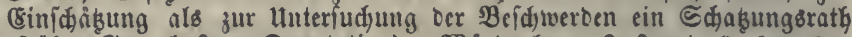

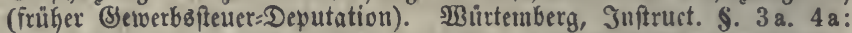

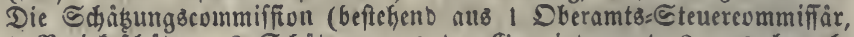
1 Bezirfsidäber, 2 Sdäkern ats ber (Semcinde und 2 aus benad)= barten Drten) wird zum Befufe ber meuen (Sinfthäbung in Folge ers hobener Beidfuerden um 2 Berjonen verfärtt. Nad) Erledigung Der Reclamationen erfolgt bie Bergleichung aller in einem Dberante erhal=

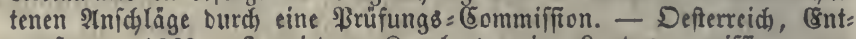
wurf von 1863: In jebem Rronlande eine Eanbescommiffion, zur Şâlfte von ben \&anoftäben, die andere Şâlfte von Dem finanzminifte= rium ernannt. Bezirfsconmiffionen, yon ten Semeinbevorftehern ge= wählt, ftábtifche Commiffitonen, beren Şâlfte bon ber Bemeinbevertretung aแs ben Betwerbileuten getwált wirb. 


\section{7}

\section{5. $\mathscr{A} b \mathfrak{a} \mathfrak{b}$.}

\section{3itarenten = voer Capitalíteuer.}

\section{§. 377.}

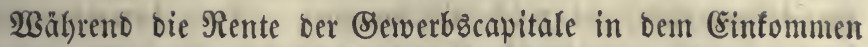
Der Unternehmer mit bem Bewerbsesverbienft vermijat vorfommt (\$. 359), giebt es aud cine vereinzelt ftehende 3 ins. rente, welche als \&eihzins von ausgeliekenen Selbjummen

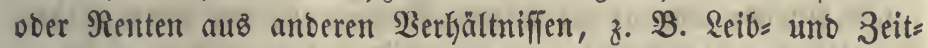
renten bezogen wirb. Wo bie 2lctienunternefunungen nidt in (Sanzen von ber (Semerbiteuer getroffen werben (\$. 375. 5)), oa gehört auth ber (se winntheil (Divibende) bon bent Anctieneinlagen bieber. Die Ëmpfänger foldter 3inzrenten pflegt man vorzugerweife Eapitaliften zu uenmen, weil fie groben= theils olyne Befdäftigung von ifren Senten leben unb bann

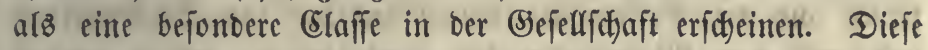

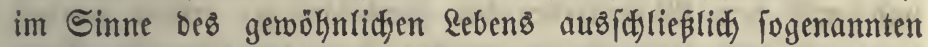
Capitale bilben feinen eigenen Theil bes $\mathfrak{B o l f s ̧ w e r m o ̈ g e n b , ~}$ aน⿰习习⿱

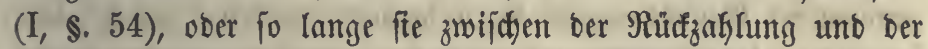
neten Prnlegung in ber Seftalt von Selofummen bei bem Capitaliften vorhanben funt. Das in Beloform auşgeliekene Bermögen fann von bem Borgenden nuf verfyiebene $\mathfrak{W e i f e}$ ver= wentet werben unt bringt baher verffhiebene Wirfungen hervor;

1) eริ werben bamit beweglid) Şůlfemittel ber Sütererzeu=

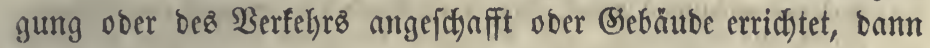
ift es als cropital vorkantoen;

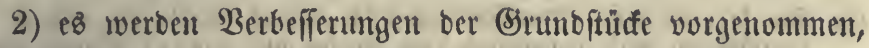

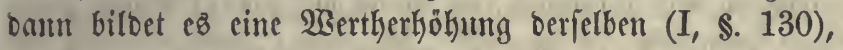

3) es toerben Riegenfdurfen unit ber geliehenten Summe erworben, bant geht cin (Eigenthumbivedyel vor unb bie Summe gelangt aut bent Berfätfer, ber fie auf beliebige Weife bemubst;

4) fie bient zu cimer $\mathfrak{B e r z e f r u n g , ~ o f n e ~ ( E r j a s ~ i n ~ S a c h ) = ~}$

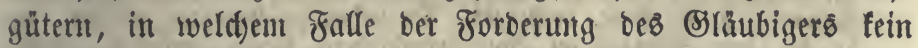
Gieraus entftanbenes Bermögen bes Sđuloners entiprid)t.

Sine Befteutung, bie ben (süterquellen in ber Bulfsivirth)= id)aft folgte (\$. 263), witrbe baher biefes Einfommen aus

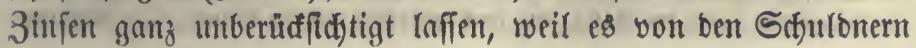




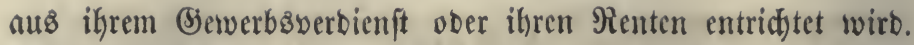
(Ein Steueriyftem aber, weldes fid) all alle 3weige bes (Ein=

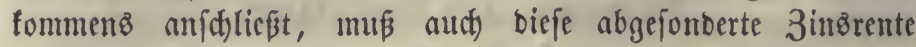
treffen, beun fie ift wic bie (Srunb= unb Şaubirente größtentheil ein foftenfreics, reines Einfommen. Die 3inzrenten= fieuer wirb gewöknlid Eapitalfeuer genant, - eine Bezeidyunng, weldye fid nur nad) ber im şrivatleben üblidjen Bedeutung Des 2 ortes Eapital redtfertigen läpt $(a)$. Eine foldte 2lbgabe war in ber älteren $\mathfrak{B e r m o ̈ g e n b f t e u e r ~ v i e l e r ~ S t a ̈ b t e ~}$ und \&änber begriffen $(b)$, wurbe aber fpäter, als jene fid in mehrere abgefonberte Steuern auflöfte, inzogemein aufgegebent. 2lud) in neuerer 3eit kat man fid) lange vor ikrer (Finfübrung geidjeut und es waren ifyr viele Stimmen ungünftig. Snjofern Dieß̄ auz ber Ungerwohntheit einer 3inzbefteuerung und ber natürlichen Albneigung vor jeber neuen Art ber Belaftung, ferner auz ber Berfennung ber Srrunbfäßze bę Steucrwejen unt nus bem $\mathfrak{B}$ iberftreben ber 3inżgläubiger erflärt werben fann, hat biefe Ungunft als vorübergekend fein (semidjt. Dodf find aud) bebeutendere, aus bem Sisefen biefer 2 lbgabe her= genommene Brünte gegen fie aufgeftellt worben, weld)e eine forgfältige unterfuct)ung erforbern $(c)$, objichon in ben lek̨tent Jahrzekenden, befonberz aber feit 1848 in vielen Staaten eine foldje Steuer Eingang gefunben und ber Erfolg bie gehegten Bedenfen fehr gefdhwächt hat $(d)$.

(a) Wans man im Franzöfithen Steuer von bem betweglidaen Bermögen (richesse mobilière) nennt, Das ift eigentlid) ein Inbegriff von (S) werb=, Sins = unb \&ohnfeuer, cine Sdaksung von allen Einfünften mit 2us: nafime Der Sirund = und Şalısente.

(b) Sie fam in bem altbeutiden Schof vor (\$. 402), fo aud in ber franzöifichen taille personnelle, wo Renten und ancere Sinfünfte zuleb̨t mit 5 ßroc. belegt waren, \$atent von 1775. - In tem fächifíden Rusfdreiben ber Rouf=, Selwetb = uno Bermoggensfteuer von 1481 war

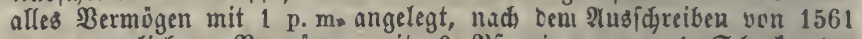
bas ausgeliehene Bermỏgen mit 6 \$fenuigen von 1 Edjoc soer 60 (Srofdyen (alio 1/120), 1671 Das betweglidje Bermigen mit 1 \$roc. Subeich, Die Rentemfeuer im $\Omega$. Sadjien, Dresben 1857, S. 7. §at Bayern wurben 1647 aud bie Binjen Der an Den Staat geliekenen Summell zu 10 ßroc. verffeuert. Darleiken an \$rivaten wurben, Da fie bei bem Nangel an Sgypotgefenbühern wenig borfamen, nidht beachtet. 1677 uno 1681 twurbe $1 / 5$ ber Sinseimafnmen als Steuer

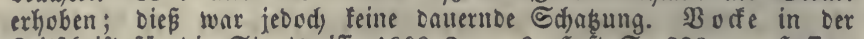

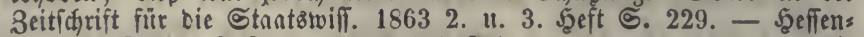
Darmft. Steuter= Inftruct. von 1658 Irt. 10: "capitalia, Davon Die "7 pensiones nod im (Sang uno nod) genoffen werben fönnen." - Soburg. 


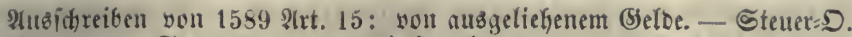
eimer bayer. Etabt yon 1606 bei 5 arl I, 177: von 1 fi. Sinz 8 Pf.,

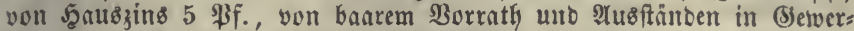
ben nur 1 Broc. Die bayerifdue Sinsefteuer, bei welcher bas Gimplum 5 Froc. Der Simien betrug, beftand nod, biz in onz 19. Sahrhunbert.

(c) Fü bie csapitalfteuer: v. Safob I, \$645 f. - Fuloa, Sandb. §. 180. - Rraule, National= unb Stantsöfonomie II, 311. -

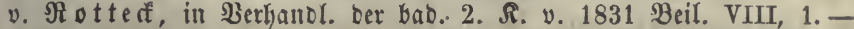
Deflen Defon. Bolit. S. 322. - v. BBenzel= Sternau, Commiffionz=

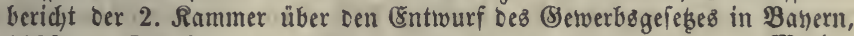
1828. - Duchesne, Essai sur les finances, Paris 1831. - Notion

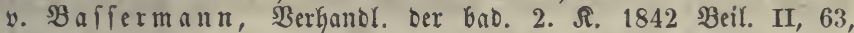
1843. 44 Beil. X, 109. Bericht y. Diathy, Beil. XIII, 115. Unter gewifien Ėinfdränfungen wirb bie (5avitalfteuer zugeyeben won 2. Smith III, 253 (IV, 203 B3á.). - §ubeid) a. a. D. (a). -

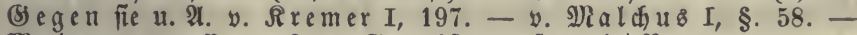

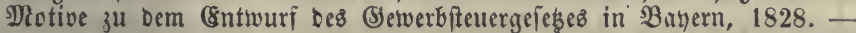
9) urfar D, Beft. S. 396-421. - 9 rnot, Die materiellen (Siruno. lagen ङ. 414. - (Berger) Rapport au Grand Conseil (Canton Vaud) sur la motion de Mr. Mercier, tendante à soumettre les créances à un impôt. Lausanne 1837. - v. \$rittwib̧, Theorie ber Steuern uno 3öfle S. 100, vgl. Deffen Rumft reich zu werten, $\$$. $635-655$. Sgelferid, Ueber bie Einführung einer (Sapitalfteuer in Baben,

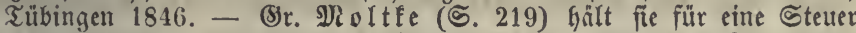
vom (S) elDe. - Berdjiebene Deinungen gefammelt bei Miurharo 5. 405 fi. - Berhancl. Der bayer. Deputirtenfammer von 1828 XI. $\mathfrak{B D}$.

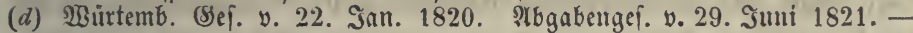
Beim. Ser. v. 29. Tpril 1821 über bie allgemeine šinfommenżfteuer, (Se). y. 24. Juni 1840, Die Beft. Des Einf. an Eapitalrenten betr. Bennizlvanifhe Sdjatsung von 1840, weldhe bie ausgeliekenen ober in offentliche unternefimungen getwenbeten (5apitale zu 1/2 p. m., Das (S) rund =

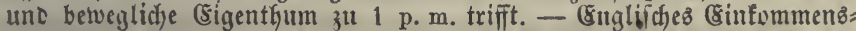
Pettergeies v. 22. Juni 1842. $=5$ u. 6 Victor. Cap. 35. - Săhf. (S) fes über bie \$erfonal= uno Sewerbfteter vom 22. November 1834, 24. December 1845, 23. April 1850 (bie Capitalrenten twerben in ber

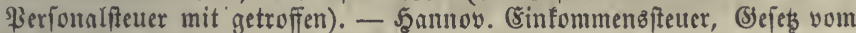
21. Detwber 1S34, neues Befés v. 20. Diärz 1859. (Die mit biefem

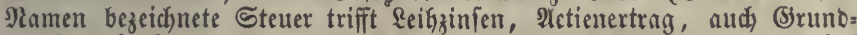
gefälle wie 3efnten 11. ogl.). - Sn mefreren Stanten hat man eine Fold)e Steuer zur Dedung vermelyrter Staatżnuganben eine 3eit lang

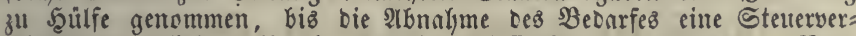

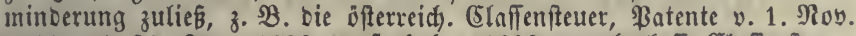
1799 und 20. 2rug. 1806, aufgehoben 1829; - turkefi. Clafieniteuer: gefes y. 31. Det. 1833, auffehoben 1840; - babifhe Eavitalfteuer, B. v. 19. Alpril 1815, in tem nämlichen Jabre wieber aufgehoben,

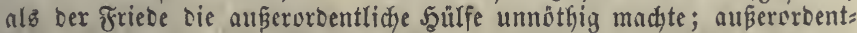
lidhe Befteuerung im (Srofíh. Şeffen, (S)efę y. 17. Nov. 1824. Die Finanzerlegenfyeiten von 1848 au haben zur Heberwinoung jener Bebenfen gegen 3inzrentenfteuer geführt; 3. B. Bayer. (Sefeßs v. 4. Juni 1848, 21. Juthi 1850, 31. Dlai 1856. (Serftner, Dab bayer. Esin= fommen = und Eapitalrentenfteuergefeb v. 31. Mai 1856, Errlangen

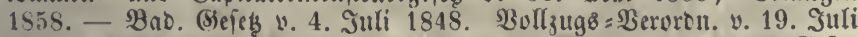

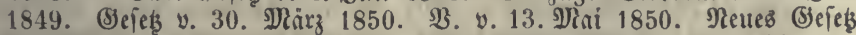
v. 7. Aprif 1860 . - Depterreich. Esinfommenzifteucr, von weldyer bie 3. Elaffe Dic Binbrenten trifft, Batent ๖. 29. Dec. 1849, $\mathfrak{B}$. v. 11. Jan. 1850. - Nach Dem Beies Des Canton Bern v. 15. Siärz 1856 wer= ben un bie (Gypothefarifa) verfiderten verzinbliden forberungen uno 


\section{$\longrightarrow \quad 150$}

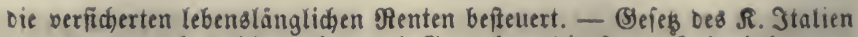
von 1864, nady reldjem aber nud (Setwerbsverdienft uno \&ohneinfommen befteuert werben.

\section{§. 378 .}

Der Şauptgrunb für bie 3ins?rentenfteuer ift bie Forberung Der (Bered)tigfeit, Daß̧ fein Theil bes reiven Einfommenż, bes jonbers fein anfehnlid) großer, und feine ungweifelhaft fteuer= fähige Celaffe bes Bolfes von Der Beiziehumg zu ben Strats= lnften befreit bleiben bunfe $(a)$. Die Steuerfreifeit ber 3ins = gläubiger ift cine unverbiente Sdyomung, wälyenb bie anberen Einmohner onrum befto höher belajtet werben. Dieje un= gleid)heit bermögen bic 2lufwandsefteuern nid)t zu befeitigen, weil fie aud) bie anberen, idjon mit Schakzungen belegten (Sinfünfte uno Stänbe treffen. Cime boppelte Befteuerung ber nämlidben (sintünfte finbet nicht ftatt, weil bie 3insirente ein bejonberes, burch) bas beiberjeitige Mittverben beftimmtez, nach eigenthüm= lidjen (Bejesen fid) rid)tendes Einfommen ift. Die Binşfteuer barf balyer in eittem yolffommenen Syftem ber Sdjakungen nidjt

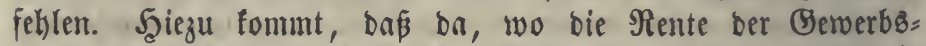

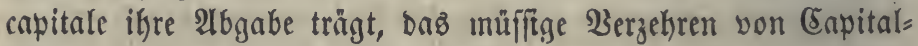
zinfen nid)t beginftigt werben follte.

Die gegen bieje Steuer nufgefübrten Srünbe betreffen

1) bie Birfungen Derjelben, unb znar

a) auf Die (S)läubiger, \$. 379,

b) auf bie Sifuloner unb auf Die ganze Strobuction, §. $379 a-382$,

c) auf Die Staatzeinfünfte, $\$ .383$,

d) auf Den Staatserebit, $\$$. 385 - oder

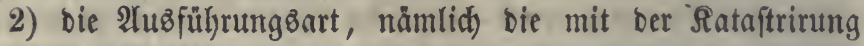
ber Zinb̂forberungen verbunbenen ভdywierigfeiten, §.386.

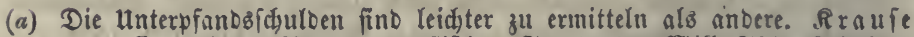
a. a. D. rednete für ben preusifden Staat 1206 פill. Thlr. Shulben auf bem (8rundeigenthum, 262 auf Den \$åiuern, 646 in Den bürger=

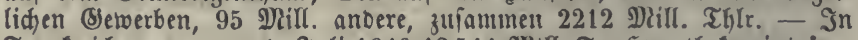
Franfreid waren am 1. Juli 184012544 গlill. Fr. Fुt)pothefeneintrage, wovon 1250 Mill. als Bürgichaften an ben Staat, bie Semeincen 2c., alfo 11294 )ill. (runb 11300) wahre Sd)ulden, unter Diejen 3767 Dill. als Darleifen, 7533 Dill. beim Raufe you Riegenfdaften ủber= nommen; Finanzminifter (S) o u D d) a $u x$, Assembl. nat. 10. Det 1848. Unter biefer Summe find aber viele fajon getilgte, nur nod nidht gelofdste Gdulden begriffen, weß̧alb Thiers nur 4500 \$lill. annahm 


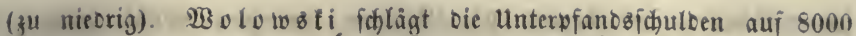
Ditl. Fr. an, Journal des Écon. Det. 1857, ebenio be \&avergne. Sn Belgien follen gegen 600 Mill. Fr. Syppothetenanleifen fein. Im §. Italien betragen Diefelben nadh amtlidjer Angabe 4694 शRifl. Fr. oder 215 Fr. auf den Ropf, Die Sinjen (zu 5 झroc.) nehmen 27 \$roc. cer (Srunbrente hintweg. Plebano et $\mathrm{Musso}$. 246 . - In Baben zeigt ber Durd)fđnnittzertrag ber Steuter von 1854-56 194 Mifl. fi. Ecihforberungen, D. $1857-58203,8$ פill. $=152$ fl. nuf Den Ropf, 1862 an 220 Dill. ober 160 fl. a. D. R. - Babern: Ânidlag für

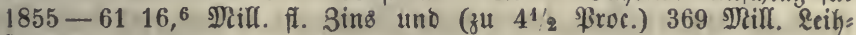
fummen voer 82 fl. a. D. ̊. - Würtemberg, D. $1855-56$ mit 3ujab

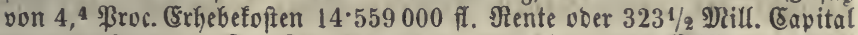

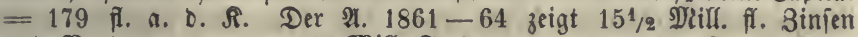

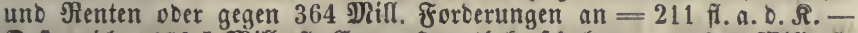
Defterreich 1476,7 Difl. fi. Conv. Szypothefenichulden $=1809$ Yial. fi.

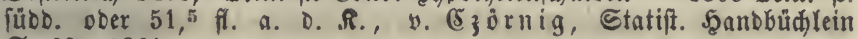
ฐ. 63,1861 .

\section{§. 379 .}

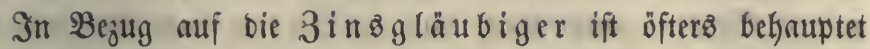
worben, biefelben feien aud) ohme befonbere Steuer fijon mittel= bar getroffen, weil bie auf anberen befteuerten Berwendungen Des Bermögens laftenten Sdjaķungen bie Reigung ber Capi= taliften z̆um 2 Luşleihen verftärfen uno vermöge bes vermełrten

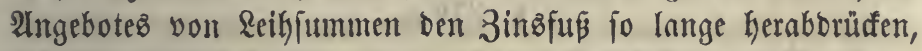

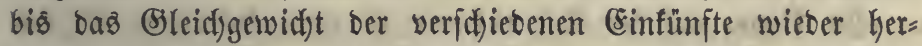

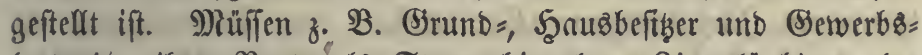

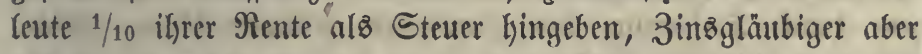

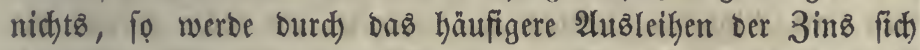
nuf $9 / 10$ feines fritheren $\mathfrak{B e t r a g e s}$ ftellen. Dagegen ift zu bemerfen

1) Die oben bezeid)nete Wirfung ber Nicttbeftenterung ber Binsirenten fönnte nicht fo grop fein als man amnahm, benn

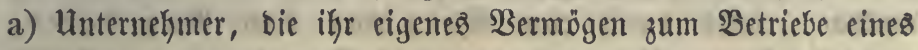
(Setwerbez bentben, werben burch bie (S)ewerbfteuer nidft belwogen,

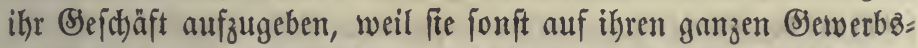
verbienft verzict)tent müptent uno mur nod) Eeifzinfen einnähymen. Ferner werben b) bie Befitier yon Riegenfidfaften ber Brunb= uno Scaubftcuer willen biefe Segenftänbe nid)t verfnufen, un 3intşgläubiger zu werben, Denn bas vergrö̋̈erte $2 \mathfrak{A} g e b o t$ würbe Den \$reis ber Riegenjunaften erniebrigen, fo baß fie bann bei

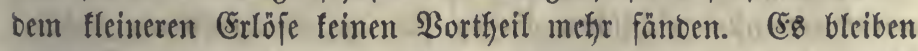

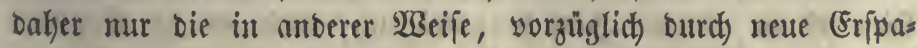
rungen gejammelten, nod) nid)t angelegten Capitale in (o)lo: 
form übrig, bei benen bie Befizker zwifden verfdjicbenen $\mathfrak{B}_{c}=$ mųungen zu wählen Kaben uno bic vielleid)t zahlreid)er alz bei einer vollftünbigen Befteuerung zum Aluzleiken gelnutgen, biés beträgt aber im Banzen nidft viel.

2) 2lber ferbft wenn man iene Birfung in vollem Maaße zugiebt, fo ift fie bod) fein Srumb, bie Befteterung ber 3inz= rente zu unterfaffen, benn biefe Mapregel würoe nutr bas (Sleid)= gewidyt ber verfdhicbenen. Menten wieber herfteflen, ber ftärfere

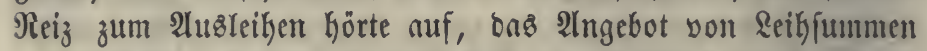
würbe wieber fleiner, ber 3insfuß ginge etrons in bie Şöke

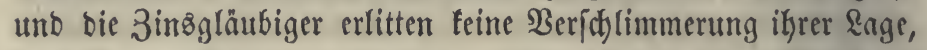
Die Statacaffe erbielte aber eine neuc Steuts cinnahme. Man fönnte bie obige Sd)lusfolge ebenjogut auf anbere Steutern anwenten und $3 . \mathfrak{B}$. Die Entbehrlidfeet ber Beswerbfteuer zu behaupten futhen, weil, wo biefe fehlt, mehr Bermögen auf Sewerbe Gingelenft würbe uno beren (Ertrag fid) verminberte.

\section{§. $379 \mathrm{a}$.}

In Bezug auf bie Sd)uloner ift zu unterfudyen, ob ben

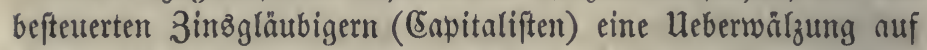

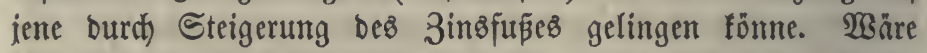

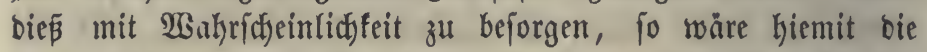
Berwerflidffeit biefer Steuter fogleid) erwiefen. Der $\mathfrak{B}$ Bunfa) und Das Beftreben ber (Eapitaliften reidjt offenbar midft bin, eine foldje $\mathfrak{U} e$ berwälzung zu berwirfen, wenn iffren nidjt bas Mitwerben Dabei günftig ift. Dieß bentbar, theils burct eine $A$ bnahme bes 2 ngebotez, theils burd eine Bermegrung Des Begehres you Reih= fumen.

Das Ingebot verleifbarer capitale würbe bann abnehmen, wem bie Eigenthümer, un ber Eteutr auşumbeidjen, eine anbere Antwentumg vorzögen, woj̆t fid) folgente möglict) Wege Darbieten $(a)$ :

1) Eigene Betreibung von Benerben, wobei man im Ses

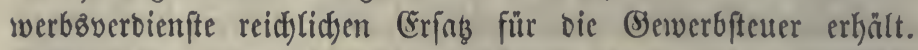
Dießs ift in anderer Şinfict)t juträglid), weil es bie Conpital=

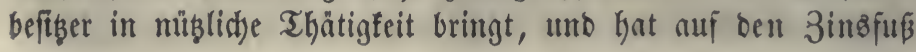




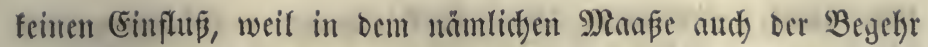
yon Conitalen abuefmen mus, benn fo lange bic Belegentyeiten Diefelben mäblich anzumenben fid) nicht vermebren, werben bie eigenen Unternekmungen ber Capitalbefiber mur bie Stelle ber mit geborgten Gummen betriebenen cinnehmen.

2) Infauf yon \&änbereien ober Sebäuben, bie jeboch eben= falls mit Steuern belegt uno nicht fo wohlfeil zu erlangen fint, bấ man bie 2lbgabe nicht empfänbe (\$. 313); überbieß würben biefelben jogleid) im Jreife fteigen, wenn fite băufiger begebrt würber, unb entidi müfen in biefem Falle bie $\mathfrak{B e r}=$ fäufer fich wieber um eine werbenbe Inwentung bes saufgeldes bemühen, eş treten aljo nur anbere $\mathfrak{B}$ eftzer ber verleikbaren Summen allf.

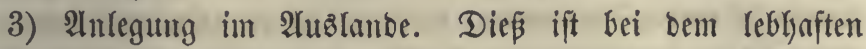
Berfegr in Staatzpapieren, Actien unb bevorzugten Sifuld=

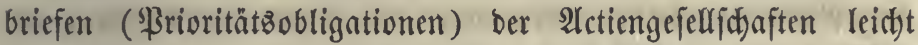

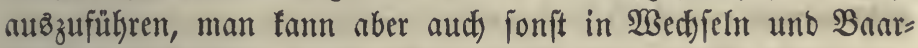
ienoungen Summen auper Ranbes (chaffen, bie bann ber ein= Geimifchen Betriebfamfeit entgehen. Daßj eine foldje SBirfung ber 3 inşfteuer allerbings eintreten fann, muß zugegeben werben.

(a) Dá̃ man ber Steuer willen Capitale aufzelyre, ift am wenigften glaub= lid,. - Stein, \&efreb. S. 444: Die Steuter wirb niemala von bem= jenigen getragen, Der fie nad) Dem (Sejége zablen follte, fonbern ftets von Demjenigen, für Den das Cavital ben höheren (S)braudsonerth hat, uno Da bießs ftets Der Sdyuloner ift, fo wiro wrincipiell Das (Bsegentheil von bemjenigen erreicht, was bas Befes will. Dagegen ift zu bemerfen,

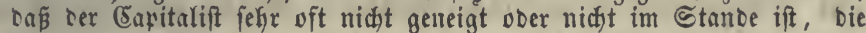
Seihfumme felbft zu benuben (yon ifrem (Sebraudystwerthe Inwendung

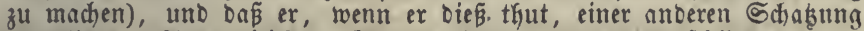

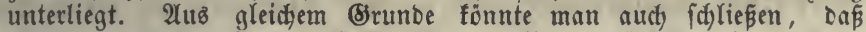

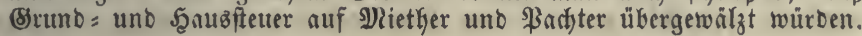

\section{ङ. 380 .}

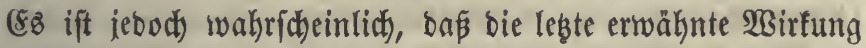
bei einer mäfigen unb billigen Anlegung ber Steuer nid)t to

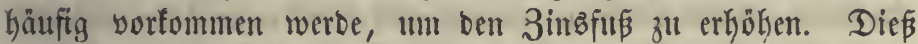
läpt fich fo barthum:

a) Dieienigen Enpitale, bie ben Stiftumgen, Eorporationen, Semeinben, 9) tinteriährigen 2 . gehören, bleiben wegen ber geringeren (Sefahr imterkalb beż Lanbez;

b) ebenfo bie Capitale foldjer ßribatperfonen, weldye ber

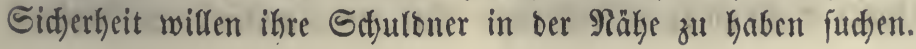


(Ein Theil ber Rentmer liebt bie Anlegung in Ctaat\$papieren überthaupt nidjt, viele aber zieffen ben auslänoifden bie cins beimifacten vor. Tritt in einz̧elnen 3eitpuncten eine bäufige

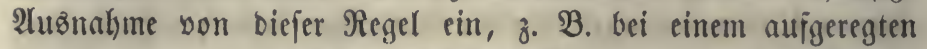
Berlangen nad) böberer Binteinnałyme, jo ereignen fid) leidjt Berluite, burd) weldse bie Capitaliften wieber zu größerer Bors fictit ermahnt werben. Die grope Menge foldher Unterpfanbs= forberungen, bie nidjt aus Darteiłen, fonbern aus (Erbthei= lungen ober aud) aus 26blölungen herrülyen (ygl. \$. $378(a)$ ), pflegt ebenfalle ftehen zu bleiben, ob fie gleid) fünbbar uno ben eigentlict)en Reihforberumgent ähnlich fino. Pur ber fleinere Theil ber verleifbaren Sunmen ift folglid) fo beweglid), baß er fidjon bei einem geringen Untericticbe im Ertrage von einem Sanbe in bas andere wantert. Dieß gilt inżbejontere yon bem beweglidyen Bermögen ber Bantferren, weldjez jebodh alz Theil Des Betriebscapitales mefyr unter bie Serverbfteuer fällt uno nidjt genau von berfelfen erreid)t wirb $(a)$;

c) ber $\mathfrak{B}_{\mathrm{e}} \mathrm{ugg}_{\mathrm{g}}$ von Binfen aub einem anteren Ranbe ver: urjad)t größere Bemüthungen unb Sopten;

d) venn ber 3ingsun bei ber 3unalyme bez 2 sohlftanbes finft, fo müffen bie (Sapitaliften gróßere Berlufte ertragen, als

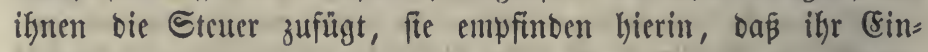
fommen cin reines ift, weld)es ohne Ract)theil für bie Büter= erzeugung burd) gebieterifdje Umptånte verringert werben fann,

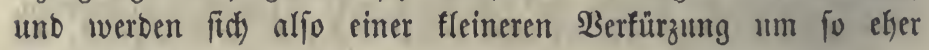
unterwerfert;

e) Die Capitaliften find in ben Stanten, wo bieje Steuer befteht, verpflid)tet, bie im 2luslanbe auzgoeliekenen Summen gleidffallz zu verfteuern, bagegen bleiben gewöhritid bie inlän=

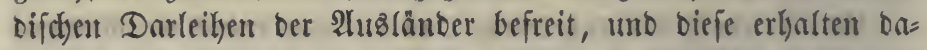
Durd) eine (Ermunterung, Summen you mapen herbeizulenten. Das unberweglidje $\mathfrak{B e r m o ̈ g e n ~ b e f t e u e r t ~ m a n ~ z w a r ~ b e r ~ R e i d f t i g f e i t ~}$ wegen all Dem Drte, wo ca fich befinbet (\$. 262), bie Zinto = rente aber, ba bie Edullouer uno bie verpfäubeten Oegenftänte

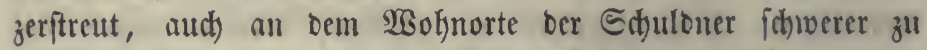
ermitteln find und von bem Steuerpflithtigen bie Steuer un= mittelbar nidjt wohl zu erbeben ift, wirb am beften am $2 B 0 h n=$ fize ses (Empfängers beftetert. Nur wem man bic Stenerpflic)t 
nid)t auz ber gefammten Stantsbürgereigenidyaft, aljo bem (5)nufie aller Staatzanftalten, fonbern allein aus ber $\mathfrak{B} e=$

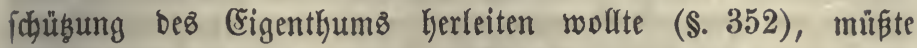

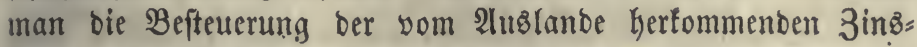
einnahmen míbbilligen und bagegen bas innerhalb des \&anbes angelegte $\mathfrak{B e r m o ̈ g e n ~ b e r ~ F r e m b e n ~ z u ~ b e f t e u e r n ~ r a t h e n ~}(b)$. Wemu

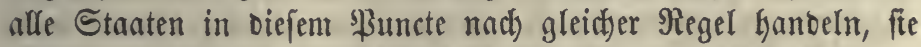
mögen mun ben $\mathfrak{B g h}_{\text {nfth }}$ bes Eapitaliften ober ben Drt ber Anlegung zum Sirunde ber Steuerpflicht annehmen, fo ift abgejehen von ber ungleid)en Scidtigfeit ber Berkeimlidbung, für ben Befitzer Des beweglidben Bermögens in Şinfictst auf Die Steuter gleid)gủltig, wo er baffelbe ausleift. Wirb bie Steuer nad) Der erfteren Methode angelegt, fo erfält bie Regie= rung bes reicheren, mehr leikenden Bolfes mehr (sinnahmen als bie bes ärmeren borgenben. Werben von \&anb zul $\mathfrak{E}$ and $a b=$ weichende Regeln angewentet, to ift eine boppelte Belegung

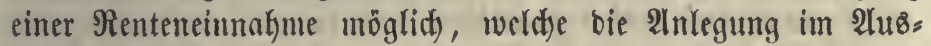
lanbe erfdjwert (c).

(a) Biele benten fid das Capital als ein in feinem Lande gebundenes, wie auf Flügeln hinfdictebendes sout, weldes, twenn es fidh hie und ba

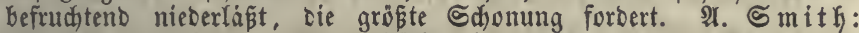
"Der Eigentryümer voul (Srunoftưden ift nothwendig ein Bürger bes \&anoes, in weldhem feine Beifizung liegt; aber ber Eapitalift ift eigent= lid ein $2 B$ eltbürger und nidt nothwendig an ein bejonderes \&and ge= tnipft. - Esine Etetter, welche das Capital aus einem befonderen Eanbe treiben würbe, mäste, foweit fie biés thäte, jebe Duelle bes Einfommens, fowohil bes Doerfinuts als bes Bolfes (society) aus: tructnen." III, 254. (IV, 294 Bar.). Diefe Folge ift von einer nad ridjtigen Srrunofäben anaelegten Steuer nidjt zu erwarten, aud ift, was ben Borderfas betrifft, bei eimem groß̈en Theile bes Eapitales fdjon

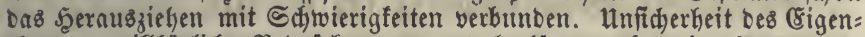

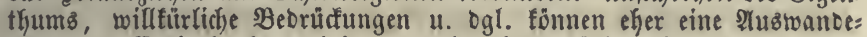
rung ber Cavitale Kervorbringen, als eine mäs̈ige Steuer in einem wobigeorbneten Stante. In einem fleinen reidjen Stante wäre Dings anters, weil man hier Das 2luzlano ganz nahe hat und ofnehin

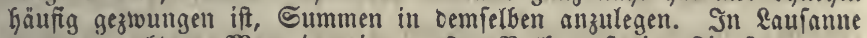
wurbe, nadibem $\mathfrak{D i e r c i e r}$ in großen Rath auf eine Sinsfteuer an= getragen hatte, in neuen Reifyerträgen ausbebungen, baß oer Sđulbner Die Steuer, wenur fie eingeführt würbe, tragen follte. Das wäre in einem gröseren Staate fohwerlich zu erwarten, auth bleibt es zweifels

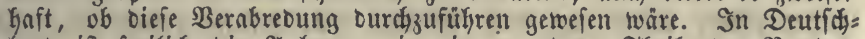
land ift freilid bie 2inlegung in einem anderen Theile bes Bundes= gebietes fehr gewöhnulich.

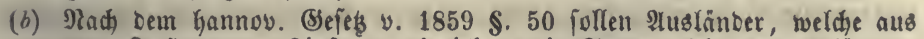

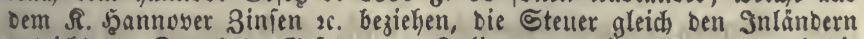
entrideten. Das bad. Befers y. 4. Suli 1848 wollte (Prt. 3) aud bie im eante wohnenben Fremben beiziefjen unt madjte hiebei zwifden 


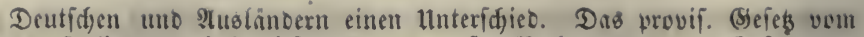

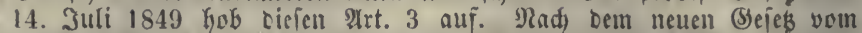

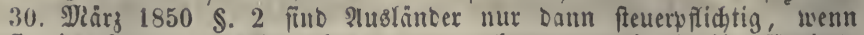
fic im Ennde bes Ermerbes wegen wohnen und founit igr (5avitals

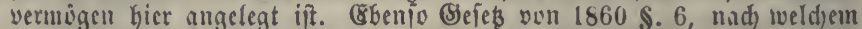
ferner babifice, im Ennve wohnende Stantsbürger, oie auds in eillem mberen Ranbe Das Stratżburgerrecht haben, für Das aus diefem \&anbe herrifyrende (Eintommen befreit fund (\$. 4), und weun fie um शtuslance woknen, Gaben fie nut bie aus inlandifiden $B$ ezugsorten fommenden Renten zu verfteuern (\$. 5). SBic Der a. $\$$. 6 aud bas Baryer. Befebs v. 31. STinz 1856, Dod) oljne Die Befduränfung "Des (Erwerbes ivegen". In Defterreid wird nad) Der 23. v. 28. Afuril 1859 Die Steuer von Dell Sinfen Der ๔tantzidjulobriefe bei Den Stantsenfien abgezigen und Dieß

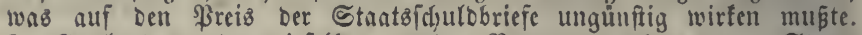
Jm शluslande werben Diefelben um ben Betrag ber abgezogenen Steuer niebriger freljen und bei fwateren Anleiken mur man, foweit die

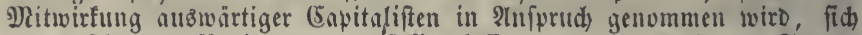
etwas fdwerete Bebingungen gérallen laffen, woourch ber in ber G'teter:

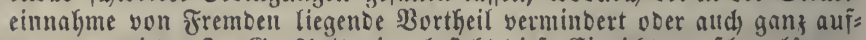

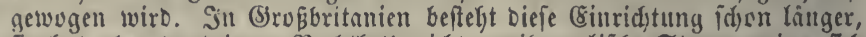
fie Kat aber. Dort jenen Saifjtheil nidyt, weil englifide Staatspapiere fich

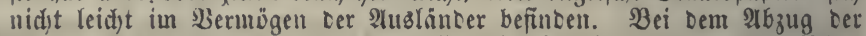
Steuer an Den Binfen läs̆t fich freilich Die Befreiung der ausländifchen

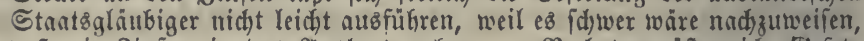

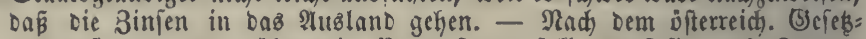
entwurf yon 1863 ïber dic sientenfteuer foll ebenfalls auf Stantg= angchorigfeit ober Alufenthalt feine Siufficht genonmen werbell. Rad) Dem italienifden (Sefes von 1864 follen Die Atuslander für alle

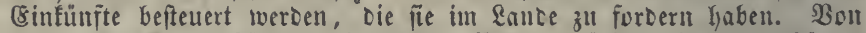

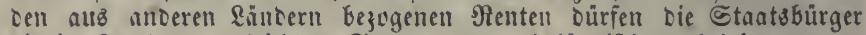
Die im Itublance entridstete Steuer an Der inlandijchen abziehen.

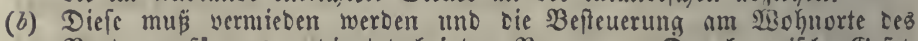
Rentenempfängers verbient Dabei Den Borzug. - Das Bareriface (5ejes \$. 7 erlaubt ben bayerifdyen Stantzburgern, Die Steuer, bie fie im

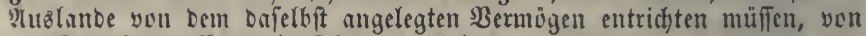

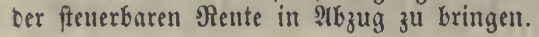

§. 381 .

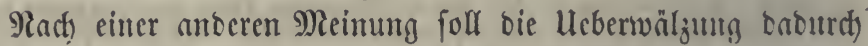

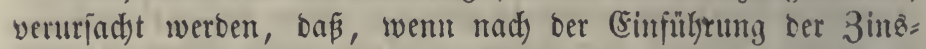
ftetuer bent Edjulbuern an ihren Steutrm eine entipredyente Erreinterung zu Theil wirb, bießß Die Reigung zum Borgen

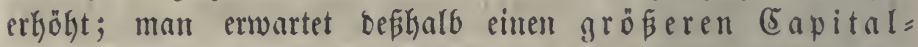

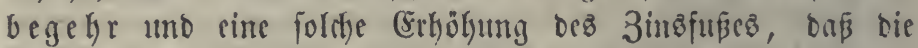
Borgenten nod) eben foviel Binz bejallent wie jutwor, bic Eapitaliften aber für bie Steter entfinäbigt werben. Diefe Bermuthung berulft auf folgendem Sdjluffe: Der Bewerbs=

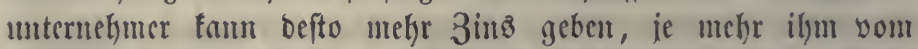

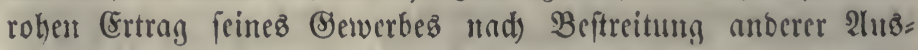

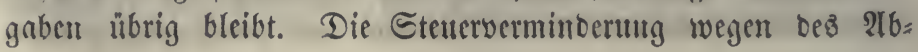


zแgz oer Echulbzinjen vou dem fteuerbaren Sinfommen gewälurt ifym eine Erpparumg an Den 2luzigaben und crmuntert ifn $D e \beta=$ halb, mehr zu borgen $(a)$. Der Capitalift, ber einer Sd)mäle=

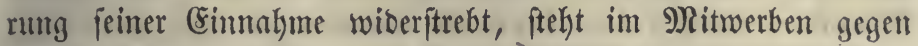
Den Sduldoner, weldyem cine Alubigabe abgenommen wirb, ohne= bin im Bortheil, und biejer entichliept fidt) leidter, in Sanzen nod) foviel zน geben ก(ż bizker, wenn er bas ftärfere Mit= werben wagrnimint $(b)$.

(a) Freilich geht diefer Bortheil für ifn wisber verloren, wenn ber Bins

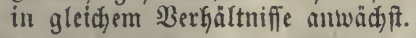

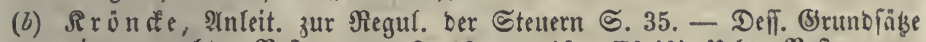
einer gered)ten Befteterung $\$$. 19. - (du Thil) Ueber Beffetterung im (5rof̧h. Şeflen 5. 26.

\section{§. 382 .}

Dieje $\mathfrak{W i r f u n g}$ ift nidyt wabridseinlich, weil a) ein $2 \mathfrak{A b z u g ~}^{4}$ (5umften ber veriduldoeten Steuerpflidtigen an ifren Sd)nb̧ungen

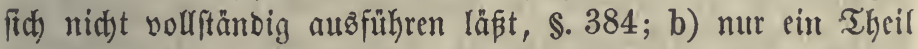
ber Sefulden zu gewerblidjen 3tweefen gemadyt wiro, währeno viele anbere aus ber Errwerbung von Riegenid)aften (Immmobilien) oder auz Berluften uno Unfällen Gerrïhren unb Dann, wenn Der Sctuloner fith in cincr befferen \&nge fteht, fogar bäufiger abgetragen als bermebrt werben; c) weil bie Belegentheiten, Capitale in linternehmungen zu verwenben, in bem voraus= gefesten Falle fict) nidjt erweitern $(a)$; d) weil ferner, wenn bie geringere Alugagnbe, weldte aufgenommene Enpitale bem

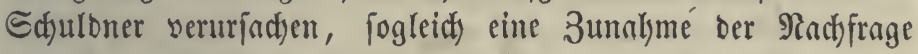

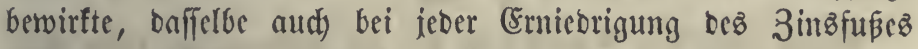
gefdychen und biefe hieburdy in furzem wieber nufgehoben wer= Den müpte; dieß ift aber gegen bie Erfahrung. Capitalifeutern

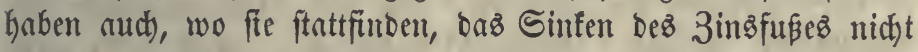
verhindert, und es ift nidft befannt, onß fie Denfelben böker erkalten hätten alళ anberøิwo.

(a) Smith III, 252.

\section{§. 383.}

Durd) die vorftehenden Säķe wirb die Bejorgníp einer Stei=

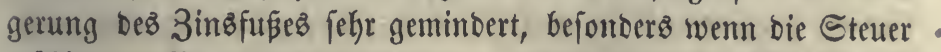
mäßig, 子. B. mur $1 / 10$ ober $1 / 15$ ber Binfen ift. Die Eapi= taliften fömen fduwerlid) ifre Sdulbner mit ber Drofyung Des 
Sửnoigens zur Bewilligung eines höheren Bimjes bewegen, weil fie feine Atusftct haben, in Falle ber Şeimzahlung bie Summen antersimo beffer unterzubringen. Bei ben meiften

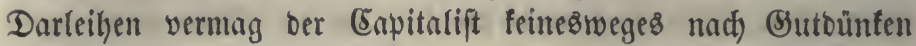
zu forbern und zu gebieten, vielmehr fteht er unter ber Madtht

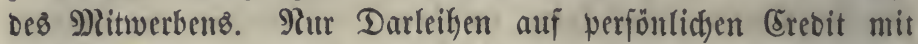

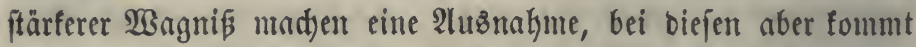

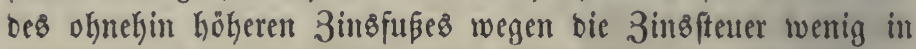
Betradjt. Se mefre man bieje Steter anteren Sd)aķungen ägnlid) zu madjen weis, ohne baburd) bie Befteuerungsggnund=

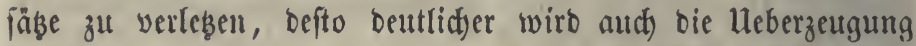
hervortreten, baß man iene wie jebe Steuterbelnitung bes reinen

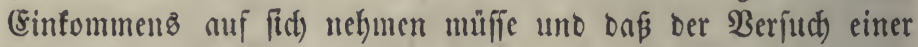

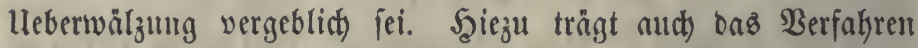
bei, ben Fuf ber Etetter anfangz gering anzuezen, um bie Bürger erft an bicjelbe zul getwöhnen. Bon dem gefeslidjen Berbote einer Meberwälzutg ift wenig Erfolg voraużulehen, weil man bem Bläubiger im IUtgemeinen nidft verbieten fann, einen Gökeren Sins zul verlangen, aud) bic Ungehung burd) münblide $\mathfrak{B e r a b r e b u n g ~ l e i d y t ~ i f t ~}(a)$.

(a) 3. 3. bei ber in ber efremaligen englifden income-tax enthaltenen

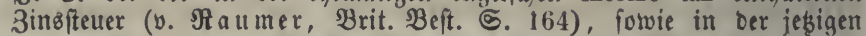

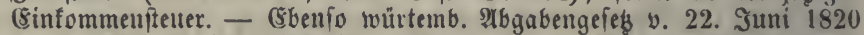
§. 14: Rein (Eapitulberizer ift bered)tigt, fid oie Gteuer vom Sd)uloner vergüten zu laffen, bei Strafe bes 15 fadjen. - Bayer. Sinsfteuter, Berurbn. v. 1794, (Sef. v. 1848 §. 1, Sef. v. 11. Juli 1850 शrt. 1.

\section{\$. '; 84 .}

2Bem man bell Edjulbnern bei ber Befteterung ifrer (Ein= fünfte ben 2lbzug ocr zu entrid)tenton Binjen geftattet (\$.401), fo wiro hicourd ber Burtheil, ben bie 3inserentenfener ber Stantzafafie getwäfrt, bebeutento vermintert, icboch nicht ganz zerftört, weil ç viele Binfororbenungen giebt, bei benen fein

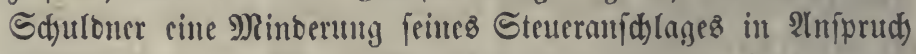
nefmen fann, z. B. Die Stratsiffuldoen unt bic Forberungen

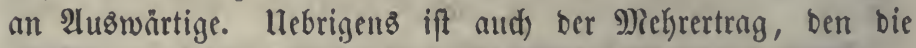
3insfteuer abwirft, nid)t ber einzige (Srumb für ihre (Empfehlung,

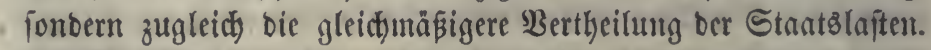
Die Beiziehung einer bisher zut menig befteuerten Elaffe von Bürgern wutrbe ats Grintoen ber Berectitigfeit uno Stant: 
flugheit jelbft bann rathjam fein, wenn fie gar feine Bermekrung

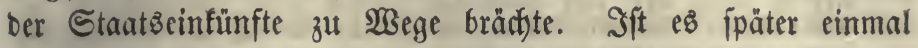
nöthig, zur Deffung vermehrter Staatzobebürniffe bie Steucru

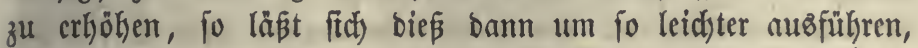
in je ridftigerem $\mathfrak{B e r b a ̈ l t n i f f e ~ a l f e ~ E i n f u ̈ n f t e ~ u n o ~ a l l e ~ S t a ̈ n b e ~}$ Der (Befellichaft belegt fint.

\section{§. 385 .}

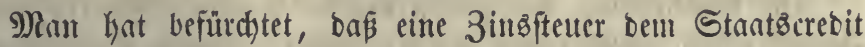

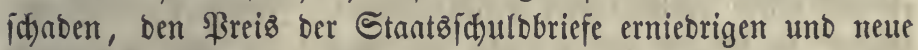
2unleiken erfdweren mödte. Allein eine allgemeine Mapregel,

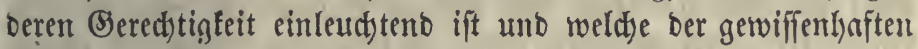
Erfüllurg eingegangener befonberer $\mathfrak{B} e r b i n d l i d$ feiten nidjt im Wege fteft, fann bem (Erebit Des Stantes nid)t idfaben, zumal Da fie biefem neue Şülfzిquellen eröffnet. Der \&eifyertrag, ben Der Strat mit feinen (Släubigern abfalofi, verbietet bie Befteuc= rung berfelben nidyt, benn er fann ifnen feine Befrciung von allgemeinen Bürgerpflict)ten verj(b)ffen, uno ez ift in 2lnjehung ifrer Steuerfouldoigfeit gleichgültig, von wem fie ifre Zinjen beziefen, wie z. $\mathfrak{B}$. auch ber (Eigenthümer einesz an ben Stant vermietbeten Şaulfes fidf) ber Şausfteuer nicht entzieben fann $(a)$. Eine geringe Erniebrigung besె Eurję̧ ber Stantżpapiere fönnte zwar nach ber (Sinführumg bicfer Steuer cintreten, fie wirb aber neben ben anderen. mädjtigeren Mrjachen, bie ben झreiz biefer Sduldobriefe beftimmen, nid)t leidyt wahrgenommen. Nit ifr

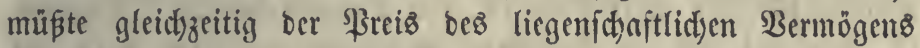
fteigen (\$. 312). In Dem Maaße, wie bie Stantöobligationen aud von atzländifden Capitaliften begefyrt werben, ift biefe Wirfung ber Steuter fduvidjer, befonbers wo bie Tilgung oer

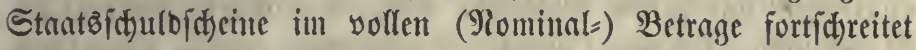
uno bie Schulbenmaffe nid)t großß ift. Unter ungünftigeren Sd)ulbverkältuiffen fömte $\mathfrak{e}$ freilid) rathfam werben, bie $\mathfrak{B}_{e}=$ fteuterung ber Staato̊gläubiger uno fomit bie ganze 3inøిfteuter nod) zu verfdieben. Sdjon bießs erforbert bie Billigfeit, ba man eirre fold)e 2 lbgabe nid)t gantz furz nad) einer Şerabjez̧utg Der 3infen von ber Staatbifuuld neu cinfüfre.

(a) In Der norbamericanifajen Union ift Den Negierungen ber einzelnen Etaaten bie Befteuerung ber Etaateffuldobriefe unterfagt, aber nidjt Der Sounbesgetwalt. In Erropbritanien if bell Etantsgláubigern ber 
3iins free of all taxes and charges zugeingt, aber fdjon \$itt legte

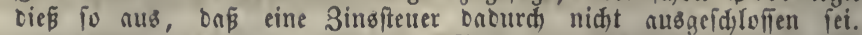
Gladstone, Financial statements S. 31. - Bei ceun Sinfumment: ftenergefes vou 1864 in $\Omega$. Stalien wurbe von ber Deputirtenf nmmer

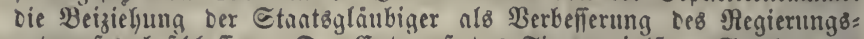
entwurfes beidsloffen. Der Entwurf bes Finnizminifters Sella twar ragegen, weil eine aifnlidye 3ufidjerung gegeben mar; Bortrng bes Dinifiters bei de Parieu V, 249.

\section{§. 386 .}

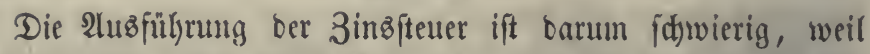
es an offen vorliegenten Sennzeidyen ber 3insforberungen ge= bridgt. Daker ift bie Angabe Der (5läubiger ober Sd)ulnner nid)t ju entbehren und eine rid)tige $\mathfrak{B}$ efteuerung wirb folglid) burd) Die 3unerläffigfeit biefer Erffärungen bebingt. Wenn

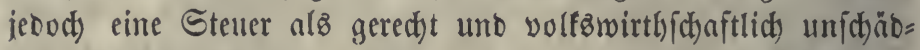
(id) anerfannt wirb, fo barf man fid) burd) änßere Sd)mierig= feiten nicht abhalten laffen, bie fid) ohuehin mit ber 3eit ver= minbern, inbem fowohl bie Sefdidfidfeit ber Bermenten uno

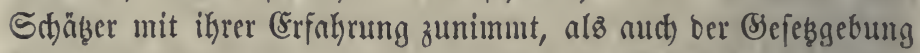

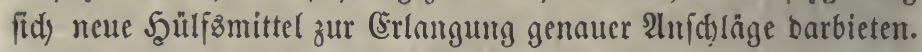

3 wifd)en oen eimzelnen Irten von Forberungen findet in

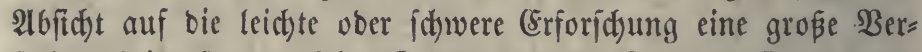
fdrebenheit ftatt. Die Sduldoen bes Stantes fino genau befannt, bypotbefarifdse Forbcrungen laffen fidt) nuв ben \$fant= büd)ern leidjt ermitteln, ebenjo auch bas Bermögen oer Stif= tungen, Corporationen unb Minberiährigen nแв bent oberbor= munb/haftlidyen Berrid)tungen ber Stnatb̄behörben. Dagegen ift man bei ben im 2lublanbe angelegten umb ben bloß muf perjönlichen Erebit in Sillutoe bargelichenen Summen von

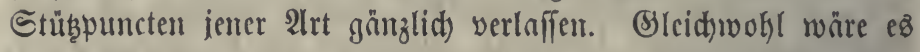
ungeredt, nur gernoe biejenigen 2lrten von Enpitalforberungen zu befteuern, bie man genou zu erforidyen vermag, uno biés würbe bie Eapitaliften crmuntern, ifre Eapitale ben fteuerfreien Darleifen zuzuwenben, woburd) Dann Die \$frnofduloner zu etwas hökerem 3infe genöthigt werben fönnten.

\section{§. 387.}

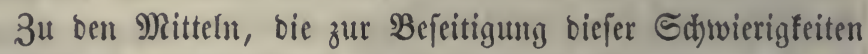
vorgefdlagen ober wirflid) angewentet worben finb, gefören vorzinglid) biefe: 


\section{1}

1) 9) )ittelbare (intirecte) Befteuerung Deß Capitaliften, inben Der Ed)uldoner ermäctigt wirb, jenem eine Dem Steuerfuße ents fpredjente Summe an Den Zinfen abzuzieben, währent er felbit

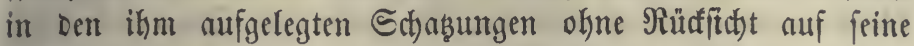
S(t)ulden belegt wirb. Den Stnatżgläubigern macht bie Regie= rung ben Steuerabzug bei Der 2lusbezalylung ber 3injen $(a)$. Nur für bie ausె'wärts angelegten Capitale finoet cinte ummittel= bare Entrictung Der Binżgläubiger zufolge ifrer 2ngaben ftatt, und bie Staatżcuffe erbält Daker mur von biefen leß̧tgenannten

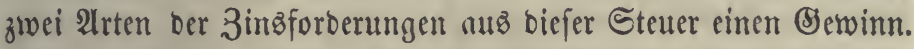
Şierin liegt an und für fith fein Tabel gegen biefe (sinrid)tung, Denn die Steuerfäbigfeit ber Schuldoner ift in ber That fo viel

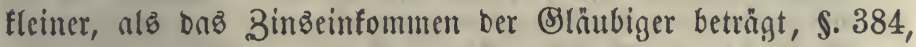
401 a. Sin Borzug Diefer 2uroromng ift, baß bie Steuer= behören fowie bic meiften Capitaliften alle Bemühungen und Unanmehmlidfeiten erfparen, bie mit ber Erforfdung ber in= ländifjen Bribatidjulden verbunden fein würben. Dod) ift

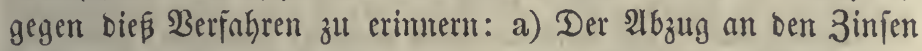
muß bei ben mandbfaltig verwidelten Єduloverbältniffen zu vielen Streitigfeiten zwifften beiben Theilen 2lnlä́ geben unb b) Den Släubiger mefr alz cine unmittelbare Steuerforberung in Berfudyung fezen, Dem Schuldoner, Der ifym an ber Stefle Desె Eteuereinnchmers bie Steuer nbziehen will, bie volfe

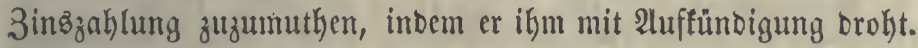
Sette 3umuthung liegt beskalb un fo näker, weil ocr Schuld= ner feite biskberigen Sdhakungen aud) fermerkin bezablt uno bie Regierung ifm nur eine Erleidterung burch Die (Erlaubniß bes 2)zuges zubenft. Würbe aud) bie gebrohte 2uffünigung yon Seite Des Släubigers im Banzen genomment feinen (̌rfolg baben (\$. 383), fo fomn bod) mantber einzelne Schuldner aus Furdht vor Den Unannehmlidteiten eines neuten Inlehens uno wegen Dess mäpigen Steuerbetrages zur Ractgiebigfeit bewogen werber. c) Die Staatżgewalt erlangt biebei feine Senntnís

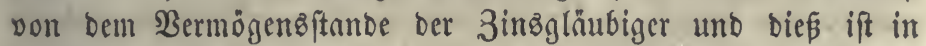

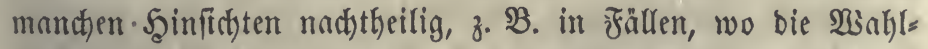
fähigfeit ober $\mathfrak{W a ̈ h l b a r f e i t ~ v o n ~ c i n e m ~ g e r v i f f e n ~} \mathfrak{B e r m o ̈ g e n ~ a b h a ̈ n g t . ~}$

2) Sefeşlid)e Berpflichtung Der Släubiger, afle ober wenig= ftens bie über ein Jabr ausigcliekenen Eummen bei einer Stnat8= 
behörbe eintragen zu lafien, mit ber 2(nbrokung, baв́ fie im entgegenge ésten Falle nidft flagbar fein follten $(b)$. Dieß if

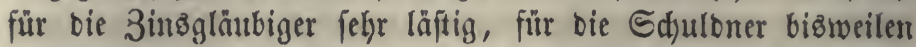
höd)ft wibrig unb nadtheilig, bie ungleidye Dauer ber Dar= leihen über und unter ein Эahr veranlaß̧t mandje unbeabfidtigte

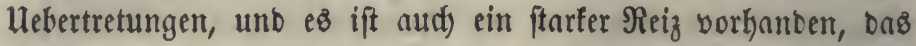

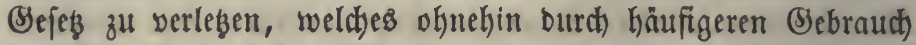
von Anteiken auf furze 3eit ungangen werben fann. Die ben Beamten zur Pffid)t gemadjte Beríd)weigung ber (Einträge bes feitigt ben Radttheil nidyt völig.

(a) Bei Der Kolländif̧en Bermỏgensfteuer yon 1/2 \$roc. (1673) waren bie unterpfanbiduloner ermächtigt, ifyen (Släubigern jenen Betrag an ben Sinfen abzuziefen, de Parieu, Hist. S. 75. - Solwohl bei ber früheren britifhen Einfommensfteuer (ber ๔diuloner zag 10 \$roc. $a b$ ), als bei ber heutigen (2rt. 102. 103) ift Dieje (8inridytung anzutreffen, bie mit ber Eigenthümlidfeit jener Steuer zufammentängt. Der Sdjulb: ner ift als fdulbenfrei befteuert und zieht bem Slâubiger cen Betrag Der Steuer yon ben Sinfen ab; Bertrïge, weldye bieien शibzug aufbeben follen, find ungültig, unb ber (Släubiger, welcher Den $2 b_{z}$ ug nicht zu=

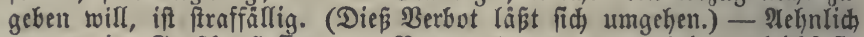

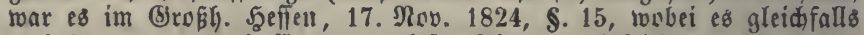

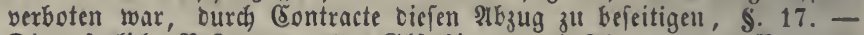
Die nämlidie $\mathfrak{B}$ efteuerung ber (Släubiger burd) Rkzug von' 5 ßroc. an

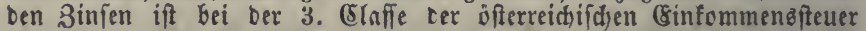
eingeführt. Die Begrünoung Des (8ntwurfes für tas Itentenfteuergefes bemerft S. 4, baß "nad) ber gemad)ten Erfafrung bie zur Entrichtung Der Intereffen Berpflid)teten rogen angebrokter Rünoigung Des (5apitals

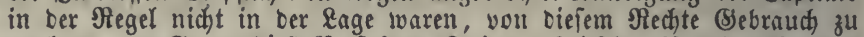
maden". - Begen Dieß Berfahren Rries, Beitidar. für vie gefammte Staatswiffenid). XI, 489. - $\mathfrak{u} \mathfrak{m} \mathfrak{p}$ fen b a d, Lehrb. I, 200.

(b) v. Iafob II, S. 1057. - Dagegen u. a. (E raig III, 77. - Nad

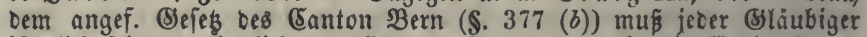
jährlich feine verzinblichen verficherten furberungen in ein Capitalfteuer: regifter eintragen lafien.

\section{\$. 388 .}

3) Die meifte Empfehlung verbient bie 2tnorbnung, baß

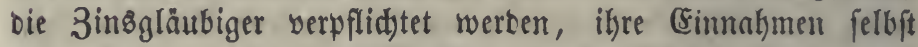
anzugeben und baß biefe (Erflärungen Durd) eine Drtz= ober Bezirfs = Commiffín seprüft werben. Dbidhon hiebci bie Ber= fuct)ung zu falfd)en श̂ngaben groß ift uno biefelben nidjt ganj unterbleiben werben, fo fönnen bod) ben Steuerpflidstigen mehrere getwidftwolle Beweggrünbe bargeboten werben, fid) yon ber Wahrbeit nidft zu entfernen $(a)$. Dazu bient: a) Die gefés= lidje Beftimmung, baß bie Alngaben (Declarationen) burdh bie 子u ihrer \$rüfung unb zu ber Erthebung ber Steuer beauftragten 
Berjonen getheim gebalten werben follen $(b)$. Die namentlidje 2lufführung ber einzelnen şoften ift entbehrlid), fo Iange fein 3tweifel über bie im Banzent angegebene Cumme entfelyt (c). Man hat aud) hie und ba (Elaffen angeorbnet, in weld)e ber (Eapitalift fith einzureifen hat, bamit cr fein ausfftehenbes $\mathfrak{B e r}=$ mögen ober Binzeinfommen nicht ganz gentau anzuzeigen braudje. Je megh aber in ben höheren Elaffen bie oberften uno unterften (3)ränzzahlen yon einander verfdjieben fino, befto größer ift bie Ungleidhkeit zwifden ben in einerlei Elaffe gehörenden Steuer= pflidjtigen $(d)$. b) Furdjt bez Canitaliften vor bem nad) feinem Tobe in vielen Fällen zu erwartenden Runbwerben feiner $\mathfrak{U} \mathfrak{n}=$ reblicffeit. $23 \mathrm{emn}$ aud bie (Einz̧ielyung einer Strafe nad) bem Tobe befien, ber fein Bermögen zu niebrig nngegeben hat $(e)$, nicfte gered)t ift, weil fie Unidhuldige trifft, fo fint bod) wenige

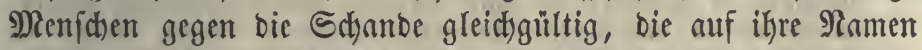

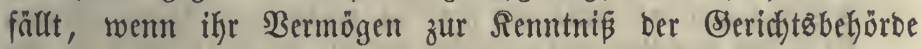
fommt $(f)$. c) 21norbmung ciner mäkcren Unterfictumg in fol= d)en Făllen, wo aus ber Rebensw weife ober anberen offentunbigen

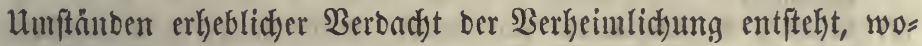
bei bann bie zur Sriffung beftellte Commiffion ben Enpitaliften zur Angabe feiner einzelnen (sinnahmsqueflen ankalten fann $(g)$. d) Einrechmung ber Enpitalfecuer unter biejenigen 2luflagen, Deren Srößß̨e zur Beftimnumg ber $\mathfrak{B a h l f a ̈ h i g f e i t ~ u n o ~} \mathfrak{B a ̈ h l b a r =}$ feit für Scmeinbe= Pleuter, Stänbeverfammlungen $x$. gebrautcht wirb. e) Man hat ofter burch gleidzeitige Beiziehung anderer

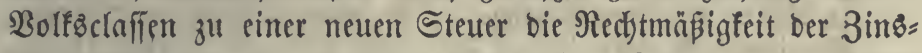
fteuer füblbarer zu madjen gefutht $(h)$. Wenn biefe nnberen (Elaffen nod) feine Sdjaķung getragen haben und wenn alle 3weige ber Einfünfte in ridjtigem Berbältnís belaftet werden, to ift jemes Berfafren zuläffitg, es hat jebod' feimen groben

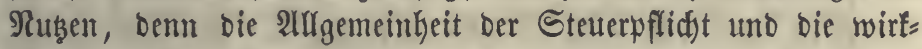
licte Belegung aller (Einnahuten fann, aud) wenn bie einzelnen Steuern veridjiebene Bentennungen unt Cinridjtungen haben, alరె befannt vorauto̊geję̧t werben.

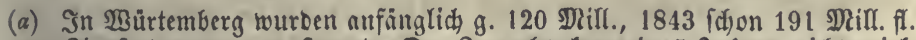
Sinbforberungen verfeuert. Der Sumads fann in 5 Sahren nidht wirf: lid 71 शRifl. betragen Gaben, es müfen alfo die Ângaben vollftäntiger gelvorben fein. - Die babifäen Értlärungen gaben für 1850 ein allళ= petgendes Bermigen von 192 SRifl., barauf folgte eine Plbuafgme ber 
Grflärungen, bie im D. 1851 - 55 gegen 1861/2 IRill. zeigter. Bon 1855 trat ein erkebliches Steigen ein, im D. von 5,9 פRifl. jährlich oder 2,69 \$ruc. Der mittleren Summe zwifich Dem anfänglidjen uno lez̧ten @tande. Diés fann bie wirfliche Bermehrung Der ausgeliekenen Summe fein.

(b) शuß̈er Der witerrehtliçen 2bficht, Die Stantscafie zu verfürzen, fommt

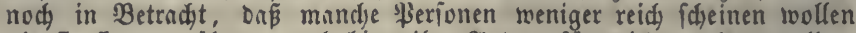
als fie find, während aud bismeilen Anbere für reidjer gelten wollen.

(c) Bei Der B̈fterreidifichen Claffenfteuer fonnten bie Ingnben berifegelt ber Drtsbefiorbe überfiejert werben und wurben bann nur you ber \&andess = fiefle (Fegierung) eroffinet. b. Aremer II, 209. - Bei ber babiffien Gapitalfteuer von 1815 übergaben die Capitalipten ebenfalls ifyr Ber=

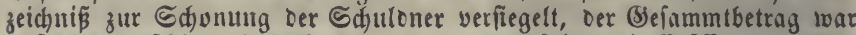
auf tem umfdlage bemerft und nur bann erfolgte Die Bröfrnung, wenn oer (Släubiger auf Bins ober Sapital gegen ten Sdhuloner flagte, um zu fehen, ob ber \$opten wirflich alngegeben fei. Nach tein bad. (Sefes yon 1850 werden Staatzpapiere, Actien tno andere verzinglidse forberungen nur in ifrem Gefammtbetrage, linverzingliche Forberungen, Seit= uno Reibrenten aber im Einzelnell angezeigt. - Saumuber, angef. (B)efeb von 1859 \&. 62: Eine allgemeine Declaration allf EGgre uno Bemiffen if zuläfing, es fann aber mit Ssestehmigung oer oberiten Steuerbehöbe eine fpecielle Declaration verlangt werben. Wenn ber Stenerpflichtige Die Ërflärung nicht zur red)ten 3eit abgiebt, fo fann

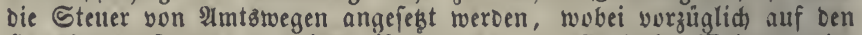

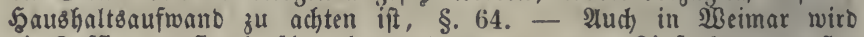
Die Fafîton verftegelt übergeben uno nur oer ganze Sinfenbetrng auṕen angemerft.

(d) SBenn z. B. alle Nenten von $30001-40000$ in Die nämliche Clafie fallen, io entrichten 2 Betfonen gleidyviel, ceren Steuerfähigfeit fait im Berbältnín 3 zu 4 fteht. - In Bayern Gat Der Capitalift nux Die Blaffe anzugeben, in weldhe fein Renteneinfommen fällt. Die Clafien Der Яienten find 1) $25-50$ fi. , 2) $51-75,3) 76-100$, fooann von $101-500$ je 50 f. weiter, von $500-1000$ fteigt jede Elafie um 100 , bon 1000-2000 um 200, von 2000-5000 um 500, von 5000 an um 1000, von 10000 an um 5000 , enclid yon 30000 an um te 10000 fi., 3. B. Die 38. Slaffe umfät Einfünfte von $40001-50000$ f. In Rurfefien waren gleidjalls folche Blafien angeorbutet. Iede Der 24 Claffen Gatte ifr Simplum, 3. B. Glafie 24 won $51-75$ Thlr., Simplum 1 \&r., (S1. 13 von $901-1000$ Thlr., S. 2 Thlr. 12 Sr., (5). 1 von $5001-5500$ Thlr., S. 20 Thlr. 20 (5)r.

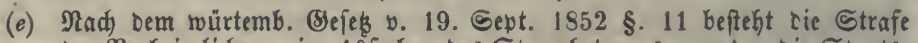
ber Berkeimlichung im 10 fachen bes Stenterbetrages, um ten bie Stant\&: caffe berfürzt worden ift; fie wirb auch onn exhoben, wenn bie 2 ber: fihweigung erit nad bem ToDe eines Capitaliften befannt geworben ift, bod mit 3jäfriger Berjährung. - Baden, Sefes von 1850 §. 16: Die Strafe ift das Bierfadhe Der Ṡteuerverfürzung und wiro aud aus bem Nachla Eteuerpflichtigen Gaben bie Erben biunen 3 गlonaten Nnzeige zu machen, wenn Der (Erblaffer eine zu niebrige Ingabe gemad)t hatte uno müfien foviel nadjablen, als bie Eteuer zu niebrig angejest war, foweit feine

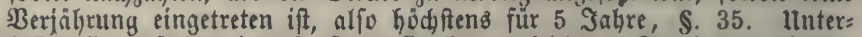
lafien fie oufe Anzeige, io fegen fie fich zugleid ber Strafe bes 4 fadien aub, wenn es nicht erweislich aus einem \$erfelgen geidjah, in weldiem Falle mur eine Dronungsifrafe uno bei eimem entidjulobaren Berieken gar feitue Strafe verhängt twiro, §. 32. - In Babern, Befę̧ v. 1856 \$. 21 , ift, tocnn vie unridtigfeit nach bem Toce bes Steuerpflidtigen 


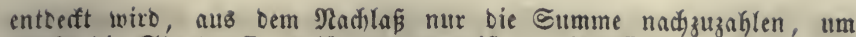
welche bie Stantzeaffe verfürzt worben iff. - In Meimar (Sefes vom 24. Juni 1840 §. 12) Gaben bie (5rben für bie nach bem Tobe bes Grblaffers entoectte Berkeimlicfung bie Strafe für hỏhitens vier Sakre zu bezahlett. Die Strafe ift für jedes Sahr bem verfhwiegenen (Snpi= tale gleids.

(f) Dießs ift twenigftenz bann ber Fall, wenn Abmejenbe ober Minberjährige miterben, ober ein legter sille vorhanben, ferner wo eine (5rbichafts: fteuer zu erfeben ift. - Ueber Die in 2Tthen eingeführten Denunciations:

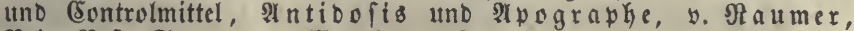

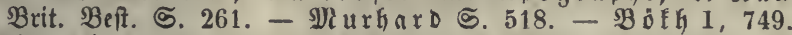

(g) 230 bei Den Schabungen Die Schulden berühfifhtiget werben, Da bient auch bie Angate Derfelben einigermaß̈en Dazu, die Ertläung Der (Enpi= taliften beffer zu pruffen. - Umpfenbad) (Rebrbud) Der Finanzwifi. I, 205) empfiehlt aubführliche 2ingaben ber Schuloner als Shülf8̈mittel zur Rataftrirung Der Eapitalforberungen. - Der Difterreidifidse (Sejes= entwurf von 1863 legt Den Gduldnern bie Berpflidytung auf, ifre zu entridjtenden Renten anzugeben uno ertwähnt Dagegen feine foldje DB: liegenlyeit Der (Släubiger. Diefen roetten bie Ingaben Der Berpflichteten von ber Steuerbehorde ihres Drtes zugeftellt. Bei \$fandbriefen uno

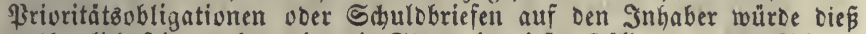
unthunlich feill, baker wiro bie Steuer in rieien Fällen yon ben Sdyuld = nern geforbert, bie fie Den Stläubigern abziehen bürfen. (Den Sinfen=

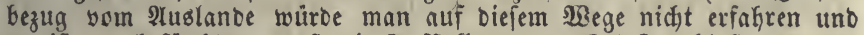
es if z" Befürchten, Dnß 2urzeigen Dex oft weit von Den (S) läubigern wohnenden zahlreidjen Sdjuloner fehr fawierig fein werbe. Die Angabe Der Nentenempfänger hat fidh in mefreren Eanbern als ziemlich braubbar gezeigt uno wird (iich ficher entbehren Inffen.)

(h) Beifpiele: Die Diferreich. Énfienfteuer, meldje zugleidy Die \$ribatbefol=

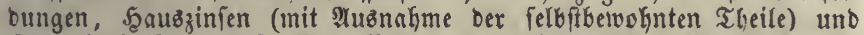
(Semerbseinfinfte traf. Bom Betrage bes Einfommens twurben Schuld: zinfen, $\mathfrak{a f t e n , ~ a n d e r e ~ a u f ~ e i n e m ~ S e t w e r b e ~ l i e g e n t e ~ S t e t i e r n ~ a b g e z o g e n , ~}$ ber cigere unterhalt aber nidht. Der Stellerfú frieg von $21 / 2$ Broc. (bei $100-300$ fl. 23. 23 . Eimnahme) bis auf 20 \$roc. (bei 140000 fi. uno mekr). - Itngef. furhefi. (Sefes, nach weldhem Befoloungen (nad)

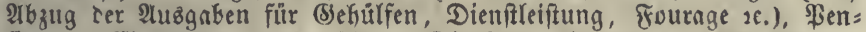
fonen, Einfommen aus Göheren Dienften, Fachtungen uno (Sruno= gefälle mit ben (Eapitalzinjen zufammengeworfell wurben. - In Wurs= temberg find mit ben Envitaliften zugleich bie Befoldeten befteuert worben. - In Englano bilbet Die Sinbfteuer einen Beftandtheil Der income- ober property-tax; fo aud in Weimar. - Stalienifjes (Sejes, ค. §. $377(d)$.

§. 389.

Beitere Bemerfungen zu ber 3insirentemfteuter.

1) $\mathfrak{B}_{\mathrm{ob}}$ ithätige Stiftungen uno foldje, bie für ben Unter= ridjt beftimmt fino, haben Befreiung von biefer Steuer anzu= iprect)en, ygl. \$. $264-($ a) .

2) $\mathfrak{B}$ nล ben Steuerfú im $\mathfrak{B e r g l e i d}$ mit ber Şöhe anberer Sd)abungen betrifft, fo ift

a) anfangs eine niebrige Belaftung ber Binsirenten rathfam, bem bie Reuheit ber Stenter madt, daß bieje yon Manden 
als ungebüfrlid) angefehen wirb, aud) empfindet man fie in ben gewohnten Kaušwirth(d)aftlid)en $\mathfrak{B}$ erbältniffen läftiger als eine herfömmliche Steuer uno bieje Umitänoe geben einen ftärferen Reiz zur Unreblid)feit. Meberbaupt ift es billig, nad) Der langen bölligen Stetterfreiheit Die Abgnbe nur allmälig auf bie Şöhe

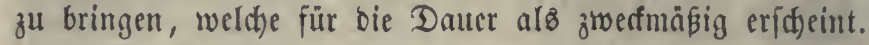

b) Esె fino (Stünbe vorbanben, aud) fortwährent bei einem

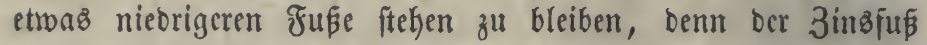
wird im Fortgange bes 2 Bohlftanbez, wenn Friebe unb Dronung ungeftört funb, allmälig niebriger, zubem geft ber Zinz nid)t ganz regelmäfig ein, eż fommen Unterbrectungen, 2Inrufen ber (Beridjte, Concurje uno mandje $\mathfrak{B e r l u f t e ~ v o r ~}(b)$.

3) Eine bejondere Berüdfidftigung erforbern foldte ßerjonen, bie bon ben Zinjen eines fleinen Capitales nur gerabe nod) leben fönnen und nuper Stand find, burd) 2lrbeit etwas zu erwerben, benen alfo ber Bortheil, über iffe 3eit frei verfïgen zu fönnen (\$. 259), nictsts hilft, z. B. WBittwen, $\mathfrak{B}$ aifen in

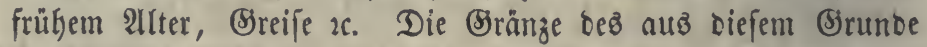
fteuerfrei zu laffenten Zinzeinfommens muß jebod) fo gezogen werben, baßi bie fünftlichen Bedürniffe ber Gökeren Stände ausigeichlolfen bleiben $(c)$.

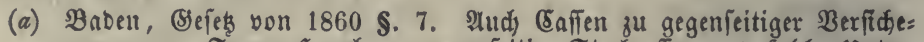
rung gegen Feuer, Sagel $2 c .$, gegenfeitige Sterbcafien uno foldje unter:

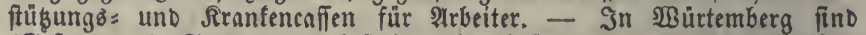

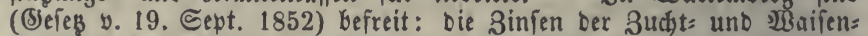

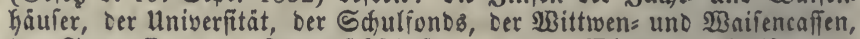

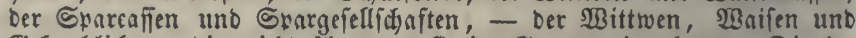
(Sebrechliden, bie nidst tiber 100 fi. im Ssanzen einnefmen. Die be= freiten (Eapitale beliefen fich 1826/27 auf 101/4 Jlia. f. Ne mminger, Safirbücher, 1829, II, 96. - Weimar, §. 14: Nur Das Eparenfen= guthaben uno bie im Jahre 1815 ber Stantscaffe freimillig vorgefhofie: nen Steuern find frei.

(b) $\mathfrak{B g l}$. FulDa, Şanbbuc §. 181. - Die mürtemb. Eapitalifeuer war allfangs $1 / 3$ Froc. (20 fr. yon 100 fl.), Damn feit $1830 \%$, feit 1833 $1 / 5$ ßroc., feit $18361 / 10$, feit $18491 / 4$ \$roc. Seit 1 S53 ift fie 4 \$3roc. Des fteuerbaren (Ertrages (ocer, wenn man 5 \$roc, annimmt, $1 / 5$ \$roc.

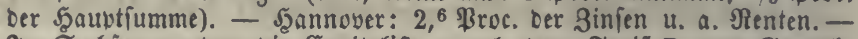
In Enchien werben bie Capitaliften nad bem Tarif $D$ zum Sewerb: feuergefes getroffen; 1. Cl. $21-50$ Thlr. gebell $1 / 5$ Thlr. ober 0,57 ßrocent Des IJtittelbetrages von 35 Thlr.; erft bei ber 2. (5l. ( 450 500 Thlr.) erreicht bie Eteter 1 Bruc., bei bet 23. (ङ). $(22-2400$, Mittel 2300 Thlr., Steuer 46 Thlr.) mad)t fie 2 \$3roc. uno yon ber 36. (E). an ift fie $2 \% / 5$ \$roc. Bei cinem fteigenoen Steuterfabe ift es nidgt gleidygultig, ob bie Sinbeinnakmen ber verfdjiebenen famirien= mitglieber cinzeln angelebt vber zufammengerednet werben. Das bayer. Sefes $\$ .6$ veroronet leşteres bei ben in einerlei \$aub̆altung lebenten 
Ehgegatten unb Rimbern. - Defterreid): 5 ßroc. Des Einfonmens. Bayern: Das Dittel Der Slaffengräzen giebt einen fteigenden Steuer:

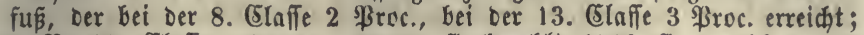
3. B. 38. SInffe, $40001-50000$ fi. bezahlt 1500 fi., meldjes von $450003 \frac{1}{3}$ Proc. ausimąt. - Baben: 1 p. mille bes Capitals, alfo, 4 ober 5 Proc. Sins angenommen, $1 / 40$ ober $1 / 50$ beffelben.

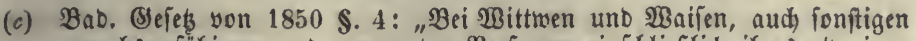

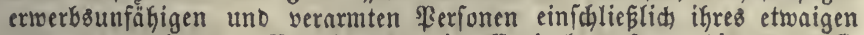
anberen rentirenben SBermogens" eil Eapitalvermögen bis 2000 fi. (S)efes von 1856 S. 4: Wittwen uno $\mathfrak{B a i f e n , ~ D e r e n ~ E a p i t a l r e n t e ~} 200$ กี. nidht überfteigt uno wenn fie nidht nod fonft 200 fi. Einfommen bes: ziehen, nur Den Galben Eteuerfaz. Siefes von 1860 §. 7: Wittwen, âlternlofe Ninderjälyrige, ferner erwerbsunfähige ßerfonen, wenn Der (5apitalwerth ifrer fteuerbaren Sinien uno Senten uno ifres fonftigen

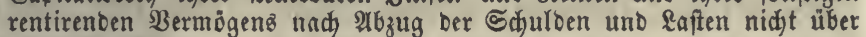
4000 fi. betriggt.

\section{\$. 390 .}

4) Ein ganz geringer Betrag von Zinbeinnabmen follte überkaupt billiger $\mathfrak{B e i f e}$ unbefteuert bleiben, fowohl wegen ber mëlye ber Erforidung, als $1 \mathrm{tm}$ bei ber arbeitenden Claffe Die Neigung zum Ueberiparen nidft zu fdwäd)en; namentlid) gilt Diés bon ben in Sparcafien angelegten Summen $(a)$.

5) 3ur Bildung bes Steueranichlages fann entweber die 3inseinnahme ober die Reihforberung (Şauptiumme, Capital) gebraucht werben. Sentes hat fïr fich), Daß Die Steuerfähigfeit auf Dem Sinfommen beruht, baß unverzinzlidye forberungen hiebei von felbft auper 2Inją̧ bleiben unb bie (sinnahme bei Sdulbbriefen von wedffelnbem \$reife (Eurje) leid)ter zu vers anjhlagen ift als bie Şauptfumme. $\mathfrak{B}_{0}$ Die Sataftrirung nath) ber leşteren vorgefdrieben ift, ba geht man von ber Innahme

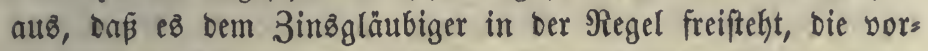
theillfaftefte Anlegung zu wählen, ferner baß bie höbere Rente meiftens bie weniger fithere ift, eine Berftcherungsిprämie in fid falliefst uno Deşbalb feine ftärfere Befteuerung berbient. Sebe von beiben Methoden fülyet in gewiffen Fällen zu Unbilligfeiten, bie man aber burd) näkere $\mathfrak{B}$ eftimmungen zum Theil bejeitigen fann (b).

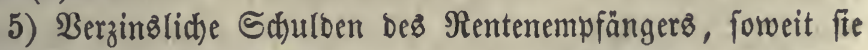
überkaupt eine Berüffift)tigung bei ben Sdłał̧ungen verbienen $(\$ .400 \mathrm{~b})$, forwie bie auf ber Renteneinnafme haftenden privat= redttidfen Laften werben bei Dem Steueranfidlage in 2lbzug gebracht $(c)$. 
6) Für mandide verwifelte Fälle fint befonbere Beranfdhlas gunģిgrunbjä̧̉e aufzuftellent. Dahin gehören:

a) 3eit = unb Reibrentert, beren gegentuärtiger $\mathfrak{W}$ erth nad)

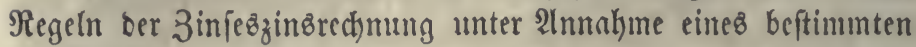

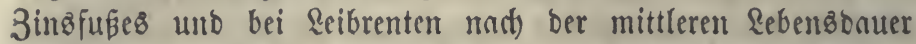
aufgejud)t wirb (d). Thkeilzahlungen in fefitgeiegten Friften, wenn bie nod) ausftehenben Theilfunmen unverzingslid fint, werten ebenfalls nad) ihrem gegenwairtigen $\mathfrak{B}$ erthe angeidjlagen.

b) Etnatziffulobriefe, beren \$reis anfelynlid) unter bem berictriebenen (Nominals) Betrage fteft. Müfyrt bicfer niebrige

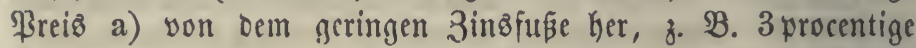

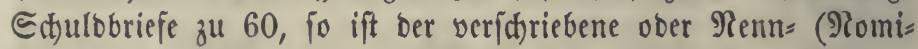
nal $=$ betrag nicht maß̈gebento, ber Stetteramichlag fann aber ebenjowohr nach bem 3infe als nach bem (Eurie geidhehen. b) Rührt jener yon bem geringeren Bertrauen ber Capitaliften, aljo yon ber bei ber Anlegung vorbantenen Befahr her, fo

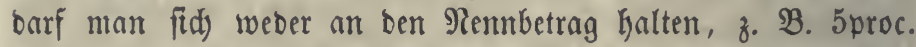
Dbligationen zu 70, nod) an ben 3ins, weil biefer eine $\mathfrak{B e r =}$ fitherungebrämie in fid) falliçst, bie nidyt befteuert merben barf. Saier ift aljo allein ber Marftprciż (Eurళ) zu Srumbe zu legen. WBiffen aud) bie Steuerpflidtigen ben mittleren ' 3 reiz bezి leşten Iahres nicht anzugeben, fo fann es ber oberen Steuerbehörbe

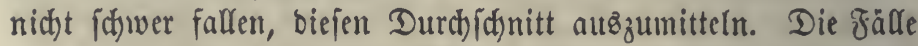
a) uno b) fino nidjt okne Mühe zu unterfdeiben, baker ver= bient überlyaupt bie 2lnlegung nadh bem Eurfe ben $\mathfrak{B}$ orzug (e).

c) Bei 2 ctien giebt Dic Divibenbe ober ber Marftpreis bes

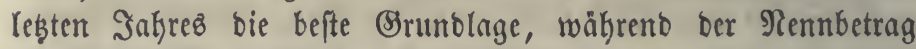
wegen ber fekr ungleiden Divibende unbraudber ift.

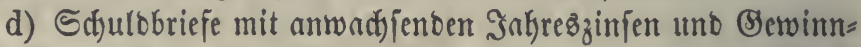
verloofungen (Rotterieanlekenslooje) werben nur nad) bem Renn= betrage ober ben hieraus zu berechnenden 3injen angejegt $(f)$.

7) Unverzinglidje Forberungen fowie foldye, beren Berjin= fung eine gewiffe 3eit lang unterbroden iff, verbienen Befreiung bon ber Cteuer $(g)$.

8) Das Sintafter bebarf einer jäfrlictjen Durdjfidjt, inbem biejenigen ßerfonen, bei benen eine Bermehrung beß 3inzein= fommens über einen gewififen geringen Betrag hinaus oocr eine Beränterung in ber 3ujaumenfę̧ung Diefę Einfommenz ein= 
getreten ift, zu ciner neuen Ingabe verbunden fint, jebe $\mathfrak{B e r}=$ minberung aber angemelbet werben fann.

(a) In Srofbritanien war anfangs ein Einfommen yon $150 \&$. St. frei,

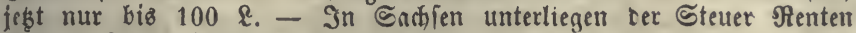

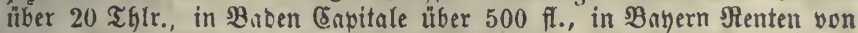

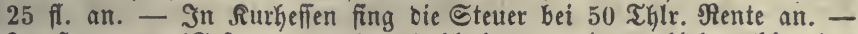
In Şannover (\$)ei. y. 1859 \$. 56) Bleiben yon jecem Giehergehorenten Gintommen $100 \mathfrak{T h}$ hr. fteuerfrei.

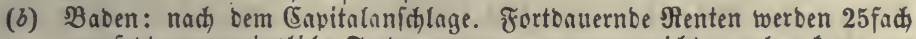
angefebt, unverzinsliche Forberungen, wenn man nidbt anaeten faun, zu weldter 3 eit bie Berzinfung anfangen mirb, zu $2 / 3$ bes Betrages. Sift Der 3inz unter 4 3iroc., fo wiro Das 25 fache als Envital angenommen. Bei wechjelnoem Binsfur entideibet ber Dutrdichnitt ber 3 Borjahre, §. 8.9.

(e) Mian hat bagegen angeführt, es ftefe im Belieben bes Canitaliften, feine Schulden mit einem Theile des ausfetenden Bermögens $a \mathfrak{b} z u=$ tragen, affein eళ giebt Fälle, wo biés gar nidjt ober nidjt ohne Berluft au\&fühtbar ift. Berhanblungen hierubuer in Bayern bei (Berfiner

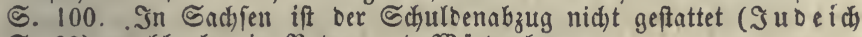
5. 33), wohl aber in Baben und Battentberg.

(d) Bab. Bef. §. 17. Eeibrenten follen nah bemielben 8fach zu Capital angeidhlagen werten. Für Beitrenten ift eine Şülfostafel aufgeffellt, bod werden fie höchfteno mit Dem 20 fudten Betrage angefeght. - Eine

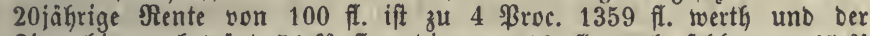
Sins hievon beträgt 54,36 fl., die zu 100 fl. now fehlenden 45,64 bleiben als zutr Tilgung geförend auß̧er Ânfä.

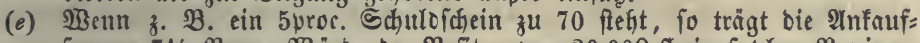

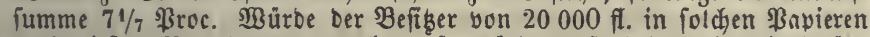
nach biefem Nennbetrage angelegt, fo würbe er fo belyanbelt, alo bezöge er 5 ßroc. von einer ganz fideren Forberumg, was nidjt billig ift.

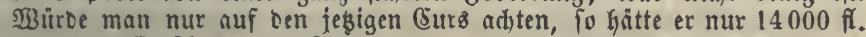
ober 700 fl. Sims zu verfeuern.

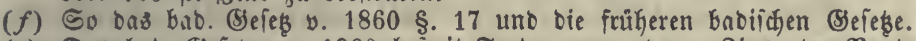

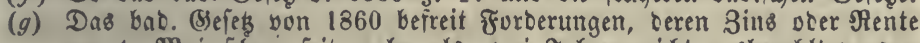
am 1. Niai fichon feit mehr als zwei Jafren nicht attbezalylt werden fonnten. Itnverzingliche Forberunget von unbeftimmter Berfallat fommen mit bem halben Nennbetrage in 2nnág; haben fie beftimmte

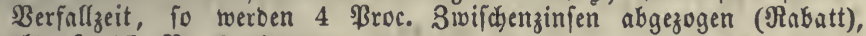
ebo. §. 17. Nr. 3. 4.

\section{6. $\mathfrak{A} \mathfrak{b} \mathfrak{a k}$.}

\section{Beiteuerung bez Arbeitsuerdienftę.}

\$. 391.

Das lebiglid) burd Rohnarbeit erworbene $\mathfrak{B e r m o ̈ g e n ~ b a r f ~}$ fo wenig als ein anberer 3 weig beffelben unbeftetert bleiben, inteß ift eine auf ben fteuerbaren Theil bes \&ohueinfommens gelegte 2lbgabe feine fehr ergiebige Duelle von Stantzeinfünften. Sie ift aud) in ben meiften sänbern erft in neuerer 3eit cin=

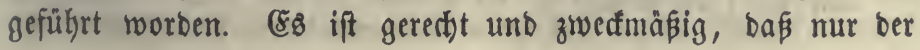




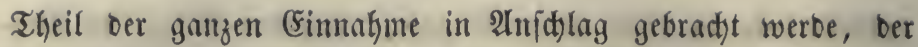

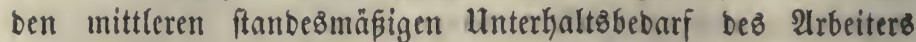
uno feiner Familie überfteigt (reiner थ rbeitsverbienft), fomie überhaupt ber mit einem Einfommen nothwendig ver= fnüpfte Roftenaufwanto in 2tbredynung fommen muß $\$$ \$. 259. 3war if ber bou perfönlid)en berhältmiffen bebingte Unterhaltz: bebarf ber (Einzelnen ungleid) uno unerforidylid) $(a)$, aber für ben 3 wedf ber Befteuerung genügt ganzen (Sruppen uno Elaffen zu betradjten uno ben burds= fidfnittlidjen nothrenbigen Bebarf mit bem muthmaflidjen (Ein= fommen zu vergleichen. Da ber ftandes̊måßjige Bebarf feine idjarfe Berefjnumg zuläpt, ber gefammte (rohe) Rohnverbienft aber viel leidfter zu erforidjen iff als ber reine, fo bält man fict) in ber 2tnlegung ber Steuter getwöhnlict) an ienen, uno biés ift zuläfitg, woferne man mur ben Steuerfuk in foldyer

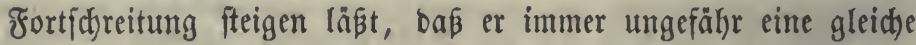
Quote bes muthmaß̧lidyen (reinen) Eohneinfommens bilbet (b). Dagegen ift bie fürzere Dauer bes lek̨teren fein (Sruntb, Daffelbe fđjwächer zu bejteuern, als ein immerwälyrenbes Einfonmen, weil aud bie Steuer felbjt von jebem Arbeiter nur fo lange erfoben wirb, als er im Bezug bez Lofnez ift $(c)$. Die bei tünftlicheren $\mathfrak{B}$ efdăftigungen im \&ohne mitbegriffene $\mathfrak{B}$ ergủtung ber Borbereitungsfoften (I, \$. 194) follte, weil in ihr ein softenerją̧ enthalten ift, geringer belegt werben, uno obidjon ein gennuer Heberfallag biefer Summen nidjt möglid) ift (I, \$. 191), mü man bod) bei ber Fefféţung bes Steuers

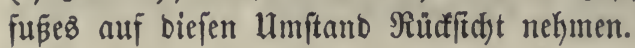

(a) Şierauf legen Sुoffmann uno Rries (in ben §. 301 (a) genannten

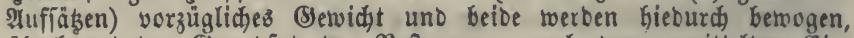
überhaupt ben (Sirundfas ber Befteuerung nad Dem ermittelten (sin= fommen zu beftreiten. Bgl. \$. 298 (b). - Stein (\&efrb. G. 257) glaubt, ber reine $\mathfrak{L}$ ogn fönne praftifich nicht birect bepteuert, fonbern müffe burd bie Sonfumtion betroffen twerben.

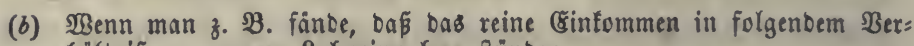
Găltnís zur ganzen Lohneinnahme ftủnbe:

$$
\text { bei } 400 \text { f. Sohn } 25 \text { f. rein ober } 6,25 \text { Proc. }
$$

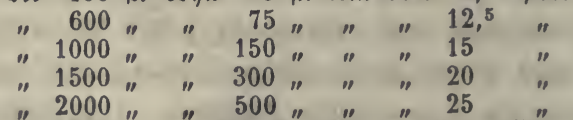

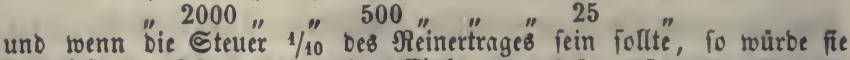
bei biefen 5 Gäben Des roken Sinfommen $2,5-7,5-15-30$ uno 
50 f. betragen und wäre zu $0,6-1,25-1,5-2-2,5$ \$roc. Der ganzen Einmahine gu beftimmen.

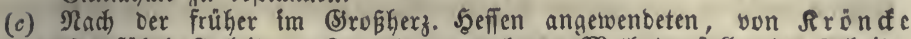

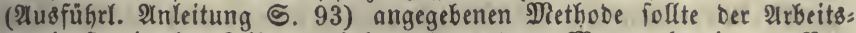
berbienft wie eine Reibrente behanbelt werben. Man nahm in ber $\mathfrak{B}$ or: ausfesung, Daß̧ ber (8rwerb nit bem 20. Jahre anfange, eine 15jährige weitere \&ebensoatter an, zog hievon 6 Jahre für Siranfheiten $2 c$. ab unb erhielt fo cine 9jährige Siente, beren anfänglicher $\mathfrak{W}_{\text {erth }}$ (bei 5 Эroc. Sins) Dem 7 fachen Iohresbetrage gleich ift. So twürben alfo 800 fi. 2Irbeitsvertienft einen Capitalanfdilng von 5600 fi. geben. Şiebei iff fomokl sie Rebenstauer zu furz (fie beläuft fich im 20. Jahre auf etwa 35 Sabre), als Die Seit ber unterbrechungen zu lang an= genommen, überhaupt aber if ber $\mathfrak{L}$ ohn eines 2 rbeiters nicht toie eine

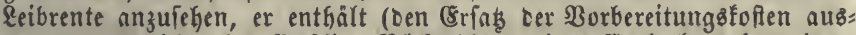

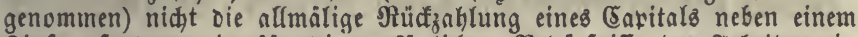
Sinfe, fonbern ein für bie perfonlichen Bebủrfniffe bes शrbeiters in febem Sakre beftimmtes Sinfommen, und fo lange baffelbe bauert, fo lange fann es auch beftetert werben. Die Steuer hört ja ebenfalls mit bem Tobe bes 2rbeiters auf! Die ourch Die Ratur Des Rohnes gebotene fhonende Befanolung Deffelben wirb in Göherem (Brabe erreidht, twenn man nad obigen Säben bie Berfbiebenkeit oes roken und reinen Arbeitslohns beachtet. Allerbings follte ber Arbeiter etwas von feinem

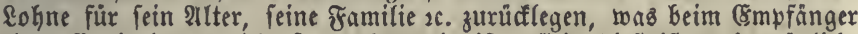
einer Capitalrente nicht fo nothwendig iff, allein bießs ift auds moglidh, weil von Der Steuer immer nur eine Duote Des muthmafichen reinen Eittommens in PYnjpruch genommen wiro. - Die Betrachtung bes Lohneinfommens als einer \{eibrente finbet fich aud bei $\mathrm{Mac} \mathrm{Culloch}$, Taxation 5. 127, Dagegen hat nun aud Mill, Princ. of Polit. Econ. II, 358 (1849) bie im §. entwidelte 2inficht ausgefprodien. Indé⿱ wifl Der $\mathfrak{B e r f}$. Bei Der Befteuerung bes lohns nicht ben llnterfyalt ab: zieken laffen, fondern nur bas, was ber Frbeiter für feine alten Tage, für feine Rinber $2 c$. zurüdlegen follte, alfo nur etwa $1 / 4$ bes $\mathbb{R o h n}=$ einfommens, fo tá Geies Des Canton Reuenburg von 1860 §. 8 (f. \$. 402 a $(a)$ ): von

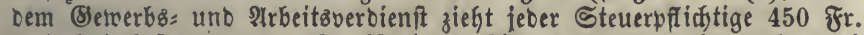
Unterhalteffoiten uno 150 fr. für jebes Sino unter 18 Jahren ab; Dod mú jeber minbeftents $11 / 2$ Fr. entridjten.

\section{ङ. 392 .}

Unter biefe Steuter fallen alle \$erfonen, bie ein blopes Qohn=

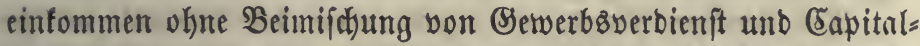
zinz genießßen, uno zwar in ben mandffaltigen 2trbeitşzweigen, yon ben einfacten $\mathfrak{B}$ erridtungen ber Taglöhner an bis zu Den hödffen Dienften ber Rebrer, Sünfter, Seifflichen, Ferzte, Beamten 2c. Dod) fant man fogleich) foldje Crlaffen von

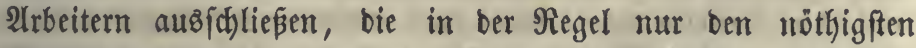
Unterfalt bezieken unb baher nicft als fteuerfähig anzujeben

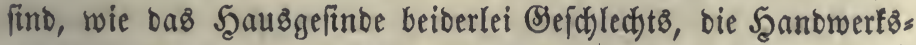
gefellen utnd überkaupt foldje Bekhülfen, beren Beftetterung auf bie \&ofnhterren zurüaffallen würbe, zumal ba bic 2 trbeiter, wenn 
fie nidft beföftigt werben, bodh obnehin 2lufwanosfteuern ent= ridyten můfien, - ferner bie am färglidfften gelohnten Arbeiter,

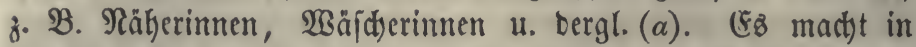
Şinficht auf bic Steuerpflidtigfeit feinen Unteríchied, 1) ob bie 2lrbeit unmittelbar zur Siütererzengung, zum Şanbel, zum (S)ütergebraud), ober zu perfönlict)em Bortheil bient; 2) ob bie Bezahlung nad) ber 3eit erfolgt ( gehalt), ober ftüđfweife für bie cinzeInen Irbeit\&leiftungen, wic

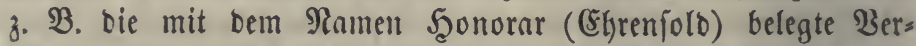

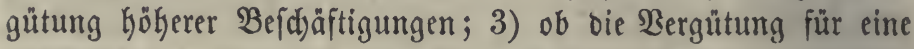
gleichzeitige, ober wie bei Siukgegehalten für eine beentigte Thätigfeit, ober aud), wie z. $\mathfrak{B}$. bei geiftlidfen $\mathfrak{P}$ rintmben, nur

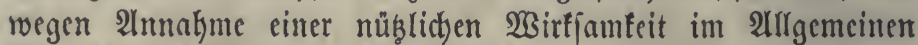
gegeben wirb; 4) wout wem unb in weldyer form ber 20 hn bezaklt wirb, z. B. von \$rivaten ober Eorporationen, - in Scld ober zum Theil in Raturalient.

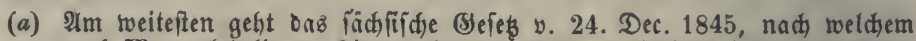
aud Iaurerlebrlinge, Rinbermäbden, Immer, Spinnerinuen und Spu= lerinnen Gdabung geben müfTen, Die beiben leştgenannten 2 Sqr. jäbrlid). - In Der ungarifden ßerionalifeuer (\$atent v. 2. Nlov. 1850) werben in Der 1. Sategurie Dienfitboten, Esefellen, Taglibner 2 . je nad ber 230 hnumg mit 20 fr. Bis 1 fl. Conv. belegt, val. \$. 397 (d). Sit Den Deutiden uno flavifhen \$rovinzen unterliegen \$rivatlebrer uno

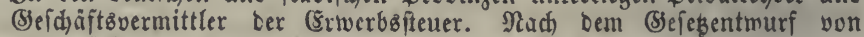
1863 foll Das Eohneinfonmen in Der 2. Glaffe Der (5rwerbiteuter ge= truffen, aber Taglögner, Şülfzarbeiter, \&ebrlinge, bejellen und Şaub= geïnde freigelafien, Aerzte, Alovocaten, Notare 2 . Dagegen in ric 1. Elaffe, welche bie Sewerbsunternefmungen umfät, gebracht wer= ben. - In Der italienifben Esinfommensiteuer von 1864 giebt über= Gaupt ein Einfommen unter 250 \&ire mur 2 sire Steuer.

\section{\$. 393.}

Die freitige Frage, ob inzbejonbere bie Staatzbiener bes fteuert werben bürfen $(a)$, ift im 2luggemeinen (grunbjäß̨lid) zu bejahen, weil bie Steuerpflidyt lebiglid) yon bem Dafein eines reinen CEintommen bebingt wirb, unt wenn biefez vorhanten ift, bie yon bem Stante befoloeten Dienfteiftenten in 2 befidft auf bie Befteterung benienigen, weldye yon einem anberen Dienftherrn, z. B. Der Sirdje, ber Bemeinbe, einer Befelts=

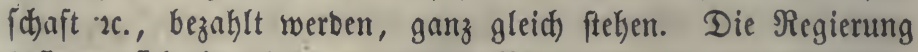
befinbet fid) in einer zweifadjen Beziehung zu bem Beamten, nämlid) theil's alz Befteller, Bezałler uno Annoroner feiner 
Dienftgeidjäfte, theils als Befteterungsgetwalt. In biejer Şins fidft ift ber Staatzbiener wie jeber anbere Angehörige bes Staates̉ ben alfgemeiuten Bürgerpflidten unterworfen (b): Man mus jebody in jebem gegebenen sande und 3eitpuncte nod)

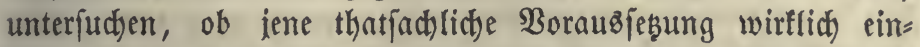
trete, D. h. ob bie Bejoloungen und Belyalte 2 . Der Stantżs beamten, in $\mathfrak{B e r g l e i d y ) ~ m i t ~ b e r ~} \mathfrak{B}$ ezahlung anberer 2 Arbeiten unb

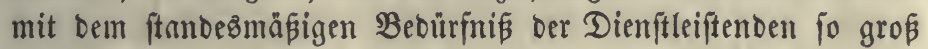
feien, Daß eine Steuerfähigfeit (ein reines Einfommen) vor= Ganden ift, vergl. \$. 57.

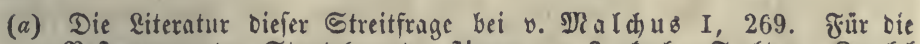

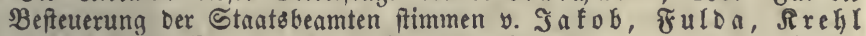
u. A., fermer Diurhard, Befteuerung S. $_{479}$, - gegen Diejelbe

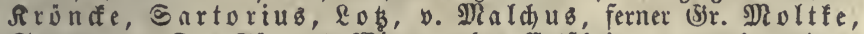

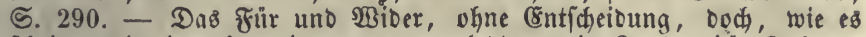
idjeint, mit einer Şinneigung zu Dem leb̧teren, in 3 a d) a riá, Ibbano=

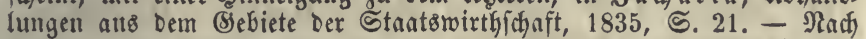
Gregorius Tholoz., De rep. III, 5. \$. 39) wurbe in Benedig eine Steuer von Befoloungen erfoben.

(b) $\mathfrak{B g l}$. $\$$. 385 . - Quo facilius etiam tributa tolerent privati, ab is praestandis excipi non debent magistratus, nam rem per se ingratam populo gratissimam reddit imperantium exemplum. B oxhorn, Instit. politicae L. I. B. 10 . §. 18. N. XV.

\section{§. 394.}

(5)egen die 3uläfifigeit Der Bejoldungşfteuer find hauptfäd)= (id) folgente (Srünbe gelteno gemad)t worben: 1) Die $\mathfrak{A n}=$ ftellung fei ein Bertrag, ez burfe Daker bie Befoldung nidyt verfürzt werben. - Dief wiberlegt fith Durd) bie Unteridjeibung Des allgemeinen ftantżbürgerlicten $\mathfrak{B}$ erbältniffez von bem bejon= beren beş Bramten. 2) Die Sinnakme auz Stantsobienften iei von Dem (Ertrage gewerbemä̈iger Bejuäftigungen fehr ver= fdjieben, indem ber Stant in ber Feffteķung ber Befoloungen und anderen Dienftbezunge ein naturlidjes Monopol habe, feine Beamten fpärlid) bezahlen fönne, und dieje nid)t im Stande feien, Durd) Fleis uno unternebmungågeift iffe Cinfünfte zu erhöhen, zubem ihre Einnahme vollftändiger befannt jei, als bie von Sewerbtreibenden, weldte man weniger genau mit ber Steuer zu treffen vermag $(a)$. - Dieje Säß̨e beweijen nictjts

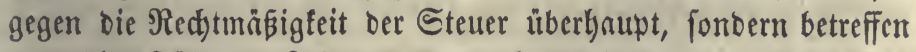
mur bie Şöhe berfelben und madjen allerbings eine mäpige Befteuerung rathjam; bagegen tommt aud) wieoer bie Sidjerlyeit 
untb lebenslänglidje Fortbauer ber Befuldoungen in Betradjt. 3) Statt Befolbungen zu bewilligen uno bann wieber etwas von ifnen finwegzunet)men, follte man fie lieber fo gleid) nicbriger anjeb̧en (b). - Shierauf ift zu ermibern: a) Wab bie Erfhebungs= weife betrifft, fo geidiegt bieje aud) wirflid) ganz leid)t burd) einen 2 bzüg bei ber 2luzzahlung ber Befoloungen. b) Die

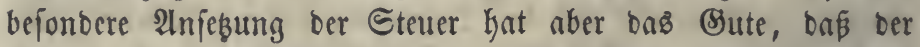

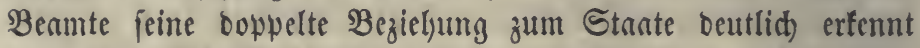
und feine Berufathätigfeit mehr nad) (sebilhr vergütet ficlyt. c) Der Steuerfús ift Beränoerungen unterworfen, bie fowohl von ber Şähe ber Schakungen im (Banzen, alz yon bem wed)= felnben wirthifdaftlidjen 3 uftanbe ber veridjiebenen. Bolfäcla fien herrüheren fönneı. WBaren z. B. Befoldungen in einer 3eit bewilligt worben, wo ons Betreibe ober nud) alle Rebenżmittel gegen Nünzmetalle hoch im Breife ftanben, fo fönnen iene unter geänberten Uumftänben eine ftärfere Befteterung ertragen, alz bie zu einer anberen 3eit feftgejeşten $(c)$. 4) Die Steuer fei idfäblich für ben Stanţ̇bienft, inbem fie bie Befoloungen zu fehre verringere, unb fie wiberfitreite bem monardjifdyen \$Brins cipe, inbem fie bie Borrecte ber Benmten aufbebe uno baburd bie ber Srone felbft gefähroe $(d)$. - Der crfte Cinnand fälut Ginweg, wenn bie wirflidte Einfühthung fowie bie Fortoauer Der Steuer von ber erweislidjen Steuerfähigfeit nbbängig ges

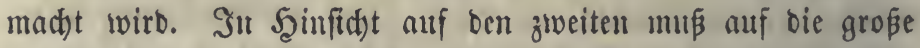
Beridjiebenkeit zwifden bem Stantsoberbante und beffen ver=

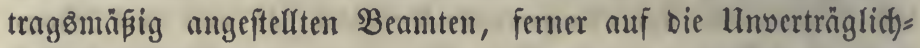
feit ber Steuerfreifeiten mit ben alfgemeinen ftautzred)tlicten Srundfäßgen hingewiejen werben. 5) Die Steuter werbe leidjt baburd) unwirfjam gemadt), báp man ben Beamten 3ulage

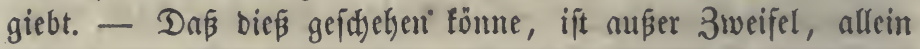
eine foldje $\mathfrak{B}$ ereitelung bez erroarteten $\mathfrak{B}$ ortheils burd) bie Stantzgewalt felbft fann hier nidjt in Betradjt gezogen werben,

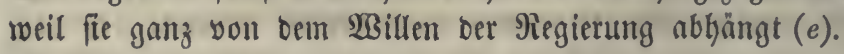

(a) Sad̆ariả a. a. D. S. 39.

(b) Sinclair, History etc. exflät es für eine hanogreiflidje Thorheit, mit ber einen Şano Befoldungen zu geben uno mit ber anberen wieder cinen Theil berielben wegzunehmen.

(c) Zadariâ, S. 44, hẩt foldje, z. 3. twegen geänberter (Belopreife, unter ber form ber Befoloungsffeter gemadjte 2ibzüge nidht für eine wahre Steuer. 
(d) 3 a d)ariả ธ. 49 .

(e) Die Befolbungberbibhungen ber Beamten in netlerer 3eit laffen fid aus

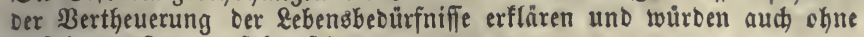
Befoldungffetuer erfolgt fein.

§. 395 .

Dogleid) bemnad) im Allfgemeinen bie Befoldungşfteuer für gered)t unb zwefunäpig zu balten ift, fo fann es bod) ba, wo

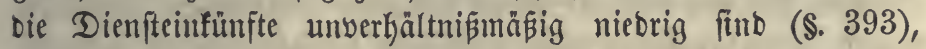
rathfam fein, alfe ober bod) wenigftens bie unteren Beamten für ję̧t unbefteutert zu laffen. Sก ben höheren Stufen bez Staatżbienftez pflegt wegen ber Seltenkeit ber erforberlidjen Fähigfeiten unb ber fdjwereren Berantwortlidfeit bie (sinnakme To hod) zu fein, Dá fie eine Befteuerung erträgt. Die Reben= einfünfte und 2 mtşwohmungen, nad) mittlerem Betrage, müffen mit eingerechnet, bagegen foldye ber 21 mtz̧fïfinung wegen ge=

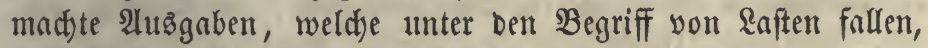

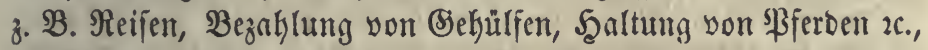
in $2 b_{3}$ ug gebradht werben $(a)$. Die Rukegehalte, als ofyehin fnapp bemeffen, follten nidjt nad) gleidjer Niegel wie bie $\mathfrak{B}_{e=}$ joldungen behandelt und bie $\mathfrak{B}$ ittwengehalte ganz frei gelaffen werbell $(b)$.

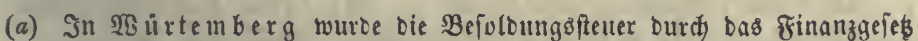
yom 22. Suni $1 \leqslant 20$ eingefüfrt, nadjoem Die Befoldoungen fid)on 1799 und 1813 bis 1815 , Dow in biejen Jafhen mur von 2000 fi. an, in Der Bermögensffeuer beigezogen worben waren. (Seíęz v. 20. Suli 1821, 19. Eept. 1852. 2t/s fteuerbar (rein) gilt

bei einem Berbienfteinfommen yon $2-500$ f. 0,1 beffelben

bei bem Dielgrbetrage von. .

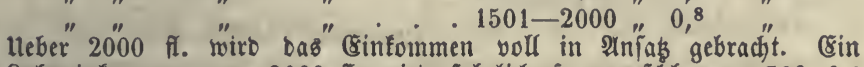
Qohneintommen yon 3000 fi. wiro folglidy fo angeidhlagen: $500.0,{ }^{1}$ $+500 \cdot 0,{ }^{2}+500 \cdot 00^{4}+500 \cdot 08^{8}+1000$, zufammen 1750 fi.

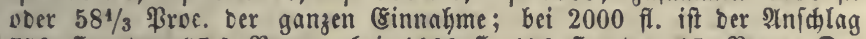
750 fi. oder 37,3 ßroc., bei 1000 fr. 150 f. voer 15 ßroc. Dex

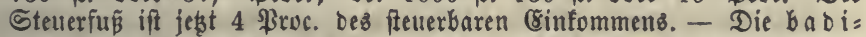

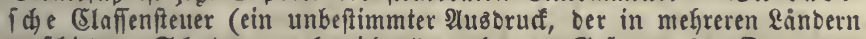
verídjiebene Edjakungen bezeidjnet) nadh Dem (Seféb y. 31. Det. 1820 trifft neben ben Staatsbenmten auch alle anberen Befolbeten, Lefrer,

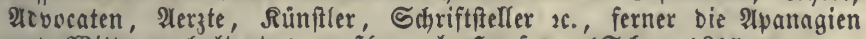
uno BBittwengehalte bes grofiferzogl. S2aufes. (Sdjon 1815 war zum Behufe Der seriegstoften eine änlidie Steuer von $1 / 30$ Der Ëinfunfte angeoronet worben, es fam aber nur ber halbjährige Betrag wirtlid zur (Erhebung.) Sie murbe zul Shülfe genommen, um bei ber Ëntwer=

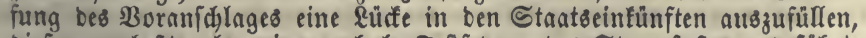

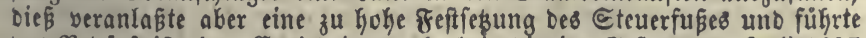

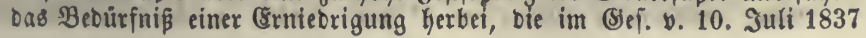




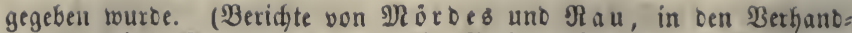
lungen beiber Rammern yon 1837.) Nad) Demí. toirb jebe Befoloung mit einer getviffen 3afil vervielfacht, um Daraus bas Éteuercapital zu biloen, tocldes nach Dem Fußje Der Semerbiteuer, aljo jest mit $23 \mathrm{fr}$. auf 100 fi., belegt wirb. Diefe Bervielfadsungsizakl ift bis auf 2000 fi. 3, - von 2001-3000 fi. 6, von 3001-4000 ก̂. 7, von 4001-5000 fi, $8, \ldots$ von 8001 fi. an 12 . Man mus aber, wie in 2Sürtemberg, jeoes (sinfemenen in bie beridjiedenen Taujende zerlegen und für jedes Derfelben bie entiprectjente Bervielfadjung anwenden, 3. BB. bei einer (Einnafgme vou 4700 fl. if Das Steuercapital $2000 \times 3+1000.6$ $+1000.7+700.8$, oder zufammen 24600 fl., toowon die Steuer jest 94 fr. $18 \mathrm{fr}$. ober 2 Broc. ausmadt. Die 28 ahl ber Yiultipli=

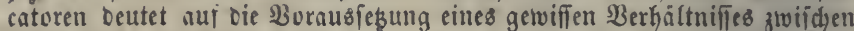
rohem uno reinem Sinfommen. Da z. B. 2000 fi. Befoldung $2 c$. wie 6000 ก. Betriebsiapital behandelt rerben, melche $240-300$ fl. 3ins abwerfen, fo ift angenommen, Das in jenen 2000 fl. ungefäly $12-15$ \$roc. reines sinfommen enthalten feien. Dagegen zeigt bas Steuercapital von 24600 กิ. ein vermuthetes reines (Sinfommen von $984-1230$ fi. $=$ 22-26 \$roc. an. Beredjnet man bic ganze Eteter eines gewiñen (Sinfummens, io erfält man bei 1000 fi. 11 fl. 30 fr. oder 1,15 \$roc., bei 2000 ศ. 23 f.. oder 1, 15 \$ruc., bei 3000 fi. 46 f. voer 1,53 \$roc., bei 4000 fl. 72 fl. ocer 1,8 \$ruc., bei 5000 fi. 103 f. $30 \mathrm{fr}$. oder 2,17 ßroc., bei 6000 fl. 138 fi. ster 2,3 ßroc., bei 10000 fl. 310 fl. $30 \mathrm{fr}$. ober 3,1 Broc., bei 30000 fi. 1230 fl. 30 fr. oder 4,1 \$roc. Der Ertrag wor nad) Dem älteren Sefes im D. von 1835 und 1836 190033 fi., Dagegen im D. von 1839 und 1840122768 fl., $1844-46$ 144911 f. Sm Э. 1851 waren 25303 (Stafienteuerpflidgtige, 1859 waren 23826 mit einem Eteuercapital bou 34.431140 กิ., 1863

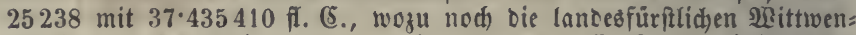
gefalte und Ipanagien tommen, Die 18632283 fl. Steuer einbrachten, baher ber Boranjhlag von 145785 fl. nebit 12981 f. mutfmaslidjem

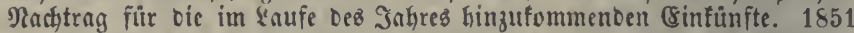
bezugen bie 25303 (Elafienfteuerpflichtigen ein angezeigtes (Sinfommen yon 9.241840 fi., wowon 8.925 700 fl. in Summen bis 2000 fl. 1859 betrugen bie dieier Steuer unterworfenen biufünfte

$$
\begin{aligned}
& \text { Giz zu } 2000 \text { fi. . . } 10.477770 \text { fi. } \\
& \text { yon } 2001-3000 \text { fi. . . } 255410 \text { " } \\
& \text { 3001-4000 f. . . } 77790 " \\
& \text { Die Gỏkeren . . . . } 101510 \text { " }
\end{aligned}
$$

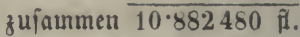

In Bayern waren bis zur Einfïhrung ber (Sinfommensfteuer nad) cem (Eoict voun 10. Dec. 1814 Befoldete in Der 5. Claffe Der Framilienfteter zu $1 / 4$ \$roc. igres Dienfteinfommens angefest. Nach Dem (Befes bom 31. Dhai 1856 hort bie biăkerige (allgemeine) Einfummenzfteuer auf und unter Dieiem Ramen beiteht nur eine Steuer von foldhen Esin: fünften, bie nidbt fdon einer anberen ๔disung unterliegen, alio bon

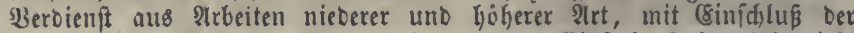
Befoloungen, (Sebalte, Siukegefialte u. ogl. Einfache Qognarbeit giebt

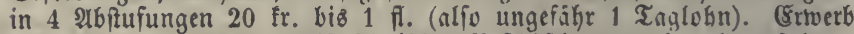

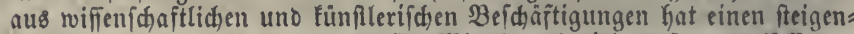

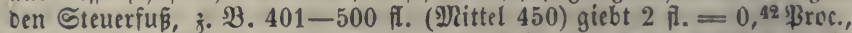
$3501-4000$ (\$ittel 3750) 35 fl. $=0,93$ \$roc., $5001-6000$ f. 55 fi. oder 1 ßroc. u. f. f. regelmásig I Đroc. Bon Befoloungen entridhten Die eriten 600 fi. $1 / 3$ stroc., Die folgenben 300 f. $2 / 3$, alle meiteren Sinnakmen 1 \$roc. - In Defterreid waren bie Stantsbeamten unb Rehrer unbefteuert; Decret v. 7. शpril 1810. v. Rremer II, 200. 
In Der offerreid). Ginfommensffeuer (\$atent v. 10. Dctober 1849) zahlen

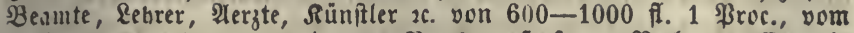
fueiten 1000 2, vom britten 3 \$roc: II. f. f. - Nach bem Srwerb:

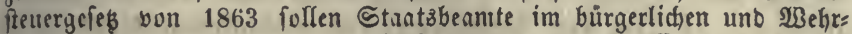
Dienti, Die Finanzmache unb Die Invaliben von ber Erwerbfteuer frei bleiben. Der Bortrag Des Frinanjminifers v. 5. Detober 1863 bemertt,

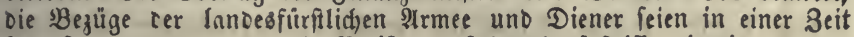
feitgefest worben, wo bie \$reife Der \&ebenbbebürniffe niecriger waren uno Die nieberen CInfien Des Beamtenfennces hátten, wie befunnt, mit Nafhrungsforgen zu tämpfen. (Bermuthliđ trägt hiezu oas gefuntene \$apiergelo bei.)

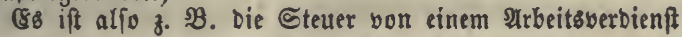
in von 800 ศl. 2000 ศ. 3000 กิ. Bantern . . $31 / 3$ fi. $(0,41)$ Baben : - 9,2 " $(1,15)$ ß3ütemberg . 4," " $(0,55)$ Defterreid . . 8 "(1) 15 f. $(3 / 4)$ 25 f.. $(0,825)$ 23 " $(1,15) 46$ " $(1,53)$ $30 "(1,5) \cdot 70 "\left(2 \frac{1}{\prime \prime}\right)$ 30 " $(1,5) 60 "(2)$

Die in Rlammern beigefügten 3aflen zeigen, wie viel \$rocent Des ganzen (Einfommens Die ๔teuer betrigt. In Deferreich ift oer $20=$ (Suldenfus (ङonv.=\$2.) gemeint. - In \$reußen entridhten bie Beamten Elafien= fteuer, wobei fie nach ifger birthidjaftliden \&age im Banzen mit anbe= ren Elafien bon Etantżburgern vergliden werben follen, ohne Dá beftimmte 2rbgabenfïbe aufgeffellt worben wären. $\mathfrak{B}$. v. 25. 2ug. uno 12. Dec. 1820. In einigen Regierungsbezirten hat man folgenbe Regel angenommen: bon 150-200 Thlr. 4 Thlr. Steuer, von 2-300 Thlr. 6 Thlr., yon $3-400$ Thlr. 8 ThIr., von $4-600$ Thlr. $12 \mathfrak{T h I r . , ~ v o n ~}$ 6-900 Thlr. 18 Thlr., von 1000-1200 Thlr. 24 Thlr. u. . w. Sinnho10, Die Elafienfeuterberfafiung Des preus. Stants. 1831. In ๔adfen fteigt die Befoloungsfteuer mit ben Einfunften von $8 / 15$ bio nuf $2 \frac{1}{2}$ Proc.

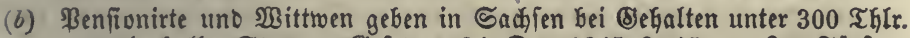
nur bie halbe Steuer. (Seleb ø. 24. Dec. 1845 §. 15. - Im Fürften=

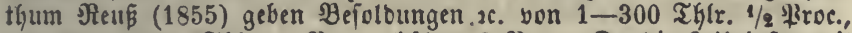
bon 301-1000 ThIr. 1 \$roc., höhere 2 \$roc. Da bie \&eifzinien mit $1 / 6$ Sroc. Des Eapitals belegt fino, was bei einem Sinsfußs von 4,5 \$roc.

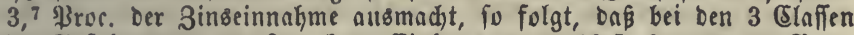
Der Sbefoloungen Das fteuerbare Einfommen zu 13,5, 27 uno 54 \$roc. Der ganzen Eimnahme angenommen worben ift. - Sannov. Befoldungs: uno Erwerbiteuer (1859): Die erften 140 Thlr. 1/5 \$roc., die zmeiten 1/s ßroc., Die weitere Sinnahme bis 1000 12/s, bon 1-2000 Thlr. 2, Das Beitere $2^{3} / 3$ Proc.

\section{§. 396.}

Beitere Bemerfungen über bie Befteuerung bes \&ohnes. 1) Der Arbeitglohn ift zwar felten zum Begenftanbe einer ausidhließent auf ifn falfenten und alle feine 3weige treffen= ben Steuer genadt $(a)$, allein in ben meiften Stanten ift er nuf irgeno eine Weije mit Edjakungen belegt worben; bald hat man ihn ber Sewwerbiteuer unterworfen, balo mit ber Eapitals fteuer verbunben, balb bie verifdicbenen 2 Irten ber Rohnarbeit zu verfalebenen Steuern gezogen u. Dgl. (b). Dieje Behands.

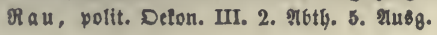


lung ift einer gleidförmigen, bie (Eigenthủmlid)feit bes 2Trbeiţ=

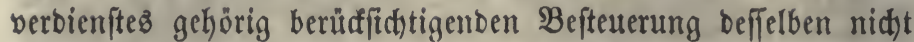
gủnftig. 2) $3 u$ ber 2Anlegung ber \&ohnfteuer bient zunäd)fít bie eigene Angabe bez Steuerpflidtigen unt bie \$rüfung Der= felben burd) einen 2 (ub (d) bei Bejolbeten in einem Dienfte bez Stantez, ber Bemeinbe, ber Sirct)e, ber Stifungen 2 . ift ez fo leidt, unrid)tige Angaben zu erfennen, oná bie Steuerbehörbe biejelben faum zu bejorgen hat (c). Dieje Angnben erforbern eine öftere Erneuerung, z. $\mathfrak{B}$. alle 3 ober 5 Sahre, ober fogar jährlid, unb jebenfalls müffen offens funbige 2 tenterungen, wie Bejoloung berhöhungen, Erweiterung

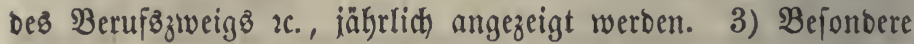
Soften, bie nid)t ben perfönlichen Unterbalt, fonbern bie Bes

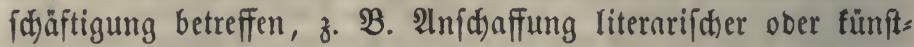
lerifd)er Şülfs̈mittel, fowie bie Raften, fint yon ber Durd)= (d)nittöeinnahme abzuziełen.

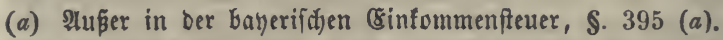

(b) Die ehemafige taille personnelle in Franfrein) (ygl. §. 316) traf ben

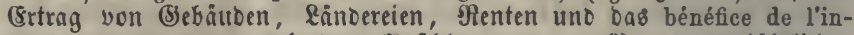

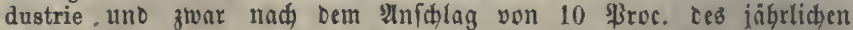
2rbeitsverbienffes (1/10 du prix des journẻes); Der Eteuerfú mar 5 Proc. (1 sol par livre); ein Şanbwerfer ober Taglöhner, ber jährs= lich 200 2trbeitstage Gatte, murbe mit 20 Tagen angefdelagen uno ent: ridjtete ben Berdienft eine Declarat. v. 11. 2ug. 1776. Encyclop. 2(6th. finances II, 657. Baben: Taglöhner, Rohnbebiente, Srautidnneider, Spielleute 2r. find zur Selwerbfteuer gezogen, zu welder bie Taglöhner mit 500 ศ. Eteuer= capital eingetragen werden; Dienfiteiftende, bis zu ben Ecribenten,

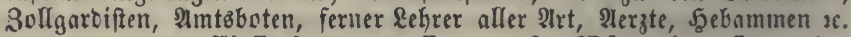
werten von ber Elaffenfeterer getroffen. - In $2 B u ̈ r t e m b e r g$ fino neben cen Staatsbeamten auch bie 2erzte, 210vocaten, Şanolungögehülfen,

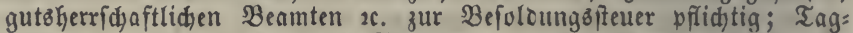
loffner u. Dergl. zahlen feine Sdjakung. - In Breusen fallen alle Göheren Dienfte unter bie SInfienfteuer, im ङroß̈h. Szefien unter Die Berionalfeuer, ebenjo in Sachien, wo bie \$erjonalpeuer mit ber (Bes werbfteuer verbunden ift. - In Janmover befindet fich eine Befoloungs=

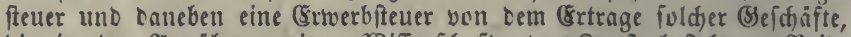

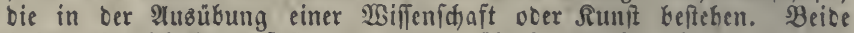
Gaben einerlei Gteuerfü uno werben überhaupt als zufammengehörig betrachtet (\$. $395(a))$. 2. für $1855-6099000$ Thglr. - 2ntere 3weige ber \&ohnarbeit entridften nur \$erfonalfeuer, \$. $400(a)$.

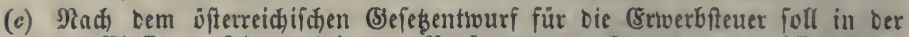
2. Elañe Derfelben bei ben Bezügen aus Etaats = und biffentlidjen Fonoscaffen bie Steuer fogleid) bei Der 2tuäbezahluna abgezogen wer:

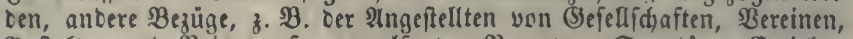
Inftalten uno Bribatwerfonen, alfo ber Beamten, Eecretire, Erzieher,

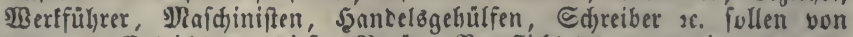

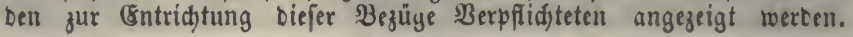


Nur Beifliche Gaben ifre (Sefhalte felbft anzuzeigen. Nan mü fid

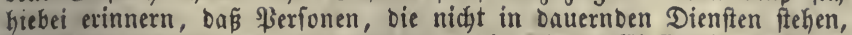
wie 2erzte, शrovocaten, \$ribatlehrer xc. in Die 1. Elaffe biefer Steuer gefest werben; hier wäre bie eigene Angabe ganz unentbehrlich, man wiro fie aber auch in ber 2 . nidht leicht miffen tönnen.

\section{7. $\mathfrak{A} \mathfrak{b}\lceil\mathfrak{a b}$}

\section{Sopf = und Perionaliteuer.}

\section{§. 397.}

Die Ropfiteuer, weldye ohne Rüffict auf Bermögen und (Sinfummen bloß nach) ber 3 ahl ber ßerfonen aufgelegt wirb, entiprach ben finbesalter bes Steuerwejens, in bem fie fich Durch bie Reichtigfeit ber Anlegung uno Erfyebung empfahl (a).

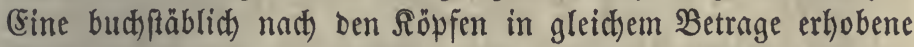
Steuer ift aber Den allgemeinen Srumbjäzen Der Befteuerung fo fehr wiberftreitend und ifres nothwendig fehr niebrigen $B$ etrages wegen (\$. 251) fo unergiebig, baß fith) bald bas Bebürfni einer $\mathfrak{B e r b e f f e r u n g ~ f u ̈ h l b a r ~ m a d y t e , ~ i n b e m ~ b i e ~ S t e u e r ~ n u r ~ v o n ~}$ ben (Erwachfenen, ober mur von Den Şauşvätern und ben ein= zeln lebenden ßerionen erhoben wurbe. Nactbem längit an= Dere ergiebigere und gered)tere Steuern eingeführt worden find, hat fid bod) neben ifnen in einigen Etanten iene ber Ropf= fteuer ähnlidje, aber in ber angegebenen $\mathfrak{W e i f e}$ gemilberte $\mathfrak{A b}=$ gabe unter bem Namen \$erfonalfteuer erfalten (b). Sie แuв fehr niebrig feil, um von Allen ertragen werben zu fönnen.

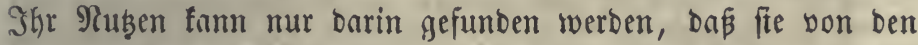
feiner anberen Sd)abung unterworfenen Staatżbürgern, aljo namentlich ben \&ohnarbeitern, einen billigen Beitrag liefert,

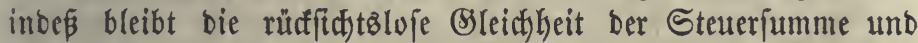
bie mühfame (sinforberung berfelben aud) von benjenigen Stnats = angehorigen, weldbe icton nuf anbere $\mathfrak{B e i f e}$ befteuert finb, immer eine wejentliche Unvolffommentheit biefer Steuer $(c)$. Daher find auth) meiftens in biejer Werjonalfteuer Abjtufungen nnd) ben (Sraben ber Steuerfähigfeit angebract worben, woburd) jene fict) wefentlich veränberte und zu einer (sinfommensfteuer, jebod) von febr unbollfommener (Sinridftung, wurbe $(d)$.

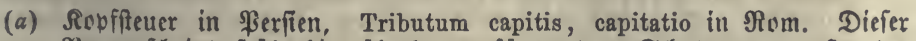
Slame fdgeint früberhin überhaupt für anbere Sdyabungen auper ber 
(5rundifeuer gebraudht worten zu fein, alio von bem (sinfommen aus 2rbeit und beweglidyem Bermogen. Erit feit Sonpiantin if Die Rupf: pelter, auch capitatio humana genannt, bon Der (Setwerbfteuer ber sauf= leute uno fabrifgerren getrennt. \$erionen ohne (Srundeigenthum hießen Damals plebeji, Daher nutr bicje jener Ropfiteuer in Nom unterworfen

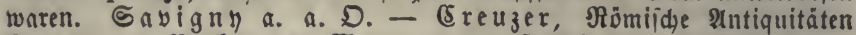

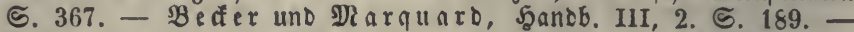
In verfdiedenell ettropäif̧,en Etaaten fino früherhin Sopfîtuern in mandyfaltiger $\mathfrak{B}_{\text {eife }}$ vorgefommen, in (Slarus befteht eine foldie nods jest, fomie in mefreren nurbamericanifden Etunten unter bem Ramen poll-tax, z. $\mathfrak{B}$. in Enlifurnien 5 D. bon jecem Rovf, in Sndinna $3 / 4$ D. , aber nidht von allen झerionen. Nach Der ehemaligen öfters reichifien \$erfonnlfteuer (\$atent v. 23. Nov. 1802) zahlte jece ßerion über 15 Jahre jährliç $30 \mathrm{fr}$., Wüterhin 2 ff. Nur Das Dilitair unb erweislich Dürftige maren befreit, in Tirol uno Borarlberg rourde von Dienftboten und Taglöhnern nur Der halbe Betrag entridtet. Diefe Steuer beiteht feit 1830 nicht melyr. Beríbiecene Borichläge älterer Schriftiteller zielen Dahin, einige Ablufung anzubringen, z. $\mathscr{B}$. $\mathfrak{B}$ ergi us, Bolizei = uno Cameralmagnzin V, 347. - Nah) $v$. Sa of (Die iffentr. Abgaben (. 17) ivirb bie \$erionalfeuer als eine Der Drei fundamental: ober Utifeuern (neben ber Ginfommens: uno ber Steuer yon befonberen \&eiftungen Des Stantes) betradtet, indem fie Der für alle Stantsbürger gleichen Sorge bes Stantes für Schus uno anbere periönliche Bortheile entipricht. Der Berf. erfennt jeboch an (ङ. 71. 72), Daß bie reine Berfonalfteuer wenig trägt, viel foftet unb verhant ift, uno räth, fie burch eine शtufwanosftetter von Segenftänden bes allgemeinen Berbraudjs zu eriegen (ङ. 82). - Stein (\&ehrb. S. 285 ff.) nimmt bie reine Berfonalfteuer im \$rincip in Schuz, weil fie auf bas reine Eabital Der whyfichen शrbeitgfraft gelegt werbe. (2ud wenn man Diefe Rraft (umpafieno) Eapital nennen wollte, fo märe fie Dod feine (Srundage ber Befteuerung, weil bas aus ber Arbeit fließzenbe Lohneinfommen

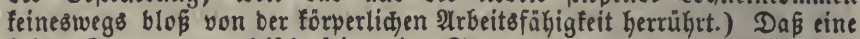
foldhe Steuer unpraftifa fei, wirb S. 287 zugegeben. - Heber Diefe Steuer de Parieu, Impôts I, 125.

(b) In Franfreid beftand fofon fehr frühe eine capitation, Die fid vielleidut

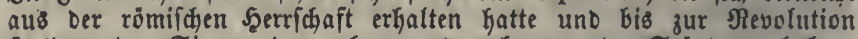
fortbauerte. Sie wurbe auch von ben beborzugten Stänben erfoben, belche yon ber taille réelle $(\$$. 316) befreit waren, fie war aber nach Bermögensumftänben angelegt, F. $_{(d)}$. - Die Geutige franzöfifde \$erfonalfieuer ift von 1791, uno befteft aus bem Dreifachen Betrage Des \&ohnes gemeiner Scandarbeit. Der Sab Des Tagelnknes tarf zu Dieferm SBefufe nach Dem Sefés vom 21. April 1832 nicht über $11 / 2$, nidht unter $1 / 2$ Fr. angenommen werben und wirb für jese (\$) bon bem Conseil général ces Departements beftimmt. Jebe \$erfon, Die ifre eigenen (Sinfünfte hat, wenn fie auch nod im âlterliden Şaufe wohnt, if feuerpflidtig. Cine Nenge näkerer Borfbriften beftimmt, mer feuerpflidtig fei. Dienftboten 3 . 2 . Fino befreit. Diefe Steuer ift mit Der Wiofnungsfteuer $(\$ .426)$ fo bermifht, Das ber von beiben zu erzielenbe Ertrag im Sanzen feftgefest uno auf Die Dewartements und Arronbiffement bertheilt wirb. In leß̧teren wirb cie \$erfonals - fetter nad ben oben angegebenen (Srunblagen ermittelt und das nod Fehlende als $\mathfrak{B}_{0}$ hnungsitener umgelegt. Der Stammbetrag (principal) beiber ift für $1860 \quad 37.589798$ Fr., wozu 37 ßroc. Suidoläge für ธtant8: unD $9 \cdot 167360$ für Departementsansgaben fommen, zufammen 60.698000 $5 r$., ofne bie 9 Mill. zu (Semeindeausgaben. - Nobena: 1 Rira bon jebem männliçen Eintwohner bon $14-60$ Jabren, unb 
aleidhviel als Semeinteumlage. - Die nieberlänbifhe unb belgiłđe Berfonalfeuer hat bas 2 befen einer Ropfitetter nidyt mehr unb befteht aus fedjs einzelnen 2lbgaben, weldse fämmtlid zu ben श्Vlufwandsfteuern

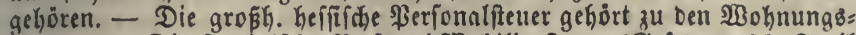
fteuern. - Die jarbinifde ßerional=9lobiliarfteuer (Sefes v. 28. 2upril

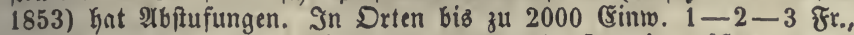
in Drten von 2-6000 (Einw. 11/2-3-41/2 Fr., in größ̈eren $2-4$ -6 frr. Şiezu fommt ein 3uichlag nach ber 3ahl ber Dienfibsten unb ein anberer nadh bem Betrage ber $\mathfrak{W}_{0}$ henungamiethe. - Bei ber Berionalifeuer in Şerzogthum \$arma twurbe jeber (S)emeinbe eine @umme

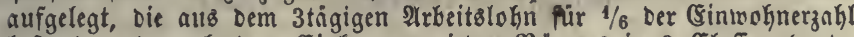
beftand und nad) bem Esinfummen jebes 2 ärgers in 3 Elaffen (unter 1000 Fr., $1-2000$ Fr. und mehr) umgelegt wurbe.

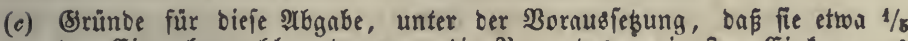
Der Sintwoknerzagl und gegen $1 / 2$ \$roc. Des geringften Sinfommens treffe, bei sololtfe S. 158.

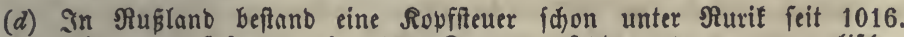
Gie wurbe foriter burd) anbere Steuern eriegst, unter ber mongolifach Seerridhaft wieber eingeführt, nod)mals aufgehoben. Seit jieter I. (1722) befteht fie fortwährent. Sie trifft alle mannliden Eintwolgner

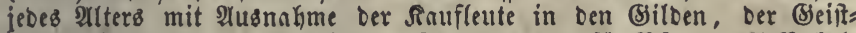

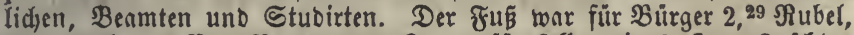

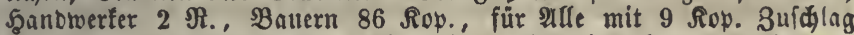
für \&ands und 2 Bafferiftrnêen. Die auf jebe Semeinbe fommende Summe

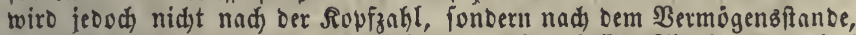
auf bem Lanbe nadh bell 2intheilen am Ianbbefis (Tiaglo) umgelegt uno im Sanzen voll einer Sảhlung (Nevifiton) zur anberen entrichtet. Die Errjebung von ben Einzelnen leitet ber Drtsuorfteher (starosta).

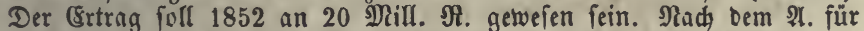
1862 war ber Fú von Stadtbetwofnern 22 Rop. bis 2,5 R., von Dománen:, emancipirten $\mathfrak{B n u e r n}$ unb in ben weftlichen uno baltifchen Provinzen $1 \mathrm{NR}$, von fibirifben freien Bauern, Solafen, Tataren $2 \mathrm{c}$. 15 Rop. $-2,67 \Re$. Der Crtrag war auf 28 Nifl. $\Re$. geidabt; in cen Stäbten hat aber 1863 bie Rovfiteuer aufgehört, \$. $374(a)$. -

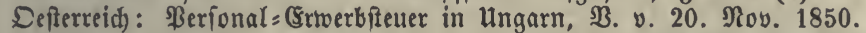
Tnglofner, א̧äubler unb Deren Familienmitglieber, Dienftboten, (Ses fellen 2c. bezahlen $20 \mathrm{fr}$. - 1 fl. für ben Ropf, fleinere Bauern, Beamte, (Seiflide, Alerzte, 2lovocaten, Şanbwerfer, Raufleute 2c. 1-6 fi.; bie anderen sititglieber ber Familie Galb foviel auf ben Ropf. Serfonen, tie 100 fl. unb mehr birecte Steuern tragen, zahlen 4-10 fl. zu jener Steuer, igre 2ungehorigen bie Şâlfte. Dieje Sdjab̧ung gilt nur als proviforifh. Rebnlide 2rbgaben find aud in Broatien unb Sieben: burgen. Ertrag in Ungarn $185723 / 4$ Mill. fl. $=19 \mathrm{fr}$. auf Den Sopf Der (Sintwohner. Borid)lag einer außerverbentliden \$erionalifeuer im Difterreich. Staate für bie Seit vom 1. Nov. 1863 bis Grnbe 1864: alle \$erionen vom 16. Jahre an in 3 claffen $1 / 4-1 / 2$ uno 1 fl. -

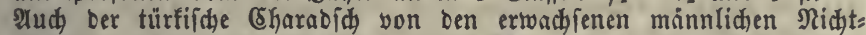

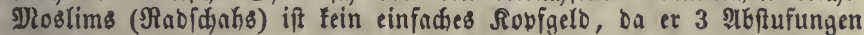
hat, nach Urquhart (Turkey and its resources. Lond. 1833. S 87) 10,6 uno 3 \$iafter, newerlich 60,30 uno 15 heutige \$iafter zu $6,1 \mathrm{fr}$., de Parieu I, 127. - Plud bie \$erionalfettern in Der SBallachei und Serbien find abgeftuft, z. B. in ter Stabt Belgrad in 12 Elaffen yon 5-3280 Eteuerpinfter (120 auf bie tỏln. \$Narf, alfo zu $12 \% \mathrm{fr}$. iüob.) ; 2. 1862/3 12 פill. \$. von 200000 Steuerpflidtigen. Tobcana feit 185535 Elaffen, Sardinien feit $185311 / 2-6$ Fr., \$arma 3 Elafien. - Die franzofffde capitation war in ben ßrovinzen, two 


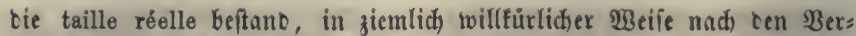
mogensumftanben angelegt, in Den anderen Provinzen eine Quote Der taille, au marc de la livre, - Die fog. capitation taillable. Encycl. Ibth. Finances I, 190. Re ffer giebt ben (Ettrag ber Capitation auf $41 \frac{1}{2}$ Mill. Fr. an, Admin. des fin. I, 5.

\section{8. $\mathfrak{A} b\lceil\mathfrak{a}$.}

\section{Allgeneine Eintommenछิteuer.}

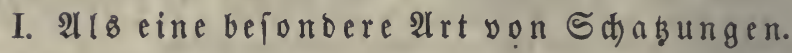

§. 398.

Währeno bie in 2lbją̧ $1-6$ abgehanbelten Sdjakungen bie veridfiebenen 3weige ber (Einfünfte, jeben nad) feinen Eigen= thüm(id)feiten, zu treffen beftimint find, hat man aud) verfud)t, fämmtlidje Bürger bes Staates einer alfgemeinen Sdyak̨ung zu unterwerfen, bei weldher auf bie Berjhiebenkeiten in.ben bejon= beren Brunolagen ber Steuerfähigfeit feine ober nur geringe Stücffid)t genommen wirb. Die (Sinfüfrung biefer Steuer ging

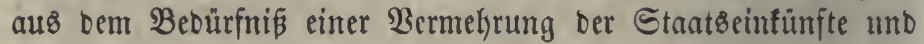

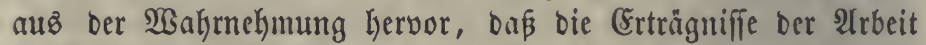
uno bes berweglidben Bermögens in ifrer neuerliden 2usbeh= mung burd) bie folyon beftehenden Steuern ju wenig belaftet feien. Soldue aflgemeine Sdhabungen fino balo auf bie (s:in= fünfte, balb auf bas gefammte $\mathfrak{B e r m o ̈ g e n ~ D e r ~ B u ̈ r g e r ~ g e = ~}$ legt worben $(a)$.

Sine allgemeine (Einfolim menziteuer, yon ber fidon in früheren 3citen einzelne Beippiele vorfamen $(b)$, hat in ben Ießzten Sabrzebenoen vorzüglid)e Alumerfiamteit auf fid) gezogen, weil man in ifre bas befte Mittel zu crbliden glaubte, Die (5)runbjäz̧e ber âfgemeinheit uno (5leid)förmigfeit ber Befteue= rung nad) ber Steuerfähigfeit aller Bürger (\$. 250. 254) in Atůführung zu bringen. In mehreren Stanten ifit neuerlid) neben anberen Sd)nkzungen cine Einfommenzึfteuer eingeführt worben (\$. 400), aud) hat man biefelbe alz einzige હdhaß̧ung

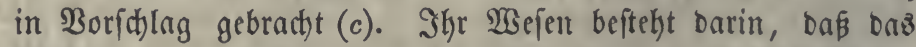

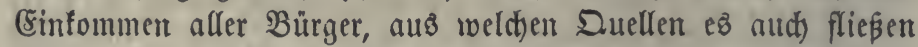
mag, auf gleidförmige Weife ermittelt uno nad) gleidjent ober bod) wenig veridhiebenem Fupe belegt wirb, fo rafi esే fich fiir jeben Eteuerpflidtigen in eine Şatptiumme zufammengezogen 
Darftefft. Şiebei unterbleibt bie forgfältige Erforidung ber ein= zelnen Cintünfte, weil fie langwierig, mübfam uno foftbar ift uno bie Sinfommenzfteuer in mefreren Staaten gerabe zum Behufe einer balbigen $\mathfrak{B e r m e k r u n g}$ ber Staatzeinfünfte an= gewendet worben ift, ferner weil man auf eimem fürzeren $\mathfrak{W B g}_{\text {e }}$ eirten genügenten ungefähren Ueberid)lag bes fteuerbaren (sin= fommens erlangen zu fönnen glaubt. Da ein Theil besి Cin= fommens fefyr veränderlid) ift, fo müffen bie Steueranjaläge jäbrlict) erneuert werben. Die (Srünbe, weldje man für bieje Steurer geltent machen fann, liegen 1) in ber Reictigfeit uno (Simfactheit ifrer 2lnlegung $(d), 2$ ) barin, baj alle Claffen von Staatzbürgern non ifje beigezogen werben, alfo auch biejenigen, weldye zu ben biškerigen Sdjabungen nidyt beitrugen, z. $\mathfrak{B}$. in vielen Ränbern bie Sing̊gläubiger; 3) in ber für bie Steuer= pflidftigen wohlthätigen Berüdftctigung ber Sdulben, beren Sinjen von bem fteuerbaren Cinfommen abgezogen werben fönnen.

(a) de Parieu, Histoire des impôts généraux sur la propriété et le revenu. P. 1856. Der Berf. bemerft, Daßj Diefe Steuergattung mehr bei Den germanifichen als bei ben rumanifden $B$ olfern vorfomme, weil jene eine mehr patriardjalifice 2uffonfung bes Stantes haben uno bei ifhrer rubigeren Semüthzart bie Berpflichtung zu gewifienhafter eigener 2ingabe Des Bermogenzifandes leidter ertragen. - (ङs if jeood aud Der (sin= flús ber Staatzuerfaffung zu beadten. In Freiftaaten uno Donardjien mit guter Stänbeverfafiung herridgt mekr aufopfernde Baterlandoliebe als in unbeichränften Nonardjien, beionbers wenn in Diejen feine ftreng = gefeşliche und weife Regierung befteht.

(b) Das Stetterwefen fritherer Beit war in Den einzelnen Länbern fehr ver= fdieden eingeridhtet. Dan erfennt in ben mandifaltigen Berjudien, neue Steuern neben ben altet, nidjt felten zu parfer Bebrüdung Der unterthanen, einzufübren, häufig Den Nangel fefter Brunofäßze uno Deutlicher (sinfidht in bie Bertheilung bes Bolfzeinfommens. - $3 \mathfrak{u}$ cen Sinfoummensfteuern fheint bie efjemalige colletta (collecta, Steuter) in Benua zu gehören, $4-8$ denari von ber lira; alfo $1 / 60-1 / 30$, was

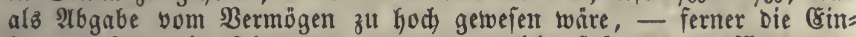
fommenzifteuer in Florenz von 1442, weld)e fpäter progrefitio rourbe und alle Einfünfte treffen follte, de Parieu, Hist. ธ. 26. 51. In mandien \&ändern wurben bei erböhtem Stratßbedarf einmalige ober mefrmals wiederfolte Shakungen vom Sinfommen in Feinen veridhies Denen Stweigen erhoken, z. SB. in Nieberofferreich 1526 als Türfenfteuer 1/2 Broc. von. Renten uno Befoloungen, nom Befts Des sidels, Der Sirche uno Der 3 Butrger von $100-500$ fl. 2 Sdfilling, von $500-1000$ fl. $1 / 2$ fl., von $\mathfrak{B a u e r n}$ ungefähr Daflelbe, von Sleinodien 2 Sdhill. von 100 fi., vou Einwohnern ofne Riegenidjaften $2 \mathrm{fr}$. von 100 fi. D ber=

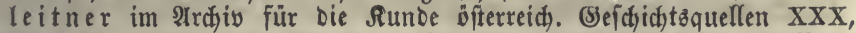
ธ. 1 fi. - Decima in Bortugal feit 1645, abgeändert 1654, 10 ßroc.

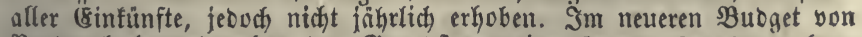
Bortugal fommt neben Der Srrumbiteuer eine decima dos juros (bon Tenten) und industrial vor, de Parieu, Traité II, 49. - In 


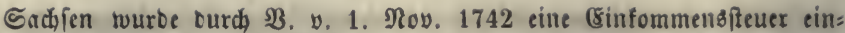
gefüfrt, mit fteigenben Siben, von 100-1000 Thlr. 1 \$roc. 1747 trat eine (Elaffeniteuer mad) 17 Elafien an igre Stelle, wobei man nad

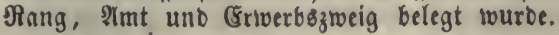

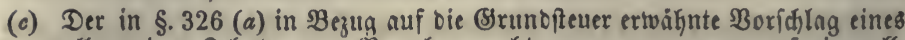
allgemeinen Sehnten von $\mathfrak{B}$ a $u b a n$ geht genau genommen auf eine all= gemeine (sintommensiteuer, bie alle anberen Steuern erieben foll. Shon bie empfoblene (8rbebung ber Duote ber lanbwirth/d)aftliden (5rzeugnifife

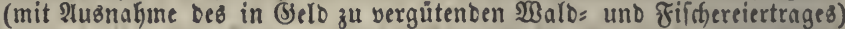

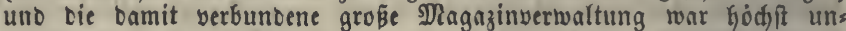

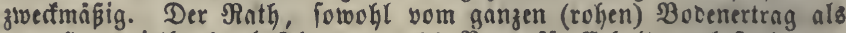

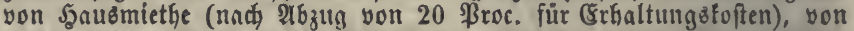
Befoloungen, Berbienft ter (Setverboleute, ber 2tyocnten, Rotare, EnGn= arbeiter gleidhe Duote zu nefmen, zeigt bie Berweddslung Des Grtrnges uno bes Einfommens, wobei bie Srunbeigenthümer zu idswer belaftet whirben. Die gleidbe Behanolung ber veridjiebenen Arten von Ein= fünften hat biejer Boridhlag mit ben meiften fpäteren gemein; nur fanbwerfer follen nad) $\mathfrak{B} a \mathfrak{B} \cap \mathfrak{n}$ geringer, zu $1 / 30$, beftetert werten.

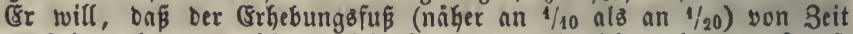
zu Beit nach ben umfänben feftgefest twerbe. Iufti madjt onaraf auf= merfiam, Daß $1 / 10$ als einzige Steuer nidjt ausreidye. - Sraf SD i r a be a u ber ältere madte ben Borfhlng eituer einzigen Ropfiteuer-(capitation), welche im Srunbe eine Sinfommenffeter getoefen fein wirbe. Sie

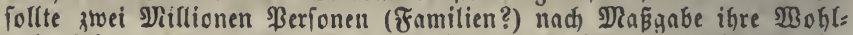
habenkeit (aisance) treffen, in 20 (slafien von 3 \&iv. (1 écu) bis 730 giv. Cteuer. Der Berf. nahm an, jebe biefer Clafien enthalte 100000 Steuerplidatige; er erwartete einen (Ertrag von ungefáhr 700 श2ill. \&., alfo über 100 פNill. mehr als bas ganze bamalige Etratseinfommen. (Die Bornusfeģung einer gleiden \$̇nzahl von Mnitgliebern in jeber (Elafie zeigt groß̧e Unfenntniß̈ ftatiftifdoer Berkältnifie.) Encycl. méth.

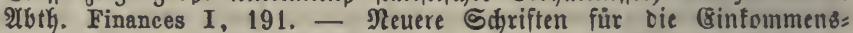
feuer: Lip 8, Heber bie allein waljre unb einzige Eteuer, Erlangen 1812. - Şermes, 15. Şeft. - 3a da a riä, Staatzrw. S. 425433. - $\mathfrak{A} u \times h a \times D$, Befteuerung $\widetilde{S} .506$ (hier zugleid viele 2uteritĩten pro et contra). - Esin 2uffab im New Monthly Review, überfegst in $\mathfrak{B u c h}$ hol, $\mathfrak{R}$. Nonatzidyrift, Sevtember 1834. -

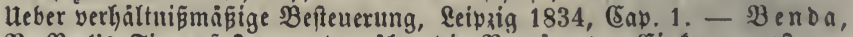
$\Re$. ßeel's Finanzigitem, ober über bie Borzuge cer Ėinfommenвfteuer, Berlin 1842. ((S)eht nicht in Die Steuertheorie ein, fondern fuht nur Die Staatzanleiken zu taceln.) - (Sr. Mo vitfe S.254. - v. Eparre,

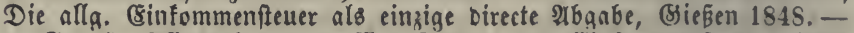

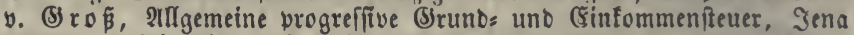
1848. - 3iegler, Sur focinlen Reform, 1850. - J. St. Mill, Princ. of pol. II, 378. - v. (S) rafienried, Heber die Esinfummens: fteuer, Bern 1855. Dagegen: v. Si a ld) $u$ \& I, 175 mo rie bort an= geführten Sdriftitller Sartorius, \&ob, Fuloa, Sismonoi. Edinb. Rev. Apr. 1833. S. 143. - Ma c Ćulloc h, Taxat. S. 113. David in Journ. des Econ. XX, 368. - Cochut in Revue des 2 mondes, 1849, I, 115. - $B$ a u mit a $\mathrm{f} f$, 3ur Einfommensiteuerfrage.

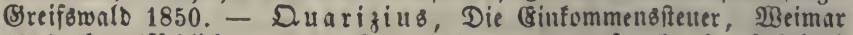
1853 (Gauptfädlich gegen v. Sparre), - Umpfenbach, \&eforbud I, 137.

(d) Die Einfommensfteter ift aus biefen Srunbe aud zu einer nuper= orbentlichen शluflage wohl geeignet. Die ziemlia gangbare Eintheilung

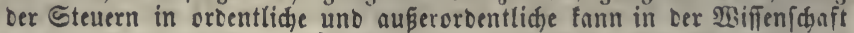
nur infoferne anerfannt toerben, als manche 2trten von Stettern, tie 


\section{$\longrightarrow 185 \longrightarrow$}

zwar eintriglich aber fonft unvollfommen find, eher auf ein ober einige Jabre, als Dauerno angewendet werben bürfen.

§. 399.

Die Sd)attenfeite ber (Sinfommensffteuter ift bie Ungenauigfeit

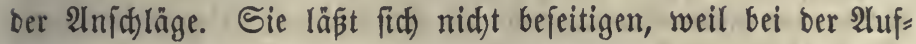
fteflung berfelben auf alfe Rennzeidyen unb StüBppuncte berzidytet wirb, bie bei ben einzelmen 2 rten yon Einfünten anwenobar fint. C:s bleiben baker für ein allgemein=gleidfförmigez $\mathfrak{B}$ er= fahren mur folgenoe zıvei Şülfömittel übrig:

1) Die eigene 2Ingabe ber Steuerpflidtigen, bie ungeadtet Der auf unrifttige Crtlärungen gefebten Strafen bei biefer Steuer befonbers unzuverläfitg ift, weil es bei einem Theile ber (5in= fünfte an Mitteln fehlt, bie Unwakrkeit zu entbeffen (\$. 283), zubem auch) bie Borfdriften über bie Bered)mungşart bes fteuer=

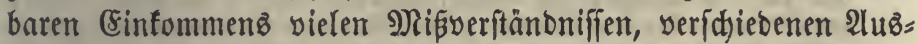

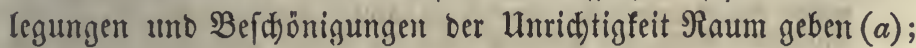

2) Die \$růfung Diefer Angabe uno bie Sdäķung bur(t) einen

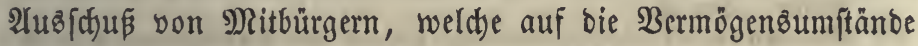
uno auf bie Rebensweife jebes Steuerpflichtigen zu adjten haben. 2ud) hier werben großje Fehler begangen, weil z. $\mathfrak{B}$. baż wer=

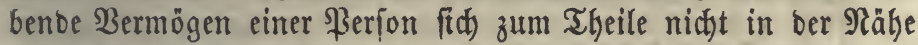

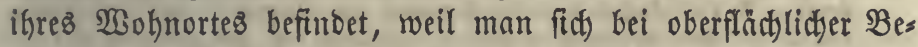
trac)tung leid)t über bie (Einträglid)feit eines Errwerbsazweiges tăufcht, weil ber 2lufwano ber Familien bei ben verfchiebenten

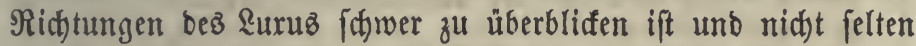

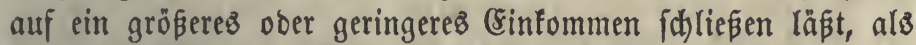
ber Steuerpflidtige wirflid) beziegt u. ogl. (b). Erhalten bie zur Feftę̧ung ber Steuernnichläge befteflten ßerfonen bie $\mathfrak{B}_{\mathfrak{e}}=$ fugnißß, zur ßrüfung ber eigenen 2Ingaben ber Steuerpflictigen

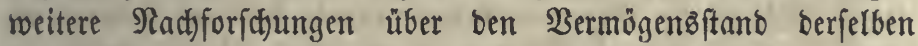
borzunehmen, wie bießs alleroings bei ber 3inserentenfteuter nid)t zu umgeken, ift (\$. 388), fo erregt dieß Einbringen in bie

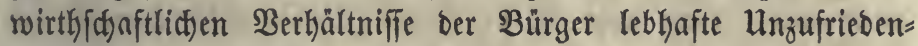
beit uno $\mathfrak{B i b e r f t r e b e n . ~}$

Der Borftlag, bie Steuern burth 2lbgeoronete erft im ganzen Staate auf bie \$rovingen, bann in biefen auf Bezirfe u. f. w. vertlgeilen zu laffen, unb enbliah in jeben Drte bie auf benjelben

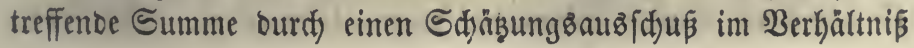




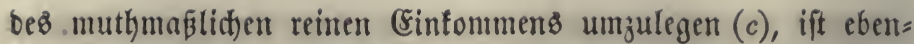
fallz nid)t befriebigent, weil man ohne Satafter ber fteuerbaren

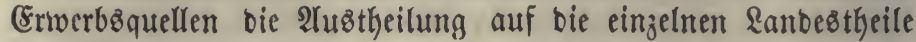
nicht mit ber erforberlicten Senauigfeit bewirfen fann, unb

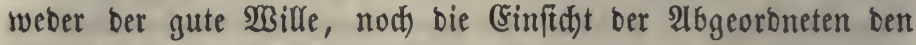

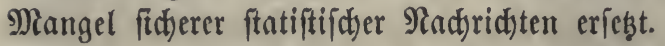

(a) BgI. bie bei $\mathfrak{D}$ urgaro S. 523 fi. mitgetheilten Etellen mefrerer Sderiftfetler. - Bei y. (B) raffentied (a.a. D.), ber auf bie

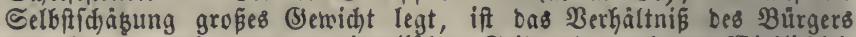
zum Stante melyr yon ber ioealifdsen Seite als nad) Der 2 Birflichteit beurtheilt. - In Erosébritanien if bie Mangelgaftigfeit ber eiyencn Angaben in zahlreidjen Fällen augenfdjeinlid geworden, z. B. bei 28 (SetverbBleuten einer Straße, Die ihr Esinfommen zur Stetter auf

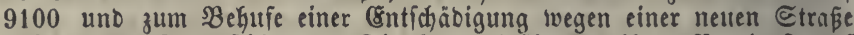
auf 48159 \&. anfdiflugen. Die Jurt beftimmte ifren Bertienft auf 26973 \&. SIa Dftone, Unterhaus, 18. April $1853=$ Gladstone, The financial statements of $1853,1860-62$, London 1863, ๔. 28.

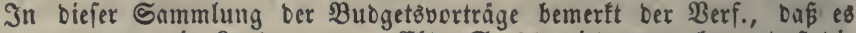

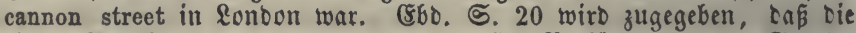
eigene 2ingabe (self-assessment) zu groß̧en $\mathfrak{B e r f u ̈ r z u n g e n ~ t e r ~ S t a a t 8 = ~}$ einnahme führe, Die ungleidheiten ber Steuer vermelgre und zur İm= moralitat verleite, which is, i fear, essentially inherent in the nature of the operation.

(b) Nurhard, S. 531, fowie Sdīn und ber Ungenannte im Şermes regen auf bie Berbinbung biefer Sd)äbung mit ber eigenen 2lngabe

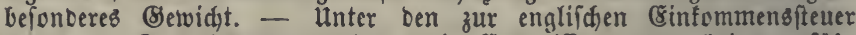
gezogenten Setwerbsleuten nahmen bie Commiffare 1848 bei ungefähr 70 ßroc. Der \$erionen Die eigene Angabe als genügeno an, bei 25 \$roc. wurbe ber 2 Unifhlag von biejen (5ommiffaren aufgefellt und beibehalten,

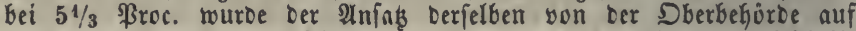
Berlangen ber Steuerpflidfigen geminbert. Rries in ber Beitforift für bie gei. Stantsiv. $X, 510$.

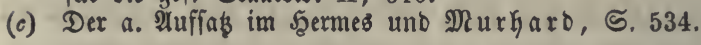

\section{\$. 400 .}

Nach Den vorftelyenten Săben ift bie allgemeine Einfomments= fteuer nidjt bazu geeignet, an bie Stelle aller einzelnen Sd) ał̧ ungu geję̧t zu werden, \$. 398 (b). Die unvermeid= lid)en Mängel ber Steueranid)läge würben bei bem hohen Fuße eimer foldben einzigen Sinfonmenzjpteuer in einem fdyer zu ertragenden Manße fühlbar werben und es wäre nicht zu ber= antworten, wenn man bie burd) Iangiährige Bemühungen unb Erfahrungen getwonnenen Şülf̈̈mittel zu einer geredften Belegung

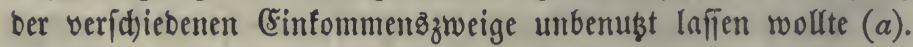

Eine Einfommengfteuer neben ben anberen Sd) a un ungen einführen, heift bem länger beftehenben nod)

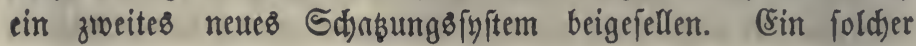


3uftand ift offenbar unvollfommen, weil bie 2rtzaht von Steuern unnöthig bermehrt wirb, weil bie neu Ginzugefommene Steuter wefentlidje Mängel an fith) trägt (\$. 399) und bie Ungleid Geiten ber bizherigen Befteuerung mur minbert, nicht ganz be= feitigt. $\mathfrak{B a r}$ z. $\mathfrak{B}$. ein gewiffer Theil bes Einfommens im

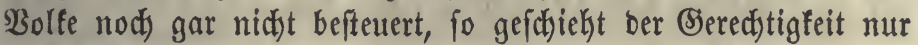
in Fehr geringem $\mathfrak{R a n a ß e}$ Benuge, wenn iene Cinfünfte und zugleid) alle anderen fdyon mit Sdjastungen belegten ber (Sin= fonmensfteuer unterworfen werben. Dod) ift bie Einfüfrung ber leşteren bann zu rechtfertigen, wenn man in ben älteren

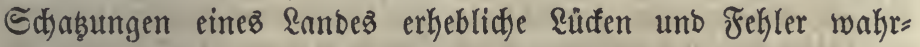
nimmt, benen man nidft leidft unb fifnell abkelfen fann, fo

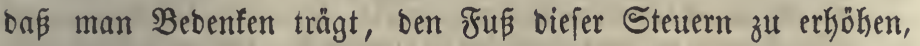
ober fogar eine Şerabjeķung beffelben für nöthig eradjtet. In biefem Falfe bient bie Cinfommenzffteuer nut zur Cergånzung

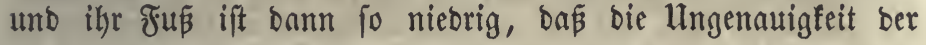
2nnlegungsint weniger empfunden und bagegen anbere $\mathfrak{B o r t h e i l e}$ (\$. 398) erreidft werben (b). Man follte jebud) bann bie Esin=

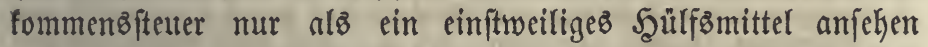
ıtnd auf eine grünbliche Berbefferung fämmtliçer Edjaķungen Bebadit nefimen.

Wenn in einem \&anbe für cinen Theil ber (sinfünte fdoon

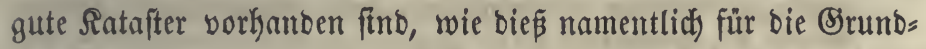

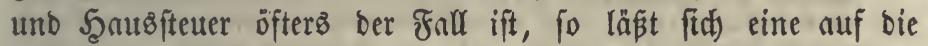
übrigen nod) nicft belafteten 3weige befdfränfte (Sinfomments:

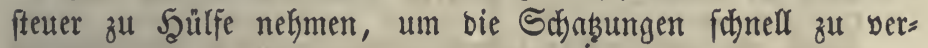
yollftänbigen $(c)$.

(a) Diés bemerft atdh Der Finanzminifter Gella in bem Boridalage zu

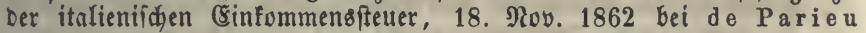
V, 248. $\mathfrak{B B}_{0}$ man ein Ratafter habe, ober audy mur Den Infang eines folden, ba fei biȩ́ beffer als bie méthodes assez incertaines bei ber 2inlegung einer allgemeinen đintommensfteuer.

(b) In (5) robritanien if eine sinfommensfteuer breimal cin= geführt worcen. 1) Die auf \$itt's Boridhlag befchloffene income-tax yon 1798 ließs Crinfinfte unter 60 \&. St. Frei, traf bie von $60-65$ \&. St. zu $1 / 120$ u. f. f. in feigendem Betrage, bei 200 \&. exreidjte fie Den Sał von 1/10. Den Setwerbsuerbienft ber \$achter nahm man zu

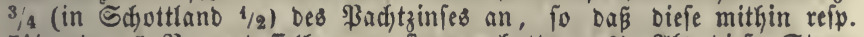
$71 / 2$ ober 5 \$roc. Defielben zu feuern hatten. 2) श्रls biefé Steuter mach Dem frieden von 2 tmiens aufgehuben tworden mar, wurbe fie bald barauf 1903 wieber eingeführt unter sem antlichen $\mathfrak{R a m e n}$ property-tax. Sie toar einigermaßêt abgeftuft, bon 150 \&. St. an belief fie fin auf 
5 Broc. Des Esinfommens. 1805, nach ben Boridlägen von fox uno (5) renville, wurbe fie wieber auf 10 ßroc. aller Einfünte geiest, 1816 aber, in Folae vieler Rlagen über bie läftigen Nadforidungen, vom \$arlament aufgehoben. Sie Gatte von $1810-1815$ im Durds,

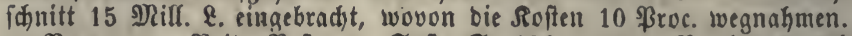

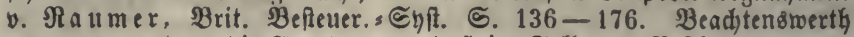

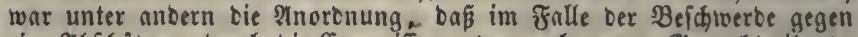
eine 2lbidjäkung burd bie (Sommiffare voer auch, wenn (Sewerbtreibenbe ihre Bermógensumptänce geheim Galten wollten, bejonbere Sdbieb : manner (referees) ernannt tourben, Denell man im lesteren falle bie auşübrliche शadweifung vorlegte. (S) I ab fitone (Financial statem. ङ. 15) zeigt, wie nüblich biefe Steuer von 1798-1815 gelvirft hat, inbem fie bei ben gropen Rriegsausgaben Das Deficit uno Das Beburrf" níß neuer Anleigen bejeitigte. - 3) Die neue Einfommensfteuer (ङef. ๖. 22. Suni 1842 , 5. u. 6. Victor. Cap. 35.) wiro amtlid (unpafieno) property - tax genannt. $\Re$ obert $\mathfrak{B}$ eel beantragte fie am 11. N)ärz 1842, bei Borlegung bes Boranlalags, welder bei ten banaligen

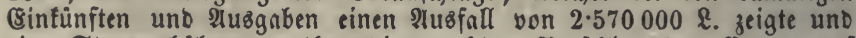
eine Steuererhibung nothiwendig madte. \$3. (4)lug ben Ertrag allf 3.771000 \&. an, Der wirfliche Ertrag im D. $1842-51$ war aber 5.697000 \&. Nady bem (Sefes follte Die Steter nur bis 1845 beptehen,

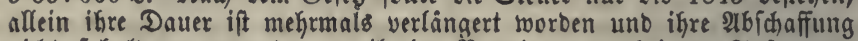
nidht fobald zu erwarten, weil eine Berminberung bei ben Alufwanos= fettern efher Noth thut. Da bie britifde Erundfeuer hödit mangelhaft uno niebrig ift, eine befoncere Betwerb= uno Capitalfeuer fehlt, io ift

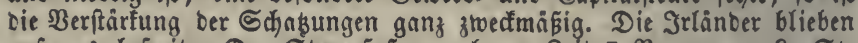
anfangs befreit. Der Steuterfup war lange 3eit 7 ßence vom $\&$. St. = 7/240 oter 2,91 \$roc., bei ßadtern 31/2 ßence som \&. Ct. Des

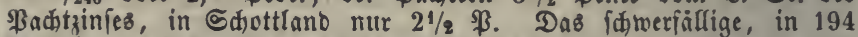

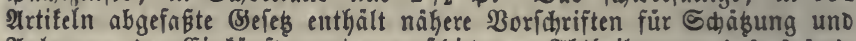
2̂nlegung ber Einfünfte unter verídiebenen Abtheilungen (schedules),

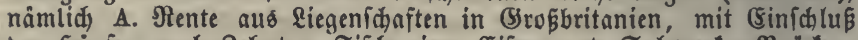

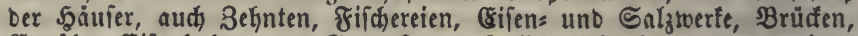
Canåle, Eijenbahnen $2 c$. Sruntiteter, ortliche Abgaben uno umgelegte Beitråge für Drainirung, Esinfriebigung ober Einoủmmung werben von

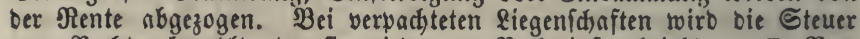
vom \$achter bezahlt, ber fie wieber am ßadtzinje abzieht. - B. Ber= Dienft ber ßad,er, welder nad, ber \$adjtrente beredinet wirb. C. Sinfen uno Divibenben, welche aus ben Stratzeinfünften bezahit werben, aber mit Freilaffung ber Einnahmen, welche an Unterftübungs = gefellifaften, Sparcaffen, Die Staatscaffe, Die Ronigin uno bie fremben (Sefandten fallen. Die @teuer wirb bei Bezahlung Der Binfen bon

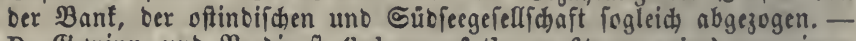
D. Selvinn unb BerDienft (balance of the profits or gains) bon einem Sewerbe, Sefdáft, Beruf 2 . (profession, trade, manufacture, employment or vocation), nady Dem Durdjichnitt ber Drei lebeten Jahre, wobei

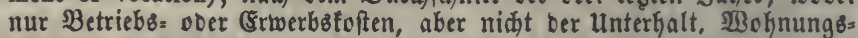
miethe ober Sdulben (mit 2usnahme ber für hbledt anerfannten) von Dem Berbienft abgezogen werben. 858 ift geftattet, ein Hebereinfommen (composition) allf 3 Jahre zu idjließen, mit 3uidus von 5 \$roc. zu

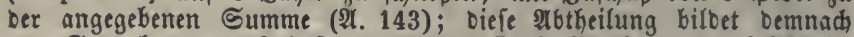

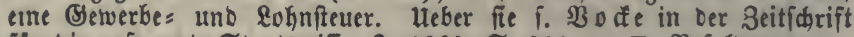

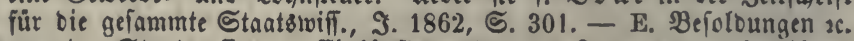
aus ber Staatécaffe. - Einfunfte unter 150 \&. twaren nach obigem Seiebe frei (Art. 163). Wer auf mittelbarem $\mathfrak{B}$ ege, burch शtbug an ber Sinseinnabme, zur Steuer beigezogen twirb uno nadweift, bas fein Sinfommen 150 \&. nidt erreidt, erhalt bie Steuer aus ber Staatscafle 


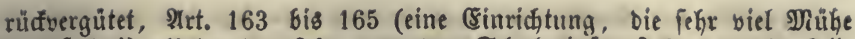

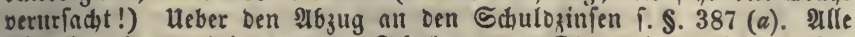
Sinseinnahmen, bei benen ber Echuloner ben Eteuerabzug nidjt mađen

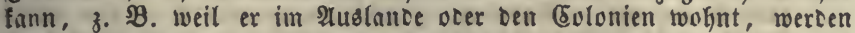

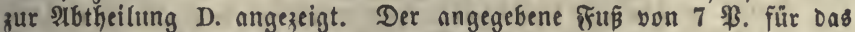

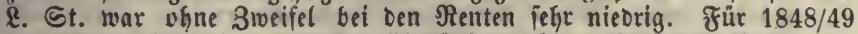
berechneten fich bie beftetterten Einfünfte auf ungefähr 186 פill., für $1852 / 53$ auf 219 Dill. Das Gefés ๖. 28. Suni 1853 (16. 17. Vict. Cap. 34) beftimmt, Dấ auch (Sinfinfte von $100 \mathfrak{l}$. Bis an 150 \&. Der Stetter unterliegen, jeodch nur 5 ßence vom $\mathfrak{L}$. St. oder 2,08 ßroc. entridbten follen, ferner wurbe bic Steuer nud auf Jrland aubgebefnt. Nnit) Demfelben (Seies follte bie Steuer nur für bie Sahre 1853/54 und $1854 / 55$ ben Fus bon 7 \$. behalten, in ben 2 folgencen follte Derjelbe auf 6 , bon 1857 an 3 Jahre lang auf 5 \$. ermäBigt merden, wobei

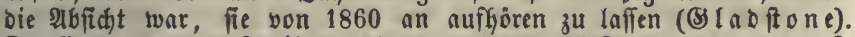
Der (Srtrag bom 5. शtpril 1853/54 twar 6.991 $149 \mathfrak{l}$., woyon $552007 \mathfrak{l}$.

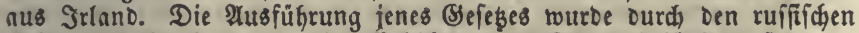
Rrieg unterbrodjen, Der eine Erfojolyng oer Stanteinfünfte erforberte.

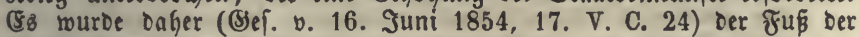
(Sinfommensfetuer verdoppelt, und am 5. S) ni 1855 (18. Vict. Cap. 20) famen now 2 \$. Ginzu, alío im (Sanzen 16 \$3. vom $\mathfrak{Q} .=6 \%$ \$roc., bei Den Einfünften von $100-150$ \&. $11^{3} / 7$ \$., wobutch ber Ertrag von $1855 / 56$ auf $15 \cdot 402901$ \&., yon $1856 / 57$ auf $16 \cdot 384494$ \&. ftieg.

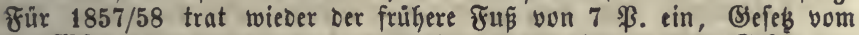
21. Wärz $1857=20$. V. C. 6 , unb von $1858 / 59$ an Dem Seießs von 1853 gemả

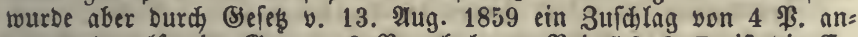
geordnet, alfo im Sanzen 9 S. exhoben. Bei Sched. B. ift bie Er= hỏhung in Englano nur $2 \frac{1}{2}$, in Shottlano und Jrlano nur $1 \frac{1}{2} \$$. Einfuinfte von 100-150 \&. geben fortwährend mur 11/2 \$. Für 1860 wurben $10 \Re$., für (sinfünfte von $100-150$ \&. $7 \mathfrak{\$}$. befdlofien (23. V. C. 14), für 1861 und 18629 und 6 \$. (24. V. C. ... 25. V. C. 22), für 1863 von allen Einfiinften 7 ß., (S)efes v. 26 . V. C. 22 -8. Suni 1863. Befteuerte Einfünte in Siroßßbritanien 1860/61:

$$
\begin{aligned}
\text { unter Schedule A } 138 \cdot 191087 \text { \&. } \\
\text { B } 16.554930 " \\
\text { C } 29.083200 " \text { " } \\
\text { D } 93.689881 " \text { " } \\
\text { E } 20.071240 \text { " } \\
\hline 298.304987 \text { I., }
\end{aligned}
$$

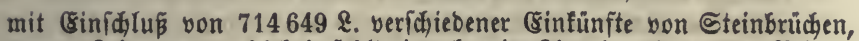
fines, Beitrenten. Shiebei fehlt jeood Die Sinseinnahme von \$ribat: fdulonern, weldie nicht ermittelt werben fann. 1861/2 war Das Esin=

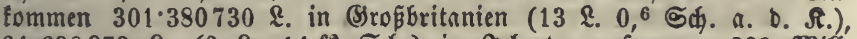

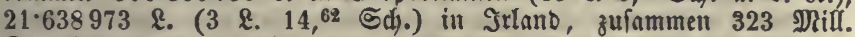
Der Ertrag von $1857 / 58$ twar 11.767300 , von $1858 / 596.812232 \&$. $1861 / 210^{\circ} 990103$ \&. im Ealenderjahre 186211.104000 \&. - Ueber

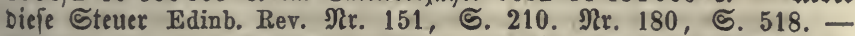

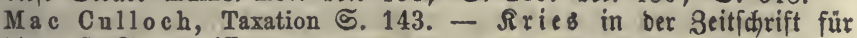
bie gef. Stantsmifi. X, 197, 497. - Hubbard, How should an income tax be levied? 1852.

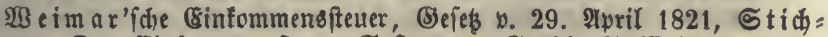

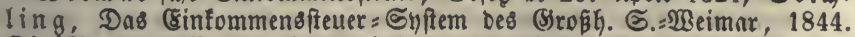

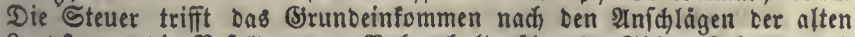

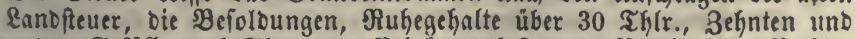

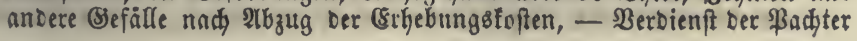


(zu 1/. Des ßadjtzinfes angenommen, - frei bis 50 Thlr. ßacht=

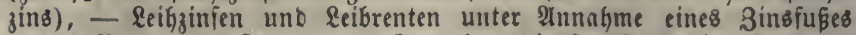
yon 3 Proc., - pobann ben (Setwerbogerbienft. Fud fier ift haupt= fählid Die gleiche Behanolung hỏd it ungleidjer sintünfte auffalleno.

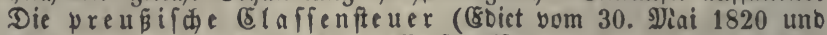
fpátere) wurbe (fowie bie altere ßerionalfeuer feit 1811) in allen Dörfern und Denjenigen Stäbten erfoben, weldye Der Siahl = und Shlachtaccife nicht unterworfen waren, fo bas beibe (S)attungen yon Steuern einanber ergänzen uno annäherno im (S)leidjgetwidate itekgen

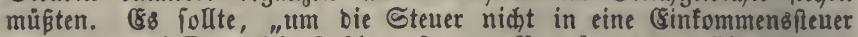

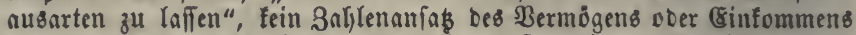
ausgefpredsen werben, fonbern nur eine auf wenigen und leidst erfenn= baren Merfmalen berubienbe Abfufung ftattinben; gleidjwohl machte

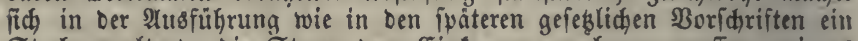
Streben gelteno, Die Steuer Dem Sinfommen mefr anzupaffen, wie es

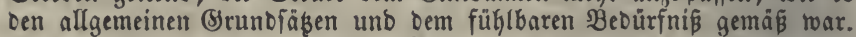
(\$\$ wurben anfangs 5, fpater $(\mathfrak{B}$. v. 5. Sept. 1821) 4 (Slaffen mit 12 Stufen angeorbut, in benen fowohl Familien als einzeln \&ebende

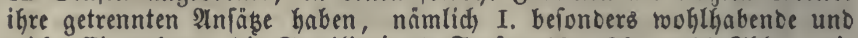
reiche Einwohner; Die Familie in 3 Stufen $48-96-144$ Thlr. , Die

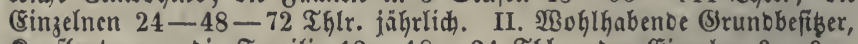
Saufleute 26 ; Die Familie $12-18-24$ Thlt., Der Einzelne $6-9-$ 12 Thlr. III. Seringere Bürger uno Bauern, cie $\mathfrak{g a u b h a l t u n g ~} 4$ 6-8 Thlr., Der Einzelne $2-3-4 \mathfrak{T h l t}$. IV. Taglögner, Sefinbe. Sier zahlte in ber unterfen Stufe jebe ßerion zwifhen 16 unb 60 Jahren jǘgrlich $1 / 2$ Thlr., aber Gödftens brei ßerionen in einer Familie; in ben beiden folgenden Stufen bie \$̧außhaltung $2-3$ Thlr., ber Gin= zelne $1-1 \frac{1}{2}$ Thlr. Die शufnakme und Shäbung gefdah bon Den (5) emeindevorftänen unter \&eitung Der \&anbräthe. Sinnholo, Slaffen= feuerverfafiung Des preus. Staats, \&iegnís 1831, 40. - Şaniemann ธ. 133. Wुoffmann, Die Lefre von ben Śteuern ङ. 152. Bei einer foldyen ungefähren Schäbung nad) Den offentunbigen Bermogens: umftanden find viele Unridgtigfeiten unvermeiolid, bie nur veniger

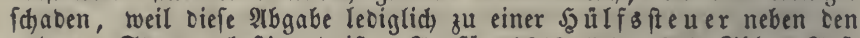
anberen Steutern beftimmt iff. 2. für 1849 7.571652 Thlt. शuf= hebung ber biskerigen Befretungen, 7. Dec. 1849. - Auf cem ver= einigten Ranbtage von 1847 wurbe nađ längeren Berbanolungen ber

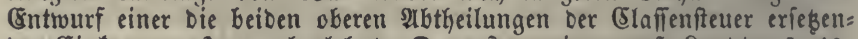
ben (Sinfommensfteuer abgelehnt. Der erfte verein. preuß́. Lanotag 1, 40, II, $1576-1694$. - Im S. 1851 (Sefes v. 1. Maa) fum jeced) cine

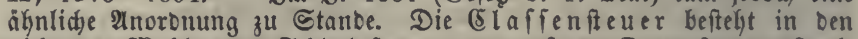

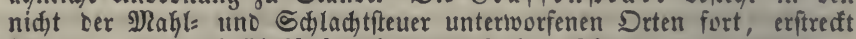
fid aber nur auf Crinfünte bis 1000 Thlr. Sie hat 3 Şauptclaffen, weldhe ungefägr ben biskerigen (blafien II-IV entfpreduen uno in cenen bie Jahresfteuer 1) $2-3$ Thlr. , 2) $4-10$ Thlr., 3) $12-24$ Thlr. für Die Familie if. Der lestgenannte Betrag macht 2,4 \$roc. Des höditen Einfommens von 1000 Thlr. aนs. Die Einfdäbung gefdieft

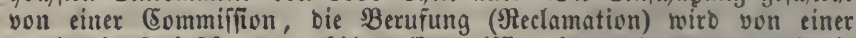
Durch bie Rreisfänbe gewählten (5ommififion begutadatet und curdi) bie Bezirfsregierung entfdieben. - Şokgere Ginfünte in allen Drten ofne Unterfobied unterliegen ber \& infommensfte uer, weldhe 3 \$roc. bes Eintommens betragen foll und 30 Gtufen von $30-600$ Thlr. jährlids entyålt. Gine Commiffion für jeoen lanbräthlidjen fircis ober jebe eximirte Stabt beftimmt auf Boridalag Des Eanbratfs ober (5ommiffars Die शnfä̉e nach vorgångiger \$rüfung, toozu fie auch Unterpfanosbücher und Iften ber freivilligen (S)erifhtsbarfeit nadjeken Darf. In makl=

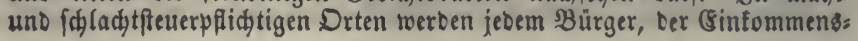


fieuer zu entridgten hat, 20 Thlr. an Derfelben abgeredinet. Raften und Edulozinien werben abgezogen. Fohertrag

$$
\text { भ. } 1859
$$

भ. 1860

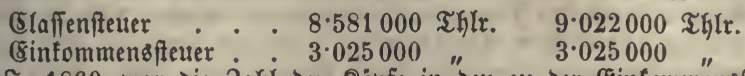

Im $\Im$. 1860 war Die 3 ahji ber Ropfe in "bell zu ber Sinfommensfteuer beigezogenen Familien 239190 , alio treffen auf ben Ropf 12,65 ThIr.,

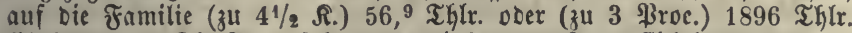
Einfommen. Die Angeförigen ber einfommenzfteuerpflidtigen Familien fino 1,35 \$roc. Der Einwohner, und zwar 0,8. \$roc. in \$ofen, 1 in Sreuken, 1,45 in Der Rkeinprovinz, 1,57 \$roc. in Sachfen. - Die clallenfteuerpflichtigen Drte Gatten 15.657230 (Sinwohner, oer mittlere Stetterbetrag war 0,57 ThIr. auf Den Ropf, in Boien 0,53 , Der Sikein= provinz 0,6 , Sadjen 0,66 Thlr. Die Slafl= und Sdhlachtifeuer betrug im 2. 18602.677000 ober 1, 32 Thlt. auf Den fopf. Bon Den Ein= fommensefteuerpffichtigen wohnen 45 Sroc. (nach Der Ropizahl ber Fami= lien) in bell 83 mahl= uno idhlachtfeuerpflidftigen Stäbten, obgleid biefe nur $1 / 9$ Der ganzen Bolfemenge enthalten. Es trägt oaher im D. Der Ropf ber Einwohner

in Den 83 Stäbten

im nibrigen \&ande

Ëinfommensfteuer . . $0,67 \mathfrak{T h} \mathfrak{l}$.

गahl= u. Shlachtiteuer 1,32"

$$
\text { zujammen 1,99 Thlr. }
$$

Einfommensfteuer . 0,16 $\mathfrak{T} \mathfrak{h}$ r. Elafienfteuer . . 0, 0, 57

zuammen $0,{ }^{73} \mathfrak{T h} / \mathrm{r}$.

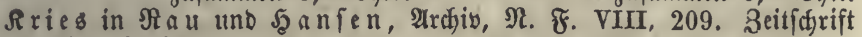
für bie gei. Stantsin. XI, 359. - de Parieu, Hist. S. 168.

In Sdy warzburg= Sonbershaufen beftelyt feit 1853 cine Ein= fommensftetter nach Dem Borbilo ber preúf. Blaffenfteuer, mit 5 Elaffen, Deren unterfte 8-40 Sgr., Die oberfte 60-180 $\mathfrak{T h}$ ir. entrichtet. भud Dloenburg hat eine ähnlidye Steuer.

$\mathfrak{B}$ ayern hatte nach bem (Sefeş v. 4. Suni 1848 eine allgemeine (Sinfommensffeuer, Die burch (S)efę v. 11. Juli 1850 verändert wurbe. Bon jebem Ginfummen blieben 200 fi. frei. Ertrag 1852/53 854244 fi. Diefe Steuter hörte Durch Das (Scieb v. 31. Mai 1856 auf, Denn Die

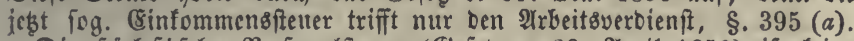

Die fäblifdye Berfonaliteuer (Sefes v. 23. April 1850) ift feine allgemeine Einfommensffeuer, Denu fie trifit nur Beamte, Selehrte, sünifler, Eapitaliften uno anbere \$erjonen, bie weber zur (Śruno= nod zur Betwerbftetter gehören.

Die Berionaliteuer in Şannover (1834 eingefülyt, neues Seießs vom

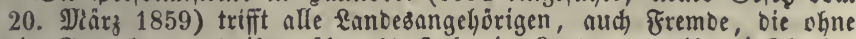
cin Semerbe 3 treiben liber $1 / 2$ Jahr im Lanbe vertweilen. Sie hat 12 Elaffen, in benen ein werkeiratheter $M_{\text {lann }} 1 \frac{1}{5}-58$, cin Iebiger

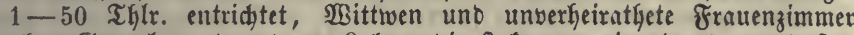
shne Setwerbe und anberen Rohnverbienft fummen in eine ber unterfien

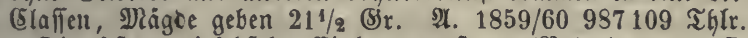

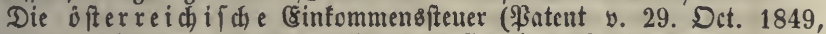
B. ฟ. 11. Samuar 1850) Betrifft ebenfalls nicht afle Claffen bon (sin finften und wirb in $\mathfrak{B}$ ezug auf (Srund = unb Saubiente burch eine

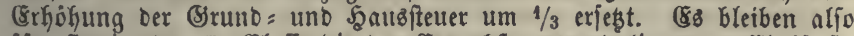
fur fie in Der $I$. CElaffe bie ber Erwerbfteuer unterliegenden Esinfunfte

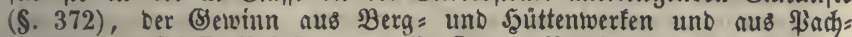
tungen, Ir. SInffe Befoloungen, Wenftonen, Beroienft Der Sd)rifteftler,

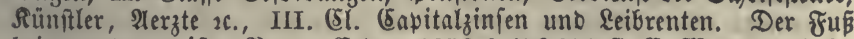
bei I und III ift 5 \$roc. (8rtrag 18568.458830 ff. (5. $\Re$ I $=13 \frac{1}{2} \mathrm{fr}$. auf Dell Sioџf. 2 . $1863 / 647 \cdot 965000$ f. ordinarium, $1 / 5$ außerorbent= lider 3ufblag 1.593000 fi., ferner 6.165890 f. Struer von ben 


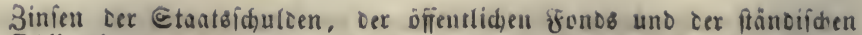
- Dbligationen, zufamment 15.723890 fi. j. 28 . - Nach Iem (S) feßz= entiourf von 1863 foll bie bisferige (Sinfommensftener als bauernoe

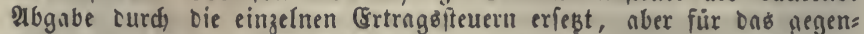

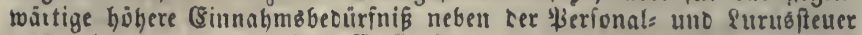
aud eine auperorbentlidie Glaffeniteuer ven jebrm (Sinfommen von 600 f. an eingeführt werien. (5) follte ein (sinfsmmen von $600-$ 1000 fi. зu 3 , von $1-3000$ fi. zu 5 , von $3-6000$ fi. zu 6 , vou $6-8000$ fi. zu 8 3ehnteln, von 8000 fi. an madh feiner ganzen Strojese angeldilagell weicen.

Soburg unD (S) otha haben feit 1850 eine Einfommensftetuer, Das

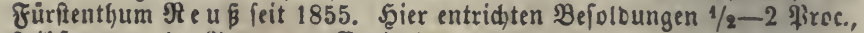
Seikfummen $1 / 6$ झrec. Les Envitales.

Die Einfommenbfteuer in $\mathfrak{B}$ remen (Befeßs 7. Nlai 1849, 24. Juni 1850) beträgt 1 ßroc., bei (Sinnahmen von

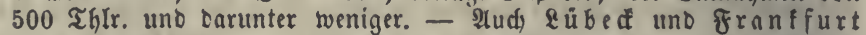

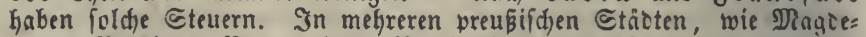
burg, Breslau, Branbenburg if bie Einfommensfleuer als fäbtifdje uninlage eingeführt.

Die efjemalige $b$ abifde Ertwerb= uno Bermogensfteuer (\$atent und Beroronung Ð. 31. 2ug. 1808, aufgeh. 1813) traf Das "reine (Sin= fommen" in bem Sinne, oas bie \&aften, Edulozinfen, 3ehnten u. ogl., nidht aber Unterbaltofoften abgezogen murben (\$. 5), Dech rurben Apanagien, Befoloungen uno senfionen nur in Galbem Betrage an= geíst. Der Fuß mar fteigeno, von $1 / 2$ \$roc. (bei $301-600$ fi.) bis 6 ßroc. (über 150000 fi.).

(c) Dehrere Beifpiele fino fajon in (b) angeführt. Şieher gefjort ferner die fog. Steuer vom bemeglichen Bermogen, §. $377(a)$. - In Franfreich war am 23. 2lug. 1848 von Dem finanzminifter (S) o u $b$ as a u $x$ eine Eteuer

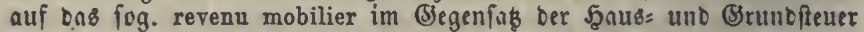
vorgefalagen worben, Der bie Capitalrenten, Die Bjetwerfe, Der Santel, Die Befoloungen, Daв Einfommen Der 2lerzte. Acuccaten $2 c$. unterliegen follten. Bericht von $\$$ arieu, abgebrudt in beffelt Traité V, 309. Der Niegierungsentwurf wollte einen Ertrag von 60 Dlill., Dié Com= miffion empfahl Diefe \&uflage nโs Duvtitåtgiteuer im ₹uß bon 3 ßroc. Der Esinfünfte einzufübren. Der Sorfd)lag wurce abgelehnt. Siernuf empfalys $\$$ affy am 9. 2uguit 1849 eine allgemeine (Sinfommensfteuer

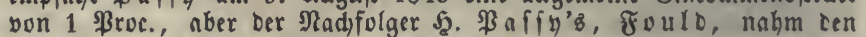
Borídilng zurúc; de Parieu, Traité II, 62. - (Sod) ut in Rev. des 2 mondes, 1849, I, 115. - शud Ler niecterläntifde Entwurf von 1849 (5 \$roc. Der Fenten, 1-5 \$roc. Der Befoloungerl, 20-80 Eent. 3uidlag zu ber \$atentfteuer) twurbe nid)t ausigeführt. He uschling, De l'impôt sur le revenu, Brux. 1851. - Das fdùn angeführte Eteuer:

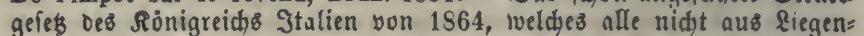

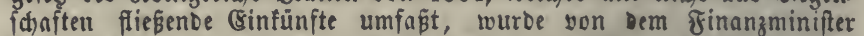
Sella 1862 vorgelegt, von feinem Radjfolger $\mathfrak{M}$ inglyetti bei ben Berhanolungen Der Rammern 1863 vertheidigt uno im $\mathfrak{3} .1864$ an= genommet. Die jübuliden थngaben Der Steuerpflidtigen Dienen zur (Srunblage, werben aber einer firüfung unterworfen. Nach cem Regic: gierungbentwurfe follte tie Steuer 55 Ilifl. Rire einbringen uno einft= tweilen auf ztwei Jahre eingefübrt werben, nach ten Rammerbefhllüfen fâflt bie leb̧tere Beptimmung Kintweg, ber Ertrag wiro auf 30 গlill. gefest. Diefe Summe wird auf Die \$̇rovinzen und in benfelben wieder auf bie Drte von 6000 Einwo. folvie auf Die Berbande mehreerer (S)

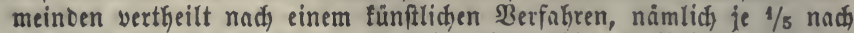
Der (S)runt: unb Saaubfeuer, ber Eintooknerzahl, ber Befoloungen aus 
ber Gtaatzcaffe uno ber Divibenben Der Actiengefellfidaften, ferner ie $1 / 10$ nad) Dem 3ollertrage, Dem Boftertrage, Dem Ertrage Des enregistrement und Stempels. Plebano et Musso S. 272. 534. de Parieu V, 292.

\section{§. $400 \mathrm{a}$.}

3u ber guten (Simrid)tung einer alz Ergänzung ber anberen Sd)ab̧ungen bienenden (sinfommentifteuer gehört hauptjächlid) Folgenbes:

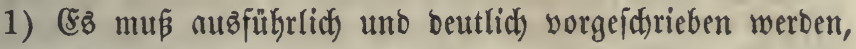
wie jebe Art son fteuerbarem (Einfommen zu bered)nen und was als Raften = unb Roftenbetrag abzuziehen fei. Der 2luborud "reines Einfommen" wirb in verfhiebenem Sinne gebraudst unt ift baker nidht genügeno, um ofye näkere Beftimmung bas zu befteuternbe Einfommen zu bezeidjnen. In jebem Falle müfien wenigitens bie mit dem $\mathfrak{B}$ etriebe eines Benerbez, einer Rohnarbeit ober ber Benußzung einez werbenten Bermögents = theiles verbunbenen 2lubagaben, z. B. Reallaften, Erhaltungż=

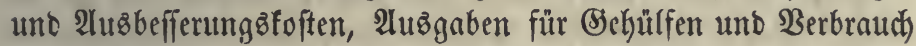
von Stoffen u. bgl. von bem Ertrage abgeredfnet werben, um das Einfommen zu finben.

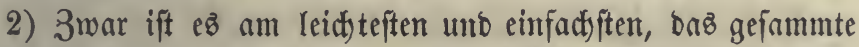

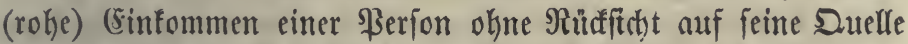
zur Sirumblage ber Befteuerung zu nefmen, wie bieps auth in ben meiften Sefeben über biefe Steuer geidefyen ift, alfein bieß

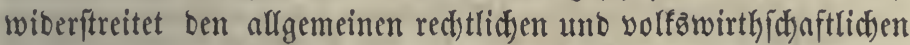
(Srunbjäzen, §. 258. 259. Der burch 2rbeit errungene $\mathfrak{B e r}=$ bienft wiro burch) ben 2ufwand bes Unterhaltżbedarfes bebingt,

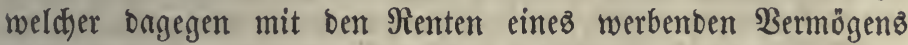
nidft in biejem nothwentigen 3 ufammenthange fteht. Daß eine gewiffe Csinnahme von Brund = oder 3inbrente eine gröpere Steuterähigfeit gebe alsె gleicher $\mathfrak{B}$ etrag von Eintommen cines (Sewerbsimannes, Befolbeten $2 c$, ift in ber Anlegung ber ein= zelnen Schabungen längft und allgemein anerfonnt worben unb biefer Unterjached follte aud bei ber alfgemeinen Einfommens: fteuer ourd) Feftfeb̧ung eincs ungleichen Fuß̧ez für beibe Şmupt= gattungen von (Sinfunften berủdfitdtigt werben, vgl. \$. 391.

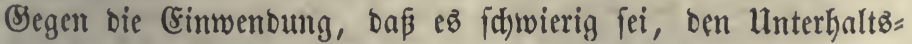
bebarf icoç Betwerbsimannes uno \&oknarbeiters zu ermitteln, 
ift zu erwibern: es ift bock cin ungefährer Ueberfd)lag bes zum

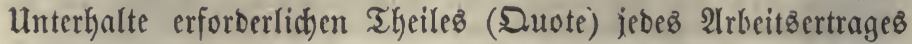
möglid) und die verfachebenen Sefeze liber bie Steucr von bem

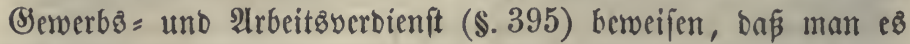
alz notfwendig und attęfülurbar erad)tet hat, burdy einen mit Der (Srö̈ße Des ganzen (rohen) Eintommens fteigenden Fuß

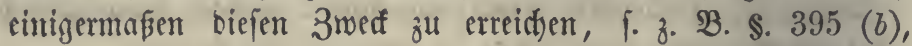
uno eine foldye Einridtung, wenn fie gleid) nidyt in allen ein= zelnen Fällen zutreffen fann, ift immer beffer alz bie gleidje

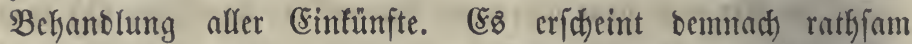

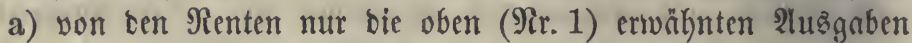

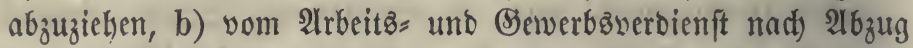
ber nämlichen Roften unb Raften eine fteigenbe Dutote alb Steuer zu nehmen, fo baßj ber in jebem (Sinfommen biejer 2rrt anzu= nefmente reine Ertrag wie eine Rente von gleidfer Eröße befandelt wiro $(a)$.

3) Csinfünfte unter einem getwiffen nieorigen Betrage von Diefer Steuer freizulaffen, ift nid)t alfein eine Erleidterung bes

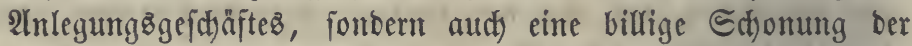

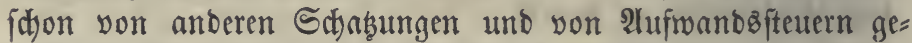
troffenen Bürger von niebriger Steuerfäbigfeit $(b)$.

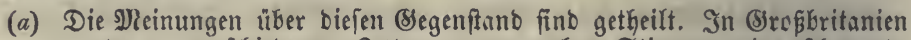
murbe zu berfjiebenen Beiten von manden Etimmen eine fdjonende Behandlung Des yon ber Lebenzonuer beoingten Einfommens verlangt.

Dis raeli als Sđabcanzler fhlug vor (Itnterfaus, 3. Dec. 1852), bei Dem vererblidsen (permanent) Einfommen, D. G. Den Sienten, 7, bei ben vergängliçen (precarious) $5 \frac{1}{4}$ \$s. vom \&. St. zu erfeben, alpo bei

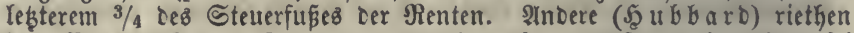
$2 / 3, \Re$ D e b u if $1 / 2$. Dagegen wurbe bemerft, Das (Srunbeigentfum jei vollftandiger belegt als die Siewerbe, es bezahle fohon mehr alz den

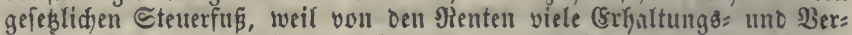
waltungsfoften, Nachläffe 2c., zufammen gegen 16 \$roc. abgeken, folglid̆ Die Steuter eigentlid) 9 fatt 7 \$. yon $100 \&$. ausmadie (Gladstone a. a. D. S. 21), ber Arbeitzuverbienf fei ben \&eibrenten gleid zu adyten (ebo. S. 28, nach obigen Gäben nicht ridhtig), audh ift es anetfannt, baß́ bie Schedule D am ungenaueften ift. - Nan forlte jerod ben

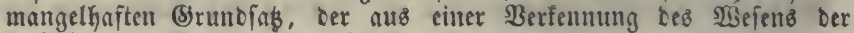
veridiebenen (sinfommenszmeige herrifget, nidjt Durd) bie unvollftinbige 2ưfïfrutg entichulbigen! Daß̧ bie fürzere Dauer nidyt oer wahre

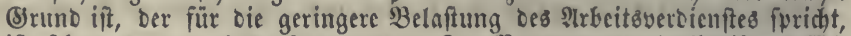
ift fibon \$. 391 bemerft worbelt. Im Bortrage bes italienifden SRi= nifters Sella (bei de Parieu, V, 264) wiro oie Shwierigfeit her=

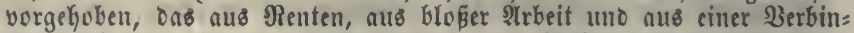

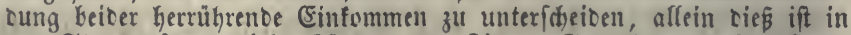
Den Steuergeieben vieler Länoer, wo Sins:, Sietwerb = und Lohnfeuer getrennt fiul, längft ausgeführt. - Weun ein Ranogut von 100 Dorgen 


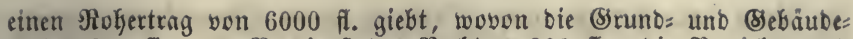
rente 1600 f., Der Berdienft oes \$achters 900 f., Die Betriebs: und (5ihaltungsifoften 2500 fi. betrngen, fo ift als fteuerbares (reines) (sin= fommen die Rente und etwa $1 / 6-1 / 5$ Des Badtuerbienftes anzujehen, indem $4 / 5-5 / 6$ bes lekgteren zul ben unvermeiolichen Unterhaltafoften

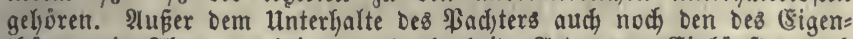

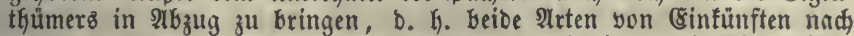
gleichem Fußje zul belegen, wåre offenbar unrichtig, weil feine wirth

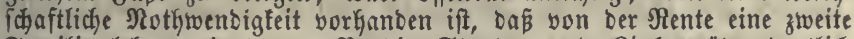
Familie lebe, wie Das z. $\mathfrak{B}$. Die Stantz= und Rirchengüter Deutlid

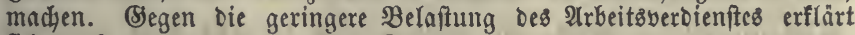
fich auch de Parie u, Hist. F. 330 unb Traité II, 77 wegelt Der

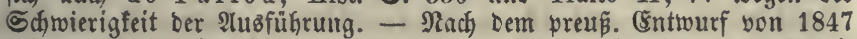
follte Das "fundirte Einfoinmen" 3 \$roc., Das "unfundirte", aub 2rbbeit

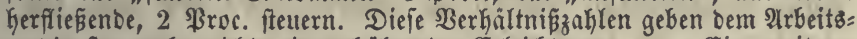
berdienfte noch uicht bie gebührenbe Erreichterung. - Ein tociteres Beifpiel giebt die nuperorbentliche Einfommensfteuer in Sadjen $(\mathfrak{B}$. v.

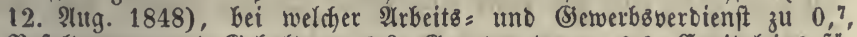
Befoloungen uno (Sehalte zu 0,8 , (Sruncrenten zu 0,9 , Eapitalzing für voll angeidjlagen wurbe. - Stalienif́des Sejes von 1864 mach ben Beíhlüfien Der Rammern, §. 24: Fortwaifrende Einfünfte, z. B. 3ins aแถ Darleifyen, werben für voll berechnet, - vorübergefjende (tempo-

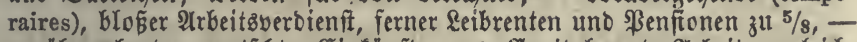
borübergekenbe gemifhte Einfünfte aus (Eapital unb Arbeit zugleid, (๖. K. Setwerbsyerbienft) zu $6 / 8$. - Sefes Des Cantons Neuenburg v. 30. Närz 1860 bei de Parieu V, 391: In. Der Beftelerung Des Bermógens un Dagegen Des (S) werbs: und 2rbeitsertrages foll fets bas Berfältniß̄ yon 1 per mille (aljo bei 4 গroc. Fente $=21 / 2$ \$roc. berfelben) und 1 \$roc. beobadjtet werben. - Heber ben Unterhaltøabzug f. \$. 391 (c).

(b) Betipiele fino bei bell einzelnen Shasungen angegeben. Sn (Sroß $\beta=$ britanien find Einfunfte unter 100 \&. St. in Mingoeburg unter 300 ThIt. frei, in Bayern waren nad Dem Séfeş yon 1848 Sinfunfte bis 200 ff. und in jedem Falle bie eriten 200 ff. frei.

\section{S. $400 \mathrm{~b}$.}

(Ein Steigen des Steuerfües mit der Şöhe bes fteuerbaren Cinfommens ift bei bicjer Steter theils yorgeffila= gen, theils wirflid) angeorbnet worben. Alggefehen von Brünben einer verwerflidjen, bem Steuerwejen fremben Staatafunft $(b)$ fann für biefe fog. progreffive Steuer bie Errwägung geltento gemad)t werben, baß̄, ie größer baz Csinfommen einer \$erion ift, ein befto gröserer Theil befferben für leidyt entbefyrliche, bem Rurus angelyörente $\mathfrak{B}$ erwentungen ausgegeben wirb uno Dafer, wenn man baz Einfommen in cine $2 \mathfrak{n} z$ afjl gleidjer Summen zerlegt, ber concrete $\mathfrak{B e r t h}$ ber leşten, entbehrlidffen Summe befto niebriger ift, ie mekr foldje Summen vorhanben

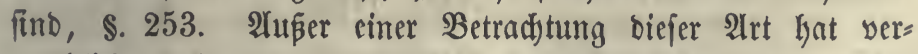
mutflid) aud) bie Şinfidft auf bas Arbeitseinfommen, bei 
weldyem allerbings das Steigen bes Steucrußes ganz an= gemefien ift (\$. 391), zu Der (Smpfehlung riner progrefifiten Steuer im 2tugemeinen beigetragen. Begen biejelbe fprect)en aber folgente jehr erheblidye Strünoe: 1) Die 2lbnalyme bes concreten $\mathfrak{B}$ erthez ber Theilfummen findet nur bei bem 2 luf wande für perfönlidye 3wede in vollem Manße ftatt, nidft bei ber Eriparung neuer Capitale ober bei ber Berwendung fïr gemeinnủbsige 3wede, fie bängt aud) zu fehr von inbivibuellen Umitüuben ab uno if zu ungleicförmig, um bei ber Befteues rung berüafifdtigt werben zu fönnen. 2) (ङs läßst fict) feine 3ahlenregel für bie Fortfdyreitung bes Steuerfuß̧es als bie allein ridtige ober als bie befte angeben. Daker würbe eine gewiffie SBilftür herrid)en unb man fönnte leidt)t zu einer fortid)reitung fortgeriffen werten, bie fid) in ifren Folgen alz iđ äblich erwiefe. 3) Cine fortgefeste Steigernng führt zu bem \$uncte, wo eine weitere Bermel)rung bes (Sinfommens burd) bie Steuer ganz aufgezehrt wirb, พละ ganz wiberfinnig wäre. Soll aber, um bieß zu verhindern, bie Steigerung bei einer genviffen Şöhe desె (Sinfommens aufbören, to ift $e$ unbillig, bei niebrigeren $\mathfrak{B} e=$ trägen beffelben bie Suote nod) zunehmen zu laijen. 4) Rod) weit unter ienem \$uncte wirb Durd) ben zunchmenten Steuer= fuß Berjuctung hervorgerufen, Die wahre (Sröße bes (sinfommens zu verkeimlicten ober bie Steuer zu ungehen (c). 5) Wäre bie Steigerung überbaupt zwecfmäßig, fo müßte fie im ganzen Sd)aķungęwejen angewendet und baher aud in ber (Sruno=, Şaub =, Sewerbfteuer 2 . eingefülyrt werben. Dann würbe fie aber wegen ber grofien Raft für $\mathfrak{B}$ ohlthabende uto ber mit ber Berwaltung eines ausigebehnten Befizes verbunbenen Sctwierigs

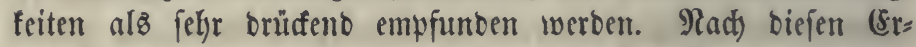
wägungen erfdyeint bie allgemeine progrefifive Steuer nidft als empfehlensiwerth.

(a) Sdjon in ber alten florentinifion Einfummensitener von 1442 forvie in oer holländifdjen yon 1742 , ferner in ber furfüd)fifden von 1742 foun ein fteigender fur vor. Sebstere betug

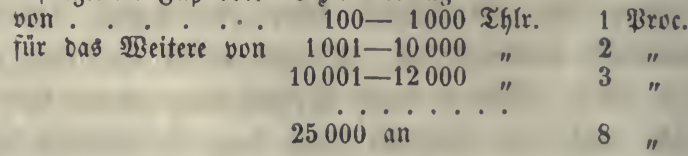


fo ba施. B. cill Esinfommen yon 15000 Thlr. eine Nbgabe von 370 Thli. trug. Subeid a. a. D. S. 11. - de Parieu, Hist. 5. 50. 88. Die Rational= Sonvention genehmigte am 7. Februar

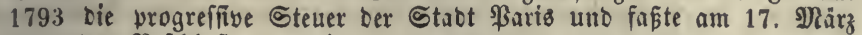

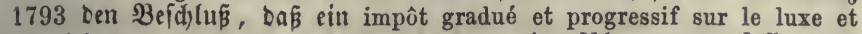
les richesses, tant foncière que mobilière, eingejührt werben folle, twos

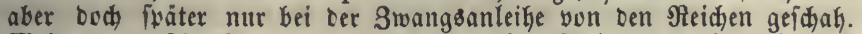

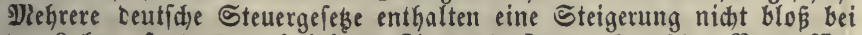

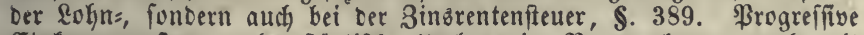
Einfommensfteuer als fäbtif(he Umlage in Branoenburg, aud mit idwadher Steigenung in Röln unD Düffeloorf. - Eintommensifteuer in Bajel = Staot v. 12. Sept. 1840 : von Einfunften bis 3000 Fr. 1 ßroc., vom Diefrbetrage bis 6000 Fr. 2 ßroc., yom weiteren Mehrbetrag 3 ßroc. Demnach geben z. $\mathfrak{B} .10000$ Fr. Einfommen 210 \&r. = 2,1 ßroc.

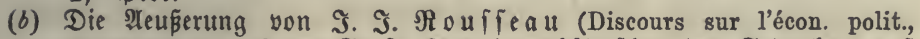

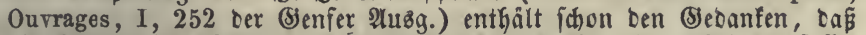

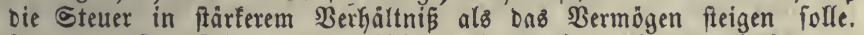
In ber erften 3eit Der framzöfifien Sevolution trieb ber Şaß́ gegen bie Reiden zu Diejem Sorfdalage. In neuerer 3eit fand Derjelbe in

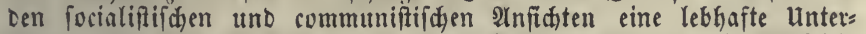

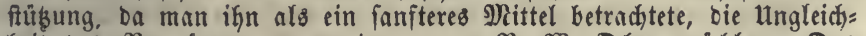

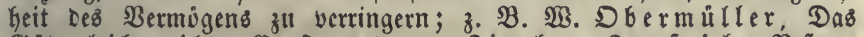

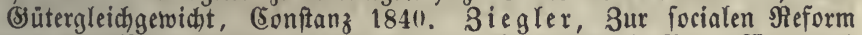

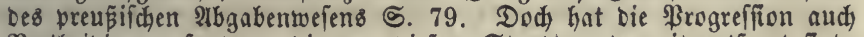
Bertheidiger gefunden, Die von Diefem Stanopuncte weit entfernt fint, 3. B. v. SÉ Segen die progrefiftue Steuer $\mathrm{Mac} \mathrm{Culloch}$, Taxation S. 141. Jollivet, De l'impôt progressif. Paris 1793. - Thierz, Heber baz (Sigenthum, D. v. Dbermayer, 1848, S. 195. - v. Syarre S.59.

(c) Dieß̧ fann auf mefrfadje Weife gefdueken, Jollivet 5.14.

\section{AI Snbegriff ber einzelnen Sđagungen.}

\section{§. 401.}

Wenn in cinem Staate bie fämmtlid)en einzeluen Sdjab̧ungen

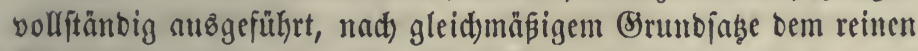
Einfommen angevapt unb mit aller Sorgfalt eingerichtet, wenn fte enblid) unter einanber in ein ridjtige $\mathfrak{B e r b a ̈ l t n i}$ gebrad)t

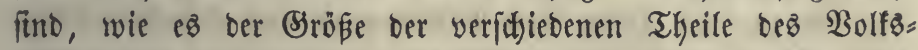
einfommens entipricht $(a)$, fo biloen biefe Steuern ein wohl= gefugtes (5anzes, eine allen Anforberungen entipred)ende $\mathfrak{B}$ efteues rung oer (sinfünfte, uno madben bann eine befonbere (Sinfommens:

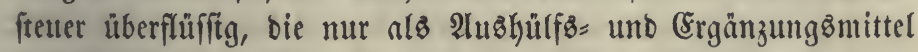
empfeh)(ensitwerth wäre uno yon ibren Mängeln nict)t zu heilent

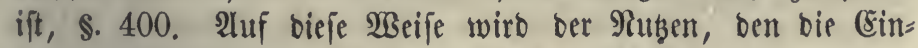
fommenziftetuer leiften fönute, in anberer $\mathfrak{B e i j e ~ b e f f e r ~ z u ~} \mathfrak{W e g e}$

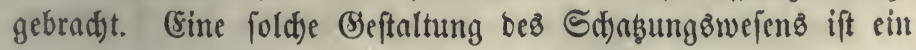
3iel, bem man alfmälig näker zu fommen trachten foll. Die 
volfftünbige (Erreid)ung beffelben gelingt mur lautgfam und müh)= fam, theils weil hiezu viele $\mathfrak{B o r a r b e i t e n ~ u n t ~ E r f a h r u n g e n ~ e r = ~}$ forberlid) fint, theils weil man Itenterungen in ber Befteuerung, weldje immer mandjerlei Störungen im $\mathfrak{B}$ erfeh) berwirfen, nid)t gerne oft vormimmt (\$. 270) unb burd)greifenbe $\mathfrak{B e r b e f f e r u n g e n ~}$

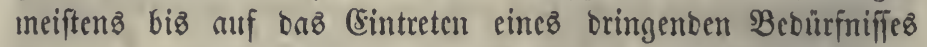

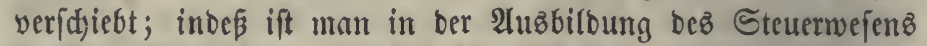
bod) in mand)en Etaaten finon fo weit gefommen, Das man einen

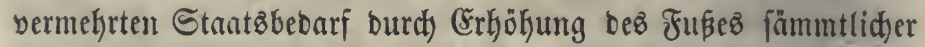
Sd)akzungen becten faum, ohne eine eigene (Sinfommenşteuer nöthig zu haben.

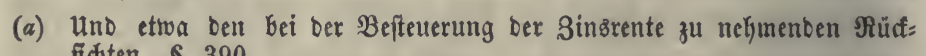
fidsten, \&. 390.

\section{§. $401 \mathrm{a}$.}

Bern man barauf bebad)t ift, burd) bas (STeidjmaás uno bie gute 2 nnlegung ber veridjiebenen Sdjaķungent bent Erfolg zu ' berwirfen, ber fonft von ber Einfonmensfteuter erwartet wirb, fo verbient es nod) befonbers unterfuct)t zu werben, ob bie Berüffictigung ber Sdjulbzinjen, wie fie bei iener Steuer

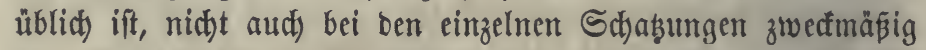
fei. Betradtet man bie Bround = uno Şauðrente ganz für fid (objectiv) ifrem $\mathfrak{B}$ egriffe nad), als Reinertrag ber unbeweglidten Bermögenstheile, io gehören allerbings bie Schulbzinfen, bie Der (Eigenthủmer zu entrid)ten hat, nidft zu ben abzuziehenten Soften, weil fie nidft wie bie Reallaften ein mit bem (Erfd)ei=

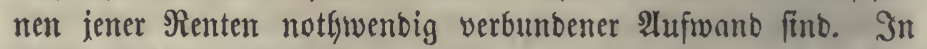
einer Ertragsfteuer als foldser brautchen fie nicht berüđa= fichtigt zu werben. Intubers verbält $e$ fo fich aber, wenn man

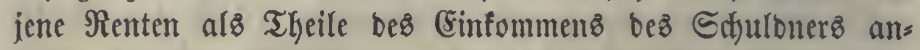
fieft, bem mur ber Heberreft über bie idfuldoigen 3injen verfing= bar und fteuerbar bleibt, aljo auz bem Sefict tspunct ber (Eill= fommens befteuerung, $\$ .262$. Bei tem Seswerbseinfommen ift bieß jogleid) einleudtent, Denn bie in bemfelben begriffene 3insente barf in ber sewwerbfteuer mur foweit, als fe bem Unternehmer nus bem eigenen Theile Dez Enpitales zufälnt, belegt werben, $\$$. 359. Daffelbe gilt yon ber 3inzrentenfteure in bem Falle, wo ein (Eapitalift aud Sdyulden hat, \$. 390.5), und bie nämlicten Grünbe finto aud) auf bie obengenamnten 
Sienten anwentbar. Die Bimfen bilben nitft eine in ber freien Wahl bes Steuterpflid)tigen liegente, fondern eine yon bemfelben

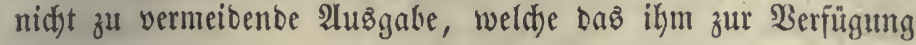
ftehente Einfoumen, folglid) feine Steuerfähigfeit fdymälert. In Den biäherigen Steuergejęzen ift biejer Begenftanto meiftens unberdytet geblieben, เoaz wegen jeiner eigenthümlid)en Sdhwie= rigfeiten leicht ou erflären ift; ie ftärfer aber bie bürgerlidyen Cinfünte von ben Steuern betroffen werben, befto mefyr ifit es

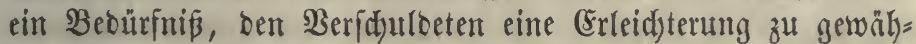
ren $(a)$. Die Beftattung einez 2 bzuges an ben Sdabzungen wegen ber Sdyulden ift feinesెwegesె burd) bą̧ Bepteben einer Binzrrentenfteuer bebingt, benn bie \&age beş Schuloners, in weldyer alfein ber (s)rund zu jenem 2lbuge gefunden werben fann, bleibt biefelbe, ber Binżgläubiger mag beftettert fein ober nicht; allein on, wo biés geidjeht, hat man allerbingz mehr Alufforberung, biejen 2 lbzug zu bewilligen, theils weil erbidtete Sdulbangaben eher entbectt werben, wenn ber Ssläubiger

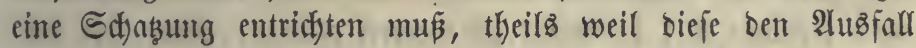
vergütet, ber fonft auz ber Erleichterung ber Berjululoten ent= ftehen würbe, vgl. \$. 383.

(a) Sn Nom war bie Ridhtbeadjtung Der Schulden bei bem tributum eine urfáache you großem Druffe gegen die \$lebejer, währeno die \$atricier yon Der Bemußzung Deß ager publicus fein tributum gaben.

\section{§. $401 \mathrm{~b}$.}

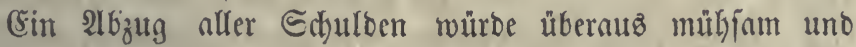

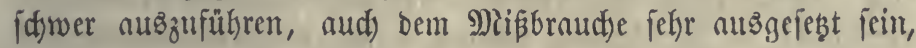

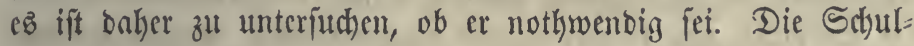
Den ber Hrivatperfonen fönnen in ztwei Sattungen getheilt werten:

1) (Ex we willen gemacht werben. Şieher gefören nicht aflein ânleihen

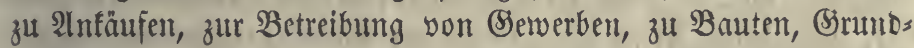

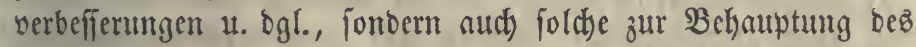

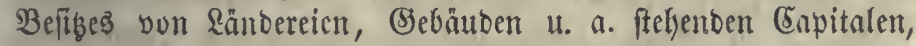
wenn man fonft zur Beftreitung bringender 2 tıtgaben fict) jener Segenftänoe entäuß̃ern müß̄te $(a)$.

2) $\mathfrak{B} e r z e \mathfrak{r} u n g z$ f (Eiumalyne haben und mur als ein Borgriff (Inticipation) auf 


\section{$-200$}

bie (Eimnahmen fünftiger Sahre zu betrad)ten find, mögen nun bie 2lus̊gnben, für weld)e mun borgt, bermeidid) ober noth= wendig fein.

Der $2 f_{z} u g$ ber Binfen von Ectulben ber erften (Sattung ift burd) baz $23 e j e n$ berjelben nad) ben voritehenten Säken ges red)tfertigt. Bei ber zweiten (B)nttung ift biejer 2lozug Durd) Die (Sered)tigfeit nidst geboten, weil ber Etaat fiti) nidft um

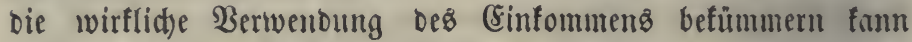

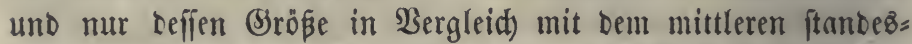
mäßigen Bebarf ber Steuerforberung zu Sirunoe legt, zubem

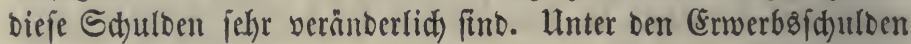
wäre houptfäd)lid) bei benjenigen ber 2lbzug ber Sdjulben nöthig, weldhe bem Sdultbmer ben Sdyein einer größ̈eren Steuer= fähigfeit geben, wie z. B. Infäufe von Riegenichaften ober Neubauten, weld)e alsbald zu ber Şausftetuer angeidhlagen werben. Bei (5runbverbefferungen Dagegen ift biés nid)t ber Fall, weil bie Srunofteueranjdjläge mur nad) langen 3wifdsen= zeiten erneuert und beridstigt zu werben pflegen. Nun läßt fid aber meifters nidft mehr ermitteln, wie ber Sdjuldner bie ge= borgte Summe verwentet hat, bie Unterfochoung obiger zwei Sattungen ift mithin nidjt ausführbar uno man mus über= haupt in biefer 2 ngelegentyeit auf volle Brtmuigfeit verzichten.

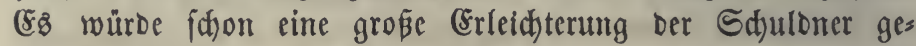
währen und an leidjteften zu veranjblagen fein, wenn man 1) Die fämmtlițen Unterpfands = und 2) die Sduulben ber (sese werbsileute in शfbred)nung bringen ließe, bie Ickstgenannte 2 rt ber Schulben nur injoweit, alz fie regelmäßig verzinft werben

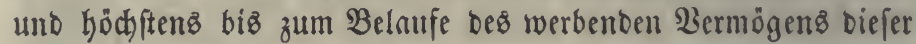
Bewerbsunternefhmer, aud bon ben Sgypothetenidgulden nur biejenigen, meld)e nid)t offenfundig zu Meliorationen verwentet wurben, für bie nod) feine Sirunofteuererböhung ftattgefunden hat, uno beide 2rten mur, wenn bie Släubiger Inlinnber fint, weil Dann nöthigenfallz leidter eine Radjjorid)ung möglid) ift (b). Diejer $2 b_{z} u g$ bürfte mur auf Antrag bes Єd)ulbners, nid)t yon 2 mts

(a) Ein Semerbsmann, Der mit geborgtem (Sapitale wirthidaftet, fann mit

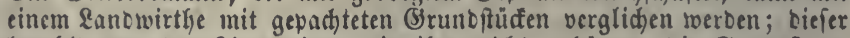

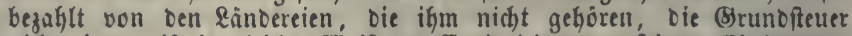
nidht, jenem ift in gleider Weife ber Eapitalzins von feinem Einfommen 
abjuredunen. Esin Şaub = Doer Srunbbefiber, Deffen Fente faft ganz von feinen \&eibzinien verfdlungen wirb, ift offenbar überbürot, wenn er foviel abgeben muś, als ein fduldenfreier yon gleidjem liegen= fhaftsbeitbe.

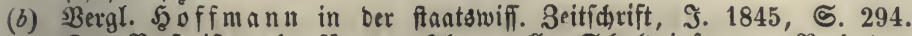
Der Berf. ift mehr für Den Albzug aller Sduuldzinien. - Nad bem

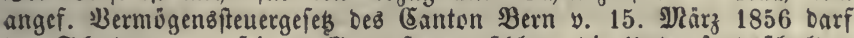
Der Sduloner an feinem (Srunditeueranidalage bie unterpfandsfdulden abzieken, wenn Der (Släubiger im alten Theile Des Cantons wohnt (uno folglid, yon ber Forberung bie (Sapitalfteuer entrichtet). Die cavitalfteter hat hier Den námliduen \&up wie bie Brundfteuer. Sino Die Sinzrenten niebriger befteuert als bie Ssrunbrenten, fo tönnte

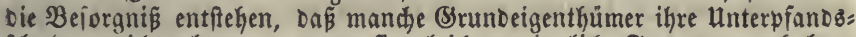
fdulden nidht abtragen, wenn fie gleid) verzinglidje forberungen kaben, um aแs ber Berfđiedenheit Des Steuerfües Nußsen zu ziehen, ba z. B. in Baben Die Brunoftetter $19 / 6000$, Die Capitalfteuer nur 1 p. m. ober

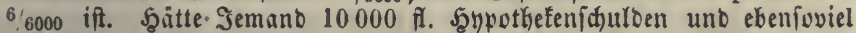

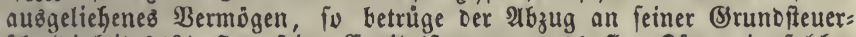
fubuloigfeit $31 \frac{2}{3}$ fi., feine Capitalfteuer nur 10 fi. Säme ein fold)er Runftgriff öfter vor, fo fönnte zur Berhütuma Deffelben gefeslich ver: oronet werben, Daß bie verfteuerten Gapitalforberungen bes Brunbeigenthumers überfteigen. Bei einem geringeren unteridiebe in bem Fupe beiber Steuern ift jenes Berfahren wenig zu befürdten.

\title{
9. $\mathfrak{A} \mathfrak{b} \mathfrak{\mathfrak { a } \text { bุ. }}$ \\ Allgemeine Bermögen̊̊fteuer.
}

\author{
§. 402.
}

Die größte (Einfahbleit uno Bleidförmigfeit in ভteuerwejen hat man bižweilen vermittelft einer S(j)ą̧ung zu erreidjen

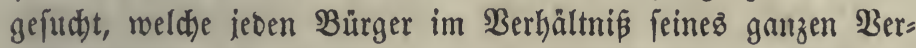
mögens ohne alle Rüffictst auf bie Befdaffenkeit ber Beftano= theile befiflelben treffen follte. Dieje yon megreren neueren Sd)riftftellern (a) wieber empfohlene Bermögenz fteuer fam fd)on im Alterthum vor (b) und war fobann währeno bes

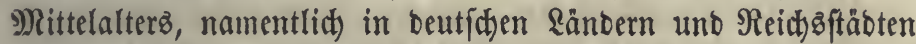

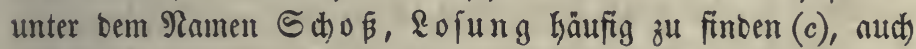
beftefyt fie noch jeģt in einigen Stanten theilz als einzige Schaksung, theils neben anberen $(d)$. In ben vorzüglid burd) Şandel uno (Semerfe reid) geworbenen freien Stäbten uno \&rei= ftaaten fübrte zu biejer Steuer Das füblbare Bebủrfní, Das

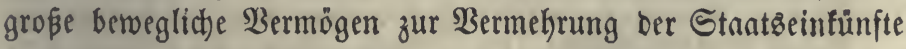
beizuzielyen, bie Unfenntnís anberer mühjaner anzulegender Steuern uno bie in ben Republifen üblidfe Strenge, mit ber 
Die Bürger zur (Erfüllung ilfrer Pflidten gegen die Sejantmtheit angebalten werben. Man hat bie Bermögensftetuer yon wiffen=

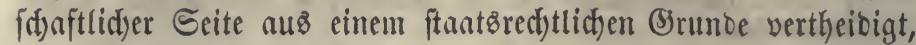
weil man nämlid) bie Steuerpflid)t uno baz $\mathfrak{B}$ efteuerungszed)t aแz bem Sd)uke ableitete, ben ber Stant ben Bürgern gewaihrt,

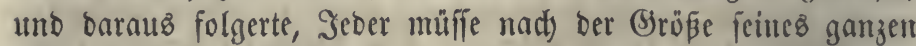

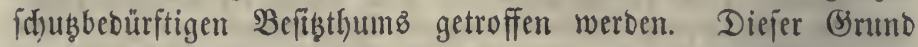

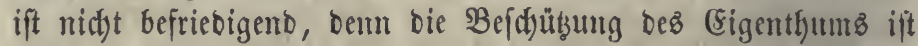
nidft bie einzige Sorundrage ber Beftetterung (\$. 25U), unt bie

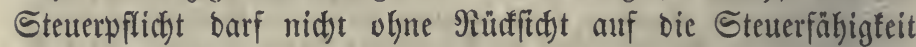
bemeffen werben. Der Staat würoe feiner Beftimmung ent=

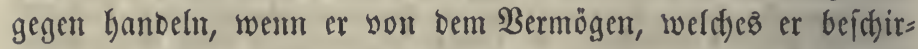
men folf, einen foldyen Steuterbeitrag forberte, ber baffelbe mit Der 3eit aufzegrte. Daz Stnatżredyt fann zwar einige Erfor= Dernifie einez guten Steuerinftems angeben, aber bie Brundjüge

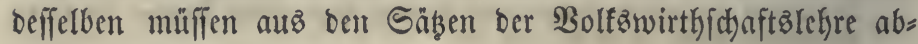
geleitet werben.

(a) $\mathfrak{S a r l}$, Saanbb. I, 515 (ipäter flat fíd) ber $\mathfrak{B e r f a f f e r ~ f u ̈ r ~ e i n e ~ a l l g e m e i n e ~}$

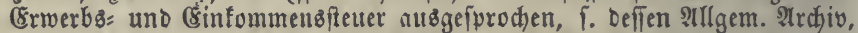

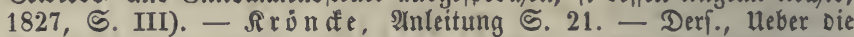
(Bruubjäßze einer geredjten Befteuerung, I. 216h. - Ii a thy, Borfóläge

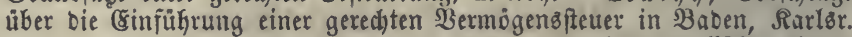
1831. - Pebrer, Histoire financ. II, 342 und mefjere englifje, ebend. Seite 335 genannte 2 luffäąe. - Dagegen 1. 2. Ma Culloch, Taxation S. 114.

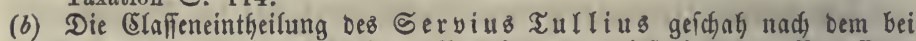

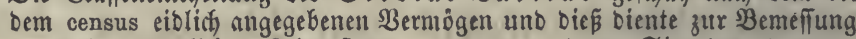
Der auserordentlichen Rriegsffeter, tributum, Deren Eimplum $1 \mathrm{p}$. m.

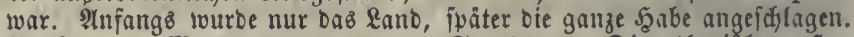
Beder uno Marquarot III, 2. S. 124 . - Die athenilife auBer= orbentlid) Bermógenffteuer (Eisphora), weldhe nur in Beiten eines erhoblen Staatsbedarfes und in einem fuse yon $1-5$ \$roc. erfyoben wurbe, traf ebenfalls in ber frubteren Beit bei ber Solonifden

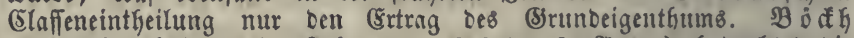
(Stant\&faushaltung ber 2athener I, 643 Der 2. 2tusg.) betradjtet bie bei ben orei oberen (Elaffen angegebenen (Selofummen nid)t als bie Steuer, fondern als Den 2trichlag (Stentercapital, $\tau / \mu \eta \mu \alpha)$, tweldher niebriger war als ber Berfehrswerth. Die Baffen yon 500,300 uno

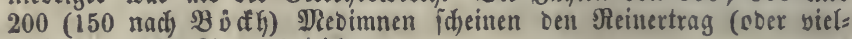
leidjt ben rohen?) zu bejeidnen.

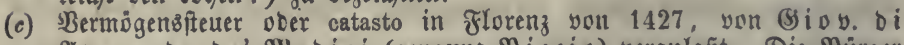
Ayerardo De' Niebici (genaum $B$ iccio) veranlapt. Die Bürger

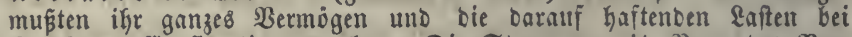
Strafe ber Confiscation angeber. Die Steuer unar $1 / 3$ \$roc. Des $\mathfrak{B}_{\mathrm{er}}$ mogens. Bemerfenswerth ift, dás für jeben Sopf cer Framilie 200 Fiorini abgezogen twutben. Della decima I, 26. - de Parieu, Hist.

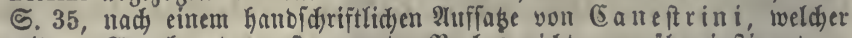
mit Den 2 ngaben bes erftgenanuten Budbes nidit ganz übereinftimmt. - 


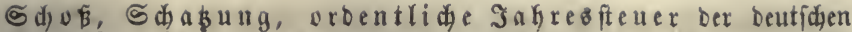

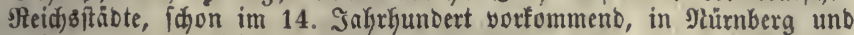
einigen anberen Stioten $\mathfrak{L}$ ofung genannt, Knipschild, De jurib. et privileg. civitatum imperial., 1687, S. 418. Nlad Dem Nürnberger

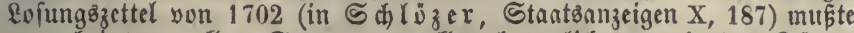
man bei ber wollen Steuer yon allen belweglichen werbenden (sintern uno Borräthen 1 ßroc., mit Freilafiung yon 100 Simra (Setreite und 3 Fuber $23 e i n,-$ yon Şausimiethen, Sienten uno Sinfen aus frembem Eigentfum $1 / 6$, vom Ërtrag eigener \&ändereien uno von ben Einfünften aus Dem Dbereigentfum $1 / 12$ abgeben ("verloofungen"). Bejreit waren Sierrathen, Rleiber, Şausrath. Diefe Meifoung von Bermogens: unt Einfommensifteuern wurbe naw ber eigenen \&ngabe ber 3 ürger ofne anbere Sidjerung als burch Den (Sib erhoben. Bei \&änbereien in eigener Berwaltung wurben Die Baufuften, überall aber bie Sdhulden abgezogen;

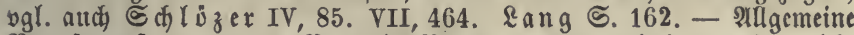
Sermógensfteuer von 5 ßroc. in Bayern, 1395 erfoben, aber nidyt fortbauerno. - Steuterveroronung von $\mathrm{Ulm}$ yon 1709 (aub \&ändereien 1/4 \$roc., auts verliekenem Bermogen 1/2, aub Borräthen, Baarjaaft 2 .

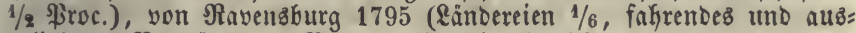
geliehenes Bermögen 1/3 \$roc.). \$2 a rl, Şanbb. II, 29 unb 53. Der gemeine \$fennig (Feit 1411) war eine auperurbentlidue

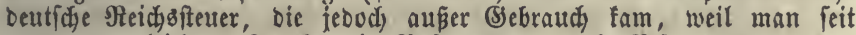
1548 zu gleidjem Stwedfe bie Befteuerung nad Sionermonaten yorzog. Dieje wurben mady einer feftifefenden Matrifel Der eimzelmen

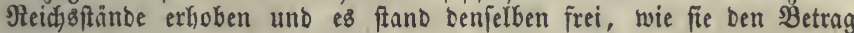
von iffen llnterthanen aufbringen wollten. Der gemeine \$fennig beftand 3. 3. 1542 in $1 / 2$ \$roc. Des Şermögens, was aud in ben vereinigten

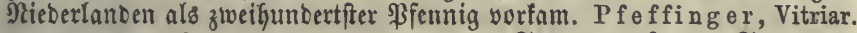
illustrat. III, 384. - Klock, De aerario S.712. - $\mathfrak{L a n g}$ S.182. -

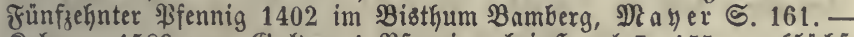

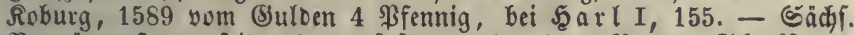
Bermögendfteuer feit 1454, fpäter unter Dem Namen Schodfiteuer, S wimmelfennig I, 390. - Seeff. B. v. 19. Dec. 1576 über bie 2uffringung ber Tüfenfteuer, von 100 fi. 1 Sdyredfenberger nad)

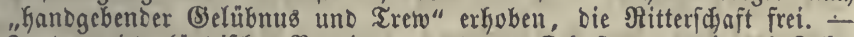

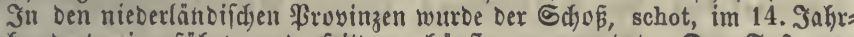
Gunbert eingeführt uno feitbem häufig angementet. Der Fuß twar meiftens $1 / 2$ Sproc., bod wedbfelte er ofter. 1723-34 exhob man yon Sduldbriefen uno Actien $1 \frac{1}{2}$, von Actien ber weftindifaen (Sompagnie, 5ुăufern und 3efinten 1 , von \&ändereien $1 / 2$ ßroc., f. Die für bie hol, ländifhe Finanzgeididyte lehrreidhe Gdyrift: (de Rovère van Breugel) Over de belastingen, het beheer der geldmiddelen ... staande de republick der vereenigte nederlande, Amst. 1837 , S. 86 . - de $\mathrm{P}$ arie u, Hist. a. a. D.

(d) Defrere Sdyeizercantone, 3. PB. Sürich, Seieb v. 21. Suni 1832, 1 per mille Des reinen Bermogens und capitalifirten \&infommens, 1864 11/2 p. m.; (Ertrag 968000 ₹r.). - Sdanfhaufen, 23. Februar 1834, (alle nidht zum (Sewerbabetriebe Dienenden Şauzgeräthid)aften frei, Steuereinfeit 1 p.m.), - (S) larus (getwöhnlich 2 p. m.), - St. (Sallen (1 p. m., Ertrag gegen 60000 fi.), Senf, taxe des gardes, im 16. Salyr= hunbert eingeführt, 1798 aufgehoben, 1816 wieberfergeftellt. Die erften ober einzigen 5000 Fr. fino frei, von 15000 biz 50000 Fr. zahlt man $1 / 2$ per mille, von bem Nebrbetrage 1 p. m. Wुerf = und Şaus=

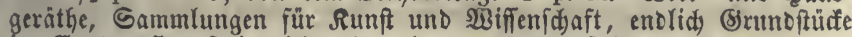
im Eanton find frei, nicht aber bie aแts wärts befeffenen. Ertrag 1831: 166700 f.. (zu $15 \mathrm{fr}$.), $1835-44$ D. 108000 Fr., J. V u y, Essai sur la taxe des gardes, Genève 1838 unt $50 t$ tinger, Staatôh. Der 
fdweiz. Giogen. S. 113. - In einem Theil ber norbamericanifden union befteht bieje Gdyakung als State ober mil tax unb bilbet einen

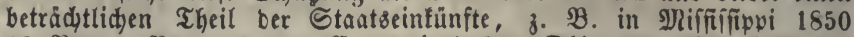
88 \$roc., Bermont 73, Connecticut 60, Dhio 50, Narblano 40,

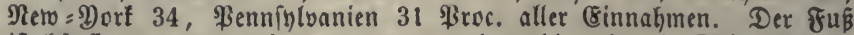
if haufing 1 p. m. (Daker mil taxe), aud wohl mekr; in Dhio 1844 I, 1848.493 p. m. Ealifornia 1/2 ßroc., Indiana $18491 / 4$ Broc., Sllinois 2 p. m. uno ver Ërtrag biejer Eteuer fteigt jäfrlich um 7 ßroc. Rew = श orf crbob $1843-451$ p. m., $1846.470,{ }^{6}$, feit $15480,{ }^{5}$ p. m. Die frenge eioliche Berpflichtung (feit 1851) brad)te eine farfe $\mathfrak{B} e r=$ mefyrung bes (Ertrages zu 2 ege. 1851 war hier bas liegenidaftlid)e Bermógen (real estate) auf 888 , bas betweglidje (personal estate) auf $1961 / 2$ গill. D. angédblagen.

\section{§. 403 .}

Die Bermögensifteuer, wenn fie ifrem Begriffe nad) ftreng Durd)geführt wirb, unterfdeioet fith von Der Befteuerung Der (Sintommenszzweige hauntfäd)lich in folgenoen Stüfen:

1) Sie trifft bas nidt werbende Bermögen gleid) ftarf wie Das werbentoe. (Eine fold)e Belegung ber Senulamittel ift nicht nachlyaltig und jum Theil mit jehr läftigen uno gemeinjäăb=

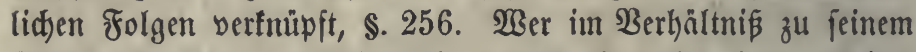
Einfommen ein ungewöhnlid) gropes Mobiliar hat, erleibet Berlufte, bis er baffelbe fo weit ernicorigt hat, oaß er bie Steuer aus feinen (Eimnahmen zu tragen im Stanbe ift, unb or mus hiebei neben oen überflüfigen aud febr werthoolle Dinge ber Steuer willen aufgeben. Şiezu gefellt fid) bie grope Sd)wierigfeit ber Erforjdung folder $\mathfrak{B e r m o ̈ g e n z ̇ t h e i l e . ~ W B i l l ~}$ man gehâffige Nachfud)ungen beż Mobiliars sermeiben, fo ift man auf bie eigene 21ngabe ber Steuerpflichtigen befdränft, bie nur $D a$, wo frenge fittlidye und religioje . Srunbfäze herrfden, bie erforberlicbe 3uverläfígfeit hat $(a)$, zumal on aud) ber Beld=

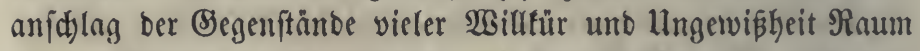

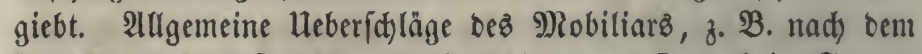
Berbältniß̄ zum Scauşptentercapital (b), tvenn fie aud im Banzen Der (Erfabrung entiprecten mögen, fallen bod) auf Die eingelnen

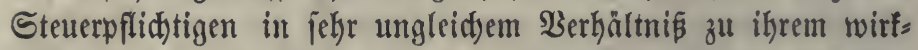
lichen Berize. Dephalb hat man hie und oa Theile bes Ses= braudjoborrathes ganz von ber Steuer befreit (c).

2) Sie belegt bie werbenden Siüter nidt nach iffer (Ertrages= fähigfeit, fonbern nad) ifrem \$reis= ober Roftenanjallage, twas

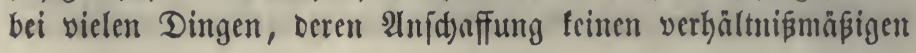


Bortheil bringt, 子. B. bei wenig benuķten Majdeinen, umnöthig foftbaren Beräthen $2 x$, ferner bei Eapitalen, bie verichiebene Binjen abwerfen, bie Eigenthümer fehr bejdyert. Mit 2lus:

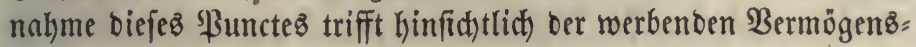
theile bie Bermögenşfteuer mit Der Einfommengิ fteuer überein.

3) Der Brunbfab ber Bermögenzibefteuerung ift auf bie aus ber 2lrbeit Gerfließenden (Einfünfte nid)t anmenbbar. Man bat biefe nur herbeizieken fömuen, inbem man aus iknen cin ein= gebilbetez Stammyermögen (Eapital) berechnete, wie bieß oft geidechen ift.

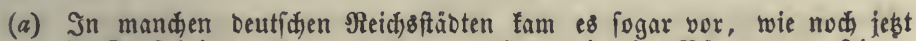
in (Senf bei ber taxe des gardes, Dnß́ ber einzelne Bürger ganz feinem

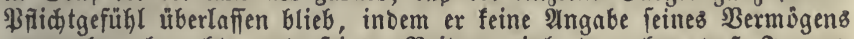
zu machen brauchte und feinen Beitrag einlegte, ofhe Dá̧ Semano beffen Srópe erfufr: "gefdworne Steuer"Knipschild a.a. D. ๙. 421. IR a c (b) a velli (Discorsi sopra la prima deca di T. Livio I, (Sap. 55) preift Diefen Sug beutficer Treue mit gropem lobe: Neque enim dubium est, quin singuli justam portionem solvant, quod alioquin totam summam contributae pecuniae minorem fore opporteret, quam alias esse soleret, atque illine patefacta fraus aliam indicendi colligendique tributi rationem suasisset, latein. Ueberi. Francof. 1619,

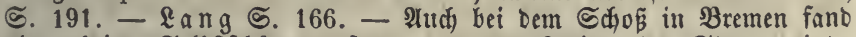
bie gekeime Selbitidrąung ftatt, uno Das Steigen ber Steuer zeigte,

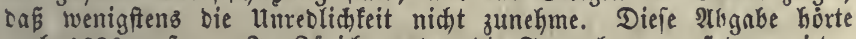
nach 1830 auf. - In 3ủrid werben bie Formulare, auf benen jeber Steuerpflidtige fein $\mathfrak{B e r m o g e n ~}_{\text {mo }}$ (Sinfummen angegeben hat, nad) vorgaingiger \$rufung Durd) ben (Semeinterath in ein Fegifer ein= getragen, weldes 14 Tage Jebem zur Esinfidht offen liegt und oann bon einer (5ommiffion nud)mals geprift wiro, angef. Sefebs $\$ .12$ fi.

(b) Wie bei $\mathbb{N a t h}$ a a. a. $D$.

(c) $\mathfrak{B g l}$ §. 402 (c) von Nưrnberg. Dab Dortige Befés, Daß́, um Den Ctiat nicht zu verfürzen, Niemand mehr won oen genannten fleuer= freien Dingen Gaben folle, als fein Stanb exforbert, war fo unbeftimmt, Dás es feine 2 irfung Gaben founte.

\section{\$. 404 .}

Die $\mathfrak{B e r m o ̈ g e n s f f e t e r , ~ a l z ~ f o r t b a u e r n b e ~ A b g a b e ~ b e t r a d t e t , ~}$

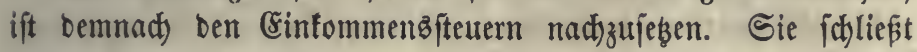
feinen $\mathfrak{B o r z} u g$ in fitd), ber nidft, wie z. B. Die Beiziełung ber Eapitaliften uno bie Erreidterung ber S(f)uloner $(a)$, aud) bei jenen Steuern angebradtit werben fönnte, utmb zeigt gerabe in

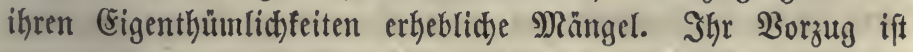

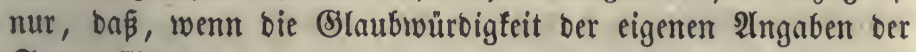

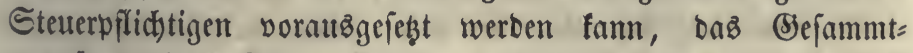
vermögen einez Steuerpflidtigen leidter anjulfęen ift alz feine Einfünfte, benn ienes ift in jebem 3eitpuncte eine beftimnte 


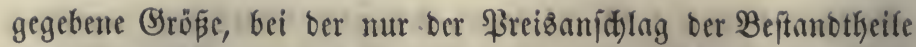
eine Ungewiskeit in fid) enthält, bas (sinfommen aber jefr

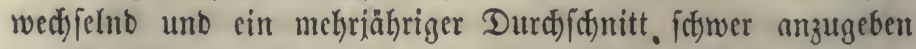
uno zul prüfen. In \&änbern, wo bie Sđjabungen bis̄her ge= fehlt haben unb bie langfame, befdwerlict)e 2lnlegung gefdeut wirb, mag allerbings bie Bermögenb̧fteuer für ben 2 nfang bequem fein, biz man bei fteigenbem Stnatzbebarfe zu einer

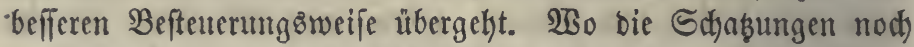
unvolfommen ober unvolfiandig finb, on fann in 3eiten eines außerorbentlid) vermefyrten Stants̊aufwanbez eine allgemeine Bermögenżfeuer, ลโż eine Iluflage yon furzer Dauter, eher gerectitfertigt werben, weil unter folden Umftänoen, bie bejon= bere Dpfer forbern, Ungleidfbeiten leictster ertragen werben, eine minber genaute গegulirung weniger fchäblich ift unb überfaupt bie gefchilberten Nactheile bei ein= uno zweimaliger (5rkebung nod) nicht jefre fidftbar werben (b).

(a) Şierauf legt Dathy, a. a. D., (Sewvicht.

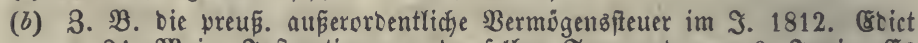

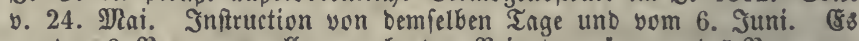
wurben 3 \$roc. von allem loerbenden \$rivatvermögen und 5 \$roc. von

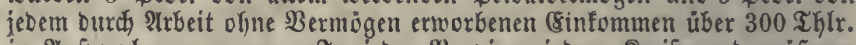

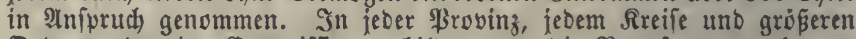
Drte twurbe eine Summiffion gebildet, um bie Bermógenzangaben zu

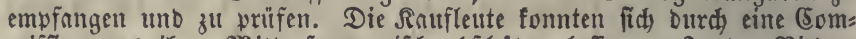

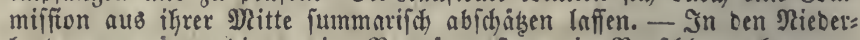
Innoen war neuerbing eine Bermógensffeuer in Boridilng gefommen,

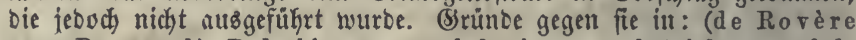
van Breugel) Bedenkingen over belastingen op het inkomen of de bezittingen der ingezetenen. 'sGravenhage, 1843, S. $16 .-$ Die yon

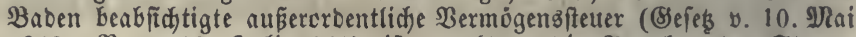
1849 , B. v. 23. Suli 1849) ift, nadjoem Die Pingaben ber Steuer= pfiditigen fijon abgeliefert waren, nidgt erhoben worben. - In Defters

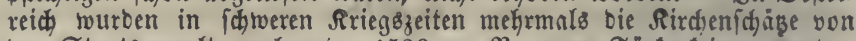
Der Staatêgewalt verlangt; $1526 \quad$ z. B. zum Türfentriege wutroen 13293 Mart Silber und 55 Miart (Sidt abgeliefert, 15292595 शtarf Silber und 9138 Sfiutb Niunze. D berleitner a. a. D. (\$. 398 (b)).

\section{. 405 .}

Eine $\mathfrak{A} \cdot b g a b e$ von (Erbid) aften funt alb eine nuf ben

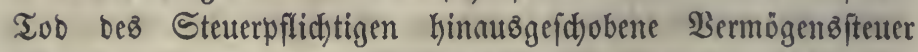
angefeken werben und hat fürt fict), baß fie wenig empfunben wirb, weil ber Erbe fie entridstet, bevor er nod) bas ererbte Bermögen als bas feinige betrad)tet hat. Eine in biejer 2lbftcht aufgelegte (Erbidaft sifeuer würbe fid) von ber (Erbidaftis 
gebüht alz ciner 2logabe für bie in bem (Erbredte liegenten Bortheile (\$. 237) nidft allein burd) ifren Göheren Betrag,

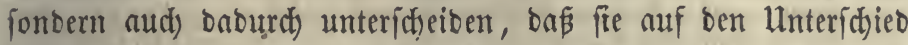
ber Teftaments = und Snteftaterben, fowic bei bicfen auf bie

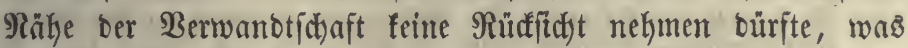
iebod) bei ben beftehenten (Erbfdaftzabgaben nirgentos gefdekèn ift. Eine nad) Den angegebenen (Sefictitspuncten angelegte (Erb= idjaftsfteter ift fêtr unvolffommen, benn 1) trifft fie bie einzelnen Berlaffenfduaften äuperft ungleidy, je nadjoem ber Ẽrblaffer lange

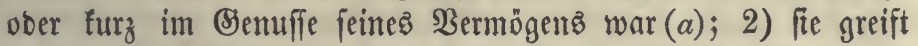
ihres hohen Betrngez wegen ben Stamm Des Bermögens an und giebt feinen foldten Alntrieb zu Erfparungen, wie eine jähr= lidje 2lbgabe, zumal oa Seber weí, baß inn bie einmal ent= ridftete Steuer nie wieber erreidt. 3) Wenn man bie Errb=

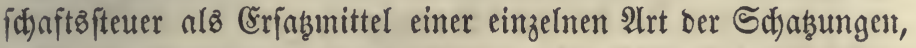
子. B. Der 3inzffteuer, betrad)tete, fo wäre fie noch barin fehler= haft, baß fie auch bie anberen $\mathfrak{B e r m o ̈ g e n z t h e i l e ~ m i t ~ b e t r a ̈ f e , ~}$ beren Ertrag fidon fonft befteuert ift. Wisollte man bebkalb bas unberveglidje und bas von bem Eigenthümer felbit in ein

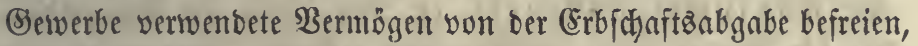
fo würbe boch iene $\mathfrak{u}$ ngleidjkeit nidjt ganz befeitigt, weil bie

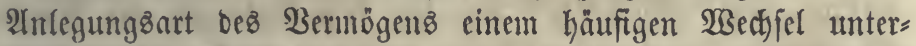
liegt und z. B. Siegenfdaften yon bem Erblaffer erft fürzlich

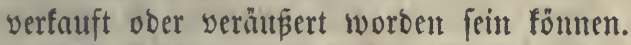

Die शrbftufung ber (Erbjd)aftäabgabe nach ber Rähe ber

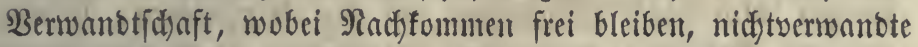
Teftamentberben bngegen aum meiften abgeben (\$. 237), ift billig,

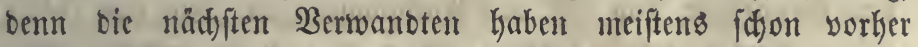
einigen Mitgenuf bes ßermögens gefabt uno baffelbe einiger=

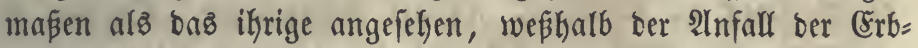

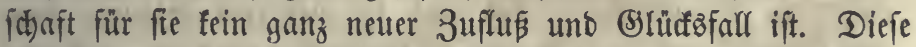
2trorbmung twiberftreitet aber bem 3 wede einer affgemeinen

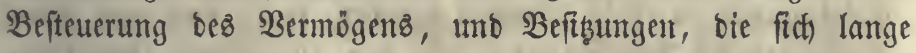
fort in geraber Rinie vererben, tragen ber ๔taatä caffe nid)tz $\operatorname{cin}(b)$.

(a) Diefem शrangel ift nidht abzukelfen, benn es wäre allzu umftänolid, bie Eteuer in jebem Falle nach ber Dauter Des Dermogensbefibes ab: zumeffen.

(b) In Der neueften 3eit ift jifters ber Borid)lag gemadt worben, bie Grb= folge ber Geitenberwanbten auf bie näkeren Grabe zu befarinfen uno 
bie Gieourd) erblos werbenben $\mathfrak{B e r l a f f e n f d y a f t e n ~ z u m ~} B$ eften ber 9 rrmen zu vermenten, wozu in ben (S) Prrmengut angeiammelt werten mißßte, aud fönnte vieß roenigitens mit

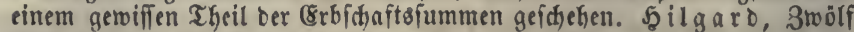
Baragraphen über ßauperizmus, 1847. - de Ma u rocordato, Essai historique sur les divers ordres de succession ab intestat. Par. 1847, 5. 7. 100. - B rater, Die Feform Des Erbrechts zu Sumften Der

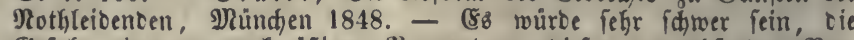

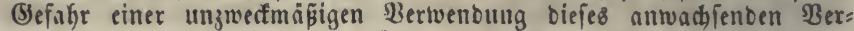
mogens zu entfernen, aud würbe, wenn man nidjt aud bie freikeit Der Teftamente bef̧rểnfen wollte, Durd häıfigere มbfafiung berielben ber Şeimfall umgangen werben.

2. Şauptif ü

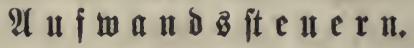

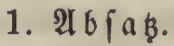

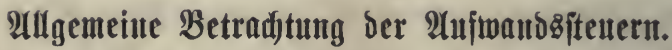

s. 406.

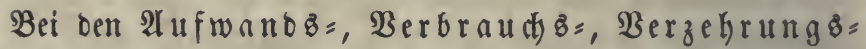
ober Confumtionsfteuern (\$. 292) wird bie Steuerfähig= feit oer $\mathfrak{B}$ ürger nicht im (Einzelnen erforidht, fonbern es wirb voraubigefeşt, biefelbe laffe fidt) aus bem Aufwanbe Der Bürger für serviffe 3 wecfe erfennen, fo baß man burd) eine an biefen Aufwand gefnüpfte Steuererfyebung alle ungefähr in gleid)em Berbăltniß̄ zu ifrem Cinfommen treffen tönne. Diefe Eteutrn hängen alfo nid)t unmittelbar mit ben (sinnahmen, fonbern

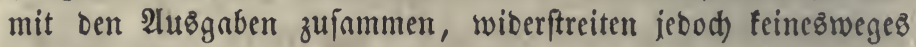
Dem Srundfaz̧e, daß́ nur baz (Sinfommen uno jtwar bas reine, belegt werben folle, fonbern bilben mur einen anderen $\mathfrak{W e g}_{\text {, }}$ biefen 3wedf zu erreidjen, als bie Sd)ab̧ungent. Dbidjon fie allgemein im (Sebrand) futo unt in mefreren Stanaten fogar Dem (Ertrage nad) bie Єd)akzungen übertreffen (\$.416), aud) viele Erfahrungen zu ifren (sumften ipredyen, fo ift bod) ihre 3wed:

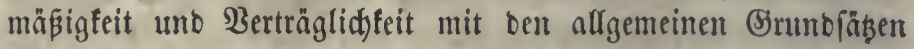
ber Befteuerung in neuerer 3eit ofterz in 3weifel gezogen wors Den (a). Nit ber Abwägung ber Borjüge ber Sdjnb̧ungen uno ber Aufwanbsfteuern fteht zugleich) bie Bergleidung ber ins birecten Erhebungsheife in 3ujammenthang (\$. 294), weil bie 
eritgenmute 2 rt bon Stentern gewölynlid) umnittelbar, bie zweite aber grö̈tentheils mittelbar erfoben wirb.

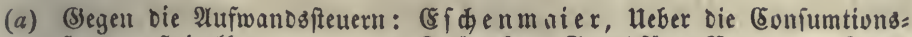

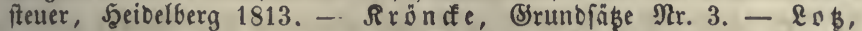
5.andbuch III, 175. - v. Riedtenftern, Aphorismen und Notizen

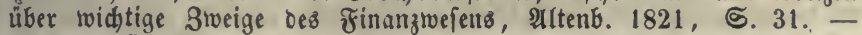
$\mathfrak{B} \in \mathfrak{h} r$, SBitthfih. Des St. S. 142. - v. ulmenfein, Heber bie Borzüge uno SRängel ber indirectell Befteuerung, Düffeloorf 1831. -

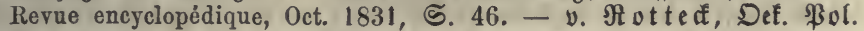
๔. 345 fi. - Fär diejelben: v. S v nnenfels, (Sirumbjäbe III,

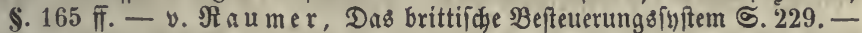
Monthion S. 123 . - v. Jafob I, 563. - ₹uloa §. 202 ff. v. Ilaldu\& I, §. 60. - de Hogendorp, a. Sdrift. - Mac Culloch, Taxation S. 148. - J. S t. Mill, Princ. II, 420. - In ber Sdyrift: Ueber bie billigite Bertfeilungstregel ber Stetern, Berlin 1850, wiro vorgefdlagen, bie Steter nur nad Len Rusgaben ber Bürger anzulegen und biée in Steuereinheiten auszubrüffen, weldhe aus bem geringften (rinfommen einer Familie, auf Den Ropf ausz

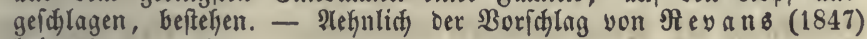
bei Mill II, 380 .

\section{§. 407.}

I. Berbältuif ber Steuer zu ben Einfünften.

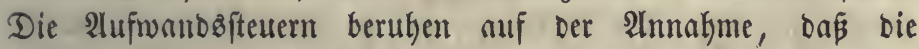

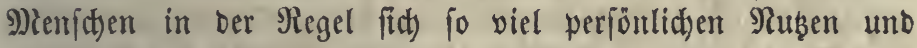

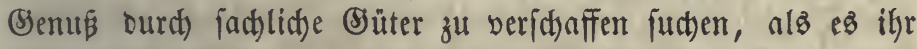

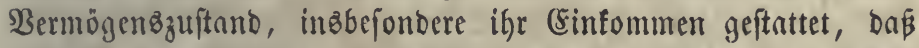
folglid) ben veridjiedenen 2lbftufungen Dez leşteren in jebem

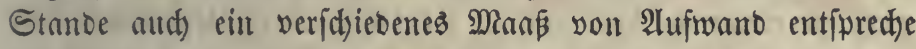
und burd) eine nad) biefem aufgelegte Stetter bie (Sinfünfte in ridjtigem Berbältnißß getroffen werben fönnen $(a)$. Dieß i ît auch im 2utrgemeinten wahr, nur läßt bie Ratur biejer Steuern,

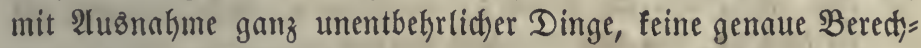
mung über bas Berbältní ber Steuerbeiträge jeoes Einzelnen

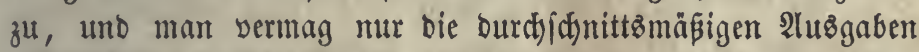
veridfiedener Bolfżclafien zu beobadten, um barnnd) Den Fuß ber Steuern in einem angemeffenen $\mathfrak{B e r h a ̈ l t n i} \tilde{\beta}_{\beta}$ anzuoronen. Sm Einzelnen geben hảufig aus mandjerlei zufälligen Brünben bei gleidfen Eintommen (Einige mefrt, 2Indere ongegen weniger

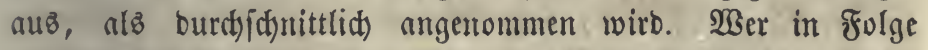

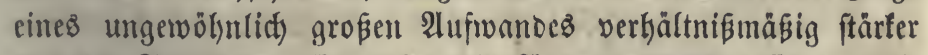
won ber Stetter getroffen wirb als Anbere, ber fanm fid), forweit Die 2luzgaben entbegrlid) finto, nidht betlagen, ba es nur bei

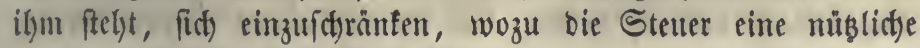

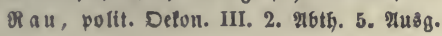


Warmung giebt. Wer bagegen bejonbers fwarfam lebt, trägt

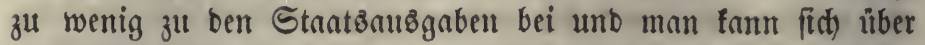

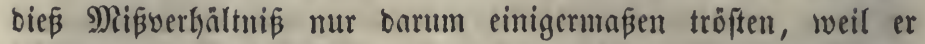
in ber fidnelferen 2hubäufung von Eapital ber Befellidjaft unb mittelbar aud) ber Stantzeaffe fpäterbin wieber einen Eríņ̈ für bie zu geringe Steuerentridjtumg giebt. Uebrigens bürften boch

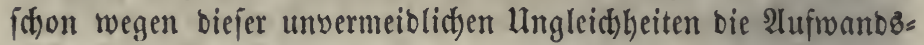
ftettern nidjt bie einzigen fein, vielmehr ift ez ratbjam, neben ihnen bie Edjaķungen beftefyen zu laffen, was aud) baraus erbellt, bas fie, infofern fie auf Rebensimittel gelegt finb, bie Arbeiter unb Eewerbsiunternefmer im $\mathfrak{B e r g l e i d}$ mit ben Srumb=, F̧aub = unb Capitalbefizern zu fdiwer belaften. Rönnte man alfen 2 ufwano befteuern, fo wübe es nod) leidter fein, bie Belaftung ber Steuerfähigfeit anzupaffen. Da biez aber offen= bar unaubfüfbrbar ift, fo mu范 man gewififc Steuergegenftänbe

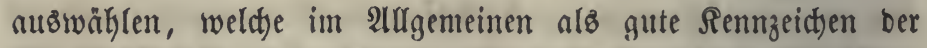
Steuterfäfigfeit gelten fönnen unt aud) in anberen Seinfict)ten

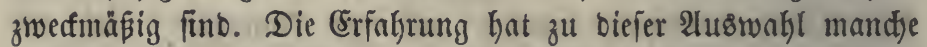
nüb̨lidhe Relyrent bargeboten uno man ift im Stanbe, wenigitens

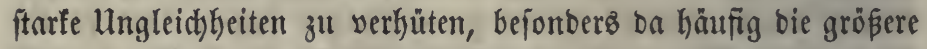
2(uø̇gabe für bent einen 3weft burd) geringere Berzebrung bei einem anberen Begenftanbe aufgerwogen wirb, beunod) aber ift

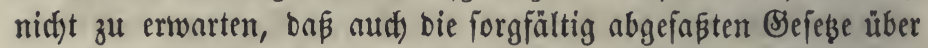
bie 2tufwanbsftettern eine vollfommen gleidfförmige Belaftung afler Familien nady itgrer Steuerfähigfeit bewirfen.

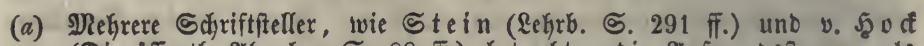

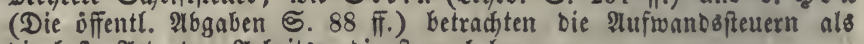
Die befte शtrt, Den शrebeitbuerbienft zu belegen.

\section{\$. 408.}

II. Bolfswirthidaftlide $\mathfrak{B}$ irfungen. Wirb eine

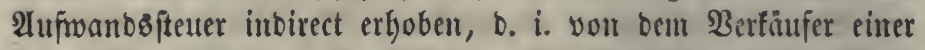
Waare ober Reifturg vorgeidyolien, fo empfintet biejer einen Intrieb, bie Steuer auf bie Räufer zu überwälzen, was aud in ber Regel (\$. 273) bald erfolgen mus, inbem, wenn ber şreiß nid)t in bie Şöhe ginge, bie Berfäufce ber beftenerten Waare bas 2tngebot verringern ober ganj aufgeben mürben. Dic Säufer fönnen fidh bei einem nicht ganz umentbehrlidjen Begenftanbe baburd helfen, baj fie cine etroab fleinere Menge 


\section{$-211$}

befielben verzekren, alfo im Sanzen bafür nicht mehr aubgeben

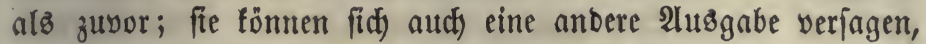

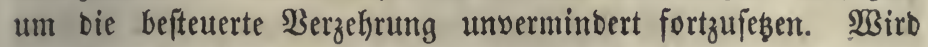
eine 2 rt besె 2lufwanbez unmittelbar (birect) befteuert, fo liegt

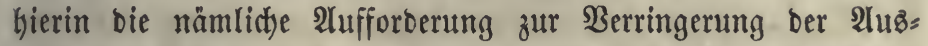
gabe, mur baß̋ feine \$reiserlyöhung burd) Ueberwälzen ftattfinbet. Die Wirfung einer foldyen Steuer ift alfo feine anbere, als bie

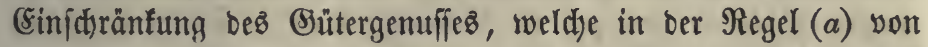
einer jeben Steuter verurfadt wirb, \$. 273 . Nur bann wäre

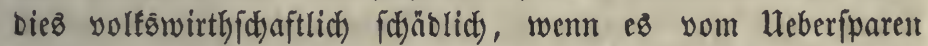
abjielte ober zum 2Angreifen bez Capitalz antriebe, ober eine Entbefrung an ben für Reben, Sejuntbeit, Bildung 2 . noth= wentigen ober fehr mithlididen Dingen veranläte; biefe Folgen fönnen aber burd) gute 2 anlegung eben fo gut verthütet werben, als bei ben Schaşungen. Şat eine 2lufivanbsfteuter fdjon längere Beit beftanben, fo hat fid bie Rebenzimeife nad) ifh eingeridftet unt mant ift baran gewöhnt, fie als einen wejents

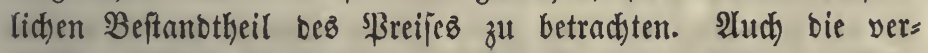
minberte Şervorbringung jenter Segenftänbe ift feine ben $\mathscr{2} \mathfrak{u f}=$ wantbeffeuern allein anfängenbe $\mathfrak{B}$ irfung unt vergütet fith burct) ftärfere Errzeugung berienigen amberen (s)iter, weldye ver= mittelft ber $\mathfrak{B}$ erwentoung ber ভtantzeinfünfte ftärferen $\mathfrak{B}$ egehr erhalten $(b)$.

(a) Mit Nus̊nahme Des in \$. 268 erflärten Falles.

(b) 8s wirb von ben Aufwandsfteuern gerühmt, Dafi fie theils bie 3efrer,

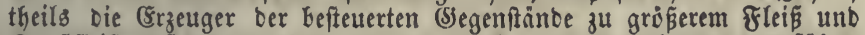

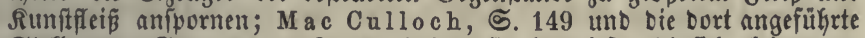

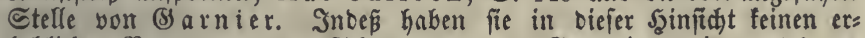
heblidjen Borzug vor Den Śbagungen. - Sarnier, in Traité des finances 2. ed. S. 144, fpricht gegen bie शufmanbsfíteuern.

\section{§. 409 .}

Man hat ez als einen Radbtheil ber 2ufwandsftetern an=

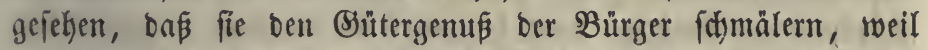
mit ben 21tşgaben für befteuerte (Begenftänbe aud) bie Steuer amväd)fit, während bie Sdjab̧ungen gleid) bleiben, ber Steuers pflidetige mag einfaufen, was uno foviel er will. Diés ift allerbings läftig, es fteht aber audj mit einer vortheilfaften Eeite ber Alufwandsfteuern in Berbinbung. Seber Einzelne ift

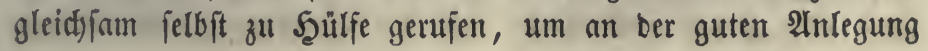




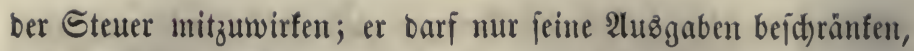
um audi) feinen Steuerbeitrag zu verminbern. Diefe Freikeit, weldye mur bei ben 2luflagen auf bie nöthigften Dinge ganz l)inwegfällt, ift ein wohlthätiges Edjuķmittel gegen ben Drud ber Steuern, Denn man entbehrt leid)ter einen Bemú, als man

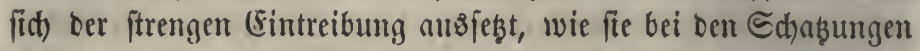
vorfommt, ind geräth folglid) bei einer vorïbergehenoen 3als= lungsuunfähigfeit weniger in Bebrängniß $(a)$. Diejer llmftand uno bie Beforgniß̄ yor ber $\mathfrak{B i l l f u ̈ r}$ in ber Anlegıng ber Edjaķungen Gaben beigetragen, bie Alufwantogftettern bei fold)en Bölfern beliebt zu madjen, bie ben Beif)ränfungen ber bürger= liden Freiheit am meiften abgeneigt fint. Daher wurben icton in früheren 3eiten, als bie S(j)aßzungent nod) fekr mangelhaft waren, Alufwantôfteuern bereitwillig übernommen. Sino bie befteuerten Gienüffe von einer allgemein beliebten 2 rt, fo hat

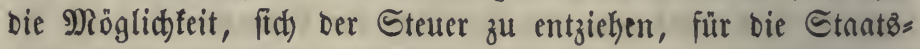
einfünfte wenig Radbtheil (b).

(a) Die शlufwanbsfeuern fino Darum getabelt worden, meil fie bezahlt werben müsten, wenn ber Befteuerte ein Bebürfniş empfintet. Allein man fann aud fagen: - wenn er bei Belo ift, um ein Betứrniś zu befrieoigen.

(b) Die Befhauptung (Ef denmaier's (ङ. 54): "Der Beitrag zum

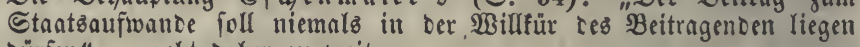
Dürfen" - geht Daher zu meit.

\section{§. 410 .}

Bei ben Unterfud)ungen über Sortheile uno Radjtheile ber 2lufwandsfittuern fommt viel barauf an, auf weld)e Besenenftänbe biefelben gelegt werben. Sind es ganz unentbelyrlide Dinge, fo laften bie Steuem in ber That fitwer auf ben unteren

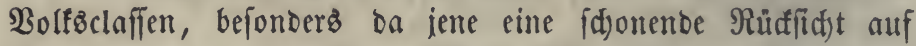

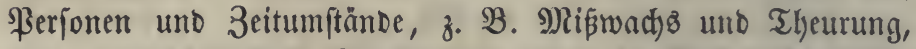
nidjt leidjt zulaffen. Cie fönnten baker cin Bolf bis zur (Er= f()öpfung auşangen, okne baß man burd) ibren abnehmenten Ertrag über ihre $\mathfrak{B}$ erberblichteit belefyrt würbe $(a)$. Wenn ba= gegen mur nüblliche uno angenef)me, bem \&urus angehörente

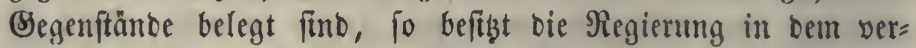
änberliden Ertrage biefer Stenern ein Siennzeidjen für bie Birfungent berfelben. Bermehrt fid) bie (Einnahme ebent to ftart ober fogar nod) ftärfer alo bie Bolfämenge, fo berweift 


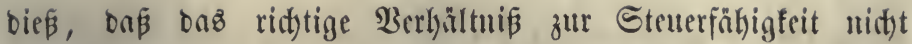
ilberfd)ritten tworben ift(b). Sime fortwährenbe 2lonalyme witrbe Dagegen anzeigen, baß bie Steuer f(t)wer empfunben wirt uno

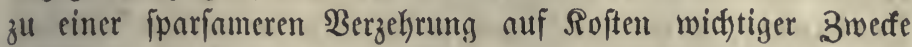

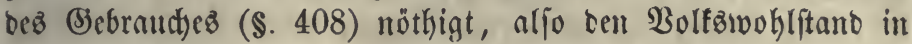

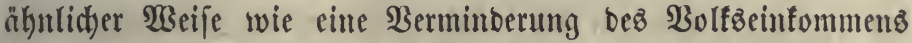
(d)mälert (c). Dod) ift ez nod) fein fdhlimmes Zeid)en, wenn oer $\mathfrak{B}$ erbraud) eines (5)genftanbes uแ fo viel geringer wirb, als bie nuf ifn gelegte Stener betrïgt. 2uth) bie Folgen cin= zeluer (Ercignifie, z. B. einer $\mathfrak{B e r a ̈ n}$ erung in ber volfżwirth=

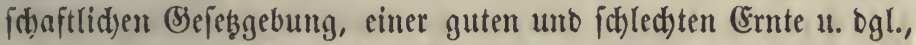

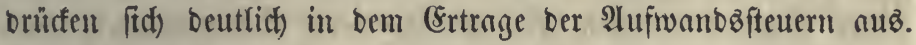
Die Eimunhme aus Sdhabungen ift viel weniger veränberlid). 3u ben müblidfen Seiten jener Steuern pflegt man bie von felbft erfolgende Beiziehung von Fremben, bie fith im Ranbe auffalten, zu red)nen, währent man biejelben gewöhnlid) nid)t mit Sdbazungen belegt, weil bieß won ber Regierung iffes Baterlandes geidieft. Da iebod) umgefehrt die 2lufwants: fteuern ber im 2luzlande verweilenten Bürger ber Staatżcaffe entgeken, fo haben in Diejer Şinfiddt nur foldbe Ränder Bervinn, in bellen bie Fremben inehr verzehren, als ben abwejenten Stantzoutrgern ins Atเsland gejentet werben muß $(d)$, und je brüfenter in einem Stante biefe Snttung ber Steuern ift, befto

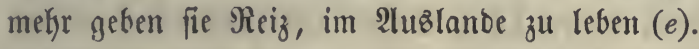

(a) Bgl. v. It fmenfteill ङ. 19. 32.

(b) In Frantreich hat von $1820-26$ bie $\mathfrak{B o l f s m e n g e ~ j a ̈ b r l i d ) ~ u m ~} 2 / 3$ Broc., ber Ertrag ber bort fogenannten droits indireets (gröbtentheilz Trant: ftentern) 3 \$roc., Der \$atentfteuer $32 / 3$ \$roc., Der 3ölle um 4 \$roc. zugenummen, D upin, Forces product. et commerc. I, S. XVI. Die Bapierptetter nafm yon 1849-1858/9 in Englano um 46, in Shottlano um 62, Irland 27 Proc. zu. - Die offerreidifiche Branntweinfteuer fiteg zwifd)en 1851 und 1856 yon $4 \cdot 333000$ auf 9.393000 f., alfo über baz 2fadje, boch zum Theil aus anberen Utráaden.

(c) 3. B. Der Estrag Der Mialzifteuer auf Den Sobf Der Esinwofner war in (3) resbritanien und Srland in Den Safren 1831, 1838 und 1841 4,5-

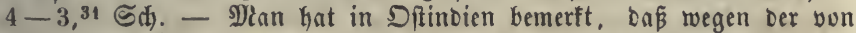
Ritima und Betwohngeit Gerrührenden höd) einfachen Rebensiveife ber (Sinwohner Die mit 2lufwandoffettern belegten Gadggüter, wenn fie nidgt unentbehrlich fino, balo auser Bjebrauch fommen, weşalb man

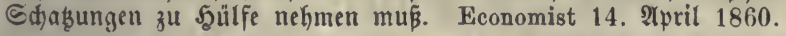

(d) Dieß̄ if befonders für fleine Straten yon Berwidt, wenn fie burd Bäber, Naturf(b) onkeiten 2c. Frembe anzielyen.

(e) Dießß zeigt Daß Beifpiel von Broßßbritanien beutlich. 
§. 411.

III. Was Die (Entrid)tung ber Aufwanosfteuern betrift, To ift biefelbe bei ber mittelbaren (inbirecten) Erbebung für bie Berfäufer, weldhe bie Ilbgabe voridbieken, allerbings bejdyer= liit), bieje fönnen fid) aber entfäbigen, inbem fie bie शlublage fanmt ben 3infen für bie mittlere Dauer ber 3wifdyenzeit bis zum Wiebererfake uno fammt Nebenverluften uno Bergütung

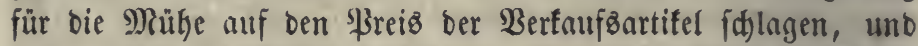
Dieß wird in ber Regel gefthehen, weil alle ßerfäufer bie lierin liegente Roftenbermefrung übernebuen müffen. Die $S_{t e u e r}$ pflid)tigen bagegen fönnen bie Steuern in beliebig fleinen abtheilungen entridbten, währent fie bei ben Sdyabungen längere 3eit hinourd) auf bie Steuerzahlung zu fparen haben uno po= wohl Ueberlegung als beharrlicter wille Dazu gehört, um ben

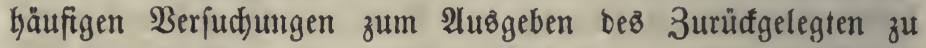
wiberfteben. Eint in gewiffen 2 usgaben enthaltene Steuer wiro alo foldhe wenig bemerft, man adjtet nur auf bic Şöhe Des zu bezablenden \$breifes in Sanzen uno bieje fordert ben Befteuerten fogleid) von felbft zu ber nöthigen (Einjd)ränfung auf. Dft weiß ber Steuerpflidatige gar uidht, Daßj er eine Steuer bezahlt, nod) öfter ift ifm wenigftenz bie Eröße Der= jelben unbefannt, ein Umftand, Der, ba eine Berkeimlidung von ber Staato̊gewalt nityt beabfithtigt wirb und Seber bie Steuergeję̧e fennen lernen fann, nid)tż Tabelnşwerthes in fid) faliefst uno nur bie leid)tere (Entric)tung andeutet. Unnittels bare Steuerzahlungen in bie Staatzaffe erregen mefir un= angenehme (Empfinbungen. Demuad) wirfen jene Steuern in höherem Sirabe ebenjo, wie eine abfithtlid)e Berbielfältigung Der Erkebungätermine, $\$ .285$ (a). Die Direct erhobenen 2 uf= wanbsfteuern fommen hierin mit ben ๔d)abungen liberein.

(a) "Die Arcife muß̧ großße Summen (Selbes aufbringen uno Dod bie Unter= thanen nidht enerviren, inbem fie tas Contingent bei lauter \$fenning ober (Sroidjen 3uiammenträgt." Entbedte Sologrube in Der Anccife f. §. 428. - Uebrigens hat טbiger Bortheil feine (5ränze, melde Gauptiädlid Daburd beftimmt wiro, in welden Terminen bie Ein= nakmen Der Befteuerten eingeken.

\section{§. 412 .}

IV. Ertrag für bie Staatôcaffe. A. Beränder= lid)feit. Da ber jährlid)e Aufwano für bie beftetterten Segen= 
ftänbe theils son ben Einfünten ber Steuerpflichtigen, theils von ben ßreifen ber Benußmittel abhängt, fo ift bie (Simnahme aus biefen Steuern von Gabr zu Sabr wedjelno, uno hierin liegt ein Radytheil ber 2ufwandoffeuern. Snoej ift berfelbe geringer, als man auf Den criten Blič vermuttyen fönnte, benn

1) Die Erfahrung zeigt, baß bie jäbrlicţen Sdłwantungen fid) in geuviffen (Siänzen halten und von bem Durchfdanitte einer Reife bon Sabren nid)t ftarf abweidjen $(a)$, auper bei

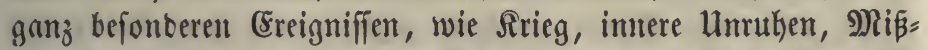

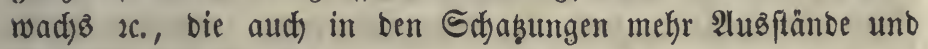
Rad)läfle mit fid) bringen;

2) Die 2lufwantoffteuern bringen bei ber 3unakme beş Bolfs: woblftandes nad) und nad) beträd)tlid) mehr ein, während bie 3unakme ber Sdyabungen langfamer erfolgt;

3) Die Summen, welde die Stenterpflidtigen fhulbig wer= ben, geken fogleid) ein, bei ben Sifakungen bagegen erfolgt ein Theil ber Znhlungen erft ppäter (ez bleiben 2luşftänoe) unb aud) nicht ganz volffändig.

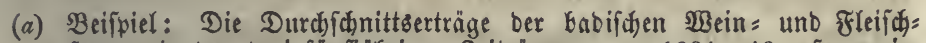
Petuern in ten orei fünfjährigen Seiträumen von 1831-46, fermer im 12 jähr. D. $1848-59$ waren wenig von einanber verichieten, nämlid̆

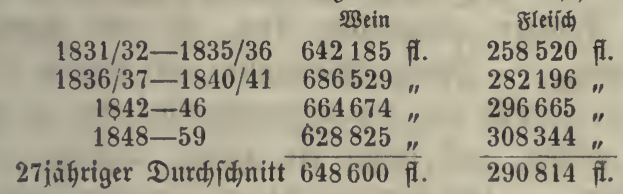

Beim Fleif́che fallen bie Sahre 1848 uno 1850 aus, fo baß ber $D$. nur 25 Jahre umfä́t. Bei Dem $\mathfrak{B}$ eine war das max. eines Sahres (1859) 931488 fl. ober 43 Proc. ůber bem Mlittel, bas min. (1831/32) 463206 fl. oder 30 \$rve. unter Demfetben. Bei ber Fleifdeftuer fand in biejem 3eitratum das max. 21 ßrvc. über, Dab min. 18 \$iroc. unter Dem Dutrdjidgnitt - In Franfreich entfernte fich in ben 10 Safren 18211830 fotwohl Der hödhte als ber niebrigite Jahresertrag Der Tranfiteuer nicht mefre als 6 Proc. won Dem Durdfíd)nitte. - Bon 1851-56

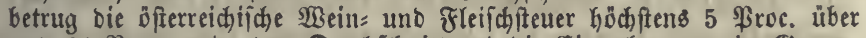

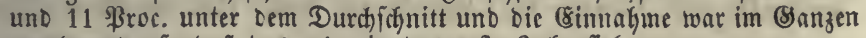

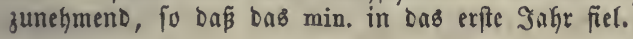

\section{§. 413.}

B. Sefahr des Betruges. Man fann bie Entrichtung einer 2lufwandbfteuer ungehen, wenn man bie eingelne That= fact)e eines 2tufwanbes, von ber bie Stetterfauldigfeit beftimmt 
wirb, ben Steuterbeamten zu verkeimlidfen vermag. Seierin liegt

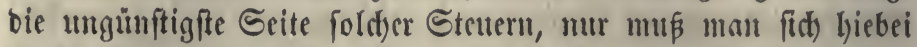
ftets erimnern, baß bie Bröße biefes llebels zun Theile you ben Steuereintid)tungen abjängt. Die einzelten Folgen funb nadjitehenbe:

1) (5z befteht cin Reiz zum Steuerbetruge, ben ber Etaat burd) Strafen wieber nufaukeben fuct)en muf. Die WBirtung

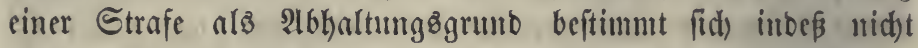

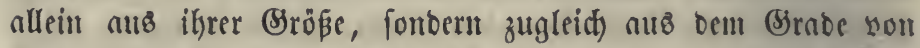
Bahlyfdcinlidjfeit, Daß fie ben Sdjuldigen errrid)en werbe (\$. $283(a)$ ) unt bie Scoffmung, unentbeft zu bleiben, trcibt Da, wo ein beträd)tlid)er (Sewvinn z"ll erwarten ift, ftets you Reutem zu biefer Bepeşwibrigfeit an. Diejelbe pflegt, als ein erft burd) bic 2 hnorbmungen bes Stantes funftlid) herborgerufe= nes Bergethen, in Der Meinuung ber meiften Menidyen milder als anbere Berbredjen beurtheilt zu werben. Sie wirb bald yon ben Berfäufern felbft, bald von ben Bethülfen berfelben, oft

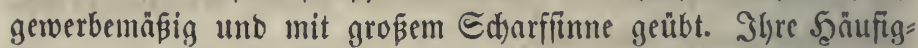

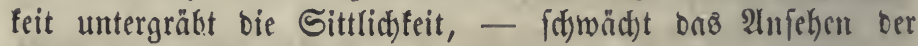
Befeßbe, - ftelft bie Bürger bem Staate feinolid) gegenibber, zieht, befonberz bei ben 3öllen, Mienfdyen, bie ofters mit nor=

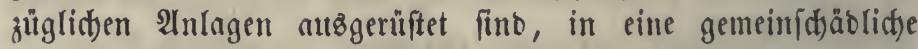
Befchäftigung, - bringt Bewimfte nuf Soften ber anderent Bürger, weil rod) bie 3ehrer gewöhnlid) cben fo hoke \$reife bezablen müffen, als wenn bie Steuer wirflid) vorgefduoffen worben wäre, - id)mälert bie Staatzesinnahmen uno ftürzt mit ber 3eit audh oie Uebertreter felbft meiftens in bas Berberben.

\section{§. 414.}

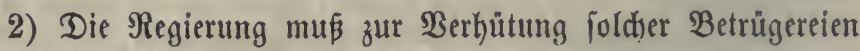

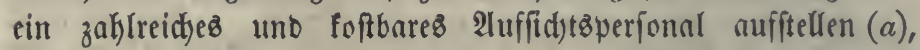

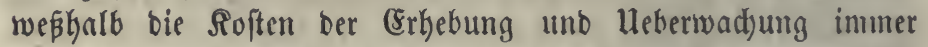

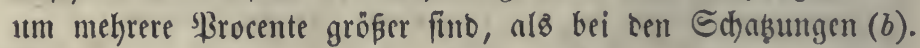
Dieje bem Bolfe zur Raft fallenten Soften fino eine unpro= Ductive uno unfrudtbare Berzehrung. Freilid) if bagegen bie Erhebung ber 2lufwanbzfteuern fehr leicht, wenn nur ber Steuters fü feftgeftellt ift, währeno bie Anlegung ber Sdyab̧ungen fofts fpielige $\mathfrak{B o r a r b e i t e n}$ nöthig madyt. 
3) Ulm be॥ Steuerbetrug zu verbüten, แmüffen mantberlei Förmlidffeiten vorgefdrieben werben, in benen cine Duelle yon

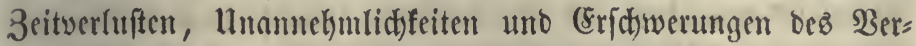
fefreb fowic eine Befahr liegt, burd) Untadjtamfeit jelbft ohne gefę̧wibrige 2lbfitht in Strafen ober Berzögerungen verwiffelt zu werben. (58 ift eine Menge von obrigfeitlicten Beboten unt Berboten nothwenbig, weld)e theilz ben Steuerbetnty felbft betreffen, theil(z aber nur auf bie Errfdyerwng beffelben hin=

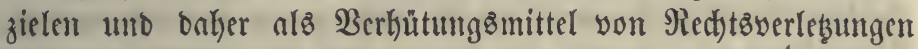
cinen wolizciliden (Egarafter haben. Dieje nadtheilige Eeite

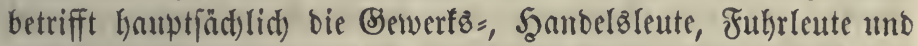

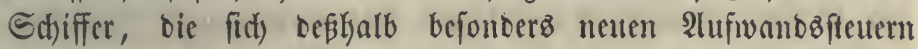
höchft umgern untertwerfen. Da fie jebod) wegen ber täglictent llebung leidf)t mit allem bem, was you ilfmen geforbert wirb, befannt werben unt, wenu fie nitht auf Betrutg autgehen, all= mälig lermelt, fid) ftrafloz zu erfhalten, fo wiro biefe Folge ber 2 ufwantosfteturn bei guter (Sinrid)tung mit ber 3eit leidter ertragent.

(a) Diefe "Finanzwadye" foftete in Defterrei $18475 \cdot 721000$ fl. Conb.

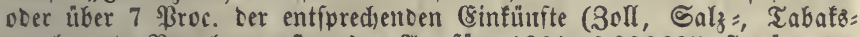
regal und $\mathfrak{B}$ erzehrumggfteuer), 2 . für $1864 \quad 6.326337$ fi. ô. Doer 4,5 अroc. Der entiprechenden (sinfünfte (von Salz uno Tabaf nur den Neinertrag berec(inet).

(b) Heber Baben i. §. 286 (a). - Sadjen 1858-60: Directe Steuern

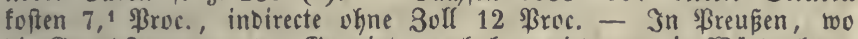
Die Brrumbifeuer yon Den Bemeinten erfoben wird, uno in $\mathfrak{B}$ ürtemberg,

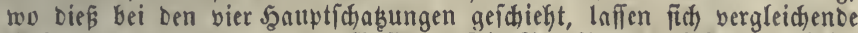
softenberedsuungen nicht aufiftellen. Die Tranffituern foften in 28 ir: temberg 1858-60 19 अroc., nnd Dem 21. 1845-48 fofteten fie nur $12^{1 / 4}$ Broc. - Der Atufwand für 3oll uno andere indirecte Steuern in Franfreich) (ofgne Tabaf uno Sdjieß̧pulver) beredynet fid 1859 auf

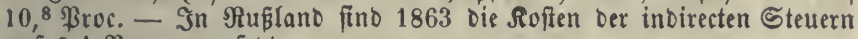
auf 8,1 ßroc. angejéţt.

\section{S. 415 .}

$u_{m}$ n̈ber bie 3uläfifgteit ber 2ufwanosffteuern ein Untheil zu fällen, muß man noch Folgendes crmägen: 1) Die Radt)= theile, befonders bie in $\$$. 413. 414. gefdjiltorten, werben fehr von ber Szöhe bes Eteuerfußes, fo wic von ber Atuswahl ber (Segenftäntc unt (Erthebungsformen bebingt uno fönnen baher

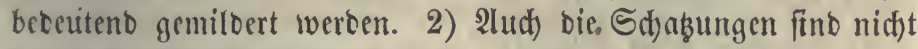
frei von vielerlei Mängeln, uno biés ift einer ber Şauptgrünoe, aแz benen man fid) mit ben 2lufwanbsfteuern ungendtet jener 
Unbollfommenbeiten befreunden fann. Dazి Urbilo ber Sd)ab̧un= gen, bie Belegung aller Bürger zu einem gleidten Theile ifjes reinen (Einfommenz, ift ein nirgends erreid)tes und faum ie volftänoig erreid)barez 3iel, weil ber Erforidtung uno Sdhäßung Des Esinfomunens grope Şinderniffe im $\mathfrak{W e g e}$ ftehen; bald wirb unvermeiblid) eine $2 \mathfrak{l n z a b l}$ von Steuerpflidtigen, bald ein (sin= zelner zu niebrig angelegt, bisweilen aud) überbürbet. $\mathfrak{B}_{e}=$

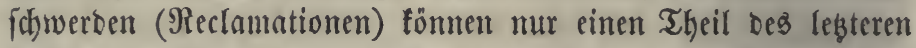
Feblers befeitigen, zumal on fie nidjt gegen bie Steuergefeze, fonbern nur gegen ifgre Bolfziehungzweife zugelaffen werben Dürfen. 3) Die (Erfahrung hat die Unjouablidfeit Der sad)

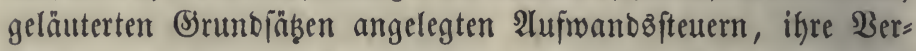

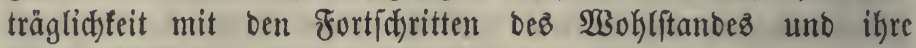
3 wedmäßigfeit in ben meiften Staaten bargetlynn.

§. 416.

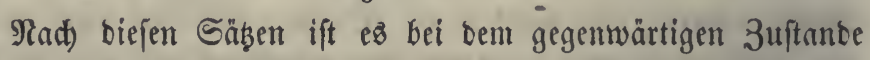

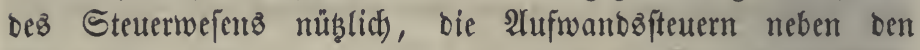
Sd)azungen beftefen zu laffen, um burd) bie Berbinbung beiber Sattungen bie unvermeiblichen Fehler und 9aththeile einer jeben

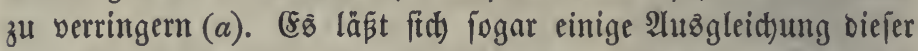
Unvolffommentbeiten infoferne annehmen, als ber, weldyer bei ben Schabungen überbürbet ober zu wenig getroffen ift, feine

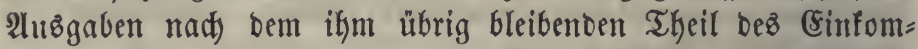
mens ridftet und alfo bei ben Ilufwantôfteuern leicht befto weniger ober mehr giebt. Wie fid in einem gegebenten Staate bie auf beiben $\mathfrak{B}$ egen eimzuzielenden Summen zu einanber ber=

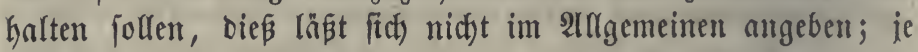
weiter aber die Shabiıngen hinter ben Inforberungen ber Steuertheorie zurüfbleiben, befto mefr muß auf bie थufmandz= fteuern gelegt werden, fo baß fie z. B. unter geviffen $\mathfrak{U m}=$

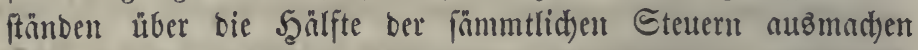
burrfter, währeno fie in andern Fälfen bỉ zu $2 / 5,1 / 3$ ober nod) weniger herabfinfen fömuen $(b)$. $\mathfrak{D b}$ in fpäteren 3eiten oic $\mathfrak{A n}=$

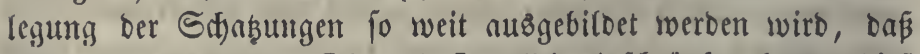
man ohne Bebenfen fiț auf fie alfein befdränfen fonm, bieß läßt fid) nod) nicht entid)ciben.

(a) Die zu Anfang Der franzififden Sievolution unternommene Ruihetung ber inneren Rufwanosftemern trug zur Berrütung Des Staatshaushaltes, 


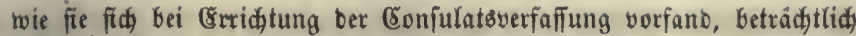
viel bei. Thiers, Histoire du Consulat et de l'Empire I, 10.

(b) Bei ben fratiftifchen 2ingaben Kieruber fino Beridytigungen nöthig, weil in ben Stantoredhnungen bie (sinfünfte nidjt freng nach wifienidaft= liduen Begriffen aufgefügrt find, namentlich müfen bie Sebühret aus=

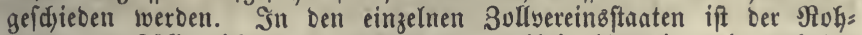
ertrag ber 3ölle nidjt ganz majgebent, weil in ifm eine, je nady ber Lage unb (S)räuzlänge fehr ungleidje Roftenvergütung aus ber Bereins:

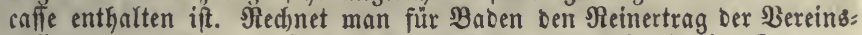

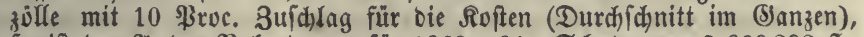
fo ift ber 2 . Des Эohertrages für 1862-64: Sd)akungen 3.689232 fl., 2ufwandsftetuern (ohne 20 afferzölfe u. a. (Sebühren) $3 \cdot 643889$ fi., ober faft gleichviel. In \$reußen fommen 1860 auf Die शlufwantoffteuern 51,9 \$Broc. (28 গitl. Thltr. won 59 Dill. Thlr. Steuer), in Nieberlano 2. 186050,2 \$roc., in $\mathfrak{B a b e r n}$ gerabe 50 \$roc., in $\mathfrak{B}$ ürtemberg 53,8 \$roc. $(4 \cdot 310200$ yon 7.998952 fi. $), 1861-64$ nber 55,8 \$roc., in Sadjen an 36 ßroc., im Srof̧herzogthum Şeffen $43,^{8}$, in $\mathfrak{B e i m a r}$ 43,4 , in Belgien 185948,7 Proc. Der Steuereinnafyme, in Defter=

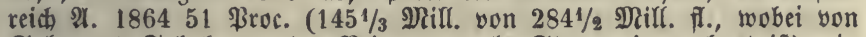

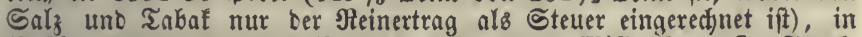

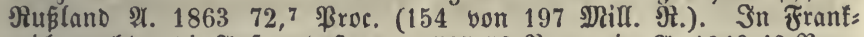

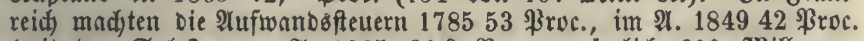

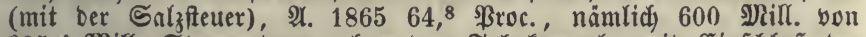

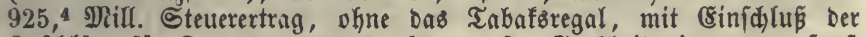
3ufáläge für Departementsantsgaben. - In Srobibritanien waren fomft

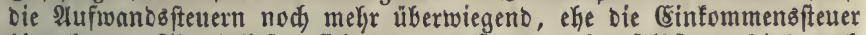
hinzutam. Sie beliefen fich 1831 auf 97 , aber felbft $1858 / 59$ noch auf 83 \$roc. aller Steuern, im Sahre wom 1. Detober 1862-63 auf 78 Proc. $(42 \cdot 816000$ von $57 \cdot 561000$ \&. St.).

\section{§. 417.}

Die Srunbfäże für bie gute (Sinridjtung ber Alufwantos: ftettern folgen größtentheils auś ber obigen Darftellung bes Bejents diejer Steuern.

1) Ez ift rattfam, biefelben fowohl im Berbältni位 zu ber

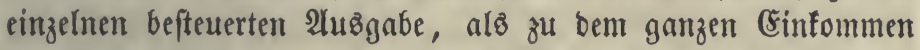
Der Steuerpflidtigen mäßig anzuféen. Denn hoke Steuern reizen niđbt allein ftärfer zum bäufigeren Steuerbetrug uno ver: urfact)en wegen ber nöthigen fitrengeren $\mathfrak{H}$ eberwadumgsima größ̈ere Erkebungsfoften, fonbern ermuntern aud) zu einer $\mathfrak{B e r}=$ änberung in ber Serzehrung, inbem man fith im (Sebraudbe bes belafteten Segenftandes ftarf einfajrånft ober wo möglich zu anberen wohlfeileren $\mathfrak{B}$ efriedigungs̊mitteln eines Bebürfniffes Gimwendet. Dieß ift zwar ofterz wirthjdjaftlid) betradjtet nidjt unvortheillgaft, aber es entzieht bod) Der Regierung bie erwartete Cinuahure, fo ba

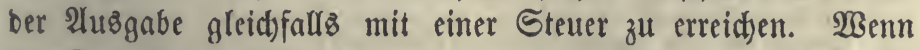
Der Steuerfus ergoht wirb, fo fteigt bie (Eimtuhme nidjt leidjt 
in bemílben Berbältníp wie ber Tariffaz̧ $(a)$. Db unb wie

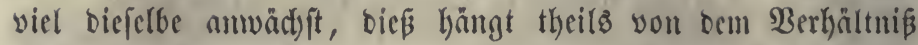
bes neuen Steuerfabez zu bem früheren, theils von bem 13 erthe bes (5)genftanoç für bie 3ehrer, von ben Bermögensెแmftünben Derfelben, oer \&eidjtigfeit ober Sd)wierigfeit beฮิ Betrugez ab.

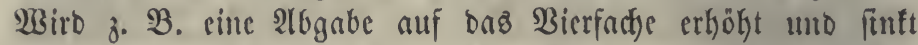
ber offenfunbige $\mathfrak{B e r b r a u d}$ auf $3 / 8$ ober $1 / 2$, fo wirb ber $\Re(u k)=$ ertrag auf Das $1 \frac{1}{2}=$ ober 2 fadje fteigen. Sn vielen fällen hat mant bagegen vou ber Steuerermäßigung einte Bermehrumg ber C̈imnlyme empfunden $(b)$. Se uad) ben genamten llmftänben

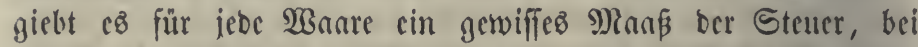

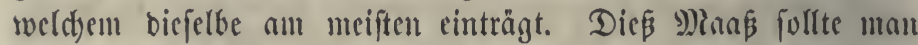

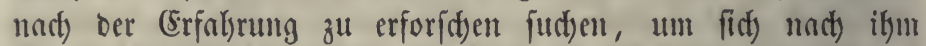

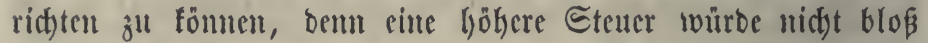
Der Stantseaffe Berluft bringen, fonbern aud) ben Bürgern eine

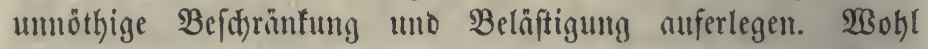
aber faun eż mỉllic) fein, bic Steuer nuch mit cimem Dpfer für bie Stantöcafie nod) weiter herabzulezen (c). Dagegen fint aber aud) febr niebrige Steueränze bei Wanren, bie nidht in

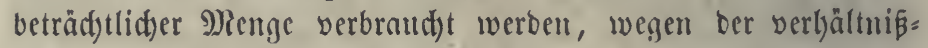

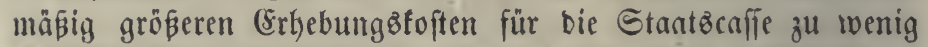

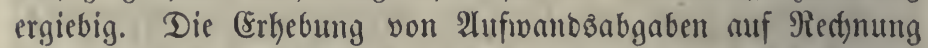
Der Semeinden (ber jog. Detroiz) muß mad) ben nümlicten (5runtojäben beuththeilt uno befdränft werben $(d)$. Sino fie auf Die (Segenftänbe gelegt, von benen aud) Der Staat eine Steuer forbert, fo werben feine bejonberen Erhefungafoften erforberlict). Bicle foldbe örtlidje 2lbgaben werben an Den Thoren ber Stäbte

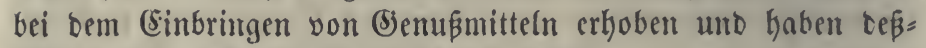
halb ifyre befonberen Nadytheile, \$. 429.

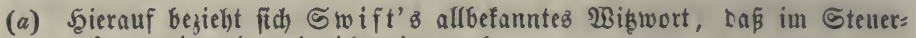
wefen zwei mal zwei nicht vier mache.

(b) Biele Erfafrungen bieíer 2irt find in Sroberitanien gemadit morben. «ls man 1784 Den Theezoll von 119 auf 12 \$roc, ernietrigte, Fiel ber 3ollertrig nur von 700000 auf 240000 \&., währeno er verfält:

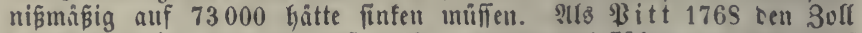
Der Franzweine bon 99 auf $50 \mathfrak{l}$., Der portugiefiff)en von $94^{4} / 5$ auf $32^{4} / 5$ \&. Et. von Der Toume herabiebte, nafm (im D. Ser orei vorher= gefjenten und ber vier fwâteren Sahre) tie verzollte (sinfuhr um 71, ber 3ollertrag um 14 ßroc. zu. Die 2 bgabe voll framzofifiden \$Beinen murbe 1525 von 11 Sd). 5 \$. nuf 6 \$. etmásigt. Der mittlere (Ertrag Der vier lezten Jakre war $106000 \mathfrak{l}$., Der ber trei folgenten 115000 \&. - Die Berboppelung Der Niggabe yon Slas in 3.1813 
feigerte Den Durdichnitţbetrag nut von 340000 auf 395000 $\mathfrak{E}$. Bon Dlivenól war bie 3olleinnahme in Sropbritanien bei bem 3ulle yon 11/, Sh). pr. (Sallon im D. von 1820-24 51332 \&., Hady Der Szerabfegung auf $2 / 3$ Sd). aber, welde $1825^{\wedge}$ gefdah, wurben you $1828-31 \mathrm{im}$. D. 59914 \&. St. eingenommen. - 1825 ermäß̈igte

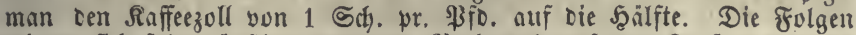
zeigten fidh fefhr günftig, Denn Der ßerbraud auf ben Ropf, Der 1821 16 Ioth gewefen war, fiteg 1831 auf 1 PFo. 11 loth, ber Stetterertrag auf Den Sopf yon 6 auf $8 \mathfrak{F}$. Sm Sahre 1840 murben bie meiften

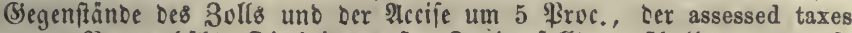
um 10 \$rsc. erhöht. Die beiden erften 3tweige follten Deß̧halb 1.833000 mefhr einbringen, aber ber Defurertrag yon 1841 war uur $262000 \mathfrak{l}$.

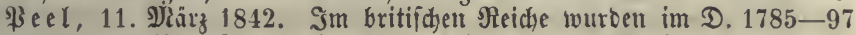
17.736000 \$fo. Tabaf eingeführt bei 1 Sch. 7 P. 3oll, aber 1832

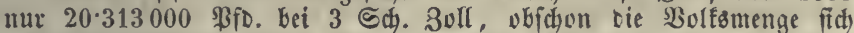

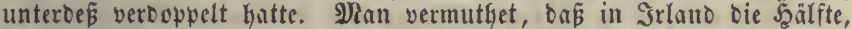
in (Srufbritanien $1 / 3$ ober $1 / 4$ Des verbraudhten Tabafв eingeidy wärzt

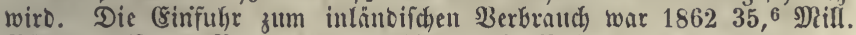
\$fund, alio 15 Proc. mefyr, währeno die Bolføimentige von 1830-60 um 80 \$roc. Jugenoumen hatte. Swifdyen 1825 uno 1828 wurben foviel Berminterungen oes 30lles und Der Accife vorgenommen, oaf́,

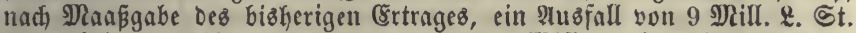
Gätte eintreten müffen, aber es wuroen nux 3 Mill. weniger eingenommen, ogl. Parnell a. a. D. S. 43 ff. - Bei Dem 3olltarif yon 1842 erwartete man wegen ber vielen (8rmäß̄igungen einen Minberertrag von 1.450000 \&., aber bie Einnahme, die $1840-41$ im D. 23.581000 \&. mar, fiel 1842 nur auf 22.771000 \&. und betrug 184322.850000 \&. Die von 1801-21 erhöhten 3oll= und शccif́çäß̨e wurben auf 21.681566 , tie it biefer 3eit aufgefobenen ober ermäpigten auf 4.134173 \&. an= gefdylagen, es Gätten alio $1821 \quad 17.547393$ \&. mekr, uno wegen Der Bolfsmefrumg you $29^{3} / 4$ Proc. ftatt ter muthinafichen 36.878260 fogar 47.849543 \&. eingeken follert, es gingen aber 9.083729 \&. weniger als Diefe Summe ein. Dagegen war 1849, weil für 13 \$nifl. \&. 3oll und Accife aufgehoben worben war, mit Rüfficht auf bie Bolfsvermeh)= rung eine Einnahme von $23.415968 \mathfrak{l}$. zul erwarten, wâfrent wirflich 34.622284 \&. ober 11,2 Millionen mefr in bie Étantzcaffe floffen. Porter, Progress S. 4S8. 490. - 1784 wurben in Preufen Die Raffee⿻2ccije von 6 auf 3 (Sr. vom \$funt gciebt, tovourd bie (sin= nahme von 3 anf 500000 Thli. antudy, 23ie Der Gold 5.167.

(c) Die britiface Steuer auf Geife trug am meifen, nämlich 1 ๔ch. $7 \frac{1}{4} \mathfrak{B}$.

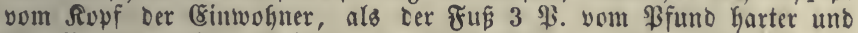
$13 / 4 \mathfrak{B}$. von weicher Seife war, bie J̧erabfebung auf refp. $11 / 2$ und 1 \$3. erfühte Den sBerbrauch Des Ropfes you 6,23 auf 9,2 \$fo., Der Steuerbetrag fiel aber auf 1 Sd. $13 / 8$ \$. Porter, Progress of the nation, 570.

(d) In ben Dörfern pflegt die für die Semeinbecaffe exforberliche Rbgabe

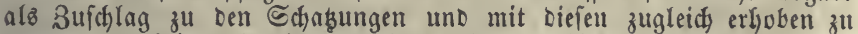
werben, wobei auch bie alsbärts lebenoen (sigenthumer von Riegen= ichaften getroffen werben. - Das 20 urt octroi (yon octrier, bewilligen, ermächtigen, aus auctorare abgeleitet) bezeid)net futwogl eine laubes: Gerrliche Betwilligung im arrlgemeinen, alz eime ftätifhe 2tufwanosfteuer inbefondere. Sil \$ariz fam fhon 1323 eine foldse von 1 den. p. livre $(1 / 240)$ Der eingehenten $23 a a r e n$ vor, wovon Der Rönig aber $1 / 230 g$, tvie Denn 1562 die Şälfte aller Detrois für ben Stant beftimmt uno 1681 bie Fortoauer cer meiften Detrois veroronet wurbe, Encycl. méth. शrbth. Finanes III, Frtifel Octroi. - Die farfen Detrois im Geutigen 
Franfreid, finb ein (Segenfant vieler Befdwerben. Nađ Barrill on (Supression des 0. Lyon, 1841) fino 1420 Drtidjaften, weldje 75 Yrill. Fr. auf biciem 2 Bege in bie Semeinbecaffen bezahlen. Bon 1806 bis zum (Sefes v. 17. Maai 1852 bezog ber Staat 10 ßroc. afler ftäbtif́ct

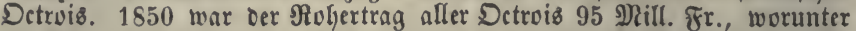
37 Rilf. von ßaris. 1863 beftanden 1514 Dctrois. \$aris Gatte 1862 78,8 Dill. Orinnahme. Suf ben Ropf ber (Einwohner fumen in mandien Drten nutr einige Eentimen, in \$larfeille 25, in \$aris 40 5r. 24uz= rührlidje Angaben bei de Parieu, Traité IV, 135. - Im Rónigreiḑ

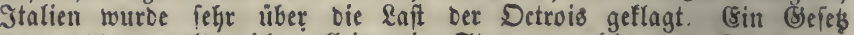
yon 1563 regelt nidht allein Die Steuer, weld)e ber Staat von geiftigen Flüfingfeiten uno Fleifd) erkebt, foncern aud ten ben (Semein= ben geftatteten 3ufd)lag zu bieien Siegenftänben uno geftattet toeitere

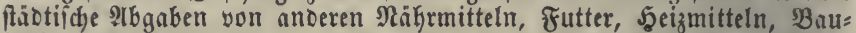
ftoffen, Seife, Fett u. a. Dingen. Der Tarif bes̆ hỏdiften zuläfifgen Slbgabenfabes wirb von Der siegierung beftimmt. Die Semeinbe fann Die OErkebung ber Steuer uno Bemeinbenbgabe felbit übernefmen, wenn fie für einen gewifien Grtrag ber erfteren hajtet. Was über Dießs Dimi= mum eingeft, wirb gleicheitlich zwifden ber Stants = uno (Semeinbe= cafie getheilt, de Parieu IV, 377. - In Belgien beftanden 1860 in 78 Semeinben ftábtiche Iufmantsfteuern von vielerlei Segenftänen, mobei mehr Erkebungoperional befibaftigt war alz bei ben Steuern Des Stantes uno viel Steuerbetrug yortam. Der Nohertag war

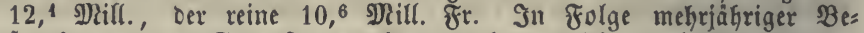
fprechungen Des Begenfandes fam Dutrdy Den Finanzminipter Fr $r$ è Drbau bas Geies vom 18. Suli 1860 zu Gtande, in twelchem bie Dctrois abgefdafft twurben. (Ss bleibt nut von Bier, Bronntwein

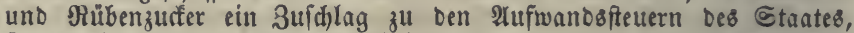
ferner ein 3ufchlag zu Dem (Einfufgrzoll alf $\mathfrak{B}_{\text {ein }}$ uno Branntwein,

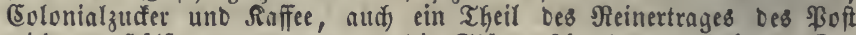
twirb zแl Şilfe genummen, um bie Stíbte fijablos zu halten Der (B)fammterting Diefer Nittel (mutlymaflich minbeftens 15 פrill. Fr.)

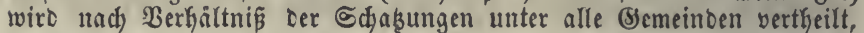
fo Dá̧ audh Diejenigen, weldje feine Detrois hatten, theilnefymen (gegen

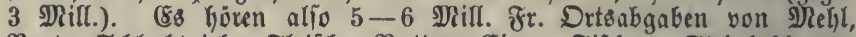

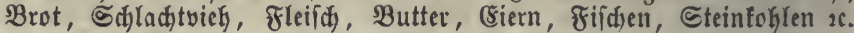
auf. Jebe Semeinbe mú menigitens foviel erhalten, als ifr Detroi

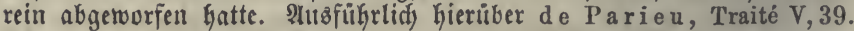

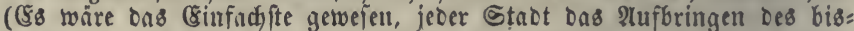
herigen Detroi=Ertrages vermittelft eines 3uidjlages zu ren Schabsungen zu überlaffen, was jeowd bei bem beftekenten Steuerfyftem nidt gerecht uno billig ífien. Dian muste es Daher vorziehen, einige Itufromos: fituern in ganzen Staat zu erhoben, wo feine Roften uno Beichwer lidgfeiten verurfachte. Die (Semeinden, Die fein Detroi Gatten, fönnen ifje Antheile zur Bermincerung ifeer Utmlagen ober für antere 3wedfe benuben, es bleibt aber ber 3weifel librig, ob bei biefer (știchäbigung Der Stäote vermittelft allgemeiner Stantbeinfunfte niat andere Drte verfurgt werben.) - 7 babijhe Stiote haben joldje fäotifdye 2luflagen. In Danufeim betrugen fie 185436634 fl., wowon 27268 ff. yon Mehl, 3508 fl. vou Bier, 3214 fi. von Szeizmitteln, 2593 fi. von Wein. In Sartsrube fommt audh eire ftiotifde 2tbgabe von Siegen=

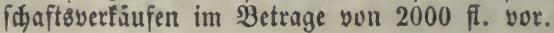

\section{\$. 418 .}

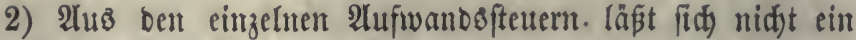
fold)es vouftānoiges (Sanzes mit einer guten Bertbeilung unter 
bie verjujebenen 3weige ber Cinfünte bilben, wie es bet ben Sd)abungen erftrebt werben fann, Dod) mus aud bie Befteue= rung bez Âfwanbes auf eine gentaue Statiftif ber Erzeugung,

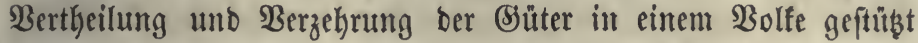
werben. Şieratz ift zu ermeffen, weldye Wirfung eine gewiffe Steuer auf bie verictiebenen $\mathfrak{B o l f b}$ claffen nach bem Umfange

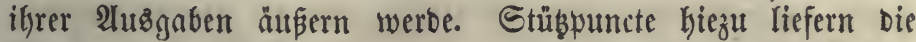
Erfabrungen über ben Ertrag ber beftehenben Steuern unb über

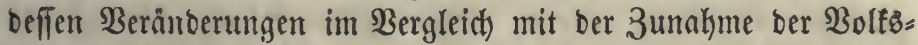
merge, \$. 410. $\mathfrak{B O}_{0}$ es an anderen ftatiftiftyen Thatjacten

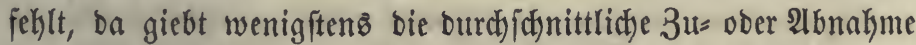
Des $\mathfrak{B}$ erbrautckes auf ben Fopf Der Einwofyner ein 3eidjen, ob man bie Eteuer nod erböhen bürfe ober vielmebr erniebrigen můfife.

3) Unter übrigens gleicten Unttänben find biejenigen Segen= ftänbe vorzuziehen, bei benen am wenigften Betrug zu befürchten ift, wazె von ber Dffenfunbigfeit ber Şervorbringung, ber $\mathfrak{B} e r=$

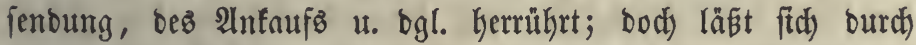

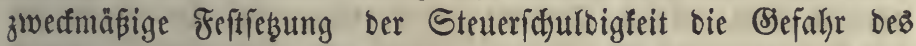
Betrugez betrïctltict) berminbern $(a)$. Dagegen werben folche

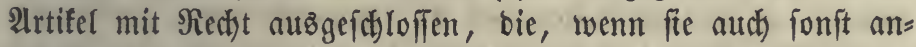
gemeffen fein möbten, im Berkältnís zu ben Roften ber Cers hebung, Ueberwatfung unt Berredfnung zu wenig eintragen witrben.

(a) In (E)rofbritunien fint zweiräbrige \$erfonenfufrwerfe fteuerbar, wenn fie über 21 \&. foften. Stan fudit ber Stetter burd mandherlei Sunft= griffe augzumeiden, z. B. vermittelfit einer Sdyenfung voer bes gleids= zeitigen Sinfaufes einer \$eitfije um fehr hohen \$reis u. bgl.

\section{§. 419 .}

4) Die Anfwanbşfteuern folfen ifrer Beftimmung nad) auf

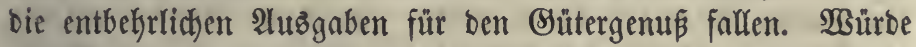

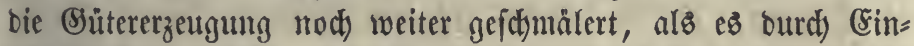
(d)ränfung Der Räufer unbermeiblid) ift, fo wäre bießs ein nicht beabfictigtes uno burdh nichts vergủtetes Hebel. Steuern nuf Dinge, bie als $\mathfrak{B}$ eftandtheile beछ Capitalnufwande zur Şervor= bringung anberer Shüter bienen, z. B. Stoffe zu $\mathfrak{B e r f z e t g e n , ~}$ zum Şäufer= unb Sdjiffabau, Berwanblungs = unb Şülfşftoffe unb bergl., wiberftreiten biefer Regel. Die $\mathfrak{B i r f u n g}_{\text {foldter }}$ 
Steuern läßt fid) nid)t gettan verfolgen, weil fie fidt auf bie Sreife einer Menge von altberen Ergetgniffen fortickst; es ift Daker ungewifí, von weldyen (Slaffen bez $\mathfrak{B}$ olfes uno in weldjem

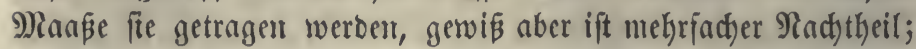

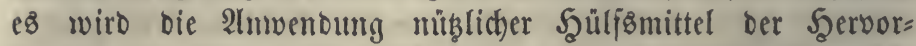
bringung verfinbert ober erfatwert uno ber inländifde Bewerbs: mann burd) Bertheuterung ber (Erzeutgniffe bei bem Mritwerben

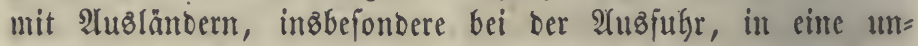
günftigere Stellung gefert. (sine fold)e Steuer fidsabet ber Bolfżwirthfthaft mehr, als ifre Ertrag anzeigt, weil fie mandse einträgliche Unternehmung ober Berbefferung gar nidyt zu Stanoe fommen läpt $(a)$.

(a) Parnell a. a. D. S. 22.

\section{§. 420 .}

5) $3 \mathfrak{u}$ ber Sidjerkeit ber beabfidtigten Heberwälzung wie zur Erreidjterung ber Steuerlaft trägt $e$ bei, wenn bie Eteuer furz vor bem Uebergang eines Begenftandes an Den 3ehrer erhoben wirb. Dießs läßst fich fo barthun: a) Der Binz für Den bei ber inbirecten (Erbebung zu leiftenden Steuerborichus mus im streife dez befteuerten Séegenftandes meben ber Steuer felbft erjeģt werben, unto ba bie Umlaufszeit bes Capitales nidjt genau befannt ift, fo rechnen bie Berfäufer wohl audh auf ben ungünfitigen Fafl uno forbern mehr 3infen, als fie im

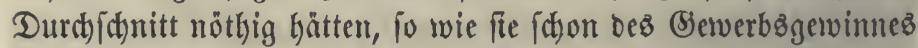
wegen mehr als ben üblidyen Sinz anjezen. Se elyer biejer Borid)us beim Berfanfe erftattet wiro, Defto geringer ift bie Bertbenterung ourdy ben 3 ins $(a)$. b) Es werben verjajiedene Berlufte verhütet, die fonft zullegt wieber von Den Räuferm

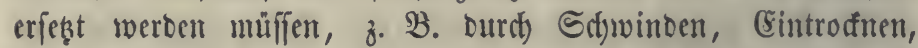

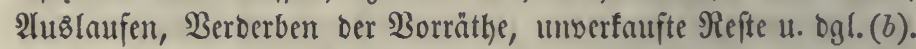
c) Etcuern, bie in cinem früberen 3uftante eines Buttes,

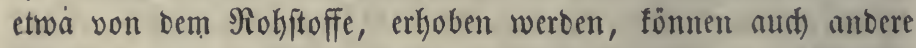
Berwendungen beffelben treffen, bie man nidjt zu befteuern

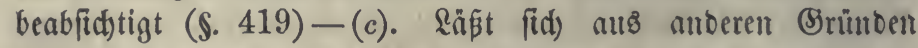
eine Alkgabe biejer 2 rt nidjt vermeiben, fo bei ber Alu\&fulye ber finufwaren bie bezalylte Steuer vergütet werben, was jebod) nidjt ohme veridjiebene Unbequemtidyfeit ift. 
(a) Sebuh erfolgt bieie Bertheuerung burdh bie Binfen barum nidat voll=

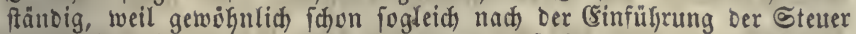

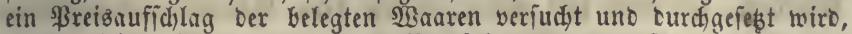

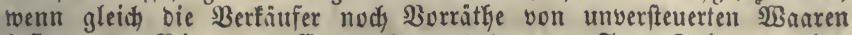
Gefiben. - Ricardo (ङap. 29) wentet gegen 5 a SWenn bex Fabricant bie Gteuter yon 1000 Fr. erft nad einem Jafye eriebt erfält unb baher 100 Fr. Sinfen barauf fallägt, fo hat bagegen ber Confument ben Nuben, bie 1000 Fr. eill Jahr fwiter zu bezahlen,

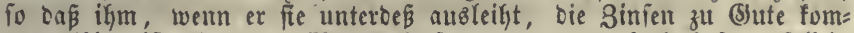
men (Gier ift bie franzöfifdhe Heberiebung II, 283 fehlerhaft). Inllein

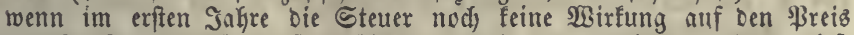

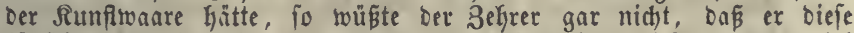
fünftig höher bezahlen muß, uno an bas 2ušleihen tiejer ganzen, bei

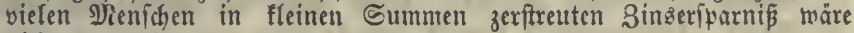
nidjt zu benferi.

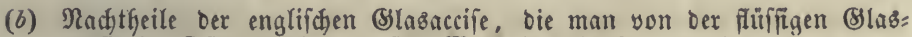

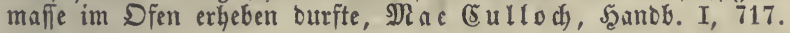

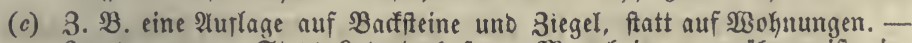
In ber neuen Stant \&ubwigghafen, Miannheim gegenüber, ift eine fitotifdye Umlage (octroi) nuf $\mathfrak{B a u p t o f f e}$ angeoronet worden. Die \$apier= fteuter in Englano beläftigte die Şutmacher, bie Berfertiger fünfllidjer

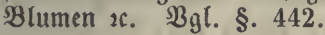

\section{§. 421.}

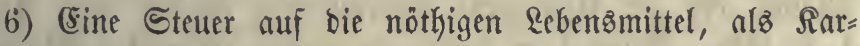
toffeln, Mehlfrüd)te, Seeizftoffe, Leinwand u. ogl., ift fefhr ein= träglich unb wirft ungefähr wie eine Ropffteuer, weil ber Bei= trag eines Scoen hautptfäct)lich von ber 3ahl feiner Şauşgenoffen beftimmt wirb, aber eben Darum verleß̧t fie ben Sirundją, baß

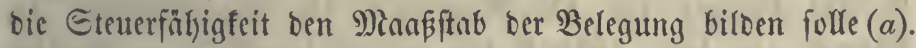
Man lyat foldte Eteueru in ber (Erwartung vertheibigt, baj fte auf bie Sohntherren libergewälyt werben, weil ber Solyn zu jeber 3eit ben nöthigen Unterkalt verghnten munfie, I, \$. 192. 2Tuein auf biefe lleberwälzung ift nidjt mit Sidjerfscit zu rechnen. Der \&olgn entfpriclyt nur bem mittleren Bebarfe uno bie $\mathfrak{B e r}=$ theuerutg ber Rebensinittel wirb wenigftenz ben $\mathfrak{B a t e r}$ einer zablreidyen Familie nicht vergůtet. Der $\Omega_{0}$ hn zeigt überbaupt

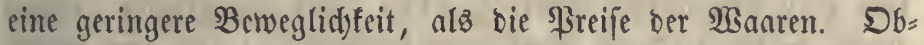

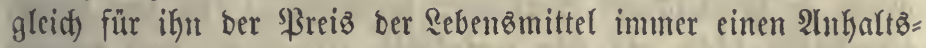

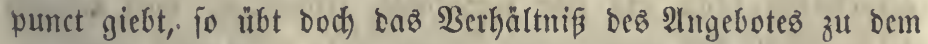
Begebre von 2lrbeit it verfdiebenen $\mathfrak{B}$ ejdäftigungen unb (Segen= ben einen mäctytigen Einfluß auf bie Rage ber \&ohnarbeiter. So lange ber Rohn nod) oberhalb ber burd) ben unabweizlicten \&ebensbebarf beftimmten Bränze fteht, faun or bei ungünftigem

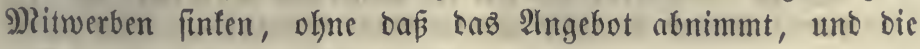
Rau, polit. Deton. III. 2. शตtদ. 5. शนвg. 
Berthetterung ber Rebens?mittel vermag ifn nidtt fogleid) zu erhöhen, fonbern erf́t bann, wenn eine 2bnakme bes 2ingebotó von 2rrbeit bei gleidjem ober zunebmenbem $\mathfrak{B}$ gegehre bemertlid) wirb. Sit bieß nidyt ber Fall, fo bleiben bie erwähnten Steuern ganz ober zum Theile auf ben 2 trbeitern liegen, und bann finto aljo bie Steutern ber genamnten 2 rt fehr nadjtheilig.

(a) v. Sgogendorp vermuthete, Dá̧ felbft bie blö́en Taglöhner bei einem Sahreseinfummen von 150 fl. etwa 16 \$roc. Leffelben abgeben fönnen (waś fehr żeifelkaft ift) und will, Das burdy paffende 2luswahl ber

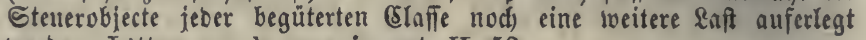
werbe. Lèttres sur la prospęr. nat. II. 52.

\section{S. 422.}

Sene Ueberivälyung ift aber aud ba, wo fie gelingt, nidjt ohne bebenflidye Folgen $(a)$. Wemm bie größere \&ohnnüganbe nidjt burd) eime anbere Siofteneriparung aufgewogen werben fam, fo mut ber Rohnherr futyen, fie burd) eine \$reiserböhung jeiner Erzzeugnifife erfę̧t zu erfhalten $(a)$, und zwar und bem Manße ber zutr Erzeugutug erforberlicten Menge bon 2trbeit, I, S. 203. Errangt er nidjt bent yoffen Eráą ber Megrnuz= gaben, bie ikm ber höhere Rohn und bie vertheuerten Cintäufe yon Betwerbserforberniffen verurfachen, fo wirb fein Bewerbs = verbienft gejdymälert unt bie Fortbauer bes Bewerbes bebroht. Erfolgt bagegen für ben 2lugenblif die \$reiserhöhung ber

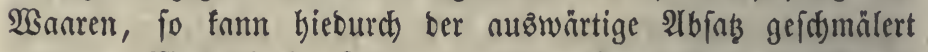
werben. Wans bie im \&anbe verzehrten Biegenftänbe betrifft, io fällt ifre Sreizergöhung allen Denienigen Bürgern zur \&aft, weldye fith nitht wieber eine Bergütung in \$reife anberer

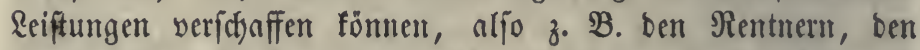

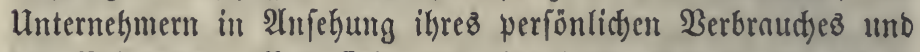

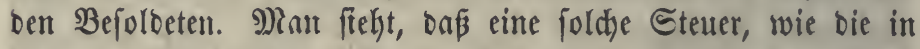
bem oben betractsteten Falle (§. 419), weit eingreifente, fitwer genau zu überblifenbe 2 Birtungen herborbringt, bie nur tarum

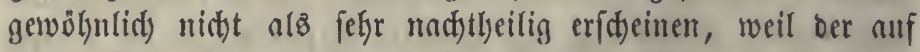

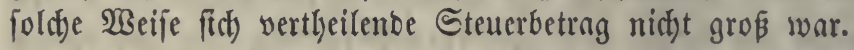

2luz alfen biejen Erwånumgen folgt bie Mnrätblidfeit einer Beftetterung ber unentbebrlidffen Dinge (b).

(a) Heber biefe Hleberwailzung 2 . Smith III, 292. - RicarDo,

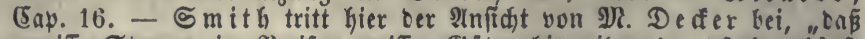
gewiffe Steuern im \$rcife gewiffer (Suter bioweilen $4-5$ fad gehänft 


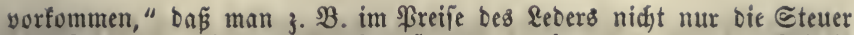

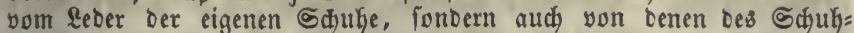

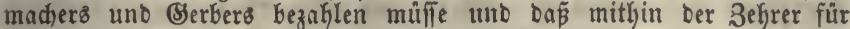
alle \&anbezerzeugniffe etwas mehr auşzugeben Gabe, um Den auf Die arbeitente Claffe fallenden Theil ber Reberfteuer zu vergüten. Sdyon RicarDo hat bie fierin liegende nebertreibung miberlegt. Da Die

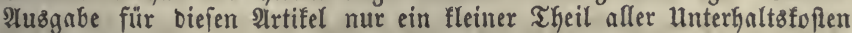
bes शrbeiters ift, fo fönnte felbft im Falle einer vollftändigen ueber= wálzung ber 3uịlag, ber noch atz biejer ttriache zu Dem Reberpreife fỏmmt, nur unfühlbar gering fein, $e$ if af aber riberfanpt nicht anzu= nefmen, Dấ $\mathfrak{B}$ eränoerungen in einem Der vielen fleinen Beftandtheile

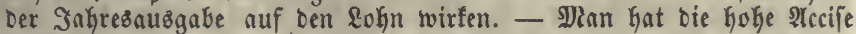
it Şolland und ben baburch betwirften Goken Lohn als eine ber $\mathfrak{H r}=$ fachen vom Berfall biejes Ranbes angejehen ( $\mathbb{a} z a c$, Betrachtungen

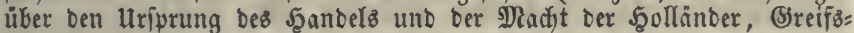
walo 1790, IV. 91), uno Die britifhen Fnbrifherren Drangen aus biefem

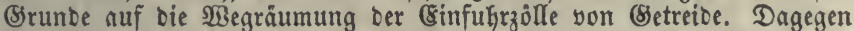
hat man in (Sirof́fbritanien uno Franfreich vielfältig aus ber Şỏke ber

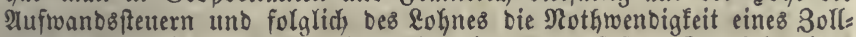
fhubes abzuleiten verfucht. Das bisherige Steuerinftem Esropbritaniens if effenbar in Diefer Şinfidyt fehlerhaft.

(b) Nec imponi debent tributa is rebus, quae ad vitam praecise sustentandam sunt necessariae, sed iis potius, quae deliciis deserviunt, aut curiositati, aut ostentationi et pompae. Sic enim fiet, ut correcto immodico luxu major oneris pars incumbat in ditiores et magis potentes, et subleventur agricolae et opifices, quae communitatis pars vel maxime fovenda et conservanda est in rep. D. Sa avedra Faxardo, Idea

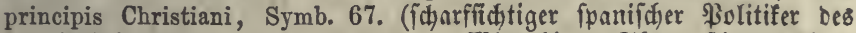

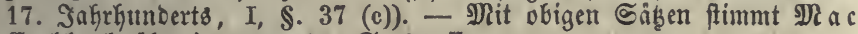
(5) UI o d überein, Taxation S. 98 fi.

\section{§. 423.}

7) Bei ben entbehrlidjften, einem verfeinerten \&urus an=

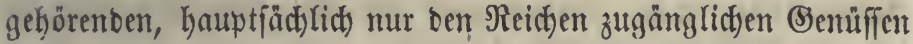
würben fehr hohe Steuerfäbe gered)t fein. Dieje find baher ofterz angerathen worben $(a)$. (Es ftehen ihnen iebod) anbere Riüffict)ten entgegen, Denn theilz trägt eine foldye Stcuer wenig ein, weblyalb auth) bie Erthebung zu foftbar wirb, - theilz bewirft bie ftarfe Bertheutertng von Dingen biejer 2Yrt bei ber

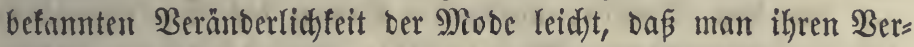
braud) aufgiebt und auf eine anbere 2lubggabe verfäll, \$. 417. Daher bürfte ber Steuerfús bei ben erwähnten Begenftänoen nur mäpin fein, wobei aber yollendo ber Errtrng für bie Stantz= caffe gering wirb. Die Befteuerung folder Sienufuittel ift

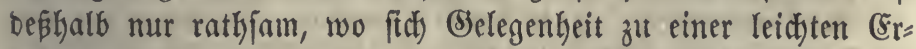
hebung barbietet, wie bei bell 3ölert. Am einträglichfen find bie Eteuern yon $\mathfrak{W a a r e n ,}$ weldye, ofne zut ben bringendften Bebürfniffen zu gebören, bod) allgemein gefdäbt finto uno in 
großer Menge berbraudt werben, namentlid) aud) yon ben beffer bezahlten Rohnarbeitern. WBirb auf bieje $\mathfrak{W e i j e}$ aud bas geringe reine (5infommen ber Arbeiter fdjon einigermaßen belegt, fo

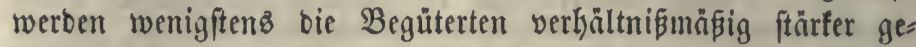
troffen. Den \&olynarbeitem läß̈t fid) Dafür, baß fie vielleid)t

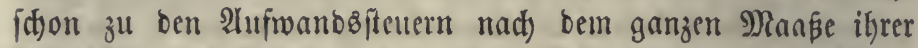
Steurrfähigfeit beitragen, bei ben Schabungen bie gebörige St)onumy bewilligen, \$. 396. Sine Steigerung bes Sohnes ift von foldyen Steuern nicht zu erwarten, weil fie bie in ber ungünftigften \&age ftehenben 2(rbeiter nid)t treffen.

8) Die Steuer follte nicht zugleid) nod) anbere Preisz= erhöhungen veruriachen, bie nicht ber Stantęcafie, fonbern ein= zelnen (Semerbtreibenden $2 c$. auf Roften iffer Mitbürger zu Sute fommen. Dieß́ fönnte Dann geidjehen, wenn ein nidjt befteuerter Segenftand zu gleicher Berwendung tauglid) ift, wie ein mit ber Steuer belegter, und jener beß̧halb ftärferen $\mathfrak{B}$ egehr erbält (b).

(a) 3. B. yon Rousseau, Discours sur l'éc. pol.

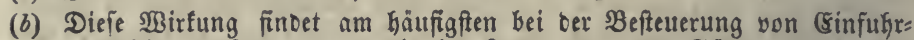

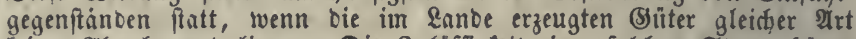

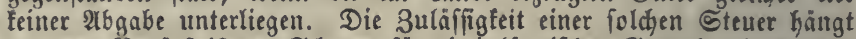

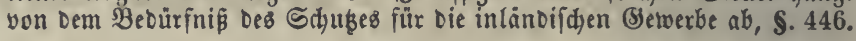

\section{§. 424 .}

Die mandbaltigen, in ben einzelnen Staaten eingeführten

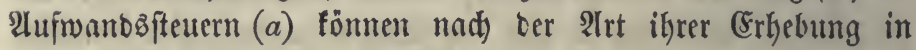
folgenbe 2tbtheilungen gebradht werben:

1) unmittelbar erhobene ober birecte, 2. श्bjaz;

2) mittelbar erfobene ober in birecte, unb zivar

a) von Wraten, bie im Snnern beż \&anbez im $\mathfrak{B} e r=$

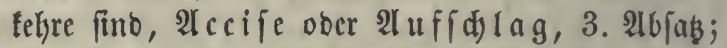

b) bon Waaren, weld)e bie Bränze bes Stanţgebietes überfđjreiten, Es ränzzölle ober 3 ölle im eigents (id)en Sinne, 4. 2bją.

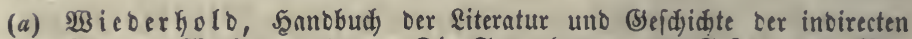
ङteuern, SRarburg 1820. - Die Sammlungen von Befepen und Ber= orbnungen vertieren wegen Der Gålifigen Beränderungen meiftens balo

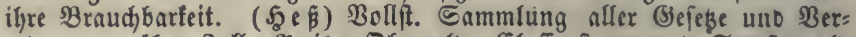
oronungen über 3oll, Rccis, Dhmgelo, Slaffenfteuer uno Etraß̈engelD im Sroß̧. Baben, Rarlorulye 1827. Sammlung aller now gültigen

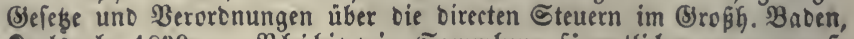
Rarlstuke 1839. - Philippi. Snmmlung fämmtlider netuer preuß̈. Befeß̧e über Die indirecten Steuern, Röln 1830. Nahtrag 1836. - 


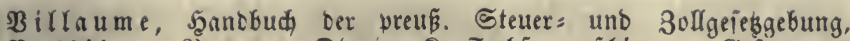

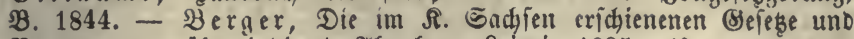
Beroronungen über inoirecte Abgaben, \&eipzig 1835, $4^{0}$.

\section{2. $2 \mathfrak{b} \mathfrak{a b .}$}

\section{Uumittelbar erhobeue alufwatosftetern.}

§. 425.

Die ummittelbare Orrbebung Der Steuer von ben \$erjonen, weldye einen gerwiffen 2lufwanto madyen, ift infoferne einfadjer, nIక fie bie Beizief)ung einez Dritten, ber bie Steuer vorichiept

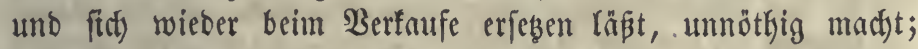
bennod) werben bie meiften, gewöhnlichften unt ergiebigften 2lufwambzffeuern mittelbar erthoben, weil biés bei ifmen leidter 子น betwerfftelligen ift, indem ein Berfäufer ben $\mathfrak{B}$ orfdus für

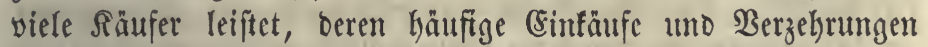
von ben Steutbermenten nidjt überwadjt werben fönnten. Brünoe für bie ummittelbare Errkebung finden Statt

1) bei bem (Sebraudje von Begenftänben Yanger Dauer, bie einen jäfrrictjen $\mathfrak{B e r l u f t}$ burd) Binzి unt 2tbnuşung, ober eine Miethausgabe ober aud nod) Unterbaltafoften veruriachen, wenn

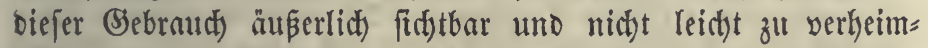

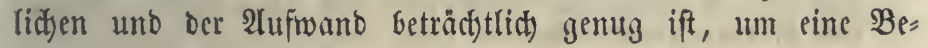

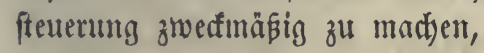

2) wenn veridjiebene 2 lügaben fortbauerno für cinen ge= wiffer 3ned gemadt werben unb baher als zufaumengehörig cine Befteuerung zuläfitg mad)en (z. B. Dienfitboten);

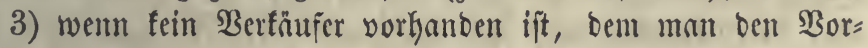

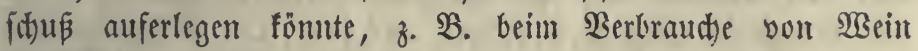

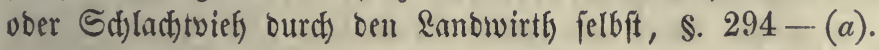

Dieje birect erhobenen 2tufwanosfteuern fino größtentfeils foldje, bie man im engeren Sinne \&uxusfteuern nennt, weil

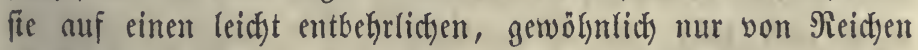
gemadten 2lufwanto gelegt fint. Sowohl beß̧halb als barum, weil man fie nidyt hodt) anjeben barf, Damit ber Ruxus nidft in antere Ridjtungen gelenft werbe, pflegen fie wenig einzu=

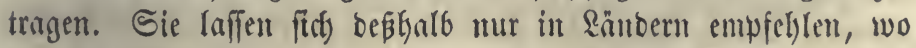

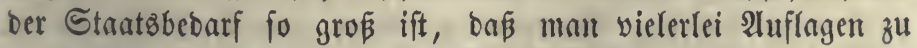

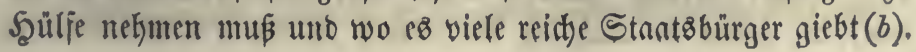


Sิn Srop̧britanien finbet man bie meiften 2 ufwandsfteuern diefer शrt $(c)$.

(a) De \$arieu nimnt vier (Battungen yon Stettern an: 1) yon ben \$erionen, 2) yon ben Sndguntern (richesses), 3) von bem (Süter= gebraud (jouissances), 4) von bem Berbraud) (des consommations). Traité II, 100. Die britte SSattung bilden bie oben erflärten un= mittelbar erhobenten 2lufwanteffetuern. Diefe vier (Basttungen laffen fí leidyt unter bie beiben Sgauptclaffen: Sdjaksungen und शufwanosfteutern bringerr.

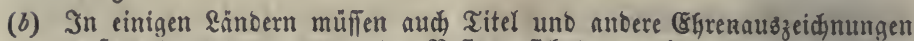
verffeuert werben, wenn ber Befiber fid Darum beworben hat. Mag

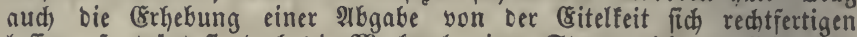
laffen, fo trägt fie boch Die Mierfmale einer Steuer nicht an fich, weil fie mach teinem wirthifhaftlidjen tumitanbe aufgelegt ift, fie erficheint

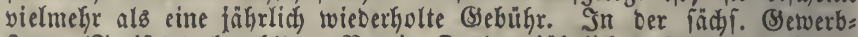
freuter (Tarif B) bezahlt z. B. ein Doctor jährlich 2 Thlr., Şoftanz:

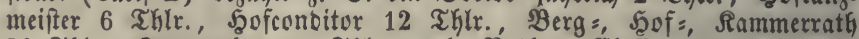
30 Thlr., Sammerherr 40 Thlr., geh. Nath I. Élafie, (Seneral, Sovf= mardjall 120 Thlr.

(c) Die assessed taxes wutrden im Safr 1798 als Rriegsfteuern eingeführt, feit 1820 aber auf mandjerlei Weife gemildert und Srland murbe 1823 $\mathrm{gan}_{3}$ befreit. 1840 erföhte man ben Fuß aller Diejer Eteuern um 10 \$roc., intoffen find feitbem verífjiebente einzelne Beränterungen vorgenommen worben. Grtrag im Sahr bis zum 31. Närz 1859 2.027384 \&. Sn Der mit taxes bezeidjneten 2abtheilung bes britifiden Boranidjlages ift auch bie (Brundpeuer enthalten. Sieht man bieíe nadi ifrem Betrage yon $1856(1.161200$ \&.) von Den taxes ab, welde im D. $1861 / 2$ und $1862 / 3 \quad 3 \cdot 176500$ \&. trugen, fo bleiben für Die \&uxusfteuern 2.153000 \&. übrig. - Die preuß̃. \&uxusfteuern (Şoict

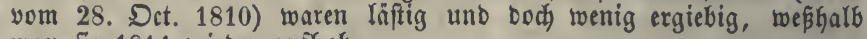
man fie 1814 wieder amjgob.

\section{§. 426 .}

Die erheblidjfte ber hieker gehörenben 2 uflagen ift bie $\mathfrak{W}$ o h $=$ nungs fteucr, bie vou jebem Bürger, er fei Şaubeigenthümer ober Mietfimann, nach bem muthmaflidyen Miethzinfe ber von

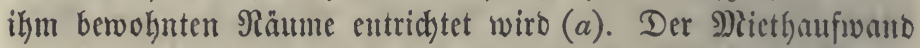
ift in vielen Fällen ein gutez Renuzeict)en Der Bermöglidjteit,

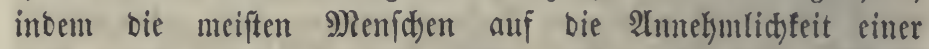
gerăumigen, bequemen uno gefälligen $\mathfrak{W o h n u t g}$ groß̧en $2 \mathrm{Berth}^{-}$ legen uno baher bie Wohlfabenden eitte ifrem (sinfommen

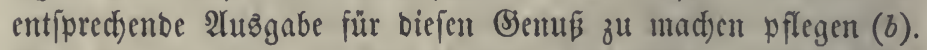

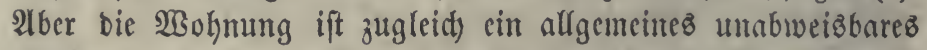

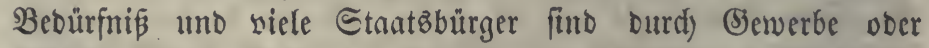
anderen Beruf, Brößje Der Familic 2c. genöthigt, eine 20 ohnung von einer gewiffen 2lusbehnung, \&age uno Befdaffenteit zu mietlyen, wenn fie aud) im Berbältniß zu ibrem Einfommen in 
läftigem Maaße foftbar ift. 2Tnbere, z. B. Sapitaliften uno viele \$enftonirte, baben bierin eine freiere $\mathfrak{W a b l . ~ N u r ~ b e r ~}$

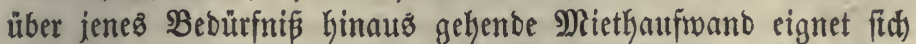
Daker zur Befteuerung, uno eine Miethfteuer, bie yon allen Bürgern einen gewiffen gleidhen Theil ber ganzen Miethaubabe

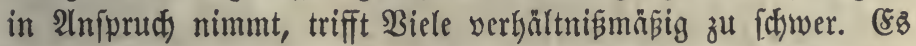

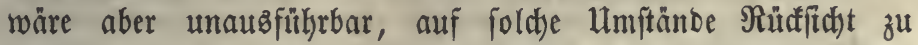
nefymen uno in jebem einzelnen Falle ben entbebrlichen Theil ber Miethausigabe zu ermitteln (c). Şieju toumt, baß eine

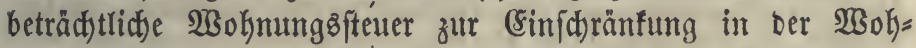
nung aufforbert, hieburch oft ber (Sefunbkeit fdrabet, auch bie

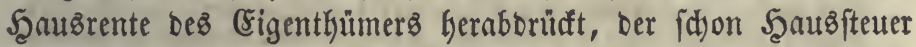

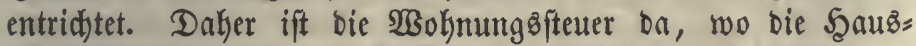
fteuer unb bie anberen Schabungen vollfänbig unb gut ein= geridytet fint, nidyt zu empfehlen. (Slaubt man in einem sanbe biefelbe nidjt entbehren zu fönnen, fo ift es wenigitens rathjam

1) einen geringen Miethbetrag fteuerfrei zu laffen, wobei aber bie (Sränze, über weldher bie Steuer anfangen foll, fdywer zu beftimmen ift, weil bie Miethpreife in veridjiebenen Drten fehr ungleid) fint;

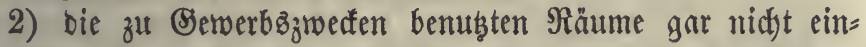
zuredinen, wenn fie fifon in eimer Serverbfteuer berüditctigt finto.

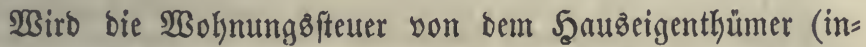
birect) erhoben, uno bemielben erlaubt, fie yon ben Mieth= bewohnern erftatten zu laffen, fo ift biejer Eriag nidyt fitder, weil er mit bem Miethzinz serbunben ift, bon bem Miethbs= mann als Theil beffelben betrachtet wiro uno bie erfjöhte Mieth= ausigabe viele Familien antreibt, fith in ber $\mathfrak{W a h l}$ ber $\mathfrak{W o h m u n g}$ fparfamer einzuridyten.

Sine nad) ber 3ahl unb (Siröße ber gegen auken gehenben Deffmungen (Thüren unb Fenfter) bemefiene Steuer belaftet nod) barum befonbers ungleid), weil fie ie nad) ber Bauart einen serfdiebenen Betrag erreidt. Bei neuten (Sebäuben faum man auf Eriparung an ber Steuer Bebadbt mehmen, bei älteren ift man burd) bie zufällige Eimridtung berjelben gebunben $(d)$.

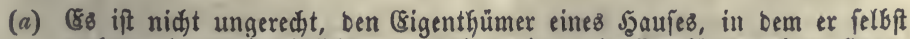

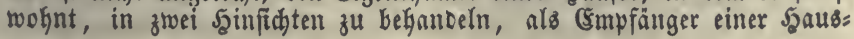


Dh rente und als Betwokner, vorauge vermicthen wären, \$. 347. 348. शber eine Wohnungsfteter if nur in 3citen uno Drten paffeno, wo viele \$erfonen in IRiethe wobnen. Dns alte Raudigel' (fumagium) unb Sceerogelo (focagium) toar eine

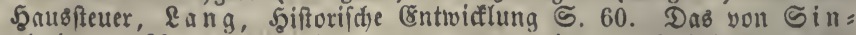
clait erwakgnte Şecrogelo (hearth money) im 17. Jahrhuntert war wegen bes Druffes für bie Dürftigen und wegen. Der Befidtigung Der

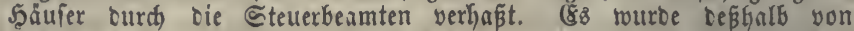
Wilfelm III. aufgehoben und ourch bie yon aupen zu regelnie frenfter= ftener erfest, wovon fleine \&anbhäufer (cottages) frei blieben. Mac

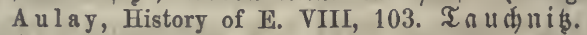

(b) Der (Englanber Derfer fd)lug 1743 vor, alle nnberen Irten ber 2 lecije

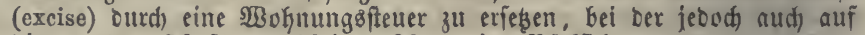

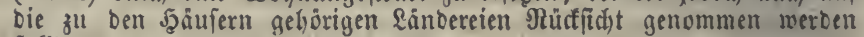
follte; de Parieu, Traité II, 120.

(c) Die MRiethaubgabe if bisweilen nur $1 / 10$ ober noch weniger, fie feeigt aber nuch offers nuf $1 / 5$ uno felbft $1 / 4$ Des Einfommens. - Die fran=

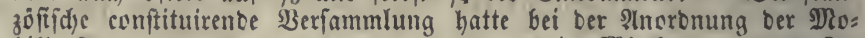
biliariteuer (contrib. mobilière) angenommen, cine Miethe von 12000 Fr. entipredie einem 121/2 fadjen (Einfommen, $3-5000$ Fr. Dem 8 fadjen, $2000-2500$ Dem 6 fachen, 500-1000 fr. einem 4faden, 100-500 ₹r. Dem 3 fadjen, eine Diethe unter 100 Fr. aber Dem Dopvelten fteuerbaren sinfommen, uno es wurben 5 Proc. Diefes angefolngenen binfom:

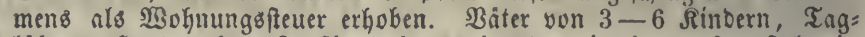
lögner, Santwerfer, Raufleute famen in eine niebrigere, Sageftolze in

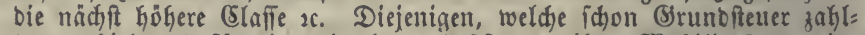
ten, etrfielten bafür eine niebrigere Feftiebung ifgrer Nobiliariteuer, in= bem man biefe nur bazu beftimmte, Das (Sinfonmen aus beroeglidem Bermögen, Jewerben uno (S) Salten, salaires publics et privés, zu belnften. (ङo fönnte man auch oen Slangel ciner Binørentenfteller

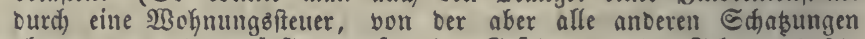
abgezogen werben ourften, exfeben). (Befes vom 18. Februnr 1791. Code des contrib. dir. II, 25.

(d) Befteuerung Der Wolgnungen in Franfreid: 1) Contribution mobilière; nelt georonet im finnngeiels vom 21. Thril 1832, cine

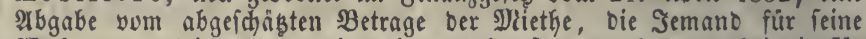
Bgoknung entridtet ober im eigenen Şaufe vermohnt, wobei cie für

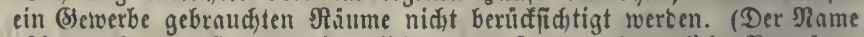
rührt Daker, Dá̧ man eigentlid) Das gejanmte beweglidłe Rermögen zu befteuern futhte, fid aber wegen ber Dalei vortommencen Schwierig:

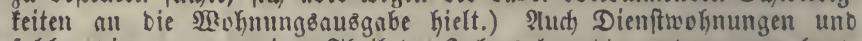
polde, bic man unr cinen Theil bes Sahres benubst, merbest angerechnet. Nur möblirte $\mathfrak{B}$ ofmungen fitto fteuerbar, aber wenn bie Simmereintid)= tung (Mobeln) Dem Bermiether gefort, fo wiro ber für fie in $\mathrm{cem}$ I)iethzinfe enthaltene Theil abgezogen. Dürtige bleiben frei. Diefe

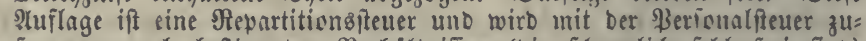
fammen nad beptimmten Berbältniffen (bie fowerlid) fehlerfrei find) unter bie Departements, Ârrondiffements uno (Semeinden, in tiefen aber nach ben valeurs locatives umaclegt, vgl. §. 397 (b). Beridjie= bene Berfudbe, bie Steuer ną) ten Bermógensumptänben ber Bewohner eilluridyten, fino yon bem Staatsenthe als Dem (Befebe widerftreiteno unteriagt worben. Den Semeinden, weldbe ein Detroi haben, ift erlaubt, die \$erional= unb Mlobiliarfteuer ganz soer zum Theil aus Der (Scmeinbecalle zu bezahlen; bavon mad)en jebst nur noh adt Stabte (B)braud). Bl ock, Dictionn. S. 561. de Parie u, Traité II, 116. Ver ganze Betrng Der Yliethen wurbe 1823 auf 304,1829 auf 384 D)tiff. Fr. angefalagen. Mefrere Stäote Gaben Dieje Steuer ganz ober 


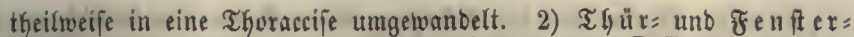
fte uer, von Thüren, Die inz Freie gehen uno von Deffnungen, weldhe Sidjt von aufien in bie Bebättoe fallen lafien uno mit BIas uder einem

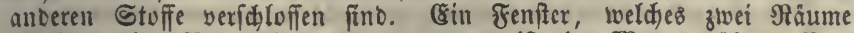
erkellt, wiro fiur zwei geredhnet und es ift eine Menge näkerer Bors fijriften gegeben worben um zu beftimmen, welde Deffmungen Die Steuerpficht begrünoen. Ställe, Sdjeunen is. fino frei, aud bie Berfråume groß̈er Fabrifen (manufactures), bie Semád)e ber offent= liden Lehr = unD Siranfenanfalten, aber nidjt bie usines, in Denen

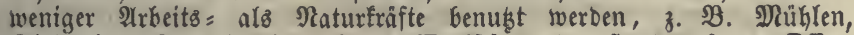
(S) iefereien, 3uderfabrifen, fermer Werfitätten ber Şambrerfer. (DFfen= bar fehlt Gier Dent (Sefes ein fefter (Srundfab und bie Sränzbeftimmung ift oft willfürlich.) Diefe Steuer wiro ebenfalls repartirt, boh mit einem Tarife, Der zur IImlegutg ber auf jebe Semeinbe treffenben Summe

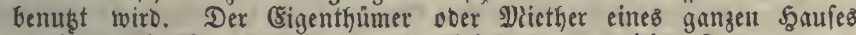
entridhtet bie Stetter, if aber berechtigt, wenn uidhts An beoungen wiro, fie von jebem Mitethomanne fich erfeben zu Iaffer. Der Tarif ift nad) ber 3ahl ber Deffungen uno ber (sinwohnerzahl Der Drte abgeftuft. Bei einem Saaule von 6 uno mehr Deffnungen 3. B. bezahlt (ङ)efes bon 1832) in Stribten von 10-25000 (8inw. ein Thorweg (porte cochère) 7,40 Fr., eine geinöfnlidue Şnusthür uno cill Fenfter im (Erogefd) of́ und ben beiben erften Studwerfen 90 (5ent., ein Fenfter im oritten Stodwerf und ff. 75 (Eent. Bei weniger als 6 Deffnungen wiro zเvifijen Fenfern und Thüren nidjt unterífieben uno es zahlen 3. BB. in Drten unter 5000 (sinw. 5 Deffnungen 2,50 Fr., 4 Deff= nungen $1,60 \mathrm{Fr}$. 3 Deffnungen $0,90 \mathrm{Fr} ., 2$ Deffnungen 0,45 , cine einzige 0,30 Ft., in Stioten über 100000 Eintw. geben 4 Deffnumgen

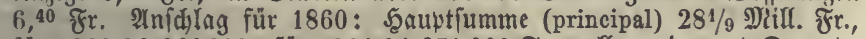
fứr $186329 \cdot 360000$, für 186434.971000 Fr., allgemeine uno Devart.=

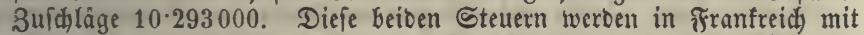

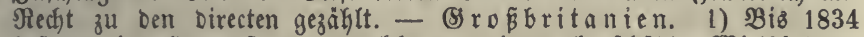

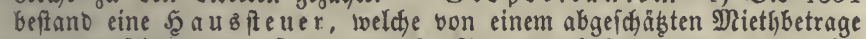
bon 5, feit 1825 erft von 10 \&. St. an erkoben wurbe und oaker

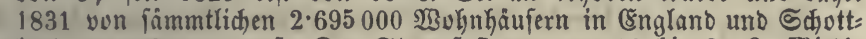
lano mur 430000 traf. Der Steuerfus war von 10 bis 20 \&. Inieth=

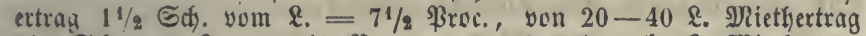

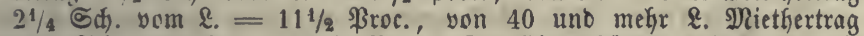

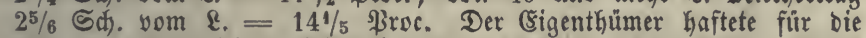
Steuer, bie ex feinen Dietysleuten beredinen founte. 1831 trat eine Ermäsigung vou Saanbelzgebäuben ein. Errtrag 1830-33 im D. 1.352126 \&. St. - 2) Die Fenferfteuer, window duty, traf in gleider Weife, wie bie Şausfteuer, bie Eigenthümer uno Nietheleute uno begann, feit Der im Jakgre 1823 eingetretenen Szerabfeķung auf bie Faälfte, bei Şäufern mit 8 Fenftern; 1840 wurte fie um 10 Proc. erböht. Borber betrug fie 8 . $\mathfrak{B}$. yon 8 Fenfter $16 \frac{1}{2}$ Sd,., von

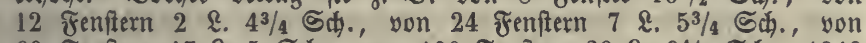
60 Fenitern 17 \&. 5 Sd., yon 100 Fenitern 29 \&. $81 / 2$ Sd). 1848 waren gegen 3 श्ill. Şäufer frei uno 487411 Der Fenfiterfteuer unter: worfen, weldje 1.813629 \&. St. eintrug. Sie wirfte nadbtheilig auf

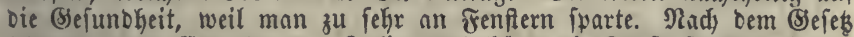
14. 15. Vict. (Eay. 36 (24. Suli 1851) Görte bie Fenfterfteuer auf und

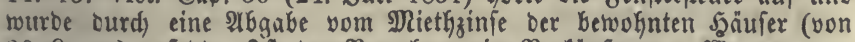
$20 \mathfrak{L}$, an) eriest. Sit Der Bewokner ein Berfüufer yon Waaren oder

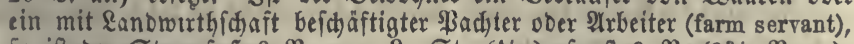

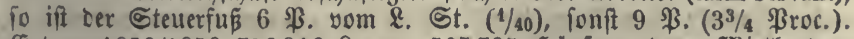
(8rtrag 1858/1859 778916 \&. yon 505795 5auiuern, Deren \$liethertrag

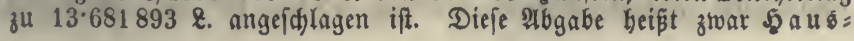


fieuer, if aber von Der Sdjakung biefes Namens weientlid veridie:

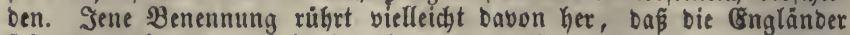

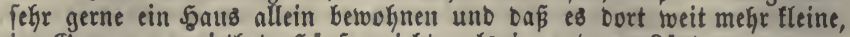
im (Sanzen vermietbete Şäufer giebt, als in anberen \&änbern.

In $\mathfrak{B}$ elgien wie in ben Nieberlanoen beftehen alB Theile ber

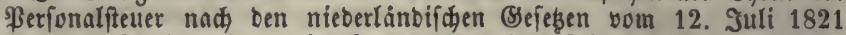
und 28. Juni 1822 (bgl. oben §. 396 (b)) folgende hieher geforige

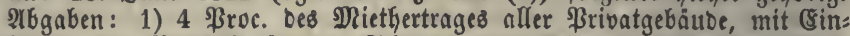

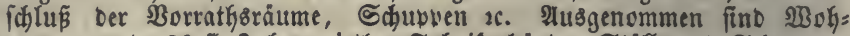
nungen unter 20 fl. Jahresmiethe, Fabrifgebäube, Ställe unb Søeunen, Sirdjen, Sdulen $x$. Der Eigenthümer ober Nitether Des ganzen Jaaufes fann fich bie 2 bgabe von ben פliethern einzelner Theile erieben lafien. 2) Thür unb fenfterfteuer mit ber nämlid)en Beptimmung. Im (\&rD: geidjó uno ben zwei exfen Stvofwerten für eine auf Straje ober Şof

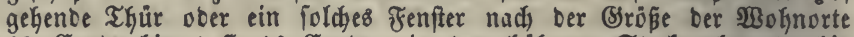
40 Cents bis 1 fi. 10 Cents, in Den hoberen Stodiverfen 40 bis 50 Cents. 3) Bon jeber Feuerftelle (Eamin, Dfen, Sceerb xc.) 40 bis 75 Centz bis 1 fi. 75 Eents, je nacjbem eine Stelle, ober ztwei voer brei und mefyr vorkanben fino. Aluch hier gilt bas Drige in Anfehung Der Shiethleute. (Ertrag Diefer brei Arbgaben in Belgien im Jafre 1857 1) $2 \cdot 307230$ Fr., 2) $3 \cdot 166143$ Fr., 3) 962347 Fr.

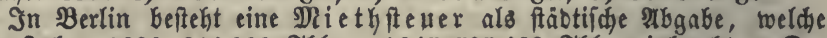
im Jahre 1838300000 Thlr., 1847735462 Thlr. einbrachte. Der

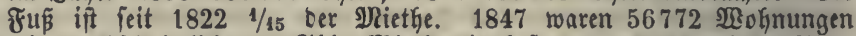
mit burdidnnittlich 115 ThIr. Mietfpreis beftettert, 13452 mit 35 ThIr. NRiethe im $D$. wegen ber Dürftigfeit Der Bewokner fteuerfrei. Inter diejen fteuerfreien befanden fid 5857 bon $1-30$ Thlr., 5 von $201-$

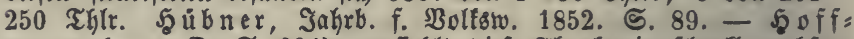

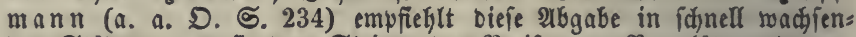
ben Stábten, two fie bem Steigen tes \$reifes ber Baupläbe entgegen= wirfen fann.

\section{§. 427.}

Anbere in mefyreren Staaten eingeführte Steuern biefer 2 rt fint auf folgenbe Begenftänbe gelegt:

1) Şunbe. Die Befteuerung Derfelben hat zugleid) einent guten polizeilidyen Bruno, weil wegen ber Befafir ber $\mathfrak{B a f f e r}=$ ficheu eine Berminderung ber 3afl ber Scunde zu wünichen ift, auth) bie Steuererkebung mit ber jährlicjen nothmendigen $\mathfrak{B}_{e}=$

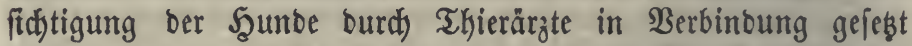
werben faum $(a)$. Die beiben 3medte biejer 2 lbgabe fallen bei foldjen Şunben hinweg, bie Semant einez Serwerbes ober ber cigenen Sidjerbeit wegen zu halten genöthigt ift, nur nuxifien

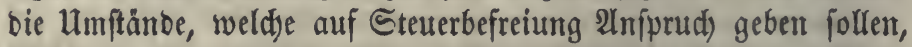

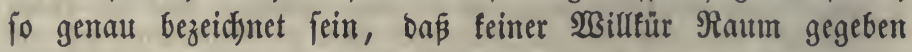
wirb $(b)$.

2) Dienftboten unt überfanpt Bebiente für perions lidje 3 mede ber Familien. Die in einem Serwerbsbetriebe be= fdäftigten F̧augigenofien werben fijon in ber Berwerbfteuer 
berüffictigt, audi) follte billigerweife eine zur Bebienung ber Familien nothnenbige $\mathfrak{A} \mathfrak{n} z$ ahl von weiblichen Dienftboten, alfo etwa zwei, fteuerfrei fein, es bleibt aljo mur eine größere $\mathfrak{A}$ n=

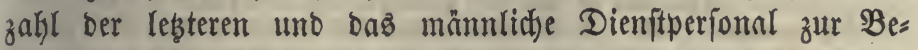

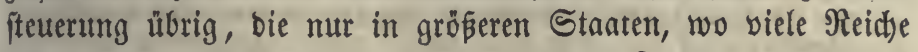
leben, eine zur Cinführung einer fold)en Steuer ermunternbe Einnahme gewährt (c).

3) $\Re u t f d$ en $=$ und $\Re$ eitpferbe, bie bló zum $\mathfrak{B}$ ergnügen gekalten werben, fowie bie zugehörigen $F u h r$ werfe. Alut) biefe 2 uffage wirb mur ba, wo viefe Reidje woknen, einen belohnenten Ertrag barbieten und bie Feftefesung ber befreienden umftänoe ift bei ifre ebenfalls fojwierig, fonft aber fann fie wohl in Sdjut genommen werben $(d)$.

Man hat hie und ba nod) andere Siegenftänbe eines bauern= Den Sebrauches unmittelbar (bei ben Befítern) zu beftetern verjucht, indés ftehen biefelben ben oben genannten in ber einen ober anberen Beziekung nad), inbem fie balb zu wenig Ertrag geben, balo zu fidwer genau zu ermitteln find und zu bäufiger Berbeimlidfung Belegenteit geben 2 . (e).

Die ganze berweglidje, in ben $\mathfrak{W}$ ohnungen enthaltene Szabe (mobilier) ift ber vielen nöthigen Âtżnahmen unb ber fidwies

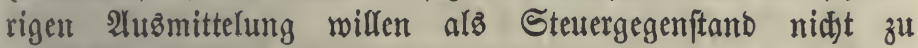
empfehlen $(f)$.

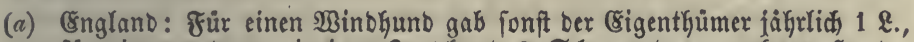
für einen anberen einzigen Sagbhuno 8 Sd., unb wo mefreere suunde, 14 Ed. für jeben. פDit 36 \&. jẩhrlid fonnte Seber bie Steuter fǘr

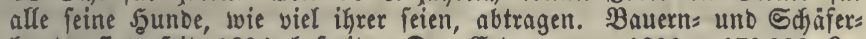
Gunbe Fino feit 1834 befreit. Der đrrtrag war 1833: 173888 \&., 1848: 134827 \&. Seit 1853 weerben für jeben 5ुund 12 ๔d. ents

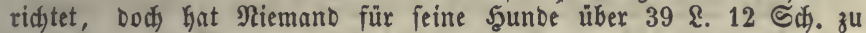
bezaglen. Sthâferfutude fint frei. $1858 / 59$ waren 326450 5unbe. Der Ertrag war 1860/1 197520 \&. - Baben, Seéés y. 23. Dct. 1833: 1 fi. $30 \mathrm{fr}$. von jebem Şunbe, 1 fi. yon einer Şüunbin, alle Befretiungen aufgetfoben; $1 / 3$ bes Betrages fiel an bie Bemeinden. (Bef. v. 10. Sept. 1842: yon einem männlidien Saunde 4 fil., yon einem weibliffen 2 fi.

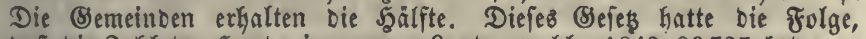
Dá̉ bie 3ałl ber Jुunbe im ganzen \&anbe, weldye 184239727 betragen Gatte, fid 1843 auf 24957 verminberte. Beefé vo 20. Dec. 1848:

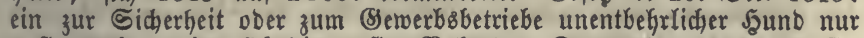

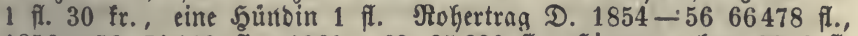
$1856-5871448$ fl., $1860-6285823$ î. Shievon gehen 2876 fi. Erthebungstoften ab, es blieben alfo für jeben ber beiben Theilnehmer 41980 fi. - WBürtemberg, f. (b). - Sro bern unb Nadytigallen, 2.. 1857-5940000 fl. - Bremen, 1817:

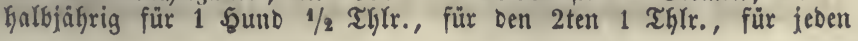


weiteren $1 \frac{1}{4}$ Thlr. - In Franfreid ift neuerlid mefyrmals eine Fुunbes fetter yorgejd)lagen worben, Das (Sefeb v. 2. Mini 1855 führt fie als Semeinterbgabe ein. Sie faun $1-10$ Fr. bon einem Şunbe betrager. Die Regierung bejtimmt für jebe Sremeinbe ben Eteuerjas, roobei bie zur Iago ober zum Berguligen gehaltenen Şunde Göher belegt werben als andere. 1856 zấhlte man $1.870850,1860 \quad 1.748514$ Saunbe. de Parieu II, 149. - In Belgien fommt biefe Cteuer als \$rovincial: abgabe vor.

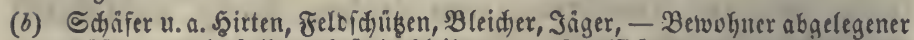
5̧b̈e u. Ogl. follten befreit bleiben. - In 23 ütemberg beznhlte man fruber in Fâllen eines foldhen B̉edurnfniffes $24 \mathrm{tr}$. für einen Souno, Dagegen für einen entbelyrlichen 4 fl. uno fïr cinen Jaģofuno 1 fí. Diefe Eteueriäbe twurben 1S39-1841 hernbgelebst, allein cie 3nhl cer Szunde mefyrte fich fo ftarf, Daß man 1842 bie frithere 2 tbgabe wieber: herferlte und für ben zweiten und jeben toeiteren \&uxushund eines (Eigenthümers nod) 2 fl. Steuer zulegte. Die Scálfte Des Seinertrages

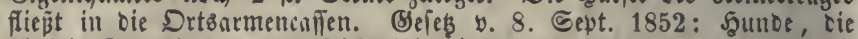
für eill Bewerbe oder zur Gidherkeit bienen, ber erfte 2 fi., jeder weitere 4 fi., alle anderen refp. 4 unt 8 fi. 2 . für $1858-60$ roh 83102 , rein für Die Stant8cafle 38602 fi., श. 1861-63 roh 91000 fl., rein 41771 fi.

(c) İn Şollano fam fđjon im 17. Jahrhunbert eine Dienftbotenfteter vor. In melyrexen $\mathfrak{L}$ änoern wird für ben zweiten und jecen folgenden Dienft: boten ein fteigenb höherer Ctemerbetrag geforbert als für ben erfen; 3. B. Niederlande: 1 Bebienter 5 fl., einer von $12221 / 2$, einer von mefr als 1240 fi. Es find 5 Claffen von Dientiboten. (Srzieherinnen fino befreit. - Die englifde Steuer yon männlidben Bedienten trifit aud) bie Belwerbsgefullfen, weil in Brobbritanien feine (Sewerbsfteuer befteht. Adferfnedgte find feit 1823 frei. Nan bezahlt für einen $\mathfrak{B}_{e}=$ bienten 1 \&. 1 Shh., aber wenn er unter 18 Jahren ift, nur bie Şälfte. $1858 / 59$ waren 227875 Beoiente, für weld) 197190 \&. eingingen. Bor 1822 war bie Steuer 2 \&. 8 Sd). - In Belgien ift Der Fur $6,{ }^{36}-14,84$ Fr. yon jedem Bebienten. Grtrag 1857: 638548 Fr.

(d) Srob̧ritanien hat megrere Săbe für verfdjebene fuhrwerfe, aud iteigt Die \$agabe mit Der 3ahl Der frthrwerfe und \$ferbe, Die Jemand befigt, 3. $\mathfrak{B}$. eine einzelne 4räbrige Ruthdse giebt $6 \mathbb{\&}$, eine von zmeien $6 \mathfrak{\&}$.

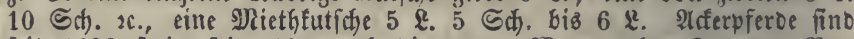
feit 1822 frei, feit 1823 auch bie carts, 1 agen ofine feocrn. Bon

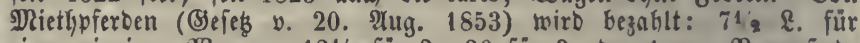

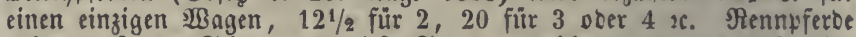
geben 3 \&. 17 ธd.), uno Diefe ๔teuer, weldbe $1857 / 85470$ \&. ein= bradgte, ift 1857 zur शccife übertragen worben. Sonft giebt cin \$ferb

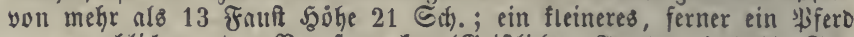
zu getwerbliden oter Bertifbztweden (Seiftliche, Rerzte xc.) 101/2 §क. Bierräbrige $\mathfrak{W a ̈ n e n ~ e i n i p a n n n g ~} 2$ \&., zwei= ober mefripannig $3^{1 / 2} \mathfrak{\&}$., aber unter 30 Soll $\Re$ andhohe refw. 1 und $1 \frac{1}{3} \mathfrak{\&}$., zweträcrige $3 / 4$ und 2 \&. $1857 / 8$ twurben bon 244118 veridjietenen 28 ägen $312775 \&$, yon 525000 ßfercen 355253 \&. entridtet. (Sine Rutide mit \$rerten, Bedienten, शlbgaben, wirb auf mindeftens 250 \&. jäfrliche sujten an= geidflngen. Bibl. univ. Det. 1835. Porter, Progress of the nation S. $531 . \cdot 3^{\mathrm{d}}$ Report of the Commissioners of inland revenue, 1859, ธ. X. - Şiezu fommell nod) zwei fonberbare Steuern, nämlich 1) yon

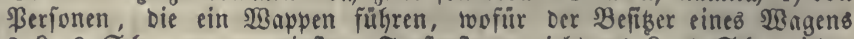
2 \&. 8 Sd)., wer wenigitens Fenfterfteuer giebt, 1 \&. 4 Sd., jeber

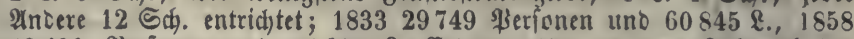
42433 \$erionen unb 54634 \&. Ertrag; 2) von bem (sebrauch bes 


\section{7}

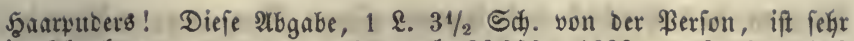
im Abnefgmen; eछ waren 1820 no 29000,1833 nur 9472,1858 1040 ßerfonen, welde 1222 \&. entridjteten. - Niederläno. Bfertes fteuer, von einem \&uxuछ̊yferb. 25 fl. fährlich, yon zmeien 55 , von orcien so und yon jebem lweiteren 20 f., bon 2 Pferden eines 2 trates und

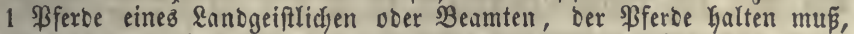
je 15 f., yon einem \$ferbe ber ßofthalter, \$ferbeverleifer 2 c. 8 fl. -

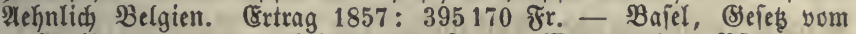

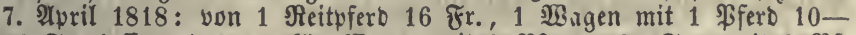
16 Fr. (offen Dber gedecft), $\mathfrak{B a g e n}$ mit 2 ßferden 30 fr., mit 3 Pf. 40 fr., mit 4 Bf. 50 Jr. - Bremen, $\mathfrak{B}$. v. 28. Dec. 1816: von 1 Sutfác mit 2 ģferben jährlid 25 Thlr., bon jebem anberen zum Bergnügen gefaltenen Pferbe 5 Thlr., yon einem Bemerbäpferbe 21/2 Thlr. - Sarbinien, Sejeb v. 1. Mai 1853: Fuhrwerfe für eigenen (Sebraud), 2 räbrige mit 1 \$ferte $7,50-10$ Fr. nad) ber (8in= wohnerzakl Der Drte, 4 räbrige mit 1 Bferbe 15-20 Fr., mit 2 Sferben

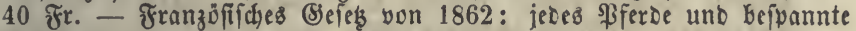
Fuhrwerf, weldhes für ben perfönlichen (sebraud) (service) bes (sigen= thưmers uno feiner Framilie bient, giebt eine Stcuer; 4räbrige ₹uhr= werfe in \$aris 60 Fr., in anberen Srten 10-50 Fr., 2räbrige ebenjo

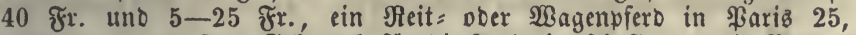
anberşwo 5-20 ₹r. (Sebrauch für bie \&anbwirthidhaft ober ein \$atent: getwerbe ift frei. Die Bemeinbe exhält $1 / 10$ Des Critrages. 2 . 1865 2.850000 Fr. ofne 300000 Fr. Sujhling für Semeindenubgaben.

(e) Staat Birginia 1849: von einer golbenen uhr jågrlich 1 Doll., won einer geringeren Sorte 50 Sents, won Tajdembren aus Silber oder

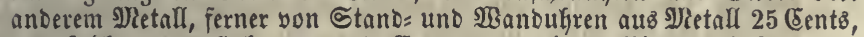

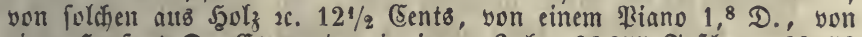
einer Şarfe 4 D. E8 wurbel in jenem Jahre 28875 Taiden=, 69458 Stand= und $23 a n d u h r e n, 4715$ Sianos und 21 Sarfen verfteuert, zu= fammen unit 38027 D. Ertrag, von (Sold= uno Śllbergefd)irr 2954 D. Etaat Jolwa, Steuer von 1311 แhren uno 47 ßianos. - 2. nieverl.

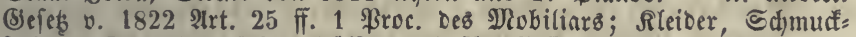

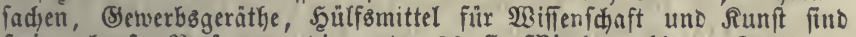
frei, ebenfo ßerionen, Die unter 20 fi. Niethe zahlen. Gtatt Der

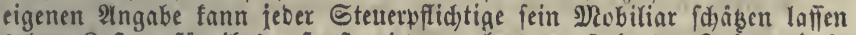
(ohne Soften für ifn), fonft wird es als oas 5 fache Der Sakresmiethe angefdlagen. Recueil de lois ... concernant les contributions directes, douanes et accises ... Brux. 1837, ऽ. 25. 33. - Ertrag in Belgien 1.440000 Fr. - In manden \&ändern twurben früberbin Steuern von feibenen Rleibern, tapezirten Simmern u. Dgl. berfucht. Beifpiele Bei de Parieu a. a. $D$.

\section{3. $\mathscr{A} \mathfrak{6} \mathfrak{a}$ \\ Accife ober Autifiblag.}

§. 428.

Daz Unterfdeidende ber 2 ccife (a) ober, wie biefe Steucrs art im Deutichen am beften benannt werben fann, beß $\mathfrak{A} u f$. fd) lageb (b) befteht Darin, daßj bie Stcuer von gewiffen

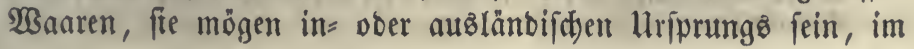


Sanern bes Ranbes bei irgento einem $\mathfrak{B}$ organge währent ihrer

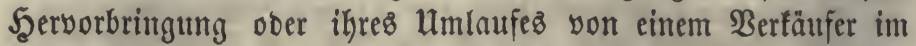
Eewerbsbetriebe boridjufweife entridjtet wirb. Dieje idjon fefsr alte 2lrt ber 2 ufwanbsfteutern if in ben meiften Stantert aud ję̧t eine ber ergiebigiten uno fann bei guter (Einrid)tung bem

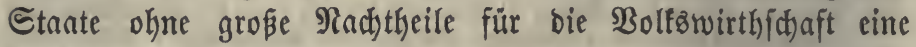
betråd)tlid)e (Sinnaf)me zu $\mathfrak{B}$ ege bringen (c); oft ift fie icbod), burd) fehjlerhafte 2tuorbunngen, bie Uriache harter Bebrïfungen

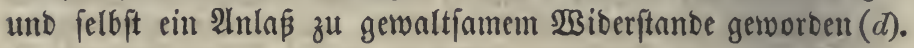

(a) Das Woort Accile ftammt, wie bie yon $\mathrm{Du}$ Cange gefammelten Stellen beutlid zeigen (Lexicon s. v. Assidere, Assisa, Cisia), yon assidð̌re, auflegen, fefffę̧en, her; man fagte z. B. im Nittelalter Assisa panis - assisia super venalibus (2lbgabe vour Feilichaften) DDer rerum venalium; talliam assidere, cine Sdabang auflegen, twie nod) Geutzutage assessed taxes in Englano. - Assisa für Etänbeverfammlung ift wohl aus bem neutrum assidêre abzuleiten, Sighnng. Excise, bie

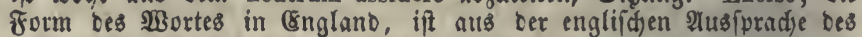

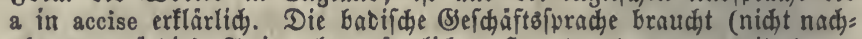

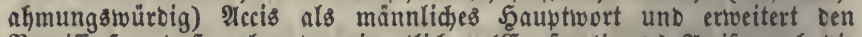

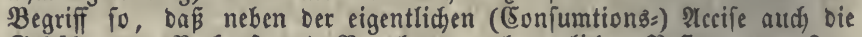

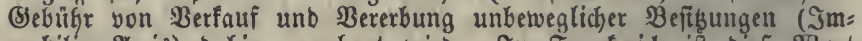

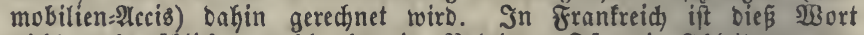
nidyt mefr äblid, wohl aber in Belgien. Für bie शrbleitung yon asseoir, statuere, audb Skinner, Etymologicum linguae anglicae s. v.

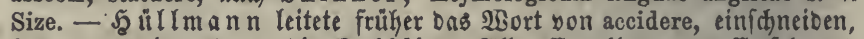

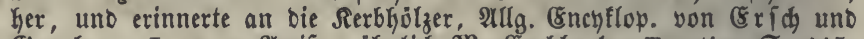

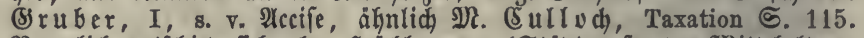

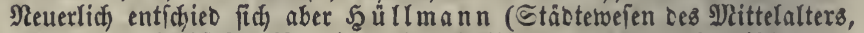
II, 115) gleidffalls für bie obige (đreflârung. Cisia, fpanif́c) zisia, beutfi Sife für eine Tranfffetter if entweder eine 2ibfürzung von accise ober fommt von Delt Rerbhölzern, Die zur 2tbredinung Dienten, Daher aud) incisio, incisura, Sd,nitt. Dic ipanif́che alcavala, eine albgabe von anfangs 5 \$roc. Der feilgebotenen Dinge, wutroe in ben driftliden Stanten nach Dem Beifpiele Der Iraber eingeführt. (Itrabifín) kabal, empfangen, keblah Das Empfangen, aud Das Empfangene, uns ins: beiondere (selo.) Nad, Nariana ift fie 1342, nad Ferrera 1349 eingefưfirt worben. Das $\mathfrak{2 B o r t}$ fommt aber fifon früger yor in oen yon ben MRauren eroberten Begenden, wofür $\mathrm{D}$ u $\mathrm{C}$ a $\mathrm{n}$ g e Urfunben yon 1101 und 1213 anfühtrt. Sm Sahte 1349 erfolgte Die Errföhung auf 10 Procent, wozu im 16. Jahrfunberte nod vier weitere Bufकlag= procente famen, Daker die Benenmung alcabala y cientos. In Den einzelnen Srovinzen erthielten fid manderlei iBeridfiedenheiten. - Im Deutfiden

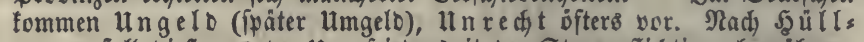
mann foll Dieß aus ber unzufriebenheit ber Eteuerpflidatigen herrühren, wie mala tolta in Englano uno Franfreid, intoćs bedeutet $u n$ nidit immer eine SNipbilligung, wie z. B. Ungerid)t im Sadfenfpiegel (I, 57), Das \&erid)t Des (s)augrafen. Def̧Galb betradjtet \&ang, S. 105, bas ungeld als eine aufierorbentlidje abgabe. Daffelbe war eine Tranffetuer, wofür audi ber Mame \&icent vorfain. Ungelo ober 3yie

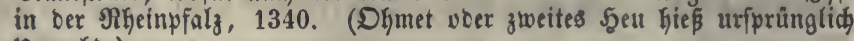
unmako.) 
(b) Noch heutiges Tages in Defterreidh unb Bayern in biejem Sinne üblid. Caroliniface Bahlcapitulation von 1711 Cap. 8: "NBann aud einige... fid unterftanoen haben .... bie ein=, aubs = unb burdgehenbe $\mathfrak{B}_{\text {ahren }}$

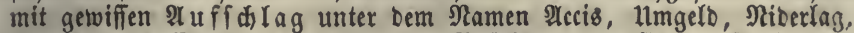

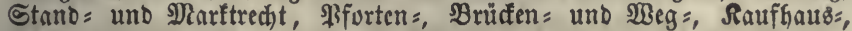
Rent =, Stein=, Pfinfer=, Stein = Fugren = unb (5onto = (Eelder, N)tutter= Steuter unb andern Dergleichen imposten zu beidimeren."

(c) Sró̧eв $\mathfrak{L}_{0 b}$ in Der Schrift: Christ. Teutophilus (Tenzel), Ents Dectte (S)logrube in Der श्रccife. 3erbit 1686. 40. 5. 2tuff. 1719. Dieje शbhandlung rief mehrere Streitficriften hervor.

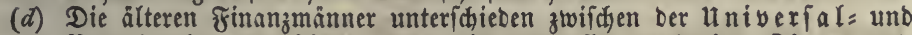
Iarticular= Accile. Sene, bie von allen verfauften Dingen ent:

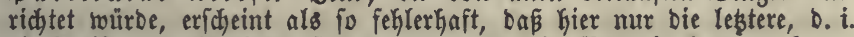
bie Necife von einzelnen Warengattungen, in Betrad fommen fann; 3. B. v. Sonnenfels III, §. 165.

\section{§. 429.}

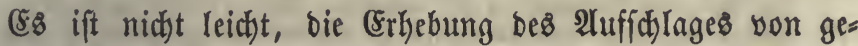
wiffen Segenftünoen fo einzurichten, Daß weber ber Betrug erfeidtert, nod) audb ber $\mathfrak{B e r f e h r}$ zu fehr beläftigt wirb. Nad

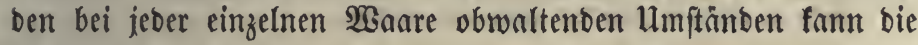
Entricttung balt bei eimem $\mathfrak{B o r g a n g e ~ b e r ~ E r z e u g u m g ~}(a)$, balt bei bem Ulebergange eines Erzengniffes in anbere Şänbe unb insbejondere an bic 3efrer angeorbnet werben $(b)$. $3 \mathfrak{u}$ ber lekgteren 2 trt gehört bie friber fehr verbreitet gewejene und nod) iegt bie und ba yorfommende Thoraccife, weldye beim Ein= tritt einer $\mathfrak{W}_{a}$ are in bie Stäbte bezahlt wirb $(c)$, uno weldte

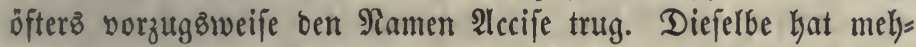
rere Radttheile: 1) Da fie nitht in Dörfern, Fleffen und offenen Stäbten, fondern nur in gejd)lofienen Drten anwenbbar ift, fo entfteft eine ungeredste Belaftung ber leşteren, bie um fo mehr

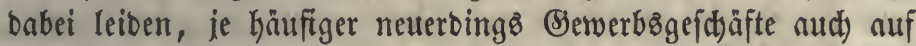
oem sanbe betrieben werben und begüterte ßerjonen bajelgft

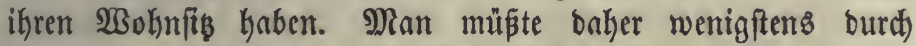
Ed)aksungen, bie ben offenen Drten in Göherem Manße ober ausidclieflid) auferlegt werben, bas Bjleidgenvidt wieber herzu= ftellen fuchen $(d)$. Die ftätfere Beftenerung ber Stabtbewolyner hat bazu Beranlafiung gegeben, benfelben aud) wieber $\mathfrak{B o r}$ üge, 3. B. in ber Betreibung von Scantwerfen (II, \$. 200) zu be= willigen, weldye fid aber nidjt mekr aufredyt balten laffen. 2) Die Thoraccife faun nidft bon foldjen WBanen erhoben werben, welche in ben Stäbten berfertigt werben; man fönnte

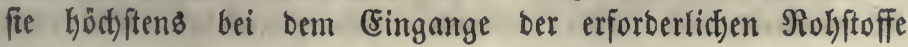


belegen (e). 3) Das 21nhalten unb Unterfudjen aller in bie

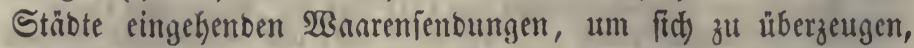
ob fie fteuerbare Dinge in fid id)ließen, ift fehr milyfam, bes idjwerlid) für bie (sinbringenben, giebt zu mand)erlei $\mathfrak{B}$ Bllfür

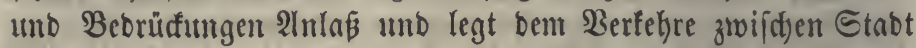

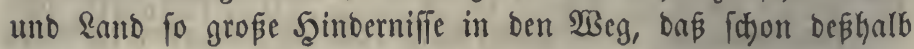
bieje Form ber 2Accife alz verwerflid) erfdecint. 4) Şiezu fomnt ber श̂nreiz zum Keimlid)en (Sinführen.

(a) Eoldje Steuern fat man bizmeilen mit dem Ramen \$roduction 8= fit uer n belegt, $z$. B. Die Steuer von Runfelrübenzucfer. Ittlein fie fino bennod) 2lufwandeffetern, nidgt Sdakungen.

(b) Narttaccíc in श̂then.

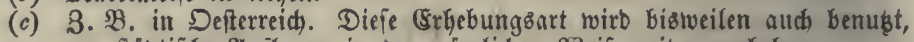

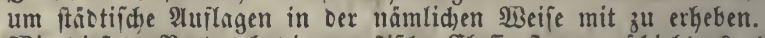

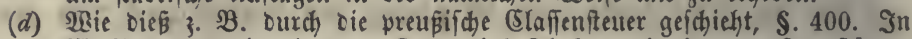
Sieftenburg wiro in ben Domanial = Electen wie in ben Eantentoten Fleiích und Wiefl befteuert.

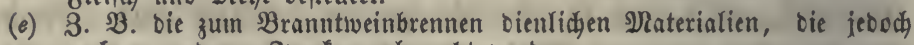
audi) zu anderen 3werfen gebraudbt werben.

\section{ฐ. 430 .}

Durd) bie Ummanolung Des 2lufid)lages in eine fefte Sunme, bie ber Berfäufer einter $\mathfrak{B a n c e}$ jährlich in bie Stantzcaffe ent= rictetet (aversum, $\mathfrak{B}$ aufd) fumme, abonnement), wirb bie Erkebung fehr erleidtert, cอ̊ fällt ber Steuterbetrug hiniveg uno eв werben alle läftigen 2uffit bennod) find hiennit überwiegende Radstheile verbunden.

(5) gebört wejentlid) zur (S)itte ciner indirecten 2ufmantos = fteuer, Dafi jeder Berfäufer eben foviel an ben Staat entrichtet,

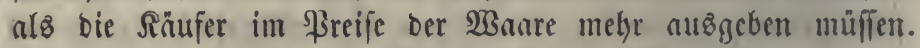
Dieß finbet aber bei ber (sinfübrung einer słaufdy fumme nidst ftatt, benu 1) wenn man aud) biefelbe wegen ber $\mathfrak{B}$ ermelyrung ber (Einwolynerzahl iälyrlid) regelmäßig fteigen laffen will, fo geht Dod) ber Sutzen rerloren, ben bie weitere (Frhöhumg besz Berbrauct)ez uno des Steucrertrages bei ber 3unahme bes Bohlftanbes herborbringt. Diefer Berluft liepe fid) mur bann vermeioen, wern man bie jährliche Berzehrung genau erfahren fönnte, was aber gerabe vou ber 2luffebunt ber Control= anftalten verhinbert wirb. 2) (5z treten ofters ftarfe Beränbe=

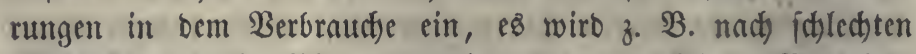
Weinjafyen melyr Bier getrunfen uno umgetebrt. Bei ciner 
genau nad) ben verbraudten Mengen erfobenen Accife gleid)t fid bie 3unahme ber einen Steuer mit ber Abnahme ber an= beren auz, bei einem 2lverjum würbe ber Stant ber einen (Elaffe von $\mathfrak{B e r f a ̈ u f e r n ~ \Re a d h l a ́ ̉ ~ b e w i l l i g e n ~ m u ̉ i f e n , ~ o h n e ~ y o n ~ b e r ~ a n = ~}$

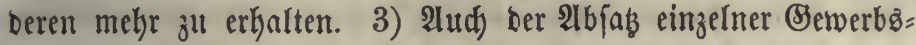
unternefyer ift fefre veränberlid). $\mathfrak{B}$ enn ber $\mathfrak{B}$ egüterte mit Şülfe eines größeren Capitales feinen $\mathfrak{B}$ etrieb verbeffert und erweitert, ober wenn burd) zufällige UM

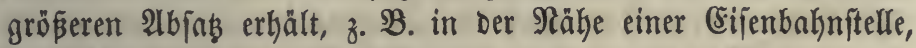
jo erfält er bei einerlei ßaujd)jumme von ben Säufern mebr Errją̧ als er vorgefd)offen hat, währent anbere Berfäufer, bie in bem Mitwerben nadjftehen, Kiebei in Sdjaben fommen. Se länger eine foldhe Esinridtung bauert, befto mehr fann bie von lebem $\mathfrak{B e r f a ̈ u f e r ~ b e z a h l t e ~ 2 l v e r ~ j a l j u m m e ~ v o n ~ b e r i e n i g e n ~ a b w e i d ) e n , ~}$ bie er nad) Der wirflichen 2luzbelhmung feines Serwerbes zu tragen hăatte.

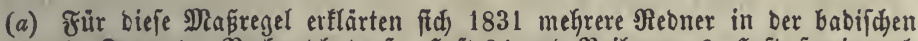
2. Sammer; Serhandl. Derf., Seft 24 unb Beilagen, 8. Seft, fowie aud biele (5)efude von Birthen, Bierbrauern, Fleifdjern 2 . \&. v. $\mathfrak{B a b D}$,

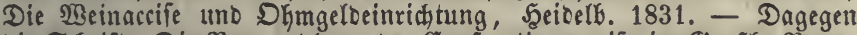

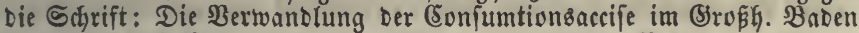

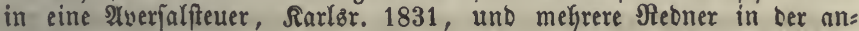
gefübrten Berfanolung. In Folge eines bon beiben Rammern nus:

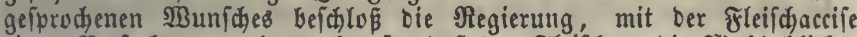

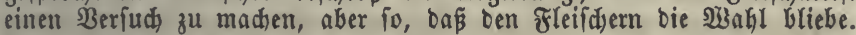

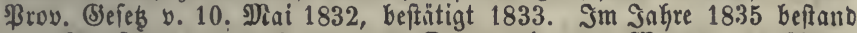
Das 2)erjum nur noch an 244 Drten mit 499 N)ebgern, wäkreno 638 Drte nit 1806 Nebgern anbere Orhebungenarten vorgezogen hatten; 20 Drte waren feit 1832 von bem 2lverfum zurüfigetreten. Daher

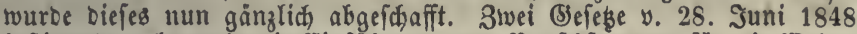

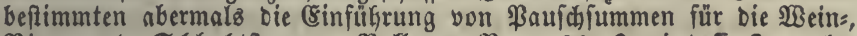

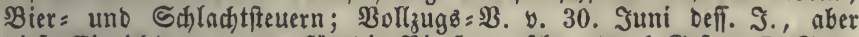
Diefe Ginrid)tung wurde für bie Bierfteuer fdjon Durdy (Sef. v. 7. Sept.

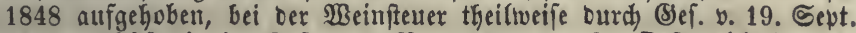
1848, vollfitundig im Sei. v. 3. Nov. 1849. - In Defterreid fommen foldye 2 b fin o un gen bei ber Berzehrungofteuer yor burdy Berabredung

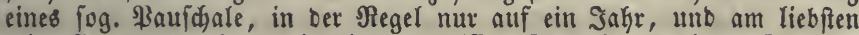
mit allen unternefymern it einem getwiffen Betwerbe an einem Drte zu= fammen. Sommt eine Uebereinfunft ber शrt nidjt zu Stanbe, fo wirb

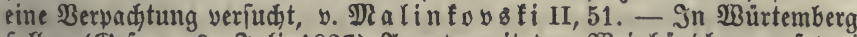

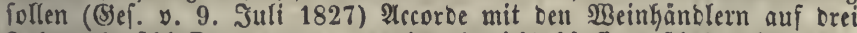

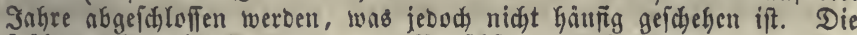
frükere allgemeine Anorbnung ber \$aujdhlumme beftano nur von 18211824; Sुanbbud S. 237. In झreupen ift eine "Firation" Der fleifd)= ftetter für alle fleifder einer Stabt nad) einem mefrjäbrigen Durd, = fánitte geftattet, $\mathfrak{B}$. v. 19. Febr. 1827. Billaume 5 . 259. -

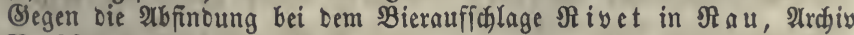
$\mathrm{V}, 86$.

PR a , polit. Defor. III. 2. 26tb. 5. 2usg. 


\section{§. 431 .}

Der Berbraud) einiger alfgemein zum (Senuß bienenben

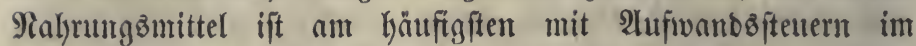
Snnern ber Ränber belegt worben. Dalin gehören aufer bem Sod)\{alze (a) Setreibe, Flcif̧) uno geiftige Betränfe.

Der Alufd)lag von bem zu menfd)lider $\mathfrak{R}$ abrung ver= wendeten (Setreide (b) trägt ben Namen Mahlaccife, Niahliteuer, weil er nad) ber gewöknlid)en (Einrid)tumg bann bezahlt werben mus, went man bas Estreioe auf bie s)entlle

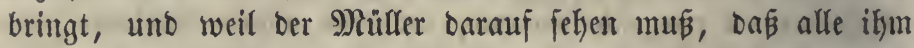

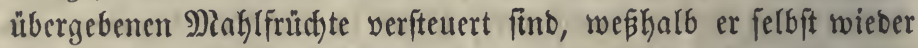
überwadt woirb. Dieje 2lbgabe hat zufolge obiger Betradtungen

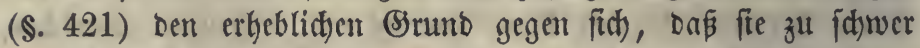
auf oie arbeitende Elaffe brüat, zumal auf bie Familien bon

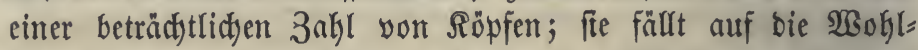
habenten nid)t viel ftärfer als auf Die Dürftigen unb muß jogar yon ben aus (seldalmofen lebenden Armen bezahlt wer= Den (c). 3ubem ift muf bem \&anbe, wo viele Meüblen von Den Drtfichaften entfernt und vereinzelt liegen, Die Beauffict)= tigung burch bie Steuereinnehmer zu beffwerlich unb foftbar, enblid) Laben mandye Familien auf bem Ennoe eigene Methlen, werben baker von ben vorgefdriebenen Förmlichfeiten beläftigt $(d)$. Deshalb verbient bie Maklfteuer feine (Empfehlung, aud ift fie in ben meiften Stanten nidjt anjutreffen. Shre Radtheile tver= Den gemilbert, aber feinesivegs gauz bejeitigt, wenn fie liber= haupt niebrig angejest wirb, voer wenn man ba, wo bie unteren

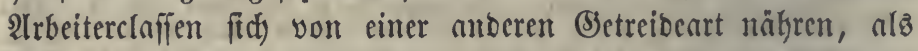
bic wohlfabenberen (sinwohner, jene Frudt niebriger befteuert,

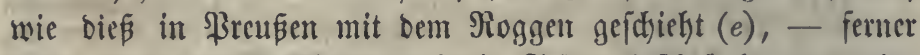
wenn man bie Mahlffeuer auf bie Stäote bcictränft, waz abcr

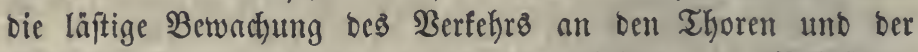

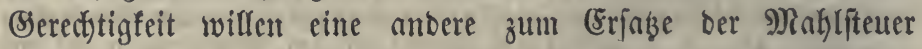

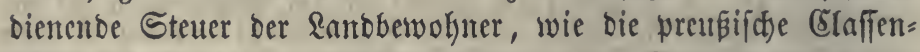

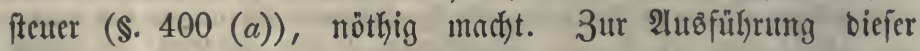
Steuer gehört 1) Das $\mathfrak{B e r b o t}$ ber Scanbmüblen $(f)$, 2) bie Berpflid)tung Der Mitller, Setreibe nidst ofyne bie begleitenbe Bejdeinigung für bie bezahlte शccife anjumehumen, genaute 
Berzeidjnifie aller abgelieferten Mablfrüchte unt igrer Eigent= thümer zul halten, bie cigenen frindte abgejonbert zu verwahs= relt ut. f. w., 3) veridjiebente Siderungåmittel, z. B. Berbot ber $\mathfrak{B e r b r i n g e n z ~ a u f ~ b i e ~ M u ̈ h l e ~ b e i ~ \Re n c t , ~}$ Bezeid)mung ber Săde eines jeben Esigenthümerz von Setreibe, hăufige Befitd = tigung burch) Accijebenmte u. bgl.

(a) Ueber bie Salzfteuer uno bas zu gleidiem S1wedf bienenbe, nur in ber Form von jener berfdiebene Salzregal \%. \$. 184 fi.

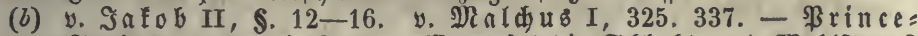

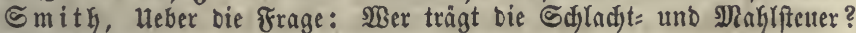
Blbinly 1845. - de Parieu II, 279.

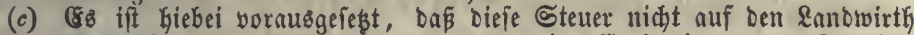
übermälzt wirb. Sie fönnte nur bann eine Erniebrigung Des (Setreide=

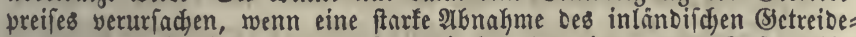

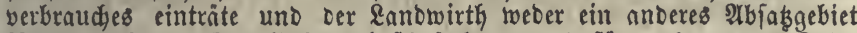
fänoe, nođ ben Setreibebau einfduränfen und bafür mehr anbere Feld = getwäbje bauen tönnte. Diefe felten eintretende sisirfung wäre aber ebenfalls cine ungünftige. Sine jefre ungleiche Befteuerung ber ver: ficiedenen Setreibearten fönnte leidgter ben Freis ber mehr belafteten Keraborücfen.

(d) In Diejem Falle ift die Maflfteuer eine birecte. In mandien Begenben, 3. $\mathfrak{B}$. bem Sdwarzwalde, haben viele Lanoleute eigene fleine $\mathfrak{D a h} l=$ mifilen an ben naken Sebirgabächen. Die babifhe Ilccife=Dronung

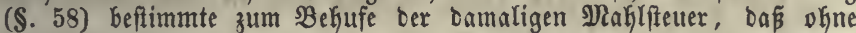

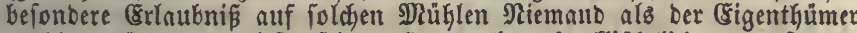
maklen bürfe uno diefer feinen Sgaugerbraud alljährlich zu berfettern habe.

(e) Die preuß̃. Mahlfteuer (Sef. v. 30. Nai 1820) Eetrảgt vom ehemaligen (Eentner (110 \$fo.) $\mathfrak{B r i z e n} 16$ (Sgr. ober 20 Sgr. (1 fl. $10 \mathrm{fr}$.$) , won$ Stoggen, Berfte, Budjwaizen, Şülfenfrfichten 2,4 (S)gr. oter 5 Sgr. $\left(17 \frac{1}{2} \mathrm{fr}\right.$.). Das $\mathrm{Mlal}_{z}$ und Das zum $\mathfrak{B}$ ranntweinbrentuen beftimmte (Setreibe ift befreit. WSirb Meghl in eine mahlfeuerpflidjtige. Stabt ein= geführt, fo wirb Der Steuerbetrag ber entiprechenben (S)treibent 11/3 fach entrichtet, bei Srüße, Sries 2 . Doppelt. Sn ben mahlfteuerpflichtigen Stäotent ift Der mittlere Berbraud beż Ropfes 821/4 PFo. WBaizen und $225^{3} / 8$ গffo. Sloggen, alio ber Stelterbetrag $25 \frac{1}{2}$ Sgr. Da man (mit (sinredunung Des s) Rahllohns) aus 100 \$fD. Rörnern ungefähr 116 \$fo. গloggen= ober 105 \$fo. Naizenbrot erhâlt (II, 314 (b)), fo trifft auf Das \$funo 23 nizenbrot ungefähr $6 / 10$, nuf $\Re$ oggenbrot $0,137 \mathrm{fr}$. Diefe

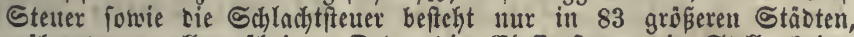
während an allen übrigen Drten bie Elaffenfteuer bie Stelle beiter einuimmt, §. 400. In Den Jahren $1848-50$ twurbe Den Stabt=

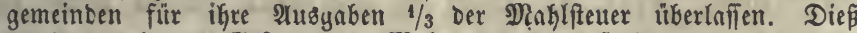
wurbe Durch Das Defes v. 1. Na 1851 §. I fortbnterno veroronet. Der Ertrag war 18441.868000 Thlr., $18461 \cdot 711000$. Seit 1848 fommen nur bie Dem Stante zufallenben $2 / 3$ ber Steuer in গRedymung.

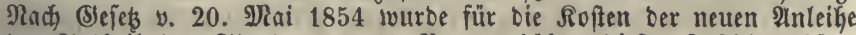

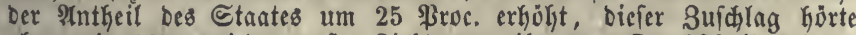
aber mit 1856 wieber auf. Sieft man ign voun Durdhidnittsertrage Der Safire 1854-56 ab, fo bleiben 1.231263 Thlr., D. 1857. 58 1.308178 Thlr. $=0,679$ Thlr. auf Den Ropf (utb zwar in Sdjleften 0,61 Thlr. (min.), in Branbenburg $0,73 \mathfrak{T h} / \mathfrak{l}$. (max.)). $\mathfrak{A}$. für 1859 1.270000 Thlr., für 18601.309900 Thlt. ober an $0,{ }^{65}$ Thlr. auf 


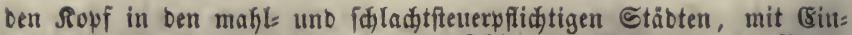

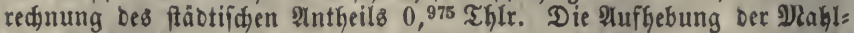

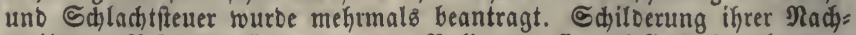

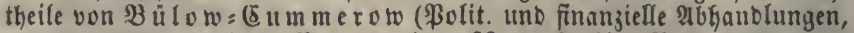

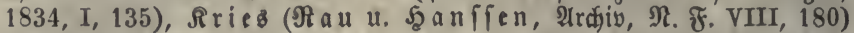

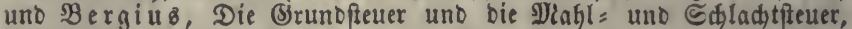
Bregl. 1853. Bertheibigung biejer Steuer von $\mathfrak{N}$ ie $\mathfrak{b}$ uhr (in $\mathfrak{R}$ a u

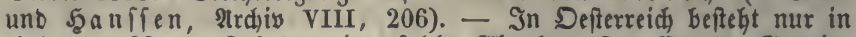
einigen gröperen Ståoten eine folche 21bgabe. Der Bentner Setreibe

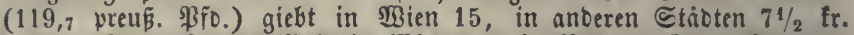

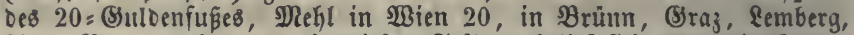
Linz, łrag 10 fr., unb in biefen Ctäbten belief fíd, 1856 bie Steuer

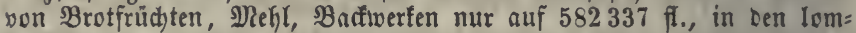
barbifijen unb venezianifden Stäbten war bie Steuer föker. - \$ei Der nieberländ. Dablftetter von $12 / 3$ fi. yon bem Secttoliter 2 Baizen, $1 / 2$ fi. von Roygen, ermittelte man, bá̉ eine familie von 5 Ropien, je nadbem fie Baizen unb Noggen ober nur lez̧teren verzefirt, $4 \frac{1}{2}$ ober $2 \frac{1}{2}$ fl. jährlid zu tragen habe, van Hagendorp II, 29. Sicbei if bie Brotconfumtion niebrig angenommen, inbem $2 \frac{1}{2}$ f., nur

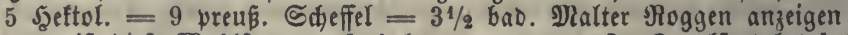
1855 ift bieje \$iahlfteuer aufgehoben worben. - In Franffurt beträgt

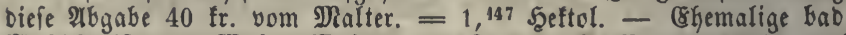

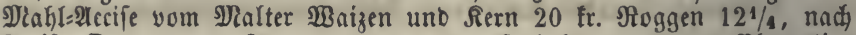
Accife= Dron. v. 4. Jan. 1812 §. 52, aufgehoben 1818. - Ehemalige weftfäl. Confumtions?fteuer, (Se)eł v. 15. Februar 1509, 14 Cent. von $1 / 2$ Szeftoliter Setreice, $4 \frac{1}{3} \mathrm{fr}$. vom preü. Scheffel. - 2uffebung Der Nahlfteuer in Neapel 1847. - Nahlfeuer in Dlectlenburg= @dwerin, 2. $1850 / 5149490$ Thlr.

(f) Dampf = uno Thiermüblen erforbern befonoere Erlaubnís uno befonbere

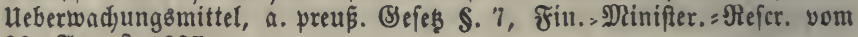
29. शैuguf 1827.

\section{§. 432 .}

Der Fleifdaufidlag (Fleifdaccife, Sd)ladtfteuer)

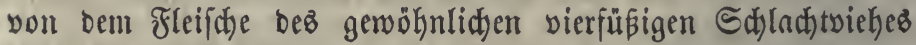

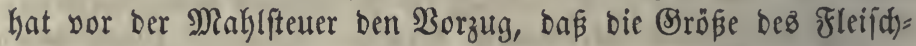
verbraut)es noch eher alsె bie Berzethrung von Michl für ein 3eiden ber Woblhabenkeit angefehen werden faun $(a)$. (Es ift

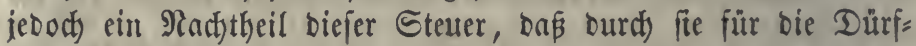
tigen bas Jleija), eine vorzüglid) ftärfenbe Epeife, vertheuert wirb, uno biefe Wirfung läpt fich) im Sanzen genommen nidft bezmeifeln, wenn fie gleid) in gegebenen frällen nicht immer

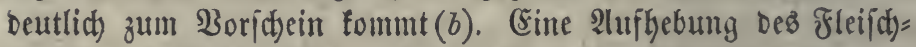
aufictages ift baher ben unterften Crlafien ber Rohnarbeiter und Serwerbslleute wohlthätig $(c)$. Eine Erleid)terumg in geringerem (Srabe wirb benfelben gewährt, wenn man bie 2 lbgabe fo niebrig anjeşt, Daß fie neben ben unvermeiblidjen Sdjwanfungen ber Sleifd)preife zufolge ber veridjiedenen Ernteerträge nid)t empjun= ben wirb, uno ween fie nidjt alfe Arten bes \&leif́d)es betrifft $(d)$. 
Wo fich öffentlidye Edjlndthälter befinben, ba fann bie Ents ridjtung am leidfteften, überhaupt in ben Stäbten leidter als auf bem Sanbe liberwadyt werben (e). Das Sdjlndten zum Scausggebraud)e ift auf bem sanbe am häufigften und läpt fich hier am idhwerften zur Steuer beiziehen, überbiés ift es ben 3ehreern befdwerlidy, einen vielleicht für megrere Monate bes ftimmten Fleifdyorrath fogleich beim Sdylacten verfteuern zu

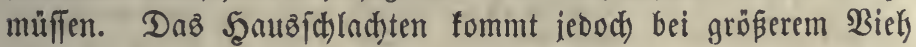
felten vor, ez ift baker fijon fehr erleidternb, wenn baffelbe nur bei Sdyeimen, Sdyafen unb Biegen unbefteuert bleibt $(f)$. Die (Entrichtung fann gefdyehen 1) nad) bem (Se wid) te, mit Sinweglaffung aller berienigen Theile, bie nidt gegeffen ober ooch nicht pfunoweife ausigewogen werben, wie Scaut, Füke, Ropf, Eingeweibe, Darmfett. Şiezu wirb eine llbwägung nad bem Sdyladten, aber yor bem 3erhauen in bie vier $\mathfrak{B}$ iertel im Beifein eines verpflidyteten $\mathfrak{W a n g e m e i f t e r s ~ b o r g e n o n m e n , ~ a m ~}$ beften nuf einer offentlidyen Wnage, worauf erft bie Steuer bezaklt werden fann $(g)$. Dieß ift umftändlich, aber bie Steuer vertlyeilt fid hiernad) am geredhteften unter alle $\mathfrak{B e r f a ̈ u f e r ; ~}$ 2) blop nad) ber Stüdzahl, wobei bie Steuerzahlung nod) yor bem Sdjladten geidjeht uno bie Erhebung leidfer ift $(h)$. Dagegen tritt ber Ulebelftand ein, baß son fđjweren Biehftüden auf jebes \$3funo eine geringere Steuer fommt als bon leidften, mithin ber begüterte Unternehmer einen (Sewinn zieht, währeno bie 3ehrer gleichen Fleijd)preis bezahlen müffen. Durd ben

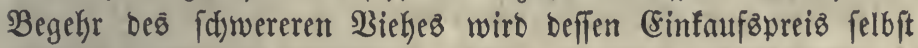
wieder erböht, uno wenn man hierin aud eine billige Beloh=

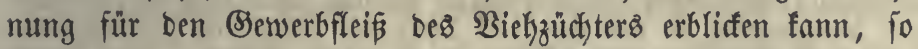

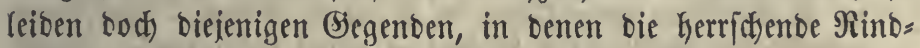
viekraffe fleiner ift, und bie fleimen \&anowirtle, bie ifr $\mathfrak{B i e h}$ ungemäftet zu verfaıfen gezwungen finb, eine (allerbings geringe) Benadtheiligung (i). 3) Die Unterideibung mehrerer nad) bem Berwidfte nbgeftufter Elaffen yon Thieren jeber 2lt fteht zwifden Der erften und zwoiten Methode in ber Mitte. So oft fid) z'vifden bem Accifeeinnehmer uno bem Fleifd)er über bie Claffe

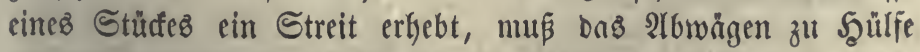
genommen werben, und on man in vielen Fällen hicrauf zurüđ: fommt, fo ift mit biefer (Elaffeneintheilung menig gemonnen $(k)$. 


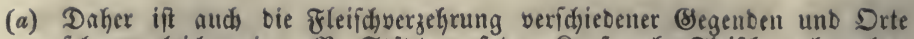
felyr ungleid, wie z. B. Stäbte auf den Rovf mehr fleifíh verbrauchen

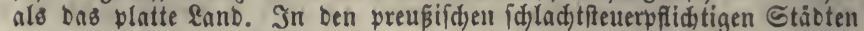
war 1849 in D. Der Steuerbetrag auf Den Ropf 18,34 Sgr., Der 2 er=

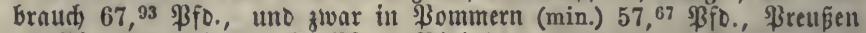

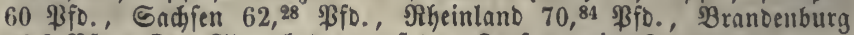
$76,{ }^{3}$ ßfo. Der Steuerbetrag auf ben Sopf war im D. $1857 / 58$

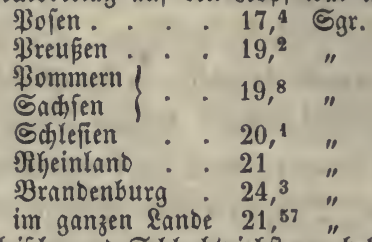

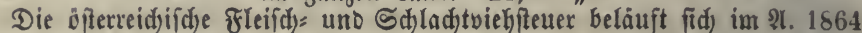
nuf 5.559860 fr. Der D. $1851-56$ war 4.932629 f., wovon 2.517053 fl. in ben geidjlofienen Stäbten. Bon jener Summe wurben $2 \cdot 615274$ fl. Durdh sbfinoung ober Berpadjung erboben. - Sndfen 2. $1861-63312600$ Thlr. $=0,245$ fl. auf Den Rovf. - In BBacen betrug bie Shlachtwiehaccife auf ben Sopf $1831-36 \quad 12,{ }^{73} \mathrm{fr} ., 1836$ $-41 \quad 13,26 \mathrm{fr} ., 1842-46 \quad 13,49 \mathrm{fr} ., 1852-5613,{ }^{6} \mathrm{fr} .,{ }^{2}, 1860-62$ $14,{ }^{9} \mathrm{fr}$. Der Errtrag im D. Diejer brei Jahye war 340236 fl. (beinake 1/4 f. auf ten Ropf), 2. 1864. 65 nur 277160 fi. ober 0,2 ff. auf Den Ropf, wegen ber aufförenten 2Hgabe von Rälbern; 1836-46

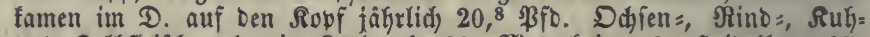
uno Ralbfleifh, aber in Rarlbrube 83, פlannheim 79, Sgeibelberg 69, Freiburg 53, Bruthial 52, \$forzheim 29 \$fD. ofne das Ralbrieifक. Bon Den fteuerfreien 2 rten twurben gegen 30 \$fo. auf Den Ropf ver= zefirt. - Der Rupf bezahlte in Diejen 6 Stäoten $60,53,51,4,41,18$, 35,76 und 25,25 fr. Die 3ahlen ủber Die Berzelirung in Bfuncen fino nicht genau ridtig, weil bas (Sewidgt ber gefhlahteten Stuide neuer: (i⿱⿱亠凶禸丸) nidat befannt ift.

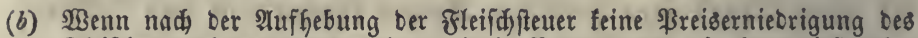
Fleifjes wahrgenommen wirb (wie in Baben 1849), fo fann biés baher

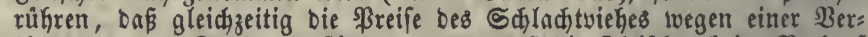
theuerung Des futters geftiegen, ober Daß̧ Die Fleifwer beim Berfauf vor Dem freien Ditwerben geidubst fint.

(c) Bropbritanien, Franfreid), Bayern, SBütemberg (Feit Dem Finanjgeießs yom 1. Juli 1839) und viele anbere Staaten haben biefe Steuer nidft. Sn Franfreich if̂t aber in einem Theile oer Stäbte eine Fleifjabgabe, bie in \$aris von einem Dhjen 26 Fr. 40 E. Beträgt. - Jn Baben war bie Fleifdnccife (Durch Sefes y. 17. Juli 1848) yom 1. Januar

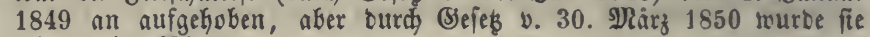
wieber eingeführt.

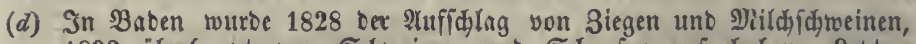
1832 überfaupt von Sdweinen uno Sdaafen aufgehoben. Reztere Erleichterung wurbe nuf ungefähr 50000 fi. angefolagen. Şom 1. December 1862 an Görte aud bie Steuer von Rälbern auf.

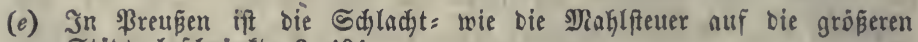
Stäbte befdrainft, \$. 431.

(f) In Wủntemberg war nur bas zum Berfaufe beftimmte Bieh fteuerbar, io if es auch in Defterreidy altf bem \&anbe. In mefyreren \$rovinzen if feine fleifdyfteuer, in ltngarn unb Eiebenburgen befteht fie nur itt Drten über 2000 Ginwobner. 


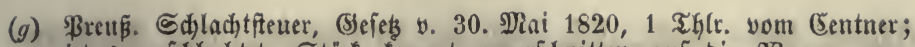

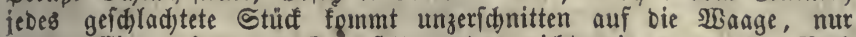

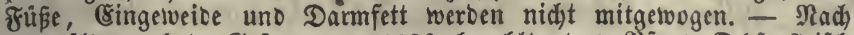

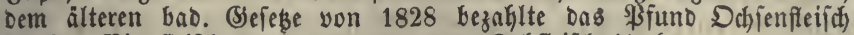
$3 / 4 \mathrm{fr}$., SRindfleif $5 / 8 \mathrm{fr}$. Farren= und Ruthfeifid $1 / 2 \mathrm{fr}$.

(h) Baben, Sefets y. 25. Niai 1835 : Bon 1 Ddfen 6 fi. 25 fr., 1 Rint, Farten, Suh 2 fl. 20 fr., einem Ralbe 30 fr.; Odfien unter 400 \$fD. werben als Simber verfeutert 2 c. 2c. Bon 1832-35 Gatten bie Fleif́cher

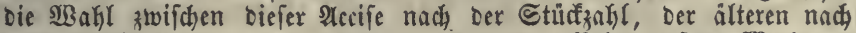
Dem (Setwichte und Dem aversum, \$. 430. Beide eriftere Shethoden ftimmen überein, wenn ein Ddhe 513 \$fo. Fleifdergetwidgt hat. - In 2Bürtemberg gab zuleetst (Feit 1836) ein Ddhie über 3 Sahre I fl., unter

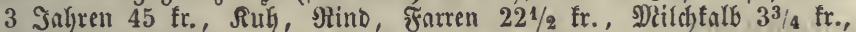
Gdjwein 6, Schaaf unt Biege $3 \mathrm{fr}$., Ramm $1 \frac{1}{1} / \mathrm{fr}$., junge Biege $1 \mathrm{fr}$. Bor 1833 waren Die Säbe viermal fo hoch. - Depterreid): ein Stürf SRinovieh über 1 Jahr alt in 2 Sien $71 / 2$ fl., in einer \$rovincialfaupts ftadt 4, an fleineren Drten und auf bem Rante 2 fl. Sn Den 9 größeren

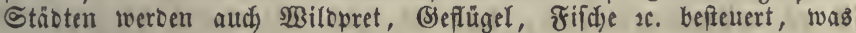
1847220000 fi. cinbradhte, 1856 in 6 Stärten 171710 ff.

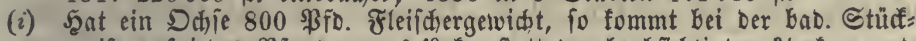
accife auf jebes Pfund nur $0,48 \mathrm{fr}$. ftatt Der beabfidutigten $3 / 4 \mathrm{fr}$., und bie Fleifictconfumenten werten ovd vermuthlid) foviel vergüten müffen. 1829-32 hatte im D. ein Dafe in Rarloruke 592, in Mannheim uno

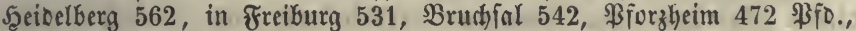

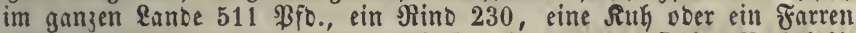

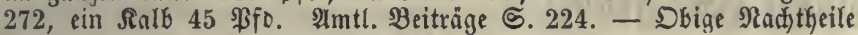
fino audi bei bem framzofifichen Detroi getadelt und 1845 yon ber Dep.=Sammer anerfannt worden. - Esin Berbefierungsmittel liegt in Dem a. Wreuf. Beféce yon 1820 \$. 11: fïr jede Stabt wiro ein getwifier mittleter Sab für das Stüí nufgeifellt und es hängt von bem

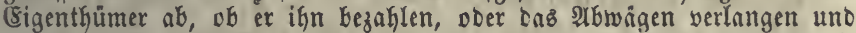
genau nad) Dem (Sewidjte bezahlen will. - In Baben betrug bie

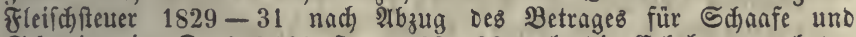
Sdiweine im D. 270000 fi., 1832-38, als Die (Erkebung nad) Der

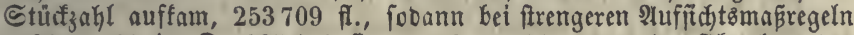
1839 ut. $40 \mathrm{im}$ D. 325470 fl., 1843 u. 44 wegen ber 216nahme Des Siefifandes zufolge Des Futtermangels yon 1842 nur 264640 fl., 1844-46 293000 fl., 1854-56 284690 fl. - In Den Nieberfanden

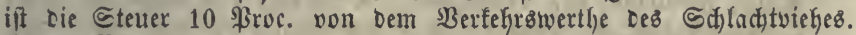

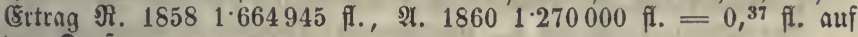
Dell Ropf.

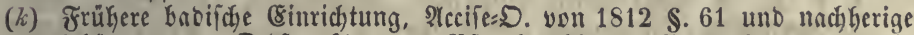
शbänoerung: Dafen über 600 \$\$fo. bezahlten 7 f. 30 fr., yon 5 bis all 600 \$fo. 5 fi. $15 \mathrm{fr}$, youl 4 bis 500 Pfo. 5 fl. , Sinder von 3 bis 300 Ffo. 3 fl. 45 fr., yon 2 biz 300 \$fo. 2 fi. 30 fr. 2 .

\section{§. 433 .}

(5) eiftige (S) etränfe find zur Befteuerung vorzủglid) gut geeignet, weil fie, ofne unentbehrlict) zu fein, bod) einen für die meiften Mtenfdyen fehr lodenten Benuß Darbieten, in all= genteinem (S)braude find, weil bie 2 Bohlthabenten fowohl auf

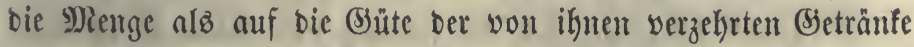
melyr z" verwenton pflegen, unt biejenigen \$erjonen, benen bie 
2togabe läftig wirb, fich leidt im $\mathfrak{B}$ erbraudje cinige $\mathfrak{B}$ efdyrän= fung auflegen fönnen. Diefe $\mathfrak{T}$ ranffeuern fint in ben heutigen europäifjen Staaten idjon feit Jabrhumberten in Ses brauch) uno werfen beträdytlidje (Einnahmen ab. In 21rfehung Der Begenftänbe biefer Steuern finten yon \&ano zu fand Ber= fójicbentyeiten ftatt, inbem $\mathfrak{B}$ ier und $\mathfrak{B r a n n t w e i n ~ i n ~ f a ̂ l t e r e n ~}$ Ränbern mefhr einbringen als in warmen. Wo fein Rebbau

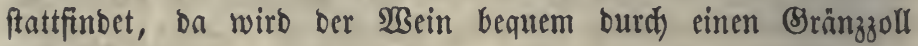
getroffen $(a)$.

Die Befteuerung geiffiger Betränfe bient zugleid) ben über= mäß̈igen (S)

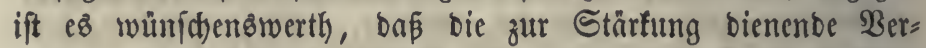
zefrung Der arbeitenden Elaffe ictonend belaftet iwerbe. Man fönnte baker eine foldbe Şöke ber Tranffteuern nidht billigen,

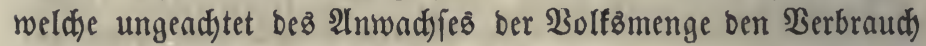
biejer setränfe im Eanzen verminberte ober aud) mut auf gleidjer $\mathfrak{s}$ öhe erfielte.

(a) Franfreich $1825-1829$ im D. 105.980000 Fr., nad Der Fiebuction bon 1831 und 183264.226000 Fr., 183570.809000 Fr. oder gegen

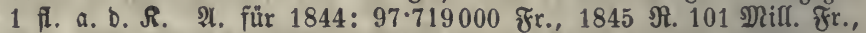

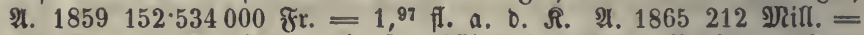

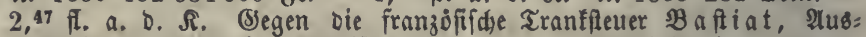

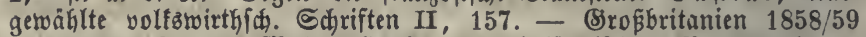

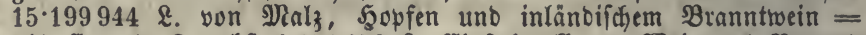

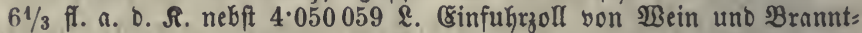
wein, $1861 / 6215.489500$ \&. Accife uno 3.746333 \&. Einfuhrzoll, zufammen 7,7 fl. a. D. A. - Belgien D. $1851-5713.679988$ Fr.

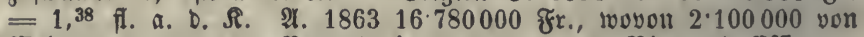
IBein, 5.950000 von Branntwein, 8.730000 von Bier uno Efing. -

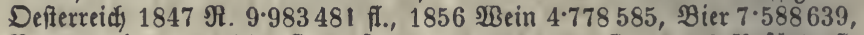
Branntwein $9 \cdot 393336$ fi., zufammen $21 \cdot 760560$ fl. oder 0,76 fübc. กิ. a. D. R. 2. 1864 Bein 5.949000 , Branntwein 17.630000 , Bier

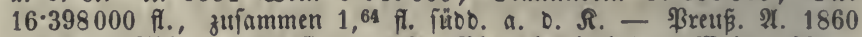
$7 \cdot 882000$ Thlr. $=0,{ }^{74}$ fl. a. D. $\Re$. (Bier niebrig belegt, $\mathfrak{B e i n}$ grópten= theils burch ben (Sinfuhrzoll getroffen.) - 2 ürtemberg 2. 1858/61

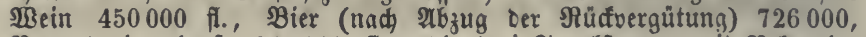
Branntwein ebenio 247000 fl., Die Drei Tranfifeuern mit Rebenein= nakmen (mit obigem $\Re$ fbug) 14477000 f. $=0,85$ fl. a. D. R. Die Soften belaufen fich auf 16 Proc. - In Banen trugen bie Tranfifeuern im D. $1831-46931323$ ff. $=0,76$ fi. a. D. $\Re ., 1854-56935566$ fi. $=0,71$ fl. D. D. $1860-62 \quad 1 \cdot 314428$ fi. $=0,96$ f.. ๙. D. $\Omega$. (wegen ber guten iseinjahre).

\section{§. 433 a.}

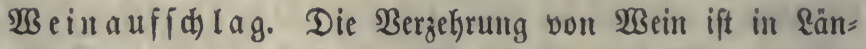

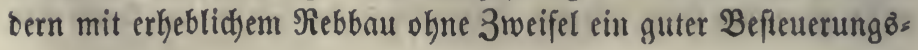


gegenftand unb unter ber Boraub̧ę̧ung, baß bieje Steuter yon Den 3ehrern getragen wirb, fann biejelbe für unichäblic) an= gejeken werben. Nur bann würbe eine nadjtheilige Wirfung eintreten, wenn fie ben $\mathfrak{B}$ erbrautd verminberte uno fomit ben ßreis bes 2 Beines nad) 2 (bzug ber Stetter erniebrigte, fo baß

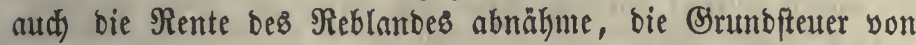
bemfelben als übermäpig erifjiene und zugleid) bie zahlreidje

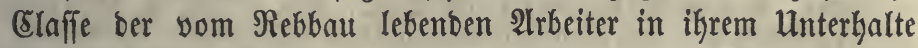
beeinträđtigt würbe. In einem foldyen Falle müste bejonbers ber 26 fäs ber geringeren $\mathfrak{B}$ eine, bie in minber günftigem Boben und Rlima gebaut und in Menge von ben Mittelclafien

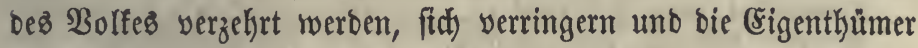

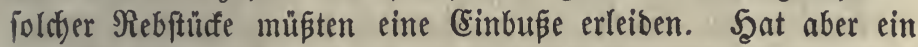
gerwiffer Wreinauffidlag fdjon längere 3eit beftanben, fo hat

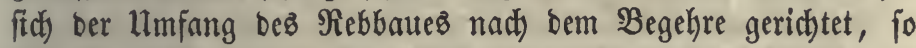

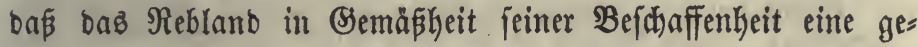

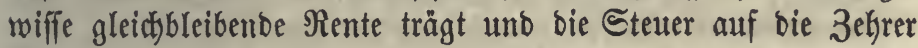
übergetwälzt wirb. Die großje Beriffiebentheit im Errtrage und

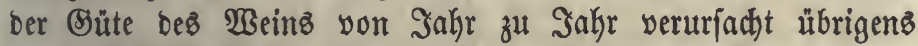
ftarfe Sct)wanfungen in ber Steuereinnahme $(a)$. Ein hoker Futí biefer Steuter hat nod ben Radttheil, zur Berfälidjung bez 2 seinz anzureizen, weldye ber Sefundbeit idjabet uno bie

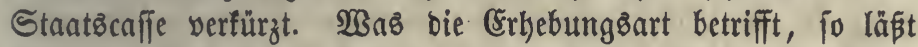
fid) feine (sinrifftung finben, weldye nidjt burd) Förmlidjeiten uno Ueberwadtungämittel einer ober ber anberen Elaffe yon (Einwohnern bejdyerlid) fiele. Alußer ber Einziefung an ben Thoren ber Stäbte (b) fann bie Errkebung geidethen

1) bei ber Erzeugung bes 2 Beines ober balb nad) berfelben,

2) furz vor ber Berzelfung, bei ben Sdjenfwirthen und ben 3ehrem, bie fidh einen. gewiffen Borrath einlegen $(c)$.

(a) Beifpiel. Baben 1855498163 fi.

$$
\begin{aligned}
& 1856615616 \text { " } \\
& 1859931488 \text { " } \\
& 1861756901 \text { " }
\end{aligned}
$$

(b) Bergl. \$. 428. E̛in Foldues droit d'entrée befteht in Franfreid in Stäoten yon 4000 Ginw. (anfangs 2000) uno barüber. Nach ben Wुeinpreifen fino bie Departements in 4 Elaffen, nadh ber Bolfszahl bie Stäote in 7 शbtheilungen gebracht, zu benen nod \$aris als 8 . tommt.

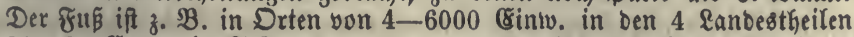
$30-60$ Cent., in Stäbten yon $20-500000,90-1,80$ fr., in Stäbten bon 50000 ช̇inw. und Darüber $1,20-2,40$ frr., in \$aris 8 Fr. vom 
Şettuliter, hier ift aber bieß bie cinzige Weinabgabe, §. 434. Die शुein= fteuern in Frantreich fino 1850 (S)egenftano einer forgfältigen unter= fudjung getworben, bei weldher aúper ber müntid)en Bernefinung vieler

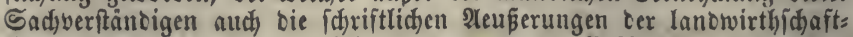
liçen Bereine, Der Şandels̈tammern uno ber Bräfecten fowic vieler Fribatperionen gefammelt murben. Enquête législative sur l'impôt des boissons, Paris 1851, II $\mathfrak{B} .4^{0}$. (शhd) vum Biere ift Einiges ver= hanbelt worben.) Die franzöifiden Steuergeję̧e fino Darauf gegründet, Daß̧ Der $2 B e i n$ bei brei Beranlaffungen bequem yon einer 2tbgabe erreidht werben fann, 1) beim Berienben, 2) beim शusfduenten im 2Birfys: halle, 3) beim Einbringen in eine Stabt, Enq. I, 72. 2. für 1859 12.449000 Fr. In Frantreid) twurben fion 1324 ( fbiebene Abgaben vom 2 Bein aufgezåhlt, von benen jeboch mefrere

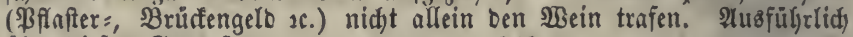
über biejen Bsegenftano de Parieu II, 343.

(c) Ueber bie Weimfeuern in Deutid)lano, $\mathfrak{B}$ ier $\{$ a df, Heber Beff. $5.245 .-$ Bayern Kat feimen 2 seinaufichlag. - Welchen Nachtheil unzwedtmäвige Stettereinridytungen Gaben fönnen, diés zeigt folgentes Beifpiel. In

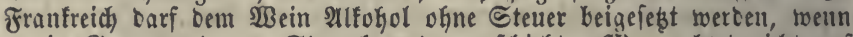
es in (Segenwart yon Steuerbeamten geidieft. Sitan adtet nidat auf bie \$enge bes 3ufabes. (8s wirb baher häufig zu veridjiebenen Malen

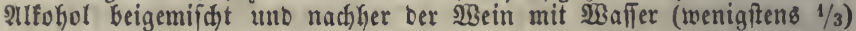

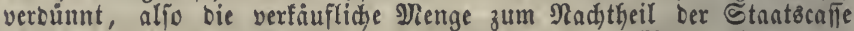
vermelyrt. - $\mathfrak{I n}$ Belaien if bie Accile yon franzoffichem Wein ver:

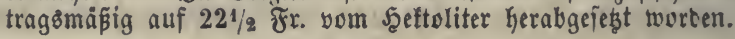

\section{§. 434 .}

3u 1. Wirto ber $\mathfrak{B e i n a u f i c h l a g ~ v o n ~ b e m ~ j a ̈ l h r l i c t e n ~ E r z e n t g = ~}$

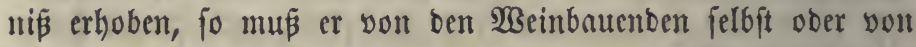
benen entricjtet werben, bie jenen ben neuen 2 Bein abfaufen.

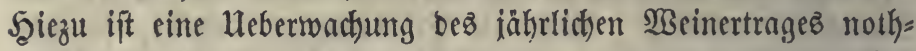
wentig, bei ber aud) Şausfurtumgen nidjt zu umgehen finto

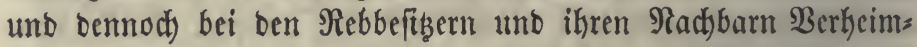
lid)ungen nidft felten vorfommen. Die Steuer trifft biebei atd

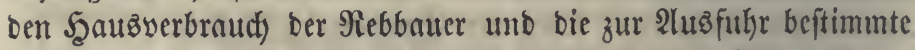

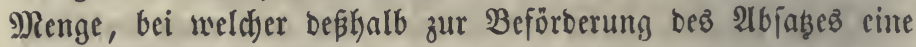

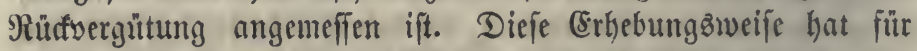
fid), Daß man bie Drtidjaften unb felbft bie Fflurbezirfe fentt, wo bie Tratben gewadjen find, uno biernutb einen Beftente= rungsmaafiftab abnelymen famm, ber freilid) wegen tor gropen Beridjiebentyeit ber Sangrgänge nidyt zurcidyent ift. Dangen futo bie crwähnten Meberwad)ungsimittel fehr läitig, es werben Mijdjungen eridjwert (a) uno bie Steuerentridtunt nöthigt in ben vielen Fällen, wo Der Wein lange aufbetwahrt wiro, ju

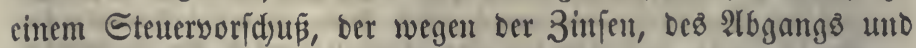

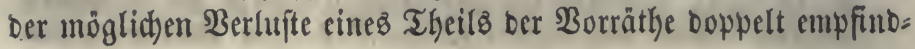


lid) twird unt ben $\mathfrak{B}$ ein nod) ủber ben blopen Steuerbetrag vertheuert (b). Diefer Radtheil wirb etroas gemilloert, wenn bie Entrichtung erft bei bem Ulebergange bes $\mathfrak{W e i n s}$ alls ben Sä̈non bes (Erzeugers an einen Räufer verlangt wirb (c).

3u 2. Die Crkbebung vor Dent Beginne bes $\mathfrak{B}$ erbrauches

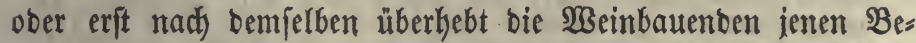
f(t)werben gänzlid) unb läpt auch ben 2 seintbanbel im Sropen von ben meiften $\mathfrak{B} e j$ chränfungen frei. Die Uebertvadyungsిmittel fint bauptiäd)lid) gegen bie Sdjenfwirthe gerichtet, bie in ifrem

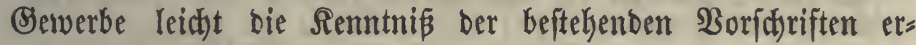
langen uno fict) vor Strafe hüten fönnen. Şiezu gehören fol= gente 21noronungen: a) Die Sdyentwirthe müffen ifren zum Rleintyerfaufe beftimmten $\mathfrak{B}$ orrath yor ber Einfelferung verifteuern, ebenio biejenigen 3efrer, weldye fid einen Borrath im Bropen erfaufen. (58 wird Daher bei ber 2lnfunft eines \$orrathes fogleid) bie 2 nzeige bei bem Steuereinnehmer gemadt, weld)er fith von ber Ridytigfeit ber 2Ingabe, z. B. burd) Neffung, über= zeugen barf. b) Die Relfer Der Schenfwirthe werben öfteren Beftctigungen burch Steuerbebiente unterworfen. c) Sebe Wein= verjendung innerfalb bes \&anbes mus von einem fradjtbriefe ober anberen zum 2luşweife bienenben urfunben begleitet fein, weldye bie 2uffitchtżbeamten fid yorzeigen laffen fönnen $(d)$.

(a) In \$reufen if Segenwart bes Steuerbeamten nỏthig, wenn ålterer

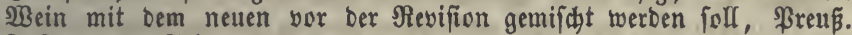
Inftr. v. 8. Febr. 1826 §. 4.

(b) Heber bie Nachtheile biefes système de l'inventaire, weldes, jebuch in läftigerer form, in Franfreid, nad 5jähriger Dauer wieber aufgefjoben tworben ift, Rapport au Roi S. 103 fi. - Enquête I, 69 und an anberen Stellen.

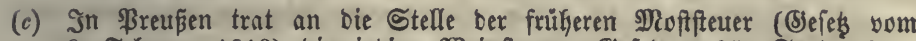
8. Februar 1819) bie jebige Weinftener. Sefeb v. 25. Sept. 1820.

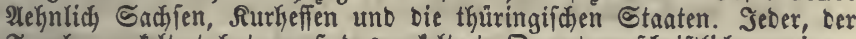
Trauben gefeltert hat, mús bas gefelterte Duantum fojriftlich anzeigen.

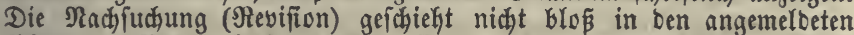

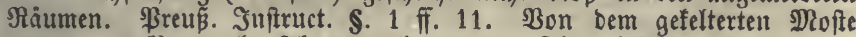
werben 15 \$roc. als Abgang abgezogen. Die wirfliche Berfeutung

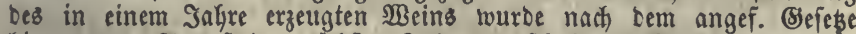
bis zum 1. 2uguft bes nádften Jahres verfabben. 23 urbe unterbeffen Der $2 B e i n$ verfauit, fo Gatte Der Räufer Die Aecife zu bezahlen und bem 23einbauenben bie Duittung zu übergeben, ber fie bei Orntrichtung feiner Gteuer fatt baar mit ablieferte. Nad Eabinetsorbre v. 28. September 1834 merben bie nod unverzegrten und unverfauften $\mathfrak{B}$ orräthe Des IBeinbauenben gar nidht verfeuert, fonbern nur in Das Fegifter Des folgenden Safres eingetragen. Sährlich wiro am 1. \$lai uno 1. No= 
vember bis bahin verzefrte ober aus ber (Semeinbe reggebradate $23 e i n$ verffeuert, Derienige aber, Den Semanb von Dem Errzeuger erfauft, wirb fogleid, vom Raufer verfteuert. Allle 2 Beinberge werben ein für allemal in eine ber 6 Elafien eingereift, in benen bie Steuer yom Eimer $\left(1 / 2\right.$ Dhm) $1 \frac{1}{6}-5 / 6-7 / 12-5 / 12-1 / 3$ und $1 / 4$ Thlr. Betringt. Da

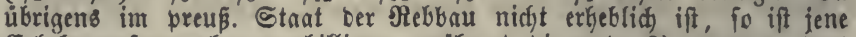
(Erkebungsform eher zu billigen, währenb bie unter 2) genannte bort bei ber viel gröseren 3aki von areintwirthen mefr Befdwerbe ver:

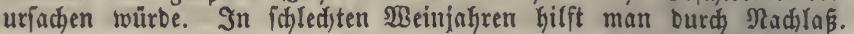
1849 waren 61885 Nlorgen vorkanben, wovon 48517 in Rheinlanb, in weldyem allein bie 3 erften Slafien vorfommen. Die Ctetter bradte 1829 bis 1835 im D. 116394 ThIr. ein, woyon 104375 aus ber Rheinurovinz. Ş offmann, Stettern S. 297 ff. Durdfidnitt 1855

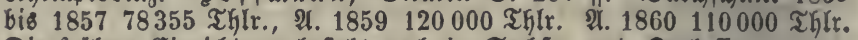
Die frübere Einrichtung beftegt nod in Sachjen unb surkeffen.

(d) Die heutigen 2 Beinfteuern in Frantreid, beruken in ber Şauptiadye auf bem (Sefes v. 28. April 1816, Dod mit manden Nabanberung im (8in= zelnen. 1) Die Sdjenfwirthe entridhten beim 8mpfang eines Borratfyes bas droit de détail (3apfgebüfr) von 15 ßroc. bes Raufpreifes, 2) Serionen, weldye 25 \&iter ober melyr faufen (bor 1852 erft von 50 Liter an), ohne Bieberverfäufer zu fein, Bezahlen Das droit de circulation, weldjes in ben 4 Bezirfen Des Lanbes 60 (Eent. Bis 1,20 ₹r. vom Şeftoliter beträgt uno alfo fehr niebrig ift. Bei einem \$reife von 30 Fr. if bie 3apfgebühr 4,5 Fr., alfo $3^{3} / 4 \mathrm{mal}$ foviel als bas hödfte droit d'entrée. Die (Elaffe, nad weldyer bie Steuer zu entrid, ten ift, beftimmt fich nadh bem 2 ohnorte bes Räufers. Dian nafm 1849 an, Daß́ an 18 Nifll. Ëinw. in Den Drten ofne droit d'entrée leben uno alfo entweber droit de circulation ober de détail entridten. WBie ber Wein, fo wirb audy Der Dbftwein behandelt, nur mit niebri= geren Sriben. 3u biefen beiben arbgaben fommt 3) bas droit d'entrée,

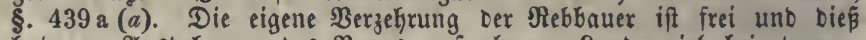
hat zur Ausbefnung Des Banes auf ebenem \&anbe viel beigetragen. Dan fallagt bie Ropfzahl in Den von aller Weinfteuer befreiten Fami= lien ber (Srunbeigenthumer und ßadter auf 12 Dill. an. Das Sejes vom 21. April 1832 geftattet ben Stäbten über 4000 \&intw., bas droit d'entrée, de détail unb de circulation mit einancer zu verbinben uno baburd bie befdwerlide Hebermadung zu vermeioen, die fonft Das droit de détail erforbert. Nad) Dem (Sejeş ๖. 25. Juni 1841 Darf Das droit de circulation nidyt mejr in biefe taxe unique gezogen wer: ben, bie beim Eingang in bie Stäbte erfyoben wirb. Der Eteuerfús richtet fich nach Den (8rfahrungen ber brei Borjahre. 4) In \$aris tritt eine Thoraccife an bie Stelle aller anberen Abgaben von $2 B$ ein unb $\mathfrak{B r a n n t w e i n , ~ d r o i t ~ d e ~ r e m p l a c e m e n t . ~ S i e ~ i f ~} 8$ fr. vom 5eftol. $23 e i n$, 4 Fr. vor Doftuein. I. 1860 :

droit de circulation, Dbftwein einfdylieslid, . 10.000000 fr.

droit de détail, ebenfo uno mit Sinfihluß oes

Branntweins........107.000000

droit d'entréc unb taxe unique aux entrées, mit

Dbftwein unD Branntwein ..... 14.542000

Gteuer in \$aris . . . . . . . 20.500000 ".

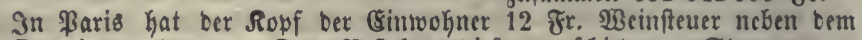
Detroi zu tragen. Das Beftehen biejer verjdjiedenen Steuern ver: urjacht eine foptbare frkbebung uno eine fehr ungleidge Bertbeilung Der Steuerlaft unter bie veridyiebenen Drtidaften. Die farfen Wein: 
Detrois ter framzöfictien Stäbte fino vielen lebłaften unb aud

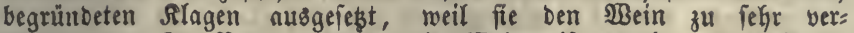

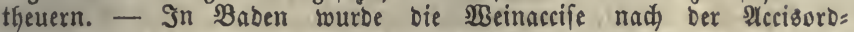
nung von 1812 nach 7 Slaffen bes 2 Beins erhoben uno belief fid auf 4 fr. $10 \mathrm{fr}$. bis 25 fi. yom Fuber. शads Dem Befes vom 31. Juli 1828 war fie $1 / 15$ yon Dem \$reife Des 2 Beins am Drte Des Berfattfs oder bei auslänbif́chem an Dem Sinlagsorte. Şiezu fommt bei Sdhenfwirthen Das Dhmgelo, \$. 435. WBer Wein zum Ber= faufe im Brofen einlegt, hat teine Alcife zu geben, jebod bie Srlaub= ní̄ zum Şalten eines \&agers einzufyolen. Şiebei unteridjeibet man 1) গ⿺einhanblungsfeller, aus Denen Bein bis zu 15 Naaß in Fäflern unb bis zu 24 Flafden herab verfauft werben Darf. Der

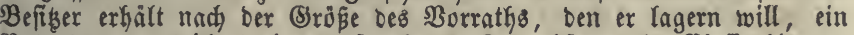
Batent und entriditet eine entiprectiende Betwerbfteuer (1. Clafie biz 10, 9. (Slaffe über 150 Fuber). 2) 23 einlagerfeller, als benen nidyt unter $1 / 2$ Fuber $(5$ Dhin) berfauft merben barf und bie überhaupt ftrenger überwacht finb; eฮ̊ wirb aber von einem folchen mur eine jähr= liche 2lbgabe won 6 fi. entrichtet. In ben $2 \mathbb{B}$ irthichaft selfern Dagegen Darf nur verfteuerter Wein aufbelvahrt rerben. Für bie थuf=

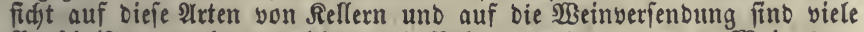
Borfdriften gegeben, weldbe burd, Befanntmaduung bom 9. NDai 1855,

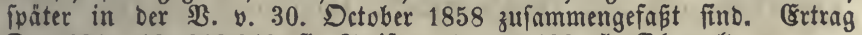
D. 1831-46 293040 fi. Âtccife uno 369622 fl. Dhmgelo 2c., zu= fammen 662662 ff., max. 845779 ff. (1834), min. 463206 fi. (1831).

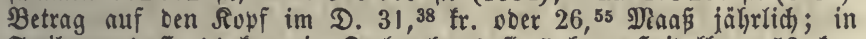
Freiburg 1 fl. $14 \mathrm{fr}$. , in Sartsruge 1 fl. 5 fr., Jgeibelberg $52 \mathrm{fr}$, Mannkeim $39,5 \mathrm{fr}$ - Der D. 1854-56 war 280319 fl. शccife uno 269214 ff. Dhmgelo, zufammen $25 \mathrm{fr}$. auf ben Siopf. D. 1857-58 473726 fi. श्रccife, 366042 fl. Dhmgeld, zufammen $38 \mathrm{fr}$. ๙. ๖. R. Reues Sefets von 1858 F. §. 435. D. $1860-62$ Accife 455763 fi.,

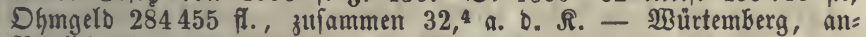
fänglich 15 , von 1833 an $13 \frac{1}{2}$ ßroc., feit 1839 mur 10 ßroc. vom SHreife bes ausgefdentten 2 seins. Crrtrag im D. 1854-56 419694 fi. 2. $1858 / 61450000$ fi. Heber bie Nadjtheile ber würtembergifden

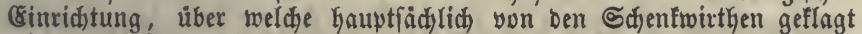
wirb, Deffner' Commiffitonbberidt über bie indirecten Steuern,

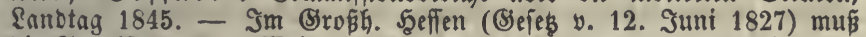
bie Tranfifeuer von $\mathfrak{S B}_{e}$ in jebesmal entridtet werben, wenn biefer im Sropen an einen neuen Eigenthumer übergeht. Sie betrug bisher $30 \mathrm{fr}$. von ber $\supseteq \mathrm{hm}$, feit 1856 fü Sdjenfwirthe nod ebenjoviel, für andere \$erfonen 2 fi. Şiezu tommt bie 3apfgebühr, \$. 435. - Die Difer= reichifdje $\mathfrak{B e r z e g r u n g s f t e u e r ~ v o n ~} \mathfrak{B}_{\text {ein }}$ wirb in ben beutidyen, flavificen tmb italienifhen Rrunlänbern in gefdlofienen Stäbten von bem ganzen Berbraud, beim Sereinbringen, in offenen Drten nur von Dem RTein= berfauf unter einem Eimer erfoben und meiftens burd abfinbung mit einzelnen Sdjenfwirthen ober Der Sefiammtheit berielben an einem Drte. Sier giebt ber Eimer 1 fi. $20 \mathrm{fr}$. Conv., in Den Stäbten 1 fi. $40 \mathrm{fr}$. In Ungarn uno Siebenbürgen if Diefe Steuer exit 1851 eingefübrt worben, mur in Drten von 2000 und mefr Erinwohnern unb von ber ganzen Serzehrung; nadh $\mathfrak{B}$. v. 12. Nai 1859 befteht die Steuer all= gemein und fitr alle Drte. Ertrag im D. 1851-56 4.796929 fi. Conv., Ioobun 3.178599 fi. aus bem offenen Ranbe. Sene Summe madit 0,163 ff. fübD. auf ben Ropf. 2. $18645 \cdot 949354$ fi. B. $=0,19$ fl. fǘd. auf ben Siopf. - In mehreren \&änbern befteht noch bie áltere

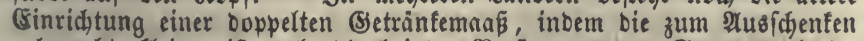
gebrauchte fleiter ift, als bie bei ber Berfteuerung zu Srunbe gelegte,

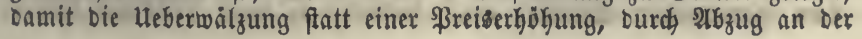




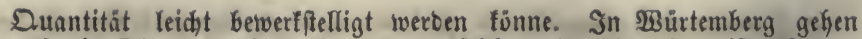
auf Die Dhm 176 Edjenfs uno 160 श्didmaafe, bie erftere ift alfo um 10 Proc. fleiner, um Die frukfere Steuer von gleidem Betrnge zu ver= güten. In 3urid, Gat ber Snum 90 Steuer= unb 100 Sdenfmaaße, औi a II, शrdjib I, 412.

\section{§. 435 .}

3ur $\mathfrak{B e i n a c c i f e ~ g e b o ̈ r e n ~ n o d ~ f o l g e n b e ~} \mathfrak{B}$ emerfungen:

1) Die von ben 3efrern für eigenen (Bebraut) in beträd)t= lidjer Menge erfauften und cingelegten $\mathfrak{B}$ einvorräthe wurben in frükerer 3eit, alz ber Weinauffallag auffam, gar nidst von bemfelben getroffen, aud gejdieht bießs hie uno da nod) jeşt nidbt. 218 man fie fpäter ebenfalls belegte, bielt man es bod) für billig, fie geringer zu belaften, als bie Berzebrung im Wirthbhauje. Die Beweggrünbe Kiezu fand man barin, baß Der $\mathfrak{B e r b r a u d}$ ber Şmüvorräthe langfamer erfolgt unb baker Die Steuer von bem 3efrer lange vorausbezahlt roerben mús, währeno berfelbe fie bem Sdjenfwirthe bei ber $\mathfrak{B e r z e f r u n g ~ e l j e r ~}$ uno in ganz fleinen abtheilungen vergütet, ferner baß̧ man

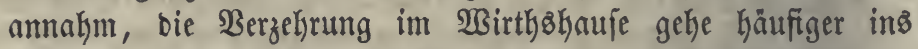
Uebermaaß ober laffe wenigftens leichter einte Befdränfung zu.

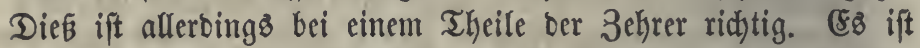
Daker meiftens bem Schenfwirth) (Rleintwerfüufer) ein höherer Steuerfus angeiebt ober neben ber allgemeinen Steuer nod) cine zweite, bns $5 \mathfrak{h m g e l}(3 a p f g e b u \mathfrak{h r}$ ) nuferlegt worben $(a)$.

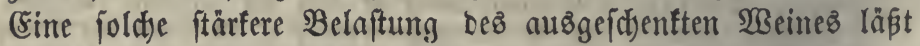
(iid) zwar im 2ulgemeinen red)tfertigen, aber fie ift gewöhnlid) zut hod) beftimmt worben, bent ein Theil ber Befyer ift mur barum

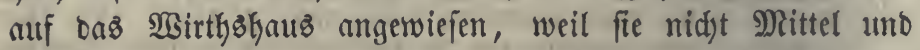
Selegentreit Gnben, in Sropen cinzufaufen, uno bieß gilt namentlid son ber פebrzahl ber Rohnarbeiter.

2) Die $\mathfrak{B}$ einfteuer follte ben alfgemeinen $\mathfrak{B}$ efteuterungägrutmo= fäksen gemīa iebe zur $\mathfrak{B e r z e f r u n g ~ g e l a t g e n d e ~ \Re e n g e ~ n a d ) ~ i f r e m ~}$ Berfehrgiwerthe treffen, ber zufolge ber alf Boben, Rlimn, Rage zc.

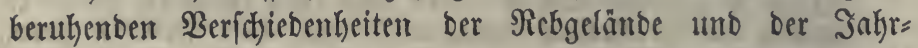
gänge fehr ungleid) ift, fo baj bie beften Weine cintes sanbes leidyt bas 5=, ia bisweilen bas 10 fadje bon bem \$reife oer geringften gelten. (E⿱ licke fid) fogar rectitfertigen, wenn von ben geringeren Sorten eine fleinere Duote erfjoben würbe (b). 
Eine foldye Bemefintung ber Steuter ift aber fdyvierig auball=

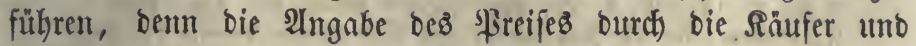

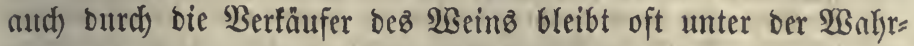
heit uno mur burdh forgfältige Ueberwadjung von ben Steurer= beamten berichtigt werben; bał̧u gehört baż Roften Dezె 2 seinz yon $\mathfrak{R a ̈ n n e r n , ~ b i e ~ i n ~ B e u r t h e i l u n g ~ b e f f e l b e n ~ g e u ̈ b t ~ f i n t , ~ a u t h ~}$

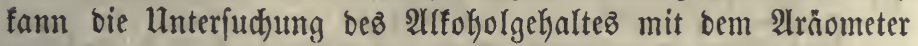
孔แ Şülfe genommen werber. Diefe Mittel zut $\mathfrak{B e r h u ̈ t u n g ~ D e z ̇ ~}$ Stenterbetrugez unit ben Strafen, weldje anf wiffentlich gemadte falidje 2 tngaben gefebt werben (c), find gleid) mandien anderen bei ben 2lufwanbäfteuern vorfommenben 2lnoronumgen fowohl für bie Steuerverwaltung alz für bie Steuerpflictigen läftig, fie raffent fit aber nur vermeiben, wem man entweber 26 fin = bungen mit ben 2 Beinmirthen verabrebet $(d)$, ober auf bie Unter= idfeibung ber verfidiebenen $\mathfrak{W}$ cinjorten verzidjtet unb bie Steuter bló nady ber Nenge anlegt $(e)$.

3) Wenn ber Aluffidlag erft von ben Weinwirthen entrictet wirb, fo faun ber eigene Berbrauth ber $\mathfrak{B}$ einthändler am leidt)= teften bernittelft einer \$3aufdjiumme beftetert werben. Bei ben Weinbautenten aber fino fowohl die Bermögensumftänte als

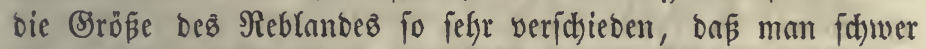

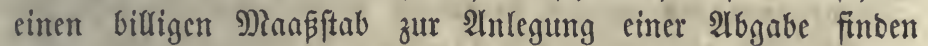
wirb $(f)$.

(a) In Franfreid wirb biejer Swedf baburdy erreidyt, Daß̧ Das droit de détail Gober ift als bas droit de circulation, $\$ .434(d)$. - Das bab.

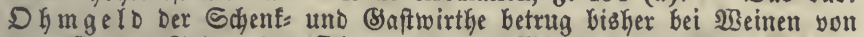
250 f. wer Fuber (10 Dhm von 100 Naan ober 150 Riter) ober weniger $1 \mathrm{fr}$. yon ber \$laás, bei fuftbareren fo viel als bie Necife.

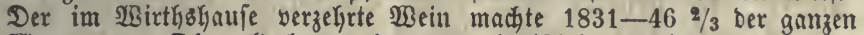
Wienge, זas Dhmgelo betrug in ben brei 5jährigen 3eitabidnitten 56 , 59 uno 51 ßroc. Der ganzen Ginnahme, 1854-56 nidyt volf 49 ßroc.

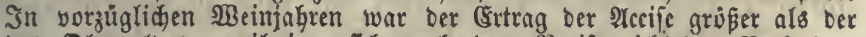
Des Shmgeldes, weil jene fid nach Dem \$reife ridjtete. Siads bem (Sefes von 1858 ift Das Dhmgelo ganz gleidfürmig $0,8 \mathrm{fr}$. yon Der Mané oder 1 fl. $20 \mathrm{fr}$. von ber Dhm. - Die groph. hefi. $3 \mathfrak{a} \mathrm{f}=$ gebilgr ift in 4 (Elafien 2 f. $40 \mathrm{fr}$. bis 6 fi. $40 \mathrm{fr}$. von Der Dhm. -

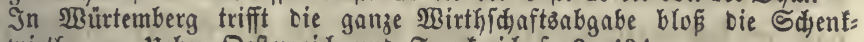
wirthe, - Ueber Defterrecich und Franfreidy f. \$. 434.

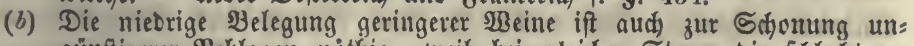
günftigerer sieblagen nothig, weil bei gleidjer Steuer bie idhledteren SBeine tweniger 2 bfäs finben würben.

(c) In Baben beftano bis 1858 ein \$orfauforedyt ber Accifebedienten, mit 10 \$roc. Suifhlag. Die \$reiszeugniffe nurben vom श्रccife = Srkeber

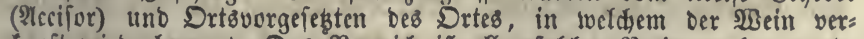
tauft wirb, bezengt. Das Berzeiđhniß́s aller foldher ßreisangaben wurbe 


\section{6}

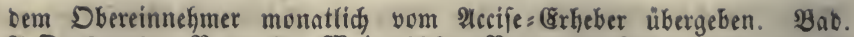

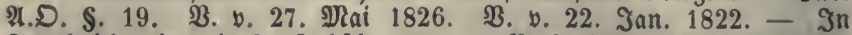
Franfreich wiro bie Sapfgebügr von bem Berfaltfopreife beredjnet, Den

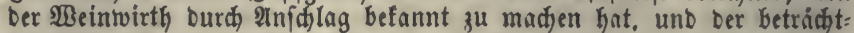
lid) hojher ift als Der (Sinfaufspreis. Dießs erleichtert bie Ueberwadjung, wenn nidjt zu viele verídiedene Sorten und \$reife borfommen.

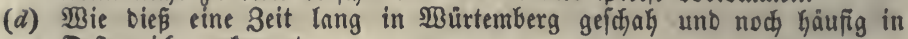
Defterreich vorfommt.

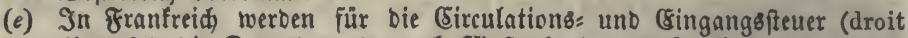
d'entrée) bie Departements nach Slaśgabe ber getwöhnlich bort getruns fenen $\mathfrak{S B}_{\text {Beine }}$ in 4 Elaffen getheilt, in benen Das droit de circulation 60-80-100 uno 120 Eent. yom Şeftoliter beträgt. Bei Dem droit d'entrée wirb außer biefen 4 (Elafien noch Die E̛intwohnerzahl ber Etäbte

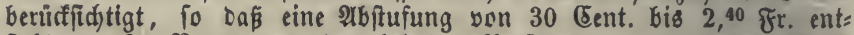
feft. - In Baben war ber bei ber Berfteuerung angegebene \$reiß Dew \&ubers im Durdfdnitt 1831-36 126 fi.

$$
\begin{array}{ll}
36-41 & 111 " \\
42-46 & 167 \\
47-56 & 145
\end{array}
$$

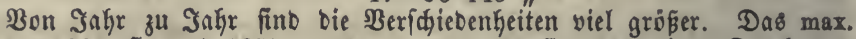
von 224 fl. trat 1855 , Das min. yon 92 f. 1850 ein. Durd Das

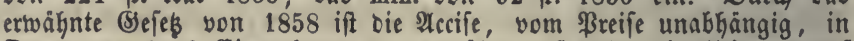
Drten yon 4000 Eimwoknern und Daruber auf $1 \mathrm{fr}$., in tleineren auf $0,8 \mathrm{fr}$, von Dbftwein auf $1 / 4 \mathrm{fr}$. von ber Miaás beftimmt worben. Diefe neue Feffétung entfpridyt Dem Durdfidnitt Des bisherigen Steuer: ertrages, trifft aber Die Einzelnen iefgr ungleid. $\mathfrak{B g e i n}_{\text {zu }} 20$ f. Die

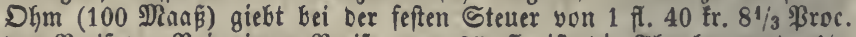
Des \$reifes. Bei einem \$reife yon 25 fl. ift Die 2ugabe getade $1 / 15$ $(62 / 3$ अrsc.), wie früher, Kei 80 fl. beträgt fie nur 2 \$roc. Die geringen $\mathfrak{B}$ eine werben am meiften vertheuert.

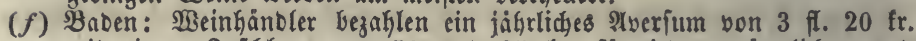
mit einem 3uidhlage von 50 und $25 \mathrm{fr}$. für jeben männliçent uno

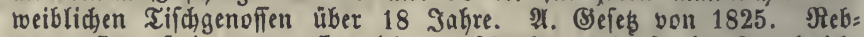
bauer finto frei, wenn fie nicht autôfdenfen; ebento in Erantreid, S. $434(d)$.

\section{\$. 436 .}

Der Bieraufidjlag ift in vielen Staaten wegen ber ftarfen, in neuterer 3eit nod) anjefnlid) zunehmenben Bier= verzegrung eine ergiebige (Einnahmzquelle, vorzüglid) in ben fălteren, zum Rebbau wenig ober gar nid)t gecigneten \&änbern, wo ber $\mathfrak{B e i n}$ für bie meiften Einmokner zu foftbar ift $(a)$. Man Dürfte jebod) ben $\mathfrak{B e r b r a u d}$ biejes für bie arbeitente

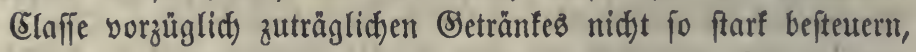
Daß er fid verminderte, ober baß ein Theil ber 3efreer cinten

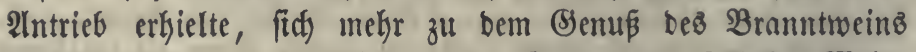

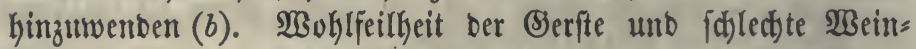
jahre vermehren vorübergehento ben $\mathfrak{B}$ erbraud) bes Biereళ unt Den Ertrag biejer Steuer. Berbefferungen in ber Bierbrauerei tragen fortwähreno hiezu bei. 2tud hier finb mefjere (Erthebung 
arten veriucht worben, bei beren Bergleichung nur von einem Mefyr ober Weniger ber Mängel und Scjwierigfeiten bie Rebe jein fann.

1) Entridtung von bem Rohftoffe. Die üblidften bis jekst angewenbeten $\mathfrak{W e g e}$ ber Befteuerung fino $(c)$ :

a) 9) $a I z a u f(d) I a g$, beim Scyroten bes Malzes nad) ber 2lrt ber Mablfteuer zu entridyten $(d)$. Dieß if einfach und verurfacht Der Regierung geringe Roften, wenn Das Malz auf fremben Miulylen gefdyroten wirb, ift aber nidht fo leidgt auf grope Brauereien mit eigenen Sdyrotmühlen anmenbbar (e).

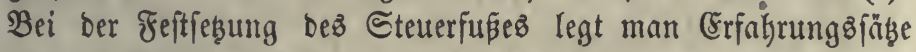

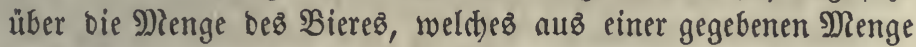
bon Nalz gebraut werben fann, zu Erunte $(f)$. Ein erbeb=

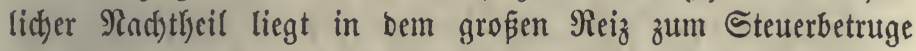
uno in ber Befalir eines Cinberftänoniffes zwifden ben Bier= brautern und Nüllern, weß̧halb man, nad) ben biżkerigen (Er= fahrungen, entweber vielfadje lleberwadungämittel unb ftrenge Strafbeftimmungen zu Şülfe nefmen, ober häufige Ünterfaleife gewärtigen muß $(g)$. $\mathfrak{W}$ o eine obrigfeitlid)e Biertare befteft,

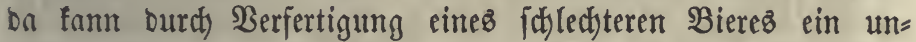
billiger (Sewinn gemad)t werben, inbem baun aus gleidtem Malzuorrathe mekr, alв bas Biefes aunimmt, erbalten wirb.

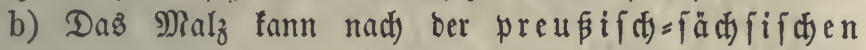
(Sinrid)tung furz bor feiner Berwenbung zum Brauen, nament= lich vor bem Uebergießen mit heißem Baffer (Einmaifden) verffeuert werbelt, wobei biefe Berridytung in Anwejenteit bes Beamten borgenommen wirb, nadjbem ber Brauer bie Erflärung gegeben lyat, wie biel Sdyrot er zu jebem Sube ju nehmen, und wie biel Bier er zu bereiten gebenft $(h)$. Auf Diefem $\mathfrak{B e g e}$

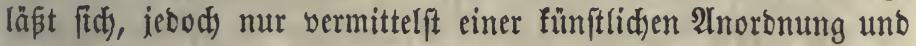
einer genauen Beauffidjtigung bes ganzen Brauberfabrens, ber (Einzug bes Bierauffid)lages ziemlid) ftcter ftellen.

(a) Benaue ftatiftifhe Huterfudfungen über Erzengung, Berzekrung unb Eteuerbelegung Des Bieres bei E $n$ gel, Jahrb. Der Statifit uno Stantswirthidhaft im Rönigreidf Sachjen I, 565. 1853.

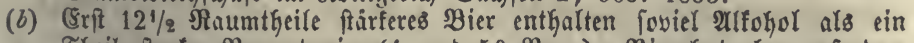
Theil farfer Branntwein (4 unb 50 Broc.), Bier hat nber außerbem viel Sighlenfaure und enthält zugleid) Summi und unzerfebten Sưfer, tooturdh es näGrent wirb. Die Ërfagrungen über bie Berânberungen

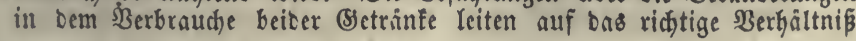


ifrer Befteuerung hin. - In Broßgbritanien war bie huhe Befteueung Des SBiers ber (segenftant vieler Befdyerben. Die orei Itbgaben bis 1830 madjten gegen 150 \$roc. vom \$reife ber (S)erfte aus und be= trugen etura 17 ङd). vom Barrel sorter (9 f.. $20 \mathrm{fr}$. von ber bab.

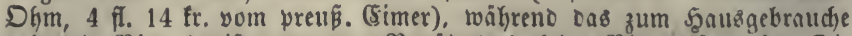
gebraute sBier (meift von Den $\mathfrak{B e g u t e r t e n )}$ feine sBiernccife gab. Die Malzconfumtion foll (nad, Siontgommery Martin) bon 1714$1723 \mathrm{im}$ D. $3^{1 / 2}$ Difl. Duarter geweien fein; 1814-1823 aber war fie nur 3.230000 Qul., 1820-1829 3.900000 Quu., fie hat alio mit

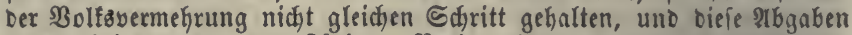
Gaben beigetragen, Den färferen Berbraud ber warmen (B)etrinfe ber: vorzurufen. B̉on $1684-1693$ ivurben im D. jährlich an 7 श्ifl. Barrels, von 1694-1703 wegen ber 9 tbgaben nur 41/2 Dill. $\mathfrak{B}$. ver= fteuert, $1746-1750 \mathrm{im}$ D. an $6,1824-1828 \mathrm{im}$ D. $8^{3} / 5$ श्itu. $\mathfrak{Z}$.,

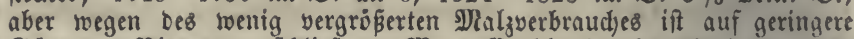

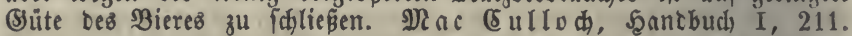
II, 253. Der Steuerfú ift neuerlid) (feit 25. Februar 1822) in ben

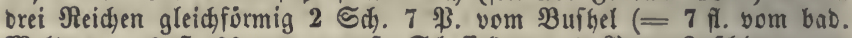
Malter $=2$ fl. 33 vom vreus. S(beffel) uno 5 \$roc. Sufdlag, nur wurbe er 1854 für Die Siriegsjohre auf 4 Gdh. erhoht. Die Nalzifeuer trug im D. $1831-18334.992159$ \&. St., 1837-1842 5.154 801 \&. St. Sier find Die Folgen von Der Rufhebung ber Bieraccife im Inthre 1830 fidtbar. Der Durdhidnitt $1857 / 8-1859 / 60$ mar 5.979029 \&. Der Malzperbrauch auf Den Ropf ftieg 1836 auf 1,78 3 uffel, 1837-1841 war er nur 1,5i Bufkel. Porter, Progress II, 52. 1848/9 wurben

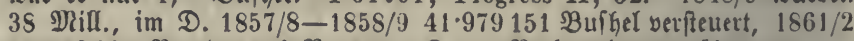
$41 \cdot 118168$ B. ober $1,4 \mathfrak{B}$. a. D. $\Re$. - Berfandlungen über sell von Beel befämpften uno aud verworfenen $\mathfrak{B o r d a l a g , ~ D i e ~}$ Nalzfteuer aleidfalls abzuidnffen; Unterfaus, 10. গ̉äz 1835. - B a illy II, 418.

(c) Die Malzfteuer in (Sirobsritanien wiro nad monatlider Angabe tes

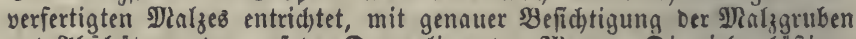

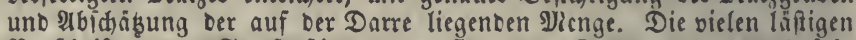
Borichriften uno Strafbeftimmungen fino (11. (Seorgs IV. c. 17.) fefr

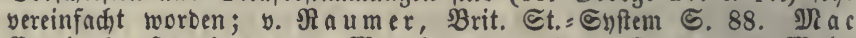
(5 ullo(), Şanbb. I, 254. Nan hat neuerlid, angefangen, Dem Nialze roke, aber gecourte Sserfte beizuleben; Daher wurbe 1855 befoblen, Das

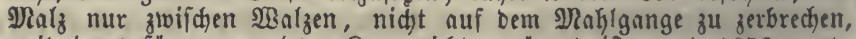
weil jenes für ungemalztes Sorn nidgt genügent ift, uno 1856 wurte

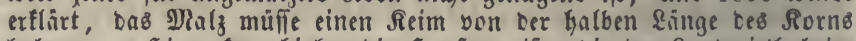
haben. - Şieju fam bisker bie Şopfenaccife, Die ser \&ancmitth beim

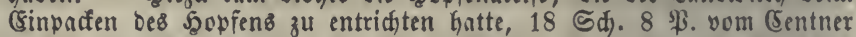

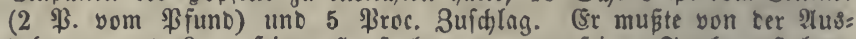
behnung und Lage feines \$copfenlandes, yon feinen Trodenanfalten,

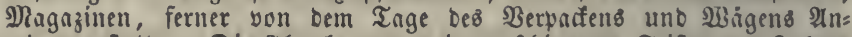
zeigen erfatten. Die Abgabe wurbe in veridjiedenen Friften Des Sabres entrichtet. Im Inhre 1860 (23. 24. Vict. C. 113.) murce bie ङteuer

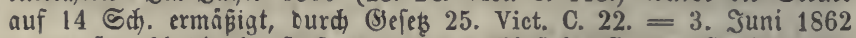

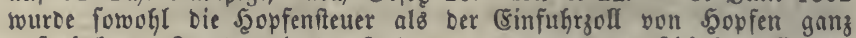
aufgefoben. In ben leb̧ten Iafiren war wegen ter folledjten (Ernten viel Şovfen eingefuifrt worben. Neuefte 2ngaben:

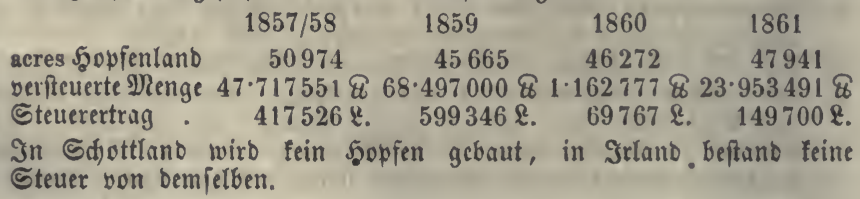


(d) Bayern, ältefter Bieraufichlag 1542, foonnn 1612 auf 1 Pfennig yon cer I) Ran erhobt. 1634 fam Der zweite, 1672 Der britte, 1706 Der

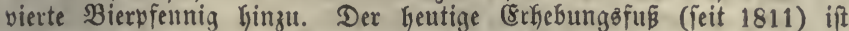

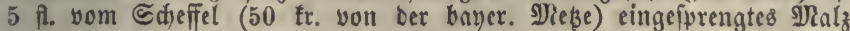
(=1 f. $14 \mathrm{fr}$. yom preuß. Sdueffel $=3$ fl. $21 \mathrm{fr}$. vom bad. S)alter),

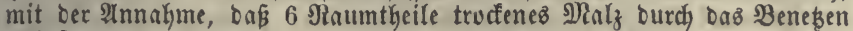
(Sinfprengen) firh auf 7 vermehren. Bei Der 2 tısfuhr merben $40 \mathrm{fr}$. Für Den (Eimer rüdvergütet. Der Bayer. \$Ralzaufichlag (nur in ben

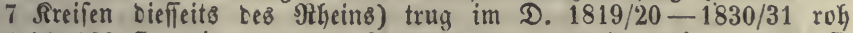
5.045083 f., rein 4.729035 fi., $1837 / 38-1840 / 41$ roh 5.556200 fi. rein 5.379149 fl., $1851-55$ roh 5.861561 fl., rein 4.656190 f̂.

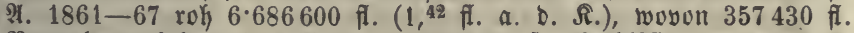

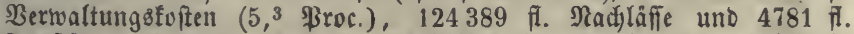

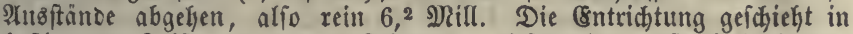
beftimmten Friften nach bem Schroten, biefes aber barf erft beginnen, wenn ber Eigenthümer Nalz gemefien und ben Erlaubnifichein (Pollete) erkalten, ber \$ñller

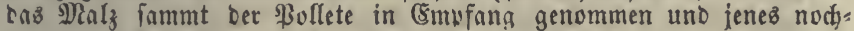

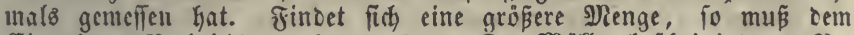
Sinnehmer Nadyridht gegeben werben. Der Miuller befócinigt Den Bes

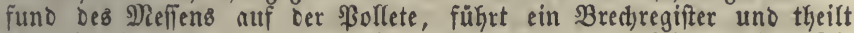

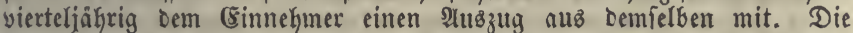
Brauereicn unb Dảhlen Iverben häufig befintigt. Das für biefe Steuer beftefle \$erional befteht ats 35 Auffehern, 609 Simmehmern, 14 Bes anten an 7 Dberauff(h)lagsimern in Den 7 Srcifen uno einigen Dber=

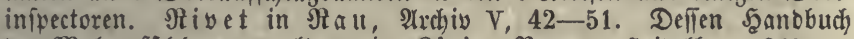
ter Malzauffahlagsverwaltung im Rönigr. Bayern. Sceibelberg 1842. -

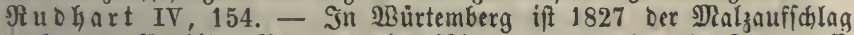
nach Dem Sorbiloe Bayerns eittgefuibrt worden, Szandb. S. 282 fi.

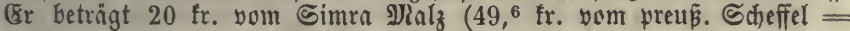
2 fi. $15 \mathrm{fr}$. yom Gad. Nalter). Ertrag im D. 1828-37 400161 fl., 1837-47 720607 ff., 1847-57 774615 fl. , Gỏdfter (Ertrag 1856/7 1.003354 fi. (wegen ber geringen $\mathfrak{B S e i n}=$ und Dbfternte uno ber gefun= fenen '(S) treitepreife). श्. 1858-60 770000 fi.

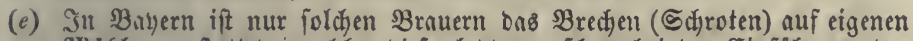
Ilüflen geftattet, welche biefe lebteren filjon bei ber Einfülirung bes

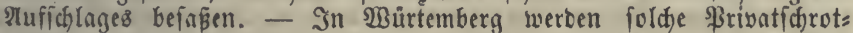
müflen, two man liberfaupt igre Beibehaltung geftattet, unter $\mathfrak{B e r}=$ fchluß ocs Afccifebeamten gehalten.

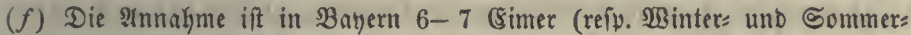
bier) auf 1 Scheffel trofnes झlalz, alfo $1,84-2,15$ গnumtheile Bier auf 1 Theil trodfnes 2)ialz. Sum Errake ber Steuer wirb bei ber obrigfeitlichen Biertaxe $1 \mathrm{fr}$. auf bie Maaß gefhlagen.

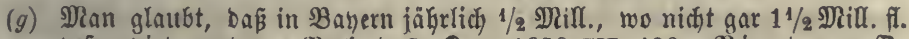
Defraubirt werben, Berf. D. 2. R. v. 1828 III, 139. Sivet a. a. D.

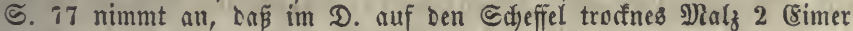
Bier mefyr gebraut werden, lvas (auf 964630 Sch.) unter Der Bors aubiebung you $54 \mathrm{fr}$. Auffidlng für ben Eimer fdyon 1.736324 fi. jâfyrlid ausmacht. Die 3ehrer müfien aber biefe 1.929000 (Simer um ben obrigfeitlich beitimmten \$reis bezahlen, im D. zul 4 fi. 48 fr. Den

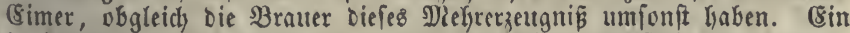
in jenem Saljre ben Rammern vorgelegter Sefebentivurf, in Dem nament: lich Rellervifitationen vorgefdyrieben waren, tam, als zu beläfigent, nidit zut Stance.

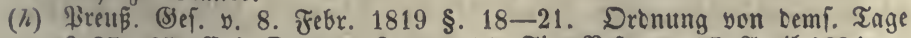

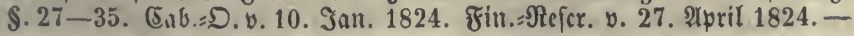




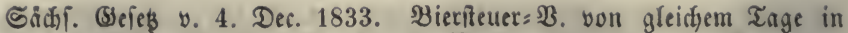
Berger S. 107. - Die Eteuer ift 16 g(5r. Doer 20 Sgr. bom Sentner geiprengtes $\mathfrak{M a l z}$ fajrot (woraus etwa 100-150 Duart Bier

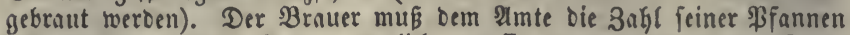
und Bottidbe (weldje fooann amtlich gemefien werben) anzeigen, ferner jedesmal Die 3eit, wenn er maifhen will, zugleids feinen Nialzyorrath und Das Daraus zu brauende Bierquantum melden, toeldes bann zur Sontrole erforiont wird. Der $\mathfrak{M a l}_{\text {zoorrath }}$ oarf nur an einem beftimmten Drte aufbewahrt nerben. Bill ber Brauer einmaifden, fo muß er

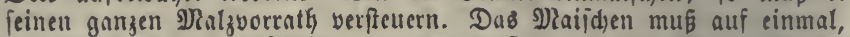
nur im Braulocal gefdjehen, uno es múp von ber vorker angezeigten Seit an noch eine Stunbe auf bie Infunft bes Beamten gemartet wers

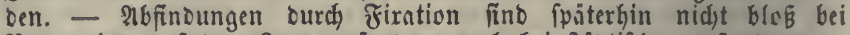
Brauereien auf bem Eande, fonbern aud bei friotifden geftattet wor: Den, preußs. (Snbinets: D. v. 2. Juti 1827 uno 17. 2uguit 1531. Bif́la me S.103.117. Eteuerertrng 1833-38 im D. 1.283926 Thlr., 1856 - $58 \quad 1.202959$ Thlr. mit (sinifhlǘ Der Uebergangsiftener (alfó gegen $62 / 3$ fr. a. D. $\Re$., fefr niebrig). - Sadjien, D. $1855-57$

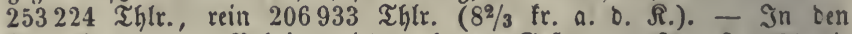
Nieberlanden und Belgien wirb nach Dem (Sefés von Ruguf 1822 tie

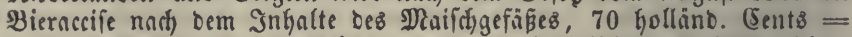
1 Fr. 48 Bent. vom Şeftoliter, yor Dem (8inmaifhen erboben. Şiezu fommen in Belgien S3tid lảge uno 10 \$roc. Stempel. Nad, netreren

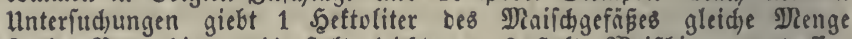

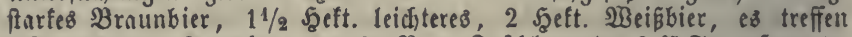

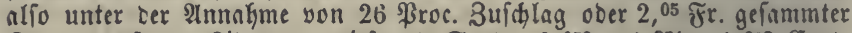
Steuer auf Dns \&iter yon biefen 3 Sorten $2,056-1,371-1,023$ (5ent. Steuer. Die vorgeidgriebenen foormlidfeiten find fegr umftinclidy uno befhwerlid. Ertrag mit (Sinfalus ber unbeträchtlichen Effigaccife D.

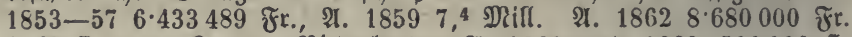

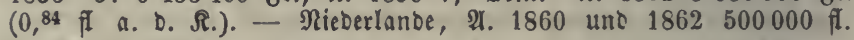

\section{§. 437.}

2) Der Bierauffdylag fann bei bell Brauen felbft mach ber bereiteten Menge entrichtet werben (a) unb biefe Alnorbnung Gat fith alz empfeflenswerth erviefen. Die (Srößje ber feffel (Pfannen) wirb butth verpflidytete Perfonen gemeffen (genid) $t$ ) (b). Der Brauer hat, fo oft er fieben will, 2lnzeige zu erftatten und bie nach bem Reffelgekalte bemeffene Steuer von bem eingelnen Sube zu entrichten, wornuf bann burd) belt Eteuerbeamtent ber für bie 3wifłenzeit beranftaltete Serfhlus bes Sdjürlodjes Ginweggenommen wirb $(c)$. (58 ift zwar nid)t leid)t bie $\mathfrak{B} e r=$ heimlichung bes Siebens, eher aber währent ber geftatteten Brauzeit ein mehrmaligez Füllent Dez Seffela zu bejorgen, Deßs= halb ift es nöthig, afles Rad)giesen von bem Alugenblicfe an, wo bas alblaffen bes fertig gejottenen Biercs beginnt, ftreng zu unterfagen $(d)$, aud) bie bervilligte Brauzeit nad) bem Stanbe Der Sunft umb nady örtlicben Berbältniffen fo zu beftimmen, 
Daßi fie zwwar zureicht, gutez Bier ju erzeugen, aber baz mehrs malige Brauen nicht zuläpt (e). Ueberbieß muß öfter nad)=

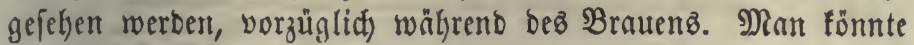
aud) verfudyen, nod) ein anberes Uebernad)ungämittel, z. B. Die Errforidung ber verbraudten Menge Sdyrotes $(f)$ ober bie ge= wonnene Suantität $\mathfrak{B i e r , ~ z u ~ S ̧ u ̉ l f e ~ z u ~ n e h m e n ~ u n b ~ b i e ~ S t e u e r ~}$

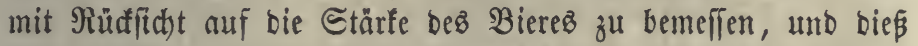
wäre müb̨lich, weil fonft die Steuer baş leichtere Bier eben fo ftarf trifft wie bas ftärfere, von weldsem eine höhere 2lbgabe entrichtet werben follte. In Sachjen hat fidf $1844-51$ bie Berzehrung bes einfacten Bieres um 5, Des Doppelbieres um

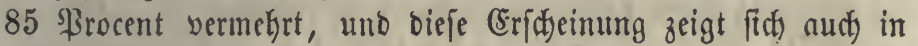
anberen Ränbern.

3) Die Erhebung von bem gebrauten Borrathe, wie er fid) nad) Der Bolfenoung Dez Єiebenz zeigt, hat gegen fid), Daß̉ ofne vorauşgegangene Beobadtung Dez Brauborgangez leicht ein Theil bez (Erzeugniffes auf bie Seite geidsnaft werben fann. Dagegen bient bie Sergleid)ung bez auf Dem Rühlichiffe, in Bottiçen und Fäffern enthaltenen Biervorrathez alz Sidbe= rungżmittel für anoere (Erfjebungz̊nrten, vgl. 2) - (g).

(a) In Franfreich befteht Diefe Erhebungsweife feit 1808, mit einer unter= brechung 1815 und 1816. Bom Infialt bes Reffels werben 20 O3roc.

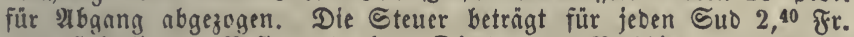
vom Sgeftoliter $(1,68$ f. v. D. GaD. Dhm), yon Naぬbier (petite bière) 60 Eent., (\$efeb y. 12. Dec. 1830. Im D. 1857-60 war ber Ber= brauch 6.790584 Sceft. (Kauptfächlid in ben norblichen Departements), Der Ertrag mit ben beiben Decimen 15.834638 ₹r, ๖. 5 o of 5 . 375 , de Parieu III, 18. - Baben, (5efebs v. 4. Nai 1825. Bei ber $\mathfrak{B e}_{e}$ rathung mit 10 eingerufenen $\mathfrak{B}$ rauern im Jahre 1843 hat man bie

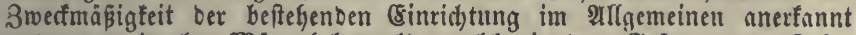
und nur einzelne Dängel bemerft, weldye in bem Sefeb v. 28. Febr. 1845 abgeanoert worben find ; Berbanol. Der 2. Rammer bon 1843-44

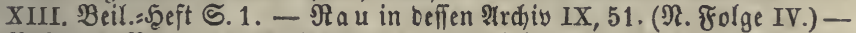
$\mathfrak{B}_{\text {oll }}$ ugg $=\mathfrak{B}$. v. 30. April 1845 . 3ugehorige Dienftanweifungen vom

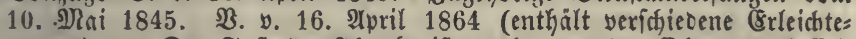
rungen). - Der Fuß ber Abgabe ift $50 \mathrm{fr}$. von ber $5 \mathrm{hm}$ bes Reffel= gebaltes (yorber 1 ff. mit Rbzug yon 2 Sollen für ben Stand Des Seffel(s). (Ës wirb angenommen, Daß́ auf Die Dhm bon bollentetem

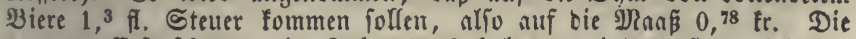
genauen Erforjđungen im Jakre 1843 Kaben gejeigt, Daß̃ ber Abgang beim Sieden, 2bfühlen, (Sähren uno \&agern bei Sommer = (Engers)

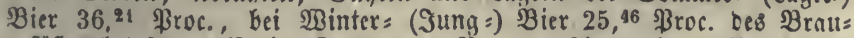

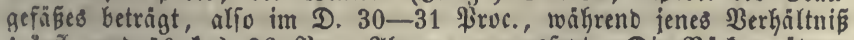

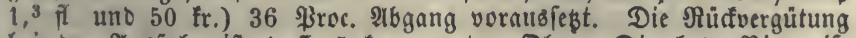
bei Der 2lusfuhr ift 1 fl. $5 \mathrm{fr}$. yon ber Olgm. Die bab. Bieraccife 


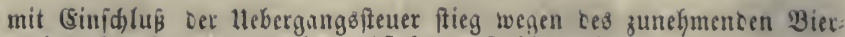
verbrauches beoeutend, wie nadjftehenbe 3njlen zeigen:

\begin{tabular}{|c|c|c|c|}
\hline & Grtras & $\begin{array}{c}\text { Ertra } \\
\text { auf Den Sopf }\end{array}$ & $\begin{array}{l}\text { Mutbmabilider } \\
\text { Berbraudi } \\
\text { auf Den Siopf }\end{array}$ \\
\hline $\begin{array}{r}1831-35 \\
36-40 \\
42-46 \\
54-56 \\
57-59 \\
60-62\end{array}$ & $\begin{array}{l}191897 \text { ก. } \\
243981 \text { " } \\
379234 \text { " } \\
324328 \text { " } \\
417672 \text { " } \\
458348 \text { " }\end{array}$ & $\begin{array}{c}9,4 \text { fr. } \\
11,4 " \\
17,24 " \\
14,8 " \\
18,7 " \\
19,9 "\end{array}$ & 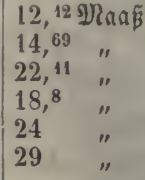 \\
\hline
\end{tabular}

Die Orinnakme fanf 1847 wegen ber Setreibetheuerung auf 273643 fl., 1862 fant fie bagegen auf 518348 fi. - Surkeffen, Sefeb v. 6. Mainz 1831, 24 Stunden Brauzeit, 5 Sgr. vou ber Dhm ( $=0,75$ Bad. $)$. (Sroß̈h. Seffen, Befes v. 12. Sept. $1827,40 \mathrm{fr}$. von ber Dhm Des

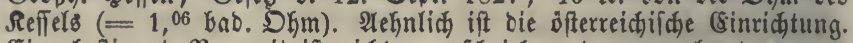
Eime beftimmte Brauzeit ift nicht vorgefdrieben, bagegen aber bas gange Berfalyren yom (Einmaifden bis zum Pblafien von ber sühle unter

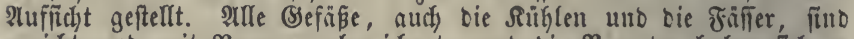
geaicht uno mit Nummern bezeichnet, uno bie Beamten haben fich zu

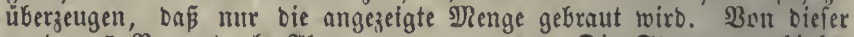
werben 5 \$rocent als Rbgang angenommen. Die Steuer war bisher yom (simer Bier 1) in Wien 2 f. $30 \mathrm{fr} ., 2)$ auf Dem Eande und in fleinen Stäbten $45 \mathrm{fr} ., 3$ ) in (S)alizien $20 \mathrm{fr}$.; Diés madjt im $241 / 2=$ (8)

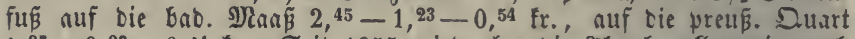
$1,87-0,93-0,41 \mathrm{fr}$. Seit 1855 wirb aber tie $216 g a b e$ allgemein nad ber Nenge uno bem 3udfergehalt ber Bierwurze bemeffen. Ertrag im D. $1851-57 \quad 7 \cdot 451093$ fi. \&. 186416.397976 fi. $=32,8$ fr. fitoD. auf Den Rupf.

Die Gad. DRaa (= 11/2 Riter) wirb bemnady verffeuert in

$$
\begin{aligned}
& \text { Rurbefien .... 3u } 0 \text {, } 23 \mathrm{fr} \text {. } \\
& \text { Sgeffen = Darmftabt " } 0,34 \text { " } \\
& \text { Bayern .... " } 0,49 \text { " } \\
& \text { Broen ...." } 0,78 " \\
& \text { \$reusen . . . " } 0,45-0,91 \mathrm{fr} \text {. } \\
& \text { Franfreid ....." } 1 \text { fr. }
\end{aligned}
$$

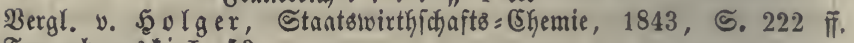
Tegoborsti I, 53.

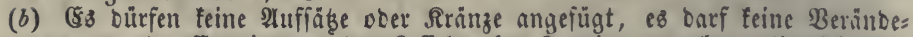

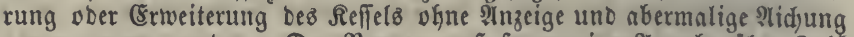
vorgenommen werbent. Der Brauer mǘ ferner eine Ingabe liber $3 a f$ l uno (Selyalt aller (Sefápe exftatten.

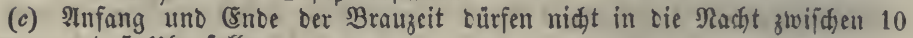
uno 5 uhr fallen.

(d) Das frubere Berbot alles Rachfüllens hatte zu viclen Beftrafungen und Befdwerben von Geiten ber Brauer Anlnás gegeben. Das neue bao.

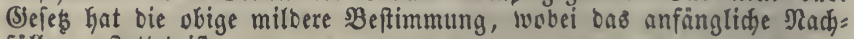
filllen geftattet ift.

(e) Früfer bei Braunbier 30 , bei $23 e i$ bier 18 Stunten. (Sine gleich)=

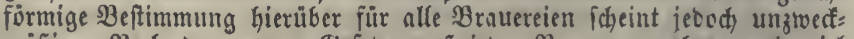

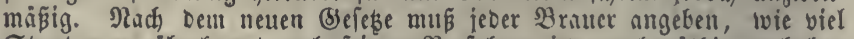
Stunden ex überkaupt nach feinem Berfahren jedesmal nothig zu haben glaubt, uno bas Stemeramt entfheicet hieriber und 2införung yon Eadjuerfintigen, Doch ift eine getwiffe, nach oer (Sröse Des Reflels 
beftimmte Stunbenzahl im Sejeb als פinximum nufgeftellt; bei 25 Dhm und barïber 24 Stuncen, bei ben fleinften Refieln von 5 Dhm und Darunter 12 ๔tunben.

(f) Im R. Weftfalen wurbe ber Bierauffidalag gleidjfalls yon bem Refiels inhalte erfoben; (Se fes v. 6. Närz 1810 (Bulletin v. D. J. I, 279) Art. 6. 23. Der Steuerfü twar fpäter (Sejess v. 18. Decbr. 1811) 1,70 frz. vom Jaftoliter (oder $1 \mathrm{fl} .12 \mathrm{fr}$. von Der bad. Ohm). Der Brauer muBte bei feiner Declaration aud Die \$ienge bes zu vertwen= benben Nalzes anjeigen und ein genautes Brauregifter führen. Wer

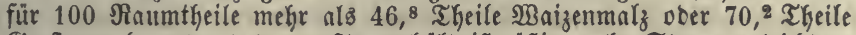
(S)erftenmals anwenbete, muste berbältnismäßig mehr Steuer entriçten.

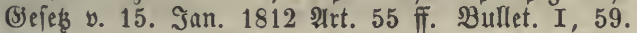

(g) Şnnnover feit 1835: $6 \mathrm{~g}$ (Sr. von ier Tonne ßier von 40 Stübden. \&elizen I, 384. - 2. 1859,6035000 Thlr.

\section{§. 438 .}

Branntweinauffdylag. Die (Stünbe, weld $)$ bie Beftue= rutg bes $\mathfrak{B e i n e z}$ und Bieres empfehlen, gelten in berftänftem

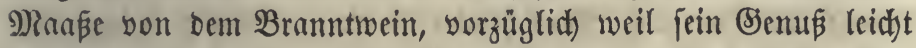
ins Uebermaaß geht, Durd 2lngewöhnung zu einem Bebürnin wirb uno bann berberblich auf Beift und fiörper wirft $(a)$. (5) wäre Daker erwünfdt, wenn in Folge ber Beftetterung ber

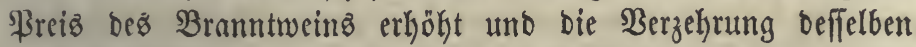
verminbert würbe $(b)$. Sndes ift biefe Wirfung wegen ber in Der Steuererbölyung liegenden Ermunterung zu Berbefferungen im $\mathfrak{B}$ etriebe oer Brennereien wenig zu erreid)en unb man bürfte fie nidyt burd) hoke Steuerfäbe zu erzwingen fuchen, theils weil bie Berwentung von mehl= uno zuterhaltigen Stoffen zum Brennen für bie Sanbwirthid)aft felyr müblid) ift (c) uno bie

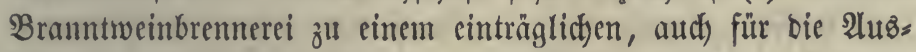
fubr betriebenen (5ewerbszaneige werben fann, theils weil Brannt= tvein uno Beingeift für viele gewerbliche 3wedfe benutst werben und weil mit bem Etenerfuße bie Siefahr bes heimlidyen Bren= nens zunimmt $(d)$. Die 2Abgabe follte aber wenigftens in ein

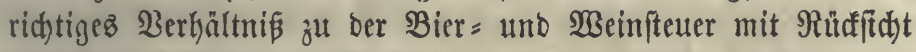
nuj bie fehr ungleiche Stärfe biefer orei Sietränfe geję̧t werben. Die 2lulegung ber Steuer hat eigenthümlicbe Sdjwierigfeiten, weldye in oer Bereitungåart Dez Branntweins und feinem ftarfen 2lttokolgebalte liegen, Denn biejer verurfacht, Daßj eine verbäitniß̈mäßig geringere Menge verzefrt wirb und bie $\mathfrak{B e r}=$ fertigung, bie Berjenoung uno ber Infauf leidjter verkeimlidyt

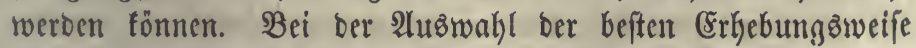
ift auf bie Betriebsart ber $\mathfrak{B r e n m e r c i}$ in einem sanbe unb auf 


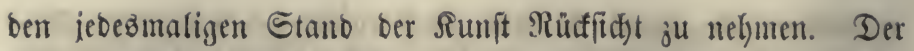
nidft zum menichlid)en Semufie bientende Branntwein follte von ber Alggabe verfdjont bleiben (e). Die Erfebung fant, wie bei ber Bierfteuter, forwohl yon ber Erzeugung, als bei cem Berfaufe gefdethen.

1) Die Maifd fteuer mad) ber preusifden (Einridtung

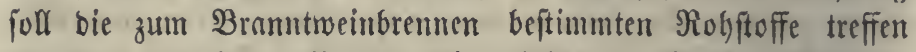
unb wirb vor iebem Brande bei mehlhaltigen Stoffen (Setreibe,

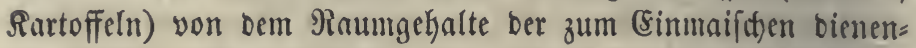

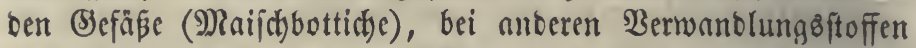
(DGft, Beeren 2c.) yon bem bereitgehaltenen Borrathe Derjelben erlooben $(f)$. Man nutí zu biefem Behufe ermitteln, wie viel Branntwein yon einer gewiffen Etärfe aus einter gegebenten Menge Maifdye uno Maijd)raum in ben (Sefäpen gewonnen werben fam $(g)$ uno wie fid) bie beridsiebenen $\mathfrak{B}$ erwandlungb: ftoffe in ber Ergiebigfeit zu einamber verhalten $(h)$. Der Eigen= thümer ber Brenterei wirb verpflidtet, bon bem $\mathfrak{M}$ mfang und ber SBeife, wie er fein Berwerbe in jebem 9) Monate betreiben

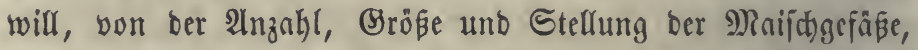
Den Tngen ber Einmaiftung eineś jeben und bez Brennens aus jeber Blaje, von ber Menge ber zut verwendenden Mefl= früd)te ober anderen Stoffe 2 . burd) Uebergabe DeB Betriebo: planes auşfülyrliche 2 Inzeigen zu erftatten. (Ex barf nur in ben

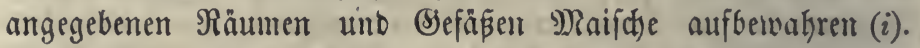

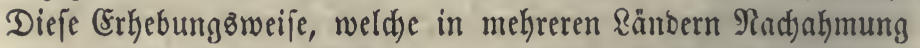
gefunben hat $(k)$, gewährt barum ziemlidhe Sidjerkeit, weil bie

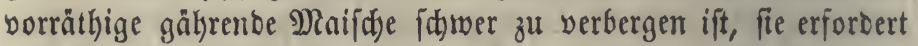
aber eine grope $\mathfrak{B a d}$ ) famfeit ber Steuerbebienten, bie bei einer groß̧en Menge fleiner Bremereien fehr müham und foftbar werben wurrbe, wep̧halb man ben Betrieb diejes Bewerbes wenigitenz bei Meklfitoffen nur in eintem getwifien beträd)tlidjen Umfang geftattet (l). 2ludi) ohne biefe Beroromung fint bie vielen zur Ueberwadyung bienenben $\mathfrak{B}$ oridjriften für ben fleinen

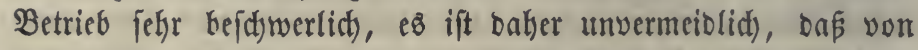

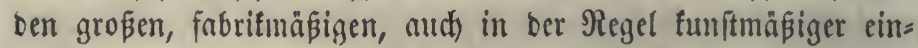
geridbteten $\mathfrak{B r e n n e r e i e n ~ b i e ~ f l e i n e r e n ~ v e r b r a ̈ n g t ~ w e r b e n ~}(m)$. Diejen

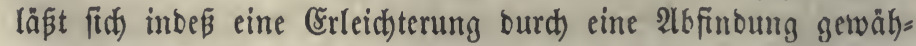
ren, bie bagegen zur Edjonung mangelbafter (Einridjtungen nid)t 
rathfam wäre, weil fie zur Beibehaltung ber leb̧teren einen Intrieb gäbe $(n)$. Uebrigenz haben fid) bod) bei biefer Befteue= rungżmeife erheblict)e Radytheile gezeigt. Sie treibt bie Brannt=

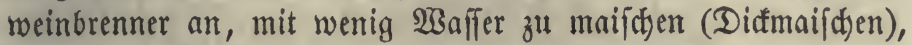
um an ber Steuer zu fparen, woburch aber bie 2llfoholerzeugung verminbert uno alfo ber Rohftoff unvollftänoig benubst wirb. Sie verbindert bie Berwentoung foldher Stoffe, bie wenig allo= hol geben, wenn biejelben aud fonft mit Bortheil gebraudst werben fömuten. Sie beläftigt biejenigen (Erzenger, weldye in ifrer (Segent nur אartoffeln von geringerem Stärfegehalt be= zicken fönnen. Die vielen nad) und nad) vermehrten uno gefteigerten Ueberwadfungsimittel, Bebote uno Berbote mit Strafanorokungen fino ber weiteren Bervolffommnung biefes Berwerfes hinberlid), in weld,em neuerlid) bie Bereitung bes

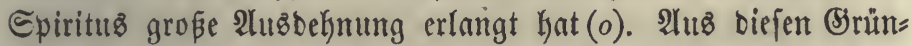
ben ift neuerlid) wiederbolt bie Umwandlung biefer Steuerform in eine andere angeregt worben, §. 439.

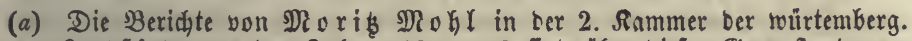
\&antitande aus ben Sahren $1852-58$ fint über Dieien (Segenftand vors

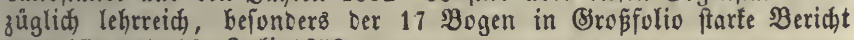
yom 17. und 18. Juli 1852.

(b) Der Branntrein bient zwar unter mandien $\mathfrak{U}$ miftänben, z. B. in einem feuthten Rlima, bei 2rbbeiten it ber Näfie u. Dgl. zur Sefuntheit, aber

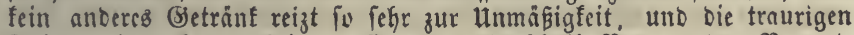

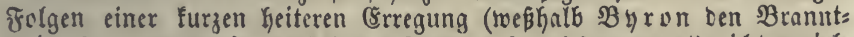
ivein the poor man's sparkling substitute for riches nennt) ridjten viele Familien zul (B)rimbe. $\mathfrak{W B}_{0}$ Der Branntiveingenú unter ben unteren

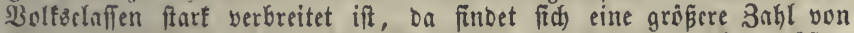

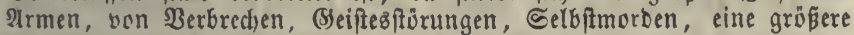
Sterblidffeit uno unfittlidfeit. Eefrreiche Belege in Congrès international de bienfaisance de Bruxelles, 1856, I, 293, - Congrès de Francfort, 1859, I, 229. - Bgl. \& ngel, Sahrb. I, 446. - Die Bẹchränfung Der Branntweinfajenfen hat in (S)ropbritanien gut getwirft. Mutch Die

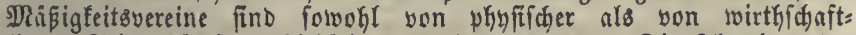
licher Seite Göhjt tooklthätig, vergl. I, §. 347. Die Albnafme ber Branntweinaccife in Srlano ift eime beutliche $2 B$ irfung yon ben Bes mühungen bes achtungswerthen (Seifliden The reno oort $183812 \cdot 296342$ (Salf. verzegrt wourben, fanf ber Berbraud 1840 auf $7 \cdot 401051,1841$ auf 6.405443 (5all. Porter, Progr. S. 556. Derfelbe (Liter. Gaz. 1850 S. 585) fdlägt Die शtuళgabe für Bramnt=

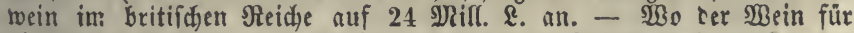

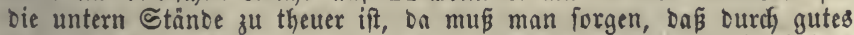
und rohlfeiles Bier Dem lleberfanonefmen bes Branntweintrinfens Esinfalt gethan iverbe. - Böttder (ueber ben Branntweingenú,

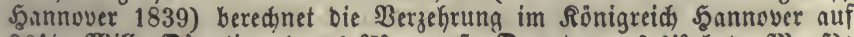
$304 / 5$ Ditl. Quartier (zu 0,859 preußs. Quart $=0,649$ bad. Dlaaßß); woram etroa $1 / 4$ ber (sinwohner Theil nimmt, fo ba ́s gegen 100 Duars tier fährlid auf ben sopf treffen. Die 2asgabe bafür ift gegen 
5.898000 Thlr. uno Die verbrauditen Şalmfrüd) uno Rartoffeln trut: Den ben Brotbebarf für $1 / 8$ ber (simwohner Darbieten. - In Belgien ift 1838 cine befonbere Bewerbiteuer auf bie Branntweinfdenfen ge= legt worben, um bie $3 a h l$ berfelben zu verminbern. Diés ift jeoods

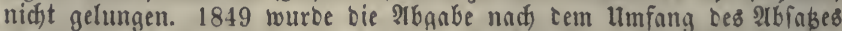
abgeftuft. Im D. 1857-59 waren 58578 Ed)enfen, weldhe 912121 Fr. eutridfteten, 1845-47 nur 43080 mit 959323 fr. Steuer. - In Sachfen war im D. 1840-50 Der Branntweinberbraudf (ă $50^{\circ}$ Tr.) auf Dell Ropf ber (sinwokner 9,10 Rammen (zแ 0,935 \&iter), Die Iusgabe Dafür 1,518 $\mathfrak{T}$ GIr., bie Steuer 5 Sgr.

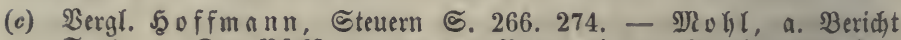

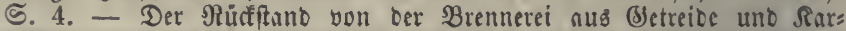

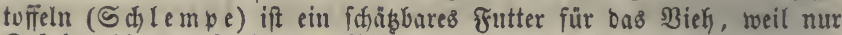
Stäfemehl und 3urfer zur Biloung bes Alfohols berbraudht werben,

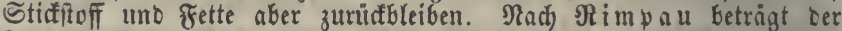
Futteriverth ber Sd)lempe von Sartoffeln bis zu $3 / 4$, von Noggen uno (Serfte bis $1 / 2$ won bem ganzen Räfrwerth bes rohen Stoffes. Nach (Engel (a. Iahrb. I, 406) madyte die Sd)lempe bei mittleren (Setreide: uno Saeupreifen in Sadjen im D. 1840-51 von Setreibe 46,5, yon Sartoffeln 34 Proc.

(d) In Grofbritanien ift fowohl Diejer Betrug als bie heimliche Sinfuhr

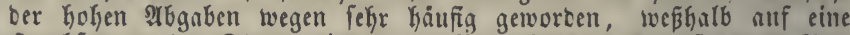

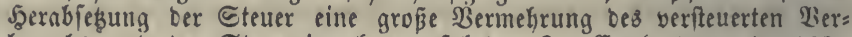
braucts und ber Steuereinnafme erfolgte. In Congland wurte 1827

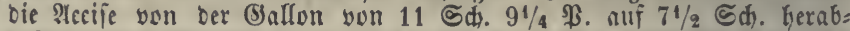
gefest. Die Berzefirung war 1824-1826 im D. 3.959990 ह5., 1 S2S bis $1834 \mathrm{im}$ D. $7 \cdot 471052$ (5). In Srland war brei Jnhre vor 1824

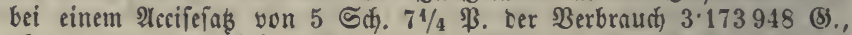
aber '1826-1829 bei 2 Sd). 10 \$. Steuter 8.561346 (S). In ben Drei Rönigreidjen lourben verftettert:

18218.698620 Ball. für $5 \cdot 916903$ \&. St.

$183022 \cdot 744271$ " " $5 \cdot 209559$

$184922 \cdot 962012$ " "5.793381"

Mac Cullod, Scanob. I, 694, und "neuere शngaben.

(e) Der SBeingeift (Spiritus) Darf nidjt unverfteuert bleiben, weil man burd Berbunnung unb Sufäbe leidht trinfoaren Branntwein nus ifgm bereiten fann. Inlein bie Sriñoe für bie Steuerbelegung bes zu menich= lichem Senufi beftimmten Branntweins fallen bei ber Bertwentoung teffel= ben uno des Spiritus für anbere Swedfe Ginweg uno es if bejGalb zwectmäsig, eimen foldjen (Sebraudy von Der Steuer frei zu lafien, roent

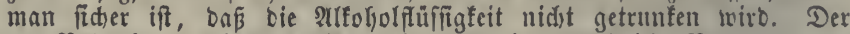

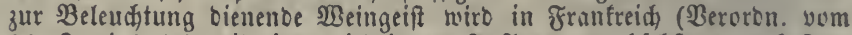
14. Juni 1844) mit einer niebrigeren 2tuflage von hidditens 25,8 frs. vom Sुeftuliter belegt, toenn er minbeften mit $1 / 5$ Terwentinol, fienil $2 c$. verfebst und baburd ungeniepbar gemadat ift (dénaturé). $\mathfrak{B g l . \$ . 4 3 9 ( a ) . ~}$

(f) ßreuß́. Berorbn. v. 1. Dec. 1820 unb neuere Borfariften, \$hilip $i$

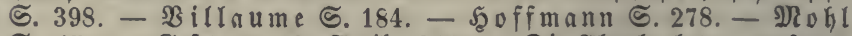
ธ. 47. - Befeb̧ v. 19. Alvril 1854. - Die Albgabe betrug anfangs 1 g(S). yon 20 Su. Maijdraum, bann (5.:D. v. 10. Jan. 1824) 11/2 Sgr., fobann (巨.:=D. v. 16. Juni 1838) 2 Sgr. von je 20 Dut.; für \&ancwirthe, bie ifre eigenen Früdte verwenben, nur im $23 i n t e r=$ Galbjagre uno in befdiranttem umfange (nicht liber 900 Du. Bottid)= raum an einem Tage) brennen, $12 / 3$ Sgr. Seit 1854 ift Die Steuer

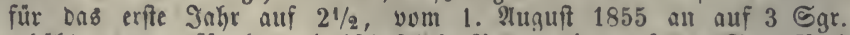

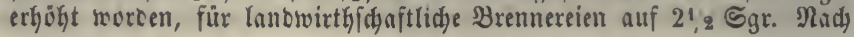


Der Grfafyrung yon 1843 fommt etra ${ }^{1}{ }_{11}$ Des Crtrages auf oie Bren: nereien, meldie utu $12 / 3$ Sgr. yon ter Duart geben.

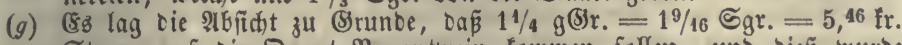
Steuer auf die Duart Branntwein fommen follen, und biés wurbe eime 3eit lang feftgehalten. Man redmete anfangs, baß̉ bie Duart (3u 50 \$roc. Tralle छ) aus 25 Du. Naijdraum erzeugt toerbe,

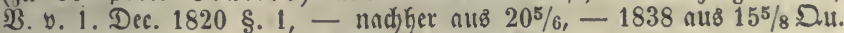

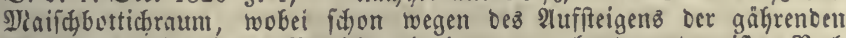
Maifhe ein Theil teB $\mathfrak{B}$ ottid bem (Sefeb yon 1854 fúceint 1 Ggr. auf bie Duart Branntwein ge= redynet zu fein, zu weldjer bemuad $62 / 3$ Duart IInif(b)bottid)raum er= forberlid) find. Die Berīnberungen Des Steuerfuß̧eళ twurben Darum

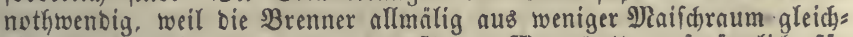
viel SBranntwein zu erzeugen wusten. Jian hatte urfwrünglich für 1 Duart Branntwein 6 Bfuno troffine Frudt uno 48 Bfund $\mathfrak{B a f f e r}$

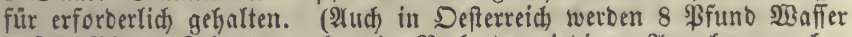

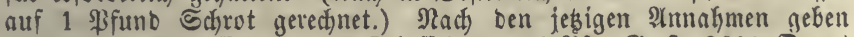
60 (Eentner Rartoffeln uno 6 Scheffel $=360$ \$F . Serfte 3600 Duart 9haifidraum, tooraus (bei 15 \$roc. 3udfex in ben Sartoffeln) 260 Du. Allfokol oder 420 Dut. Branntwein von $50^{\circ}$ Tr. getwonnen werben fónnell, ๖. Salviati a. a. D. S. 53.

(h) Bon 1 Simer cingeftampften Rernobftez, Beeren, $\mathfrak{B}$ eintreber 4 Sgr., yon 1 Csimer Trauben= ober Dbftwein, NBeinbefe, Steinobft 8 Sgr.

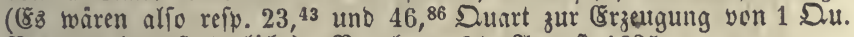

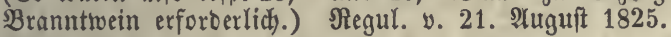

(i) Dกв Abbrennen (die Deftillation) mú́ am 3. uno 4. Tage nach bem Ěinmaifdhen gefdehen. - Die Entridjtung Der Steuer erfolgt zu Ente jedes \$lonatz, fann aber grofen Brennereien gegen gehorige Sicherkeit vom 1. Detober bis zum leb̧ten September Des folgenben Safrez creditirt werten. \$reú̃. $\mathfrak{B}$. v. 27. Dec. 1825 und 18. Febr. 1843. Für Brennereien, welche Dbit, Beeren, SBein unb Scefe verarbeiten, ift

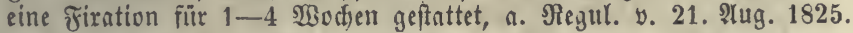

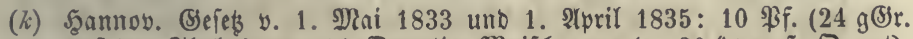

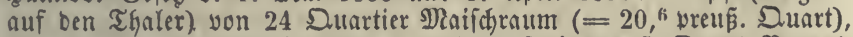
alfo (zu $1 / 15$ Branntweinertrag) $2,73 \mathrm{fr}$. auf die prens. Duart Brannt= wein; Sereb v. 9. Febr. 1849: gleidye Steuter von 16 Duturtier. Die Staaten, weldie zu bem thüringifdyen 3ollverein gehören, Gaben Die preusifiche sinridjtung ganz angenommen, fo aud bas $\Omega$. Sachfen,

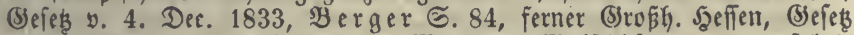
v. 16. Gept. $1842,6 \mathrm{fr}$. you 20 Diaa

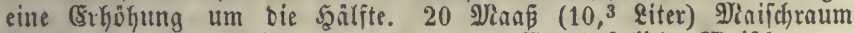

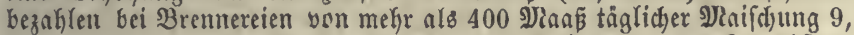
bei fleineren $7 \frac{1}{2} \mathrm{fr}$., 20 Dl. eingeftampite 23 eintreber uno Rernobit 6 , 20 M. Wein, . Weinthefe uno Steintobit $12 \mathrm{fr}$. Die Eingangrabgabe

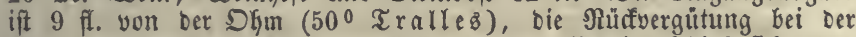

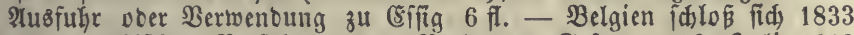
tem wreukifden Berfahren an. Nach Dem Sefes v. 18. Suli 1833

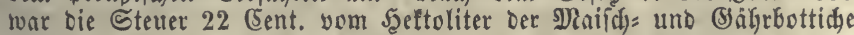
für je 24 Stunben शrbeitszeit, b. G. wohl für eine (Sährungszeit, ba

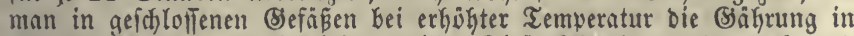
12-24 Stunben zu betwirfen toeís. Diefe शlogabe twurbe nach und und erhöht, 1842 auf 1 Frame, Durdy (Sefes y. 20. Dec. 1851 auf $1 \frac{1}{8}$ fr. uno 90 Gent. von Dbft, von Strup uno 3udfer 2,36 Fr.

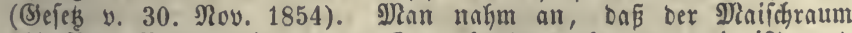
$5 \frac{1}{2}$ \$roc. Branntwein von 50 (S). gebe (was aber zu wenig ift), uno

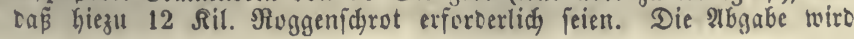


um 15 \$roc. ermäBigt für foldge Brenter, weld)e 1) eine einzige Blaje von weniger als 5 Şeftoliter befiken, 2) nuf je $1 \frac{1}{2}$ Seftoliter bes Yaifdraums 1 Stüd Oinboieh Galten uno zugleid 3) auf gleiden Siatm ie 1 Seftar Iano in 5 silometer Slake bauen (alpo fü fleine lanowirthfdaftlidge Brennereien). Für bie (Entridtung twiro gegen Sidherbeitsleiftung (Ereout betwilligt, auf brei Termine von je orei I)? nate 3wifdenzeit. Flenn ber Brenner in ber 3wifdenzeit Branntwein

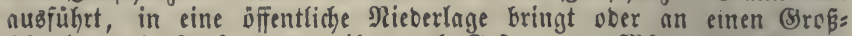

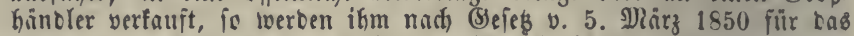
Şeftuliter yon $50^{\circ}$ (S) a $y=\mathbb{Q}$ üf $\{$ a 22 Fr. abgefdrieben (décharge) uno

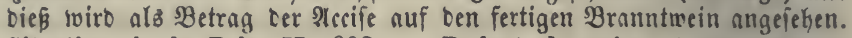
Situation de la Belg. II, 692. - Budget de voies et moyens pour 1859 , ऽ. 13. Die verftetterten Maifiräume waren 18406052169 , 1841 aber 5.772702 Şeft. Beridat von 30 u De, Chambre des Représ. 13. April 1842 Nr. 250. Ertrag 18463.323000 Fr. N. 18625,8 Mill. -

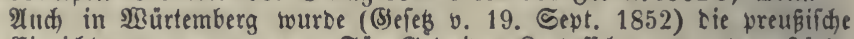
(Eimricitung angenommen. Für Setreide, Rartofieln uno nnoere fârfe:

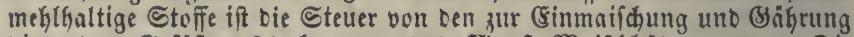

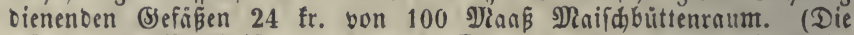
würtemberg. Shan temberg auf 20 Duart wur $2,9 \mathrm{fr}$. fintt $10 \frac{1}{2}$ in $\$$ reußen.) Bon Dbft, Beeren, Weintreitern wird Die Steuer nadh Der Mienge Des verbrnuchten

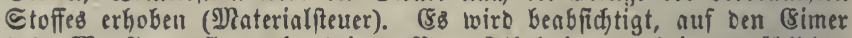

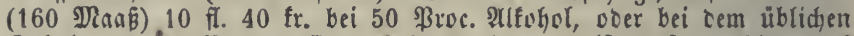
(Sehalt von 44 ßroc. 9 fl. 23,2 fr. zu legen, alfo auf Das giter 2,16 uno $1,9 \mathrm{fr}$. tie bab. IRans $3,{ }^{23}$ uno $2,85 \mathrm{fr}$. Beim Rleinverfanj tvirt nody eine befoncere 2 bgabe von 4-100 fl. erfuben. $2.1858-61$ von Der Erzetigung 155000 fi., vom Rleinverfauf 59000 fi., lleber= gangzifteuer 75000 fl., abzuziehénber Niüferfas 42000 fl., alfo magre Eimnahme 247000 fl. - Defterreid), Seoffammer= Decr. v. 24. Pluguft 1825, beim Brennen aus mefligen Stoffen uno Rernobit $9 \mathrm{fr}$. vom (Eimer bes Mlaifdgefäвев, bei Steinobft, Wein, Weinkefen, $13 \mathrm{fr}$.,

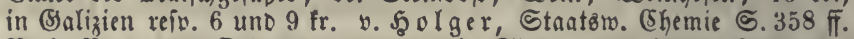
$\mathfrak{N a d} \mathfrak{B}$. v. 30 . Dct. 1849 wurbe die Stetter von beiben 2irten Der Stoffe auf 10 uno 15 fr., Durd $\mathfrak{B}$. v. 6. Sept. 1853 auf 14 uno $21 \mathrm{fr}$. bom Eimer IJinifhraum erföht. Heber Das (Sefes von 1862

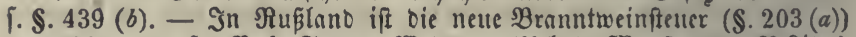

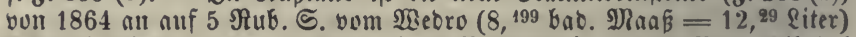

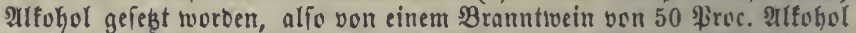
34,5 fr. alf bie bab. Daan $=23 \mathrm{fr}$. alf Das Riter. Die 2abgabe twiro fällig, wenn ber Girzeuger ben Branntwein im (Sirupen berfaujt. Diejenigen 3 renner, tweldye fidh anfeifhig madjen, Len (Ertrag von 0,34 Webro Alfofol aus 1 Fud $(32,76$ 3ollpfund) Roggenichrot ocer

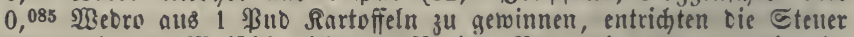

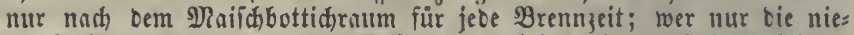

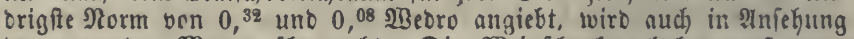
ber erzeitgten Nenge überwadht. Die Weinidjenfen haben auber ter (Setwerbiteuer nod) eine Ricenzgebühr ie nad Der (Sroje Der Drtidaften

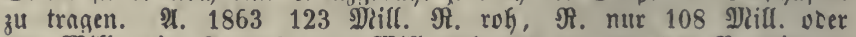

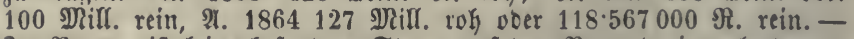
In Bayern ift feime befonbere Steuer auf Den Branntwein gelegt, nur wiro bas zur Bereitung befielben beftimmte Malz mit Dem Dialzauf= idlage mitgetroffen.

(l) In Sireußen (B. v. 1. Dec. 1820) bürfen an einem Tage nicht unter 600 Duart Mlaifhraum beclarirt werben uno Maiidbottiche unter 300 Duart werben fünftig nidht mehr zugelafien. İn treußs. Ctaat waren 18537442 Brennereien in sBetrieb, von benen bie gröste 
23045 Thlr. Maifdfteuer entridtete. 1367 Brennereien verarbeiteten feine Neklftoffe.

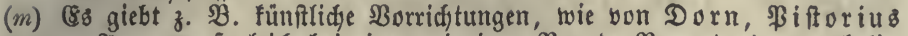
I1. 2ิ., um fogleich bei einem einzigen Brande Branntwein yon belie: biger Stirfe zu erhalten, mährend bei bem liblichen Berfabren erfi cine

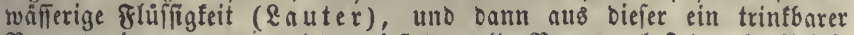
Branntwein gewonnen wiro; Dieß Doupelte Brennen foffet megr 2lrbeit uno Brennfoff, fann aber mit bem einfadjen Brenngeräth im Rleinen unternommen twerben. - Ueber bie \&age Der Ileinen lanowirthfdaft= lidjen Brennereien 3̧eller, Seitfdrift für die heff. Innow. Bereine, 1858 , ๔. 343.409.

(n) 3. $\mathfrak{3}$. in SBelgien (l).

(o) ๖. Salviati, 3ur Fabricatfeuerfrage in Betreff Der Spiritus: und

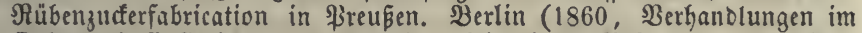
Defonvmie:(Sollegium). - Innfe, Die Directe Befteuerung Des Epi=

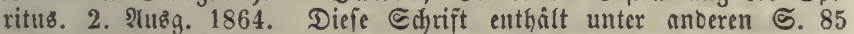

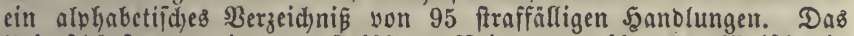
lleberichöyfen ber in Dem (Sefápe aufifeigenten gaikrenden Shaifdye in ein anoeres nicht fichon vorker angezeigtes Befáz wiro z. B. aldh olne

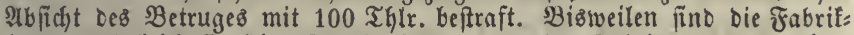
Gerren, obgleid fie feine Gchulo Gatten, won ben Arbeitern ber Alnzeiges geblifir wegen angegeben und barauf fdjer geftraft worben.

\section{§. 439 ,}

2) Befteuerung bei ber (Erzeugung unb zwar

a) Durd) genaue B̧eobachtung ber bereiteten Menge. Şiezu wirb bei bem in (5roß̧britanien üblidyen Berfabren eine müh fame Ulberwadyung ber Bremereien mit ftrengen, läftigen Boridyriften für bie Brenner angewenbet, bie 2ufficht ift foftbar und $e B$ bürfen nur große Unternefymungen zugelaffen werben, weil fonft cin zu großes \$erional gehalten werben müpte $(a)$. Durch fünftlicte $\mathfrak{B}$ orridjtungen zum Meffen beż in ber vers id)loffenen Borlage fid) fammelnben Borratlyes unto Unterfutdung Des 2llfoholgehaltez fam aber die 2ufnahme beffelben erleidytert uno ein Theil ber 2luffitchtamnaregeln erfpart werben, fo baß ber $\mathfrak{B}$ etrieb eine freie $\mathfrak{B}$ ewegung erfält $(b)$.

b) Erkebung nach) Dem Snkalte ber Branntweinblaje für icoen einzelnen Brand mit Annahme einer gewiffen Brennzeit, wobei in ber 3wifdjenzeit ber Şelm verfiegelt ober amtlid) auf= betwahrt wirb; $\mathfrak{B} \mathfrak{I} \mathfrak{a}$ enzinz $(c)$. Dab $\mathfrak{B}$ erfahren hiebei. ift leicfter als bei ben erfteren Methoden, allein ber Blajenzinz hat fich Darum als mangelfaft erwiefen, weil begüterte unb gefdicfte Unternekgmer burd) Berbefferungen in ben Brenngerñthen uno im Berfakren eimen $\mathfrak{B}$ rand in fürzerer 3eit bewirfen fönnen,

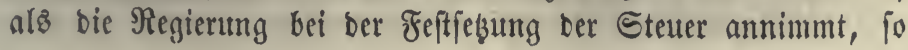




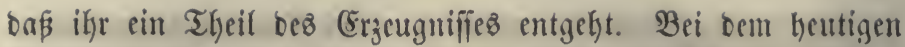
Stande der Sumft in biejem (Sewerbe läpt fidt) ïber bie Dauer eines Branbez gar feine fefte Sicgel auffitlen $(d)$. - Eine

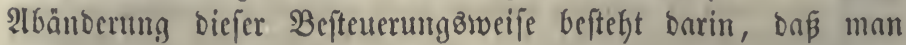
auf eine gentuue Belegung ber bereiteten Menge ganz verzidjtet

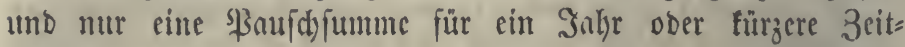

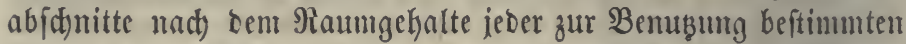
Blafe erfebt, Reffelgeld. Die Şelme (Şüte) ber nidjt ver= fteuetten Blajen (Seffiel) werben von ben Beaunten verfiegelt.

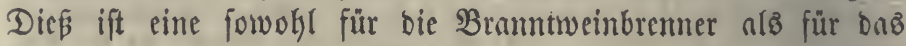
Steucrperional bequeme 2ibfintung, aber fie tönnte mur bei einem ganz niebrigen Betrage ber 2 bggabe empfohlen werben, weil bei belt einzelnen Unternehmern bie 3ahl ber in glcidjer 3eit veranftaltetent Bränoe jeljer ungleid) ift uno daljer auf eine gerwiffe Nenge des Erzeugniffes bei guten Bremeinrid)tungen

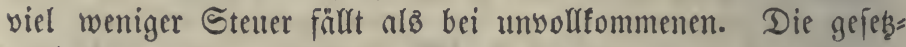

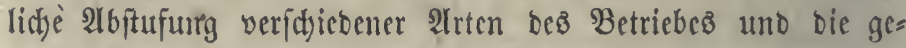
ftattete Entriç)tung Der Eteucr für fürzere 3eiträume verminbert Diefe Ungleidheit, olyne fie ganz zit entfernen. Daz Sefficlgelo bringt baker mur wenig ein (e).

3) Befteterung beim $\mathfrak{H e b e r g a n g}_{\text {in }}$ ben $\mathfrak{B}$ erbraud), namentlid) beim Eintegen in ben Reller ber Styenfwirthe, wie bei bem $\mathfrak{W e}$ einauffidjlnge, wälyrend bie Branntwoinbrennerci und Die SBorräthe ber Unternebmer berfetben frei bleiben. Dieß ift einfach) unt bejonbers in $2 B$ einlänbern, wo biefelben Wisthe

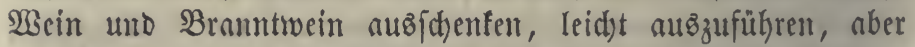
ez finto hiebci viele Unteridjleife z̆ beforgen, wen! mant nidjt eine Ueberwadjung Der Brennereieu zu Şülfe nefymen will, um bie von benfelben abgejebte Menge son $B$ raumtuvein zu erfahren, woburd) wieber bie Einridjung fehr umftündid) roiro $(f)$.

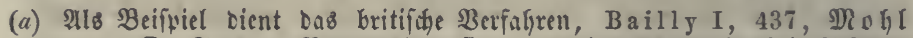
a. a. D. 5. 37. Brennereien find nur in ober nahe bei Ctibten

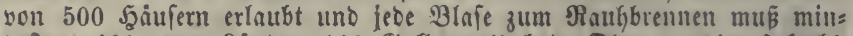
teftens 400, zum Rautern 100 Ballons ( 3 bad. Ohm $=41 / 2$ Sycftol.) Galten. $3 \mathfrak{u}$ allen Berridjtungen ift voraubgegangene 21 zeige und $2(n=$ wefenfeit eines Beamten erforderlid. Die Benunten erforiden und verzeidynen bie verfertigte uno verfaufte Dienge you Branntmein, aud wercen bie Borratthe nadigciefen. Der Brenner Darf nidht in Riteinen

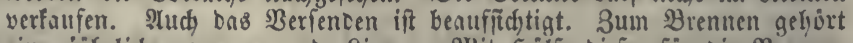

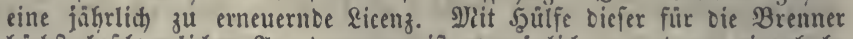

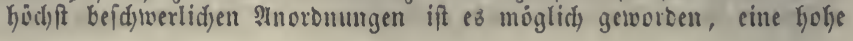




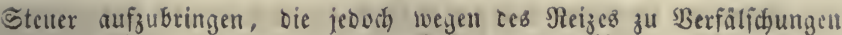
uno heimliden Srennereien oft beflagt worden ift. Der Betrag Der Anccife ift ofter veränbert worben uno war bis 1858 audy in ben orei Theilen Des britifhen Stantes verfótieden. 1821 twar er in (Englano

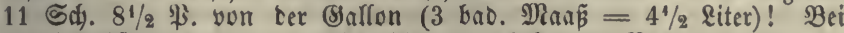
cer Szerabfebung anf $71 / 2$ Sh. ffieg Der befteuerte Berbrand yon $1 / 3$ auf ungefähr $1 / 2$ Ballon jâhrlich auf ben Ropf, Porter, Progress 5. 555. Nachoem vom 2lnfang 1855 bie Steuer in Englano auf 8 (đ). erhofht worben war, trat Durd, Das (Sefes 18. 19. Vict. C. 94 (14. 2)uguft 1855) Diefer Sas aud für Sdyottland cin. Die irlän= bifhe 2lbgabe, vor 1555 nutr $2 \frac{2}{3}$ Sh.., wurte nad) unb nad) gefteigert uno nach bem (Sefes 21. Vict. C. (15. Nai 1858) war jener Betrag

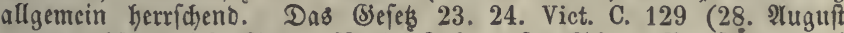
1860) erhöhte biefe Steuer für $1 / 2$ Jahr auf 8 Sh. 1 \$., fodann auf

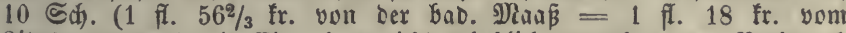
Riter), moourd bie (Einnafime nidht erfeblich vermefint, oer Berbraud) aber vermincert wurbe. (5) war

\begin{tabular}{|c|c|c|c|}
\hline & Berbrauç & & Steuerertrag \\
\hline 1859 & $24 \cdot 254403$ & (S)allon & $9 \cdot 701764$ \\
\hline 6( & $21 \cdot 873384$ & 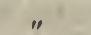 & $9 \cdot 702807$ \\
\hline 6 & $19 \cdot 700250$ & 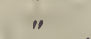 & 9.850126 \\
\hline
\end{tabular}

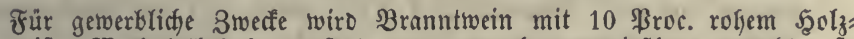

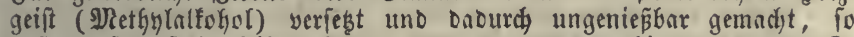
Daßj er fteuerfrei bleiben fann. $1858 / 59$ wourben Kiebon 336410 (S).

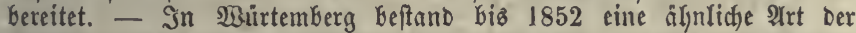
Steuer, aber mit unvollpandiger Heberwadung umb mangelfhaften (sinrichtungen. Die Abgabe war nach bem Befes vou 18271 fl. $45 \mathrm{fr}$. yom (Simer neben ter \$nalzfecuer ober 5 fl. yon $\mathfrak{B r}$. aus anderen Stoffen. Sur Heberwadyung Diente bie Anzeige bei Dem

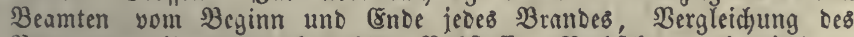
\$robuctes mit Dem verbraudaten Nohftoffe, Nachfehen, ob nicht zu anderer 3eit gebrannt wiro: Daneben wurben 15 ßroc. vom abgeichnigten

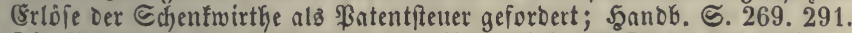
Die Brentmerei aus cigenen Eszeugnifien blieb unbefteuett und auf Den

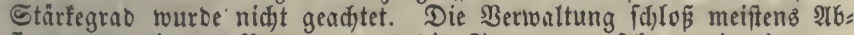
finoungen mit Den Brennern und bie Steuer trug fefre wenig ein.

(b) Für Diefe (Sinrid)tung Die in §. 438 (o) genannten Eifjriften und $\mathrm{Na-}$ gorny, La question de l'eau de vie. Varsor. 1864. Esz fino bereits zweftmásige Się̧apparate erfunden worben. - In Sdymeden befteht Dieje Einrichtung für grofere, feit 1857 für alle Brennereien, in Depter= reich ift fie Durch (Sejeg vom 9. Iuli 1862 eingeführt worben. Die

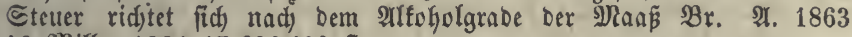
16 Nill., $1864 \quad 17 \cdot 630400$ กี.

(c) 2teltere bad. Iccife und Dhmgeld, auf 24 Stumben $1 / 2 \mathrm{fr}$. von ber

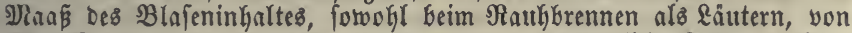

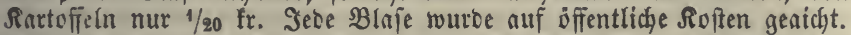

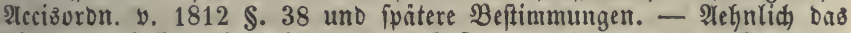

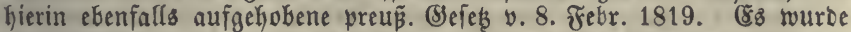
vorausgejeşt, Dás man in 24 Stunden 1 Suart Branntwein von $50^{\circ} \mathfrak{T}$ r. alts 4 Suart Brafeninhalt erzettgen fönne, von Denen Daker $11 / 4$ (Sr. erboben wurbe. Für größere oder fleitere \$Brennereien follte Der Gteuer:

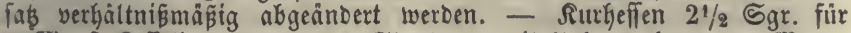
4 IJtan von Dhaifde. B i e r $\{$ a ff a. a. D. S. 284.

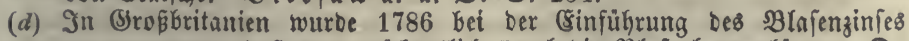
angenommen, Dá̉ man wöbłentlich 7 mal bie Blaje leeren fönne. Da 
fungen Die (bebrüber Sligo in \&eith an, igre Blafen flacher und weiter zu maden. Nun twurde Das Brennen fáon 1788 40mal in oer 180 che bewerffefligt, 1798 fonnte bie 2 lafe in 8 शlimuten, fpăter logar in 3 Mimuten geleert werben. Der Blafenzins war von 30 Shill. bis alif 5 \&. voum Sallon SHlafenraum exhoht worben. \&a uderdale,

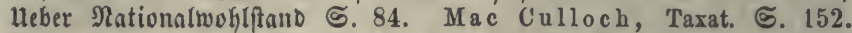

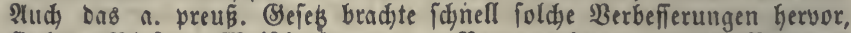
flactere Blajen, Slaijdmarmer x., $B$ enzenberg, Heber \$reußens (Seld Fanshalt 5.24 . Wegen Diejer Mangel if Der Blajenzins faft überall aufgegeben worben.

(e) Gin foldies Reffelgelb beftand in Baben feit 1814 neben Dem Blafen= zinje und Der Brenner tonnte zwifđen beiben Entridjtungsarten mählen. Durch Das Sefç v. 14. Diai 1828 tourbe Das Reffelgelo zur allgamci=

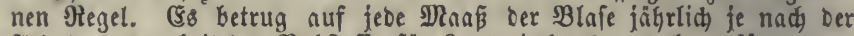
2irt Der verarbeiteten $\Re$ ohftoffe für \&anowirthe $2-4 \mathrm{fr}$., fur anoere Brenner 4-8 fr. Nad) Dem (Sefes v. 22. Juni 1837 war Der Eteuer=

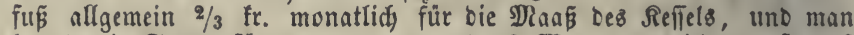
fonnte bie Steuer für 1, 3, 6, 9 uno 12 शounate entridyten, fo Daß alfo z. B. Eanowirthe, bie blóp ifre Erzengniffe zur Brennerei wer= wenben wollten, bie Errlaubnis nut auf einen Mlonat ober fodann etwa nod auf einen zweiten \$lonat zu nekmen brauditen. - Die sefiel werden geaidat. Niemand Darf ofne Einfolung Des Breunfheins, twelcher als Stenerquittung bient, brennen, Niemand feinen Reffé (Blaie) ober Şut cinem 2nnderen leifyen. $\mathfrak{B}$. v. 12. Dct. 1837. Snftr.

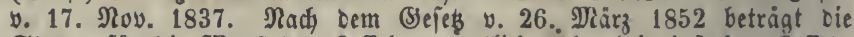
Steuer für Die झRanés bes Reffels monatlid $3 \mathrm{fr}$. Bei einfachen Reffeln (Blafen), $4 \frac{1}{2} \mathrm{fr}$. wenn ein Bortwämer vorljanben ift, $6 \mathrm{fr}$. bei Dampf=

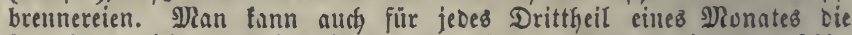
Alogabe entriditen. Dieje if Demnad für Den Nonat bei Den veridie=

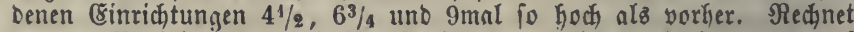
man z. 2 . bei einem einfadyell Serätge monatlich 50 Branbe und auf

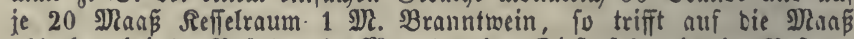
$14 / 5 \mathrm{fr}$., bei 90 Bränben im Sionat $1 \mathrm{fr}$. Dieje fehr nieorige Befteue= rung if hauptiädylich Darum gewählt uno beibehalten worben, weil bie Branntweinbresnerei in Baben meiftens von fleinen untermehmern, Deren viele zugleid, \&anowirthe find, getrieben wirb. Im Jahre 1829 war Der mittlere Snfalt einer Blaje nur gegen 30 Daná, 1843 war Die 3ahl Der Brennereien 22211. 1850 warelt 27072 fieffel von

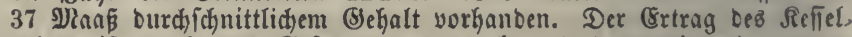
geldes ift Durh Das (s)efes won 1837 bedeutend vermindert iworien. \&r war $1831-1836$ im D. 36905 fl., 1837-1840 mur 24826 fl., 1842-1846 20721 fi. Dns Befes von 1852 erhobte ifn im D. $1854-56$ nuf 64705 fi., $1857-5878471$ fi., $1860-6277270$ fi.

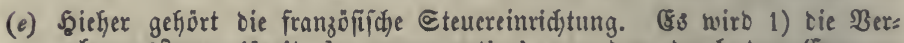
zefrungefteuer (droit de consommation) yon bem burd) ben (5rgeuger verfauften Branntweiu im Betrage von 50 Fr. (1830-55 nur 34 Fr.) für Das Şeftoliter झrlfohol erfoben, uno wenn Der getoöhnlicbe Brannt=

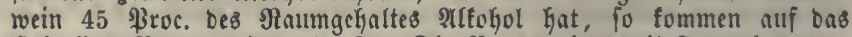
Seftoliter Branntwein $221 / 2$ Fr. Die Bremereien, mit शusnahme Der= jenigen, in Denen mur Die vom $\mathfrak{B}$ efiber felbft getwonnenen Beriwand: lungeftoffe berarbeitet werben (bouilleurs du crû), fino forgfältig in ijrem Setriebe itbertwadgt, Gaben Die Beit Des Brennens, Den Borrath you Maifde ober anberen Sttoffen und Die erwartete Iienge von Mlfohol vorker anzuzeigen, wobei ber rebztere nidjt unter $2 \frac{1}{2}$ Proc. Der Niaifde betragen Darf. Die Berjenoung fteht unter frenger Heberwadjung. (Srophänoler (bis zu 1 Şeftol. Kerab) feken ebenfalls unter ber झuffid 
cer Steuerbeamten, ifre Borrathe werten alle Bierteljahre autgenom: men, jeber neue Empfang wirb yon ifnen angezeigt, uno bas bei jeber Befichtigung Feglende wiro verfteuert. Die fog. bouilleurs du crû ent= richten Die Steuer mur bon Dem verfauften Borrathe. Wohnen fie in einer Stabt bon 4000 ober melyr Einwohnern, fo find fie ebenfalls ber Ueberwadjung unterworfen. Bon 1861 ift bie Steuer vom Sheftoliter \{lffohol um 25 Fr., und mit 2 Decimen 3uidlag um 30 ₹r. erhỏht worben, wovon man bei einem Berbraudie yon 800000 Sgeftoliter 24 Nill. Fr. Sinnahmsivermefrung erwartet. Der Berbraud, roar im D. $1858-60839744$ Seft. Silfuhol ober 2,32 Riter auf ben Sopf,

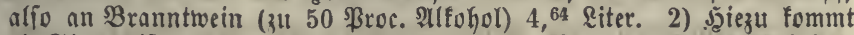
Die Thuraccife, droit d'entrée, von 4-16 Fr. für bas Fुeftoliter झlfohol, ie nach ber Sintwohnerzahl ber Staot. - Niederlänoifabe \$rcife 22 fi.

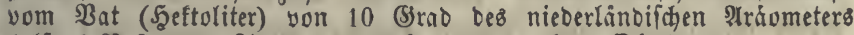
(alio 0,22 fi. yom Riter ober $30 \mathrm{fr}$. yon ber bad. Dhm).

Betrag Dex Bramntweinfteter:

(5) roBbritanien, 1862 .

Siezu fommt Der Einfuhrzorf mit : $2622728,2,{ }^{9} \mathrm{ft}$

Riederlande, R. 1862 - . 5.772000 fi. $1,67 "$

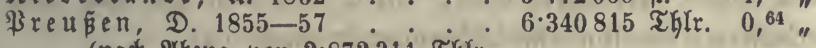

(nac) Abzug von 2.872311 Thy

2. 1861

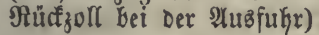

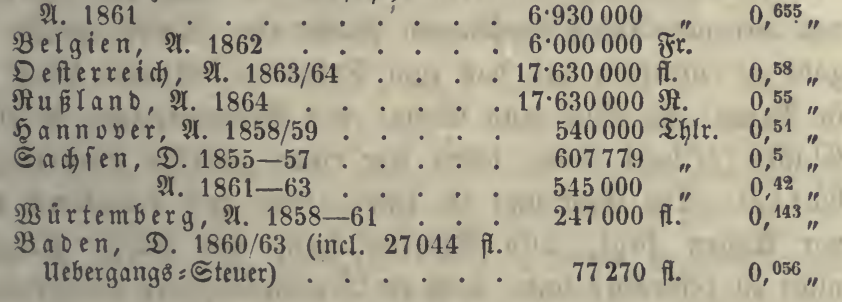

๑. 440 .

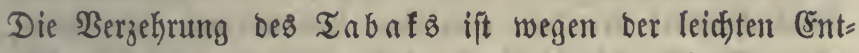

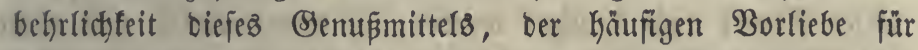
baffelbe uno ber großen barmuf gewenteten 2luzggabe $(a)$ ein vorzüglid) guter Befteuerungägegenftano. Eine Tabaffteuer ver= urfacht für bie 3efree meniger Bejdywerben als bie meiften anberen 2 uflagen, fie vermag baker andere brüffentere 2 bggaben zu erfeşen ober baz Etantseinfommen mit ben geringften $\Re a d t=$ theilen für bie Bürger zu vermehren; Der Einfühthung Diefer Stetter fteken aber in Şinftet nuf bie Erhebung grope Edywie= rigfeiten im $\mathfrak{B}$ ege. Nur in sånbern ohne Tabafbau ift es leicht, die Blätter fo wie ben verarbeiteten Tabat vermittelft Des Einfulfrzolles zu treffen $(b)$. Für bie inlänbifichen $\mathfrak{B l a ̈ t t e r}$ aber läßst fich zwifchen ber Serwinnung und Berzegrung fein Seitpunct finben, in bem fie vollftänoig uno ohne viele $B_{e}=$ läftigungen beftetert werben fönnten, autíl) find bie Blätter,

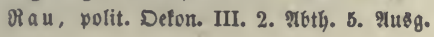


nod) mehr aber bie Sorten bes verarbeiteten Tabafo nad) (S) üte

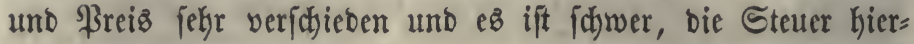
nad) abzuftufen $(c)$. Dieje Srünbe haben in mebreren Etnaten

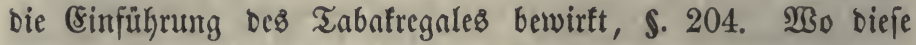

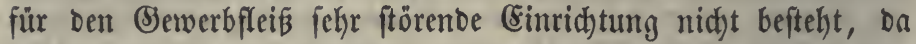
muk man barauf verzidten, cine grope (Einnahme nus bem Tabafverbraud) zu zieken; inbę lenfen bie obigen Betradjtungen

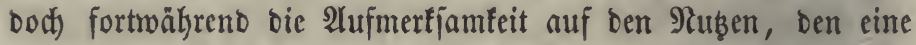

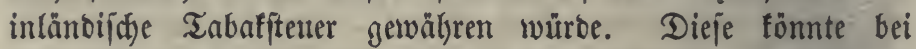
freier Errzeugung und freiem Scanbel mit Tabaf auf mefreren Wegen erhoben werben. Seiner biejer $\mathfrak{B}$ ege ift yon Sdymierigs feiten uno Unbequemlidfeiten frei, bod) läpt fidch hoffen, Dá̉ man Dahin gelangen wirb, einen berjelben auf eine $\mathfrak{W e i f e}$ zu verbeffern, bie ifn empfehlenswerth mad)t $(d)$.

1) Befteterung bei bem $\mathfrak{A} \mathfrak{n} \mathfrak{a} \mathfrak{a}$, fo baß ber Ranbwirth

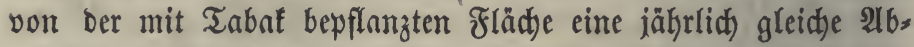
gabe zu entridjten hat, Daళ̉ zum Tabafbau beftimmte Rand aber

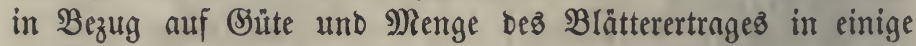
Elaffen getheilt wirb, beren jede einen gewiffen Steuerją er= fhält (e). Die Errfhebung ift leidjt, weil bas Tabatland offen

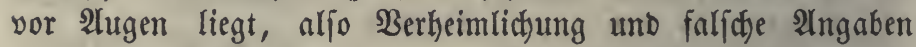

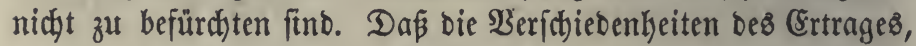

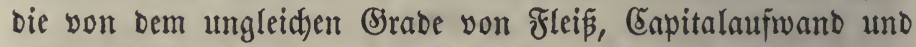
Sejhidflidfeeit bei ben einzelnen \&anbwirthen herrühren, bei biejer Steuter nidjt beadjtet werden, ift unvermeiblid) uno nidft alż Mangel anzulehen, mohl aber, Daß̧ bie Sahreserträge ihrer Beid)affenteit, Menge uno ifrem \$reife nad) veränberlid) fint, bie Steuer folglid mie eine Schasung fid nady Durdjidnnitts= werhẩitniffen ridjtet uno wie eine erbfindung erideint, \$. 430. Diéß verbindert fidjon eine vollftändige Heberwäljung auf bie

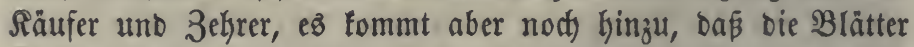
gropentheirs in ber Ferne abgeję̧t werben müffen uno bas Mitwerben anderer (Érzengungşäntoer zu beftehen haben. In ungünftigen Gahren fann leid)t ein Theil ber Ranbwirthe ge= nöthigt fein, Den Tabafbau aufaugeben, wenn nidgt burd) Stetternad)läfie geholfen wirb. (Eine Steuter biejer 21rt muß baher niebrig angefest werben und ift wenig ergiebig $(f)$.

2) Beim $\mathfrak{B}$ erfaufe ber getwontenen Blätter burd) ben 


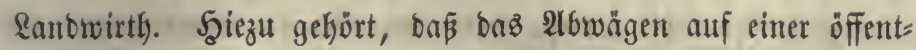
lidjen $\mathfrak{W}$ anage vorgefdrieben wirb $(g)$, bie fitd in jeber Semeinbe, beren B̈ürger Tabaf bauen, befinben mue. Der Säufer hat bie Steuer nad) ber Zahl ber Centner zu entrichten. Şier entipridyt bie 2lbgabe beffer bem wirflicten (Ertrage, bod) treten wenigftens bie Nacttheile ber Steuerforberung bon Berwandlungseftoffen ein, \$. 419. Bei einem beträd)tlict)en Fußße ber Steuer müß̈ten für veridfiebene (5egenden wie bei Dem unter 1) angegebenen Berfahren veridtiedente Steuerjäbe für ben Centner beftimmt,

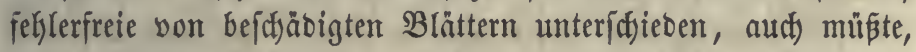
ım heimliche Serfäufe zu verhinbern, eine Ueberwadung ber nuf ben Feldern gewonnenen Menge angeorbmet werben, wo= burch) bie (Eryebungşfoften bei einem im Sanbe zerftreuten Tabat: bou anjegnlich werben würben. Cine siüfvergütung bei ber

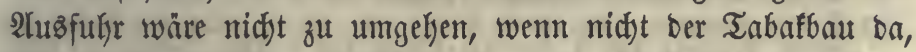
wo er am meiften entwiffelt ift, eine (Eridultterung erleiben foll $(h)$.

3) Bei ber $\mathfrak{B} e r a r b e i t u n g$, inbem die Fabricanten bei Dem (Sinfaufe von Blättern unb bei ber $\mathfrak{A b}$ fendung von fertigem Tabaf unter gentaue 2lufficht geftellt werben. Şiebei vermag man häufigen Betrug nicht zu verhüten, wenn man nidjt foft= bare umb orüdenbe Eontrolmittel häufen will, befonberz no bie Berarbeitung wie bei ben Cigarren zum Theile von vielen fleinen Unternehmern gefdieht (i).

4) Bei bem Rleinverfaufe, ber bam ben Fabrifferren, wofern fie nicht um bie bejonbere Beredjtigung nadjufuen,

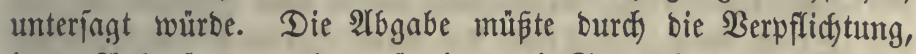
ieben Infauf anzumelden, fowie burch Stempelung aller ßafete gefichert werben $(k)$, aud würbe man genöthigt fein, bie $\mathfrak{B e r}=$ fäufe ber Fabrifherren zu überwadjen. 3nhlreidje Umgehungen ber Eteuer whirben fid faum verbüten laffen. Eine bejonbere

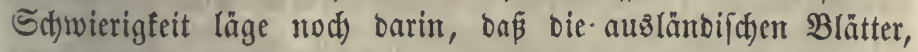
bie oft mit inlänbifchen bei ber Berarbeitung vermengt werben, fidon burdy ben (Einfulyzoll belegt fint.

(a) Man fann im Sollverein bie Kinfuthr pon rohem und verarbeitetem

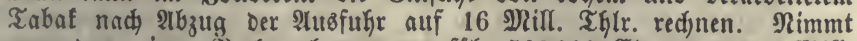
man Dazu einen SBerbraud, von ungefälyr 500000 (5tr. ober $3 \frac{1}{3}$ Mtill. Thaler an inlänoifchen $\mathfrak{B l a ̈ t t e r n , ~ f o ~ f o m m t ~ f o j o n ~ e i n e ~ s t u t g a b e ~ v o n ~}$ 


\section{6}

191/3 פRill. Thlr, heraus, wozu aber nod Die Berarbeitungs = und Berfaufófoften zu fȩ̉en fino.

(b) Daker ift in Englano ber Tabafbau ganz verboten, aber ber Schleidh= hancel mit Tabat if cafelbft ungeheruer.

(c) Bei bem Esinfuhrzoll gefdiegt Diés ebenfalls nidht, aber berjelbe nirb gewobnlich fo hod) gefest, Daß geringere Sorten wenig eingefülyrt werten.

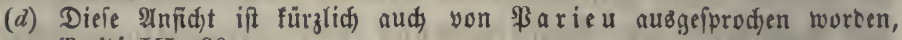
Traité III, 90.

(e) Wreußi. Tabafifeuer, neu georbnet curd, bie Cab.=D. v. 29. Ilärz 1829. (58 werten vom Morgen $6-5-4-3$ ThIr. entridjtet und es miro

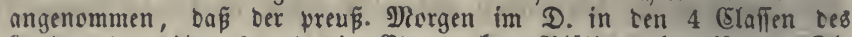
Santes $9-71 / 2-6$ und $3 \frac{1}{2}$ Btr trodene Blätter geten fönne. Die ABfid)t ift, ben Centner mit $2 / 3$ Thlr. zu Belegen. SBer 6 D. SRuthen ober mefr bepflanzt, hat 2inzeige zu machen. Die Sahlung gefdielyt bis Ende Juli ober früher, fobalo cie Şälfte Der vorjährigen Ente

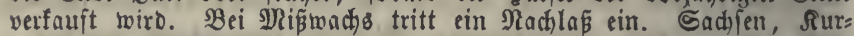
heffen, oer thüringifche Ränberverband uno Braunichweig haben diefe Einridytung ebenfalls angenummen. Ertrag im preußs. Etaat 1856-58 im D. 124144 Thlr. nebft 55916 Thlr. Hebergangęfeter von ter Einfuhr aus anteren beutíden \&ändern.

(f) Bei 9 (Sentnern uno einem ßreife yon 15 fl. wäre Der Errös bes preuß. Mlorgenz 135 fl. und vie ๔teuer von 6 Thlr. betrủge 7,7 \$roc.

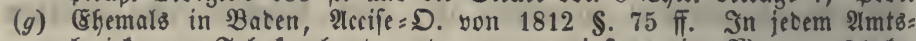
bezirfe, wo Tabaf gebaut wurte, war wenigitens eine $\mathfrak{W}_{\text {aage. }} 24 \mathrm{fr}$.

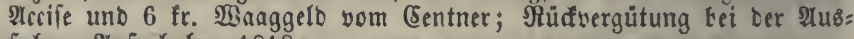
futbr. Fufgefyoben 1818.

(h) Dieß gilt insbefondere in Deutfhland yon ber babifich und baberifden

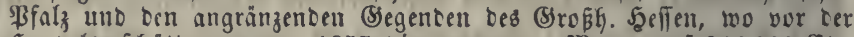
Sandeleerfhủtterung von 1857 cie gewonnene \$lenge nuf 300000 (5tr. gefdäkst wurbe uno gegen 500 Miill. Eigarren verjenbet wurten. $D_{a}$ eine foldje Єteuer, wenn Der Berfefyr im 3ollverein nicht gefemmt twerben folf, auf গeçnung Des ganzen Bereinz erhoben werben müste, jo würben jene \&änder bie Beidjwerben cer Heberwadyung uno cie Nachtfeile Der @teuer tragen müffen, während nur ein geringer Ertrag auf ifre Stantzicafien täme.

(i) Eine foldhe Abgabe murte 1797 in Franfreid eingeführt unb trug im

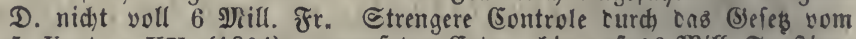
5. Ventose XIl. (1804), worauf Ler (8rtrag bis auf 16 शnill. Fr. frieg; Inftruction für cas Erkebunggrerional in Code des droits réunis II, 128 (A. XIII). Die ๔teuer war 40 (Sent. bam Rilogramm Blätter (9 f. $20 \mathrm{fr}$. vom Centner).

(k) In Mürtemberg veriuchte man 1812 nad Der शuffebung ter Tabafs: regie, sen Fabricanten uno Sänolern nach Faffionen über bie von ifnen

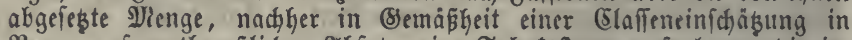

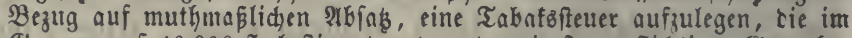
Sanzen auf 40000 f. Veftimmt und unter vie feuerpflidigen (Semetbs = leute repartirt wurbe. Plufgefoben 1828. - In Nuslano befteht bie oben bezeichnete Esintichtung mit geftempelten ßapierbäncern (BBanbes rollen). Der Fabrifherr fauft alle vier Ylonate feinen Bebarf an

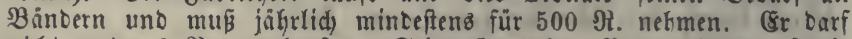

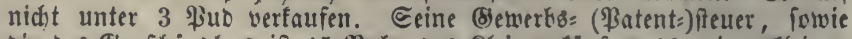

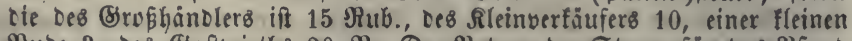

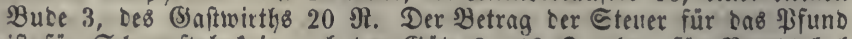
ift für Schupftabaf fe nach ter (Süte $8-46$ Sopefen, für Noudtabaf

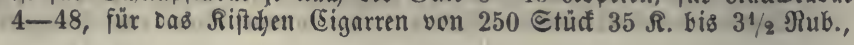


fïr Tabat in $\Re$ Rollen $56 \quad \mathbb{R}$. bi $2,929 \%$. (Sigarren werben aud in Bündeln zu 25 Stüá uno felbft zu 10 Stüd verfauft uno mit ent: fprectenoen Stempelbänbern veriehen. Sämmtliche Borfariften im 5. Banbe bes Swod, 1857. Der Itrkeber biejer Pnorbnung, Sraf (Eancrin, fagt: "Das Deittel Der Banderolle, aud) bei Rarten ge: bräuchlich, füfrt fich gut ourch." Defon. ber meníhl. (Sejellíd. S. 252.

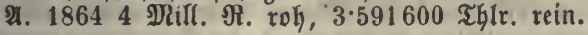

\section{§. 441 .}

Epielfarten und Ealenoer find in bielen, 3eitungen in mebreren \&änbern mit einem 2luffichlage belegt worben, zu Deffen Eidterung man fith Der Etempelung bebient, \$. 231. (Sine Befteuerung ber Spieltartent ift voltżivirthjdaftlict) obne Sadłtheil, nur trägt fie wenig ein uno verleitet zu vielen $\mathfrak{M}_{\mathfrak{m}}$ gehıngen. Die Einfuh) von Spielfarten vom 2huslande fowie Der Berfauf unb (Sebraud) ungeftempelter $\Re$ arten muß bei Strafe unterjagt werben, wenn man aber alle Eteuerbetrugşfälle ver= hüten wollte, fo würbe eine fehr foftbare und umftänolidye Beauffidtigung, namentlid) ber Sartenfabrifen, nothwenbig merben $(a)$. Bei mäpigen Säßzen uno mit einer auf Fabrifen, Raufleute uno Birthabäujer $2 c$. bejhränften Controle ift gegen Diefe Albgabe außer ihrer Eeringfügigleit nidts eingunenten. Der Ealenderitempel ift fehlerbaft, weil biele Ealenber als ein Mittel ber Belebrung eher Begünftigung alB $\mathfrak{B}$ elaftung ver=

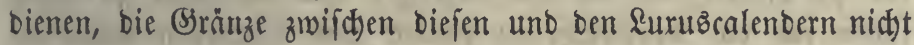
idjarf angegeben werben fann, aud nidjt abzujeken ift, warum Diefe von allen Drudfichriften uno Runftwerfen allein eine Steuer tragen follen. 2lud) ber 3eitungsiftempel ift in Şinfitht auf bie

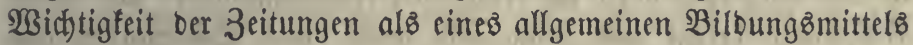
nid)t zu billigen, und wenn man ifn als ein Mittel augefehen hat, bie $\mathfrak{B e r b r e i t u n g}$ foldjer Tageblätter zu eridjweren, beren

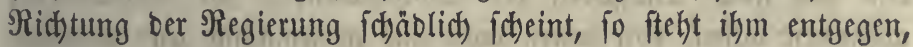

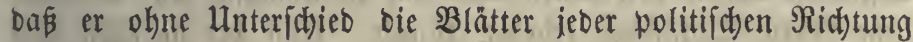
trifft (b).

(a) In Eranfreich muß tas ßapier zu Den Sarten Dem Stante abgefauft merben. L'impôt sur les cartes, qui ne produit annuellement que 500000 fr. environ, est le moins important de tous ceux que perçoit la régie et celui qui est le plus exposé à la fraude. Rapport au Roi do 1830 ธ. 113 . 2. 18621.571000 Fr. cinfdslieślich 200000 für Das gelieferte \$apier. - In Sropbritanien trug oer Rartenftempel

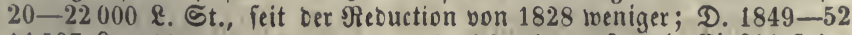
11597 l., $1853-5512671,1856-5914575$ \&. mit Esinichlus ber IBurfel; bie Abgabe if 1 Sa. vom Epiel, feit 1862 nur now $3 \$ 3 .-$ 


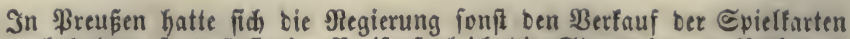
vorbehalten, fo Daß fie im Preife fogleidj bie Steuer bezog. Nadj bem (Seies v. 16. Jumi 1838 ift Die ßerfertigung freigegeben, bie Fabriten fino beaurîid)tigt, bie Etempelgebühr ift 8 unb 3 Ggr. vom Spiel. In Baben if jeit 1831 Der Rartenftempel aufgehoben.

(b) In Gropbritanien ift 1836 Der Stempel bon 4 auf 1 \$. (3 fr.) vom Stüd herabgeießst worben, weil viele Bläter heimliá ungeftempelt aub= gegeben worben waren. 1831-35 war im D. Die Einnakme $459407 \mathfrak{I}$., $1837-41255403$ \&., bie 3ahl ber 3eitungsblátter vorfer 33,5 , nadj= her 56,7 Mill. 1854 wat ber Ertrag wieber auf bie fräkere \$öhe gelangt uno belief fid auf 488010 \&. Das Befes 18. 19. Vict. C. 27 (15. Juni 1855) Gebt Den 3eitungbitempel auf nuß̈er bei Der Berien= bung mit ber ßopt $(\$ .216(g))$. Ertrag 1856/57-1858/59 im D. 158127 \&.

\section{§. 442 .}

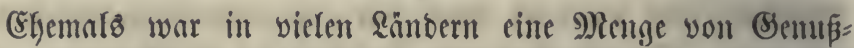
mitteln ber Ilecife unterworfen, theilz alfgemein im sanbe, theilz in ben Etïbten, wo fie an ben Thoren yon ben ein= gebradjten Borräthen erboben wurbe (\$. 429)(a). Mandje biefer Irten bez 2uffidlagez haben fid) biz nuf bie neuefte 3eit erhalten. Sntés hat man gute Srünbe gefunben, viele berfelben nad) uno nad) nufjulyeben. Bald war ber Segenftanto von ber 2 rt, baß feine $\mathfrak{B} e r t h e u r u n g$ für bic Serwerbe ober für

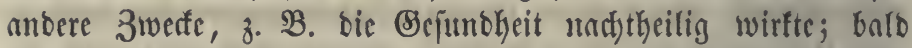
waren bie Beranftaltungen uno Ueberwachungasmittel fowohl

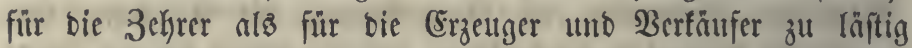
fotvie für bie Regiernng zu foftbar und erfdjenten bann als boppelt verwerflict), wenn mur eine geringe (Eimtahme ergielt werben founte $(b)$. Daker fint in ben meiften Stanten nur bie

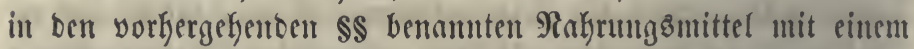
शlufichlage belegt und man fucht mefr burd) Sdjaßzungen uno 3ölle belt Stantzbcoarf nufzubringen. Demuod) ift es benfoar,

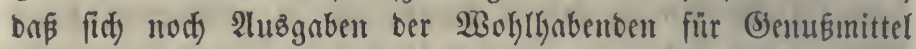

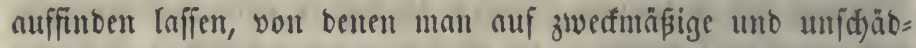

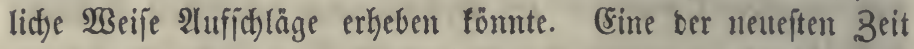
angebörenbe Steuer ift bie auf $\Re$ ufelrübenzuder gelegte.

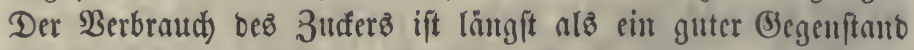
Der Befteuerung anerfanut worben. So lange man mur Rohr= (Colonials) 3uter anwenbete, genügte zu ienem Bellufe ber

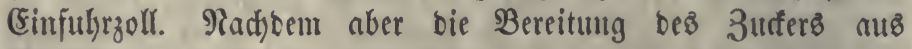
Runfelriben aufgefommen unb rajd) angemadyfen war und Dephalb bic 3ollcimalyme von Robrgutfer ftarf herabjanf, wurbe 


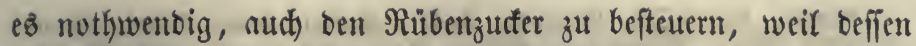
Stetterfreifeit wie ein übermäziger Sd)ubzoll zum großen (and)= theil ber Stantocafie gewirft haben mürbe, ygl. II, $\$$. 214 (e). Die Bereitung bes Rübenzuders gefchieht gemöhnlich in einer fleinen 2Inzahl großer Fabrifen, beren Benuffitstigung fein ftarfes Steuerperjonal erforbert, auth) hat bie (Erfahrung gelehrt,

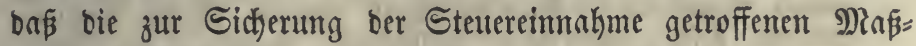
regeln bie 3unahme ber Fabrifen nidht verfindert haben. Die Erkebung fann bequem nach ber Mienge ber verarbeiteten \$itben geifteken, weil bieje an wenigften zu verbergen fint, entweber beim Cinbringen berjelben in bie 3ucferfabrif ober bei ifrer Berfleinerung (c), uno nach einer gewififen 2Tmahme über bie

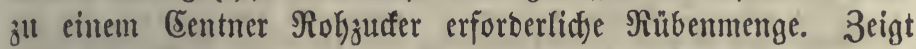
fidf bieje Innabine bei ben Fortictritten ber Rumit als zu nie= brig, fo wirb fie abgen̈ndert oder ber Steuerfü erböht. Den Steuerbenmten muß geftattet werben, in ben Fabrifen fid bie lleberzeugung zu verjळaffen, baß feine unverfteuerten Rüben

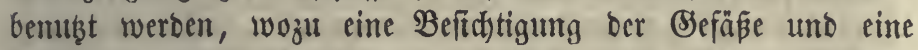
Beobachtung Der $\mathfrak{B}$ orgänge im $\mathfrak{B}$ etriebe bient. Andere Befteue= rungżnten, bie man in einigen \&änbern angewenbet hat, um bie in bent ungleidfen 3uffergehalte ber Rüben liegende Un= billigfeit zu vermeiben, erforbern eine nody ftärfere lleberwachung und fino baher fowohl foftbarer als befduwerlidjer (d). Wübe man bloß nad) Srünben bez Steuerwejenz hanbeln, fo müste

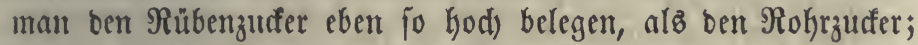

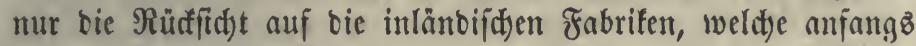
in ber gänglidjen Steuterieigeit einen gropen Sdjubs genofien Gatten uno bei ber plöglidjen Eleidffellung beider 3utferarten zum Theil mit gropen Berlujten für bie (Eigentlgủmer zu

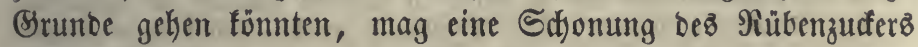
anratben $(e)$.

(a) Эn ber Surmarf Branbenburg bewilligten Die Rambitanbe 1641 eine Accife, für weldye im nämlidjen Safyre eine Berorbnung erlaffen wurbe.

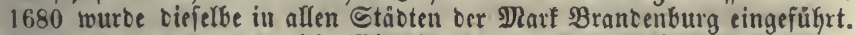
Friebrids I. uno Friebrid, Wilkelm I. vermehrten bie Hefteuerung b: gegenfänbe und erfoghten bie Steuerfä̧ze. Friebrich II. errichtete 1766 ein eigenes "Accife: unb 30ll= Departement", in weldiem berbeigezogene franzöifdie Beamte angeftellt wurben. Diefe Dberbehorbe tourbe 1787 wieter aufgehoben, bie Accife felbft aber erfielt fich bis in ben Anfang Des 19. Jahrhunberts. Sie traf auber bem Defil, fleifa und cen geiftigen Setränfen vielerlei Nałrungomittel (Dbft, Sartenfrühte, Eier, 
Butter, Răje, Del, (Sewiurze, Buterer, Rafiee), fermer Tabaf, TBadb, Zalg, Leber, \$elzwanren, Flachs, Shanf, Baumwolle, rohe Nietalle,

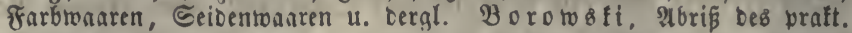
Eameral= und finanzwefens I, 266 Der 3. 2tuzig. Die ftrengen Accife: borid)riften waren eine läftige Beid)räntung ces Berfebrs uno ein Theil

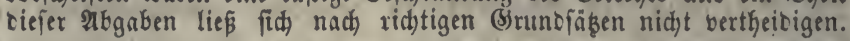

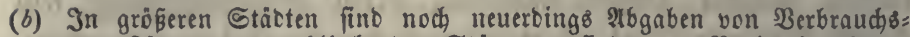
gegenfänien ber wohlhabenden Gtảnde zu finben, 3. $\mathfrak{B}$. in 5̧amburg,

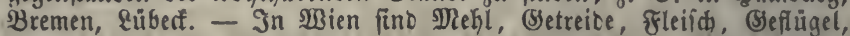

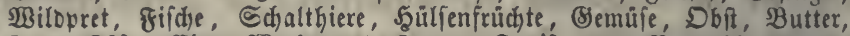
Fett, Ráie, Esier, $\mathfrak{W a c h s}$ und Rerzen, Epeife= tno Brennol, Brenn= holz, Eteintohlen, Şonig, 3iegel, Bauteine, Baulano, Sinit, (Sips einer Serzefrungsffeuer unterworfen, bie 18564.037880 fl. einbrachte.

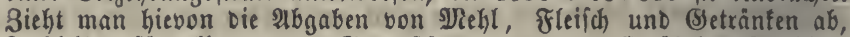
to bleiben für alle anberen Begenftände $2 \cdot 027026$ fi. ïbrig. In Lin?, Srag, Brün, Lemberg, (Sraß̧ find 44-46, in ben italienifchen größ̄es ren Étåbten 61 (Segenfianbe biejer Thorabgabe angegeben. Der Eteuer: ertrag aller 27 Stäote war im D. 1852-56 10.274184 f. - In Baben gab es nach Der Accisorbnung von 1812 eine Abgabe yon Del,

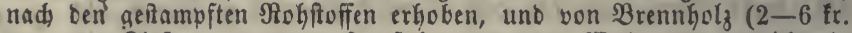

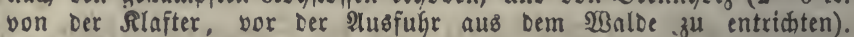
Beide 20 gaben hörten 1820 auf. - In Srof̧britanien fino mehrere Beftanotheile Der 2 ecife nach und nad theils bermincert, theils auf: gehoben worben; 1830 bie Bierfteuer (g. 3 \$lill. \&.), \&eder $(340000$ \&.), (Siber (g. 30000 \&.). - 1831 Rattune uno bedrudtes \$apier, 550000 \&. (nach शlbzug Des ftarfen (Erfabes bei Der 2tusfufr). - \&ichter, 500000 \&. Sterl. - 1833 tourde ๔eife auf bie \$aälfte kerabyefest, - 3iegel herabgefest um ungefähr 37000 - 1834 ๔tante, $75000 \mathfrak{l} .1835$ (S)lasaccife um $1 / 2$ vermintert. 1836 Papier auf Die Şálfte. Die Rccife= einnahme von 1834 toar um ungefähr $1 \frac{1}{2}$ Nill. \&. St. höher, als man biefer Errleichterung zufolge hätte vermuthen follen. - 1845: BInsaccife aufgehoben, 624000 \&. -1850 Biegel = und 3 adfifteine $(459078$ \&.), - 1852 Eeife $(1.171000$.$)$. Die lebtere Cteuer be= trug feit 1841 nom \$fund harter Geife $1 \frac{1}{2}$, von weidher 1 B., vorker feit 18213 unb $13 / 4$ \$. Die Şerabfełung fteigerte Den Berbraud Des Sopfes von 6,23 auf 9,20 , zulest auf 9,71 \$fo. - Die \$apierfeuer wurbe 1711 eingeführt. Cie mar feit 1836 von allen Corten 11/2 \$3. $=4,9 \mathrm{fr}$. für bas Deutfale Sollpfuno ober ungefähr $2 \frac{1}{2} \mathrm{fr}$. auf tas Buch. Im Iahre $1859 / 60$ wurben $217 \cdot 827000$ SFund ßapier für

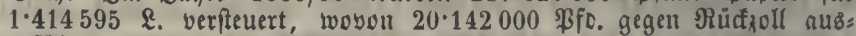
gefügrt twurben, alfo blieben $1.258464 \mathfrak{\&}$. (Srtrag uno $197 \% / 3$ glill. Pfo. innerer $\mathfrak{B e r b r a u d}$, eine offenbar. verwerfliche $2 b \mathrm{gabe}$, ठie aud Die viel fachen Anwenoungen Des \$apieres zu anoeren 3wedten als Gdbreiben

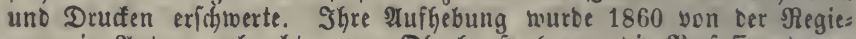
rung in Antrag gebrad,, vom Dberhaue (gegen cie Serfantung) ver: worfen, 1861 genehmigt, Sefes 24. Vict. C. 20 (12. Juni). - In

ben Rieberlanten Accife (accijnse) von Seife 10 f. von 100 Rilogr., 2. 18601.225000 fi. ooer 21 fr. a. D. R., - bon Steinfohlen, nad brei ๔orten abgeituft, $\mathfrak{A}$. mit 38 ßroc. 3ufchlag uno 10 ßroc. Stempel $1 \cdot 250000$ fl. ober 21,8 fr. a. D. R., - bon Torf, 2-10 Eents auf oie Tonne, 2. 1.640000 fi. ober $28,2 \mathrm{fr}$. a. D. $\Re$. - Franffurt

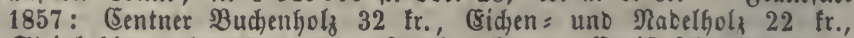
Steintohlen $3 \mathrm{fr} ., 52 \mathrm{eu} 5 \mathrm{fr} .$, Stroh $1 \mathrm{fr}$. - (\$8 ift fehlerhaft, ben Szeizbeoarf ber unteren Blaffen uno cen SBerbraud Diefer 厄toffe in Fabrifen u. Igl. ebenfalls zu belaften, nur um ten entbehrlichen 5eiz= aufwant ber \$egüterten zu treffen. B⿺on 1863 an follte biefe Ruflage 
aufforen.) In (Srobbritanien befteht bie Steinfohlenfteuer nur nod fir \&onoun und wird für orttiche Bauten und andere Berbefierungen

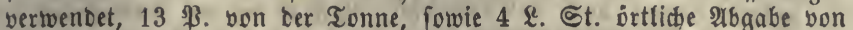
1 tun (252 (S)all. $=113 / 4$ Seftol.) $\mathscr{B}$ ein; verlängert bis 1872 burch (Be eles 24. Vict. C. 42,1861 . - Steuer von Ghnee in ber Stabt Reapel fur bie Staaţicafie, 2. 476000 Fr., Plebano S. 216. -

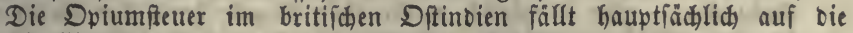
chinefificen Räufer und if vohlthätig. Sie trug 1861/62 6*359269 \&. Sterl. - Eine Steuer von Speifeol bei ber Einfuhr in Staote bon 2000 uno mefir (simwohnern beftano in Frantreich 1817-22. Sie trug gegen 3 Mill. Fr.; de Parieu, Traité II, 299.

(c) Die Uebereinfunft ber 3oltvereinzftaaten bom 8. Nai 1841 geftattete einftweilen bie $2 B a h l$, ob man Die Steuer bon Dem fertigen Erzeugnís, ober von ben siuben, und zwar beim Esinbringen ober erft vor bem 3erfleinern erkeben wolle. Man hat jebod fpriter bie lebstere Nethode vorgezogen, wie fchon tie preuß. $\mathfrak{B}$. v. 21. Närz 1840 , welche als Borbereitung für bie fünftige Bepleuerung eine fogenannte (Eontrolabgabe

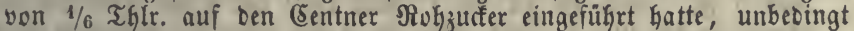

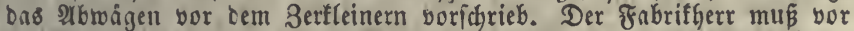
Dem 2Infang Der Berarbeitung 2nzeige machen, worauf Das Bertwiegen

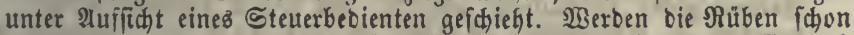
zerfanitten uno getrodfnet in bie Siederei gebracht, fo werben fie nad vorausgegangener 2anzeige bon jeber 3 ufuhr amtlich abgewogen, wobei

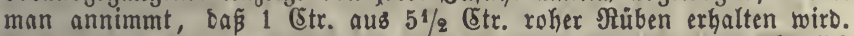
Ban. (Seleb ๖. 21. Sept. 1846. - Im 3olloerein tourbe anfänglich

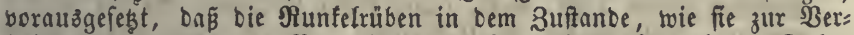

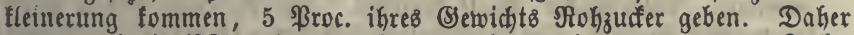

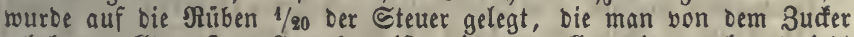
erheben wollte. Sene Annahme iff, wie man allgemein anerfannt, jebt zu niebrig.

(d) Belgien: Unterfuchung bes in gemefienen Pfannen befinblichen Saftes auf feinen Suffergefalt, nach weldyem bie Steuer berechnet wirb. Franfreic: Befteuerung Des fertigen rohen ober raffinirten Sucfers Durch Beraleichung mit gewiffen Nufferfiüfen (types) nach Der helleren ober bunfleren Farbe (oie jebod nidt genau maśgebend ifi). Die ganze Berarbeitung mú bon anweienden Beamten übertwacht wer=

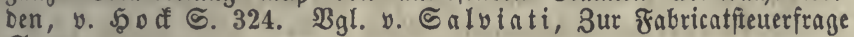
ธ. 31.124.

(e) Die Steuer begann im 3ollverein im $\$$. 1841 mit einem Sabe von 10 Sgr. $=35 \mathrm{fr}$. für ben (Eentner $\Re$ ohzuder. (58 twar eine Erhóhung

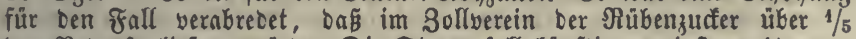
Des Betarf8 Yiefern würbe. Die Cteuer foll fünftig wenigftens $1 / 5 \mathrm{bom}$

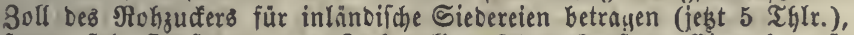
ferner foll fie fammt bem 3utferzoll auf ben Ropf Der (sinwohner fo viel betraget, als im D. 1838-1840 ber 3utfer= uno Syrupzolf aus= machte. Diefer 3ollbetrag berechnet fich zu $61 / 3$ Sgr. auf ben Ropf. Seit 1844 fließ̧t Die Rubenzudferfteuer in Die Bereinscaffe. Cie wurbe 1844 auf $1 \frac{1}{2}, 1850$ auf 3 Sgr. vom (Sentner Núben, ober nach obiger Annahme auf 1 Thlr. und 2 Thlr. bom (5entner Nohzuder

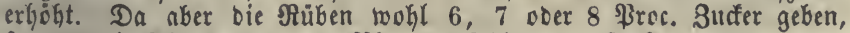
fo war bie शlbgabe nur ungefáhr $11 / 2$ Thltr. vom Suder. 1853 wurbe fie auf 6 Ggr., vom 1. Sept. 1858 an auf $71 / 2$ Sgr. $=261 / 4 \mathrm{fr}$. gefest. Fechnet inan 7 \$roc. Suderertrag, fo treffen bemnach 3,571 ThIr. Steuer auf Den (Sentner 3uder. Der Ertrag im 3ollverein if jährlich geftiegen unb belief fich $1862 / 3$ auf 9.070584 Thltr. fatt ber 10.740000 Thaler, weldbe von Der Einfugr ber entiprechenben Inenge Nohrzuder 
eingegangen wiren. Im nämliden Iahre betrug ber Esinfuhrzoll von 3uffer für eingeimifde Siebereien nur nod 1.943478 Thlr., ano es

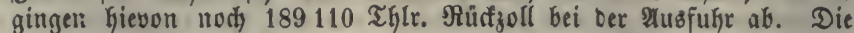
vou ben शïbenzufferfabricanten oringeno begehrte Steuerverguitung bei ber Rusfufr wurbe ourch Uebereinfunft oer 3ollvercinsftaaten vom 25. Tpril 1561 gewáhrt. Sie betrảgt fïr jeb̧t $2^{3 / 4}$ Thlr. vom Eentner

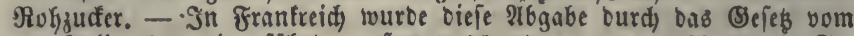
18. Jutli 1837 eingeführt, anfangs 10 , Dann von 1839 an 15 Fr. von 100 sil. mit 10 \$roc. Suffhlag. 1850 folgte eine Erfhöhung auf 25 Fr. Die Fabrifen behaupteten fid ungenditet biejer Belapung. Der Stetterius twurbe nach bem (sejęs v. 2. Sulti 184345 Fr. wie

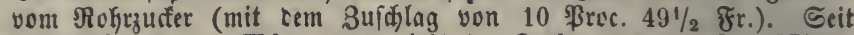

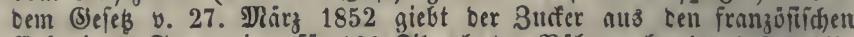

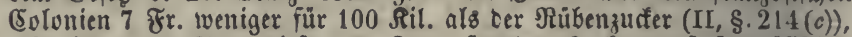
alfo jener 38 Fr., Diefer 45 Fr., frember Butfer auf franzöfíidjen Gdjiffen 45-50, auf fremben 57 frr. Sufolge bes Sefebes v. 28. Suni 1856 foll übrigens ber 3olf bes Evlonialzuders bis zum 1. Suli 1858 um 7 Fr., von ba an bis 1. Juli 1859 um 5 Fr. und von biefem Tage an bis zum 1. Suli $1861 \mathrm{um} 3$ Fr. temporar ernietrigt iverben. Das (Sejes v. 23. Diai 1860 beftimmt für SRüben= แnb franzijifiden Eolonislzuder bie Auflage auf 25, mit bem 2 Decimen 30 fr., auf

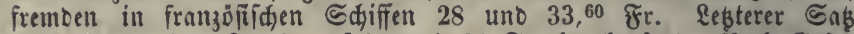
wurbe 1861 (17. Jan.) auf 25 uno 30 Fr. Kerabgefegt. शad) (Sefes

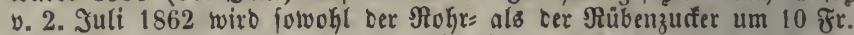
vom imetr. Bentner höher befteuert als bisfer. Beieß v. 7. शnai is64: Frember 3urfer 2 fr. mehr, זranzöfifder Eolonialzurfer bis 18705 Fr.

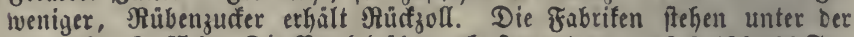

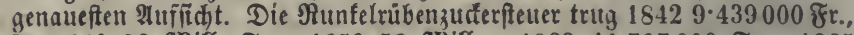

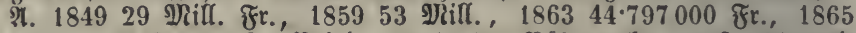

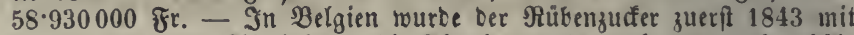
20 Fr. yon 100 sil. belegt, bie शrgabe wurte nad) uno nad crhöht uno if feit bem 1. Juli 185739 Fr. Nofrzudfer giebt feit 1843 45 Fr. Accife. 2Benn Der Ertrag beiter Steuern unter $4 \frac{1}{2}$ Dill.

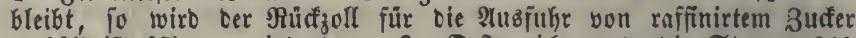
verhältnifmäpig berminbert. - In Defterreich tourbe vie Steuer 1849

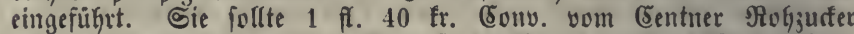
betrigen uno wurbe mit $5 \mathrm{fr}$. auf ben Centuer roker $\Re$ üben gelegt. Später exfolgten Eerföbungen. Bom 1. Nov. 1857 wercen $18 \mathrm{fr}$. von rohen, I fi. $39 \mathrm{fr}$. von getrodfneten $\Re$ üben erfoben. 1859 famen 20 ßroc. 3uid)lag hinzu, nad (5)efes v. 29. Det. 186230 Đroc.

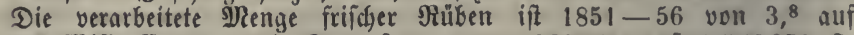
7,4 פria. Eentuer, die Gteuerfumme von 368340 auf 1.576879 fi. geftiegen, die 3ágl Der. Fabrifen vout 100 allf 131. \%. 1864 6.592000 f.

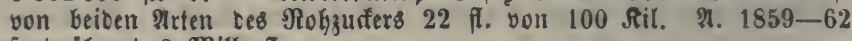
fortwägreno 2 \$ill. ff. 
4. 2 b斤ab.

(5) $\mathfrak{r} \ddot{\mathfrak{a}} \mathfrak{n} z \mathfrak{z} \mathfrak{z} \mathfrak{l} \mathfrak{l} \mathfrak{e}$.

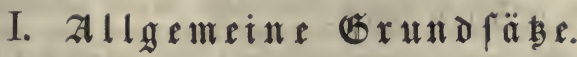

§. 443 .

3 ölle ober Mauten $(a)$, D. h. Alggaben yon ben in

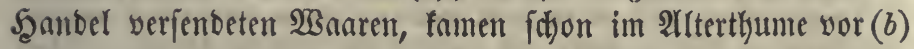

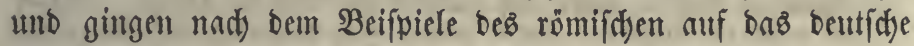
Reid) über (c). Sie wurben an einzelnen Şandeläpläzen, be=

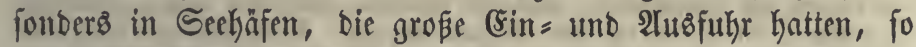
wie an Brücfen und Straß̧en yon ben ein= und augigebenten

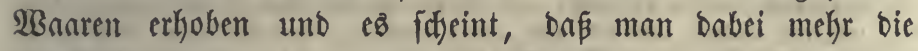

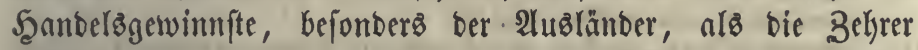
treffen wollte, twie bieß aud in äbnlidjen Fällen nod) in fpäterer 3eit gefdina $(d)$. Sm 2Rittelalter wurben bie 3öle unter ver= fobiebenen Paunen $(e)$ febre vermefhrt unb bäufig von mädtigen (Srunbfyerren, theils mit lanbegherrlidjer Bewilligung, theils eigenmäctitig ohne foldte erlyoben. Man betradytete fie als cine (Entridstung für Den (Sebrauth ber Strapen, Brüfen 2 . , fowie für ben Sdjub, ben bie $\mathfrak{B a n a r e n}$ in einem Sebiete genoffen $(f)$. Der Zoll war für verffjiebene 2 Baranen balo gleidt, bald ver=

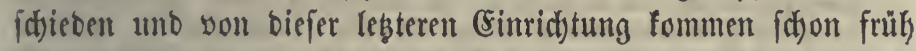
Beifpiele yor, wobei ofterb bie albfidt gehegt wutroe, bem aub= wärtigen Şanbel eine gemeinuntbige Rithtung zu geben $(g)$.

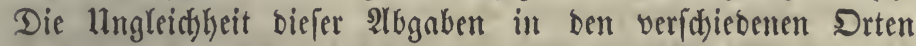
unt Begenten bes santez, bie planloje, zufällige und bödjft ungleidge Bertheilung ber 3ollftätten in \&ande, bie bäufige Unbeftimuntheit ber Tarife, bieje fehlerhaften (Eintridtungen madten bie 3ölle für bie Bolfäwirthfid) aft weit nadtheiliger,

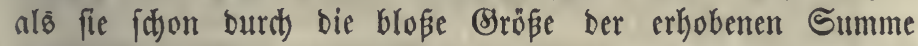
waren. Altumälig tremten fich bie 3ölle yon ben 2 Beggerbern umb anberen ähnlidjen Esebühren $(h)$ unto verwanbelten fid), wie bie (Befd)loffertheit ber Stantögebiete fid) anzbilbete unto

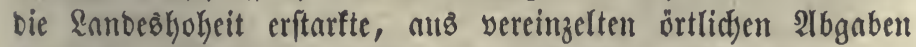

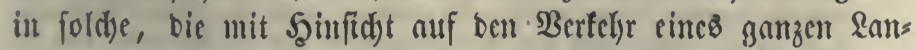

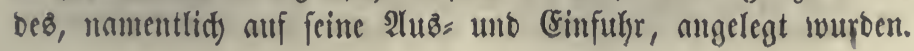


Im 17. Gabrhunbert entwiđelte fid) ienes finftlidhe Bollwejen, weld)es heutiges Tages bie Bränzen aller grö̈eren Stanten umgiebt $(i)$, bngegen veridwanten bie inneren 3 ölle immer mehr $(k)$, jo baß man jek̨t unter 3öllen idjled)thin blok bie EOränzzölle zu verftehen pflegt.

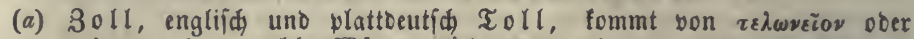

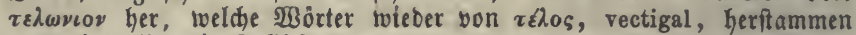
uno eigentlich bie 3ollfatte bebeuten. 2tus teloneum wurbe, wie alte Urfunben u. a. Echriften zeigen, tolenium, toloneum, tolneum, toletum gemadt, ferner if aud tonleium, tonlium, altiranzofifich tonliu, tonlieu, hicraus zu erflären, onher aud tonloier ocer toulaier, Bollner. - Thol, toll heist im (Englifd)en unter anbern eine Şanbelsgerechtigfeit eines (5)runbbejizers, InD Dab $\mathfrak{B}$ eggeld. - Na at, mutaticum, muta im Latein Des I)ittelalters, vielleidyt von bem gothifhen mota, motastad, welches bei Ulfilas eine Abgabe anzeigt. Dießs 23ort ift Demnach

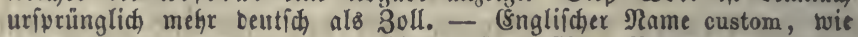
coutume, bon consuetudo - âltefter franzofíficer Name resve, rève, fpáterer traite, traite foraine, von tractura, transitura. - Stalienif́, dazio, baher aud Deutí, Daz.

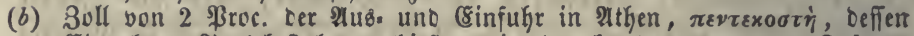
Ëinnehmer \$entefoftologen Gieß̈en; in Den buntesoverwanoten Étäoten

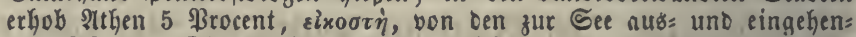
Den (S) ủtern. Die Nub́fuhr melgrerer Dinge twar in Athen verboten,

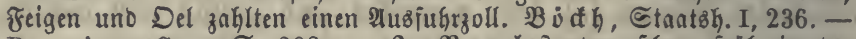

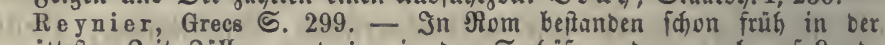
alteiten 3eit 3olle, portoria, in Den Seehâfen, Dann aud auf Lanb= ftraben uno Brüfen. Sie twurben fpaterfin ofters aufgehoben uno wieber hergeftellt unb betrugen meiftens $2 \frac{1}{2}$ \$roc. (quadragesima) bom

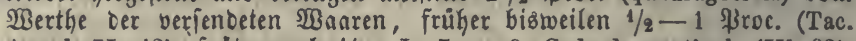
Annal. II, 42), fpáter aud $1 / 8$, L. 7. u. 8. Cod. de vectigal. (IV, 62). Bielen Stäoten twurbe zur थufhülfe igres Şaushaltes bie 3ollechebung bewilligt. L. 10. eod. L. 1. Cod. nova vectigal. (IV, 62). Die \$anbeften (L. 16. \&. 7 de publican, et vectig. XXXIX, 4) entyalten ein Berzeich= ní Der zollbaren Waaren. v. Ulmenfte in, Sragm. Beidichte Der 3ölle in Teutichland, \$alle 1798, ङ. 14.

(c) b. ulmenfein S. 40. - Das Sollweien in Deutichland, geificht: lich Beleuchtet, Franff. 1832, ङ. 2 .

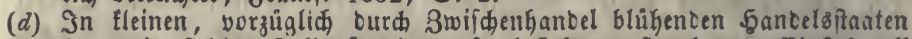
fann ein folches 3ollmeien lange fortbeftehen. Samburg: Einfubrzoll feewärs bis 1829 1,2 ßtoc., $1830-414 \mathrm{p}$. m., feit $18425 \mathrm{p}$. m., zu Eanbe ober auf ber (slbe bis 18414 , von 1842 an 5 p. m., \&uв: fufr zur Gee bis 18231,2 \$roc., $1824-41$ 1 p. m., $1842-56$ $11 / 4$ \$roc., feitcem zollfrei, zu \&ano und auf ber Slbe bis 18234 p. m., feitbem twie zur See. Sefammtbetrag 1856-63 im D. 1.073 310 פlf. (5our. (zu $43,28 \mathrm{fr}$. ).

(e) Ripaticum, pontaticum, rotaticum von Rarren ofne Deichiel, temonaticum

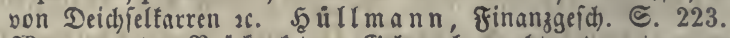

(f) Wer yon ber Brüffe feinen Bebraud machte ober einen getvifien Drt nicht berifhrte, war zollfrei. Das 3ollmeien in Deutílano 5 . 12. -

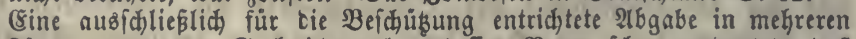
Ráncern war Das Geleitsgelo, Defien Name idon anbeutet, Daß

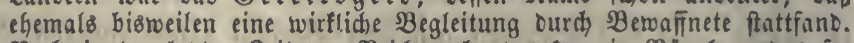

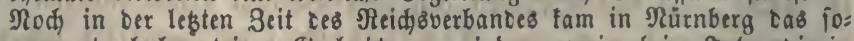
genannte lebentige (S) leit bor, inbem zreimal im Jabre cie in 
einer "Seleitsfutfde" nach Seipzig unb Franffurt a. DR. reifenben Rauf: leute von Beamten uno bürgerlid)en Peitern Der Fürften, Durch Deren Ränber fie reiften, begleitet wurben. Inoere Raufleute unb Fuhrleute,

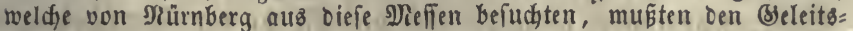

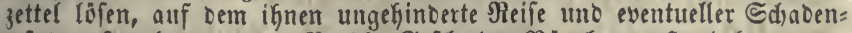

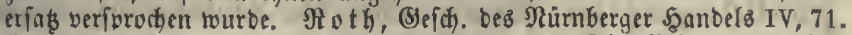

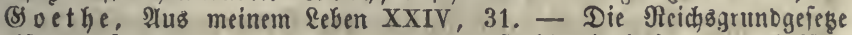
eiferten fortwährend bis zur neueften $\mathfrak{B a g}$ alcapitulation bes Raifer Franz $\Pi$. von 1792 gegen unbefugte Bermebrung ber 3ollptätten. Dlan fennt viele einzelne 3ollverleifungen, Dagegen auds 3ollfreiheiten einzelner Stätte; Nürnberg hatte in einer groben Inzahl von ๔täbten bie 3ollfreifheit, bie in einem Theile derfelben jährlid mit fumbolifden (S)efdenfen uno Jeierlidfeiten (3. B. Dem ßieifergeridht in Franffurt a. פi.) erneuert werten muste. Si oth a. a. D. IV, 1-39. (5) oethe a. ฉ. D. ธ. 33.

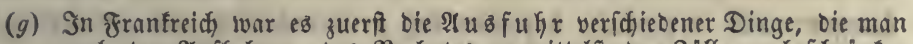

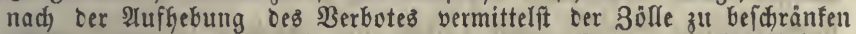

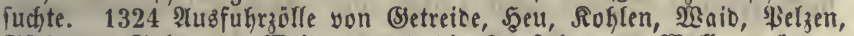
Tübern, Salz uno Wein. 1349 bie Ruøfufy von Wolle verboten, 1358 gegen einen 30ll wieter erlaubt. Pastoret, Borrebe zum XVI. Banbe ber Ordonnances des Rois de la France (5. XCI. - 2uch

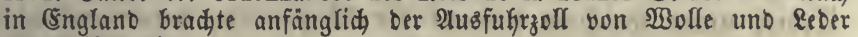
am meiften eim.

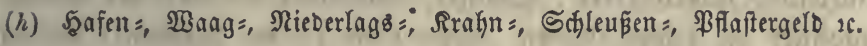

(i) In Franfreid) Grachten Die 3olltarife von $1664^{\circ}$ (nur in Den ßrovinzen Der 5 grosses fermes ausigefüfrt) und yon 1667 (allgemein für oas ganze \&and) zuerft Dronung und Bereinfachung in Das unglaublid)

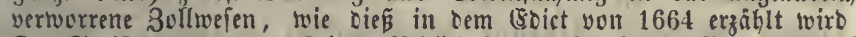
Der Tarif yon 1667 traf Gautptiächlich frembe 3euthe; 3. B. Das Ctürf

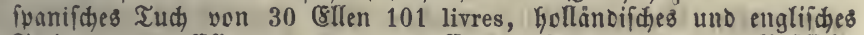
Tuch von 25 Ellen 80 livres, 1 Centner Antwerpener uno Brüfieler Tapeten 290 livres, - ferner Reterwaaren, Spiegelglas,, Seife 2 .; v. Na a ten s, Sejebe uno Beroronungen oer einzelnen europáifden Mãd) (Söttingen 1802, I, 20. (58 blieben aber noch bis 1789 viele Uebelfänce; gewifie $\mathfrak{X a a r e n}$ bezahlten bei ber Binfuhr in bie 5 grosses

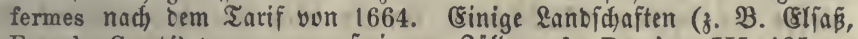
Franche-Comté) waren ganz frei von Söllen; de Parieu III, 135. $\mathfrak{B g l}$ I, $\$ .34(b)$.

(k) Auser etwa in ben Gtaaten, beren \$rovinzen now in feine gleidy=

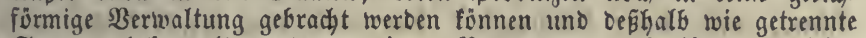
Staaten befiancelt iwerben, wie z. B. Ungarn nod bis 1850 feine eigene 3olleinridytung hatte und Die Bränze gegen bie anberen Theile

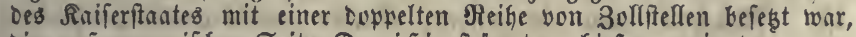
bie auf ungarifher Seite Dreí̈igftämter fiefen, wie ber unga=

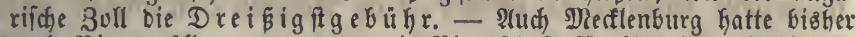
nod) $\mathfrak{B}$ innenzolle, von cenen Die Ritterfd)aft für ihre lanowirthichaft=

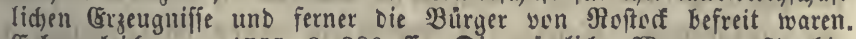
(Erbvergleids) von 1755 §. 280 ff. Die nämliche Waure muste big: weilen mehrmals 30ll bezahlen, auch war zwifhen eins, ausgeführten und im inländifhen Şanbel berfenbeten $23 a a r e n$ fein unterichied. Inteffen twaren die 2tbgaben fehr mä́ig. Die 25 \&anozollämter in Meiflenburg $=$ Gdfmerin trugen mur 32650 Thlr. (श. 1850/51), alfo weniger als oas 2 eggelo, am erkeblichffen war ber Tranfitzoll auf ber Gifenbahn uno an cen zwei Elbzollfellen, zufammen 246220 Thlr. 1861 wurbe bie \$erlegung aller Sille an bie (Strinze befd)lofien. 


\section{6}

\section{s. 444 .}

Die Eigenthümlidfeiten ber heutigen 3ölle von formeller

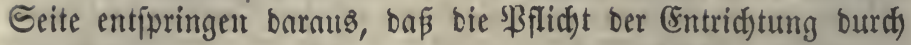
ben Ulebergang ber $\mathfrak{W a n r e n}$ über bie Ranbeß̈gränze begrünbet

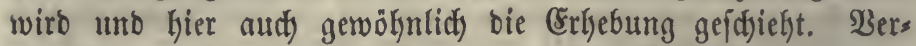
gleidjt man fie in biejer Şinfidyt mit ben 2luffid)litgen, fo er= giebt fich Folgenbes: 1) Der intere $\mathfrak{B e r f e f y r}$ eines Lanbez wirb von ben 3öllen fehr wenig beläftigt. 3war hat man zur Sidje= rung ber Zollgefälle einige Beauffitftigung ber Waarenjenbungen im Snmern nöthig gefunben, inbeß find bie üblid)en Bejdyrän= fungen nidft erheblich), beziehen fich) gröbtentheil(s nur auf wentige hodjwerzollte artifel uno lafien bie meiften Siewerbe ganz un= geftört. 2) Der Berfefir mit bem 2lualanbe wirb gewiffen

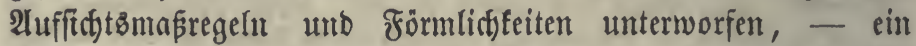
Uebel, unter weldyem forwohl bie Reifenden, befonbers aber bie Raufleute, Fabritferren, Sthiffer, Fubrleute 2 ., alछ bie Sränj= bewohner zu leiben haben. Für biefe ift ber Radytheil ba am größten, wo bie Staatägänze nicht zugleid) natürlicte Sränze bes Ranbes ift, fonbern burds ftart bevolferte, in viels fadjem Berfegre ftehenbe sanbjdaften hinzieft. Die oben= genannten Siewerbaleute madjen fith zroar bald mit ben $\mathfrak{B o r}=$ fidriften bes 3olfwejens vertraut uno lernen fidt) nach benfeloen zu bequemen (\$. 413), aud) fann man ben fleinen Bränz= verfehr burdh 21usnahmbeftimmungen erleidtern, gleidjmohl

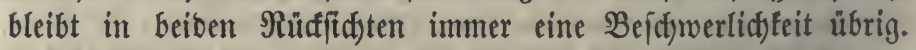

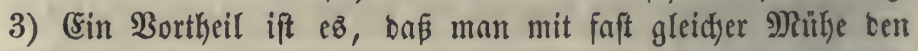
3oll yon vielen, ftatt von wenigen $\mathfrak{W a a r e n g a t t u n g e n ~ e i n j i e h e n ~}$ fann, unb bieje Reidjtigfeit hat vielfältig fogar bazu verleitet, Daß man mehrere uno höhere 3ölle anlegte, alอె zu rechtfertigen ift. Mact)en mu in einem sanbe volfsitwirtlyidjaftlidje und

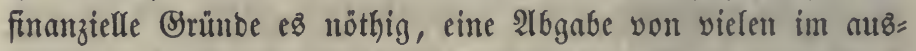
wärtigen Şanbel fich bewegenben Gütern zu erfeben, fo ift

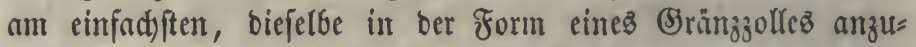
oronen. Wollte man ben $\mathfrak{B e g}_{\mathrm{e}}$ ber 2 ecife wählen, fo würbe

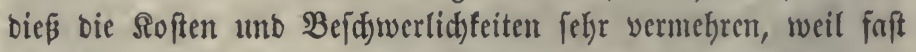
jeber Segenftand jeine cigenen lleberwadjungzanfalten erforbert. Fanbe nan bagegen in eincm Lanbe bei ber 2lbwejentyeit eines

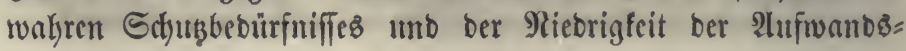


fteuers mur wenige frembe $\mathfrak{B a a r e n g a t u n g e n ~ m i t ~ e i n e r ~ S t e u t e r ~}$

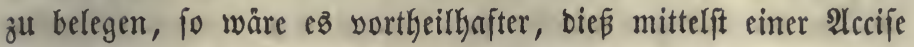
zu beweritelligen und bas ganze Sierüft ber 3ollanftalten hin= wegzulaffen. Dieß ift inşbejonbere in fleinen vereinzelt ftehen= Den Staaten, ferner in foldten, bie ein jehr zerriffenez Bebiet

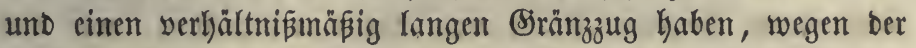

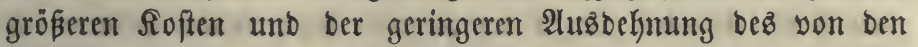
Böllen nidyt beräftigten Binnenlandes vorzuziehent. 4) Die 3ölfe werben meiftens indirect erhoben, weil bie $\mathfrak{B} e r j e n=$ oungen über bie Bränze größ̈tentheilzz von Serwerbtreibenben, hauptfächlid) von Sinfleuten veranftaltet werben, bod) wirb auch nidjt jelten ein 3oll unmittelbar von bemienigen entridytet, ber eine Baare zu eigenem (Sebraud) einführt.

\section{§. 445 .}

Es bezeidynet ben Sinohcitszuftano ber Stantäflugheit in früheren 3eiten, baßj man oft in ber Belegenkeit, 3ölle zu

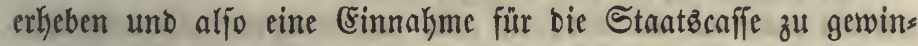
nen, fdon einen Beweggrund fanb, biep zu thun, ohne fids Red)enfd)aft barüber zu geben, ob es auf gerect)te unb zwed=

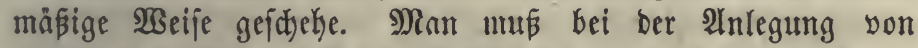
3öllen zwei Scauptzwede unteridjeiden $(a)$ uno es if ein noth= wentiges Erforbernif einer guten 3olfeinridtung, oa fid) bei jeben 3ollfab oen (Sruno beutlid) madt, aus bem ber= felbe angeoronet unb beibehalten wirb.

1) Sinb 3ölle bazu beftimmt, Der Stantögewalt eine be=

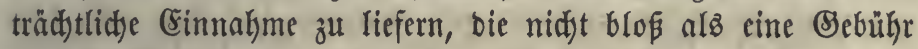
von ber $\mathfrak{B e r j e n d u n g ~ z u ~ b e t r a d ) t e n ~ i f t ~ ( \$ . 4 4 4 ) , ~ f o ~ e r i d ) e i n e n ~ f i e ~}$

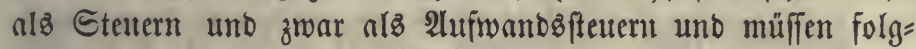
lid) Den für bieje geltenden 2 Inforberungen entiprechen, $\$ .417$ ff.

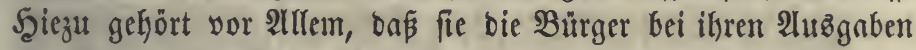
für entbehrlicje Begenftände im $\mathfrak{B} e r b a ̈ l t n i \beta$ ber Steuerfähigfeit treffen. Soldye 3ölle werben bizmeilen Finanz=, beffer aber Steuerzölle genannt (b). Ė wiberftreitet biejer $\mathfrak{B}$ eftimmung, 3oll von süters zu forbern, weld)e zur Befriebigung eines nothwentigen $\mathfrak{B}$ coürfniffes bienen ober beren 2Injetaffung über=

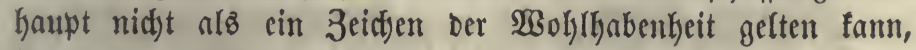
ferner vou Şülfämitteln ber Siütererzengung, wie $\mathfrak{B c r t z}$ fuge, 
Majdyinen, roke Metalfe u. bergl. Wirb eine Ruruşwaare, weldye bie Bürger jowohl von inländifden als von fremben Erzeugern erfaufen, mur bei ber Einfugr mit einer 2tbgabe belegt, fo ift biés ben Erunofäz̧en ber Befteuerung zuniber, auछggenommen wenn bie fremben $\mathfrak{W}$ anaren foftbarer futo und alfo einem böheren Srabe bon \&urus entipredyen, wie bies bejonbers ebemals wegen ber höheren Fradytfoften meiftens ber Fall war. Bei mand)en Böllen wirb aud) eine Belaftung ber

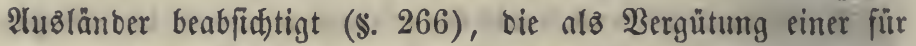
biefe gefdekenen Reiftung ober B̧ewilligung nnzujeken ift. In ben gröperen Stnaten liefern bie Bölle einen beträdttlidjen Theil ber Staatbeinnalyme (c).

(a) In einzelnen Frâllen hat man nod anbere 3wedfe ins Tuge gefaßst, 3. B. einen zur Staatzyertheibigung Dienenten Segenftand im \&anbe zu befalten (\$ierde, Salpeter), ober einem anderen Bolfe in feinem Getwerbfleífe zu ficaden.

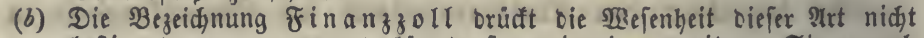
beftimmt genug aus und fonnte fogar in einem weiteren Sinne ald Der anberen 9 rtt $(\$ .446)$ beigelegt werben.

(c) In Franfreich find 1859 bie 3ölle okne Salzifteuer unb Sdjifffahrts:

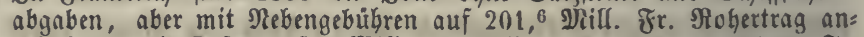
geid) lagen, bie Roften auf 30 \$ill. ober 15 ßroc. 2. $1864159 \cdot 545000$ fr.

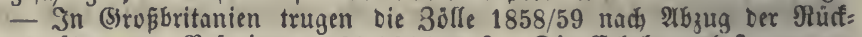
vergütungen, ßrämien 2c. 23.998379 \&. Die Ërlębungsfoften waren 838202 L., aber ofme bie 3ollketwachung an Den Rüften. Errtrag 1861 23.774000 \&., 186224.036000 \&. - Defterreiđ, D. 1854-56 (8in= nahme $22 \cdot 175502$ ศ., Ruften 3.311675 fl. $=10,4$ ßroc. श. 1862 $16 \cdot 717900$ fi. B.., Rofen $2 \cdot 563000$, aber ofme ben Intheil, ber yon Den Roften Der Finanzwadhe $(7 \cdot 377600$ f.) auf Die 3ulfeinnahme fallen muईs. 2. $186417 \cdot 704000$ fl., शtusgabe $2 \cdot 394000$ fi. - Deuticher

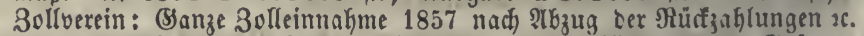
26.595 647 Thlr., Roften Der Errfebung uno 2ufficht an berl Bräzzen

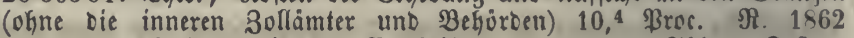
25.902749 Thlr., rein zur Bettheilung 22.985978 Thitr., Soften, Bergútungen 2 . zufammen 11,3 \$roc. - Belgien, D. $1854-56$ $11 \cdot 112651$ Fr. 2. 186314.405000 Frr., wobei aber einige (Sinfuhty=

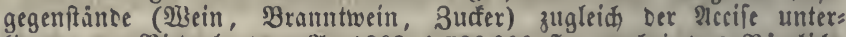
liegen. - Nieberlante, N. 1863 4'729000 fl., wobei oas Nämliche wie bei Belgien zu bemerfen if. - Nuplano, 2. $186435 \cdot 671800 \Re$., Roften 4.710360 N. ober 13,2 Broc. - Norbamericanilde $\mathfrak{B}$. Et.'

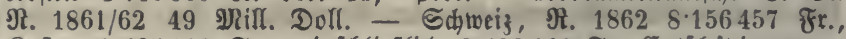
Roften 3.425100 Fr., cinfchlieflid $2 \cdot 432000$ Fr. (Entidjäcigung an Die einzelnen Cantone, alfo Bertualtungsaufiwand 12 Pruc. - Der rohe Grtrag auf ben Ropf ber (sinwofner war in bett leģten Gahren:

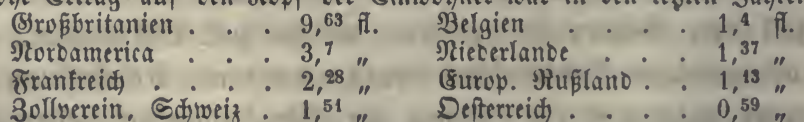

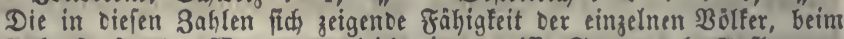

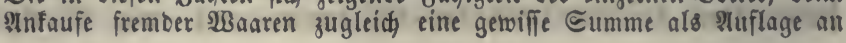




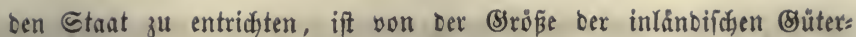

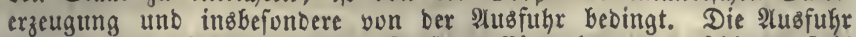
in ten lebten Jahren auf ben Ropf ber Einwohner ausgefalagen fieht in ähnlidjer, Dod nidit genau gleidjer Stufenfolge: Nieberlanbe 1860/61 109 f.. (ftarfer Colonialganoel), (Sroß̧britanien 186249,7 f., Belgien 186144,2 f. , Franfreid 22 fi., Solloerein 17,76 fl:, 9orbamerica 1860/61 17 fl., Defterreich 186211,2 fl. (Bei Brobsbritanien, Belgien

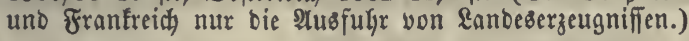

\section{§. 446 .}

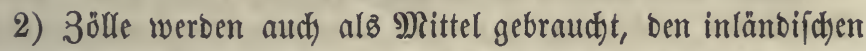
Erzeugern im Mitwerben mit ben $\mathscr{A}$ lublänbern eine Begünftigung zu geben, bamit fte im inneren Marfte bökere Wreife forbern fönnen oder geringere Soften aufzumenden haben $(a)$, als es bei voller Freiłyeit

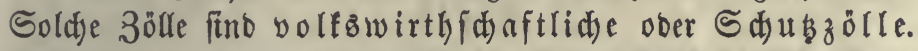
Bei ifnen tritt ber Ertrag für bie Stantżcaffe alz Nebenjache

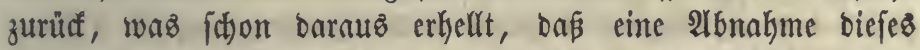

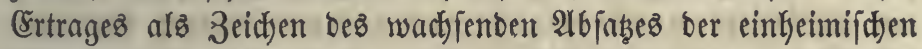
Erzeuger für erwünfdyt gehalten wiro unb baß man frükerfin

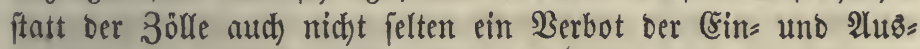
fulyr angeoronet hat. Sefubzölle, bie nidyt wie bei ber Einfubr

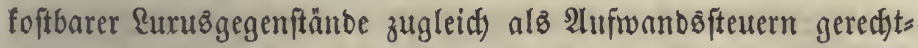
fertigt werben-fönnen, werben nid)t nad) ber Beitragşfăhigfeit Der Bürger aufgelegt, find baker feine Steuern, fonbern eine zu Sumften des Sewerbfleifez den Erzeugern oder Behrern nuf:

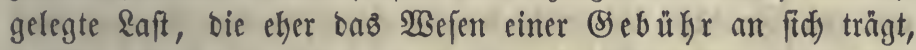

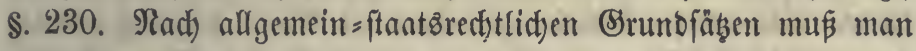
bie Befugniß ber Staatżgewalt zugeben, Dem ausెwärtigen Berfebre ber Stantżbürger Sdyranfen zu feb̧en, wenn eв bas

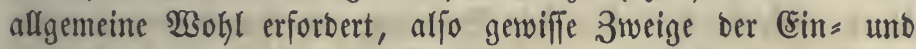

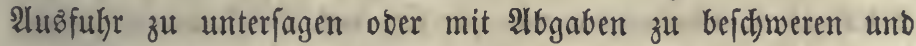
ber Shutzzoll ift bie Bebingung, unter weldyer ein foldtes Taufdgefdäft mit bem Aluslanbe geftattet wirb. Aber eime foldje Bebütyr von bem Sinfaufe oder Berfaufe einzelner $\mathfrak{W a a r e n}$ ift nutr zuläfifg, wenn fie für bie Fortbauer ober Ërböhung bes Woblftunocs als notfwendig erfannt wirb. Wo bieß nidft erweis= licf wäre uno wenigftens ber zu erwartente Erfolg mit ber Belaftung ber 3ollpflicttigen in einem Mippuerfältniffe ftünoe, ba fönte bie Frage in Errvägung fommen, of es nid)t gered)ter 
wäre, bie \&nft auf bie Stanatg̊gefaumtheit zu überitefmen, wem fie überfaupt noch) für zuläffitg erad)tet wirb $(b)$.

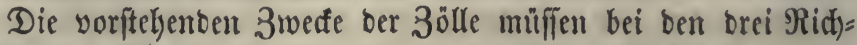
tumgen ber $\mathfrak{B a n a r e n b e t w e g u n g ~ i m ~ a u z ̇ m a ̈ r t i g e n ~} \mathfrak{B} e r f e h r$, nämlid) Der Ein $=$ 24us = unt Durdfufur befonbers betradtet werben.

(a) Diés ift bie Beftimmung Der शusfufrzölle, §. 454.

(b) Dieß fönnte burch eine (Erftattung Des entridjteten 30lles ober ourd) eine unmittelbare Bergütung an bie zu begünftigenden Erzeuger ges

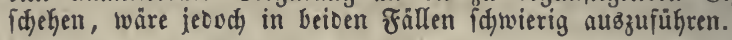

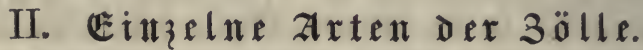

\section{A. Einfubrzölle.}

\section{§. 447.}

In bem 3olfwefen ber europäifłen Stanten bilbet bie Csin= fuhr ben ergiebigiten Siegenftand ber 3ollbelegung $(a)$. WBas Den erwähnten volfawirthidaftliden (S) fubrzolle (\$. 446) betrifft, fo wirb es ziemlid) alfgemein an=

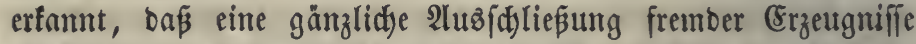
burd) hohe, einem (Sinfulyrberbote in ber Wirfung nabe fom= menbe 3ölle weber vollftänbig gelingen fann, noch aud), foweit fie (Erfolge hat, für bie $\mathfrak{B o l f s i w i r t h i d ) a f t ~ v o r t h e i l g a f t ~ f e i n ~ w u ̈ r b e . ~}$

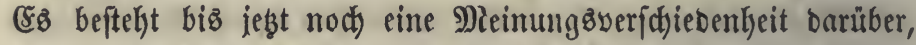
ob bie Begünftigung ber inländifhen Bewerbe burdh 3olfichus ober bie Freikeit besి aubిwärtigen Şanbels ten $\mathfrak{B}$ orzug ver:

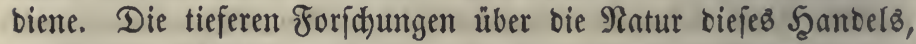
fowie viele (Erfahrungen über bie vortheillyaften Folgen einer

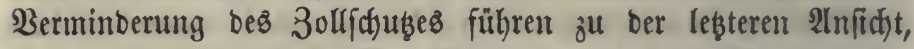
II, \$. 205 ff., 297 ff. Die Befreiung beछ ŞanbelB von allen Schubjöllen, obfdyon an und für fid) bas $\mathfrak{B o l l f o m m e n f t e , ~ f a m ~}$ jebod) bei ben gegebenen Berbältniffen, bei eincu unter ber Begünftigung vieler 3 ölle entwifelten Sewerberwefen in einem einzelnen Staate ohne bie Befalyr von Störungen im Sewerbes wejen nidgt plöb̨lich eingefüh)rt werben, es if vielmegr ratbfam, bie Setwerbsleute barauf vorzubereiten und fich ienem 3iele all= mälig zu nähern. Snbeß ift bie Beibelyaltung foldjer 3ölle, nod) mefr bie nete (sinfübrung ober bie Erböhung Derfelben mur zu redffertigen, wenu ifre Notgwentigfeit in jebem eins 
zelnen Falle aus den gegebenen Sewerbs̄berfältniffen eines Ranbes nadygeniejen wirb, und bies ift nur bei 3öllen son begränz̧ter Dauter möglich (b).

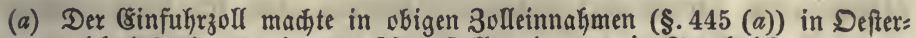
reich (1862) 92 , im beutichen 3ollverein 99 , in Franfreid, 98 \$roc., in Belgien 99, $\mathfrak{3 r o c}$ aus. - Esin bemerfenswerthes -\$Beifpiel niebriger 3ölle giebt bas fhweizerifhe 3ollgefers vom 19. Jumi 1849.

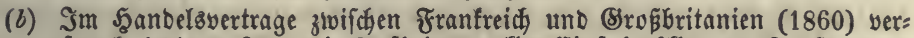

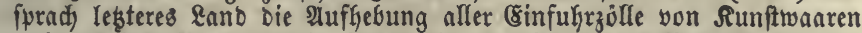

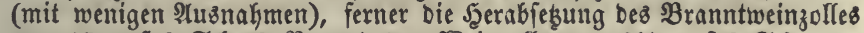

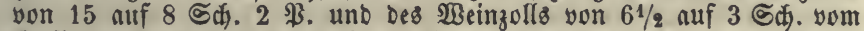
Ballon. Franfreid hebt alle Berbote son 1861 an auf uno erkebt

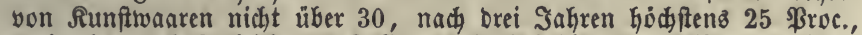
erniebrigt audy fogleich ben 3olf von Steinfohlen uno Esien. - Nach

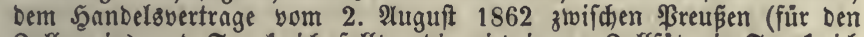
3ollverein) uto Franfreich) follten bie niebrigeren 3ollfäze in Frantreid 1864 eintreten, im 3ollverein follten bie für ifg verabrebeten 3ollfäbe

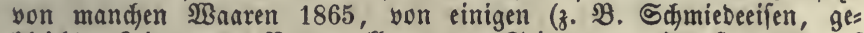
Gleidter Reinwant, Baumwollen = und Seidentwaren) erít 1866 auf cen nieberfen Betrag fommen. Diefer Bertrag ift exft Enbe September 1864 von allen 3ollvereinsftanten genehmigt worben.

\section{§. 448.}

Die 3ollbelegung von eingefüfrten 2 aaren gefdah in älterer 3cit nur ber Befteucrung willen. IIlsz fpäter, haupt=

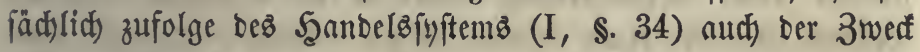

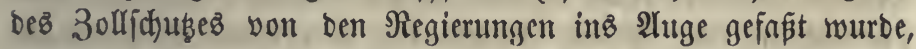
traten bei ben einzelnen $\mathfrak{B a n r e n g a t t u n g e n ~ v e r i c h i e b e n e ~ F a ̈ l l e ~ e i n . ~}$

1) Cin Steucrzoll ging bistweilen mit ber 3eit von felbft in einen Sdubzolf über, wenn nämlid) ber burd) ben 3oll fowie ohnehin burd) bie Fradyttoften erföhte Wreis einer fremben Wanre intänbiface Bewerbsleute ermunterte, biefelbe hervor= zubringen, ba bas inlänbija)e Erzeugnißí von einem 2lufichlage frei blieb. Şiebei ging für bie Stantseaffe bie Summe verloren, melche bei ber Befteuerung bes ganzen Berbraudjo auf bie vers zefrten inlänbiffen (Erzeugniffe fallen würbe. Diefe find übri= gens oft nur wegen ber Sdywierigfeiten ber Erfyebung feinem 2luffalage unterworfen worben. Werben fie ziwar beftentert, aber niebriger als bie fremben, fo bilbet Der Unterfictied ben Sduuzzoll $(a)$.

2) Mandue $\mathfrak{W a a r e n}$ wurben bes Sdukes wegen unter einen

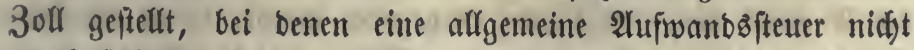
zwedfmäpig fein wủrbe, weil fie zu einem nothwenbigen Bebürnini 


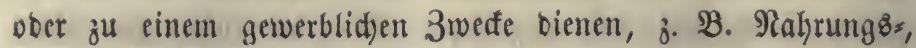
Şeilluittel, Berwerbsg geräthe ut. bgl.

3) Der Steuerzmed tritt ohne Einnifdung einer Sdjubs abfidst rein Kerwor bei foldjen Waaren, bie im Lanbe nidft erzeugt werben fönnen, z. B. Colonialwaaren mit 2lužnabme Deछి 3ưfers.

(a) Als פeifpiel bes Sufammentreffens ber beiben 3werfe bient ber Tabat:

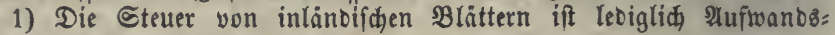
fteuer, \$. 451.

2) Die 3ollbelegung ber fremben Blätter war uriprünglid, Steuer: zoll uno if es zum Theil nod, injoferne toftbare Sorten getroffen

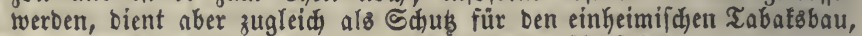

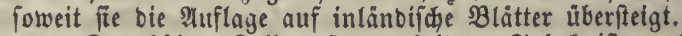

3) Der hobere 3oll auf verarbeiteten Tabaf ift zugleid) Sduk für bie inländifchen Fabrifen, wenn er gleid) bei ben feineren Sorten nud als Steuer eridjeint.

Bei bem 3ucter fommt zu 2) aud ber Sduk ber Colonien bes Dutterlandes gegen anbere Erzeugungslänber Ginzu.

\section{§. 449.}

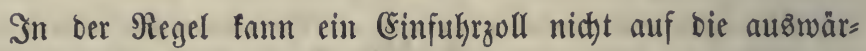
tigen $\mathfrak{B e r f a ̈ u}$ er übergewälzt werben, weil bieje vermöge bes Mitwerbenz igre \$reife idjon fo niebrig ftellen muiffen, baß fie bei einer $\mathfrak{B}$ erminberung berfelben nidjt beftefen fönnen, weşhalb fie eher einen anberen Martt auffiutben ober bie Şer: vorbringung ber Waaare befdaränen und ifrem Bewerbfleifece

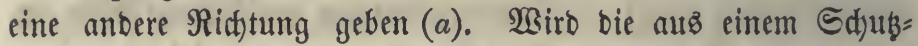

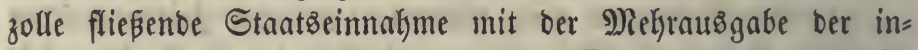

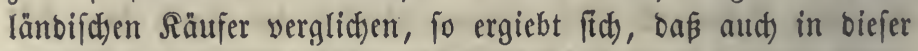
Şinftedt verfajiedene Fålle möglid) fint, II, \$.206. 1) $\mathfrak{B e n n}$

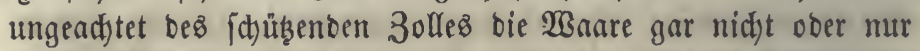
wenig im \&anbe hervorgcbradt) wirb, folglich ber Sd)us un= wirffan ift, fo muß ifr \$reis gernbe um ben 3oll (ober mins beftent bie Sd)leidthanbelprämie) über ben Betrag fteigen, Der bei freier Sinfuhr beftehen würbe uno biefe ganje \$rciserhöhung fliept, bie Keimlid) eingeführte Menge augigenommen, in bie

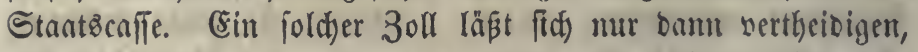
wenn er zugleid) cine gute 2lufwanbsfteuer bilbet. Sm ent= gegengefesten Falle ift er eine unbillige Bejd)werbe für bie Săufer. 2) Findet eine (Erzeugung in \&anbe ftatt, bie aber bie (Sinfulfr nod) nidjt ganz entbehrlid) madyt, fo ift bie $\mathfrak{B e r}=$ theuerung biefelbe wie im yorigen Falle, aber bie Mehrausagabe 
Der Răufer bertheilt fith zwifd)en ber Stanatżcaffe und ben ins länbifd)en Senverbsiuntermehmern, unt bieje gewinnen babei, wenn ifre Erjeugungstoften nid)t fo viel betragen, als bie

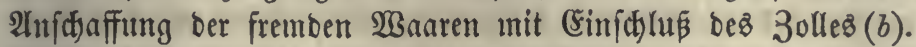
3) Bermag bie inlänbijche Şerborbringung ben ganzen Bebarf einer $\mathfrak{A r t}$ von $\mathfrak{B a}$ aren zu liefern, fo wirb ber \$reiß berjelben you ben Roften ber einfeimifhen Unternefymer uno yon bem Mitwerben ber leksteren beftimmt uno fann leidyt niebriger wer= Den, als Der Şreiz Der gleidjartigen eingeführten (s)üter. Ramn ber inläntifche Sewerbsimann auth) bei soller Freifeit bas frembe Mitwerben aushalten, fo hört bie Einnahme aus bem 3olle ganz ober größtentheils auf und man fann benjelben hinwegs nefmen. Bebirfen aber bie (Erzenger not) einez Sd)ukes, , wiro ben 3ehrern wie im vorigen Falle ein Dpfer auferlegt, nur ein fleineres, unb bie Staatżcaffe bezieht bayon wenig.

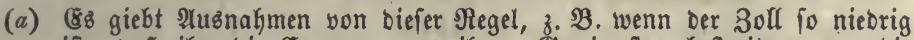
ift, Daß ifn bie Erzeuger aus ifren Beminnften beftreiten, um bie Brobuction nidht aufgeben zu müfen, ferner ivenn ein anberes Lano feiner Lage nadi) feinen Sgauptabias in Demjenigen Staate eriwarten mus, Der bie 3olle autflegt uno baburch Die Erzeuger in jenem \&anbe getwiffermaß̧en beferriht 2 .

(b) Dft berfeblt eine foldhe Maaßregel aud ifren Swed uno bringt ßerionen Nuben, Die man nidit begünftigen wollte. In Ëngland z. B. zahlten

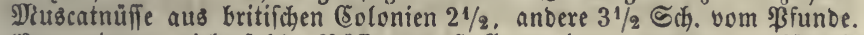

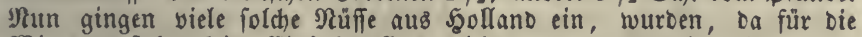
Bieberauţfufr fein (Einfufyrzoll entrichtet zu werten brauchte, von englifwen Saufleuten nad) Dem (Eil) und von on zurüd nad) England gejencet und fier nad bem niebrigeren Sage verzollt, wobei nuf baz

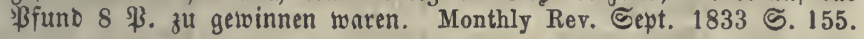

\section{\$. 450 .}

3ölle als Steuern werden, wie die immeren 2Uffalläge, auf foldye auzlänoifdye Waaren gelegt, bie ber Bermögende

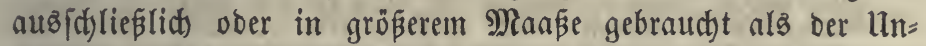
beguiterte, die aljo nidjt zur Nothourft, fonbern zum $\mathfrak{B}_{0}$ hlleben, zum Sergmügen oder \$runte bienen. Diefe Steuerzölle fino einträgliçer alż bie Sđłubzölle $(a)$. Shre Beibebaltung ift in ben meiften Staaten notlywenoig 1) wegen iferer Unentbefrlich= feit für bie Stantżcaffe, 2) wegen ber burdf bie Ritufidyt auf bie inneren 2 nfichläge entftekenbe forberung ber (serect)tigfeit. a) Wirb eine $\mathfrak{B a n r e}$ bei ifren inländifdjen Erzeugern mit einer Accije belegt, fo würbe biejen ein Nadtheil zugefügt, wenn 
nid)t zugleid) yon ber (Einfulgr ber mämlid)en Begenftänbe eine wenigftens gleid)e Steucr erhoben würbe. b) शlber aud) an= bere, mur zu cinem unb bemfelben Şauptzmefe bienenbe Bsăter müffen bei ber Cinfulfr befteuert werben, um nidjt ben Ber= brauch) uno alfo bie Erzeugung ber accizbaren inlänbifdjen Erzeugniffe zu jehr zu fdjwäd)en, wie z. B. ber $\mathfrak{B}$ ein=, Biers, Bramutwein= unb Fleifdjaufidjlag cinten 3oll auf frembe Epeifen

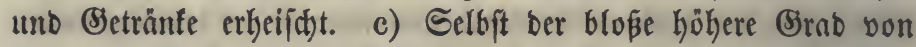

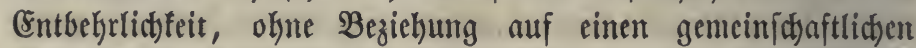

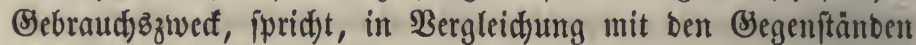
ber 2lecife, für 3ollbelegung eingelyenber \&urusigegenftänte.

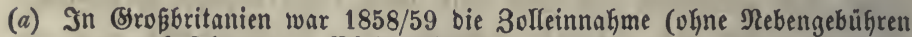

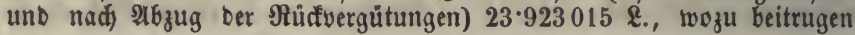

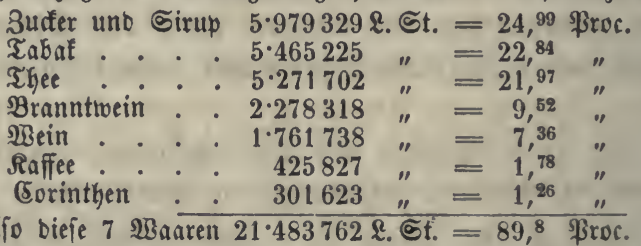

Im beutichen 3ollwerein war 1861 bie ganze Einnahme an Einfuhrzoll $24 \cdot 848430$ Thlit.; Die Şautptgegenftânbe Der Steuter waren

\begin{tabular}{|c|c|c|c|c|}
\hline Fee uno Safao & $7 \cdot 370873$ & $\mathfrak{I} \mathfrak{h l t}$. & & \\
\hline Tabat . . . & 2.695985 & " & $=$ & 10,8 \\
\hline $\begin{array}{l}\text { WBein } \\
\text { 3uffer }\end{array}$ & $\begin{array}{r}1 \cdot 248552 \\
862001\end{array}$ & $"$ & $=$ & $\begin{array}{l}5 \\
3.5\end{array}$ \\
\hline trodfene Sứtruidjte & 815540 & ", & $=$ & 3,6 \\
\hline Ri & 701170 & 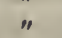 & $=$ & 2,8 \\
\hline ürze & 443443 & " & $=$ & 3,8 \\
\hline intwein & 440357 & " & $=$ & 1,17 \\
\hline arin & 351937 & " & $=$ & 1,4 \\
\hline & 304368 & $"$ & $=$ & 0,8 \\
\hline
\end{tabular}

Diefe 11 Waaren zufammen $15 \cdot 134426 \mathfrak{T h y l r} .=60$ ßroc.

(Der eingeführte Sucfer Gatte 1857 now 6,4 \$roc. Der Einfulfrzolle

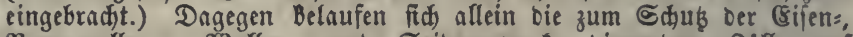
Baumwollen:, SBollen: und Eeibengetwerfe Dienenden Bolle auff

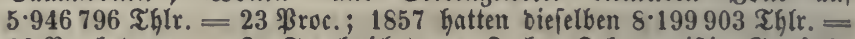
39 \$rc. betragen. - In Franfreid́) tragen Butfer, Rafav, geiftige (Setränte, Bfeffer, Baumwolle 1241/2 INill. Fr. = 63 \$roc. Des Eingangszollez,

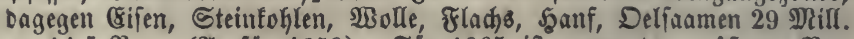

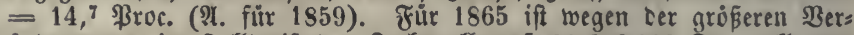
anderungen im 3olltarif ber 3udferzoll auf 88.673000 ₹r., alle an= Deren (Einfuthrzalle fint nur auf $72 \cdot 196000$ Fr. angejdjlagen tworben. In Defterreid bradten 1858 Raffee, Buffer, Setwurze und Branntwein 35 Proc., Dagegen Ȩifen und Ëifentwaaren, Baumtvollentwaaren mit

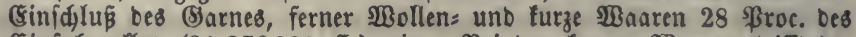
Eeinfufrzolles $(21 \cdot 276000$ f.) ein. Bei ben furzen $\mathfrak{W}$ aaren trifft ber Steuer = unb Sdjuzztweff zufammen. 


\section{§. 451 .}

Bas die cinzelnen Begenftänbe ber Einfuhrzölle betrifft $(a)$, fo fällt ber Ssrund einer Befteuerung bei foldsen $\mathfrak{B a a r e n}$ hin=

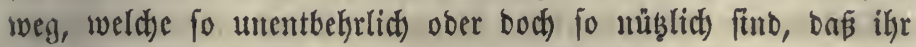
Infnuf nidjt als 3eidyen ber Steuerfähigfeit angejeben werben faun, ober baß wenigftens ifye Bertheuerung nid)t beabfid)tigt werben follte. Dahin gebören $\mathfrak{z}$. $\mathfrak{B}$. Die gewöhnlidyften $\mathfrak{R a ̈ h r =}$ mittel, Sceizftoffe, Bauftoffe Der gemeiuften 2lrt, Sileibungzitoffe

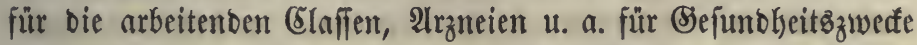
beftimmte Dinge (b), Şillfsmittel für Wiffenid)aft, Rumft unb Scrwerbe, als Büd)er, Runftwerfe, Muftcalien, Mlodelle, Stücte, bie zu Sammlungen beftimunt find $\mathfrak{u}$. ogl. Se mefre man bar= auf bebad)t ift, fid) von ben Srünben ber 3ollbelegung Rechen= fichaft zu geben, befto mehr Begenftänbe finbet man, die ganz voin 3olfe befreit zll werben verbienen, wie benn aud) in ben

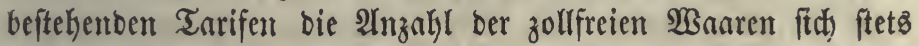
vermefyrt (c). Bei manchen anberen (Sinfulyrgegenftänben treffen

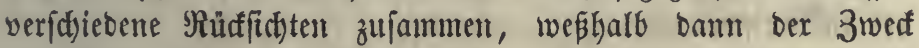
ber Befteuerumg oes Alufiwandes nicht allein masgebend ift. Die Waaren Inffen fith in biefer Sgimftet to eintheilen:

1) Rohft offe, und zwar a) foldbe, die in ihrem natür= lid)en 3 uftanbe ober mit geringer $\mathfrak{B e r n ̈ n b e r u n g ~ a l s ~ ( S ) e n u ́ p m i t t e l ~}$ verbrautht werben, wie z. B. viele Colonialwanten, Sübfrüdte, 2uitern, Wein, Branntwein, Bier 2c. Scier ift bei ber Feft= fez̧utg eines 3olles mur Darnuf zu adyten, ob und wieweit ber Berbrauch bes Stoffes nach) allgemeinen (Snunbfäksen fth) zur Erkebung einer 2 lufwanbzfteuer eignet (\$.419 ff.), ohne Dap̃ er burd) bicje ftarf berminbert wirb, ferner in weldyem Manape bie Belaftung bes entbehrlidyen 2lufwandes für bie Stnatzeaffe Bedurfuí ift $(d)$. 3uffer und Raffee, in mantben Ränbern auth) Thee, find alfgemeine Sährnittel geworben uno werben felbft bon Dürftigen gebraucht, befonbers ba man mit ifrem Beiftanto leicfter yon Brot oder Rartoffeln leben fann $(e)$. Demnod) ift cine Befteuenung biefer Dinge unvermeiblid), weil

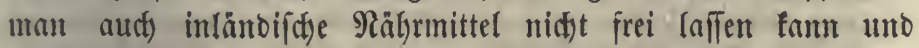

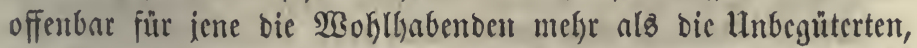
bie Stäbter mehr alz bie Ranbbewohner aufwenten, mur swäre

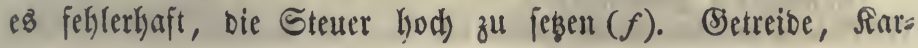


toffeln u. Dergl. bleiben am beften gaulz zollfrei. b) Soldse Stuffe, bie in ben Kerborbringenton Serwerben als Berwanto=

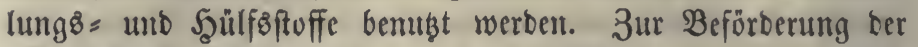
inlänoifdjen Betriebfanteit ift die zolffreic Esinfuthr foldter Dinge nüblid), bejonbers wenn man auf eine शlusfuffr ber Siunftwaaren red)nen famn, für bie man, wenn ein beträđttlidjer

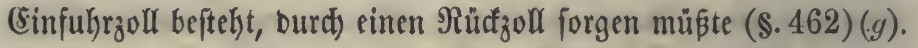
Fintbet aber ein ftarfer inlänbifcher $\mathfrak{B}$ erbraud) Der Simftwarare ftatt uno gehört berjelbe zu bem \&urus, fo baß er ciniger= mapen mit ben Braben ber 2 Goflgabenteit zufammenfältt, io

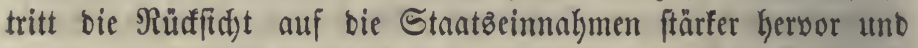
es ift cin Steuerzoll nidjt zu vermeiben, bei bem man iebod)

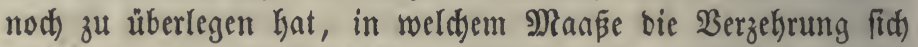

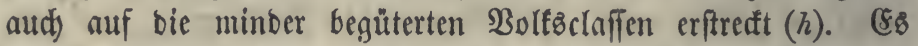

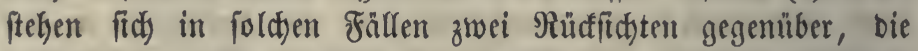
man bei jeber $\mathfrak{B a a r e}$ nad̆ ifrer beiberfeitigen Stärfe müroigen

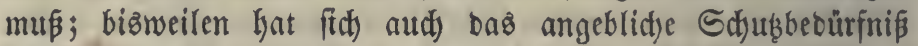
ber inländifften Eroarbeit eingemifatt, II, \$. 128.

(a) In ben folgenden Beifpielen aus mefreren neuen 3olltarifen bebeutet

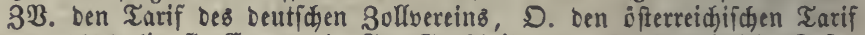

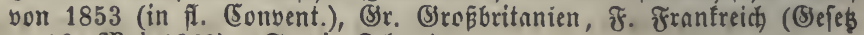
v. 16. Nai 1863), S. Die Sdiweiz.

(b) Dpium war fonft in Defterreid mit 120 f. für ben Eentuer belegt, jest nur mit $12 \frac{1}{2}$ fi. Gonv. (Sr. 1 Sd). vom \$fund. Im $3 \mathfrak{B}$. geben Arzneiftoffe nur $1 / 2$ Thlr. - sieis, entfullfet, $3 \mathfrak{Z} .1$ Thlt., D. $45 \mathrm{fr}$., Sr. früber $4 \frac{1}{2}$ P. (131/2 fr.) vom Sentner, jeģt nur von Reismehl fowie von allem anbern SRefl, Sago, Tapioca, Nubeln (vermicelli) $2 c$.

(c) Samentlich ift bies in Den britifichen 3ollgefeben ber neueften 3eit in auffallendem Maaß̧e wahrzumefmen.

(d) Auftern u. a. Schalthiere $3 \mathfrak{B}$. 4 Thlr. (Şandelsbertrag mit Frantreid)

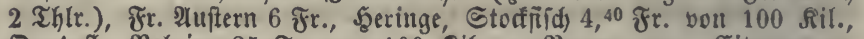
D. 4 fi., Belgien 25 fr. von 100 sil. - \$omeranzen, Eitronen 26 .

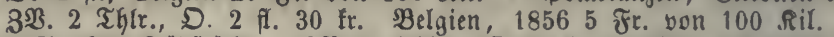

Trodne Silofrüdte. $3 \mathfrak{B} .4$ Thlr.,

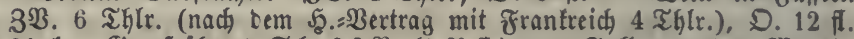

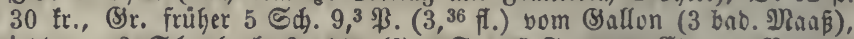
jeß̧t nur 2 Sd). (bgl. \$. 447 (b)), S. 1,5 fr. vom (Str. - Brannt:

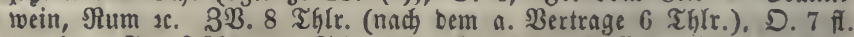
30 fr., (Sr. früter 15 Gd. ( $81 /$ fi.) vom (Sallon, jebt 10 Ǵch.

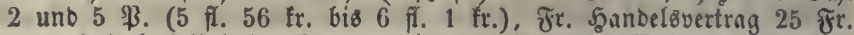

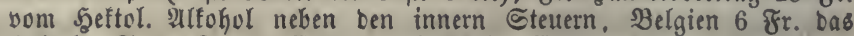
Seftol., S. $3,^{5}$ Fr. ber Eentner. Trüfeln, Eaviar, Dliven, Eapern $x$.

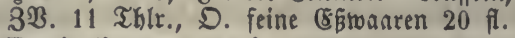

(e) Tea is the poor man's and the poor woman's luxury, (5) la fit one im Unterfaus 2. Februar 1860.

(f) Die genannten Stoffe Gaben fid tros ber Ungunft, mit ber man 
anfänglich ifre Cinführung betradtete, unaufGaltiam eingebrangt uno ifr Berbraud if nod im Steigen. Durftige helfen fid unter anbern ourd) geringere Gorten unb Beifügung bon (Erfagmitteln, namentlid bes Rinifees.

Rtohzucfer für Siebereien D. 7 fl., $3 \mathfrak{Z} .5$ Thlr., (Sr. nady ber Farbe $12 \frac{2}{3}-16$ Sh., S. $3 \frac{1}{2}$ Fr. yom Eentner.

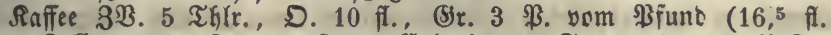
yom 3ollcentner), $\mathfrak{F r}$. von franz. Colonien $36 \mathrm{Fr}$, andere $50,40 \mathrm{fr}$. von 100 R., S. 1,5 Fr., Belgien 15 Fr. von 100 R.

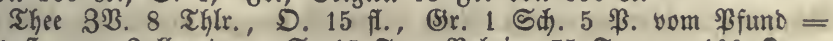
91 fi. yom Sollcentner, S. 15 Frr., Belgien 75 fr. von $100 \Omega$

(Setwüze Belgien 20 ßroc., Simmt 200 Fr. von 100 న., D. feine (3immt, (Setwürznelfen) 25 fl., feinfte (Yusfatnůffe uno Blüte, જanille, Safran) 50 fl., 3․ 71/2 Thlr., (Sr. nur \$feffer 6 \$. vom \$funo

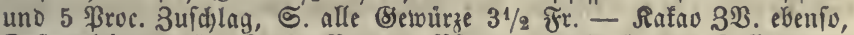
Defterreid, 71/2 fl., (S). 1 P. vom Bfuno $=5,35$ fl. yom 3ollcentner, Belgien 15 fr.

(g) Daher find gewobntiक manderlei Sdymufgegenftande, wenn fie roh

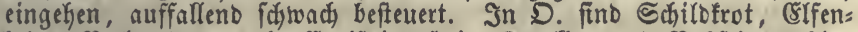

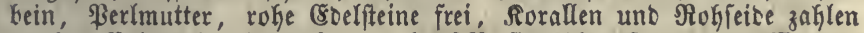

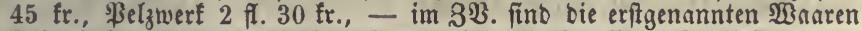
frei, Geibe und rohes \$elzmerf 521/2 fr. In (Sr. find alle Dieje (Segen=

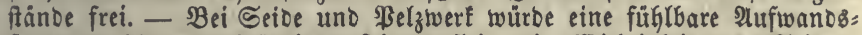
fteuer wohl zut redffertigen ieil, allein bie Widjtigfeit oer Seiben= treberei $2 c$. macht fie unrathiam.

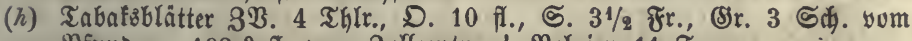
Bfano $=192,9$ fi. wom 3̊llcentner! Belgien 11 Frr.

\section{\$. 452 .}

2) Bei ben halbfertigen $\mathfrak{W a a r e n , ~ f o g e n a n n t e n ~ S c a l b = ~}$ fabricaten, wäre ein Steuerzoll unziwedmäpig. In Şinftcht auf ben Sdjus ber Sewerbe treffen ganz entgegengefeste 3 wedfe zufammen, inbem fữ bie weitere Berarbeitung jener $\mathfrak{W a a r e n}$ eine geringe, für ifgre Errzengung aber eine bohe Aluflage in Injprudb genommen wirb, II, \$. 213 a.

3) Die Runftwaaren hat man nidft felten ofyne beut=

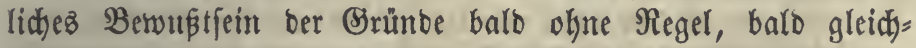
mäß̈ig, etwa nad) einem gleichen Theile eineż mittleren Şreifes, ober nach) $\mathfrak{B e r f j a ̈ l t n i \beta ~ b e r ~ z u ~ i f r e r ~ S ̧ e r b o r b r i n g u n g ~ e r f o r b e r l i c t ) e n ~}$ Menge von 2lrbeit belegt, \$. 449. Nad) ber obigen Unter= facheidung ber beiben 3wedfe ber 3ölle follen bie bem böheren \&uxus augehörenben Waaren höker befteuert werben als foldje, bie cin Beburfniß̄ befriebigen, und biefe werben, wenn fie fdyer zu entbegren fino und einen Sdus entweber nictst braudjen ober nidjt verbienen, am beften ganz frei gelaffen. Roftbare 3eutje, Mobewaaren, gropi Epiegel, Spiben, Teppidje, feine Irben = unb SIlasmaaren, viele Arten ber fogenannten furzen 
Waaren, woblriect)ente Stoffe u. ogl. fint vorzüglid paffente

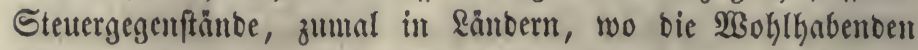

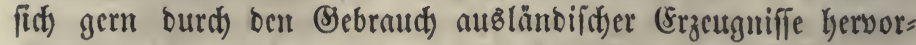
thut unb biefe einen höheren \$reis haben, als bie gleid)= namigen intänbifden. Dod) jollte ber 3ollfä and bei biejen (S)ĭtern nid)t zll hod) fein, weil er, vornefymlid) bei foftbaren

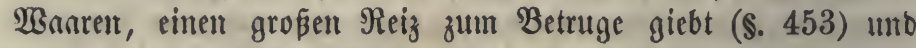

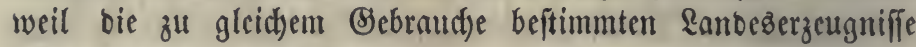
feine 2 bogabe tragen $(a)$.

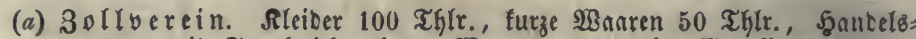
vertrag mit Franfreid): furze $\mathfrak{W B a r e n}_{\text {aus }}$ eblen Mletallen, Berlen, Rorallen, Steinen 50 Thlr., Rumftblumen und Sd)mufféteru 34 , fpảter 30 Thlr., anbere furze, (Salanterie: unb Duincaillerie:23aaren $2 c$. 25, von 1865 an 15 Thlr., - fertige ßelzwaaren 22 Thlr., Eigarren

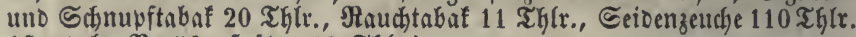

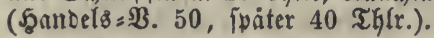

Defterxeid. Feinfte Baumwollen=, Reinen=, SBollenwaren, (Bold: und Gilber=, feinfte furze $\mathbb{B a n r e n , ~ f e i n e ~ S e i b e n t w a n e n ~} 250$ fi., fertige Rüridjnerwanten $100 \mathrm{f}$. Die früheren 3olle waren weit höher, 3. B. Stidereien, Sdjminfe, gepolfterte DRobeln, feines \$orzellam, golone Dofen, Geibenburdüren 2c. $36 \mathrm{fr}$. vom Surtoen ober 60 \$roc., ver= goloete Sironleudjter 2992 f., leinene Ed)leier 1605 fl., Seisentwaaren 892 fi., Leinenbatift 535 fi., eble wohiried)ende Dele 187 fl., 230 ollen= zeuche 116 fi. - \$elzwaaren, leberne Şanbfhute, Seibenwaaren

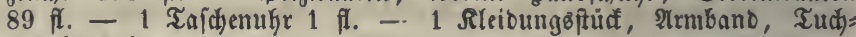
nabel $36 \mathrm{fr}$.

(5) robbritanien. Bis 1861 gaben Seibenfute bas Stüd 7 Sđ)., Geibentüll (net) Daв \$fund 10 ङळ. $=638$ fl. Der 3ollcentner, Geiben= bånber 5-10 ๔

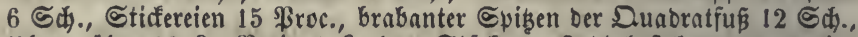
Uhren über 10 \&. \$reis $1 \mathfrak{\&}$. Das Stúcf $2 c$. Jebt beftehen nux twenige

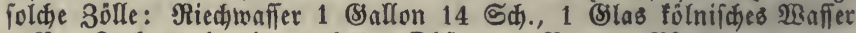
6 \$. , Sudferwerf, eingezudertes Dbft 2 . 2 \$. vom \$fund.

Sळtreiz. Die meiften Runftraaren 8 und 15 Fr., welded ber höhite Sollfas ift.

Der griedjifde Tarif yon 1857 beruht auf bem (Stumbią, yon Sohftoffen (beren jebod) mehrere frei find) 5 , bon Runftwaren in ber Regel 10 \$roc., nur von Ruxuswaaren mefir zu erfeben.

\section{§. 453.}

(Eime nadtheilige Fulge hoher 3alle ift ber Sthleidhan= bandel ( einen Theil ber 3olleimahme entjieft, \$. 413. Der Antrieb jul ify liegt neben bem getyofften Serwinn zugleid) in bent Reize einer gefährlidjen Rebensıveife, meldje, bem Siriege ober ber Sagb vergleidfbar, fowohl sift als Siraft erforbert unb ent=

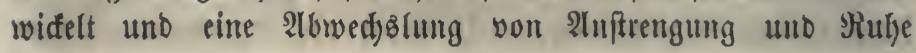


Darbietet. Die ftets fid erneuernben Sunftgriffe Der Sdyleid)= Gänbler madyen foftbare uno befdwerlidje (Segenanftalten noth= wentig (a). Die Sefabr bes Sd)leidjhandels ift geringer an Meeres = ober Stromgränzen, am größten in Sebirgs = uno Walbgegenden, ferner bei Waaren, yon benen eine gewifle (Sewidhtzmenge einen hohen \$reis hat unb hod) verzollt wirt, aljo bie heimlidje Einbringung anjehnlichen Bewinn bringt, wie feine Zeudje, Bänber, Uhren, Metallwaaren. Die Roften

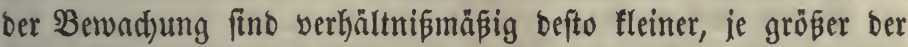
mit 3öllen umgränzte Fläd)enraum uno je fürzer bei gleidher

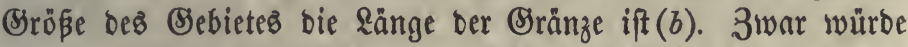
aud) bei niebrigen 3olfäken ber Schleich hanbel nid)t ganz ausz= bleiben, went bie Sränze nadtäffitg betwad)t wäre, aflein or würbe bod minber häufig unb leidfter zu verbüten fein, eż würbe baher eine größere Menge von $\mathfrak{W a a r e n}$ zur $\mathfrak{B}$ erzollung fommen, zumal ba man von ben wenig vertheuerten aubzlän= bifdyen 2 Baaren mehr verbrautdt. Deshalb hat bier, wie bei ber 2lecife, oft nach einer Errmäßjigung ber Säke bie Ěinnahme fich erboht, ober wenigftens nidjt um fo viel abgenommen, als man bătte fdhließ̧en follen, \$.417. Selbft bei gleidyem Ertrage für bie Stantżcaffe wären bie niebrigeren 3olljäßze vorzŭglid)er, weil fie einte 3unahme im $\mathfrak{B}$ erbraud) uno Sütergenuß ber 3ebrer verurfachen. (s)ut angelegte Sdjaķungen maden es möglid,

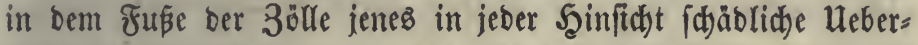
mañ zu vermeiben.

(a) Die \$ramie bes Sdjleidjhandels ift in Franfreida angegeben worben zu 4-10 \$roc. yon uhren, 10-15 ßroc. yon Rattunen in ber Rüften=

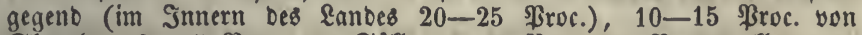
Shatols, $12-15$ \$roc. von Tül, 16-25 \$roc. von Baumwollengarn, 25 ßrcc. von Rirnftallglaż. Bgl. §. 417. - Villermé fils, Des douanes et de le contrebande. P. 1851. - Nan hat 1831 ben aus ber Geimlidjen (rinfugh entffandenen Berluft ber britifden Sollcaffe auf 11/2 Mill. \&. angeidjlagen. Mlac (E)

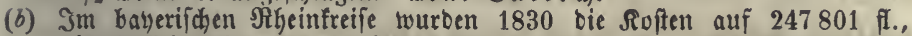

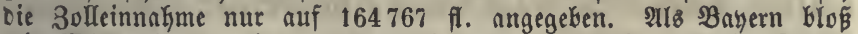
mit $23 u r t e m b e r g$ verbunden war, betrugen 1829 bis 1831 im D. Die Ėinnahmen 3.609823, bie 2lusgaben 1.603505 fl. voer 44 Froc. Des

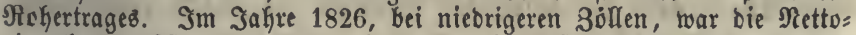

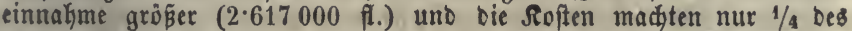
ganzen Ërtrages aus. SBerfandlungen ber bayerifhen Rammer ber 2tbgeorbneten yon 1834 III. Beilage 3 S. Seite 114. - Im beutifien Bollwereine fint bie Roften ber rerkebung uno Bewadjung an ben

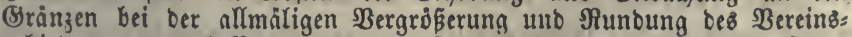
gebietes von 16,4 \$roc. (1834) auf $14,{ }^{74}$ (1836) und ppâter auf un= 
gefäry 10 \$ruc. Kertuntergegangen, vgl. \$. $445(c)$. Für 1862 beliefen

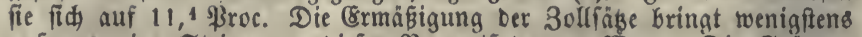
anfangs eine Steigerung Diefes \$rocentiakes zu 2 sege. Die Bränzen Deß Bereins haben 1066 Deilen \&änge, bei einem Flächenraume von

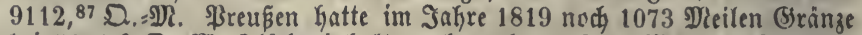
bei $5073,{ }^{8} \mathfrak{Q}$. $=92$. Fläbeninfalt zu betwaden. Sede Neile Brånze hat

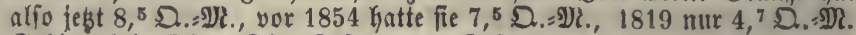
(Sebiet bei fich. Die Soften ber Srranzuerwaltung betrugen 1862 2665 Thlr. fur bie \$ieile, Dafer hat jebe D.= Meile 313 Thltr. aufs zubringen, wäkrend nach Diefem $\mathfrak{D a p j t a b e} 1819505$ Thlr. nuf fie gefommen fein würbe. SBäre ber Keutige Sollverein ein sireis ober ein Duabrat, fo hätte er nur 338 ober 382 Nieilen Bränzlänge uno

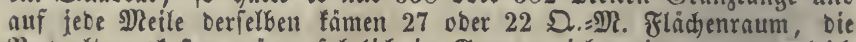
Berwaltungsfoften wären folglid, im Banzen viel geringer, wenn gleid nid)t genau in jenem Berbältnís, weil Dann jece (Sränzmeile aud ein

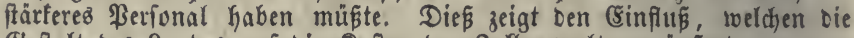
(S) falt Des Lanbes allf Die Roften ber 3ollverwaltung äǘert.

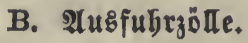

\section{§. 454 .}

3ölle von ber 2Yusfugr inlänbifdyer Erzeugniffe wurben in früheren 3eiten băufig angelegt, weil mast von ifnen eine an= fehnlidye Staatseinnahme erwartete, ohne über bie Wirfungen

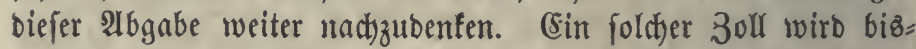

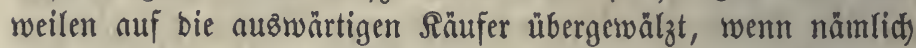
biefe bie Waare hod) genug fdäken, um fie mit ber bon bem 30 lle bewirften \$seiberhöhung zu bezahlen und fie anberswoker nidgt wohlfeiler ober gar nidyt beziefsen fömnen. Sime foldte

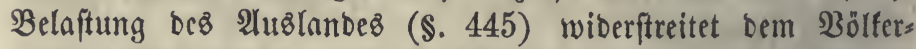
red)te nicht, benn fo wie ber (Einzelne befugt ift, mit Sewwinn zu verfaufen, wenn er baju (Belegenkeit finbet, fo fteht e\& aud)

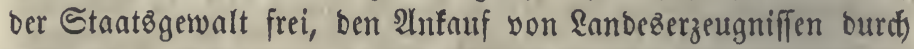
auşwärtige $\mathfrak{A b n e f m e r ~ a n ~ b i e ~ B e b i n g u n g ~ z u ~ f n u ̈ p f e n , ~ b a ß ~ f i e ~}$ Dabei eine 2lbgabe entricbten ober bem Berfäufer vergüten; allein bieje 9lapregel wirb bod) im 2luzlanoe alz läftig empfun= ben uno fann leid)t Erwiberungen herborrufen. Ferner ift bieje

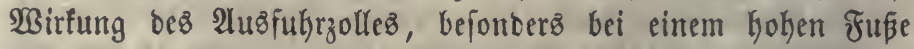
beffelben, unfțer, benn bie fremben fäufer werben burd) ihn angereigt, fid bie $\mathfrak{W}$ aare auf anberem $\mathfrak{W}$ ege zu veridtaffen ober ein Erfaşmittel aufzujuchen. Eelingt bieß̧, fo geht ein ein=

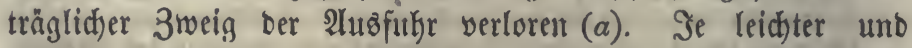
auşgebreiteter ber Şanbeläverfehr zwifchen ben $\mathfrak{B}$ ölfern und ie 
funftreidyer bas Sewerbetwefen wirt, befto weniger ift es ratt)= fam, Daß man in allzu feftem $\mathfrak{B}$ ertrauen auf einen Borfprung im Nitwerben bie 2luş fufyr mit 30̈llen bejchwere.

(a) Der शhusfuhrzoll yon ungefähr 3 Sch., ben bie Englånber 1833 auf

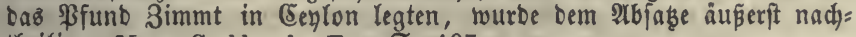
theilig. Ma c Culloch, Tax. ङ. 197.

\section{§. 455 .}

Selingt ben Berfäufern die Ueberwälzung bes 3ollez nidht, fo fälft er ifynen zur Laft. Err verliert bann bas $\mathfrak{W}$ ejen einer Aufwandz̧feuer unb bilbet eine auf biefen 3 weig bes aubs= wärtigen Şandeloె gelegte 2lbgabe (\$. 445), bie, wenn bie (Sewimufte nicht beträchtlich) fino, eine Berminberung ber 2 (ub = fuhr verurjadyt unb ben Sfreis ber ß3aare Keraborüdt. Die inlänbijcten Erzeuger berjelben fommen bieburch in Racththeil, währeno bie einkeimijhen Räufer einen Bortheil erhalten. Dies ift aud bei vielen 2lubfulyrölllen beabfitytigt worben, benn man wollte balb bie inlänbifdue $\mathfrak{B e r a r b e i t u n g ~ e i n c e ̨ ~ e i n = ~}$

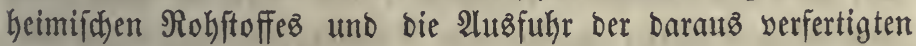
Bewerfizwaaren beförbern, bald wenigitenz ben 3efrern bie श्njchaffung eines unentbehrlichen (Sutes, wie Setreibe uno Şolz, erleidtern. Snt erften Falle ift es ein Edukbzoll, mur in entgegengefester Ridjtung, als bei ber (Sinfuhr. Die \$reiz= erniebrigung fdymälert ben Berwinn Der (Erzeuger, es entffeht baher ein Beftreben, Den belafteten 3weig ber Şervorbringung aufzugeben und oas 2lngebot fo lange zu verringern, bis bie \$reife wieber Göher geworben find. Befhieht bieß, fo wirb bie Beftimmung bes 3olles verfehlt und nur bie Aluşfuhr ohne NuBen berminbert. Dauert aber wegen ber Sdywierigfeit, einen (Semerbszweig zu verlaffen, Der niebrige Streiz nod) fort, fo fällt er hauptfächlich auf bie (Sinunbrente, weil foldbe 3ölle vor= züglid) bei Robftoffen vorfommen und bie (Srunbeigenthümer jener WSirfung am wenigften auşweid)en fönnen; es entíteht

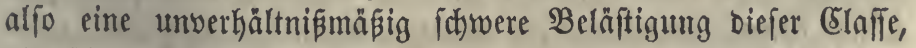

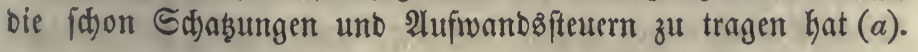

(a) In Grobititanien wurbe ber 1842 aufgelegte Ausfuhrzoll von Stcin=

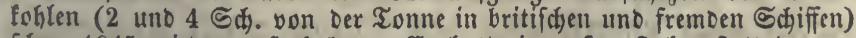
fajon 1845 wieber aufgehoben. (Er hatte im exften Jahre ftatt ber ge= Gofften 140000 nur 48000 \&. eingebradht. 


\section{§. 456 .}

3ur Begünftigung ber Bewwerfe ift biefes einem anberen 3weige ber Şervorbringung zugemutthete Dpfer fo wenig nöthig,

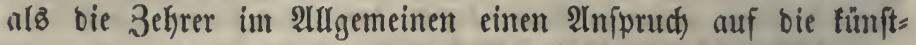
lid)e Erniebrigung bez \$reifez ifrer Bebürfnißmittel haben. Nur bei ben wettfuolffen Dingen, ober bei Stoffer, beren Erzettgung nicht beliebig uno fannell 'erweitert werben fann, wenn zuglcid) bie inländifde Radjfrage fidjon einen belofnen= ben Steis bewirtt, liepe fid) ein foldjer 3oll nod) etwa billigen, 3. B. ber mit ben \$reifen fteigende 2hเsfuftrzolf yon Betreibe (II, \$. 127), ferner cin fdjon beftehenoer 2 (u\&fullyzoll yon Şolz, wern beffen plöblidfe 2lufbebung ben 3ehreen fehre befdiwerlid fein würbe. Demnod) ift aud in biejen zälfen eine allmälige Berminberung unb eitre fpätere Abjdaffung ratbjam, bamit bie

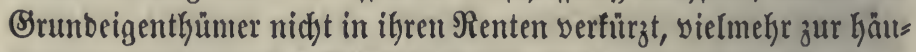
figeren Erzeugung bes 2husfuhrgegenftanbes ermuntert werben (a). Der 3olf von veridjiebenen anberen, nidjt nad) Bebủrfnis ver= mefrbaren Stoffer, z. B. von Rebenprobucten, twie Şäute, Thierhaare, Snodjen, - ober yon Ergeugniffen ber Sago ift zwar ber inlänbifd)en (Sewerbsthätigfeit wenig nadtheilig, ent= Gält aber immer eine unnỏthige Beeinträdjtigung Esinzelner. Der Scauptgrunt zur Bertheibigung foldyer 3ölle ift ifre $\mathfrak{B} e=$ ftehen in anberen \&änbern, mes benen be

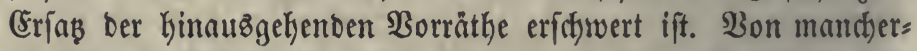
lei Dingen fint iebod) biefe 3ollte fitjon ohne Radtheil auf= gehoben worben unt man fann in ifrer शbidjaffung unbebent=

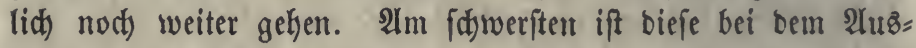
fuhrzoll von \&umpen (Şabern), weil bie vorkanbenen ßapier=

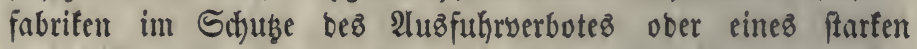
3ollez entfanoen fint. Şier wie bei anberen Ueberreften ber

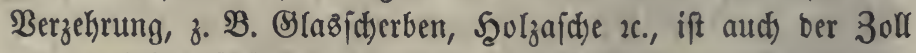
am wertigften fafäblid), ba er mur ben 2luffäufern foldjer Begen= ftänbe einen Göheren Setwinn entzieht. $2 g l$ II, \$. 128. 298 (a). Dieje Betrad)tungen zeigen, baß bie 2lußfuhtrzölle, mit wenigen unt unerkeblidjen 2 uşnahmen, nufgekoben zu merben verbienten, wohin audi) unverfenubar bas Streben vieler Regierungen in ber neueften 3eit geridjtet ift (b). 


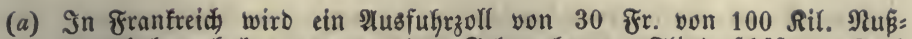

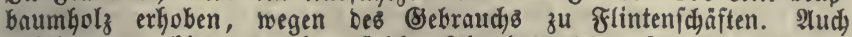
Lufrinde war bis 1860 einer folden 2 Gbgabe unterworfen, de Parieu III, 138.

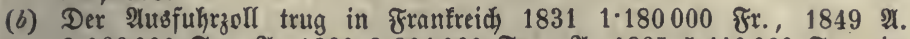
2.066000 frr., $\mathfrak{A} .18603 .804000$ Fr., A. 18655.410000 Fr., im

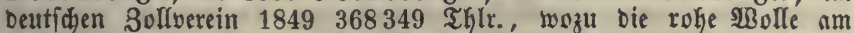
meiften beitrug; 1856226866 Thlr., 1857198013 Thlr. - 9ad

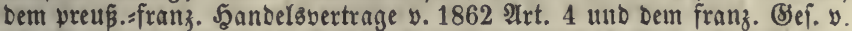
16. Nai 1863 befteht in Franfreich nur noch ein शlusfubrzoll yon nidjt wollenen \&umpen, ßapierkalbzetig ober grober ßappe 12 fr. von 100 Sil., ferner pon alten Sdhiffotauen 4 Fr., im Sollverein geben

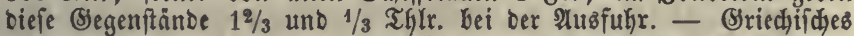

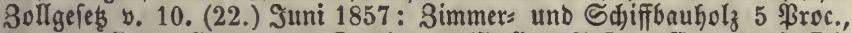
Baumbolle ber Centuer 1,5 Dradmen, 130 lle 2,20 Dr., Eocons bie Dfa (ca. 21/2 Bfo.) 0,7 Dr., ferner find Felle, Berberhaare, Bieh, Bein einem शtusfubrzoll unterworfen, aber biejer wirb je nad) 2 Sabren bei allen WBaren um $1 / 5$ ermäjigt, Gört alfo nad) 10 Sakren auf. - Sdweden, Tarif ๖. 7. Dec. 1860: Gartes Nubgolz 5 ßroc., ferner 3oll von

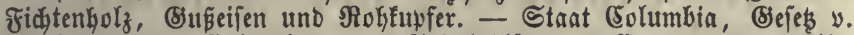
16. Det. 1861: Ehinarinde uno Tabafsblätter, 2 Sentavos vom Rilo: gramm $=1$ ßc. yom Eentner.

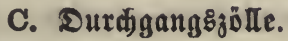

\$. 457.

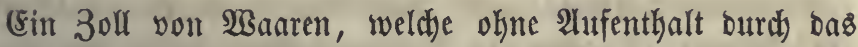

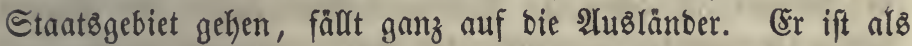

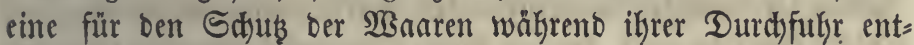
rid)tete (Bebühr anzufehen, bie, ohne ungeredyt zu fein, Dod) leicht ftatt ber beabfichtigten Begünftigung ber inlänoifden

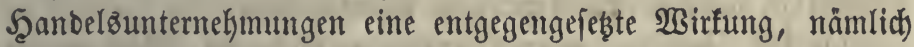
bie Sericheuctung bez $\mathfrak{W a a r e n z u g e s ~ a u f ~ a n b e r e ~ S ̧ a n b e l s ̈ f t r a ß e n , ~}$ verurjadyen faun, II, \$. 311. Wirb Der Durd)gangs = (Tram= fito $=3$ oll yon ben aus offentlicten ober \$ribat $=$ Rieberlagen wicber ausgefüfrten $\mathfrak{W a a r e n}$ erkoben, fo ift er eite Belaftung Des 3roifjentjandels und follte wegen ber Sdjwierigfeit ber Uleberwälzung ben Betrag einer Bebülyr für bie Befchäfte Der 3olrbeamten nid)t überfteigen. Nan barf baher ben Durd = ganggzzolf nidjt aus einem bloß finanzieflen Stanbpuncte bes trad)ten, fonbern imuß vielmekr aus (Srunben ber Bolfşwirth= (đ)aftopolitif feine 2lufbebung für vortheilkaft halten $(a)$.

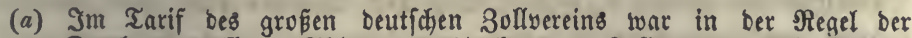
Durdagangsoll $1 / 2$ Thlr. $=52 \frac{1}{2}$ fr. vom Sollcentner, bei $\mathfrak{B a a r e n}$ aber, beren orin = und शxusfuhrzoll zufammen weniger ausmaht (wie

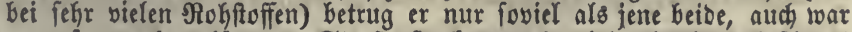
er auf manden fürzeren Straßenfitecfen nod viel niebriger beftimmt 


\section{$-304$}

(3. B. auf $1 / 2 \mathrm{fr}$, yom (Eentner) ober ganz aufgeboben worben. Da= gegen war er auf Strapen, weldje die ruffifiche ober polnifhe Eranze überfureiten, bei veridhiebenen $23 a n r e n$ hober, bis 7 f. vom Eentner. Ertrag $1848 \quad 316422$ Thltr., 1849472245 Thlr., 1856379985 ThIr., 1857382956 Thlr. Neuerlich ift bie Ruffebung aller Durdagangbzolle als wünfhensiverth anerfannt worben und bieje Dlaafregel if vom 1. Mnarz 1861 an ourd Uebereinfunft Der Bereinsftanten eingetreten. In Franfreid, ift Der Tranfitzoll nady ber $2 B a h l$ bes Ssigenthümers 25 Eent. von 100 Sil. ober 15 Sent. yon 100 Jres. Des sireifes ber

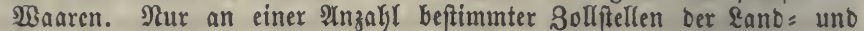
Geegränze fỏnnen Tranfitogüter ein= uno ausigeken, Die Durdffuhr ber Baaren, Deren Einfuhr verboten ift, ift nur auf wenigen \$uncten er: laubt. Droonn. v. 29. April 1831 unb neuere. - Deflerreid): Der Durdjganggzoll hat nur ztwei Säze, 15 und $6 \mathrm{fr}$. vom Centner Brutto, bie bon vielen 23 aren erfoben werden.

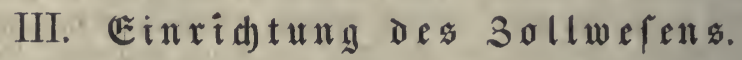

\section{\$. 458 .}

$3 \mathfrak{u}$ ber Entwerfung ber $\mathfrak{T} a \mathrm{rife}$ if eine volfftänoige uno

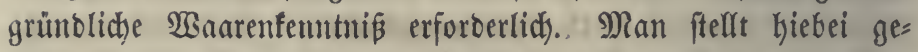

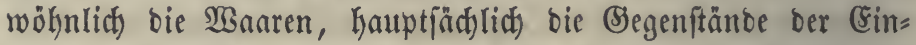
futbr, in foldye 2lbtheilungen zufanmen, bei benen aus Bründen Der Befteuerung ober ber Bolfşwirthf(d)aftapolitif ein gleid)er

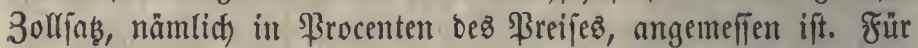

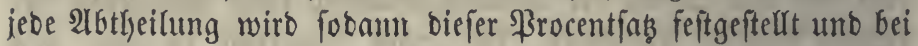
ieder $\mathfrak{B a n a}$ angattumg angegeben. Bei biejem Bejdyäte tommen

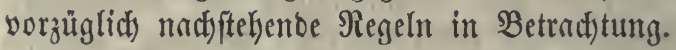

1) Die 3olfääze werben entweber nad) ber Menge ber verfenbeten Waaren (Setwidt), Stüfzahl 2c.) beftimmt (jog. ipecififche $30 ̈ l l e$, beffer Ma a

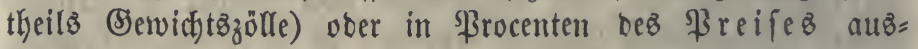
gebrüatt (ad valorem nad) ber englifften $B_{e}$ ejeiffuntug). Bei Baaren yon ziemlidy gleidjer Befdaffentyeit, wie eż bie $\Re 0 k=$ - ftoffe gewöbnllid fino, ift bie 3meffmäfigfeit oer Berzollumg nad) ber Nenge außier 3weifel. Bei Runftwaren, weldye ftarfe Abftufungen ber Feinkeit zulaffen, ift oft bie zweite Art ber Feftję̧ung bez 3ollez vorgezogen worben, weil nad) bem

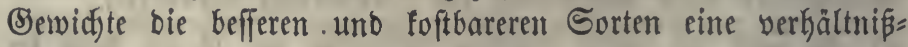
mäßjig geringere Steuer geben würben uno ifre Berfertigung geringeren Sdjug geniepen würbe, vgl. II, S. 214 (a). Die 3olrbeftimmung nad) bent \$reife hat aber ben Radtheil, baß 
Den 3ollbeamten nidft wohl ber gegenwärtige Mittelpreis jeber

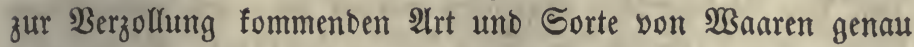
befannt fein fann, zumal ba berfelbe fich) oft veränbert, bie eigene 2 tngabe beż 3ollpflidtigen aber nid)t zunerläffitg ift, meil Derjelbe feines Bortheilz willen in Berjuctung ift, jeme zu niebrig

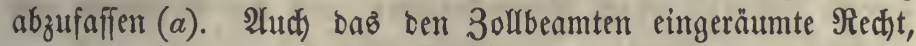
bie zu niebrig angegebenen (beclaritten) $\mathfrak{B a a r e n}$ mit einem gewiffen 3ufdlage, z. B. von 5-10 \$rocent, an fidt zut bringen (Borfauf, $\mathfrak{P}$ räemtion), bietet feine Ginreichenbe Sidjerkeit bar, wern nidst oft bayon (Sebraudy gemadjt wirb,

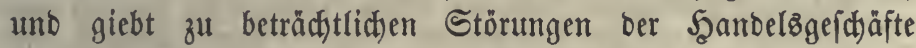

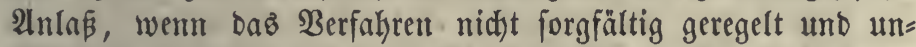

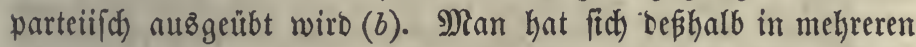
¿änbern bewogen gejehen, einen gewiffen unveränberlidłen \$reiz (valeur officielle) für bie 3olfentridtung vorzufdreiben (I, \$. $429($ b)), wab bann mit ber 3ollbelegung nad) bem (Se) wid) te 2 . bem $\mathfrak{B}$ ejen nad) übereinfommt. Dieje ift einfady,

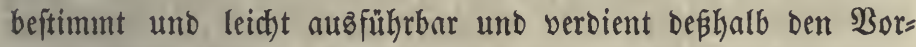
zug. Snffen fith bei Rumftiaaren Ieidft erfenmbare Unteriftei= Dungsimerfmale ber verichiebenen Sirnbe von Feinheit angeben, fo fönnen für mełrere Sorten aud) veridjiebene 3ollfäß̧e auf= geffeflt werben $(c)$.

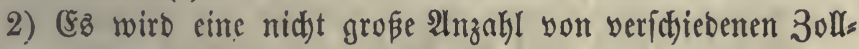
fäzen in bequemen 3 ahlen angenommen $(d)$.

3) $\mathfrak{B}$ enn man für alle nicht bejonbers benannten Begen=

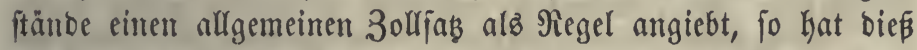

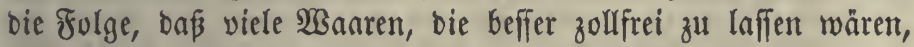
einer 2lbgabe unterworfen werben, und felbft wenn biejer all= gemeine 3olfaß̧ bie Erȫpe einer geringen Eebühr nidjt ủber= fteigt, fo ift feine Errbcbung zeitraubent unb bejdyerlid) (e).

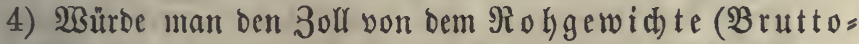
soer Sporcogewidte), b. h. Dem (Sewidhte Der Waare fammt Der Sacthülle, erheben, fo läge hierin eine Ungleidheit bei ver=

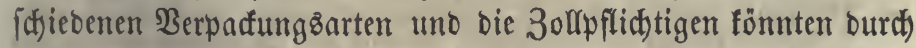
immer leidtere Berpactung bem Zolfe jum Theile ausineid)en. Nur bei fef)r nieorigen Tariffäßzen fömte man bié überjeken. Bei bökeren ift es zweefmäßig, a) nach den im Şandel ge= maditen Erfahrungen für jede 2 ret yon $\mathfrak{B a n t e n}$ uno yon $\mathfrak{B e r}=$ 


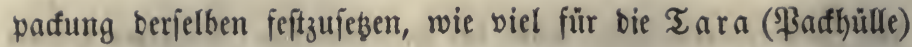
yon bem Rohgewidte abgezogen werben foll, um bas zollbare

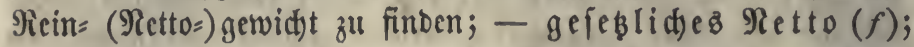
b) fowohl ben Bollpflidtigen als ben 3ollbeamten zu geftatten, Daß́ fie in einzelnen Făllen bas wirflide Reingervid) t

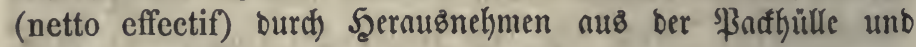
abgejonbertes 2(bwägen ausmitteln laffen $(g)$.

(a) \$reup. = franz. Scanbelspertrag von 1862 \$. 14: 88 foll ter \$reis am (8ntftehungs= ober \$erarbeitungsorte mit Beifügung Der Berienoungs: unb Berfidjerungs foften unb ber (Eommiffionsgebühr angegeben werten. -

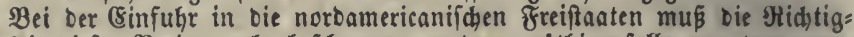
feit biefer \$reizangabe befdworen werben, nothigenfalls von tem ames ricanifien Conjul im ausführenben Lanbe. - Brafil. Bollgefes bom

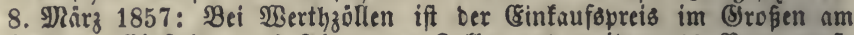

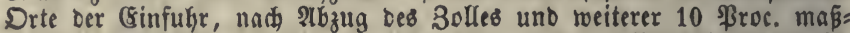
gebeno. Nad, $\mathfrak{B}$. v. 30. Juli 1850 fann aud Der \$reis im शusfufy = lanbe mit 10 ßroc. 3uidjlag genommen werben.

(b) Franfreid: : Birb ber an Drt und Stelle beftehenbe Narttpreis zu niebrig angegeben, fo fonnen bie \$aaren mit 10 ßroc. Sufdlag für ben Staat erfauft werben, worauf man fie auf গiedymung befielben verfauft. Bom Ssenvinn fällt bie Şálfte in Die Staatscafle, bie anbere Seálfite an bie ßenfionseaffe und dic mitwirfenten 3ollbeamten. Şo df ธ. 248. - \$reußs.= franz. Şancelsvertrag 2rt. 15-18. Borfauf mit 5 ßroc. 3uid)lag; ber 3ollyflidtige fann aber bagegen bie 21bidsäbung

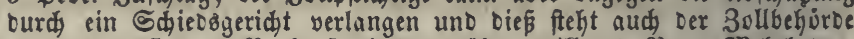
zu, twenn fie ber Borfauf nidt ausüben will. 5 \$roc. Nethrbetrag

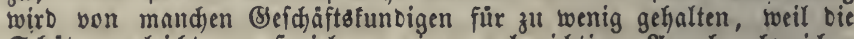
๔đảsung leidt um foviel bon einer aud ridtigen erngabe abweiden

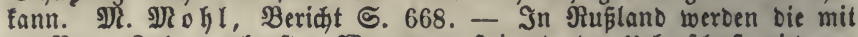

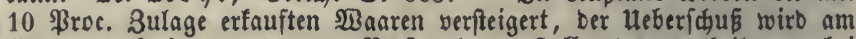
Ence Des Şahres unter oas ßerional Des 3ollamtes vertheilt, wobei Der 2nzeiger $1 / 4$ erbält. Brafilien: 5 \$roc. Suidjlag.

(c) Der Bereinstarif hat faft nur Säbe nad Dem (Setwidyte, außer bei Betreide, Şolz, Epiegelglas und Bieh. - In ben meiften Tarifen

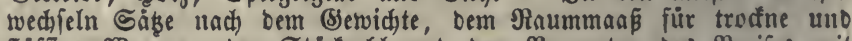

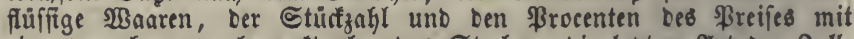
cinanoer ab, man bemertt aber bas Streben, bie lestere Art ber 3oll= fäbe zu befeitigen. In Erofibritanien wurben z. D. bis 1860 fünftlide Blumen mit 12 Sdfill. vom Eubicfue berzollt, ben man zu $3 \mathfrak{\&}$. St. anidlug. Tafdjenubren zahlten $1 \mathfrak{\&}$. bom Stũd, wenn baffelbe ůber 10 \&. zu fuázen war, lonft golbene je nach ber feinbeit 5 uno 15, filberne $2 \frac{1}{2}$ und 5 Sdjill., Stand= und $\mathfrak{W}_{3}$ anduhren (clocks) unterlagen

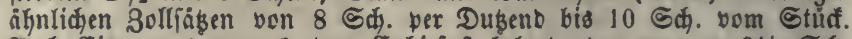

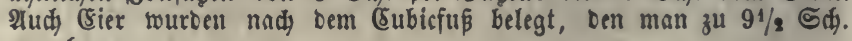
annahim.

(d) Der 3ollvereinstarif Gat 34 verfobiebene (Seldfäze, roorunter 8 unter 1 Thlr., 26 bon $1-110$ Thlr. \&\$ fint nur 43 Şauptnummern bon ISaarengattungen, beren jebod einige in viele unterabtheilungen zers fallen. Diefe (Einfabheit gewährt in oer Berwaltung großen Sortheil,

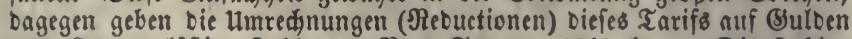
uno Rreuzer läftige Sahlen, z. \$. 4 Ggr. $=171 / 2 \mathrm{fr}$. D Die Sablen bes bab. Tarifs yon 1827 fiegen, wenn man aud bie Bulden in 


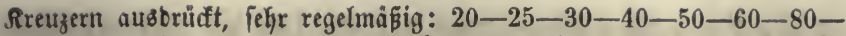
$100-125-150-200-300-400 \mathrm{fr}$, , wozu bann 1833 nod $600 \mathrm{fr}$. ober 10 fl. famen.

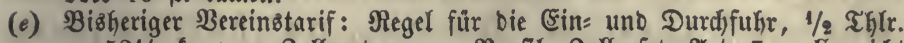
$=521 / 2$ fr. vom 3ollcentner. - \$Brafil. 3ollgefés 2rt. 7: alle nidt benannten uno nidjt nady Iefhnlidfeit mit einer anberen 28 aare zu behandelnden 3ollgegenftände geben 30 Broc. Des $\mathfrak{B} B$ erthes! - Rad bem nurbamericanifden 3ollgejes yon 1846 follten alle nidgt benannten Waaren 20 \$ruc. ad valorem geben: Der americanifache Tarif if ganz nad \$rocenten Des \$reifes im Ëinfuhrorte eingeridjtet. Der Gödffe Sab nah Dem Tarif yon 1857 ift 30 , yorher 100 ßroc. NBăhrent bes Butrgerfrieges von 1862 an fint bie 3ölle aniefnlich erfibgt worben.

$(f)$ 2elynlidie Beftimmungen find unter Den Rauffeuten üblid, unt Das

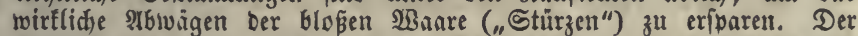
Tarafas if entweder eine 3ahl won \$rocenten, ober eine 3akl won \$fumben bei Berwarfungsarten pon äblider Beidjaffenheit uno gleidjer Quantität, 3 . $\mathfrak{B}$. eine Indigofifte $14-22 \mathfrak{P f D}$, eine Theefifte $18-$ 26 \$fb. (J2aure). - Jm Tarif bes 3ollvereins ift bei ben höher zu verzollenben $\mathfrak{W a n a r e n}$ bie Tara in \$rocenten angegeben, mit unters

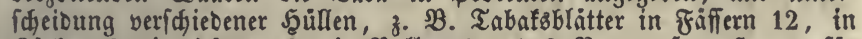

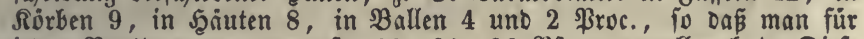
jeben Bruttocentner nur refp. 88-91-96 \$3F. zu verzollen hat. Diefe amtliç,en Tarafäze mưffen abgeänbert werben, wenn man wahtrnimmt,

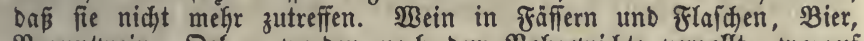
Branntwein, Del 2c. werben nach Dem Riohgetwidjte verzollt, worauf

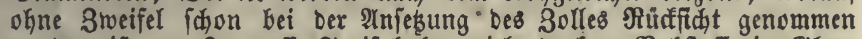
worben ift. - Im ruff. Tarif haben viele trodene Rokftoffe in Blas: oder Steingefïíen 20, in hölzernen 10, in Säfen 2-5 \$roc. Tara, Säuren, Sarbellen, Erüdyte in gläfernen ober fteinernen Befäpen fogar 40 ßroc.

(g) Beionbere Beptimmungen můffen verorbnen, was bei biejem \$bwägen als Tara abgehe, wohin $3 . B_{\text {S }}$ ßaduapier und Binbfaben, Einlages

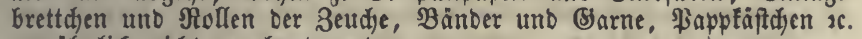
getwobntidh nidjt geredinnet werben.

\section{§. 459.}

Das 3olfwejen ift in ben europäijden Staaten von formeller Seite jefre aubgebilbet worben. Die Menge von Borfuriften. uno Beranitaltungen, bie auf bie fidhere Errbebung ber 3 olle abzwedfen, ftellt in ifyer (Sejammtheit ein funftreidjes verwideltes Syftem bar, weldyez nọch tăgliđ) verbolfitảnbigt wirb. Nan barf bei biefen (Einridtungen nidjt blop ben Bortheil ber Staats= caffe im 2luge haben, bielmekr mus man bedenfen, baß befdyer= lid)e Sebote unb Berbote mit Strafanbrofungen bie in ber Sröße ber 2lbgabe enthaltene \&aft vergrößern, web̧halb man bei jeber netuen Mapregel ben Madtheil für bie 3ollpflidtigen gegen ben Nuken für bie 3olleaffe abwägen follte. Soldue

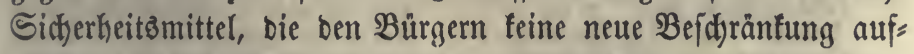
erlegen, fint beß̧halb vorzuglid) empfehlensiwerth. Die wid)tigs ften Anoronungen finb nadjftefienbe $(a)$. 
1) Es muß bafür gejorgt werben, baß̧ bie zollbaren Waarens jentungen, weld)e bie \&anbeg̊gränze überid)eiten, eine 3olls erbebungsftelle (3ollamt, Station, 3ollftätte) berübren. Şiezu bient bie (Errid)tung foldjer 3ollitätten an allen für ben bequemen $\mathfrak{B e r f e h r}$ mit bem 2lußlanbe biencrben Straßen (30ll= ftraß̧en), unt daz $\mathfrak{B e r b o t , ~ z o l l p f l i t y t i g e ~} \mathfrak{B a n r e n}$ auf anteren

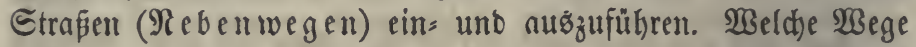
für 3ollftraßen zu erflären jeien, dieß́ ift in jeber Begend aus Den Bedürfniffen bes Şanbels zu beurtleilen. Llı ben Roftenaufwand zu verringern, pflegt man an ben minber leb= haften Strapen fdhwädyer beję̧te Zollämter zu erridjten, von benen bagegen aud imanthe widtigere (Gejd)äfte nidjt vorgenom= men werben bürfen $(b)$.

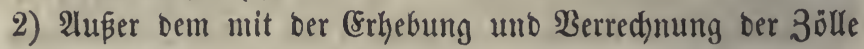

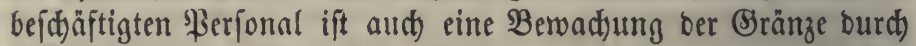
militairifa) organifitrte Nannid)aft nothwendig; beibe (Elafien von 3ollbebienten müffen mit vorzủglidjer Beartstung ber per= fönlidjen Eigeniftaften angeftellt, zugleid) aber, um bie $\mathfrak{B e r}=$ judung ber Befted)lidffeit zu idjwächen, gut befolbet uno ftreng beauffictitigt werten $(c)$.

(a) Die franzoffichen 3olleinridytungen fint bejonbers freng unt haben in anberen Ränbern mehr ober weniger Nadjahmung gefunben. Heberfidt Derfelben bei Block, Dictionn. Art. Douanes. - \$go ff 5.237. Im Deutichen 3ollverein ift bas jebt geltende 3ollgeies und bie 3oll= ordmung in jedem sereinsfante bejonders verfindet worben, mit ge= ringen शlbtweichungen, in ßreußen unter Dem 23. Jan. 1838, Baben

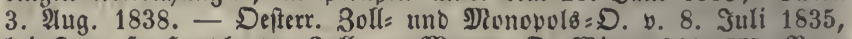

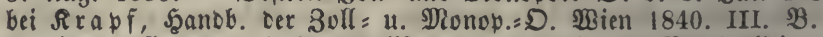

(b) Bereins = 3olloron.: 1) Saauptzollamter, weldhe in Der Fegel allein Die Durdjgehenoen $\mathfrak{B}_{\text {naren }}$ und biejenigen eingehenten, Die an inmere 30ll: Aemter getwiefen werben, behanceln burfen. 2) গeben $=30$ llamter

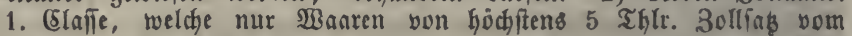
Gentner, ober hofher belegte nur bis zul einem nidyt hiber 50 Iflt. gehenben 3ollbetrage zu behanbeln Gaben. 3) Neben=3ollamter 2. (El., für ben fleineten Sräzberfehr, die feinen 3ollbetrag über 10 Thlr. von einer Labung beforgen burfen. Şiezu fummen Injagepoften. Das

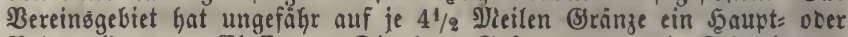

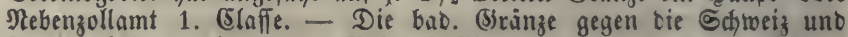
Frantreich hat 10 \$a aupt=, 17 গeben=3ollämter 1 . uno 34 bergl. 2. Elaffe, nebft 8 Anmeldepoften, welche gleichfalls bie Befugniffe oer Neben= 3ollänter 2. Slafie haben. SRechnet man ohne bie fleineren Rrümmungen Diefe Brảnze zu 60\% \$ieilen, fo fommt ungefähr auf jede Neile ein 3ollamt, ofne bie Inmeloepoften. In einem Şaubt=3ollamte if ein

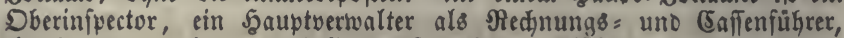
ein Sauptcontroleur angeftellt, nebit mefreren 2(fiñftenten.

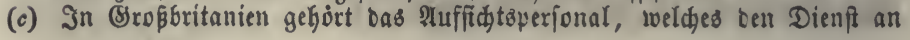


Den Siüfen zur See verridhtet, zur Sriegsfeemacht, uno biefe Trennung ift bem Ërfolge Ginberlid,. B ailly, Exposé I, 313.

\section{\$. 460 .}

3) Ėz würbe ben Sdjleidthanoel feht erleidftern, wenn bie

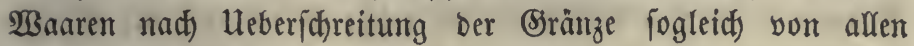
weiteren Nad)forid)ungen frei wären. Um aber biefe nidjt zu läjtig werben zu laffen, ift eś zweefunäfig, mur einen Streifen

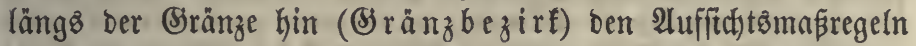
zu unterwerfen $(a)$. In biciem Bezirfe, Deffen Begränzung gegen baz $B$ innenland auf allen Straß̈en auf eine beutlidje

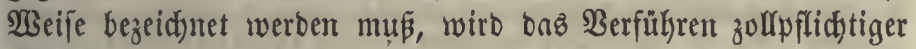
Waaren an getwifie Förmlidbfeiten gefnüpft $(b)$, audb müffen bie hier aufäffigen Fabrifterren und Sinfleute unter einige

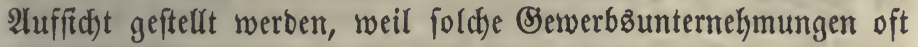
zum Salleidfhandel bemuţt werben $(c)$.

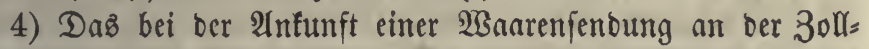
ftätte eintretenoe $\mathfrak{B}$ erfahren begreift folgente Şandhungen in fid :

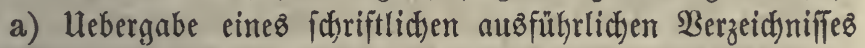
ber $\mathfrak{B a n a r e n}$ burd) ben Führer Derfelben, $\mathfrak{B a} a r e n a n z e i g e$,

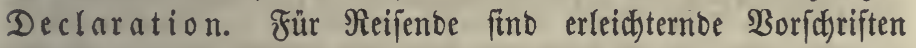
nöthig $(d)$.

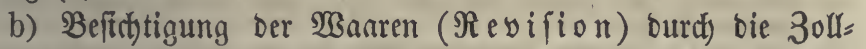

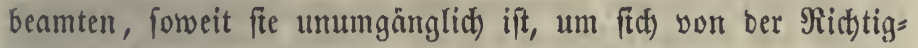
feit ber 2lngabe zu überzeugen. Sie gejhieht in Segenwart bes

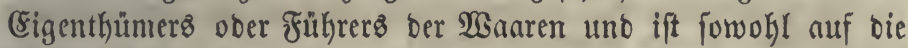
Mentge als auf bie Art beríflben geridjtet. Şiefei, wie bei ber ganzen 3olfbehanolung, müffen bie Beamten verpflidtet merben, gegen bie Eigenthümer und Fühther ber 2 Gaaren fajonent unt gefällig zu Werfe zu gehen, forveit es of ne eine Berfürzung Der Zolleintünfte geidhethen fam (e).

c) Bered)nung bes f(d)uldigen 3ollbetrages nad) bem Tarif.

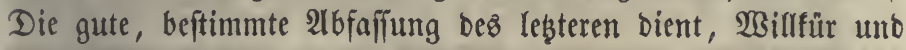
Itngleidfförmigfeitent zu verhüten. Im Falle einez Streites zwifthen ben 3olrbeamten uno ben 3ollpflidftigen über ben anzuvenoenten Tarifīas hat eine böhere Beförbe zu ent= idjeiben $(f)$.

d) Bezahlung $(g)$, Beideinigung uno Berrect)nung bes 3oll= betrngez. Die Errhebung von Rebengebühren für verf́djiebere 
(Sejdäfte ber 3ollbeamten ift nidht zu billigen, weil Daburd) bie 2uszgabe über bie bei ber Entwerfung bes Tarifs bejd)loffene (Sröße vermehrt wirb und bejonbers bie (Eigenthümer ber nicbrig belegten $\mathfrak{W a a r e n ~ v e r b a ̈ l t n i ß ̄ m a ̈ p i g ~ z u ~ f t a r f ~ b e l a f t e t ~ w e r b e n . ~ E i n e ~}$ 2lusిnafyme madben (Sebülyren für foldbe Berrichtungen, bie zur (Erleid)terung Desె 3ollpflidtigen übernommen werben $(h)$.

(a) Die Breite biefes Sränzbezirfes ift veridieben beftimmt. In Franfreid) an ber \&anbgränze 20 Silometer, an Der Siufte nur halb foviel, babei reidft aber bie 2luffidut noch 20 Rilometer $(2,7$ D. Neilen) ins Neer; Rỏnigreich Stalien feit 186210 sil. ins शleer uno 2 Sill. yom 11 fer lanbeinwärts. Im beutichen 3ollverein fino ebenfalls zwei \$leilen als

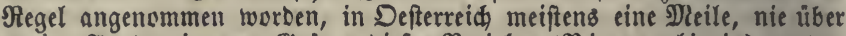
zwei. $\mathfrak{A n}$ ber inneren Sränze biejes Bezirfeళ (Binnenlinie) werben ofters controlpoften erridtet, um bie an ben Esanzzämtern behandelten Waaren nod)mals einer oberfläb)lichen $B$ efidjtigung zu unterwerfen.

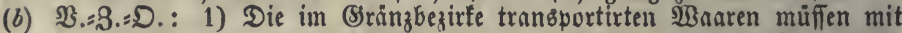

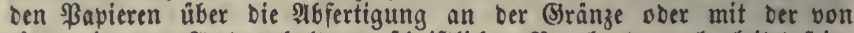
einem inneren 2 imte erfyaltenen fapriftlidjen $\mathfrak{B}$ eurfunbung begleitet fein. S. 83 ff. - 2) Baaren, welde nidst auf biefe $2 B$ eije bei einer 3oll= ftelle befanbelt wurben, bưren nidt ohne einen \&egitimations= id) ein, ben eine 3olffelle, ber Srtsoorftant oder ein Raufmann ober Fabricant felbft ausfellt, verjentet werben, §. 87. Dods wiro biefe Bedingung nur bei benjenigen zollbaren $\mathfrak{B}_{\text {Baaren }}$ geforbert, cie für ben

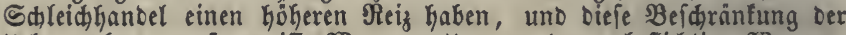
Heberwadjung auf gewiffe $\mathfrak{B a a r e n g a t t u n g e n ~ ( c o n t r o l w f i c h t i g e ~} \mathfrak{B B a}_{\text {Barem, }}$

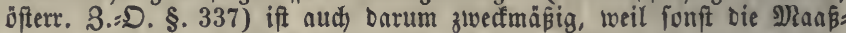
regel unmöglid, pünctlid genug ausgefügrt werben fönnte. - 3) Der Transport barf, außer burd, bie \$oft, nur in ben Tagesftunben ge= idjeten, \$. 86.

(c) $\mathfrak{B}_{.}=3 .=D_{.:}$Soldhe Betwerbtreibente fönnen angegalten werben, úber

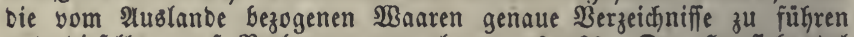
und biefelben auf Berlangen borzulegen. \$. 88. Der Şaufirthandel

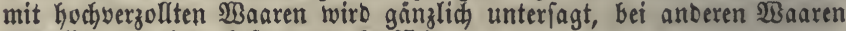
unterliegt ex einer befonderen 2 uffifitit.

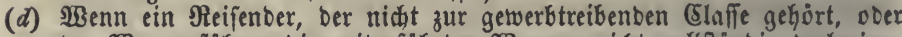

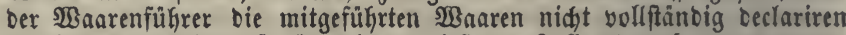
zu fönnen verfichert, fo übernimmt biés Das 3ollamt nach vorgenomme=

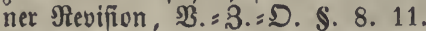

(e) Shieker gehören bie sBeftimmungen über bie förperlidje Durdjuchung.

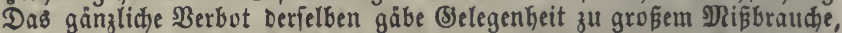
aber aud bie willfürlidye शnmenbung if nidjt zu bulten. Nads \$. 39 bes 3ollgejeges fann berjenige, welder burdfitudt werben foll, verlangen,

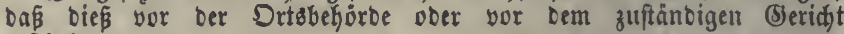
geidelye.

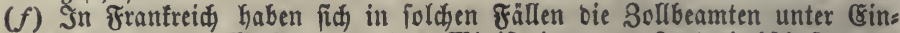
fenbung von Muftern an bas Minifterium ber \&anbwirtbifaft, Des

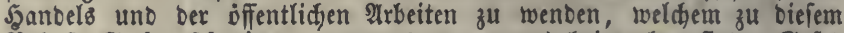
Behufe Saduerftänoige (commissaires experts) beigegeben fino, (Befés

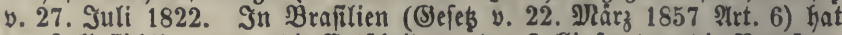

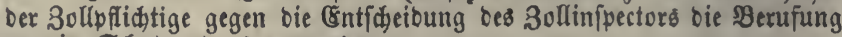
an ein Sdiakamt, thesouraria.

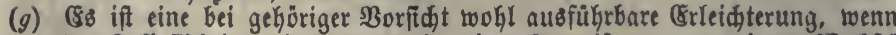
ber 3olfpflidtige bie Summe in einer Antweifung ober einem $23 e d f e l$ 
entridten Darf. In Srobbritanien ift es exlaubt, 2ntweifungen (cheques) auf fidere Banten an bas 3ollamt abzugeben, welde unverzughtid, bie Ilcceptation beifeben; worauf bie Inweifung yon ber englificen $\mathfrak{B a n f}$ auf Reduung Des Traffaten an Das 3ollamt bezahlt wirb; Die Bant bon ernglano hat aud befonbere customs-cheques eingeführt, bie fich Der 3ollpflidtige veridaffen fann unb Deren Betrag bas 3ollamt yon jener Banf eincaffitt. Die exfigenannte Einridgtung befteht feit 1862 nud im Sinnigreich Stalien.

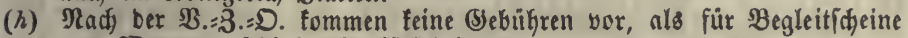

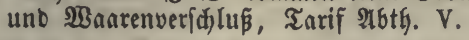

\section{§. 461 .}

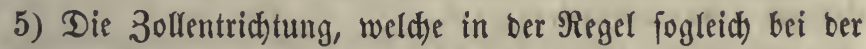
(sinfubr gefdeben mus, fam in gewiffen Fällen zur (Erleid)= terung bes Berfehrs hinausgefchoben ober ganz befeitigt werben.

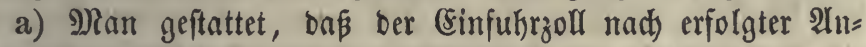
zeige, Unterfucf)ung uno Berechnung an ber Eränze erf́t bei cinem inneren 3ollamte in ber Nähe bes $\mathfrak{W o h n o r t e s ~ b e r ~} \mathfrak{W a a r e n}=$ empfänger bezahlt wirb, wobei bafür geforgt werben mus, bá

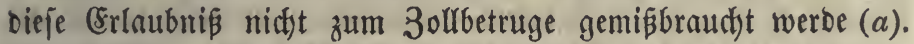

b) Die genaue Beftatigung und bie Berzollung fann in offentlicten Riederlagen (agerhäufern, Badhöfen, S马allen, entrepôts) gefdueben, in weldye bie (Einfuhrgegen= ftänbe von ber Sränze aus gebradjt werben. Dlyne biefe Ein= ridstung müpte ber $\mathfrak{W a a r e n e m p f a ̈ n g e r ~ e n t w e b e r ~ a n ~ b e r ~ S i r a ̈ n z e ~}$ einen Bevollmächtigten auffitflen, ober bie $\mathfrak{B a a r e n}$ bei ber Eröffnung ber Frad)títüfe blop Dem Fubrmann ober Sdjiffer

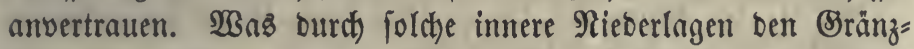
orten wegen ber geringeren \&ebhaftigfeit bes Spebitionsagefdäftes entgeht, dos gewinnen reid)lid) bie (sinwohner ber inneren \&anbegrgegenden, inbeß faun man ber Foften willen mur an ben lebhafteren Şanbeläpläß̨en foldhe Rieberlagen erridyten (b).

c) Die Rieberlagen, fowohl an Bränzorten ala im Snnern, gewähren ben Sinufleuten aud) ben Bortheil, bie 2 aaren fo lange unverzollt aufbetwahren zu tönnen, bis fie verfauft wer= Den uno in Den $\mathfrak{B}$ erbrauch übergehen.

d) Die Rieberlagen bienen feruer zur Beförberung bes

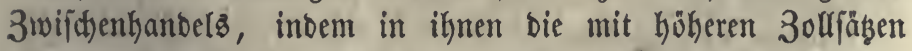
belegten $\mathfrak{W a a r e n}_{(c)}$ umverzollt gelngert, fortirt, umgepaft unb

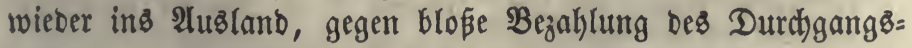
golles, wo berjelbe nod befteht, verfendet werben fönnen, 
II, §. 308. 309. Sie ftellen ein im Innern bes \&anbes bes

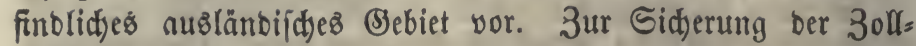

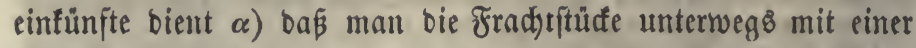
ungebung verfieft, bie es unmöglid) mad)t, fie unentbeft zu

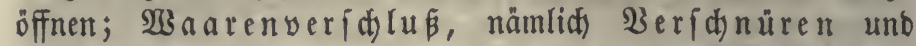
Berbleien, Blombiren; $\beta$ ) bá̈ ber Waarenfübrer bie Şaftung für ben Eingangazzoll ober bie etblieferung in bie Nieberlage ober bie 2luzfuhtr übernimmt uno nöthigenfalls hier=

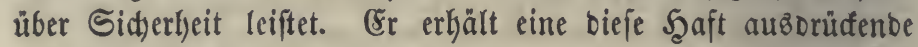
Urfunde, Begleitidein $(d)$.

e) Etatt ber öffentlid)en Rieberlagen fönnen, unter gehörigen

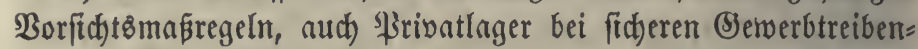
ben bewilligt werben, II, \$. $309-(e)$. 2Aehnlid)er 2 rrt find

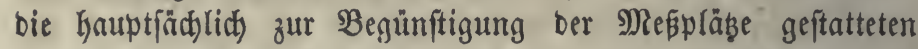
Contirungen; es erbalten nämlidy fichere (srob̧bänoler bie Berwilligung, frembe, einem böheren 3ollfabe unterliegertbe Baaren nad) genauer Revifion einftweilen unverzollt zu fid) zu

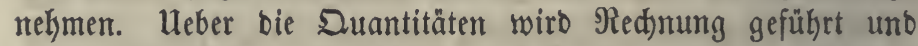

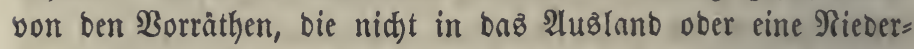
lage geführt werben, wirb ipäterhin ber 3olf nadigezahlt $(f)$.

f) Bei beträdttlidsen Summen fann ben 3ollp flidtigen, weldte gefjörige Sidferbeit barbieten, bie Bezahlung auf gewiffe 3eit gefriftet werbert; 3ollereoit $(g)$.

(a) $\mathfrak{B} .=3=$. D. \$. $50-53$. Die $\mathfrak{B}$ aaren gehen unter einem Begreitficein

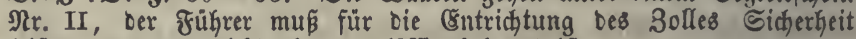
leiften, wenn er nicht als zuberlấfíg betannt ît.

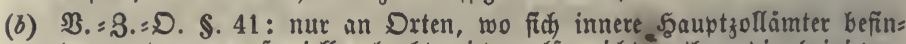
ben uno wo es fipeciefl erlaubt wirb, alfo nidst nothwendig bei jeiem

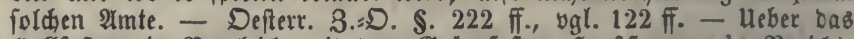

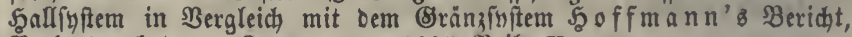
\$̇erh, Der bab. 2. Rammer yon 1835 Beil. V.

(c) $\mathfrak{B} .=3 .=$ D. §. 25. 41. 59. Nur Raufleute, Spebiteure uno Fatrit= Gerren habell Das Nieberlaggrecht. - Die britifden Saupthäfen Gaben grope, feuerfeit gebaute docks, unter benen fich aud gerảmige Refler

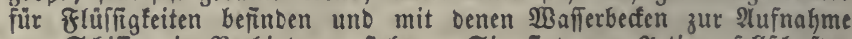
bon Sififfen in Berbinbung ftehen. Sie fino yon Plctiengefeldidaften erbaut worben.

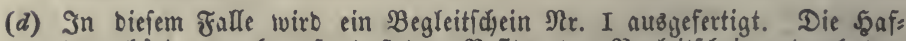

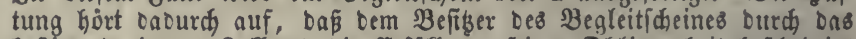
beftimmte innere 3ollant bie Erfüllung feiner Dbliegenfeit befacinigt wirb. Der Begletthein twiro nuf getwiffe Seit, wie es bie Entfermung ber beiben Suncte exforbert, hodiftens $4-6$ Donate, ausigeftellt.

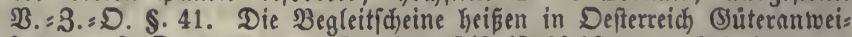
fungen, 3.:D. \$. 122. - Die \&agerfrift ift hodgftens zwei Jahre, Das 


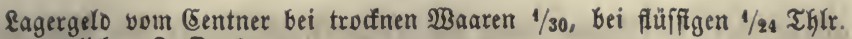
monatlich. 3.:D. §. 61.

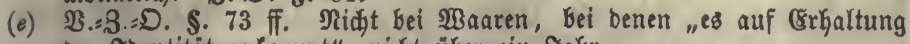

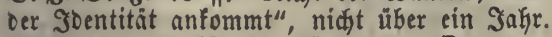

(f) DRejoronungen für franffurt a. D. D., 31. NRai 1832, unb Reipzig,

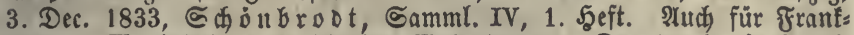
furt a. D2. Befteht eine ähnlide Neforonung. Der burds bie Conti= rung bezwedte Crebit für bie 3ollgefälle twirb in ber Fegel nur auf

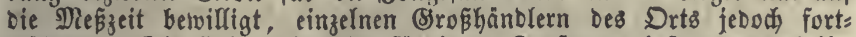
während. Die Errlaubnis wirb für jeden Saufmann befonders ertfeilt. Die 3ollbehörbe fann für bie creditirten 3ollgefälle Sidjerkeit forbern.

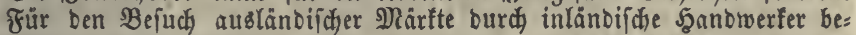

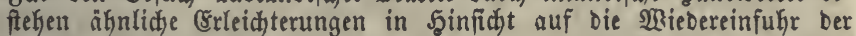
unverfauften $\mathfrak{B}$ orräthe, $\mathfrak{B} .=3 .=5 . \$ 78 .-30 l l c r e b i t$ für bie 3uder= fiedereien in Defterreid auf ein \$ahx, 3.5. \$. 218. I rapf I, 371.

(g) Franfreid): bei Summen über 600 Fr., auf 4 Monate. Bei augen= blidflicher 3ablung genieß̧en bie 3ollpflichtigen bei biejem Betrage einen Natabatt von 4 Sroc. für Das Sahr. - Auch im 3ollvereine geniésen Raufleute uno Fabrifferren, bie jährlic wenigftens 3000 Thlt. Soll entrichten, einen Crebit bis auf ein Jakr.

\section{§. 462 .}

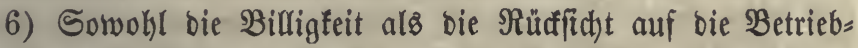
famfeit uno bie Bequemlidfeit ber Stantżbürger, bejonberz zur

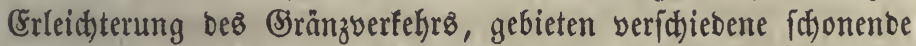
Beftimmungen für foldte Fälle, wo ber 3 wed ber 3olferbebung megfärt. (Segenftänoe fold)er Aus̈nahmen find u. a. Eleine Suantitäten zollbarer Wraren uno Begenftänoe, bie fijon in ben (Sebrauch) übergegangen finb $(a)$, ferner fold)e Senbungen, weldje feine wafre (Sinfuhr bilben, inbem 2 saaren blö ber Berarbeitung willen Ginaus unb fpăter umgenrbeitet wieber herein gehen, ober aud umgefehrt $(b)$, fodann fijon verzollte Waaren, weldhe alf bem $\mathfrak{W e g e}$ von einem inländifd)en Drte

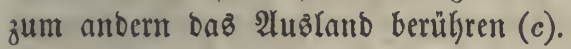

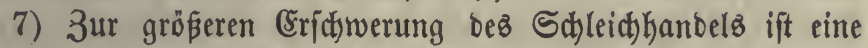

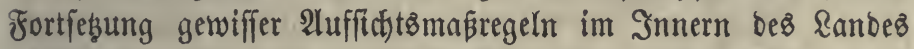
nöthig befunben worben. Dieje Binnenüberwad)ung (Binnen= controle) jollte wenigitens auf biejenigen Waaren, Fälle, 3eiten uno Begenden eingefdränft werben, bei benen fte für

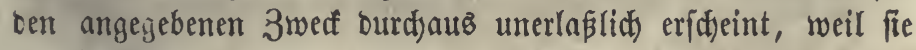
ben $\mathfrak{B e r f e h r ~ i m ~ S a n b e ~ e r j a f w e r t . ~ D a s ~ S ̧ a u p t m i t t e l ~ b i e f e r ~ i n n e s ~}$ ren Ueberwachung ift bie Borfdyrift, Dá gerwiffe hodbelegte $\mathbb{B}_{a}$ aren in größeren Duantitäten nid)t verjenbet werben bürfen, ofne Daß Der Berfenter ifnen einen Fradtbrief mitgiebt, ben er porber Dem Steueramte zur Einficht und Stempelung vors 
gelegt hat, ben bann aud) ber $\mathfrak{B a a r e n e m p f a ̆ n g e r ~ b e i ~ b e m ~ n a ̉ d d = ~}$ ften Eteuerante ftempeln laffen muß $(d)$. Dieje MRaßregel wiro hauptfäd)lid) wegen bes zur Entbefung voridfriftşwibriger Sen= bungen zuläfitigen 2lnbaltens uno Unterfud)ens ber \&abungen läftig $(e)$.

8) Bei bem (Eintritt von Durd)gangø̊gütern mus onfür ges forgt werben, baß nidbt unter bem Borwanbe ber Durdyfufte bie Entrid)tumg ber CEinfuhrzölle umgangen werbe. In Ermanges lung anberer Bürgidjaften bleibt nidjts übrig, als bas allers bings für bie Manremführer brüđenbe Mittel, Den Einfufrzoll an ber Erränze erlegen zu Laffen, ber bann beim Wieberautstritte

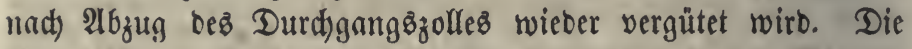
Durd)gefübrten Siüter werben veridjmüt unt mit bem Begleit= idjeine verfehen $(f)$.

9) (ङs giebt 3öle, weldhe ben inlänbijden Bsewerbsleuten bas Mitwerben auf fremben Mäften erfd)weren unb baher, ihrer Beftimmung zuwiber, ben nuşwärtigen 2 bfaß̧ gefähroen, wie bic 3ölle von eingeführten Berwandlungsftoffen. (5s ift

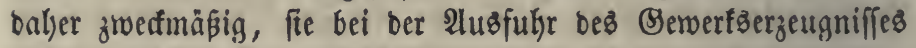

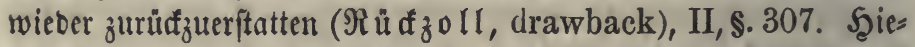
bei ift bejonbere Sorgfalt nöthig, um bie Rüfvergủtung für jeben (Eentmer ber Rumftwaare nad) Maßjgabe ber verbraudten Menge

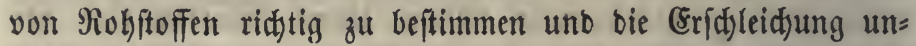

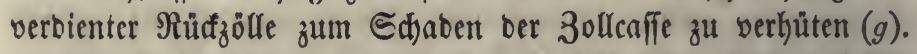

10) Daz ganze 3ollwejen múp io geregelt werben, Daß ber

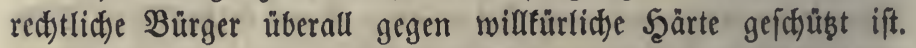
Strafgejege find unvermeiblid), bod) follte immer zwifden beabs

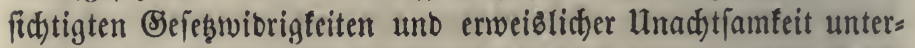

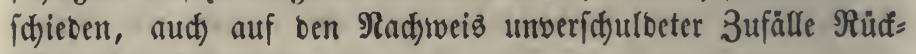
fidit genommen werben.

(a) 3. B. Borräthe, von benen ber Soll nicht über 1 Sgr. beträgt, ober bis zu 4 Rotben; (Sarben vou eigenthümliden ober gepadjteten \&edfern

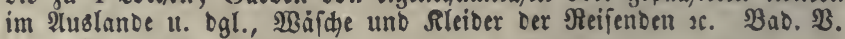
v. 3. Dec. 1835 .

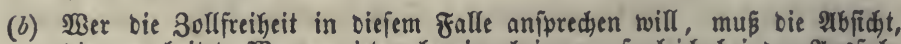

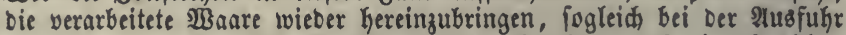
anmelben, aud Darf fein 3weifel baruber obwalten, baş bie nảmlidien

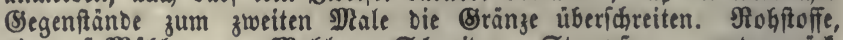
bie auf Mliklen zum \$lablen, Sdjneiben, Stampfen 2c. unb zurüd: gehen, ober bie zum Bleidhen, Spinnen, Fürben, Weben, Berben 2 . gejenbeten $\mathfrak{B a a r e n . ~ D a s ~ \Re a ̈ m l i d e ~ g i l t ~ y o n ~ B i e h , ~ w e l d e s ~ a u f ~} \mathbb{B}_{\mathrm{e}} \mathrm{iben}$ 
Des Nadbarlanbes gebraht wirb uno wieber zurüffefrt; ebeno. Deftert. 3. = D. \$. 222.

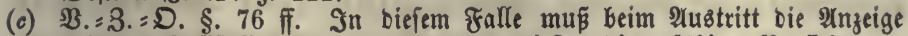
bei Der 3ollftelle gemadit uno von biejer bie nothige Borfidgt an= getwent bet werben.

(d) $\mathfrak{N a c h}$ ber $\mathfrak{B} .=3 .=$ D. S. 93 fi. finb ber Binnencontrole unterworfen: baumwollene Stublimaaren uno 3udfer bei Duantitäten ůber $1 / 2$ Centner,

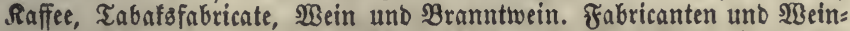

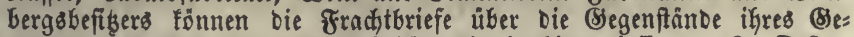
werbes auch blós bei ber Drtsbehörbe Feglaubigen laffen. - In Defters reid) beftehen ảhulidje Boridyiften für alle $\mathfrak{B a a r e n ;}$ fermer finb bie Bufferrafinerien แno Baumwollenipimereien befonbers überwacht uno bie Steuerbeamten befugt, bie \&ảben unb Borrathoråume ber Bewerf\$s: und Sandolsleute zu burdhiudien.

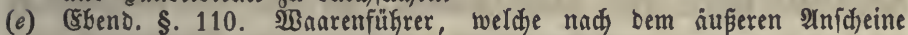
controlpfichtige Waaren fübren, fonnen aufgeforbert werben, 2ubfunft zu geben uno bie Transportzettel 2 . Dorzuzeigen, alth bie Enoung zur nákeren Befictigung an eine $30 l l=$ ober \$olizeiftelle führen zu laffen.

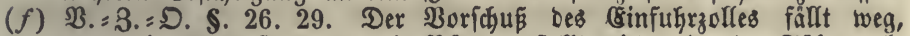
went ein Unterpfand ober ein Bürge geftellt twirb, ober ber führer als zuverláfíg befannt ift.

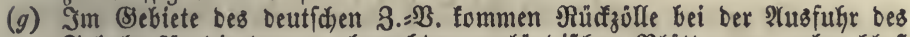

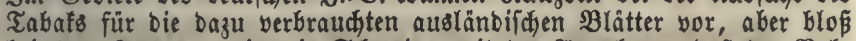

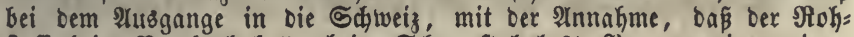

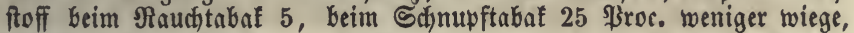
als Die fertige $23 a a r e,-$ ferner yon bem 3olle auf Nohzutfer bei ber शusfuhr von rafinirtem. - In Bropbritanien fommen nach bem Befes

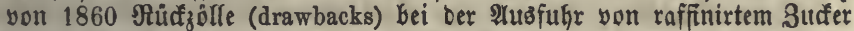
(171/6 Sdjill. vom (Eentnex ber beften Gorte), unb yon verarbeitetem

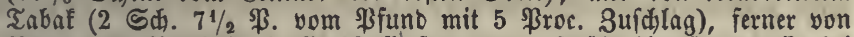
Nub: uno $\mathfrak{B a u b j o l z}$ (voller Bollerfab) yor. Fruhkerfin fanben fie bei mekreren $\mathfrak{W a a r e n}$ fatt. Sie beliefen fid 1858/59 auf 304025 \&. St.

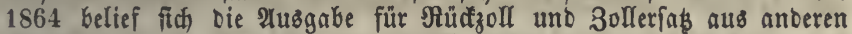
(5) rünben (3. $\mathfrak{B}$. Bef

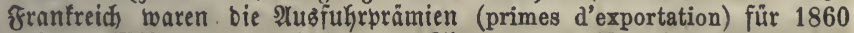
nuf 35 פNill. Fr. angefalagen. Sie wurben für eine Nienge von Sunftwaren naळ Ná̧gabe Der verbrauditen Stoffe gegeben, wozu

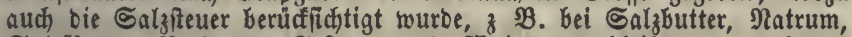
Galzfäure. Nach bem Befeb b. 16. Slai 1863 bleibt mur noch ber

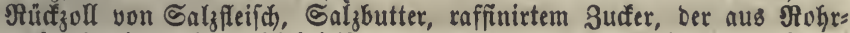

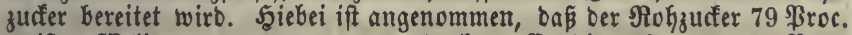
weifen פelis, quatre cassons uno trudnen (Eanbis gebe, ober 82 ßroc.

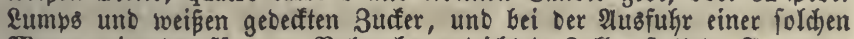

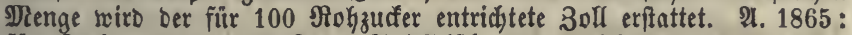
für Sudfer 42.205000 Fr., Salzfleifh uno Galzbutter 190000 Fr.,

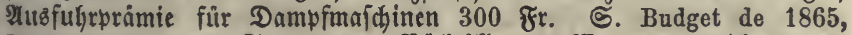

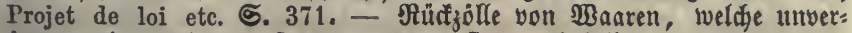
andert wieber Ginausgeiendet werben, finb entbehrlid, wenn man bas Syftem ber unverfteuerten sieberlagen annimmt. 


\section{Drittes 3uth.}

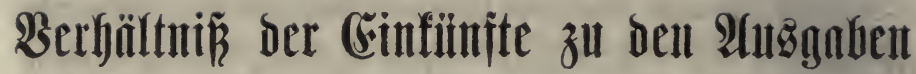 bes Stmats.}

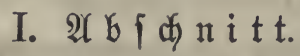

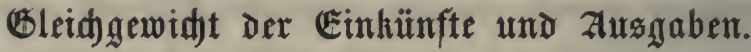

§. 463 .

Sebe Stantzantżgabe fekst eine fđu) früker ober wenigftenz furz zuvor in bie Stantzonfie gelangte entiprectienbe (Sinnahme vorauz. Daker ift fdon von älteren Edyriftftellern (z. B.

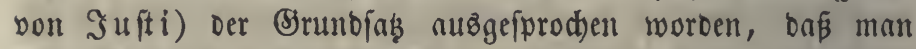

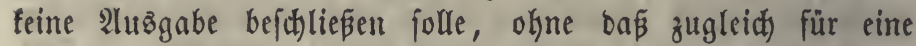

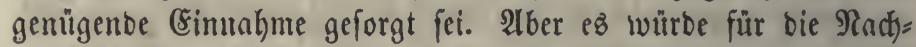
haltigfeit im Finanzwejen (\$. 7) nicht hinreidjend fein, wenn man bie Selozufluffe (Einnahmen) olyne weitere Unterfocibung zur Beftreitung ber gleidzeitigen ober wenigftenz bem näulicten

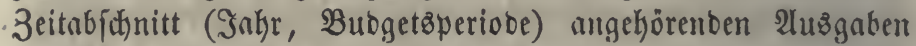
anwenten wollte. Rur folde (sinnathmen, weld)e nid)t mit

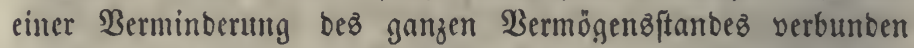
find uno raker weber bie Büterzuflüffe ber folgenten Iahre

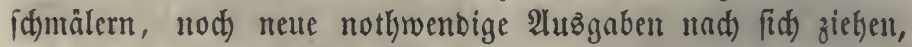

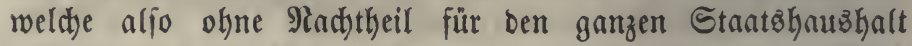
aufgezehrt werben fönmen, D. h. Die (E infünfte eines Jahres

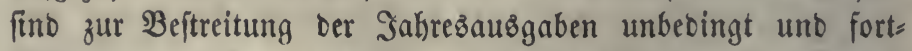
bauernb broudjbar, I, \$. 70. Die gute Dromung im Finng $=$ wefen wie in ieber Wirthidjaft wirb baher am leidjteften uno fidjerften aufredt erkalten, wenn ber 2 ufwand jebes 3eits 
abidnittes aus den in bemielben empfangenen Einfunften genommen wird und nid)t über bas Maá berfelben hinausageht $(a)$. Da aber mit jebem 3 weige oer Einfünfte gewifice nothwendige Roften uno \&aften zufammentängen, welche aus bem Crtrage ber erfteren borweg

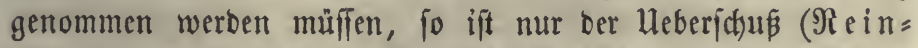
ertrag) beliebig für bie Staatzbecürfniffe verwenbbar. Sinb auz früheren Sabren überiparte Summen vorkanben, fo bieten aud) bieje zu Dem Stantвaufwanbe eines fpäteren 3eitraums eine Şülfe, bie aber mur vorübergebend ift. Sur Dam ift eв unbebenflid, über biefelbe ganz zu verfügen, wenn man ver= muthen fann, baßj autch ber Alufwano nur augenbliaflich biefe Mittel in Anprud) nehme uno in ber Folge wieber auf Das Maap Der Einfünfte herabfinfen werbe.

(a) 2uf foldhe 2tusgaben, bie wie eine Capitalanlegung wirfen, indem fie

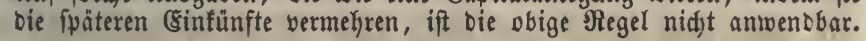

\section{§. $463 \mathrm{a}$.}

Eine Unz̧ulänglid)feit ber (Einfünfte zur $\mathfrak{B} e$ ftreitung Des be= (d)loffenen nitht werbenden Stantzanfwandes woird Deficit genannt $(a)$. Ein foldyer 3uftano barf nidyt regelmäß̈ig vor= fommen. Er entfteht außer ben Fällen, wo eine Regierung zu gropen Berbefferungen Inleifyen Durch) freien $\mathfrak{B} e$ (d)lü zu Şülfe nehmen zu Dürjen glaubt (\$. 474), zufolge zwingenber Umftände, nämlid) bald auz Der unerwarteten Abnahıne Der Einfünfte, bald auts bem Steigen ber nothwenbigen 2lusgaben, wozu Sirieggిrủitungen uno Siriege fowie Staaţินmwälzungen bie bäuftigte und ftärffite Beranlaffung geben $(b)$. Sönnten bie erforberlichen Selojummen nidgt zeitig herbeigefdafft werben, fo wäre bie Regierung auper Stand, bie befhloffenen unb bereits fällig geworbenen 3ablungen wirflid) zu leiften. Dießs wäre eine Ungeredtigfeit gegen bieienigen \$3erfonen, weldse redtlidue Anjprühe an bie Stantzecaffe haben, eళ̊ würbe biejelben zun Theile in Bebrängní̈ bringen uno bie Regierung bei fwäteren Berträgen über \&eiftungen zur Bewilligung böherer fłreife nöthi=

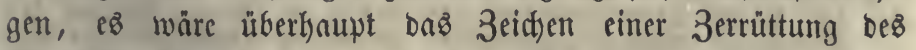

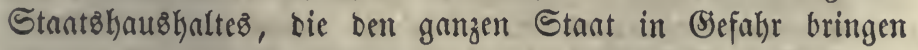
müste. Sn ber Eridjeinung eines Deficits liegt folglid bie

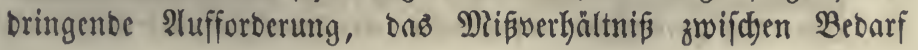


und Mitteln zu heben. (ङ) muß biezu vor Altem ber augen= bliaflidjen $3 e r l e g e n k e i t$ abgetjolfen werben, inbem man weitere Einnahmen aufbringt. Dieß fönnte gejd)ehen

1) burd) Angreifen besienigen Staatżvermögens, weldję ein bleibenbes Befibtlyum bitbet uno in fortwährenbem (Sebrauche feine Beftimumung erfüllt. Selten wiro fith Belegenteit bieten, eitre Menge von nid)t werbenten $\mathfrak{B e r m o ̈ g e n t h e i l e n , ~ w e l d y e ~ f u ̈ r ~}$

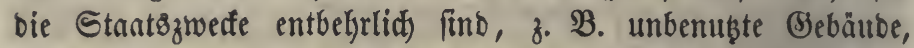
zu verăuß̧ern $(c)$. Der Berfauf werbenber Shüter (Ränbereien, Sebäube, Eifenbahnen mit 3ubehör zc.) verringert bas fünftige

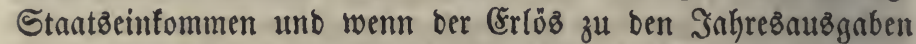

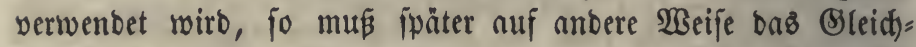
gewid)t hergeffellt werben, eริ müßten benn in biejen 2tużgaben aud) Anlegungen auf bauernbe swerbente Bermögenstheile in gleidjem $\mathfrak{B}$ etrage vorfommen (d). Soldye $\mathfrak{B}$ eräuperungen laffen

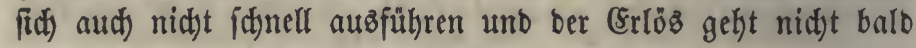
genug ein, um bie nöthige Şülfe zu gewähthen.

2) Durch Borgen. 2lud) vor ber näheren Unterfuctung

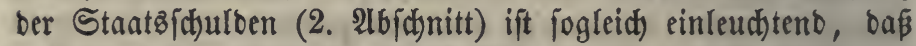
bas fortgeféste Betreten biefes $\mathfrak{W}$ eges mit ber Radjhaltigfeit ber 2 Birthjfjaft nidjt verträglid) ift (e).

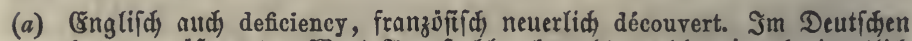

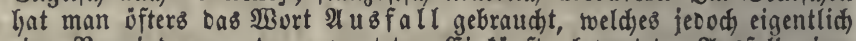
eine SBerminderung Der erwarteten Einfünfte beDeutet; PUusfall einer

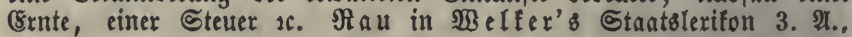
IV, 330. - Esin mäsiger Nethrbetrag Der 2turgaben wiro bisweilen

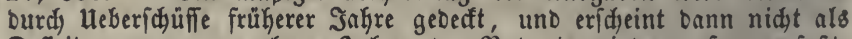

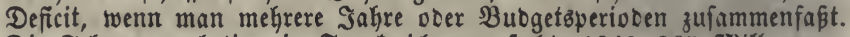

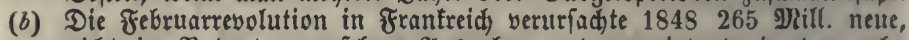

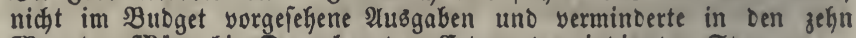

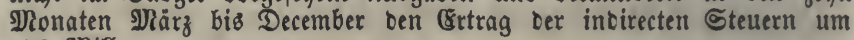
158 शitil.

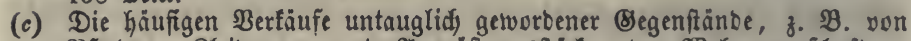

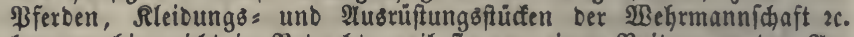

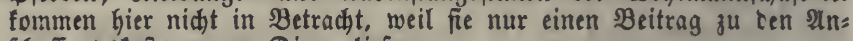
fidafifungsfoften neuer Dinge liefern.

(d) In Franfreidy wurbe 1831 unter \&afitte' \& Ninifterium zur शuff Eringung yon 200 शill. Fr., bie man zu aukerorbentliden शैusgaben nóthig hatte, ein Berfauf von ungefähr 300000 Seettaren Staatsforfen befdlofien, \&. $138(a)$. - ^. Stalien, f. (c).

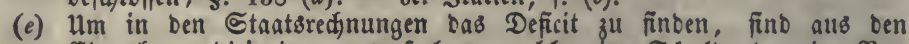

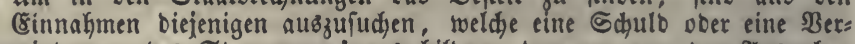
minberung bes Stammvermogens bilben, bagegen yon Den शlusgaben

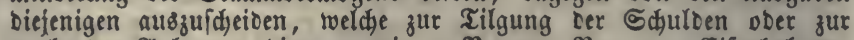

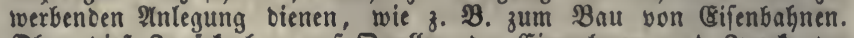

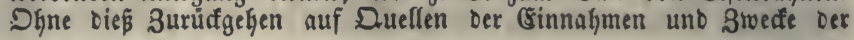




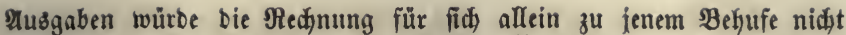
genügen. - Das Deficit Der franzififiden アegierung vor und nad Der

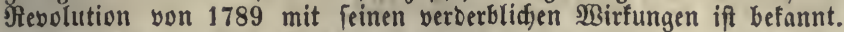

Defirere europaiiche Stanten Gaben aud neuerlich längere Seit bin= ourd ein Deficit wakrnehmen laffen, weldes offenbar ein gropes wirth= idaftliches llebel mar, wenn aud bas llrtheil Darüber, ob und wie es Gätte verhutet werben fonnen, fefre fowierig ift. In Defterreid war, nachbem 1846 Die orbentlidjen Ginnahmen 1,1 gitll. fl. meljr als bie orbentlidsen शusgaben betragen Gatten, im D. $1848-55$ Das Deficit Der orbentliden 2usgaben gegen 44 MRifl. fl. $=17,5$ Proc., mit Şin= zurechnung Der auberurbentliduen शluzgaben aber (oline bie gleidzeitige Xtbahlung von Sdulben und die Eifenbahnanlagen) 86.380000 fi. $=$

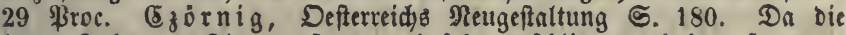
lez̧ten Jakre Den Finanzzuftand nod) fehr verfaliminert haben, fo wurbe im Szerbft 1859 eine befonbere Commiffiton gebildet, um über (Sripa=

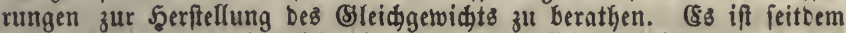

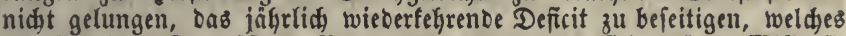

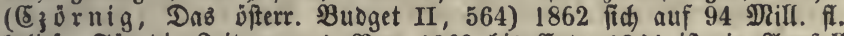
belief. Fir die Seit vom 1. Nov. 1863 bis snde 1864 ift ein थusfall von 109 mith. fi. berechnet. - Im papptlidjen Staate war Das ourds= fannittliche Jahres= Deficit 1828-30 gegen 400000 Scubi, 1831-33

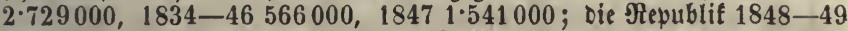
Ginterließ̄ ein Deficit von 4.827000 Sc. 1852 und 53 war Das Deficit zujammen 2 sill. Sc., uno wenn man Den zugefesten Estós aus verfauften গenten zufest, jogar 2.783000 . Daв Jahr 1853 allein zeigte cinen श्tuffall von 12,3 \$roc. Der 2Tusgaben. Şorn in Journ. des Econ. XXI, 73 nad, Narqu. ßepoli, unb Staatoredunung für 1853 (Conto consuntivo generale della publica admin. per l'esercizio 1853, Roma 1855). - Epanien und S3ortugal leiten ebenfalls an einem wieberkolten Deficit. - In Franfreich war fdon unter \&ouiz \$Gilipp Das (SIeidjgewid)t geftort und am 24. Februtar 1848 fand fids

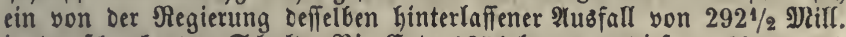

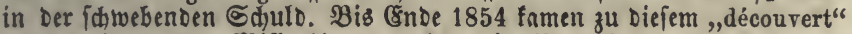
nod toeitere 594 Dill. Ginzu, ohne bie Bermehrung ber fundirten

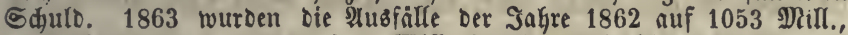
ber Jahre 1862 und 63 auf 75 Intill. beredjnet, bie fdwebenbe Gduld (nad) श6z̧น ciner Ginnakme von 157 Itill. aus ber Sinsherabiegung) betrug alfo 971 S)ill., Bericht bes Dinifter $F$ oulD, 1. Dec. 1863. In Sirofbritanien war in ben 32 Jaf̧ren $1829 / 30$ bis $1860 / 61$

$$
\begin{aligned}
& \text { in } 18 \text { Jafiren cin शusfall yon . . 48.771356 \&. } \\
& \text { in } 14 \text { Safjren ein Ueberidup von . 42.066 } 112 \text {, } \\
& \text { alfo Defraudgabe } 6.705244 \text { \&. }
\end{aligned}
$$

Bon jenen $48^{3} / 4$ Ilill. famen aber 32 Mill. auf bie Soften bes Rrim= frieges 1854-56; redjnet man alfo biefen Alfwand $a b$, fo-ift ein

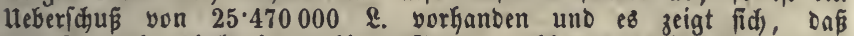
Der Staaţhaußgalt im ruhigen Sange wohlgeorbnet ift. Economist

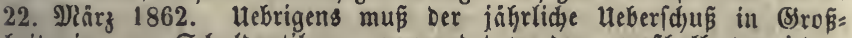
britanien zur Sduldentilgung verwenbet werben, weßjhalb oas jebes: malige Deficit neue Anleihen erforberte. - Dns Sönigreid) Stalien Gat

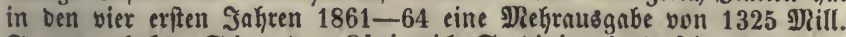
Francs gefabt. Sdjon Das Rönigreid, Sarbinien hatte feit 1848 jähr: lid)e 2usfälle, \$. 484 (c). Diefer Suftano rübrt yon Den foftbaren

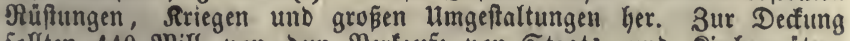
follten 440 Nill. bon Dem Berfaufe von Staats: und Rirdiengutern eingehen, bie Gteuern wurben erbjht, bie Gduld twudg ftarf an, aber aud ber Eetwerbfleis if im Steigen. 
§. 464 .

Benn Dagegen die Einfünfte eines Staates fortwähreno

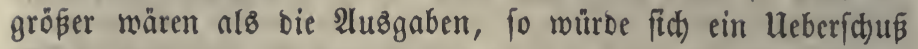
bilben, den man beruben fönnte

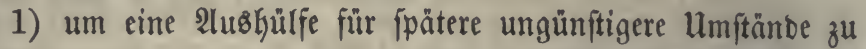
geben, in benen man zu nuperorbentlid) erhöhten 2luşgaben ge=

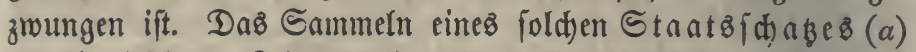
war in frükeren 3eiten, bei geringer Lebhaftigfeit Deb \$erfehrs

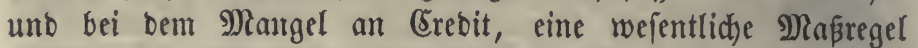

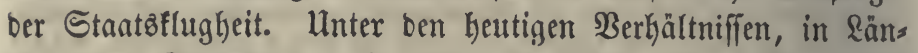
Dern, wo Bewerfe uno Scanbel biele Capitale in rafisem 4 m laufe befajätigen, bie oft in Belbform umgefest werben, unb wo fowohl Regierungen als Pribatperionen bas nöthige $\mathfrak{B e r}=$ trauten bei ben (Eapitalbeftzern finben, es ift unnöthig, weil

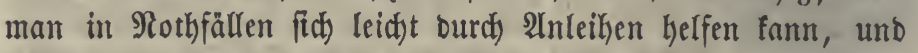
ez if umrathfam, weil bas Tobtliegen bebeutenber Belbfummen einen $\mathfrak{B}$ erluft für bie Setwerbthätigfeit uno bas CFinfommen bes Bolfes bewirft, - weil ferner oas $\mathfrak{B o r b a n b e n j e i n ~ f o ~ g r o p e r ~}$ Summen leicht zu hiberflüfifgen 2 tuggaben verleitet, bie bann Die angejammelten Sajäze bald erjajopfen (b);

2) $\mathrm{um}$ werbend angelegt zu werben und ein Cinfommen abzuwerfen $(c)$. Nag aud ein foldjes $\mathfrak{B e r m o ̈ g e n ~ f u ̈ r ~ b i e ~ \Re e g i e = ~}$ rung bequem fein und für bie Steuerpflichtigen einte (Erleid)terung

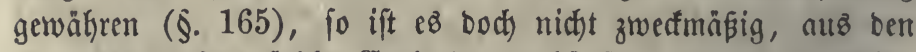
Stantzeinfünften folḑe Eapitale anzufäufen, uno es ift beffer, burd) Steuerberminderung bie \&aften Des $\mathfrak{B}$ olfez zu erleichtern, was wenigftenz zum Theile eine Bergröß̈erung Der Capitale im Bolfe, alfo ber sfütererzengung uno mittelbar vieber bes

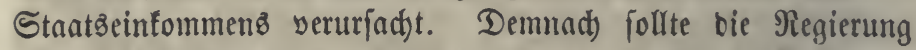
feinen Mebrbetrag ber Stantzeeinfünfte gegen die 2użgaben regelmäpig beabftctigen, auper etwa in fo geringem Umfange,

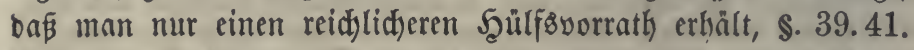
Unter bie 2lusgaben ift jeood) aud ein gewiffer Betrag zur Sdjulbentilgung aufjunefmen. (Ergiebt fid) von felbft ein Ueber=

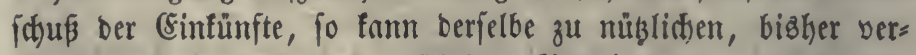
iđ)obenen 2 lusigaben ober zur ftärferen $\mathfrak{B e r m i n b e r u n g ~ b e r ~ S đ j u l b e n ~}$ gebraudst werben. 


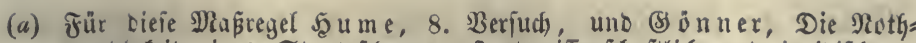

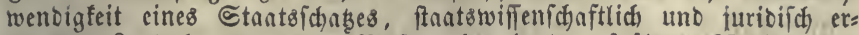
woger, Ranozh. 1805 (Ler Berf. nahm in bem fusteren 2Berfe: yon

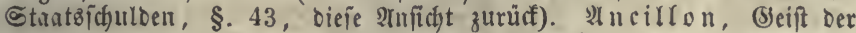
Stratzuerf. 5. 297, mit Rüfficht auf Frierrich II. - (S) envyefi

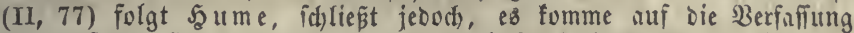
und auf cen Şandelbreidsthum an. 2צud Safob I, \$. 731 fi. zeigt,

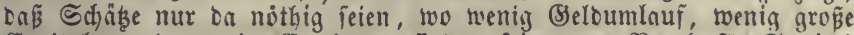
Enpitale und wentig (Sredit zu firten feien. - Vergl. A. Smith III, 355. - ๖. Sonnenfelв, (5)rundfäge III, §. 190-195. los III, 424. - Mac Culloch, On taxation 5. 396.

(b) ๔mith a. ๙. D. bemerft, Dấ in alteren 3eiten jeder Fủrt auf einen Sdans bedacht wir, wie nod) jest jeber Şäuptling in ber Tartarei. -

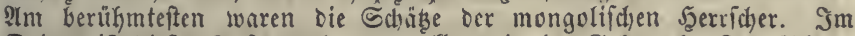
Drient ift biejes infammeln now allgemein im (sebrauch. Im Shabe Des Dei von Silgier fanden tie Franzofen 183049 Mitl. Fr. Friebrich II. yon \$reusen fand 8.7000010 Thlr. im Sdabe feines Baterz. Der von ihm hinterlafiene Etanţfकhas war, obgleid geringer als mun ifin fich vorftellte, Dod) ser griste europaifiche in neuerer Scit,

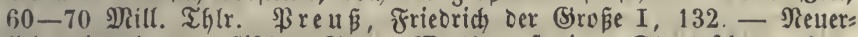

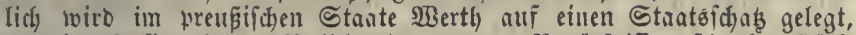
ber im Falle einez plöblid eintretenten Bebürfniffes fduefle Şülfe

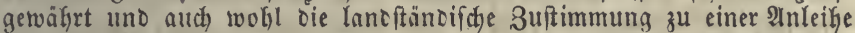
fir ben Plugenbliaf entbefrrlich macht. Rad) Dem (Snbinetsbefehl vom

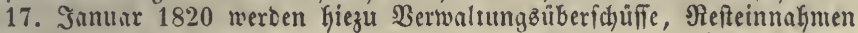

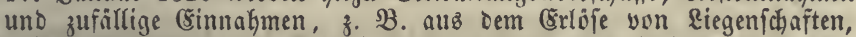
"Die nicht Domänen find", wie Berg=, f̧ütten= und Salzwerfe, benuşt. Diefer Schab betrug 186212 Nith., 186320 Nhifl. Thlr.

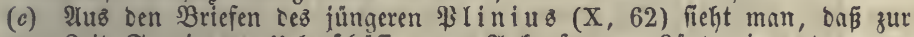
Seit $\mathfrak{x}$ aja

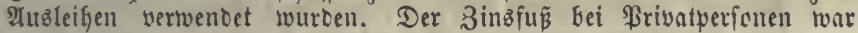
12 Broc., Der Stant hatte aber Mäke, foviel zu erkalten.

\section{§. 465 .}

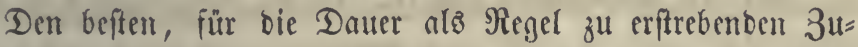

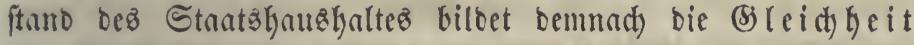

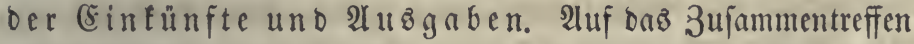

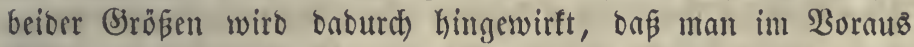
für jeben beborftehenden 3eitabjhnitt bie Summe ber vorgu= nebmenden 2lubgaben feftetgt uno bamit bie zu erwartenden Cinfünte in Mebereinftimunung bringt. Eine folche Boraus= beftimmung ber in einem beborftebenden 3eitraume fu machen=

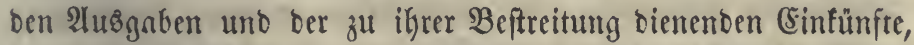

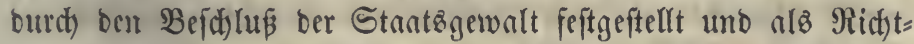
id)mtr für bic Finamzgewalt vorgefdrieben, heipt $\mathfrak{B}$ oranid)lag, Etat, $\mathfrak{B} \lll$ get $(a)$. Wolfte man obne eimen foldsen, baz

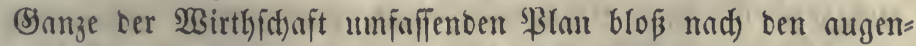
blifflict)en Beranlaffungen bie 2lusignben bef̧ließen, fo wåre man unaufförlid) in (Sejakr, bie ourd) Dic Bimahmen gebotene

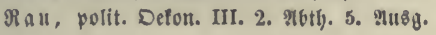


(S) unterlaffen, weil man auf minber nothwendige fdon zu viel

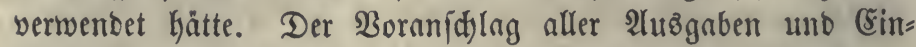
nahmen ift baher bie nothwentige Bebingung jeber guten

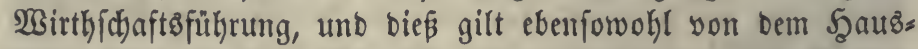
Galte eines einzelnen Bürgers, einer Semeinbe, eincr 2lnftalt, alsె yon bem Des Strates. Der genefmigte Boranjichlag ent=

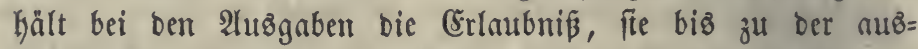
gefprochenen Summe vorzunetymen (bie fog. (Eredite), bei Den (Einfünften ben muthmaßlid) angenommenen Ertrag ber (Einnahmsqquellen, bie theils von einer gegebenen $B$ ejdaffentyeit find, theil(z, wie bic 2luflagen, yon bem feftzufegenton (Entrid)= tungşanke bebingt werben. Da in bem Fußse ber Sdjaķungen am häufigften Beränberungen vorfommen, fo pflegt bei ber Eefțę̧ung Des Boramidhlagę eine Beftimmung bierüber ges troffen zu werben. Ueber Die Entwerfung bez $\mathfrak{B}$ oramidlages ¡. §. $561 \mathrm{ff}$.

(a) État, rovfür man in Deutifjland früher bas lateinifđje $\mathfrak{B s o r t}$ status gebrauchte. - Budget, eigentlidh im \&nglifden ein Gad, Beutel, yon Dem altfranzofifichen bouge und bem nod) leşt übliden bougette, fodann

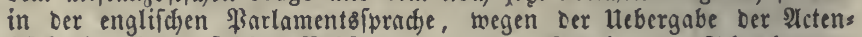
fuñfe in einem folden Behalter, ber yom Sanjler Der Schabfammer Dem \$arlamente vorgelegte (Etat (Daher (Sampe's wunberlide Heber= feşung: BeDarfotafde). - Stalienifh preventivo im (Segenfak yon consuntivo, ben Rechnungsergetniffen Des verfloffenen Sahres.

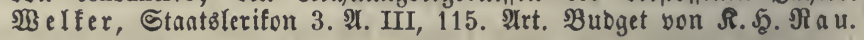

\section{§. 466 .}

Unter bem Druffe unerwarteter gebieterifdjer Umftänbe tritt bišweilen im \&aufe einez Sahrez ein Deficit ein, befīen Jorgen man tragen mufs. Someit fid) aber bie Eintüfte uno 2 uzz= gaben bei Entwerfung Deå Boranichlagez für einen netten 3eits abidnitt vorausbeftimmen laffen, foll bie Regierung Darauf Bebact) nehmen, ein Deficit zu vermeiben, beffen ofteres ober

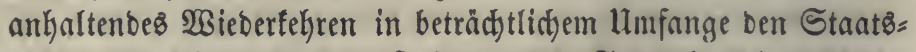
crebit idjwäd)t uno Den 3uftano bes Staatshauß̧haltez ver= foflimmert $(a)$. Şiezu giebt es zwei Mittel:

a) Berminberung Der 2luछ̊gaben. (Sin Theil ber Etant8= ausigaben ift iffer Beftinmung nad) nothwenbig; namentlid) gilt bieß yon ber Civilllifte, - von Dem 2lufwante für bie ăupere und innere Sidjerkeit, von ben fioften ber für bie 
Stantżzuefe erforberlichen Anftalten, - uno bon ber Erfüllung eingegantgener $\mathfrak{B e r b i n t}$ lid)feiten, z. B. Befoldungen ber Stant: biener und 3ins ber Etaatzidjulben. Man barf annehmen,

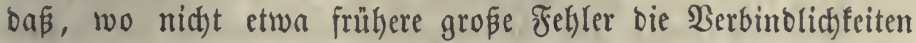

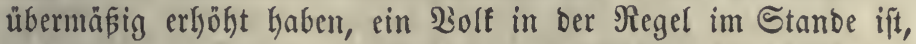
bie zu ben fortlaufenben 2lusigaben biefer 2art nöthigen Mittel auz feinem Cinfommen aufzubringen. Snbeß ergiebt fich manche (B) legenkeit, ohne lungeredtigfeit uno (Sefähroung beż Stratż= wohlez eingelne 2lużgaben ober Theile von foldjen zu eriparen,

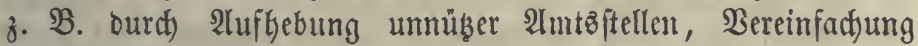

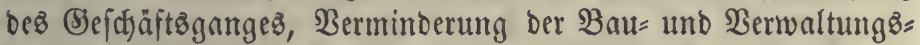
foften u. ogl., aud) famm man oft nüblicke, aber minber noth)= wentige 2ltsigaben ofne erheblidye Nadytheile cinftweilen ausz= jeben Inffen. (E⿱亠乂 muв aljo eine jorgfältige Unterfuctung auf bie (Entbectung foldjer Alusigabenverminoerungen gerichtet werben $(b)$.

b) Bermefrung ber Cinfunfte. 2lu beften ift

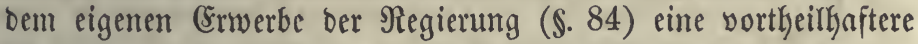
Bentzung Der bazu bienenden Bermögenżtheile ober eine $\mathfrak{B e r}=$ minberung ber Betriebazfoften eingepinthrt werben fanm. Coldje Berbefferungen erforbern jedoch oft längere 3eit. Sn nod)

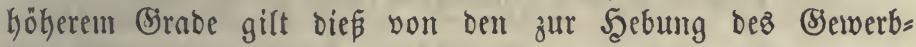
fleißez bienenden Maßregeln ber Bolfzwirthjđ)aftzpflege, aus benen ipäterhin eine 3umahme des Steuerertrages zu erwarten

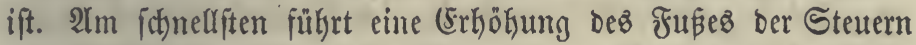
und (Sebühren ober bie Cinführung neuer 2luflagen zum Biele.

(ess läpt fict) unter ben gegebenen Umftänoen in einem Ranbe erfenten, ob baz eine ober anbcre biejer beiben Mittel ober eine nette 2lnleike ocn Borzug verbiente. Bizrweilen ift bie gleidzeitige Berbinoung ber beiben eritgenunnten Mittel zu empfey)(ent. Uebrigens madyt bei einer guten Finnzuertwaltung

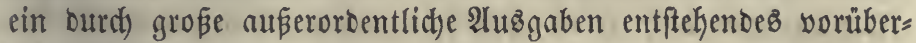
gekentes Deficit bie hier genannten Maß̈regeln nur infofern nöthig, alz für bie Roften ber Sd)ulbvermebrung zu jorgen ift $(e)$.

(a) Without such a consummation (Şerftellung Des (Sleidgetwidsts zwifichen शufwand und (Einfommen) no country can be prosperous or contented at home, nor feared and respected abroad. Wells, The true state of the national finances, 1842 , $\widetilde{S} .32$.

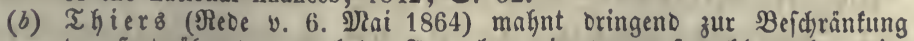
Der fortwähreno vermefrten Alusgaben, in oenen fowohl nothwendige alढ seulement agréables, quelquesfois mauraises enthalten feien. 


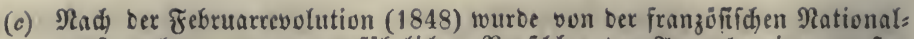
verjammlung, um ben gefährliden Borid)lag ber stubgabe einer großen Menge \$aviergelo zu befeitigen, Die (Srunofeuer um 45 \$roc. erboht, eine Eaft, Die fdwer empfunden wurbe uno grofe Unzufrietenheit erregte. Cie horte 1852 wieber auf. Durd Befes v. 23. Juni 1857 wurbe bei ben in= Directen Eteuern zu Dem idjon larige beftehenden 3 uidhlng von 10 \$roc. ein zweiter gleich grofer (décime de guerre) eingeführt, die surfolyols

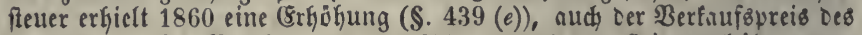
Tabafb. - In ßreußen rourbe 1855 uno 56 Der Siriegganleife wegen Die Elaffen=, Einfommens: uno Sdylachtfteuer um $1 / 4$ eigiht, in Sros= britanien 1854 und 55 Die Einfommensfteuer von 7 auf 14 und 16 ๔d).

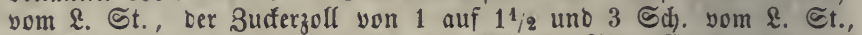
Der Raffeezoll von 2 auf 4 \$. vom \$funo, Theezoll von $1 \frac{1}{2}$ auf

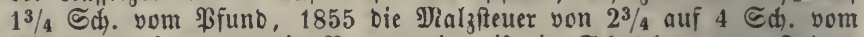
\$fund, aud wurbe Die Branntweinaccife in Edjottlano und Irtand erhỏht, §. $439(a)$. - Im Rönigreid Stalien wurben 1864 eine Steigerung Der Salziteuer, श̧zuge von Den Befoldungen u. Dgl. zu Sallfe genummen. In Den americanifden Nordfaaten fanden wieber: holte Eifjohungen ber 3ollfäbe ftatt, aud wurben ancere newe Eteuern zum Bortheile Der Bundescaffe eingeführt. Der $\mathfrak{A}$. für $1862 / 63$ ent= hält 37,6 Mill., für $1863 / 6477,6$ Mitl. D. innere Steuern neben $72 \frac{1}{2}$ Nill. 3olleinnahme. - In Defterreid ift im Rriege von 1859 (13. Mai) ein Suid)lag von $1 / 6$ zur Bruno= und Szausfteter, yon $1 / 5$ zux Ertwerb: uno Einfommenbfeuer angewronet worben und Diefe $34=$

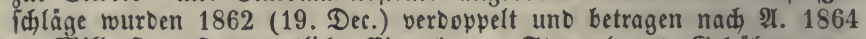
16 श)ifl. fi. auperoroentliche Einnahme. Etempel uno Sebuhren von

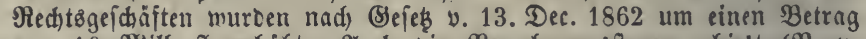

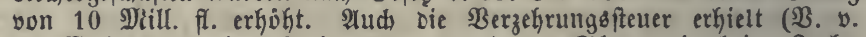
17. Dai 1859) cine Steigerung um $1 / 5$ Der Säbe, Die beim 3urfer Durd) (Sefés v. 29. Det. 1862 auf 30 \$roc. gebradjt twurbe.

\section{§. $466 \mathrm{a}$.}

Se vollftänbiger im Rnufe ber 3eit bie auz ber Soee bes Staates abzuleitenden veridjiebenen 2 lufgaben beffelben erfannt werben, Defto ftärfere uno mandffaltigere Infprüd)e werben an

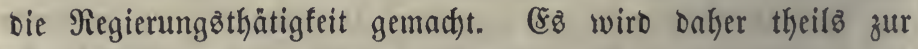
Bervolffommmung ber fđon beftehenten Stantzeinridfungen ein größerer Aufwand nöthig, theils erweitert fich auch Der Rreis Der Begenftänbe, Denen bic Regierung igre Sorgfalt zumendet.

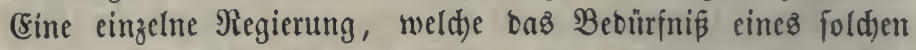
Fortichreitens nicht feloft empfände, würbe f(j) on ourch Dasి $\mathfrak{B}$ ei= fpiel anderer Stanten Darauf hingeniefen werben, Daß fie nidjt zurüufleiben bürfe, was bei ber Staatônertheibigung fogar ge= fährlich wäre. Die Bergleidung oer Boranfd)läge eimzelner Stnaten aus berichiebenen 3eitaltern zeigt beutlid) die von biefer fortichreitenden Entwidflung lyerbeigefübrte Bermehrung

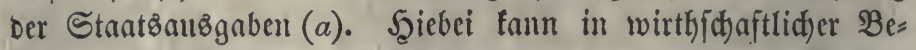
zief̧ung Die Bejorgniß̄ entftehen, Daß̉ 
zu bem vermehrten Anfwanto fehlen möhte und hieburd) eine notfwendige $\mathfrak{B e f d y r a n f u n g ~ b e f f e l b e n ~ g e b o t e n ~ f e i . ~ Z u r ~ M i n b e s ~}$ rung biejer Beforgniß tragen folgende Umftände bei.

1) Mand)e bişherige 2lıżgaben fönnen unterbleiben, wenn getviffe Stantsmañregeln, die mit einer Bebormunbung ber Bürger verbunben waren, zufolge ber größeren Reife bes

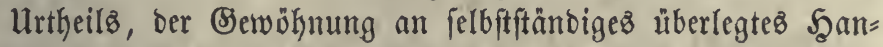
beln unb bem lebhafteren (Semeinfinn in Bolfe, alz entbehr $=$ (ich) erfannt werben, wenn inzbejonbere ben Einzelnen, ben Semeinben, oen $\mathfrak{B e r e i n e n ~ m e h r ~ F r e i b e i t ~ e i n g e r a ̈ u m t ~ w i r b , ~ f o ~}$

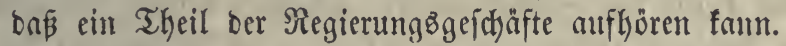

2) Man lernt yon 3eit z" 3eit neue $\mathfrak{B e g e ~ f e n n e n , ~ u m ~}$ bie Aนถిgaben parjamer einzurid)ten.

3) Ein grofier Theil ber Staatżcinfünfte giebt bei ber

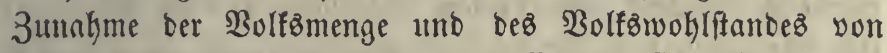
felbft einen größeren Ertrag, z. B. bie Einnnlymen aus

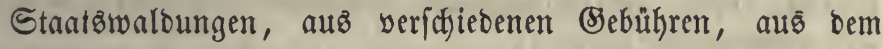
Salz = und Spoftregal, aus veridhicbenen Schaşungen, auż ben inneren 2lufwanosffteutern, felbft aus ben 3öllen, unb auch bie Scerabfebung voer 2Ufbebung einzelner fäblicter (Entrichtungen verfinbert im Sanzen Diefen günftigen Errfolg nid)t.

4) Die unter Dem Einfluffe einer verbolffommneten $\Re$ gies

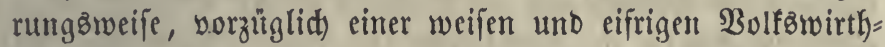

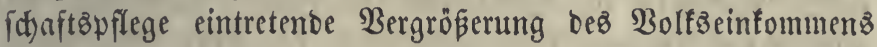
in $\mathfrak{B e r b i n o u n g ~ m i t ~ e i n e r ~ g e r e d ) t e n ~ u n d ~ v o l f s i w i r t h i d ) a f t l i d ) ~}$ zwecfmäß̈igen (Einrichtung beż Steuerwefenz mad)t aud) eine erböhte Befteuerung ohne ftärfere Belaftung ber Bürger zuläfiftg.

2llle biefe günftigen $\mathfrak{B e r n ̈ u b e r u n g e n ~ f i n d ~ j e b o d ) ~ b e r ~ \Re a t u r ~}$ ber Sache gemä́z mur in langfanter Fortfdyreitung zu erwarten (b).

(a) In jebem einzelnen 3weige Der Regierungsausgaben fommt bas Bebürf=

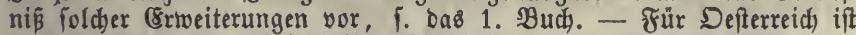

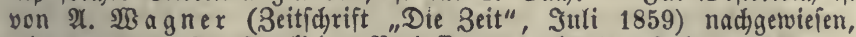
wie toegen großer ftantlicher Berbefferungen in ben Jahren 1848-57

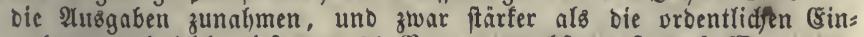
nafymen, obgleich bieie um 70 Pruc. anmudffen; f. auch $2 \mathfrak{B}$ agner, Dromung Des iffert. Staatshaushalts S. 44.

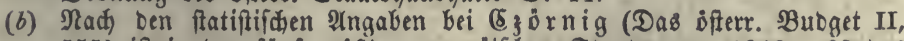

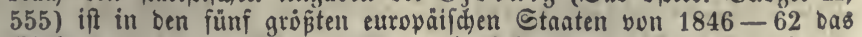

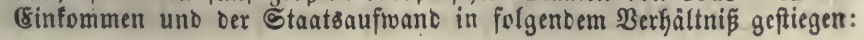




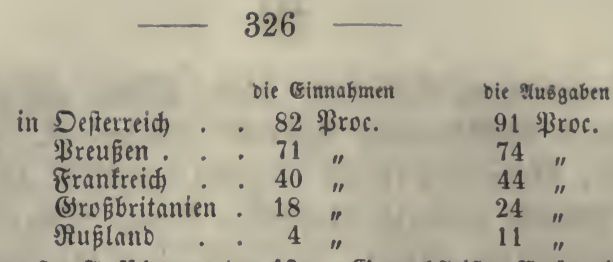

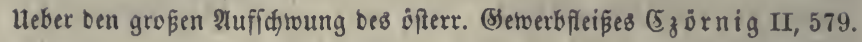

\section{§. 467.}

Unterfutht man, biв zu weld)er Şöhe bie 2 uflagen gefteigert werben fönnen unb oüren, fo ift zu unteridyeiben:

1) eirre unbedingte (abjolute) Bringe, bis zu weldyer man mit Şülfe von 3wangsిmitteln gelangen fönnte, ohne auf

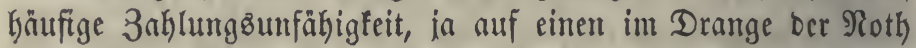
entftehenden Biberftano zu ftoßen ober bie Bürger Des Unent= befrlidjen zu berauben. Eine fold)e 2lusbehnung ber 2luflagen

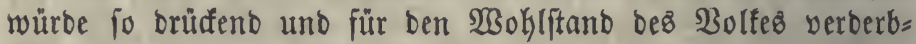
(id) fein, daßj mur bie fallimmften Engen, in bie ein Etnat gerathen inag, eine Inmäherung an Diefez 2(eußerfte auf furze 3eit reditfertigen fönnten;

2) eine volfarwirthid)aftlide (Sränze, bei ber nod) feine Berminoerung Der Eapitale uno ber (S) ütererzeugung eintritt: Alud) eine foldhe Belaftung wäre f(t)on mit fdweren Beoräng= niffen für einen Theil ber von bem Ruruz ber Wohlhabenben lebenden 2lrbeiter verbunoen, uno bei bem 2lnwad) fe ber ßolføి menge ofne Bermefyrung oer Capitale mü̈te fie fogar allmälig

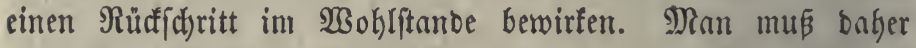
auch Scheu tragen, biẹe Bräuze zu erreicţen. Da übrigenż

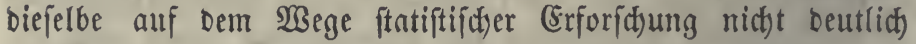
zu erfennen ift, fo mus man fid) an alfgemeine Seidjen, als Etelterniluftänbe, 2lbnabme ber Serzefrung, 3unafime Der

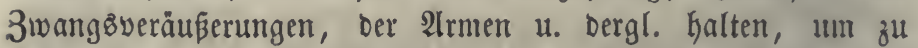
beurtheilen, ob eine Bermekrung ober eine Ermäßigung Der 2uflagen rathjam fei, \$. 275.

§. 468 .

Die Folgen einer (Erfjöhung ber Auflagen unter gegebenen

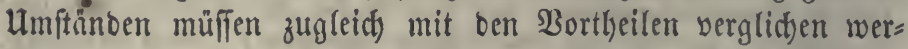
ben, weldje aus ber Berwenbung ber auf biejem $\mathfrak{B e g e}$ erlangten neuen Staatzeinfünfte für bie öffentlicben 3wede zu ervvarten fino. Diefe Bortheile fino ie nad) ben Begenftänben ber 2lus. 
gaben verictieben, währent bei bem Amwadje ber 2luflage bic

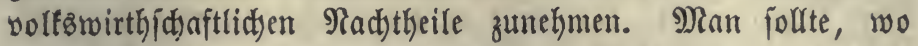
man nicht einer Rothwendigfeit folgt, jonbern wäblen fann, feine 2luğgaben beid)ließen, Deren Aufbringung ben Bürgern ein größeres Uebel zufügt, als bas burd) fie zu Wege gebrachte (S)ute betrågt. Dießß ift zwor nidjt leid)t zu erfennen, weil bie Entbehrung Der Steuerpflidttigen uno bie mübliche Folge einer

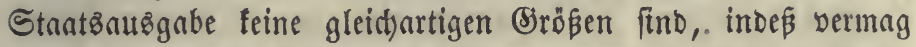
man bod) mit Şülfe von Ërfahrungen und forgfältigen $\mathfrak{B}$ eob: adtungen beibe $\mathfrak{B i r f u n g e n ~ g e g e n ~ e i n a n d e r ~ a b z u n a ̈ g e n ~ u n d ~ D a s ~}$

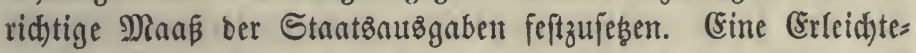
rung liegt biebei barin, Daß man feine neuen Stanten yor fith hat, fonbern in bem biskgerigen Umfange ber CEinfünfte unb

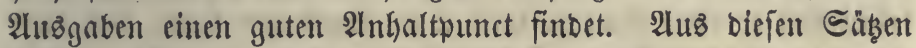
folgt, Dá̧ man weber bie Summe ber Etantåaubgaben bes idfließen foll, whne audh auf bie Reidtigfeit ober Edjwierigfeit

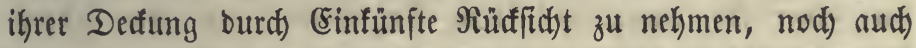
bie lebeteren für fich allein feftéçen barf, ofne zu überlegen, ob fie für ben jestigen Beoarf zureidyento fein werben; vielmebr hat

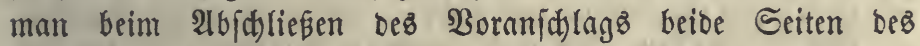
Begenftaubes zugleidt) ins 2luge zu faffen. Neben ben bringends ften ober nübslidjften 2 tuzg gaben pflegen immer auth anbere in Boridslag zu formmen, bie eher veridjieblidt) fint ober weniger Nuß̧en bringen. Da man nun in feinem 3eitpuncte alfe über=

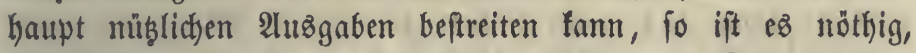
ben 2lufwand foweit zu befdyränfen, als es biẹ Sdjonung ber Bolfsenirth (đ)aft erforbert.

\section{469.}

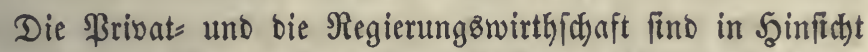
auf bie Entwerfung eines Soramidlages verictieben, indem

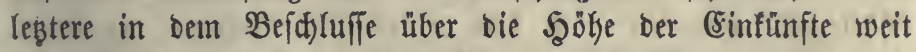
freier ift als jene, \$. 9. Der (Einzelne fieft fid) Durdh bas von

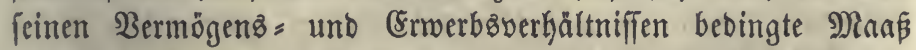

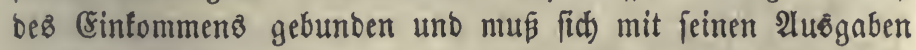
Darnad) ridften, fo lange er irgent im Stanbe ift, bamit alts zufommen. Die Stantzeintünfte bagegen Kängen großßentheils yon bem fufpe ber 2luflagen ab, beffen Beftimmung ber Staats= 
gewalt freifteht, \$. 465. Sieft man bie Möglichfeit unjdäb= lidjer Erfparumgen, fo oronet man cine Şerabjeksung ber 2 uf = lagen an, währeno in ber ßrivatwirthid)aft an baz 2lufgeben cines Theiles ber (Einfunfte in biejem Falle nidjt gebadyt wirb. Inbej fteflt man fid) bod) bie Berfdyiebentheit zwijdyen beiben 2Irten ber Wirthjhaft zu großß bor, wenn man behauptet, im

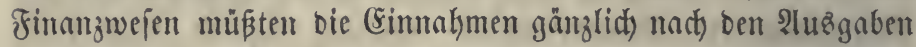
cingerid)tet werben. Dießs geidjefht nur etwa in foldten fällen, wo man wegen bes geringen Stnatzbebarfes weniger (Sinfünte

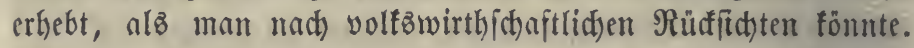
WBo aber bie StnatBbebürniffe über cinen fo geringen Umfang

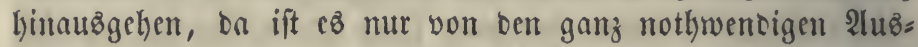
gaben wahr, daß fie ohne Şinblid auf bie Deffungsimittel bejd)loffen werben fömnen, weil man amnehmen fann, baßj bieje in jebem lebensิfähigen Staate fith aufbringen laffen. Jene Meinung fomte nur baburd) entftehen, daß man fith ben $\mathfrak{B}_{e}$

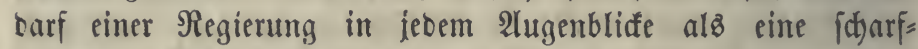
bejtimmte Bröpe badte, waz er nicht ift $(a)$.

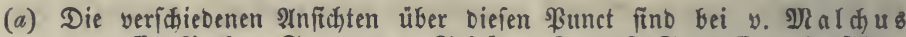

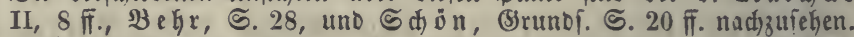

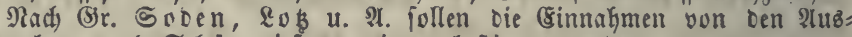
gaben, nach Sch ơ biefe yon jenen beftimmt werben.

\section{§. 470 .}

Der Boranifhlag, wenn auds mit reiffier lleberlegung ent= worfen, fam bod) nicht unbebingt wie ein Befes nollyogen werben, vielmehr weithen unvermeiblid) biżweilen bie Rect)=

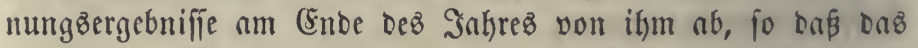
ill ifm beabfithtigte (Ebenmanß ber Einfünfte uno 2ubgaben jerftört wirb, Denn 1) Der Ertrag Der Cinfünfte hängt nidyt ganz son bem Befhluffe der Staatägewalt $a b$, vielmebr fino

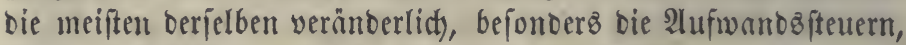

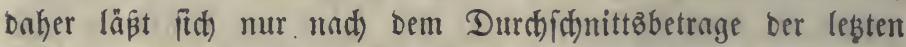

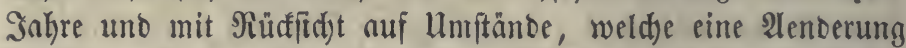
vermuthen laffen, ber wabridseinlid)e Belnuf autzinitteln; 2) bei

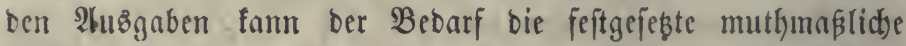

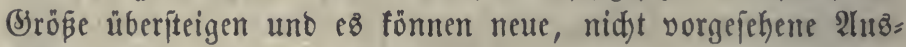
gaben nöthig werben. Dieje unvermeiblicten Ueberidjreitungen

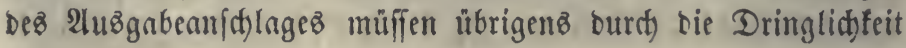


ber $\mathfrak{B e r w e n t u n g}$ geredftfertigt werben, währent ber Minber= betrag ber Csinfünfte, foferne er nicht von ber Berwaltungsiweife herrührt, eine Thatjacte ift, bie bloß als foldhe erwiejen zu werben broucht, ygl. \$. 41.

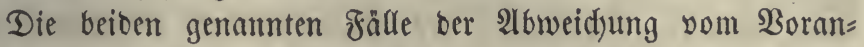
id)lage find ungünftiger 2Irt. (5s fino jebod) aud) andere mögs (ich), nämlich ein Mefrbetrag ber (Einfünfte uno eime (Eriparní; an ben für unftr̈noige uno außerorbentlid)e 2 tużgnben angenom= menen Gummen, unt cs if wahrid)einlich, bnß bie günjtigen unb ungüuftigen 2lenterungen fid) zum Theile auffeben werben. In jebem Falle hört iebod) ber Boranichlag, obgleid) er feine

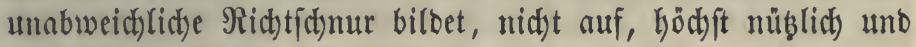
nothwentig zu fein.

\author{
II. $\mathfrak{A} \mathfrak{B}\{\mathfrak{d} \mathfrak{i t t}$.

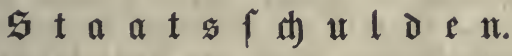

1. 2lotheilung.

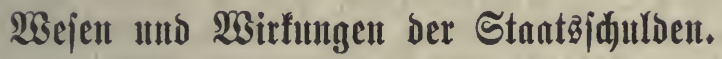

\section{§. 471.}

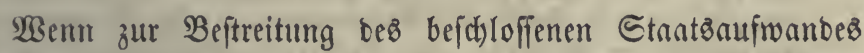
bie gegentwärtigen Staatseinfünfte nid)t zureichen, eine (êrföhung

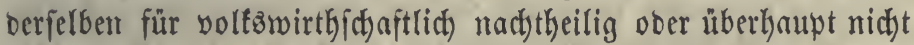

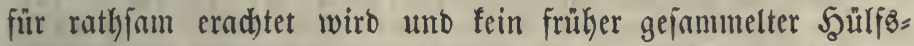
vorrath zur Berfügung fteht (\$. 463), fo mus dic fehlento

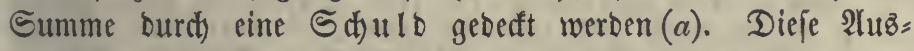
hülfe hat bie Stelle jener vielen ungeredten, theils liftigen, theils gewaltthätigen Mittel eingenommen, beren man fid) ehes

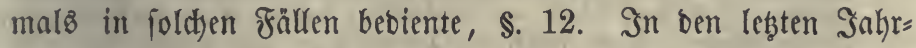
Gunberten hat bas Sctulbenwejen ber meiften Straten foldje

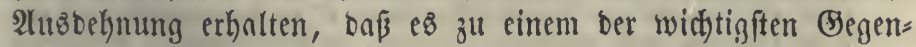
ftände bes Finanzwefens geworben ift $(b)$. Sowohl für bie Anfuabute als für bie fortbauernbe Berwaltung und bie $2 \mathfrak{b}=$

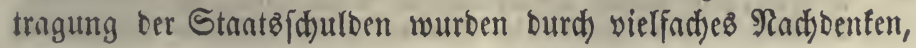


ourd) bie $\mathfrak{B}$ enutbung zahlreidjer (Erfahrungen uno Berjutbe mübs lidje Regeln ber Finangflugheit gefunben, fo Daß große 2luz= gaben uno bie ihretwillen gemadjte Stnatzid)uld mit einem

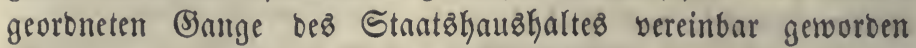
fint, uno bie Befeftigung bez Stantšcrebitez erleict)erte bas Borgen fo fefyr, ban man bavon jogar zu oft (Sebraud) madjte. Diefes eben fo autsegebchnte als vielgeftaltige Edulbembejen ber europäifthen Stanten ift zwar als Beweiz bes wohtver=

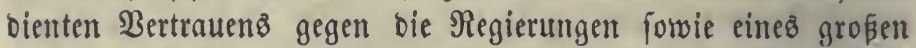

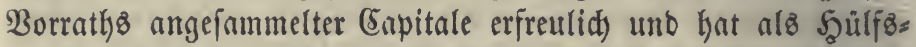

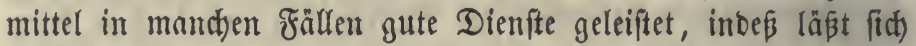
nidjt verfennen, Daß aud) große Radjtheile aus bemielben ent= ftanben finto. Die Betraditung dez Schulbenwefens mú bather mit ber Unterfuctung feiner volfswirthf(d)aftlichen Wirfungen begimner.

(a) Ueber Staat\&fhuloen überbaupt Montesquieu, Esprit des lois XXII, Ch. 17, 18. - \$into, a. Edyrift, f. I, S. 42 (d). - Eteuart

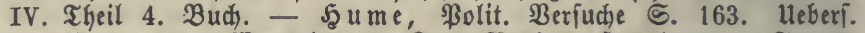
yon Rraus. - Slortimer, (Srundäbe Der Sandungs:, Staats: uno Finanzwiffeniकnften, Deutid, von (5ngelbrecht, \&eipzig 1781, S. 505 ff. - . S mith V. B. 3. Cap. III, 353-421. - v. Sonnen: fel 18 , Srundi. III, §. 190. - S is mondi, Nouv. Princ. I, 317. ธay, Sรanbbuch VI, 99. - Lob III, 433. - ๖. Di al中u I,

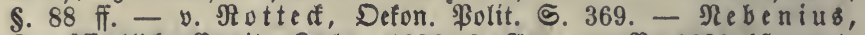

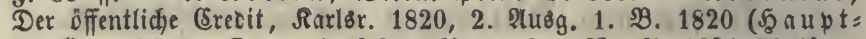
werf). - Wels, La magia del credito svelata. Napoli, 1824, II. $4^{0}$. $\mathrm{Du}$ fresne St. Lé on, Etude du crédit public et des dettes publiques,

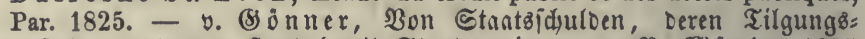

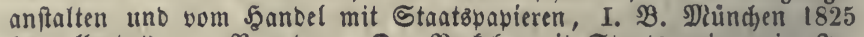
(unvollendet). - $\mathfrak{B}$ en $\mathrm{e} \mathfrak{c}$, Der Berfebr mit Stantspapieren im In=

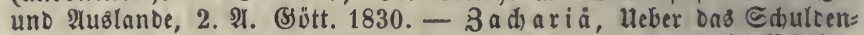

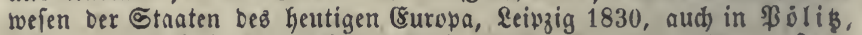
Jahrb. Der (Sefdichte und Staatafunit, 1830 , II, 192, 299. - \&ex,

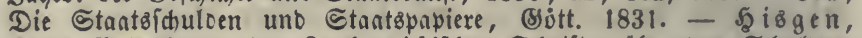

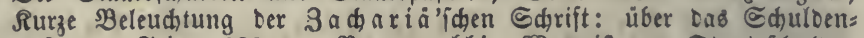

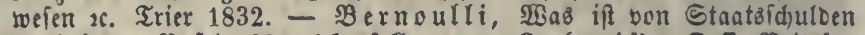
zu Galten, Baiel 1832 (ebenfallB gegen 3acha riä). Deff. Beitråge

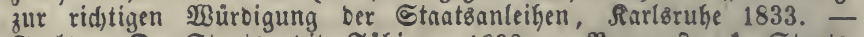
Fuloa, Der Etanatereoit. Tubingen 1832. - $\mathfrak{B}$ aum ft arf, Staat8=

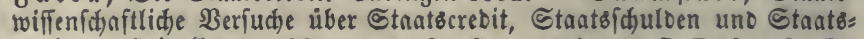
papiere, Şeidelberg 1833. - A. de Gasparin et J. Reboul, De l'amortissement. Paris 1834. - Influence of the public debt over the prosperity of the country, by M. B. Lond. 1834. - den Tex, Over den invloed van Staatsgeldleeningen of de vermeerdering. of vermindering van den nationalen rijkdom, in Nederlandsche Jaarboeken voor Regtsgeleerdheit en Wetgeving, II, 169. - (5 a ncrin?) Ueber Den Etaatsfredit. Bon einem rufi. Stnaţmanne. \&eipzig 1840. ๖. Eancrin, Defon. Der menid)liden Sefellidaften, Stuttgart 1845, ङ. 284. - Mac Culloch, Treatise on the principles and practical 
influence of taxation and the founding system, 1845, S. $396 .-$ Diezel, Das Syftem ber Staatsanleifyen, 5ुeidelb. 1855. - Garnier, Traité S.201. - v. Şo df, Die offentl. श્રbgaben u. Shulben S. 265. W3agner, Die Dronung bes offerr. Stantshaubhalts, Bien 1863, S.1.

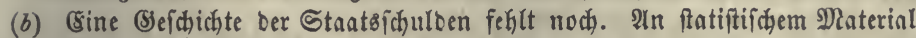
if am reichften: Bern. Cohen, Compendium of finance, containing an account of the origin, progress ant presend state of the public debts, revenue, expenditure, national banks and currencies of France, Russia etc. Lond. 1822. - Bis zum Inhr 1820 findet man ons Bepte

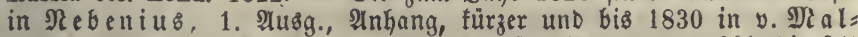
Ђ 1859 erfheinembe Sammlung: Horn, Annuaire international du crédit public. - Uleber Sroß̈britanien vorgüglich Hamilton, An inquiry concerning the rise and progress of the national debt of Great Britain, Edinb. 1813. 3. 2uछ̊g. 1818. - Pablo Pebrer, Taxation etc. of the whole British Empire, I, 247 Der franzoffichen Ueberfebung.

\section{§. 472 .}

Wer Sdulden madht, beridafft fith bie gegenwärtige $\mathfrak{B} e=$ nub̧ung eines fremben $\mathfrak{B e r m o ̈ g e n s ~ g e g e n ~ b i e ~} \mathfrak{B e r b i n b l i c h f e i t ~ z u ~}$ ppäteren Reiftungen an ben Bläubiger. Die Regierung hat zwar bie Nadyt, biés auf mand)faltigere 2lat zu thun, als ein SHrivatmann, inbeß w wurbe nidjts ber Beftimmung bes Staates mebr wiberftreiten, alz eine bon ber Regierung gegen ifre (3) Iäbiger begangene Ungerechtigfeit; Daker Darf bie Finanz= wiffenfidaft nur bie mit ber (Serechtigfeit vereinbarlichen 2lrten bes Schulbenmadens und ber Behanblung bes Schuldenwefens für zuläfítg anerfennen. Die Rehren Der Stantäflugheit ftimmen

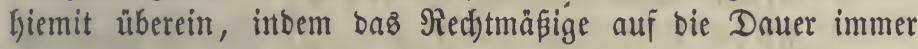

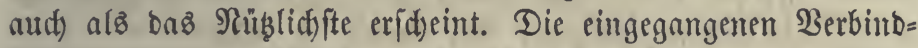
lidffeiten follen vollftänbig und princtlid) erfülft werben. $\mathfrak{B}_{\text {enn }}$ Der Staat Sduulden mad)t, fo ruft er bie Şülfżmittel fpäterer Safre und fogar fpäterer Sefdyledter zum Beiftande auf und zerlegt eine für ben 2 lugenblict zu fđhwere saft in viele fleine

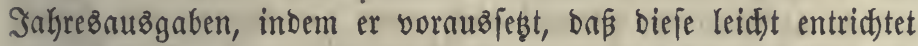
werben fönnen (a). Wer burdh Sdulloen Den $\mathfrak{B e r m o ̈ g e n s ̧ z f t a n d ~}$ Der Narffommen berichlimmert, fann freilid) von biefen nidjt zur rechtlicjen Berantwortung gezogen werden, aber befto größer ift feine moralifde Berpflidytung gegen fie, ifnen nidst unbebacht= founer uno ungered)tfertigter $\mathfrak{B}_{e i}$ e bie Folgen eines früheren 2lufwantes aufubürben, zumal ba er nidjt weis, weldye Stantz= ausigaben fie felbft zu beftreiten haben mögen. Aud ben

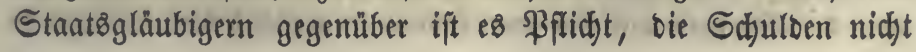




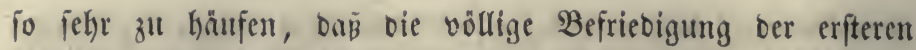
unmöglid) werben fönnte $(b)$.

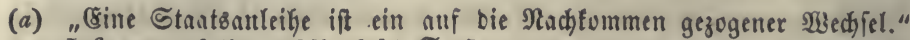
Influence of the public debt $\mathfrak{S}$. 5 .

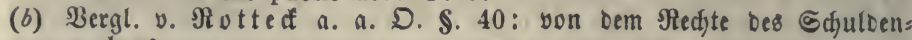
madjens.

\section{§. 473 .}

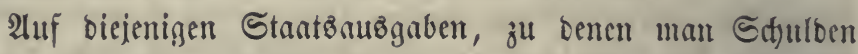
madyt, find bie von bem Stantzanfiwande überfanpt geltenten Regelı (\$. 26 ff.) amwenobar, uno zwar in erföhtem MRanße,

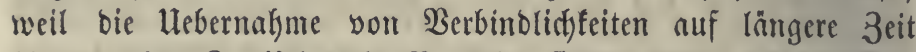

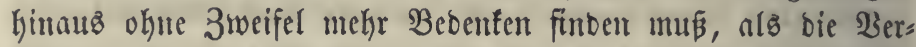

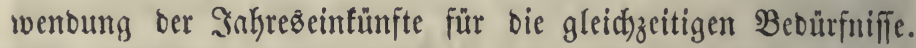
Dieje Alusgaben follen burd) bie von ihnen zu ermartenben Bortheile gerechtfertigt werben (\$. 468), Die bald in ber $216=$ wentung einer Befahr, bald in einer Förberung bez Bemein= wohlez liegen fönen (\$. 26). Währent alio bie 3 wede,

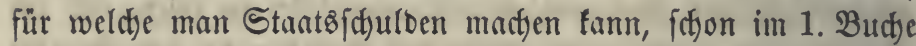
betradtet worben find, find hier bie $\mathfrak{B}$ irfungen, welde bieje Sdjulben alz joldse herborbringen, in Bergleid) mit ben burd) ifre $\mathfrak{B e r w e n t}$ ung zu erreidjenden $\mathfrak{B}$ ortheilen zu betradten. Sene $\mathfrak{B i r f u n g e n}$ fönnen fith bezieken

I. auf bie gamze $\mathfrak{B o l f z} w i r t h j(d) a f t$, und zwar

a) bie Bütererzengung, $\$ .474$ fi.,

b) bie Bertheilung be\& Einfommen\& und bie bamit zu= jammentyängente $\mathfrak{B e r z}$ ehrung, \$. 476,

II. auf bie Stantżgläubiger, $\$$. 479 ,

III. auf bie $\mathfrak{E} a g e$ Der Regierung, \$. 480 .

\section{§. 474 .}

I. a. Wirb ber Stantabebarf neben bem Ertrage bez eigenen Errwerbez ber Regierung burd) Aluflagen gebect, fo fudjen bie Eteuerpflictstigen fo Innge nlo möglid) bieje aus iften (Fin= fünften zu beftreiten, inbem fie ihren Germis einf(d) räufen, ohne ihr Stammbermögen anzugrcifen, fo baß́ folglid biz zu einer

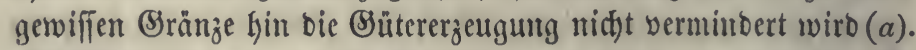
S(j)ulben bagegen, uno inşbefondere bie bäufigite uno befte 9 rt Derfelben, bie 2Anleiken, ziehen Beldpummen herbei, weldje fonf yon ben $\mathfrak{B}$ ürgern auf eine werbenbe unb meiften hersorbringente 
Weife angelegt werben würben. Die bom Staate geborgten Summen find theils neue, nod nidyt gewerblich angetwentet,

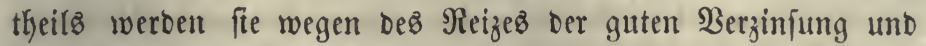
leichten Anlegung aus Dem umlnufenden Capital ber Semerbz: leute gezogen, entweder Durdh Den (Entichlup Derfelben, ober Durch) Sünoigung ber ifnen yon ben Cenpitaliften gegebenen Darleiken. 9) Mit ber (5apitalberminderung ift wegen bes ver=

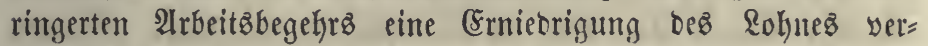
bunden (b). Diefe Sdymälerung ber Betriebsimittel für Den Bewerbflei if ift eine allgemeine nothwending Folge, wenn gleid) manche bem Staate geliebenen Summen nod) feine bejondere Benukung gefunden hatten und oaher nict)t zu erfenmen ift, weldyem Sewerbszmeige fie zugefloffen fein würben $(c)$. Da= gegen ift ber (Bebrauth), Den bie Regierung won Den geborgten Summen martt, von verfichiebener 2lrt.

1) Berben biefelben auf unmittelbar hernorbringende (Sie= werbe ober auf Berfebrzanfitalten gewenbet, fo wirfen fie als Capitale ober bienen zu Berbefferungen ber Srumbftüfe, fie bringen folglid) eine vermebrte Sithtererzengung herbor.

a) Wenn Die Unternehunungen ober Ränocreien, in benen jold)e Capitalverwendungen gemadyt werben, fid im Beftze ber Regierung befinden, fo entfteht eine Bermefrung ber Staatz= einfünfte, burch) weldse, wenn fie von entfprechender Srößße ift, ber 2lufmano vergủtet wiro. Se länger bie Sirfung Dauert, mit befto fleinerer jährlicher Reinertragęvermebrung wiro fichon Das aufgemendete (5apital vergḧtet $(d)$.

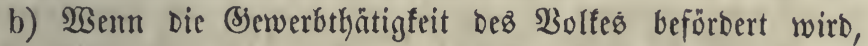

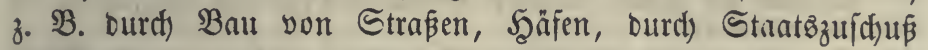
zu Trodenlegungs = uno Bewäfferumgranlagen u. Ogl., fo ent= fteht ein Anwachs Desి Bolfseinfommens, aus bem bie Foften ber Anleiken burch erhöhte Steuern aufgebracht werben fönnen. (Eine genaue Bered)mm hierhber ift in vielen Fällen nid)t wohl möglid), weil" fid) bie Wirfungen cimer einzelnen $\mathfrak{B e r}=$ anftaltung nidjt keraubifinoen laffen, aud) bald von Sakr zu Sahr zunehmeno, balb abnehment find ; biefelben erftreffen fids ferner nid)t inmer auf alle Landesitheile ober Bolfseclaffen, wenigftens. nidht in gleidhem Manaße. In mandjen Fällen gelangen bie ausigegebenen Eummen nuf foldbe Beife in bie 
F̧änbe Einzelner, daß̧ fie bei benfelben wicber in bie Reihe Der Eapitale eintreten (e).

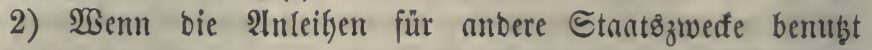

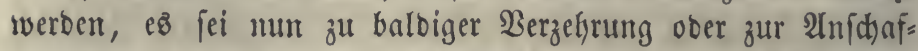

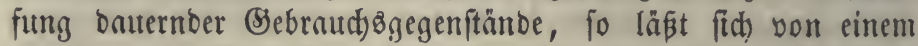
Theile fold)er 2 lügaben zwar ebenfalls ein mittelbarer günftiger Einfluß auf bie Şervorbringung von Sadjgütern annefymen (\$. 27, Nr. 2. b); aber es ift nictst zu ermitteln, wie groß

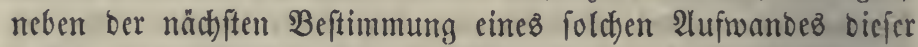

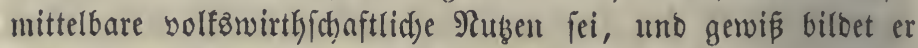
niç)t felten feine volfitänoige Bergütung für bie nufgezehrten Capitale. In foldjen Făllen muß alfo überlegt werben, ob

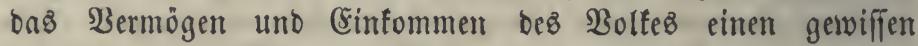

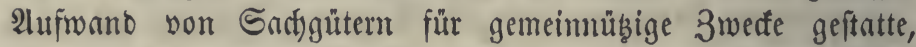

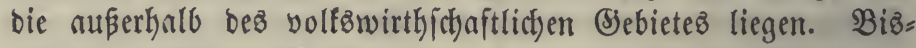
weilen, 子. B. bei Siriegen mit einem ungünftigen 2 ไügange,

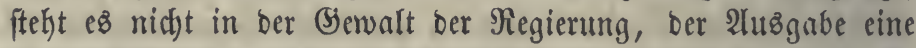

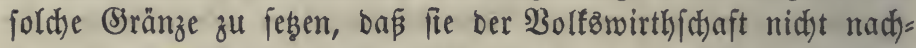
theilig wirb. Die Erfahrumg zeigt, baß in ben einzelnen

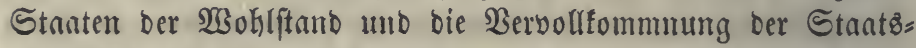

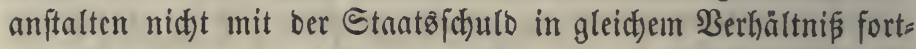
geidtritten find $(f)$.

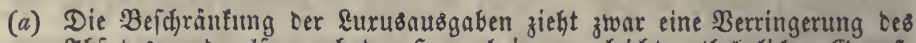

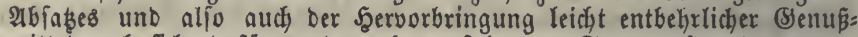
mittel nach fich, Dafür werben aber zufolge Des Stantzauftoandes antere Sachgüter begefrt.

(b) Wenn auch Der mit Şülfe von Anleifyen außgebefnte Stratżaufwand Irbeiter befhäftigt, fo gef fieft bieß bei einer nidht herborbringenben 2lusgabe nur einmal, máhrend ein Theil des Eapitals bieß̃ jährlich von Neuem betvirft.

(c) Daß̧ (Ssitermafien abfichtlic) Darum erzeugt würben, um zu Strats: anleifyen angetwendet zu werben, ift nicht erweislich und wiberftreitet Der Erfakrung, zumal ba Die Regietung ifr Bebuirfnís zu borgen nicht lange genug vorker anfünoigen fann. Wudh leiket man iem Stante nidht Dartm, weil man glaubt, Diejer werbe oie Summen beffer antwenben alz bie Infaber berjelben, fondern weil man biefe

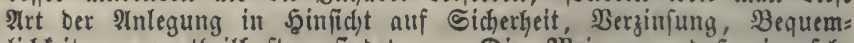
licjfeit xc. vortheilhafter findet. - Die झleinung, Daß́ ein fehr groß̧es "Disponibles" (Eapital vorkanoen fei, aus weld)em bie Durleiken an Den "Stant ofme Nadjtheil für Den (selverbfleis geidjopft werben fönnen (Diezel $\$$. 55. 100), beoarf einer Beleuchtung. 1) E8 ver= feht fich, Daß weber ber ganze (Srlös Des neuen (S)ütererzengniffes, bon bem vor झlllem Die Roften zu beftreiten unb bie in Seloform zurüf: fefrenden umlaufenden (Eapitale yon Neuem altz̧zlegen fino, nod) auth)

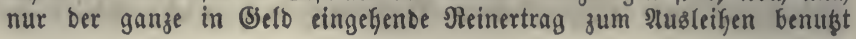


werben fann, weil man von ifjm unterfalts = und andere 29uggaben

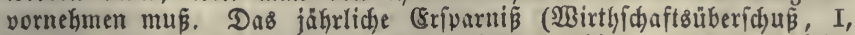

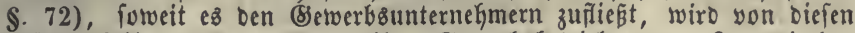

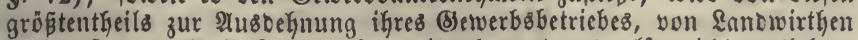
auch sit zum 2nfauf von \&anbereien benubst und alfo nicht verliefen, folglidh ift nur ein ziemlich fleiner Theil bes jährlichen (S)ütererzeug= niffes zu Yebterem (sebraud) bienlich, hauptfächlich das Eriparniś ber nicht getwerbtreibenoen (Einwohnex, nach) 21bzug ber zur Sermelyrung Des (Sütererzeugnifies beftimmten Summen. 2) Bon länger vorfhan= Denen, in (Selo umgejebten (Sütermaffen fino berleifbar a) biejenigen, für bie man noch feine in allen Şinfichten befrieoigende Art Der An:

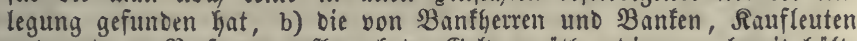
und anberen ßerfonen aufbewahrten Belovorrätbe, bie man bereit bält, um eine Bselegenbeit zu cinträgliçer Benubung irgend einer 2art ab= zuwarten, Die fog. hoards (Şorte) Der englifhen Edyriftifeller. Der Sefammtbetrag ber Reihfummen if in jedem \&ande unbefannt und wechfelno, aber aแs ben Unterzeichnungen zu neuen Stantżnnleiken fönnte man ign leidht überidjäben, Denn Biele bieten megr an, als fie

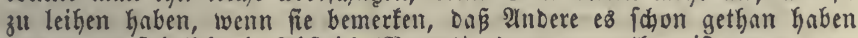
unb wenn folglich ein 2ibftrich (ReDuction) zu vermuthen ift, ocer wenn fie auf einen leidhten Berfauf Der in ifrem Befige befinolichen älteren Beridreibungen oder ber mit Der erfen Einzahlung erworbenell Dbli= gationen reduen.

(d) 3. B. bei einem 10 jährigen Mehrertrage find zur Errfattung jährlich (zu 4 ßroc. Sins) 12 Sroc. Des einmaligen Capitalaufwandes, bei einem 100 jährigen nur 4,08 \$rve. erforberlich.

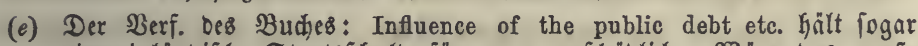

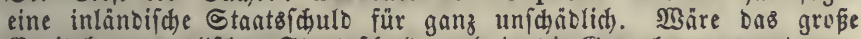
Eapital ber englifhen Staatsichuld nod in bie Slewerbe getwenoet wor= Den, fo wören, glaubt er, viele thörichte unternefmungen (bubble speculations) uno niedriger Sins entftanden uno mandje (Enpitale verloren gegangen; cie Gdjulo beförbere Das (Sapitalifiren Dergeftalt, Daß̧ mit

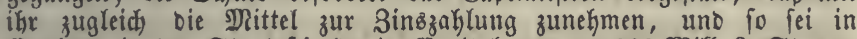

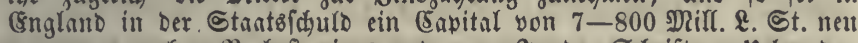
gewomen, ofne Berluft eines anderen. In Der Sdyrift: „Ueber Den

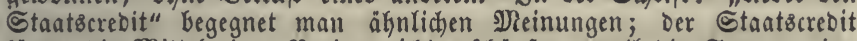
fönne bie Mittel einer Nation nicht exfdyopfen, weil bie Summen ins Bolf zurüdfefren, ons (5apital gebäre die Sinfen aus fíd felbft $2 c .-$ Auch Diebel in Der a. Sdrift beftreitet Den Sabs, Daj bei ben

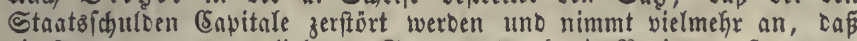

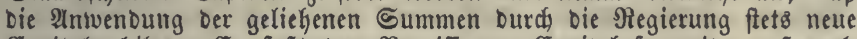

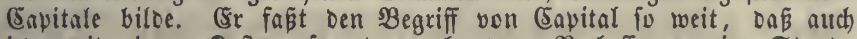
jede mit einem foftenaufwande verbuncene Berbefferung im Stante,

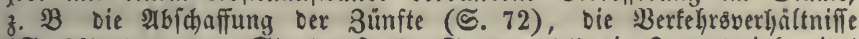
(ङ. 99), Der ganze ธtantżuftand (ङ.83. 104) eilt Immaterialcapital genannt wiro. "Stantzanleiken, welche nach Dem wakren \$rincip bes Stantseredites aufgenommen werben, find feine Sdjulden ber Nation, fondern ein Capital berfelben", ๔. 201. - Dieje Säke find cen in §aufgeftellten nicht wiberftreiteno, weil fie fich auf Dab im weiteften Eimne fo genannte Eapital, D. K. auf Nuben irgeno einer Art für Des

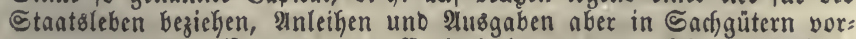
genummen uno alfo aus cem Sapital im engeren Simne beftritten werDen müfien. IRandje Inleifen fönnen Durd) bie Nothmendigfeit, Den Stant zu fhüßzen, ober Durch Die Bervolltommmung Der Stants = anftalten gerechtfertigt fein, wenn fie gleich, volfswirth) ein Dpfer erforbern. Diefes bliebe freilid ganz unvergütet, wenn bie 


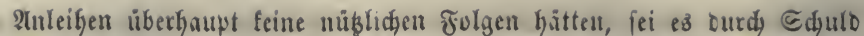

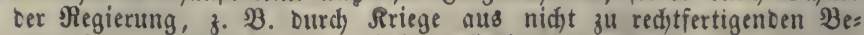

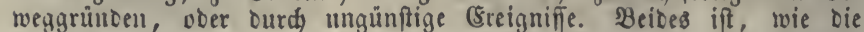
Grfakrung zeigt, ifters cingetreten. Bolfer find nicht fichon Durum reid) gemorben, weil ifre Regierungen ftarf berfdulbet fino, foncern

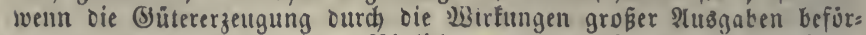

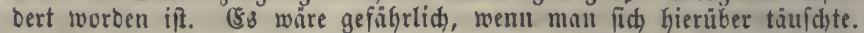

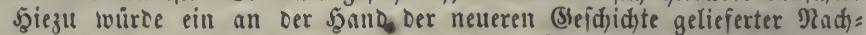

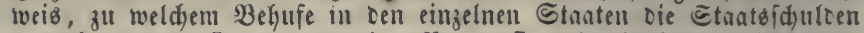
gemadit wotben find und weldhen Nubent fie gebradht haben, iefre lehrs reid) fein. Srof́britanien, Nieberlande, Evanien, \$ortugal 2 c. "Das (Enpital, Durch Deffen Aufborgen die Sd)uld entitand, if unwioer:

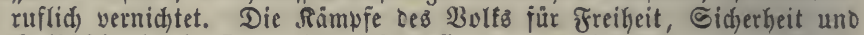
Selbittindigfeit fün mit Soülfe beffelben nusgefuchten woroen, แnab= hängigfeit, Sidherheit uno Freikeit fino bie Slüter (commodities), zu Deren enfuuf man es verwendete, aber in anderer Seftalt tann es nie

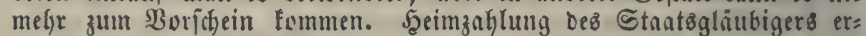
id)afft fein verzelytes (Eapital, foncerm ubberträgt mur auf ign ein

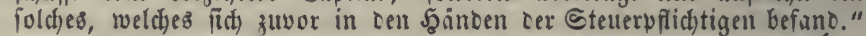

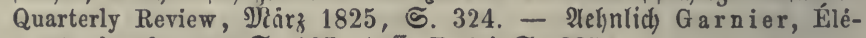
ments des finances 5 . 107, Deரi. Traité 5.225.

(f) Beifpiele: Dic bell franzofifhen \&uzgewanterten unter \&ubwig XVIII. eritatteten 1000 Mill. Fr., Die oen Eflavenbefisern in Den tritifden Befibungen bezablten 20 Mill. \&. St., Der 3uinus Des Stantes zur 26lôjung ber bäuerlidjen Laiten, ver Bannrechte u. Dgl.

\section{§. $474 \mathrm{a}$.}

Wenu die Anleifen imerbalb oez sandes gemacht werben, fo werben fogleid) anfangz bie (Sapitale oem Siewerbfleipe ber Bürger entzogen uno erit fpäter bei ber Sceimzahlung bemfelben aflmälig zurüffgegeben. Soweit aljo bie Stants̊nużgaben nicht umınittelbar voer mittelbar probuctio wirfen, wirb einftweilen bie Bütererzengung vermintert. Die fpäter zur Tilgung gejan= melten Capitale fönuen nid)t alsิ vollftänoiger (Srjaß̧ ber an= fänglid) verzebrten gelten, weil fie aus oen Eteuerbeitrögen ber Bürger herftammen, uno dieje bei niebrigeren Stcuern zum Theile felbft nette Enpitale erübrigt haben würoen. Dic Bereit= willigfeit ber Enpitaliften, Dem Etante zu leifhen, betweift nicht,

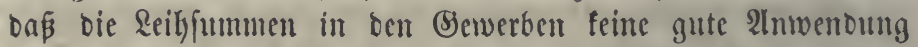
finoen fönnten, weil jene nur bie eintrïglid)fte 21nlegung ifres Bermögenz, bie mit ber Sidjerbeit vereinbar ift, im 2luge habent,

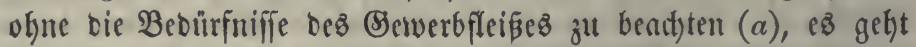
vielmelyr daв Siegentheil aแz ber häufigen Watynetmung her:

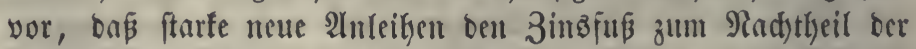
(5ewerbsunternefyer erböben. Şiezu fommt, Daß ber für bie

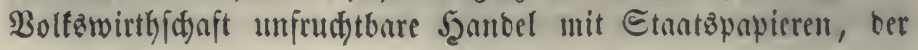


viele Capitale und 2 trbeitsfräfte befd)äftigt (I, \$. 441), bei

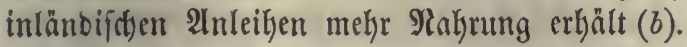

(a) Eafitte (Dep. S. 22. Now. 1830) fiellt ben Begenfak bes Borgens uno bes Alufbringens burd Steuern grell Dar: Le contribuable se plaint, le capitaliste se présente lui même .... L'impôt prend les capitaux, où ils ne sont pas ... (inl bell am folled)teffen angebauten Bsegenten 2 .) ; l'emprunt les prend, où ils sont, dans les grandes villes ... L'impôt les prend, où ils coutent 10,12 et 13 p. c., l'emprunt là où ils coutent $4-5$ p. c. (Diefé Darftellung wäre nur riditig, wenn von fehr hohen Steuern bie Rebe ift, weldje etwa eine anjelynlide Innleife entbehrlid mad)en iollten.) - Dagegen bie Edjrift: Should the money required to pay the expenses of the war be raised by loans or by taxes? Lond. 1855. - Garnier a. a. D. ङ. 109.

(b) Nitortimer a. a. D. S. 547 erfannte fidon bas Madjtheilige bieies Sandels uno ber aus ifym entifanbellen Jobberei, während \$into ber Neinung war, biefelbe fei für bie borgenden Negierungen fefhr vortheilgaft.

\section{§. 475 .}

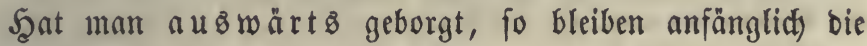

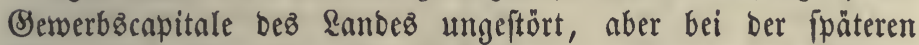
- Abtragung muีffien Capitale, bie aแछ Dem Ertrage ber Steuerm argefammelt fitto, Ginaugigejendet werben uno entgeken folglid Den intlänifdyen Semerben. Şiebei ift aljo Der Radytheil hin= ausgef(t)oben, bie Tilgutg geidjieht nur allmälig uno wenn in

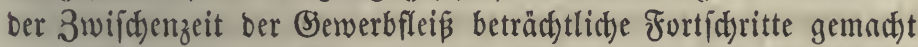
hat, fo wiro bie 2lbzahlung Durd) Den erböhten Wobliftano erleid)tert. So lange feine Tilgung erfolgt, fint nur bie Binjen auper \&anbes zu entrichter. Sehen bie geborgten Capitale in Belbform ein, fo bringen fie bie Wirfung einer Belovermegrung hervor (I, S. 272), ihre Berwenoung feb̧t nnfangs bie Sewerbe in ftärfere Thätigfeit uno vermag bei ciner beträd)tlid)en Summe fogar bie \$reife der Dinge zu erhöhen. Wenn man jeboch foldte 2lnleifen als ein Mittel betradten wollte, bem Capital

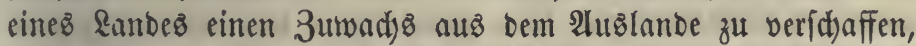
fo müpten bie geliekenen Summen aud) wirflid) alв (Capitale angelegt werben, weldjez jebod) bei einem Theile ber mit ihnen

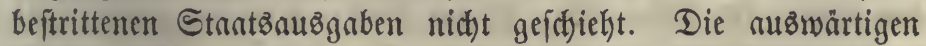

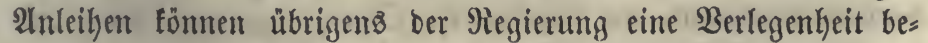
reiten, wenn ihre Sdjulbif)eine im 2lus(anbe auj einen niebris geren \$reis finten als im Smmern, und beß̧halb in Menge zum Berfaufe herbeigejendet werben, woburd) ihr \$reis herabs gebritat wird. 
Şiebei ift jebod) ju crwägen, Daß Reihjummen. (eid)t von einem \&anbe in ein anberes geten, woferne ber 3inşü be= trädytlid) verifticoen unb bie Inlegung gleidt) fidser ift. Daher

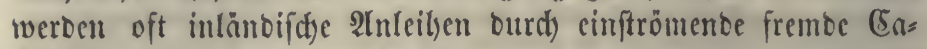
pitale wieber erfekst unt untgefefret gehen audh wohl, wenn bie Regierung von fremben borgen wollte, bie Edfuldbriefe in bie Şände inlänbiftyer Enapitaliften über. Die Banfferren ins= befonbere fenten igre Capitale bahin, wo fie ant meiften ein= tragen. Deß̧hnlb madjt es in 2michung ber hier betrad)teten

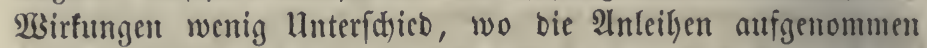
werben, und man faun biek unbedenflid) ba thun, wo man bie günftigften $\mathfrak{B}$ ebirtgungen erlngt $(a)$. In einem reid)en \&anbe ift unb überhaupt unter leidten Beoingungen zu borgen.

(a) Nebenius a. a. D. ธ. 704.

\section{§. 476.}

I. b. Die Sdutben ziclyen eine fortoauternbe neue शtügabe für 3ins unt Tilgung nad) fid). Alud) in Şinfid)t auf bie Bertheilung Des Bolfseinfommens unterideiben fid)

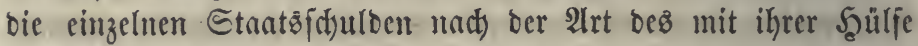
beftrittenen Alufwanbez. Sit berfelbe werbeno für bie Stantö= caffe ober bod) yolfsimirthid)aftlid) probuction (\$. 474), fo bietet bie auz ihnen herfliefente ober erleidsterte Bermekntung ber Stnatsecinfünfte die Mittel zu iener jährlidjen 3ahlung oar (a). Sft bieje Wirfung gar nidjt vorkanten, ober reidjt fie wenigs ftens nidjt foweit, als bie jäfrlid)e 2luşgabe für bie Sdjulb, fo Gaben bie Steuerpflidfigen anf lange 3eit eine grösere Summe nufzubringen, beren Ertrag in bie Şänbe ber 3intz= gläubiger (囚apitaliften), einer groß̧enthcilö unproductiven, von ifren Renten lebenden Bolfsclaffe gelangt. Nur ber zur Til= gung verwentete Theil bient zu einer erzwungenen Conpital= fammlung, \$. 474. 475. Wenn foldje Staatsf(d)ulden nicfit vorhanten wären, fo fönnten bie Steutern geringer fein unt ben Steucrpflidutigen würbe ein größerer Theil iłgrez Cinfom= menz bleiben. Dieje würben fid) melyr (Bemur veridgaffen, fid) zum Theile weniger bes (Ermerbes willen anftrengen uno aut) mehr überiparen, \$. 474. Wäre ctwa bic Steuerlaft bie 


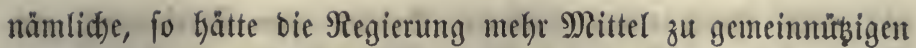
2lıbgaben für bie Begenwuat. Die Capitaliften fönnten gleiçe 3inbeinnahme von \$ribatidytonem beziehen, aber ihr CBin= fomment beftünte Dann in einem 2ntt)eile an bem mit Şülfe

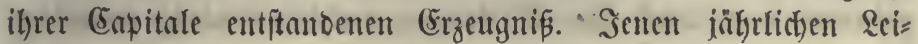
ftungen ber Bürger ftefen bie mit ben 2Inleiken im Sebiete ber Regierungsttjätigfeit · herborgebrad)tent Wirfungen gegenüber,

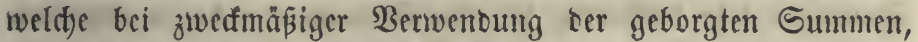

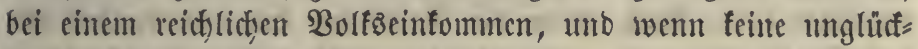

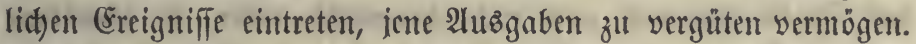

(a) VEenn die Beförberung Der Shütererzengung eimem Sanbestheile ober

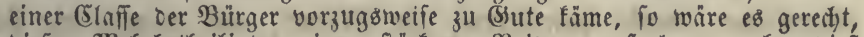

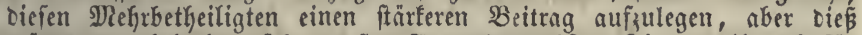
toürde mur bei einer feht grofien \&usgabe ratbfam fein, weil ood für andere Eandestheile und Bewerbszzeige ebenfalls cin Aufwand vor: fommt, auch bie vortheillyaften Sirfungen nidht fid)arf begränzt finb.

\section{§. 477.}

Früherhin wurbe öfters bie Meinung gehegt, eime Staatz= fichuld an inlänbifche (Släubiger fei barum unfchäblich, weil "bas $\mathfrak{B o l f}$ fich) felbit idjuldig jei uno bie 3injen zahle". Dieß war irrig, bemn alfe Steuerpflichtigen müffen einen Theil ihrę Einfommens abgeben, um eine $\mathfrak{A n}_{j} a \mathfrak{l} \mathfrak{l}$ von 3 inzempfängern

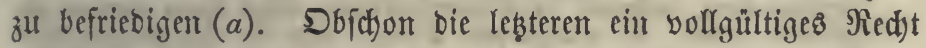
auf biefe (Einnabme haben, io ift bod) unverfennbar bie von

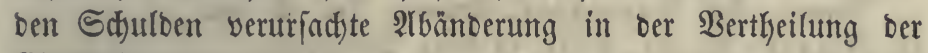
Cinfünfte cine unvortheilhafte, uno eine unüberlegte Bermeh)=

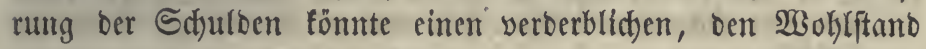
untergrabenten, mandhe 2rebeiter in Dürftigfeit uno 2 rmuth

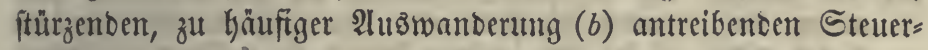

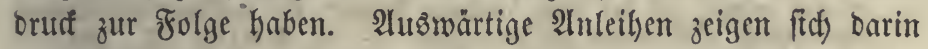
unvortheillyafter alz einheimifaje, baß bic 3injen nicht im $\mathfrak{a} a n b e$ verzekrt werben unt baher feinem Stantäbürger Bejtäftigung geben; biejer Racththeil minbert fith intefifen, wenn bie Binfen Den 2luslänbern burd) 2 saarenifentungen vergütet werben unb

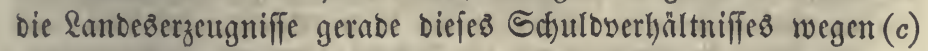
cinen gröferen und vortbeilkafteren 2 bją̧ finben, als er fonft fein würbe. - Man hat audh öfters bie aus einer grofen

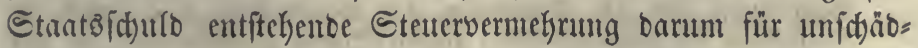
(ict) gelyalten, weil bie Bürger fith an bohe Steuern gewöbnent 
uno nus ihnen einen ftärferen 21ntrieb zum Flcipe und zur Sparjamfeit erhielten, \$. 268. Dieje Erroigung fann zwar

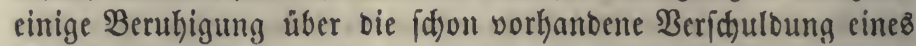
Stantez gewaifren, aber eine weber yon ber Rothwenbigfeit gebotene nod) bur(f) ifre $\mathfrak{B i r f u n g e n ~ v e r b a ̈ l t n i s m a ̈ b i g ~ f r u d t b a r e ~}$

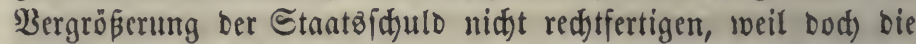
vermehrte saft Der Steuern ben Capitalanwad) idywåcht und Diejenigen fehr befdywert, bic ifre (Einnahme nid)t zu erweitern

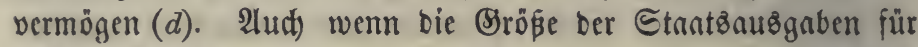

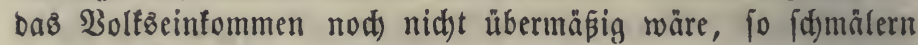
Dod) bie 2lug̊gaben, weld)e von einer früheren Berwenoung für offentlidbe 3wede herrithen, 'bie Mittel, mit benen bie Fülle gemeinnübiger (siurid)tungen für bie Segenwart unterbalten meroen fönnte (e).

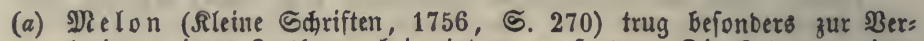
breitung jenes Irrthums bei, inbem ex fagte: "Die Sdaulben eines

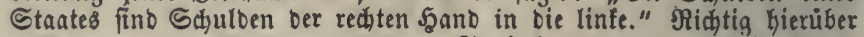
Montesquieu XXII, Cap. 17. - Smith III, 388. - Nicarbo, 17. (5ap. S. 257 Der Uteber. yon Baumftarf (II, S. 6-9 Der franz. Weberi.) ift ber \$ieinung, bie 3inszahlung fei feine Laft für bas Bolf, weil es ungetwís fei, ob ber Ssmufänger oder ber 3ahler bie Summe beffer verwende, unb nad ber Bernidstung ber Edulto Dow Das Eapital unb Esinfommen bes \$olfes nod Daffelbe bleibe. - Allein Die Ctaatsglaubiger nebmen meiftens ifren unterhaltsbedarf aus ifjer Sinbeinnakme, währent bie Steuerpfliditigen, wenn ihnen weniger $a b$ : geforbert würbe, bie nachgelafiene Summe nidft für ihre nothwendigen Eebensbedưrniffe zu verwenten brauchen und baher mehr zurúflegen

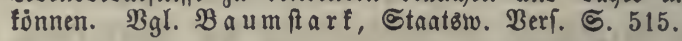

(b) Nicarbo S. 261. B. II, 12 franz. Heberię̧ung.

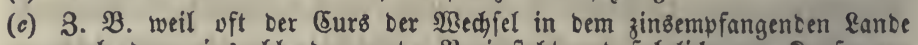
nach bem zinzzaflenben unter \$ari fteht uno folglid zum Saufen ex: muntert.

(d) Der Jrtthum, Dá bie Staatsobligationen ein neu exidaffenes Bers mögen feien, weldees bie Confumtion ber geborgten (Sütervorråthe wieber eríę̧e, ift bei bem heutigen Stante ber volfz̈wirthidgaftliden

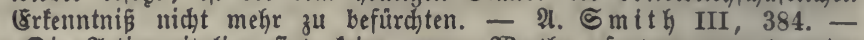
"Die 2Activcapitalien fino feine neuten 2 Berthe, fonbern nur traurige und famerzhafte Erinnerungen an bie vernichteten", Rebenius I, 669. - Bergl. oben I, S. 279. - Dennod findet jene Borftellung nod) immer ibre Anfänger, $z . \mathfrak{B}$ in ber Edjrift: Ueber Den Staatss crebit S. 33, nad) weldher bie Staatsidhuldbriefe bis zu eitrem gewiffen Srabe bie Stelle ber flingenden Nänze vertreten uno alfo Die Cavitale Der Ration vermehren follen; ferner in Ler Sdarifit: De Schuld van den Staat, als aanwinst van het National-Vermogen, 's Gravenhage, 1839, f. den Tex in Nederlandsche Jaarboeken roor Regtsgeleerdheit en Wetgeving, II, 352. - INortimer a. a. D. fudt Şume's

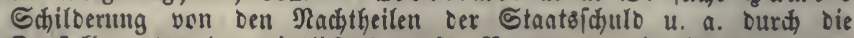
Darftellung bes (vermeintliden) groben Nukens zu wiberlegen, ber aus

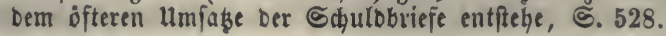




\section{1}

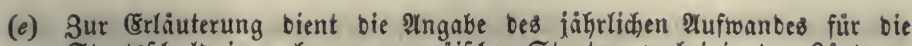
Staatofidulo in mehreren europaifhen Stanten, robei in ben Rảnbern, meldhe Stantzeifenbahnen haben, unter a) Die ganze शlusgabe für bie Sdulb, b) biefelbe nad शtbug bes auf bie (Sifenbahnidulo fommenben 2ufwandes angegeben ift. In ber 2. Spalte ift bas Berbältnis zu

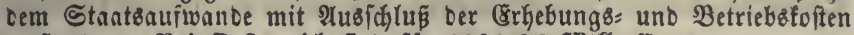
berfanden. Bei Defterreich find für 186437 Mrill. Ëw. angenommen.

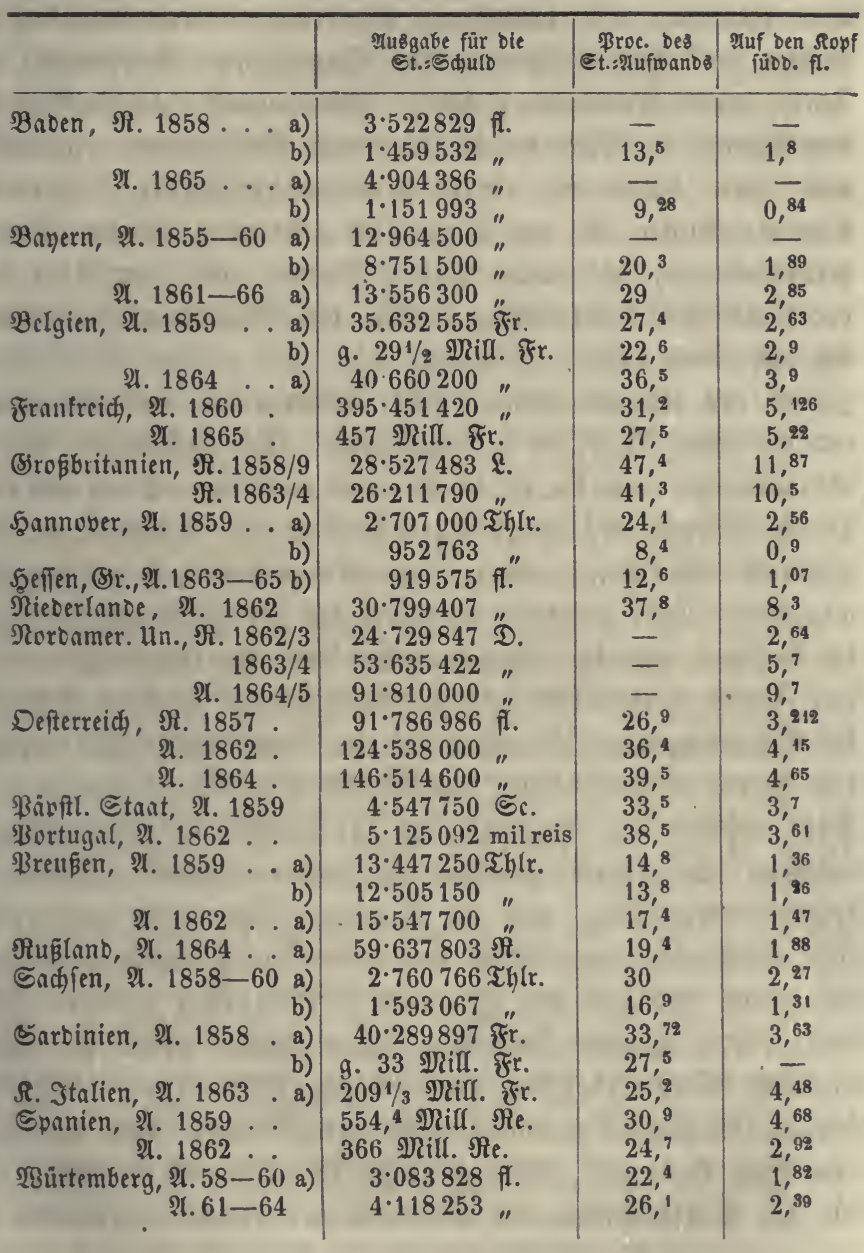

§. 478 .

Wenn anfehnlidye Staatzaubagaben nothrwenbig finb ober für müblich eractstet werben, fo mus man aud) bie grope augens 
blifficthe (Erleidfterung in Infdhlag bringen, weldye in bem

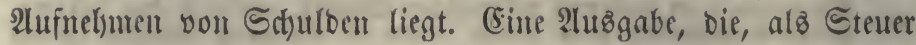
gefordert, vielen Bewwerben die nöthigen Capitale unt vielen Steuerpflitttigen einert Theil ber Ilnterhaltšmittel entziehen, alfo umerid)winglich) ooer wenigitens fehr brüfent fein whitbe, wiro num mit ben idton zum 2lubleifen beftimmten ober bod)

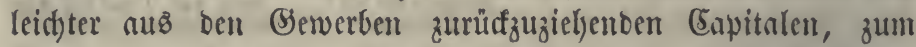
Theile yom Altublande gebeft. Min braud)t einftueilen mur

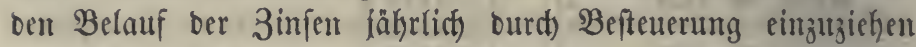
unt fann bafer mit einem gerwiffen verfügbaren Theile ber StantBeeinfünfte für ben 2lugenblif eine weit gröpere Wirfung hervorbringen, als wemn man ifn unmittelbar zur Beftreitung Des Bebürfniffes verwenten wollte, bic Albzahlung aber vertheilt fith) auf einten langen 3eitrnum $(a)$. Die gropen 2lus̊gnben in 3eiten beż Siriegez oder anberer außeroroentlict)er Berhăltniffe madyen baher 2 mleiken unvermeiblidy. Die 2 mmafyme, Doß bie Staatzbürger eine für ifhr (Sinfommen z̆u fd)were Eteuterlaft ourch Privatauleihen leidht nufbringen fönnten (b), ift unhaltbar, benn

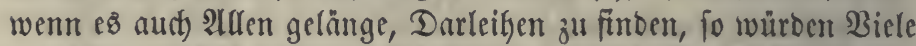

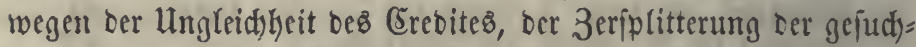

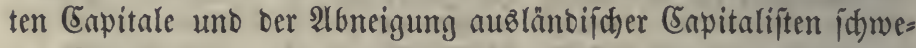
rere 3infen zu entridjten Kaben, überbiés bleibt audb bie Anlegung ber Sdjakzungen, an bie man fidh in einem foldhen Falle vorzüg= (id) Kalten müßste, immer unbolffommen unb bei einem fo hohen Fupe würben bie llngleidheiten ber Ratafter höd)it empfindlid werben. Bei einer gewiffen Şöhe der Steuern eridjeint es

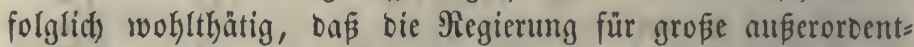

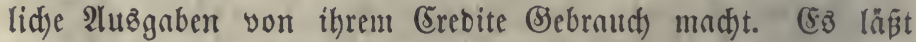

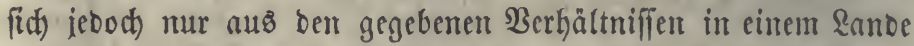
beurtheilen, ob bab 2lufnetymen einer Sefuld ober bie augen= bliffictbe Steuererböhung ben Sorzug verbiene (c). 2lud) für

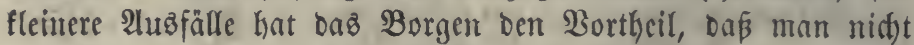

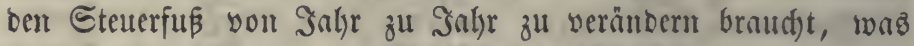

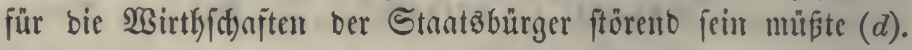

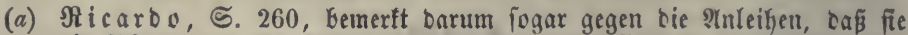

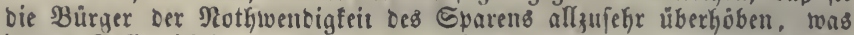
in bem falle ridgtig wäre, wenn man fdgon borgte, wöhrento oie Éteuers

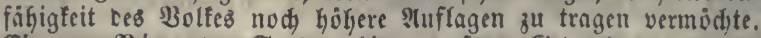

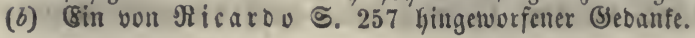




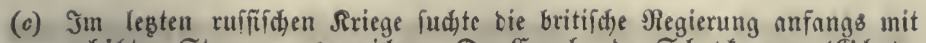
erhobten Cteuern auछzureiden. Der Eanzzer ber Schabfammer (B) I $D$

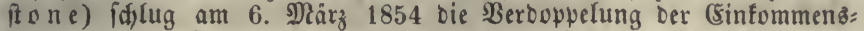
fteuer vor unb lagte u. a.: "Der Rrieg hat einen gewifien (S)Ianz unb

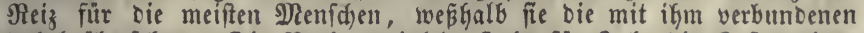
uebel überfeken. Die Nothwenbigfeit, Jahr für Sahr bie Roften cines Rrieges zu bezahlen, ift ein heilfamer Bnum. Slan muś nun über= legen, was man thut und im Boraus bie Bortheile berechnen, Die aus ber tibernommenen 2 tusgabe zu erwartell find." Der auf (S) I a fit one's Intrag gefaß̄te Bejd)luß̈ fonnte aber nidyt wieberholt werten, alsz ber

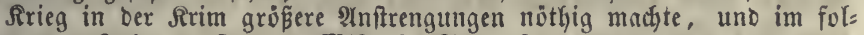
genben Sahre musten 16 Dill. $\mathfrak{Q}$. St. aufgenoumen werben

(d) de Gasparin et Reboul, S. 13: L'impôt variable c'est pis encore que l'impôt excessif.

\section{§. 478 a.}

Aนज ben vorftehenden Säken über bie Wirfungen ber

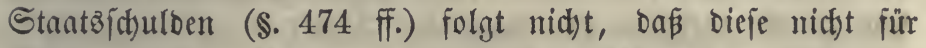
andere 3 wedfe alz bie gewerblicke Capitalanlegung zu Sunften

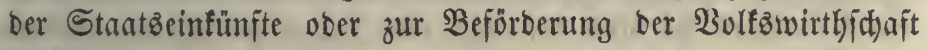

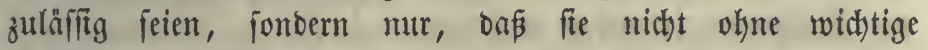
Srünbe gemadyt werben bürfen, unb oaßs, wenn fie nicht zur Erhaltung bes Stantes ober burd) cine andere Notfmendigfeit geboten fino, ber von ifnen zu erwartenbe $\mathfrak{B}$ ortheil für ben Staat mit bem von bem Bolfe zu übernefmenben (S)üterauf= wanoe verglichen und Darnady Der Befdylü gefaßt werben foll. Der Unterichied in Der Dauer Der WBirfungeu einer Stantz= augagabe if bisker in ber Finanzberwaltung wenig beadtet

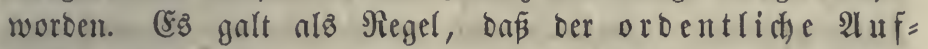
wand bou Sabr zu Sabr aus ben gleichzeitigen (sinfinften bejtritten werben müffe, weil fonft ber Etantşhaushalt nicht nacblyaltig uno ber @taat nicht lebenşähbig fei. Bei bem außerorbentlichen 2 ufwande beurtheilte man aub feiner

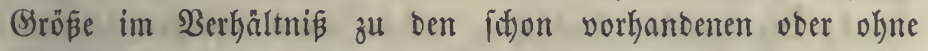
Sdywierigfeit zu ermeiternben Einfunften, ob eine Anleike zu Saulfe genommen werden folle. Neuere Sibriftiteller haben ienen Unterichied mefir hervorgehoben uno ben Sabs aufgeitellt, bie Seredytigfeit fordere, baß alle fortbauernto wirfenoen Stantz=

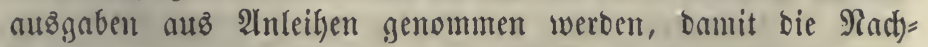
fommen zu bem 2lufwanbe, Deffer Früd)te fie genießsen, gehörig

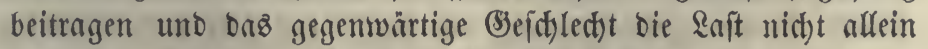
z̆lt tragen habe $(a)$. Şierüber läßt fith Folgendes bemerfen: 
1) Mod) abgefefen bavou, ob bie Decfung bes auf lange

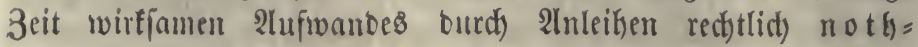
wendig fei, ift fie wenigftens zuläfig uno bei grofen 2luz= gabeu, weldye bie Eteuerfähigfeit ber Siegemwart zu ftarf in

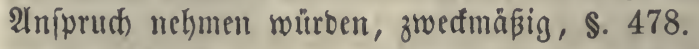

2) (Es ift aber in früberen 3eiten vieles Rüblid)e, beffen Folgen nod) empfunben werben, mit ben gleidzeitigen Mitteln von ben Borfahren zut Stanbe gebrad)t worben, okne baß ię̧t nod) etrona bafür geleiftet zu werben braudte, ez ift onfher

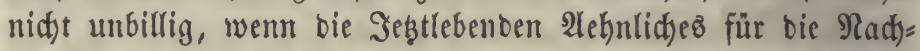
fommen thun, wo es leid)t gejdeken fann, zumal ba fie bod) aud) nod) an bem Benuffe ber $\mathfrak{B}$ irfungen theilnefymen (b).

3) Die Wirfungen einer einmaligen 2 tużgabe find ie nad) bem 3wede berfelben von ungleider Dauer.

a) In vielen zăllen ift biejelbe immerwährent, wenn z. B. ein Ulebelftant gänzlich) bejeitigt, eine \&aft abgelöft, ein bleiben= Des Befitthum erroorben wirb $(c)$.

b) W3irb ein für einen Stantżzmed beftimmtez Sadigut

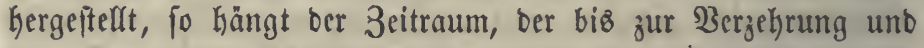
forglid) zu bem Beoürfni $\beta_{\beta}$ einer abermaligen 2 (n)

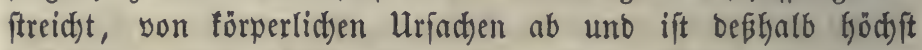
veríchieben $(d)$. Woolle man hiernu im Einzelnen genaue

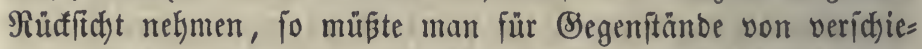
bener Dauer neben bem 3ins beछ 2 ufiwandez entiprect)ente Tilgungarenten ausimitteln uno vermittelft ber Steutrn aufs bringen, bamit nidft fpätere (Befichledter zu einer "früheren 2lus= gabe nod) beizutragen hätten, bie fie fdjon wieber son Reuem übernełmen müffen. Dießß wäre fđjon ber Ulmftäntlidfeit wegen unausfithrbar.

4) Bei mandjen $\mathfrak{A} u$ grgaben, bie in einem gewiffen Beitpunct als unvermeiblid) erfdeinen, ift feine Dauer Der Folgen zut erfennen. Ess ifit z. $\mathfrak{B}$. bei ben Roften Der Rriegbriffungen, vber bem 2hufwant wegen eines unglüfflicten Ëreignififez $(e)$ un

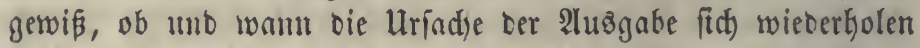
werbe. Bizweilen wirb ber (Erfolg burd) einen fpäter ein= tretenten Umitant aufgethoben ober geiftywädt; in einzelnen Făllen ift bie gute $\mathfrak{B}$ irfung im Eaufe ber Zeit balo allmälig abrehment, bald wadjeno, ilberbaupt läpt fidd biejelbe oft 
weder ifrer Stärfe nod) ifrer Dauer nadh in bent 2 ugenbria, wo ber 2lufwand gemadyt wirb, beurtheilen $(f)$.

5) Demnad) eridjeint eine genaue 3erlegung unto 2luzidjei= bung aller, aud) ber orbentlidfen 2lusggaben in mebrere Elafifen nad) biejem Befiettispunct weber als rechtlid nothwentig, nod)

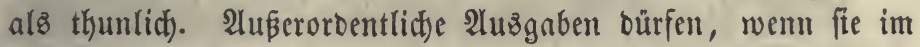
Berbältniß̄ zu ben Şülfömitteln ber Begenmart eine gewwiffe (5röß̈e erreiden, ausิ 2tnleiken genommen werben, bod) ift es ratthan, ba, wo fie hauptfädblid) Dem jestigen Menfd)enalter bienen, bie Steuerfräfte mehr in 2nnfpruch) zu nehmen, als bei einem offenbar lange bauernben Erfolge. Inleiken find alfo

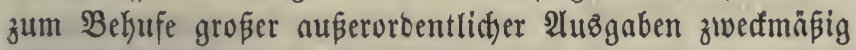

a) went fie nothmentig fint,

b) wenn fie bie Stantäeinfünfte ober zunächft bie Büters erzengung unt bas Einfommen bes $\mathfrak{B o l f e s}$ anffaltend zu vermehren verfpredjen,

c) wenn fie 3 anderen widtigen Berbefferungen im Staate bienen, fo baj bie unberedjenbare mittelbar probuctive WBirfung nidjt ber Şauptzmed ift, unter ben oben an= gegebenen Boraubję̧ungen.

Benn ein genaues Ébenmana zwifden ben Stantzlaften uno bem (S)enuffe ber Stanţanftalten in jebem 3eitalter nidjt Gergeftellt werben fann, wenn bie in ruhigeren 3eiten Sebenten fu ben wirthf(t)aftlidfen Dpfern beitragen müfien, bie in fitwies rigeren \&agen bes Strates nothwendig waren, ober audi) etwas zum Beften ber Radjfommen aufwenben, fo ift bieß nidft fon= berlich) zu beflagen uno entipridyt ben SFflidten ber Bürger gegen ben Stant (bab Baterland).

(a) Dief ift in Dem a. Buche: Influence of the public debt $(\$ 471(a))$ ausgefprochen, von Diezel a. a. D. weiter ausgeführt worben.

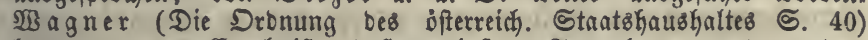

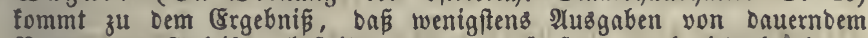
Nuben aus Inleifen beftritten retben oü rfen, bgl. jebod, ebenba ๙. 62. - Stein (Eehrb. 5. 471) räth ein geregeltes Syftem Der

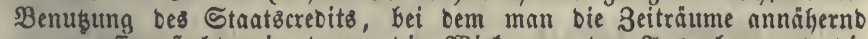

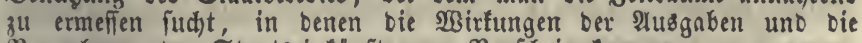
Bermehrung Der Śtaatseinfünfte zum Borfaein fommen.

(b) Wenn man annimmt, Daß̧ Die Steuerpfiliht im Durdhidnitt in einem getwiffen 2uter, 8. B. mit 25 Jakren, anfange, fo lást fich aus ben Erfahrungen über bie $3 a$ hl ber Lebenben von jebem Alter uno über bie mittlere \&ebensbauer jebes alters bie mittlere \&ebensbauer ber Steuer: pflidtigen berednen. Nady einem flüdtigen, auf bie Belgifden Grifah: 
rungen geftübteu Ueberid)lage itheint viefelbe 24 Sabre zu betragen, wobei zu bebenfen ift, baß bie jüngeren, nod, lange lebenden Steuer:

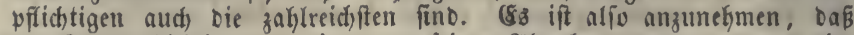
oer Steuerpflidjtige ven einer aus jeinen 2 bgaben vorgenommenen ein=

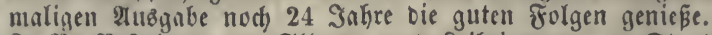

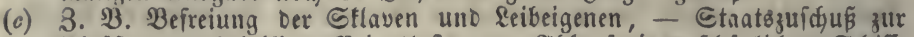

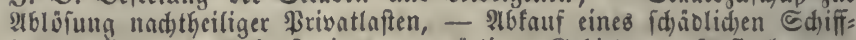

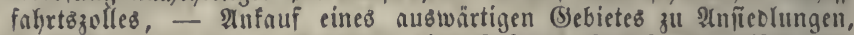
zu einem Sonfen $2 .$, - Inlegung ciner Feftung, Landitrabe, Sifenbahn,

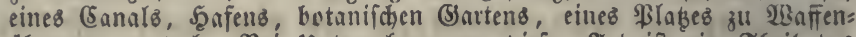
übungen $\mathfrak{u}$. Ogl. Bei Unternefmungen ciejer शrt ift cin Theil bes

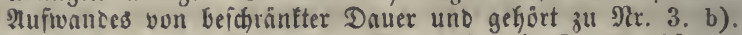

(d) Bon fefr langer Dauer find Baumerfe wie Etantzgebảube, Brïțen, Dautern, Dämme, ferner Gammlungen $2 c$., - von mittleter Dauer Drainanlagen, Sédjübe, Sdhiffe, itefiende Dampfmaidjinen, - von fürzerer Bferte, $\mathbb{B a f f e n , ~ B e r a ̈ t h e , ~ B a h n i c h i e n e n , ~ I l a f d i n e n = ~ u n d ~}$

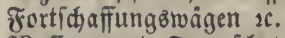

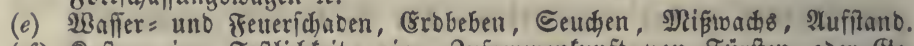

(f) Roften einer Feftlichfeit, einer 3ufammenfunft von Füriten ober (B)e=

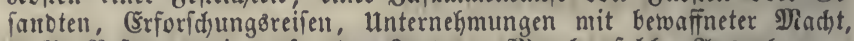

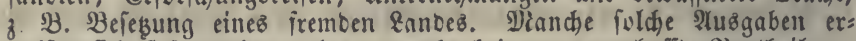
weifen fid foäter als nublos, mandbe bringen unverboffte Sortheile.

§. 479 .

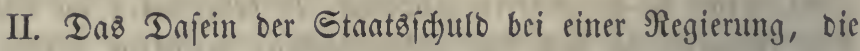
fich) Bertrauen erworben hat, ift fử Capitaliften erwünidst,

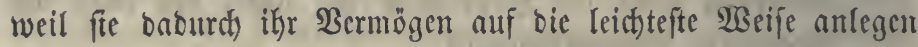
fönnen $(a)$. Zinstragende Stantżf(d)ulobriefe fino zul jeber Zeit zu erfaufen und eben fo leid)t wieder zu verfaufen, wenn man bie Eumme zurihfieken will, auth ift bie (Erkebung ber Zinfen jefre leicht uno bie Altzbezahlung erfolgt bei einer guten Finanz= berwaltung puntuctid. Dagegen gereidten bie in bem Santod

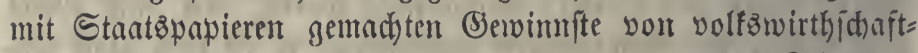
lictjem Stanbpuncte auz nidjt zutr (Empfehlung bes Situlben= wejens uno itberfaupt ift ber erwähnte Nutben beffelben in Bergleid) mit ben bargeftelltest Nadtheilen niddt hod) anju= ifflagen, I, S. 441. Hebrigens fann bie aus ber bequemen Unterbringung ber Selofummen entipringende Ermunterutg zum Ueberiparen aud auf andere Beife, im Sleinten mit Sparcafien, im Sroß̧en mit Erebitwereinen, guten Reifbanten u. Dgl., zu TBege gebradit werben uno ber (Erfinoungageift witroe $D a$, wo feine Stantsifyuloen fino, unfehlbar fold)e (Erebitanftalten her= vorrufell $(b)$.

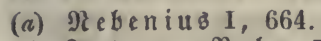

(b) In Dem a. Butche: Influence of the p. d. etc., wiro tie Etautsiduld als ein widjtiges Belebungsurttel ber (Eirculation und bes Unternef)= 
mungzgeiftes geffilbert; Sdiweben Gabe barum zu wenig Sapital uno

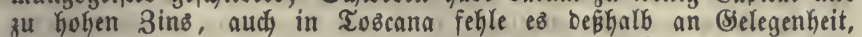
Sapitale gut anzulegen. - Şier ift uriadje uno WBirfung verwechielt. (S) werfe und Sandel erzeugen bie Capitale, welche Dann bem Stante gerieken merben.

\section{S. 480 .}

III. Wirfungen ber Sdulden auf Die Rage eimer Regierung. 1) Die Staatżgläubiger haben bei einem getwaltjamen $\mathfrak{B e c h}_{\text {fel }}$ ber Serfaffung, beż Füritenhaujez, überfaupt bei jebem Umfntrze ber beftekenoen Dromung einen Berfuft zu befürbteu $(a)$, baher ift ifre 2lnbänglictfeit an bie Regierung in 3eiten ftürmifoter Bervegungen ober ßarteifämpfe fehr nübslid), aber in ruhigen 3eitell, ober wo fonft ftärfere Banbe ber 3umeigung uno ber

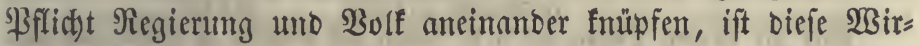
fung ber Schulben von geringerer Erheblichfeit. 2) Der ffreis

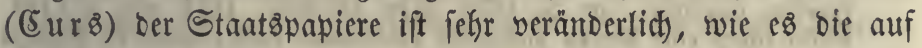

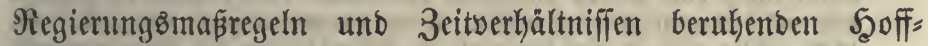
nungen uno Beforgniffe ber Stantögläubiger mit fith bringen, I, $\$$. 438. Seine Siöpe in einem gewiffen Strate, fowie fein Steigen und Sinfen Dient baker zu einem Rennzeichen, woraus Die Regierung ben Stano ber öffentlichen Meinung, insbefonbere bie Borftellungen einer wohlfabenden und unterridyteten (Elaffe von Bürgern wahrnekmen, unb bald eine Crmmuterung, bald eine $W_{\text {Sarmuth }}$ idjoppfen fann (b). Freilid) wirfen aud) vielerlei frembartige Urjacten auf biefen Curz, wef̧halb man nur mit Borficht Sd)lüffe auf ifn bauen Darf und überbaupt fann biejer

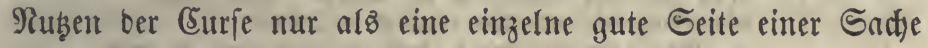
gelten, bei ber bennod bie Nadtheile überwiegend fino. 3) Eine verbältnifmäßig große Schulb, weldhe bie 2ufnabme netter Sd)ulben erjofwert uno bisweilen ganz berkinbert, ift ein läftiges

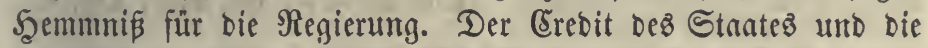

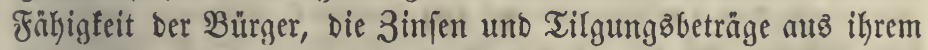
Einfommen abugeben, haben ihre Eränzen, unt es ift fehr bedenflich, wenn ein Staat feine Schulden fđjon biz an bie= felbe aubigebebnt bat, weil ihn mun für neue Sefafyren und Bebürniffe fein Şülfsmittel mehr zu Sebote fteht. Die Regie=

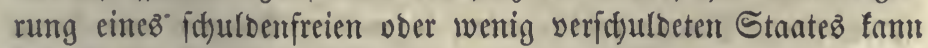
fit) in ben 2lngelegenheiten ber inmeren uno ausెwäntigen ßolitif weit freier betwegen und weit mehr Sraft entwifeln (c). 
(a) Benn bie in Sparcaffen nietergelegten Eriparniffe ber arbeitenben Elaffe in Stantspapieren angelegt, D. h. Der Negierung geliehen toerben, fo

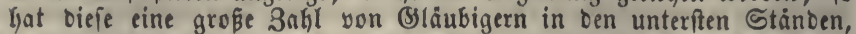
morauf man in Franfreich aus bem oben angegebenen (S)runbe befons beres (S)widht gelegt hat. Das (Suthaben Der Sparcaffen bei ber Caisse des consignations et dépots war im April 1845 auf $396^{7} / 8$ DRill. Fr.

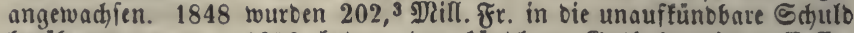
Gerübergenommen. 1856 betrug Das fünbbare Suthaben jener Enffen

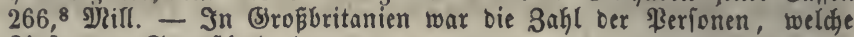
Sinfen ber Staatíctulo bezogen:

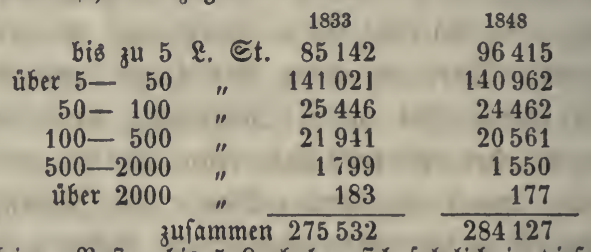

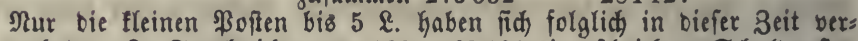
mehrt. - In Franfreich twaren 1825162833 eingefdriebene Sdultopoften (parties inscrites), im Э. 1830 f́jon 195570,1834 aber 213168 , wobei indés eine ßerfon mefrmals vorfommen fann, wenn fie \$apiere von veriđiedenem Singfuß befipt. Documens statistiques, 1835, S. 166. 1845 záhlte man in ben 5procentigen Gduldobriefen bei \$rivatperionen 36833 ßoften unter 100 Fr. Renten (Durdidnitt 55), 40186 yon $100-500$ (D. 260), 13424 von 500-1000 fr. (D. 740), 9710 von $1-2000$ (D. 1440) und 9009 von 2000 Fr. an.

(b) Dießs ift von 3 a hariả a. a. D. vorzughlid herausgefoben worten. "Wenn .... to onrf man wohl behaupten, Dá fein (gróserer) "Staat ofine Gdjulben fein barf, wenn feine 2ingelegenkeiten mit Stetigs feit uno Befonnenkeit verwaltet werben follen. - Für bie altariedifichen

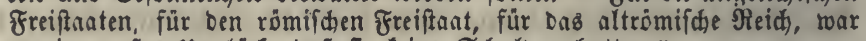

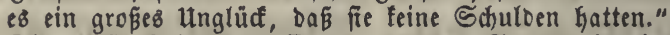

(c) Die groß̧e Sduulbenmaffe ber neueren Staaten hat jene riefenmásigen

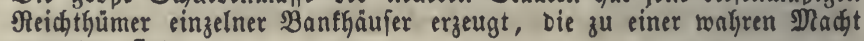
gelvorben fino.

Who hold the balance of the world? Who reign

0 'er Congress, whether royalist or liberal?

- Who keep the world, both old and new, in pain

Or pleasure? Who make politics run glibber all?

The shade of Bonaparte's noble daring?

Jew Rothschild and his fellow Christian Baring.

Lord Byron, Don Juan, XII, 5.

\section{§. 481 .}

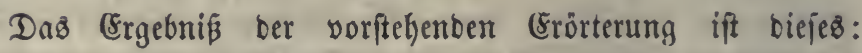
Sdjulben, burd) weldhe nidft bie Regierung unmittelbar eine fortbaucrube Bermefrumg ifres Cinfommens ermirbt ober ber

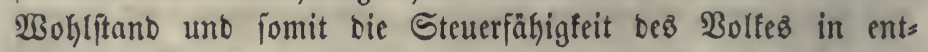
fprectendem Raaße erhöht wirb, legen ben Butrgern eine lange fortbauernbe wirthidjaftlidje Raft auf. Sie fönnen mur gered)t= fertigt werben, wenn fie zur Beftreitung unvermeiblidjer 2 us $8=$ 
gaben ober zur Şervorbringung cinez,, Daż Dpper von ๔ad)=

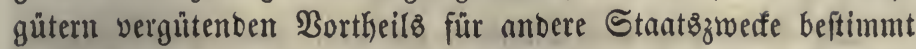
find, wenn in biejem Falle bie aus ber Sauld entftelyende

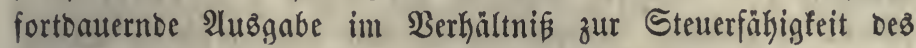
Bolfes nidht übernäáig ift, aud) ber 2ufwand nidht ofne gröpere Rad)theile aus Steutern beftritten werben tann. Da idon uีberkaupt jeber weber nothwendige nod) nüblidje Stants= aufroand zu tabeln ift, fo erfdeint ein foldher in erföhtem Maape verwerflid, wenn er mit Saülfe von Sdyulben vor=

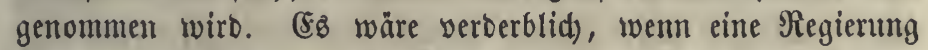
über Die WSirfungen ber Staatsfhuloen irrige Borftellungen hegte und baburd) bewogen würbe, obige Srunbfäz̧e zu ver= leķen. (şz ift jeboch) mid)t möglid), die Fälle, unter benen bas

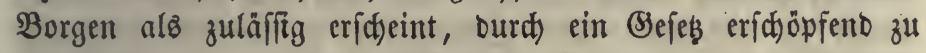
bezeidhnen $(a)$; mur die reiflichjte Ervwägung in jebem einzelnen Falle fann baber yor bem Mißjbraudbe ichüben. In Staten mit einer ftänbifd)en $\mathfrak{B e r f a f f u n g}$ gebört die 2lufnabme von Sdjulden zu Denienigen Regierungshandungen, weldye ganz vorzüglid) Die 3uftimmung Der Stänbe erforbern. Diefe Säkse find jebod) nidht auf einen geringen Betrag yon Anleiken an= wenbbar, Die Darauz entipringen, Daß Der Boranfidlag Der 2usgaben um eime fleine Gumme überfdritten werben muß ober Die Cinfünfte unter bem angenommenen Maaße bleiben. Fin foldber mäßiger 2lub̂fall fann (päterbin leicht Durd) eincu

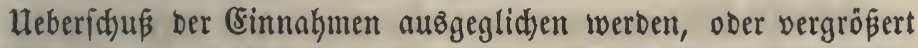
wenigfterts bic Schuld nidjt mehr, als in furzer 3eit wieber abgetragen wirb.

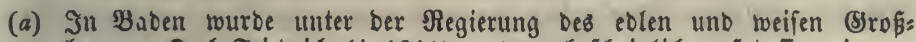
herzugs Sarl Friebrich ( $\dagger$ 1811) und wahricheinlich auf beffen eigenen

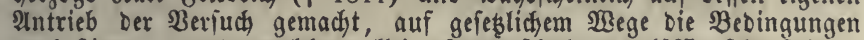
zu beftimmen, unter weld)en alfein Staatbichulden zuläfing fein follten,

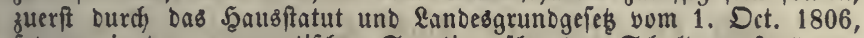
coban in ber "pragmatiffen Sanction über bas Sdjuldentwefen" vom

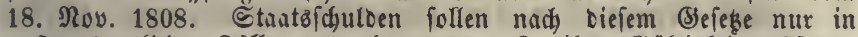

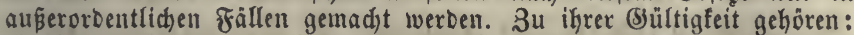

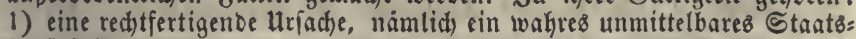
bedurfnís, und zwar entweber cine bleibende Randesverbefíerung, ober

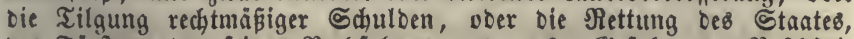

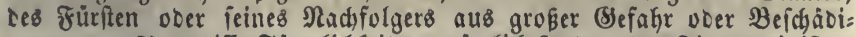

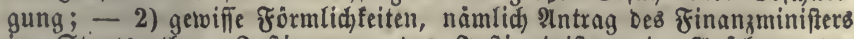
im Staatsrathe, Buftimmung Des Suftizminiffers in 21nfehung Der Rechtsfrage, foDann Stimmenmehrheit. Das Dafein biefer Beoingungen mus in ber Dbligation angefühet fein $2 c$. 


\section{0}

\section{§. 482 .}

Die शuinahme von Sdulben nuf Dem 3 ege von Anleiken gefdieht befto leidter, ie megr Der Stant Reifoertrauen (Eredit) geniebt. Diejer gewährt ifm nid)t blok bie Sidyer= heit, in alken Fällen eines plöblid)en Bebürniffes fich bie $\mathrm{er}=$ forberlidyen Summen veridtaffen zu fömen, fonbern bewirft aud), Daß̧ Diéß unter ben günftigften Bebingungen geidjeken fam. Nur ber (5rebit geftattet in einzelnen fdwierigen \&agen eine foldbe Fülfe Der Rraftentwidelung, bie zur Meberwindung

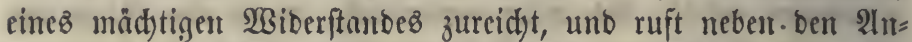
ftrengungen ber Staatżbürger aud) ben Beiftano aużwärtiger

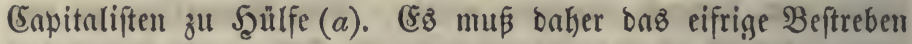
jeber Regierung onkin geridftet fein, fid) ben ausigebehnteften Erebit zut erbalten. Der Stantzecrebit beruht auj Denjelben (5)runburachen, wie ber (Erebit ber einzelnen Bärger (I, \$. 278), nämlich) Der guten Meinung von ben Şülfsemitteln und ber

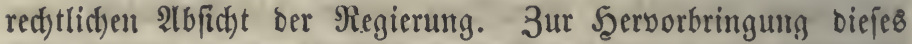
Bertrauens wirfen vielerlei Thatumftände zufammen, bie theils in Der Siemalt einer Negierung, theilz außer berfelben liegen, von benen jeood) fein einzelner für fich alfein entfdeibent ift, inbem vielmefgr alle zufammentreffen müfïen.

(a) গebenius I, 249.

\section{§. 483.}

Dic Şauptbebingungen beż Stantżcrebites Infien fid) 10 überblicfen $(a)$ :

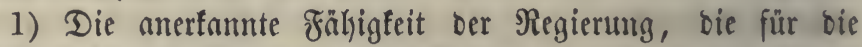
๔d)uld nöthigen 2lusggaben zu beftreiten (b). Dazu tragen bei:

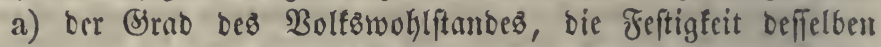
uno bie beutlid) erfennbare 3unahme beffelben, woraus aud) bie Reidtigfeit einer Steuererhöhung hervorgeht. 2lı Rennzeid)en ber befriebigenden Stenerfähigfeit bez Bolfez bienen ber 1 mmang ber Wroduction, ber fdyon benußsten uno nod) auf Benußzung wartenten (siiterquelfen (3. B. baufäfiges öbez \&anb), - die Befdaffenteit ber

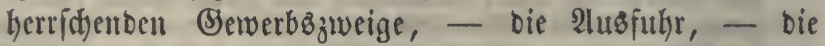
Bolfżmenge, - bie wirthf(t)aftlidje $\mathfrak{a} a g e$ ber veridjictenen Elaffen, - ber (Erab von wirthidantlider (Sinfidst, 


\section{$-351$}

Errwerbzeifer 2c., und ber Fortidyitt in alfen biefen $4 \mathrm{~m}=$ ftänoen;

b) Der gute 3uftand Desి Finanzwejents, inzobejondere bie gute Bemubung oer Cinnahmsaquelfon, bie Dromung und Spar= fanfeit in ben 2tubgaben, bie ftrenge lleberwadung in ganzen Stnatżhaußzhalte, burch bic jebe Beruntreuung, Berictwentung, Begünftigung 2c. verhütet wirb, - Die Bollftändigfeit, Deutlid)feit ber veröffentlidten Boran= (d)läge uno Redunungen, - bie mäßige Scöhe ber Steutern, bie gute 2 Inlegung berjelben und bie $\mathfrak{B}$ irfung, bie fie

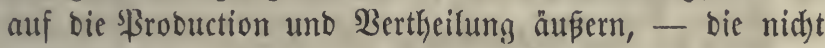
beunrulfigento (s)öpe ber fdjon vorbandenen Sctuld in Bergleid) mit ben zu ifrer Berzinfung uno abtragung verwentbaren Staatzeinfünften;

c) Die Feftigfeit ber ganzen Staatzeinridtung, - alfo gute Staatôverfaffung $(c)$, - natürliçe und fünftliçe $\mathfrak{B}_{e=}$

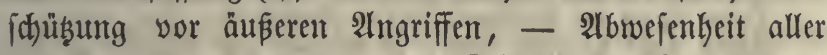
(Sefalyren für Dronung und Frieden im Snnern des Stantes; Dagegen find bebrohte Stellurg gegen Das 2lus? lano, leibenjhaftliche Warteiungen, 3wift und (5rofl im

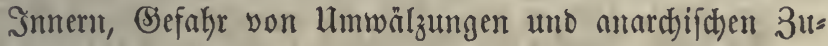

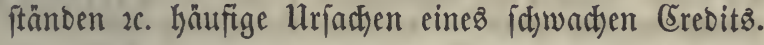

2) Die Uleberzeugung, Daß eine Regierung ftets ben feften Yorjałs hege, ifren (Släubigern bas zu leiften, was̉ ifnen zu= gefagt worben ift. Beifpiele begangener Ungered)tigfeit fidwähthen ober vernidyten ben (Crebit, Serwiffenhaftigfeit, troßz aller Sdfwie=

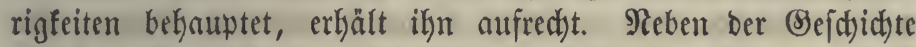
Der Sdyuloverwaltung eines \&andez trīgt aud) ber ganze (S)eift

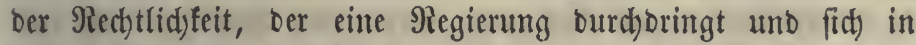
vielen Beranlaffurgen funo giebt, bazu bei, ifr baz Bertrauen oer Capitaliften zul gewinnen $(d)$.

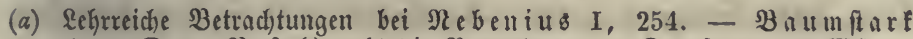
(a. a. D., 1. Beriud) geht bie Berwaltung Der Domånen, Das İünz=, Steuers und Ed)uldenivefen, aud) bic formefle (sinridytung bes Staats: Gaushaltes in Eimzelnen burch, um, Den Einflus jeber Slañregel nuf Den (Erebit aufzufudjen.

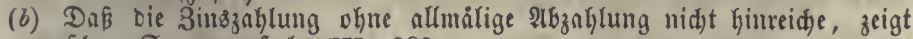
fdjon Sonnenfels III, 382.

(c) In Den Sionardien mit 'Bolfswertretung trägt es viel zur Befeftigung Des Crebites bei, Daß zu Den Anleihen (\$.481) fo wie zu Dem Etants: Boranfdlage bie Suftimmung ber Stande erforberlich ift unb von biefen 
bie Stantorechnungen forgfältig gewrüft werben. In abjoluten Mlowar= dien fann leidter von einem einzelnen Dinifter eine idäblid)e Draßregel ausgefübrt twerden. Sonnenfels III, 381: "Se unbefdrantter eine Devnardjic ift, Defto begrånzter ift ifre (5redit; Der Despotismus hat

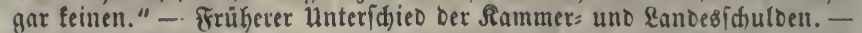

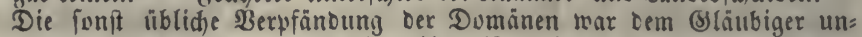
nüs, weil es nicht zur wirflidjen Esinweifung in bic verpfänceten (Segen=

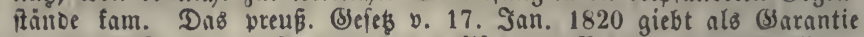
ons gauze Staut8vermogen an uno exflät Den Betrag Der verzinslichen Edulo mit 180 Dill. Thlr. für gefdlofien, fo Daßs neue Darleifen

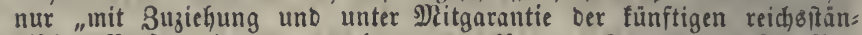
bif́chen Beríammlung" gemadht werben foumen. Art. II. - Die Ber= offentlid)ung Des ganzen finanz= und insbefondere Des Gdjulbenweiens wortt gunftig auf Das Bertrauen uno if Daker aud in Denjenigen Staaten zu empieflen, wo bie. Berfafiung nicht idjon fiezu verpflichtet.

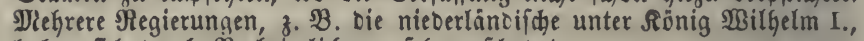
haben fith Durch Serheimlicfung fefr geidhabet.

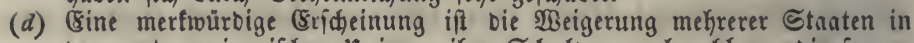
ber norbamericanificen union, ifre Sduloen zu bezahlen, die fogen. Repubiation. Sie ging vom Staate Nififfifipi aus uno tourbe auf bie Behauptung geitüt, Die Anleiken feien nidst in gefeşlicher Form gemadht, aud gróstentheils unreblich berihleubert worben. Şies ourd entifand 1841 ein ungeheures Sinfen ber Sdyulofdeine mefrecer Stanten, bis auf ungefẩy 20 \$roc. (Fün 巨tanten füo fकultcenfrei.) Daher flagte Der \$ráfioent $\mathfrak{z} y$ lex (Botichaft v. Dec, 1842), Dá̉ Die union niaht vermodit Gabe, in Gurova eine Anleike zu Śtande zu bringen, obidion europäifhe segierungen um niebrigeren 3ins gelieken

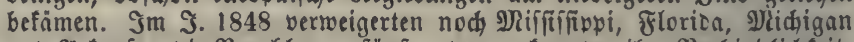
und Artanfas bie Bezahlung, fünf andere erfannten ihre Berbinblichfeit,

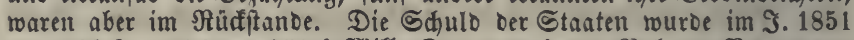

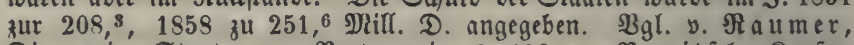
Die berein. Staaten von Norbamerica 1,406 . - Nopiti申, Raufm. Berichte ऽ. 285. 1849. - American Almanac for 1859.

\section{§. 484 .}

Beitere Bemerfungen über ben Staatzerebit.

1) (5z ift nidht vorherzujehen, wie weit fid) ber (5rebit eines wohlgeoroneten uto regierten Stantes erftrefen fönne. (5in

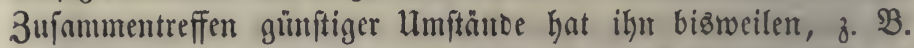

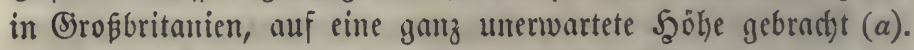

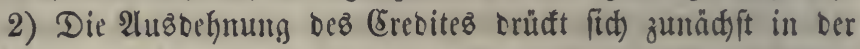
Bröße Der Summe aแt, bie eine Regierung gelichen erhalten faum, unter übrigens gleidyen llmitünben aud) in bem nicorigen

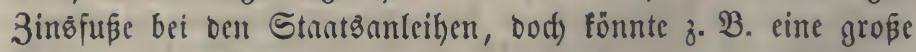
Infäujung von Capitalen voer eitte Stodung in ben Serwerben

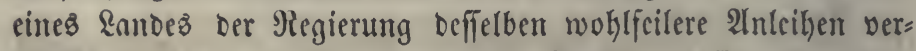

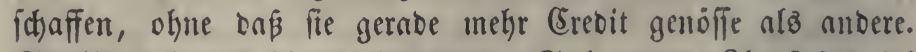

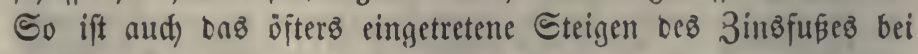

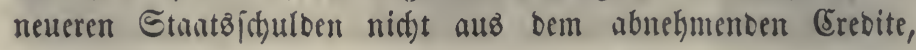


fonbern nuß bem fteigenten Begehre von Reiffummen zu er= flären.

3) Biele Regierungen fino ber $\mathfrak{B e r f u d y u n g ~ u n t e r l e g e n , ~ v o n ~}$

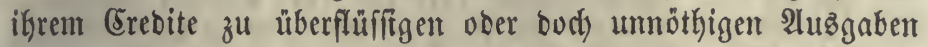
(Bebrauth zu mactjen, weil fie für bie geborgten (Enpitale zu= vörberft mur bie 3infen aufubringen hatten. Bon biefem

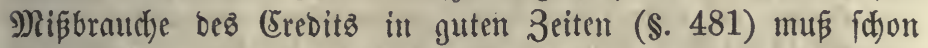
bie Crwägung ber langwierigen Inftrengungen, bie eime Schulb biz zแ ifter gånzlicten शlbtragung erforbert, umb ber (B)bante,

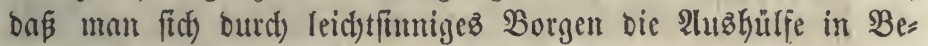
brängniffen veriperrt, bringeno abmabnen $(b)$.

4) Die Sduldoen ber beutigen europäifdyen Stanten rithen größtentheilz von fđwweren Sriegen her, bie anf tieje Weife nod) lange furt it ben Friebenżzeiten nadwirfen. Die Friege werben heutiges Tages mit einem Sraftaufwanbe gefüfrt, weldher felbft bei günftigem 2luzgange ofne Sd)ulben faum zu beftreiten ift. Die hieburd) angehäufte Sthulbenlaft vieler Staaten hat

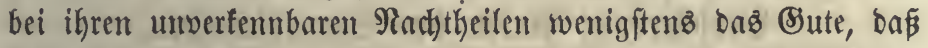
fie von netten Rriegen abjält, Deren Soften entweber bie Bränzen

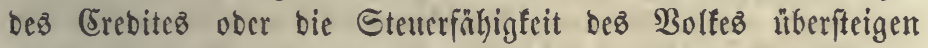
fönnten $(c)$.

5) Dic (Sejdidjte ber Stnatşidulben zeigt beutlich, wie

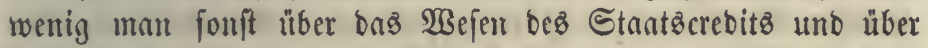
Die befte Benubungarart beffelben unterridtet war. Die Cimftet in biejen (Segenftand hat fid) im jesigen Sahrhumbert libernus verbolltommnet, woourd) theils bie aus bem Eduldenwefen entpringenben Dpfer für bie Steuterpfichtigen verminbert, theils die Rechte Der Stantżgläubiger mehr geftuert worber fint.

(a) Sgier fam ber beifpiellofe Alufidiwung ber Betwerbe und bes Sganbels hinzu, um eine Gdjulbenmafie exidjwinglidy zu madjen, bie einen anbern Stant eronilut hätte.

(b) 2. Smith fdjilbert, wie bisweilen fe!bft ber Bürger mit ber Fortfesung eines Rrieges zufrieben ift, Der ifym antegente Retrigfeiten bereitet und

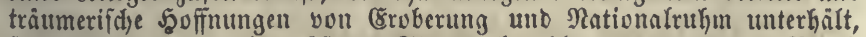
fo Dá̉ man gerne die gröp̈eren @teuern bezahlt, III, 376. - Bergl. S. $478(c)$.

(c) $\mathfrak{B g l .} \$ .478(c)$. - Nur wenige Stanten fino Kentiges Tages fajulden=

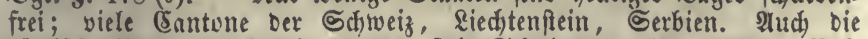

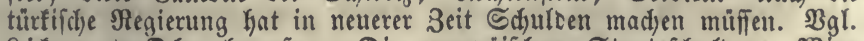

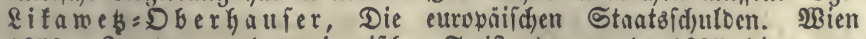
1850. In Den norbamericanif̧en Freiftanten twurbe 1835 bie gamze Sdulto abbezahlt, twelche atts bem Befreiunggfriege unb Dem fpăteren 
Sriege mit (Srof̧britanien herrilkrte uno 1816 ifren Göditen Stanb (1271/3 9)Rill. Dofl.) erreidt Katte. Allein 1837 in ber 3eit Dex Banf: berwirrung wurben fidun wiecer zinstragenbe Sdabfammeridjeine aus: gegeber, um Den शxusfall in ben Eintunftell zu Defen, unb zur Esin= ziekung jener Sheine twurben 1842 uno 1843 Inleigen von beinake 15 grifl. Doll. gemad)t. Im Rriege mit Mexifo ift oie Sdjulo betraidt=

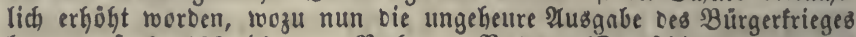
fommt, f. \$. 488 (c). - Nach v. ReDell (Deutidyland uno cas übrige (Suroua S. 1016.1079$)$ belief fid 1854 Die Sduld Der bentiden

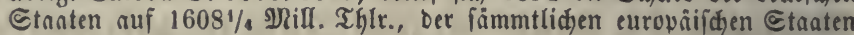
auf 12854 פill. Thltr. ober 48,23 Thlr. auf ben Ropf. - In feinem curopäifden Staate hat bie Ed)ulo farter zugenommen als in

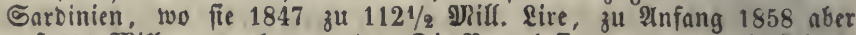
auf 677 Mial. angegeben wurbe. Die Beranlafilungen waren bie Rriegbs= entidsioigung an Defterreich mit 78 Milf., Die Ruften Der Rriege bon 1848 und 49 mit ungefähr 127 Itill, bie Roften Des firimfrieges mit

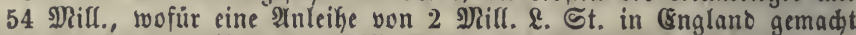
wurbe, unb ungefäbr 167 शlife. Roften ber Gifenbahnen bis 1854. Reuerer 2nwadj f. §. 463 (e).

\section{2 btheilung.}

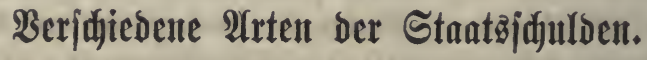

§. 485 .

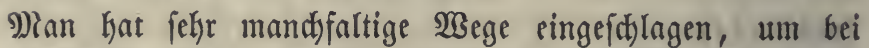
einer Unzulänglichfeit ber Staatछ̄einfünfte bie Benußzung eines fremben $\mathfrak{B e r m o ̈ g e n s ~ z u ~ S ̧ u ̈ l f e ~ z u ~ n e f u m e n . ~ M a n d j e ~ b i e f e r ~} \mathfrak{B e r}=$ fucje entftanden aus ber Unfenntniß̄ ber wahren Srunbjäze Der Finanzflugheit unb ber Scoffnung, Durd) nette funftlidye $\mathfrak{B e r}=$

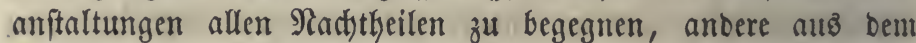
Beftreben, bas Sdjuldemmadben zu verbeffen, ober ber Iloficht, burd) anbere Formen, Namen unt Bebingungen bie Capitaliften geneigter zu machen uno anzureizen $(a)$. Ein Theil diejer Maßregeln erict)eint bei genatter \$rüfung nlsె verwerflich, on fie mit ber $\mathfrak{W u ̈ r b e}$ einer von fittliçen Srunbfäben geleiteten Regierung uno ber Sdjonung ber $\mathfrak{B o l f z z}$ wirth/d)aft unverträglid) finb. Die Arten ber Shulden zerfallen zuvorberft in zwei Şauptclaffen, erzwungene und vertragşmäß̈ige, bei welchen bon Dem Stantzecrebite (Sebrauth) gemad)t wirb. $3 u$ Der erfteren Art hat man fich ofterz gerwentet, wenn man nidht auf einen Ginreidenben Erebit ju bauen wagte, fie fint jebod) größstentheil(s weit nacththeiliger als bie freimilligen Anleiken. 


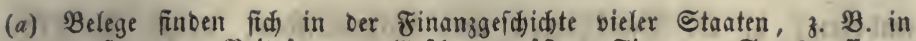

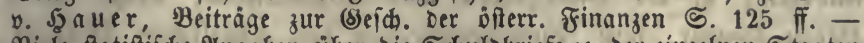
Biele Patiftifde Angaben über bie Gdulobriefe $2 c$. Der cimzelnen Stanten

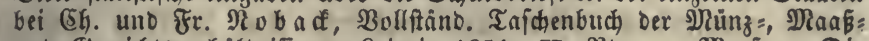
uno (Selvichtżverhâltnifie 2c. Reipzig 1851. II. 23D. - NR ofer, Die Anlage in SRerthpavieren. Ctuttg. 1860. Deff. Beitidyrift für Capital

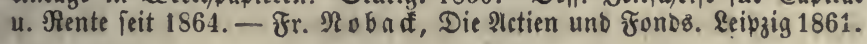

\section{§. 486 .}

3u ben erzroungenen Staatzidulden funb zu rechen:

I. $\Re$ uี ff trauen zu einer Finanzberwaltung mefir zerftören, als wenn fie Die verfprodjenen 3ahlungen nicht zur rechten 3eit ausfüfren und alfo die Forberungen ber Beamten, Zinzిgläubiger, Bewerbs:= leute zc. nicht befriebigen fann, \$. 463 a. Es ift baber nöthig,

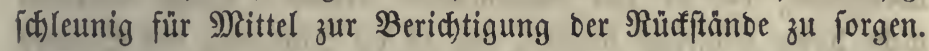
Den Inthabern foldyer Forberungen verzinzliche Sdhulbidheine einzuhänoigen, twie bießs bizzweilen geichah, ift nur eine geringe Milberung Deş Uebelítanbez, weil bie meiften Eläubiger biejer 2rt bie aubftebenoen Summen zu ifhen 2lubggaben nid)t ent= behren fönnen uno beim Berfaufe ber empfangenen Sduldofdeine gewöhnlid) etwas cinbüpen.

II. Seforberte Steuerborfdüffe (Anticipationen).

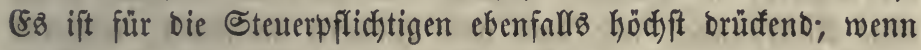
fie ifgre Steuern auf einen gewviffen 3eitraum voraus entrichten muifien. Die seftattung eines bie 3infen vergütenben 2 bzuges

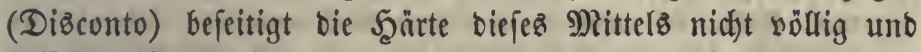
baffelbe ift ebenfalls nur als augenblicflidye গlothbülfe ciner

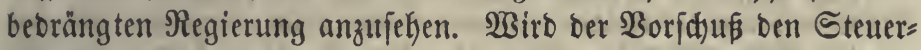
pflicttigen freigeftellt, fo gefjört er in bie 2. Claffe ber Sdjulden.

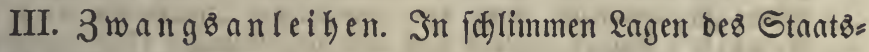
haushaltes gewäkren fie zmar eine augenblictliche Şülfe, aber biefe ift mit erbeblichen Nachtheilen verbunben. Dic Nöthigung 孔u einem Borfchuß müpte, um gered)t zu fein, gefeslids alle Stenerpflidtigen treffen, beren reines Cinfommen ein gewiffes Naaß überiteigt, aber aud) bann, und abgejehen von ben $\mathfrak{U n}_{n}$

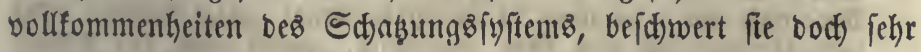
ungleidmäßig, weil bas Alufbringen und Entbekren einer ge= wiffen Summe bei einigen SIaffen ber Steuerpflidtigen, z. $\mathfrak{B}$. Den (S)rund = und Şaubeigentfüutern, nod) fduwerer ift als bei 
anberen, 子. B. Bantlerren und Eapitaliften, vergl. \$. 478.

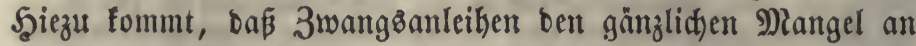
(Erebit vermuthen laffen unb baburd) ihn wirflid) erzeugen.

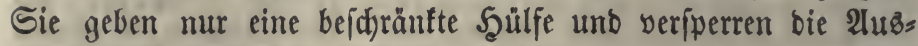

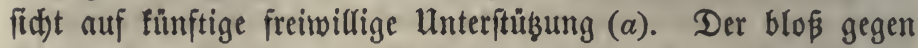
Bemeinben, Stiftungen, Bormunber 2c. geridjtete 3wang, bie auszuleikenben Summen in Staatżithulbbriefen anzulegen, ift ein Mi isbraud) ber obervormunbidjaftlid)en Serwalt.

IV. Búrgfdiftzgeloer (Eautionzcapitale) ber Beamten, bie mit ber Bermaltung offentlidjer Belber beauftragt

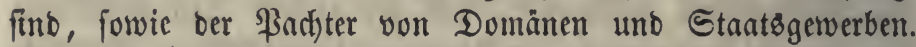
Man pflegt bieje Bürgidjaftzijummen ber Sdjulbverwaltung zu übergeben, bie fie ben Ingeftellten verginft. Wenn biejelben niidjt höher fefitgejeşt weroen, alz ez bie Sidjerung bes Staates gegen $\mathfrak{B e r l u f f e}$ erforbert (\$. 567), fo ift bieje Cinridtung zwects måsig, aud) wirb fie allgemein angetroffen, nur gewährt fie feine bauernbe 2luşüllfe. Beftehen bie Cautionen nus Ginter= legten Staatß̊papieren, fo müfien bieje yon anbern Befízern erfauft werben unb bie Schulb wirb hieburd) nidft vergrößert, aber baar eingezahlte Summen bilden einen befonberen Theil ber Sdjulb, in weldtem jährlid) viel $3 \mathfrak{u}=$ unb 2 lbgang burd)

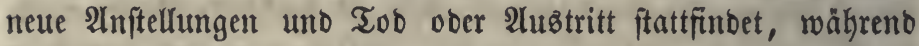
ber Eefammtbetrag ziemlid) gleid) bleibt (b).

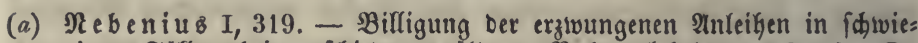

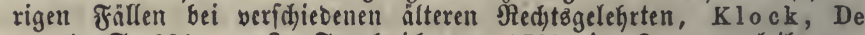
aerario S. 331. - In Frantreid, war 1793 eine 3wangbanleike von 1000 I)

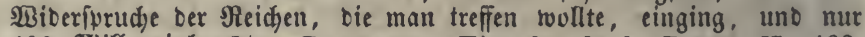
400 Slifl. einbradte. Bresson, Hist. fin. de la France II, 192. 245. Thiers, Hist. de la revolution franç. VIII, 188. 510. Die ipatere 3mangsanleike unter bem franzönfकen Directorium wurbe auf (5) a u o in's Betrieb logleid nad Dem 18. Brumaire 1799 abgeidafit. (88 follten 100 IJill. Fr. geliehen werben, bie eine Jury nads ben Rataftern unb nad eigenem Ërmefien auf bie Cteuerpflidatigen umzu= regen hatte. (S) a u b in erieste fie burch einen Stenerzuidhlag von 25 (5t. auf bie Brumb = uno Diobiliariteuer, zur \$̧âlfte in Crebitpavieren bes Directoriums zahlbar. - In Defterreid entitand 1705 eine 3twangs: anleike von ber Şälfte bes im \$rivatbefỉe befundidyen Silbers, in natura ober in Sielo zul entridten. 1760: Seloer Der Stiftungen, Dinberjâhrigen $x$. musten in iffentlid)e fonds gelegt werben; 1794 Smangbanleike zu $3 \frac{1}{2}$ \$roc. verzinslid, genau nad, bell Cteuer: anid)lägen bemefien uno von mäsigem Betrage, wie eine Steuer: erhobung anzuieken. Dieß Berfahren wurbe mehrere Jahre lang roieber: fult. Die Berzinfung Diefes seriegsonrlehens hörte 1804 auf. Das Patent vom 1. Juni 1798 grünbete cie log. Irrofirungsanleige. Die 
Inkaber oer Banfobligationen mußten naimlid 30 \$roc. Des Nominal= betrages baar zufdiésen, bagegen erhielten fie fatt ber 4proc. neue 5proc. Dbligationen für Das (sanze, Die jeood) 1811 ebenfalls unter Die Sinserniebrigung fielen, \$. 516. Aelynlidjer 3wang zum গad)= fafilen weiterer $20-50$ \$roc. bei ben fog. Supferamtscapitalien, Batent bom 1. Juni 1800 . b. Şa uer a. a. D. Tebaloi, Die Belbangelegenkeiten Defterreidjs S. 7. 2uch Das Inleken von 1806 war unit 3roang verbunben. - 3wangsanleige in ber Lombarbei 1850. -

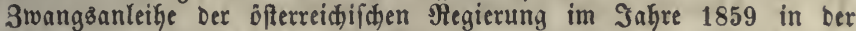
Lombarbei uno ßenetien, 75 Mill. fi. zu 5 ßroc., zu 70 für 100 9emnbetrag einzuzahlen. Der auf Die Rumbarcei fommenbe Theil fonnte wegen Der unglürtlid)en 2 Benbung Des Rrieges nicht eingezogen werben. - Batber. Şwangsanleike von 1809. - Bab. $\mathfrak{B}$. v. 28. Dec. 1813, nach welder zur $\mathfrak{B}$ eftreitung Der Rriegżtoften bie Bermögenderen einen Beitrag geben follten, gegen Borjdupfidjeine, die mit 6 ßroc.

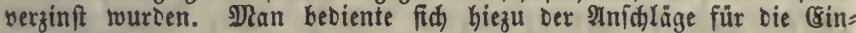

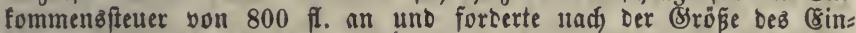
fummens 20-40 \$roc. beffelben. - Swangsamleike ber fpanifden

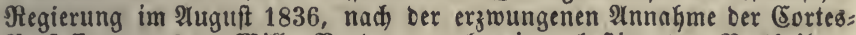
Berfafiung; 200 Difl. Sienlen, nad) einer beftimmten Bertheilung unter bie \$rovinzen von Dell Steuerpflichtigen einzutreiben. - Srongzి= anleike von 1854 im ફ̧erzogthum ßarma, 5 ßroc. Des Cinfommens aller Stantsbürger, nur Srumbeigenthümer unter 200 \&ire uno Beamte unter 1000 Sire Erinfommen ausgenommen.

(b) \$reuken: Betrag Der Enutionen 18607.840000 Thlr. - Baben: Den (Eaventen werben feit 1832 beiondere Cautionsfifjeine auछgeliefert

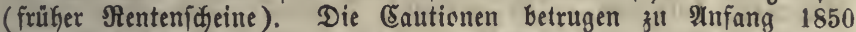
477900 fl., 2lnfang 1859760344 f.., 2tmfang 1865875532 fi. CEin şoftneifter hat 1000 fi., ein Domänenverwalter, Dbereinnehmer 800 f., Boftoerwalter 500 f., \$oithalter 3-500 f., ßoftwaceer und Brief= träger 300 fl., ein untererfeber $1-400$ f. zu binterlegen. - In Franfreid betrugen 1860 Die Cautionen gegen 250 Dill. Fr., Sint

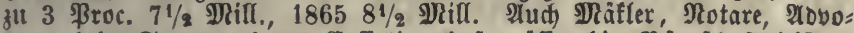

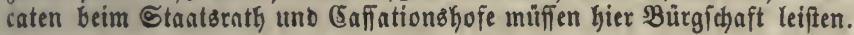

\section{§. 487 .}

V. 2usgeben von Stantspapiergeld, weldes für ein gejeşlid)es 3ahlungsిmittel erflärt wirb, nlfo einen 3nangss. umlauf hat (I, \$. 300, II, \$. 252) und beliebig bon Den Staatsิcaffen zu Den Staatşauszgaben gebraudt werben fann $(a)$. Dá̧ baffelbe bagegen aud) bei allen Stantsecaffen bei 3ahlungen angenommen merben mußs, ift fein Sdub gegen 9)ifbraud, weil bie eingegangenen Simmen von Bapiergelo fogleid) wieber

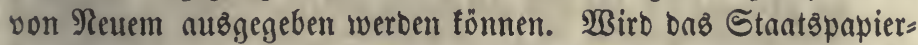
geld (bie fog. (Eaffenfdjeine) bei öffentlidben (5affen auf jebes: maliges Berlangen ber Befizer gegen gute Münze eingelöft, fo find bieje gegen Berluit gefduübst, weil fid banı bas şapiergeld

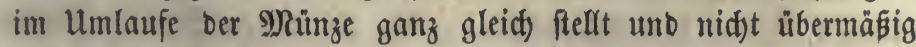
vermebrt werben fann, obne fogleid) wieber zurüfuftrömen. 
Bei einer geringen 9)enge beffelben wirb von ber Einlöjung wenig (Sebrauch) gemadt, weil es genügt zu wiffen, baß man biefelbe beliebig verlangen fann. Das Auzgeben eines einlöss lidben झapiergeloes bilbet eine beutlid) aubgepprodbene Sdullo bes Staates. Diefe ift jeboch von eigentfümlicter 2 rt, benn 1) fie braud)t nid)t verzinft zu werben, 2) bie Släubiger fint

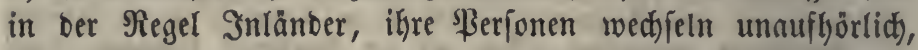
3) bie Tilgung wirb burch ben Umlnuf bes \$apiergeloes fort=

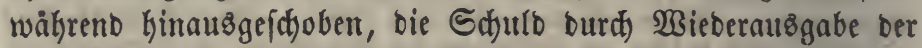

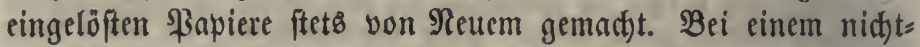
einlös̆lichen Staatöpapiergelbe befteht zwoar feine anbere an= erfannte Berbinolidfeit gegen bie Befţer beffelben, alż bie 2(nnakme bei 3ablungen an bie Stantbenfle, bod) ift im âl= gemeinen eime $\mathfrak{B e r p f l i c h t u n g}$ ber Regierung nid)t zu verfennen,

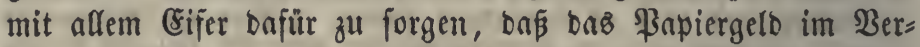
fehr ber Mảnge gleid) (im \$ari) ftehe uno bie Bürger, benen bieß 3eidyen einer Metallurenge aufgebrungen wirb, niḍt in St)aben fommen." Sit einmal bennod) bas Jjapiergeld im Sreife (ङurfe) gegen Münze gefunfen, fo läßjt fich) ber Berluft Der $\mathfrak{B}$ efizer nad) ber nidht genau vergüten, weil er beim Unlaufe jebes Stủdes fich unter bie aufeinanterfolgenben $\mathfrak{B}$ eftiger sertheilt unb im. (sinzelnen unerforficlid) ift, aber jene Berpflichtung

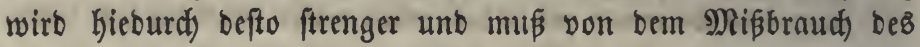
\$npiergelbes bringent abmaknen. Dft ift, um biefer $\mathfrak{B e r p f l i c}$ = tung zu genuggen, bas Stantzopapiergelo theilweife gegen ver, zinzlid)e Sdjulbidxeine zurüđgezogen worben.

(a) Es giebt Bettelbanfen, beren Eigenthümer ber Staat ift uno meldye Reib= aeidaffte u. ogl. Betreiben, I, \$. $317(a)(c)(g)$. Eo lange fie ibrer Beftimmung gemán vertwaltet werben, fommen ihre @idjeine mit Dem Bribatpapiergelde überein, fie entfernen fidh aber yon Demfelben, wenn bie Esinlôfung aufhôrt. - In Defterreid if Supfermủnze ausgevrägt worben, weldye ben פisiener Banfzetteln gleid, galt uno fo fehr über

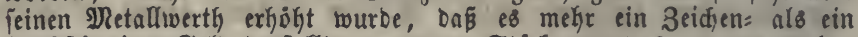
felbefteandiges Selo barfellte; es waren Stücte von 1, 3, 15 uno 30 fr.. Die aber zugleid) mit bem Papiergelbe auf $1 / 5$ herabgefegt wurben. -

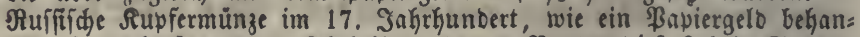
belt, f. Radjtrỉge zur 1. Rbtheilung bes 3. Banbes bief. \&efirb. S. 447.

\section{§. 488.}

Die angegebenen (Eigenjafaften, inzbefonbere Die Unverzins: lid)feit, haben bem Stantsిpapiergelbe bei bielen Staatsిmämtern cine großße Empfehlung gegeben. Eine mäpige Nenge \$apier= 
geloes, bie mur einen Theil ber umlaufenben größeren Münz= forten erfegt, in Berbinbung mit punctlicter (sinlojung unb Arnnahme bei ben Stantżcaffen, ift unjwäblich, fo lange ber gute 3uftand bez Finanzwefens währt. 2llein in unglüdlidjen Sriegen uno anderen Bebrängniffen zeigen fict) ernftlict)e (sefah) ren. Selbft jener mäßige Betrag beş ß̊paiergeldes würbe bann nidft im ßari mit ber Münze erfalten werben fönnen, nod)

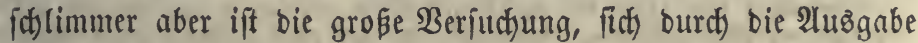
von neuem ßapiergelde zu helfen. Da hiebei bie Einlöjung

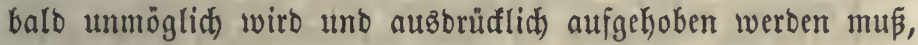
fo bleibt ras Sinfen bes Eurjes nidht alts, bie in bem ge= funferten ßapiere eingehenden Stantbeinfünfte reidjen immer weniger zat, weil bie Streife aller Dinge in bie Şöhe gehen, und man fieft fict) ftets zu einer neuen Bermehrung Des ßapier= geldes fingebrïngt, II, \$. 252-254. Diejer 3uftand minßste

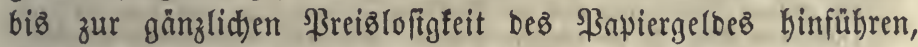
wenn man nidjt Mittel fänbe, früber ber 2Infäufung beffelben

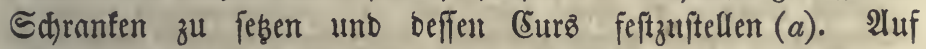
weldyer Stufe bes llebels man auth) bem weiteren Alnwach) befielben Einkalt zu thun anfängt, fo ift baffelbe nod) immer größer, als wenn ein gleid)er Betrag an Schulben auf andere Art, inşbejonbere burch Anleiken gemadt worben wäre. Der

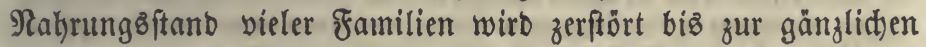
Berarmung, bie Bewerbe leiben, währent Einzelne bagegen bei bem 2lbtragen ifrer $\mathfrak{B e r b i n b l i c h f e i t e n ~ i n ~ b e m ~ g e j u n f e n e n ~ ß a p i e r e ~}$ einen Berwinn madjen. Die Berwirrung im Belbwefen unb in

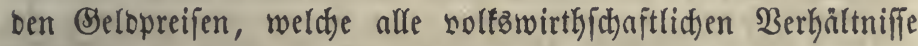
burchbringt, muß eine Zerrüttung und \&äfmung besి ganzen Berfehrs berurfactien, unb aud nachbem man bie Sceilung zu veranftalten angefangen hat, bauert $e z$ nod) lange, biz bie großßen Berlufte beridimergt uno erjest fint. Diefe vertheilen fich auth) böchit zufällig und ungleidförmig unter bie Staats=

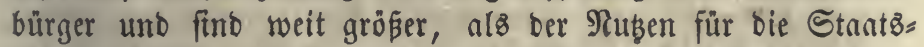

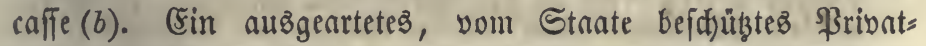

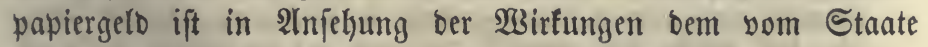
felbft ausigegebenen gleid) zu adten, I, \$. 300 .

(a) 3um ßeifpiel Dienen Die Grfahrungen mełrer neuterer Stantert, I, \$. 315 bis 317. II, \$. 254. - Die \$ुemmung biejer Berwirrung gelingt 
nidyt jeoesmal fogleid). Die Dfterteidjifden (sinlofungsfdeine, von betien je 100 fl. für 500 fl. Banfnotell autgegeben wurben, fanfen nod)

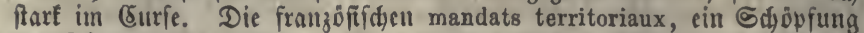
Des Directoriums vom 16. Jitirz 1796, Die zum Theile Dazu beftimmt war, Die tiefgefunfenen Rfïignaten gegen $1 / 30$ ifyes Nominalbetrages

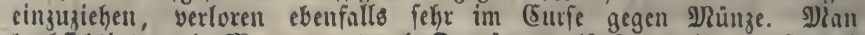
beabfichtigte, Die Manbaten Durch Domänenverfïufe zu tilgen, fo La man bie Stantslänbereien vhne Berfteigerung nach ter Tare von 1790

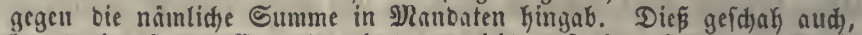
fonnte indés Den Curs ber legteren nidjt aufredst exhalten, weil bie Ränbereien fehr gegen ben bamaligen sreis gefallen waren und Die auf $1 / 2-1 / 3$ \$roc. gefunfenen 21ffignaten bei ber llmwed)Blung gegen Dlan= baten viel zu hod gerechnet wurben, audj bas Bertrauen zu allem Bapiergelde zerftüt wwar. Die Nanbaten galten anfangs (Februar 1796)

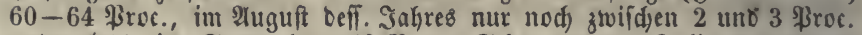
und zulebet, im Eepteniber 4,58 \$roc. Sthun am 26. Suli 1796 wurte angeoronet, Daß Die Dlanbaten bei Der Ueberweifung yon Domảnen nur nad Dem Curfe angenommen twerben follten. Sie verid)wanden aus bem Umlaufe und bie verborgen geweiene Mänze fam häufig zuแ: \$or= fđcir. Thiers, Hist. de la revolution fr. VIII, 190. 341. Bergl. Stord, Sanob. III, 111. - Die americanifje llnion hat im Bürger= friege feit Juli 1861 biel Stantspapiergelo (10g. greenbacks, wegen

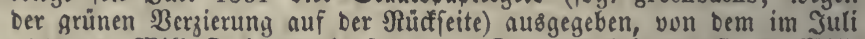
1864453 शill. D. im Umlauf waren. Darunter befanden fid 21 शill. fractional currency, o. h. \$apiergeld für Theilfummen bes Dollar. Rach (S)eießs v. 25. Febr. 1862 Darf bas StaatspapiergelD (treasury notes) in 6proc. Stantofd)ulobriefe umgewanoelt werben, toeld)e nad) getwifīer 3eit zurủafłuzahlen fino. Dn\& शufgelo (premium) gegen (sold betrug zu 2mfang 1862 gegen 52 \$roc., im Juni gegen 100, im Suli 1864 an 180 , Anfang 1865 über 100. - Die ruiftiden

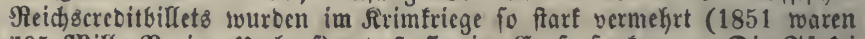
735 গৃill. $\Re$. im Umlauf), Dá̧ fie im (Eurfe fanfen. - Die Türfei hat ebenfalls cin im (Eurfe farf gefunfenes \$apiergeld (Raime), weld)es, on bie Regierung anfing, es mit einer verzinstichen Rtnleife einzuzichen, 1862 auf cinell \$reis yon 50 \$roc. in Silber ftieg.

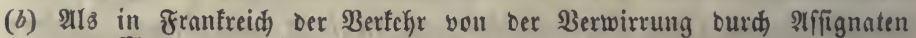
und Ilandaten befreit worben war und fid wicber belebte, trat bie Roth berer, Die in \$apiergelo von ber Etantscaffe bezahlt tourcen, Deutlich Kervor. Le gouvernement, c. a. d. ses chefs, ses agens de toute espèce, militaires, administrateurs ou magistrats, ses créanciers, étaient réduits à une affreuse détresse. - Les rentiers mouraient de faim, les fonctionnaires donnaient leur démission. Thiers VIII, 344. Die lebten 20000 Mill. Fr. Rrfignaten Gatten ber Stantzcafle un= gefägr nur foviel als 100 פilf. Fr. IJünze genüb̨t. Dic gefeslidse Breibbeftimmung ber nótfigften 28 naren (tas "maximum") uno tas Berbot, ein शgio auf \$rinze zu nefmen, 1793, bei Ctrafe son 6 Saliren Sudthaus, Gatten bas Hebel nur äger gemadyt unb man Gatte 1795 Dieje Garten uno Dod unausfïgrbaren Ssefese zuruifnelgmen múfien. Thiers V, 152. VII, 42.245. 387. - In (5hiun war es im 11. und 12. Jafrefundert üblid), bei ber शusgabe von \$aviergelo zu be= ftimmen, nad) svieviel Jahren ballelbe wollptentig eingeloft fcin follte, aber Diés twurbe nicht pünctlid) vollzogen unb tie Edbeine fanfen im Breife. Die nad) 7 Jahren zahlbaren Riav=tidjav von 1155 ficlen tergeitalt, Das cin Reisfudien nad) heutigen franzofifiden (Seloe 75000 Fr. galt. Nat. Rondot in Journ. des Econ. XX, 113 (Inmuar 1850). 
§. 489 .

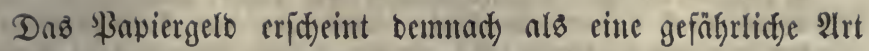
you Stantzifullben. Nur fortbauernto hobe Einfidyt uno Feftig=

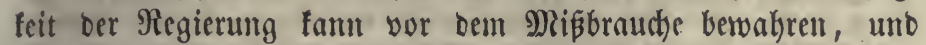

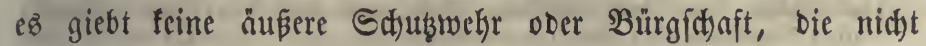

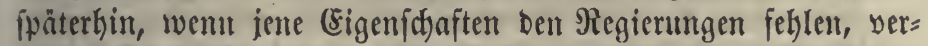

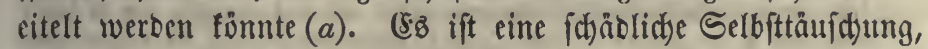
wenn man glaubt, eine große Summe neuer \$apiere unbemerft

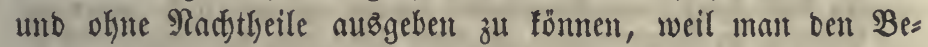
lauf Derfelben vielfeidyt verbeimlidgt. In Zeiten, wo man be= trädtlicke Sdjulben zu madfen gezmungen ift, Darf man fid) aud) aut wenigften bie Fähigfeit zutrauen, bas Şapiergeld Durch Csinlöfung ftets im Shari zu erbalten. Daffelbe ift befikalb

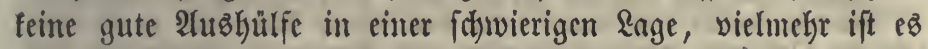
nur unter foldyen Ulmftänben unidäblich, wo man es leidft entbehren fönte uno Glö ben Bortbeil ciner Zinzeriparung in bejdränftem M) Raßße beabftedtigt. Dieß ift Der Fall, fo lange

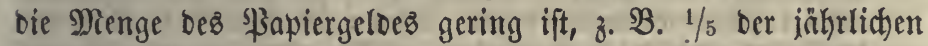
Stantzeinfünfte, fo baß bie Möglichfeit, Daffelbe einzuzieben uno Dafür verzinzlidye anleiken nufzumehmen, feinem 3weifel unterliegt (b). Alu wenigiten hat onsienige Stantspapiergelo gegen fid), weldes nur nuf beftimmte Zeit, alş Boraub= nahme (Inticipation) gewiffer Sinfünte, aubgegeben uno bei ober nad) bem (Eingeken berfelben eingezogen wirb $(c)$. Berzinzliche Sdulbbriefe, felbft wenn fie auf fleine Summen, 3. 3 . 50 ober 25 fr. Iauten, find nidt alb \$apiergelo an= zufeken, weil man fie wegen ber Berzinjung gerne behält uno wegen ber beim 2lus̈geben nötbigen Bergưtung ber angelaufenen Binfen nidyt to leidt und gerne wie Belo bei Zahlungen an= wentet $(d)$.

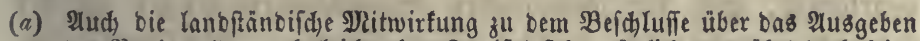
bes Sapiergeloes, obgleich ohne Sweifel fehr nübslich, getwährt bod, feine unfehlbare Gidberkeit gegen Miśgriffe, weil in Diefer Pngelegenkeit, Die

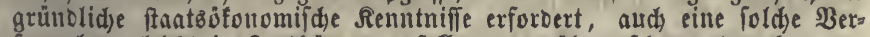
fammlung leidyt in Irrthümer berfallen oder überrafdyt werben fann.

(b) Die vermehrten Gtaatżnuggaben bei veruinberten Sinfünften Gaben 1848

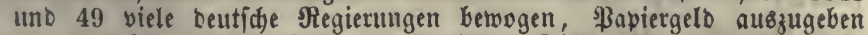
ober Das fijon ausgegebene zu vermehren. Dies geidah zum Theile in fehr mäß̈iger Nenge, z. B. Baben 2 Mill. fl. $(1,47$ fl. alf bell Sopf), fpäter 3 פRill., in $\mathfrak{B}$ ütemberg ebenfalls 3 SRill. $(1,66$ fl. auf ben Sopf $)$, 子um Theile aber in einer Denge, welḑe ber inlânbiłdje llmlauf eines 


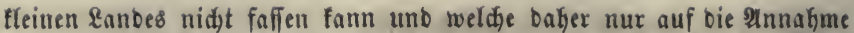
in anderen Deutidien Stanten beredynet fein fonnte; Furbefien $21 / 8$ Still. Thaler $(5,76$ f. auf ben Ropf), SReiningen und Roburg= Botha ie

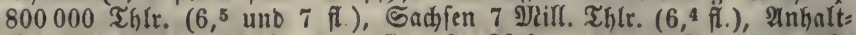
Bernburg 300000 Thlt. (10,5 fl.), A. = Sitthen 500000 Thlt. $(19,7$ fi.

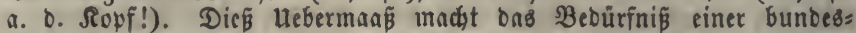

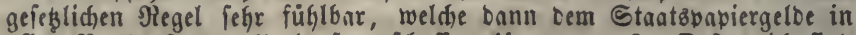
allen $\mathfrak{B}$ undesiftaaten umlauf verfdaffen fönnte. - In Defterreid) find 1818 mefirere Arten bon Staat8̊papiergelo ausgegeben worben, naments

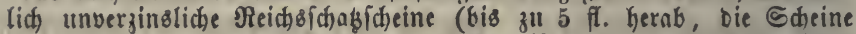
von $100 \mathrm{fl}$. nn trugen 3 Broc. Sinb), Anmeifungen auf bie ungariichen Ranbeseinfunfte, Treforideine im lombarbif(h)= venezianifden Rönigreid

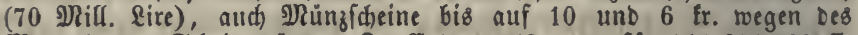
Mangels an Sheibemünze. Sul Snbe 1852 war für 144.631168 fi. wahres (unverzinstiches) Staatspapiergelo vorkanben, woldjes im (Eurie ben Banfnoten gleidh fano, ๖. \$a a er, Neuere Heberfidjt 2 ., 1853, ธ. 127. Bon Diefen \$ुapieren und ben (verzinslidien) (Enfienanwei= fungen befás Die $\mathfrak{B}$ anf $51^{1 / 2}$ DRifl., Die aber barum nidht weniger Theile

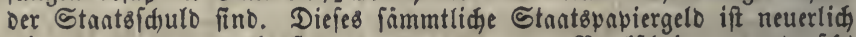
wieber nus bem Umlaufe gezogen uno gegen Banficheine umgetaufd worben, weldje nod immer unter \$ari ftehen, febr. 1865 zu 89 ßroc.

(c) In Defterreid wurbe 1761 eine neue $\mathscr{D e n g e}$ bon $\mathfrak{B a n f}_{j}$ etteln aus: gegeben, bie bei ber beabfidtigten Anleike bon 7 Dill. fi. eingezahlt unb eingezogen werben follten. - Inticipation ber preußs. Bermogens = uno Ginfummensfteuer (\$. 404) burd) geftempelte Treforficheine, Die bei cer Entrichtung Diefer Steuer uno auds fpäter für baar bei ben Etaat8s coffen angenommen werben follten. Eoict v. 24. Ilai 1812. Die Durd bie Steuer eingehenben Treforideine follten bernid)tet, Die auf Diefe Weife niăt eingegangenen aber aus bem Steuerertrage eingeloft und bernidytet werben. Goict v. 19. Inn. 1813. Şiemit fino bie anderen nicht geftempelten, im Hmlaufe gebliebenen Treioridheine, neuerlich Cafien= anweifungen genannt, nidht zu verwedfieln, vgl. I, \$. 296. - Nieber= länbifđje Mänzfacine, §. 201.

(d) $\mathfrak{B g l}$. I, §. $293(e)$. In neuerer Seit hat man ojters folde Dbliga= tionen ausgegeben und bie Sinsberechnung ourch eine aufgebrudte Tabelle erleidtert. Sie Dienen zur Anlegung fleiner Eriparnific uno verid)affen hieburd alleroings ber Stegierung eine gröpere IDenge bon Darleikern.

\section{§. 490 .}

Die Borgủge ber freiwilligen Anleiken (\$. 485) erkellen aus ber vorftehenben Betraditung ber erziwungenen Staats= fdjulden. Der Blä̈tbiger Keiht unter Bedingungen, bie er genehmigt, uno bie fämmtliden Staatzbürger tragen zu ben hieraus errwadjenden Eaften burd) Steuern gleidförmig bei. BBährent ber allmäligen Bermethrung ber Etantbidulben ift man aud) bei ben Anleifen auf mandyerlei (Einritftungen ver= falten, bie fidh madh folgenber Esintheilung orbmen laffen $(a)$. Die Anteitfen bienen

I. zu einer bloß augenbliffidjen 2tubhülfe ( $\{$ d webende Sdul $(b)$, ober fie werben 
II. auf längere 3eit gemadt.t.

A. Einfad) verzinzlid) 2 Inleifen. Şier treten Berjhiebentheiten in Den über bie Şeimzahlung getroffe= nen Berabrebungen ein, inbem nämlich

1) eine getwiffe Frift zur albtragung feifgejest, ober

2) bem Eläubiger bie fiủnoigung geftattet, ober

3) Demielben lebiglich ber 3insbezug ohne bas ser= iprectien einer 3urüdzahlung ber Forberung felbit zugeftuert wirb; Renten. Bei biefen giebt es wieber eine boppelte 2 rtt, bie $\mathfrak{B e r z i n j u n g}$ bes $\mathfrak{E} a=$ pitals zu bezeidynen, es wirb entweber

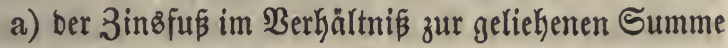
ausg gebrülft, ober

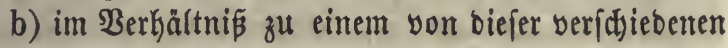
Renn= ( Rominal $l$ ) Betrage.

B. 2̂nleiken mit einer bie $\mathfrak{B e r z i n j u n g ~ u n d ~ a l l m a ̈ l i g e ~ T i l s ~}$ gung enthaltenoen Rente; Зeit uno 2 eibrenten.

C. Inleihen mit einem Tilgunģ̄plane, wobei bie aufs gefdobenen 3infen nadjbezahlt und (Sewinnfte ver= looft werben; Rotterieanleiken.

(a) Bggl. Nebenius S. 329 ff. - Baumarf S. 228.

\section{§. 491.}

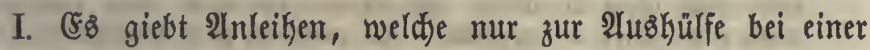

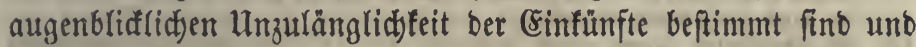
baber nur auf furze 3eit, gewöhnlid) nicht über ein Sahr hinaus, gemadjt werben. Sie werben, als vorübergehent, nid)t in ben bauernben Berzinfungsి = unb Tilgungôplan aufgenommen, fon= bern bleiben lebiglich auf bie Csinfünfte jebes einzelnen Sahres angewiejen. Man Gat fie neuerlich mit bem Namen (d) we= benbe $S_{d} u(b$, dette flottante, floating debt, belegt $(a)$. Diefe fann 1) bavon Kerrübren, baß bie 2lusgaben unb bie zu ifrer Decfung beftimmten (Sinfünfte nicht gleichzeitig zujammen= treffen, unb baker, weil iene nidjt verichoben werben bürfen, aud) fein genuggender Betriebsyorrath in Bereitfdaft ift (\$. 88), bie nöthigen Summen einftweilen geborgt werben múffen. Dieß gefdieht beffer burdh 2lufnehmen bei Capitaliften, als burd) freimilligen Borfđuß einer Aluflage bon ben Steuerpflidtigen, 
vergl. \&. 486. 2) Die finwebente Sduld fann and Daraus entipringen, Daß̧ überkautpt bie (Einfunfte bes Jakres nid)t zu= reichen. In biefem Folfe werben bie vorläufigen Inleiken nid)t fo leidgt wie bie unter 1) ermähnten in furzer 3eit wieber be= feitigt, benn wemt in ben folgenben Sakren feine Meberichüfe vorl)anben futb, fo entifegt aus ber elbtragung biejer Sd)ulden nad) 2lblauf bes furzen, feftgefebten 3eitraums abermals eine Unzแlänglid)feit ber verfügbaren Einfünfte, bie zu neuem Borgen in ähnlidjer Weife nöthigt. (E)lingt e\& nicht, mit Şülfe von (Simahmşüberidutifen ober Eriparungen fith in ben folgenben Gakren von biefer fawebenben Satuld zu befreien, fo bleibt nid)ts übrig, als fie in bie fortbnuernbe herüber zu nehmen $(b)$.

Die Roften biefer Anleiken finb heutiges Tnges nidjt mefir fo großs wie ehemala $(c)$, bejonbers ba, wo fid) großje Banfen befinben, weldye bie nöthigen Summen gegen Sdjulbbriefe ber fdrebenten Sathlo, Sd) a fammerideine, bons royaux ober du trésor, exchecquer bills, vorftreden $(d)$. 2lefynlidje Inleiben, went nuth nidjt gernde mit foldjen Edjeinen, bie in ben Umlauf fommen, find überbaupt nidjt zu vermeiben; fog. Eaflenanleigen.

(a) Der franzöfifide Finanzminifter $\Re$ oy [prad) in ber Deputittenfammer, 25. Sulli 1828: Ce sont ces emprunts à échéance, que nous nommons det te flottante, ce sont ces engagements remboursables, soit qu'ils aient pour objet un déficit reeel ou une avance de fonds, soit qu'ils aient pour objet de subvenir à des paiemens pour lesquels les fonds ne sont pas encore rentrés.

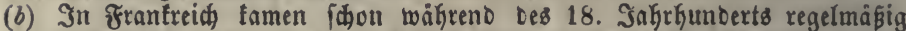
folde 2nticipationen auf Daz folgende 3ahr bor. Sie betrugen 1715: 186 Mallionell \&iv. - 1770, bei Terray's 2tntritt, 154 sRill. 1773, bei beffen Ptbgang, 30. Mill. - 1775, in Turgot's zroeitem

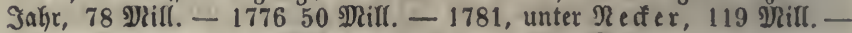
1782, Fleury, 184 Mill. - 1789 แod) 225 Nill.

(c) Nach $\mathfrak{R}$ e f er, Admin. des fin. II, 251, tofteten bie Inticipationen oft 8-10 \$roc. jährlid, weil fie mefrmals im Sahre erneuert werben mußten, wobei immer $1 / 2-1$ ßroc. ßrovifion außer Dem 3ins yorfam. $\mathfrak{N}$. verlängerte fie auf ein $3 a h r$, mit 1 \$roc. Bebrifr und $41 / 2-5$ \$roc. Bins. - Plud in Deutiden Stanten famen nod) in Den eriten Decen: nien bes 19. Safrefunberts (5affenffulden yon 8-9 \$roc. Soften yor.

(d) Bons royaux, feit 1848 bons du trésor in Franfreid, getwojnnlid von ber Banf übernommen. Der hödffite zuläfítige vrbentlidje Betrag Derélben (vorbefnaltlid' befonderer Bewilligungen) wiro jährlidg im

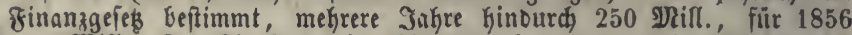
150 शNill. Der Sinźfús wiro ôfterz verändert uno ift niebriger bei bons auf $3-5$ פThonate als bei lingerer Frip. Itebrigens werden in Fraufreid) zur (djwebenden Gdjuld nud) verídjicbene andere Beftand:

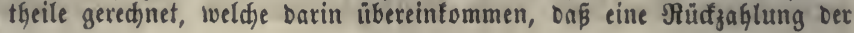


einzelnen Sdulopoiten geforbert werten fann, wenn gleich im Stamzen Der Betrag ziemlich gleid bleiben mag. Dabin gehoren auper ben bons now 1) Summen, bie von ben (Semeinoen, Departements uno Stiftungen ber Sdjulbentilgecufie übergeben fino, 2) Die bei biefer an= gelegten Sparcafiengeloer, 3) bie von ber Şinterlegungscaffe auf lau=

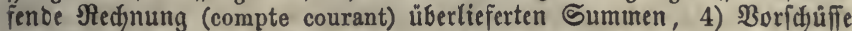
ber BBanf uno ber Devartementzeinnefimer 2c. Die fhwebenbe Schulo ift von fehr wedjelnoem Betrage; fie wat z. B. Enbe 1830223 Nill.

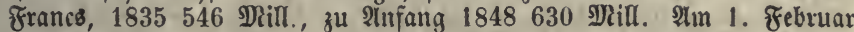
1851 war fie 577 Inill., wovon 113 פdill. in bons, 1855 ftieg fie auf 886 פRill., am 1. Jamuar 1858815 Mill., 1859810 Mill., mobei 159 Mill. bons du trésor, 1860 gegen 600 INill., wovon 135 Nill. bons, 1864 fam fie alf 972 פrill. Die शnleike bon 300 פrill. in 3wroc. Sdulobriefen ber confolioirten Sdulo war baju beftimmt, bie ihtwebente Sdult zu verminbern, die 186523,7 glill. Sins erforbert.

Exchecquerbills in Brof́britanien (feit 1696, wo fie $\mathfrak{D}$ on $=$ tague einfüfrte) mit Tagezzinjen, währent bie fonfif ähnlichen navy bills exft nach $1 / 2$ Jafjre 3ెing trugen. Ihre Summe wiro jälytlich vom Barlament bemilligt mo ein Theil von ifr wirb auf oer Banf über= nommen, weldhe hieburdh it ber Reidytigfeit bes Suruidziehens ifrer Noten gehinbert wirb. Nuch (S) erflärt eine grofe Sifuld biefer Art (a great and unmanageable debt) in fdwierigen Beiten für fehr hemment. Bergl. Parnell, On fin. reform S. 267. Bailly I, 87. Der Sins wirb beim 2użgeben neuer Sdjeine nad, Dem jebesinaligen berridienden Binsfuße beftimmt, aber fo,

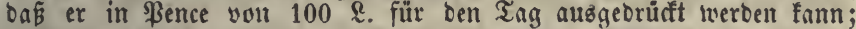

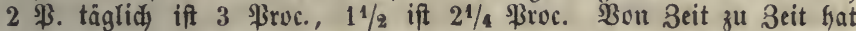
man einen Theil von ifnen in eine 2rt ber bleibenben Gd)uld um= getwanbelt (funoirt). Die griste in einem Sabre ausgegebene Summe

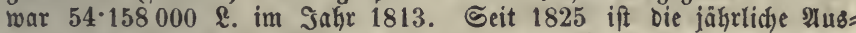
gabe (issue) unter 30 Dillionen, 1832 war Die umlaufende @umme 25.696000 \&. St., Der Sinz 659000 \&. St. Sm Inäz 1835 uxurben 28 Nill. e. bills funbirt, wie ez 1829 mit 3 Mrifl. geidfeften war. Im Jahre 1840 ftunden $21 \cdot 688000$ \&. St. nus, für 1852 ber Belauf

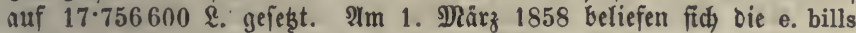
und bonds (ïber 1 Jafir hinaus) auf $25.911500,1859$ auf $18.277400 \mathfrak{R}$., weil im Ialyre 18587 Mill. Sparcaffengelder funbirt wurden. Die

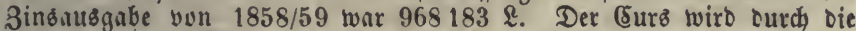
श्uzahl von Gdillingen bezeidnet, bie man beim थnfauf yon 100 \&. St.

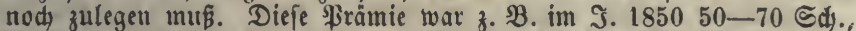
im Juni 1859 17-21 Sお., im November 1840 aber faujte man bie Sdheine um 2 Sd. unter Bari ein.

\section{§. 492.}

II. Á. 2luct) bei 2lnteiłen nuf längere 3eit wirb gewöhnlid) wie unter ßribatperionen ein Binb̧fü auzbeoungen, nact) wels

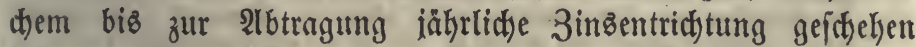

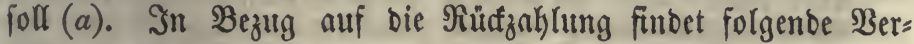
idiebentheit itatt:

1) Biele ältere Stantżanleifen wurben auf beftimmte 3 eit abgejhlofien. Diép fann jebod) grope Berlegenheit ver=

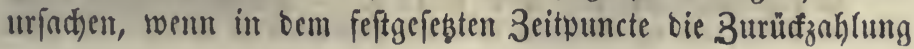


burd) bie Umfänbe erjawert wirb, fo ba $\beta$ man entweber anbere Anleken unter läitigeren Bebingungen zul Stanbe bringen ober vielleid)t eine Berlängerung ber 3eit von ben (8)läubigern zu

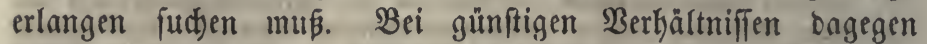
toürbe es vortheilkaft fein, bie Sdulben beliebig früber $a b=$ zablen zu fömnen unb es ift baher ratbjan, fich biep im $\mathfrak{B e r}=$ trage borzubehalten. In einem Staate, ber burd) gute $\mathfrak{B e r}=$ waltung feinen Crebit ungef(jwäd)t erbalten hat, ift bie $3 \mathrm{~W}=$ fid)erung eineż Şeimzahlungsిtermines unnöthig. Neuterlid ift bei mand)en 2lnleiken eine regelmäpige Tilgung von Sahr zu Salyr nad) feftgefester Fortidjreitung ausbebungen worben, wo=

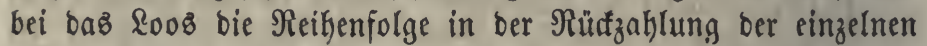
Theil=Sd)ulbbriefe beftimmen mus (b). Diefe Einrichtung hat auf Das Bertrauen ber Darleiher günftig geroirft. Sie ift weniger läptig als bie berprochene 2lbtragung in einem ein= zelnen Jabre, bod) fnnn bie Fortfesung ber Abzablung in

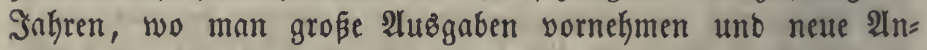
leiken zu madjen hat, bejdwerlid) fallen, baker bürfte bieje Bebingung wenigftens nur bei einem fleinen Theile ber Staats= fduld eingefüfyrt werben.

(a) Shon im Alterthum fommen zahlreide Beifpiele von Anteifen ber Staaten vor, befonbers bei ben reidhen Tempeln, wie z. $\mathfrak{B}$. bem grofen

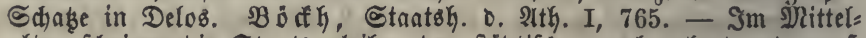
alter fheinen bie Staatzanleifen ben fäbtifhen nad)geahmt uno zuerft in ben italienifden freiftaaten aufgefommen zu fein, in Senebig 1171

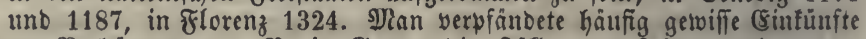
zur Berbuirgung, 3. B. in (S)emun bie Solle unb ipáter aud andere

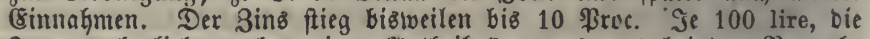
Jemand herlieh, gaben cinen 2intheil (locus, luogo) bei ben Berpach)=

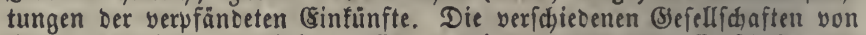
Staatogläubigern vereinigten fidh zu einer gropen (Bienofienichnit, ber

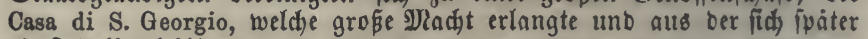
bie Settelbanf bilbete. I, $\$$. 310 . Bizarus, Senatus populique Genuensis rerum domi forisque gestarum historiae S.79. Shúl $\mathfrak{I}$ mann, Stibte= weien IV, 106. Gelbft bie ßäpite fonnten in Selcverlegenheiten nidjt umbin zu borgen uno Dab Sinsverbot Des fanoniffien গiechtes zu utm=

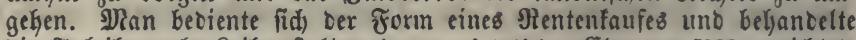
Die Inleiken als \&eifanftalten (mons pietatis). Clemens VII. erridhtete 1527 einen monte, um (Seld zu 10 \$roc. aufzunefymen, toofur bie Sutter ber apoftslifhen Rammer verpfanbet wurben. Die (Släubiger erhielten Borred)te, z. B. Sidjerkeit gegen Eonfiscation und Befugnís, fu (S) unfen unehelidier sinber zu teptiren. \$aulus IV. nafym 807000 Soloftuce zu 10 ßroc, auf 9 Jahre auf, \$ius V. verlängerte bie Dauer und feste Den Sins auf 7 \$roc. ljerab $2 c$. Gregor. Tholoz. De rep. Lib. XIII. Cap. XVI. \&. 10 II. - Die Regierungen Gatten oft פlukge, bie erforberliden Inleiken zu Stanbe zu bringen uno fahen 


\section{7}

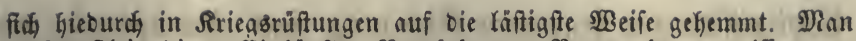
muste Rleinobien, Ginfünfte, Borrathe von Bergtwerfserzeugniñen ver= pfänoen, Beamte umberfenten, um Reidse zu Borfduifien zu berwegen it. Dergl. Sinzelne Beifpiele Gievon finben fict) unter 2inderen bei Dberleitner, Defterreidbs Finanzen und Siriegstweien unter Ferdi= nano I. NBien 1859. - Bei bem heutigen beffer geregelten (Sange Des Staatskaushaltes und ber Durd) 2uifnalyme in ben Boranidhlag gefidjerten Berzinfung find jene Sdjwierigfeiten nidjt mefr vorkanien.

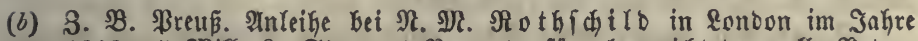
1818,5 शtill. \&. St. zu 5 ßroc. (wofür aber nid)t ber volle \$Betrag eingenommen wurbe), mit ber Beftimmung, daß im erfen Jahre 3 \$roc., im zweiten $2 \frac{1}{2}$, im britten 2 , im vierten $1 \frac{1}{2}$ uno vom fünften an jäfrlich 1 Sroc. abgezahlt werben follte. 1830 wurbe ter Neft diefer Inleibe in eine 4procentige umgetwanbelt, bei ber ebenfalls 1 ßroc. und bie Simfen ber eingeloften Dbligationen yon 1835 an zur Tilgung ver:

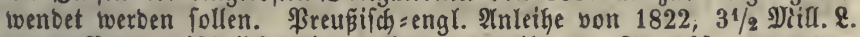
zu 5 ßroc., jährlich mit 1 \$roc. zu tilgen. Framzóf. obligations trentenaires mit Tilgung in 30 \$. - Biele 2unleifen mit beftimmter Tilgungezeit in Norbamerica.

§. 493.

2) Sculben mit freier $\Re$ ünobarfeit für beibe Theile find zwar ben Capitaliften erwủnfwt, um zu jeber 3eit über iftr $\mathfrak{B}$ ermögen beliebig verfügen zu fönnen, jebod) für bie Regies nung all żu nadththeilig, weil bie Rünbigungen gerabe Dann häufig werben, wenn bab 2 lufbringen ber erforberlichen Summe fidmierig ift und bie Bläubiger neue vortheillyafte Bebingungen erzwingen fönnten.

3) Inleihen, bie von Seite bez Şläubigerz unfünbbar

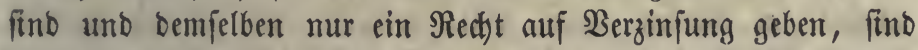
in neuerer 3eit bie bäufigften geworben. Soldhe Sdjulbzinjen werben in Franfreid) $\Re$ enten im engften Sinne genannt, rentes perpétuelles, engl. perpetual annuities $(a)$. Die $\Re$ Regie= rung ihrerpeits mus fith Das Recht vorbehalten, bic Summen

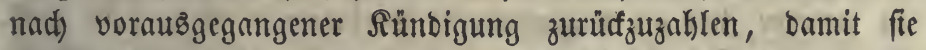
im Stanbe fei, bie Sdjuld zu verminbern, wenn fie bie Mrittel Giezu befít. Da fie immerwährenbe Dauer und das csin=

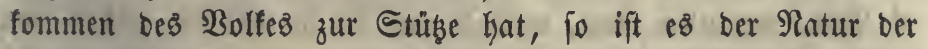
Sache gemäßa, daß̧ man ihr unter biefen Bebingungen leifht uno bie Släubiger tönnen biejelben um fo leidtter eingehen, weil bie Sd)uldbriefe bei gutem (Erebit bes Staatez ftetz yer= fäuflid) finto und alfo ber Befiţer bie Darauf verwendete Summe beliebig zurüdzuzietyen vermag. Die Sdjulbidjeine bilben fogar einen beliebten F̧anbelsigegenftand, inbem fie nidjt bloß von 


\section{$-368$}

(Eapitaliften zur bequemen 2tnlegung ifyes $\mathfrak{B e r m o ̈ g e n z , ~ f o n b e r n ~}$ audi) yon Speculanten bez Serwinnez willen erfauft werben, I, \$. 439 .

(a) Doer annuities fidlectttfin. Ygl. §. 494 (c).

\section{§. 494 .}

3. a) Die natürlidjfte Itrt, eine joldje 2nnleike nuf Nenten

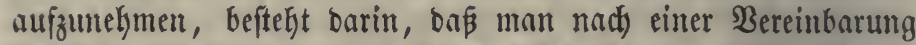

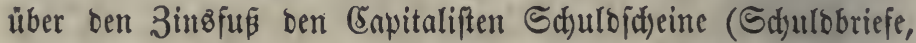
Dbligationen) über bie vorgejdjolfene Summe auşfetlt. So hat man ez lange 3eit binturd gehalten. (E) war jeboch unver=

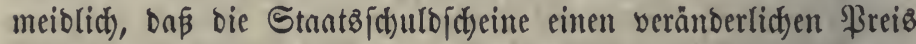
(Curz) erhielten, weil ein gewiffer aus ber Stantscaffe zu empfangenter 3ins̄betrag balb mehr, bald wentiger geictäßzt unt begetyrt wirt. Wenen ber \$reiz einer Dbligation im $\mathfrak{B}$ erfehr über ben Betrag ber bargeliekenen Summe hinaufgeht, fo Gaben

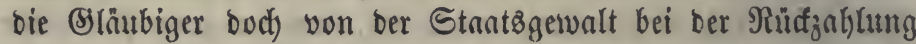
nidjt mekr alz biejen $\mathfrak{B}$ etrag nmzufpredjen, bagegen fino fie autd, wemn ber (Burs unter benjelben fintt, nid)t idjuldig, eine geringere Summe als Tilgung anzumefmen $(a)$. Der Curs

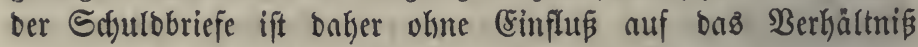

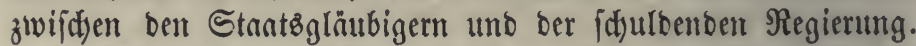

b) Radjbem bie in einem \&ande vorfanbenen Stantzidjuld= idjeine im Berfehr unter ßari verfauft und gefauft wurben, fonnte bie Regierutg leidft auf ben Sebanten tommen, aud) bei nẹen Aluleihen bie ভdyeine un einen \$reis binzugeben, welder niebriger war als bie vorgefdriebene, zur Beftimumung

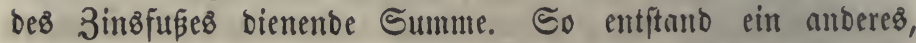
in neuterer 3eit oft angemendetez $\mathfrak{B e r f a h r e n . ~ M l a n ~ f t e l l t ~ z . ~} \mathfrak{B}$. 3 procentige Sdjuldobriefe auf 100 fl. aus und empfängt bafür nur ie 75 fl. baar, fo ba 4 ßroc. verzinfen mußs, weil 3 von 75 fo viel ift, als 4 von 100. Um 100 gelieken zu erhalten, muв man bemuad) 133 veridgreiben und es ift baker bie wirflid) geborgte von ber verfdriebenen (Nenn= ober Rominal ) Eumme zu untericheiben (b). Dab (bejdäft wird als ein Rententuuf an= gefechen und bie Tilgung geidsiegt in berfelben 2 Beife burd) ben 2nfauf ber Sbligationen nad) ifrem jebesemaligen Marttpreife 


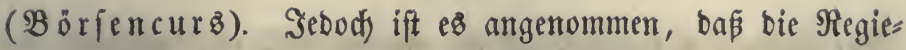

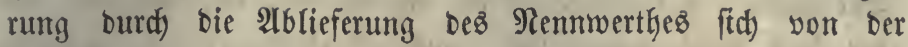
Sdfuld befreien bürfe, und biefe 2tbtragungäweife if bann allein zulläffifg, wenn ber Cours fid) über bas \$ari erhoben hat $(c)$.

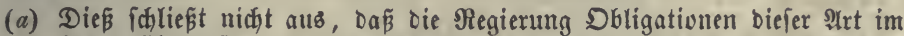
freien (sinfaufe nach cem jeoesmaligent (Eurje einlófen oarf, nur wurbe es nid)t zur Befeftigung Des (Sredits gereidjen.

(b) Diefe शrt zu borgen wurDe zuerft in Englanb unter ber Rỏnigin शinna angewendet, fum aber erf̂ feit bem americanifden Ririege regelmäpig

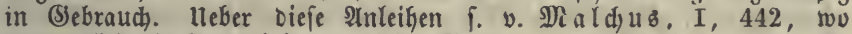

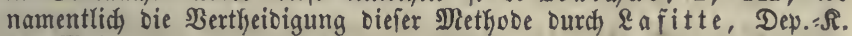
14. Nai 1828, mitgetheilt ift. - Entficieben gegen fold)e Inleiken find: Nebeniuz ธ. 355 ff. - Bernoulli, Beiträge $\subseteq .43 .-$ Parnell 5. 274. - Ma c Culloch, Tax. S. 435.

(c) In Frantreid) war lange 3eit von gar feiller \&eibjumme (Gd)uldocapital)

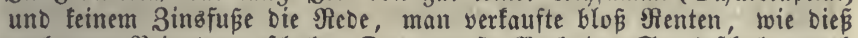
aud von ßribaten gefdah. Das "groge Bud ber Staatsfduld" nad Dem (Sefes vom 24. Pluguft 1793 erwähnt feine Eapitaliumme, Daher ift man nod jegt getwoknt, fich dic Sdjuld nidjt als ein gewiffes geborgtes Capital, ponbern als eine Miaffe fduldig geworbener Menten vorzultellen, Deren ßreiz veränderlich ift. Soldje rentes constituées à perpétuité famen feit Franz I. vor. Şiebei war aber die શ̇blôjung fủr Den Betrag, ber bem gefeslidjen Sinje entfpridt, immer als erlaubt angeieken, uno von Sulfy unb Colbert waren folde Rbzaklungen wirflid, ausgeführt worben. Das (Sefes yom 1. Maa 1825 prach

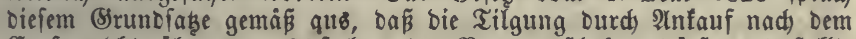

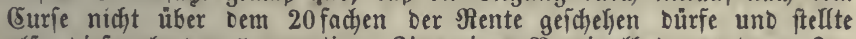
alfo Diefe als den 5 procentigen 3ins eines গNominalbetrages bar. In=

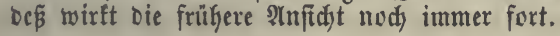

\section{§. 495 .}

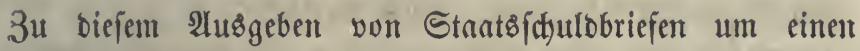
unter ifrem Rennbetrage ftehenben Sreiz bat man fid haupts

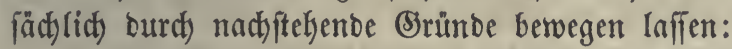

1) $\Im_{\mathfrak{n}}$ fdjwierigen 3eiten befonment man nidjt immer um ben landübliden 3ins gelieken, alfo mus man ben Släubigen mehr verfpredsen. Statt aber gerabezu 7 ober 8 Proc. zu bes willigen, bebient man fid iencz Mittels, fowohl um bas im Brivatrechte nod) beftefyende $\mathfrak{B e r b o t}$ höherer Binfen nidjt offen zu verleşen, alz um zu vermeiden, daß̧ bie einzelnen Theile Der Stantzifjuld fehr veridjiebene Binsfüe haben und baß etwa bie 3infen in unbequemen Brudttheilen aubigebrüđt wer= bett mủpten $(a)$.

2) Man hofft, baß wegen ber Beliebtheit foldter 2 mereiken bie (Eapitaliften fith mit einer niebrigeren $\mathfrak{B}$ erzinjung begnügen. 
Die $\mathfrak{B o r l i e b e ~ b e r ~}$ Slăubiger für biefe (Einrid)tung entipringt aus ber Jूoffnung, am Stamme ifrer Forberungen zul gewinnen, wenn ber (Gurs ber Sdultobriefe fteigt. Se weiter nämlid) ein Etantappapier unter \$ari ftelyt, ein befto ausigebefnterer Epiel= raum ift für bie Errhöhung Des Ceurję geöffnet, währeno biefer

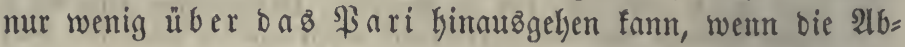

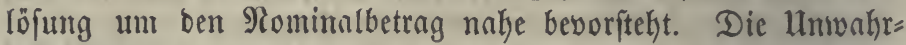

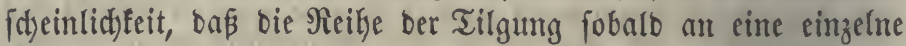
Obligation fommen werbe, ermuntert bişweilen, nod) cinige Frocente über \$ari zu bejahlen, wenn man feine anocre gleid) gute Siclegenheit hat, Capitale auszuleifen, aber ein bebenteno höherer Curs ift blop bann zu erwarten, wern man gewis ift, Daß fürs Erfte feine Einlöjung in \$ari eintreten werbe (b). Für bie Epcculation auf eine (Eurşerböhung fino baher foldje sapiere au willfommenften, beren 3inş fuß nod) unter bem

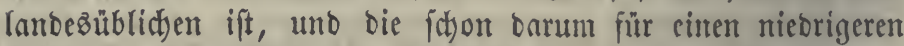
Eurz an bie Hebernefymer ber 2 nnleibe abgelafien wurben $(c)$. Dieje ziefen z. B. 3procentige Dbligationen (3 Procento nad) Der fürzeren Bezeid)mung) zu 75 Den 4 procentigen, bie fie im

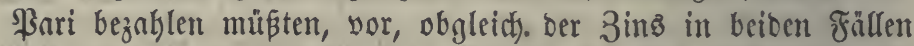
gleid) ift, weil fie hoffen, bie erfteren vielfeidyt auf 80 ober 90

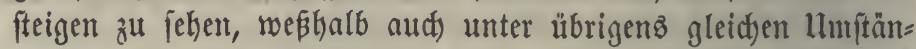
Den ber Curz ber Dbligationen einez unb beffelben Stantez fidi) nidyt genau nad) bem 3insfüe ridftet (d).

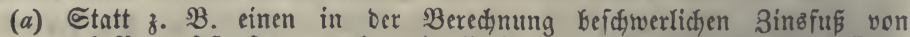
6,3 \$roc. feftzuieben, wiro cin \$reis von 79,36 für 5 procentige Dbli= gationen beoungen; bie Unterhanolung ift leichter uno man fann fich Durd Sugeben und Nadhlaffen eher näbern

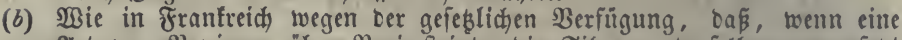
2urt von ßapieren über \$ari fteigt, bie Tilgung berfelben ausgeíçst bleiben folf. Die Dortigen 5 Srocents fiegen beshalb fehr hoch. Jhr

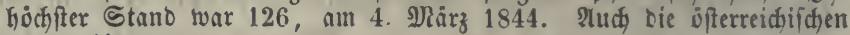
famen bis 112.

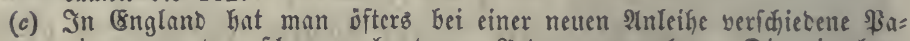
viere von ben fdon yorhanbenen 2trten atragejeben. Die einzelnen Dbligationen als Theile bes (Samzen Keißen scrips (von subscription), ifr Inbebriff omnium. (\$8 wurben 3. B. 1791, แm 12 פNill. \&. Ct. baar zu erfalten, hingegeben 18 Nitll. 3vrocentige tmo 3 פrill. 4proc. Storfz, zufammen 21 \$Rill., weldhe 660000 coer $5 \frac{1}{2}$ \$roc. trugen. Bei Den im Sabre 1814 geburgten 24 IXill. gab mant fur je 100 \&. baar

80 \&. St. in 3 proc. reduced (númlicf) annuities),

$23 \frac{1 / 2}{2}$ " 3 " consols (consolidated ann.), 30 " " 5 " consols

zufammen $133^{1 / 2}$ R., weldge $4,{ }^{6}$ \&. Sins fofteten. Bei mefreren foldaen 
Anleihen wurben zur Ërgånzung auch langjährige Beitrenten beigefügt,

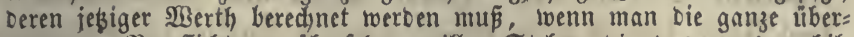
nommene Berpflidstung überieken will. Stehen bie bas omnium bil= tenten serips im Surfe höher, als fie yon ben (B) äubigern übernomnen wurben, fo maden biefe fogleid) cinen (B)etwinn, loeldher bonus genannt

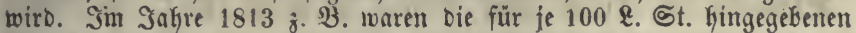

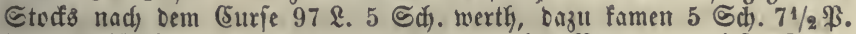

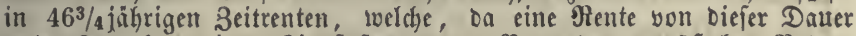

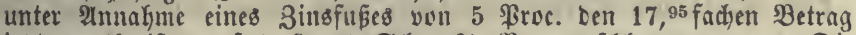
iest werth ift, auf 5 \&. 18 Sd). $73 / 5$ s. anzufdalagen waren. Die 3 scrips maditen alfo 103 \&. 3 G Unterzeidynern fogleid $3^{1 / 6}$ Proc. Serwim.

(d) Beipicle. 2Tm 21. Februar 1848 (yor Der Umwålzung) war in \$aris bei Den Renten yon

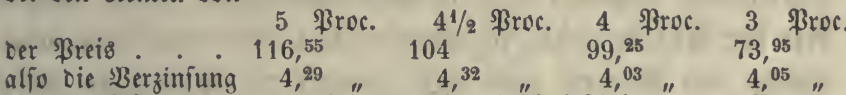

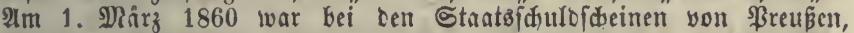
Bayern, SBurtemberg, Baben, Brof̧. Şeffen, Naffau unb frantfurt in ber legetgenannten Staot

bei Dbligationen you 5 \$roc. $4 \frac{1}{2}$ Proc. 4 Proc. $4 \frac{1}{2}$ ßroc. 3 Proc. Durchfdhnittzurciz $\quad 103,87 \quad 102,{ }^{, 25} \quad 98,83 \quad 95,08 \quad 87,62$ folglich Berzinfung $4,81,4,38$ " $4,64,3,{ }^{\prime}, \quad 3,42$,

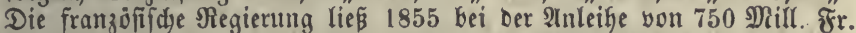

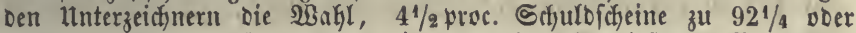

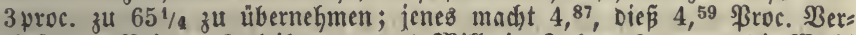

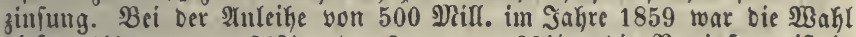
Diefe: $4 \frac{1}{2}$ proc. zu $90^{3} / 4$ ober 3 proc. zu $60^{1 / 2}$; bie Berziniung ift in beiden Fälen 4,95 \$roc., aber co wutrben $4{ }^{6}$ mal foviel Sdjuldofdeine yon 3 als $4 \frac{1}{2}$ sfoc. verlangt. - Bei Dem llmtanlád Der $4 \frac{1}{2}$ proc. in

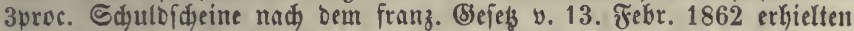
Die BBefizer Der erfteren für je 100 Fr. Derfelben 150 Fr. in 3 \$roc.,

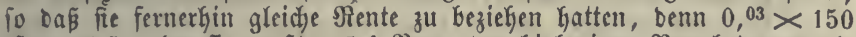

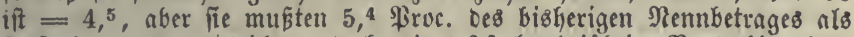

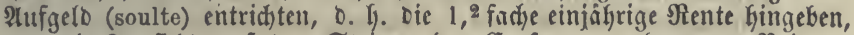

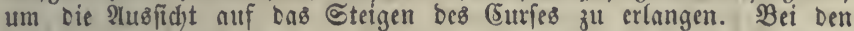
4 \$roc. betrug Die soulte 1,20 \$roc. 3u biefer llmtaufdhung waren

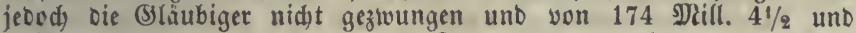
4 ßroc. wurben nur 134.914451 Fr. Jur Ummandlung angemeloet. Diefe Mnaßregel bradjte Der Staatscafie 157.631000 Fr. ein, Die zur Berminoerung ber fojwebenden Sdfuld bienten. Der Nenubetring biefes

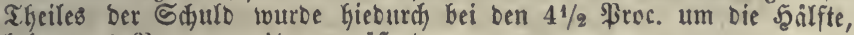
bei ben 4 \$roc. um $1 / 3$ vergrößert.

§. 496.

Der nämlidye (Srunb, weldyet foldye Anleihen ben Capitaliften unto Speculanten angenehm madyt, beutet auf ibre nachtheilige

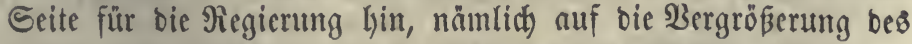
Sd)uldenftammes in Folge bes Strigens ber Eurfe. Şat man z. B. Sduldobriefe zu 60 hingegeben, unb gel)en fie in ber Folge bis auf 80 in bie Şöke, fo foptet bie Tilgung burds

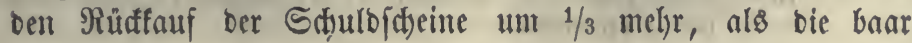




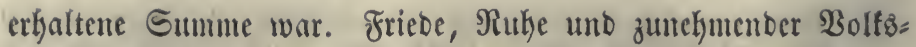

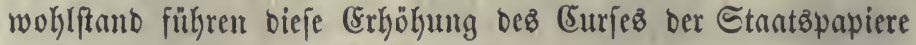

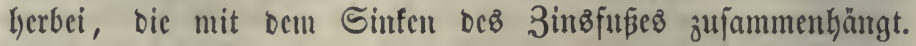
$\mathfrak{B}$ enn z. $\mathfrak{B}$. Diejer von 5 auf 4 SBroc. fällt, fo wirb eine gerviffe Niente bei gutem (Ercbite ftatt bes 20 fad)en mun mit Dem 25 fadjen Betrage erfauft, und wenn 3 procentige \$apiere biskyer zu 60 ftanoen, fo múffen fie mun auf 75 fommen, wo= bei nod) zu erwägen ift, on Staaten, bic vollen (Erebit genießen, fid mit einer geringeren Berzinjung begnủgt alz in Privatbarleilyen. Die bejdriebene Art ber 2tnleityen hat in neuerer 3eit bei bem Mebergange vom Sirieg zum Frieben und von innerer 3errüttung zu befeftigter gefestictjer Dronung bie Sdjuldemunaffe mehrerer Staaten fehr vergröpert unb baburd) bie Släubiger überauz bercichert $(a)$. (5a bleibt hiebei mur nod) zu unterfuthen, ob, wic man belyauptet hat, bie Erfparung an ben Bimfen jenen großsen Edjaben, ber

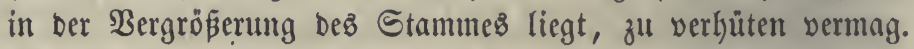

(a) Die neuere Finnnzgefdjidjte ift voll von Beifpielen diefer 2nteifyen. In

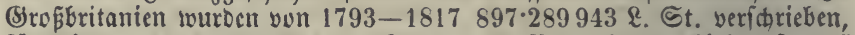
für die man nur 584.874557 ․ oder 65 \$roc. Gant erhielt, fo dá́ man, wenn die (Sinlöfung z. B. bei einem \$ireife vun 90 gef́dehen

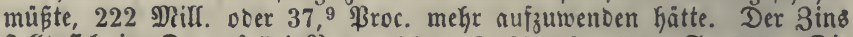
fiellt fin im D. alf 5, Pruc. Mac Culloch, Tax. S. 445. Die

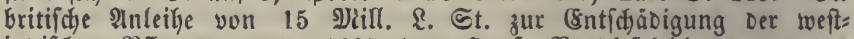

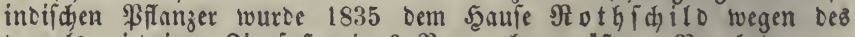

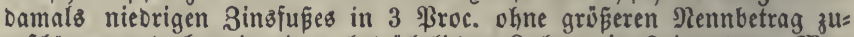
gefdylagen, boch mit einer beträchtlichen Bulage in Beitrentell. Mlan gab nâmlidy für je 100 \&. baar 75 \&. in 3 proc. consols, 25 \&. in 3 proc. reduced, nebft 3 Sch. 7 \$. Langen Beitrenten, Die bis 1860 laufen und Deren jegeiger $2 B e r t h$, zu 4 \$roc. geredjnet, auf 10 \&. 11 Sdh. anzuffiblagen ift.

Beifpiele yun foldyen Anleifen in 5proc. Dbligntionen, iweldye um nadiftefende Curfe übernommen wutben:

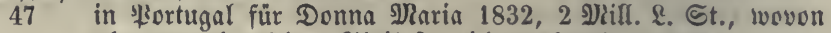
aber nutr ein tleiner Theil fogleid) ausbezafit mutrde.

51 für biefétbe $1833,1.200000$ \&. St.

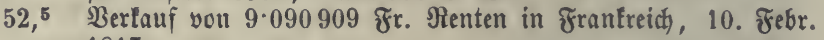
1817.

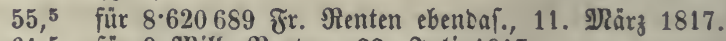

61,5 für 9 פilll. Nienten, 22. Juli 1817.

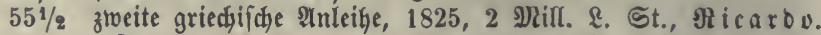

59 erfte

60 Reapel, 1821, 16 s)ill. Dutati (zu 2 fl.).

60 Spanien, 1823, (3) b Gardt, 16.700000 \$iafter, aber es gingen von ben 60 iogleich 5 \$roc. \$ruvifion ab, alfo eigent= lid) nur 55 .

70 Defterreid 1818, 50 Mifl. 1 . Metalliques (weil in Silber: münze verzinzlich). 


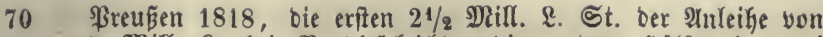

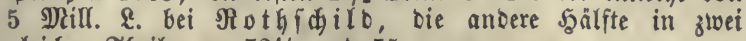
gleichen Theilen zu 721/2 und 75 .

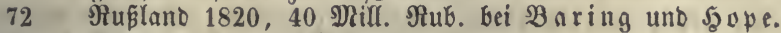

73. 75 Neavel 1822, 20 Mill. Ducati.

75 Brafilien 1824, 3.200000 \&. St., aber nur 1 Mill. aแళ. bezahlt, bie andern $2 \cdot 200000$ \&. zu 85 abgegeben.

75,5 Sefterreid, 35 Mill. fl. 1854.

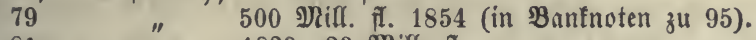

81 "1823, 23 Mill. fi.

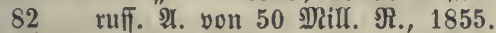

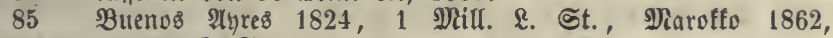
501000 \&. St.

87 Defterreich 1826, 15 פitl. fl.

$89 \frac{1}{2}$ Sruß̈britanien 1847, 8 Nill. \&. zu $3 \frac{1}{3}$ ßroc.

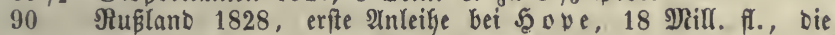

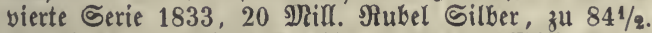

94 griedhifde garantirte Anleike 1833, 60 Mill. Fr., $\Re$ oth $=$ idilb, - ruffiche $\mathfrak{A}$. 1862,375 Nill. Fr.

95 preuß. Anleike von 30 Mill. Thlt. 1859.

97 uno barüber, oftindifhe श्रnleife in Önglano, 5 Mill. \&. St., 1859.

Beifpiele 6 procentiger $\mathfrak{A n l e i f e n : ~}$

62 Türtei 1859,620000 \&. St.

63 2. Des $\mathfrak{R}$. บon Merico, 1864, 200 Mill. Fr.

68 Tüfei 1862, 8 Mrill.' $\mathfrak{2}$. St. in \$ari zurüffuzahlen mit 2 ßroc. jährlicjer Tilgefumme.

Defterreid) borgte 184140 Nitll. fl. gegen 5 ßroc., weldhe fogar zu 104 ausgegeben wurben, alpo 4 \$roc. ü ker \$ari, aber mit ber 3u= ficherung, Daß 15 Jakje lang ber Sins nidgt herabgefest werben Dürfe.

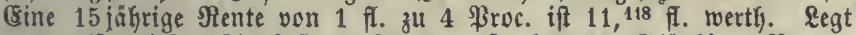

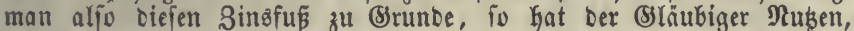
meil er mur 4 กิ. mehr bezahilt. - Defterr. Anleife von 72 SRifl. fí.

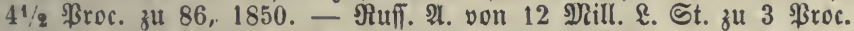

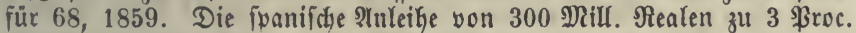
murbe 1856 von 9 ) ires für 42,56 übernommen, aber wegen ber noch

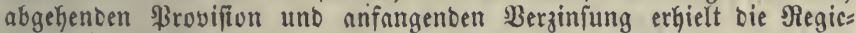
rung eigentlich nur 38 ! - In Franfreid wurben von $1815-1823$ $1457 \cdot 223920$ Fr. geborgt, bie veridriebene Summe betrug $2068^{3} / 4$ Yitll. Fr., ber Davon zugefidjerte Bins 5 झroc. ober 103.439000 Fr., es waren alfo im D. Die Sduldbriefe zu 70,43 \$roc. ausgegeben wor: ben uno Die (s)läubiger zogen 7 ßroc. Der baraeliekenen Summe. 1815 wurben für $3 \frac{1}{2}$ פtill. Sienten ober 70 \$lifl. in Shulobriefen nur 35.863 200 Fr. oder 51,23 \$roc. baar erfalten, 1823 war bei ben verfauften $23 \cdot 114510$ Fr. Senten $=462 \cdot 290320$ Fr. Nennbetrag ber baare Crmpfang 413.980981 Fr., alfo $892 / 3$ Proc. Documens statistiques (5. 167. Bou 1814-1847 wurben 2629 श) men unb 3424 Mill. verifrieben. Die 3 Proc. wurben bei ber Sings= erniebrigung unter $\mathfrak{B i l l e l e ~ i n t ~ S a h r ~} 1825$ zu 75 autżgegeben, bei ber Inleike von 1841 (150 গnifl.) zu 78,52, aber wegen Der betwilligten Termine wirflid, nur $76,75,-1844$ (200 פill.) zu 75 Fr., 1847 (250 গRill.) zu 75,25. 1848197 \$till. 5 झroc. zu $75,25,1850$

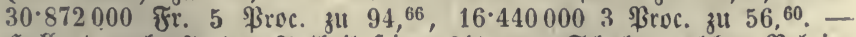

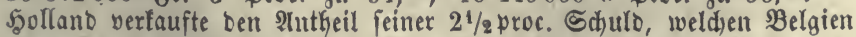
libernehmen muß̈te, nämlich 80 Mill. fl., $1845 \mathrm{im} \mathrm{D.} \mathrm{zu} 63,39$ für 100 , Den grópten Theil zu 60 an গothidirto. 


\section{§. 497.}

Um dic 3inberparung, weldbe bei ciner Anleitye mit höhes rem Nennbetrage eintritt, genau bemeffen zu fönnen, müpte man bei ben llebernegmern einer Inleihe zugleid) barüber unter= hanbeltt, wieviel 3ins fie it Dem Falle berlangten, went ifnen feine hökere Pominaljumme bewilligt wütbe. Wäre z. $\mathfrak{B}$. unter biefer Bedingung ber geforberte 3inz 5 \$roc. und fönnte man Die 4procentigen Doligationen zu $88 \% / 9$ anbringen, fo brauthte man für je 100 mur $112^{1} / 2$ in Sdulobriefen binzugeben, weldye nur $4 \frac{1}{2} 2$ 3inz foíten, eछ twitrbe aljo $1 / 2$ Proc. eripart $(a)$. Bei

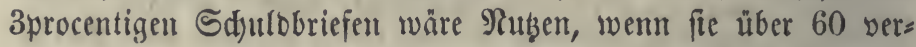
fauft würben; ein Ulebernahmsppreis von 75 z. $\mathfrak{B}$. Foftete nur 4 Froc. 3infen, wobci man $133^{1 / 3}$ fl. für 100 veridjreiben

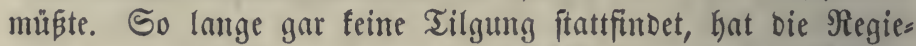
rung Den vollen $\mathfrak{B o r t b e i l}$ biejer geringeren 3inåausgabe. Rommt

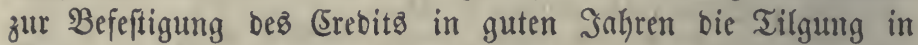

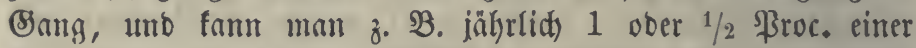
Schulo zur Einlöung verwentoen, fo exfolgt bieje bei einem

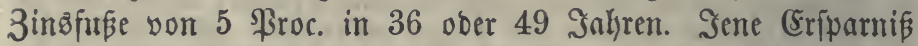
an ben 3infen bietet alfo bie Mittel Dar, mit Der 3eit bie ganze Sduuld zu tilgen, uno biep ift um fo reid)ter, ie weniger Der ßreiz ber Shuldobriefe über Den Curs bei ber Mebernalyme geftiegen ift. Iluż biejem (Srunbe hat man öfter baş $\mathfrak{B e r =}$ ict)reiben einer größeren Nominalfumme für gauz und äblid erachtet. Selbft wenn man im \$ari tilgen müßte, fo würte man Die obigen $112^{1} / 2$ fl. mit $1 / 2$ \$roc. jährlid in 50 Sabren, bie $133^{1} / 3$ fl. mit 1 Jroc. Jabrezanügaben in 38 Jahren heim= bezahlen $(b)$.

(a) Denn e8 ift $88^{8} / 9: 100=100: 112^{1 / 2}=4: 4^{1 / 2}$.

(b) Dffenbar ift ber Bortheil befto grôßer, ie langfamer bie Tilgung erfolgt,

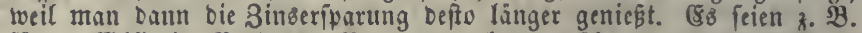
für 1 Nifill. in Pari $4 \frac{1}{4}$ Froc. zu geben, wäfrend man $3 \frac{1}{2} \$$ Proc.

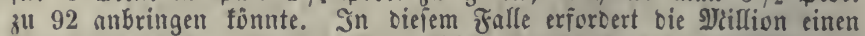
Rennbetrag von 1.086956 ff., tweldjer 38043 f. oder $38^{8}$ Sroc. Der wirflich erhaltenen Summe Sinfen foftet unt man eripart hiebei 4457 กि. YSill man bie Eduld outh eine 15jäfrige 3eitrente tilgen, fo if bie jährlidje शluzgabe in beiben fällen

1) für 1 Mill. 孔u $4 \frac{1}{4}$ ßroc. 3ins 42500 ff. rilgung 49019 วนโุมmก 91519 กิ. 
2) für 1.086956 in $3 \frac{1}{2}$ ßroc. 3ins 38043 fl. Tilgung 56333 zufammen 94376 ff.

Soier ift alfo bie 2. Methobe foftbarer. Bei einer Tilgung in 30 Jabren wưroe fie jährlich 491 ff. weniger foften.

\section{§. 498 .}

(Ez läpt ftch feine Regel Darüber anffitellen, wie viel bie Capitaliften bei einer 2 Inleilye biefer 2 rt an ben Bimfen nad)= laffen, um cinen gewiffen höheren Rennbetrag zu erfaufen,

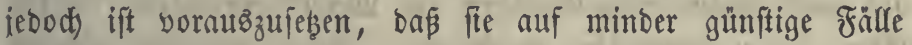

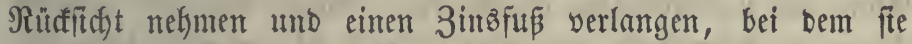
nicht verlieren $(a)$. 2lus bem $\mathfrak{B}$ ertrage alfein läpt fich jeboch nidjt berechnen, ob ber Staat gewinnt ober berliert, benn ez fommt zugleid) auf bie nathfolgenben (Surje ber Staatzifhuld= briefe an, wobei mefrere Fälle möglid) find. 1) Wenn einige 3eit hinburch) ber (Surş unveränbert bleibt, fo genieß̧t ber Staat Die Simfenerfparnis, ohne theurer tilgen zu müffen; allein bicß fest Sirieg oder anbere ungünftige Ereigniffe boraus, in benen man gewöhnlich gar nidjt zur 2tbtragung ber Schulden gelangt. 2) Tritt ein balbiges Steigen bes Currés ein, jo wirb bas Tilgen burd) Siücffauf nach) bem Curfe foftbar. Sene Beränbe= rung beweift aber, Daß̧ bie Capitaliften mit einem geringeren Sinzิ fuß̧e zurrieden finb. Wenn man feine Dbligationen unter

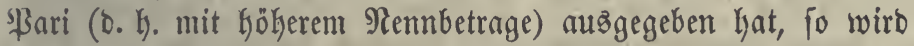
in biejem Falfe früher eine Şerabfeşung ber Sinfen möglich, bei welcher bann bie nämlict)e Erfparung ftattfindet, wie bei Der bisker betracteten Nethooe, fo dap folglich Deren Borzug nur furze 3eit Dauert. Şat man z. B. bei einem hohen Zinsิfußpe ftatt 5 proc. Sdjeine zu 90 zu geben, lieber 6 proc. Schuldbriefe im ßari bezahlt erhalten, fo wirb unter günftigeren Uumftänben ber \$reiz Derfelben fogleich etwas über 100 hinaufgehen, man fann folglich bie Sijulben auftünoigen uno neue etwa zu $5 \frac{1}{2}$

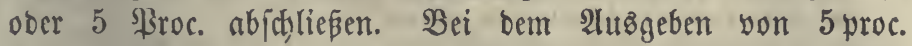
Dbligationen zu 90 wäre biefe Maß̧regel erf́t Dann zu berwirfen, went biefelben über 100 geftiegen fino, was offenbar länger bauert. Wenn im erfteren Falle bie Beränberung icton nad) 10 Sakrent erfolgt, fo ift unterbeffen Durd) eine 10 jährige Sings eriparung von $1 / 2$, Gödfifents $1 / 16$ ber Schuld getilgt worben, 
wobei bie in ber (Surseryöhung liegenbe Sd)ulbwermehrung ein itberwiegender Sadthtyeil ift. Da mun Umftänbe ber in 1) bes trad)teten 2 rt nid)t lange allzuhalten pflegen, fo barf man bei ber $\mathfrak{B} e r g l e i d) u n g$ ber beiten 2 trten von 2 Inleiken teine fo lange bauernbe Sinserfparung annehmen, wie es yon ben 21nbängern ber Anteiben mit höherem Nominalbetrage geideken ift. In vielen Fällen hat bies Berfahren bebeutenben Sdjaben gebradyt unt man muß baffelbe fowohl nad) ben einzelnen (Erfahrungen, als nad) alfgemeinen (Srünoen ber $\mathfrak{S a h r f t}$ einlictfeit, in ber

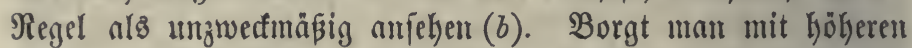
3injen, fo itbernimmt man eine jesige Beid)werbe von befannter (Sröße unt hat bie Şoffnumg, bald zu niebrigeren 3infen zu gelangen. Borgt man mit Göherem Rominalbetrage, fo erfauft

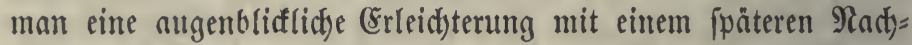

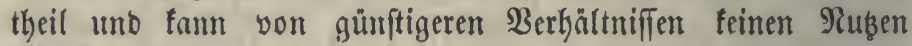
mekr ziefent $(c)$.

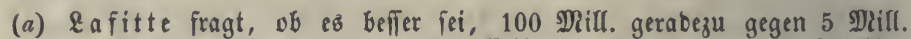
Binfen aufzumekmen, ober $133 \frac{1}{3}$ शRill. gegen 3 Proc. ju beridreiben uno alfo mur 4 शnill. Sins zu geben. Später febt er folgenbe $B_{e}=$

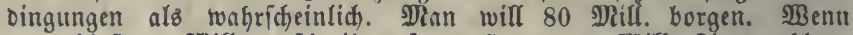

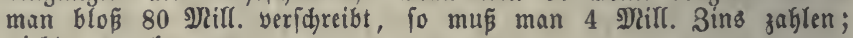
giebt man aber aus

86,4 Nifl. in $4^{1 / 2}$ ßroc. zu 92,49 , fo braudft man 3.890000 3ins 94,5 " " 4 " " $34,21.780000$ " " 103,39 " " $3 \frac{1 / 2}{1 / 2}$ " " 77,39 " " 3.620000 " 115,33 " " 3 " " " 69,42 " " " 3.460000 "

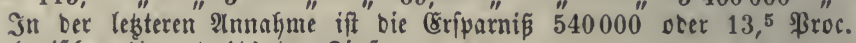
(zwifden $1 / 7$ und $1 / 8$ ) ber Sinjent.

(b) Bei ber erwaignten Ilmwanolung ber franzojifiden $4^{4 / 2}$ in 3 Proc. (\$. $495(d)$ ) trägt Die Eaar empfangene soulte zu $4 \frac{1}{2}$ 马roc. nur 7 शill. Simfen vber 5,2 Proc. Der bigherigen Sinzanzgnbe ein, wenn

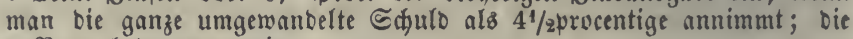
4 Proc. betrugen wenig.

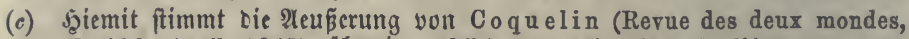
$\mathrm{X}, 132$. Arril 1845) überein: Offrir aux créanciers de l'état une augmentation future de capital, en échange d'une perte d'intérêt présente, c'est en quelque sorte déplacer les rôles; c'est mettre la prévoyance de l'avenir du coté des hommes qui meurent, et ne laisser à l'état, qui doit virre, que le souci du présent.

\section{§. 499 .}

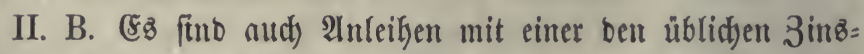
fü inberfteigenten Rente gemadft worben, weldye aljo neben ber $\mathfrak{B}$ erginfung aud) eine allmälige $2 b_{j} a h$ lung enthält, fo baß nad) einer gewiffen 3eit bie gamze Edjuld erlijat. Bon joldjen 
temporären ober 3eitrenten im weiteren Simne ift im Arfgemeinen Folgenbes zu bemerfen $(a):$ 1) Die Capitaliften, bie Kiebei yon einer gewiffen Summe eine größere Rente er= halten, alsz bei einfactsen 3insobarlehen, zefren gewöhnlid mit ben Sinfen aud) zugleid) bie jährlid)e Sduldobzaklung auf, uno es erfolgt alfo bieburd) bie 3erftörung von Eapitalen. Freilich leiken aber nuf foldje 3eitrenten nur foldje ßerjonen, bie ohne bas 3ujeşen ihres 2 ermỏgenz mit ben blopen 3injen nidjt aublommen fönnen uno bie, wenn ber Stant feine 3eit=

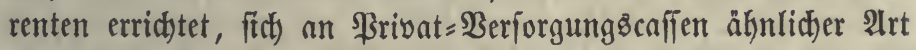
wenben müffen. I, \$. 234. Die meiften $\mathfrak{B}$ egüterten fint jebod) bedacht, ifr Bermỏgen für ifre Erben zu erhalten, weß̧halb bie Zakl berer, bie auf iene Beoingung einer tilgenben Rente ein= geken rolfen, nidyt grop ift und für ben Stant feime befonders günftigen Bebingungen zu erwarten finb. Aud) hat man überall

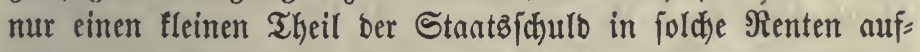

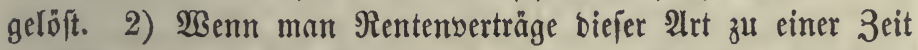
eingeht, wo Der 3inz̧fußs niebrig fteht, fo ift Die Regierung fiđ Binfe, fo begiebt fie fid Der Belegenkeit, yon einem fpäteren Sinfen beffelben Nuken zu ziehen, weil bie cinmal feftgefesten Zeitrenten feine 2 bänoerung mekr zulafien. 3) Bei einer großjen Summe von 3eitrenten fönnte es läftig werben, Daßj man zu einer unausggefesten Tilgung gezwungen ift, aud wenn bie

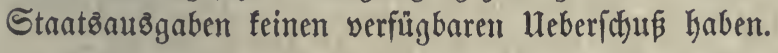

Şieraus ergiebt fid), baß foldte 3eitrenten feine (Empfef)= lung verbienen, obfdjon fie auth feime gropen Nadjtheile an fict) tragen.

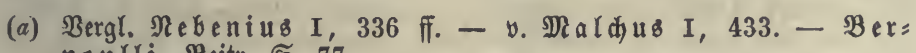
noulti, Beitr. S. 77.

\section{§. 500 .}

Die 3eitrenten im weiteren Sinne zerfallen in folgenoe 2Trten:

1) Beitrenten im engeren Sinne, annuities for terms of years, auf eine beftimmte 3ahl yon Jalyren. Sie Inffen eine genaue Beredynung zu $(a)$, éntippredfen aber am wenigften ben 3wedten ber Capitaliften (\$. 499), fino weniger beliebt uno nidjt fo leidjt ofne Berluft zu verfaujen, alo eine einfactec 
Dbligation. In Englanto finto fie öfter als in anbern Ränbern, theilß als 3ugabe zu anbern Stantzpapieren (\$. 495 (c), $496(a))$, theils abgejonbert nusigegeben worben, uno zwar bisiweilen auf einen langen 3eitraum (b).

2) Eeibrenten, rentes viagères, annuities for life, auf Rebenฮై fidst auf bie mittlere Rebensoauer befferben befinment wirb. Der (Eapitalift if biebei für feine ßerion ganz fitjer geftellt. Der Stant hat befto weniger $\mathfrak{B a g n i} \beta$, ie zuberläfítgere (Erfahrumgen

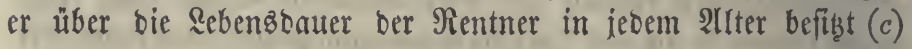
und eine ie größerc 2 Inzahl von \&eibrentengläubigern vorkanoen ift, weil bei einer größeren Menge von Făllen bie Eeję̧ęe ber

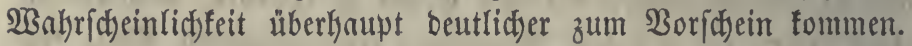
$\mathfrak{U m}$ nidjt für jeben eintretenden Capitaliften eine befontere

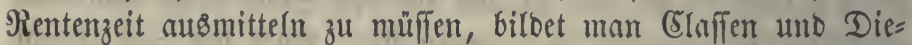

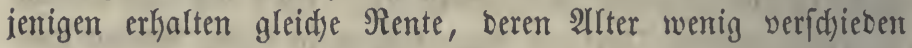
ift (d). In einigen \&änbern werben in ben Stantzred)mungen

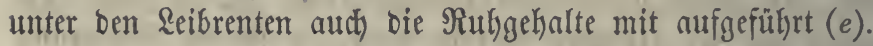

3) Tontinen, bei benen mefrere Theilnehmer von ungefälgr gleid)em elfter mit einanber in Bsemeinjd)aft treten uno bic burd) Den Tod einzelner Mitglieber erlebigten \&eibrenten ben Ueberlebenben zuwadjein, biż ber leşte geftorben ift $(f)$. Die Sooffmung auf eine fteigende Cinnahme verleift biefen Inftalten einen befonberen $\Re$ eiz. Wegen ber mühjamen, umftänblicten Berwaltung eignen iebod) fich Tontinen beffer zu Privat= $\mathfrak{B}$ er=

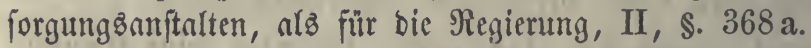

(a) Se nađ Dem angenommenen Binz̊fúpe fam für ein Capital von 100 f. eine Sente gegeben werben

von 5 \$roc.

6

10

20 bei 5 \$roc.

auf $\overline{37}$ Iabre

15 bei 4 ßroc. aแI 43 Inture

29

13

$51 / 2$ bei 3 ßroc. auf 31 Jahre

23

12

(b) গach Smith (III, 370) wurbe fdon unter Wilkelm III, und शnna in Ernglano ofter gegen folde 3eitrenten geborgt, 子. 23. 1693 eine Million auf 16 jährige Nenten von 14 \$rocent (เvas fư Den (s)laubiger fefyr vortheilfaft war, oa ein Sinşfús von 11 Đroc. Daju gehỏrt, um

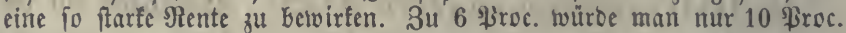
16 Safyre Ginourdy zu entrichten brauden). Bon 1793 bis 1519 worben 525110 \&. St. Seitrenten feftgefęt, Dic fämmtlid, bis 1860 erloichen, und ztwar immer alz Daraufigabe zu ben ausgeliefertell Doligationen yon immerwährenoer Simsoauer; 1795 twurben aud zum Behufe Des fogenannten taijerliçen 2ulełens 25 jäbrige Renten im Betrage vou 
230000 \&. St. zugefiddert, nämlid für je 100 \&. St. baar empfing ber (S)äubiger 83 \&. St. $62 / 3$ B. in 3 vroc. Sduulbbriefen unb eine 3eitrente von 5 \&. St., Die, weil ber jesige $\mathfrak{B e r t h}$ einer 25 jährigen Эente (zu 5 ßroc. berechnet) ons 14 fache ift, zu 70 \&. St. angeíd)lagen merben muste. 1822 wurben bie Staatżpenfionen mach ben forgfältigften Beredhungen Finlaifon's in lange 3eitrenten umgewandelt, wobei Der Jahresbetraa ber 2lusgabe yon 5 auf 2.800000 \&. St. Gerabgebracht wurbe. Der Betrag ber Seit= unb Eeibrenten, weldse bie britifhe

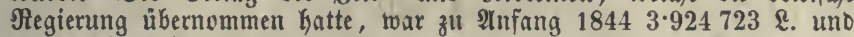
wurbe einer immerwährenbe Siente yon 1.550762 \&. an $\mathfrak{B e r t h}_{\text {gleid }}$ geiest, 1849 waren es 3.725993 \&. Der (Surs ber 3eitreiten ift bem

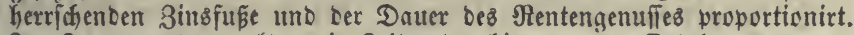
Im Jamuar 1851 galten Die Seitrenten biż zum 10. Detober 1859 uno 5. Januar 18607 \&. 7 und 16 Sdf. $(7,35-7,8)$. Der jebige SBerth

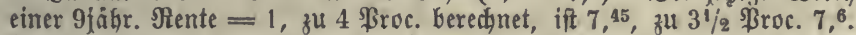
Im Nobember 1859 galten bie 3eitrenten biz शpril 1855 Das 171/2 fadje, alfo fử beinake $25 \frac{1}{2}$ Iahre. (Sine 25 jähr. Sente ift bei $3 \frac{1}{8}$ Proc. 17,173 werth, alfo zeigt ber \$reis an, on $\beta$ man fich mit einem nies

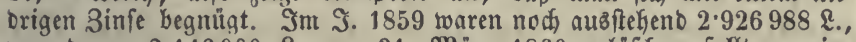
von Denen $2 \cdot 146000$ \&. am 31 . Niarz 1860 erlofifjen follten, eine Erleidterung, auf bie fich iđon mefrere Jahre vorker bie Blicfe rich)= teten. Dau fhlug 1858 Den jebigen $\mathfrak{B}$ erth biejer 3eitrenten auf 48 Millisnen \&. an, Financial accounts $1858 / 59$ ङ. 41. 77. Die Stantobrechnungen geben bie terminable annuities im Jafhre 1861 auf $1.843875,1862$ auf 1.893157 \&. an. - Der \$lan einer Seitrente bei Fuloa (5̧anbb. §. 255) ift für bie einzelnen Capitaliften von einer Anleifie mit beftimmtem Tilgeplane nidyt verfobieben, weil fie nady und nach bas Capital felbit zurüid erfialten.

(c) Dieje if länger alz bie allgemeine Rebenzbauer in einem Lanbe. Heber bie Berechnung Dettinger, 2nleit. zu finanz., polit, unb jurib.

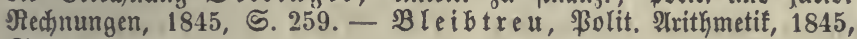
ธ. 445 .

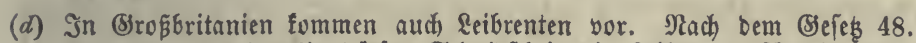
Ge. III. c. 142 (1808), Dürfen ๔đuldofbeine in \&eibrenten für eine ober mekrere \$erionen nach einem, für jeoes \$lter aufyeptellten Tarif um= getwanbelt werden. Diefi gefdieht nod fortwälyrent. Prm 5. Jan. 1851 befiefen fich bie \&eibrenten auf 972143, am 31. IDảrz 1859 auf 1.030179 \&. Smith (III, 374) leitet Daraus, Das in Franfreich mehr begüterte Menf̧ien fein Setwerbe betreiben, oie gröbere Beliebtheit ber verfuiebenen Arrten von Beitrenten in biefem \&anbe in Bergleid

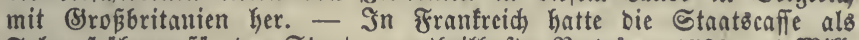
Frolge früberer für ben Staat unvortfeilhafter ßertrảge, 1793100 Mill. Francz \&eibrenten zu entrichten, 70 Mifl. auf 1 Ropf, 27 Mrill. auf

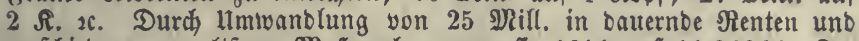
berfichene getwaltiame \$lapregeln waren fie 1814 auf $14 \cdot 346367$ Fr. berminbert. 1830 betrugen fie nod $7 \cdot 271914$ Fr., wowon 5.476455 auf 1 Ropf an 26009 \$erionen, 1.670635 ₹r. auf 2, 949933 auf 3 , 29831 Fr. auf 4 Röpfe. Bon ben Beredjtigten waren 754 Rebendé 1736-40 geforen, 1810 von $1741-45$ x. D'A u diffret, Rapport ธ. 173 und Beifage 33. 1860 waren nod 723833 Fr., fur 1865 find 438321 Fr. alte Reibrenten vorhanben, Die Reibrenten ber Arters= veriorgung (II, §. 368 a (d)) betrugen $18602.727000,1865$ mutf) $=$ må̃liç $4 \frac{1}{2}$ Milll. Fr.

(e) Dies follte twenigitens mur bei benen geidsehen, bie aus einer bejonberen,

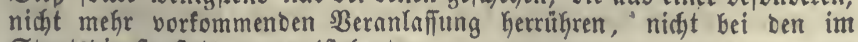
Staatobienite ftets neu entfegenden. 
(f) Bgl. Sonllenfels III, 415. - A. Hooke (An essay on the national debt and the national capital, Lond. 1750) rieth, Die ganze

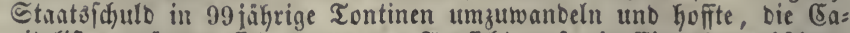

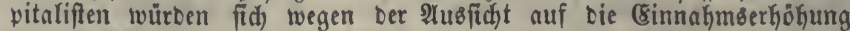
beim 2uళfiterben von Theilnehmern mit bem getwobnlidgen Sinsfupe begnủgen, झlortimer S. 591 .

\section{§. 501 .}

II. C. Rotterie=2lnleihen $(a)$, eine neuerlid) vielfältig

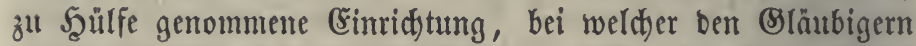

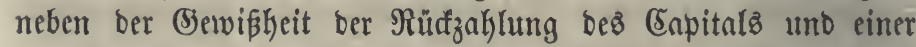

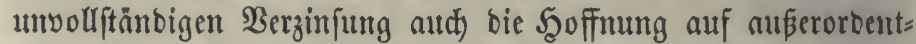
licke Berwinnfte bargeboten wirb (b). Die gewöhnliche 21norb= mung ift folgende: Die ganze geborgte Summe zerfälut in eine $\mathfrak{A n z a b l}$ gleicher Theile, für beren jeben eine Dbligation (Eooz,

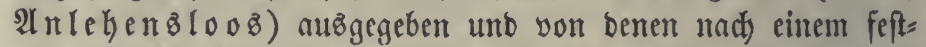
gefesten \$lane in einer beftimmten Sngregreife jährlid) eine gewiffe 3ahl burd) baz Looz gezogen wirb. Aluf einige ber= felben fallen bei jeber 3iekung nady bem ßlane groß̧e, auf anbere mittlere unb fleinere Sewvinnfte, für bie übrigen heratts: gefommenen, uno zwar bie meiften, wirb nur bas Capital fammt ben feit ber (Eröffmung ber Anleike angewachjenen ein= fachen 3infen auşbezahlt. Die Mittel zur Bezaklung jenter Bewinnfte fließen aus folgenden Duellen: 1) Da bie 3injen

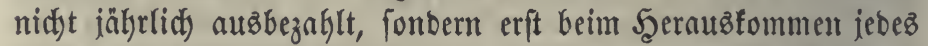
\&oofes nadjgeliefert werben $(c)$, fo erpart man bie 3wijd)en= zinfen (d). 2) Die Eapitaliften haben fid) Der (Seminnshoff= nung ivillen auth) oft mit geringeren alsz ben üblicken Jimfen für ben ungủnftigiten Fall begnügt, woourd) eine weitere Summe erpart wiro.

Die auf ein $\mathfrak{L}_{0}$ sommente ganje 3ahlung, entlyalte fie nun blop Capital und angelaufene Zinfen, ober aud einen

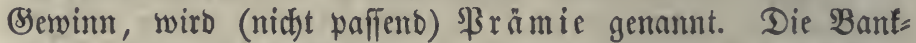
bäufer, weldye foldbe 2lnleiken übernalymen, haben, um bei jeber

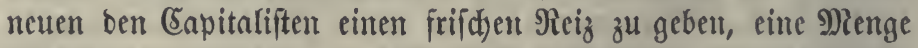

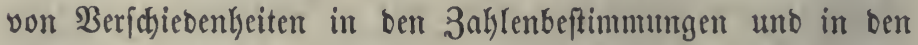
anberen beigefügten $\mathfrak{B}$ ebingungen ausigebadft, $z$. $\mathfrak{B}$. in ben 3wifdyenzeiten zwifden ben Berloofungen $(e)$, ber Berbinbung

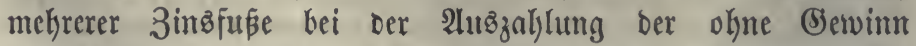
Gerautigefommenen Roofe $(f)$, überhaupt in ber FeftFebung ber 
im ungünftigiten Falle zu erwartenden $\mathfrak{B e r g u ̈ t u n g ~}(g)$, in ber 2lnzahl, Sröpe und Bertheilung Der Serwinnfte $(h)$, ber 3eit ifrer 2ub̧bezalylung (i), ber \&änge ber 3eit, innerhalb beren Das ganze (Bejđäft beenbigt wirb (k) u. Dgl. Die Roofe er= balten fortlaufente 3ahlen. Wegen ber grofen 2lnzahl von Loofen pflegt man biefelben in albtheilungen (Serien) zu zerlegen, weld)e ebenfallz mit 3ahlen bezeidynet werben, uno ев werben jebešmal zuerft die Serienzahlen gezogen, fobann etwaz fpäter bie fämuntliçen Zahlen ber ben heraużgefommenen Serien gehörenden Roofe.

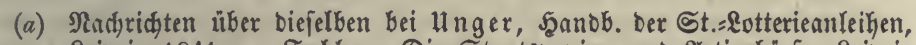
Reipzig 1841. - Feller, Die Stantspapiers uno Ictienbörfe, Reipzig 1846. - Salomon, Die ofterreidy. Staat8papiere, Wien 1846. -

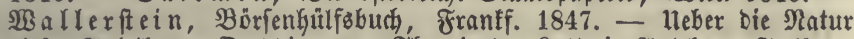
Diefer Anleihen: Dettinger, Theorie Der Rotterie=2nulehen, Freiburg 1844. - Deff. Inleit. 子. finanz. Redn. S. 165. - v. \&indenau,

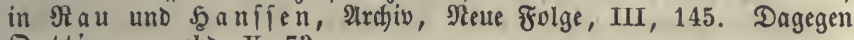
Dettinger, ebD. V, 73 .

(b) Shon bei ber offerreidjichen Anleike yon 6 Mill. fl. im Sakre 1795 wurben Sewinnte verlooft, aber nur in bem 12 jäfrigen Seitraum vor

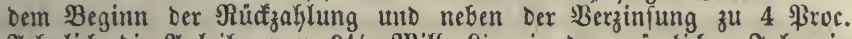

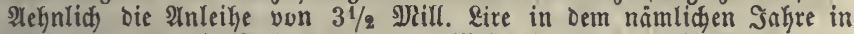

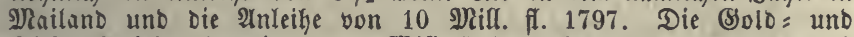
Silber = शntehenslotterie von 10 शill. fl. im Jahre 1802 (es wurbe auch ungepragtes N) Nünzmetall angenommen) fowie bie 1805 und bann nod)= mals 1806 ausgeidriebene ifterreid. Anleife von 20 glifl. fl. Gatten

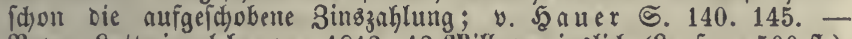
Bayer. Rottericanlehen von 1812, 12 ग्lill. verzinglich (Roofe zu 500 fi.),

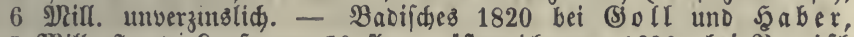
5 s) uno $\Re$ othidilo, 20.800000 fi. im 20 Sulben=fupe, in Roofen zu 100 fi., - anberes öfterr. von 1821 mit benfelben Şäufern, 371/2 Niill. in Loofen fu 250 fi., welde im Berfehr Den গamen $\$$ artialloofe tragen, - Gamnöb. 1822 bei $\mathfrak{B}$ erend, 2 Nill. Thlr. Sodfe zu 100

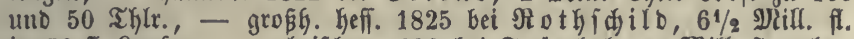
in 50 fi. Roofen, - polnifheb 1829 bei $\mathfrak{F r a ̈ n f e l , ~} 42$ Mill. fi. poln.,

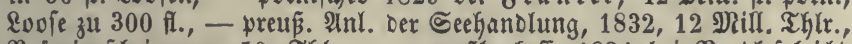

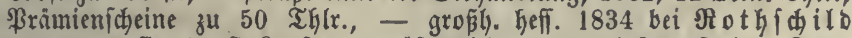
2.375000 fl., 25 fi. Roofe, - ofterreid, 1834 bei Arnftein, (S) eys müller 2c. 25 still. fl., \&oofe zu 500 fl., - ruffifh=poln. von 1835

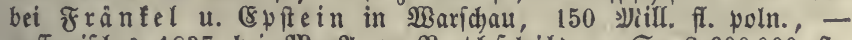

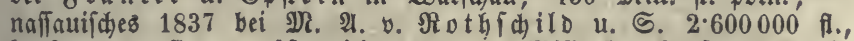
loofe zu 25 fl., - ofterreid. 1839, 36 Mill. fi., Sooje zu 250 fí.

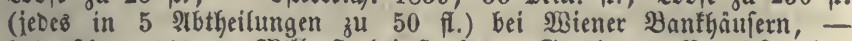

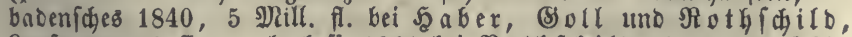

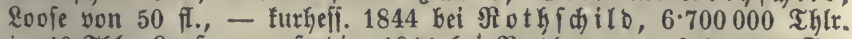
in 40 Thlr. Loofen, - farbin. 1844 bei $\mathfrak{B}$ eth $\mathrm{m}$ ann, 3.600000 Fr.,

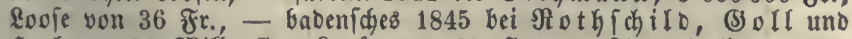
5aber, 14 शiff. ff., Loofe von 35 fl., - fhaumb.=lipp. 1846,

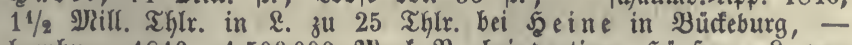
Gamburg. 1846, 4.700000 Dlarf $\mathfrak{B}$. Bei Dortigen Şäufern, \&. von 
100 Y)arf, übernommen zน 95, - ofterreid). 1854,50 Mtill. f1., $\mathbb{L}$. von 250 กิ., - preus. 1854,15 פlill. Thlr., \&. zu 100 Thlr., anf.=beff. 1857, 2 Ylill. Thlr., \&. vou 100 Thlr., - fifwedifdes 1860 ,

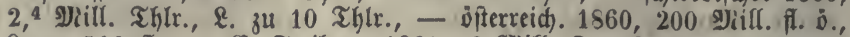
\&. zน 500 f., - 5. Freiburg 1861, 6 গ্lill. Fr., $\mathfrak{l}$. von 15 fr. -

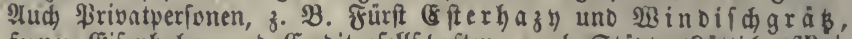
ferner (Eifenbahn= uno (Srebitgefellichaften, aud Etäote (Rittich, I)ai = lano, Neuenburg) haben foldbe Pnleigen abyeidylofien.

(c) Dod fummt bei einigen Fulehen aud eine jäfrlidye Berzinfung vor, wie fकun bei bex ojterreid. zweiten Anleife von 1820. Bei Der ofter: reid. Pnleife bon 1554 werben jährlidy 4 ßroc., bei ber preusifinen von Dem nämlichen Iahre $3^{1 / 2}$ \$roc. Sins ausbezahlt, Die ofterreid. Anleike von 1860 giebt jogar 5 ßroc. Jabreszinien, Dennod wourten

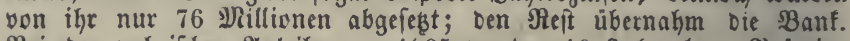
Bei, Der polnifden Anleifye von 1835 wurben 10 Jahre lang \$ramien verlooft, bie ủbrigen Roofe werben feit 1846 jährlid zu 4 ßroc. ver: zinft unb cie Simfeu Der 10 exften Jahre bei ber Afbtragung Der Dbli= gationen nadjgezahlt.

(d) Wenn z. B. ein Loos yon 100 fi. exît nady 20 Jahren zur Sahlung gelangt uno mit ben 20 jährigen 3infen zu 4 \$roc., alfo im (Sanzen mit 180 fi. abgezaflt toird, fo fommen oer Stantscafie die 39 fl. Sinfeszins zu (Jute, Denn eine Rente bon 4 fl. woidgit in 20 Jahren auf 119 fi. an, fatt beren nur 80 fi. Binjen nadjbezallt twerben.

(e) Bald 11/2, bald 1, bald $1 / 2$ Sahr. Die bab. Anteife yon 1845 gat fogar jẩnrlid 4 3iéhungen.

(f) Aeltere pretı. Anleike: abwedhfelnd in bem einen Jafyre eine Berlovfung

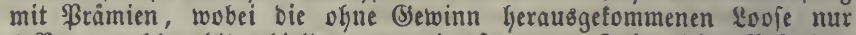
4 \$roc. nachbezalylt erbielten, Dann im folgenden Jafre feine \$ramien, fonberl für alle verlooften Éd)eine gleichmápig 5 Hiroc. Binfen. Neue 2nleike von 1854: in Den ungeraden Jahren erhalten alle gezogenen গummern glcid)viel, zulę̧t (1895) 125 Thlr. oder 25 Thlr. 3inz für 25 Jahre, in ben geraben Safren fommen (S) winnfte vor.

(g) (Sroß̧h. Geif. 50 fi. Loofe: In oen erften 10 3iebungen wurden für einen beträhtlichen Theil Der Kerausgefommenen \&oofe ocm Befiber nur 100 fi. baar uno ons lovs zurüfigegeben, welches in ben folgenden Siehungen nodmals cingenorfen wurbe. - Bei mefreren Plnleiken bleibt bas D)inimum in ben exfen Biehungen gleich uno feigt exft ppater; $z$. $\mathfrak{B}$. ofterreich. Anleihen von 1820, 4 3iefungen finourd 120 fl., in oer 5ten 125 fi. (100 fi. Stamm und 5 Sakirezzinien zu 5 \$proc.), fotann 130,135 u. f. f. BBei Den offerreidifchen Lovfen yon 1839 betrug ons Dlinimum fogleid in Der erfen Siehung oas Doppelte Des angelegten Capitalb, nämliक 500 fi., aber es bleibt bis zur lę̧ten Siehung gleid), 10 Dấ zuleģt Der nadjbezaklte Sins nur $2 \frac{1}{2}$ \$roc. jâfrlidy aแzmadjt, nåmlid $250+40.6 \%$. Defterceid. Anleibe von 1854: Die geringite Brảmie ift fortwägreno 300 f., alip 50 fl. Sins neben oem zurüf: bezahlten Stamm. 2Ber fdon 1855 whe einen hoblgeren Sewinn her: ausfam, bezog alio 20 \$roc., in Jagre 185610 \$roc., 18585 \$roc., in oer legten Siefung fann man nur auf 4 'jtoc. rcdjnen. Inleiké von 1860: Daв झlinimum ift fortwifhrent 600 ก. ober 100 f. über Dem Setrag einç \&oviez. Dießs madjt alfo z. B. nads 1 Jafire 20 Proc., mad 10 Jahren 2 \$roc., im leģten Jahre, 1903, nur 0,46 \$roc. für jebes berfifiene Jahr. In Baben hat man bei ben fwei neucren

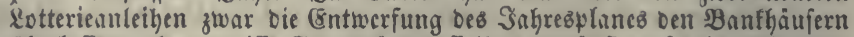
überlafien, aber gewiffe (Strunozilge Deflelben vorläufig gefçlich beftimmt. So veroronete Das Sefeß v. 21. Jebr. 1S45: Die Regierung leiftet

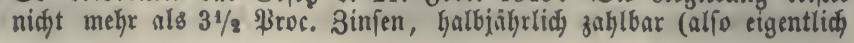




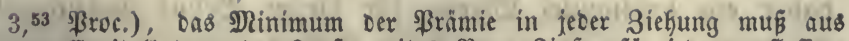
Dem (Eavitalbetrage des \&odies mit 2 Froc. Sinfen für jedes verfloffene gahr beftehen $2 c$.

(h) Se fpäter die Jaauptgewinnfte gemadt werben, Defto mehr gewinnt man an ten Sinfen berfelben. Daker läß̈t man bie höhften (Sewinnfte auf bie rebten Infre fallen, was zugleich ein fortbauerno feigendes Interefife

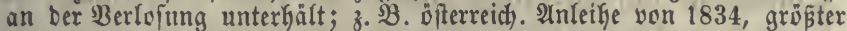
Betwinn 320000 fi., weldher oreimal, nämlich in ber erften, vorleşten und leşten 3̇ekung vorfommt. \$reußs. Wiaximum 100000 Thlr., in Der erften uno in ber leb̧ten Siehung zu gewinnen.

(i) Seivöhnlich einige शlonate nad ber ßerloviung.

(k) Bon ber \&usftellung Der Dbligationen (bie meiftens $1-2$ Jahre vor Der erften Siefing geidah) bis zur leżten Siehung verfięén

15 Jafire, Gamoùv. Anleike,

20 " offerreidiface von 1820 und 1821 ,

24 " fardinifice,

25 " beide preupiface von 1820 uno 1854, polnifhe von 1829, babiídje von 1840,

26 "sfterreidjifdse von 1834,

$381 / 3$ " (d)webifiche von 1860 ,

39 " ifferreichifhe von 1839 ,

40 " babifhe von 1845, anf.=beff. von 1847, fidaumb.=lippeide bon 1846 ,

45 "großjh. heff. von 1834,

48 " hamburg. von 1846,

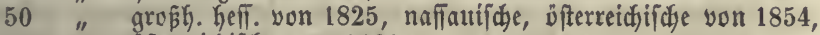

57 " Dofterreichifiche von 1860.

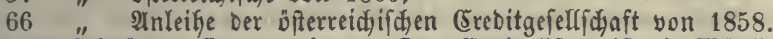

Reb̨tere S̈eiträume find zu lang. Den Capitaliften ift bie siöglichfeit einer fo fpäten গachzablung oer Sinfen nidht angenefym, uno biefer Umitand mag, nit Dem unter $(g)$ bemerften bazu beigetragen Gaben, Daßs Die Geff. 50 fi. Loofe in ten exfen Sahren wenig beliebt waren und beträchtlich unter ifrem Nominalbetrage verfatift wurben; $z$. $\mathfrak{B}$. im Iai $182636 \frac{1}{4}$, im Jautuar $182734 \frac{1}{4}$, uno im Naảrz 1829 erî

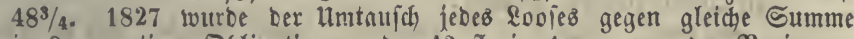
in 3 procentigen Dbligationen oder 42 fi. in 4 proc. von Der Negierung angeboten. (Eurz am 1. Närz $185175^{3} / 8,6$. Februar 1860 121, Sanuar 1865138.

\section{§. 502 .}

Der Entwurf einer Rotterieanleifye wirb fo gemadt:

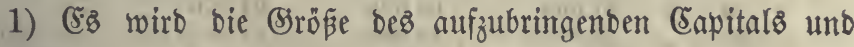

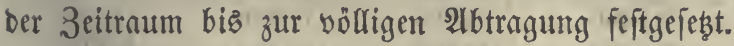

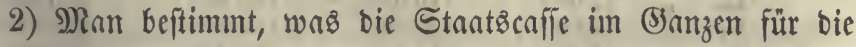
Inleife zu leiften habe, inbem man bie Theilnehmer an ber felben wie eime Befelfichaft betradjtet, welcte mit ber Negierung

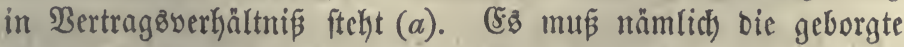
Summe nad) einem gewiffen 3inşfüe (b) verginft uno affmälig burd) jährlidje 3ahlungen abgetragen werben. Sebes Sahr ift 
baker ein beftimmter Betrag für biefen Befuf auszzubezahlent. Je weniger man in ben erften Jafren abträgt, befto größer bleibt bie 3inşfumme unb befto ftärfere Tilgungen müffen fpäter vorgenommen werben $(c)$. Bei einigen Alnleiten leiftete bie Staatżcafe anfangż nidht einmal bie volle Berzinjung, fo baß

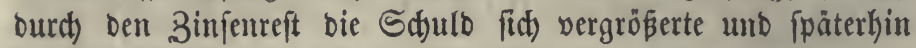
Die Safreşleiftungen un fo viel größer werben mupten.

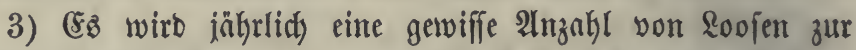
Biehung beftimmt und bie ganze jährlich zu verwentente Summe Dergeftalt unter biefe Looje vertheilt, baß einige mit anjehnlichen, mehrere mit mittleren (5ewinnften aubigeftattet werben, bie meiften aber mur ben für jebez Săbr berectneten Minbeftbetrag (Minimum) erbalten $(d)$. Die fämmtlid)en Wrämien an bie Soosingaber biz zum Sd)luffe ber Dperationen müffen ber Summe ber jährlichen nad) 2) beftimmten Berwentungen aus Der Staatżcaffe gleich) fommen (e).

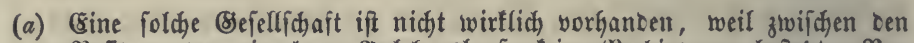
Befizern ser einzelnen Inlehensloofe feine sBerbinoung beftelyt. Nur

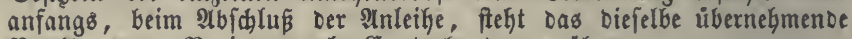

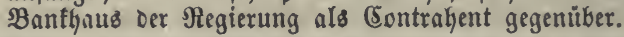

(b) Bei ber grofig. Keffiffchen Inteifye murden für bie erfen 16 Sahre 4, für bie folgenden 35 aber 5 Proc. beredynet, bei den zivei bab. Panleifen

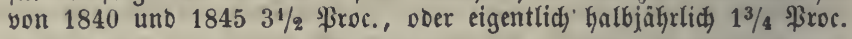

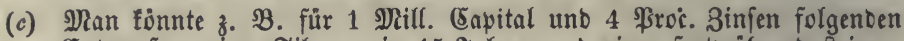
Entwurf zu einer Tilgung in 15 Эałren uno einer fortwähreno peigen= ben Iahreşausgabe madjen:

\begin{tabular}{|c|c|c|c|c|c|}
\hline naต & & 3 in 8 & Tilgung & (5) & 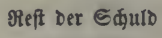 \\
\hline 1. & fahre & 40000 & 10000 & 50000 & 990000 \\
\hline 2. & " & 39600 & 15000 & 54600 & 975000 \\
\hline 3. & " & 39000 & 20000 & $59^{\circ} 000$ & 955000 \\
\hline 4. & $"$ & 38200 & 25000 & 63200 & 930000 \\
\hline 5. & $"$ & 37200 & 30000 & 67200 & 900000 \\
\hline 6. & " & 36000 & 35000 & 71000 & 865000 \\
\hline 7. & $"$ & 34600 & 40000 & 74600 & 825000 \\
\hline 8. & " & 33000 & 50000 & 83000 & 775000 \\
\hline 9. & " & 31000 & 60000 & 91000 & 715000 \\
\hline 10. & $"$ & 28600 & 75000 & 103600 & 640000 \\
\hline 11. & " & 25400 & 90000 & 115400 & 550000 \\
\hline 12. & $"$ & 22000 & 110000 & 132000 & 440000 \\
\hline 13. & " & 17,600 & 130000 & 147600 & 310000 \\
\hline 14. & " & 12400 & 150000 & 162400 & 160000 \\
\hline 15. & $"$ & 6400 & 160000 & 166400 & 0 \\
\hline & $\mathrm{m}$ & 11000 & 1.000000 & $1 \cdot 441000$ & \\
\hline
\end{tabular}

(d) Beifpier. I. Bad. 50 f. Roofe, 29. Biefyung 1865. - II. Defterreid. 2nleige von 1839, 27. Bief̧ung 1865. - III. Deferreid. Inleige von 1860, 10. Biefung 1865. 


\section{5}

3ahl ber zu ziekenden soofe

Dinimum

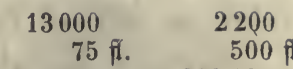

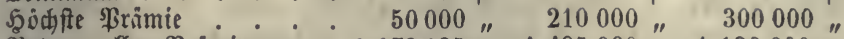
B̉etrag aller ßramien . . 1.073125 " 1.495000 " 1.130000 "

Rämen alle Rovie mit bem

2nin. Geraus, fo betrügen fie $\frac{975000 " \text { " }}{98125 \text { f.. }} \frac{1.100000 \text { " }}{395000 \text { f. }} \frac{660000 \text { " }}{470000 \text { f. }}$

oder ßroc. . . . . $\quad 9,2426,{ }^{4} \quad 41,6$

(e) 3. B. bei Der preußj. Anteife von 1832 wurben in 25 Safyren ver= ausgabt:

$$
\begin{aligned}
& \text { Eapitalbetrag . } 12 \cdot 000020 \text { Thlr. } \\
& \text { Binfen . } \cdot \frac{10.903180 " 1}{22.903200 \mathfrak{T h l r} \text {. }}
\end{aligned}
$$

unb io God belaufen fid bie in Den 25 Siefungen vorfommenten

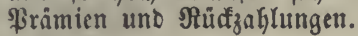

\section{§. 503 .}

2tu vorftefenoer Darftellung ber Rotterie=2Unleiken laffen fith) leicht ifre Birfungen ableiten $(a)$.

1) Für bie Stantşcaffe find fie wie einfache verzinżliche Anleiken mit einem feften Tilgeplane zu betrad)ten. Bringt man fie, wie es in vielen Fällen gefdehen ift, mit einem niebrigen Sinsfupe zu Stande, fo find fie vortheillyaft, mur bießs fann läptig werben, baß man auth in folden 3eiten bie Tilgung fortjesen mú, wo man bie erforberlicken Mittel für andere 3wede nöthig hätte. WSerben bie 2Inleiłen zu einer 3eit ge=

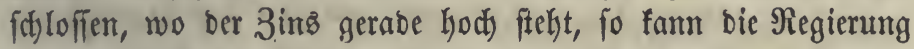
von bem fpäteren Sinfen beffelben feinen Nutzen für bie Steuter= pflidytigen zieben, während ber fteigente Curs ber loofe bie Befficer bereictert. In ben beutidyen Staaten, weldye foldye Anlciben unter 3ugrunbelegung eines 3inşfußę von 5 ßroc. eingingen, ift biejer Nad)theil fehr fühlbar geworben, ba unter=

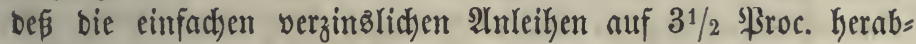
gefest weroen fonnten. Dagegen find in neuefter 3eit megrere äbnliche \&eifyerträge unter gưnftigen Bebingungen zu Stanbe gefommen $(b)$.

2) Die CEntbehnung ber jährlichen Zinseinnahme ift befto läftiger, ie weniger anbere Sinfünte ber Soosbefizer bat. Nur reidje SBerfonen fönnen fo viele Roofe befizen, dapi fie mit

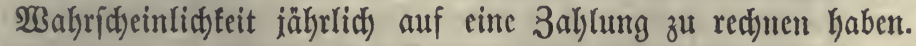
Daker legen bie meiften Menidjen mur eine im Berbăltnís zu ifrem gefammten Bermögen oder Einfommen geringe Summe 


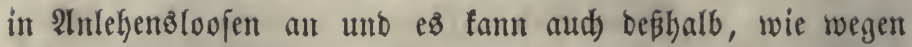

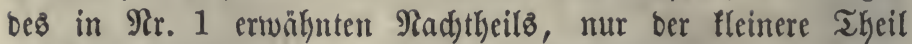

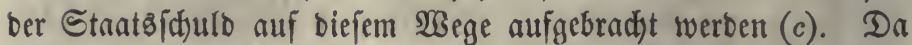
jebod) Dieje 2 rt ber 2 Inleifen in vielen Stanten nicht vorfommt, fo crflärt fị) ifr guter (Erfolg in mefreren Fällen aus bem

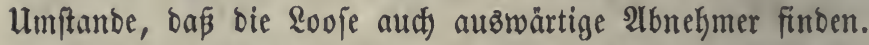

3) Die Soosbeftiser erhalten in jebem Falle ify Capital unto einige Berzinfung, und mand)en berfelben ift es̊ nidyt unan=

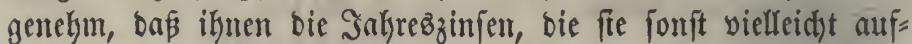
gezefyrt hätten, biż zur Şeimzahlung aufgefpart werben. Nur bie Wenigen, weldye bie eingehenden 3 infen fogleid) wieber werbend anlegen fönnen und wollen, bringen ben Berluft ber 3wifd)enzinjen in Anjdylag. (Erwägt man biezu bie einzelnen beträdtlictyen (Setwinmite, weldye meiftens an wohlhabenoe \$er= fonell gelangen und von biefen größtentheilz werbent angelegt werben, fo fann man ben Eotterieanleifen nidyt eitre fo nact)=

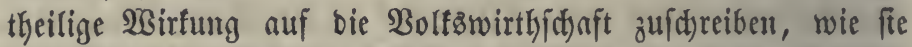

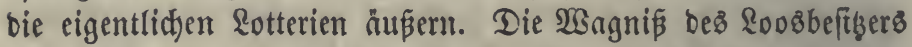
ift gering unt bie leibenfdaftlidje Spielfucht finbet in Dem langen Zeitraum bis zur 2 bzablung ber ganzen Inleike feiue Befriebigung. Dod) fälut biejen Inleiben zur Rnjt a) Daß viele Räufer von Roofen bie Servinnb̧hoffnung höher fdäken,

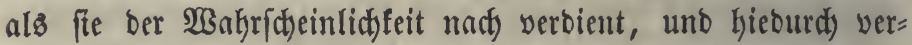
leitet werben, bie Roofe über ifren $\mathfrak{B e r t h}$ zu bezahlen, daß

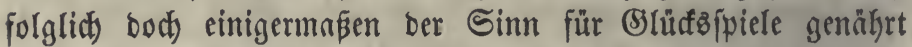

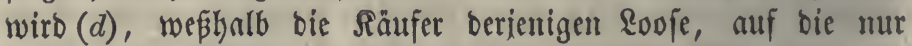
ber minbefte Betrag (minimum) einer Biefung fällt, verlieren, wenn fie biefelben um einen bökeren \$reiz erfauften, b) baß eine Beranlafiung zu Unternefnumgen Dargeboten woirb, bei

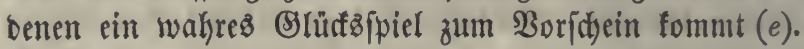

(a) Berbanol. Der bab. 1. Rammer von 1839/40 ßBeilagen, II, 137 (B্e: ridht yon $\Re \mathfrak{a} u)$. - Dettinger, Thenrie $x$. S. 46 .

(b) Die bab. Inleifye von 1845 wurbe yon ben Banthäufern um einen

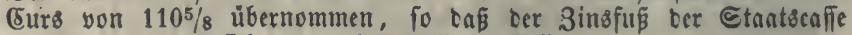
$\left(3,53\right.$ von $\left.110^{5} / 8\right)$ fid nur auf 3,19 Proc. fellt.

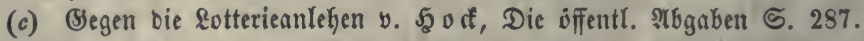

(d) Der ßreis Der Roofe ift oft Göher, bistweilen jetoch, bei Anleifen mit minber annefmliden $\mathfrak{B}$ ebingungen, aud niebriger als ber Dinteftbetrag ber nád)ften 3iefung. - Curfe in franffurt mit Beifügung ces Mini= mum in ber naddffolgenten Biefung: 


\begin{tabular}{|c|c|c|c|c|}
\hline & 1. März 1858 & 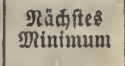 & 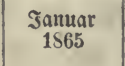 & $\begin{array}{c}\text { Măd } \\
\mathfrak{M} i n\end{array}$ \\
\hline 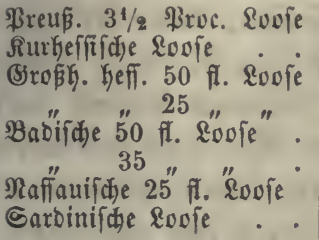 & $\begin{array}{l}113^{1 / 4} \text { Thlr. } \\
55 \\
124^{3} / 4 \text { fl" } \\
32^{5} / 8 " \\
86 \\
52^{1} / 4 " \\
32^{3} / 4 " \\
45 \text { Fr. }^{\prime \prime} \text {. }\end{array}$ & $\begin{array}{l}105 \text { Thlt. } \\
42 \text { fl" } \\
124 \text { fl. } \\
36 " \prime \\
68 " \\
44 " \\
35 " \prime \\
41 "\end{array}$ & $\mid \begin{array}{c}127 \text { Thlr. } \\
51 \\
138 \text { f." } \\
39 " \\
121 " \\
52 " \prime \\
38 " \\
-\end{array}$ & $\begin{array}{l}112 \text { Thlr. } \\
60 \text { f". } \\
142 \text { fl. } \\
40 " \prime \\
75 \text { " } \\
49 \text { "' } \\
37 \text { " } \\
42 "\end{array}$ \\
\hline
\end{tabular}

Bei Den offerreidjifien Roofen wirb ber Curs in Frocenten angegeben, es ftanden z. $\mathfrak{B}$. im Januar 1865 die 250 ff. Loofe von 1839 zu 132 Sroc. (n. Nin. 500 fi.), Die 250 fl. \&. von 1854 zu $74 \frac{1}{2}$ (11. श). 300 fl.), Die 500 f. \&. von 1860 zn $82 \frac{1}{4}$ \$roc. (n. INin.

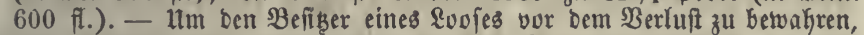
ber ifm aus bem Scerausfommen mit Dem Dinimum erwäh ft, hat man befondere Serfichertungen für foldhe Roofe unternommen, eine Erfinbung bon 23 . 3. 20 ertheimber in Frantfurt. Bender $\mathbb{S}$. 519.

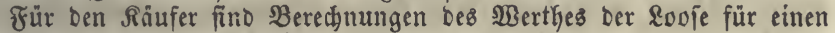
gegebenen Beitpunct müb̨lid. Dettinger, Inleit. S. 177. - $\mathfrak{B a}=$

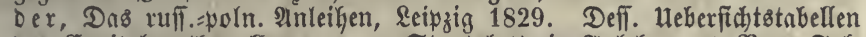
Des Capitalwertfis aller... Staatslotterie =2Mrlehen, $1 \mathrm{SOg}$. Fol. 1834. - Bernoulli, Beitrỉge S. 69 ff. - Feller, S. 9. 139. Salomon a. a. D. - Da zuerft bie Serien und fodann nach einigen

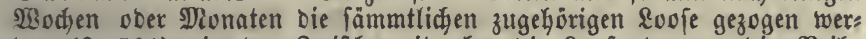
Den (\$. 501), in Der 3wifhenzeit aber bie Loofe ber an bie Neife fommenden Serien ofters verfauft werben, fo exhält man auch Ber:

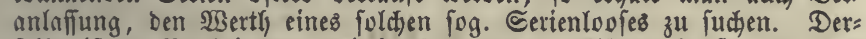
felbe ift $z$. $\mathfrak{B}$. Bei Den Drei in $\$ .302(d)$ exflärten \&oofen vor Den nảdften Siehungen I. 82,52 fr., II. 679,54 fi., III. 1027, 27 fi. MRan

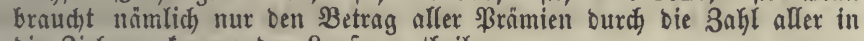
rie Siefung fommenden \&oofe zu theilen.

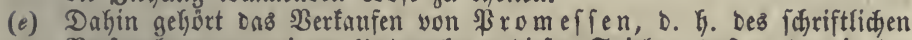
Berfuredjens von einem unternehmer biejes Spiels, Daß̉ ex Den in Der nảdjften Biekung auf ein benanntes 2008 treffenben Selwinn bezaklen

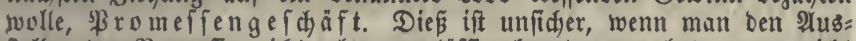
feller ber ßromeffe nidit als zuverlaffig fennt, zumal ba man nicht

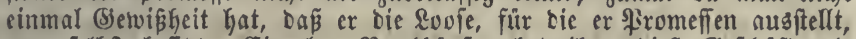

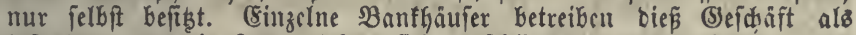

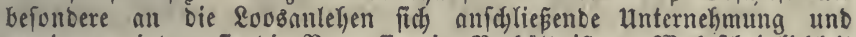

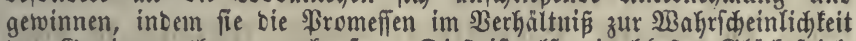

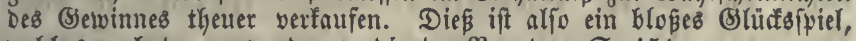
tweldyes verboten zu werden verbient. Bender 5.451.

\section{§. $503 \mathrm{a}$.}

Demnad) finto bic Loobianteifen, obgleid) bişweilen für bie Stantzenffe bortheillyaft uno yon ben gotterien weit verfajicben,

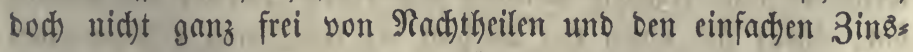

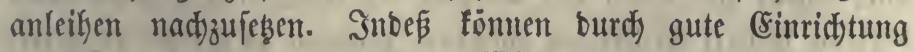
Des SHlanes iene engünftigen Wirfungen gemilbert werben. a) Es follte bie als Minimum zugefid)erte Berzinjung in feinem 


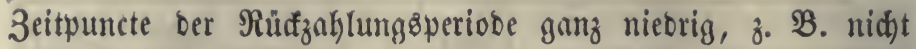
unter 3 ober 2 \$roc., folglid) ber auf Serwinnfte berwenbete Theil ber 3nllungen nicht fehr groß fein, bamit bem 3ufalle weniger überlaffen werbe, ygl. \$. $502(d) ; b)$ ez ift nid)t gut, wem bas Minimum in ben erften 3iefungen fogleid fo hod) gefeb̧t wirb, Daß barnus ein ftärferer Reiz zum 2lnfaufe ent= ftelyt uno ber Curs ber \&oofe über ifyren $\mathfrak{W e r t l}$ gefteigert twirb; vielmekgr follte bas Minimum fortwährenb unb regelmäpig zu= nehmen, bamit bie Befiber ber fpät heraugfommenden Roofe nicht in unvortlyeilfaftere \&age fommen $(a)$; c) bie jährlidje

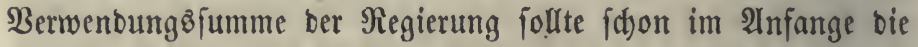
Sinfen überfteigen, fo bak bie Tilgung ber Sctuld fogleid) beginnt uno in ben leşten Sahren meniger anfteigt; d) bie Loofe follten nidft ouf jehr fleine Summen geffellt fein, weil fie fonft aud) in bie Şänbe berienigen $\mathfrak{B o l f s c l a f f e n ~ g e l a n g e n , ~}$

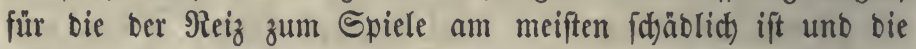
eher auf bie eigentlichen Eparanftaltent hingelentt werben follten.

(a) Nekrere neuere Berloofungsplane lañen beutlich tas Beftreben Der Banffåufer erfennen, Die \&oofe nur anfänglid beliebt zu madjen.

\section{§. 504 .}

Eine 2lnleihe fann auf mefreren $\mathfrak{W e g e n}$ zu Stanbe gebrad)t werben $(a)$.

1) Sie wirb im Sanzen burd) einen cinzigen $\mathfrak{B e r t r a g} a b=$

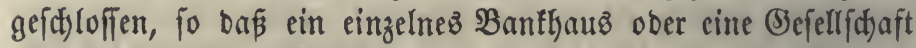
Mekrerer bie aufzunehmende Summe zu leifen verfpridgt unb bafür eine $\mathfrak{2} \mathfrak{n} z a \mathfrak{l}$ yon Sdjulbjđjeinen auf fleinere Beträge, 3. B. von 100, 500, 1000 fl. ober Thlt., erbält, weldje fo= bann an einzelne Eapitaliften verfauft werben, fo bas das Banffauz als Bermittler zwifden biefen uno bem Stante auf= tritt $(b)$. Cine betrådbtliche 2Imleife muß wegen ber Edjwierig= feit, bie Summe auf einmal zufammenzubringen, in mehreren Eriften einbezaflt werben $(c)$. Der Hebernebmer ber Anteihe, wenn er aus eigenen Mitteln ben erften Theilbetrag bezahit hat, pflegt fict) Durd) ben Berfauf ber erhaltenen Dbligationen jogleid) weitere Mittel zur nädjten 3 ahlumg zu ver(d)affen u. F. . Dft ift er im Stanbe, in Rurzem allê Sbligntionen abjurę̧ent und fid fo son aller Theilnakme zurula zu ziehen, bod) mus 


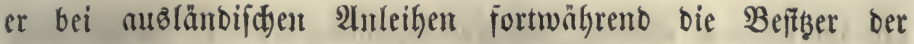

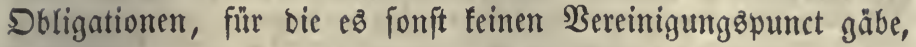
in ifyren Snterefien vertreten. Sein Ruben liegt bišweilen in einer beforberen Bergütung (\$rovifion), bie ifm ber Stant berwilligt $(d)$, fonft aber barin, baj er bie einzelnen Sduldobriefe an bie Eapitaliften um böheren Sreis verfauft, als er fint biefelben bezahlt hat. Nan hat oft bie Curje zum Nad)theile ber Räufer burd) mand)erlei übertriebene Plupreifungen fünftlich it bie Şöke treiben fehen (e), bišweilen ift aber auth) Der vortheilhafte $\mathfrak{B e r f a u f}$ nicht gelungen.

2) Es ergeht eime 2lufforberung an alle Capitaliften, weldse Summen barleiken wollen, fich zu melden und anzuzeigen, wis= viel Seber zu geben gejomen it. Der 3inşü wirb fit)on in Der 2lnfünoigung genannt und man mú ifn fo zu beftimmen

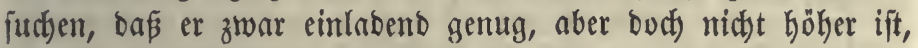

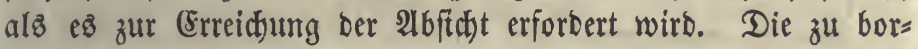
gente Summe wird folglich von vielen einzelnen Darleihern erbaltert. Şiebei fallen die Bortheile, bie fonft einem Banf= haufe bewilligt werben müfien, nun bem State ober ben ein=

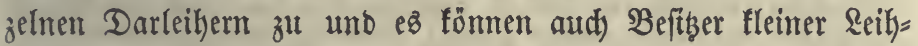
fummen leidst theilnehmen. Diefer $\mathscr{B}$ eg ift neuerlid) oft mit guten Erfolge gewählt worben, bejondersె wenn ber 3twef, fïr ben bie Anleike gemadt wurbe, von fo einleudtender Widtigs feit war, baß bie Cinlabung zur Wnterzeid)nung alsz ein श्tufruf an bie $\mathfrak{B a t e r l a n d s l i e b e ~ z u r ~ U n t e r f t u ̈ k z u t g ~ b e r ~ \Re i e g i e r u n g ~ g a l t ~}(f)$.

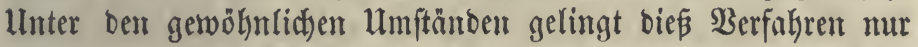
Damn, wenn bie Regierung vollen Erebit genießst, wenn bie Bebingungen für bic Capitaliften befriebigend unb verwenbbare Reikfummen in binreidjenber Menge vorkanben finb. Werben größere Summen angeboten als man braucht, fo wirb von jebem Unterzeidner mur ein Theil bes angemeloeten Betrages angenommen, ober ben fleineren Capitaliften ober ben früheren Ammeloungen ber $\mathfrak{B o r} u g$ gegeben.

(a) Rebenius S. 396. - Eancrin, Defonomic ber menfdididen (Se). ธ. 287.

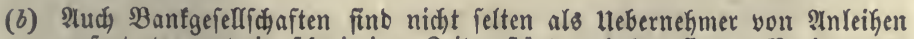

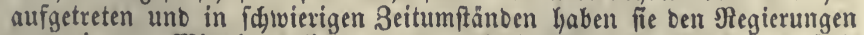
aus eigenen Mitteln gelieken, woburd, fie aber ofters in eine üble \&age gebradt wurben, I, \$. 309. 
(c) Um genau zu erfennen, wie groß̉ ber \$ufwano bes bie Darleige über: nefymenben $\mathfrak{B a n f f y a u}$ es ift, wirb ber Tag zu Srumbe gelegt, an weldhem bie Berzinfung (jouissance) anfängt, und berechnet, wie hodh fich bie Sinfen ber vornusgekenden 3nhlungen unb bie Sinserfparungen ber ipäteren belaufen. - Das bayer. Sefes v. 30. 9lov. 1847 geftattete Die Itufualyme einer 4 proc. Inteife, bei weldjer bem Darleifer fü jebe eingezablte Summe zugleid, ber naimlidge Betrag im älteren $3^{1 / 2}$ proc. Sdullobriefen auf 4 \$roc. erhöht werben follte.

(d) Wan fönnte aud, whne einen feiten (Surs Der Hebernafime auszu= beoingen, Dem Bantfaufe gegen eine frovifion bie Squlobriefe in (Eommifiton geben, um fie po hod als möglid auf Rechnung bes Stants zu vertaufen, bon Eancrin S. 288.

(e) Namentlich bei ben offterreidj. Iotterieanlehen bon 1820 unb 1821.

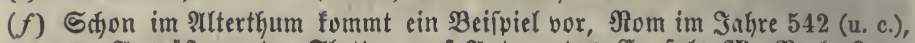

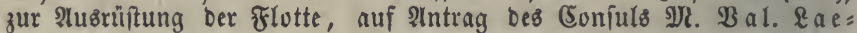
vinแs, Liv. XXVI, 32. - İn lonbon fam, alz man vernakm, dá eime 3twangsanleife beabfidtigt worben fei, yom 1. Dec. 1796 bis

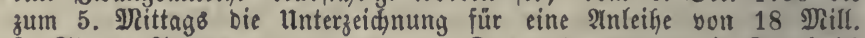
\&. St. zu Stanbe, loyalty loan. - Das prêt national in Franfreich nach Befeb vom 21. April 1831 in 5 \$roc. Brachte 21.422400 Fr.

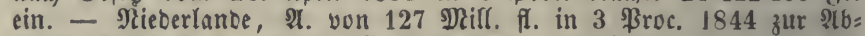
lófung ber 5 Proc., toozu alle Bolfsclafien wetteifernd beitrugen, Der Rünig übernahm etwas über 10 शRill. - Defterreich. jog. Plational= anleken yon 1854, 500 Drifl. fl. zแ 5 Proc. mit Friften, fo Doñ erft nach zivei Infren alles eingezahlt werben muste. In ber Şoffmung, bas \$apiergelo auf Bari gebradyt zu Feken, machten bie unterthanen Anitrengungen, um bie erforberlidue Summe aufzubringen. (1859 wurbe befannt, Daß für 110 \$ill. fl. Schulbbriefe toeiter, über 500 פrill. fl. finaus, ausgegeben worben waren.) Boridhlag einer neuen patriotificen Inleife, bei ber alth ungewriggtes (Solb uno Silber angenommen wübe, um Seräthe $2 c$. mubbar zu maden, bei $\mathfrak{B}$ o searolli, Die Finanzen Defterreichs, Leipzig 1859. - Fü bie franzöffche Anteife von 750 शill.

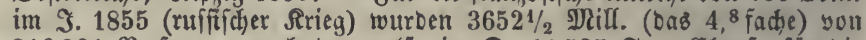
316864 Berionen angeboten, alfo im D. 11527 ₹r. (56enio für bie 500 פill. 1859 (öfterreidjifher Rrieg) 2509,6 Mill. (Das 5 fadje) von 690230 Unterzeidnern, D. 3635 Fr. So grofé \&eiffummen fätten nicht wirflich zufammengebradyt werben fonnen, bie unterzeichmer rech)= neten offenbar fdou Darnuf, oaßs nur ein Theil angenommen wercen

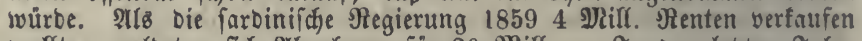

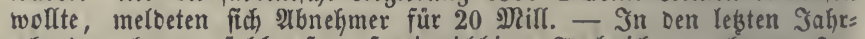

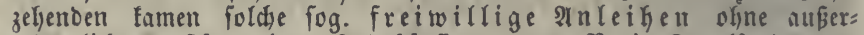

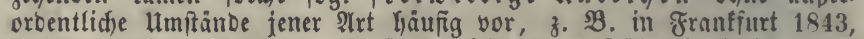
Baben, Bayern, Sadjell. In Defterreid war es früherhin tiblid, ofne Befanntmadung über Umfang und Bindfü einer Anleifye Die cinzelnen Dbligationen unter ber Sand zu verfanfen, wie fid (B) belentibeit zeigte,

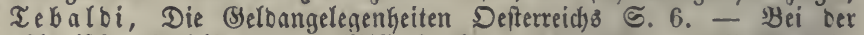

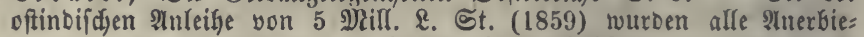
tungen unter 97 abgelefint, $\mathrm{ez}$ famen aber aud) höbere vor, 500 \&. zu 100,3000 zu $98^{3} / 4,13500$ zu $98^{1 / 2}$ 2c. Dafer nafm man von ben zu 97 angebotenen Summen nur 38 Proc, an, bie anberen aber voll= ftrinbig.

\section{§. 505 .}

Der Bertrag über cine 2Inleike ber erften 2rt (\$. 504) fann burd) Unterbanblung mit cinem cinzelnen Banflatie zu 
Stanbe gebradjt werben, wobei es jeboch rathjam ift, unter ber Şand auf metreren Seiten Erfunbigungen cinzuziehen, um fit)

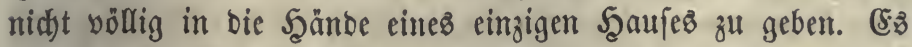
fann aber aud) ein offenes Mitwerben veranjtaltet werben, inbem man bie Srößße und einige Bebingungen ber beabfictigten Inleike befannt madht, bie Banflyerren zur Uebergabe idjrifts licher 2nerbietungen ( $\mathfrak{u b}_{\mathfrak{b}}$ miffionen, soumissions), mit beizufügenber Bürgidjaft in Staatzpapieren, aufforbert uno fo= Dann bei ber Eröffrung ber eingelaufenen Errflärungen bem= jenigen bie $2 \mathfrak{n l e i k e}$ zuld)lägt, beffen 2 nträge bie vortheilhafteften find. Diés in England üblidfe uno aud) in anberen sändern

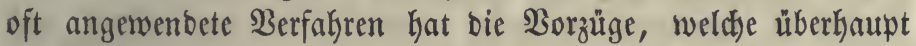
Der Deffentlidfeit in Finanzgefdäften zutommen, es liefert ben

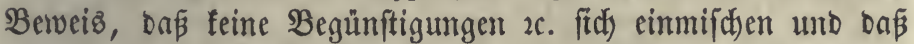
unter ben obwaltenten $\mathfrak{U}$ mitänben feine günftigeren $\mathfrak{B}$ ebingungen

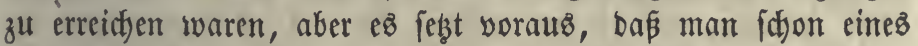

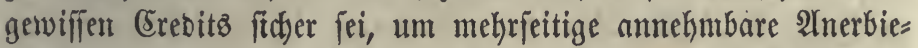

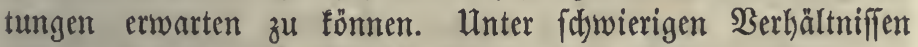
voer in fleineren Ränbern ift es fitherer, ben erfteren $\mathfrak{W e g}_{\text {ein }}$ zufdhlagen, bei bem man bod) ebenfalls einigerimaken bas \$it=

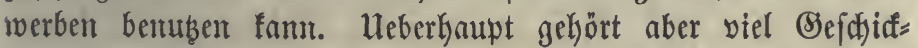

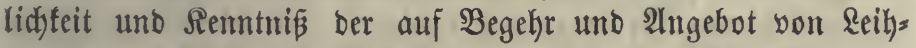

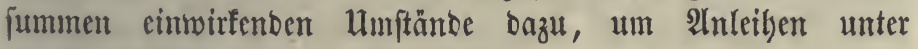
günftigen Bedingungen abzuldyließen.

\section{§. 506 .}

Die cinzelnen Stantsfduldideine ober =briefe, Staatsobligationen, Staatbpapiere, stocks (a), wer= ben auf fold)e Summen aubzgefertigt, wie fie ben Mitteln flei= nerer und größerer Capitaliften entfpredjen und zwar nad)

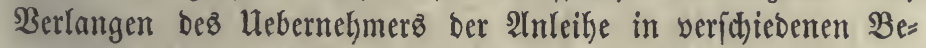
trägen, \$. 504. Sie wurben fonft allgemein wie bie Sdjulb= briefe eines Sribatmannez eingerid tet, to Daj fie ben Ramen

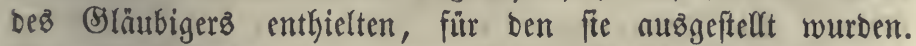
Reuerlid) Gat man fete in vielen Staaten fo abgefäst, baß́, wie beim SBapiergelde, jeber Beftịer fogleid) alz (Eigenthüuer gelten fann, weil fie feinen Ramen enthalten und beşhalb fein Beweis ber gehörig erfolgten Abtretung nöthig ift. Soldje Sdjulbbriefe 
a If ben \$nhaber (au porteur, on bearer) ober (5erti= ficate find bequem fowohl für bie Negierung, weil bie befdwer= lidje Budfühtyrung über bie (Sigentfüumer jeber Sbligation unb bent Mebergang berjelben in anbere Şänbe ganz bejeitigt wirb, als für ben (Sigentlyümer, weil fie leicht, ofne alle Förntlichfeit uno Müke zu verfaufen fint. Die Sdulofdine auf $\mathfrak{N a m e n ~ ( r e n t e s ~ n o m i n a t i v e s ) , ~ b i e ~ f o g . ~ I n i c r i p t i o n e n , ~}$ bebiurfen bei jeber Bern̈ußerung einer Umict)reibung in beur

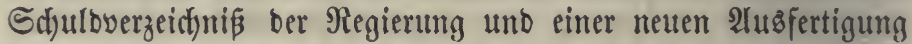
für ben Räufer $(b)$. Sie geben größ̈ere Sicherheit gegen Dieb=

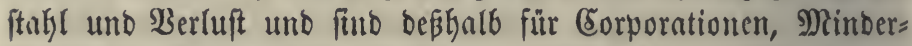
jährige ze. bejonbers geeigutet, verurfactben aber Mühe uno Soften bei ber Ulebertragung und finb barum weniger belicbt, und on bie Bejdfwerlidffeit nod) größer ift, wenn ber Berfauf im 2luslanbe geidhieft, fo verbreiten fid) joldye Sduldofbeine nidjt fo weit, als bie ber erfteren \&rt. Dieß̧ liegt wegen ber größeren Unabfängigfeit vom 2lus̆lanoe in Den 2lbfidten ber Regierungen, aud ift es mitblich, in jebem 2lugentid gentau

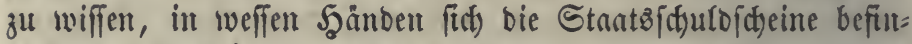

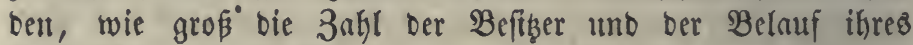
Beffizez ift u. Dgl. Nan hat zwar bie Erfdywerung ber Ueber= tragung barum für zuträglich erachtet, weil biejelbe mefyr vout bem Epeculanten bei häufigen Sefdäften in Stantôpapieren gefdyent wirb, als von bem Capitaliften, ber biejelbe fauft, um fie fu behalten, unl weil ber Stodahandel feine (Erleid)terung verbient. Allerbings ift biejer vielfältig mit \&eibenjid)nft getrie=

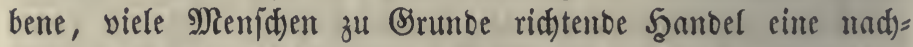
theilige Folge bes Keutigen Styuldentwejens, bejonbers oer häufigen (Curşid)wanfungen, I, \$. 440, 441. Da icood) bei

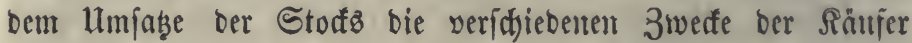
nidjt ju unterfdeiben fint, fo ift einte Erictyerung aller (S)

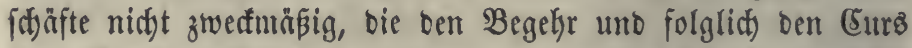
einer 2 rt von \$apieren bod) immer einigermaßen Geraborüden fönnte. Die Unternekmer einer Inleike ziehen bez leidfterent

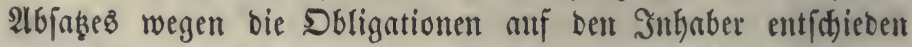
vor. Stantoboligationen, Deren (Surs hod) und feft fteht, haben, wemu fie gleid) leidft übertragbar finb, bod) wenig গeiz für

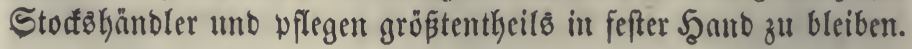


Dieje Errvägungen haben in ben beutiften Stanten bahin geführt, bie Sdfulbidteine in ber Regel auf ben Inthaber zu ftellen. Dod) ift ez müblid), ben SEläubigern nuf Berlangen bie Cintragung auf Namen zu geftatten, wie biés neuerlid) öfters geidjieft.

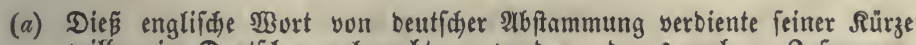
willen im Deutfiden gebraudit zul werben, $b_{a}$ es audi zu 3ufammen=

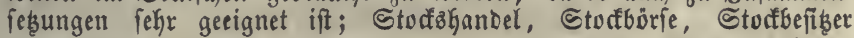
(stocks-trade, -burse, -holder etc.). - Fortune, Epitome of the stocks and public funds, english, foreign and american, 16. 2tusgabe yon Morier Evans, Lond. 1851.

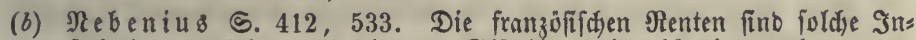
fcriptionen, bei Denen bie bem (Släubiger eingefänbigte urfunbe mux

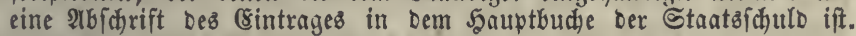
Le grand-livre de la dette publique est le titre fondamental de toutes les rentes inscrites au profit des créanciers de l'état. Decret vom 24. 2tuguft 1793. Für Die in jebem Departement wohnenden Bläu=

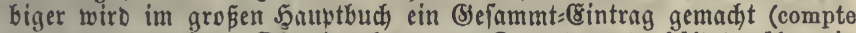
collectif) uno jeber Dbereinmefgmer Des Devartements hält Danüber ein befonderes Buch, feellt ben (Släubigen Infcriptionen aus und beforgt

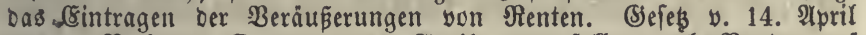

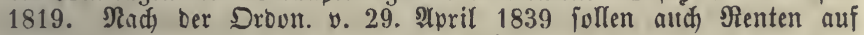
Den Inthaber ausgegebent werben, wenn bie \$nhaber Der inscriptions des rentes nominatives die Utmtaufdutung begefren; ausgenommen finb bie

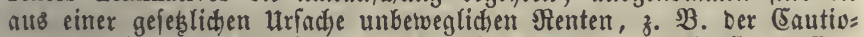

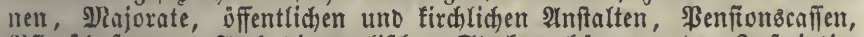

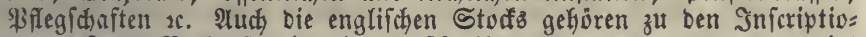
nen. Seber $\mathfrak{B}$ erfauf twiro im $\mathfrak{n}$ midreibeamt (transfer office) angezeigt

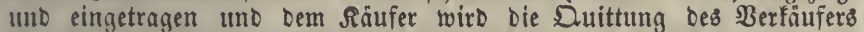

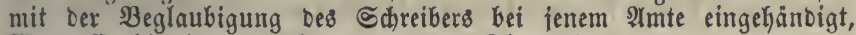

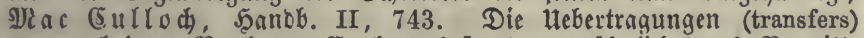
werden bei Der Banf von (England beiorgt, getwöhnlid Durd) Bermitt= lung von $\mathfrak{N a f l e r n}$ gegen $1 / 8$ Broc. (sebüht. 4-6 Sgochen yor Der 2(uszaklung ber Sinfen fann nidjt libertragen werben, aud barf man cinen Schuldidnein nidgt zmeimal an einem Tage umidreiben lafien, Fortune S. 27. - Bei Den ruffififen Infrriptionen fann ber Ber: fauf ourdy eine fidriftlid)e, im शluslanbe von einem ruffifiden Conjul

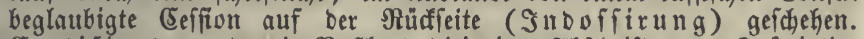

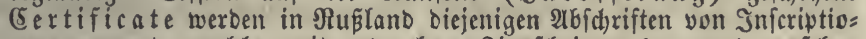
nen genant, weldhe mit gebrudten Bingffheinen (coupons) verfehen find und beren Binfen man Daker im Auslanbe, namentlid in Amfters Dam und Saamburg erlyeben fann; aflein bie Certificate mit 3ings=

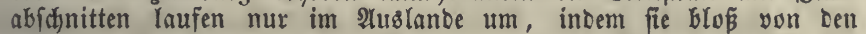
leihenden $\mathfrak{B a n f G a ̈ u}$ ern, mit seneymigung bez Staates ausgefertigt fint. - $\mathfrak{B}$ on ben neapolitanifan Injeriptionen ift ein Theil burd

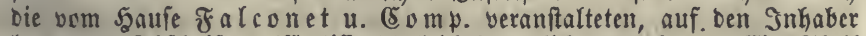
lautenden Stbid)riften (Eertificate) leidtberweglid) gemadit. - Erin Theil ber Kammöberiden lantofdaftliden Dbligationen feht auf Ramen. 
3. 2tb theilung.

\section{Berwaltüg Der Stantziduldeu.}

1. Sุaupt ff ư đf.

Borbercitende Maß̃regelı.

§. 507.

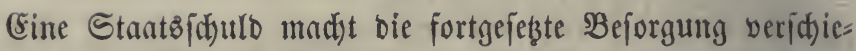
Dener auf biefelbe fich beziehenber (Sefdäfte nothwendig, beren Snbegriff bie Berwaltung ber Staat werben famu, uno für welde ein geregelter Song Bebürnifís ift. Wenn man ben Stantighasbalt erft aus einem verworrenen 3uftanbe in einen wohlgevrbueten Ginüberzuführen unb nament=

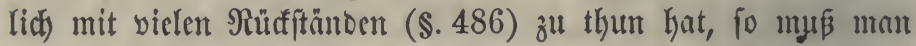

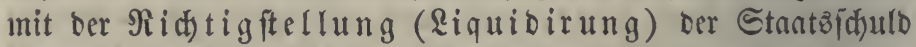
beginnen, nämlid) mit ber Unterfudfung aller eingelnen forbe= rungen an Den Stant nad) ifrer Ned)tågültigfeit, ifyrem $\mathfrak{B} e=$ trage uno ifyren Bebingungen, woraus tamn eime 3u[ammen= fellung bes ganzen Sdyulbenftanbes, allenfalls mit Unterfd)ci= Dung von Claffen unb Unterabtheilungen gebiloet wirb. Diefe Borarbeit giebt von ber Sröß̨e ber Schuld genaue Erfenntniß uno bient unbegrünoete शnjprücbe zurĭaf zu rocifen. Die Unter=

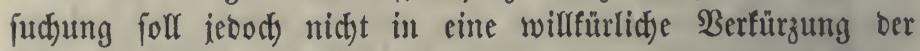

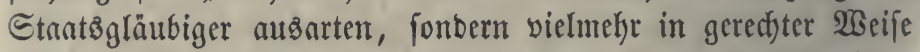
geführt werben, wobei Sebem bie Belegenkeit offen bleibt, feine

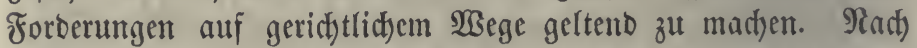

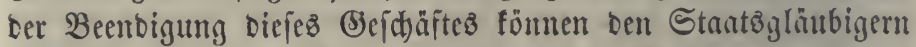
Sduldobriefe gleidher 2 int jugeitellt werben. 2lud) im Fortgange Der Sd)ulbverwaltung, fo oft bie Sduld burd) (Sntfdäbigungen uno Einverleibung alter ober neuer Forbenungen vergrößert

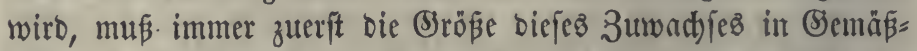
heit ber Sefeze genau mugigemittelt werben, bebor man zur

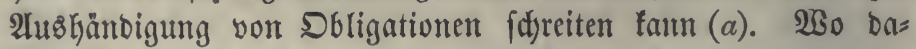

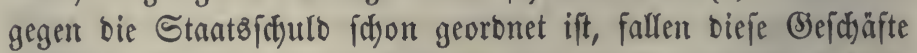
hinweg. In ben meiften Stanten, bie einte beträdytlidje Sdjulb haben, finten fich mehrere, aus veridfiedenen 3eitpuncten uno 


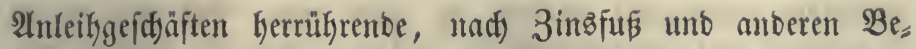
bingungen bon einanber abweidyente Theile ber Staatşfduld neben einanber. Das gleidzeitige Beftehen vieler fold)er $S$ dyuld = theile ift eine unmöthige Befdyerbe und bie 3ufammenziehung in wenige Şauptmaffen wünidents]werth, aber biefelbe wirb balo ourd) bie zugeftcherten Redyte einer Elaffe bon Bläubigern, balo

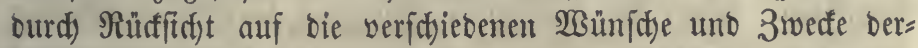
jelben und ifre 2 lbneigung yon einer $\mathfrak{B}$ eränberung erfatwert.

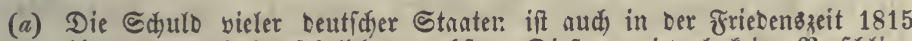

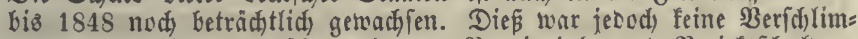

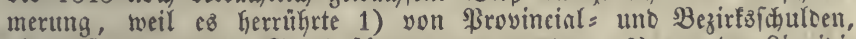
bie auf ben ganzen Stant übernommen wurben, 2) yon ber Riauidi=

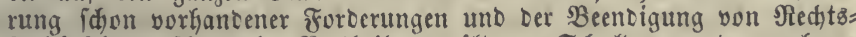
fireitigfeiten liber bie Bertheilung älterer Sdulben unter mefrere Stanten, 3) von Stantabeiträgen zu ber Abbōiung von aufgefobenen

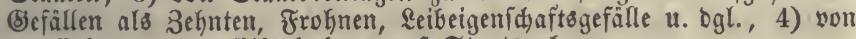
Der Erbauung Der Esifenbaknen auf Stanţredjunng.

\section{§. 508.}

3ur guten Befanblung des Sduldentwejens gefjört wefent= (id) Die Erritftung einer befonberen Caffe und einer berfelben vorgefebten Befjörbe, weldyer bie ganze Sdultowerwaltung über= tragen wirb $(a)$. Eime foldye Schulbverwaltungoscaffe, die man geroöhnlid) nad) einem Theile ifyrer Beftimmung

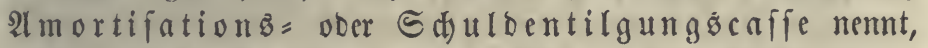
erhält gewiffe (Simnabmen theils aus ocr Stantżcafie, theilz

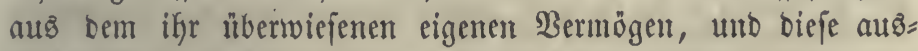

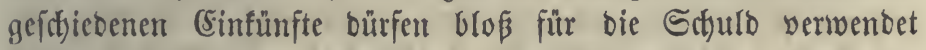

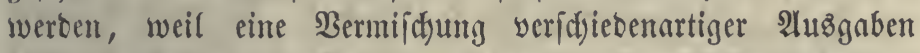
leicht Stodtungen in bie 3ablungen an bie Stantg̊gläubiger veranlafien fönnte, waż bem Stnatgecrebit fehr machtheifig wäre.

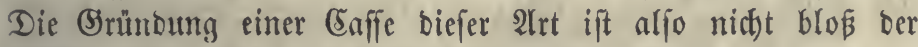
Sinkeit uno Dronung in ber Edyulbwerwaltung willen, fonoern

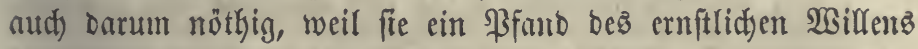

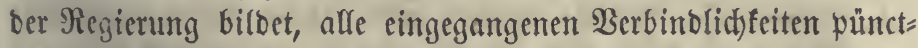
(id) zu erfüllen $(b)$. Diejer (Eaffe werben aud) bie aubiftehen= ben 3insforberutugen (2ltiva) zugetheilt, bie man, wo fein

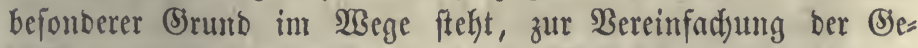

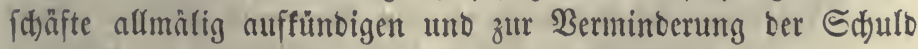

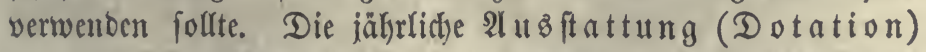
aus ber Stantôcaffe muß in Semäßheit bes Soramfdylages 


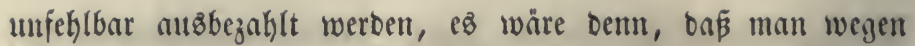
vermebrter Staatsbedürniffe bie Tilgung eimftellen müste. Ilm baz $\mathfrak{B}$ ertrauen zu ber Sdjulbverwaltung zu erböhen, hat man oft bejonbers fidjere Stantzeinfünfte bezeidjnet, aus benen bie

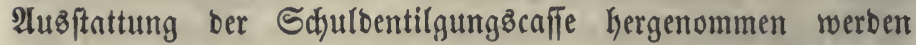
folfte (c). Dießs fönnte nur bann eine größere Sictjerkeit genäkren, wenn bie beftimmten Summen fogleid) unmittelbar von ben befonberen Enffen bes benannten Eimnahmszzweiges in bie Amortifationz̊caffe abgeliefert würben; aber biefe Bors fehrung ift bei einem georbneten Finanzwejen unnöthig, bei einem zerrütteten 3uftanbe wirb man alf ifre Befolgung nidjt

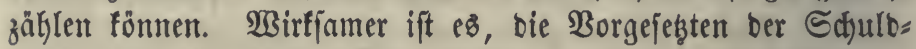

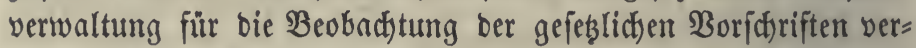
antwortlid) zu madjen (d). Borzüglid) bienlid) zur Befeftigung bes Crebitż ift bas ben Ranbitänben eingeräumte Red)t zur ßrüfung ber ganzen Єdfulbverwaltung von Jabr zu Jahr.

(a) In Srop̧britanien wirb fie von ber Lonooner Banf befurgt.

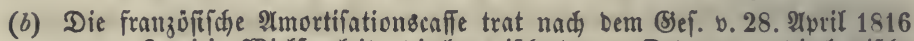

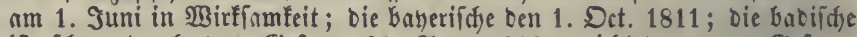

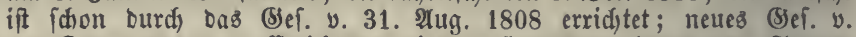
31. Dec. 1831. - Erridgtung einer "Şaubtverwaltung Der Stanat8

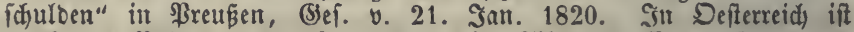
ourd) Das Patent y. 22. San. 1817 eine Tilgungscaffe gegrunbet und

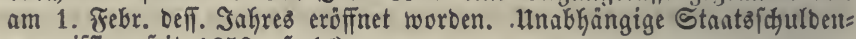
commififion feit 1859, ケ. (d).

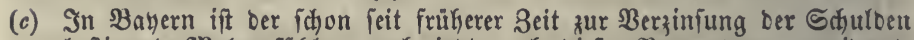
befitimmte \$ialzaufichlag aud jebt nuch biefer Berwenoung getwiomet, mit bem Borbefalte einer (srganjutung; Finanz= Ber. v. 28. Dec. 1531 \$. 3. - Baben, Finanz= \$eץ. v. 1835 \&. 6: Die reinen Ěrträgnifie ber Forft:, Galinen=, Berg = uno Şüttenverwaltung bis ouf einen getwifien $B$ etrag. Neuerlidy hat man Die Bezeidynung beftimmter (Eins fünfte allfgegeben.

(d) Ingef. Bad. Befers y. 1831: Die Dotation ber IImortifations = (5afie

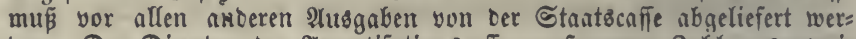

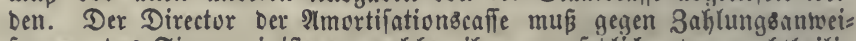
fungen bes frinanzminifters, weldhe ifm ungejéglid soer naditheilig fheinen, proteftiren und fid nothigenfalls an Das Etaatsminifterium

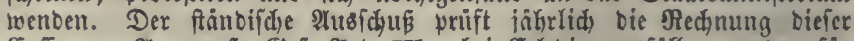

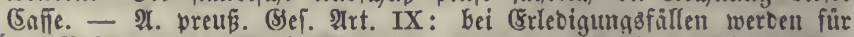

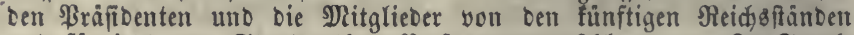

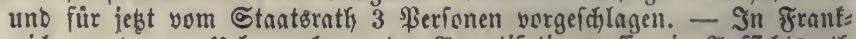

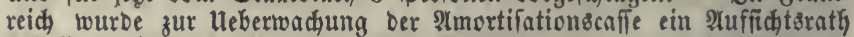
beffellt, beftelyeno in 1 \$air, 2 Nitgliebern Der Deputirtenfammer,

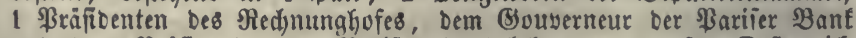

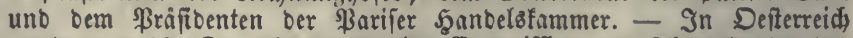
wurbe am 23. December 1859 eime Commifín aus शrgeoroneten bes Şanbelsftanbes zur Heberwadung ber Sdjulbverwaltung gebilbet. 
§. $508 \mathrm{a}$.

Die Saautgejdăfte bei einer Sdyulbverwaltungzeafie find:

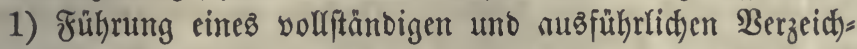
niffez aller Theile ber Stratżfduld, bes $3 \mathfrak{3}=$ und 2 Ibgangez.

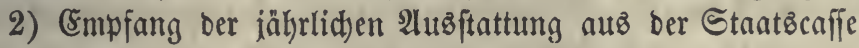

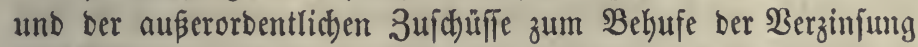
unt Tilgung und Berwenbung biejer Mittel zu ben genannten 3weden.

3) Berwaltung ber zum Domanialgrunbftof (\$. 99 (b)) gehörenben Sunmen, alfo 2hunahme Der Berfaufb = unt $216=$ löjungżgelder, ferner 2lusbczaklung ber Raufpreife für Riegen=

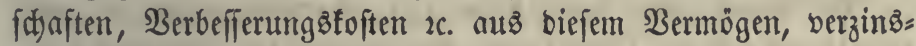

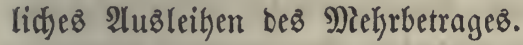

4) Einftweilige fithere 2lnlegung ber für ben 2lugenblidf

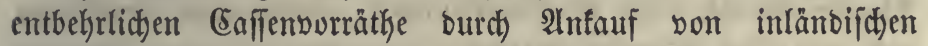
Staatäpapieren ober Darleiken auf zauftufänber in guten $\mathfrak{P}_{\mathfrak{a}}=$ pieren, iebod) nidjt ganz bis zu bem Börjenpreife, gewöhnlid)

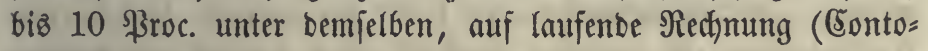
corrent).

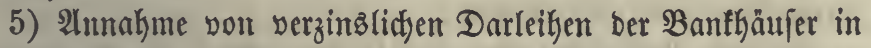

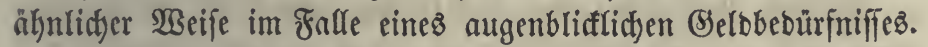

6) Borbereitende Mitwirfung zum $\mathfrak{B}$ ehufe neuer $\mathfrak{A n l e i f e n}$ aus 2luftrag ber oberften Finamzbehörbe, z. B. Erfunbigungen unb Ulnterhandlungen, ferner Empfang Der Einzahlungen, $\mathfrak{B e r}=$ fertigung und 2 ůsfänbigung ber Eafulbffyeine.

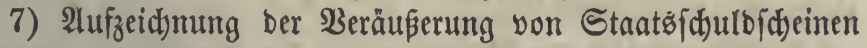

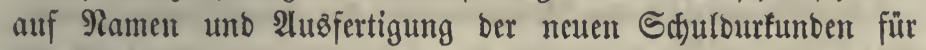
bie Răufer.

8) Umidjreibung ber Sdultbidjeine auf ben Snljaber in foldye auf Ramen ober umgefefrt, \$. 506-(a).

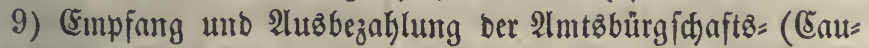
tions: ) jummen, \$. 486 .

10) Beforgungen, weldje burd) bie 3insherabjeşung ver= aula ât werben, s. 510.

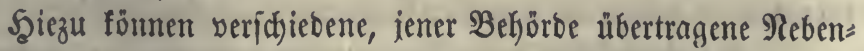
gefdäfte formen, z. B. Berwaltung ber gerid)tlid) ober frei= willig hinterlegten Eelber, ber Einftanbägelber für Stellwertreter im 2 affenbienft 2 . (b). 


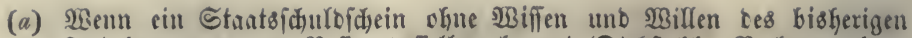
Inthabers aus Dem Befitze Defielben fommt (Diebftahl, Berlorengehen, 3erftorunß), fo liegt es Den (Serid)ten ob, oie nóthigen Edyritte zu thun, bamit ber Eigenthumer feinen Sdjaben leice unb ood bie Etaats: caffe feinem bopwelten Anfprud aubgefest werbe.

(b) In Baben aud bie Sefntleificalfe (jog. Sefjntidjultentilgungreaffe) II, $\$ .60(c)$.

2. Şa upt ft ü d.

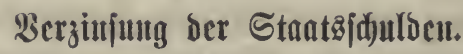

§. 509.

Die Entridytung ber Zinjen folf functlid) gefdjeben, weil

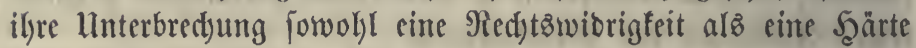
gegen bie (s)läubiger entbält und bem Stantoscrebite eine tiefe

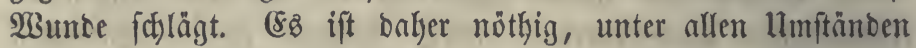
und troks afler Schwierigfeiten bie hiezu erforberlichen Eummen

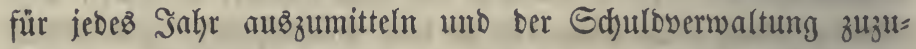
weijen. Sít bief geidheken, fo bilbet bie wirfliche fortlaufende

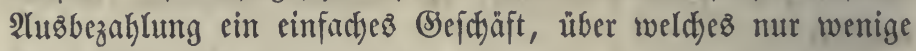
Bemerfungen beizufügen find.

1) Zur $\mathfrak{B} e \mathfrak{d}$ leunigung bes (Seldumlnufes ift wenn nicht affe Zinğzahlungen in einem einzigen 3eitpunct bes Jahres geid)ehen, wož theils bie halbjährige Zinzentrichtung, theils bie Anoromung bient, baß̧ bie Dbligationen für verid)ies Dene Şauptabtheilungen ber Staatsfduld verfhiedene $\mathfrak{B e r}=$ zinjungstermine haben $(a)$.

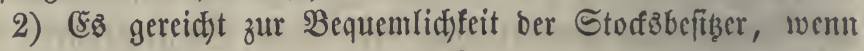
bie Sinfen nidyt allein bei ber Sduuldentilgungşcaffe in ber Saauptiftabt, fondern aud bei jeder öffentlicten Eaffe zu erheben fino. Dieje Enffen fenben bam bei ihrem ablicferungen an hölyere Cafien bie cingelöften 3inşquitumgen ftatt baar ein

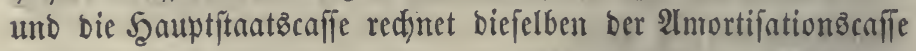
bei ifyrer 2luşftattung mit an. Zur Bequemlichfeit attsిwärtiger

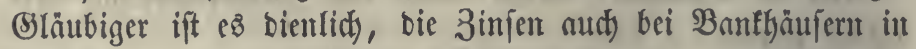

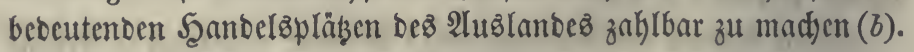

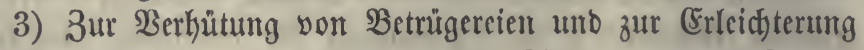

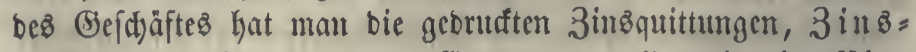
abfdnitte, 3ingbigen, Eoแpons, allgemein cingefübrt. 
Mit iebem Sdullofdein wird cin Borrath foldher Empfangb: befdyeinigungen auf eine gewiffe 3ahl von Jabren nügegeben, jebe mit ber Nummer ber Dbligation und bem Tage, an bem

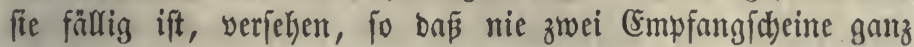
gleidylautend find und jebe ofyne einen fdyriftlidyen Beifab bei Der Crrbebung ber Binfen abgeliefert werben famn. Sino biefe Abjanitte zu Ende, fo mus man fich einen neuten $\mathfrak{B o r r a t h}$ ein= Gänbigen laffen, wozu entweber bie Borlegung Der Dbligationen felbft, ober cines auf biefelben binmeifenten mit ifnen zugleid)

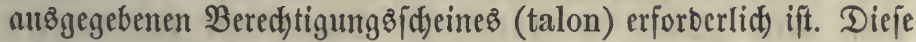

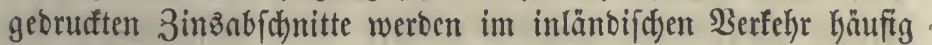

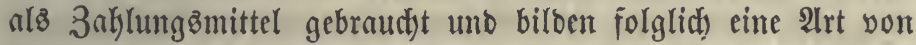

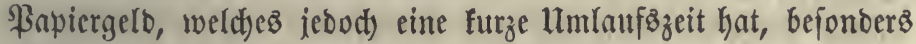
weil man eछ̉ für zwecfmåâig erachtet hat, ber Dromung im

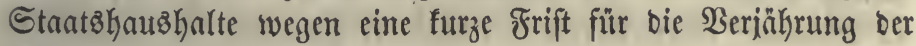
fälligen 3infen gejebslid) zu beftimmen (c).

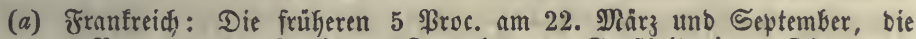
3 Froc. am 22. Suni und December. - Brof́britanien: Die 3 per cent reduced am 5. Stpril uno 10. Detober, bie 3 p. c. consols, 3 p.c. yon 1726 und 5 p. c. alm 5 . Samuar und 5. Suli.

(b) Die ifterreidjifanen Sinfen fönnen in Frantfurt erhoben werben. Die

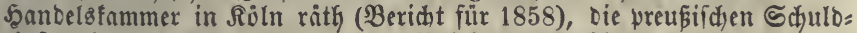
zinjen in ben Nieberfanden und Belgien auzzahlen zu laffen, Damit bie Sdjuldideine aud Dort mefr Berbreitung finben.

(c) Diefe Frift ift 3. B. in Baten, Bayern, Sachfen, SBurtemberg 3, in

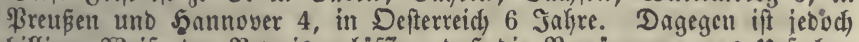

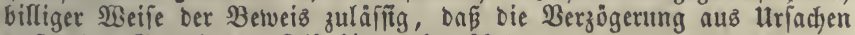
auper ber Setwalt bes Brlätbigers herrüfrte.

\section{§. 510 .}

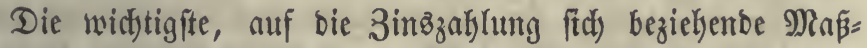

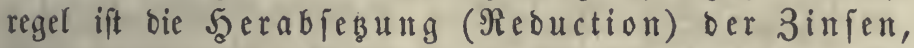
Eonverfion Der Renten $(a)$. Sie bringt eine grope (Er=

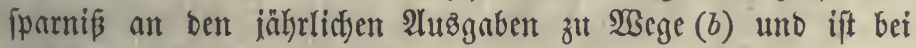
benjenigen Sdjulden, weldje von ber Regierung beliebig nadh

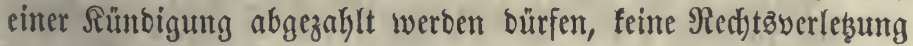
gegen bie Eläubiger, wenn man nur biejen bie freie $\mathfrak{W n h l}$ an= bietet, ob fie ifre Forberungen nad) einer beftimmten Frift, 子. $\mathfrak{B}$. einem $\mathfrak{B i e r t e l j a h r e , ~ z u n u ̈ d ~ e m p f a n g e n , ~ o b e r ~ f i e ~ f u ̈ r ~ n i e b r i = ~}$ geren Sinz feken laffen wollen. Dieje Minßregel enthält auds nidjtz Unbilligez, wenn fte mur auf einer Benutbung ber gegebenen

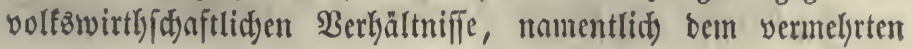


Iargebot yon Reihjummen, ber zunehmenben Sdjwierigfeit ihrer Anlegung, bem niebrigeren 3insfußpe fowie bem megr befeftigten Staatseredit berubt. Der fteigende Eurs Der Staatzppapiere,

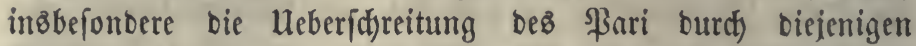
Sdjulbfdeine, weldye bie hödften Bimfen tragen, beutet an, baß bie Şerabję̧ung ausführbar fei, unb oa ber Curs in ber

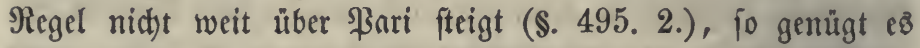
fdon, wenn bieß wenig überid)ritten ift, ja ez ift rathjam, nidjt lange zu zögern, benn ie höher ber ßreis himatfgeht, befto mehr würben bie Seäufer ber Sdjuldbriefe einbüßen (c). Sinige Sahrzekente hinourd) fonnten viele Regienungen ifre Sdjulben von 5 auf $3 \frac{1}{2}$ \$rocent herabjęen (d) unt währento vorher \$rivatperionen auf gute Scypothefen billiger gelieken er=

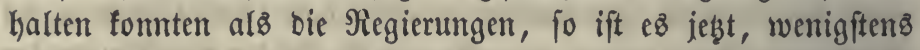
in Straten, beren Crebit uneridjüttert geblieben ift, umgefebrt, I, \$. 226. Şat man Sdjuldbriefe von verícticoenem 3inşfuße, fo muß natürtid) mit ber F̧erabję̧ung berienigen, weldje Den

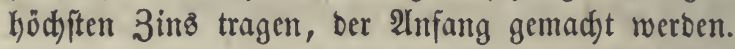

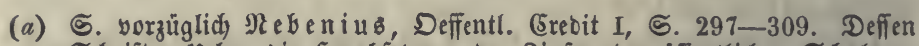
Sdurift: Heber Die Şerabjęutung Der 3infen ber iffentlidjen Sdjulden, Stuttgart 1837. - Bernoulli, Beitrage S. 1806. - 23 irth, Rationalöton. II, 510 .

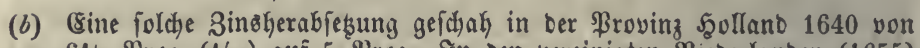
$61 / 4$ Proc. (1/16) auf 5 ßroc. In ven vereinigten Riederlanben (1655)

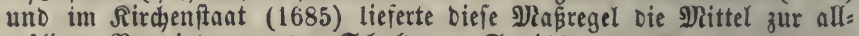
máligen Berminderung oer Sdyulden. Smith III, 377. de Parieu in Séances et travaux de l'ac. des sc. mor. et pol. \ấz 1858 ๔. 389. In England wurde tie erfte Эeduction im Jahr 1699 vorgenommen, yon 6 auf 5 \$roc. Pebrer I, 195. Daffelbe gefdah 1716 unb erfparte 324456 l. St. 1727 erfolgte bie Serabfegung Des grösten Theils ber Schuld auf 4 Sroc. Die weitere Reduction fano 1742

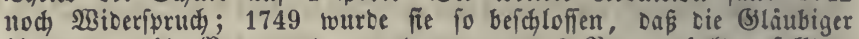
bis $17573 \frac{4}{2}$ Sroc. und von ba nut nur 3 \$roc. exhalten follten, wobei man 565600 \&. St. jährlic, eriparte. Cohen, Compend. of fin. S. 203. - Epäter entfandelt wieber Inleigen mit högeren Sinfen, und man fonnte 1822 abermals burdh Serabiebung yon 5 auf 4 ßroc. 1.222000 \&. St. jährlid eriparen. 1826 Şerabiegung einer Summe

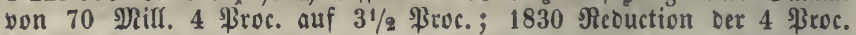
yon 1822 auf $3 \frac{1}{2}$, mit einem (Setvinn von 750000 \&. St. 1844 wurben $157 \frac{1}{3}$ MRial. 4 \$roc. auf 10 Inhre in $3 \frac{1}{4}$ \$roc. umgetwandelt,

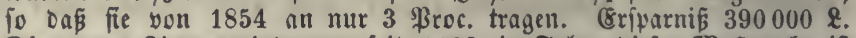
Die ganze Sinsverminberung feit 1822 in Folge tiefer 9 lafiregeln ift 2.749000 \&. Mac Culloch, Tax. S. 448. - Die Sinsherablesung

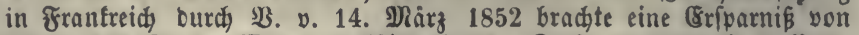
17.851 433 fr. zu NBege. - Niederlande, Decbr. 1852: Die 4 \$roc. auf $3^{3} / 4$ ßroc. zu 99 ober $3 \frac{1}{2}$ \$roc. zu 97 hernbgejest; jenes giebt 3,78 , diefes 3,6 Proc. 


\section{$-401$}

(c) Bie vor 1848 in Franfreid unb Defterreid.

(d) Die bad. Fentenfheine wurben im. Jakre 1825 von 5 auf $4 \frac{1}{2}, 1829$ auf 4,1834 auf $3 \frac{1}{2}$ ßroc. ernieorigt. Aefnntiches geichah in Den meifen beutichen Stanten. - \$reußen verfünoete Durch (Eabinetôbefegl v. 27. März 1842 Die Scerablebung Der Sinien vou 4 auf $3 \frac{1}{2}$ ßroc. Die Summe ber Schulobriefe war an 99 Mrill. Thlr. $\mathfrak{B a r}$ eimwilligte, bie Forcerung für $3 \frac{1}{2}$ Broc. ftehen zu laffen, erhielt bie 3ufidyerung,

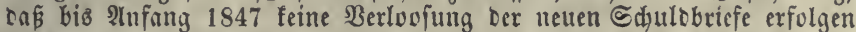
folle, uno baare Sirämien von $1-11 / 2-2$ \$roc., je nad̆ ber fpäteren

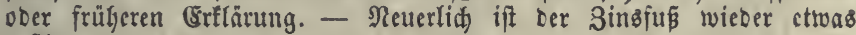
geftiegen.

\section{§. 511.}

3um Belingen einer 3inzherabję̧ung gehört Folgenbes:

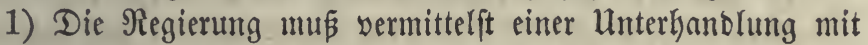
Banffyäufern Diejenigen Summen bereit halten, bie zur Şeim= zaklung ber nidft einwilligenben (s)äubiger muthmaßlich erfor = berlid) fein mögen. (Eine fehr großße Sdjuldenmafie fönnte

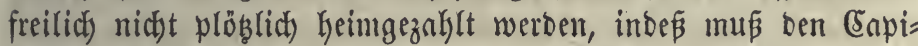
taliften für ben Falf, baß fie bie Şerabfebung nicht aunefymen, wenigftens die Sewvipheit einer Rüfzaflung in beftimmten Friften gezeigt werben $(a)$.

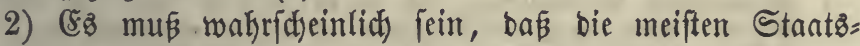
gläubiger einwilligen werben, intem fie feine anbere einträglithere 2lnwentung ifrę $\mathfrak{B e r m o ̈ g e n s ~ f i n b e n . ~ S ̧ i e z u ~ t r a g e n ~ v o r z u ̈ g l i d ~}$ bei a) bie gute $\mathfrak{W a f h l}$ einez 3eitpunctez, in weldyem man bei anderen 2Injtalten, $\mathfrak{z}$. B. Erebitbereinen, unt bei \$rivaten fowie

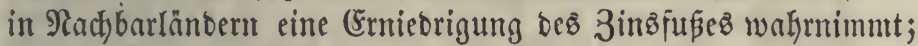
b) bie angebotenelt $\mathfrak{B e d i n g u n g e n , ~ i n d e m ~} \mathfrak{z}$. $\mathfrak{B}$. blop eine $\mathfrak{B e r}=$ ringertung um $1 / 2$ firocent vorgetrommen, ober ber Gökere 3inz nod) einige 3eit fortentridftet, ober ein anberer $\mathfrak{B}$ ortheil, z. $\mathfrak{B}$. bie Cicherung vor ber Şeimzaklung während einez beftimmten 3eitraumb, bewilligt wirb $(b)$.

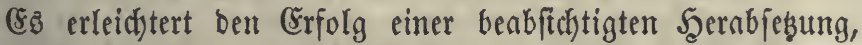
wetm bie Mehrzahl ber Stantäglăubiger aus Ṡnlänbern beftefht,

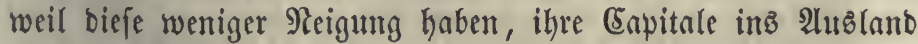
Ginüberzuziełen, alz Frembe $(c)$.

(a) D'A u diffret (Syst. fin. I, 256) räth, ben \$reis, um weldhen die netten, niebriger verzinglichen Sauldidyeine abgegeben werben follen,

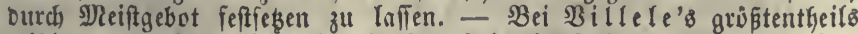

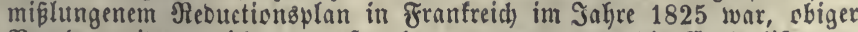

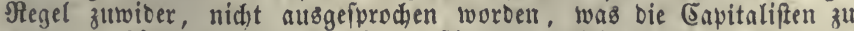
erwarten Gätten, wenn fie nidyt zuftimmten. Die Şerabiebung tourbe

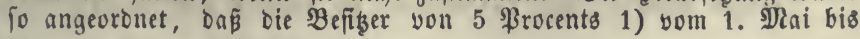

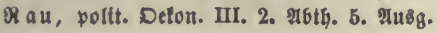


22. Juni 1826 die $28 a h l$ hatten, fid 3proc. Bapiere zu 75 geben zu laffen, wobci fie alfo für 100 in 5 \$roc. $133^{1 / 2}$ in 3 Proc. $(\$ .498$ (c)) erfielten und 4 Fr. Sins zu beziehen Gatten, uno 2) nod weiter bis

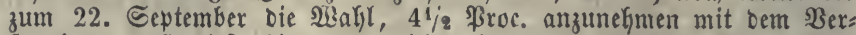
fpreden, Daßs bieje bis 1835 nidjt abgetragen werben follten. SBon

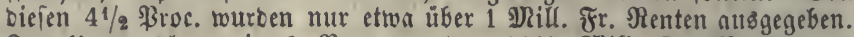

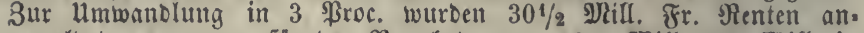
gemeloet, es wurben für ben Nennbetrag von 610 Nill. 813 Mill. in 3 Proc. Gingegebell, welche $24,{ }^{3}$ श)

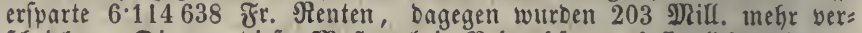

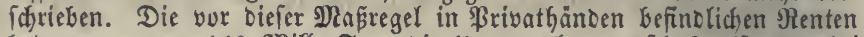
betutgen gegen 140 פill. Fr., Die Ummanolung geidah alfo mux bei $3 / 14$ DDer 21,23 \$roc. Derjelben.

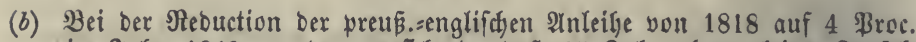
im Jahn 1840 wurbe zugefidjert, Dẩ 15 Jahre lang feine 3urüd: zablung exfolgen follte, twas jeood) einen SRủffauf nad) Dem Surje

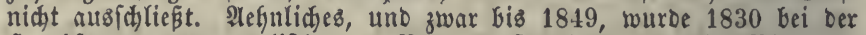
Serabfebung Der englif́ch 4 \$roc. verfprodjen. - S Sin \$lan zur Sinskcrabfebung für oie franzoffiche Staatsfchulo wurbe von \&efevre's Bubgetsberidjt von 1833 angeregt, fobann von $\mathfrak{S}_{\mathfrak{1}} \mathrm{m}$ an $\mathrm{n}$ (14. Jan. 1836) angebeutet, was Deffen 2ustritt aus bem शinifterium zur folge Gatte, Gierauf von Der Deputirtenfammer in Erwägung gezogen (Hrfadhe

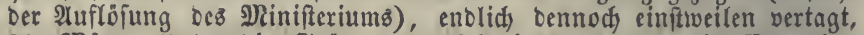
22. Nărz. unter bie Srumbe oer Rbneigung gegen bie Reouction gehorte, Daßj man fich nudh nidjt Daran gewobnt hat, bie Nenten als 3infen eines gelvifien fouldoigen Nenubetrages anzufelien, Durch Deffen Seimzahlung bie Regierung fid bavon befreien fann! \$. $493(a)$. (S) ou in fchlug vor, oen Inthabern ber 5 झrocentz nebent den 4 oder 3 Sroc. noch eine 3eitrente von 1 Fr. auf gewiffe Jahre zu bewilligen.

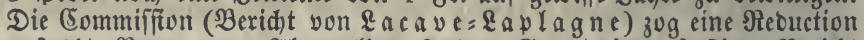
auf $4 \frac{1}{2}$ Proc. vor. ABermaliger शntrag (B) o ui n's, gunftiger Bericht

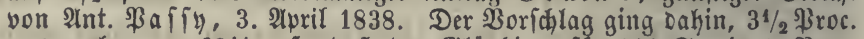

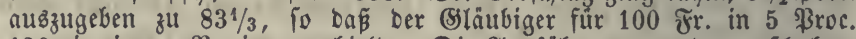

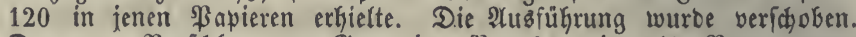

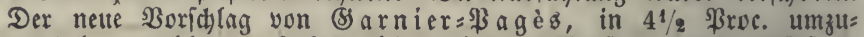
wandeln, weldye 10 Jahre niđt weiter herabgefegt werben diurfen, warb von Der Deputirtenfammer 1845 angenommen, yon Den \$airs

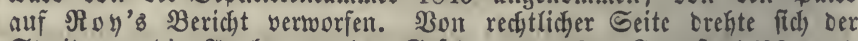
Streit um Die 21uslegung Der Siefebe vom 24. शhuguft 1793 und

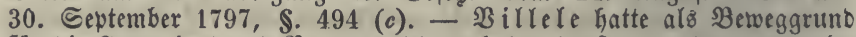
für bie 24uzgabe oer 3 \$rocents (a) auc ben umitallo geltent gemadht, Dấ biejes \$apier ben (Släubiger von felbît auf einige 3eit gegen bie

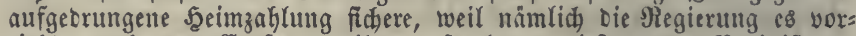
zieht, nad) Dem (S.urje zu tilgen, fo lange Dicfer unter \$ari ift. -

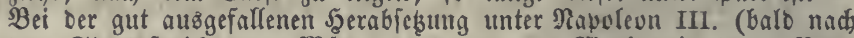
Dem Ctaatęfreich, 14. Mărz 1852) war Der Slarftpreiz ber 5 ßroc. 103,6 , Der 3 Broc. 68,6 , io Daß biefe cem Ráufer 4,37 ßroc. Sing

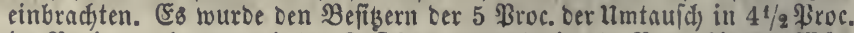

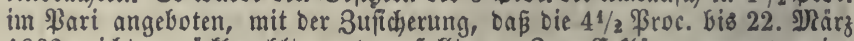
1862 nidjt zurüfbezahlt werden folltell. Sur Srflärung wurbe eine

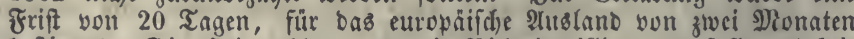
beftimmt. Die Şeimzahlung an bie Nichteintwilligenden follte abthei= lungstweife (par séries) geidjef̧en fünnen. Boon ben yorfjandenen $182 \cdot 318194$ Fr. 5proc. Renten $=3646^{1 / 3}$ Mill. Nominalcapital rour:

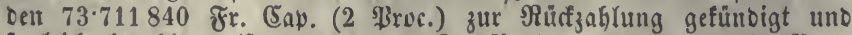
pogleich bezaglt, alfo 178.633000 fr. SRenten um $1 / 10$ ober $1 / 2$ \$rwe. 
Des Capitals verminbert. Die in \$. 495 (d) ertwähnte Mafregel von 1862 war feine förmlidhe Sinsherabfebung, fonbern ein umtauf von Gduld = idjeinen, beren Befiber fortwäkreno gleidjen 3ins bezogen, aber bie Daraufzaklung trug (3u 4 Froc. geredjnet) $6,{ }^{3}$ Nill. Sinfen oder

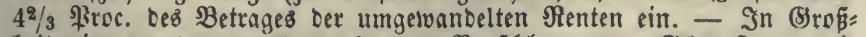

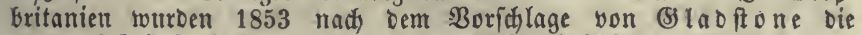
3 proc. Sübjeefdyeine und einige andere fleine Shuldheile umgetwandelt.

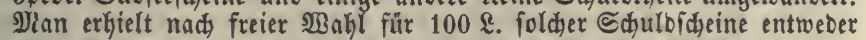
$82 \frac{2}{2}$. in $3 \frac{1}{2}$ proc. ober $110 \mathrm{~L}$. in neuen $2 \frac{1}{2}$ proc. Stoffs, ober in Sdjaķtammericheiten, weldje bis $18642^{3} / 4$ und bann $21 / 2$ Sroc. tragen. -

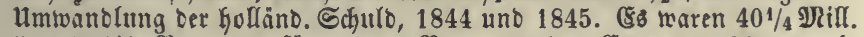
5 und $4 \frac{1}{2}$ \$roc., wofür man 4 Froc. um ben Curs von 96 ausgab. (Sin Theil jener Óbligationen ging jebod) fdyon bei ber Damaligen frei= willigen 2ulleike (\$.504) ein, in weld)er 67 ßroc. in älteren Śdjuld: briefen unb 32 \$roc. baar eingezahlt wutroen. Aud bie 5 proc. Dbli= gationen Der Colonialfaulo im Betrage oon $32 \frac{1}{2}$ शRifl. wurben in 4 procentige umgetwandelt, weld man zu $95 \frac{1}{2}$ auzigab, fo bas ber Jnhaber eigentlid 4, 18 Broc. Sins erhielt. Wer nidjt einwilligte, wurbe am 1. Septbr. 1844 heimgezahlt, (5eies v. 8. Juli 1844. - शtuch in Belgien erfolgte nạ (Sef. y. 21. Wlärz 1844 cine umwanolung ber 5 in $41 / 2$ Sroc.

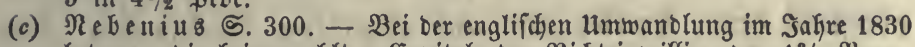
betrugen Die Keimgezahlten Capitale Ler Nidteinwilligenden $13 / 4$ \$roc., bei Der Şerabfebung im Jahre 1844 nur 150000 $\mathfrak{L}$. St. ober 1 per

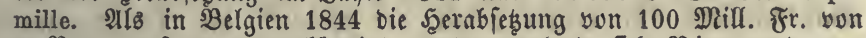
5 Broc. auf $4 \frac{1}{2}$ angefundoigt twurbe, meloete fich Niemano zum

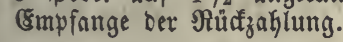

§. 512.

Die Binghkerabfebung Darf wegen iffres Nukents für bie Steuerpflichtigen nidjt unterlaffen werben, wenn bie umftänbe zu ifgr aufforbern. Unter ben Cinwenbungen, bie man gegen fie erfoben Gat, ift am unerheblichften bie Befauptung, Daß

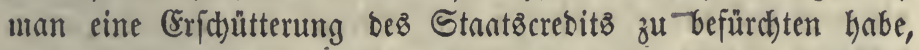
ba bas Esegentheil burd) biele Erfahrungen berwiejen worben ift. Mefr $\mathfrak{B e n d}$ tung verbient bie Anftcht, es liege in jener Mafregel cin Miß̈braud) ber Madht bes Stanteछి, nämlid cine Unbilligfeit uno Şärte gegen bie CEapitaliften, benen eine wlößz= liche $\mathfrak{B}$ erringerung ifgrer Einfünfte, in mand)en Fällen fogar cine Sdymälerung ifyres Unterbaltes auferlegt werbe. Die ihnen

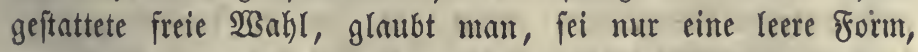
weil fte bei ber Unmöglidfeit einer gemeinfdyaftlid berabrebeten Şanblungstweife uno bei ber Sdyrorigfeit einer balbigen anber weitigen Unterbringung ifrer Erapitale von ber Sceimzablung feinen (Sebraud) madjen tönnen unb mitbin nothgebrungen zus ftimmen můffen. Seiezu fomme, baj̃, wenn ber Strat das Beifpiel gegeben habe, nud bie Sdjulbner von झrivatperionen 
unb 2niftałten zur Bewilligung niebrigerer Binjen gežwungen werben und mitfin bieje Unternekmung bie Urfacte ber all= gemeinen 3interniebrigung fei $(a)$.

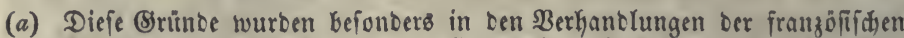

Sammern gelteno gemadts. v. (E a ncrin. Defon. Der menidir. (S)ef.

ธ. 299: "Rentenrebuctionen find eine Irt von fucceffivem Banferott" (bod) erflärt ber Berf. bie (E onverfion, nämlich) mit (Eintwilligung ber (Släubiger, mur für ein halbes unredgt).

\section{§. 513.}

3ur Beurtheilung biejer Begengrünbe bienen nactftetenbe Bemerfungen.

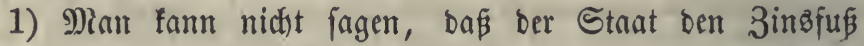

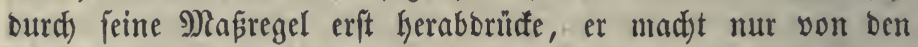
Umftänben (Sebraud), bie ben Bins erniebrigen uno befd)leunigt höchjtens beren 2 Inerfentmung unto allgemeine Wrirffamfeit. Die

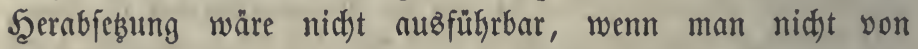
Banfbäujern für einen Theil ber Sdyuld bie 3ufitherung von Darleiken um niebrigere Binfen erfielte, unt objtyon bie Banf= herren fịd) hiebei zunäd)ft mur jener leidttberweglidjen, zwifd)en mefreren Stanten hint und herfdyebenden Berbmafien bebienen, bie fie ftets in Bereitifhaft Galten $(a)$, fo würben fie bod) bie Şand nidft bieten, wenn fie nid)t auf Den Beiftand vieler

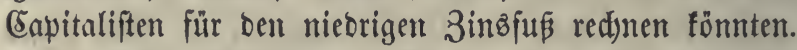

2) Die Şeratieşung erfolgt auth) nid)t ganz unvorbereitet,

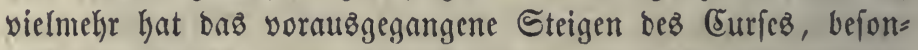

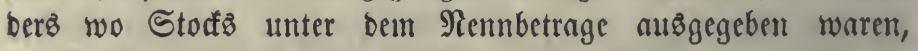

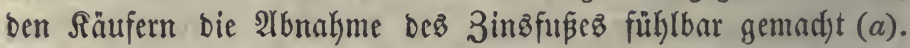
शtre biejenigen aber, weldje noch) um einen niebrigeren Eurs eingefauft haben, verlieren weniger ober nidjtb.

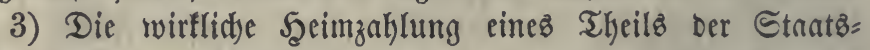

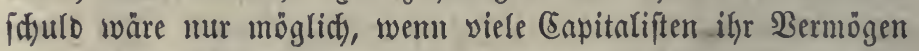
aus anberen 2 Inleguturgen zurüdzögen, um es Dem Stante zu leiken, woobtrd) bei iften biagherigen Sdjulbnern ober ben von ihnen betriebenen Unternekmungen cin netter Begehr vout Beld=

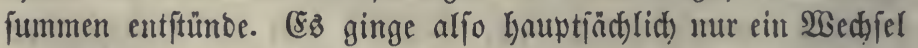

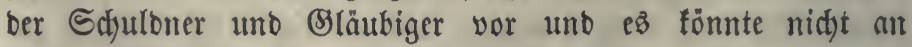
Eelegentheit fehlen, bie eingegangenen Enpitale wicber anzulegen, aber freilid) nidjt un fo hoke Binfen als bisher $(c)$. 
(a) In Franfreid waten 1831 nur gegen 6 गill. Fr. fogenannte rentes

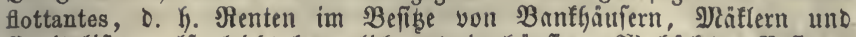

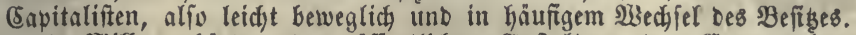
$10 \%$ Difl. gefjorten ben offentlichen 2nftalten ober (5ompagnien, $120^{1 / 2}$ פRill. twaren fogenannte rentes classées, D. h. unter viele Eigen= thimer vertheilt und in ziemlid) fefter Jand. 3u Ënde Des Sahres 1830 follen nur 4 פifl. rentes flottantes gewejen fein. Revue encyclopéd., Dct. 1831, ङ. 75. - 1846 waren yon Den 134 I)ill. 5 proc. Menten 38 Mill. im Seftis ber Bemeinden, Dffentlidyen uno ßrivat: anftalten, 25 शiall. waren aus gejeglichen Srünben faft in ganz

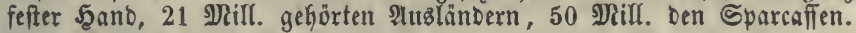
D'A u diffret, Système fin. I, 263.

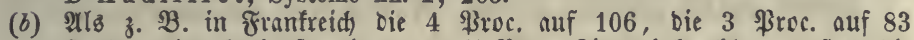

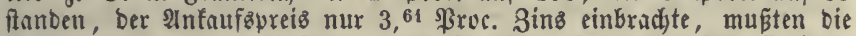
Befizer Der 5 ßroc. einfehen, Dá fie nidht länger im Senuffe ifyrer Bortheile bleiben founten.

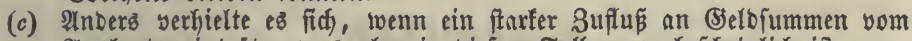
Altslanbe einträte, was aber in biefem Falle unwahridjeinlich ift.

\section{§. 514.}

4) Rleime Capitaliften, Die 3eit haben unb ez nidht foheuen, fid) mit oer Cintreibung ifrer 3imfen zu bemüben, fino aller=

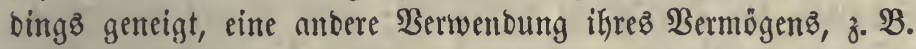
Das Darleiłen auf Unterpfänber, vorzuzieken, wenn ber Staat

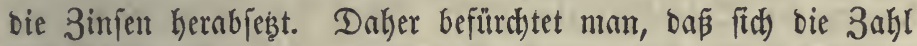
ber Stantôgläubiger vermindere. Alfein biefe Bermintorumg

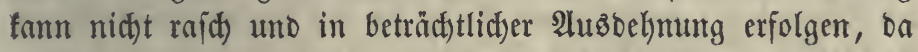

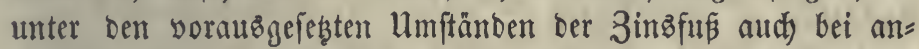
Deren Darleiken Gerabgegangen fein wirb unb ift baker nicht bedeuteno gemug; um gegen bie großen Bortheile ber 3ins= eriparung in bie $\mathfrak{B a a g i d y a l e ~ g e l e g t ~ w e r b e n ~ z u ~ f o ̈ n n e n ~}(a)$.

5) Die গegierung folfte jebod) nicht allein auf bie 3inbz=

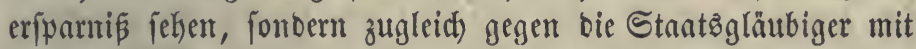

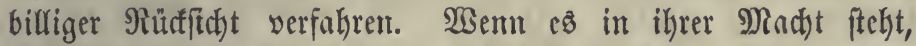
biejelben burd) eine plöblict)e Anhäufung von Canitalen ein=

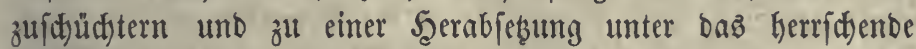
Maaß ber 3infen zu nöthigen, fo ift bie Bemubung foldser Runftgriffe uncbel und verwerflid) (b). Man múp alfo vor einer Uebereilung Der Reouction warnen. Dieje Maß̈regel wirb Dann Das $\mathfrak{B e r t r a u e n ~ g e g e n ~ d i e ~ \Re e g i e r u n g ~ a m ~ w e n i g i t e n ~}$

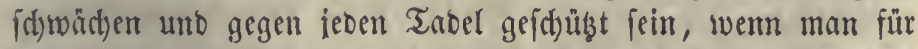
ben ganzen Gerabzulesenden Betrag bie zur Seimzahlung ers forberlictyen Capitale zur $\mathfrak{B e r f u ̉ g u n g ~ h a t , ~ f o ~ b a ß ̃ ~ m a n ~ b i e ~}$ angebotene 2lbtragung aud) wirflich mเz̧นfülyren im Stanbe 
wäre. Bei einer gropen Sdłulbenmaffe ift biefę nur allmälig möglid $(c)$.

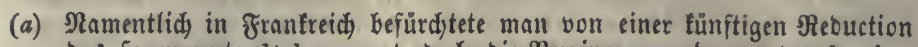
Das fogenannte déclassement, 0 . h. Die Berringerung ber rentes classées, §. $513(a)$, beren Sunakme man aus guten (S)ünoen für zuträglich́ gerjalten hat, ugl. \$. $490(a)$. - Die auf einzelne \$erfonen einge=

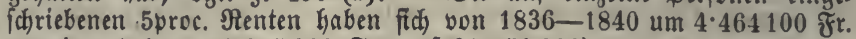
berminoert (von 96.215900 8r. auf $91 \cdot 751800$ ).

(b) Bgl. $\mathfrak{A}$ e beniub , Deff. Erebit S. 299. 304.

(c) Doळ follte bie Orfflärung aller (Släubiger für einen gewiffen Theil ber

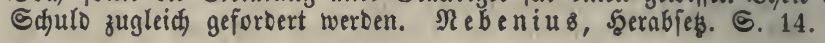

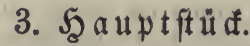

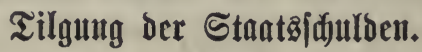

§. 515.

Db und in weldfem Erabe bie alfmälige 2Gtragung ber

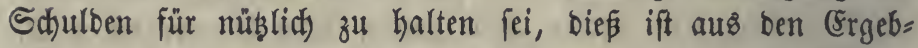
niffen zu beurtheilen, zu benen bie Unterfudjung über bie $\mathfrak{W}$ ir=

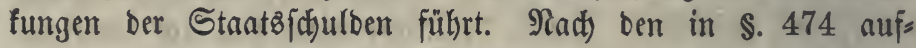
geftellten Säken find auch) in Beziełung nuf bie 3wedmäBigfeit ber Tilgung bie ver/djiebenen 2 Irten ber mit 2 Inleifyen bejtrittenen Aügaben zu unterfcheiben.

1) Der burd) Sefabren für ben Staat ober utnerwủnjdte Ereigniffe nothwendig geworbene Errhaltungzaufwand fowie bie

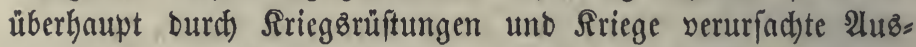
gabe hat in früheren 3eiten bie meiften Staats/fhulben nad) fii) gezogen und ift nod) jebt eine felye bäufige Beranlafilung berfelben. Se weniger eine Regierung es in ifrer Bewalt hat zu verfindern, Daß foldje Urjactjen eine Bergrößerung ber Stants = fdulto betwirfen, befto bringenber ift bie Berpflidtung, in guten

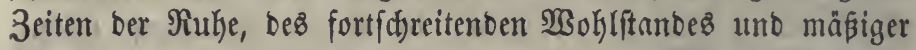
Staatsిms gaben auf eine Berringerumg ber Sdjulden bebadft zu jein. Würbe man foldse ßeriooen unbemuşt verfitreidjen laffen, fo fönnte leid)t bie Sd)uld fpsiter zu ciner fdjweren Raft anidjwellen. Die bringente Maknung zur Edjulboerminberung

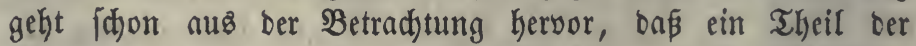
Staaten in neuerer 3eit in ben Sriegsiafiren weit mebr neute Sdjulben angefäuft hat, als fie in ben bajwifden liegenten 
Friebenzzeiten wieber abtrugen $(a)$, uno baj biejer Edjuld = anwacts bie und ba emftlidse Beforgniffe erregt. Die regel= mäßige Tilgung bient aud) zur Berufhigung ber Stanţ̧gläu=

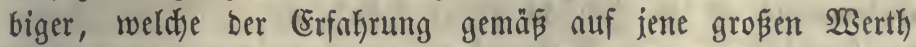

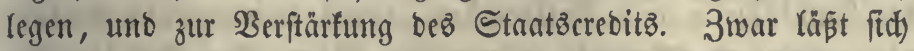

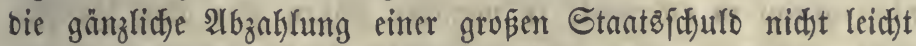
hoffen, weil fie nur in einem Iangen 3eitraume möglid) wäre, währeno befien aud wieber neue Safulden gemadt werben müffen; alfein es ift faton viel werth, wenn eine beträdtllidye Berninterung bewirft wirb, fo baß bie fpäter wieber nöthig werbende $\mathfrak{B e r m e k r u n g}$ weniger $\mathfrak{B}$ ejorgniffe erregt $(b)$.

(a) 2. Smith III, 378, hat fhon diefe 1 Bahrheit bargeftellt. -

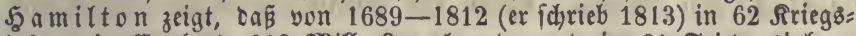
jafren in England 618 Nill. \&. geborgt, uno in 61 friebensjahren nur 38.909000 \&. abbezahlt worden fino, alfo ift Der 21 nwadis $15,{ }^{63} \mathrm{mal}$ fo großj als bie 2rbnafme. Nady einer netteren Sufammenffellung (Companion to the Almanak, 1860, S. 141) Gaben yon 1691-1859 Die 82 Sriegsiafre vie Sdult um 885.873690 \&. vermehrt, in ben 86 Friebensjafiren ift fie um $81 \cdot 795136$ \&. vermindert worben. Der ame= ricanifide Sirieg von $1774-83$ fteigerte fie um $104,{ }^{6}$, Der franzöfiche yon $1793-1815$ um 621,3 , Der ruffifice von 1854-56 um 32,8 Milf. Die ftärfife Abnahme fano fratt yon 1815 bis 1854, nämlich yon 861 auf 769 \$lill. \&., alfo um beinake 92 Mill. ober um 10,69 \$roc.

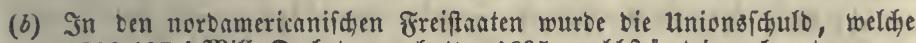
1816127,4 शill. D. Betragen hatte, 1835 volffändig abgetragen. Die Szanbelätrifte von 1857 zog wieber eine neue Schuld nach fich. Starfe Sdjuloberminberung in \$reußen, f. \$. $523(b)$. - In ben Niederlanden twurben 1850-59 114,4 গlifl. fi. zur Tilgung verwendet,

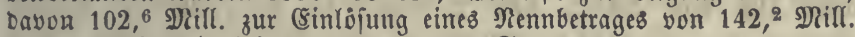
v. $\mathfrak{B}$ a $\mathfrak{k} \mathfrak{h}$ a er bei Horn, Annuaire 5.161.

\section{§. $515 \mathrm{a}$.}

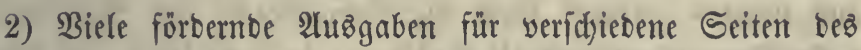
Staatzlebenz (\$. 474) verurjachen eine Bermefnung bez SBolfz: einfommenz, und bieß ift entweber ifre nächfte Beftimmung (Maßregeln ber Bolfswirthfdhaftäfflege) ober eine wilfommene Folge einer anderen $\mathfrak{B e r b e f i f e r u n g ~ i n ~ b e n ~ S t a n t z e i n t i c t u n g e n . ~}$

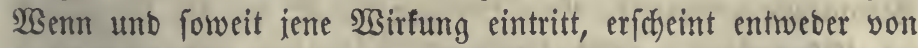
felbft eine $\mathfrak{B}$ ergröß̈erung ber Ctaatbeinfünfte, Gauptfädjlid Der Stetern, ober eine Bunahme ber Steuerfähigfeit bes Bolfes, fo baß bie 3injen ber zu foldjen 3wecten gemadjen Inteifen gamz ober zum Theile ohne eine verbältnismäßig ftärfere $\mathfrak{B e}$ laftung ber Bürger von benfelben fortwähreno aufgebradjt 
werben fönnen. Dod) (predyen aud) bei biefen Sdjulben er= heblid)e (Brủnbe für eine allmälige 2lftragung:

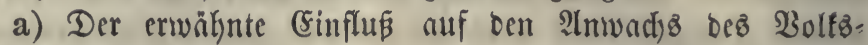
einfommens ift in Şinfíd)t feiner Stärfe und Fortonuer fowvic ber \&anbeştheile uno Bolfşclaffen, benen er vorzüglict) zufällt, nid)t genau zu erfemnen, in mandyen Fällen aber obne 3weifel nid)t genügent, eine immerwährenbe 3inşvermebrung nufau= wiegen.

b) Unyolffommenkeiten bes Steuerwejens werben bei einer Errböhung ber Eteuern fübltbrer.

c) Bon 3eit zu 3eit werben anjefynlidfe nußserorbentlide Atubgaben uno große neue Edjulten unvermeiblid), es bringt

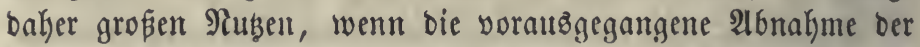
ălteren Sdjuld Mittel hiezu barbietet. In 3eitabjunitten, bie

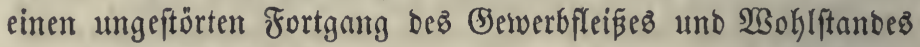
zeigen, ift ez folglid) rathjam, einen fleinen, leid)t für biejen 3weff zu erübrigenten Theil ber Staatbeinfünfte zur 2lbtragung von Edjulden anzuwenden unt bamit eine fpätere Steuterver: minberung ober eine Bergrößerung anoerer Stantżmtg̊gaben yorzubereiten.

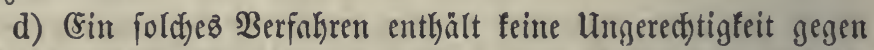
bas jezige Menjujenalter, bejonbers ba bafielbe viele früdjte

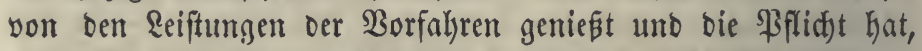
aud) für baz $\mathfrak{B}$ ohl bes Stantez in ber 3ufunft etwas zu thun, wenn es leidjt geifteken faun.

3) Eapitalanlagen für bie auf Staatżrect)mung betriebenen Setwerbe, - fowohl Regal= als bem allgemeinen Mitwerben

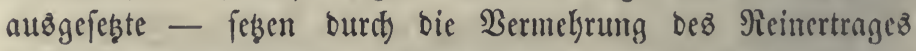

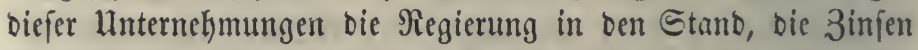
zu bezaklen. Dennod) ift ez rathfam, aud) bei foldyen Anteiken auf Tilgung Bebadft zu nelymen, benn $e B$ find fpätere Störungen

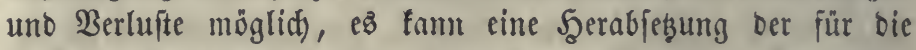
Stantsenffe geforberten Entridtungen, z. B. bei ber Benuz̧utg Der Eifenbahnen, empfeblenzwerth erifheinen uno es werben neue $\mathfrak{B}$ erwenoungen ähnlid)er 2 (rt erleid)tert.

In ber Staatzidjuld pflegen, mit 2tuछ̇nalyme ber in megres ren Sänbern abgejonbert gehaltenen (Eifenbahnichuld, bie ats veridjebenen Urjadjen entftanbenen Beftandthcile vermifdjt zu 
fein, fie find fogar nidft mefhr genau befannt, bie Tilgung wirb baker ofhe Rüffidft auf jene urfprünglidje Beftimmung Der einzelnen 2 Inteifen betrieben uno bie Sajuld wirb in biejer

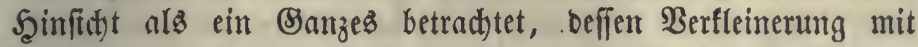

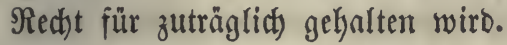

\section{§. 516 .}

Eine $\mathfrak{B e r m i n d e r u n g}$ ber in ben Stantsifthulben liegenten Raft vermittelft einer Red)tşverleşung gegen bie Bläubiger wiro nad) einer 2lefnlidfeeit mit bem, was bei sriwatichulonern vor= geht, Staatboanferott genannt $(a)$. Diefe Bezeidinumg fönnte auf eitte unridtige $\mathfrak{B o r f t e f l u n g ~ v o n ~ b e n ~} \mathfrak{B o r g a ̈ n g e n ~}$ führen, weldye yon bein nadt) bitrgerlidjem Rect)te eintretenden (5ant $=$ ( Concurs $=$ ) verfahren ganz veridfieben find und mur in

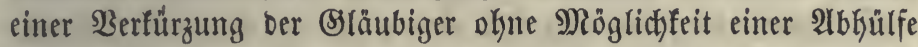
auf geridjtlid)em 2 sege beftehen. Dieß gefdieht oft mur theil= weife unb fann fids in verfdiebener $\mathfrak{W e i f e}$ wieberkolen. Die

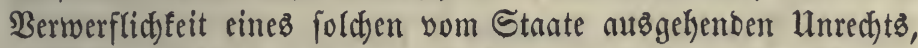
weldyes zugleid) ben (Erebit auf längere 3eit lähmt, fann feinem

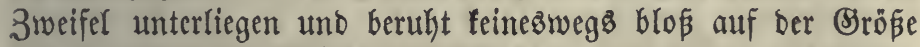

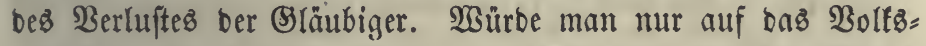
vermögen im Banzen adften, fo würbe fogar bie Bernidftung

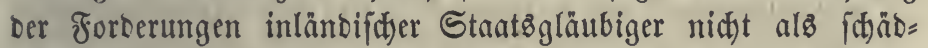
(idi) erfdteinen, weil zugleid) bie mittelbar auf allen Steuer= pflictitigen laftenbe Echuld wegfällt, \$. $474(a)$; waz aub=

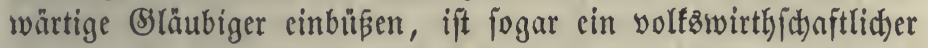
Sewvinn, aber ein theuer erfaufter! Dagegen bewirft ein کtaats= banferott in ber gewohnten $\mathfrak{B} e r t h e i l u n g$ ber Cinfünfte eine

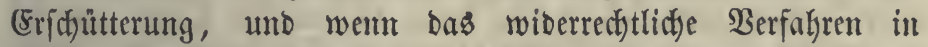

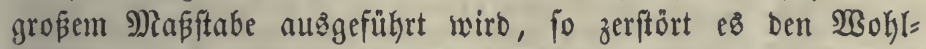
ftand vieler Familien unt zieht vielfeid)t cine $\mathbb{M a n f e}$ von 2 (rmuth unt (ETenb nad) fid), bie mur langiam überwunben werben fann.

Die Finanzgefdidjte zeigt vielerlei $\mathfrak{W}$ ege, auf benen bie Regierungen fid auf Roften ihrer Bläubiger eine (Erleid)terung verid)afft Gaben uno verfdiedene 2loftufungen bes Berluftes, Der benfelben zugefügt worben ift. In frülyeren 3citen, als man in ber Finanzperwaltung Den Brumbias ber Seredtigfeit nod) nidft gewiffentyaft fefthielt, famen unandjerlci Sdjritte biefer 
Irt vor, bie nidyt einmal immer in einer foftwierigen \&age einen Milberunggిgrumb fanben. Meiftens hat man foldye Maß̧regeln unter einer form vorgenommen, weldje ben 3wed verhüllen follte, obgleidt) es leid)t war, auz bem $\mathfrak{B}$ ortlaute ber Berorb= mungen ben wahren Sinn zu erfennen. Dahin gebören z. $\mathfrak{B}$. bie Münzerf(d)lec)terung ober bie \$reizerhöhung gewiffer Mänz= forten, um bie Edulben in bem geringhaltigeren (Selbe leicfter ju tifgen (\$. 196. 199), basి 2lusigcben von ๔d)ulofd)cinen, bie unter \$̧ari ftelgen, an ber Steffe ber fälrigen 3infen $(b)$. In ber neueren 3eit fino melyrere Regierungen burd) großjc Finanzberlegenlyeit, hauptfächlid) wäkrend ober in Folge eines fd)weren Rriegez, bewogen worben, auf ganz offene SBeife von

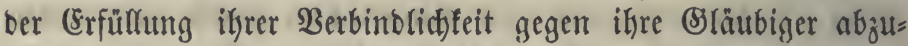
gehen, inbem fie balb bie Zinşzahlung cinftweilen einftelften,

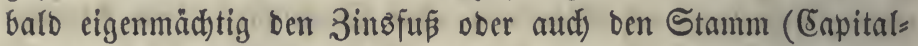

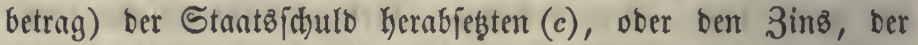

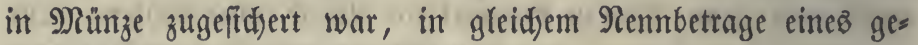
funfenen ßapiergeloes bezaklten $\mathfrak{u}$. Dgl.

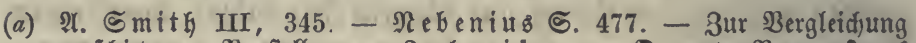

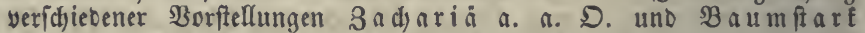
๔. 496. - Der Atbbé Terray (franzür. Finanzminifter yon 1768 bis 1774) åuß́erte, que la banquerote etait nẻcéssaire une fois tous les siècles, afin de mettre l'état au pair; qu'un roi ne risquait rien d'emprunter, parcequ'il était le maitre de ne plus payer les anciennes rentes, quand elles avaient été servìes assez longtemps! Bresson I, 578 .

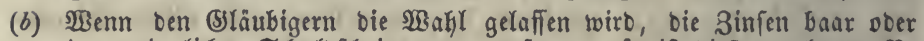

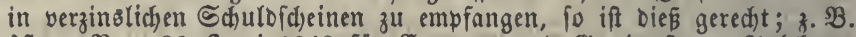
Difterr. $\mathfrak{B}$. v. 20. Suni 1849 für Coupons und (Sewinnfte an 2rnlehens: luofen, wieber aufgetgoben 1. Sept. 1852. Im Jafjre 1849 beliefen fich biefe capitalifïrten Binfe uno \$ramien auf $1 \frac{1}{2} 2$ Mill. fl.

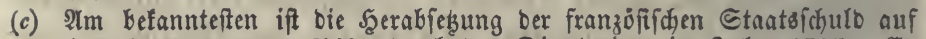

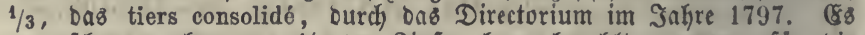
war fdjon vorker nur $1 / 4$ ber Sinfen baar bezahlt tworden, für bie anderen $3 / 4$ gab man Scheine (Bong) auf Staatzgunter. Nun wurbe

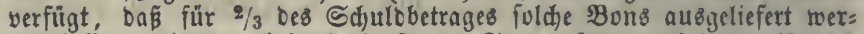
ben follten, bie man beim 2infaufe von Staat8̊gütern anbringen fönnte. Aflein Die Bons fanfen im Berfegr unter $1 / 6$, und Der Berluft ber (Släubiger war groß́. Thiers, Histoire IX, 133, 322. - Daffelbe twurbe in ben fpăter ant franfreich gefommenen \&änbern, 3. B. Şolland, uno auth im Rönigreich 2sefffalen unternommen, wo bas Sefes yom 28. Suni 1812 bie altere, von ben früheren Negierungen herfammente ङduld auf $1 / 3$ herabfegte. - Im Defferreid twurbe 1807 bie Ber= zinfung ber 3wangsanleife von 1794 (2 Still. fi.) eingeftellt und bie Tilgung in 25 Jahresbetrigen angeorbnet. Uteberhaupt bietet bie (5hronif

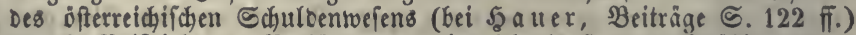
mand)e Beifpiele von Berfügungen, bie nicht bló̉ unz̧wed̆mäpig waren,

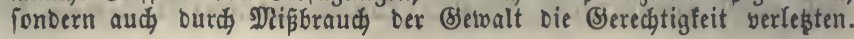




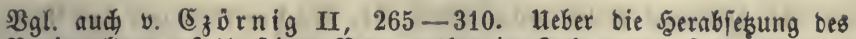
ßapiergeloes auf $1 / 5$ feines Nennwerthes im Jahre 1811 f. \$. 529.

\section{§. 517.}

S̃n Bezug auf foldje $\mathfrak{B e r f u ̈ g u n g e n ~ g e l t e n ~ f o l g e n b e ~ S c a u p t s ~}$ regeln:

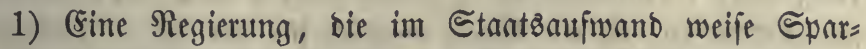
famfeit beobadjtet, bie Duellen ber Stratseeinfünfte gut. benub̨t unb fich burdh Serectigfeit uno Dromung im Staatzhaublyalte Bertrauen erworben hat, fommt nidjt leidft in eine Rage, bie zum Stantsbanferott hinbrängt. Diejer ift vielmehr gewöhnlid

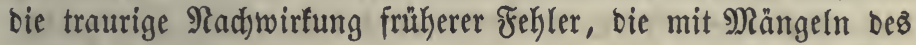
ganzen ftaatlict)en 3uftandez zufammen zu bängen pflegen. CEine gute Stantsuerfaffung, wenn fie in ridytigem Sinn in Wirfs famfeit gefommen ift, bilbet eine Schuşwehr gegen iene Fehler, bie jeboch auch bei jeber Staatsform burd) beharrlidten guten Wilfen vermieben werben fönnen.

2) Wären bie Ulmftänbe fo fđjwierig, baß bie Regierung für Den 2lugenblife iffe $\mathfrak{B e r p f l i c h t u n g e n ~ m i d f t ~ z u ~ e r f u ̈ l l e n ~ v e r = ~}$

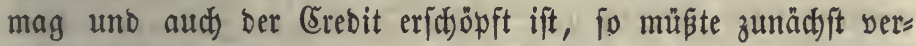
fudft werben, burd) eine auperorbentlidje, menn audi idswer laftende Steuer, burd) einen 2hifruf an bie Baterlanbsliebe ber Bürger zum Beflufe freiwilliger Dpfer in ber frorm yon einmaligen Beiträgen ober Darleiken $(a)$, burdh $\mathfrak{B}$ erpfänbung und $\mathfrak{B}$ erfauf von Staatżgütern $(b)$ u. bgl. neue Şülfs̈mittel zu veridjaffen. Sollte bießs nidjt ausfübrbar fein, wäre eine $\mathfrak{B}_{\mathrm{B}}$ idfränfung ber Binszałlungen nid)t zu umgehen, fo müfte man barauf bebactyt fein, Dás bas Uebel wenigftens fo flein als möglid werbe, uno fid gleidjmäpig vertheile, baß ferner bie, welche für iebst verfürzt werben, fpäter volle Entifchäbigung bafür

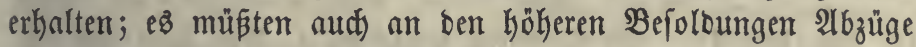
unter bem $\mathfrak{B o r b e h a l t e ~ b e r ~ \Re a d z a k j l u n g e n ~ g e m a d y t ~ u n t ~ a l l e ~ v e r = ~}$ fahieblichen 2 lużgaben eingefteflt werben, biz mit verboppelter

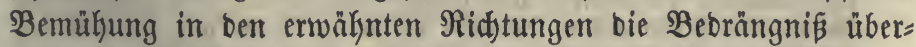
munben ift. Bebarf bie Stantzeverfaffung unb bie ganze Finanz= serwaltung einer $\mathfrak{B} e r b e f f e r u n g$, fo wirb bie ichleunige Alusfüh = rung ober wenigftens bie $2 \mathfrak{n} b a \mathfrak{h}$ mung berfelben viel bazu beitragen, ben Crebit 孔̆ keben, unb neue Şülföquetlen zu eröffnen. 


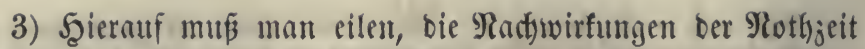
foviel als möglid) wieber aufzulfeben uno bie Dronung herzu= ftellen. Swie ein reblider Prisatmann, wenn er in beffere Umftünbe fommt, jeinen Bläubern bie Berlufte eriegrt, bie fie bei feiner 3ahlungăunfäbigfeit erlitten Kaben, fo ift aud) bie Siegie= rung biezu verpflidtet. (Es ift jebod) zugleid) nad) ben Uumftänben zu unterfurthen, ob ein Errag möglidy ift; ber oftere Uebergang von Sthulbbriefen auf ben Șnthaber in antere Şänte madt dieß bei einem Theile ber släubiger (bie nid)t etwa Corpo= rationen find) zweifelfaft, wenn man nidjt (nad) $\mathfrak{R r}$ 2) fijon bet bem CEintritt ber Berlegentgeit Gierauf Riüfitht gentommen Gat. 2Aแs bent Mitteln ber Steuerpflidftigen Denjenigen, tweldje Etantzidullbitheine um niebrige Entre erfauft Gaben, unber= biente Sterwinnfte zu geben, während bod 2thbere bab, waz fie

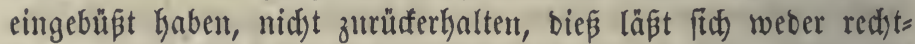
lidy ver(angen, nod) auth mur amrathen. Sn mefyeren Staaten Gat man bie Scfuldobriefe, beren Binfen Kerabgefegt worben waren, allmälig uad) bem Soofe in bie volfe Berzinfung ober

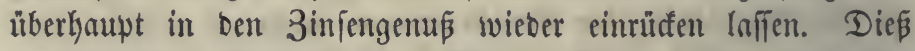
verbient feine (Empfeblung. Aluf ie längere 3eit pin foldyer

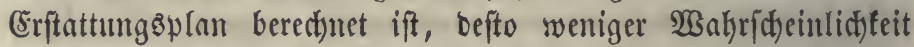
hat jeber S)läubiger, bald an bie Reihe zu fommen uno befto niebriger muí mittin ber \$ireiz ber zu verloofenten Sdjulds

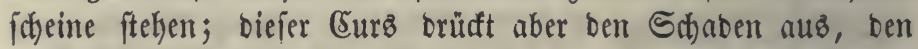
viele Siläubiger unwiberruflid) erlitten haber. (E\& ift baher it einem foldten Falfe beffer, alle Befizer foldyer gejunfenen Edyuld=

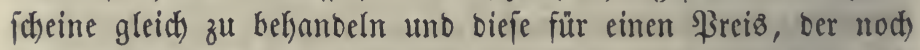
ůber Dem gegenwärtigen Börfencurre fteft, gegen nette, punuctlid) zu verzinfende Dbligationen umzunedyfén. Aluf biefe $\mathfrak{B}$ Beife wer= ben fich bie angerwenteten Summen am geredteffen vertheilen (c).

(a) $\mathfrak{B g l}$ §. 504. - In Defterreid twurbe am 3. Ipril 1792 eine frei=

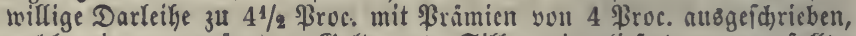
weldipe in ungenuinztem (Sold und Silber eingeliefert twerben follte. 1793 wurben bie sirdfen uno Elöfter nufgefortert, bie entbefretidgen (3)ols = uno Eilbergeråthe freimillig zu tiejem 3werfe uno zur faifhrutig bes Srieges zu vertwenten. - Freinillige Borausbezahlung Der 1865 fälligen Grumbfteter im Sinngreid) Stalien in üterrafd)eno groperem Betrage.

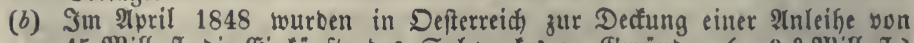

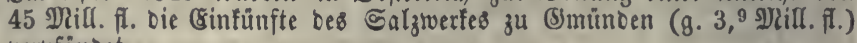
verpfäntet. 


\section{3}

(c) Rebenius S. 480 fi. - Şier fino bie Fillanzoperationen breier Stanten in neueften Seiten zu erwähnen.

1) In ben Rieber lanten wurbe nad) Der wiebcrerlangten Eelbft: itämigfeit Des Stantes 1814 Die auf $1 / 3$ reducirte @dulo (\$. $516(a)$ ) wicter in ihrem vollen Betrage hergeftefit, Giermit jecods zugleich eine

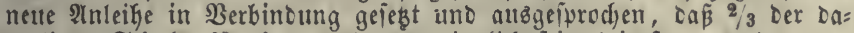
maligen Sdhulo fïr jebt nod unverzinslich fein (oie fogenamite a us =

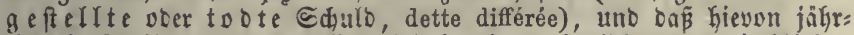
lid ein Theil (neuerlich 5 Mill. fi.) in tie verzinglidge ober wirflid)e, a ctive Gdyuld einrüfen follte, fowie von biefer eine gleid)e Eumme getilgt würte. Die Dbligationen Der Domalz gebilbeten wirflichen

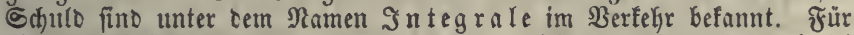

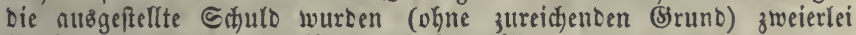
\$apiere autgegegeben, Eertificate und Lovbbillette (billet de chance, Kansbillet, $\mathbb{R} a n z e n$ ), in Denen Das SBerlooien Der zum Sinsigenuffe gelangen= Dell Nummern geichah. Diefe rurden zum Theil 1825 fogleidh auf 25 Sahre voralts verlcoft, woranz mieber cer unterichieo Der verlsoften uno Der foüter zum Roofe fommenben Ranzen entfand. Der Sinbaber cines an Die Neike gefonmenen Ranzbillets muste fich natürlich and ein (Eertificat auf gleidhe Summe veridjaffen. Der (5urb einer erft nad 1850 mitloofenden Ranze von 1000 fl. war zulebst gegen 25 fi., Der (Sertificate $9-10$ fi. für 1000 fl. Das (Sefes von 1841 veroronete

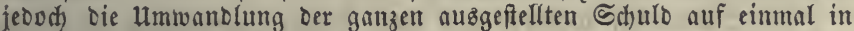
eine verzingliche, in Semäpheit bez Damaligen Curfes Der erfteren. Man gab für 1000 fi. in nod nicht verlooften Ranzen 50 fl., für 1000 fi. Eertificate 18 , zufmumen 68 fi. in $2 \% / 2$ toc. Sdyldobriefen, welche zu $50-51 \mathrm{im}$ Gurfe ftanden, alfo ungefähr foviel als 34 fl. baar. Die

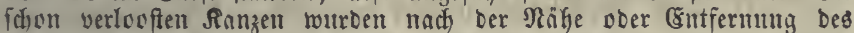

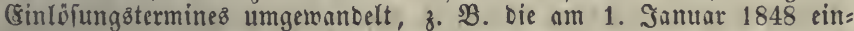
lösbaren mit 752 fl. in $2 \frac{1}{2}$ yroc. Gdueinen für 1000. Die Giedurch

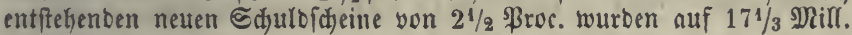
angeichlagen.

2) In Epanien erflärte Das Decret yom 16. Noy. 1834 1/3 Der aus? wartigen Edjuld für unverzinslid) ( $p$ a fiiv). Für bie anberen $2 / 3$ wurben meue 5 procentige Dbligationen ausgegeben. Unter ber aus: wärtigen ๔dulo befanden fich Die Anleigen Der Cortes von 1821 uno 1826, weldie, oa fie yon 1823 an nidht anertannt waren, im Eurfe fdyon fefre nieorig, unter 30 \$roc., fanden. Dod twar 1831 ein Theil

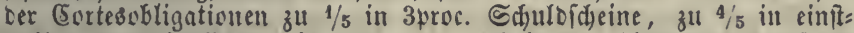
meilen unverzingliche, bie nach unD nach in ben Sinżgenuṕ vorrüden follten, umgetwedfelt worben. So entfano alfo fidon 1831 eine aus = geieste Śbulo, weldye vorzugstweife d. différée (deuda differida) im Segenfaze Der meuen d. passiva genannt wurbe. Bei ber 5proc. Sdjuld

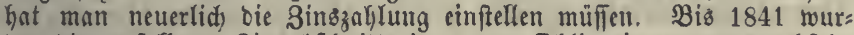
Den bie verfallenen Sinsabidjnitte in 3 wroc. Dbligationen umgetwedjfelt. In Dem Selebe v. 4. 2lug. 1851 ift bas Sdjuldenteren neu georonet worben. छछ giebt eine nette deuda perpetua differida, beten 3inछ vicr Jahre lang 1 \$roc. war und bann alle zwei Jahre um $1 / 4$ \$roc. freigt (alfo $186013 / 4$ ), bis 3 ßroc. erreid)t werben, ferner eine unverzinstiche ๔d)uld. \$reis im Februar 18603 proc. Sdullo $42,1 \frac{3}{4}$ proc. $32 \frac{1}{2}$, im Santur 18653 ßroc. $41 \frac{7}{8}, 2$ \$roc. 41.

3) In Defterreich ivurben Durdy \$atent yom 20. Februar 1811 bie

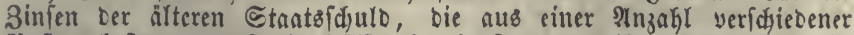

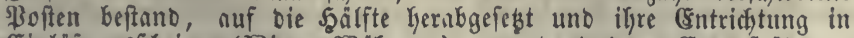
(Einlöiungsfd)einen (NBiener $\mathscr{B a ̈ h}$ rung) angeoronet, Deren (5urs fpäter zu 250 gegen 100 Silber feffgeftellt trurbe. Der Neunbetrag biejer Sdyulb 


\section{4}

war 1816608 शill., 1818 nach ber Umwantlung eimes Theiles nod

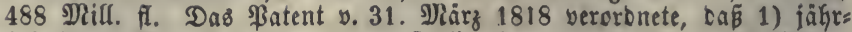
lidh für 5 \$Nill. fi. folder älterer Doligationen (5 von ben 488 Serien zu 1 IRill. fl.) nad) Dem loofe in ben (Senus ber vollen Sinjen, uno zwar in Silbergelo, cinrüfen follen (was ein grofer Sortheil für bie Befiber war, benn fie erlyelten ftatt ber bibferigen $21 / 2$ \$roc. in $\mathfrak{B}$. $\mathfrak{B}$., weld) 1 stoce. in Silber galten, nun 5 Froc. in lebterem, uno ber

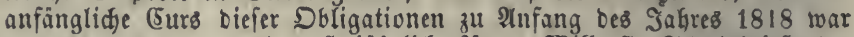

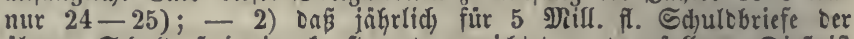
älteren Schuld frei eingefauft uno vernichtet rerben follen. Diés if feitoem bủnetlid geidjehen. Im Mai 1841 waren nod 245.819000 fi. biejer älteren Sdjulo yorganoen (Tegoborsfi I, 47. 43), im Suni 1848 nod 1651/3 Dill., auf 2\% Proc. reoucirt 144.486000 fi., 1862 nur nod) 56 Mifl. Shr (5urs war $50-60$. 3u 60 eingeloit uno zu 5 Proc. verzinft würbe fie $4 \frac{1}{3}$ IRifl. jährlich foften. Jeb̨iger (Eurs gegen 63. - Auch ßortugal, Beru, Benezuela uno Neugranada Kaben eine nusgeftellte Gibulo.

\section{§. 518.}

3u ber Tilgung ber Edfulben in geredter $\mathfrak{B e i f e}$ Inffen (iid) folgente Mittel benuß̨en:

1) Summen, welthe auto bem Stammvermögen bes Stantes hergenommen fint und Daker beffen Errtrag für bie 3ufunft verminbern. Dahin gefören a) Einnahimen aนz Domänen= verfäufen und Befällnblöjungen, \$. 94-98, vergl. 198 ff. Durdh ben allmäligen Berfauf fann, to lange die Etantżgüter ausireid)en, eine fortwährenbe (Einnakme erzielt werben, bie jebod) eine gleidzeitige $\mathfrak{B}$ erminterung ber Staatzeintünfte ver=

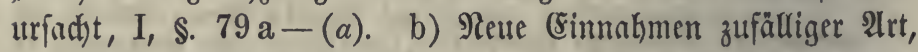
bie feiner Fortbauter fähig inno, $\mathfrak{z}$. B. 3ahllungen yon mberen Stanten (b), eingezogene Rirdjengüter (c) u. Dgl.

2) Esin fortwährent für bie Sdjulbentilgung befimmter Theil ber Staatzecinfünfte. Ûm die Srunbfäßze ber Befteuerung

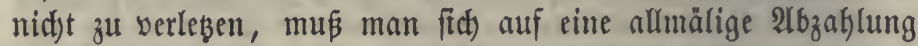

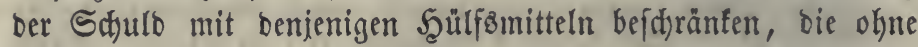
übermäßige Belaftutng bes $\mathfrak{B o l f e ß}(d)$ zu ienem 3wede verfüg= bar werben. Şiezu fann ein vou felbft erfolgenber $21 n=$ wact) ber Eintünfte, z. B. zufolge böherer Sgolzpreife, eine beffere Benub̧ung Der Esinnakmı̊quelfen, eine Errhöhung ober Bermefyrung ber Eteuern uno Beberilyren ober eine Berninterung anberer Staatżaugagaben $(e)$ bienen.

(a) Beifpiele in §. 94 (b).

(b) Die 3ahlungen Frantreidjs an bie berbünbeten Mäajte nadj bem zwei=

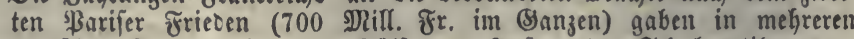
beutichen Stnaten eine gute şülfe zum Anfang ber Edguldentilgung. 


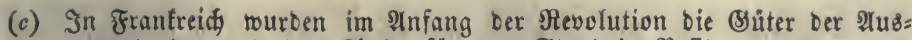
gevanberten uno ber Rirche für ven Staat in Befig genommen uno

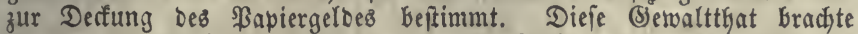

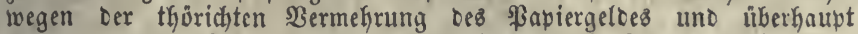
wegen ber unbefommen Finamzerwaltung ben Etaate menig Bor= theil. - Die Einziefung Des reichen Rirdjengutes in Spanien unter

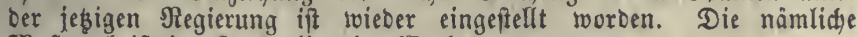
Inarregel if im $\Re$. Stulien im Werfe.

(d) Şiemit ift bie Berwerflichfeit aller berjenigen Entwinfe zur wlokglidjen

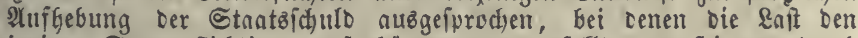
jesigen Steuerpificjtigen aufgebürbet merben follte, es fei mun ourch bie Heberweifung ber Schuld an bie fämmtlidjen Stantbburger nach

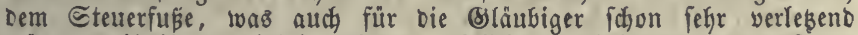
wäre, weif ifnen hiebei mehrere, vielleidt unbefannte uno entfernte Shulbner aufgeonungen würben, - ober burd) eine fehr hoke augen= blifliche Befteuerung, moraus bie Regierung oie SDittel zur völligen

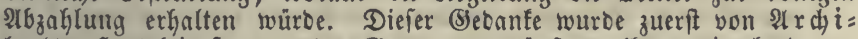

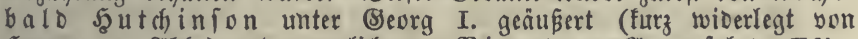

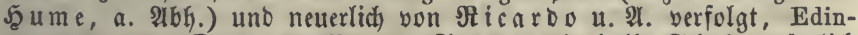
burgh Review, Det. 1827, 9r. 92, S. 407; Die balbe Schulo, nämlich

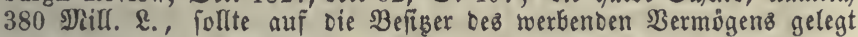
werben, welches ungefâgr 2330 Mill. \&. fein mỏge, fo oấ bie Shulo eines Jeden ungefî̉y 12 ßroc. (16 \$roc.?) feines \$Bermögens hin=

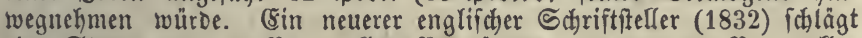
eime Steuer bon 20 ßroc, allez $\mathfrak{B}$ ermögenz uno von 50 \$roc. alles Arbeitz = uno (Serwerbeinfomment vor. Pebrer (Hist. financ. II, 342) entwidelt einen Tilgungß̋plan vermittelf ciner Steuer von $9 \frac{1}{4}$ \$roc. bes ganzen \$rivatvermügens, aller Befoloungen, Binfen oer Stants=

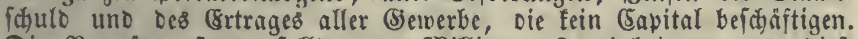
Die ßBermongensfteuer follte 500 Nillionen \&. einbringen und Dieje Summe gerabe aud an Der Gduld abgezahfi werben, woran jedoch 71 Diff. alв Steuerbeitrag ber (S) läubiger felbft abgehen, man hätte

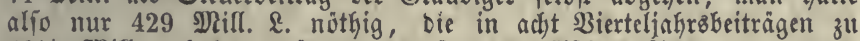
$53 \frac{1}{2}$ \ill. erfoben würben. - Sm preusifhen ङtaat war baran

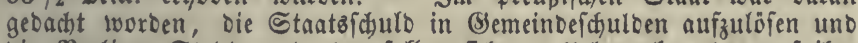
bie Berliner Stabtweroroneten follen fich zur Uebernahme Dez auf ifre Stadt nad) Dlaşgabe ber Solfomenge treffenden Theils (17 Thlr. per Ropf) erboten haben, was freilich für bie 5 amptifabt, in ber bie Durch=

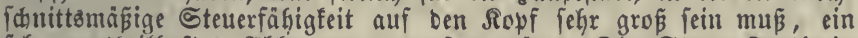
fehr bortheilhaftes abfommen gewejen wäre. Die Stabt Ranth in Sdyleften vertheilte ifye (Semeindeiduldon unter cie Bürger, Die fie

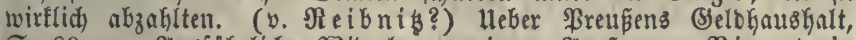

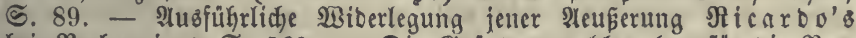
bei Nebenius S. 563. - Die (s)runde, weldhe oben für Die Bor= züglichfeit ber Ituleihen gegen erorürfenbe Steuern angegeben worben

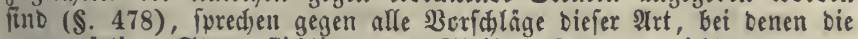
gegentwartigen Steuerpflidigen zum Theil zu Srunbe geridjtet uno aus

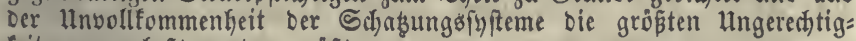
feiten veranlaß̧t werben müsten.

(e) Şicher ift and) Die (Erpwarung aus ber Binbrjerabjebung zu rechuen, fos

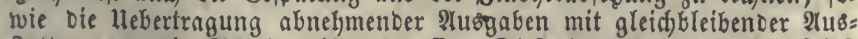
ftattung an bie Sd)ulbentilgungseaffe. Dieje braucht inbej nicht felbft mit ber Beforgung fo veriळiebenartiger Antsgaben beläfigt zu werben, wenn ify nur die eriparten Summen richtig zufommen. Ein Beifpiel ciner folden Berwidfung giebt bas baserifde ๔dultogejes v. 22. Suli 1819, nad weldjem Der Sdjuldentilgecaffe $2 \cdot 800000$ fi. Benfionen bes 
Gecularifations = uno IRediatifirungs = 8tats überiviefen wurbell, burd

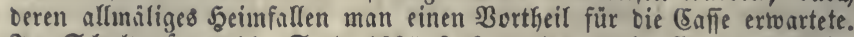
Im Edulogef. y. 11. Sept. 1825 \&. 6 wurben nod alle anberen bis= herigen \$enfiunen, im Betrage von 3.422000 fl., Diejer Eaffe zugetheilt $(\$ 63(a))$, wofür fie aber uur $2 \cdot 700000$ fl. Dotution empfing, roe $=$ halb ifre geftattet wurbe, Summen zu borgen, bie bei bem Seimfalle ber Benfionen wieder getilgt werben fonnten. So entitano cine befoncere Benfion = शmortifationscafie. Bis 1829 Gatten fich bie ßenfionen auf 4.115749 fl. verminoert, bis zum 1. Dct. 1832 auf 3.596000 fi., ob=

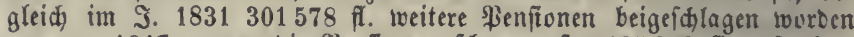
warell. 1847 waren die \$enfínen fdon auf 1.135979 fl. gefunfen. Die Sdyuld ber ßenfionscafie belief fidh 1837 auf $15^{3} / 4$ গnill. fl., 1847 auf 11.916646 fi., bie atth wieber unter ben झctiven ber allgeineinen Amurtifationscaffe aufgefülyrt wurben. Bon 1850 an erhielt fie jähr= lidh nur nod $21 / 2$ פill. ff., es wurben ifr aber 1850,1852 und 1856

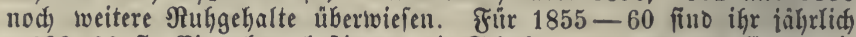
1.029000 fi. Cinnafme beftimmt, Die Schuld von 6.800000 fl. an Die allgemeine 2linortifationscafie wurbe aber im Actibftanbe ver lebsteren wie im \$afifivum ber eriteren geftrichen unb es hörte bie Berzinfung uno Tilgung auf, Sto ff a v. Neuforn, Saubb. S. 765-769. Die gange Anoronung ift alb ein Borgen zur Beftreitung eimer lau=

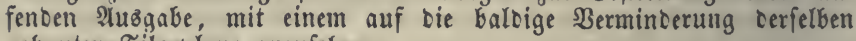
gebauten Tilgeplane anzufehen.

\section{§. 519 .}

Im Fortgange ber Tilgung ergiebt fid cine neue und ftets anwachjente Şülføిquelle aus ben erparten 3injen ber abge= tragenen Sthuldopoften. Das Mittel, Durch) weld)es man bie Berwentung ber 3injenerpparung zur weiteren Tilgung ganz

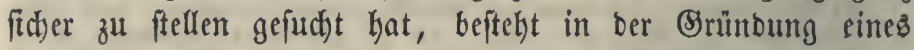

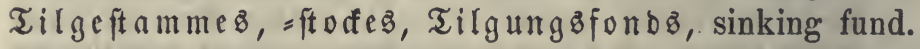
Mit biefem Namen bezeidjutet man eine in ben Şänben ber

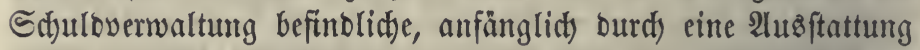

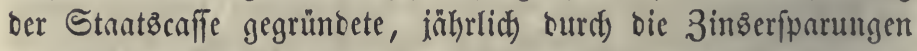
anmadyfente Bermögenżmaffe, weldye entlich, nad) einer genau yoraus zu beredjuenten Fortf(t)reitung bie ganje Sdyulo in fid) aufnebmen unt alio bie völlige 2btragung Derfelben betwirfen foll. Sad) ber in Englano empfohlenen und cine 3eit lang angewenbeten (sinridtung $(a)$ follen bie getilgten Edyulofdeine als Theile bez Bermögens biefer Tilgungżnrfalt angejehen uno berfelben fortwäbreno aus ber Stantzenffe verzinft werben.

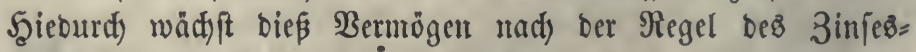
zinfes an uno eŝ ift leidjt zu bered)nen, nad) weldyer 3eit mit einer gewiffen anfänglidjen Duote ber Tilgung, z. B. $1 / 2$ ober 1 ßroc., bie Edjullo erlöidjen müpte.

Der Tilgeftamm wiro wie eine bejonbere ßerfon betradjet, 
weld)e bie Iftragung ber Sdhuld übernommen bätte, bie getilg= ten Summen werben wie ein Suthaben berjelben behandelt,

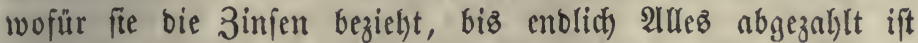
unb Der Tilgeftamm nad) ber \&öung feiner 2lufgabe auffört $(b)$. Bon cimem foldyen Tilgeftamme hat mall hie uno ba über= ipannte Erwartungen gekegt, weil man bem Zinjeszinfe cine gewiffe überats große Mad) zudfrieb uno überfah, baß ber=

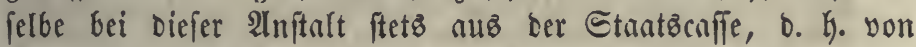
Den Stetterpflicttigen, beftritten werben muß $(c)$.

(a) Nachoem fhon vorker in Şollano uno im Rirchenitnate oas bei Der Binskerabfebung eriparte \$rocent ber Binien zur Tilgung vertwendet worten mar, wurbe in Srubbritanien 1716 ourd $\Re$ ob. SBalpole Der erfte fürmliche Tilgeftamm erridhtet, Der nad) Dem \$arlaments = befdlutie bie Heberidunte mehrerer anderer (5affen aufuehmen uno zu feinem antern 3̂edfe al[3 zur Abtragung Der vorbantenen Gduld gebraudht werben follte. Alllein bun 1728 an wurbe er mit ber $\mathfrak{B e r}=$ zinfung neterer Shulben belafet uno 1733 fing man an, einen Theil feiner Csinfünfte zur Befteitung ber Stantzausgaben beizuzieken, wo=

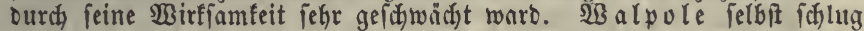

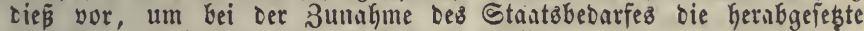
Srundfeuer nicht wieber erföhen zu minten. 1735 wurbe ber Tilge= ftamm ganz aufgezehrt. 1786 wurbe von $\mathfrak{B} 3$ ill. \$itt ein neuer Tilgeftamm von 1 Dilll. jährlicher Sinnafyme geftiftet, mit oer Beftim=

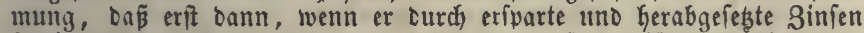

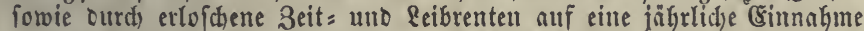
von 4 glifl. \&. ङt. angewahien fein würbe, bic 3infen ber meiter Geimbezahlten Dbligationen bem \$arlamente zur Berfügung überlafien werben follten. Die Schuld belief fich camals auf 267 शRill. \&. St.

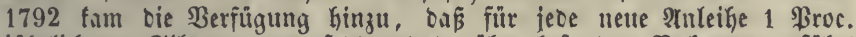

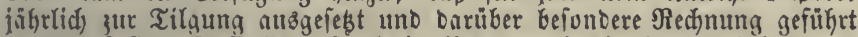
werben folle. Dafielbe gefingh in Bezuy auf Die Iangen 3eitrenten. Der aufgeptente Srunding rourte jebod bei ber \$enge netter Sdultoen boul 1798 an nidht Durchgangig befolgt. 1802 warf man bie beiben verfhiedenen Tilgeftümme in eitten general sinking fund zulammen,

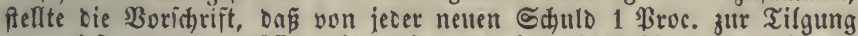

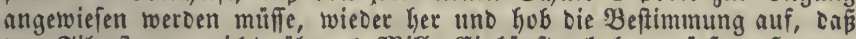
oer Tilgeftamm nidht über 4 Mill. Einfünfte babell dürfe $\mathfrak{F}_{\text {enty }}$

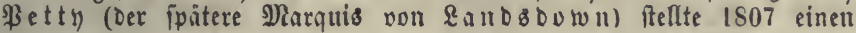

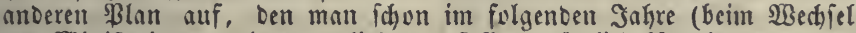

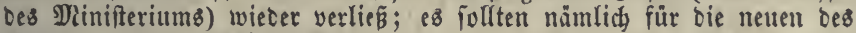
Sirieges willen nötfigen शnleiken immer 10 ßroc. für Bins, Berwals tungşfoften und Tilgung angewentoet, und dié́e Summe follte aแs Den Rriegsifeuern genommen werden. Da mun Gieburd) eine \&üffe in Den

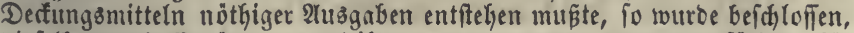
Diefelbe ourdb Ergänzungzanteiken (supplementary loans) zu füllen, für Die wieder 1 ßrec. Les Nominal=, oder, bei Dem (5urje ber 3 \$ruc. за $60,1 / 60$ bes wirflichen geborgten Betragez als Tilgeftamm beftimmt

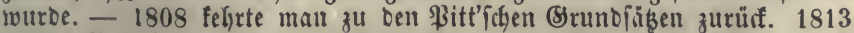
wurbe $\mathfrak{B}$ an i ittart' s verwidelter \$lan angenommen, Der Gatwtiaidylich Darauf hinaus lief, bấ ein Theil ber Esintünte Der Tilgecafle, jo weit ex Der bereits abgeloften Sduld yon 1786 entfprads, zur Berzinfung unt Tilgung neuer शluleifen zu verwenden toar, bá̉ bie fond für

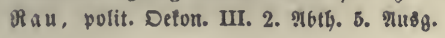


alle einzelnen Anleiken zufammen geworfen, Die lesteren ber Seitfolge naw abgetragen werben und nad ber Tilgung einer jeben bie burds fie begrübeten Einfünfte Des Tilgeftammes frei berivenobar werben follten, Daß nber bei jeder neuen Anleike für jenen Tilgefono geforgt werben muifie. - 1819 trat eine widjtige Beränderung ein. Dan befdylós, Das Esinfommen Des Tilgeftammes (151/2 Dill. \&.) zu ben

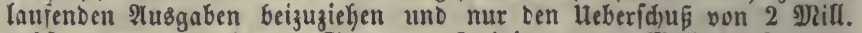
nebft anberen, Durch netle Steuern aufzubringenben 3 Dill. zur Tilgung anzumenben. In biefer $\mathfrak{B}_{\text {eife }}$ gandelte man aud in ben folgenben Sahren, bis 1828 formlich als Srunbfaßs angenommen wurbe, Das fünftig nur foviel in jebem Ialjre getilgt werten folle, als bon ben (sinfünften nad) Beptreitung Des Stantsaufwanbes wirflid) ủbrig bleibe (10. (Seorgs IV. (5ap. 27), womit alfo ber Tilgeitamm ganz aufhörte. - Jga mil: ton a. a. D. Cohen S. 200 ff. - Rebeniu 1. 2usg. S. 42 Des Inlyanges. - Pebrer I, 199 fi.

(b) $\mathfrak{W B}_{0}$ tiefe Einridytung befteht, Da findet man Den jedesmaligen wafren Sduldenfand, indem man von ber Summe ber borkandenen Shuld=

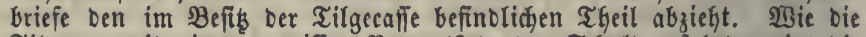
Tilgung mit einem gewiffen ßrocentfase Der ๔ajulo erfolgt, zeigt bie Tafel II, $\$$. 118. Der Fortgang Der Tilgung läist fich aud aub fol= gender Tafel bequem exfennen. Berben zu Ânfange jedes Sahres

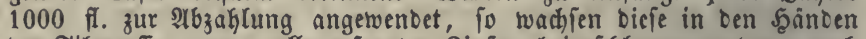
ber Tilgecaffe, wenn alle erfparten Sinten beigefalagen werben, nad Dasgabe Des zu Srunte gelegten 3insfües zu ben in ter Tabelle angegebenen Summen an.

\begin{tabular}{|c|c|c|c|c|}
\hline Berforif. 3abre & fu 5 æroc. & fu 4 Proc. & fu $3 \frac{1}{1} / 2$ Proc. & 8u 3 Proc. \\
\hline 8 & 10026 & 9582 & & \\
\hline 9 & ....... & ........ & 10731 & 10463 \\
\hline 14 & 20578 & & & \\
\hline 15 & $\ldots \ldots$ & 20834 & 19971 & \\
\hline $\begin{array}{l}16 \\
19\end{array}$ & ${ }_{32065}$ & $\cdots \cdots$ & $\cdots \cdots$ & 20761 \\
\hline 20 & ....... & 30969 & 29269 & \\
\hline 22 & ...... & $\ldots \ldots$ & ...... & 31452 \\
\hline 25 & 50115 & - & & \\
\hline 28 & $\ldots \ldots$ & 51966 & & \\
\hline 29 & . . & $\ldots \ldots$ & 50622 & \\
\hline 31 & 74298 & - . & $\ldots \ldots$ & 51502 \\
\hline $\begin{array}{l}35 \\
36\end{array}$ & $100628^{\circ}$ & 76598 & & \\
\hline 37 & ..... & $\ldots \ldots$ & 76628 & \\
\hline 39 & ....... & ....... & $\ldots \ldots$ & 77663 \\
\hline 41 & $\ldots \ldots$ & 103819 & & \\
\hline 43 & $\ldots \ldots$ & $\ldots$ & 100238 & \\
\hline 46 & . · . & $\ldots \ldots$ & $\ldots \ldots$ & 99396 \\
\hline 49 & 208347 & & & \\
\hline 56 & 301715 & 207797 & & \\
\hline $\begin{array}{l}60 \\
62\end{array}$ & $\dot{411} 469$ & $\cdots \cdots$ & 203394 & \\
\hline 65 & $\ldots \ldots$ & 306767 & & 200162 \\
\hline 70 & $\ldots \ldots$ & . . . & 299050 & \\
\hline 72 & $\ldots \ldots$ & 411898 & & \\
\hline 77 & - ․ㅜㅇ & $\ldots \ldots$ & - & 300001 \\
\hline 78 & 605876 & $\cdots \cdots$ & 403161 & 401898 \\
\hline 86 & $\cdots \cdots$ & $\ldots \ldots$ & $\cdots \cdots$ & 401898 \\
\hline
\end{tabular}


(8) fino hier nur biejenigen 3ahlen angegeben, weldje zeigen, in tweldjen Salien oie getilgte Summe ungefähr auf bas $10,20,30,50,75$,

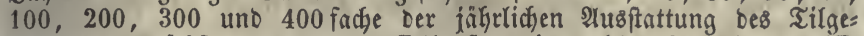
fammez anwảchf, ober, was Daffelbe fagt, in welcher Beit eine gewoifle Sdjulo mit einer jäfrliden Dotation von $10,5,3 \frac{1}{3}, 2,1 \frac{113}{3}, 1$, $1 / 2,1 / 3$ und $1 / 4$ Proc. ifres Betrages getilgt wercen fann. Mian feht

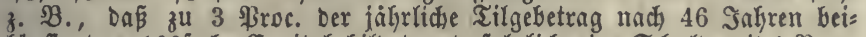
läufig das 100 fache Eapital bilbet uno folglidy eine 5 dyuld mit 1 ßroc. jährlich in 46 Inkren abzutragen ift.

(c) Der Urkeber Diejer irrigen Anfid)t, Der Englänber D. Price, 1771

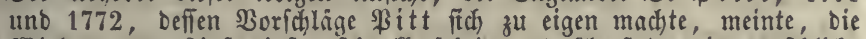

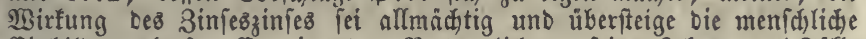
Sinbiloungżfraft. (5r nimmt zu Berbeutlichung feiner \&efren orei Frille an: 1) (58 twerben jährlich $200000 \mathfrak{L}$. zut Tilgung verwenbet, unb

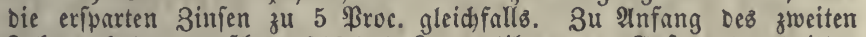

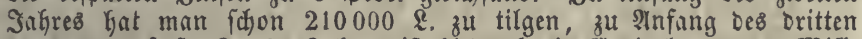
220500 u. f. $\tilde{f}$. In 85 Safren ift hieburch ein (Eapital von 262 शill. abbezahlt, oa 1 fi. Seitrente in 85 Jahren auf 1307,34 fi. antwähft. Im lesten Jahre oiefes Seitraums beträgt bie Tilgung 12.650870 \&.

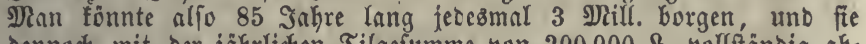
bennod mit ber jährlichen Tilgefumme yon 200000 \&. vollftảndig ab= tragen. 2) INan tilgt jâfrlid 200000 \&., wenbet aber bic exiparten

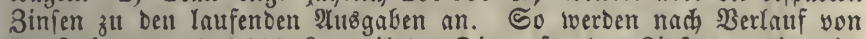
85 Jakren $17 \cdot 200000$ \&. getilgt. Die exparten Sinfen madjen im leşten Sahre 850000 \&. ober zufammen 36.550000 \&., fo Dá ber

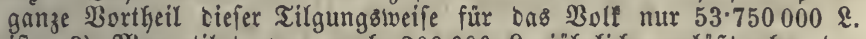
ift. 3) Dan tilgt zwar aud 200000 \&. jẩhrlich, exläpt aber ben Bürgern oie Stettern für bie exparten Sinien. So ift ber ganze Bor= theil zu Sinfang Des 86. Jahres nur eine Tilgung von 17.200000 \&. In biefem Falle, fagt ßrice, trảgt bas zur Śchuldentilgung aus: aegebene Beld gar feime Sinjen, im zweiten Falle wenigftens nur ein=

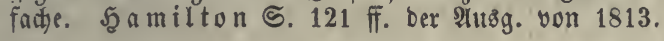

\section{§. 520 .}

Einem foldjen unwanbelbar auf bie Benukung bes 3infess= zinfer gebauten Tilgeftamme (sinking fund) ftehen folgende Srünoe entgegen $(a)$ :

1) Es wirb bei biejer Cinrichtung erforbert, baß bie Staats= cafie neben ber jährlicten Tilgefumme aud) nod) biż zum (sr= löfden ber Єaull ben ganzen Zinzbbetrag aufwende. Şiebei

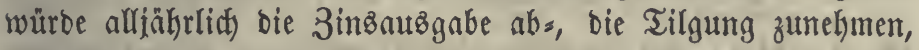
bis enblid) im leksten Sakre nur nod) Der 3ins bes zugleid) abgetragenen Sdulbreftes zu entrichten wäre (b). CEs ift aber fdrwer, in einem fo langen 3eitrnume, uno went fijon eine beträdjtlidje Bermúmberung Der Sduld ftattgefunben hat, Dem Berlangen ber $\mathfrak{B u ̈ r g e r}$ nad) Steuererleidtertung, ober, wenn bie Stantzausgaben fich bermehren, ber 2(bneigung vor neuen Steuern zu wiberftehen. Beibe Umftänbe geben einen 21ntrieb, bie Einfünte ber Tilgecnffe zu bejdyränfen, inbem man einen 
Theil ber abgetragenen Sathulopoften alz gänzlich erloidjen an= feleht und feine Binjen mehr für benfelben in die Tilgecajie

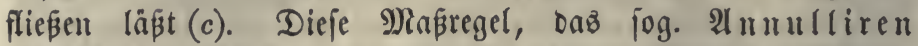

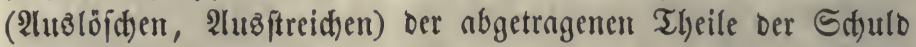
pflegt audt) mit einer wirflichen $\mathfrak{B e r n i d}$ tung Der eingelöften

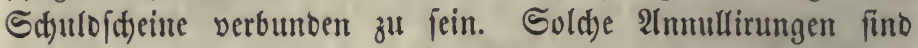
in Ränbern, wo man fid) zul bent Syfteme bez Tilgungsfitommes

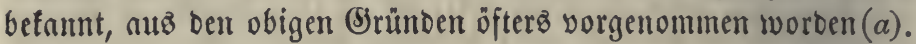

(a) Şamiltun in Der a. Shrift hat Das Berdienit, Dieien (5)egentano zuerft in Gefles Ridyt gefebt ful Gaben. - Nebenius S. 425 . de Gasparin et $\mathrm{Reboul}$ (5. 29. - In Franfreid, wirb vie @d)uld: abzablung nach bem ftrengen Syfteme beš Tilgungsîtammeš a mortis sement genannt. $\mathfrak{B g l}$. Ganilh, Dictionn. analyt. unter Diefem IBOrte.

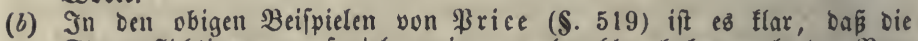
Steterpflidstigen um foviel weniger zu bezahlen baben, als ber Bur= theil ber Tilgecafie niebriger bargeftellt ift. Das fideinbare \$araboron,

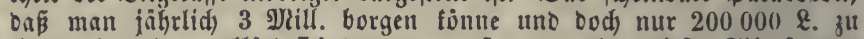

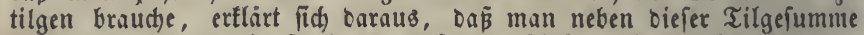
nod fortwảhreno bie ftarf anmadblenden 3infen afler biejer Anleifen

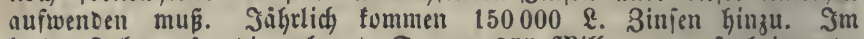

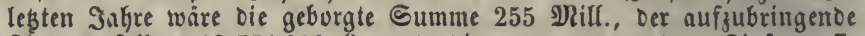
Sins berielben $12 \cdot 750000$ $\mathfrak{l}$. und die galize verwentete 3inienmafie 332 Dill. \&., tworaus nebell Dem Tilgungsbetrage von 17 Nillionen (85 mal 200000 fi.) Die \$littel zur 2lbtragung hergenommen werben mü̈̌̈tell.

(c) \$itt wollte die Shuldentilgunģcommififun fo unabhängig und fidher

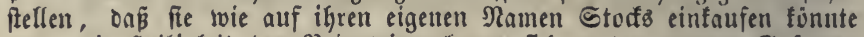
uno "Die Şeiligteit Des \$ribateigenthum fid zu ben antern (S) xunDen gefellte, welche Rrone uno ßarlament von einem (Singrifif in ben Siang cer Tilgung abjalten", Rebe am 29. Nara 1786. Fox zeigte Da= gegen, wie wenig auf bie unverriafte Befolgung eines foldjen \$lanes zu zaiflen fei. Debate upon the establishing a fund for the discharge of the national debt, 1786. - In \$reupen follen nad) Dem (Sefés vom Januar 1820 2ut. V Die exfparten 3infen immer nur iumerhalb eines Seitraums bon 10 Jahren oer Tilgecaffe verbleiben. Daher wurbe 1842 wegen Der bis Dafin betwirtten Sduloverminderutng uno ber aus ber 3insherabjesung entfandenen (Erfparung von jifirlich einer

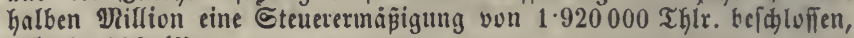
vgl. §. $186(b)$.

(d) Beifpiele. Die franzojifide Tilgecaite wurbe 1816 erridtet mit einer

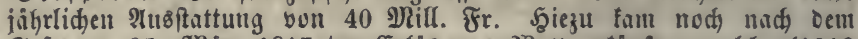

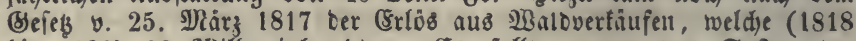
bis 1829) 88 Itill. cinbrachten. (\$8 follte genalt Das Eyftem Der Tilgeftammes befolgt werben. शtber man wich mekrmals ab. 2tls Billele bie Gdulo burd bie 1000 ynill. in 3 \$roc. zur Entidadois

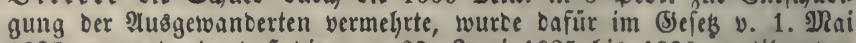
1825 angeoronet, Daß bie bom 22. Juni 1825 bis 1830 zu tilgenten Nenten annullirt werben follten, weldie fid auf 16.020094 Fr. Beliefen, faft ganz in 3 ßrocents. - Nad) Dem (Sefeß̧ vom 27. uno 28. Sumi

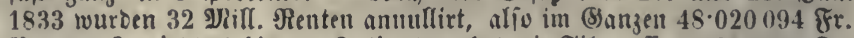
ßum 1. Juni 1816 bis 14. Suli 1848 hat bie Tilgecaffe 80.950700 Jr. 


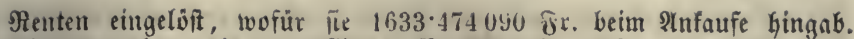

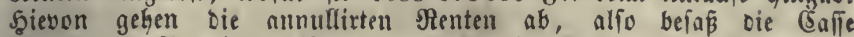
32.930606 Fr. eigette Nenten, weldse ein Rominalcapital von un= gefähr 860 פill. ausmachten, ferner $42 \frac{1}{2}$ Nill. Fr. in 4 uno 3 uroc.

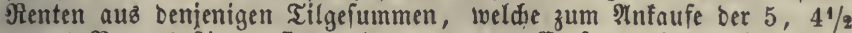
unb 4 Эroc. beftimmt fittb, aber wegen Des (Eurjes Derielben über ßari nicht hiezu vertwendet werben fonnten und Daker angefammelt wurben

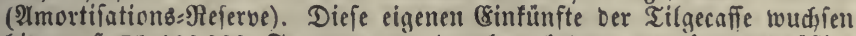
bis nuf 75.400000 fr. an uno baneben betrug Der buogetżmäвige

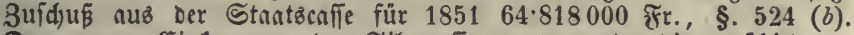
Das ganze Esinfommen ber Tilgecaffe twurbe unter bie berfhiebenen Theile Der Sdjulo nach bem Nennbetrage vertheilt. Die ftarfen nuser= orbentlichen 2äugaben feit 1840 , vorzuglich für bie Befeftigung von

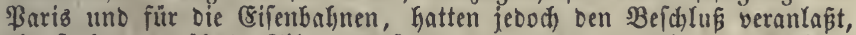
bie foebelt ertwâhnte Tilgungareferve von 1842 an mit fur Decfung ber feit 1840 entftanbenen 2usfälle zu verwenten (Sefés v. 11. Juni

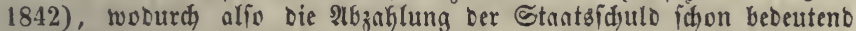

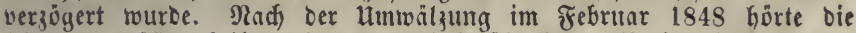

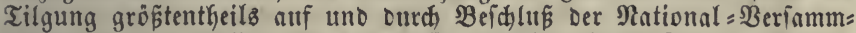
lung vom 14. Sulti 1848 tourbe fie gainzlidy eingeffellt unt bie Dazu

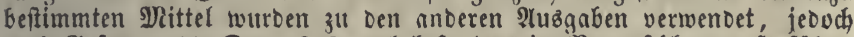
nac (Sefes v. 12. Dec. 1848 noch befonberø im SBoranialage aufgeführt, fotwohl iti Der Attzgabe für bie Schuld, als in Der Einnahme, was Demnach für Den शlugenbliaf leere Form ift. Der jäfrliche Betrag Der iog. Tilgungärejerve wurbe bem Namen nach Durds 1 \$roc. Der neuen

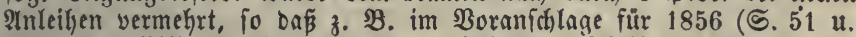

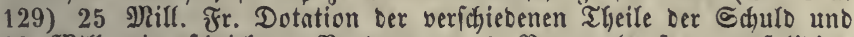

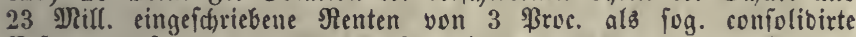

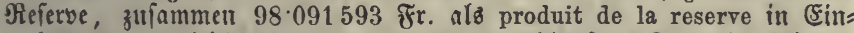

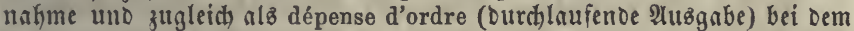

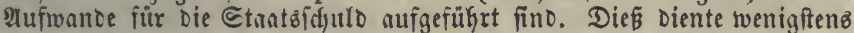
zur 21nerfennung Des Brundiakes. Für 1859 wurbe die Tilgung mit einer Sahrebfumme von 40 \$Nill. Fr. woieber in (Sang gefeşt, für 1860 wurben 60 s) illl. Giezu beftimmt, aber im Sanuar 1860 Durch die (Snt=

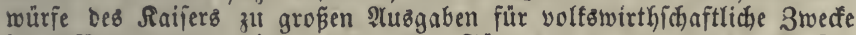
jener $\mathfrak{B}$ ertwenbung wieder entzogen. Für 1860 waren 29.578103 Fr. Dutation Der Tilgecaffe uno 37.153153 fr. 3 proc. Renten, welde

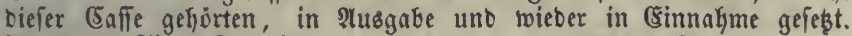
2. 1865: Tilge= Dotation . . . 118.022745 Fr.

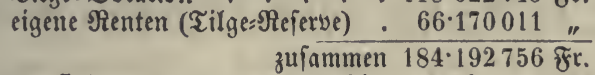

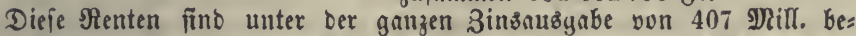
griffen. Bon obigen 184 Mill. 2usgaben exfdeinen 92.022745 wieber beim orbentlichen $\mathfrak{B u b g e t}$ in Einnafme, Der Sieft Der Dotation mit

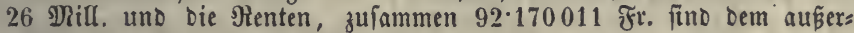
vrbentlichen $\mathfrak{B}$ ubget als Einnahmen zugetwiefen. Projet de loi pour la fixation des recettes et dép. ordinaires de 1865 S. 35. 120.

In Defterreid wax von 1817 an bas punctlide Syftem bes Tilge: fammes befolgt worben. Das ßatent vom 1. Det. 1829 verorbnete,

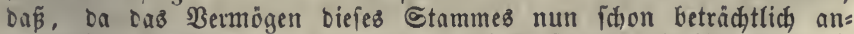
gewadjen, Derfelbe auf feine eigenen Coinfünfte uno bie igm von 3eit

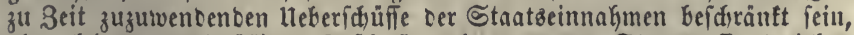

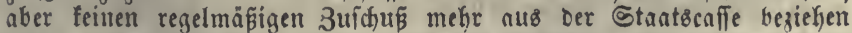
folle, suser für fünftig hinzufommenoe Anleiken, für Die wenigftens 1 śrac. jährlich anzumeifen ift. Das Bermögen ces Tilgeftammes ift unveräufertid, uno nur von Seit zu నecit zur wirflidpen Tilgung 
beftimmt. Nar Die bis zum leß̨ten Ditober 1829 eingeloften Dbliga=

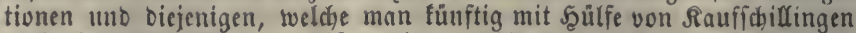

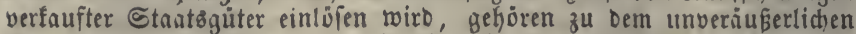

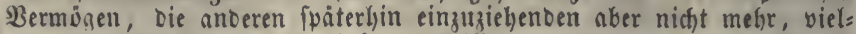

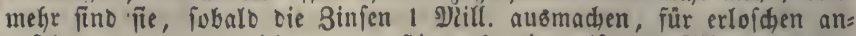
zujehen uno zu berniditen. - Sieburdy wirb nlfo oer Tilgungsbetrag fiatt eines freigenben zul einem ziemlid gleidbleibenoen. Su Ence 1844 beftano Das Bermögen bes Tilgungsfonos in 177.700000 fl., am 30. Juni 1848 war es $171 \cdot 306000$ fi. Doer, auf 5 ßroc. zuruicf: gefüfyrt, $162^{3 / 4}$ Dill., weldye alfo über 8 NRill. Sins cinbrachten.

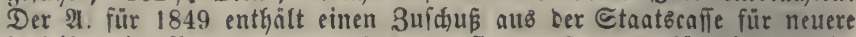
Inleifen im Betrnge von 1.974950 fi., auser ben für bie Rotterie= anleifen erforberliden $3 \cdot 146130$ fl. Itub $2 \cdot 505147$ fi. Tilgungerente an Die $\mathfrak{B}$ anf für $\mathrm{I} a$ vo von Derielben eingelöfte \$apiergelo. - Bon 1817 bis Slitte 1851 war bie Esinnafyme Der Tilgecaffe 384.858962 fl., woun 124 Mill. aus ber Staatbenfle, $260 \cdot 852028$ ff. aus Sinfen

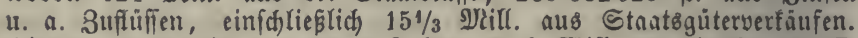
Şicuon wurben in ben lebten Jakren 28,8 Iill. an bie Staatzicafie abgegeben, Der Sieft zu Tilgungen vertwentet. Bon ber netren in Silber verzinslichen ๔chuld twurben, wenn ber Rennbetrag auf 5 \$roc. umgerechnet wiro, 293 Nilf. mit einem \$ufwanbe von 290 Drifl.,

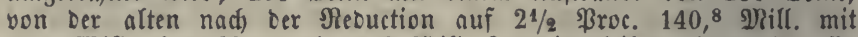

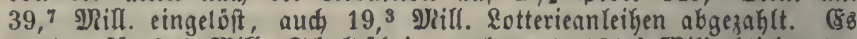

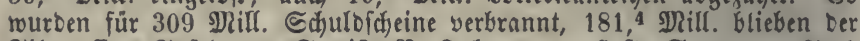

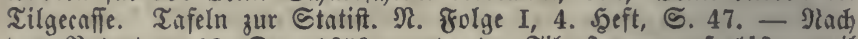
Dem ß̉atent v. 23. Dec. 1859 Ivurbe Der Tilgeftamm aupgelöt, tweil Die Ylittel, bie er erforberte, zul neuen Inleiken berivenoet rerden musten. Sein Bermogen zu Snde jenes Jahres betrug in ๔d)uld:

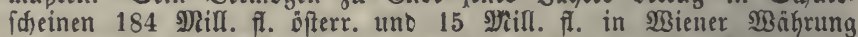

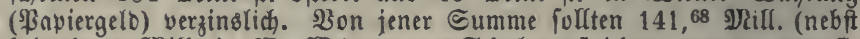

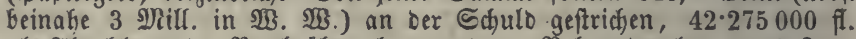

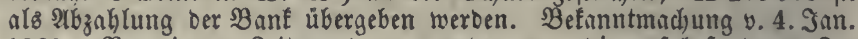
1860. Bon jenem Seitpuncte an werben nur bie auf befonberen $3 u=$ fidjerungen berukenoen $216 z a h l u n g e n$ fortgejest uno von ber 5 procent. Shuld in Diftert. Währung (\$apier) wiro jäfrlich $1 / 2$ ßroc. getilgt. (E) zrnig II, 306. Für 1864 enthält Der $\operatorname{Boranid}$ lag (ङ. 20 uno (Silåt. ङ. 30) eine Tilgejumme von 37.135000 fl., wovon 11.838000 fl.

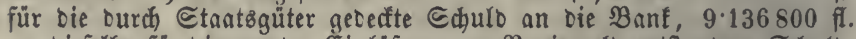

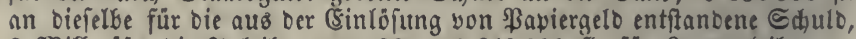
6 Milf. für bie Anleike von 1861, 4.643600 f̂. für Soosanleiken 2 .

\section{\$. 521.}

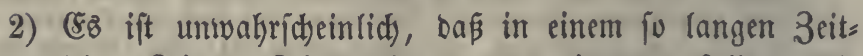
raume feine Rriege, Rriegsirüftungen 2t. eintreten follten, die eรื nöthig madien, bie zur Tilgung beftimmten Simmen für anbere bringenbere 3werfe zu verwenten. Die Bertbeibiger

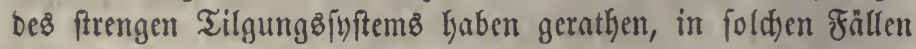
bennod) mit ber plammäвigen Tilgung fortzufabren, aud) wenn man gleidjoitig nene Inleiben aufnefmen muspte $(a)$, bamit

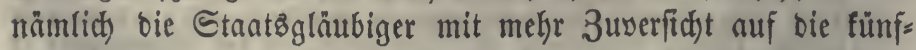
tige abnatgme ber Sđyulo bauen tönnen. Dicfes Berfakren 


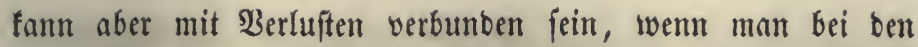
neuen 2Inleiken ungünftigere Bebingungen eingehen muß alß bie, unter welchen man tilgt $(b)$. Eine ftarfe Bermehrung ber Schuld wärbe aud) bei ber Fortfekzung ber Tilgung, bie bod immer langfaum von Statten geht, ifr Beunrubigenbes nidjt verlieren. Daker ift auf bie erwähnte (Einrichtung wenig $\mathfrak{B}$ erth fu legen, wenn mur bie Stratżgetwalt überhaupt beharrlidy ben (Srunofą̧ im 2luge hält, jebe unnöthige $\mathfrak{B e r m e h r u n g ~ b e r ~ S d u l d ~}$ zu meiben uno beren Berminoerung eifrig zu erftreben.

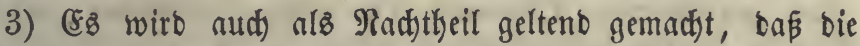

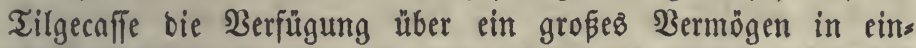
gelöften Sbligationen uno über ein beträdtliches jährlict)e Finfommen erbält, uno baß́ Gievon Durch Wieberverfauf ber eingezogenen Sduldofheine Mipbraud) gemadyt werben fönnte. Dießs if jedods unerbeblid), weil ein foldes Berfahren burd) (Bejese und 2lufficht, unmentlich burd) balbige Bernidtung ber Sdjulbidfeine ober eine ben Berfauf verbinbernbe Bezeidyung

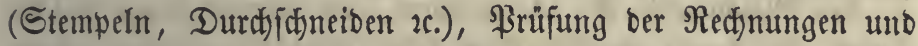
Bergleiđung ber vorräthigen Urfunben verfindert werben fann. Ueberkaupt ift es unnöthig, bie getilgte Summe als ein facin=

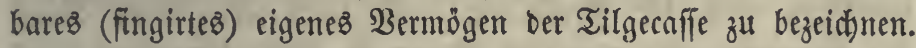

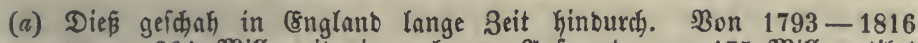
waren 284 Mill, mit einem baaren Mufwanbe von 175 Mill. getilgt worcen, bie ๔djuld ftieg aber Dennod, weil 870 \$Nill. nell geborgt

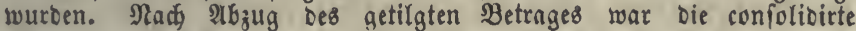

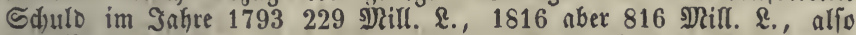

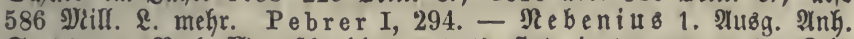

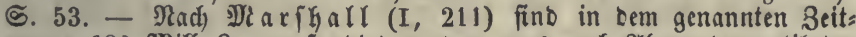
raume 883 \$ill. \&. neu funbirt worben, was nad 2t6zug ber getilgten Summe cinen 2 nnwach von 599 गilf. $\mathfrak{L}$. anzeigt. - Bis 1827 wurbe bie eingelöfte Summe von Staatspapieren nod als ein Theil ter ges fammten Shuld aufgeführt, weß̧̧alb man bie ganze und bie noch nicht getilgte Sduulo (unredeemed debt) forgfältig unterfdueiben muste. Bon 1828 an wiro nur nod bie nidjt getilgte eigentlidge Squld in ben Rectjungen angegeben.

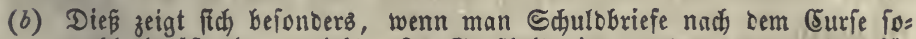
rookl einlöft als ausgiebt. In Sropbritanien wurben 1793-1813 für 14 פifl. \&. weniger Dbligationen eingelöft, als man, nady Dem \$reife Der neuen Ânleiken, für gleichen Betrag zu veridureiben genöthigt war. In Frantreid) entitano ein Berluft von 105 Inifl. Fr. am Sdulditamme Daraus, Daß man im Durchfanitt feben Franfen Nente für $18^{3} / 4$ Fr. zurüdffaufte uno zugleid bei ben neuen Эientenverfäufen nur $15^{3} / 4$ fr. bafür erhielt. Marshall II, 212. - de Gasparin et Reboul ธ. 45 . 
\$. 522.

Demnad) eridseint eine freie Tilgungsueife in (Segenfabe bes ftrengen Tilgevlames als zmedmäfiger. Sie fann nact) folgenden Regeln angeorbnet werben.

1) Der Betrag aller getilgten Sduldobriefe wirb fogleith als erlofdyen behandelt und in ber Bered)mung bes 3insbedarfez nidft mefyr berïffichtigt.

2) Soweit bie Regierung nid)t bur(t) einzelnte \&eifyerträge gebunden ift, wie bei Loosanleifen und nnoeren Safulben mit einer zugeftcterten Tilgequote (\$. 492), wirb mur biejenige Summe jährlid) zur 2 bzaklung bemubt, weldye aus ben Stantzిs einfünften neben ber Beftreitung ber anberen nöthigen 2 luz: gaben zu biefem 3weffe verwenbbar ift. Bleibt nictbt für biejen 3werf übrig, ober wirb es fogar nothwendig, nod) zu borgen, fo wirb bie Tilgung eingefteflt. Man foll aber biefe Unter= brectung zu vermeiben fuchen und mur gebieterifden lumftänoen nachgeben.

3) (Sleidjwohl ift es rathfam, im Soranjalage foldher Sabre, in benen muthmaßlid) feine Eduldovermehrung ftatts finben wirb, eine gewiffe Tilgejumme unter bie 2lużgaben aufs zunehmen und bie 2lbzablung nach einer feftgeftellten Regel mit Benubung Der eriparten Binfen fo lange fortzufezen, alB

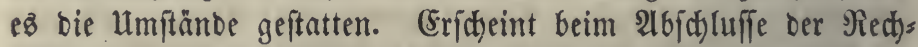
nungen nod) ein weiterer verwenbbarer Ueberj(t) zur Befhleunigung bes Tilgegeidäftę herbeigezogen werben $(a)$. WBerben nber größere Auzgaben ober neue S(j)uloen nöthig, fo

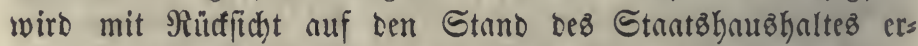
wogen und bejctoffen, ob bie Binserpparung und bie Tilges fumme ju jenen 3medfen verwentet werben foll. Wird eine

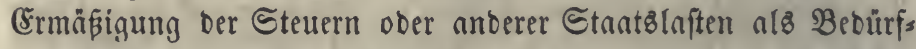
nís erfannt, fo wiro ein Theil ber 3inseriparung zum Erją biefer (Einnahmşyerminberung benußgt und folglict) ber Tilgung entzogen.

(a) In Baben wiro auf je zwei Sahre ter Tilgungoplan feftgeiézt. Seit

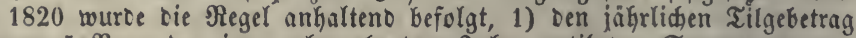
um 5 ßroc. Der im vorkergefenden Jahre getilgten Summe zu ver= mefren, twas feit ter Erniebrigung Des Sinsfubes fogar mefr ausinadyt als bie erivarten Sinfen; 2) für jebe Bermefirung ber Sduld fogleidh jäfrlid) $1 / 2$ \$roc. ihres Betrages zur Tilgumy anzumeifen. Rlle älteren und neueren Sdulotheile werben jebod zufammengeworfen. Die Til: 
gung betrug bemnady 1845: 478695 fi., 1847: 528739 ff., 1851: 641244 ff. bei einem reinen Sduldenftano von $13 \cdot 384800$ fi. Im Jahye 1852 wurbe eine langfamere Tilgung eingeführt, es find nåmlich 1) 500000 fi. als fefter jäfrlidber Tilgebetrag angenommen, 2) von

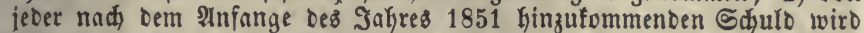
jährlid) $1 / 2$ ßroc. nls veränberliđer Tilgebetrag hinzugefügt, 3) Diélem mandelbaren Beftandtheile werden jebesmal 5 \$roc. Feines vorjärigen Betrage beigefdlagen. Die Tilgefumme war bemnach für 1858: 581329 f. 2 . für 1865 :

500000 f. fefter $\mathfrak{B}$ etrag,

119003 " wanbelbarer $B$ etrag für 1864,

5950 " 5 Proc. Suid)lag,

124 " $1 / 2$ \$roc. von 24951 f. neuell Sdulden $625077 \mathrm{fl}$.

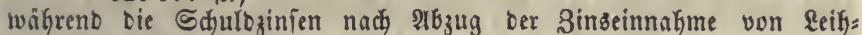
forterungen fid nur auf 515615 fi. belaufen. Fitr bie (Sifenbahniduto wirb im शnfange nud $1 / 2$ ßroc. jeber Inleike ausgejest, Donn aber jährlich 6 ßroc. Der vorjifirigen Tilgung beigerïgt. İm Iafre 1862 war tie Tilgung 626972 fl. = 1,064 \$roc. Des reinen Sd)uldenftandes

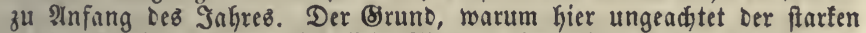
netten Inleifen eine aniefnlide Tilgung fortgeiest wirt, liegt in ber Sutweifung reichlicher Mittel für bie befondere rilgecafie der Eifenbahnen,

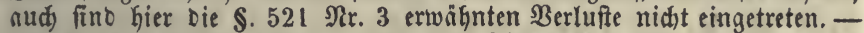
In Bayern twurde $1831-1837$ ber Tilgebetrag auf $1 / 2$ ßroc. Der ङdyulo gefegt, weldje 878000 fi. ausmadite; fpàter $2 / 3$ \$roc.

\section{§. 523.}

Weldyer Theil ber ganzen Sduuld bei ber Entwerfung einez

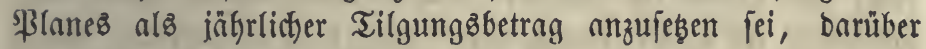
fann feine allgemeine Regel aufgeftellt werben $(a)$, vielmebr hat man fith nach ber Steuerfähigfeit ber Bürger uno bem jebesmmaligen Bebarfe für bie anberen Stantşausgaben zu rid $=$ ten. In vielen Stanten hat man neuerlich bas Tilgegefdäft mit Summen von $1 / 2-1$ ßroc. Der Sduld angefangen. Je weiter jebod) Die Tilgung mit Şülfe ber 3inseriparung fort= fdyeitet, ein befto gröperer Theil ber nod) übrigen ऽduld wirb jährlich abgezalylt, uno felbft ofne Benubung Der erübrigten

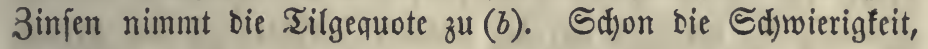
Die es̊ ben (Släubigern verurfacht, jährlid) große Summen unterzubringen, giebt einen Beweggrund, bie Fortfdreitung in ben jäbrlidjen 2lbzallungen allmälig langfamer zu madjen ober ganz zu hemmen.

(a) У. (5) onner a. a. D. S. 67 glaubt, man brautde nidht über 1 ßroc. jägrtid) zu vernenden uno es fönnte aud fidon $1 / 2$ \$roc. hinreidend fein. Breuß̧. Beję̧ y. 21. Jan. 1810: I Proc. jăhrlid.

(b) $2 B e n n$ bei ben fpater neu Ginzutommenten Sdulben nur bie an= fängliche Duote zur Tilgung angewiefen wird, fo entifeht hieraus eine

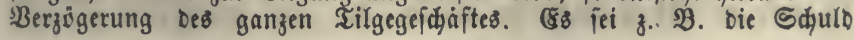




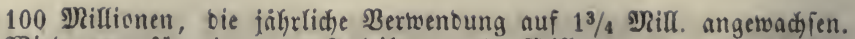
Birb nun für eine netle Inleife von 20 Dlifl. nur ber etwa im $\mathfrak{x} n=$ fange ber Tilgung angetwenbete Betrag von 1 \$rec. hinzugefügt, io ift bie ganze Salurestilgung 1.950000 uno beträgt mur nod) 1,625 ßroc.

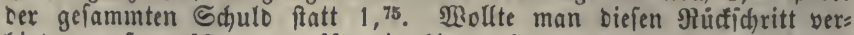
hinbern, fo múste man für bie finzugefommenen 20 g)ifl. ebenfalls $13 / 4$ Broc. oder 350000 f., D. h. im SAnzen $2 \cdot 100000$ f. beftimmen.

\section{§. 524 .}

Die Tilgung ber Sduld geffieht entweber burd) Sceim=

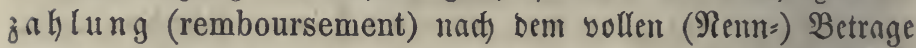
oder burd) (sinfauf ber Sduldurfunden nad) ihrem $\mathfrak{B}$ ör fenpreife ( $\Re$ uffauf, rachat). Dieje beiben Arten ber Tilgung fint forwohl bei ben verzinzlidjen Sa)ulofdeinen, alz bei bem Stantzpapiergelde befonberz zu betradten.

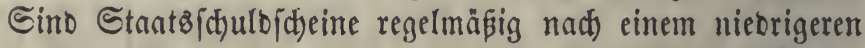
Eurie auşgegeben worden, fo erjuteint ber Darleiher als Säufer

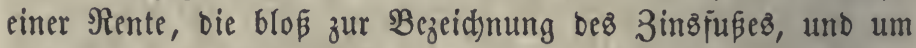

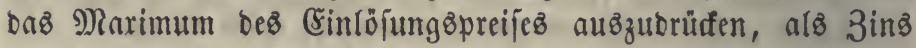

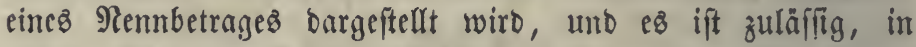

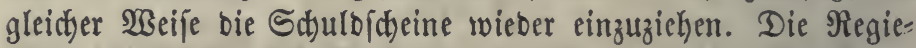
rung hat gegen bie Inhaber folder Dbligationen feine $\mathfrak{B}_{\mathrm{er}}=$ pflictutth zur Şeimzahlung, wenn über Diefe im $\mathfrak{B e r t r a g e ~ n i c h t s ~}$ feftgejeşt worben ift $(a)$. Bei biefem Rüdfaufe muß man mit oer 3unahme bes alfgemeinen 2 sohlfítandes uno bes Staats= crebites nad) und nad) böhere ßreife bezahlen (b), woburd) bie

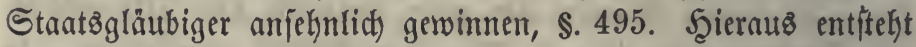
eine Vergögerung uno Erifhwerung bez Tilgent, uno wenn bie Dbligationen in häufigem $\mathfrak{B e r f e h r e ~ f i n d , ~ f o ~ w e r b e n ~ b i e ~}$ Sewinnfte aแts bem fteigenden (Eurje nid)t einmal burd)gängig benen zu Theil, weldye zur 3eit, als bie 21nleiken gemad)t wurben, bie $\mathfrak{W a g n i}_{\beta}$ auf fid) nafmen. 2luein bie Befeftigung Dez Crebites ift eine fo günftige (Erfd)einung uno jeigt fids) namentlich in ber (Erleid)terung neuer Inleiłen und ber 3inz= herabjesung fo vortheilfaft, Daß eв nicht rathjam fein fann, bemr Steigen ber Curje entgegenzumirfen. Dod) follten biefe

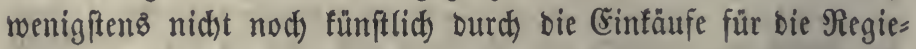
rung in bie Şöke getrieben werben, wephalb eв bienlid) ift, bie zuแ Rüdfauf beftimmte Summe gleid)mäßig unter bie ver= fdiebenen $\mathfrak{B o ̈ r}$ entage zu vertheilen und offentlid) befannt zu 
madyen. Şat eine 2 rt von Schuldoideinen bas ßari über= ftiegen, fo hört ber Rủffauf atf und ę bleibt, went man nidjt bie Tilgung berfelben ganz einftellen will, mur bie Sceim=

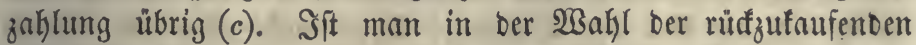
Sd)ulbbriefe ungebunden, fo verbienen für ben 2 ugenbliaf bies

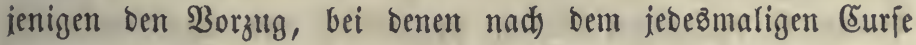

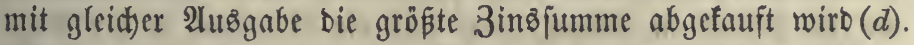
Bollte man aber nur eine 21 rt yon Edjulbjdeinen cinlöjen, fo witrbe biefe bald im ßreife fteigen uno ber 2 nfauf foftbarer werben, weßßjalb eine gleidjmäsige Tilgung ber veridbiebenen

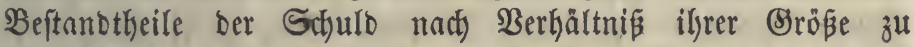
empfeklen ift, wofern nidjt bejondere Ulmftände ein anderes Berfahren rathjam madjen, vgl. (c).

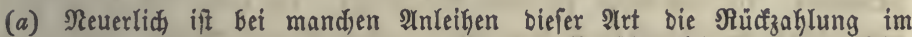
bollen Nennbetrage zugefichert worben, z. $\mathfrak{B}$. D̈fterreid. Nationalanleife yon 1854.

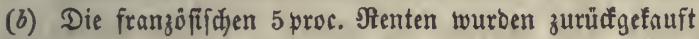

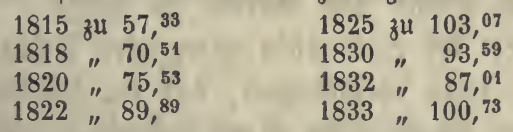

tie 3proc. 1832 im 4. Quartal zu 67,91, - 1839 im 4. Dutartal zu $81,45,1845$ im 4. Quartal zu 82,48 fr.

(c) In Franfreid mutroe 1831 auf $\mathfrak{L} a$ fitte' \& Antrag geféglidy verorbnet,

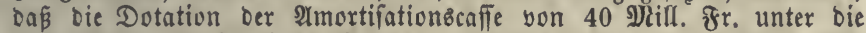
Saupttheile ber fundirten Sd)uld, nämlid $5,4^{1 / 2}$ und 3 Proc. nach

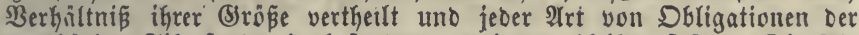
zugehörige Tilgefonos insbefontere gewibmet bleiben folle. (Die $216=$ fidht \& a fitte's war, Gieburd) bie Berivenoung Dez Tilgeftammez zu

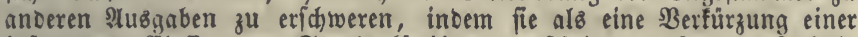
befonderen (Elaffe yon Staatsgläubigern erfogeinen wurbe.) Sobald eine (Slaffe von Sdjuldbriefen über \$ari fam, fo wurbe fie midht megr zuruifigefauft und ber ihr beftimmte Theil ber Coinfünfte einftweilen anberweitig angelegt (anfänglich in bons du trésor, feit bem Beféb $\mathfrak{y}$.

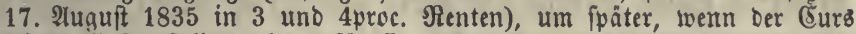
wieber finfen follte, wieber für fie ausgegeben zul werben. WBürbe eine (Elafie gamz getilgt, fo fiele ber zugehörige Theil bes Tilgevermögetls ber Stantżafie zu. Die fo yefammelte 2 mortifationsreferve (in bem $\$ .520(d)$ aufgefüfrten (区infommen von 75.400000 Fr. begriffen) war 1848 auf 15.294420 fr. Fenten in 4 ßrve. und 34.847808 Fr. in 3 \$roc. angewadifen, twurbe aber burd Sejes y. 20. uno 27. Nov. unb 4. December 1849 bis auf 3.701141 Fr. in 3 procentigen Renten annullirt, nadjoem fie fidon melgrere Sahgre andertweitig verwendet worben war.

(d) Stehen 3. B. Die 3 proc. zu 70 , bie 4 proc. zu 88 , fo if es für ben शlugenblid miblidłer, biefe zu faufen, tweil bann eine Summe yon

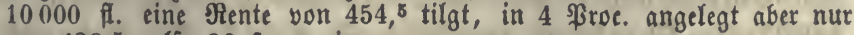
von 428,5 , alfo 26 fि. weniger. 
§. 525 .

Sinto Anfeiken mit bem $\mathfrak{B e r p p r e d y e n ~ b e r ~ S ू e i m z a h l u n g ~ i n n e r = ~}$ halb einer beftimmten 3eit abgefdloffen worben, fo ift feine Wabl in ber art ber Tilgung. 2lber aud ofne ein foldjeg

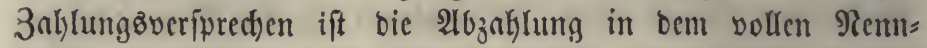

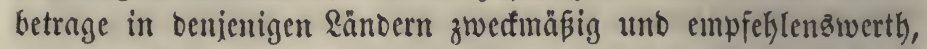
wo fe bisher in Ulebung war und bie 2utleiken in ber Regel nictst um einen nicorigeren ßreis abgegeben wurben, wo oaber aud) zufolge biefes $\mathfrak{B e r f a b e n s}$ ber (Erebit fid) nuf einem hoten Stanbe erhalten hat. Selbft bann, wenn man in cinjeliten

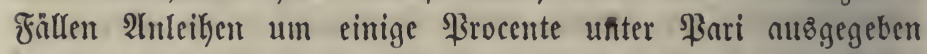
hätte, wäre es nidht rathjam, yon jener llebung abjugeljen.

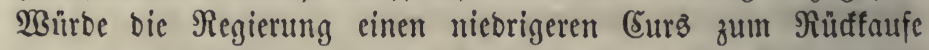

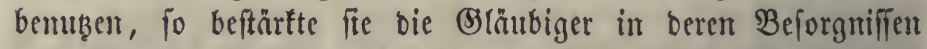
uno hätte bei fünftigen 2Inleiken ungünftigere $\mathfrak{B} e$ bingungen zu gerwärtigen, tilgt fie aber nact) Dem Rennbetrage, fo bringt fie einen hoken Stano bes Curfez zu $\mathfrak{B}$ ege. Diejes Berkalten verbient baker bei einer nidjt übergroßien Schulbenlaft ben Bor=

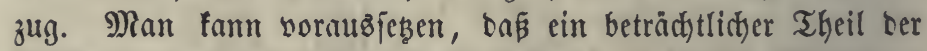
Dbligationen fith in fefter Şand befindet, z. $\mathfrak{B}$. bei Etiftungen uno Corporationen, fo baj bie uriprünglicten (s)läubiger ober ifre Erben vor bem $\mathfrak{B e r l u}$ ite gerwakrt geblieben find, ben ifnen Der $\mathfrak{B e r f a u f}$ um einen geringeren ßreiz zufügen würbe.

\section{§. 526.}

Das Stjulbenwejen eines Stnates funn, wie mefrere Bei= ipiele zeigen, ourd) unglürlidbe $\mathfrak{B e r h a ̈ l t m i f j e ~ o b e r ~ f e h l e r h a f t e z ~}$ Berfahren ober beibe Uriacten in eine \&age gerathen, bie Das Betreten biejes $\mathfrak{W e g e z s ~ ( \$ . ~ 5 2 5 ) ~ u n m o ̈ g l i d ) ~ m a c h t , ~ w e n n ~ n a ̈ แ n = ~}$ lid) Der Surs fo meit herabgegangen unb bie Sdulbenmafie jo groß ift, Daß́ man bas zur vollen Şeimzallung exforberliche Dpfer nicht zu bringen vermag. Diejes wirb audh unter foldhen Umitünoen nidst einmal von ber Berectitigfeit geforbert, wenn ber niebrige Curb fo lange angehalten hat, baß muthuaplict) Die meiften Sifulbicheine an andere Eigenthümer gelangt finb uno mehrere Beftzer nad) einanber cinen Theil besz aus ber Curseerniebrigung entftendenen $\mathfrak{B e r l u f t e z ~ g e t r a g e n ~ h a b e n , ~ b e f f e n ~}$

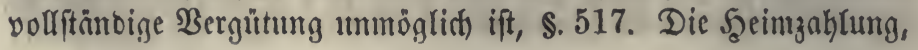




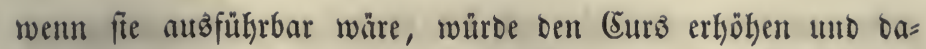

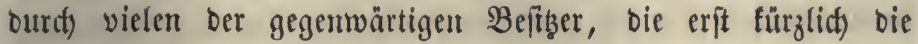
Scheine niebrig erfauft haben, einen unverhofften und unver=

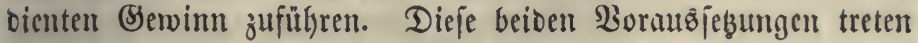
im ftärften Manße Dam eir, wenn fogar die Zinģzablungen eine 3eit lang unterbrod)en wares. Der fünftige (5urs Der Sduulobriefe hảngt in einem foldhen falle von Dem $\mathfrak{B e r h a l t e n}$ ab, veld)ez man in Şinftedt auf daz Wieberanfangen der 3inzz= zablungen eingeidylagen hat. (Ez thut Danu vor Aflem Roth, zu Forgen, Daß für bie Zutunft die Staatżgläubiger vor ähn= lichen $\mathfrak{B}$ efdübigungen bewahrt werben und es ift in foldyen Fällen baz $\$ .517$ angegebene Umwed)feln Der alten in neue Sd)ulbjheine um einen ben gegenwärtigen Curs etwns liber=

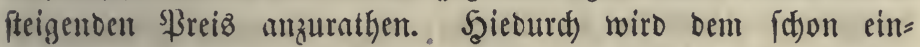

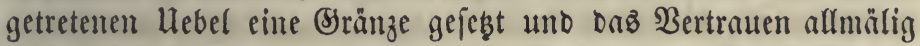
wieber hergeftellt, woferne unur bie 3inz̧zablung umunterbrodben fortonuert.

\section{§. 527.}

Bei ber Şeimzahlung ift nod) zu unterfutben, nad) veldyer

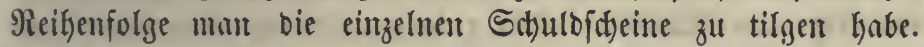
1) Sft ber Zinŝfü berfelben ungleid), fo mad)t man mit benten Den Infang, weldye die hödjiten Zinfen trager, u. f. f., ęి wäre benn, Dap recttlid)e oder politifcte Sründe $e$ nöthig madyten, einzelne böher verzinğlidbe Schuldpoften lïnger ftehen zu Infien. 2) Unter ben Edtuldidjeinen, weldye gleidsen Zinż= fuß Gaben, fann Der Borzug ber früberen Tilgung beftimmt werben a) Duraf bie Alumelbung einzelner (Bläubiger, bie vor Dell übrigen heimgezablt zu werben wïnf(den; b) fodann, wemt man mebr Tilgungsmittel hat, als bie Anmeloungen betragen,

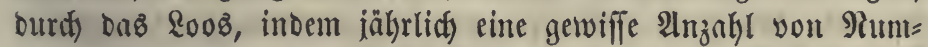
mern gezogen uno ben Beftiern ber entipredtenden Schuldobriefe aufgegeben wirb, bie Zahlung nach einer gewiffen Zeit, 3. $\mathfrak{B}$. nad) Drei M) Jonnten, in (Empfang zu nehmen; c) nad) Dem Alter Der Dbligationen, wobei aber unter benen, bie gleidyez Datum haber, wieber bas soos enticteiden mus. Der Stußen biefes Berfafyens befteht hauptfädylid) sarin, baß nidht, wie bei ber alfgemeinen Berlovjung b) ftets alle Etocfabefizer in Bejorgniß̄ 
gefeß̨t werben, vielleid)t an bie Reihe ber Şeimzahlung zu foument $(a)$.

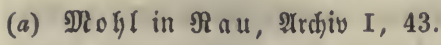

\section{\$. 528.}

Bei einem Staatzpapicrgelde, weldję zufolge ciner

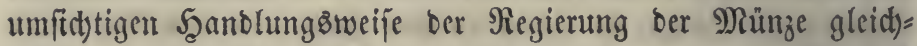
fteht, ift fein Bebürnis ber Tilgung vorhanben. Sift bas

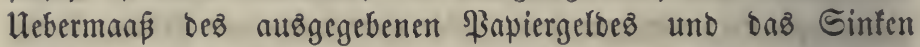
beffelben erft jeit furzer 3eit eingetreten und nod) nidjt weit gefommen, fo fann ofgne große Sdjwierigfeit ber \$reis bes \$apiergelbes in bas \$ari gebrad)t werben uno bies hat höd)ft vortheilhafte $\mathfrak{B}$ irfungen für ben gamzen $\mathfrak{B e r f e h r . ~ 2 l u d ) ~ b i e ~}$

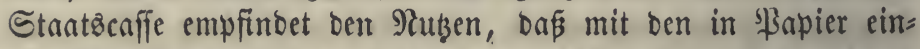
gehenben Staatzanggaben wieder mehr auzigeridjtet werben fann. 3ur Berminberung bez umlaufenden Staatżpapiergeldez bient

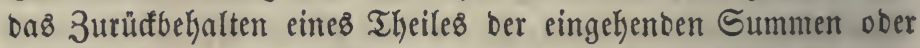

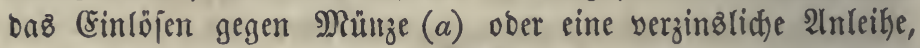
bei ber SHapiergeld für boll angenommen wirb. Bei einem ftarf gefunfenen \$apiergelo verbält es fith anberb. Wie groß inumerhin bie Radyttheile fein mögen, bie aus ber allmäligen

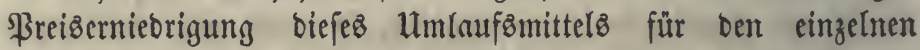
Stantsbürger uno bie ganze Bolfşwirtlyfd)aft einez sanbez ent= ftanden find (II, \$. 266. 267), fo ift bod) in biejem Falle eime Bergütung ber erlittenen $\mathfrak{B e r l u f t e ~ n o d ) ~ w e n i g e r ~ a l o ~ b e i ~ S t a a t s = ~}$

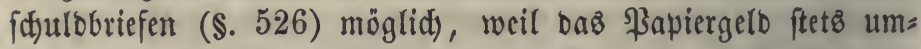
läuft uno gerabe bie Furd)t yor einem weiteren Sinfen zum bejøleunigten 2lusgeben anjpornt, II, \$. 268. Biele Familien mögen verarmut, mandje Unternefymungen zerftört worben fein,

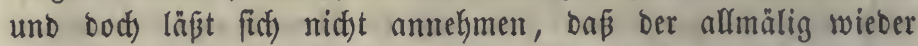
ferigente ßreis bes ßapiergeloes allen benjenigen ßerionen, weldje in Sdjaben gefommen finto, einen Errag geben werbe.

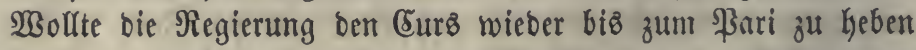
juchen, fo würbe bieß mur neute Berwirrungen im $\mathfrak{B}$ erfelgr ver=

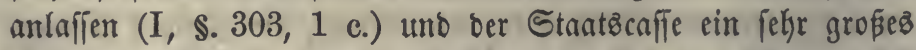
Dpfer auferlegen, währent ber hieraus entftehende Serwinn fid bod) bödjft zufällig vertheilte. (sine fortgefęte Berminterung

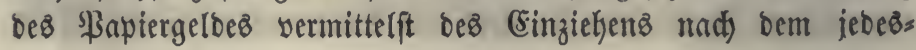


maligen Curfe ift folglich in biejem Falle nicht fo zmectmäpig,

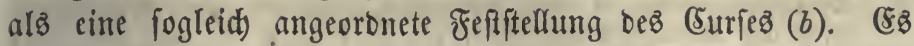
ift gut, fith hiezu eimes neuen \$napiergeldes zu bedienen, weld)es man mit allen Siräften im ßari zu balten fudt) unb gegen melches onz ältere Skapiergelo nach) bem feften Curje umgewed = felt wirb (c). Bleibt Daฮิ leģtere noch theilweife im Umlaufe, fo ift Dieß, ungeachtet bes befeftigten Preifes ber Miunze, Dod) wegen ber zwei neben einanber vorfommenden Selowährungen unbequem (d). Dogleid) nac) biefer Mapregel bie ganze um= laufende Selomenge gegen dab Bebürfnís von Ümlaufsmitteln nidft melyr zu groß ift, fo ift bod) eine Berminderung bes Sapiergeldes rathfam, um deffen (sinwectşlutg gegen Mänze auf $\mathfrak{B e r l a n g e n ~ j e b e s ~} \mathfrak{B}$ eftisers zu erleichtern, uno bas theils ins

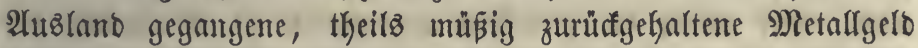
wieber in Unlauf zu bringen, aud) einem möglichen Sinfen Desె Curfes befto fidjerer zu begegnen. 3ొ Diefem 3wecfe bient

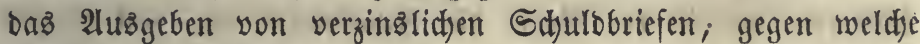
ein Theil bes \$apiergeldes eingezogen wirb, und hiemit follte

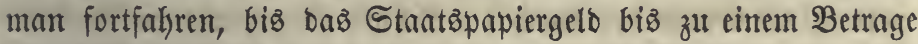
eingelöft ift, ber feine Beforgniffe mekr erwecten fann (e).

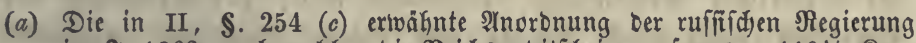

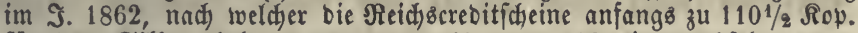
für ben Silberrubel, Dann zแl 1081/2 uno 106 eingetwechlelt werben

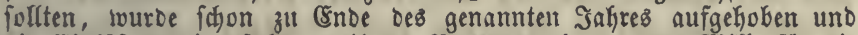

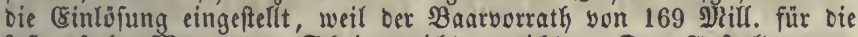

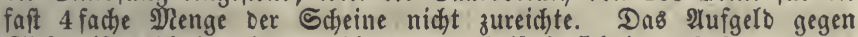
Silber ift beşGalb roieber geftiegen und beläuft fich jekt (Februnr 1865)

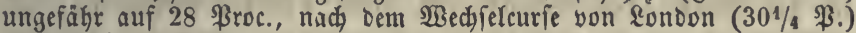

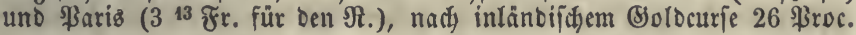

(b) v. Saf ob II, §. 909 ff., vgl. aud Forfell, Statiptif von Shweden ธ. 316.

(c) Beifpiel: Die Umwedblung Der Wiener Banfnoten gegen Einlöiungs: fdeine im Jafre 1811, trobei fene zu 20 Proc. ifres Renubetrages angenommen wurben, I, \$. 215. Diés Gatte jeood nicht ben erwar: teten \&ifolg, benn man vermodyte bas neue \$apiergelo (\&inlöfungs:= ideine) nidht in \$ari zu erfalten. (Pefnlid) in Ehina 1288 oas

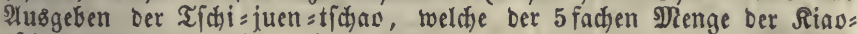
tichno von 1260 gleich galten; Natalis $R$ ondot in Journ. des Econ. a. a. D.) - Die neueren Napiregeln von 1816 nn gaben Den Befizern von Einlofungg̊f jeinen eine fo vortheilhafte Belegenheit, Diefelben an=

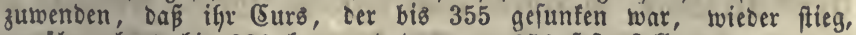
vorủbergeljend bis 220 fam unb bann zu 250 feftgeftellt rourbe.

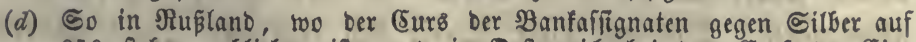
350 ftehen geblieben ift, und in Defterreich bei Dem Eurje Der (8in=

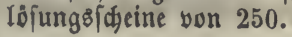


(e) In Defterreid) fonnte man getwiffe Summen von \$apiergelo uno älteren

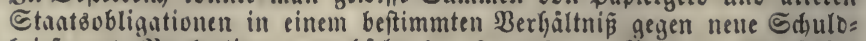

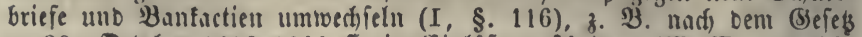

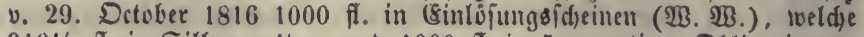
$310 \frac{1}{2}$ fl. in Silber galten, und 1000 fl. in 5 procentigen Dbligationen,

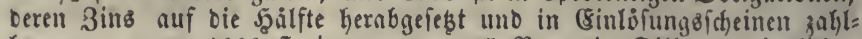
bar war, gegen 1000 fl. in neuen, zแt 5 ßroc. in Silber verzinslidjen Dobligationen, wobei alfo oie Stantoglaubiger fehr gerwamuer.

§. 529 .

UnI bie von ben Stantżffulden verurjadjte \&aft zu erfennen, ift es möthig, biejelbe in zwei Theile zu zerlegen, Die zu wers benter Inlegung verwentete Sd)uld (für Eifentonhnen, Domänen=

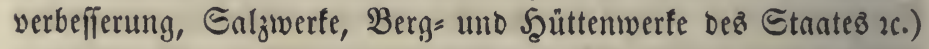
und biejenige, weldye, wenn audf zun Theil mefyr ober weniger productiv, Dod) aus Steuern berzinft unb abgetragen werben muß. Bei jebem biejer beiben Scaupttheile ift $e z$ zunñdhjt ber $\Re$ enubetrag, ben man in ben zur Finanzftatiftif geforenten Stantz: = uno SBribatiduriften angegeben finbet. Diejer zeigt in \&intern, wo in ber Regel bie Sd)ulbbriefe für voll (gegen \$ari) auszgegeben uno wo fie nud) in gleidyer Weife abgezaflt werbert, bie (Srößje ber burdf bie Sduld eingegangenen Berbind=

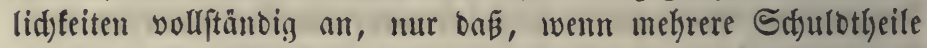
mit ungleicher Berzinfung vorfanben find, zur Senutniß ber Binjenlaft nuch biefe Theile mit ifrem Zinşufe angegeben

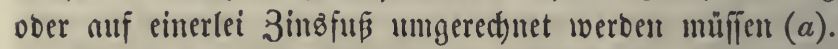

Sift bagegen bie Tilgung Durd) 2(ntauf nad) bem Tagez= preife üblid), fo geivährt ber Sennbetring feine gennue (Sinfid)t in bie Sröße ber Sduld, er giebt biefelbe höher an, alz fie wirflid) ift uno es fönnen onger für verictiedente 3wede nod) andere 3ahlen zu ફ̧ülfe genommen werben.

1) $\mathfrak{B e i}$ Anleiken unter bem Rennbetrage zeigt bie für bie Sduldobrieje empfangene Summe bent llmiang bes mit ben Anleiken beftrittenen 2hfwandes im Sanzen ober in jeinen eillzelten 3weigen, fie wirb aber gewöhnlid) nid)t zufammen= geftellt.

2) Werben alre Theile ber Sdyuld mady ifrem jebebimaligen

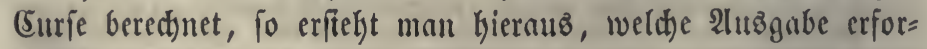
berlidy wäre, un bie ganze Sdululo in einem gewiffen Zeitpuncte abzutragen. Die auf bieje Weije fich ergebente 3ahl ändert

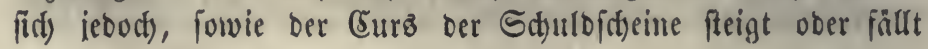




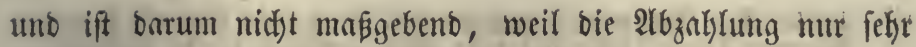
allmälig auşgeführt werben fann.

3) llın eine nicht fo wanbelbare Summe zu erbalten, als es nach 2) geidjieht, fann man ben bei fitferen 2lnleiken im

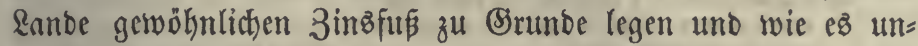
gefähr bei \$rivatichulden mit ber ifm entipredyenden 3ahl, 3. 3 . $25,22 \%$ oder 20 , Den $\mathfrak{B e l n u f}$ Der Sduldzinfen verbiel= fadjen, wobei man aljo bie $3,4,4{ }^{1} / 2$ procent. Sdulden nad)

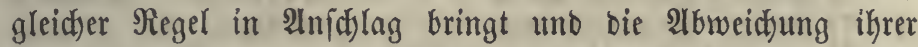

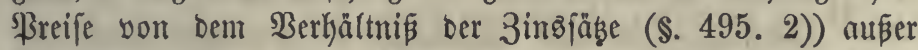
Bead)tung läßt. Şier Dürfte aber ber am böd)ften verzinżlidje Theil nidjt über bem Rennbetrage angejest werben $(b)$.

Die jur 3eit nod) nidyt berzinżlichen Theile (ausgeftellte Sdjulb) follten nidjt in bollem Betrage angejest werben, es feflt aber an einem 2(nhaltäpunct zur Umred)mung.

Die folgenden Siadjridjten find zur Beurtheilung ber Sdyul= Denlaft mur mebr ober weniger annäbernd braudbor. Bei mandyen Stanten ift bas Sdyuldenwefen fo verwidfelt, Daß fid faum eit beul 3wedfe bicjer 3 ufammenftellung entiprectender

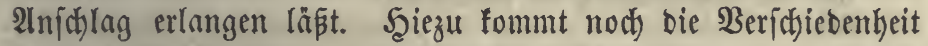
in Den Beldpreifen, indem 3 . $\mathfrak{B}$. gleicte Summe in Sroß $\beta=$ britanien weniger anbere (Süter anzeigt als in Defterreid) $(c)$.

(a) In Defterreich werben bie \$uften ber Staatsfdulb, bie einen niebrigeren

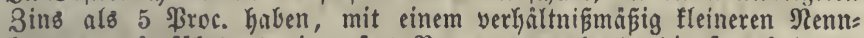
Betrage aufgeführt, $D$. i. auf 5 ßroc. umgereditet, bie fo erhaltenen Sablen fino aber böker als fie nach oer vben unter 2) angegebenen Beife heraugfommen.

(b) Beifpiel. Es feien in cinem Stante orei Theile ber Shuld mit Sinz yon 5, 4 und 3 ßroc. und einem gegenwärtigen Surfe von 83, 68

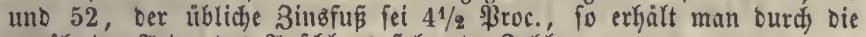

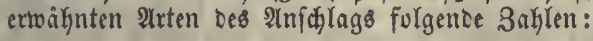

\begin{tabular}{|c|c|c|c|c|}
\hline Nemubetrag & & $\begin{array}{l}\text { nad) ber jifterretđ. } \\
\text { Beredmung }\end{array}$ & $\begin{array}{l}\text { nacid bemt } \\
\text { Eagescurfe }\end{array}$ & $\begin{array}{l}\text { nach Dem a } \|_{g e m} \\
\text { BinsfuBe }\end{array}$ \\
\hline 00000 zu & 5 ßroc. & 10.000000 & $8 \cdot 300000$ & 10.000000 \\
\hline 00000 & 4 & 12.000000 & $10 \cdot 2$ & 33333 \\
\hline 00000 & $31 / 2 "$ & $6 \cdot 300000$ & $4 \cdot 680000$ & $7 \cdot 000000$ \\
\hline 00000 & & $23 \cdot 180000$ & 16.666666 & 30.333333 \\
\hline
\end{tabular}

(c) Squloenfano einzerner Staaten.

Noro a merica. Unionsiduuld: 184215 शill. Doll., 1852 67,5 Mill., 186168,5 Dill., vor bem Rriege, wozu 254 MRill. Gduldon ber ein= zelnen Stanten famen, meiftens für (Eanảle uno Eifenbahnen. Die

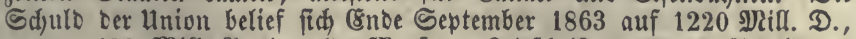

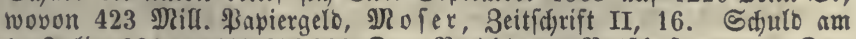
1. Juli 1864: 1740.690000 D., Beridt zur Botidgaft vom 6. Dec.

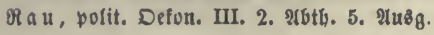


1864. Die Sübtaaten Gatten im Suli 18641544 शRill. D. Sdjulben. Gummen beiber Theile alfo 3284 शill. und nod tảglid wadfend.

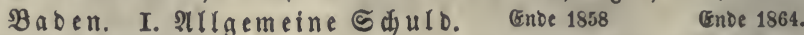

1) Eotterieanleiken ....... . 8.903021 f. 2.009028 fi.

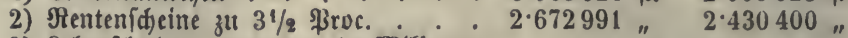

3) Regenfduldoen, worunter $1 / 2$ Ditl. un= anftunbbare Squld an ben ehemali= gen Reichopoftmeifter

4) (Eautionen

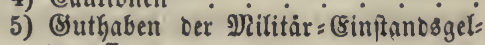
Dercaffe

6) (Sereslich finterlegte sseloer: :

7) Suidưffe zur Behntablofung .

8) Bur Berzinfung übernommene Bełnt: ablöjungsccavitale von \$farrifellen unb 3uichuife an $\mathfrak{P f a r r}=$ uno Sdul= Diente .

9) Befondere Sijulopofien, bei ienen zum Theil ber 3ins nicht Gerabgeregt werben fonnte (\$affiv:Capitalbuda).

10) Sontocorrentífulden (Domanial= und

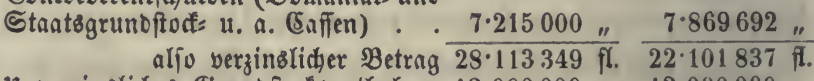
unvergingliçes Srunbftod Papiergelo . . . . . 3 3.000000" $3.000000 "$ Şievon geht Das ausftefende Bermogen

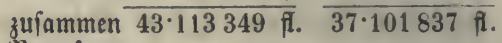
uno ber (Enfienvorrath ab (Activfand)

mit........... 9.016313 ก. 10.086207 f.

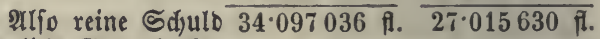
ober ofne bas unyerzinsłiche Erunoftods: guthaben uno bas \$apiergelo . . . 19.097036 fi. 12.015637 fi.

Die Tilgungsfumme von 1858 war 579039 fl. $=3$ झroc. श. 1865 625078 ff. oder 5 ßroc. oer 3infif̧ulo.

II. (8ifenbahnfd) I $43 \cdot 240224$ fl., Enbe $186268 \cdot 270507$ fl., 2lpril 186573.598000 fi. Bon 1843-62 find 5.732844 fi. abgetragen worben. Fur 1864 ‥ 65

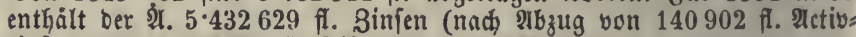
zimjen) uno 1.616692 fi. Tilgung $=2,1$ Sroc.

$\mathfrak{B}$ ayern. Die abtwedjelno geftiegene und Durch श्रbahlungen ver:

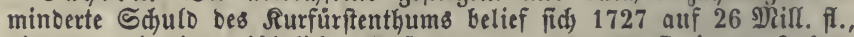
bie man mit einem fảgrlichen Antwanbe von 840000 fi. in 36 Jahren

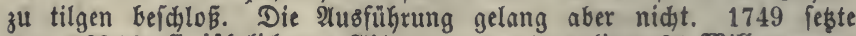

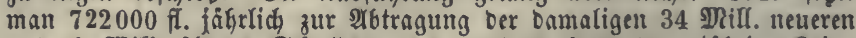
uno 6 פRill. álteren Stjulben aus, uno nadjoem ber 7 jäkrige Rrieg eine Berzögerung betwirft hatte, wurbe biв 1777 bie neuere Sduld auf 9 IRill. Gerabgebradit. 1780 war biefelbe auf 19 Dill. geftiegen, 1793 wieber auf 12 Mill. erniebrigt. Die Birfung ber Rriege war eine Srffohung bis 118 शूill. im Jahre 1811, worunter 19 פRill. 3ahlumgsrefte aus bem orbentlidien Staatsoienfte. 1818 beredinete

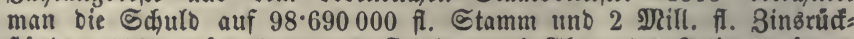
ftänbe, 1825 auf 110.337274 fi. voer nađ) 2 bug Des Pctivbermigens

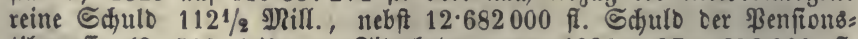
tilgecaffe (\$. 518 (d)). - Tilgebetrag yon 1831-37: 878000 fi. Material bei v. Daffinan, Befdidgtr. Ueberfidt unb Darfellung 


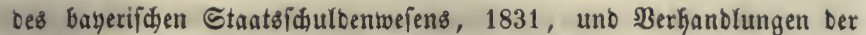
2. Rammer yon 1834 Beil. I, 183-280, II, 78-194. - 1835 war bie reine Schuld gegen 126 Mill., 1844 beinake 121 פill. fi., zu Ënde 1850 gegen 119 Mill., ofne bie Sdjuld Der ßenfions = uno Eifenbahnbau= Dotationseafie, zufammen gegen 140 Mill. Bergl. v. Neben, Finanz= Statiptif I, 142 f. - 2lm 1. Detober 1858: allgemeine ober "eigentliche" Ctaatzfdutulo 122.839495 fl., 88.643834 fi.

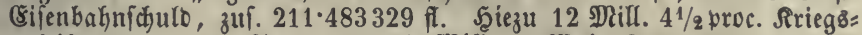
anleike von 1859; Summe 2231/2 Nill. - Nai 1862136.283375 fi. eigentliche Staatsichuld, 104.735 559 fl. Bifenbahnjकulo, zui. 241 Mill.,

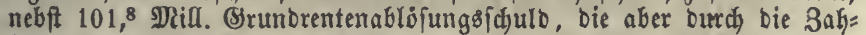
lungen ber \$flichtigen gebedt ift.

$\mathfrak{B}$ elg i en. Gduld 1862644.838000 Fr., - $1863637 \cdot 421414$ fr., 1wovon 241.724000 Fr. von lubernommenen Serbinblichfeiten gegen Das

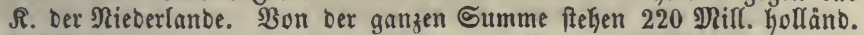
Sduld zu 21/2 \$roc., 261/3 \$Rill. zu 3 ßroc. Die Umredynung auf $41 / 2$ \$roc. giebt 529,4 Mill. Fr. (Annuaire de l'observat. 1863 ङ. 72).

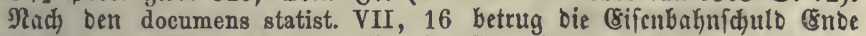

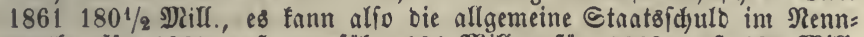
werthe für 1862 auf ungefähr 464 Mrill., für 1863 auf 460 Milf.

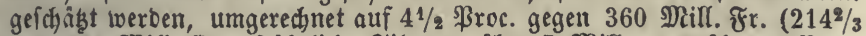
uno 168 Mill. ff.). Sẩhrliche Tilgung über 7 Mill. ooer über 1 \$roc.

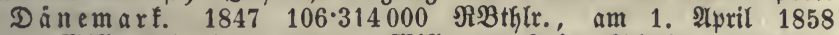
$71 \frac{1}{2}$ Dill. Thlr. innere, $43 \frac{1}{2}$ Nill. auswärtige Sdjuld, zujammen

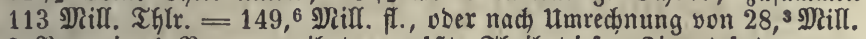
3 झroc. in 4 ßroc., weil ber gröpte Theil biefen 3ins trägt, gegen

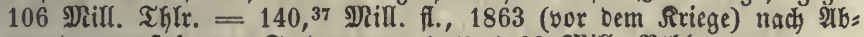
zug ber ausftehenoen forberungen (activa) 93 פlill. SBthlr.

Frantreid.

1) Confolioirte Saulo:

Infang 1859 भinfang 1865 auf $41 / 2$ ßroc.

8r. $\quad$ 8r.

Renten zu 41/2 Proc. $3842 \cdot 174866 \quad 872 \cdot 735000 \quad 872 \cdot 735000$

\begin{tabular}{|c|c|c|c|c|c|}
\hline " & & "" & $\begin{array}{r}54 \cdot 616700 \\
3689 \cdot 258366\end{array}$ & $\begin{array}{r}11.809000 \\
12266.932000\end{array}$ & $\begin{array}{r}10.497000 \\
8177 \cdot 955000\end{array}$ \\
\hline & & & 7586.049932 & $13151 \cdot 478000$ & $9061 \cdot 187000$ \\
\hline
\end{tabular}

2) 2ulcifen für Canåle $130.000000 \quad 28 \cdot 761000 \quad 28 \cdot 761000$

3) Eautionen . . . 250.000000 $283.333000 \quad 188.666000$

4) Obligat. trentenaires $\quad-\quad 45 \cdot 300000 \quad 30600000$

5) fdimebende Gdjulo $\quad 810.000000 \quad 600.000000 \quad 526.000000$

$8776.000000 \quad 14108.872000 \quad 9835 \cdot 216000$

ober fi. 6584 Mill. 4589,7 Mill.

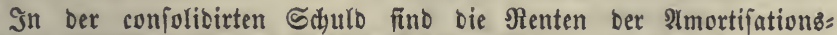
referve begriffen, weldhe jebod nicht zur Tilgung verwenbet werben,

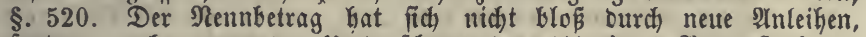
fonbern auch wegen Der umtauidung Der $4 \frac{1}{2}$ in 3 \$roc. ftarf ber=

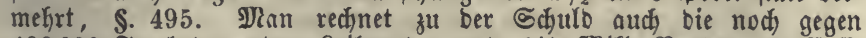
438000 Fr. betragenden Leibrenten uno $4 \frac{1}{2}$ \$Rifl. Senten Der Cañe für alte 2lrbeiter (II, $\$ .382(d)$ ), fermer bie ber Stratscafie aufgelegten Nuhegehalte uno die Dotationen (Civillifte, Senat, gejebgebenter Rörver,

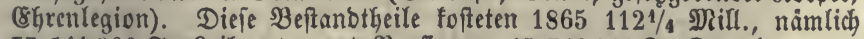
77.541000 Fr. \&eibrenten unb \$enfionen, 45.742000 Fr. Dotationen. -

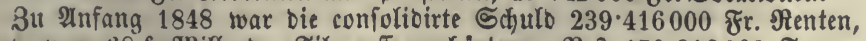

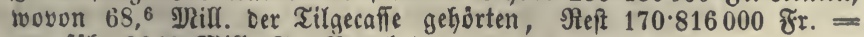

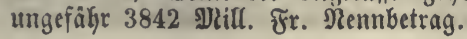


(B) rob̧ritanien. Stano am 31. Iläz 1861 nad Dem Nenn= betrage (C zornig, Das ifterreid). B̉ubget I, 72):

1) Fundirte Sdyuld, die irlänoijhe inbegriffen:

$21 / 2$ proc. nette 2tnmuitäten

$2.969061 \mathfrak{R}$.

$2^{3} / 4$ pruc. exchequer bonds

418300

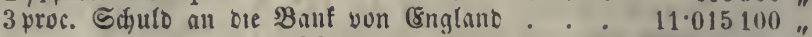

3 proc. consolidated annuities . . . . . . 406.624602 "

3 proc. reduced annuities . . . . . . 114.786809"

3 proc. neue annuities . . . . . . $246.001620 "$

$31 / 4$ troc. Sdjulo an bie irländifche $\mathfrak{B a n t}$. . . 2630709"

$31 / 2$ broc. neue annuities . . . . . . . 240746 "

5 proc. neue annuities . . . . . . . 432604 "

Beit= uno Reibrenten, 10 fad gerechnet 3ufammen 785.119550 2.

2) unfundirt:

exchequer bills. . . . . . . . . . 13223400"

exchequer bonds . . . . . . . 3600000"

Belauf 31. Därz 1863

Şaupt fumme $820.542950 \Omega$ \&.

funbirt . . . . . . . . . . . 783.306739 \&.

nicht funoirt . . . . . . . . . 164495400 "

zufammen $\overline{799.802139 \text { \&. }}$

Şier find aber 1.999261 \&. i. श्रusgabe für obige 3eit= uno \&eibrenten

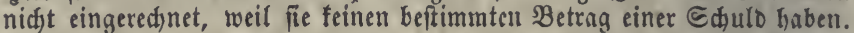
Werben fie 10 fad angefdlagen, fo exfilt man fü bie ganze Sdulo

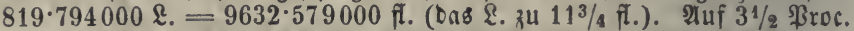

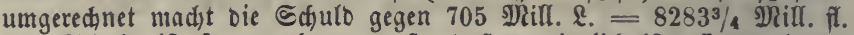

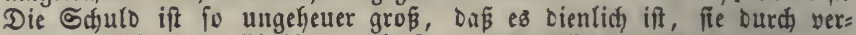

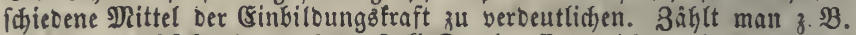
neue (Suldenftüfe (zu 1 bao. 3oll Durchmeffer) Didjt neben einander in einer Neifhe, fo nimmt obige Summe über 39000 geogr. Deeilen, voer $7 \frac{1}{3} \mathrm{mal}$ Den umfang ber Eroe ein. Echidtet man (sulbenftüfé zu einer Sñule auf (17 nuf I bab. 3oll), fo nimmt 1 Slifl. fl. 5852,35

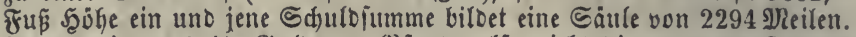
Jerner twiegen $47 \frac{1}{4}$ (S)ulden 1 \$fund, alio giebt Die genannte Summe ein (Semidht von 2,038 Mill. Centnern, die von 67900 \$ferben (3u 30 (Sentnern) allf 169754 fpảnuigen Bagen fortgebrad)t werben

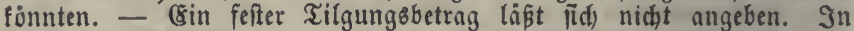

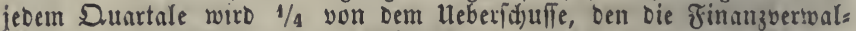
tung Der lebtverfluffenen vier Bierteljafre gegeben Gat, zum 2ubtrige verwendet. Es wurbe abgezahlt 1830-1839 im D. jüfrl. 1.379046 \&., $1840-1849$ jägrl. 1.141000 \&. In vielen Inthren ift aud nidgts getifgt worben.

Şannover. 1850

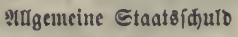

Eijenbabnidulo

1864

$18 \cdot 035200 \mathfrak{T h} \mathfrak{l}$.

$12 \cdot 332000$ Thltr.

$17 \cdot 450039$ 30.472235

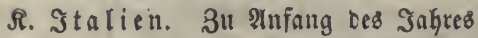

$\begin{array}{ll}1861 & 2106 \cdot 383000 \\ 1864 & 3767 \cdot 941000 \\ 1865 & 4145 \cdot 630000\end{array}$

Die Iez̧te 3ahl if $=1934 \frac{1}{3}$ Mill. fl., Die in ber Angabe für 1861

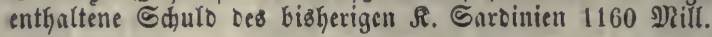

sieberlaube. Diefer Gtaat ift tief veridjuloet, fein Gdulben= wefen aber wegen Der vielen verwidelten शläregeln fdwer zu uber: 
Gliffen. Die Gdjuld entftand ourdy Die fdweren Rriege, welde bie

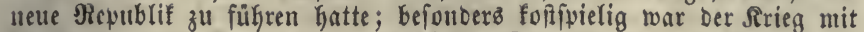
Englano unter (5romwell getweien. Den Stand ber Sdjulo im Sabre 1651 gibt man zu 140 Mill. fi. an, 1795 bei ber Errichtung oer

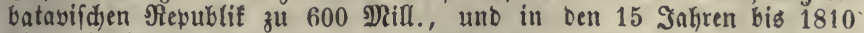
fiteg bie C(huld burd Die fhled)te Regierung bis nuf bab Dopbelte. Bon Lem ganzen Betrage von 1263 Nill. wurbe ber grópte Theil, $1240 \frac{1}{2}$ Mrill., unter Der franzöfichen Szerrichaft auf $1 / 3$ Kerabgeiest,

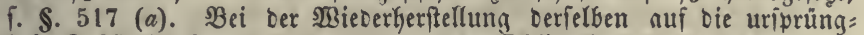
lidje Sröß̄e im Jabre 1814 murben neue Dbligationen ausgefertigt und

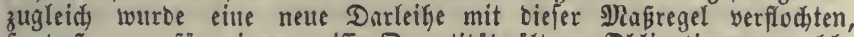

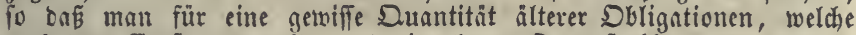
nach Dem (5urfe 676 galt, uno cine baare Daraufzaklung yon 100 fl. eine Snicription yon $2000 \mathrm{fl}$. Der zu $2 \frac{1}{2}$ \$ruc. verzinsticten ober "toirflichen" unb von 4000 fl. ber now nicht verzingliden ooer "ה "Bgefterlten" Sdulo exhielt. Durch biefe Mlapregel entítano

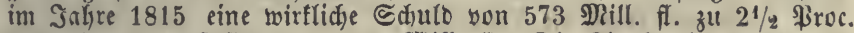

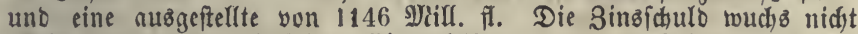
allein twegen ter allmåligen Coinverleibung ber aubzeftellten, fonbern

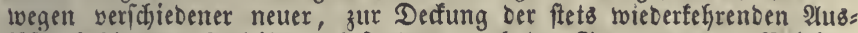
färle beftimmter Anleiken, befonders nnch Der Trenmung von Belgien, weil Die verzögerte Anerfenmung Diejes $\mathfrak{B}$ organges foftipielige Rriegż: rüfungen nad) fid) zog. 1822 Lurbe unter Dem Namen श mortiffe=

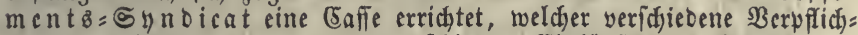
tungen auferlegt und bagegen verídjicbene Einfünfte und Sdjuldbriefe

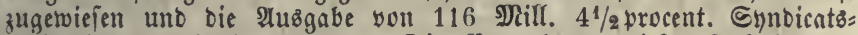
obligationen exlaubt wurben. Die Berwaltung biejer Inftalt war

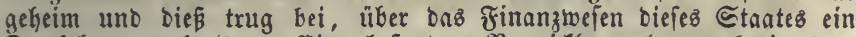
Dunfel zu verbreiten. Sine befonbere Berwidflung lag auch in Dem

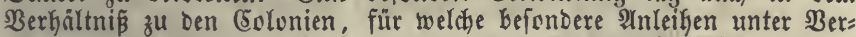
bürgung Des Stnates eingegangen murben. Ueber bie früheren Ber= Gältniffe f. Die Sdyriften yon Ditander: Sefdidytlidye Darftellung Der niederl. Finnmen feit 1813, Amfterb. 1829 (anonym). (Seichichtl. Darftellung Der niederl. Finanzen von 1830-32. Stuttgart 1834. Der Sduldenftano war:

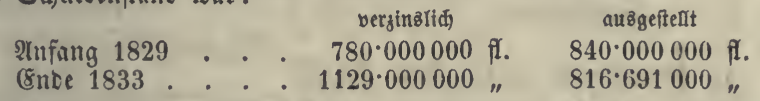

1841 twurbe die augigefteflte Schuld umgetwandelt, \$. 517. Die ganze Schulo zu शnfang Des Safres 1849 wurbe ohme die (Solonialidjuld amtlich auf $1230^{3} / 4$ Nitll. Nennbetrag mit $35^{2} / 3$ Nill. Sinz angegeben. Newerer Stand:

1859

zu $2 \frac{1}{2}$ \$roc.

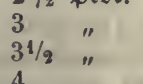

4 "

4

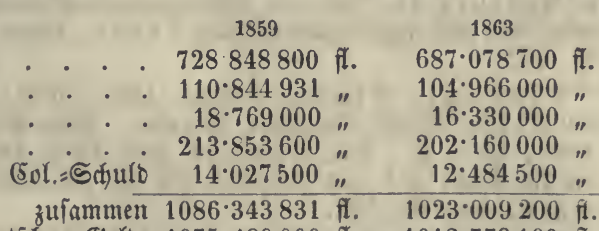

ober in fübdeutidem (Selde 1075.480000 fi. 1012.779100 fi.

Die 1023 Inifl. auf $4 \frac{1}{1} 2$ ßroc. zurücfgeführt geben $655 \cdot 184000$ fl. =

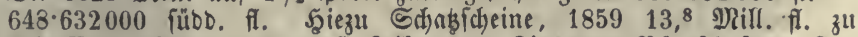

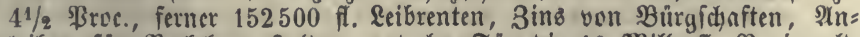

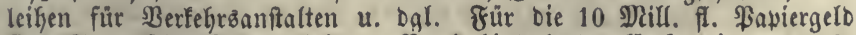

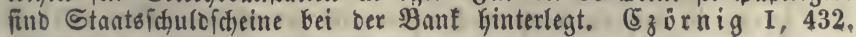
Block, Annuaire 1864 ङ. 420 . 
Defterreid. Es bezeichnet Den ůblen Suptand bes Etaatshaus: Galtes frükerer Seiten in biefem $\Re$ eidhe wie in mandhen anberen Staaten,

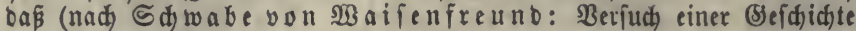
bes Diferreid. Stantserebit = und Schuldenwejens, 1. 5ूeft, 1860) zu

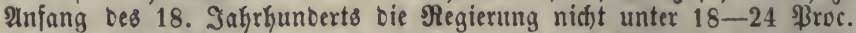
Sins borgen fonnte. Im Infre 1700 wurben 22 IRill. fl., oer gróste Theil ber Ctaatsidululo, unter bie Deutiden Erblande als ßrobincial: ifulo zur Tilgung in 12-15 Jafren vertheilt. - Berfdiebene neuere

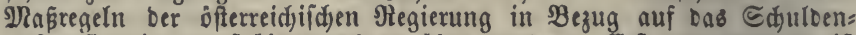
wefen fino in ben früheren $\$ \S$ erivägnt worben. Erft von 1845 an if bas Schuloenwefen genau befannt geworben. Nads ber amtliden In= gabe war im Detober 1848 bie Sdjuld

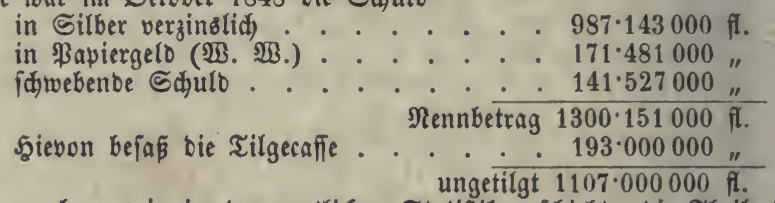

SBenn aber, wie in ber amtlidien Statiftif gefdiegt, bie Theile ber in Silber verzinften Sđulb alf 5 \$roc., ber in Wiener währung

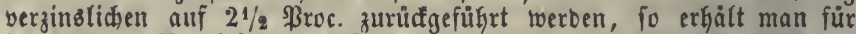
jene 877,6 , für biefe $150,{ }^{6}$ פDill. und mit ber fdwebenten Schulo zu= fammen $1169^{3} / 4$ פlifl. Die Dienge Der verfdiecenartigen allteren uno neueren sBeftanotheile madjt es fdjwer, einen Heberblif zu erfalten, ben exft bie neuen Darftellungen geben. Neuefte 21ngaben ber yom

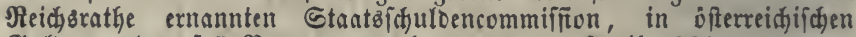
(3)ulben unb auf 5 Proc. umgerednet, am 30. 2april 1864:

I. Allgemeine ๔đuld

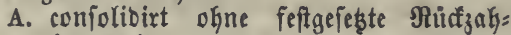

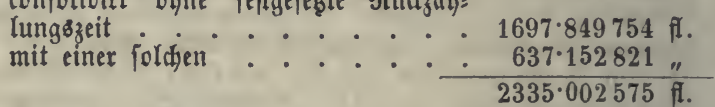

B. Squebende Squlo . . . . 158.866172"

C. Su Capital angefalagene Entichabi: gungsirenten . . . . . . . 15.227449" ชนโ์

II. Lombarbif Şauptfumme $2574 \cdot 924376$ ศิ. $=$ fübo. fi. $3004 \cdot 000000$

SRofer, 3eitfarift II, 73. शusführlide 2ingaben bis 1861 bei

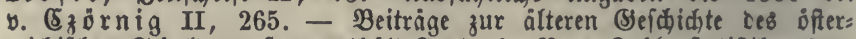

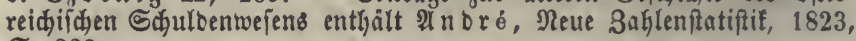
ธ. 223.

\$äplicher Staat, Mnfang 185866.471274 Scubi, wovon 62.387240 Scubi bauernbe Gdulb. Der (S) fammtbetrag if = $168 \%$ Dill. fl. Die Shuld ift zum Theil aus gropen Bahlungen an bie Sirche unb aus Dem Antwadfe Deb jährliden Deficitb entitanten. Horn, Ann. S. 235.

\$ortugal hatte lange ein zerrüttetes finanzwejen, ein jährlidues anjelunliches Deficit, ein im Surfe gefunfenes \$apiergelo. Die Sdulo wurbe 1845 im Nennbetrage auf 84132 Mill. Mil reis angegeben, welches (neuerbing 9000 M. r. auf bie foln. SRarf gered)net) 229 IDill. fí. giebt. Dem (Surfe naw ift bie Shuld weit fleiner, allein ifgr Nenn= betrag if feitbem aud nod anfehnlid gewadien. Seit 1851 if bas finanzwefen beffer geregelt, aber bod bie Drbnung nod nicht her: 
geftellt. Durch B. v. 2. Nov. 1840 twurte Die aus fünf Darleiken

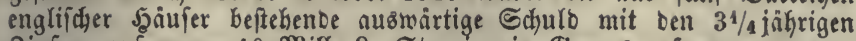
Sinfen, zufammen 10 Mill. $\mathfrak{L}$. Ct., in ein (Sanzes zufammengezogen, Deffen Sins vier Saljre lang $2 \frac{1}{2}$, Dann eben fo lange $3,4,5,6$ ßroc. Sins, enolich Dauernd 5 \$roc. tringen follte. (ङ8 famen aber fpáter wieber neue Anleifen hinzu. 1845 tourbe burw eine neue-2inleike ein Theil jener Sduld mit feigenben Sinjen in 4 Broc. umgetwanbelt.

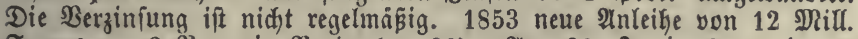
Francs zu 6 ßroc. in \$aris (zu 80). श्m 30. Juni 1857: innere Sđuld 49538,8 Mill. Mil reis, auşwärtige 50827,4 গnill., zufammen

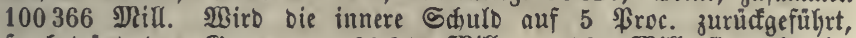
fo betraigt Das (Sanze nur 80675 श)ill. $=229$ NRill. fl., aber im Surie viel niebriger. Stand am 30. Juni 1863: Innere Schuld, 3 ßroc., 89.771 400 Mil r., auf 5 ßroc. umgerechnet 53.862150 M.r., äuBere $19 \cdot 353452$ \&. St., 1000 M. r. 孔u 55 ßence gerectinnet = 84.445397 M. r., zulammen $=174.217000$ ober nad obiger $\mathfrak{u m}=$

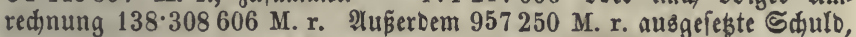
$2 \cdot 124800$ M. r. Sinsinưffitinbe. Sgautíumme $177 \cdot 299000$ ooer um: geredjnet $141 \cdot 390000$ M. r., aljo 504.216500 uno $402 \cdot 096300$ ff.

Breú̃en. Die Sthulo war

1797 bei ber Thronbefteigung Friebriđ Wilkelms III. 1806, Sđlü Des Jahres.

Die fdwierigen Berhâltnifie von $1806-19$ verur:

48.054903 ThIr. $53 \cdot 494913$ "

fadten einen 2lufwant von $287 \% / 3$ פRifl. Thlr., wovon 122 Dill. Durch) Bermebrung Der Schuls Den gebedt twurben. Siezu famen bie Sdulden ber neuerworbellen \&anbestheile, $67 \cdot 873000$ Thlr., wåkrend $4 \cdot 407000 \mathfrak{T}$ hlr. für bie 1807 abgetrete= nen lanbe abgeken. Go ergiebt fid folgenbe 3ahl:

1820 mit Sinredhung von $25 \cdot 914000$ Thlr. Pro=

vincialichulden . . . . . . . . . 217248761" 1843

$150 \cdot 103434 "$

In Dem Seitraum von $1820-43$ fino von ber Saaptwerivaltung oer Schulden 67.872083 Thlr., meiftens 4proc. Sdullopoften, getilgt wor= Den, in bett exiten 12 Jaḩren im D. um einen 2infaufapreis von $914 / 7$, in Den Kesten 10 Jahren zแ 95. (ङ\$ murben Giezu 38.610547 ThIr. Berfaufs = und Ablôfunģ่geloer von Domänen verwendet, Deren An= legung zur Shultenverminberung 1.663256 Thlr. Bins erfparte. Die gleichzeitige $26 n a k m e$ ber Domäneneinfünfte betrảgt nach genauer

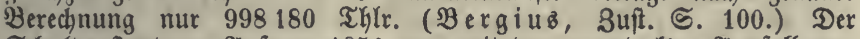
ธdjuldenitand zu Anfang 1851 war mit bem ungedectten 2ubfall von 34 MRill. Thlr., und 10 Mill. Thlr. Darlehn= Enifenidyeinen zujammen 238 Mill. Thlr. Neuere Nngnben:

$$
\text { Infang } 1859 \quad \text { Tnfang } 1864
$$

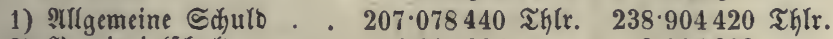

2) \$rovincialífuld . . . 4.931294"

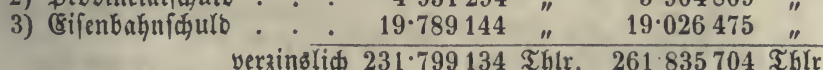

4) unverzinglich (Papiergeld) $15.842347 " 15842347 "$ zuammen $247 \cdot 641481$ Thlr. 277678051 Thlr.

Dhne die Bifenbahniduld 227.852347 " $258 \cdot 651596$ ober fübo. fI. $398 \cdot 741607 " 452.640258$

Die Tilgefumme $4 \cdot 617087 \mathfrak{I h l r}$. für 1864 ift 1,71 \$roc. Der verzinş;

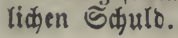




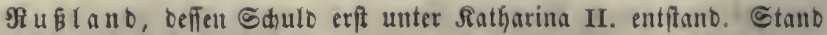
zแ ?tufang bes Saljees 1859 :

1) Terminfduloen, D. G. mit einer beftumten Frift für bie gânzlidge शrbzahlung

a. auswartige, in Şollano aufgenommene. $\quad \mathbf{4 5 \cdot 1 8 7 0 0 0 \text { f. }}$

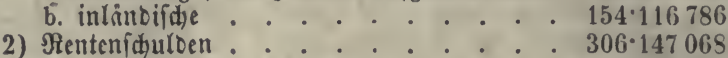

Eifenbahnichuld . . . . . . 4.620000 \&."

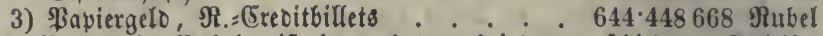

Der Betrag iu SRubeln ift je nad) Dem bei Den veridiedenen Anleiken

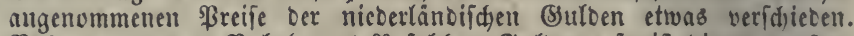

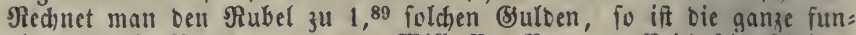

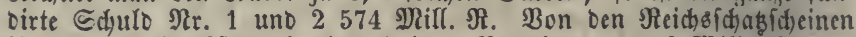

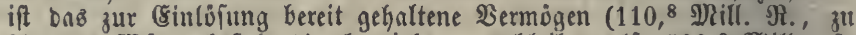

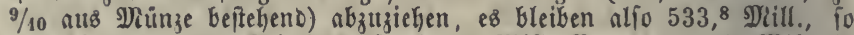

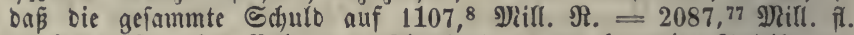
zu fesen ift, ofne \$olen und Fimulant. 1859 fam eine Fnleifye vou 12 \$ill. \&. St. $=73 \cdot 615000 \Re$. Kinzu. Bei Den meiften aแ8wär= tigen शnleiken ift 1 \$roc. jährlich zur Tilgung beftimmt, bei oer erften englifacn Anleike uon 18202 \$roc., bei ber erften 4 yroc. Inleike

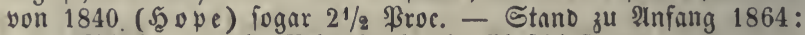

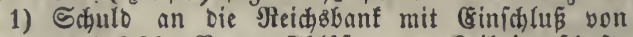

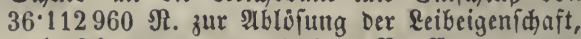
nad Abzug bon $11 \cdot 685296 \Re$. Contocorrent=

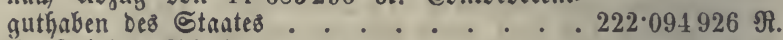

2) Gonfolibirte ङduld.:. . . . 645514505 "

3) Shakjidjeine, wovon gegen 30 शill. zur unter: ftibung ber Esíenbahugeiellidaft . . . 177.000000"

4) \$apiergelo ........... . . 636.525857" 子นโаmmen $1684 \cdot 135288 \Re$.

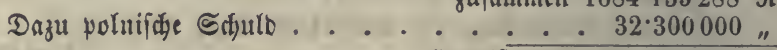
Saqutịumme $1716 \cdot 435288 \Re$. oder in füDD. Fl. $3234 \cdot 254196$

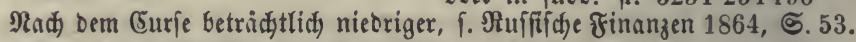

Sadfen, $1850 \quad 22.433000$ Thlr. Enbe $185860 \cdot 729555$ Thlr. $186156 \cdot 420500$ Thlr., $186360 \cdot 711600$ Thlr. nebft 7 Nill. ßapier= gelo (Eaffenbillet8) ober auf 4 ßroc. umgeredinet 65.080895 Thlr. = 113.891500 fi. Tilgung $1861-63$ jâhrlich 583144 Thlt. ober 1 ßroc.

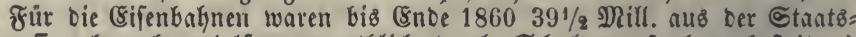
cafie abgegeben (alfo vermutblid) burch Sduloemaufuafyme befritten) worben, es waren Demnad $1861 \quad 16.900000$ Thlr. antere Sdulden borbancen; mit ben 7 Nill. Enffenbillets zufammen $23{ }^{9}$ Nill. = $41 \cdot 825000$ ff.

Sd) we ben, 2Anfang 1864:

innere ธăuld

Gievon geft ab bas Bermógen (activa) bes

Squibencomptoirs

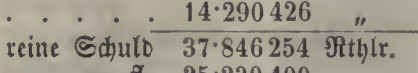

$$
\begin{aligned}
& =\text { fi. } 25 \cdot 230400
\end{aligned}
$$

Rorwegen, nach Abzug ber Activa 4.277000 Speciestflr., grósten: theils für Eifenbahnen, $=11 \cdot 328000$ fi.

Spanien gehort unter bie am tiefiten beriđuldeten Staaten. Şiezu trugen nidgt bloß̄ idwere Rriege feit bem Anfange ber franzififiden 


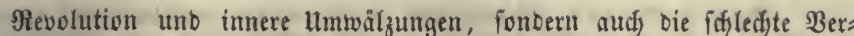

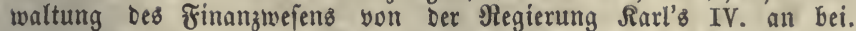
Beridjiebene Berjuche, Die Berivirung zu Yojen, hatten feinen Beftanb. Nad) $B$ orrego (Der Nationalreidthum ...... Des R. Spanien,

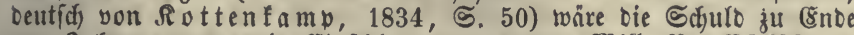

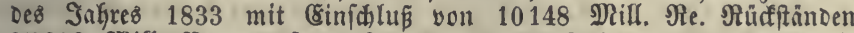

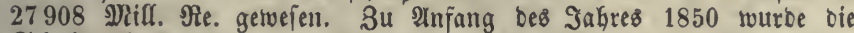

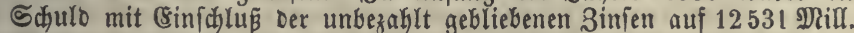

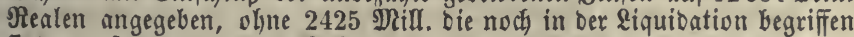

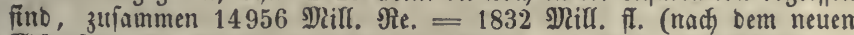
D) bes Schuldentwefens worbe 1851 beabfichtigt, aber wieber vereitelt burd

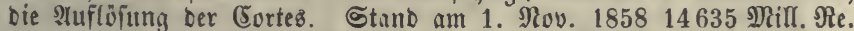
= 1792 פill. กl. Şiezu fam Die fdwebende Shuld mit 526 Mill. Bon obigem Betrage waren nur $10646^{3} / 4$ Mill. verzinslich, 4781,8 פRifl.

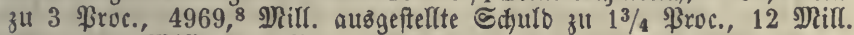
fu 5, 504 פill. fu 6 Sfroc. Der wakre Belauf ber in biefem gropen Rennbetrage enthaltenen $\mathbb{L} a f t$ if nidht leidgt anzugebell. Die Reouction auf 5 ßroc. läpt ungefägr 10000 MRill. $=1271$ sDill. fl. annehmen.

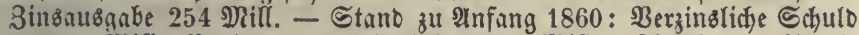

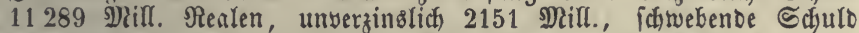

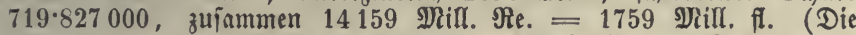
2ngabe von 15500 Nill. für December 1863 ideint 939 Nill. Dovpelt

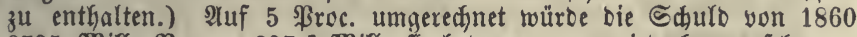

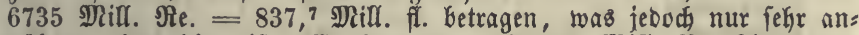

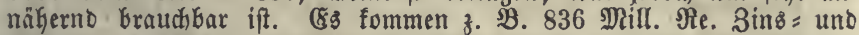

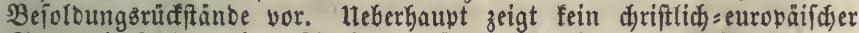
Staat bie Folgen einer åknlichen früheren 3errüttung oes CtaatBhaus: Galtes. 3ins im Jahre 1861319 Mill., Tilgung 71,7 शlifl. Die 3ahlen für 1860 bei v. (5zörnig I, 444 .

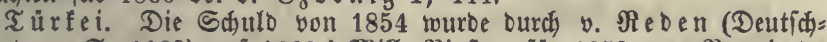
land 2c. (5. 1089) auf 1068,4 Dill. Biafter, für 1859 von \$ v uja be (bei Horn, Ann. S. 265) auf 545 झूill. Fr. berechnet. (8z gehören Dazu fowohr berzinslidbe als unverzinslidje (5affenfdjeine (Gefimb), ferner

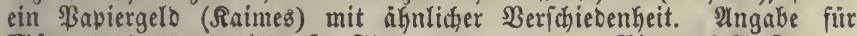

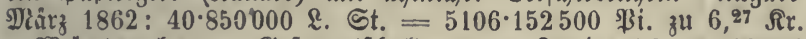

23 ürtemberg. Sefammtidulo am 30. Suni $185954 \cdot 792892$ fl., (aui $41 / 2$ \$roc.) zuritfigefükrt 50.221449 fi.), wozu in Der zroeiten

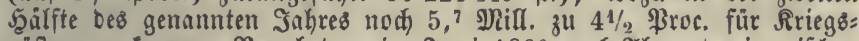
riffungen famell. Nennbetrag in Jumi 1860 nach शlbzttg Der inzwifhen gefdekenen 2 bzaklungen 63.426000 fi. Die Eifenbahnen fofteten bis 30. Juni 185937.833921 fi., woyon aber nur $31 \cdot 468860$ fr. Durch Anleifen aufgebrad)t wurben, bas uebrige nus ueberfdüffen. Da die

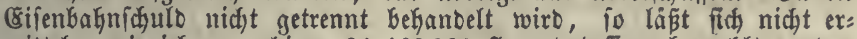
mitteln, twieviel von obigen 31.468860 fi. unterbefien abgezafilt worben fint, ber ungetilgte Theil wirb aber wohl nicht über $301 / 2$ Nill. nuts=

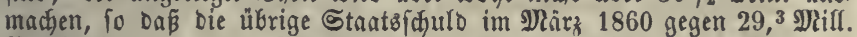
Nominalbetrag war. $\mathcal{B}$ on obigen 63.426000 idjeinen $31 \frac{1}{2}$ Nill. auf bie Eifenbaknen zu fommen. Bon Der Sdjulo am 1. Suli 1859 mit Einfchlué ber Eifenbahnichulo waren: 1) fünobar 47 Mill. fl., wovon 16.588400 fl. zu $31 / 2$ \$ioc., - 2) nicht fünobar 5.570120 fl., wovon 1.068000 fi. Militaireinftanosgeloer, 3.486200 fi. 3 proc. \$enfions= fonbs ; 3) \$apiergelo 3 शill,, zujanmen 55.572820 fl. Die Tilgung für $1859 / 60$ twar 592000 fl. $=1,12$ ßroc. Des verzinşliden Nenn= betrages. - Stand im झna 1864: 76.578542 f., woyon Gỏdftens

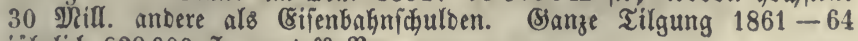
jährlich 829000 ก. $=1,08$ Proc. 
Nad) v. Reben (Deutid)land 2c. S. 1079) maditen 1857 in ganz Europa bie Stantछfduldon gegen 12854 Mill. Thlr. oder 48,23 Thlr. $=84,4$ fl. nuf Den Ropf, jeood mit Einfdlus Der Eifenbafniduloen. Fü Deutid)land außer Defterreich uno ßreußen berechnet berfelbe Berf. 463,5 glill. Thlr. ober 26,2 Thlr. $=46,5$ fi. auf Dell Siopf. Bei Lifatwe $=D$ berGaufer a. a. D. fino für ganz Europa 25703 Dilll. fi. im 20 Esuloenfupe uno 98 fi. auf Den Ropf gered)net. Slan fann

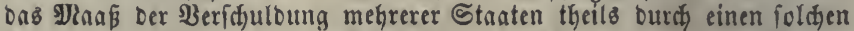

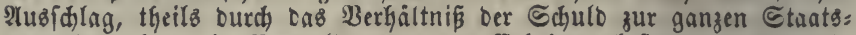
ausgabe (ohne bie Berivaltungs : uno Erhebungsfoften, §. 48 (c)),

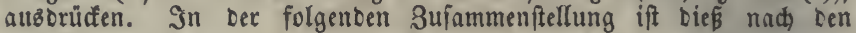

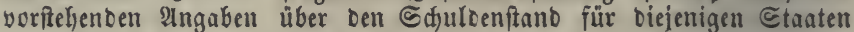
gefhehen, bei benen bie Gdjuld nady atbug bes auf Eirenbahnen wer: wenteten Theiles genau voer annahernd befannt ift. Die 3afjlen ber lebsten Swalte zeigen an, wie vielfach ber eigentlidye Stantzinufmand in ber Sdjulo enthalten ift ober vieviel Jahrebausgaben zur Tilgung ber Sdulto erforberlid) fein würben. Diefe if Giebei für 7 Staaten auf gleiden 3ingfü umgerechnet zu (Srunde gelegt worben.

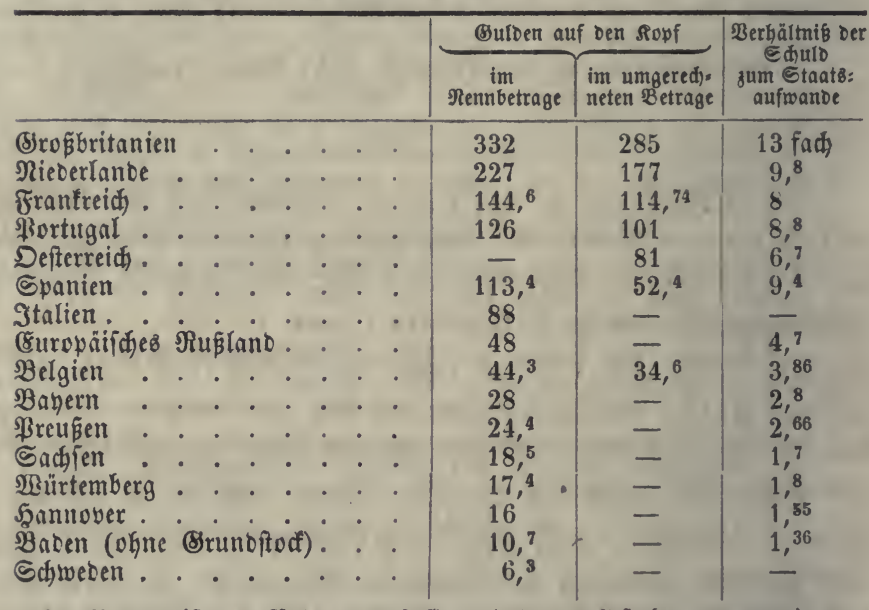

In Yaben ift ber Betrag 19,3 f. uno oas 2,45 fadje, wenn tie un:

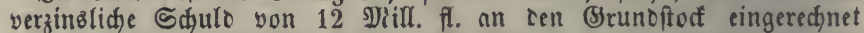
wiro. Dieie, freilid bei einigen Staaten nur auf einer ungefäbren Shäbung berthenben Bahlen forbern zu mandfaltigen $B$ etradtungen auf. Die ftarfere Berfuuloung trifit nicht ourdgangig mit hoberer Entwidflung uno WohlGabenbeit zufammen, fonbern rügt zum Theil von mangelhaftem Stantछbauzhalt her, zum Theile von fopbaren siriegen.

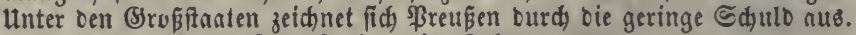
Breife yon Etaatsfdulofdeinen im Februar 1565:

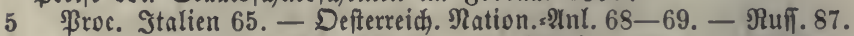
$4 \frac{1}{2}$ " Franfreid, Sđ)weden 92, - Belgien 100, - \$reüen, "Babern 102, - $\mathfrak{B u ̈ r t e m b e r g ~} 104$.

4 " weftoutiche Staaten gegen 100.

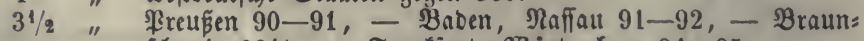
fajweig $93 \frac{1}{2}$, - Franfiurt, 3 urtemberg 94-95.

3 " Spanien $40-42,-$ Franfreid $67-68$. 


\section{3icrtes 33udh.}

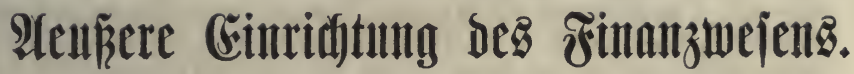

\section{I. $\mathfrak{A} \mathfrak{B}\{\mathfrak{d} \mathfrak{i t} \mathfrak{t} t$.}

Bebörden und Alemtex im Simamįefen.

\$. 530 .

Die 2 emtercinridftung im Staatshaubihalt (Finanzorga= nifation), b. h. bie 2 rt und $\mathfrak{B e i f e , ~ w i e ~ b i e ~ F i n a n z g e i d a n ̃ t e ~}$ unter veridjiebene Befbrben und Beamte vertheilt, wie bie Wirfungaffreife biejer Dienfffellen fowie bie Unterorbmung ber unteren unter bie hökeren und bie höd)fe feftgejeģt werben follen, ift viel weniger wiffenfd)aftlid unterjudyt worben, als bie in ben brei erften Büdjern bargeftellten Finanzgefdäfte $(a)$.

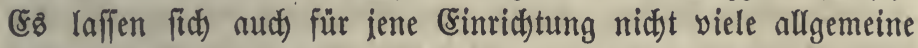
Regeln auffetlen, weil biejelbe grofentheils yon bem $\mathfrak{u} m$ mang

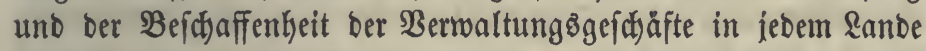
bebingt wirb, webhalb fie audi in ben eimzelnen Staaten fehr

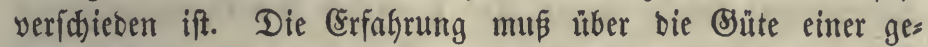
wiffen 2 noronung bes Finanzbienftez enticteiden, bod) ift bei Der 2 lbwägung ber $\mathfrak{B}$ orzüge ber einen ober anderen zu bebenfen,

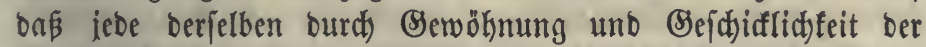
Beamten, uno in $\mathfrak{B e r b i n d u n g ~ m i t ~ b e n ~ u ̈ b r i g e n ~ B e r b a ̈ l t n i f f e n ~ i n ~}$ einem \&anbe fid müblid) erweijen fann. Sleidjwohl barf bie Betraditung über bie befte Drganifation ber Finamzerwaltung nidjt aus ber Finanzwiffenidjaft aubigejdloffen werben, uno es giebt ohne 3weifel aud) in biejem Bebiete fefte Brunbräze.

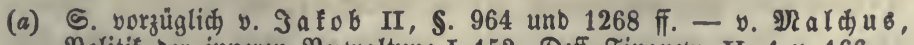
Bolitif Der inneren ßerwaltung I, 152. Deff. Finanziw. II, 1 u. 166. - 
D'A udiffret, Système financier de la France III, 1. 1854. -Iafob fapt (im 3. Budue feines 2 Berfes) unter ber Benennung Finanzverwaltung viele Regeln zulammen, welde ben Bollzug allgemeiner (S)runbfäbe betreffen; er fommt baher, auber ber Lefire von

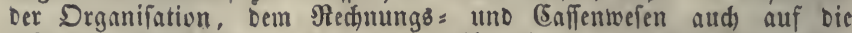
befonoeren Beichifte Der 2luggaben=, Einnahmen= uno Sd)uldenverwal= tung zurủcf. Diefe Trennung ber \$rincipien uno Der Bolfzugsregeln bei einem unb Demielben Begenftante, z. B. Der Domänenverwaltung, ift für tie gute 2uffaflung Des 3ufammengehorenden nidht vortheil=

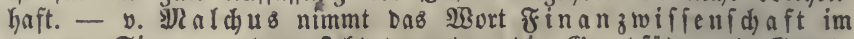
engeren Sinne, und verifejt Darunter "bie (S)rundiäze uno (S)rund: regeln, nad) weldyen Das Staatseinfoummen auf eine fold)e Irrt centrali= firt werben fann, weldhe bie Stantzangehorigen in ber SBerfolgung und

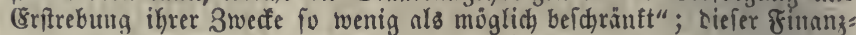
uniffenidaft wirb als praftifder Theil bie Finanzuerwaltung lehre entgegengefebt, weldje bon Der Pnoromung Des Finangaushaltes im stllgemeinen, vou Dem Staatzaufwande, von Dem (5tats:, Eaffen=

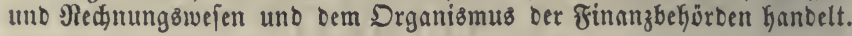

§. 531.

Die Finnangef äfte müffen ebenfo wie die Berridtumgen

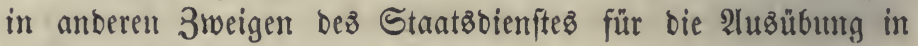
boppelter Scinfitbt vertheilt werben,

1) råumlidb, in Bezug auf größere uno fleinere 2lbfdunitte besి Staats̊gebietesิ uno zum Theile fogar nuj cinzelne Drte, 2) gegenftänolid), wegen ber in ber Natur ber (seidäfte liegenden $\mathfrak{B e r j}$ jiebenartigfeit, auf bie bas Bejeß̧ bet Arbeitştkeilung anmenobar ift, I, \$. 114.

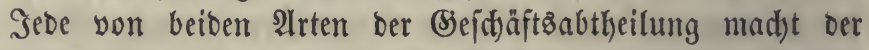
gleichförmigen \&eitung willen cine Ibftufung von unteren und höheren Diemftftellen nothwenbig. Für bieje $\mathfrak{B}$ erzmeigung gelten die allgemeinen, bie Srganifation ber Stantöamter betreffenden Regeln, von benen befonders folgenbe hervor= getoben zu werben verbienen: a) Man foll bie (Sefdäfte fo

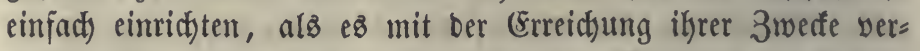
einbar ift, weil Daburd) nidjt blop ber Alufwand verringert, fonbern auch) Die Dberleitung erleidtert unb ben Stantzbürgern mandse Unbequemlidfeit eripart wiro. b) Der Wirfungsifreis eines jeocn Beamten folf nicht zu veridjicoenartige Berridjtungen

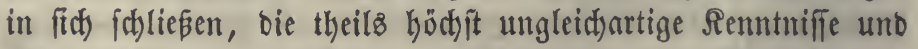

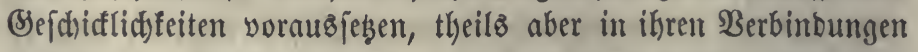
nad)theilige $\mathfrak{B e r}$ ögerungen uno Unterbredyungen veruriadben wủroen. c) (\$̇ muß zwar jebem Beamten cin gewiffer Spiel= raum eröfnet werben, immerbalb beffen er nad) eigener (Einftit 
hambeln barf, jeboch foll baburd) bie Berantwortlid)feit für jeoe

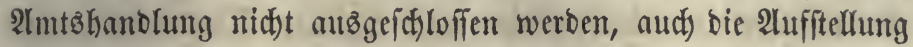
allgemeiner $\mathfrak{B o r j}$ driften und bie Fnfifung widhtiger $\mathfrak{B e j}$ hlüfle ben böheren Stellen vorbebalten bleiben. Die Finnaberwal= tung madit eine bejonbers genaue Feditfertigung ber unteren Bermten gegen ifyre Borgefebten unb bie ftrengfte \$rüfung oez

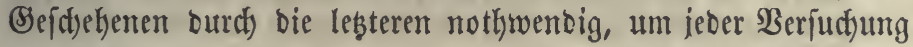
zur \$flichtwibrigfeit entgegen zu wirfen. Şieraus entfteht daz Bebürfnif́ einer guten Unterorbnung Der Steflen.

\section{§. 532 .}

Die Amtşftellen im Finanzoienft funb:

1) örtliche, welche bie Inwejentyeit einez Beamten an einem gewiffen \$uncte erforberm. Dabin gehören $3 . \mathfrak{B}$. Die Berwaltungen einzelner \&anbgüter, Furften, Bewerfzanfitalten 2 ., einzelner $\mathfrak{B} e r g=$ Şütten= und Salzmerfe, fowie ber Salżmieber= lagen, ber Mlüzftätten, ber Hoft = und Eifenbahnämter und Şaltftellen, bie Steuererbebung in ben eingelnen Semeinben, die 3ollftätten;

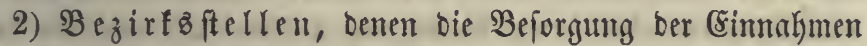
unt 2lusgaben in einem fleineren, yon bem Beamten leidft perfönlict) z"l benuffict)tigenden Begirfe übertragen wirb uno meld)e zum Theil, ie nach ber Natur ber (Sefdjäfte, nod) ort= liche $\mathfrak{B}$ ebienftete unter fid haben fömnen. Soldje Beamte fino Gauptfäd)liç (a) nothwentig a) für bie aız Felogủtern uno (S)ewerfäanftalten beftefenden Domänen uno dié Brunbgefälle, b) Für bas Forftwejen, c) für $\mathfrak{B e r g}=$ ımo Schtttemwejen, d) für bie Şoft= unb Eifenbahnverwaltung, e) für bas Stetterwejen (b),

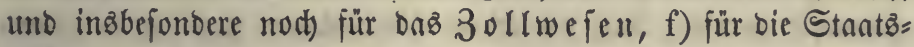
gebïube.

3) \$rovincialbeförben, Finanzammern, einem größeren Ranbestheile (\$rovinz, Regierungsbezirf, Rereis in Simne ber fübdeutichen Staaten, Departement 2c.) vorgefegt unb bauptfächlid) burd) fdyriftlidje Beridjte, 2Infragen uno $\mathfrak{B e r}=$ fügungen mit ben unteren Stellen in Berbinoung ftebeno, in fleimeren Staaten entbehrlic);

4) oberfte Ranbesbeförben, unb zwar a) bejondere, für einzelue 3tweige des Finanzwejens, (5entralftellen 
(5) eneralbirectionen (c), b) eine allgemeine, ben ganzen Staatşhauşhalt überblifenbe und regelnbe Dberbehörbe, Das Finanzminifterium.

(a) Daneben fann es nod Rotto:, Stempel=, Tabafs = $x$. Beamte geben.

(b) Şie und $b a, z . \mathfrak{B}$. in Bayern, find bie Edjaß̧ungen mit Den Domảnen

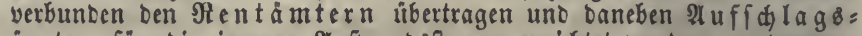
a mter für bie inneren 2Aufwandeffettern erridjet worben, anberswo, 3. $\mathfrak{B}$. in Baben, werben beibe Steuergattungen bon ben Dberein= neymereien beforgt.

(c) Die Benenmungen Der Befiorben uno Der in ifnen angeftellten Beamten

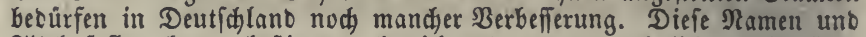
Titel follen furz, beftimmt, bezeidjnend uno wo moglid beutif fein.

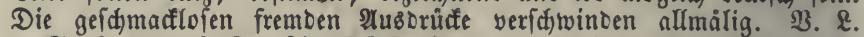
v. Se de en Dorf (Deutider Fürftenftat) Gandelt im 4. (Eap. Des III. Th.

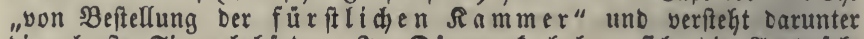

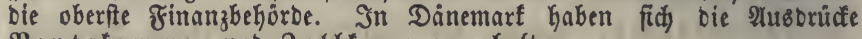
Fentefammer umb 3 olffammer erfalten.

\section{§. 533 .}

Die beiben erften Claffen von Finanzftellen fint bie $a u s=$ fükrenden und vollziehenden, bie beiben lesten bie auf= fehenoen uno leitenoen. Sene find zwar unter einnonber infoferne verjhieben, als bei einigen 3weigen von Einfüften Dem Beamten eine freiere Bewegung geftattet ift, währeno er in anberen an beftimmte und unabreidyliche Borfariften gebunben werben mus, inbeß ift bod bei ifnen burdjgehends bie That vorkerrfhenb, bei ben oberen bagegen bie \$rüfung, Ueberlegung und Befdluffaffung. Daher eignen fid bie beiben unteren Claffen zur Berwaltung burd) einzelue Beamte mit Den nöthigen untergebenen Elebullfen $(a)$, bie böheren zur Collegialberfoffung, \$. 70. Siegen bieje fann zwar, auker ber Ulmftändliçfeit, Berzögerung uno größjeren Roftbarfeit, nod) ber Umftano geltent gemadjt merben, taß bei jebem Segenftanoe nur ber benfelben

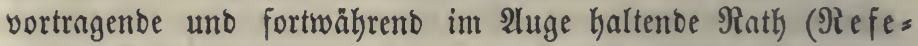
rent, Refpicient) ganz eingeweiht ift. Inbeß trägt bie Theilnahme anberer, wenigftens im erofgemeinen unterrid)teter Rătlye und ber Uleberblid bes Borfizenden fehr viel zur Reife und Umftcht in ben Entfchliefungen bei uno es ift leidfer.

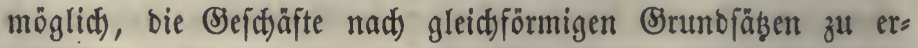

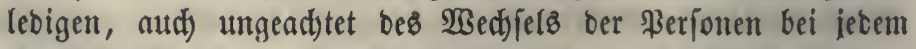
Begenftanbe gleidye 3wecfe zut verfolgen, als bei ber Bureaus

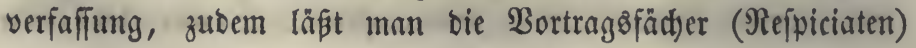


von 3eit zu 3eit wedfjeln und beftelft Rebenberidyterftatter (Coreferenten), fo Daje Seber in allen Theilen bez Bejhäftz= gebietes einfeimifd) wirb. 2Am beften ift eine foldje $\mathfrak{B e r i d j m e t =}$ zung beiber Formen, bnß

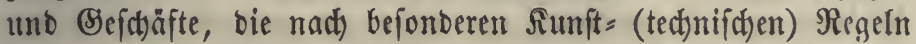
ju beurtheilen fint, bem Refpicienten uno Borfibentoen allein überlaffen werben, okne ber gemeinfamen Beratbung zu beburten.

(a) Bine Arbeichung Gievon ift im 3olloerein bie collegialifde Berfaffung ber Saauptzollämter, Deren jebes brei Beamte Gat.

\section{\$. 534 .}

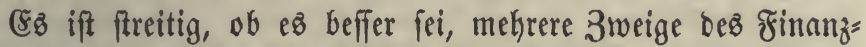

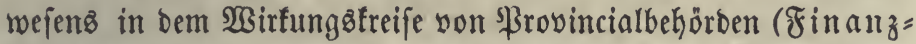
fammern) zu vereinigen, ober bagegen jebem Scauptzmeige fein eigenes $\mathfrak{B}$ ehörbenfyitem anzumeifen und ifn bemnact) einer befonberen Dberbehörbe unterzuorbmen, bie jogen. Eentrali= fation $(a)$. Reģterez ift bei einigen Bregenftänben, bie viel Ěigenthümlichez uno wenig 3 ujammentang mit anderen Theilen Der Berwaltung haben, wie bei bem Boft $_{\text {, }}$ Eifenbahn = und 3ollwejen, gemeiniglid) gefthehen, ofters aud beim Bergwertż=, Salzwerf $8=$, Şütten = und Forftwejen; Dagegen hat man bie Domånen = uno Steuerverwaltung meiftens ben SProvincial= behörben zugetheilt, bie in mefreren Staaten aud) mit ber

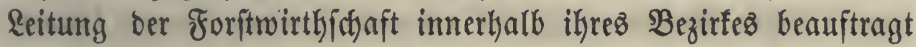
wurben (b). Sft ein Stant fo großß, Daß bie Reitung ber Bezirfsftellen burd) eine cinzige DGerbehörde wegen ber $2 \mathfrak{l n}$ aht und weiten Entfermung ber erfteren zu bef(t)werlich fein würbe, fo ift e⿱一𫝀 nüblid), in ben Eanbesttheilen M) Rittelftellen einzuld alten,

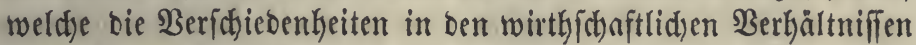
aus näherer 2lnichauung beffer tesunen. Sn bicien Mittelftellen lafien fith bie Domänen= uno Steuergefdyäfte füglid) mit ein= ander verbinten, ba bie miffenichaftlidjen $\mathfrak{B o r f e m n t m i f f e ~ f u ̈ r ~ b i e = ~}$ felben großentheils bie naimlidjen finto, uno auth ba wo beibe in ben unteren Etellen getrennt fint, Dod) ber angelyente Beamte leid)t im Stanbe ift, in beiben praftifd) bewantert zu werben. 2lud) bie Berwaltung ber Stantzoforften hat neben rein tech)= nifden Begenftänoen (\$. 533) viele allgemeine Beziefungen, z. B. zu ber Sanowirthid)aft und Irmenpflege, uno follte baker 
nicft ganz vercinzelt ftehen. Wiro cin gewiffer (Eimnakmsizweig ofne $3 \mathfrak{u}$ fammentbang mit anberen yon bejonberen $\mathfrak{B}$ efjöben geleitet, fo wirb hicourch) bie Berwaltung allerbings leidter funftwoll in fidf ausigebilbet; ift er bagegen ben \$rovincials beförben zur Befjandlung zugetheilt, fo entfiteft mehr Ueber=

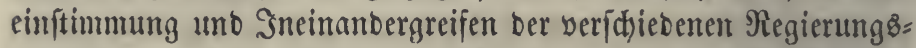
maßregeln, unb biefe fönnen volffommener nach ben Bebürfififen uno Berbältniffen jebes \&anbesttheiles abgemefien werben, auds) finto bie unteren Stelleı einer näheren $\mathfrak{A}$ fffitd unterworfen.

(a) v. Iafob II, \$. 1270. - v. Mialdus, Fin. II, 177.

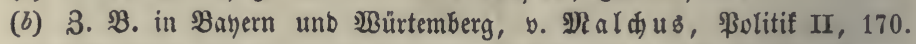

\section{§. 535 .}

Das Finnuminifterium ift ber Mittelpunct, yon weldjem

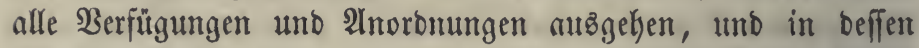
Mitgliebern fid baker aud) grünblidbe theoretifche unto praftifdye Remutnís bes ganzen finanzmejens vereinigt finben muß. Fitr mehrere bejonbers grope Şauptzweige bes Finanzivejens werben entweber einzelne 2lotheilungen (Sectionen) Des Finanzminifte= riums, ober bejonbere, bemfelben untergeorbutete Eentralbeförben (\$. 532) angeorbnet. Der Unterictied beiber (Sinrictutungen zeigt fid) vorzüglid) barin, baß bie Abtheilungen bes Minifte= rumb bei ber Bernthung widftiger Angelegenkeiten zu einer

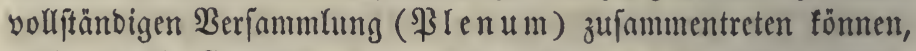
währenb bie Centralftellen nur fd)riftlid) an basి Nainifterium

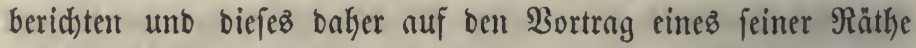
bie Anträge ber Centralftellen einer nod)maligen SHrüfung aแธ einem göheren Stanbpuncte unterwirft. Die lez̧tere Cimrictumg, nach) welcher bas Minifterium eine geringere 3ahl von Räthen

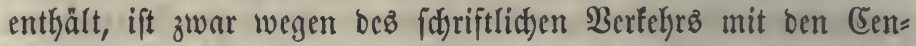
tralftellen umftändicher, beförbert aber bas reife Durchbenfen jeber Entichließ̧ung uno erleid)tert fowohl bie Berftänoigung

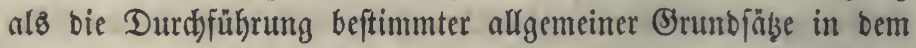
Minifterium. Nad) einer in ber Mitte ftebenoen Eintridtung erbalten die Borftände Der Centralftellen Siß̧, Bortrag und Stinume im Minifterium. Die 3ahl ber Sectionen ober Central= ftellen mus nach bem Umfange ber (Bejh)äfte bemeffen werben, weil in fleineren Stanten, ober wo gewiffe Sinnahmsaquellen 
einfad) zu verwalten finb, megrere berfelben zujammengefaßst werben föınen, z. $\mathfrak{B}$. Dnछ Furftuefen mit ben lanowirthidaft= lid) benuşten Domänen und Den Befällen (a). Ein Theil Der

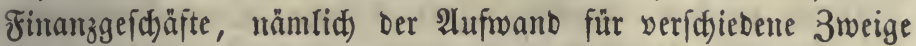
Der Stantżberwaltung und bie mit biejen Aluछggaben zujammen= hängenben গebeneinfünfte (\$.87) werben nid)t bon Dem Finanz= minifterium, fonbern von ben anberen Minifterien geleitet, benen Dep̧halb ein finangtundiges \$erional beigegeben werben muß.

(a) Die obere \$oftbehörbe hat man wegen Der häufigen \$erhandlungen mit anberen Staaten hie und $D a, z . B$. früher in Baben und Sar= Dinien, Dem SNinifterium Der auswártigen Angelegenbeiten untergeben, mit befien ફ̧auptwirfungstreis fie jebod zu wenig 3ufammenhang hat.

BaDen. Huter Dem Finanzminifterium ftehen 1) Die Domånen= fammer, 2) bie Forft= uno Bergwerfscirection, 3) bie Steuerbirection (Teitet aud bie Salzwerfe), 4) Die 3ollbirection, 5) bie Baubirection, 6) Die Staats = und Die Sdjuldoerwaltunggeaffe. - Dem Şandels: minifterium ift bie Direction Der Berfehrbanftalten (\$opt: uno Esifens bahn) untergeben.

Băyern. Das Forftbureau ift eine Alththeilung bes Finanzminiftes riums. Inter biefem ftehen 1) Die BergwerfB = uno Salinendirection, 2) Die Eottonominiftration, 3) Das Şaupt= Maunz= uno Etempelamt, 4) Die Direstion Der Berfehrosanftalten, 5) Die Eijenbahnbau=-Eommiffíton, 6) Die Solladminiftration.

Franfreid. Unter Dem Minifterium ftefyen bie administrations centrales 1) des contributions directes, 2) de l'enregistrement et des domaines, 3) des forêts, 4) des douanes et contributions indirectes, 5) des postes, 6) bic Commission des monnaies.

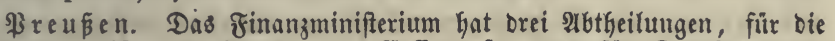
Steuern, für Das Cotats: und Cafienwefen und für Dománen und Forfen. Dagegen feht das Beneralpoftamt, fowie bie Berwaltungen

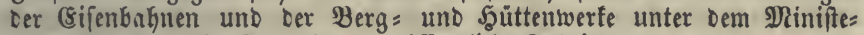
rium fuir Sandel, Sewerbe uno offentliche Prbeiten.

Sardinien. 3um Finanzminifterium gehören Die Bseneraldirectivnen 1) Der Bölle (gabelle, mit Salz= und Tabaforegal), 2) Der Steuern uno Domanen. Die Direction Der Dffentliden Altbeiten unter einem eigenen Dintifterium beforgt Die Berwaltung Der (Eifenbahnen.

WBärtemberg. Unter Dem Nhinifterium 1) Die DberT̃nanzfammer, welche wieber eine Domanen=, eine Forftoircction, einen Bergrath und eine (Eentralbehörde für bie Berfehrzanftalten unter fich hat (bie Finanz= fammern ber vier Sireife fino aufgehoben worben); 2) Steuercollegium.

\section{§. 536.}

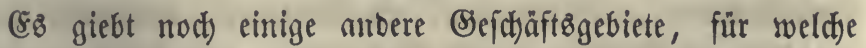
Dberbehöroen unter bem Finangminifterium gebilbet werben müffen, ohne baß benfelben eigene ßrovincial= und $\mathfrak{B}$ ezirfb= beamte untergeoronet werben. Dahin fino hauptfächlid) zu redinen: 
1) bie Sdulbverwaltung, \$. 508;

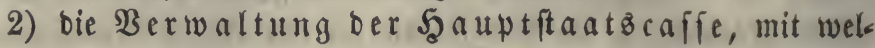
d)er alle anberen Eaffen in Berbinbung ftehen;

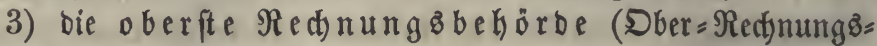
tammer, Cour des comptes), weldje bie ßrüfung ber Stant8̊rect)nungen in leb̧ter Snftanz vornimmt uno über Die zwijdyen Den Redynern uno Der Regierung obwalten=

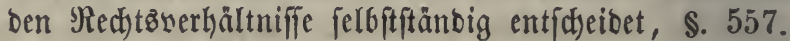

4) in groken Staaten bie oberfte $\mathfrak{B} u d \mathfrak{h}$ altung, weld

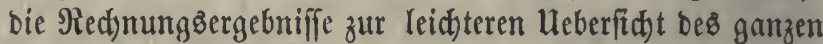

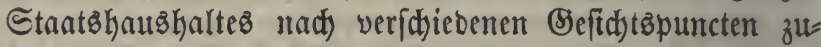
fammenftellt unb verarbeitet, aud) zu ber (Entwerfung Des Şauptetaţ (\$. 465) gebrautdt werben fann, \$. 560;

5) Die Munzuerwaltung.

\section{§. 537.}

Die im Finanzfacte angeftellten \$ुerfonen zerfallen in Şins fitht auf ifre Borbereitung uno ben Umfang ifrer Renntniffe in brei (STaाfen:

1) Soldbe, weldye blop mit guten Sdyulfenntnifien auss= geftattet find uno anfangs zu leid)teren Berridytungen gebraucht

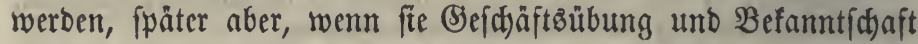
mit ben in einem 3weige Des Finanzbienftes beftekenben $\mathfrak{B}_{0}=$ fdriften erfangt haben, zu fawereren unb widjtigeren alrbeiten beauftrigt werben, z. B. Die Sdyreiber und meben ifnen aud) bie Erbeber foldyer Sinfunfte, bei benen bie Sdyuldigfeit fdjon voraus befitimmt ober leid)t zu beurtheilen ift, z. B. Der Sd)azungen, ber Accíe, bes 2Beggeldes, Der Stempelgebühr, ber \&otteries

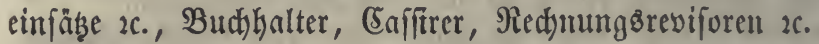

2) Siunftyerftånoige (ted)nifde) Beamte, bie eine eigenthümlidse, auser bem (sebiete ber Finnumiffenfduft liegenbe, auf einen befonberen bürgerlichen Beruf geridtete wiffenfdyafts

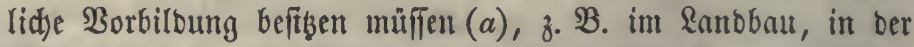
Foritwirthichaft, in Bergbau, Galinenwejen, Baumejen (jog. Şodbauten, Straßen = uno $\mathfrak{W a f f e r b a u ) , ~ b e r ~ S a t a f t e r m e f f u r g ~}$

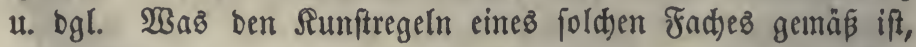
entipridjt barum nod) nid)t immer ben finanzielfen 3roeffen, und ber vielfältig wahrgenommene 2 siberftreit zwijden ben 
Ted)nifern und Finangmäntern wưtbe feltener werben, wenn

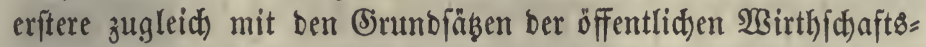
refre vertraut wären. Se meniger man biés voratşęęen famm, befto nöthiger ift, bie Tedfnifer mit beigeoroneten ober bor=

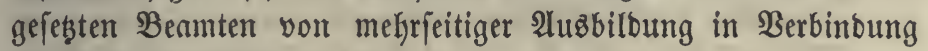
子u fę̧en (b).

3) Wiffenfdaftlide Finanzmänner. Der Befís fyftematifder Renntniffe auz bem Bebiete ber gamzen bürger= lichen und offentlichen $\mathfrak{B i r t h j d j a f t}$ lehre, ber Mathematif, ber

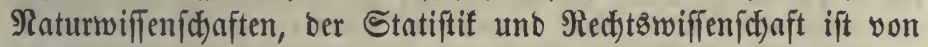
anerfannter Unentbefrlidfeit für bie höheren Stufen bez Zinang= Dienftez, auf benen ber Beamte audi) zu neuen Bsejeşen und

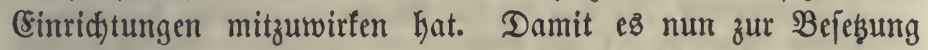
foldher Stellen an Männtern nidjt fehle, weldje fid son unten

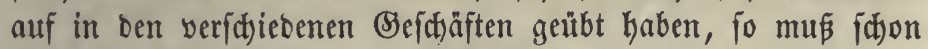
aus biefem (srumbe von einem Theile ber angehenben Sejejäftz=

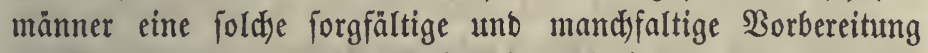
geforbert werben. Diefe ift jebod) auth in ben Dienjtuerrid)= tungen ber Bezirfaftellen, bie alferbingż iđjon mit Şülfe blober Eimübung erlernt uno betrieben werben fönnen, yon

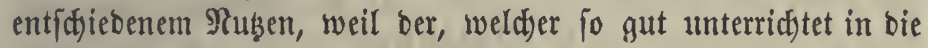
Berwaltung eintritt, bie Regeln berfelben weit idfneller auffaß̧t unt bei Atrem, was er yornimmt, ben Srand uno 3wed beut= licker erfennt, meß̧halb er mehr zu bem benbfictitigten Erfolge

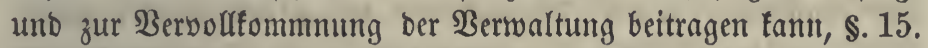
Der Sireiz ber Den wiffemidaftlid gebildeten Finanzbeamten

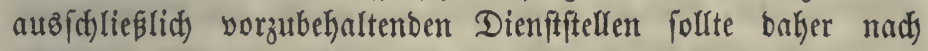
uno nad) erweitert werben, forvie bie Scäufigfeit biefer Bor= bereitung es geftattet uno in jebem einzelnen Sejoüftżgebiete

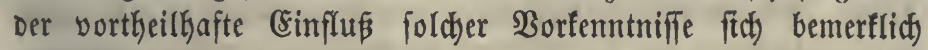
madyt (c).

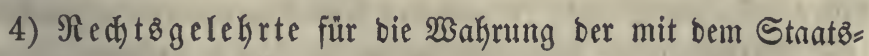
vermögen zuammentjängenden Beredjtigungen beż Stantez in

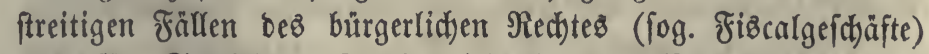
uno für Straffälle, foweit bieje in Den $\mathfrak{B i r f u n g a f t r e i z ~ b e r ~}$ Finanzbehörben gehören.

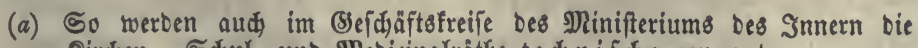

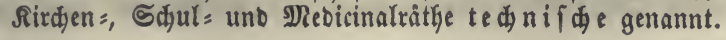


(b) Sollten bic Tedhnifer ben शRittelbegorben als झRitglieber einverleibt, ober nur berathent beigegeben werben? Eegteres ift ber Boridilag von Infob's, II, \$. 970 fi.; Eanowirtffidafts:), Furft = uno Bergwerfffammern erridetet werben, bie feine Staatsbelyobrben, fonbern blobe 2lominiftrationsiamter máren und oie Beftimmutug hätten, "bie Befehle ber Fimanzcollegien auz̧uführen und Denfelben Diejenigen Motizen zufommen zu lailen, roelde von ifnen gefordert werben". (88 ift jedod) hiebei zu bejorgen, Dás in diefen Raumern, beren Yitglieser feine „allgemeinen ftaatso wirthichaftliden

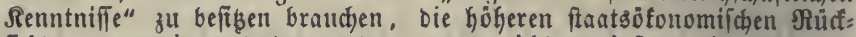
ficften zu wenig vertreten werben, wenn nidbt wenigftens ein Theil ber

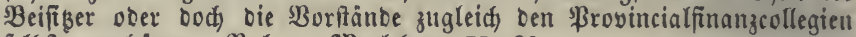
felbft angehưren. BgI. y. Ma ald u \& II, 83 .

(c) Sd) miblin, Heber Die Borbereitung zum Stantzbienfte im Bertwals

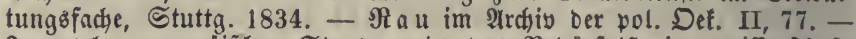

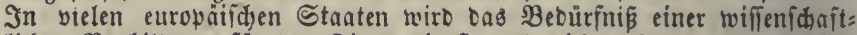
liden $\mathfrak{B}$ orbildoung für ben Finanzoienfit nod nidht erfannt, man behilft

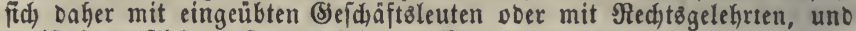

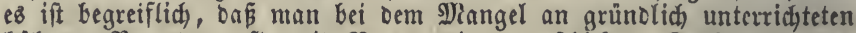
höheren Beamten oft mit Nubenen einen gefdicften Raufmann ober Fabrifferm hierbeizieht.

\section{II. $\mathfrak{A} \mathfrak{B}\{\mathfrak{d} \mathfrak{u} i t \mathrm{t}$.}

Eigentbüntidbe Gefdäftsformen im Sinanzwefen.

(sinleitung.

§. 538.

Die Piegeln für bie Formen in ben Finanz̧efd)äften finto, was mand)erlei 2 rten fd riftlidjer 2 rbeiten betrifft, bie näms lidjen, weldhe für bie Stantżverwaltung im Atlgemeinent alf= geftellt werben föment, uno gehören be ejhalb nidjt fowohl in Die Finanzwiffenfdjaft, als in bie Rehre von ben Etants= gefdäften überbaupt. So werden z. B. Berichte, Serrïgungen, Befese, Berorbmungen, Firotofolle u. Dgl. in Finn anderz abgefaß̧t, alz in \$olizei=, Rirct)ent= ober Sdjulangelegen= heiten. Dagegen giebt lidje Berrictungen, für welde, abgejehen von bejonderen 3 weden

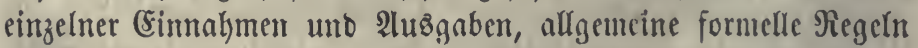

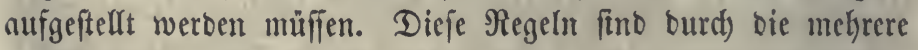

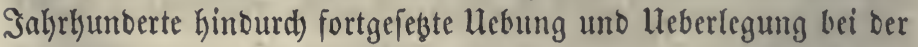
Bejorgung von Finanzgejdjäften gejammelt, fortgefflanjt uno verbolfommet worben. Sie werben iebod) leid)ter anfgefapt 


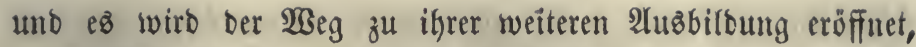
twenn man fie in einer wiffenj(d)aftlichen Darftellung mit ben

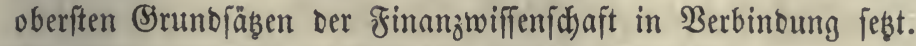
Die hieher gebörenben (Bejđäfte find vornehmlid):

1) bas finamzielle oder Rameral = Rechnungşwejen,

2) bas Ç่tatôwejen,

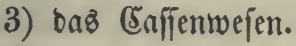

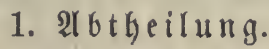

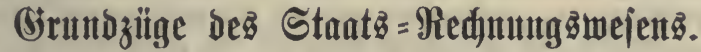

\section{§. 539 .}

Unter einer $\Re$ ed) nung veriteht man überhaupt bie $\mathfrak{B e r}=$ binbung von 3ahlen nad) Regeln ber 3ahlenlefre (2lrithmetif), um barnus irgent ein (Ergebnis zu gewinnen, und jwar be= beutet jener 2luşbrưf theils bie Şanblung Des $\mathfrak{B e r b i n b e n s ] ~ b e r ~}$

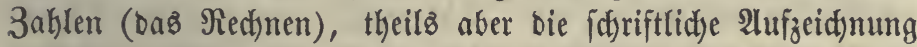
berfelben. Rectjungen in biefem (objectiven) Sinne fommen in wirthidfaftlidben (S)biete befonbers bäufig vor, weil bas Vermögen nach feinen $\mathfrak{B e f t a n b t h e i l e n ~ u n o ~ B e r a ̈ n b e r u n g e n ~ l e i d ) t ~}$

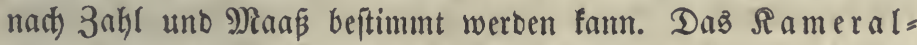
ober Stantôred) Darftellung ber in Der Finnzzerwaltung in saufe ber 3eit yorfommenben wirthidjaftlidyen (bie Sadjüter betreffenden) Thatfadyen in 3ablen $(a)$. Siebei erjofeint bas eigentliche

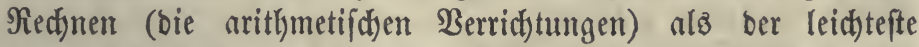

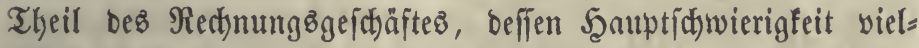
mefre in ber guten Dromung ber gropen Menge von Zahlen= angaben befteht $(b)$. Jebe einigermaßen zujammengejebste $\mathfrak{W}$ irth= f(d)aft erforbert eine forgfältige unb georbnete 2 tufzeichmung afler wirth(d)nftlid)en $\mathfrak{B o r g a ̈ n g e ~ u n o ~ B e r b a ̈ l t n i f l e ~ m i t ~ b e n ~ j u g e h o ̉ r i g e n ~}$ 3ahlen, um bem Sebảdytniffe zu Şủlfe zu fommen, um bem Eigenthümer bes bewirthjajafteten $\mathfrak{B e r m o ̈ g e n s}$ jederzeit ben Strub beffelbelt z"t vergegentwärtigen, ben lleberblid ber Bebürfmiffe uno Der Şillfsinttel żt gewöhren, Erfafrumgen über ben Erfolg eimzelner Maßjegeln zu fammeln uno überbaupt die ganze 


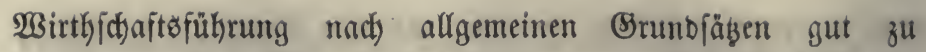

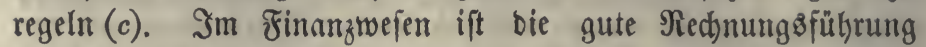
ein befonbers widjtiges (Erforberní̄, fowohl wegen bes gropen, fđwer zll überjekenben Umfanges uno ber Nanchfaltigfeit ber Bermögensttheile uno Ereigniffe unb ber Menge mitwirfenber ßerjonen, alz wegen ber ftrengen $\mathfrak{Z}$ erantwortlidfeit, bie ber Finanzbeamte als $\mathfrak{B}$ erwalter eines fremben $\mathfrak{B e r m o ̈ g e n s}$ zu tragen hat. Die Rechnungen bienen Daher in ber lebstgenannten Şin=

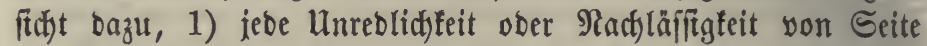
Der Bermten zu verhüten unb Die (Servigheit einer guten $\mathfrak{B e r}=$ waltung zu begrünoen, 2) Den Benmten bie Anerfenmung ifjer Bflidyterfülung zu veridjaffen uno fie baburd) gegen jeben $\mathfrak{B o r}=$ wurf ober weiteren Anfprudy fidter zu ftelfen $(d)$. Die Sunft besె Staatżrechmungsిwejenz gehört Der neueren 3eit an und ift vorgüglid) jeit bem 2lnfange bes 18. Jahrfunberts im preußi= ichen Stante, im jesigen Sahrhumbert vorzüglid) in Franfreids uno Deutfaland ausigebildet worben, wozu die lanbftänbijace Berfaffung uno Die Beröfentlidung Der Ergebniffe bes Stnatz= haub̆haltes beigetragen hat. Theoretifh wurbe biejer Segen=

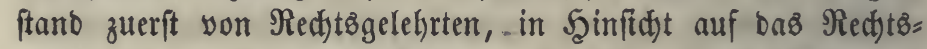

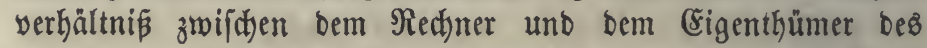
berrechneten Bermỏgenż (bem Stante) behandelt (e). (Erfit bei ber neuerliden $\mathfrak{B}$ ervolffommnung ber Finalzwiffenidaft wurbe

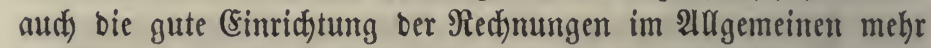
beadjtet $(f)$, bod ift fie nod) nidjt mit gleidjem (Fifer wie oer materielle Theil Des Finanzwefens ibftematific) behandelt und auf fefte Brunbjäb̧e zurủdgeführt, vielmebr gemeiniglid) ber ßraxisి überlaffen worben.

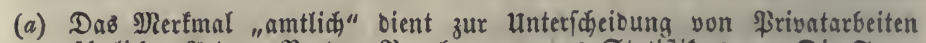
äfnlicher 2rt, 子. $\mathfrak{B}$. Den Berechnungen Deß Statiftifers. - Die Fran=

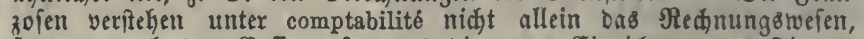
fonbern auch Das (Enfienmefen und bie ganze (simridytung Dez Finanz= twejens yon formeller Seite.

(b) Die Rehre yom Rechnungsmeien Darf baher nidyt mit ber politifden ober ङ mit ber \&ofung eingetretener berwidfelter Rufgaben burd, aritfmetif́dye Rumftmittel befdäftigt.

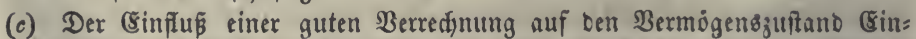
zelner wiro treffend gef́childert yon Ch. V. de Bonnstetten, Pensées sur divers objets de bien public, Genève 1815, S. 19 ff.: La plupart des hommes ne sont ni arares ni prodigues, que parce qu'ils n'ont pas uno idée nette de lour fortune et de leurs moyens. - L'habitude de 
voir en chiffres ce que l'on dépense et que l'on acquiert, eût empêché le prodigue et l'avare de tomber dans des vices, qui finissent toujours par rendre vil ou coupable.

(d) Diefelben Berhältniffe finoen bei ber Berredhum bes firchlichen, bes Semeinbebermögens $2 c$. ftatt, wobei man Def̧̧alb bie Normen ber Staatzrechnungen zum Borbiloe zul nefmen pflegt.

(e) Sdyriften von $\mathrm{Mu}$ ũoz de Escobar (De ratiociniis et computationibus administratorum, 1599 und ofter), Heeser (De rationibus reddendis earumque revisione, 1665 und ofter) u. $\mathfrak{A}$. 2uch bei (5 Iaproth

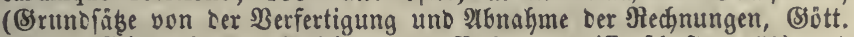

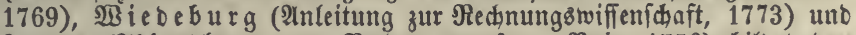

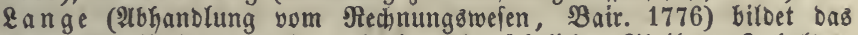

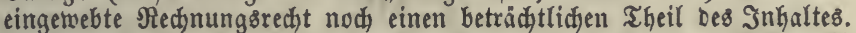

( $f$ ) lungeadjtet ber vielen über biejen Begenftano geid)riebenen Büher ift es Dod fidwer, fid allein aus benfelben zu belehren, weil mandie berjelben nidht flar, methodifh und vielfeitig genug find. Bemerfens: werth fint:

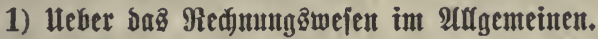

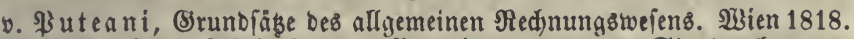

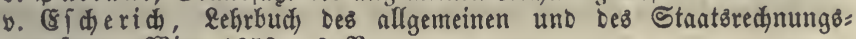
wejenz. Wुien 1852. 2 B.

\&

\section{2) Heber bie Staatärednumgen im Alfgemeinen.}

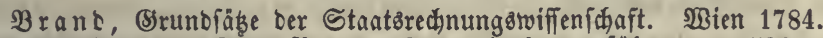

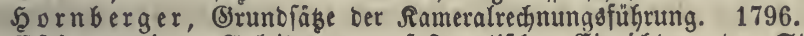

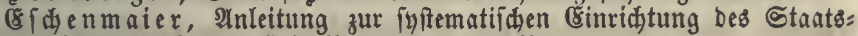
redinungsimefens. Şeibelberg 1807. 2 જ.

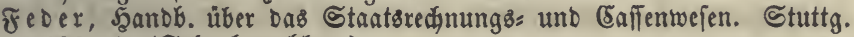
1820. 4. (Gehr braudbar.)

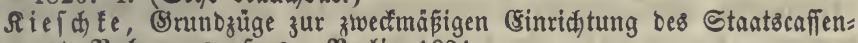

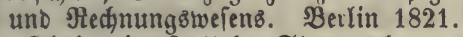

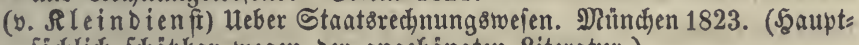

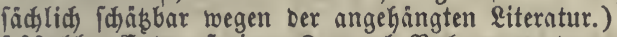

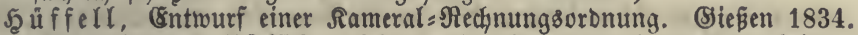

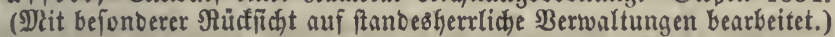

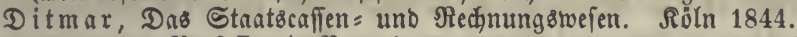

A. Tonzig (\$rofefior in \$acua), Trattato della scienza di amministratione e di contabilità privata e dello stato. Venezia 1857.58. $3 \mathfrak{B} .4^{0}$.

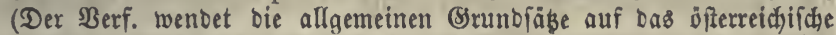
Redinungsivejen an, weldies er ausfübrlid Darfellt. Der 1. SBD. enthält eine Erflärung bes jifterreichifdien Finanzweiens in allen

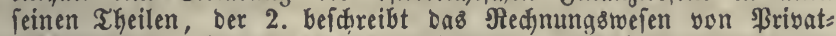
wirtbidaften, \$anbel, 2lctiengefellid)aften, Betwirthidaftung von \&anbgütern, ber 3. Das Staatsredinungstwejen.)

\section{3) In Bezug auf cinzelme Rämber.}

Fröhli

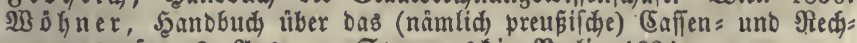

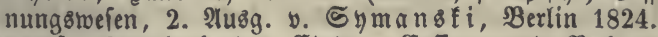

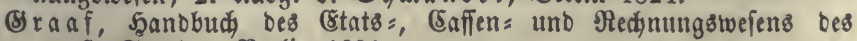
preuß́. Staates, Berlin 1831.

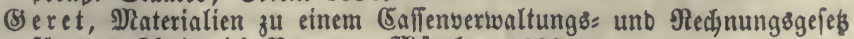
für bas Rónigreiđ Batyern. Niünđen 1823.

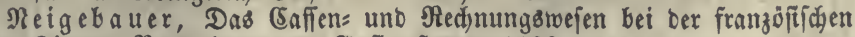
Finanz= Berwaltung. 2. Auf. Şamm 1826. 
Eine georbnete Sammlung Der widhtigften gejebliden Beptimunungen über cas franz SRednungsweien, von bem Marquis D'A ubiffret

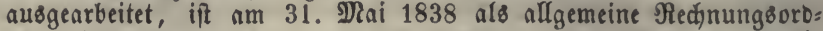
nung (réglement général sur la comptabilité publique) befannt gemađht worben. Şiez̧u gefören Die Tuffäbe in d'Audiffret, Système financier I, 275. II, 386. Die franzofifihen Einrichtungen Bilden cin mit großem Sd)arfïnn zuíammengefügtes (5)anzes, weld)es mufterhaft genannt twerben fann. Die Keutige Alusbilbung if eine frudgt ber firengen Befeglidfeit, Wahrkeit und Deffentlichfeit, weldje feit 1814 berrident getworben fint.

\section{§. 540 .}

Der Begenftano Der Stnatzredjunungen ift baz zu bervirth)= id)aftenbe Staatzevermögen. Wie überhaupt jebe wirthfdaftliche

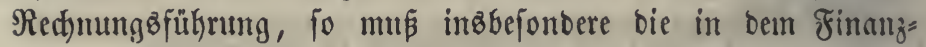
wejen beftekente mady ridtiger unb genauer Altffoffung ber wirthfdyaftlicten Srumbbegriffe uno Srumbverfältniffe eingerichtet fein (a). Die Thatfathen, weldye ourdh bie Redjmunggfüfyrung (Berrect)nung) bargeftellt werben follen, fint von z̧weifact)er 2rrt. Sie betreffen nämlich)

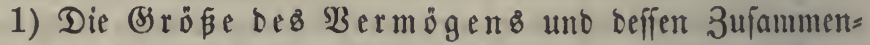
feşung nuв veriffiebenen Beftandtheilen in einem gegebenen

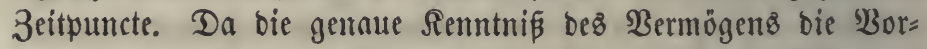
bebingung ciner guten Berwaltung ift, fo umi bafür gejorgt werben, baß biefelbe ftets leid)t aus ben Rechnungen gefdjopft werben fann.

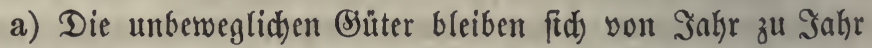

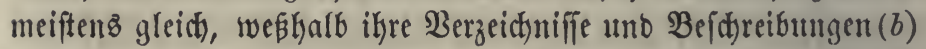
auf längere 3eit gebraucht werben fömen, menn mur jäłrlid) bie 3unahme uno 2lbnahme, uno zwar bieje mit (sinjd)lus ber Werthöberringerung (2)bnubung 2c.) aufgezeidynet wirb.

b) In ben beweglicten Bermogensitheilen für fortbaternoen bejonberen (Sebraud), fowohl zu werbenben 3weden (Sieräthe, Berfzetge 2c.), alż zแ Den verfdjiebenen 3tweigen bez Stantz= Dienftes, finbet cin ftärferer $\mathfrak{B e c t j}$ fel burd) neute Ervverbung, Bern̈uperung und Berbraud) ftatt, wephalb von 3eit zu 3eit

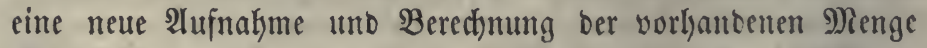

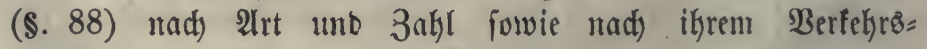
werthe erforberlich ift. Der 2luftslag wiro bei belt netl an=

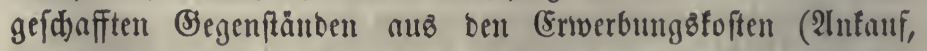
Fradjt zc.) gebilbet. Bei mandyen Dingen, 3. B. Bejtantbtheilen 
von Cammlungen, ift nur eine ungefähre Sdjäß̨ung möglid). Die Berzeidyniffe foldyer ftehenber Şülfżmittel (bie Snventarien)

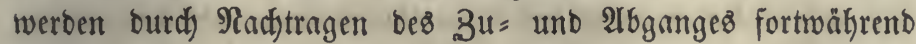
ergānzt.

c) Borräthe, bie zu balbigem Berbraudb ober zum $\mathfrak{B}$ erfaufe beftimmt find uno befhalb einen ftarfen $\mathfrak{B}_{\text {edf }}$ fel zeigen, werben von 3eit zu 3eit nadjgejehen, - Sturz, A $u f n a h m e(b)$, in ber 3wifdenzeit aber erfennt man bie jebesimalige Menge aus

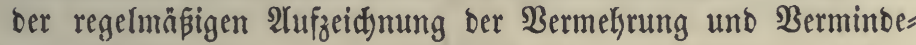
rung, i. 2).

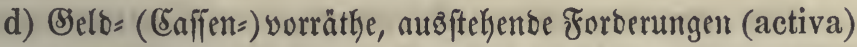
uno neu entftanoene Subloen (passiva) müffen nuछ ben unter 2) erflärten Red)nungen in jebem einzelnen 3eitpuncte leid)t zu

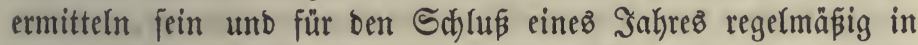
ifrem Sefanmtbetrage bargefteflt werben.

2) Die einzelmen $3 \mathfrak{Z}=$ unb $\mathscr{Y}$ bflüffe von $\mathfrak{B}$ ermögenstheilen währent eines gewiffen 3eitraums in alfen 3weigen bes Stantż= Gaub̧halteb, wobei aus ben oben (\$. 539) angegebenen Srünben feit foldser Borgang ofne 2lufzeidnung bleiben barf. Dic bäufigften in ben Rect)nungen nufzufükrenben Beränberungen

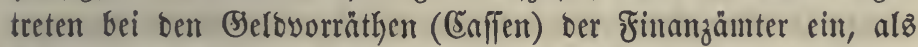
(Selbeinnabmen uno Belbausgaben, benn bic aus Sadygütern beftekenben \&eiftungen ber $\mathfrak{B}$ ürger an ben Stant unb bes lekgteren an einzelne Bürger werben in ber Regel nad) Belbpreifen beftimmt, in Selbjummen ausigebrüft unb entrid)tet. Raturalred) nungen tommen, ba bie Naturalgefälle meiftens abgeichafft finb (\$. 87), lyauptfächlid) bei ben Stantżgewerben, 3. B. für lanb= unb forftwirthfdaftlidye Erzeugniffe, Eegenftänoe

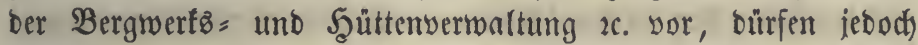

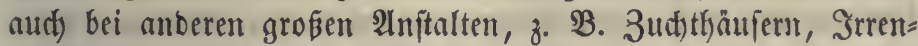
häufern 2 . nidjt feblen. $\mathfrak{B O}_{0}$ eine Raturalredtyung neben ber (Seloredyung befteht unb wo in jener veridjiebene 9 rten von Stoffen aufgeführt werben, oa finto bie Ergebniffe bes barzu= fteflenoen wirthfd)aftlid)en (s)mzen (ez jei mun baż gefammte Finnaztwejen ober ein Theil beffelben) fdwerer genau zufammen= zufaffen. Nan pflegt zwar bie Raturalien nad) einem gewiffen

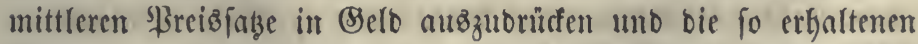
Znklen ber (Selored)mung beigufügen, aber biefer (Selbanfd)lag 
ipridyt nidyts Thatfactlidjes aus, fann bon bem bei einem wirflicten $\mathfrak{B}$ erfaute eridjeinenben \$reife amjebntid abweidjen uno gehört baker mehr ber Ctaatsbudhyaltung als ben eigents lidjen Stratsired)mungen an, §. 536.

(a) Diefe serunbbegriffe, wie fie im I. $\mathfrak{B}$. Diefes \&efrebuchs im 1. Buche entwiffelt fint, werben in mandhen \&ehrbủchern über ba\& Redjnungss

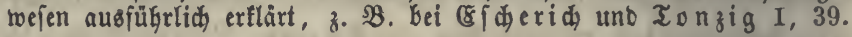

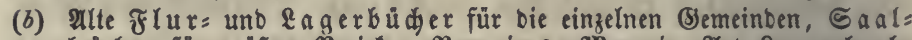

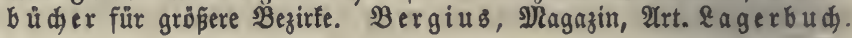

\section{ङ. 541 .}

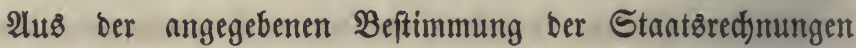
find bie alfgemeinen Erforberniffe berielben abzuleiten.

1) $\mathfrak{W a s}$ ben $\mathfrak{n} \mathfrak{h a l t}$ betrifft, fo finb biefe Anforberungen

a) Foldte, bie bei allen Stratzิ/d)riften vorfommen, nämlid

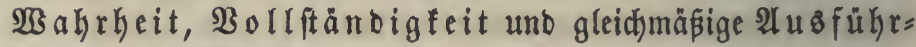
liche it ber Ingaben,

b) eine bem Finanzwefen im höheren Srabe eigenthümlidfe,

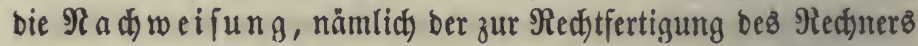

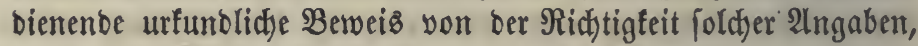
weldye einem 3weifel unterworfen werben fönnten.

2) In Beziehung auf bie Form follen in ben Rectyungen mand)faltige Angaben fo mit einanber in Berbinbung gefest werben, baß ber Rejer fowohl jebes (sinzelne leidjt herausffinbet, als auth Das Şauptergebnís ohne Mühe überblicfen uno fids) yon beffen Ridtigteit überzeugen fann. Dazu bient

a) in Şinfidst auf innere form: a) gute Inorbnung ber einzelnen 2 lufzeidyungen nad) einem ridtig gebadjten (logifden), bem $\mathfrak{W B e}_{e}$ ber Sadje entipredjenden unt leidjt verftänblid)en (Eintheilungsigrunbe, fo baj jeber überfaupt Sad)= funbige fich bald bamit vertraut madjen fann. 2lus ber beuts lidyen Auffaffung bes in einer Redynung barzultelfenben wirth= id)aftlidyen Sebietes mus aud) beurtheilt werben, was in jene

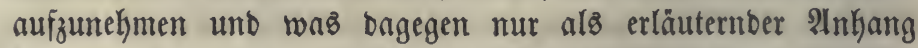
beizufügen fei; $\beta$ ) gleidförmige 2 rtt ber Darftellung, fo baß von jebem aufgeführten Segenftande baffelbe gejagt wirb, z. $\mathfrak{B}$.

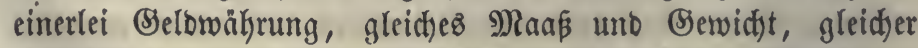
3eitraum ber (Sinnahmen uno Ausిgaben; $\gamma$ ) Rürze, (Sinfadheit,

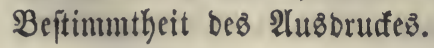




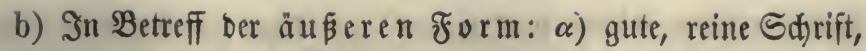

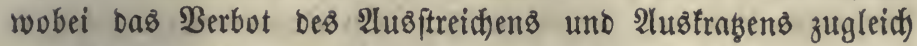
zur Berftärfung ber (S) laubwürbigfeit bient; $-\beta$ ) eine.

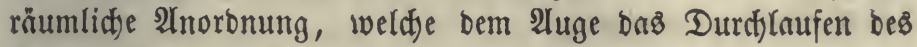
2ufgezeiduneten und bas 3 ufammenfaffen bes STleidjartigen erleid)tert. Das Mittel, bem $\mathfrak{B e r f t a n b e ~ v e r m i t t e l f i t ~ b e s ~ f i n n l i d j e n ~}$

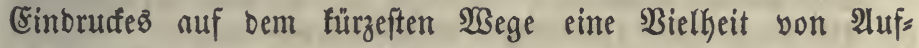
zeidjnungen zu vergegenwårtigen, ift bie $\mathfrak{T} a b e r l e$.

\section{§. 542 .}

Die gewöhnlidje Sdyrift fanm als eine fortlaufende, nur

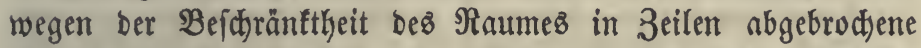
sinie angefehen werben. Die Tabelle ift bagegen eine 2 rat

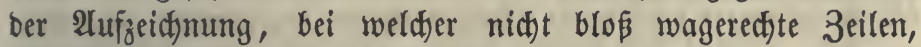

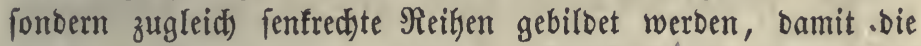
in fämmtlidten 3eilen enthaltenen 3aklenangaben yon oben nad) unten leid)t überbliaft uno zujammengered)net werben fönnen. Diefe fenfredten, mit sinien abgetbeilen Reiken heißen Spalten (Eolumen). Sebe einzelne Alufzeidnung ciner Thatjache, Eintrag, Bofition, Boften $(a)$, bilbet eine burd) bie veridjiebenen Spalten einer Tabelle fid fortzieflende 3eile, uno bie ben Spalten gegebenen Meberidyriften (Tabellen= fopfe, (Columnens Rubrifen) erfparen bie Wieberbolung ber nämlichen $\mathfrak{W}_{\text {orte }}$ bei jebem (Eintrage. So bildet bie Tabelle

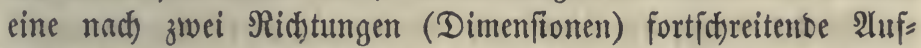

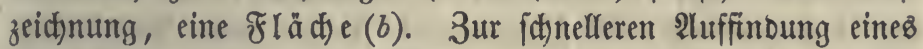
jeben $\beta_{0}$ fiten bient bie gute 2 Lufeinanberfolge ber Cinträge, weldje auf boppelte Weife geidekhen fann,

1) rein nad) ber 3eitfolge (d)ronologifde Dronung), wie ez inzbefonbere bei ber erften 2 lufzeid)nung ber Ereigniffe noth) wentig ift;

2) nad) eimer $S_{\mathfrak{a}} \mathfrak{d}=$ (realen) $D \mathfrak{r} \mathfrak{n} u \mathfrak{g}$, b. h. einer aus bem $\mathfrak{W e}$ en ber nufgezeidjneten Thatjad)en hergenommenen Eintbeilung Derielben (c). Man mus fid bei der Entwerfung eines fold)en Syftems von Boftenrubrifen eben folwohl vor einer zu fünftlidjen, verwiďelten, alz vor einer foldjen (sin= theilung hüten, bei weldyer man nod) viele fehr ungleidjartige Dinge in einem $2(b j d)$ nitte zufammenbringt $(d)$. WOQ viele 
ähnlidje Begenftänbe vorfommen, bie feine zwedmäpige Unter= abtheilung geftatten, ift es zuläffitg, fid) eines bequemen äußer= lidjen Srunbes ber Anorbnumg, 子. B. ber Amfangsbutchftaben ber Namen, zu bebiener.

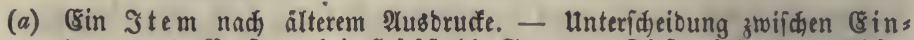
trag unt $\mathfrak{B}$ often bei $\mathfrak{S}_{\text {úffell }}$ S. 147. Diejer foll eir yollpån=

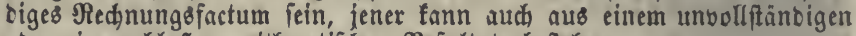
oder einem blofen arithmetifacen Rejultate beftehen.

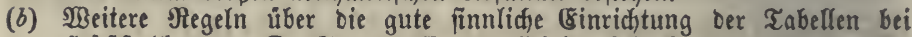

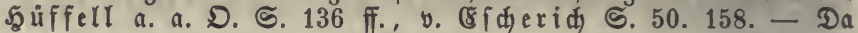

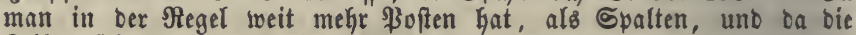
Seilen fefr geringe Breite haben, fo würbe, wenn man wageredste Eolumnen madjen wollte, bie Tabelle bei fehr geringer Şöfle in groß̉e

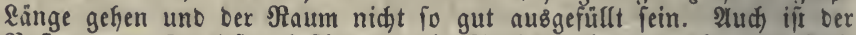
SPoften zum Fortleien beftimmt, Die Spalten bienen mefir zum 2 uf = fudjen und zum Bufammenredynen ber einzelnen Bahlen, wobei bie fents redite Stellung nüblid) ift.

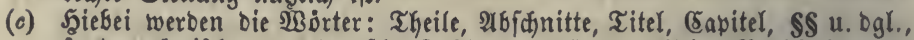
ferver römifje uno beutiche Bafilen, grope uno fleine Budftaben an: getwentet.

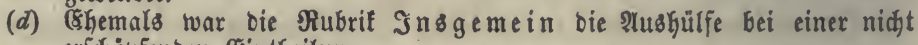
eridobjenten Esintheilung.

\section{§. 543.}

Die Spalten einer Redmung müffen affes bnsienige in fid aufnebmen, was you einem gewiffen wirthj(d)aftliden Ereigni ausgefagt werben folf. (E⿱ tommen:

1) Dronungbipalten, in benen bas bie Aufeinanber= folge Beftimmente angegeben wirb, Monat uno $\mathfrak{T a g}$, ober bei ber Sadjorbmung (\$. 542) bie Bezeidtmung ber 2tbtheilungen uno untergeorbneten 2l6janitte mit 3nhlen uno Budfftaten. Dod) fönnen bieje Spalten burd) Ueberid)riften uno 3ahlzeidjen zwifhen ben einzelnen Einträgen eriést werben $(a)$.

2) Benenungbipalten, worin bie Berantaffung uno

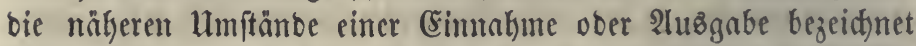
merben, unb zwar bei ben Red)nungen ber verwaltenben Stellen aubfübrlid) genug, um bic causa debendi uno ben Betrag z"l erflären.

3) 3ahlenipalten, weldye bie borfommenten Mengen von Bshitern gleidfer 21rt, unt zwar in einerlei (Eintheit nus = gebrituft enthalten, fo baß eine 3ujammenjählumg möglid ift.

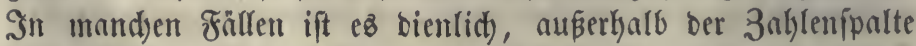

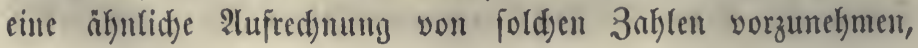


Die nod) nidjt zur 2lufnahme in bie Spalte felbft, alfo in bie Summe einer ganzen $\Re$ ed)nung reif find, z. $\mathfrak{B}$. Weil ein zu berredynendes Ereigni noch nidgt ganz vollendet ift unt nur borläufig angemerft wirb, ober weil bie 3ahlen erft in bas bei ben übrigen angenommene Naaß umgewandelt werben můffen; 3ahlen innerhalb ber \&iule, innergalb $F a l z e s$, intra lineam. Nandye Redynungen haben zwei 3nhlenipalten, beren eine die fämmtlidjen einzelnen 3ałlen jeder Arbtheilung, die zroeite nur bie Summen berfelben aufnimmt unb baher bie 3ujammenję̧ung bes Şauptergebniffez leidter überjehen läpt.

4) $\mathfrak{B}$ erweifungşpalten, um bei jebem łoften nonbere mit iffm in Berbindung ftehende 2lufzeidjnungen, z. $\mathfrak{B}$. Die

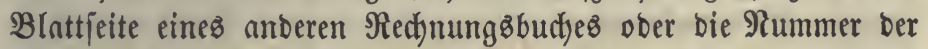
beigelegten Berweisurfunden angeben zu fönnen.

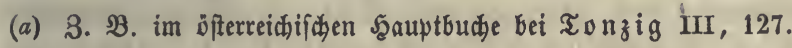

\section{ङ. 544 .}

In ber (S) IDfpalte Der Rechnungen wurben fonft mur fold)e 3aflen aufgeführt, weldye bie mirflid) erfolgte Reiftung aubotritfen uno baker auf ben (5)lovorrath ber Caffe Einflup haben. In neuerer 3eit hat man eż zwedmåąig gefunben, bei einem und bemfelben floften mebrere unter verwandte Bezies hungen gebörenbe 3ahlen in nebeneinamber ftehente Spalten einzutragen. Mlan untericheibet folgenbe Srößen:

a) Die im Boranjd)lage (Stat, \$. 465) für eine gemiffe

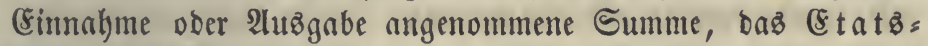
ioll. Die Etatżahl, ba fte nur eine Ermartung ober eine

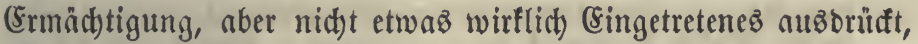

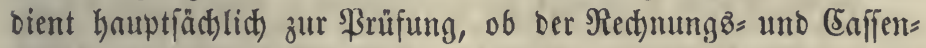
führer feine Befugniffe nidht überfdritten und überhaupt feine ßflichten nidht verlebst hat. Die Beifügung eimer Eitatşfpalte gefdieht gewöhnlid) nid)t in einer aub̧ülyrlidben Red)nung, wo

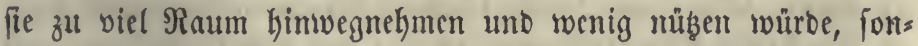
bern in eimem, ber höheren Bebörbe borgelegten 2ubjuge $(a)$. b) Diejenige Summe, zu beren (Entrictung in bem $\mathfrak{B}$ errect)= nunģzeitraum eine beftimmte $\mathfrak{B e r b i n d}$ lid)feit eingetreten ift, baz

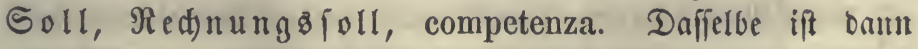
zum Eintragen reif, wenu bie Sduuldigfeit ber 3ahlung anerfaunt 
uno ber Betrag berfelben volffänbig aufgehellt worben ift. Bei einem Theile ber Einträge ift biefe Beftimmtheit fdjon am

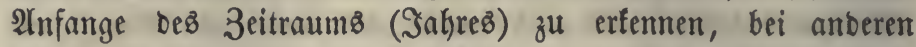
ergiebt fie fict) erft im Saufe beffelber. c) Die wirflid) erfolgte

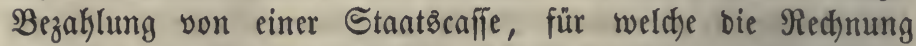
gefülyrt wirb, ober an biefelbe, bas $\mathfrak{F} a t$, Şft, realizzatione.

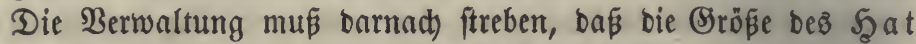

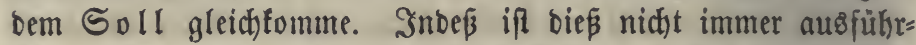
bar, weil man bei ben 3ablungepflidtigen oft auf eime $\mathfrak{U n}_{\mathfrak{n}}=$ fähigfeit ober irgeno eine Berbinberung ftöft, uno aud) bie Staatėcaffen bişweilen in ber $\mathfrak{B o l l z}$ ziefyung aller ifnen obliegen= ben 3nhlungen Sdjwierigfeiten finben. Daher pflegt bas ge= fammte $\mathfrak{S C}_{\text {at }}$ mehr ober weniger hinter bem Soll zurüd zu bleiben, bod vermag bie Sorgfalt ber Finanzbeamten fegr viel zur Annäkerung bes Şat an bas Soll. d) Der Unterichied

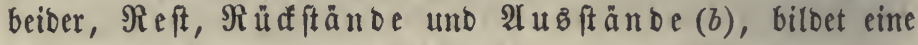
auf ben fpäteren 3eitabidunitt übergehenbe Forberumg ober Sdjuld (c). Rady einem älteren Berfahren wurbe bei jeber Bofition nur biejenige Sröß̈e angegeben, die man heutiges Tages Soll nent, fobann aber wurben bie Refte unter ber

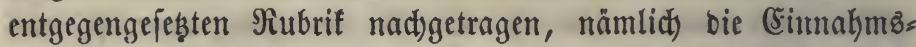

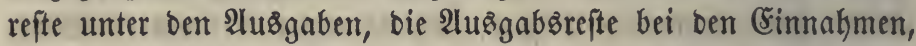
ober man führte in ber Siect)mung mur bas F̧at auf und feşte

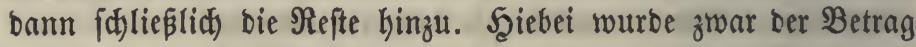
bes $\mathfrak{S}_{\text {at }}$ ebenfalls ridtig gefunben, aber bie Darftetlung war minoer naturgemä als bie nettere.

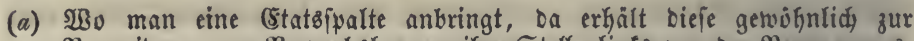
Bermeibung von Bertechblungen ifye Stelle linfs von Der BenennungB: fpalte. Slandie Rednung $=3$ ufammenitellungen erfalten nod) eine be=

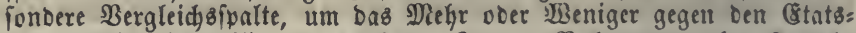
fabs fogleid bemerflid, zu madhen. In ben Rechnungen ofne Ingabe

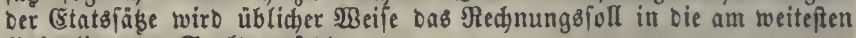
linfs liegende Spalte geiegt.

(b) Die Cinnaljmbrefte follte man $\Re$ u fit a ft ä noe nennen, man braudht jeood oft Den lez̧teren Rluborud für beibe.

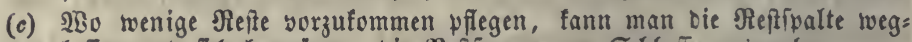

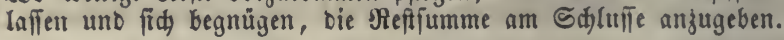

\section{§. 545.}

Eine Borbebingung fowohl zur guten $\mathfrak{B e r w a l t u n g}$ cines getwifien Bebietes von wirthidgaftlidjen Eefdjäften als zut guten 


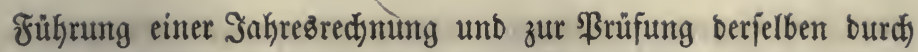
eine vorgejęte Stelle ift bie genaue Renntniß ber in ben $\mathfrak{W i r}=$

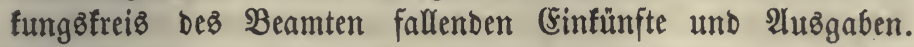

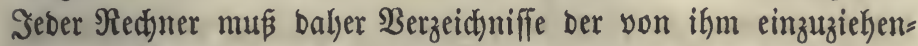

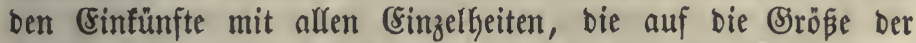
Summent uno ber $\mathfrak{B} e r b i n d$ lidfeit ber 3ahlpflidtigen $\mathfrak{B} e$ z̧ug Kaben, ebenfo Berzeidniffe ber bem Staate obliegenben Ent-

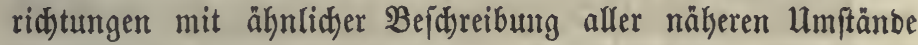

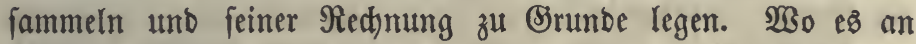

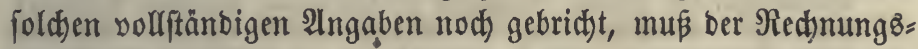
beamte fie zu Stanbe zu bringen futden, fo wie er aud alle

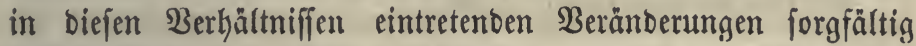
auffuzeid)nen hat, bamit jeberzeit ber gegentwärtige 3uftand flar

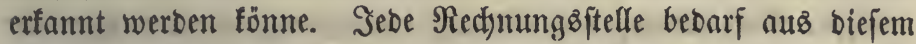
(Brunbe verjdjebener Beid)reibungen und Berzeid)nifie (Inven= tarien), zu benen bei ben mit ber Berrectymung von Sdjabsungen beauftragten Beamten audich bie Ratafter gehören.

\section{§. 546 .}

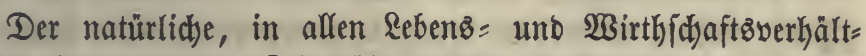

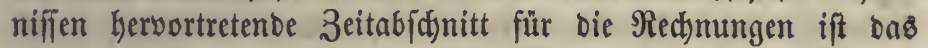
Sahr. In einzelnen \&änbern ift ber $2 \mathfrak{n}$ fang bez für bie Staatz=

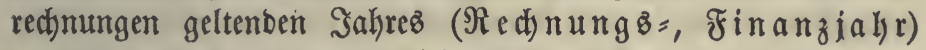
veridfieben beftimmt worben $(a)$, Dod) verbient bas Calenberjahr Den 20 orzug. Sebe mit Einnahmen und 2 tusgaben beffäftigte unb folglich eine (Saffe führenbe Finamzberwaltungsfetlle hat eine Sahresiechnung zu verfafier. Den Sngalt berielben liefert bie während cines Sahres fortforreitenbe, fogleid auf

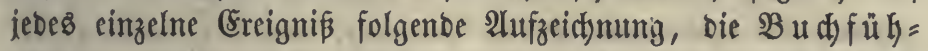
rung. Damit beibe Beftandtheile Des Pechnungögejdjäftes nict)t allein zmedmäßig, fonbern audd) im ganzen \&anbe gleid)=

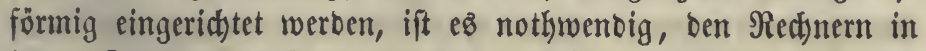
jebem 3weige bes Finanzbienftez ausführlidde Borfdriften für

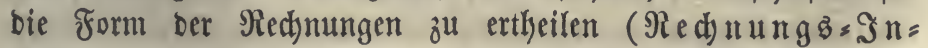
ftructionen) mit ben zugehörigen Nifftern (Formulare

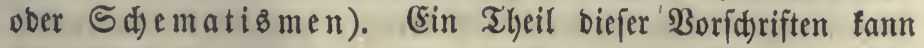

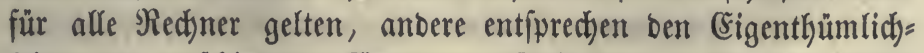

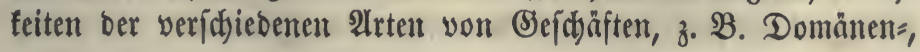




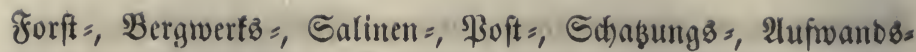
fteuer = und inzbefondere nod) 3olls, ferner Sdjuldenverwal= tung 2 c. $(b)$.

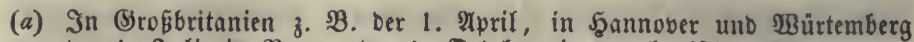
Der 1. Sull, in Bayern Der 1. Detober, in ben babifden Rirdens und

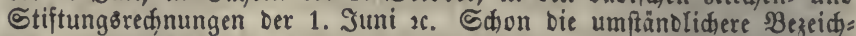
nung Der Sahreşahl, \&. B. 1859/60 ift eine Raft. Daß́ man nidht ichon immer ben 1. Somune zum 2lnfang nagm, rührt vermuthlid) von Der ßüufficht auf Domanialgefälle her, bei benen man beforgte, zu viele

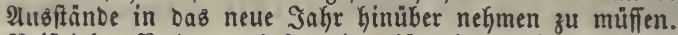

(b) Beifpiel: Rednungzinftruction für Die unmittelbar unter (Sroßherzogl. Diniferium Des Snnern, fatholifde Rirdenfection, fekenden Etiftung: Berivalter. Rarl8ruhe 1836. 4. (Berfaßit von DebattiB. Die fird =

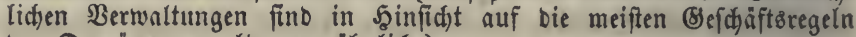
Den Domänenvertwaltungen ägnlid.)

\section{§. 547.}

3ur Buđfführung eineż Finanzperwaltungs̊amteż gehört vor

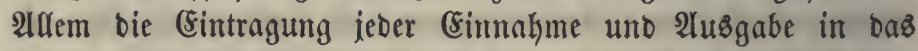
CEaffentagebud), Sournal (a), weldjes ben Stoff zur Biloung ber anberen Nedjnungen in fich fdjlieft. Heber bie (Sinrid)tung Defiflelben laffen fid) nadjftehende Regeln auffellen.

1) Berwaltungen, welche Raturalien einnelymen und auşs geben, müffen neben bem (Seld = nod) ein Raturalien $=$ Tagebud halten, weld)ez für jebe 2 rtt ber vorfommenden (Süter, $\mathfrak{z}$. $\mathfrak{B}$. für bie veridjiedenen Frudtgattungen, eine eigene Spalte erbåalt.

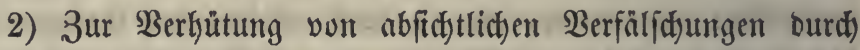

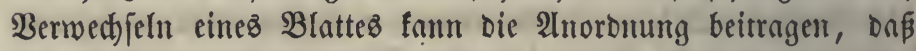
baz̉ nod) leere Tagebud) bon einem höheren Beamten paginirt und bie Seitenzabl beurfunbet wiro $(b)$.

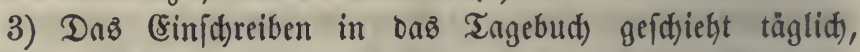
jogleid) bei bem anzugebenben Borgang, nact) Der 3eitfolge Der Ereigniffe.

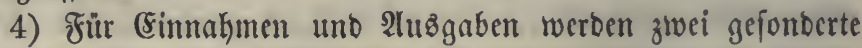
(Berofpalten gebiloct. 2lud) bie Benennungşpalten für beite Borgänge fömen getremut feir, intoç ift es aud) zuläfitg, fid) mit einer eingigen zu begmügen, in weld)er bie $\mathfrak{B e r a n l a f f u n g e n ~}$ von (Eimnabmen unt 2luģgaben burd) einanber, wie ca bie Reifenfolge in ber 3eit mit fid bringt, aufgefülyt werben (c).

5) Der Tag wird in einer eigenten Spalte ober in ber Benenmungsipalte wie sine Uteberid)rift aufgezcidynet. 


\section{5}

6) Die Berweifungşpalte beziefyt fid auf bie Seite bes Şauptbudtes (\$. 549), in ber jeber Cintrag anzutreffen ift, ferner auf bie Nummer ber Belege (\$. 553).

(a) Daffelbe ift yon bem faufmännifjen Sournale, einem Yionatbbudae, ganz verifieden, fommt aber Dem Cafienbude Der Raufleute nake.

(b) Esbenio Das 2nfiegeln ber feidenen ફ̧eftidhnur an ben (sinbano, um bas

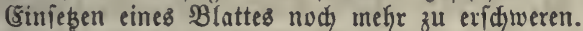

(c) In Franfreid befteht Daz Tagebud aแz je zwei einander gegenuber= fiehenden Blattieiten für Einnakmen uno 2ubgaben. Eben fo Das Tngebuch Der bab. Dbereinnefgmereien, $\mathfrak{B}$. v. 17. Jutui 1835.

\section{§. 548 .}

7) Finbet man im Tagebudje eine irrige 3akl, fo barf an iffe nichto veränbert, fonbern es mús burd) einen entgegen= gefeß̧ten Eintrang Der Fehler vergưtet werben, jo dá⿱ z. B. wegen

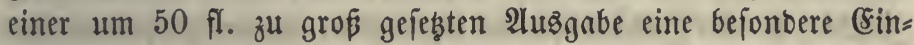

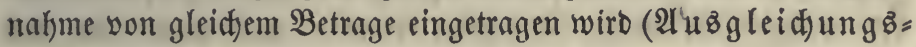
poften).

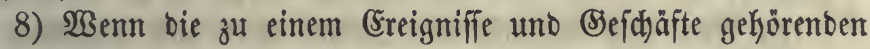
3aklungen nod) nidjt ftattgefunden haben ober nod) nidft ur= fundlid) bewiefen werben fönnen, fo werben fie einftweilen innerhalb ber Sinie vorgemerft.

9) Dbgleidf in ber $\Re e g e l$ bas Tagebuth) (a) nur bie wirt= lidjen 3ahlungen aufnehmen foll, fo müffen bod in einem folchen Falle, wo entgegengefegte 3ahlungäberbindlidffeiten burd) 2lbred)nung ganz ober theilmeife aufgetyoben werben, ber Bolfftünoigfeit wegen bie beiberfétigen ganzen Reiftungen, alz wären fie wirflid) gefichehen, in 2lufrect)nung fommen. So wirb aud baв (Erlöfd)en einer fajon in Soll aufgefüfrten Forberung

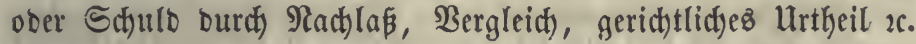

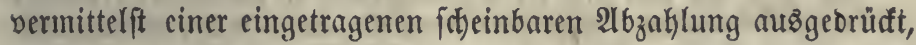
weil fie fonft beim 2lubbleiben bez Scat im Refte bleiben würbe (b).

10) Sommen felse viele fleine (Einnahmen vor, wie bei einem 3ollamte, fo ift es angemeffen, ein bejonderes cinnalymebudi zu füfren, aus weldem nur bie Şauptfummen regelmäßig ins (Eaffen= Tagebutd) aufgenommen werben. Bei einem größeren

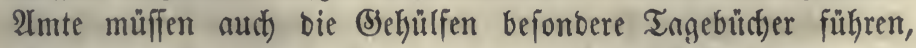
beren Inthalt balo in bas Şaupttagebudi) herüber genommen wirb. 
11) Im Enbe jeber Seite wirb bie Summe ber Einnahmen unb 2lusgaben gezogen (Seitenfumme, latus), bie man fobann auf bem elnfange ber folgenben Seite als uebertrag (Transport) wieber auffüfrt.

12) $2 m$ Sd)lufie jebes Monats (ober felfit jebes Tages) wirb bie Summe ber beiber jeitigen \$boften gezogen unb burd) Bergleid)ung ber Einnahme uno Aluşgabe ausgemittelt, wie hod) fid) ber vorhanbene (aaffenvorrath belaufen müfife. Mit

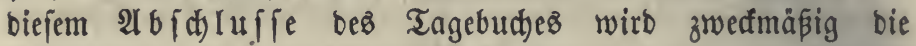
Unterfuctjung Des wirflidjen Eaffenftanbes burd) ben Redjner felbft in Berbintung gefeşt, beren Ergebnís bann in bem Tage= buthe gleidffalls angemerft wirb (c). Rleine Unterfajiebe bes red)mungsిmäpigen und bez wirfliden $\mathfrak{B o r r a t h e s ~ f o ̈ n n e n ~ b u r d ) ~}$

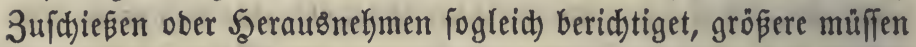
Der vorgejesten Stelle angezeigt werben uno man mus fít) bemüken, bie Mrfacte ber 2(bweid)ung ausfinbig zu mactjen.

13) Rad) bem Sdyluffe bez Jahrez wirb bas Tagebuch an bie höhere Behörbe eingefentet, bod) ift ez geftattet, eine $26=$ fdrift zurüafubefjalten $(d)$.

(a) Form bes Tagebuchs f. im 2tnhang I, Bgl. Tonzig I, 121.

(b) 3. B. A Gat 300 fi. Fuhrlohn zu empfangen und 260 fi. für gepadjtete פ্Biefen zu bezahlen, empfängt alfo nur 40 fi. baar; aber beibe Summen

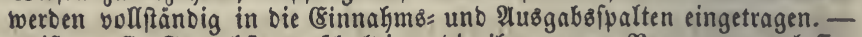
$B$ ift 12 fi. Bewerbfteuer ichuldig, bie ifm wegen Berarmung erlafien ift, io wiro biefer Betrag in Einnahme und aud wieber in शhesgabe géfę̧t.

(c) Dan fann audi an jebem anberen beliebigen Tage mit geringer शhähe Das Journal abjhliesen uno fo ben Eaffenbeitano ausechnen.

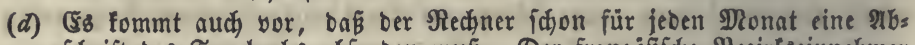

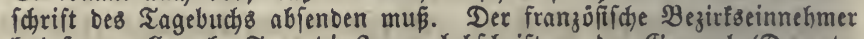
hat fogar alle zefn Tage tie Journalabfdrift an ben (Seneral. (Departe: ment8:) Sinnefmer, biefer feine Journalabidifift an bas Finanzminifte=

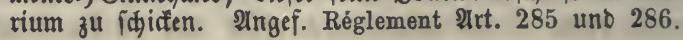

\section{§. 549.}

2us bem Tagebudje werben bie ßoften in bas nad) einer Sadjoronung angelegte $\mathfrak{S}^{2} u p t b u d$ ) (Manual, grandlivre, libro maestro) übergetragen. Bei ifm zeigt fid ber

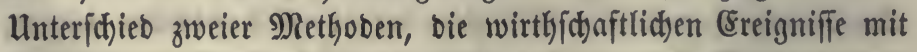
einanber in Berbinbung zu feb̧en, b. h. bes $\mathfrak{B}$ aue

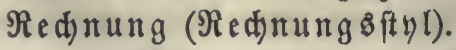


1) Der Rameralfyl befteht in eimer iyfematifden 2 th = orbmung ber in ein $\mathfrak{B e r w a l t u m g s a n m t ~ g e f o ̈ r e n d e n ~ E i n n a h u i t : ~}$

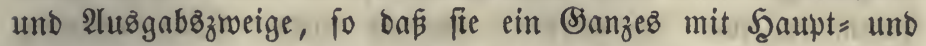
Unternbtheilungen bilben. Indem man bie Summe ieber flei= neren uno größeren श्रbtheilung und endfich bie Şauptjumme Der Esinnakmen unb 2lużgaben zieht, gelangt man zu einem

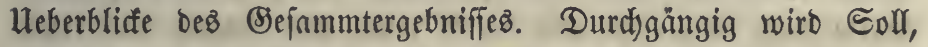

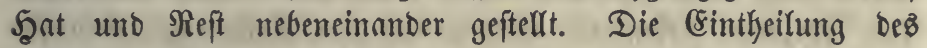

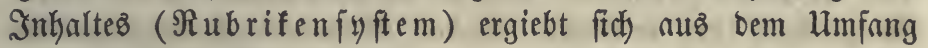
unb ber Bejdaffenteit ber zu verredjnenden $\mathfrak{B o r g a ̈ n g e , ~ z . ~} \mathfrak{B}$. Bergwert $=$, SBoft =, Steuercaffen 2 ., bod) laffen fid gemiffe Şauptunterffecibungen überall antwenten $(a)$.

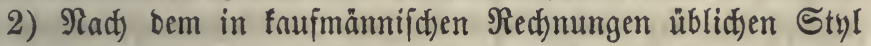
Der italienifden ober Doppelbudhaltung wirb eine Inzahl von einanber getrennter Red)nungen geführt, beren iebe

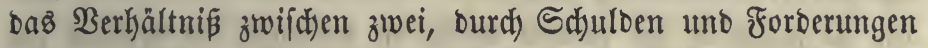
mit einanber in $\mathfrak{B e r b i n b u n g ~ f t e k e n b e n ~ \$ e r f o n e n ~ e n t h a ̈ l t . ~ E s z ~}$

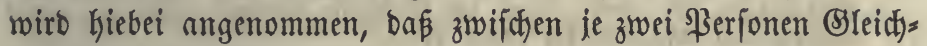
Keit ber gegenfeitigen Reifungen ftattinten müffe, Daß aljo ber Mekrbetrag (saldo) Deş yon einer \$erfon Beleifteten ein B)ut= Kaben berjelben und eine Sdjulb ber anbern begrünbe. Waas

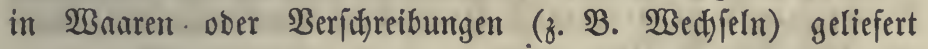
ober an 2 rbeit geleiftet wiro $(\mathfrak{z}$. $\mathfrak{B}$. bei faufmännif̧,en $\mathfrak{B}$ ejor= gungen, wie (Sommiffiton, Spebition), fintet nad) Dem Selds= anjidlage feime Stelle neben ben wirfliden 3ahlungen von

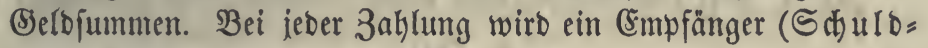
ner, debitor) uno ein seber (Şläubiger, creditor) auf= gefudt) unb benannt. \&äpt fith bei einem Cintrage eine foldje erforberlidfe \$erion nidft auffinden, fo wirb eine erbid)tete (fin= girte) ßerfon zu Şutlfe genommen, weldye einen Theil ober

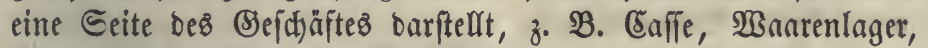
Berwinn und $\mathfrak{B}$ erluft. Sebe Reifung muß Daher zweimal in bie Rect)mungen eingetragen werben, nåmlich fowohl in bas (S) bigfeit (ङoll, debet) eines (Empfängers, woraus fid ergiebt,

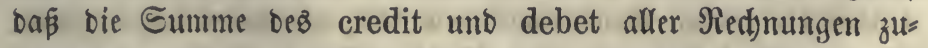
fammen gleid) fein múfie. Sebe biefer einzelnen Nect)mungen (conti) wirb für fich) abgeid)lofien, um ienen Mefrbetrag zu 
Bunften bes einen Betbeiligten zu ermitteln. Die einzelnen Redfunngen find nid)t bazu geeignet, in eine einzige große zufammengefügt zu werben, oagegen bienen einige berjelben

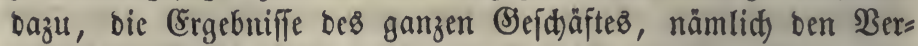

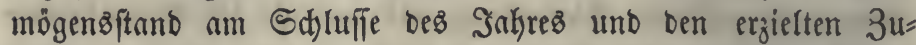
wad) (B) Bewinn) ober ben erlittenen Berluft furz barzuftellen,

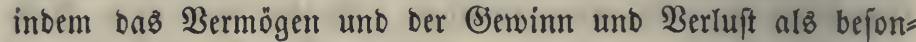
Dere ßerjonen behanbelt werben uno ifre Rechnung neben ben Red)mungen ber wirflichen in bas (Sefanmtbuch aufgenommen wirb (b).

Die Doppelbudbaltung ift bemmach bie vorftänbige Dar= ftellung ber ßerbältniffe zwijd)en einzelnen ßerjonen, Der Rame=

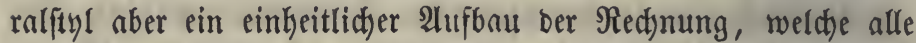
Borgänge in Beziehung auf eine einzige ßerfon, die Berwal tungôftelle (๕affe) bezieft (c).

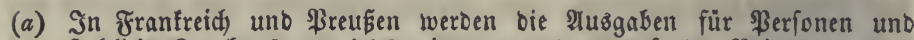
fad)liche 3medfe (le matériel) einanber entgegengefest. Bei Den meiften Redjnungen über einen Theil Der Einfünfte fommen unter ben Damit verbunbenen Alusgaben die Laften vor $2 c$.

(b) Die Doppelbudhaltung, eine Erfindung ber Staliener, if ein Durch

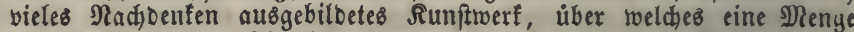
bon Anleitungen gefdrieben worben ift. Angabe vieler Sdyriften bei

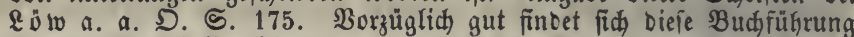
abgefandelt bei Bleibtreu, Sandbud Der (Eontorwifienidaft, Rarls= ruke 1833 , ऽ. 335.

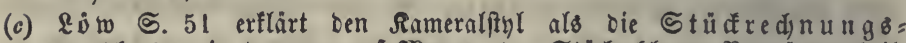
methode, in Der nur nuf Nienge ober Stüdzahl Der Bermögenstheile

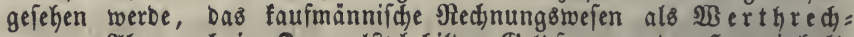

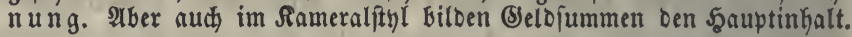

\section{§. 550 .}

Bei Der Wahl zwijd)en beiben 2lrten beż $\mathfrak{B a u e z s ~ b e r ~ \Re e c t ) = ~}$ nung ıuß auf bie Befdaffenkeit ber zu verredynenoen wirth= (d)aftlid)en (Sefd)äfte Rủffitht genommen werDen. Şiezu bietten nadjitebende Betrad)tungen.

1) Ṡm Şanbel $(a)$, und ben Banfgefdåaften beftehen bie

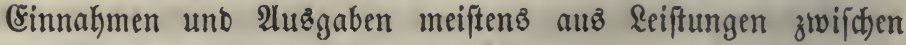
zmei ßerfonen, beren jebe das Empfangente vollftändig vers güten muß. (5s finbet eine Menge von gleidzeitigen unb auf einanberfolgenben Unternehmungen ftatt, bie unter fidf in feiner Berbinbung fteken, aber bie Berbältniffe von Forberungen unb Sdulben gegen viele anbere \$erjonen (Şanbelb̈freunbe) beftimmen. 


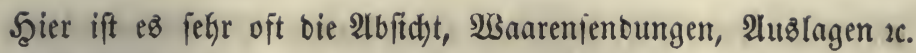
einftweilen auf Crebit unbergütet zu laffen, bis fich (Belegenkeit zu einer bortheilfaften 21rt ber Erftattung Darbietet, e\$s find folglid) feine foldhen 3ahlungszeiten vorkanben, bei benen ber

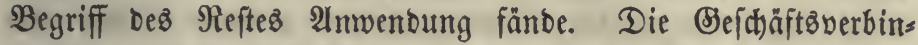
bungen mit ben Şanbelşfreunben fint eitanber ähnlid) und eine Eintheilung berfelben nach) Slaffen uno Sattungen wäre

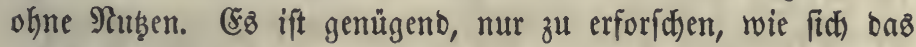
gefammte Euthaben unb bie gefammte Shuld ben Şandels: freunben gegenủber verhält.

2) In herborbringenben und Dienftgewerben (Woft, Eijens bahnbetrieb) fino bie meiften 2 usagnben als Roften für bie ganze Unternefimung anzuefen, aus benen fein (Suthaben gegen SBer= fonen entfeht, z. B. 2lntauf von 'Etoffen, 2lrbeitzlohn. Sowohl bier alछ bei einem Theil ber Eimnahmen erfolgen bie Zahlungen ohne Berzug und ohne bleibende Befbäftäberbinbung mit an= beren ßerfonen. Die Sinnahmen und 24uछgaben erforbern bagegen eine Eintheilung nad) Beranlaffungen und 3weden.

3) Bei ben Finanzberwaltungøä̈mtern, Denen gewiffe, nadh

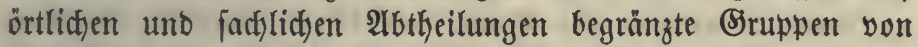

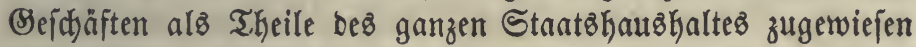
find, werben viele einfeitige 3 ahlungen angetroffen. (58 ift Gier entweder gar feíne bejonbere Eegenleiftung vorkanden (z. B. Steuern), ober biefelbe läpt wenigftens feine Aufnahme in bie Rechnungen zu (Sebüfren, Befälle, Befoloungen 2c.). In biejen Fällen ift aljo bie 2lngabe von Soll, Şat uno Reft hinreidjent.

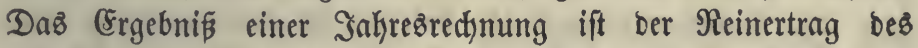

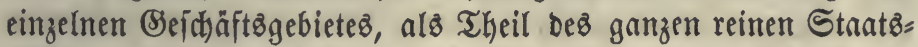
einfommens, weldes wieber für bie unmittelbaren Staatşaนs= gaben verwentet wird. Die Rothwendigfeit, für Mittel fur Beftreitung ber lebsteren zu forgen uno ber ziemlid) gleidfförmige,

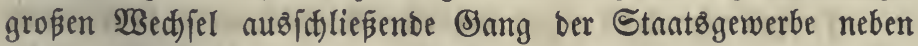
gleidjer (sigenfdyaft ber anberen Staatseinfünfte madt im

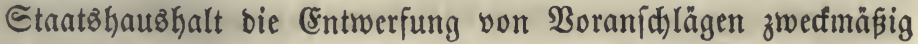
(\$. 465), bie in Den \$ribatgewerben uno Daker aud) im Rech)= mungşwejen berfelben nidjt vorfommen.

Demnach verbient in ben Staatsered)nungen ber Regel nad) ber Rameralftyl ben Borzug (b). Die Sahresiredjum bildet 
(iid) Kiebei yon felbft aus bem Şaupttuctje. WBürbe man biefes nad) ber Doppelbudblyaltung einridten, fo müste bennod) am

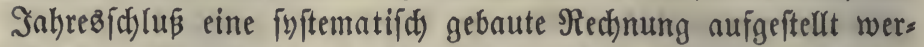

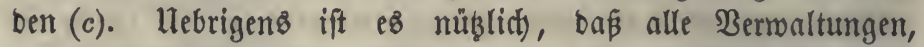
weldse in fortbauternber Berbinbung mit anberen Enffen ober ßrivatperjonen ftehen, für biefe Berbältniffife Abred)mungen füłren.

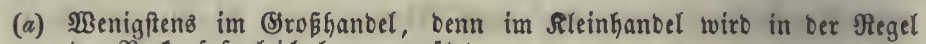
Der Serfauf fogleid, baar vergütet.

(b) In Deutidlano ift berfelbe nud Kerridjent. Bgl. Riefdite S. 120.Feber S. 47. - v. Mialdu \& II, 139.

(c) Neigebauer S. 118. - Franzöríi he $\mathfrak{B}$. v. 8. Nobbr. 1820 unb Rapport de 1829 S. 51 Der 3. Abtheilung.

§. 551.

Dab Şauptbudi) in bem Sameralftyl wirb nad) einem für

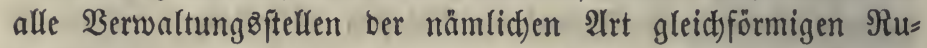

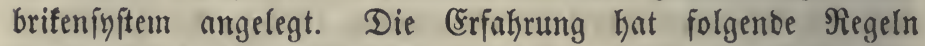
für bie Frührung beffeltben nlz zwedmäsig erfennen lafien.

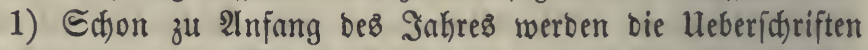
ber Atbtheilungen (Rubricirung) in bem zum Şauptbudbe bes ftimmten Banbe fo eingetragen, Daß für jeden 2bichnitt ber muthmaßlid) erforberlidje Raum leer bleibt, uno bie einzelnen Einnalyms = แtno 2lusgabspoften werben fodann, wie fie fith ereignen, auz bem Tagebudje herüber geidjrieben. Bei jeber Unterabtheilung fteken biefelben nadh ber Zeitfolge, mit Ingabe

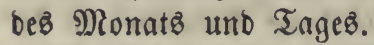

2) In ber $\mathfrak{B}$ enenmungsipalte werben bie Uumftände, weldye über bie Uriadje und ben Betrag ber Reiftung 2luffdlü geben, furz uno beftimmt angegeben, in einer Berweifungsipalte aber

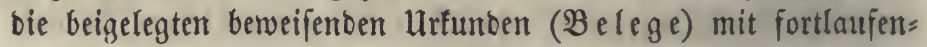
ben $\Re u m m e r n$ angezeigt, bie zu jebem Eintrage gebören. Eine anbere Spalte zeigt bie entfprestyenbe Blattfeite bez Tages bucjes an.

3) 2uf ber Geite, wo fith eine 2totheilung fdhließst, wirb nidst mefhr bie folgente angefangen, unt auf ieber Seite wirb unten bie Summe ber auf ihr ftehenden Einträge gezogen, bie man jebod) niç)t überträgt. 2Im (Enbe ieber Unterabtheilung werben bie Summen aller zugehörigen Seiten zujammengeftellt unt zufammengezählt (WBieberholung, Recapitulation), ebenfo zu Enbe jeber größeren Abtheilung bie Summen ber 
Unterabtheilungen und enolid) bie Befammtheit ber Einnakmen unb 2lusignaben. Die Bergleidung ber beiben Şauptjummen bes Şat beutet ben (5afienreft an, ber mit bem 2(bid)luffe Des Tagebuches übereinftimmen mußs. Wirb aber ber am eEnte bes

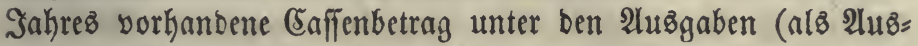
gabe an bie neue Rechnung), fowie ber zu 2Infang bes Sakres vorgefunbene unter ben (Sinnahmen verrechnet, fo müffen bie Summen ber Einnahmen uno 2luşgaben im Şat eitunber ganz gleid) fein.

4) Naturalien erfhalten ein bejonberes Şauptbud (a).

5) Füfrt ein Beamter bie Berwaltung mefrerer ganz ver=

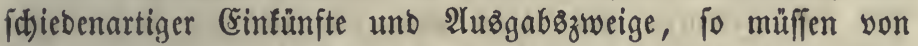
ifin eben fo viele getrennte Şณuptbủcher gebalten werben.

2uber bem Tage = unb Şauptbutbe werben je nad) Der 2 rt Der Sefdjäfte nod) verichiebene anbere Büd)er nöthig, um alle

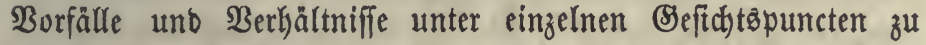
orbnen unb in Berbinbung zu feksen. Das bäufigfte biefer Büd)er ift Das शbred) idiebenen Urjachen herrükrende 3aklungşverbinblichteiten einer \$erion uno bie woirflich erfolgten 3ahlungen zujammen zu faffen, ober aud) bie 2lbrechnungen (conti correnti, comptes courans) bei gegenfeitigen Reiftungen, z. $\mathfrak{B}$. mit altoeren Craffen aufzumehmen, \$. 550. Die-zahlreichften Derzeichniffe fommen im 3ollwefen vor. Die ben 3aklenben ausigelieferten ober in ifre Duittungabüb)lein eingetragenen Befdeinigungen müffen mit ben Einträgen in ben $B$ üchern genau übereinftimmen.

(a) Boridjlag, bas Tagebud mit bem Şauptbuctje zu veridymelzen, bei (S) $r$ a f a. a. D. S. 232 . - Formulare cines Şauptbudes im 2 n= hang II. unb III.

\section{ङ. 552 .}

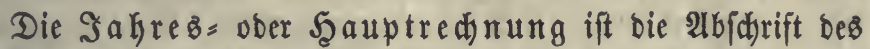
im Rameralftyle gefüfrten Şauptbudbeb, nur mit ber 2lbfürzung, baß alle Theilzaklungen für eine gewiffe Cinnahme ober 2lubs: gabe, wie fte im \&aufe bes Sakres nad) einanber vorfommen, in eine einzige Summe zujammengezogen werben, webfalb in biefer Rechnung feine Zeitbeftimmung angegeber wirb. Sie wirb eingebunben und mit einem Titelblatte verfehen, auf bem bie Benennung bes vertvalteten ßermögens, Desి 3eitraums 


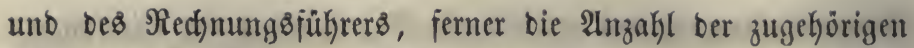
Beilagenbänte unb ber Tag ber cinjendung angegeben fein mußs. 2luct) ift es zwefmäßig, auf bem erften Blatte veridjie: bene allgemeine Nactridten, z. B. über oie Beftanotheile Dez werred)neten Bermögens uno über bas angeftellte \$erional, beffen Dienftverthältnifíe uno bie geleiftete Dienftbürgid)aft Kin=

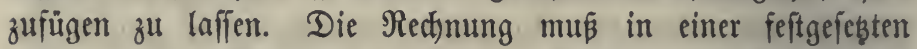
Frift (einigen Monaten) nad) bem Sdylufie bez Red)nungs: jahres faumt ben Belegen zur SHruffung abgegeben werben.

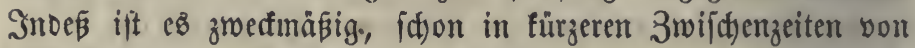
bem 3uftante einer Berwaltung Rad)ridbt einz̆uziehen, weßkhalb

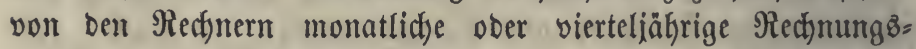

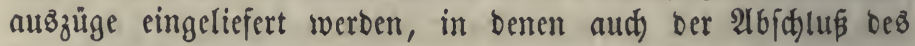
Tagebudes angegeben wirt.

\section{§. 553.}

Die Rednungzbelege (Beilagen, $\Re$ ed)nungs = urfunben, pièces justificatives, documenti giustificativi) bienen theils ieben Esintrag zu erläutern, theils aber bie Rid)= tigfeit beffelben Darzuthun. Ein Theil Der Einnahmen unb

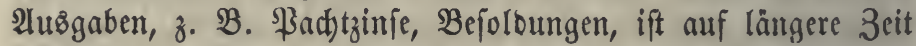
feftgeftellt unt bebarf baher teiner wieberkolten Recttfertigung,

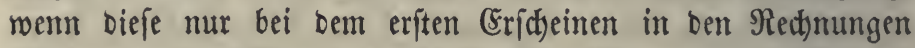
gegeben wirb. Bei ben anberen (sinträgen mus burd) bei= gefügte Urfunben bei ben Einnahmen ber Berweiz geliejert wer= Den, Daß biefelben fith nidht höher belaufen haben, als es die

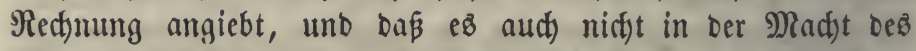
Berwalterz gelegen ift, mehr beizubringen; bei ben 2นuछ̊gaben muß bewiejen werden, Dá bie Berwaltungsffetle befugt war, fie

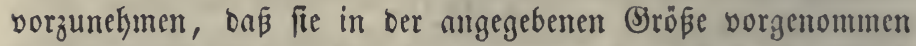
werben mußten und wirflid) vorgenommen worben find. Şiezu finb ie nach) Dem Begenftante ciner (Eimnahme ober Atuägabe verictjie=

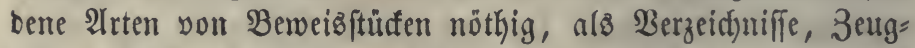
nifiee, Berträge, Befehle höherer Stellen (Anmeifungen ober Decreturen), \&rototolfe, Bejdeinigungen u. bergl. Alle bicje Belege müffen in ihrer form bie Bebingungen ber Slaubwür= bigfeit (Utrundlidfeit) an fid tragen. Daljin gehört eigen= bänbige Unterfdjrift anberer Berfonen, - Beglaubigung Der 
Unteridgriften, wenn ein 3weifel zu bejorgen ift, - 2utgabe ber Summen mit Budfitaben - Bepdeinigung ber Reiftung, für melde eine 3aklung gemadht wirb, von ben bazu befugten ßerionen, - Deutlidje Bezeidjung Dez Grumbes ber 3aflung, -

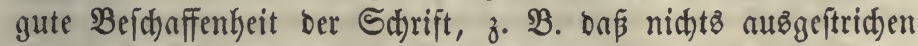
ober aużgefrabat ift $\mathfrak{u}$. ogl.

\section{§. 554 .}

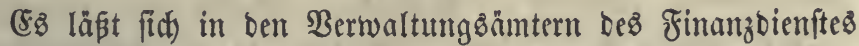
nidjt bewirfen, baß mit bem 2lblaufe bes Sahres alle für barfelbe beftimmten Eimnahmen umb alle für bie Bedürfniffe beffelben

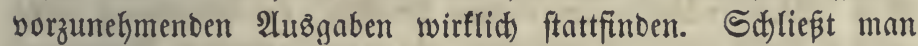
bie Rect)mung mit bem Sahre, fo ziehen fid unvermeiolid mandfe 3ahlungen in bas folgende Sahr hinüber, bie in bem vorker= gekenden ifren Bruno haben. Würbe man nun bieje mit ben Ereigniffen des nädjtfolgenden Sahres zufammentwerfen, to würbe eine Ungenauigfeit entfteken, bie befonders in foldjen Fällen nacttheilig wäre, wo Beränberungen in ben $\mathfrak{B e r w a l}=$ tunggignumbfäben, im Steuerfyftente, in Dem ßerfonale Der Beamten 2c. vorgegangen fino, bie es nöthig madjen, bie wirth)= iđjaftliden Ergebnifife eineż ieben Sahres forgfältig von ein=

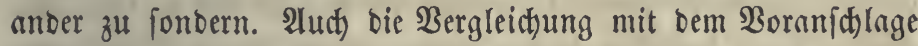

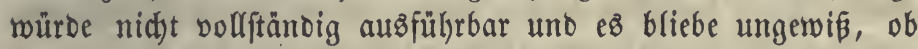
in einem einzelnen Sahre bie Finnmzerwaltung ifren Dofiegen= heiten yolffündig Senüge geleiftet habe $(a)$. Die 2umahne, baß von iebem Sahre ungefähr gleidbiele nod) unvollzogene 3ahlungżnerbindlidfeeiten in bas folgenbe übergehen, giebt feine genügende Beruhigung, benn fie trifft nid)t inmer zu. (sin Mittel, biefe Schwierigfeit zu bejeitigen, befteht in ber fran= zöfifden (Sinrid)tung, nach ber zwar nach Dem (Enbe einez Sahrez bie Nechmung vorläuftig abgeid)lofien, aber bod) zugleid) geftattet wirb, alfe bie Berwaltung (exercice) biefez \$afhrez betreffenden, ipäter vollzogenen (Eimmakmen und 2lusigaben nod)

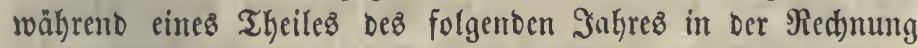

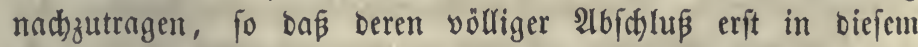
erfolgt. Diejer 3eitraum ift lang gemug, fo ba Rüffitände übrig bleiben $(b)$.

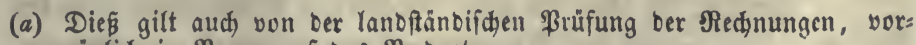
züglich in Bezug auf oas Butget. 


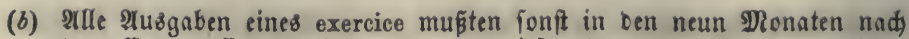
bem (Eñe beffen bereinigt und angerwiếen (liquidées et ordonnancées), alle Baflungen von Esintünften und Fubgaben bis zum 1. Detober bewirft werben, fonft erloficen bie Bewilligungen. Dody blieben ben

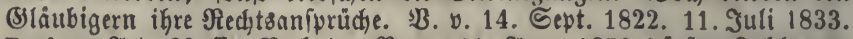

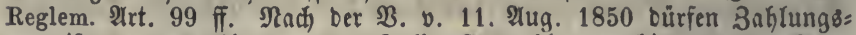
anweifungen nur bis zum 31. Suli, शిเszaklungen bis zum 31. Rug. geidehen. An biefem Tage wirb bie Rechnung enogültig gefdilofien.

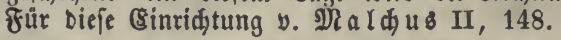

\section{§. 555 .}

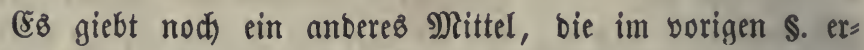
wäknte $\mathfrak{B e r m e n g u n g ~ D e r ~} \mathfrak{B}$ orgänge mehrerer Sahre zu vermeiben.

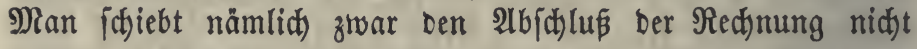
hinaus, hält aber in berfelben bie bem laufenden Jahre an= geförenben \$often yon benen, bie aus ben frükeren Jakren herrühren, ganz getrennt. Zu biejem $\mathfrak{B}$ ehufe werben wenigftens z'wei, bei einem beträdttlidjeren Ulmfange beş Begenftanbes aber brei Şauptabtheilungen ber (Einnafmen uno 2 (ügaben gemad)t:

1) Borgänge (\&tatorec)nung) bez̉ laufenden Sahres;

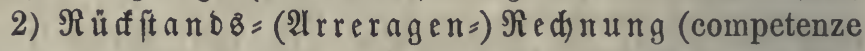
arretrate), beren Soll fhon in Der vorjährigen Rechmung feine Stelle erfielt unb in bie pätere herübergenommen roirb. Bleiben

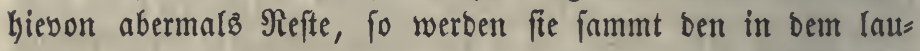
fenben Inhre hinzufommenten neuen, wieber in bie Rüffanbs: rechmung bes nadfolgenden Sahres übertragen;

3) (Etatored)nung früherer \$ahre, b. h. Die Aufs

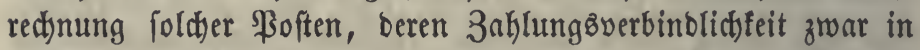
einem Boriafire entftand, bei benen jebod) bie fauldige Summe unb ber Empfänger ober 3ahlenoe erft jeķt befitimmt aubigemittelt (conftatirt) wirb, fo baß fie nod) nidjt im Solf eines früheren Jahres angefest werben founten uno baker nidjt unter ben Rüffänoen erfdjeinen, z. B. Die Roften eines Baues, beren Betrag erft nad) Bollenbung beffelben, nach ber (Eingabe und ßrüfung ber Forberungsిzettel befannt ift, - Erfabpoften, bie erfit nach ber Beentigung eines Rechtşftreites flüffitg (liquio) werben u. ogl. - Die meiften Einträge biefer Art beziehen fidd

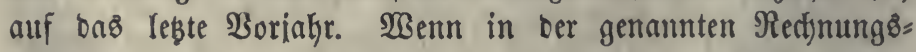
abtheilung wieber bie vorjährigen von ben älteren ßoften unter=

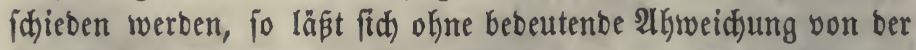
Wahrheit bas ganze, ber Berwaltung einesి Jahres angehỏenbe, 


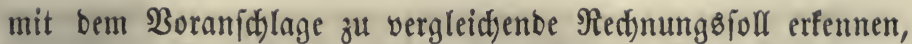
inbem man nämlid), wenn z. B. von ben $\mathfrak{B i r t h}[\mathfrak{d}$ aftzergebnifien

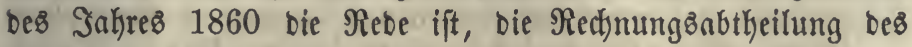
laufenden Jahres you 1860 mit ben in ber (Etatserechuung

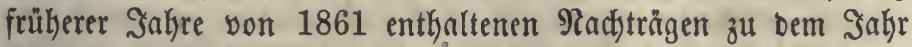
1860 in Berbinoung feşt (a).

(a) $\mathfrak{B}$. Der bab. Dberrechnungø̇ammer v. 29. Awril 1823. Im bab. Finanz=

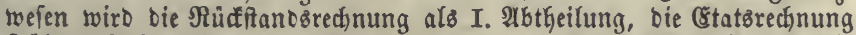

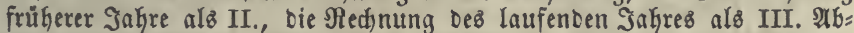
theilung bezeidinet. Seit 1834 werben in II. wieber unterfdicben a) Boften bes zunächif vorkergegangenen Jafres, b) von frükeren Jahren. Das Soll in I. ift ihon in ben Redhnungen vorkergegangener Jakre enthalten, nur II. uno III. begreifen ein neuermitteltes Soll in fid.

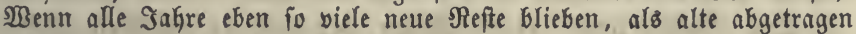
werben, fo würoe bas 5ुat von 21btheilung I. - III. mit Dem Soll von II. und III. ungefähr übereinftimmen.

(ร̧в war z. B. in Den orbentliden Staatzeinnafymen von 1857

I. Reite aus Der vorigen Nechnung (älteres Soll)

II. a) " aแb oem Sakice 1856 b) " aus frükeren Jahren

๔oII

921989 fi.

74290 "

$17369 "$

5at $15983 "$

784196 fi. 71107 $6 \cdot 105123$ Summe Des neuen Solls $\overline{17 \cdot 107949 \text { fi. }} \overline{16 \cdot 192213 \text { fí. }}$ Sauptiumme $\overline{18.029938 \text { fi. }} \quad \overline{16.976409 \mathrm{fI}}$. Das ganze Şat beträgt folglich um 131540 fl. weniger als bas neute

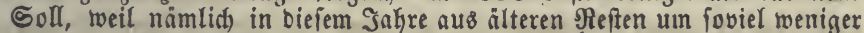
einging, als bon bem obigen neuen Goll bes Sahres in Nưfitand blieb.

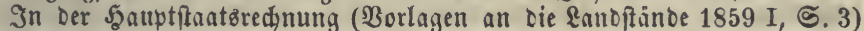
find zu obigen 3ahlen nod Die SSelD= und Naturalyorräthe, ferner bie Auştänbe Der uneigentlichen Ssinnahmen und bieje felbit vom laufenden Jahre beigefügt, vgl. $\$$. $556(a)$. - Begen Die Führung einer $a b=$

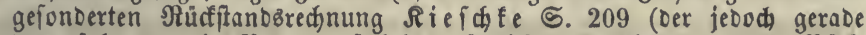

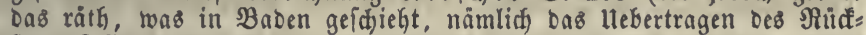

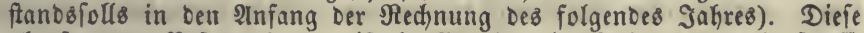

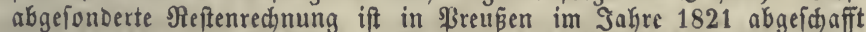

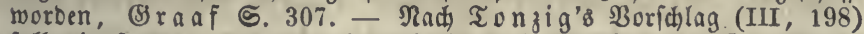
foll ein शluz̧ug aus bem Şauptbud)e nad) Dem Styl ber Doppelbudy= Galtung gefüht werben, in weldem als befondere Conti vorfommen:

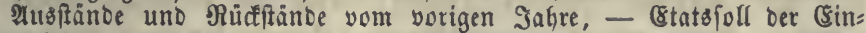
nahmen uno Ptusgaben, - Bermehrung uno Berminberung beiber gegen Den Boranidlag, - Einnakmen uno Ausgaben yon anberen

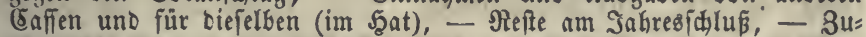
ober 2lbnakme bes ganzen Sermógens, worauf Dann nod) ausführ= lidjere Siedynungen für einzelne Theile folgen. Diefe Darfellung gewährt eine beutlide Heberficht. - Uebrigens find nuch befonbere Reft=

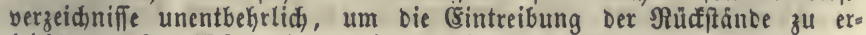
leidjtern. In \$Bturtemberg nimmt bie Şauptred)mung nur Das $\mathfrak{F a t}$ eines jeben Safres auf, fowie aud Der Boranid)lag mur auf baffelbe

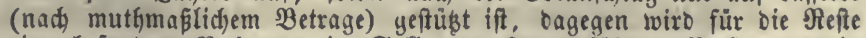

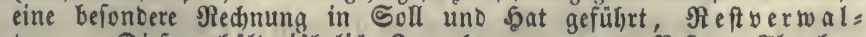

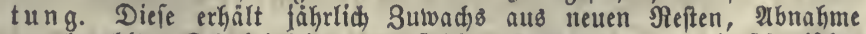

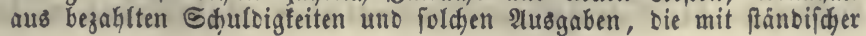


Bewilligung auf bieß̄ Reftvermògen angewieien werben. Die (5affen:

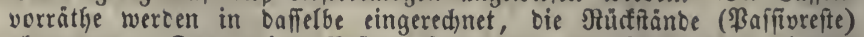

- abgezogen. Das reine Reftuermógen am 30. Juni 1857 betrug $4 \cdot 344214$ fl., wozu nod $3 \cdot 765054$ fi. vorhandene Betriebsfonos fommen. Man nahm an, Daß́ Gievon am 30. Juni 18585.527163 fi. eingegangen fein twürben, wovon 2 Nill. als Betriebsfonos Der Stants:

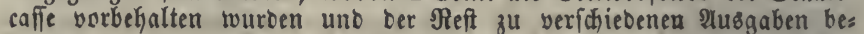
ftimmt wurbe, 3. B. 1.638000 fl. für ein zmeites (Seleife ber Giien=

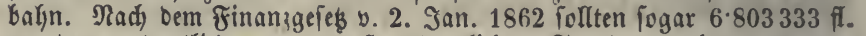
zu ben orbentlichen und auserorbentlicjen Etaatsausgaben aus Dem Reftuermogen genommen tverden. 3u ben झaffiureften wiro bie fditue:

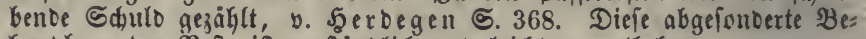
hanblung ber sefte if umptäblich uno leidgt zu entbehren.

\section{§. 556 .}

Die Rectnungen einer Finangberwaltung müffen alle ein= gehenoen unb wieber abfliekenten Belbfummen unb Maffen von Raturalien entfalten, bamit ber Red)nungsabfdylus in jebem Alugenblide ben Caffenbeftand unb Raturalvorrath, wie er fein foll, anzeigt und mit bem wirflidfen $\mathfrak{B}$ efunbe verglidyen werben fönne. (Es giebt jebod) (Sinnakmen uno 2luzgaben, bie, ob= ichon fie auf ben Eaffenbeftand Einflus haben, boch mit ben übrigen nidst vermentgt werben bürfen, weil fie fein wahrez Sinfommen und feinen wabren Alufwand anzeigen (I, \$.70a) uno baker feine Aenberung in bem ganzen $\mathfrak{B e r m o ̈ g e n b f t a n b e ~}$ bewirfen.

Şieber gefören 1) Beränberungen in Den Beftand = theilen Des Stammvermögens, twie eingezogene unb wieberangelegte Reibiummen, fermer bie 2lbtragung bon Sdful= ben, eingekende $\mathfrak{B e r f a u f z ̇ g e l}$ er von Riegenfihaften unb $2 \mathrm{~b}=$ löfungsిgelder, bie wieber irgenbwo werbent angewentet werben;

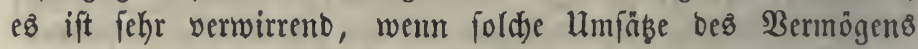

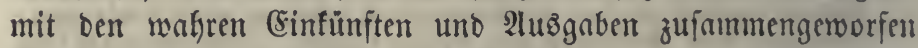
werben, Denn bie (Seldeinnahmen ftehen mit einer $\mathfrak{b e r m i n b e =}$ rung anberer Bermögenzitheile ober einer neu entitanbenen Sdutt in 3ufammenthang unb die 2lubigaben mit einer neuen Erwerbung ober einer Sd)ulbabzakling $(a)$.

2) Sinnahmen uno Altbagaben, weldje mit ben Bermin= Derungen uno Bermebrungen ber Naturaloorräthe

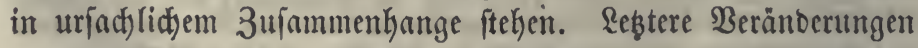

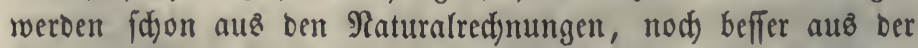

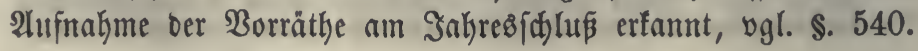




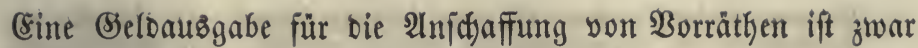
in Der (B)lbredjung wie jebe anbere 2 Auggabe aufzuführen, finbet aber in ber 3unahme ber Raturalvorrätthe ifyren Erfaß̧, ygl. \$. 88 (c).

3) Erfäpoften, D. h. Zahlungen, benen eine zweite

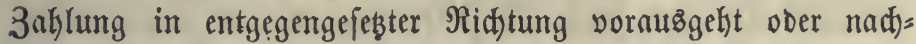
folgt, fo baß beibe fid aufheben, mögen fie mun in bem näm= lidjen Jahire zufammentreffen ober nidjt. Şieher gefjören $\mathfrak{B}$ or= fdurufie uno beren Erifattung, aud) Cinnahmen für antere \$erjonen ober Caffen; worauf eine gleid) große 2 luągabe folgen

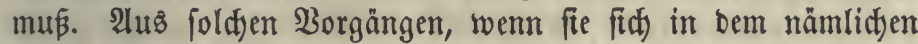
Sahte gegeneinander aufheben, entitehen bie fogemannten burd)= laufenden ßoften (recettes und dépenses pour ordre).

Die Einträge biefer 2 rt verbienen im Rubrifenfyfteme ber Red)mung eine eigene Stelle, um fie von ben wahren Csin= fünften unb $\mathfrak{B}$ erwenbungen zu unterfdjeiben $(b)$. Daffelbe gilt von bem anfänglicten unb bem am Ẽnbe bez Sahreż verblei= benben baaren Borrathe. (ङz ift üblid), jenen alz eine Eimnahme, biejen alz eine 2luşgabe beż einzelnen Sahres auf= zuzeidjnen, \$. $551(a)$. Se mehr man übrigenz bemüht ift,

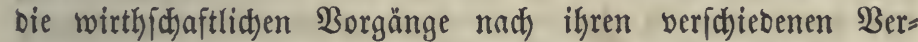

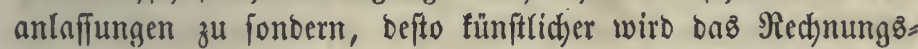
wejen unb befto fatwerer ift eż, bie einfacten Şauptergebniffe Der WBirthjidjaft heraużufinten, wenn nidjt zugleid) Dafür gejorgt wird, bás bie lę̧teren befonbers zufammengezogen werben.

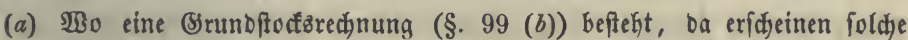
Boften als Giumahmen und 2ิusgaben für Den Srunditod.

(b) Tonzig (I, 42) febt Den introiti (Simmahmen) uno pagamenti (24us = gaben) reali bie intr. und pag. transitorj ober di giro entgegen.

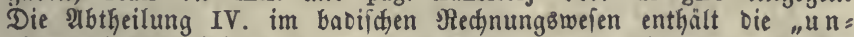
eigentlichen (8innahmen und 2 usgaben", Die man z. B. bei

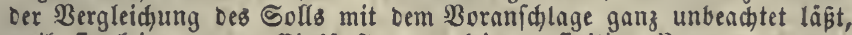
weil fie feine neuen Cinfunfte uno feine oefinitive serwenoung ber:

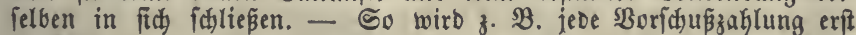

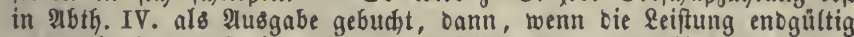
ausogemittelt (conftatirt) ift, ebendajelbft unter oen (sinnnhmen ein = getragen uno zugleich in einer ber brei erfen 2tbtheilungen in \&uछgabe

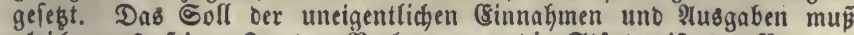
gleia) groß fein. In ben Borlagen an bie Stände ift Der Bau ver Staatsredinumg neuerlid folgencer: (Sinnabme: A. Betrie fondorednung. I. Siefte aus voriger Redyung. 1. Seloporrath. 2. Naturalyorräthe. 3. Nctiorefte, a. aแts ben eigentlichen, b. aus ben uneigentlichen Einnahmen. II. Uneigentlidse (sinnahmen bom laufenten Sabre. - B. Etatorednung. I, vou Laufenden Sahre, 


\section{$-478$}

II. vom vorkergekenben, III. von frükeren Sakjen, IV. Abgang an

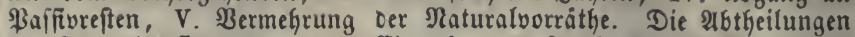

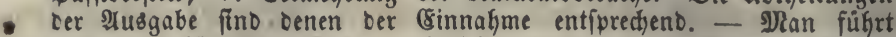
aud wohl für foldje \$often, bie feine wakren Esinfünfte uno Berwen= Dungen anzeigen, befondere Bücher, wie bie Depoftten =, Boriquṕs uno Erebitbüder. Ditmar, Staatscafienweien $\widetilde{S} .38$.

\section{§. 557.}

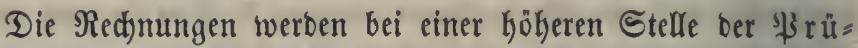

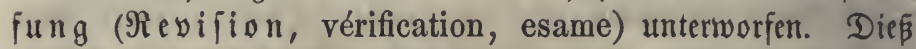
gefdieht burch befonoere, Des Finanzweiens uno vorzüglid) Des

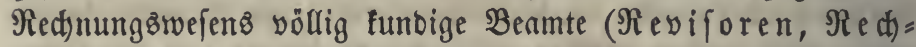

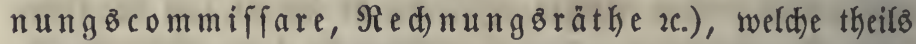
Den Mittel = und Dberbeböben in verfhiebenen Serwaltungs? zweigen beigegeben, theils nber in einer Dberbehöbe ( $D$ ber =

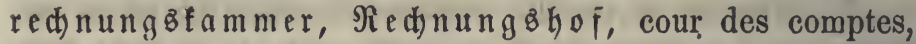
§. 536) vereinigt find. Dieje Eollegialbebörbe prüft unmittel= bar bie bon ben böheren Finanzftellen gefertigten Rechnungen, hat in zweiter Inftanz bie fdjon von ben Mittelftellen unter= fudten Rechnungen ber Berwaltungsämter zu behanbeln, über ftreitige Fälle zu erfennen und überbaupt bie Dberleitung bes ganzen Red)mungswejens zu füfren. Sie mus in Şinftct auf ibre Entfdyeibungen von bem Finnnzminifterium unabfängig und in berfelben Stellung fein, wie ein Seridftabof $(a)$. З $\mathfrak{u}$ Der SHrůfung Der Rectjumgen gebört, Daß man Den Segenftand Der $\mathfrak{B e r w a l t u n g , ~ d i e ~ D b l i e g e n t e i t e n ~ b e r ~ r e d j u n g l e g e n b e n ~} \mathfrak{B}_{e}=$

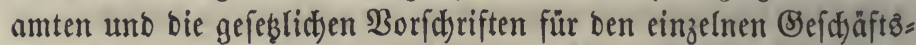
zweig genau fenme. Die Unterfuchung wiro borzuglid) auf nadjitekende Suncte gelenft:

1) Ridytigfeit ber 3ahlenergebniffe, of man z. $\mathfrak{B}$. ridstig zufammengezählt uno abgezogen, Die Duantitäten mit Den

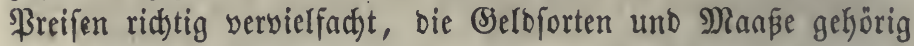
umgerechnet, bie Ergebniffe ber vorigen Rect)mung orbnungż= mäßig übertragen, bie wahren ßreife zu Srunbe gelegt hat, ob Die Znklen mit ben Belegen übereinftimmen u. Dgl. (b).

2) Beobadyung ber vorgeidriebenen Formen, 子. B. शume= rirung und gebörige $2 \mathfrak{b}$ faffung ber Belege, yorfdriftmäßige

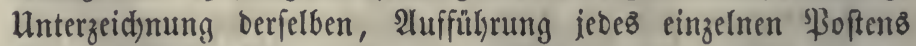
in feiner entfpredjenden Rubrif, wobei es nidjt erlaubt ift, baß 


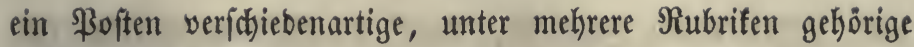
Theile umfaffe u. ogl.

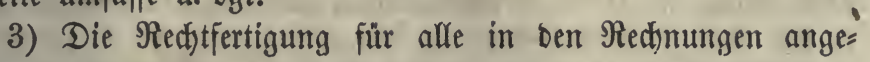
gebenen Maßjregeln ber $\mathfrak{B e r w a l t u n g , ~ o b ~ z . ~ B . ~ D i e ~ u m f t a ̈ n b i g e n ~}$

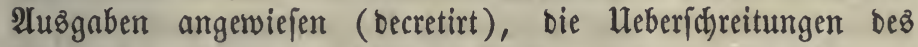
Boranjđllages yon ber höheren Stelle genehmigt, bie ftänbigen 2luø̇gaben mur innerbalb ber Sränze ber Bewilligung vor= genommen worben fino.

Man hat bei ber \$rüfung ber Rect)mungen aud) offers Darauf gendtet, ob bie Erumbfäbe einer guten 2 Birthichaft

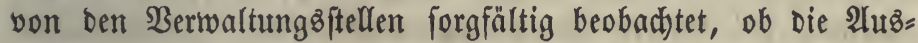
gaben überall fparjam veranftaltet worben fino, ob man bie (Sinnabmen nidjt hätte ergiebiger madten fömen, ob ber $\mathfrak{B e r}=$ mögensiftamm ftreng erbalten worben ift 2 . Diés ift jebod) eine in bie Berwaltungsthätigfeit eingehenbe, nidjt mehr bas

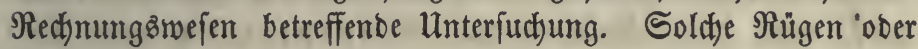
3weifel fallen baker nidjt fowohl in ben Wirfungafreis ber

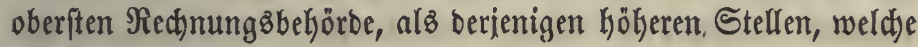
bie Berwaltung felbft fut leiten haben (c).

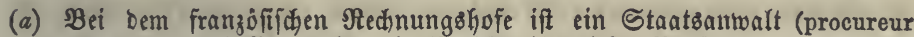
général) angeftellt. Ueber bie Serhältnifie biefer Behỏrde f. Das angef.

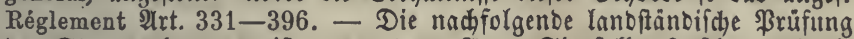
Der Staaterechnungen if yon anterer Pैrt. Sie folf exporfonen, ob bie Finamzertwaltung genau nach Den (Sefésen uno ben mit Suftimmung Der Bolfzbertretung über Den Boranichlag gefaßsten Befdylüifen geführt worben ift. Dhne fie fönnte Die \$Nitwirfung Der Stände zur Feft= fellung Des Bubgetz exfolglos werben.

(b) (ş giebt dafür eigene (Ealculatoren.

(c) Das yon Tonzig $(\mathrm{I}, 88)$ fo benannte esame morale. Die 1826 auf= gehobene Stants controle in Freupen war eine felbfteandige Dber:

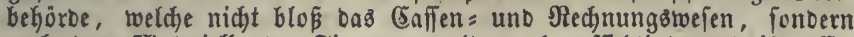
aud Das IIaterielle ber Finanzberwaltung beauffiditigte unb ifre \&r: innerungen gegen Das lestere im Staatżminifterium vorzutragen hatte. Dieje Stellung muste viele Reibungen mit bem Finanzminifterium nad fich zieken.

\section{§. 558.}

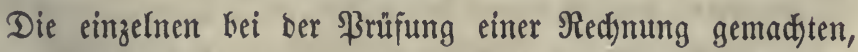
einen Tabel ober 3weifel autsfpred)enben Bemerfungen bes

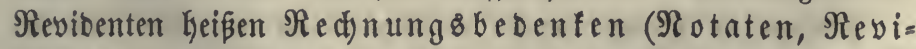
fionberinnerung, monita, observations, relievi).

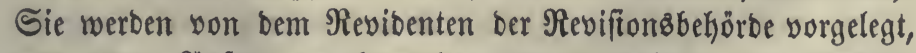

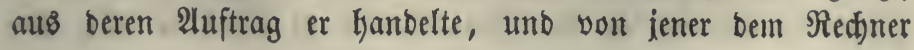


zur Beantwortung zugeftellt, wobei Die Red)unngsbelege ifm aud) roieber zu feiner $\mathfrak{B}$ erantwortung zurüđgegeben werben. Şat er fitc) über jeben beanftandeten \$unct geäußert, bie in Der form gemad)ten Fehler naditräglich berbeffert unb fein Berfahren ver= theidigt, wobei oft cine mehrmalige $\mathfrak{B e r h a n b l u n g}$ nöthig ift, fo wirb hicrïber in ber vorgejęten Behörbe Bortrag gehalten,

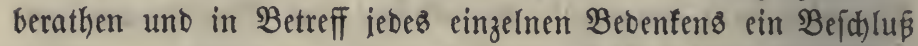
gefaßst (a). Wiro bon einer höheren Behörbe eine nodymalige Unterjudung borgenommen, fo trägt diefe ben Namen Super = revifion (b), uno erft nach beren Beenoigung uno ber Beant= wortung ber Superreviftonoserinnerungen wiro ein enogültiges

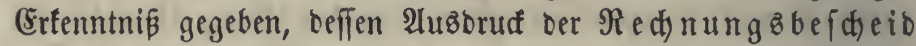
(ital. evasione finale) ift (c). Injoferne Darin bie Ertlärung enthalten ift, Daß Der $\mathfrak{B}$ enmte in $\mathfrak{B}$ ezug auf Daż Jahr, Deffen Rechnungen geprüft worben finb, alle feine Dbliegenkeiten erfüllt Gabe, wirb biefer Befdeid aud) Ib folutorium ober De= d) arge genannt. Inoeßs ift bie Freiprect)ung häufig nur eine

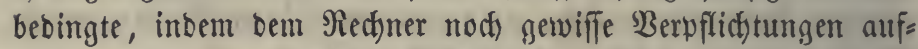
erlegt werben, z. $\mathfrak{B}$. eine Summe zu erjeben, um bie er fith verrectinet ober bie er unbefugter Weife auzigegeben ober zu erheben verjămt hat $(d)$, ober eine nad)träglid)e 3nklung zu leiften, eine Summe von einer anderen Werfon zu erbeben, einen

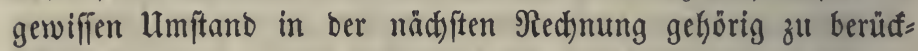
fitbtigen $2 c$.

(a) In einigen Staaten ift ein mündlides $\mathfrak{B} e r f a h$ hen cingeführt, wobei ber

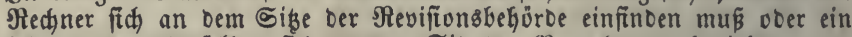

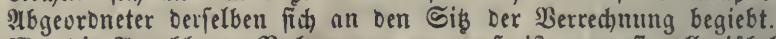

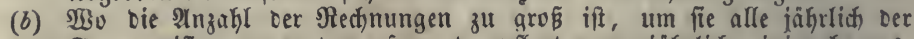
Guperrevifion zu untermerfen, on pflegt man jäfrlich einige heraus= zunctimen.

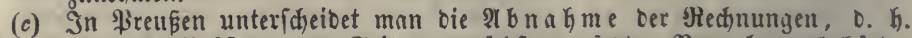

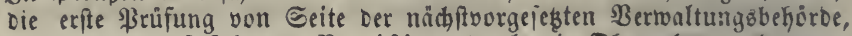
uno oie oarauf folgente Revifion burd bie Dberredmungsfammer. (5) $r$ a f (5. 505.

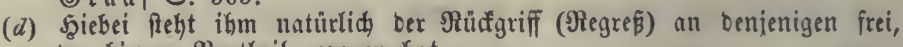
Der Gievon S3ortheil gezogen hat.

\section{§. 559 .}

Allgemeine Bemerfungen in Bezug auf bie Revifton ber Redunungen.

1) Die forgfältige łrüfung ift notfwendig, weil fonft bie größte Unordutung in Dem Finaujwefen zu beforgen wäre und 
felbft bie reblidjen Beaunten wenigiten zur Rachläffigfeit vets leitet würoen. Man mus fidb beşhalb ben Unbequemlidfeiten unterwerfen, bie bis̄weilen auß unbegrünbeten Érinuerungen entipringent.

2) (Es ift eine Şärte gegen bie verred)nenten Beamten,

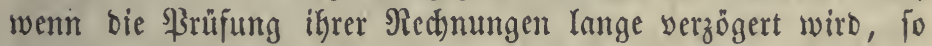

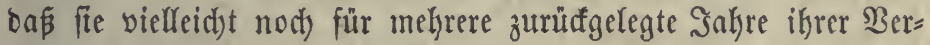
antwortlichfeit nidyt entbunten fint. Daker foll ein hinreidjen= bes Revifinzperional angeftellt und anf Befdyleunigung bes (E)ejthäftez gejeken werben.

3) Dic Revifitonserinnerungen follten nidft von Tabeljudft,

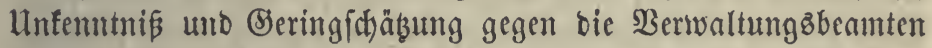
zeugen. Der Revioent foll fith mit ben eigenthümlicten $\mathfrak{B}_{\mathrm{er}}=$ Gältnififen ber zu unterfudjenten $\mathfrak{B}$ erwaltung und. ben für bies felbe beftehenben $\mathfrak{B o r i d j r i f t e n ~ b e f a n n t ~ m a d j e n , ~ b e r ~ R e c t i n u n g g ి = ~}$ füfrer burd) Deutlidye Angaben Mi

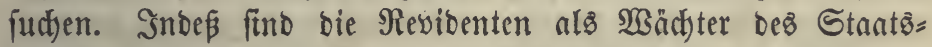

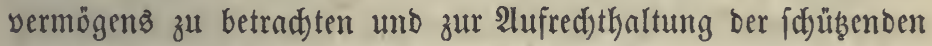
Formen verpflidtete, in benten ber Einzelne fein perjönlidez Miftrauen erblifen folfte! Die Sievifton Darf baher nidyt zat einem 2 nlaffe werben, ba官 zum Radhtheil für ben Stantsobienft zwijchen bem Revibenten uno ben Red)nern leibenidjaftlidje,

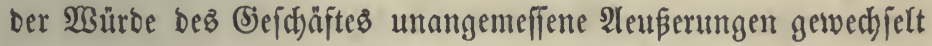
werben.

\section{§. 560 .}

Sebe Enffernertwaltung ift mur für bie bei ifge felbft ein= gehenden unb von igr zu bewirfenben 3ahlumgen verantwortlict).

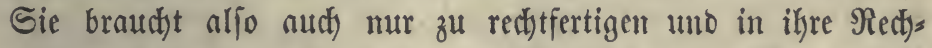
mung aufzunelymen 1) bieienigen (Einnahmen, weldye fie als Heberichüffe von untergebenen Çaffen abgeliefert empfängt, ober ummittelbar cinzieft; 2) bie 2lusgaben, welde fie felbft beftreitet, ober burd) 2luftrag von anberen Caffen vornelymen läßst.

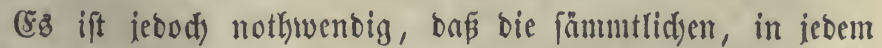

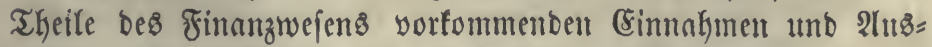
gaben nad) ber fyftematifichen 2 thorbmung zufammengeffeflt wer=

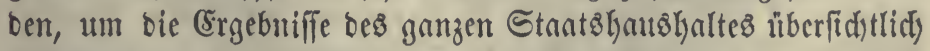
Darzufteffen uno bie Bergleidjung mit bem Boranfdjlage möglita 
zu machen. Dieß ift ein von Der Berwaltung bes Etnats= vermögens getrenntes , mit feimer $\mathfrak{B e r a n t w o r t l i c f f e i t , ~ a l s ~ f u ̈ r ~}$

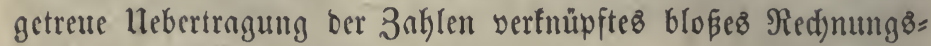
gefd)äf, weld)ez autgefülyrt werben fann

1) vort ben Berrechnern ber Göheren Eaffen, inbem fie ber= pflichtet werben, bie 2 luzgaben unb Einnahmen ber ifnen unter=

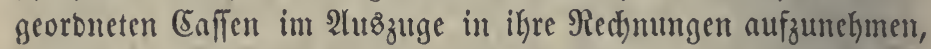

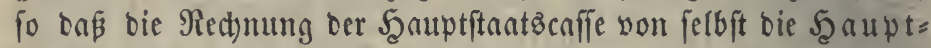
ftantzered)nung bilbet $(a)$; ober

2) Don einer befonberen Staatzbudhalterei (\$. 536), weldye nicht bloß auż ben cinzelnen geprüften Rect)mungen bie

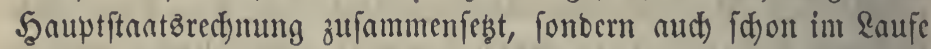

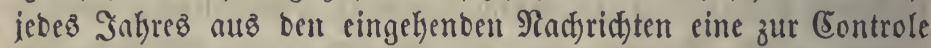
ber Redyner bienenbe Budfüfyrung beforgt (b).

(a) 2Bie bié, z. B. in \$reupen (\$) (Srundinien ber Rameralpraris \&. 42) $x$. geidjiefft.

(b) Riefdfe S. 237. - v. शlaldus, Politif II, 191. Einanz. II,

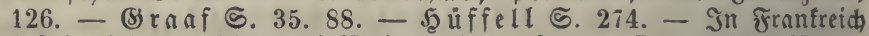
befteht bei tem Finanzminifterium eine befontere Decrtchörce für bie

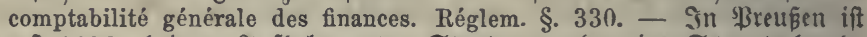

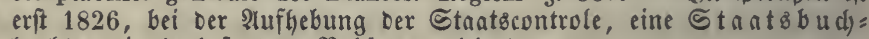
halterei als befondere Behorbe erridjtet worben.

\section{2lbtheilung.}

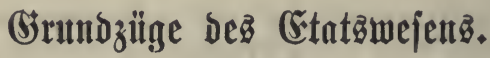

\section{§. 561 .}

Der Boranfdrag (Etat, Bubget, in Deftereid) Hräliminare, conto preventivo im Segenjake von c. consuntivo, §. 465) ift bie $\mathfrak{B}$ eredyung ber in einem beborfteben= ben 3eitabfdnitte (Jahre) zu erwartenben Eimalymen uno vorzunchmenten 2tusgaben (a). Dbgleid) bicfe über fünftige

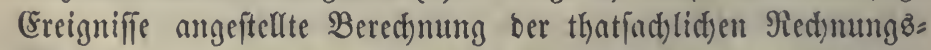

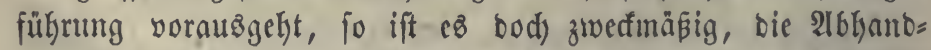

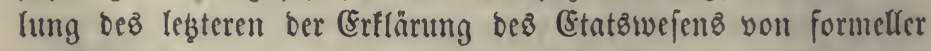
Seite voranzuftellen, benn iene, wie fie fid) weit früher ausgebilbet hat, bient aud) in $\mathfrak{B}$ ezug auf bie ankere (Sinrid)= tumg ben Boranjalägen zum Borbiloe, welde fid) überbieß nuf 


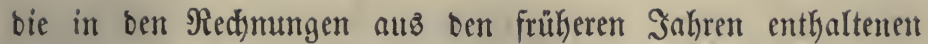
Errfahrungen ftüben. Dem Snlyalte nad) if Der Boranfdhlag von ber thatjactlidyen Rechnung weientlid) verifhieben. (Er ent= hält nämlid) 1) bei benjenigen (Sinnahmen uno 2tubagaben,

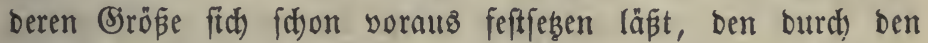

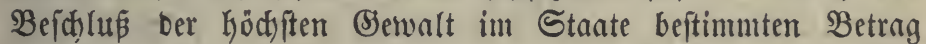
berfelken, 2) bei anberen, weldte yon fünftigen Ereigniffien bebingt werben, bie wahridseinlidse Summe berfelben. In

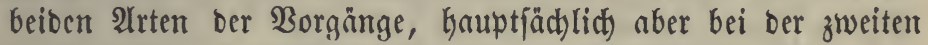

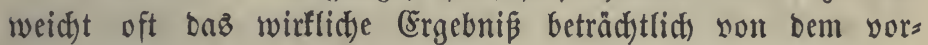
her beftimmten vermutheten Uumfange Der Einnahmen uno

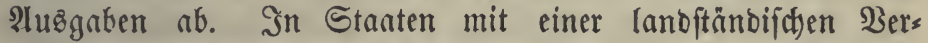
fafiumg wirb ber ganze Stantżyoranichlag mit feinen Errläute= rungen - und Begrinnoung Den Ständen zur ßrüfung uno Senehmigung vorgelegt, vergl. \$. 557 (a). Diefe $\mathfrak{B}$ eröffent= lidfung uno bie vielfeitige Beleudtung bez ganzen Stants= haushaltes wirft fehr vortheilfhaft zur $\mathfrak{B}$ ervollfommung beffelben und giebt eine 2tufforberung, bie 2Infthläge mit verboppelter Umifict) uno Sorgfalt zu entwerfen (b). Sn größieren Straten

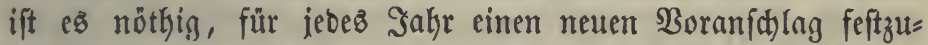
ftellen, in fleineren fann eime zwei= ober höchftens breijährige Bubgetôperiode genügen.

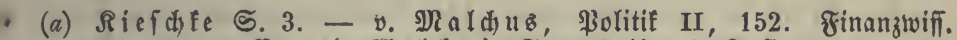

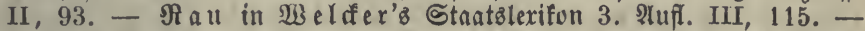

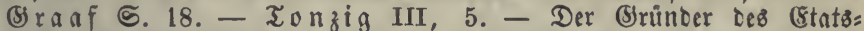

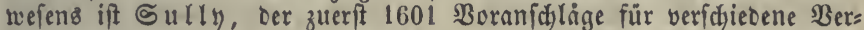

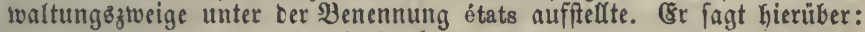
Je ne saurais croire, que l'idée de ces sortes de formules ne soit pas venue à quelgu'un, depuis que les finances ont été assujetties à quelques réglements; l'intérêt seul doit en avoir empéché l'exécution. Quoiqu'il en soit, je soutiendrai toujours que sans ce guide on ne peut travailler qu'en aveugle ou on fripon. Fluf (5olbert liés états

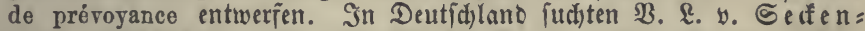

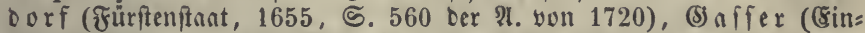

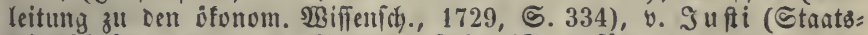
wirthichaft I, 461), v. Eonnenfels (ङrunträbe III, 25. 41) bie

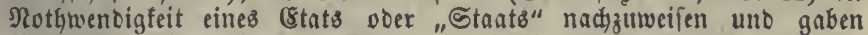

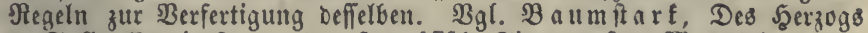

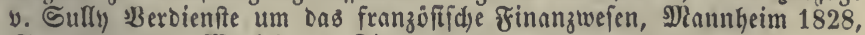

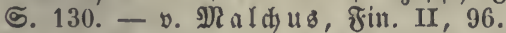

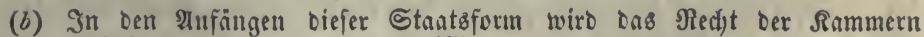

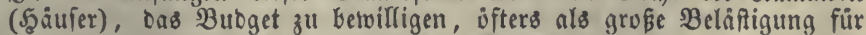
Die oberffe Finnuzbelobroe empfunderr. 'Nit Der Beit lernt man daffelbe,

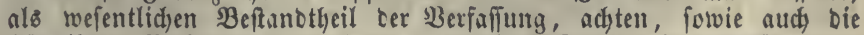

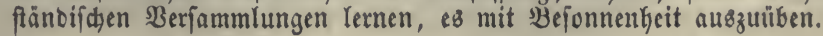


§. 562 .

Ueber $\mathfrak{W e}$ en uno $\mathfrak{B e r f e r t i g u n g ~ b e r ~} \mathfrak{B}$ oramjdläge fino Gaupt= fäc)lich folgende Regeln zu bemerfen:

1) Man muß ben Etatsentwurf von bem genehmig= ten (Etat unterideiben. Sener ift ein mit beigefügten (S)ünben uno (Erläuterungen verfehenter Borfhlag, biefer ift burch Befd)luß Des Stantsoberhauptes ober einer oberen Bebörbe feftgefteflt worben uno bient alsి Boridyrift, um, fo weit es thunlid) ift, von ben Finanzbeamten vollzogen zu werben.

2) Die Bearbeitung Der Entwürfe gefdieft in cinem Theil ber (s) auf, fo baß bor bem 2lnfange bez netten 3eitabidnnittez $z^{\mathrm{L}=}$ börberft bie unteren Finanzämter ben wahrfdeinlidjen Betrag Der Cinfünfte und bie nöthigen 2 tı̊g gaben nambaft mad)en. Bei ben Steuern, Sebülren uno alfgemein verbreiteten Regals gewerben, wie bie \$oft und (Sifenbabn, fann ber muthmaflidye Rokertrag aแts ben bişberigen Errafhrungen im Banzen an= genommen werben, ofye bnj man ifnerft begirfoiweife ermittelte. Altch in ben anteren Regierungżzıeigen (Minifterien), wo bie

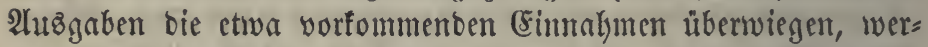
ben bie Boranfdläge fïr beibe, hauptfäd)lid) für ben 2lufwant, von ben Bezirfzbeamten entworfen unb baun zufanmengeftellt.

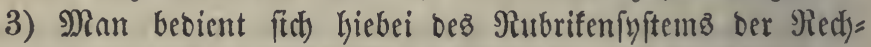
nungen (a) unb-giebt bem Boranjallage dic tabellnrifche form berfelben. (5z ift nübslid), in einer 3ahlenpulte bei ben un=

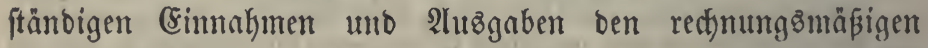
Durd)fdnittsbetrag aub einigen jüngftuerflofienen Sabren, z. $\mathfrak{B}$. 3 ober 6, in einer zweiten Spalte ben lebsten Bornmidglag, in einer britten bie neu vorgefdlagene Citatżfumme anju= geben.

4) 3ur Biloung eines foldyen Durchfdyittes müfen oft bic Jahresbeträge erft beridttigt werben, wenn nämlid) Berīnbe= rungen ftattgefutben baben, weldse bie frifheren 3ablen nidbt mefre völlig anwendbar mad)en, z. B. in Dem Fure ober ber

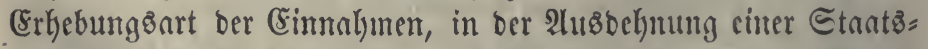
anftalt, bem Maßfiabe ber vom Etaate ju leiftenden $\mathfrak{B} e z a l y=$

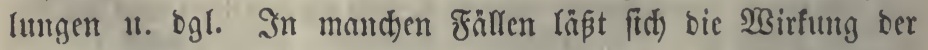
vorgegangenen Beränberung genaut beftutmen, z. $\mathfrak{B}$. bei ciner 
aufgehobenen Steuer, einer verminberten Bebülyr; in anberen Făllen, z. B. bei einer Zollermäß̋igung, fann man nur eine Bermuthung nuffitellen.

5) Diefer Durdffdyitt ift aud) nach biejen Beridfigumgen

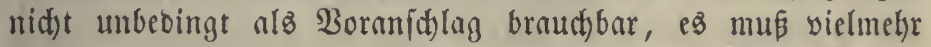
nach ben Umptänoen beurtlgeilt werben, ob ber lestere böher ober niebriger anzunefmen fei, §. 41. Die Sirunde eine foldben 2tbreichung werben in einem begleitenten Bericte vorgetragen.

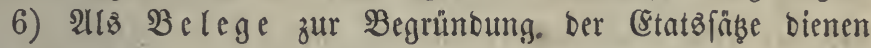

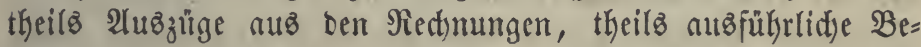
red)mugen, theilo Nactweijungen ber angeoroneten $\mathfrak{B e r a ̈ n b e}=$

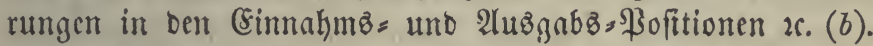

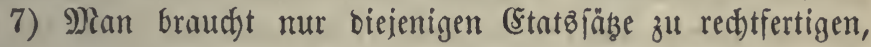
weld)e unftänbig ober bon ben frükeren verichieben finb. Şie=

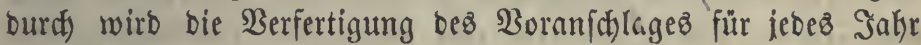
ober für einen 3eitabjdnitt bon einigen Jabren bebentend ab= getürzt.

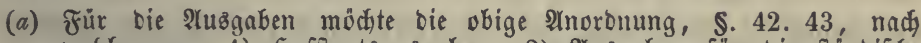

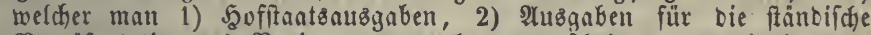

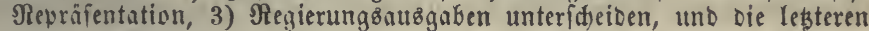
nach Den MRiniferien abtheilen finn, Den Borzug verbienen. Foür Den häufigen (Sebraud) bes Boranid)lages if e\& eine (Erleidterung, wenn bie mit ben (8infünften verbunbenen Roften (Bertvaltung8:, (Erhebungs: foften und Raften) von Dem 2ufmande für bie Stantözweffe getrennt twerbell. Fư bie (Einnahmen ift bie befte Eintheilung bie, weldje auz Dem $\mathfrak{W e f e n ~ b e r ~ C E i n f u ̈ n f t e ~ G e r g e n o m m e n ~ w i r b , ~ § . ~} 84$ fi. Dod müß̈te man neben ben felbeftänbigen Esinnahmen in einer befonderen 2 (b) theilung biejenigen auffüthren, weldhe fich gelegentlid, bei einem Bregen=

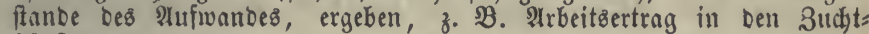
häuโern, §. 69 .

(b) Bei jeber Berwaltung werben Notabilienbủder gefühts, um alle

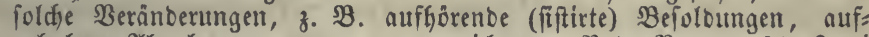
gefobene शibgaben 2c. genau zu verzeidjnen. $\mathfrak{B a b}$. $\mathfrak{B}$. vom 20. Suni

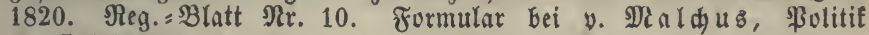
II, LXXXXIV.

\section{\$. 563.}

8) Die Etatzentwürfe ber unteren Etellen (Epecials etat8) werben bei ben Mittelbehörben gevrifft uno in ums faffentere (stats zufammentgezogen, wobei iebod) bie einzelnen

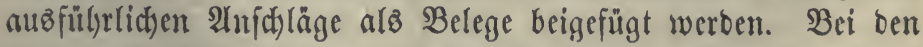

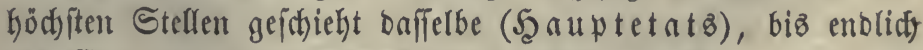

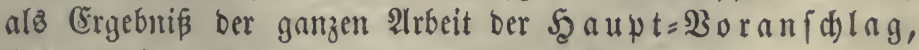
Şauptfinanzetat entworfen wirb $(a)$. 
9) Sịt biejer, abgeänbert ober nact) feiner vorgelegten Faffung, genefmigt worben, fo geken an alle böheren uno niebrigeren Behörben bie auf ben 2 Birfungsfreiz berifelben fid bezichenben, nad) Den gefaß̧ten Beidhlüffen eingeridteten $\mathfrak{B o r a m i c h l a ̈ g e ~ z u r u ̈ u t , ~}$ uแu in $\mathfrak{B}_{0} \mathbb{l l}_{z} u g$ geię̧t zu werben.

10) Um gamz fidfer zu gehen, braudst man gewöhnlid bie

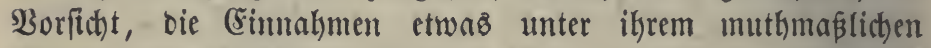
Betrage, bie 2husgaben bagegen utber bemifelben anzufesen, fo daß alfo bie wirflicte- Berwaltung aus beiben Urfadjen ein

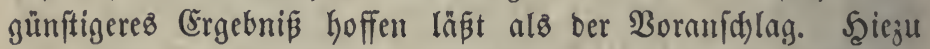

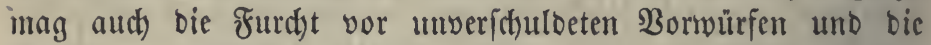
Erwägunt beitragen, Daß̧ ein Mefrbetrag Der Einfünfte und eine Erfparung an ben 2utg̊gaben erfreulid) ift, währeno bie entgegengeję̧ten Eridbeimungen unangenefime Störungen nad) fith zieken. (sleidjwohl ift eine abfithtlidje Entfermung von

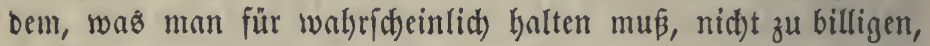

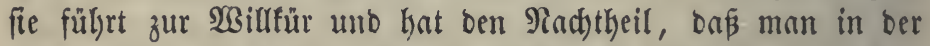
unbeftimmten $\mathfrak{S}_{0}$ ffnung auf eine Mehreinnahme bei ber Heber=

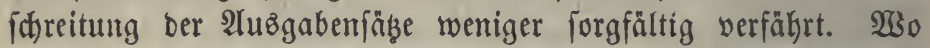
Dagegen ein günftigeres und ein ninber vortheilhaftes Ergeb= nis ungefähr gleid) wahrictseinlid) ift, 3 . $\mathfrak{B}$. weil ienes in ber leşten 3eit burd) Urjaçen eintrat, beren Fortbauer ungerwís ift, ba ift es rathjam, fith auf einen ungünftigeren Fall gefaßt

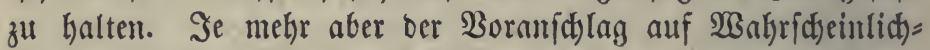
feit gegrünoet wiro, befto meniger barf man auf betrād)tlidje

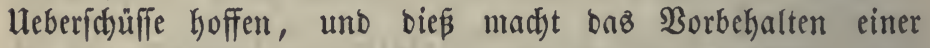

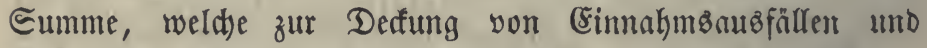

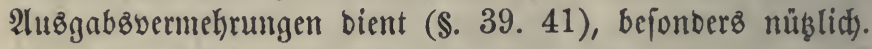

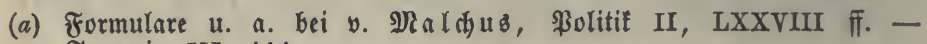
Tonzig III, 114.

\section{§. 564 .}

11) Eine anbere 2nforbertug an gute Boranid)läge ift ifre Bollftändigfeit $(a)$. Es barf fein in ein gewiffes Berwaltungsgebiet fallender unto fein überhaupt zum Staats=

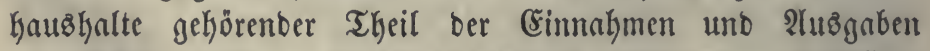
weggelaffen werben. Daker ift ez aut) nothwentig, bie (Ein= nabmen nad) ihrem volfen Betrage (gefammte, robe ober 
Bruttoeinnahme) anzufeken uno ifnen bie mit ben Ein= fünften berbunbenen Betriebs:s, (Erbebungsifoften und Raften zur Seite zu ftellen, fo bafi fitt) auz bem 2lbzuge ber lebsteren bon Der gefammten bie reine ( $\mathfrak{A} e t t_{0} \Rightarrow$ ) Einnahme bilbet. In Den $\mathfrak{B}$ oranfdylägen bieler Staaten wurbe fonft nutr ber Rein= ertrag ber (sinfünfte in Aufas gebrad)t, wobei bie ebenfallz yon Dem $\mathfrak{B}$ olfe getragenen Roften und Die 2rt, wie bie Einfünfte werivaltet werben, unbefannt bleiben $(b)$. WOollte mant einen

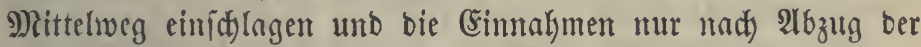
eigentlichen Setwerbzbetriebsofoften in ben Boranid)lag aufneh= men, alf̣o z. B. Dns Şulzfällen, die Şeizung in Enlinen und

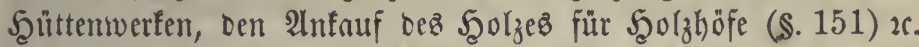
fogleich) von bem (Ertrage biefer Semerbe abjieken, fo würbe immer Der Bortheil ciner Renntniß aller Finanzmaßjegeln ber= loren gehen und ofne Willtür bie Eränzlinie ber vorweg $n b=$ jured)nenoen 2lużgabepoften faum zu ziefen fein. Reuerlid)

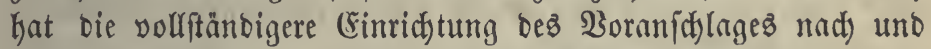
nad) mefre (Eingang gefunben. Zum Befufe mandyfaltiger $\mathfrak{B e r}=$ gleidyungen und Beredrmungen, mus man fid jeood) häufig an bie reine Eimnahme halten (c).

(a) Les budgets, qui devraient toujours presenter l'appréciation entière et fidèle des besoins et des ressources de l'état, ... n'offraient (nimlich) unter Napoleon. I.), pour les revenus comme pour les charges, qu'une expression incomplète et trompeuse, qui ne révélait ni les moyens du trésor, ni les dépenses du gouvernement et qui n'opposait qu'une limite illusoire aux dispositions des ordonnateurs. D'A udiffet, Notice historique im Anfang Des Réglem. S. 267.

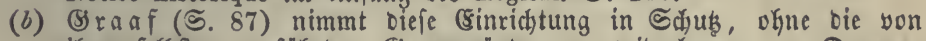
ifm felbft angefiifyrten (Segengrünbe zu wiberlegen. - Dagegen

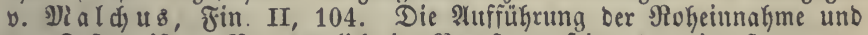
ter Roften ift $3 . B^{2}$. neuerlich in \$reusen, feit 1858 in Sannover,

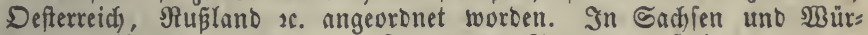
temberg ift zwar in Der Scaupt fumme bes Stantsooranidhlages nur ber Reinertrag Der CSinfunfte angegeben, allein bei jedem 3weige auch ber roke Certrag genannt, fo bas alle wejentlichen Thatiachen auf=

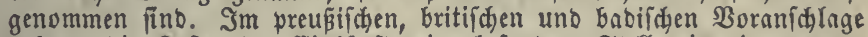
nefmen bie Roften ber Esintüfte eine befonoere Stelle ein, in anberen múffen biefe erft unter ben 2usgaben ber Dinifterien, welde (Einnahy= men verivalten, zufammengefucht werben. In vielen fatififichen $\mathfrak{A} n=$ gaben der Boranfidäge verídjebener Staaten bleibt man ungewís, ob bie robe ober reine esingnbe gemeint fei unt muß $e^{8}$ erft allo ben eill= zelnen Bablen zu exforidien fuchen.

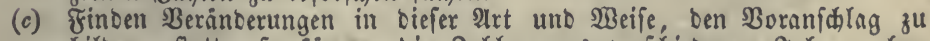
bilben, ftatt, fo fonmen bie Sahlen aus verichiebenell Jakren ofne

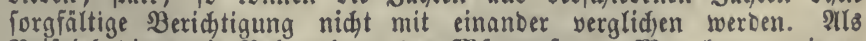

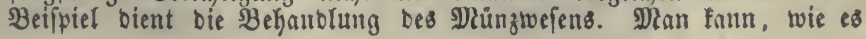




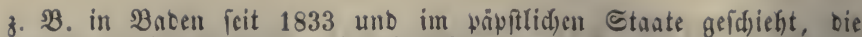
ganze zu prigende Cumme in Eimnalgme, ben Anfauf ber rohen Dletafle aber twie bie librigen foften in \&usgabe aniegen, ober wie in vielen anberen Etanten Die beiben exitgenannten Bablen Ginweglaffen und nebell Dell Betrleboffoften nur ben Sdylagidnab ober ben Berluft beim

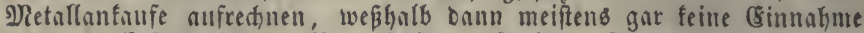

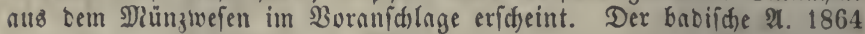

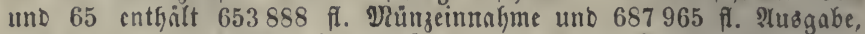
nad) Dem andeten Berfahren wirben nur 3013 fi. (Simnafime aus शiethzinz unD গRebenertrigniffen, Dagegen 15768 fl. Einbuв̈e beim Metallfauf gegen bie geprägte Eumme und 17322 fi. andere Bertwal=

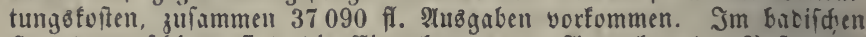

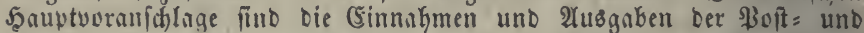

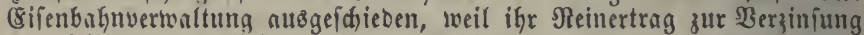
und Tilgung ber (sifenbafinf(f)uld beftimmt wiro, zum Ueberbliaf bes Sanzen funo Dafier beibe Begenitance nod beizufügen. 2tus Den ges nefmigten $\mathfrak{B o r a n i d j l a g e n ~ f u ̈ r ~} 1865$ ift baker folgenbe Sufammenftellung zu maden:

I. Jamutetat Der orbentlidjen Ëinnafimen uno Rusgaben.

1. Eimunfmen .......... 17-161020 f.

2. Enften und $\mathfrak{B e r w a l t u n g}$ foften . . . . 5.226656,

3. Neine Šinnahme . . . . . . 11.934364"

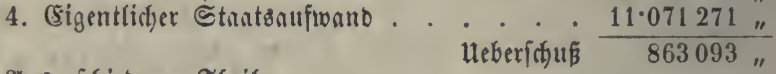

II. 2118gefdjetener Theil.

5. Ertrag ber \$oft unb Eifenbahn . . . 10.287062 "

6. Roften beiter......... . . 6.6577\&6,

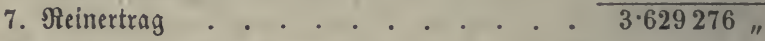

III. Summe von I. unto II.

(5) fammteinnafime . . . . . . 27.448082"

Laften und Roften ......... . 11.884442"

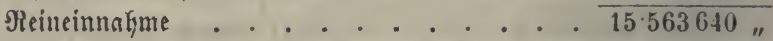

Şievent find zu beftreiten 1) ber obige eigentlidje Stratsaufmant, 2) Die Berzinfung und Tilgung oer Eifenbakniduld, 3) Die auper: orbentlichen Plusgaben, im D. fährlich 1.414679 fl., zu seren Defung aud) eine Summe nแts bem Betriebsfono zu F̧ülfe genommen wirb.

§. 565 .

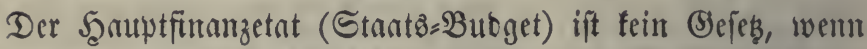
er gleid), namentlid) in Staaten mit einer Bolfz̄yertretung, in oen für bie Sefesgebung beftehenden Formen feftgeftellt wirb. Diejenigen ifn betreffenden Beftimmungen, weld)e wirflid) gefeşlicher Art futo, werben gewöhnlich in cinem mit ifm in

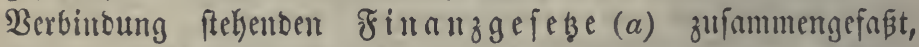

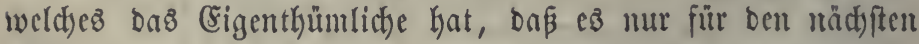
3eitrnum (bie Sstatepperiobe) gilt. Daffelbe muß enthalten $(b)$ 1) bie Benenmung ber zu erkebenden 2luflagen mit Angabe

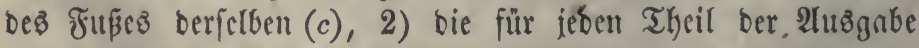
bewilligten, ben einzelnen Minifterien zugcwiefenen Summen 
ober Erebite. Reine Steuer ober Sebüly barf geforbert werben, bie nidyt im Finanzgefes ober einem anberen (S) Fese von unbeftimmter Sulltigfeitzbauer begrünoet ift. Befonbere gefeslid Des Finangefeges betreffenoe \$uncte nothwenbig:

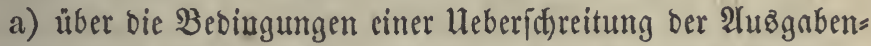
bewilligungen. In manden bringenten Fällen muß ben unteren Berwaltungsiftellen bie Anvrbmung größerer ober neuer, nicht vorgejebener Aluşgaben erlaubt werben, bod) mit ber $\mathfrak{B e r p f l i d}=$ tung, fogleid) 2lnzeige und rect)tfertigenoen Beridt zu eritatten unb nur interkalb ciner gewiffen, in 3nhlen beftimmten Sränze. In anberen Fällen erforbert bie lleberjdyreitung einer bewilligten 2uछ̇gabe bie Senehmigung ber Staatiggenalt $(d)$;

b) barüber, inwiefern es geftattet ift, Eriparungen an einem Theile ber Alubgaben für cinen anberen Begenftano berfelben

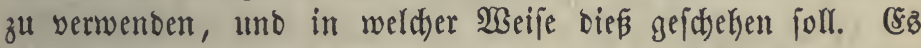
wäre nicht rathfam, bieß $\mathbb{\beta}$ Uebertragen, bie in Frantreid fog. virements, unbebingt zu unterjagen (bolle Specialität

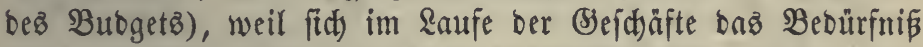
eines gewiffen freien Spielraumes hăufig füblbar mad)t, bod) folften wenigftens bie Scauptabidnitte ber Minifterialetatż punctlid) eingefalten ober Heberid)reitungen bejonbers gered)t= fertigt werben $(e)$.

(a) y. গaldus, Fin. II, 94.

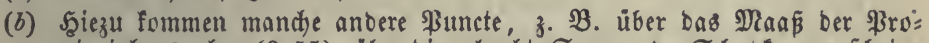
vincialaubgaben (\$.55), über bie erlaubte Summe ber Sd)abfammerfheine

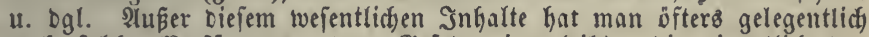
aud foldse sBerfügungen Dem (Bseiese cinverleibt, bie eigentlid, ben Begenftand eigener (S)efęge Gätten bilden follen. Der Beweggrund zu Diefer $\mathfrak{B} e r b i n o u n g ~ i f t, ~ D a \tilde{~}$ man foldje andere Beptimmungen ebenfalls,

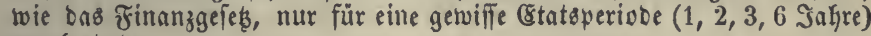
verabrebete.

(c) Bei benjenigen Entridtungen, in benen fid Gierin von einer ßeriobe zur anderen nidts veränbert, genůgt eine allgemeine Beftimmung Gier=

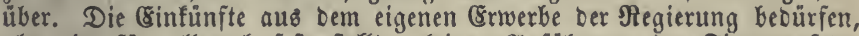
als ein für allemal feftgeftellt, feiner Anfin̈brung im finanzgefebe.

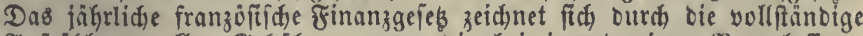

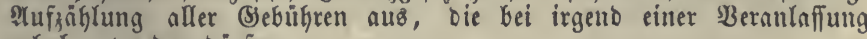
erkoben werben büren.

(d) In Franfreich wiro ber Boranfjlag im Borjahre som gefebgebenden Sörper berathen und genefmigt. Im शtnfange bes Sahres wirb er nad) ben in Der lesten 3eit eingetretenen Beoürfnifien nodumals burds= gefchen uno (gewohntich it einer größeren Summe) feftgefegt, budget 


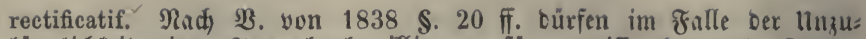
länglidhteit einex 2tuzgnbenbewilligung für gewifie benannte 3weige

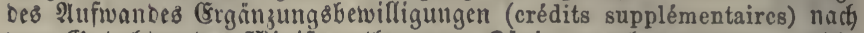
bem (Sutadyten bes Ilinifferrathes yom Rönige gegeben werben, weldhe fobann Der Mächften Stänbeveriammlung zur Suptimınung vorgelegt werben. Dringente lleberidjeitungen nnoerer \&usgaben werben exit yon Den Rammern in Der näd)fen Gikung genebmigt. शhuperorbent:

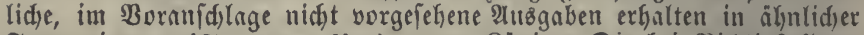
Form einen crédit extraordinaire vom Rünig. Die bei Sichtigftellung ber Iahresauggaben nüthig werbenben Nad)bewilligungen (crédits complémentaires) werben toie bie crédits supplémentaires behancelt. Das Butget für 1862 wurbe mit 1970 9lill. "votirt", bei ter "Siectiff= cation" um 193 Mill. erhöht, ourch Ergänzungsereo ite auf 2201 Mrifl. gebrad)t. Bei Der "Definitiven Siequlirung" Durd Den Rechnungshof ergab fid ein Betrng voll 2219 Nill., Thiers Nede v. 6. Dai 1864. Rad Dem Senatubiconjult v. 31 . Dec. 1862 §. 3 fino crédits supplèmentaires unb extraordinaires nur mit 3uptimmung bes gefebgebenten Rỏrpers (ourch ein (S)efę) zuläfíg.

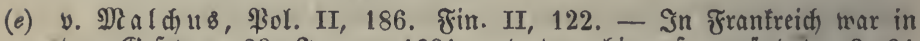
Dem (S)éç y. 29. Januar 1831 und Dem hierauf gegrünbeten $\$ .31$ Der $\mathfrak{B}$. v. 1838 fefigefezt, Daß jene Epecialität für jeres Eapitel des Boranfí)lages eimes Minifteriums gelte. Die 3ahl Der (5apitel war

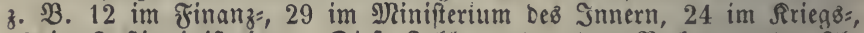
13 im Suftizminifterium. Diefe 3ahl wurbe, Dem Berlnangen Der A6: georbnetenfammer zufolge, fortwaikrent bermehrt, fo Daßs fie lifker 300

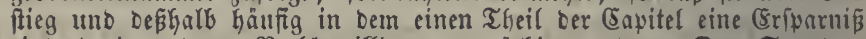
eintrat, in anderen Nadsbewilligungen nỏifig murben. Das Senatus = conjultum v. 25. December 1852 veroronet, Daß̃ nur mit Berwilligung Des Ráíers eitue Hebertragung กแв einem Capitel in Das antere zu= läfifg ift, entzieht aber biefe Bertheilung ber \$nitwirfung Des gefebs= aebenden Rörpers uno beftimmt, oá̉ Derielbe bie Summe für jebes Mrinifterium im (sanzen zu genefmigen habe. Nad bem a. Cenats=

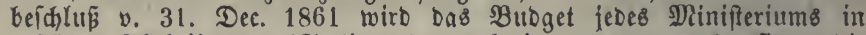
größeren 2ibtheilungen (ङectionen) genefmigt, Deren es 66 find, bie Bertheilung Der Summe unter bie Eapitel jeber Section gefdiegt vom Raifer im Stantzrath, uno in gleidjer Beife werben Mebertragungent yon einem Eavitel in ein anberes genefymigt. - In ßrettien twirb Der Boranid)lag nach Titeln genefmigt, beren 1862214 waren, Darunter aber mande mit gropen Eummen. Das Abgeoronetenfatts verlangte

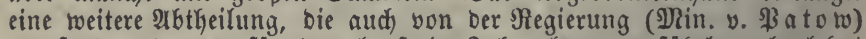
zugefagt unb nur für Das laufende Sakr als unausfifirbar abgelefnt twurbe. Diés verurfachte ben folgenreidhen Ninifterwechlel. 
 \\ 3. Abtheilung.

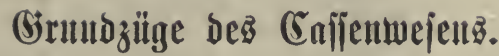

\section{\$. 566 .}

Die für bie Stantögelber beftimmten Caffien müffen fo ans georbnet und mit cinander in Berbinbung gejegt werben, baß fie leidt) iebe Cinnahme auffaffen uno jede 2 tuzgabe beftreiten fönnen, baß aber auth) jebe unnöthige 2 (n) verhütet wirb. Man fann baher untericheiten:

1) bie Shauptfantzcaffe bez Randez (a), bei weld)er alle Uleberichüffe zufammenfliefent unb yon weldter bie am Size. ber oberften Stantäbehörben vorfommenben 2 แågaben beftritten werben. Befonbere Şauptcaffen für einzelne Sweige ber

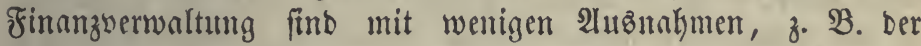

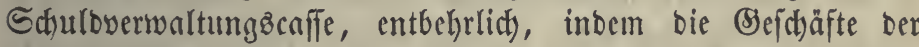
übrigen füglid) yon ber Şauptftantåcaffe bejorgt werben fönnen;

2) Brovincialcaffen, in benen bie innerbalb einez Ranbestheiles cingehenben Summen gefammelt unb zul ben $b a=$ felbit vorfummenben Regierungåausgaben verwenbet werben; bie Ueberichüffe merben an bie Şauptcaffe abgeliefert, in cin= zelnen Fällen erfolgen bagegen nati) Bebürfníp 3uidütife von Diejer;

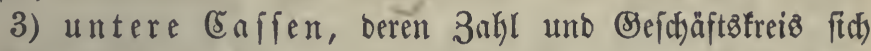
nad) Den in jebem Stante angeurbneten 3weigen ber (Einnngmb= geiduäte richtet. Sebez Domänens, Bofts, Salimen=, Eifenbahn=,

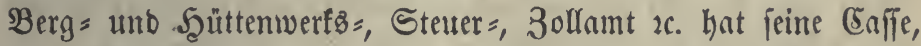
bem $\mathfrak{B}$ erwalter einer folchen fönnen aber aud) vorübergekento ober bauterno mehrere 3weige ber Simnakme unt 2lugagabe übertragen merben. 2 lüer bem mit ber $\mathfrak{B e r w a l t u n g}$ ber Eir = fünfte zufammenbängenben 2lufwant werben ben unteren Conffen aud) antere an Drt und Stelle vorfommente Altsgaben zu= gewiefen, bie fie aus 2 uftrng unt in 2(bred)mung mit ber höheren Caffe zu beforgen haben. (5s ift idjon ber Soften wegen rathfam, nid)t mefhr Eaffen anzuorbuen, als bas Bebürf= nißs Des Dienftes erforbert, fowie aud) mit ber $\mathfrak{B}$ ermekrumg ber unteren Eaffen bie Befahr yon Bertuntretumgen antwädyft. 
Soldye untere Errleber von Einfünten, Denen bie Bebingungen zu einer guten Enffenfültrung abgehen, werben verpflid)tet, bie bei ifnen eingebenten Summen nad) furzen 3wifdenzeiten an bie nädjituorgefęten Enffen abzulieferm, z. B. Die Steuererheber, Beggeloeinutehmer, ßoftwerwalter, Eijenbahnbebiente bei fleinen Şaltftelfen 2 .

(a) Sie trigt meiffens nod aus älterer Beit ber Epradyperberbung ben Namen Seneralifaatscafie.

§. 567.

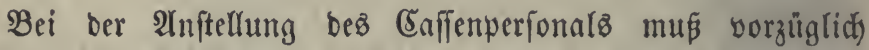

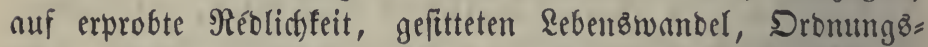

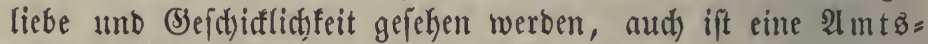
bürgfdaft (Eaution) unerlaplidy, bie jeood) für fid alfein

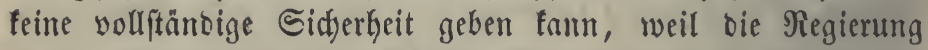
in ber $\mathfrak{W a h l}$ ber anzuftetfenden \$erjonen zu fehr bejd)ränft wäre, wenn fie eine hohe Summe forbern würbe, \$. 486. IV. Bei ben unteren (Eaffen ift gewöhnlid) mur ein einziger Etantz= beamter angeftellt, ber zugleid) bie anderen Berwaltungşgcifäfte bejorgt uno für jeine (Sehülfent verantwortlid) ift. Şöhere uno

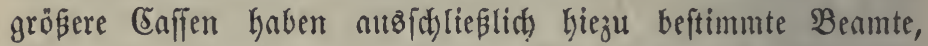
bei weld)en neben einer angemeffenen Bertheilung ber (B)efdäfte

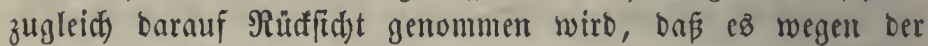
großen $\mathfrak{B e r j u d j u n g}$ zur Untrete an einer gegenfeitigen Ueber= wad)ung (5ontrole) nidjt fehle. 3u ber vollftünbigen Beję̧ung einer großen Canfe wirb erforbert:

1) ein Borfteher (Saaptcaffier, Reubant), ber

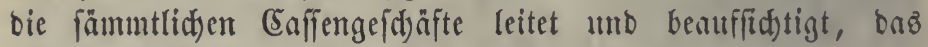
Tagebud) füfrt, iebod) nidftz jelbft einzuntehmen ober aużzu= geben lyat;

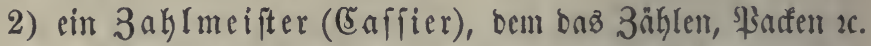
obliegt und ber ein nad) ben yorfonmenten Mtumzjorten in Spalten abgetheiltez Caffenbud) (Sournal) für (Einnahme umb Alı8̊gabe führt. Die (Saffe fteht unter bem M)itverichluffe ber beiben anberen Beamten. Grope Eaffen haben mefrere foldje Zahlmeifter nöthig, z. B. einen für bie Eimmahmen, einent für bic 2 ubgagaben $(a)$; 
3) ein Begenidreiber (Eontroleur), ber ein Begen= bud), öfters aud) bas Scauptbud) führt, alle Duittungen mit unterzeid)net und überhaupt von allen $\mathfrak{B}$ orgängen Senntní nimmt;

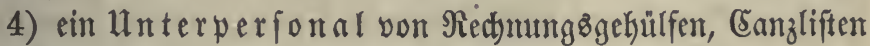
und Dienern.

(a) In Franfreid, fint für bie 2rusgaben bejontere 3ahlmeifter (payeurs) angeffellt, melche von ben DepartementBeinnefmern (recereurs généraux) uno ber Szauptitaatżcafie die nöthigen Summen empfangen. In jedem Departement ift ein folder payeur uno ein payeur central du trésor in \$aris. Drb. v. 1838 §. 306 ff.

\section{\$. 568 .}

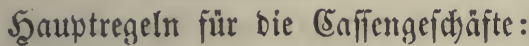

1) Die einer jeben Eaffe zugewiejenen Einnalymen unb

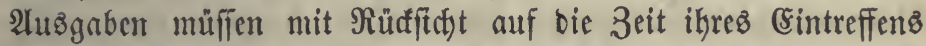
fo berechnet fein, ba in ber Niegel bie Mittel zur Beftreitung ber Alużgaben nidyt fehlen. Dieje Bertheilung ber Summen ift Das Sejhäft ber bem gamzen Enfienwejen im Stante vorgejesten Behörbe, weldye von allen Enijen bie nöthigen periobijhen

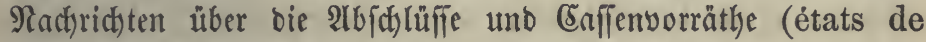
situation) cmpfängt $(a)$. Tritt in einzelnen 3eitpuncten aus =

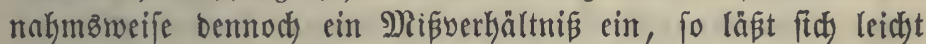

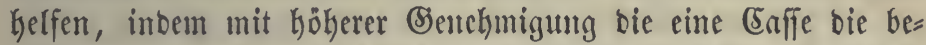
nöthigte Summe von ber anberen erhebt uno bicjer ber geleiftete 3ujd)us wie eine Ablieferung zu Sute gered)net wirb.

2) Die cin für allemal angeoroneten, forvie alfe im $\mathfrak{B} o r=$ amid)lage für eine gewiffe (Saffe nad) ifrem beftimmten Betrage aufgeführten Eiunałmen uno 2luв̈gnben bebürfen feiner bejons beren (Ermädhtigung, biejenigen aber, weldje entweber auper= orbentlidjer $\mathfrak{B}$ seife erfolgen, ober beren (Sröße nod) nidyt voraus beftimmt werben fontte (\$. 553), erforbern cinen 2(uftrag zum

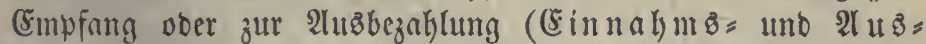
zahlungsantweifung, Decretur, ordonnancement) von einer vorgciebten Behörbe. Die 2tnweifungen müffen mit ben

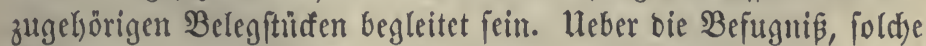
Inweijungen zut ertheilen, fint gennue Borid)riften nöthig (b).

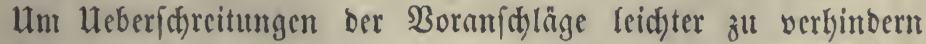

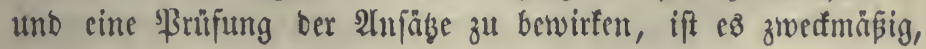


wemt bie Anweijungen bor ber 2lusefertigung burd) ben Borftand ciner $\mathfrak{B} e \mathfrak{b o ̈ r d e}$ eirtem hieju beftelltell (controlirenoen) Beamten fur ßrüfung unb 9) Xitunterfdrift vorgelegt werben. Die $3 a h=$ lungżanweifungen ber anderen Minifter, bie über ifre etatg̈= måzigen Crebite (\$. 565) verfügen fönnen, follten wenigftenz von bem $\mathfrak{B o r f t a n d e}$ bes Finanzminifteriums ebenfallz eingefehen und unterzeidtunet werben.

3) Der Enffenführer hat bei jeber ihm vorgelegten 3ahluugz = antweifung bie Befugnís Des Anweifenten, die Ridytigfeit ber Belegitücfe uno überljaupt bie 3uläffitgfeit ber 3ablung nad) ben

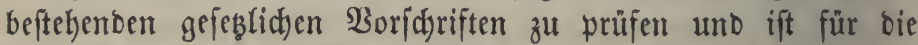
Berabjäumung Diefer Regel verantwortlid).

4) Für feine (Sinnahme barf yor bem wirflid)en (sinzug bes (Selbes eine Befdyeinigung auszgeftellt werben (ben fall einer

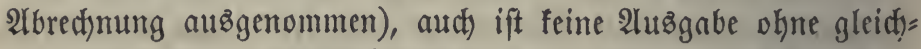
zeitigen (Empfang ber Befideinigung (Duittung) zuläfirg $(c)$.

5) Die Befdyeinigungen müfien genau nad) Der Borfdyrift abgefajt (\$. 553) und von bemienigen ausegeftelft fein, weld)er zunçdft zum Empfange beredtigt ift, wenn biefer nicht einen Anberen hiezu benollmäctigt hat. Sogerannte Snterimb: quittungen eines Dritten fömen nidt als Belege dienen uno laufen bis zum Sintreffen ber wabren Befdeinigung auf

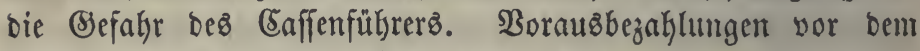
Termin ber Sduulbigfeit find unerlaubt $(d)$.

(a) In Zranfreid) beళ unter bent Finanzminiffer ftekenten directeur général du mouvement des fonds du trésor public. Âle Buhlungbinnmeifungen Der Mtinifter werben ifm vorgelegt, was er burdh Unteriकrift (visa) bezeugt.

(b) Franfreich: 2turgaben bürfen mur yon ben פliniffern ober höheren burdh oiefielben beftellten $\mathfrak{B}$ enmten (ordonnateurs secondaires) angeortnet werben. Fehlerhaft war bie $\mathfrak{B}$. v. 13. Infi 1804, weldye e\& fell ordonnateurs freiftellte, weldhe Belegftudfe fie ifren Antweifungen beifügen twollten,

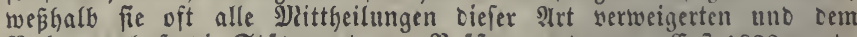

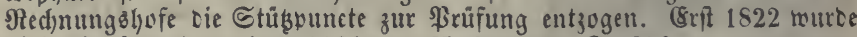
Dieß̄ abgeñncert. D'A u diffret, Notice hist. 5.273.

(c) Bei Berientoungen bient einftweilen ber S\$offichein alo vorläufige Duittung.

(d) Bei Befoldungen faun für ben fdon verfloffenell Theil Der Beit eine 2lbidlagszahlung geffattet wercen.

\section{§. 569.}

6) Eigente Selber bes Canfenfülyrers bürfen mit benen, die bem Stante gehoren, nidyt bermengt werben; eine, wenn gleid) 


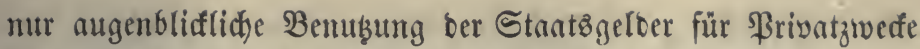
ift unerlaubt uno ftrafbar, uno $е в$ Darf ben (Eaffenbeamten auch) nidyt geftattet werben, aus eigenen Mitteln 3ahlumgen vor= fdupweife zu beftreiten.

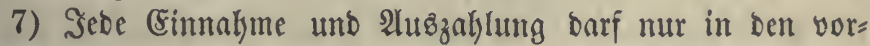
gefdriebenen guten Beloforten erfolgen. Die Sorten werben

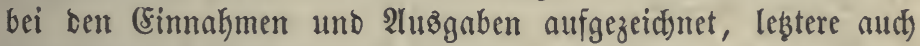
bei anjebulidyen Summen mit einem Sortenzettel begleitet. Rolfen uno Beutel braudjen mur gewogen zu werben, wenn fie wohl berfdloffen geblieben find unb eine anbere (Eaffe auf oer

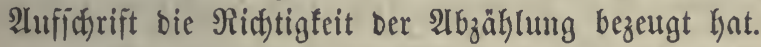

8) Bei $\mathfrak{B e r f e n b u n g e n ~ i f t ~ f u ̈ r ~ g u t e ~ B e r p a f u n g ~ z u ~ f o r g e n . ~}$

9) Die Caffe muß gegen Diebftahl gefdügt werben, wozu bie Inwentung fefter eiferner Riftell ober Sduränfe, eines roohl verwahrten (Semadjez mit einem einzigen 3ugange uno feit veridtließbaren Deffnungen, bie Nähe Des Beamtent bei fleineren Gaffen (a) und bie Alufftellung einer betoaffneten Badue bei größ̈eren $2 c .(b)$ bient.

10) Die (Enரॉe mußs von 3eit zu 3eit nađ)gezählt (geftürzt) und ber Erfund mit bem 26fdluffe ber Büd)er vergliden werben. Diep gefdieht

a) bon ben Caffenbeamten felbft in regelmäßigen ßerioben, 3. $\mathfrak{B}$. alle Monate $(\$ .548 . \Re r .11)$, fo wie aud öfterz an bie vorgejeste Bebörbe ein (5ajfenberid)t (Situations: etat, ( $a f f e n f t a t u z, ~ § .568$. Nr. 1) erftattet werben muß; ;

b) bon eincr anberen zur atufidut über cine Eafie (ङaffencuratel) beftellten Bebörbe. Man unterjecibet bies bei bie regelmäßige, zu beftimmten 3eiten eintretende शadj/d)au

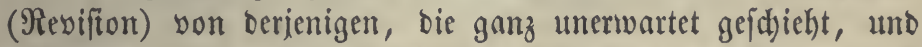
bie, ohne als 3eidyen eines $\mathfrak{B e r b a d}$ tes gelten zu fönten, bei

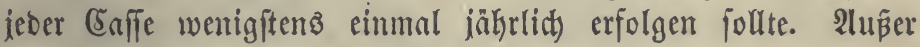
Der Unterjudfung burd) ben Borgefezten ift aud) bie 2luoronung

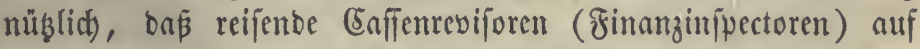
jebesimaligen befonderen 2luftrag bes Finanzminifters in ver= fdiebenen Ranbesttheilen ohne regelmäßige Reifenfulge fowohl bie Caffen als bie Rectmungs = uno bie ganze Dienftrüfrung Der Bermten unterfuchen (c). Melyrere an einten Drte fid) befinbente Enffen werben gleidfzeitig geftürt $(d)$, aud) wirb 


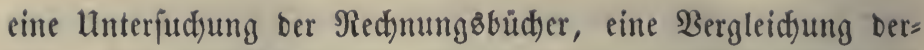
felben mit ben Belegen 2c. vorgenommen uno liber bas ganze

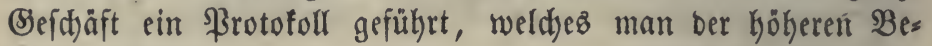
Görbe zuftellt.

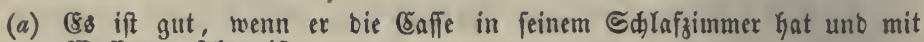
WBaffen verfeken ift.

(b) (B) $\mathrm{r} a$ af (5. 283.

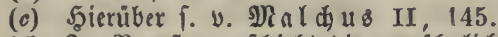

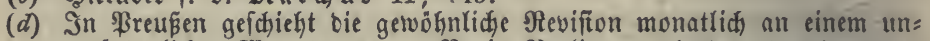
veräberlidgen Sionatstage, $3 . \mathfrak{B}$. in Berlin am lebtell ober (wenn er ein feierting ift) am vorlebten, bei ben \$rovincialfauptcallen am 18 .

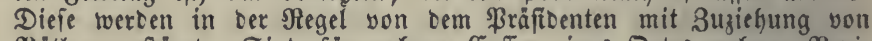

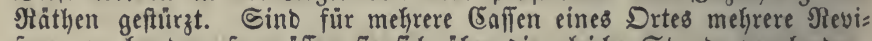
foren vorhanben, fo müffen fie fich liber bie gleidje Etunte verabreten, fonft wirb bie eine (5affe unter Berịdlué genommen, während man

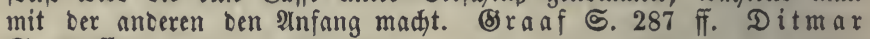
ธ. 99 ff. 


\section{Anthang.}

\section{Formular cintę Tagebutus,}

зแ §. 547 und 548.

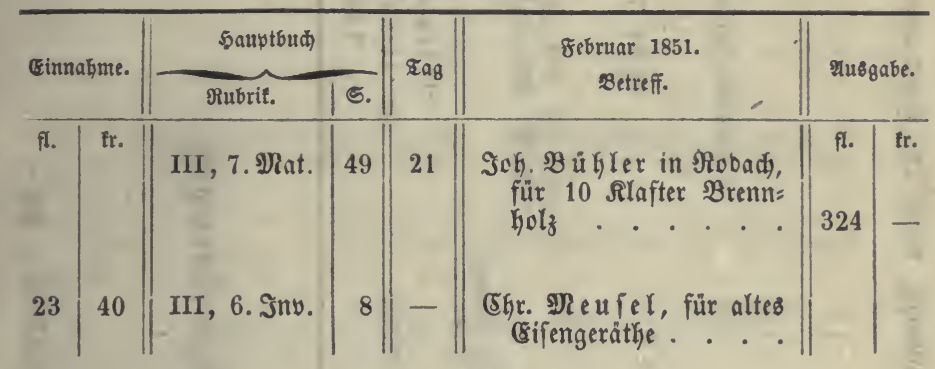

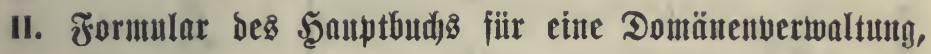
zu §. 551 .

Geite 57.

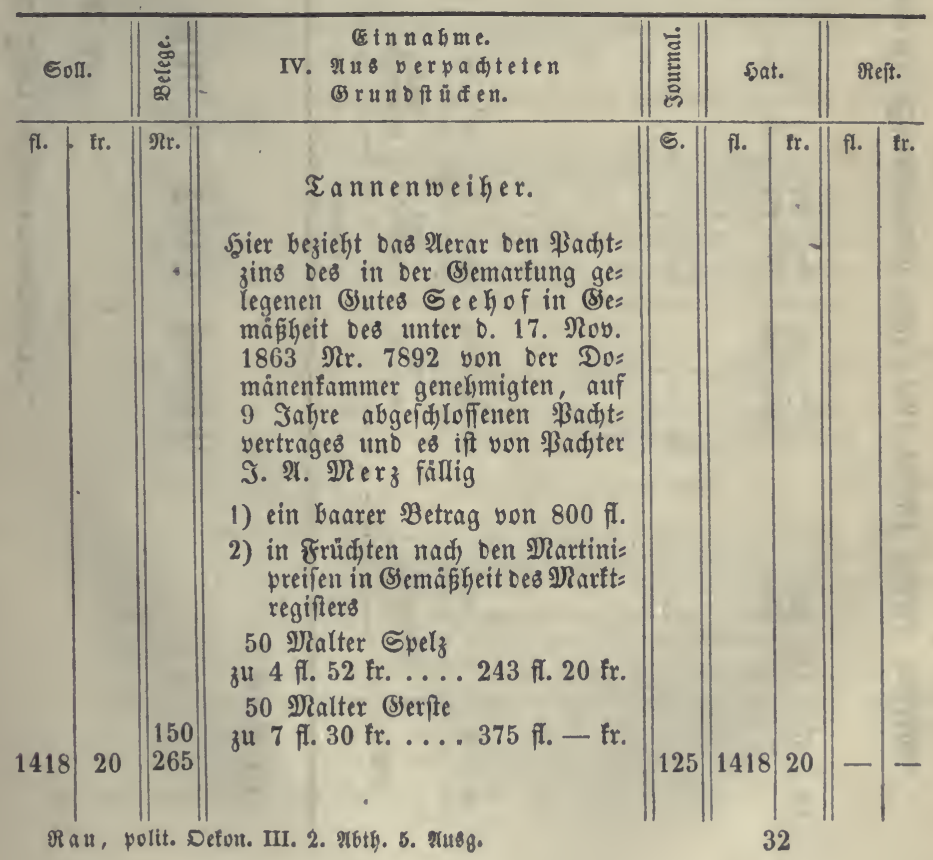




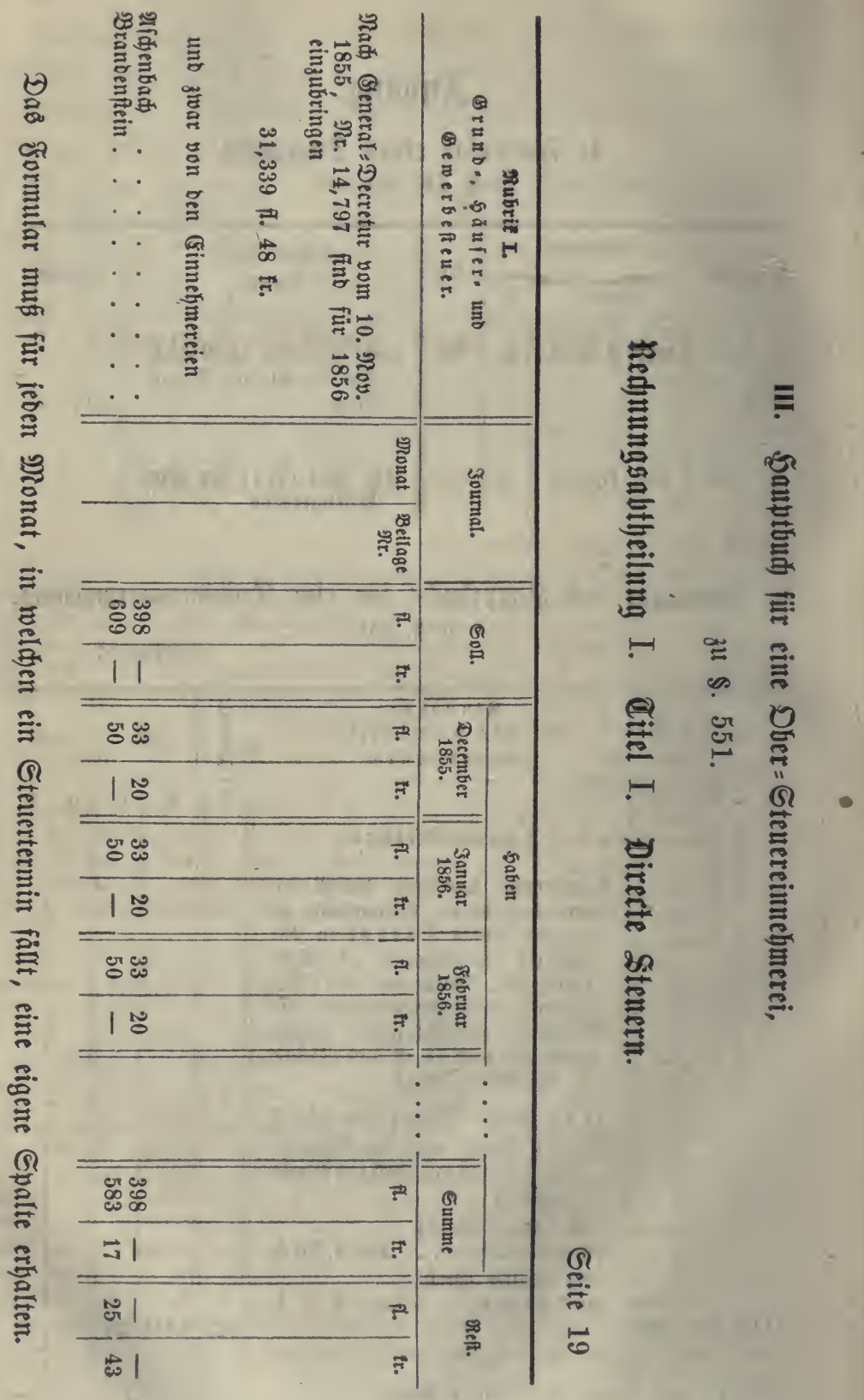




\section{Irad)träge uñ Geridjtigungen.}

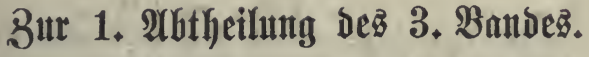

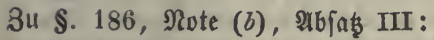

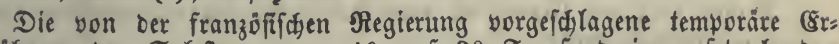
höhung ber Salzfteuer yon 10 auf 20 . Fr. fano im gefesgebenden

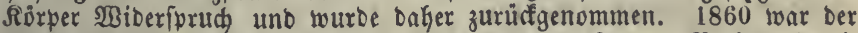
Ertrag Der Steuer auf 39.995000 Fr., Der gefammte Berbraudy mit Einfdiluß ber ftarf angetwadjenen Sobabereitung auf 22,24 $\mathfrak{P f b}$. für Den Ropf geftiegen. थ. 1865: innere Steuer 8.415000 fr., Ber= feuerung an Der 3ollgränze 22.548000 Fr.

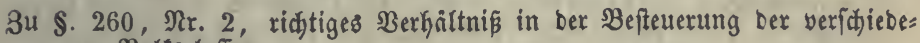
nen Bolfsclaffer.

\$rof. \& e D ne \&eyi (in Journal of the statistical society of London, Mârz 1860) fellt folgende Bered)nung für Das britifde Rönigreid auf. (Er unterfcheibet 1) bie höheren (Elaffen (reidje Erunb =, Fabrif = und Saurgerren), 2) bie mittleren (Elaffen (Raufleute, 20vocaten 2 .), 3) Die arbeitenben Ḉafien (Şanbwerfs= uno Fabrifgehülfen), 4) bie $\mathfrak{A}$ rmen.

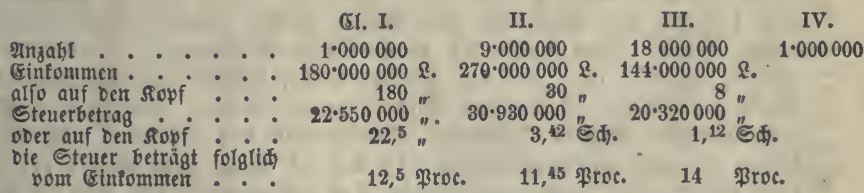

Szieraus wiro gefolgert, Daß̃ die Steuerlnft das (Einfonmen ziemlid, gleid)mäß̈ig treffe. Unter bie Steuern fino aud, Stempel, 2(rmen= uno örtlide Abgaben eingeredynet worben. Der Berf. fđeint bas gefammte ober roke Esiutommen zu meinen, ba er bei ben 2irbeitern 15 Schilf. WBodhenveroienft ter familie yon fünf Söpfen annimmt. Diefe foll alfo im D. $8 \times 5$ ober 40 \&. (470 f.) Jahreseinfommen haben (ver= mutthlich zu niebrig angeidjlagen). Shievon if aber eine Steuer von 14 \$roc. ober 1/7 viel zu hod. Nady bem mutfymaß̈licjen Neinein= fommen würben ganz anbere ơrgebuiffe erfalten twerden!

ङ. 409 feglt über bem 2unfang bes \$. bie 3ahl \$. 267 . 


\section{3ur 2. Afththeilumg.}

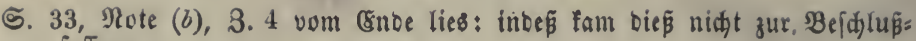
faflung.

5. 34 lies \$. 317 fatt 316 .

ธ. 41 lies \&. 318 ftatt 317.

ธ. 104, Note $(d)$ :

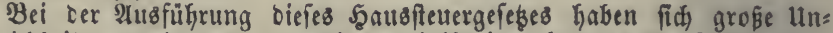
gleich heiten gezeigt und bas zinanzminifterium hat bas Beburiniß einer

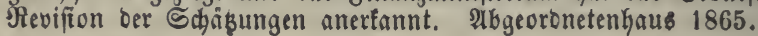

ऽ. $189, \S .430$ :

Britifde Einfommenfeuer. Nady bem a. Sefeb. von 1863 ift jebes (sinfommen unter 100 \&. St. frei, von 100 bis an $200 \mathfrak{l}$.

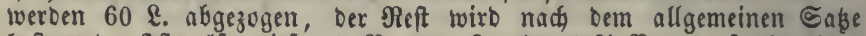
befteuert. Ift allo viefer 7 \$. vom $\mathbb{Q}$. ober 2,91 Proc., fo bezahlent 3. ㄱ. 180 \&. eine Steuer voll $3^{1 / 2}$ \&. $=1,9$ \$roc.

$150 "$ " " " " 12, " $1,75=1,74$ "

Nac (befes 27. Vict."C. 18." = 13." Mai 1864 wirb die Eteuer vom

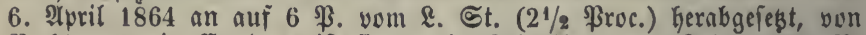
Padtungen in Englano if fie 3 , in Sdjottlano und Irlano $2 \frac{1}{2}$ ß. Daker fant Der Ertrag in bem Safye bis Enbe September 1864 auf 9.535000 \&. Gerab.

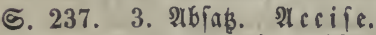

In ber americanif den 4 nion hat man eine Menge Goher uno befdwerlider Steuern Diefer $\mathfrak{A r t}$, bie nuth Dort wie in Englano excise

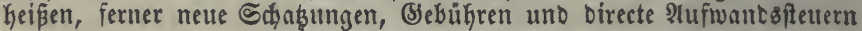

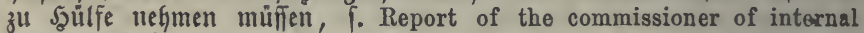

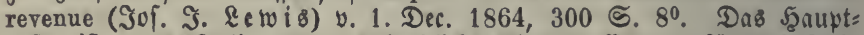

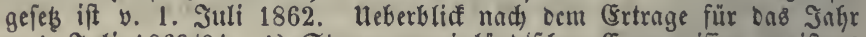
v. 1. Iuli 1863/64: 1) Steuer von inlänbifđen Erzeuguifien, meiftenz

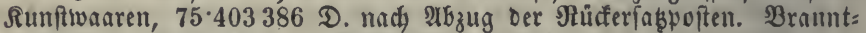
wein 20, nach (J)ejes v. 7. Mainz 186460 (5. vom Sallon, wowon man für bas nảchfte Jahr 40 פifl. Doll. exwartet, ba bie imere Brrzeugung auf 100 , ber פerbrauch auf 94 शill. (S) angeld/agen twirb uno rie Antwenbung einer netten Borridytung zum Deflen ber bereiteten Denge bevorfteht (ugl. oben $\$ .439$ (b)). Pier bas barrel yon 31 (5)all. 60 (5.,

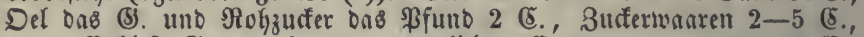
1000 (Subicf. (S) uhren, getwebte uno getwirfte Bettde, (Slaz, Reder=, Irbens, Rantidut:,

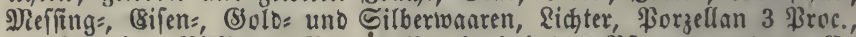

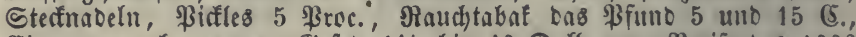
Bigarren nady netterem Sefes $11 / 2$ bis 40 Doll. bom \$reife Des 1000 nach 2 bzug ber Steuer, ber hodgfe Sab bei eimem \$reife von 45 D., -

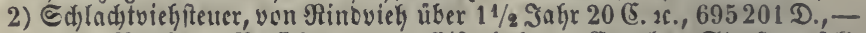

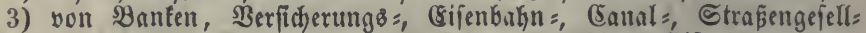

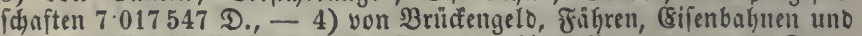

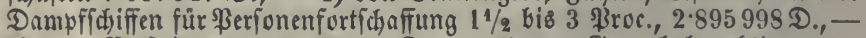
5) von Berfeigerungen 138052 D., - 6) von (Semerbbberchtigungen, licences, z. $\mathfrak{Z}$. Snatwirthidjaften 5-200, Theater, Bantherren 100, Brauer, slâtler bis 50 D. 2c., 7.145388 D., - 7) (Sinfommenfteuer von $600-10000$ D. 3 \$roc., Darüber 5 \$roc., vom Sins ber inlän= bifchell Stantopapiere 11/2 \$roc., 14.919279 D., meldge 408 Nill. (5. anzeigen. Die Erbohung auf 5 \$roc. Durd) Seję̧ v. 4 . Inli is64 


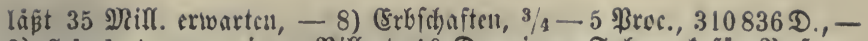
9) Sched. A., von einem Biflarb 10 D., einem Fuhrmerf für \$erfonen 1-10 D., vou (S)ID = und Silbergeräth $(130090$ D.), Dampf = unD

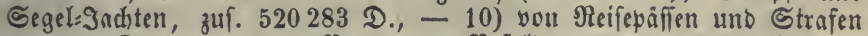
185708 D., - 11) 3 Proc. von Befoloungen 1.705 124 D., 12) Stempel von 1 (5. bis 50 D. 6.963767 D. - Sgauptfumme 116.850072 D. ober nad) 2 bjug ter Soften 108.469922 D. yon $25^{3} / 4$ Mill. Ginw. ober 4,2 D. vom Ropf. Die zunehmende llebung uno (Seidicflichfeit Der Stcuerbeamten hat Den Grtrag Des lesten

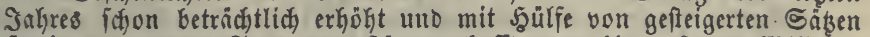
forvie von neuen Steuergegenfäncen hofft man bis auf 300 शRill. zu gelangen. Şiezu wirb unter anberen eine Rbgabe von roben Tabafs= blättern empfoblen, Die, wie die Erfahrung bei ber britifden Saopfen= feuter betweife, Yeicht unb fither yon ben Eanblvirthen zu erkeben fei, ferner $1 / 2$ \$roc. von allen $\mathbb{B} a a r e n f a ̈ u f e n . ~ M a n ~ n i m m t ~ a n, ~ D a \tilde{s}$ von bem ganzen Jahreserzeugní̄ (3700 Mill. D.) $3 / 4$ auf Den Marft fommen und im Durdfdinitt viermal umgefę̧t werben, fo Dá $1 / 2$ Siroc. von

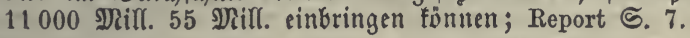

ङ. 296 fi., \&. 451.52 :

In Der norbamericanifduen. Hnion traten in ben Yesten Ialjren zur Beftreitung ber Durch Die groben sriegsanleifen entftanbenten 3ins: ausgaben mefrmalz uad, einander aniehnlidse (5rhbjungen ber (8in= fukrzolle ein, bie ben farfen inneren Nuftwantosfeuern entfprad)en.

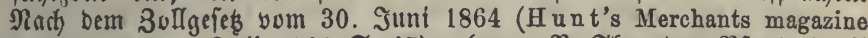
ed. by Dana, Juli 1864 G. 47) geben 3. B. Thee bas Fifund $(0,709$ Deutide Pfund) 25 (Eents, Nokzuder nad) Der Farbe $3,3 \frac{1}{2}$ uno 4 Bents, raffinirter 5, Raffee, Feigen, Corinthen 5 Cents, Branut= wein 2 uno $2 \frac{1}{2}$, fpanter 40 Cents vom Ballon $=4 \frac{1}{2}$ franzojfifhe \&iter, Wein nady Dem \$reife 25, 50 Eents und 1 Dollar nebit 25 ßrecent ad valorem, Shaumwein nidyt unter 6 Dollar von 12 Flafdjen, Bier 20 CEents, anbere geiftige Setränfe 100 ßroc., Eigarren von 25 Eents nebit 20 ßroc. ad r. bis 3 Doll. uno 60 ßroc.,

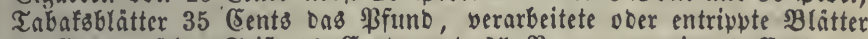
50 Cents, feine Seife 10 Sents uno 25 ßroc., gemeine 1 Cent unb

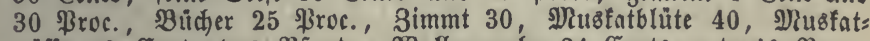

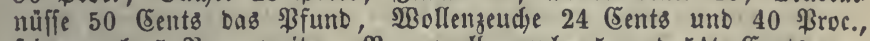
feine nod 5 \$roc. weiter, Baummollenzeuche 5 uno $5 \frac{1}{2}$ Cents vom $\square$ Marb, gefärbte, bebrufte noch 10 unb feine 20 ßroc. ad v., Seicen= zeude 50 , Bånber, Sammt 60 \$roc., Porzellan 45 und 50 \$roc., (SIn\&wanren $35-40$ ßroc. Seitbem finb nod meitere Steigerungen einzelner 3ollfäz̧e erfolgt.

ธ. 297 , §. 451 :

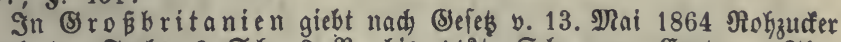
nach ber Farbe 8 Sh. 2 ip. bis $11^{2 / 3}$ (W). wom Centner, Thee

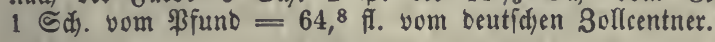

ธ. $379, \$ .500$ :

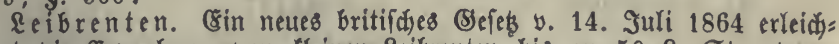
tert bie Crtwerbung von fleinen Leibrenten bis zu 50 \&. St., Deren Bezug berfjoben wirb (deferred ann.), fowie yon 3 ahlungen auf ben Tovesfall (Eebensberfidierungen) im Betrage von 20-100 \&. St. Die lebsteren find nur für foldhe ßerfonen zuláfíg, welda zugleid eine seibrente erwerben. Die Eimzahlung fann in fleinen Summen bis

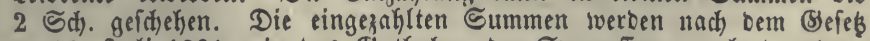
v. 14. Suli 1864 wie bas (S)uthaben Der Sparcaffen angelegt uno es Darf bon Seit zu Seit feber Betrag von Staatsfdulbicheinen in einen gleidwerthigen Betrng bon ßenten auf Seit umgewanbelt werben. 
श्रle fünf Sahre wirb yon ben zur Sdulbentilgung beftellten Com:

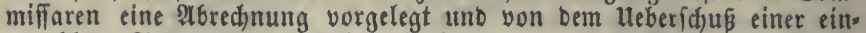
gezahlten Summe (assets) über bie 3aflungsverbinblidfeiten ein Theil, höhftens $4 / 5$, yon ber Stantsiduld geftridjen (cancelled). - 1864 twut: ben wirflid) 5 gill. von ber Sdjuld geftrichen (anmullirt) unb in eine terminable annuity (Seitrente im weiteren Sinne) verwanbelt. Im Bierteljahr Jutli bis September 1864 beltefen fids bie 3eitrenten auf 908543 \&. St.

Rorbamericantide Staatsiduld. Der am 6. Dec. 1864

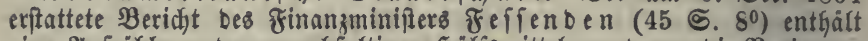
cine शufzählung oer mand,faltigen Shullfomittel, zu benen bie siegiertung

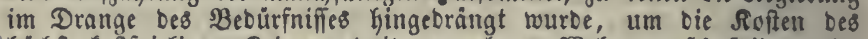

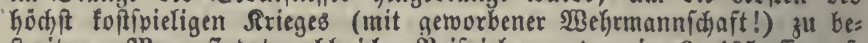
freiten. Man fincet zahlreidye Beifpiele zu ben in \$. 485 ff. auf= gefilhrten Arten bes Borgens. Anleifien mit einen hoberen Rennpreife famen nidyt yor, fein Édullofdein (bond) wurbe unter \$ari, Die zu

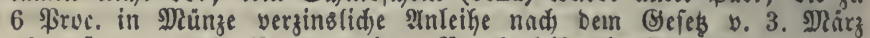
1863 fogar zu 104, 13 ausgegeben. Bon शnleifyen im 2luslanbe erwartete

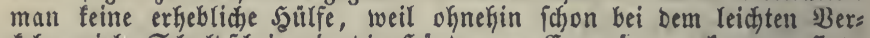
fehre viele Gdulofdeine in bie Şänbe von Europaern gefommen find. Bei ben Anleiben if angegeben, in tveldsem 3eitraume von ber 24: ftellung an fie zuruifgezahlt werben bưrfen uno muffen, $z$. B. Die 6 proc. log. $5-20$ D. bonds v. 24. Februtar 1862 , Dié fün Jafre nad) bem 1. Nlai 1862 nbgetragen werben bürfen (redeemable) uno nad) 20 Jafren heimgeznhlt werben follen (payable); von ifnen waren

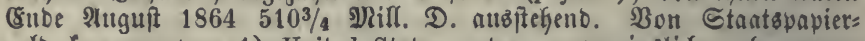
gelo fommen von 1) United States notes, unverzinslich, aber gegen 6 proc. bonds umtaufchbar; mitifteheno 433 Nifl. D.; 2) treasury notes, $5-7,3$ ßroc. Sins trageno. Die Negierung Goffte, fie wutrben weniger in úmlauf fommen, als bei Snpitalititen bes Sinsgenuffes willen liegen bleiben. Dafjer wurben fie attd mut für ifgren Stammbetrag (face value), nicht auch für bie angefallenen Sinfen als gejesliches 3aljlmittel (legal tender) erflärt, Dow viro zugegeben, Daß̧ ein betrichtlidjer Theil fich im Umlaufe berinbet. Die Rusgabe bon Sinsabidnitten (coupons) hat fich in biefem Falle nidjt zmedfmásig gezeigt, man hat beşGalb 71 DRill. ber mit Coupons verfehenen Sdjeine gegen anbere zurüigezogen, cods find nod, 79 Mill. vorhanden. Die anderen find nad 1,2 ober 3 Jahren zurücf́zuzahlen, aber nur in gefeblichen umlaufsmittefn (lawfull money) überfaupt. Der Sins wiro theils halbjährig, theils erft

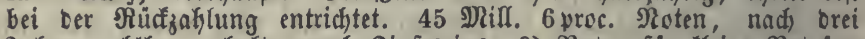
Saljen zafilbar, erhalten auc Binfeszing. 3) Poten für fleine Betráge unter 1 Dollar, fractional currency, in Betrigen von 5 Doll. gegen U. St. Noten umtaujbbar; ausitefiend $24 \frac{1}{3}$ Nitl. Die Schulo am 30. 2luguft 1864 entfielt folgende Theile:

1) in Mlüze verzinglid 889.899491 D. Sins 53.342478 D.

2) in gefęl. (Selbe verzinstich 469.197004 " "24.104642 "

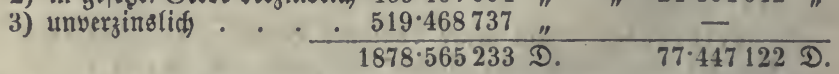

3u 3) geforen aufer ben U. St. unb fractional notes nod 61,6 शRil. für unbezahlte Rieferungen.

Im Februar 1865 wurbe wieber eine 6 proc. Anleife von 600 Dill. in log. $7-30$ bonds berwilligt. 


\section{Lienifter.}

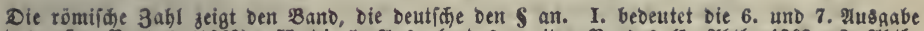

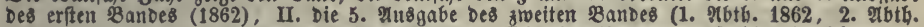

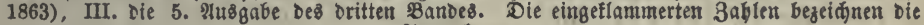
2เumerfungen.

จ.

26löfung Der båuerl. \&aften II, 53 -

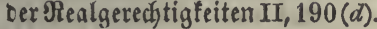

2rbrechnen I, 292.

2b|a่ I, 122. II, 31 - Giränzen I, 240 a - Des ganzen (Sinterer= zeugniffes I, 328 fi. 337 - Der

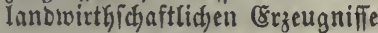
I, 364. II, 121 - ber Esewerfs= wnaren I, 393 - als Rennzeichen für bie (S) werbfteuer III, 369 . शbiakggebiet I, 165. II, 143.

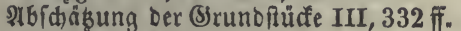

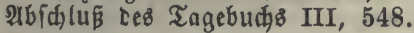

Absentees I, $340(a)$. $449(a)$.

26iolutorium III, 558.

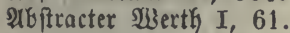

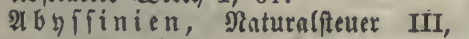
$284(a)$.

Nccife III, $428(a)$, vgl. 2Tuffiblag.

2cferbau I, 382 - Deffen $\mathfrak{B}$ eförbe: rung II, 149.

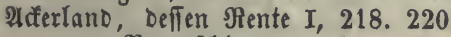
- Beranfiblagung III, 127. 128. 332.

Actien Der Bettelbanfen I, 304. 305. - Santoel mit bení. I, 438.

= capital II, $249(a)$.

$=$ gefellichaften II, 29c. $312 \mathrm{a}($ d) für (Eifenbahnen II, 260-263für Fabrifen II, 226.

शctionảre II, 250 (a).

शctipfianbel I, 415. 416.

शominiftration ber Domänen III, 104.

शomubiation III, 35.

2 egypten, Srunofteuer III, 316 (a).
Arfayala III, $428(a)$.

शllobificirung $\mathrm{D}: \mathrm{r}$ Bauerngüter II, 47a.

Almenoegüter II, $85(a)$.

2lmofen II, 356a.

Alpenwirthf̧haft I, 382 a.

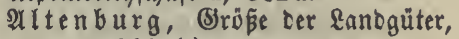
I, $368(c)$.

Artterżrenten II, 368 a.

Amortifationscafie III, 508.

Am fteroam, umínreibebanf I, 285 - Settelbanf I, 317.

Amtsbebürfniffe III, 66.

Angebot I, 152.

Angelegenkeiten, nuşwärtige III, 78.

Anhalt= $\mathfrak{i}$ bthen, Sduld III, $523(c)$.

Infergelder III, 244.

Inleihen, freimillige III, 490.

शnnuitäten III, 500.

Annulliren ber Stantsobligationen III, 520.

शrnunyme (Seifllid)aften II, 312 a (d).

शีnโäfỉgmadyung II, 15 a.

2)

Anfieolungen II, 16.

Anftellungstaxen III, 233.

Anticipatiunen III, 486, 489, 491

शntweifungen I, 286.

शtpanagien III, 48 (c).

Plpotheter II, $194(b)$.

Ap perzelf I, 395 (c).

शr raber I, 359.

2rbeit, alร (S) uีterquelle $I_{\gamma} 85.92-$ beren verfofiedene $\mathfrak{B}$ irffamfeit I, 110 - als \$reismaaß I, 179 - beren \&ufn I, 187 - für bie श्trmen II, 345 ff. 
Irbeiten, wirthidfaftlidje I, 95 offentlidue II, $7(c)$ - ber Sinber II, 202 a $(c)$.

2rbeiter, probuctive I, 111 - Deren Rebenstweife I, 191 - Wandes rungen I, $199(d)$ - Sefell: (d)aften Derfelben I, 200 - im Bergbau I, 354 - Sorge für Dief. II, 11 - शddtung beri. II, 20 - lanbwirthfojaftlicbe II, 120 (c) - Berbinoungen beri. II, 316 - 230 hnungen DetF. II, 203 - Bef̧anblung bei Der $\mathfrak{B e f t e t r e r u n g}$ in $\mathfrak{B e r}_{\text {: }}$ gleid) mit ben Nentnern III, 258 - Yeiben bei Steuern auf Die \&ebensmittel III, 421.

2rbeitäbüuer II, $199(f) .203$.

$=$ commiffion II, 344 .

$=$ fliche I, 372 .

= Gäuier II, 348. 348a-3 - 3wangs= hâuler II, 351.

$=$ lohn I, 126. 139. II, 12 Deffen Beftimmgründe $\mathrm{I}, 187 \mathrm{fi}$. - Thüneng Negel I, $200(b)$ - obrigteitl. Beptimmung befí. II, 317 - Eัrfhoffung II, $342(e)$ - bes unternefmers III, 359 Befteuterung Deff. III, 391, vgl. \&ohnifeuer - beff. Erfoging curch Befteuerung ber \&ebenb: mittel III, 422 .

$=$ theilung $I, 114$.

Arbitragen $\mathrm{I}, 291($ a) .437.

Ariftoteles I, 29.

2rithmetif, politifdue III, 14.

शrmenanftalten II, 356.

= beffreibung II, 339 a.

$=$ colonieen II, 349:

$=$ commiffiton II, $338 \mathrm{~b}$.

= Gåufer II, 356 b.

$=$ vfiege II, 335 - ber \$rivat= vereine 337 - Der Sirche 337 a - Der Bemeinde 338 - Der Staat getwalt $338 \mathrm{~b}-$ geefeblidie 339 - Statiftif beri. 356 (e).

= fiulen II, 353-355.

$=$ fiteuer II, 341 .

$=$ fiftungen II, 340 .

$=$ taxe II, 341 .

Armuth I, 77. II, 324 - Uriadjen beri. II, 325 .

Arrondirung II, 98.

Terzte, 3aGl berf. I, 111 (c).

श्राTecuranzell, f. Branoberfít)erung, Berfifberung.

Assessed taxes III, 425 (a). 9rifiguaten in Franfreid III, 487.

खffignationen I, 286.

Affuciationen I, $202(e)$. II, 5. 198.

Athen, Banf I, 317 - Sille III, 443.

Atfinion II, 206a (a).

Atomiftifd)es Beftreben II, $3(a)$.

2uflagen III, 84. 86, vgl. Steuern - Brundräge für tie 2ufl., III, 250 - nuf reldje Şoke Dief. gebracht mexben fónnen 467.

2ufnahme Der Borräthe III, 540.

शufifilag III, 424.428.

2uffichtbrath ber (S) efelfidaften II, 29c. Жufwanbsftettern II, 361. III, 292. 406 - unmittelbar erfobene III, 425 .

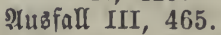

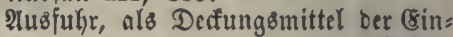
fulfr I, 424 - von veriffied. Ränbern I, 430 - Des Esetrei= Des II, 123 - ancerer Rohftoffe II, 128 - von Rumftranaren I, 394 (a) - amtlicher uno wirf: licher ßreis I, 429 - gefammte uno eigne Des \&anbes I, 430 ßrảmien für dief. II, 299.

24us: und sinfufrhandel I, 408.

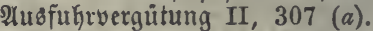

$=$ zölle II, 302 - beren Wir= fungen III, 454.

2usgaben in oer \$rivat= uno Regies rungsiwirthid aft III, $10-i$. Stratsatsigaben.

शusfommen I, 76.

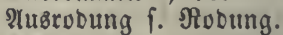

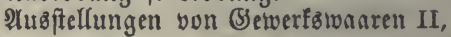
225.

2uвำteuercafien. II, 15.

Altsmanderungen II, 17. 350 - ber Iit Eeiter I, $199(d)$ - Der शrmen II, $350 \mathrm{a}$.

2นเซวนต II, $76(e)$.

शverfum III, 35.

2.

BaDen, Einfilgrumg Der PGyfrofratie I, $41(a)$ - Elaffen ber Ein: wofner I, $365(b)$ - Bertfei= lung bes Sstunbeigentfums I, 386 (c) - 5oolzpreis I, 356 S2anbelsminifteriums II, $7(c)-$

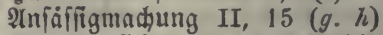
Branoverfidjerung II, 24 (c). 25 (a) - Erohnablojung II, 
64 (c. $f)$ - श्Almenogut II, $84(d)$ - (d) twerbegeieb II, $190(d)$ - Eifenbafnen II, $258(a)$ Beriorgungฮnกf. II, 368 a $(g)$ - Befintablojung II, 69 ff. III, 163 - Sreisverbande III, $54(d)$ - Neugeftaltung Der Berwal= tung $57(e)$ - Bittwengehalt $65(c)$ - Etrafanfalten $69(d)$ umlauf. Betrieberfonos 89 Domínen, Zelogüter $103(a)-$ Staatsforften 142 - Solutten= twerfe 154 - Salzregal $186(b)$ - \$often 205. 208. 216 Stempelgebükr 232 (a) - Spor= teln $234(a) .235$ (c. e) SRufaccife $236(a) .236 a(b)-$ Erbichaftsaccife $237(a)-\widetilde{F l u b}=$ zölle $244(a)$ - Beförifterungs: abgabe $245(c)$ - Steuererbe= bungsfoften $286(a)$ - Srund: ftetier 324 - $\mathfrak{Y}$ aloftetuer 332 (a. c) - ફুณuвfteter 352 (a.c) - Selverbiteuer 373 - Sapital= fteuer $377(a) .388$ (a. c. d). 389 (a. c). 390 (b. d. g) Elaffenfteuer $395(a)$ - Sunbe= fteuer 427 - Fleifchaccife $430(a)$. 432 (c) - 28einaccife $434(d)$ - Dhmgelo $435(a)$ - Bier: accíe $437(a)$ - Rerfelgelo $439(d)$ - (s)änzbetwadjungbfoften 248 (c) - Betrag ber (Sautionen 486 (b) Tilgungsart $522(a)$ - Sd)ulo 529.

$\mathfrak{B}$ aуern, $\mathfrak{B a n f} \mathrm{I}, 317(f)-\mathfrak{A n}=$ f̊̊fitgmadung II, 15 a - (Se: werbsrechte II, $194(g)$ - 2 Fb= löfungsgefes II, 61 (e) SBgeibegeies II, $74(a)$ - Stants: cijenbahn, Ditbahn II, $258(d)$ - Canal II, $277(d)$ - 28 ier: taxe II, 315 (d) - Nrme II, 327 (c) - St. Johannisuerein $338 \mathrm{~b}(b)$ - Bezirfsaubgabelt III, 55 (b) - Befoloungen $57(g)$ - Ctaatsforften III, 142. $149 \mathrm{~b}$ - Dienitgebrube $154 a(b)$ - Şüttentwerfe III, 154 - Brumogefälle III, 155 Salzregal $186(b)$ - \$oftweien 205. 208 - Eotterie 222 Befteuerung Dex verfdiedenen Rreife 280 (b) - Brunofteuer 323. 326.326 - Setwerbftetter 368 (d). 369 (b. c). $372(a)-$ Enpitalfteuer 377 (b). 388 (d)
- Steuer vom Prbeitsverdienft $395(a)$ - Einfommenfteuer 400 - Уialzauffalag 436 - \$ิmor= tifationscaffe 508 - ßenfions: Amortifationscaffe $518 \quad(d)-$ Tilgung Der ङtaatsidfulo 522(a) - Bröpe ver @chulo 529.

Banf I, 304 ๆ. Umidreibe= u. Settel= banf - von Eingland I, 311. II, $252(a)$.

= häufer I, 292 a.

$=$ noten I, 304. II, 247. 249.

= valuta II, $248(a)$.

$=$ wefen II, 247.

Banferott II, 23. 24, vgl. Stants= banferott.

Banking principle I, 307 (b). II, 249 (b).

Bannmeile II, 200.

Bannredte II, 204 a.

Banquiers I, 292 a.

Barmen I, 395 (d). 398 b.

$\mathfrak{B}$ a f Bauaubignben III, 67 - bei Domá nen III, 119.

Bäuerlide Eaften F. Enften.

Bauerngüter, beren (Erblichfeit II, 47 - Deren (S) bundenfeit II, 76.

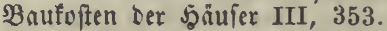

Baumwolle, Deren \$reiz I, 185 (c). Baumwollengarn, Esinfuhrzoll II, 213 a $(e)$.

$=$ verarbeitung II, 213a $(c)$ - in (Sropibritanien I, $126(b)$.

Baurente III, 345.

Bebientenfteuer III, 427.

Beburtrniffe I, 75.

Beede III, 316 (c).

Beförfterungsfoften III, 245.

Begehr I, 152.

Begleitfdyein III, 460.

Beholzungäred,t II, 161 a.

Belege Der Nedjnungen III, 553.

Belgien, Arbeitslofn I, 197 (c) (S)eldmenge I, 266 a - Banf: weien I, $317(k)-$ Padjtungen I, $377(a)$. II, $79(l)-$ Srößß̨) Der \&anogüter I, $368(c)$, 3ahl berí. II, $77(g)$ - SBergbau= betrieb II, 33 (c) - landw. Leihamftalten II, 120 (b) 3ufferaccife $214(e)-\mathcal{E}$ brs merfitatten 222 a - Strá̧en=

- lãnge $255(b)$ - Sđubzölle $215(a)$ - Eijenbafnen 272. 273 - 2rme $328(c)$ - Erfie Der Gifenbahnarbeiter $334 \mathrm{~b}(a)$ 
Statifit Der Armenpflege $346(e)$ - Armencolonien 349 - (Se: meinbealtsgaben III, $52(b)$ Bejirf8nusgaben III, 55 (c) \$ad)tersired)t III, 120 (d) Salzfteuer III, $186(b)$ - \$ro= vincialfeuer $280(a . b)$ - Dctroi 417 (d) - ßerionalfteuer 426 - Mlobiliarfteuer $427(e)$ Bieraccife 436 - Branntwein= accife 438 - アïbenzuderfteuer 442 (d) - Stantsiduulb 529.

Bergbau I, 97. 350 - Bflege befí.

II, 33 - アegal III, 172-183

- Deffen Befteueruma III, 362.

$=$ beamte II, 40. III, 171. 179.

Bergeanftalten II, 284.

Bergwerfe ber \$rivatem, sBeauffict) tigung II, 38 - 2rbgaben an Den Stant II, 41. III, 181. 182.

Bergiverfsarbeiter II, 43.

Bergzełnte II, 41. III, 181.

$\mathfrak{B}$ erlin, Eaffenverein I, $317(f)-$ Dif́contogefellich. II, $312 \mathrm{~d}(f)$.

Ber $\pi$, Bertheilung Des Srunbeigen: thums I, 368 - Srunbfteuer III, $331(a) .401 \mathrm{~b}(b)$.

B̧eiditutung II, 252.

Beffireibung ber शrmen II, 338.

Befold III, 20 (b).

Befoloungen III, 57-61.

Befoloungsfteuer III, 393.

Befferungタ̧håtier. II, 353.

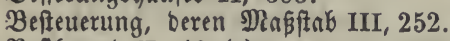

Befthaupt II, $48(a)$.

Betriebfamfeit I, 113.

Betriebscapitale III, 88.

= Wlane für bie Staatbforften III, 146 - für bie Branntwein= brenner III, 439.

Bettler II, 327.

BBeurlaubung III, 75.

Bevólferung II, 11. 12.

Bewegende Siräfte I, 90 (s).

Bezirtżaนอ̊gaten III, 53-55.

= regierungen II, 7 .

= ftraben II, 257.

Bierauffidlag III, 436. 437.

$=$ - taxe II, 314 .

Billon II, 243.

Binnencontrole III, 462.

= Ganoel I, 408 - Beforberung Deff. II, 285.

$=$ Iand, Binnenlinie III, 460.

Blafenżits III, 439.

Blutzefgnte II, 67.

Bobinuet I, 401 (a).
Bobenertrag in falten und twarmen \&ảnbern I, 87 (d).

$=$ exzeugnifie, beren श्रusfufy II, 128 - beren Cinfufir II, 132.

Bo o inus I, $37(b)$. II, $9(a)$. III, $20(a) .42(a)$.

Bonitirung III, 124. 127.

Borgen III, 472.

Bornib, Bornitius III, 20 (b).

Börien II, 283.

$\mathfrak{B}$ an Den $\mathfrak{B}$ of

Bradje I, 382 (c). II, 72.

Bradutueibe II, 72.

Brambiáäben II, 26 b. 28 (b). 29 (b).

= verficherumaen II, 24-29.

Branntweinaufficlag III, 438.

= regal III, $303(a)$.

Brafilien, Banf I, $317(q)$.

Brenuen bes જBobens I, $362(a)$.

Breslau, Banf I, $317(f)$.

Brief, einfacher III, 216 - recoms manoirter 218 - 3ahl $208(c)$.

$=$ poft in ßBezua auf ben Jannel II, 268 - Regal III, 208 fi.

Britifds:oftindifdre (5omp. II, $279(a)$.

Brotlieferung fưr die Solbaten III, 76.

= portion III, 76 .

= taxe II, 314.

Brüucfen II, 264.

Brubercafien II, 43.

Bruttogetwid

B̊udjeredit I, 306.

= fiifrung III, 546 .

- Galterei, $\mathfrak{B}$ ubbaltung, oberfte III, 536. 560 .

Bubget, orbentl. uno auberorbentl. III, 41 - SBefen beff. III, 465 f. Boranidilag.

Burenuausgabeit III, 66.

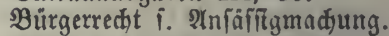

= rettungscaffen II, 334 .

= fojulen II, 222.

c.

(Sabinet, fuirftr. III, 68.

Caisses de retraite II, 368 a (d).

Balculatoren III, $557(a)$.

Enlender, beren Befteuerung III, 441.

Ganäle II, 267 - Beftreitung ber Sopten III, 79 - Ennalanleifen in Franfreid) ebento. (e).

Enmalzölle III, 224.

Eapital I, 51 - beoingt bie Arbeits= theilung I, 118 - als (Suter: quelle I, 121 - fithendes, ums

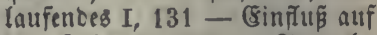
ben \&okn I, 195 - शntwadys 


\section{7}

I, $196(e)$ - in ber Ranbwirth: f(c)aft I, 215a. $369(e)$. - Schab= loskaltung für beffen Intwentung I, 224 - Sorge für bafi. II,

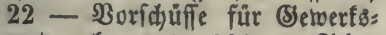
unternefimer II, 226 - @dpo: nung beff. im ङteuerweien III, 255 - Sröze Defi. in Bezug nuf bie (S) ewerbfteuer III, 367. 368 - Disponibles 474 (c).

(5apitaliften I, 54. $251(a)$.

Eapitalrente $\%$. Sinsrente.

$=$ fteuer $f$. Sinbrentenfeuer.

Capitatio III, $316(a)$.

(5arey) II. 205. 212 (b).

Eaffen III, 566.

$=$ anleiken III, 491.

= antweifungen, preús. III, $489-$ offerreich. III, 491 (d).

= curatel III, 569.

= doreine II, 151.

$=$ wefen III, 566 .

Saution Der Domanenpadyter III, 115 - ber finanjbeamten ůberfaupt III, 487 - Der Caffenbeamten III, 567.

Eentralftellen, finanzielle III, 532. 535.536 - Iandwirthidáftlidge II, $146(e)$.

(Eertificate III, 506.

Charité légale II, 339 (a).

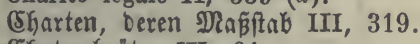

(Ehatoulgutter III, 91 .

Shaufieen II, 256, vgl. Eandftrafen.

(5haufferelo III, 238.

Ehina, \$apiergeld I, 295 (a) (Sanaile II, 267 (d).

(SFrematiftif I, $3(a) .29(b)$.

(E) hiftiania, Bant I, 317.

Cicero I, 30 .

Sirculation . Utmlauf.

Sivilingenieure II, 223 (a).

Sivillifte III, 48.

Elaffenlotterie III, 225.

= ftempel III, 231.

= fteuer, in Surkefien III, $388(b)$ in Defterreich III, $388(e)-$ Baben III, $395(a)$ - \$reußien III, 400.

Elaffification, Elaffirung ber Brunb: ftủfe III, 335.

Elofter, beren 20 ohlthätigfeit II, Dampfmajoinen I, 90 (s). 115 (c). 335.

Colbert I, 34 - beff. Fabriforo: nungen II, 217.

Eollegialverfafiung III, 70.

Eolonatuerbialtuiffe II, 46.

Colonialwaaren, Deren Befteuerung III, 451 .

$=$ zudfer II, $214(e)$.

Eolonieen II, 16.300 - für :rme II, 349.

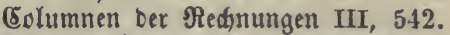

Commanbiten II, $290(d)$. 312 a (d).

Commerce général et spécial I, 430 .

Bommercientwifienidyaft II, 9.

Communiften I, 45 a.

Sompagnieen 1. Şanbelsgefellidaften.

Compenftrell I, 292.

Eoncefítonstaxen III, 245.

Concreter $13 e r t h$ I, 61.

(Eoncurrenz 1. 9) Iitwerben.

Conducteur bei Der ßoft III, 218.

Gonring II, $9(a)$.

Eonfolibation II, 98.

(Sonfuln II, 302.

Sonfument I, 324.

Eonfumtion f. Berzefrung.

Confumtionsffeuer f. शlufwantsfteuer.

Sonfumbereine II, $198(k) .365(g)$.

Eontirungen III, 461.

Sontribution III, 316. 347 (a).

(Sontroleur einer Enffe III, 567.

Soupons III, 509.

Gourt, de Ia II, $178(b) .179(b)$.

Erebit I, 278 - ber Lanowirthe II, 110 .ff. - Des Staats III, 482 - vgl. Staatzcrebit - Érebite im Jimanzgefebe III, 470.565

- crédit foncier II, 120 a crédit mobilier II, $312 \mathrm{~d}(d)$.

$=$ anfalten II, $312 \mathrm{a}$ - lanbivirth= fúaftliche II, 112. 113. 120 a.

= eridutterung II, 249 (a).

= gefellfijaften II, $312 \mathrm{c}-\mathrm{e}$.

= papiere I, 293.

= vereine, landw. II, 113-120.

$=$ weien II, 247.

Eulturen, forfilidje III, 147.

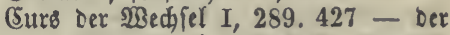
Stantespapiere I, 438. III, 495. 529 c - Des \$apiergeloes II, 252 (a). III, 488. 528 - beí Dem Softwefen III, 215.

=- fuifffulfrt II, 272.

= wågen II, 258. $259(f)$.

Danagild III, 316 (c).

Dảnemarf, şantweien I, 317 (b)

- Sdjulo III, 529. 
Darleifen, Befafy I, 225 - in Beld I, 230 - gefebl. Borfduriften ûtber bief. II, 317 .

Ded)arge III, 558.

Decima III, 398 b.

Decimaltheilung II, 230.

Declaration im Sollwefen III, 460.

Decretur III, 568.

Deficit III, 463 a.

Depofitenbanfen f. ttmidnreibebant.

$=$ geidhäft $\mathrm{I}, 306(\mathrm{c})$.

Depreciation bes \$apiergelbes I, 300. II, $252(a)$.

Deffau, Banf I, 317 - Erebit= anftalt II, $312 \mathrm{~d}(f)$.

Deutidlanb, Wedjelorbnung II, $273(a)$ - S5anbelstag II, 274(a).

Devaftation ber 2 álber II, 156.

Diafonen II, 337 a.

Diamantenregal III, 168 (a).

Diäten III, 66.

Dienfte, periontidje I, 46 a - im (segenfats ber wirthfdyaftliden 2rbeiten I, 95 - ob Gervor: bringend I, 107. 108.

Dienftwoknungen III, 67.

Differenzengeidåft I, 312.

Disiconto I, $235(b) .288$.

= gefellfwaften I, 292 a (c).

Dismembration ber 2 aulerngüter II, 77 - Der Domänen III, 132.

Disెpeniationstaxen III, 246.

Dodfs II, 277.

Domañen III, 89 - SBerfauf III, 94-100 - 2nfauf 100 a Befteuterung ber D. III, 265 1. nuch Frelogüter, Waloungen. $=$ paditer III, 111.

Domesbayboot III, $316(f)$.

Domicile de secours II, $339 \mathrm{~b}$.

Dominicalfteuer III, $308(a) .339$.

Donnumoos II, 103 (a).

Dopvelbudhaltung III, 548.

Dorfwege II, 148a.

Drainiren II, 103 (b). 104. III, $120(b)$.

Drawbacks II, 307. III, 462.

Dreiedfernes III, 319.

Drejuerlohn I, 199.

DritteløిgebüGr II, $48(a)$.

Durdhfuhr II, 314.

Durchgang శ̇子oll II, 314.315. III, 457. Durdblaufenbe $\Re$ often III, 556.

Dürftigfeit I, 77.

\section{(5.}

Effecten f. Berfdureibungen I, 293. Egartentwirthidaft I, $382(e)$.
(Eicuenid)âlıalo II, 165.

(8id)ungø̋beamte II, 231.

Eigenlöhuer I, 353.

Einforberung ber Steuern III, 187.

Einfukg vgl. शtusfukg - wie fie ber= gủtet werben fann, I, 420- - bes Setreites II, 129 - anberer lanbw. Erzeugniffe II, 132 von (b)ewertswanten $205-$ ob fie zu fürdjten 298 - \$rümien 303.

$=$ verbote II, 205.

= zoll von Setreibe II, 129 - von alloeren গohftoffen II, 132. III, 451 - von Setwerfswanten II, 205-215. III, 452 - im श̂́gemeinen II, 294. 298. III, 446. 450.

Eintommen, rohes I, 70 - reines I, 71. II, 2 - bes Bolfes I,

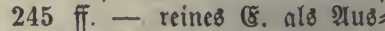
brud ber Steuerfäkigfeit III, 257.

Einfommensefteuer, unmittelbare -III, 293 - allgemeine III, 39s ff.

Sinfünfte I, 70. III, 463, f. Stant8: cintünfte.

Einlofungsidseine, ifterreid. I, 316.

Esinmaifdung III, 436.

Eimualymen I, 70 - in Der Privat= unt Regierungstwirthidjaft III, 9 - Des Staats, Deren Ergãnzung bei ber unzulänglidfeit ber (Fin= fünfte III, 463 - tuneigentlid)e III, 556, f. auch Staatseinfünfte. Einfdjäkung in bie (Elaffen ter (S)runb: fứcfe III, 336.

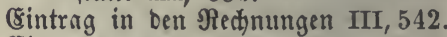
Einwanberungen II, 16.

Eifen, ßroouction I, $330(b)-$ Gre zeugung, शนo = uno (Einfufr, Soll II, 213 a (c).

Eifenbahnen II, 255 (b). $258-$ Deren Menge unb Roften 258 (d) - Bortfeile 258 a. 259 Fabrgelo, Eradit II, 259. 261. III, $219(g)$ - Ertrag II. 259a - ber Actiengeíllichaften 260. 261 - Stanţbafnen II, 263. III, 219 a.

Entittiren tes \$nipiergelbes I, $293($ b).

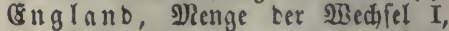
288 (a) - 2 rmenfteuer II,

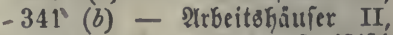
348 a - 2rmenyflege, fratiptif II, $356(e)$ - (S)runofteuer III, 315 (a). $316(e)$.

Enregistrement III, 236. 
Entrepôts II, 309.

Gntrid)tung ber Steuem III, 284 Der थีแ

Entwäfierung II, 103.

Ërblichfeit Der bäuerlichen Befitbungen II, 47.

Grbpacht Der Domånen III, 130-136 - Der Stantswwaloungen III, 144.

(ชrb) () aftsిnbgabe 1II, 237. 405.

Erbitollen II, 42.

Eroarbeit I, 97.

Erfinoungşvatente II, 203a-205(Sebuifr oafür III, 245.

Srkebung Der Steutern III, 286.299.

Ernten, Sinfur auf Den (s)etreidepreis I, 182 - Srtrag beri. II, $122(a)$. $140(a)$.

Ertrag, reiner I, 39 - roher, reiner I, 70. 71 - Beffeuerung oeff. III, 258 - als Stï̈ppunct Der (5rundifeuer III, 328- Erfor: ichung III, 332 - roher, als $\mathfrak{B}$ afì für bie Brsunoft. III, 326.

(Extragsanid)lag III, 122.

= Berednung bei Domånen III, 125.

$=$ ftetter III, 262.

Errab̧uopten III, 556.

(Erwerb ber Regierung III, 84.

Erwerben I, 69.

Srwerbsfreikeit II, 4. 5.

$=$ mittel I, 50 .

Ërzeltgungswerth I, 58.

Stat III, 465 - 'Specials, S2aupt=,

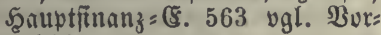
anichlag.

Gtatoentivurf III, 562.

= rechutung früberer Şałre III, 555.

$=$ =Soll III, 544 .

$=$ wefen III, 561 .

Europa, 3onen Der Fruditbarfeit I, $87(b)$ - Netrifproduction I, 272 a.

Exchequer bills III, 491.

Erecution 1. Einforderung.

Exercice in franz. Nechnungstweien III, 554 .

\section{ร.}

Fabrifen I, 398. 399 - Deren (Ex: ridjtung II, 202 - allf Irctien II, 226 - Betreibung Durd, Den Stant III, 153.

Fabrifarbeiter I, 398 a. 398 b. II, 202 a. 203.

Fabrifenoronungen II, 219.
Fabrifzeichen II, 219.

Fahrnif́ f. Branboerfiderung.

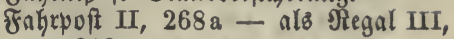
212.

Fäfrredyt III, 219 f.

Familienguiter, fürftl. III, 45. 46.

Feiertige I, 103. II, 17 \%. III, 362.

Freingehalt Der IRünzen II, 236.

Feldanzeiger III, 336.

= arbeiter, Deren $\mathfrak{B}$ ebarf I, 191 \&ohn 199. I - 3afil I, 365.

= bau, beffen \$flege II, 148a.

= eintheilung $\mathrm{I}, 382$.

- F̂turen, Deren gute Eintheilung II, 97 a.

$=$ graswirthfळaft I, $382(e)$.

= guีter, zu ben Domånen geljorig III, 103.

= iago II, 175 (a).

= polizei II, 148 .

Feldermirthichaft I, 352 (c)

b. Fellenberg, lanbwirthidnaftlidbe Âtrmenichule II, 355.

Fenfterfteuer III, 426.

Fertigfeit I, 113.

Feuerverfit)erung i. Branowerfidjerung.

Finanzbeamte, 3 Elafien Derf. III, 537.

= Dienfte, 21bfufung berf. III, 532.

$=$ gefdififte III, 531 .

$=$ gefes III, 565 .

= getvalt III, 11.

= tammern III, 534 .

$=$ minifterium III, 535 .

= organifation III, 530 .

$=$ weien I, 16. III, 1 .

= wifienfart I, 17. III, 5 (B)efdichte III, 19-23.

$=$ zülle II, 205 (c). III, 445.

firma II, 29 (c).

fiscalredjte III, 166 (c).

Fifderei, wilde I, 356 - झuffint auf Dief. II, 176 - Des Staats III, 165. 195.

Fladbrfpiunerei I, $404(c)$. II, $228(b)$.

Jleif̧aufichlag III, $430(a) .432$.

$=$ preis I, $185(b)$.

$=$ taxe III, 314 .

= verbraud I, $326(a)$. III, $432(a)$.

Fleís, Deffen urfachen I, 112.

ซ్flöß̄en Des Şolzes III, 219.

Flurfwang II, 97.

Jlüffe, fd)iffbare II, 266.

Flü̧olle II, 270. 271. III, 224.

Fohlenföre III, $76(\mathrm{~g})$.

Forberungen, inländifhe, atıwärtige I, 49. 54. 420.

Forftbeante III, 149. 
Foritbereditigungen III, 142.

= meifter III, 145.

$=$ polizei II, 160 .

= regal III, $192(a)$.

= fđus II, 153. 160. III, 147.

- fervitutenl III, 148.

= Patiftif III, 146.

$=$ wirthfduft I, 383 - \$flege berí. II, 153 vgl Walobau.

Fortichaffungsmittel II, 126.

Fourier I, 45 a $(d)$.

Fradtoften I, $170(a)$.

Fra $\mathfrak{n}$ freid, Eulturgränzen I, 87 (b) - betwegende siráfte I, 90 (S)etreibepreis I, 178(c)- Dults: einfommen I, 247.248 - SSelD= menge I, $266(a)-$ Banf I, 314 - Sิins์uี I, $232(d) .234(a)$ - Bergtwertşerfafiung II, 38 (a) - Bewaloung I, 387 (b) -

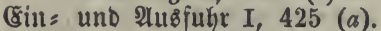
430 (c) - 3erftüfelung Des (8runceigenthums I, 368. II, 81 (a) - 8 ranbverficherungen II, $26(a)$ - crédit foncier II, 120 a - Rorngejese 131 (b) Sुüttentoerfe $213 \mathrm{a}(c)$ - Gin= fubrzölle $215(a)$. III, 451.452 - Mlaapivefen II, $230(d)$. 231 (b. d) - Etrap̃ell II, 255 (b). 256 (c) - Emäle II, $267(d)$ - Gifenbahnen II, 273 - $5 a n$ elsverträge $304(a)$. 305 (b. c) - crédit mobilier II, $312 \mathrm{~d}(d)$ - Nlagazine zur Bervfäloung von $W_{\text {anxen II, }}$ 312 b (e) - Brottare II, 316 (a) - Mrme II, $328(c)$ - Şülfs: geiellfdaften $334 b(c . g)$ - Spar: caffen II, 367 - Devartements: ausigaben III, 38 (d). 54 (c). $55(a)$ - Sriegscontribution III, 77 (a) - Eanalanleifen III, $79(e)$ - Stantövermigen III, 89 - Stantoforften III, 137 (a). 142 - Snlziteuter III, $184(c) .186$ (b) und III.

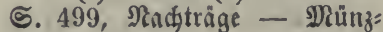
wefen $202(a)$ - Tabafbregal 204 - Boftwe fen 205 - Qotterie 222 - Stempel 231 (d.f) Gpurteln 234 - enregistrement 236 - Steuererhebung 289 Srunbfteuer 319 (i). 329 (b). 331 (a) - \$atentiteuer 374 taille personnelle $396(b)$ capitation $397(b, d)$ - $\mathfrak{c t}=$ fonalfteuer $397(b)$ - Steuer= erfebungstoften $414(b)$ - Nios biliax=, Thür: uno Fenfterfteuer $426(b)$ - \$unbefteuer $427(a)$ - Et. von \$perden u. Wäaen $427(d)$ - 23 einfteuern 433 a (a). 434 (d) - Bierfteuer $437(a)$ Branntweinfeuer 439 (e) Runfelrübenzucferfteuer $442(d)$ - Ausfubrzoll 456 (a. b) -

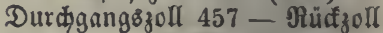
$458(g)-$ Deficit $463(e)-$ Steuererhỏhung $466(c)-3 n h l$ Der Staatsgläubiger $480(a)-$ Staatspapiergelo 487 - fatwe:

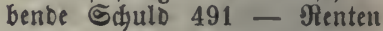
495 (c). $506(b)$ - Curs ber Nenten $494(c)$ - Umtauíd ber St.: Sdjulbidjeine $495(d) .498(b)$ - Anleifen mit hökerem $\Re(s=$ minalcapitale $496(a)$ - $\mathfrak{L}$ eib: renten 500 - Amortifationscaffe 508. 520 - Sinsreouction 511

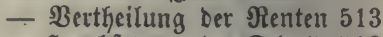
- Sernbfebung Der Sdulo 516 - Tilgung 520 - Errópe ber Shuld 529.

Freierflårung Des Bergbaues II, 37. Freifiäen II, 308.

Jreiheit, Bejdyrinfung Derf. II, 4.

Freiquartiere $\amalg, 312$.

Friendly societies II, $334 \mathrm{~b}$.

Frohnen I, 112. II, 62 - zum Strapenbau III, 79.

Frudtfolgen, Frudytwedjel I, 382.

Fufrrverfe, D. Befteuerung III, 427 (d). Funogrube II, 37.

\section{(3.)}

(Sarn, 21tsfuthr II, 213 a (c).

B)artenbau I, 379. II, 151.

= IanD, Def̂en \$reis I, 379 (b) Beranichlingung III, 129.

Sonttungsiverth I, 61 .

Sebaube, bereln Brancwerfiderung II, 25 - lanblvirthfáftl. II, $448 a$ - 2ub̊gaben für vief. III, 67 bei Dumänen III, 119 - (Ses bäubecapital III, 357 (a) vgl. Szausftetier.

Bsebirge I, 119 (b).

(5)braud)8arbeiten I, 101 - nidpt hervorbringent I, 106.

$=$ worrath $I, 51$.

$=$ wertf I, 57. 58 - Rente I, 223 (a). 


\section{1}

Bebunbengeit ber Bauerngüter II, 76 - ob bei ber Befteuerung zu beaditen III, 322. 333.

(๖) เืŭfren III, 86. 227-29.

ङeburten, beren Sูåufigfeit I, 196.

Befakr bei Darleiken I, 225 - be unternebmungen I, 239 - bei ber $\mathfrak{B r a n b v e r f f d j e r u n g ~ I I , ~} 26$.

Bsefälle f. Srrunbgefâlle - Steuer yon beni. III, 308, 339.

Sefängniffe III, 69.

Bsefyulfen in ben setwerfen I, 388 a - Deren 21 izahl III, 368.

(E)lb, als Theil bes Eapitales I, 127 - Maaf́ftab des \$reifes I, 174 - Defien 28 ejen I, 257 - als Deçungsmittel ber Sandels= bilanz I, 422.

= menge, ob fie nuf ben Sinsfú wirfe I, 235 - Srō̄éce I, 266

$=\mathfrak{u m l a u f} I, 267$.

= vreis I, 146. 174.

= frrafen III, 237.

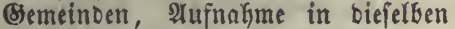
II, 15 - 2rmenpflege Derf. II, 339 - Deren 23 irthfdaft III, $18(b) .53$.

(8) emeinoeguiter II, 85.

$=$ baloungen II, 95. 115 .

$=$ meiten II, 85. 86 .

Semeinheiten, Deren Steuerpflidst III, 263.

(S)emeinheitstgeilung II; $75(e) .84 .86$.

Semeinfchaft Der Sunter I, 14 - Der Sorunbftüfe I, 206.

(8)eneralverpachtung III, 112.

Benofienidjaften II, 198 (b).

Bensbarmerie II, 71.

(S) en u a, 3anf I, 310 - Eotto III, 222.

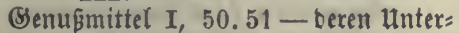
ifjeioung yom Capitale I, 128.

$=$ werth $I, 58$.

Sercidte III, 69 - beren Roften III, 234.

(S) Fande III, 78.

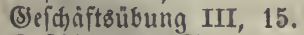

Seíhidste ber Stanten I, 24. III, 14.

Befdicflidffeit I, 113 - beren $\mathfrak{B}_{\mathrm{e}}=$ föroerung II, 21 - ber 3unft= hanowerfer II, 185.

(s)ệtlent I, 398. II, 181. 187. 199. Gefinüze III, 76.

Befellidaften, cooperative I, 201aoffene, fitlle II, $29 \mathrm{c}$ - fretunb= fdiaftlidise II, 368 - beren Eteuerpfidjt III, 263.
Befeze, yolfswirtfidgaftlidje I, 10 .

Befergebung in ber Solfswirthifafts: pifege II, 8.

Befinde, $\mathfrak{L} 0$ hn I, 190 (a) - Soft I, 191 .

(B)eftüte II, 168.

Sefunbbeitsplege III, 71.

Setrånfe, geiftige, beren Befteuerung III, 433. 451.

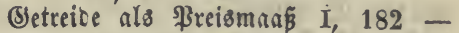
verichiebene शrten I, 183.

= aufichlag III, 431.

= ausfuhr II, 123.

= einfuthr II, $131($ a).

= Ganbel II, 121-143.

$=$ magazine II, 138 (d) - ber Regierung III, 156.

$=$ preiz, Sufammenfang mit ber

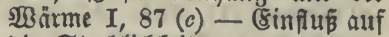
bie Sterblidfeit I, $173(b)-$ gegen Sold und Silber $I, 176$ - Berånberungen I, 182 3ufammentyang mit bem Taglohn

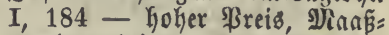
regefn babei II, 139 - niebriger Breiz II, 141.

SSewaifrsverwaltung III, 109.

Bewanne, beren Sieffung III, 319.

Sectäffer, flię̧ende I, $119(e . f)$.

(S) ewerbe, probuctive I, 348 - Deren Beförberung im allgem. II, 30 - Deren Beffeuerung III, 358.

(Setwerbefreifyeit II, 179. 190.

(Semerbseinfommen, begreift Bewerbs: getuinn und Sinsrente III, 358. 359 .

= gebäube I, 125 - beren Bepteues rung III, 342. 355 .

= geriathe I, 125 . geridjte II, 198. mann I, 136. redite III, 194. 197.

ifulen II, 223.

veroienft I, 139. 237. II, $324-$ reiner 242. III, $359-$ als MBirfung des Cápitals uno ber 2rbeit III, 365 .

$=$ fteuer III, 358.

= vorfteher II, 198.

Betwerfe I, 98. 392 - \$flege beri. II, 177. 178 - Betreibung Dutd) Die slegierung II, 227. III, 158 - weldfe vorzüglid zu begiünpigen II, 228.

(S)emerfarbeiter I, 191.

(Se)werfidaften I, 353 - beren $\mathfrak{B}_{e}=$ ante I, 39. 40. 
(S) werfseregale III, 204.

$=$ fdulen II, 223.

= vereine, freie II, 198.

= waaren, Deren ßreisverānberung I, 186 - Bezeidnung II, 219.

(S) etwidt ber 2 ägen II, 270.

(S) ewid)tseinfleiten II, 230 (d).

(B) twinn f. Betwerbsverbienft - im Tauidue I, 151.

(S)ilben II, 179 (c).

(S)ilten II, 71.

(Sirobanfen i. umfdrribebanf.

(5) I aD fit one III, $478(\mathrm{c})$.

(S) leidggewicht Der Erzettgung unb Bers zehrung I, 327 - Der Erbarbeit uno Der (Setwerfe I, 394 - Der

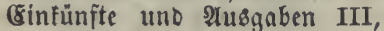
463. 465.

(S) ไücfืipiełe II, 362. III, 226.

(S) belins II, 228 (a).

Bolt I, 176 - Erzettgung I, 277a. 351 - פerf. zum Gílber I, 277 b.c. II, 250.

$=$ gemildje II, 219 (a).

= můnzen II, 233,

= idfmiebsinvten I, 304 (c).

$=$ wåkrung I, $377 \mathrm{c}$.

= waidjen III, 195.

Srabationsftempel III, 231.

(Grains II, 173.

Grảnzzollte โ. Sื่lle.

= bewadjung, Deren Roften III, $453(c)$.

$=$ bezirf III, 460 .

$=$ verfehr III, 462 .

(Srablano I, 382 a.

(5) regorius Tholoz. II, 9 (a). III, $20(a)$.

(5) riedsen, Derell Borifellungen yon

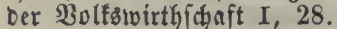

(5) riedenland, Angfubrzoll III, $456(b)$.

(S) rofbritanien, beweg. Sriffte I, $90(g)$ - Steinfoblen I, 120 (c). 350 - Baumivollen= fabrication I, 125a $(b)$ - $\$ B$ olfs = eillommen I, 247.248 - Beld: menge I, $266(a)-B$ Bnfen I, 311-13-Ulyadje bes fefje ausgebildeten (Setwerfôtuejens I, 394 (a) - Fabrifarbeiter I, 398 a $(g)$ - (süterverbraudy I, 401 (b) - शืช์fuhr I, $425(a)$. $430(c)$ - Edhifffahrt I, 431 (a) - Aufbebung Der Sflaverei II, 19 - Limited liability II, 29c (b) Bergwertzaufitiht II, $38(a)-$ 3ehutablöfung 70 - Berfügung über Das (Srundeigenthum $81 \mathrm{~d}(a)$ - Seferge tiber ten (S)etreide= hanbel 123.131 - Baumwollen= verbraud $213 a(c)-$ Esinfulyrs zülle $215(a . c)$ - vfint. Coom= pagnie $279(a)$ - Viünztweien $233(d)$ - Eifenbaknen 258. 259. 259a. 261 - Eanäle 267 (d) - Søiffafyrtogerege 272 a (5oloniell $300(a) .301(f)-$ Fूandelsuertrigge $304(b) .305(e)$ शrme 328 (c) - Şülfsycreine $334 \mathrm{~b}(a)$ - शrmentvefen 341 Mertlyăuer 348 - ßoftipar: cafien $365(d)$ - Sparcafien 367 - Bezirfşausgaben III, $56(c)$ - Salzfteter III, 186 - Poftwefen III, 206. 207. 212.213. $216 \mathrm{a} .217($ c). $219(c)$ - Stempel III, $231(b, f)$ Srumbiteuer $315(a)$ - Ein= fommensfteucr $387(a)$. $400(a)$. Nadtrảge zu III. S. $500-$ Nuben ber Steuerermāäigung 417 - Assessed taxes 425 (a) - Saนus = und Fenfterfteuer $426(b)$ Feunbe=, Betienten=, Fugrwert8: fieuer 427 - Tranfifettern $432(a)$ - Nalzauffidlag 436 (b) 5oyfenfteuer ebend. - Brannt= weinaufficlag 439 (a) - ver: fdiebene 2uffidläge 442 (b) 3ollertrng $450(a)$ - Bollents ridutung $460(g)$ - ॥eberiळuв und Deficit $463(e)-3 a h l$ Der Staatşgläubiger $480(a)$ Sdanfammeridheine 491 (d) Irt Der 2unleifen 495 (e) Scit= uno Reibrenten 500. श्ad) = tråge zu III. S. 501 - Sins: herabfesung 510 - sinking fund. 519 - Tilgung uno netes Bor: gen 521 - Bröpe ber Sdull 529.

(5rofiliandel I, 407. II, 275.

Srubenfeld II, 27.

(S)runtanidjlag III, $122(a)$.

= aนร์lagen I, 40 .

= eigenthum, gemetnichaftr. I, 206 (b) - gróвев II, 83 f. Sanoguiter.

= eigenthümer, $3 \mathrm{ahg}$ cerfelben I, 140 (a).

= gefälle bes Stants III, 156.

= rente I, 139.206- cer Boben= claileli III, $335(e)$ - bei Ses bäuben III, 345 . 
(S)runbfteuer I, 41. III, 301 - un= veränberlidje $31 \mathrm{t}$ - Beränbe: rungen $315.315 \mathrm{a}$ - 2nlegungs = nrten 316 - BBefreiung $316(a)$

$=$ fto df in Banden III, $99(b) .507$ (b)

$=$ ftúfe I, 50 - als Bsuterquellen I, 119 - in 2̧ezug auf Die

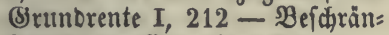
fungen ber \&rwerbung II, 82 Seritrente \&age II, 97 ๆ. 3u= runoung.

= verbefferungen $I, 130$.

Buter I, 1 (b) - fachlide, auper: halb bes Bermógens I, 47 perionlidae I, 46 - freie, wirtf= íaftlidie I, 47.

$=$ quellen $I, 85$ - Deren 3 uammen= wirfen I, $135-D$. Befteuerung III, 262.

Bưterfenoungen zwifđen ben Bölfern I, 419 .

(S)utsherrlidbe ßerhåatniffe II, 46.

\section{5.}

5ुanpuberfteuer III, 426 (d).

Sadfwald I, $382(b)$.

\$agelfdaaben = Berfiderung II, 106. Jalbarme II, 342.

= fabricate II, 213 a.

$=$ pacht I, $377(d)$. II, 16 (c).

= vief II, 109.

Sallinftem III, 461 (b).

5ุ m burg, Umichreibebanf I, 285 Soll III, $423(d)$.

5andånberungrabgabe III, 236.

5andel I, 99.406 - Deffen Sapital= bedurfní̄ I, 127 - Sweige I, 407. 408 - Esrlaubuis zur Betreibung Deff. II, 275.

Şandelsafabemie II, 281 (c).

= bilanz I, 35. 418. 430. II, 298.

= bủder II, 276.

= gejellidaften II, 277.

= faumern II, 274.

$=$ minifterium III, 70 .

= monopole II, 276.

= pllege II, 273.

politif II, 273.

redit II, 273.

regalien III, 203.

$=$ regifter II, 275.

= doiffakit II, 272.

= ifulen II, 281.

= fyftem I, 33-36.

= vertrảge II, $303-5$.

= zug I, 433.

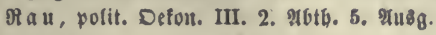

Şandohn II, 46. 48-51.

5andwerfe I, 398 - Deren Trennung II, 184 - 3unahme ber Ileifter II, 191 - nIf Dem Ranbe II, 200 - Banfen II, 334 (e).

Şanbwerføిgefellen I, 398 a. II, 186 199 - beren 3ahl II, 191. $199(g)$.

$=$ oronungen Ir, 201.

= đđulen II, 220.

= verfaffung II, 178.

= zünfte II, 179.

Scannover, Bertyeilung Dç (5)rund: eigentfums I, 369 - Reale Setwerbirechte II, 194 (b) Solltarif II, 215 - Eifenbalyn II, $258 \mathrm{~d}$ - Stantsivalbungen III, $142(b)$ - Salzftetter III, $186(b)$ - Ssewerbfteuer $368(d)$. $369(b)-3$ instentenft. 377 (b). 388 (c). $389(b)-B_{e}$ foldoung $8=$ und Ertoerbfteuer $395(a)$ Ġंulo III, 529.

SFat in Den Redjnungen III, 544.

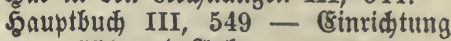
551 unb 2Thkang II, III.

Şauptcaffier III, 567.

Şâfer, Miethzinz I, 229 - Rente III, 345.

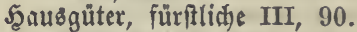

ફুaufierhnubel II, 290-92.

รุausfteuer III, 342 - in (Srops= britanien 426 .

= capital, als Seidjen bes 2 oht ftandes III, 352 (c).

5̧afengeloer III, 244.

Seberolle III, 299.

Se brảer, Armenzehnte beri. II, 335(b).

\$ुeer, ftehendes III, 74.

5eerbgelb III, $426(a)$.

5ecimzablung ber Staatsobligationen III, 524.

Szeirathen II, 12 - beren Erreidute: rung II, 15 - leidtfinnige II, 331 .

Şervorbringung I, 69.83 - S(b)ie= rigfeiten bei mandyen (stutern I, $160-$ ob fie im Sanzen zu grố fein fünne I, $330-\mathrm{allg}$. Gorge für Dief. II, 10.12.12a.

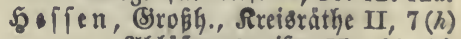

- 2ablörungstweife II, 61 (e)

- Girunofteuer III, 328 ff. -

- Staatรేโ)ulo III, 529.

freffen, Rurf. F. Rurliefien.

\$ुeuergeidaift III, $503(b)$.

ફ̧irten, wanbernoe I, 359. 
Sacdivald I, $390(c)$.

\$̧öcferhanbel I, 435 (a). II, 288.

5 ofmesgerei II, 80 (d).

5้ofiaatzauвgaben III, 42. 45-49.

Şöhenftufen bes Rances I, 87 (b). $212(d)$.

Sobheitsired)te III, 85. 166.

5olland $f$. Niederlande - oftinb. Sompagnie II, 279 (a).

5ุolz, befien langinmer $2 B u($ ) 8 I, 359 - Sorge für befi. gute Benubung II, 166 - Serwenoung III, $149-151$ - 2usfuโ)rzoll III, 456.

$=$ bedarf I, 387 .

- beftano III, 333.

= capital I, 390.

= erfwarung II, 10.

$=$ hofe III, 151.

= mangel II, 155 .

= preis I, 384. 390 a - Steigen Deff. II, 158.

- taxe III, 151.

= tranżport II, 166.

$=$ vorrath $I, 390$.

= zuwadtis I, 389 (b).

Sุuben, Jૃufen II, $76(f)$. III, $316(g)$. క̧ülfôcaffen III, 334. 334 a - für Fabrifarbeiter II, 203.

= ftoffe I, 124 .

= mittel, werfzeuglicise I, 125 a.

$=$ vorrath III, 29.

5unbefteuer III, 427.

5ूypothefenbanfen III, 120 a.

$=$ foulden III, 378.

= verfiderungen II, 112.

= weren II, 24.

\section{ร.}

Sacquard I, 125 a $(f)$.

Jagb, wilbe I, 356 - zahme II, 174.

Sagohohkeit III, 192.

= regal III, 192.

Sabrebrechnung III, 546. 552.

$=$ zeiten in $\mathfrak{B} e z u g$ auf Betreibe: vreife I, 182.

Sahrmärfte II, 286.

Income-tax III, $398(a)$.

Inbuftrie I, $98(c)$ [. auch Runfitteí.

InDuftriefdutten II, 21.

Snicriptionen III, 506 .

Jntegrale in ben Nieberlanben III, Snappidjaftвcalien II, 43. $517(b)$.

Intelligenzanftalten für ben Santel II, 268.

Sutereffen .. Sins.
Interimฮ̊quittungen II, 29c (c). III, 568.

Inventarium b. Domảnen III, 118.

Jobberei II, 312.

Jofewhinum III, $326(a)$.

Journal III, 547. 548.

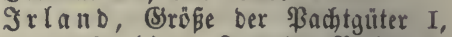
368 (c) - Eage ber \$achter I 377 (c) - fleine \$3rdjter II, 47a (d) - 2uвfukr nad (8ng= Iano I, $425(a)-$ Branntivein= verbrauch II, $327(b)$.

Stalien, R., Tnbafzregalin, 204(a) - Einfommensft. III, 400 (a). 400a (a) - Detroi $417(d)$ Deficit $463($ e $)$ - Sdult $529(c)$ - vgl. Snroillien.

Judex III, $104(a)$.

v. Sufti II, 9 (c). III, 21 (b).

Suftizwefen, Defien soften III, 69.

\section{ภ.}

Rameraloominen III, $102(c)$.

= redymungstwefen III, 539, f. aud Budffitfrung, Sahreorednung, ßrůfung.

= finl Der Redinungen III, 548.

$=$ wifienidaft III, 5 .

Sammercafie III, 92.

$=$ güter III, 90 .

Sinzen, Ranzbilleto III, 517 (b).

Sarat II, 236.

Rartoffeln, Deren \$reis I, $184(a)-$ Sinflús auf Den Sohn I, 192.

Rãjegefellịaftell I, 382.

Ratallaftif I, $3(a)$.

Satafter III, 290 - für Die (S)runt= fteuer 316.337 .338 - Roften 329.

Saufaccife III, 236.

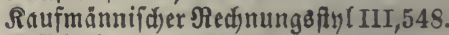

Reffelgelo III, 439.

Rinber, शrbeitżuerbienft I, 190 शrrbeit in Den Frabrifen II, 202a - arme III, 353.

Sirdie, शrmenpflege II, 337a- 2us= gaben für Dief. III, 80.

Rleinlsanbel I, 407. 435. II, 275.

Rieinfinteridjulen II, 342.

Rlima, beffen (צinfús auf bie Frudgt= barfeit I, 87 - auf bie (3runt= rente $I, 212$.

Ritowen, Deren Benubung II, $346(c)$.

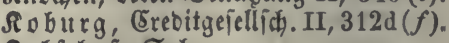

Sodjalz \%. Salz.

Röblexei II, $166(a)$. 
Rölnif̧e शarf II, $236(a)$.

Ropenhagen, Banf I, 317.

Ropwelwirthichaft I, $382(e)$.

Ropfiteuer III, 275 (c). 397. 398.

Rorn ber Dainzen II, 236.

Rônertvirthfđaf̣t I, 382.

sorntyallen, Rorntyäter II, 135.

= inagazine II, 136.

Roftbarteit I, 168.

Roften I, 56 - als Beftimmgruno DCs \$reifes I, 148. 157. 163. 165. 171 - ber Arbeit I, 189 - Des Nioggenbaues I, 212 Dев 23 aizenbaues I, 214 - Der Envitalbenubung I, 224-bes (S) Deв Rantbaues III, 333.

$=$ preis I, 156 .

Rrrâfte f. গRaturfräfte.

Sirambantel II, 289.

= mårfte II, 286.

Iranfenpflege ber Armen II, 356 (e).

Sirieg, cefien Roften III, 77.

Iripuen II, 342.

Sironthaler II, 244 (b). 245 (b).

Rulhgưter I, $372(e)$.

Rundidaft I, 49 (b).

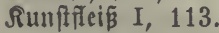

= Prazen F. Randitrapen.

Rupfergemifhe II, 233.

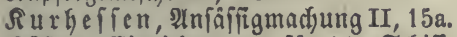
Rüften, Ëinrichtungen fủr bie Sd̆ifี: fahrt II, 275:

sutidjenterbe, Steuer yon benferben III, 427.

sure I, 353. II, 39.

\section{\&.}

Rage Der (Sirunbftüife I, 213. III, 332(c). \&agerhâufer II, 309. III, 461 - vgl. Nieterlagen.

Ranoarbeiter, Deren $\mathfrak{B e r h}$. zur Bolfs: menge I, 345 - vgl. Feloarbeiter.

Ranocscafle III, 92.

\&nnbgeptüte II, 168. III, 79.

= güter, beren Sröß̈e I, $368-1$. (bebunbenkeit, Srundeigenthum.

$=$ jäger III, 71 .

= futidjen II, 268a. III, 212. $219(b)$.

- meifter II, 200.

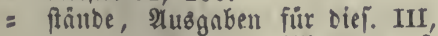
50 - Steuerbewilligung berf. III, $249(a)$.

ftrakél II, 256 - Deren Roften III, 79.
Ranbwekr III, 74.

= wirthe, Eage Derf. in Bezug auf Den (S)runbbefíb I, 376-378 II, 46 - Betwerbfteuer berí. III, 362 fi.

$=$ wirthfdaft I, 97. 358. $360-$ Eapital in cerf. $215(a)$ - 9 rt Des Betriebes I, 370 - Prege Derí. II, 44.

\&nnbiw. Erebitvereine II, 113-120.

Enften, bâuerlidae II, $52-$ Berúd: fichtigung in ber Srunbfteuer III, 308 .

Latifundia II, $76(a)$.

\&aubemium III, 46. 48-51.

\& $\mathfrak{i v , ~ D e f i e n ~} \mathfrak{B}$ anf $I, 314$.

\&ebengbauer Der Arbeiter I, 194. 201.

= mittel, Deren Preis I, 192 - Deren Befteuerung III, 421.

$=$ verfifderung II, 369 .

Reggen II, 218.

Regierung 1I, 235.

Regitimationsfiçein III, 460 .

Eehranitalten, lanbiw. II, 145 - ted)= nolugificise II, 220 - polyted)= niîde II, 223. 224 - für ten Şandel II, 228-höhere III, 80.

$=$ linge, Deren $\mathfrak{B}$ ehandlung II, 181 . 185. 199.

= worfftảtten II, 222 a.

= zeit Der Şanowerfe II, 181. 185.

Reibeigenichaft II, 19.

$=$ gebing II, $76(e)$.

$=$ gebingøిgüter II, $47(e)$.

= renten I, 234. II, 368a. III, 500 .

Eeignufalten, \&eihhn̈ufer II, 332.

= bauten I, 312 b. II, 332 (a).

= caften für bie \$blöfung ber bätter: lichen Eaften II, 60 - fuir (5)runbeigenthủmer II, $120 \mathrm{a}$.

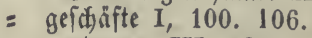

= vertrauell III, 482 .

= ว่ที I, 223.

Reinweberei, gefebl. Vorjd)riften II, $217(a)$ - Edauanfalten für Dief. II, 218.

Leipzig, Bant I, 317 - Crebit= anitalt II, $312 \mathrm{~d}(f)$.

Riquibirung ber Stnatsid)ulo III, 507.

Liffabou, Bant I, 317.

Lift I, $37(\mathrm{~g})$.

Rocumotive II, 258.

Rolynarbeiter II, $120(c)$.

\&ohnferr I, $187(c)$.

$=$ fteuer III, $391-396$.

Roosbillets in ben Rieberlanden III, $517(b)$. 
Qoofe Der Rotteriennleifen III, $503(c)$ \&ofung III, 402.

Eoth II, 236.

Eothigfeit.II, 362. III, 220.

Rutteriennleiben III, $501-3$.

Loyalty-loan III, $504(b)$.

\&แo เoig canal II, 267 (d).

\&uftbarfeiten II, 362 .

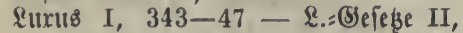
359 - Befteuerung III, 423. 425. 451.

\&uzeru, Sebủgren III, 230 (a).

\section{IR.}

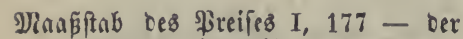
Semeingeitstheifung II, 87 ber Egrarten III, 319.

$=$ friftem II, 230.

Diagazine für (Setreibe II, 136 ff.zur Berpfänoung von 2 aaren II, $312 \mathrm{~b}(c)$ - für bie Natu= rálgefâlle Des̊ Staats III, 156. Mableimrdytung I, 216 a (b).

$=$ fteuer III, 431.

IR a ilano, Ratafter III, 328.

Miaifdifteuer you $B$ ranntwein III, 438. Mnifurate II, 83.

Minifler II, 282.

Minfute I, 260.

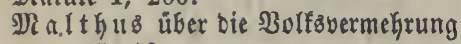
II, 13.

Mialzaufichlng III, 436.

Iin ndefter, \&ofulas I, $197(e)$.

Danbaten in Franfreidy III, 487.

Danifeft III, 244.

Darine, Deren Roften III, $73(c)$.

Darf, fölnif̧che II, 236 (a).

Dlärtte für (Setreide II, 135 - fi̊r cinzelne 23 naren II, 286 - vgl. Jabr $=$ IR., 2Boduen $=\mathbb{2}$.

Iattoronungen II, 288.

$=$ preis I, 156.

गiajdinen, Deren Erfinbung I, 115 - Nuben I, $125 \mathrm{a} .401$ beren Wefell I, 125 - 3weifel an ber Nủblidffeit I, 400.

S)äpigfeitżvereine $I, 347$.

פRaulbeerbsiume II, 173.

Dlaut III, 453

) e df len burg, (srbvergleid) II, 200(b).

Meiningen, Ereditgefelly aft III, $312 \mathrm{~d}(d)$.

Dreifter I, 398. II, 180 - Deren Bermefrung II, 191.

$=$ redit II, 181 - erfidwerte Er: werbung beff. II, 184 .
Mleifterftůd II, 186. 188.

Deliurationen I, 130 - bei Dumä= nen III, 120.

$=$ tare III, 65 .

Mercantiliyftem I, 33.

gieffen II, 284. 285.

Neporbnungen in Bezug alif 3olle III, 461.

$=$ regifter III, 319 .

Wetalle, eble, als \$reismaás I, 174 - al8 umlnufsిmittel I, 262 -

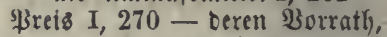
$3 u=$ uno arbnalyme in Europa 1 , 277 (a) - werben vom \$apier= gelde berbrängt I, 297 - als Decfung ber Szandelsbilanz I, 422. 423 - Deren Ëinfauf zur

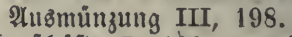

Diethgeidåfte I, 100 - nicht pro= Ductio I, 106.

$=$ fteuer III, $426(b)$.

$=$ zinв I, 223. 229 - 2tbzน̊ge von Demfelben zur \&efteuterung III,

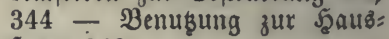
fteuer 349.

פildymirthid)aftzovereine I, 382 .

Dilitårausgaben III, 72.

$=$ colonien III, 74 (c).

Mil tax III, $402(d)$.

Mineralfoffe, Deren Setwinnung III, 323.

פtinifter III, 68.

פ̊irabeau, cinzige Ropfiteuer III, $398(b)$.

פूitwerben I, 152 - bei ber शrbeit I, 195.

Mobiliar=(Erebitgefellid. II, $312 \mathrm{c}-\mathrm{e}$.

Mobifinrfteuer in Franfr. III, $426(a . b)$ - Niederlande, Belgien $427(e)$.

Mobellfammlungen II, 225.

Monopole II, 29a.

Montur ber Soldaten III, 76.

Doratorium II, 111.

gluีnzen I, 264. II, 232 - form II, 239 - 26ตน์ถูม I, 237 a $(b)$ II, 238 - UmIauf II, 244 Bertråge Darủber III, 202.

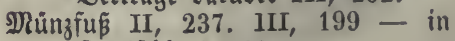
Deutichland 239.

$=$ getvidfte II, 236.

= regal III, 106-202 vgl. Sd)lag= folab.

Muftergüter II, 147.

= lager $11,225(e)$.

= fitude III, 335 .

शiuthen, Bergb. II, 37.

פlutterrolle III, 338. 


\section{R.}

Ntachfrage I, 152.

Nachlaß ber \$adjter III, 117.

ఇachnakue III, 217 (e).

Rachidjós III, $237(d)$.

Ragelfamieben I, $115(f)$.

Nahrungsbebarf I, $19(a)$. II, 136 (c).

= lofigfeit II, 326.

= mittel, gefeblidje Taxirung berf́. II, 293.

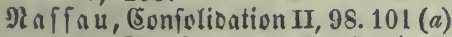

- Dominen III, 92 (c. h) -

Trennumg ber beiben (Enfien III, 92 - Srunofteter 324 - (S): werbfteuer 363 . 369 . 372.

Rationalöfonomic I, 9.17 (a).

Natrum, \$reis I, 163 (d).

Raturalabgaben II, 71 .

= befoloungen III, 59 .

= ftettern III, 284. .

Raturfråfte als (süterquellen I, 85 86 ff.

SRvigationsacte II, 272 a.

Rea el, Banfen I, 317.

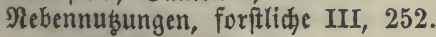

= wege III, 459 .

Reigung เer (S)runbftủfe III, 319.

Rennpreis I, 177.

Nettogewidht III, 458.

Reubaurente II, 70 a. III, 344 .

Reubrudjzegnte II, 67. Reuen burg (Neufdatel) I,
$395 \quad($ d $) \quad$ Einfommenfteuer III, 400 a (a).

ReIv ○ rf, Branoverficherung II, $26(a)$.

Nieberlagen II, 309. III, 461.

Nieberlegen ber Bauernfobfe II, $47(e)$. $76(a)$.

Nieberlande, Belomenge I, $266(a)$ - 3wifbentanbel I, 433 Bertrag mit Javan II, $305(b)$ - Ereoitbanf II, 312 e (a) \&eihbäufer $332($ d) - शtrmen= colonieen II, 349 - SRtü foftell III, 201 (c) - \$oftregal III, $205(c)$ - Setwerbiteuer $368(d)$ - \$erionalfeuer $426(c)$ - Indobiliarfteuer $427 \quad(e)$ Dafliteuter 431 - Bieraccif́e 436 - Sduldentweien 517 (b). 529.

Ricoerwalb I, 390 (c).

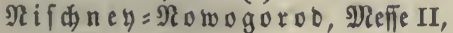
$246(f)$.

Nomaben I, 359.

Rominnalpreis f. Rennpreis.
Rorbamerica, Sduulben an oas 2ublano I, 49 (c) - Regioucn bes शโnbaus I, $87(b)-$ Ban= fen I, 317 - शैub= แno Eimfuhr I, $430(b)$ - 3oll von 20 ollen= waaren $215(e)-$ C5nnile $267(d)$ - Stantoguter UI, $89(c)$ Salzuerbrauch III, 186 (b) Bermögensfteuer III, 402 Steuererhofung III, 466 (c). Nadtrige zU III, 2. A. Sduulderi III, $484(c) .529(0)$. Nad)trige zแI III. 2. श(bth.

Rotaten III, 558.

Nothifjulden I, 236. II, 322.

Nủnberg, umidreibebanf $\mathrm{I}, 285$. Nüb̨lid)feit I, 56.

\section{D.}

Dberbaubeförbe III, 536.

= forftbefjorde III, 145.

= rechnungsfammer III, 536. 557.

Dbftbau I, 381 - Beföroerung beff. II, 151 - Beraníflagumg III, 129.

Detroy III, $417(d)$.

Dfficiere III, 75.

Dhmgeld III, 435.

Defonomie I, 2.

$=$ Sollegium II, $45(b)$.

Defonomiftifater Syftem I, 38.

Dmnium III, 495 (c).

Dresme II, 240 (e).

Defterreid, Bamf I, 316 - शus= uno 8infugr I, 430 - (s)eiell= fujaften II, $29(c)$ - Berggefeßs $36(d)$ - Sruberbautoronung 38 (b) - शแเfufr von Ruแt= waaren $209(h)$ - Shubzolle 215 - Gtnat8= unb Bezirf8= firapen, (sifenbahuen $255($ b $)$ Staatsécifenbahnell 258 (d) Stantzgunter III, 112 (b) Bergwerfżnbgaben $182(a . b)$ - Ealzregal $186(b)-T a=$ bafzregal 204 - Eotteric $222(c)$. $223(a)$ - Stempel 231 (d.f) - Duminicaliterter 308 (a) (S)runbftetter $326(a) .328(g)-$ 5ูณแB่t. 350 - Setwerbft. 372 -. Ginfommenft. 395 - \$er= fonalft. 397 - Maklit. 431 (d) - Fleif́chaccife $432(a . e)$ 23einftetter $434(d)$ - Bieraccife 437 - Brauntweinaccife 438.

439 (b) - Berzehrungspeteuer 


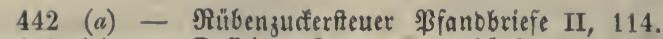

442 (d) - Deficit, Steuer: = Gäufer II, 332.

exhob hungen $463(e)-3$ wangs: = mảfler II, 333.

anleiken 486 - Lotterieanleiken \$fentig, gemeiner III, 402 (c).

501 - Eltere Stantş‡ulo 517

- Eduldentilgung $520(d)$ -

Stand Der Sdutb 529 .

Dpiumpteuer III, $442(b)$.

Ordonnateur III, $568(b)$.

Dftillien, brit. Comp II, $279(a)$

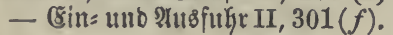

\section{अ.}

Badtatanid)låge III, 121-129.

$=$ contract III, 120 .

Padyter Der Gteuern III, $288-$ ob fie zur Bescerbfteuer zu ziefen III, 362 - vergl. Dománen= pachter.

Pawitrente I, 207. 209. 217

Padbtungen I, 377. II, 296 - bei Domänen III, 110.

अadjtzeit III, 185.

$=$ zins I, 208 - bei Domänen III, 114 - als Stübpunct für bie Brrtmbfteuer III, 325.

Bafetboote II, 268 a.

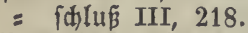

ßadfiojfe ๆ. Nieberlagen.

Papiergero I, 293 - \$rimat:\$3. II, 247 - Berfálidung II, 253 ygl. Staats=:30.

$=$ Ganbel $I, 407.437$ - Sorge für benfí. II, 316.

Farcellarmefiung III, 319.

ßari ber Mänzen I, 289. II, 251.

Pa $\mathfrak{m a}$, 3wangs̆anleife III, 486 (a).

Bafítuhanbel I, 415.

\$atente ber Şanowerf́̈meifter II, 196 f. aud "srifinoungarechte.

Batentabgabe III, 369. 374.

ßauperismuв II, $324(a)$.

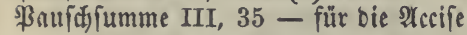
III, 430.

ß̧eel, Banfgeię I, 307 (b). 312. II, 249.

ßelzgelo I, 262.

Pender, श'nwentung auf bas Maá̃ = inftem II, 231.

ßentionen III, 62. 518.

ßerlentriche III, 195.

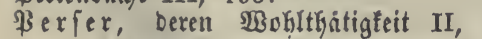
$335(b)$.

Berfien, Srrundfetuer III, 316 (a). \$erionalfeuer III, 397.

ßetty, Tilgungşylan III, 519.

\$ferbe, Deren 3udjt II, 168. $169-$ शnid)affung für bas פlilitar III, 76.

$=$ frâfte $I, 90(r)$.

$=$ ration III, 76 .

= renmen II, 169.

\$hy fiofratie I, 38. II, 9.

ঔitt, beff. sinking fund III, 519.

Plumbiren III, 461.

\$lutologie II, $4(a)$.

\$od)zins III, 182.

Polen, Stantbeifenbakn III, $219 \mathrm{f}(a)$. Solitit, wirthfdanftl. I, 13. III, 13. Polizei II, 6 - Deren Soften III, 70.

$=$ Inftalten III, 71.

= gebüfren III, 237 a.

= taxen III, $313-316$.

Bolntednifhe ๔dulen II, 223.

ßommern, ritterín. Bant I, 317. ßortugal, 2lts: umo Einfugr I, $430(b)$ - Selomenge I, $266(a)$ - Nufyebung bes Tabafzregals III, 1. शbth. Nadtringe. Decima $398(b)$ - Sdulto III, $529(c)$.

\$orzellamfabrifen D. Staats III, 153(b).

Poftcurie III, 215.

Poften Der গiedinungen III, 542.

ßoftanweifungen III, 217 (c).

= geheimui III, 219.

= Galter III, 218.

$=$ reform III, 216 a.

= regal III, 205-219.

= vertrige III, 211.

= zmang III, 206 (a).

\$rämie bei Geeverfidderungen III, 284 - für NTus= pDer Einfuhr II, 303 - für volfswirthidaftr. Smerfe III, 79 - Des Sdleidhandels III, $453(a)$ - bei \&oobanIcifen III, 501 .

\$rämiennffecurauz II, 25. 106.

$=$ geffchaft I, $440(a)$.

ßraxis, Berhấltníz zur Theorie III, $15-17$.

ßreis I, 56. 144. 146 - müblidfifer Stand I, 170 - Der (S) rund: fuliffe I, 219.

$=$ anichlag $I, 57(c)$

= aufgaben für (Setverfsleute II, 225.

= Beftimmung, obrigfeitlidje II, 201.

$=$ firkigfeit $I, 56$.

= maá, allgemeines I, 260. 


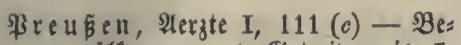
volferung und Setreidepreis I, $178(c)$ - Caffenantweifungen I, 295. 298 - Banf I, $317(f)$ - शैus = und \&infubr I, $430(b)$ - Echiffinart I, 431 - 24b= löfung Der bäuerl. Eaften II, 61 (c) - Eanovertheifung II,

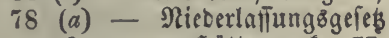
II, 81 a - Sुunttenwerfe II, 213 a $(c)$ - Strấenlänge II, 255 (b). $256(a)$ - Seehand = lung II, 279 (a). III, 143 (b) - Sanbelछిmäfler II, $282(e)-$ 3insgefebe II, $320(b)$ - Arme II, $328(e)$ - Etatiftif Der Armenpflege II, 356 (e) Sireisfparcaften II, $365(d)-$ Eparcnfieneiulagen II, $367(g)$ - Domảnenertrag III, 46 (c) - Forften $137(a)$, Deren Er: trag $143(d)$ - Stantzbergwerfe $174(a)$ - 26gaben von \$rivat= bergiverfen $182(a)$ - Salz= regal $186(b)$ - Stempelgefebe 231 (b) - Steuerbetrag Der \$rovinzen $280(b)$ - Sruno= fteuer $316(a)$. 328. $335(e)$. - 58ausftetter $342(a) .350($ d) und Nachträge zux 2. Abth. Des III. $\mathfrak{B}$. - (Setwerbfteuer 360 . 369 - Gifenbahnft. $375(c)-$ Blafien = นกD Sinfommensft. 400 I)ahlft. 431 (d) - Gd)lad)tft. 432 - 2Beinit. 434 (c) Dialzft. $436(g)$ - Brannt= reinit. $438(f)$ - Tabntit. $440(b)$ - ältere Iccife $442(a)$ - Solfvertrag mit Franfreid $447(b) .456(b) .458(a . b)$ Stantsfdas $464(b)$ - \$apier= geld $488(a) .489-3 i n b=$ reduction 510.511 - Staats ichulo 529 .

अrice, über Ṡdulbentilgung III, 519 (c).

ßrivatlnger II, 309.

Srivilegien II, 29 a.

\$robucenten I, 138.

\$roduction F. Şervorbringung.

\$robuctionsfteuern III, 429 (a).

Brohibitiviyftem II, 213. III, 446. Srolungation I, $440(a)$.

\$romeifengeidh âft III, 503 (b).

Property tax III, 400.

ßrotectionsfyitem II, 213.

ßrovincialausgaben III, 53.
Prud'hommes II, 198 (g).

\$rüfung Der ફ̧antwerfer II, 188. $195 a$.

= Der Rechnungen III, 557.

\section{2.}

Quatembergelder III, 182.

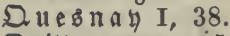

Duittungen III, 553. 568.

Duotitúţ̊fteueri III, 295. 299 a.

গ्री.

Räber, Deren Breite 270.

Nabicirte Betwerbe II, 194 (c).

Raff= und $\mathfrak{L e f e f o l z}$ II, 95.

Ragged schools II, 355 (e).

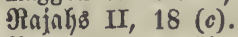

$\Re \cap \vee \mathcal{~ I , ~} 452(c)$.

Raubbau II, 38.

Яeäbificationżbetrag III, 344.

Nealcrebit I, $278(b)$.

= gewerbe II, 194.

= preiz f. Sndjpreis.

= Pteuern III, 291 (a).

গ⿻ьвь I, 379 - Beförberung befi. II, 152.

গecésgeloer III, 181.

Red)nungen III, 539 - \$rüfung beri. 557.

Redunungsbehörobe, oberfte III, 536.557.

= beícheid III, 558.

= füfrer, Borfenntniffe Deff. III, 545.

$=$ gelo I, $260(b)$.

= jafix III, 546 .

= inftruction III, 546.

= ftyl III, 548. 549 .

Rectite, bingliche im Staatỏvermogen III, 155.

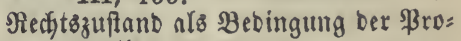
Duction II, 18.

seclamationen f. Stenerredamationen. Regalien II, 29 a. III, 85. 166 f.

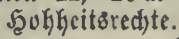

Negenmenge I, 87 (c).

Regieaubgaben III, 66 .

Regierung I, 4. III, 1.

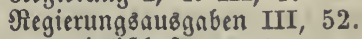

= wirthidhaft III, 1.

Regiftergebưhr III, 236.

Regulirung Der Gtcuern III, 282. 299.

Reidtfyum Dex Einzeluen I, 76.

= Der Bölfer I, 79.

Sieinertraggfdăbung für die (Grunb= fteuer III, 328.

Reis I, 260 (b). 


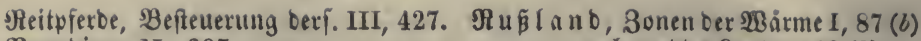
Remediun II, 237.

Remiffíunen III, 117.

Nente für busuerlidbe \&nften II, 57.

= als 2lrt ber Stantsiffuloen III, 493. 494.

Rentenanitalten II, 368 a.

$=$ banfell II, $60(c)$.

Rentes flottantes u. classées III, $513(a)$.

Ficutmer, Deren Behandlung bei ber Bepteuerung III, 259.

SReparaturen bei Domänen III, 119. Repartitionsftetern III, 295. 299 a.

Report I, 440 (a).

Republifen, Stantsausgaben in beni. III, 51.

Refervefonds III, 39.

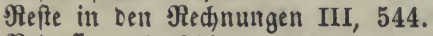

গietorfion II, 210.

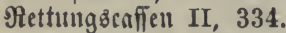

= hâufer II, 353.

Fievierforfter III, 145.

= ftollen II, $38(e)$.

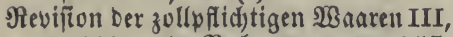
460 - D. Nied,yungen III, 557.

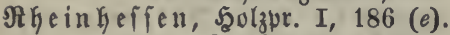

= vreusen, Ratafter III, 328.

= fdifffahrt II, 279. 281 (b).

$=$ zolf II, $271(b-e)$.

RicarDo I, 46 (c) - über bell Arbeitslofin I, 202 - über (5runbrente I, 209. 212. 216.

Stinbenmîrtte II, 165

アinbvichzucht II, 170.

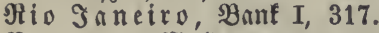

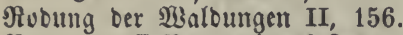

Roggen, oeff. Brvouctionsfopten I, 212.

$\Re$ om, B3nnfen I, 317 - Srunófteuer III, $316(a)$ - 3ölle III, 443 - 2nleifye unter Levinus III, $504(b)$.

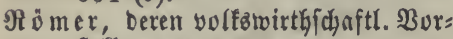
ftellungen $I, 30$.

Notterbam, Umidreibebant I, 285.

Subrifen, Spalten= unb ßoften= III, 542.

アRüfffauf ber Stratsubligationen III, 524.

= ftände Der Steuen III, 287 Der शีusgaben III, 486.

= ftanoseredyung III, 555.

= vergütumg II, 214 (e).

$=$ zölle II, 307. III, 462.

Ruthgehalte III, 62.

R 1 m ford \& Suppe II, 342.

Runfelrübenzudfer, Steuer II, 214 (e). III, 442 - 3ollid) II II, 214 (e).

- unbenubtes LanD I, $49(b)$ -

Banfwe Einfuht I, 438 (b) - 2uf= Gebung ber \&eibeigenidaft II, 19 (e) - S3uftand Der Baueru II, 47 (c) - Frohnen II, $64(b)$ - Sdubzölle II, $215 \quad(a)$ - Etrat8aubgaben III, $48(c)$ BBerg: unD Şüttentoerte Des St. III, $174(a)$ - Dlünzอerwix = rung 198 (c) - Supfermüuze III. 1. 2(Bth่. Nađ̧trảge Salzfteuer III, 186 (b) Branntweinregal $203 \quad(a)-$ Boftregar $205(e)$ - Şaเฉีteuer 342 (a). 352 (a) - Ssewerbft. 374 (a) - Ropfit. $397(e)-$ Bitanntweinft. $438(k)$ - Tabat: fteuer $440(e)$ - 3olltarif 451 . 452 - Erebitbillets 488 (a). $528(d)$ - Sdjuldentwefell III, 529 .

ธa a $\mathfrak{b} \times$ ü ffen, Siblenbergwerfe III, $181(d)$.

Sadjpreis I, 172.

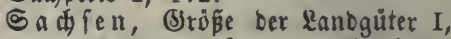
368 (c) - Ranbrentenbanf II, $61(e)$ - Erwerbung yon Ritter= gütern II, $82(c)$ - Setwerbes gefes II, $292(c)$ - Silberberg= bau III, $176(a)$ - Bergzegnt= caffe III, $182(b)$ - Sdjmelz= abminifration $183(a)$ - Salz= regal 186 (b) - Ingoredite $193(d)$ - Srunbfteuer 328. 329. 332. 335 - \$2ณu8ft. 357 - Setwerbft. 367. 372 - Eas pitalft. 389 - Stantвfकuld 529. Salpeterregal III, 190. 191.

Salzcunicription III, 185.

= gewinutung III, 189 .

$=$ regal III, 184 .

= fteuer III, 186. 189.

Gt. (S) a rlen, Bant I, 317.

St. Beter burg, Banf I, 317.

St. Simon I, 45 a $(d)$.

Sardinien, (Srunofteuer III, $328(n)$

- ßerionalif. III, $397(b)-$

St. von fuhrwerten III, $427(d)$ Sduld III, 484 (c). 529. $\mathfrak{B g l}$. Stalien.

Sdjaafzuฺt II, 72 - Beförberung II, 171.172. 


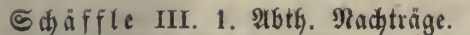
Shasfammeticheine III, 491.

Schabungen III, 292. 297. 299 a.

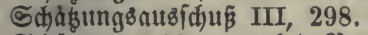

Gかäbূung I, 55 - nach D. Preifen 63. Gdauantalten II, 218.

Scheibemünzen II, 242. III, 198.

Sđ̉enfwirthob่uafer II, 362.

Schieß̧pulverregal III, $203(a)$.

Sdhifffahrt veridiedener Ränoer I, 131 - $B$ eförberung beri. II, 272 a. Sdjiffalrtsgefese II, 283.

Shlngfwas II, 241. III, 197.

Sduladititeuer III, 432.

Shlleidhandel II, $292(f)$. III, 453.

Schleufengeloer III, 244.

Şlup̧zettel II, 282 a.

Schneegränze I, 87 (b).

Shneefteuer III, 442 (b).

Sd)

Squottlanb, Banfen I, 313 Şolzpflanzungen I, 385 (c).

Sđrot Der Dünzen II, 236.

Sdjulb, fatwebende III, 491.

Sduldoen zwifhen ben Bölfern I, 420

- Der 3ünfte II, 194 - in sBezug auf bie Binsirentenfteuter III, 383. 401 a - vgl. Stants= fidulben.

= tilgung bei Crebitvereinen II, 118 - vgl. Tilgung.

= tilgungscaffe III, 508 .

Shulozinien, Ginnahme aus Dent. III, 165.

Sdulen II, 21 - vgl. Eehranftalten - für arme Sinber II, 353 niebere, Gökere III, 80 - für Sanbwerfer II, 222 - poly= technifiche 223.

Sक山て子

Sdjupfleken II, 47 (b). 47 a (c).

Sđürten II, 37.

Schuppolizei II, 6 a.

$=$ fyftem II, 213.

$=$ zôlle II, 295. III, 446.

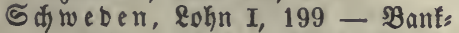
weien I, 317 - Branntweinft.

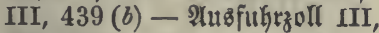
$456(b)$.

S क iveiz, श्रlpenwirthid. I, $382 a(d)$

- Norbbahn, vereinigte $\mathfrak{B a h n}$

II, 258 (d) - Crkebungs: u.

Betriebsfuiten ber Cinfünfte III,

$52(a)$ - Galzregal III, $186(b)$

- Scala ber Eantone III, 280 (c).

Gcuntixen I, 292.

Scrips III, 495 (c).
๖. Sedendorf II, 9 (a).

Seehanblung, preußs. II, 279 (a).

$=$ verficherungen II, 272 a.

Seibenzudit II, 173.

Selbitzudat I, $7(b)$.

Selbftverwaltung Der Domänen III, 104-108.

Senjalen II, 239.

Serra I, $37(d)$.

Servisftetter III, 342 (a). 358 (c).

Servituten, lanbwirthfdaftl. II, 72 forftwirth (f)aftl. II, 161. 163.

Sidyerkeitopolizei II, 6 a.

Silber, beffen झreiserniebrigung I, 171 - Erzeugung I, 277 a. 352 Berf. 子. Solde I, 277c. II, 250.

= műnzen, widjtigfte II, 255 (c).

= måkrung II, $233(f)$.

Sinecuren III, $32(a)$.

Sinking fund III, 519-521.

Sflaven I, 112 (c). II, 19.

= handel II, 19 (b).

Smith, 2., I, 43-45. II, 9Einfluß auf bie Finanzifien: (i) aft III, 22. $380(a)$.

Smuggel III, 453.

Gocialiften I, 45 a.

Soll ber Nectinungen III, 544.

Goolenleitung III, 189 (c).

Soulte III, 495 (d). 498 (b).

Sortenzettel III, 569.

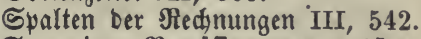

Spanien, SBewáfferungen II, 150a (c) - Tabafsregal III, 204 Drbenstaxe III, 233 (a) (S) ewerbfteuter III, $372(a)$ active und paffitue Sijuld III, $517(a) .529$.

Sparcaffen $U, 364.368$.

Sparfamfeit I, 136 - in ben Stants: ausgaben III, 28.

Sparvereine II, $365(g)$.

Spatenbau II, 79 (m).

Specialität ber đetatøீfảz̧e III, 565.

Spebition II, 310.

Speifeanftalten II, 310.

Spieldjarten III, 441.

= Gâufer III, 226.

Spinnerlobn I, 190 (a).

Spinnmafdiuen I, 125 a (b.c).

Spizenfoppelı I, 395 (a). 405 (d).

Sporteln III, 234.

Spurtweite ber Eifenb. II, 261 (b).

Staatsanleiken III, 474 - Anfänge beri. 492.

= aufwanb, sausgaben III, 24, 44 - orbentl., auperorbentl. III, 
39 - allmålige Eัrhöhung 466a

- Feît auf Die Einfinfte III, 499.

Stnat8banferott III, 516.

= bergiwerfe III, 172.

= crecit, Wirfung Der Enpitalfteuer III, 385 .

= Diener, Deren $\mathfrak{B}$ efteuerung III, $393-95$.

$=$ cinfunfte III, 27, 82 - beren unzulänglid)feit III, 463 (Bränze Derí. III, 467 - Feft: febung mit Niluffid)t auf bie शแส̇gaben 469.

$=$ eifenbahnen II, 263. III, $219 \mathrm{a}-\mathrm{g}$.

= fabrifen III, 153.

$=$ forftwirthf(haft III, 145.

- foritwiffenidjaft $\mathrm{UI}, 145(a)$.

$=$ froknen II, 65 .

= glâubiger, Deren 3ngl III, 480(a). = guter III, 90 .

hanblungвıivifienid,aft II, 9.

monopole III, 203.

= obligationen, auf Namen ober auf Den Snhaber III, 506.

$=$ papiere I, $438 \mathrm{ff}$. - Sorge für Den Sanndel mit benf. II, 312.

$=$ papiergeld I, 295. II, 251. III, 497-87 - uneinlö̊riđues II, 252 - Einziehung III, 529.

$=$ rechenfumit III, 14 .

= red)nungsivejen III, 539.

$=$ djab III, 464.

= iduldbriefe III, 506.

= fhulbetr, als Sśrund für bell Do: mänenverfauf III, 95 - $\mathfrak{B}$ er= anlafiung III, 463 - Eefhre yon Denieloen 471 - Sröße 529 - vgl. Auleiken, Tilgung, Stantbbanferott.

= frapen II, 255 (b).

= vermỏgen I, 48. III, 4-8r= Galtung III, $28(a)$ - Erwerb aus Demielben III, $85-\mathfrak{B}_{e}=$ fandtheile III, 88.

$=$ vertheibigung III, 72 .

= verwaltungspolitif III, 11 .

= waloungen III, 137 - Rein= ertrag $142(d)$ - Shiebsimenge 146.

= wirthidaftzlelyre I, 15. III, 5 .

$=$ wiffeni(hait I, 21. II, 9. III, 11. Striote, Deren Berfall II, 200.

Etammgeftüte II, 168.

$=$ güter 0. Fürtengaujes III, 45.90.

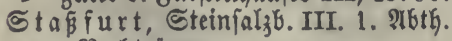
Rađträge.
Gtapelredist Ir, 269.

Statif Des \&anobaues I, 212.

Statiftif, Deren Berbảtniß̄ zur por. Def. I, 25 - Der Bolfswirth= id)aft II, 8 - lanbwirthidjaft= lidue II, $44(b)$ - zur Finanz= wif̄eniकaft III, 14.

Gteffnadeln I, $115(f)$.

Steiermarf. Bertheilung tes (5runo: befibes I, $368(c)$ - Eifenberg= ball II, $37(e)$.

Steinfohlen I, 120 (c). 350 - in (S)ropjbrit. cbo. (e). $394(a)$.

$=$ falz III, $189(c)$.

= wege II, 256.

Stempelgebühr III, 231.

Sterbliafeit I, 196 - in verfdiedenen ¿ánberm I, 201. 375.

Stettin, Sanf I, $317(f)$.

Steuern III, 84. 247 - beren Manß̋= ftab 252-259 - WBirfungen 267 - Ertrng 275. $280-3 u=$ fammentang 276 - Grfebung 286 - Eintheilung 291 - Ein= rid)tung 276 - vgl. Nuflagen.

Steueranid)lag III, 299.

= nuşfdreiben III, 282.

= befdreibung III, 299.

= betrug III, 413 .

= bewilligung III, 429.

= capital III, 299.

= caffe III, 92.

= einnehmer III, 289.

$=$ erfjebung III, 286.

= fẩigfeit III, 94. 254 - Renn= zeidben Derf. bei seridjicoenen \$rovinzen 280.

$=$ freiheit III, $230(d) .315$ a (c).

= fแกี III, 282.

= liften III, 299.

$=$ objecte III, 254. 282.

= prifit III, 263.

= quellen III, 254.

$=$ reclamationen III, 337. 376 .

= fimplum III, 299 .

$=$ tarif III, $282($ a).

= vervactitung III, 288 .

= voriduufite III, 486 .

$=$ zölle III, 445 .

Stiftungen, Bermögen II, 341 Steuerpflidit III, 263.

Stod horm, Bant I, 317.

Stodfs III, 506.

Stodífubberei I, 440. II, 316.

Stofie, rohe, Deten \$rcisveránberungen

I, 186 - Sumakme ifrer Ropten I, 215 a. 
Stoffarbeit I, 96.

= gewinnung I, 97 .

Storlennenntel II, 182.

Strafanfalten III, 69.

Stranbredit II, 272 a (c).

Strapen II, 255. III, 79.

= froknen III, 243.

= gelo III, 239.

Gtreuberedtigung II, 162. $163 \mathrm{a}$.

Strikes I, $201(a)$.

Stromgebiet I, $119(f)$.

Stüdfohn I, 112.

$=$ mefiung III, 310.

Sturz Der Borrätfe III, 540.

Submiffion III, 34 - bei Staats: auleifen III, 505.

ธuIIy I, 32. III, 561 (a).

Sitmpfe, beren थैustrofinung II, 103. Superinventarium III, 178.

$=$ revifion III, 558.

Suppenamftalten II, 342.

T.

Tabafbau im 3ollverein III, 204a (a). = fabrifen III, $204 \mathrm{a}$.

$=$ regal III, 204.

= Peuter III, 440.

Tabellenform ber 円edjungen III, 541.

Tableau économique I, 40.

Tagebuct) III, 547.

Taglohn, vergliden mit bem setreibe= preife I, $179(a)$.

Taglộner, Unterhalt sbebarf I, 190, 191 - Sofin in verídied. Ländern $I$, 199 - auf großen \&anbgütern I, 375 - was ifnen bie Ber: fleinerung ber Ssüter nübst II, 78 .

Taille III, $316(c)$. $396(b)$.

Tara III, 458.

Taxation III, 121.

Taratoren bei ber srombfteuer III, 336.

Taxen, gefétlidje ber Nafirungsmittel II, 293 - Des lohns II, 317 - Des Sinfes II, 319 - $\mathfrak{T} . \mathfrak{v}$. 2niftellumgen 2c. III, 233 - für Betwerbsconceffitonen III, 245von Dispenfationen III, 246.

Taxes, assessed II, 425.

Telegraph II, 268. III, 219 b.

Theorie, Berhåltnis zur ßraxis III, 15.

Theuterung I, 168 - Des Setreibes II, 139 .

Thierzucht I, 358. II, 167.

Thoraccife III, 429.

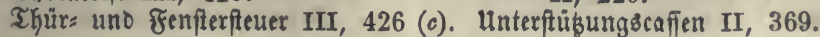

Tilgeftamm, sinking fund III, 519 -521 .

Tilgung Der Stantsidultoen III, 515 -520 .

Tirol, Alpentwirthidfaft I, 382a (d).

Todte $\mathfrak{z}_{\text {and }}$ II, 83.

Tonnengelo III, 224.

Tontinen II, $368(a)$. III, 500.

Tranffiteuern III, 433.

Tranfito II, 369 a. 310. 311.

Transportfoften, Esinfluß auf bie Brunorente I, 214.

Treforideine III, 489.

Tretmühlen II, 352 (b).

Triangulinung III, 318.

Trufififtem II, 203.

Trunffudft II, 327.332 (b). III, 438 (b).

Türfei, Szanbelžvertrảge II, $305(e)$ - Papiergelo III, $488(a)$ Stantsifuuld III, 529.

u.

Heberflũ $\mathrm{I}, 76$.

Heberiegung ber Şanbwerfe II, 191. uebervólferung II, 330 .

Heberwålzung ber Steuern III, 269 fif. - Der CEnpitalfteuer III, 379 - Der Rufwandoffeuer III,

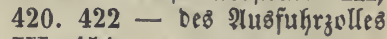
III, 454.

Heberweifen I, 292.

Uhyrmaderffule II, 222a (a).

umgelo III, 428.

umlauf ber (s)üter I, 252-56 - bes Seldes I, 256 - Der fremben शRünzen II, 260.

umichlagsired)t III, 269. 269 a.

umidareibebanfen $I, 283$.

= büdjer III, 338.

Unipedition III, 218.

Umtriebszeit III, 146.

$\mathfrak{u} \mathfrak{n} \mathfrak{g} \mathfrak{a} \mathfrak{n}, \mathfrak{B a u e r m}$ II, 19 (c).

univerfitäten III, 80.

Interhaltsbedarf I, 190, 192, 239. III, 259.

$=$ facude I, 372.

$=$ mittel $\mathrm{I}, 126$.

Unternehmer I, 136. 187. II, 29 a. - Ginfommen beffelben I, 137. III, 359-364 - Berbinoung mefirer Setwerbe III, 376.

unterpfanosfduulden II, 110.

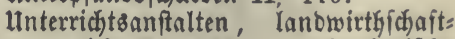
lidje II, $145^{\prime}$ - tedunologifope II, 220 . 


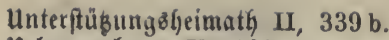

Urbarmad)ung II, 102.

IIrmaape II, 23I.

llio I, $288(b)$.

\section{2.}

Valeur, officielle, actuelle I, 429 (b). Baluta, fefte, verånberlidue I, 389. Baluation II, 245.

$\mathfrak{B}$ anfittart, Tilgeplan III, 519.

$\mathfrak{B} \cap u \mathfrak{b} \mathfrak{a}$, dixme royale III, $326(a)$. 398 (c).

Vectigalia III, $20(b)$.

$\mathfrak{B}$ ene $\mathrm{i} g$, umfdreibebanf $\mathrm{I}, 285$.

Bentilation III, 180.

Beranfd)lagung ber Länbereien III, 127.

Berbindung Der Âtbeiten I, 116 (c).

Berbrauch I, 68. 319.

Berbraudisfteuer \%. Nufiwanbsfteuer.

Berbingen Der Alusgaben III, 35.

Bereine, \$rivat:, II, 5 - lanbwirth= fonaftl. II, 146 - freie Setwerf $=$ II, 198 - für (S)etwerfibiloung II, 222 - für 2 eforocrung ber II, 225 - für शlrmenpflege II, 339.

Berfaffung, 2łuछిgaben aน๖ berf. III, 45.

Berfegr I, 8. 143 - Beförberung Deff. 1I, 229.

Berfebrobanțalten II, 7 (k).

$=$ arbeiten I, 99 .

$=$ werth $I, 60$.

Berffeinerung Der $\mathfrak{B a u e r n g u ̈ t e r ~ I I , ~} 77$ - $\{$. auch (Sebuntenfeit.

Berfoppelung II, $75(b)$.

Berloofungen II, 362 .

Bermeffung zur (Srundfteuer III, 317 -319 .

Bermỏgelt I, 2.

Bermögenซิfnmm I, 70 - Aufzefren Deff. III, 463.

$=$ ftetter III, 293. 402-404.

$=$ zuftand Der Esinzelnen I, 74 ff. - Des Bolfes I, 78.

Berpachtung Der Domainen III, 110 - i. Bachtultig.

Berri II, $9(d)$.

Berfdureibung, Effecten I, 593.

Beridinenoer II, 361 .

Berficherung f. Soranbverfiderung, 5 a gelfchaben - bes Biehftandes II, 109 - gegen Secgefahr II, 272a. Berforgungercaffet II, 364. 368 a.

Beriucisitationen II, 147.

Bertheilung $I, 140$ - Des Esinfom= mens I, 141.

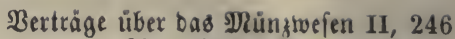

- liber bie Gdiffrahet II, 271

- liber Sölle II, 301 - über

Den Fुandel II, 307-309.

Berivaltende Staatstyảtigteit II, 8.

Bertuandlungsftuffe I, 123 a.

Serzelyrung I, 68. 318. II, 12 productive I, 323 - Eurge für Dief. II, 357 fi. - wiro Durch Goke Stetern verininoert III, 417.

Bicinalftraß̧en II, 257.

Bief nls Preismaná I, 260.

= ausftellungen II, 170 .

= leificaffen II, $120 \mathrm{~b}$.

= fand, beffen (Stojpe I, $370(e)$ - Berifijerung II, 109.

$=$ fteuer III, 363 .

= zudjt I, 359 - beren Beforte: rung $I, 167-$ Bered $)$ nutug ifires Ertrages III, 126.

Billele, Binbrebuction III, $511(a)$. Villicus III, $104(a)$.

Bolf I, 4.

Bolfsbildoung, oeren Ropten III, $\delta 0$.

= oidtigfeit II, $11(a)$.

$=$ cinfommen $\mathrm{I}, 245$.

= menge, beren Bermełrumg I, 196. II, 12 .

= ichulen III, 80.

$=$ vermögen $I, 6.48 .50$.

$=$ wirthichaft I, 5 .

$=$ wirthidaftzlehre $I, 9$.

= wirthidjaftepflege I, 17. II, 1 Roften Derf. III, 79.

$=$ wirthfकnaftopolitif $I, 17$.

Boranichlag III, 465.

Borfaufgrecht bei Bergiverfen III, 183 - bei ber Bollentridjtung III, 457.

Borrätbe, unbeftimmte I, 52 - fer: tige I, 127.

Bortheileberechtigung II, 76 (e).

Borichupbaufen II, $334(d)$.

$=$ vereine II, $332(a)$.

\section{3.}

IBanrentyanbel I, 407.

= verichlús III, 461 .

Bangenrācer, Breite cerf. II, 256.

$=$ claffen auf Esifent. II, $259(f)$.

Waifencluffen II, 368.

$=$ Gaúfer II, 355.

Wnizen, Defien ßreis I, 176.

Waro, Deffen Rente I, 386 - Deffen (B) rópe I, 387 (b). II, $155(d)$ - Eigenthumsverbältniffe II, 
155 - Nuben bes Staatsbefizes

III, 139. 141 - neue 2tnlagen

III, 140. 147 - Befteterung

III, $332-1$. Stantżwaloungen.

W3aldbau, Beförberung oeffelben II, 153. 165.

= Blópen II, 157 a

- booen, unbebingter I, 396.

= Devafation II, 157a.

= Gưter III, 145.

rooung II, 157.

= fervituten II, 161. III, 108.

= freu II, 162. $163 \mathrm{a}$.

= vertwiffung II, $157 \mathrm{a}$.

= weide II, 162. $163 \mathrm{a}$.

Walzende Gtüdfe II, 76.

ISB a lp o le, Ieff. Tilgeftamm III, 519.

Banoern Der Şantwerter II, 181. 186.

WBappen, Deren Befteuerung III, $526(a)$.

Wärme, flimatifbe I, 87 - Deren 3ufammenfang mit oen Preifen ebent. (c).

$2 \mathbb{B} a \mathfrak{r}$ đ) a , Banf $I, 317$.

Wafferbau II, 266. III, 79.

= baubeitråge III, $237 \mathrm{a}$.

= regal III, 195 .

= firapen II, 265.

= golle II, 280.

SEebemafdjinen I, 404 (d).

Wedjel I, 286 - Deren Nuken I, 288

- c curs I, 289 - in Bezug

auf bie Sanbelsbilanz I, 427.

= orbuning, Deutiche II, $273(a)$.

WeggelD II, 256. III, 238-42.

IB $\mathrm{ehrli}$ II, 355.

Weiben I, 359. 382 a. II, 85. 162 - Deß̊ Staat8 III, 174 23eiberedyte II, 72-75 - $216=$ lojung III, 165.

WB e i m a r, Einfommenfteuer III, 400. DBeinauffílag III, 433.

= bau f. গebbau.

3ieltwirthidjaft I, 16-18.

Werfzeuge I, 125.

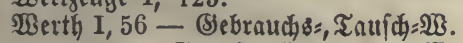

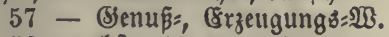
58 - abftracter, concreter 61 als seftimmgruno bes \$reifes I 247 - Der 2 trbeit I, 188.

2Berthpapiere I, $293(e)$.

DB i e n, SBerzehrungsfteuer III, 442 (b). Wiefen I, 382a - Deren Beraniala gung III, 129.

$=$ bau I, 382. II, $150-150 \mathrm{~b}$.

= weibe II, 152 .

2Bilobann II, 175.

Wirthid)afit I, 2.
Wirthfdyafṫgebåube bei Domånen III, 119.

= forn III, 128.

$=$ lefje I, 2 - buirgerlidje I, 3, 23.

= überichuis I, 72.

SBittwencafien II, 368a. III, 64. 65.

$=$ gehalt III, 65 .

Wodjenmairtte II, 287.

IBohlfeilkeit I, 168 - Der Boben= erzeugnifie II, $141-144$.

Wohlftano, Der Einzelnen I, 76 ser $\mathfrak{B o l f e r}$ I, 81. II, 1 - oer (S)eiverbbunternehmer III, 376.

2Bohlthåtigfeit II, 335. 336.

Wohngebaiube bes Staates III, 154a - Befteuerung III, 343.

Wohnungsfteuer III, 425.

Wollpreis II, 171.

Workhouses II, 348. 348a.

Wudjer II, 319 - $20 .=$ Sef̣ę̧e II, $319-323$.

23 uี r temberg， Şolzpreis I，368(8)in= uno 2) (usfukr I, $430(b)-$

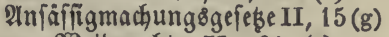
- Weiberedhte II, 61 (e) Reale Eetverbsechte $194(e)-$ Eijenbahnen $258(d)$ - Reftuer= mógen III, 88 (c) - ßachtnadh: lảifie III, 117 (b) - Staats= forften III, 142 - Satittentwerfe 154 - Brunogefălle 155 Salzregal $186(b)$ - \$ேतus: fteuercapitale $352(c)$ - Be= werbfteuer $372(a . b)-$ Capi= talfteuer $378(a) .383(a) .388$ $(a . e) .389$ (a. b) - Bejol= Dungsifteuer $395(a)$ - Scunde: feuter 427 - Branutweinfteuer 428 (k) - Etaatsobligationen

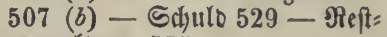
verwaltung 555 .

\section{$\mathfrak{X}$.}

Xenophon I, 29. III, 19.

3.

3ahlenlotterie, \&otto III, 222.

Sahlmeifter einer Caffe III, 567.

Saklungs̊nntweifung III, 568.

3apfgebühr III, 435.

3eche im Bergbau II, 37.

3efnte II, $66-70$ a - bes Stants III, $158-164$.

= fqulbentilgumgseafie II, 60 (c). Sెefrer I, 324.

3eidengelo I, 161. 
Seitfåufe I, 440.

= padit ber Domånen III, 110.

= renten zur 26blöfung ber báuerl. Laften II, 60 - als Stants: fduldell im weiteren Sinn III, 499 - im engeren Ginn 500. 3citungen, Deren $\mathfrak{B e f t e u e r u n g}$ III, 441. Ser\{dylagung ber Bauerngüter II, $76(b)$ - Der Dománen III, 132.

Bettelbanfen I, 304. II, 247.

Siegen, tibetaniffue II, $173(a)$.

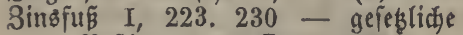
Beftimmung beff. II, 320.

$=$ reduction III, 410 .

= rente I, 139. 122. III, 359 woyon ifgre (Sirope in oer soin: nakme bes Unternefimers $a b=$ Gângt III, 364 .

$=$ rentenfiteuse III, $377-390$.

Sife III, $428(a)$.

3ollämter III, 459.

Sölle für yolfsivirthidjaftlidye 3wedfe II, 293 ரீ. - alв श्रuflagen III, $443-462$ - iweciffiche III, 458.

3ollhauspreis in Sropbritanien I, $429(a)$.

$=$ lifiten I, 428 .

- fiellen III, 459 .

= frapen III, 459 .
Solltarif III, 458.

= berein, beutidjer II, $201-$ Sin=

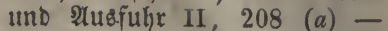
Sd)ubzille von (s)ewertsmaaren II, 215 (a). 451. 452. Alifhebung ber Durdigangszo̊lle $311(b)$ - Nunfelrübenzudfer III, 442 (c.d) - Bollertrag $450(a)$ - Roften 453 - Durdjangs: zoll 457 (a) - Tarif 458 .

$=$ wefen, befi. Einridjtung III, 458 - Eolberts I, 34.

3ubuşgruben II, 43 (c).

Budfer, Sollfdubs II, $214(e)$ - beff. Befteuerung III, 451.

3udythäufer III, 69.

= Ptiere II, 170.

Sunftweien II, 178-201.

= fdjulben II, 194.

3 ü ri đ, Bant $I, 317$.

Surunbung ber \&anbgüter II, 98.

3uwad) Der Bolfæżmenge I, 196.

= Des Şolzes I, 389.

3wangåanleiken III, 486.

$=$ abtretung II, $5(b)$.

= शrbeitğăuier II, 351.

= cursె bes \$apiergeldes II, 266.

3wangs: = und Bannrechte II, 264 a.

3wifdentyandel I, 408. 432. II, 306. 

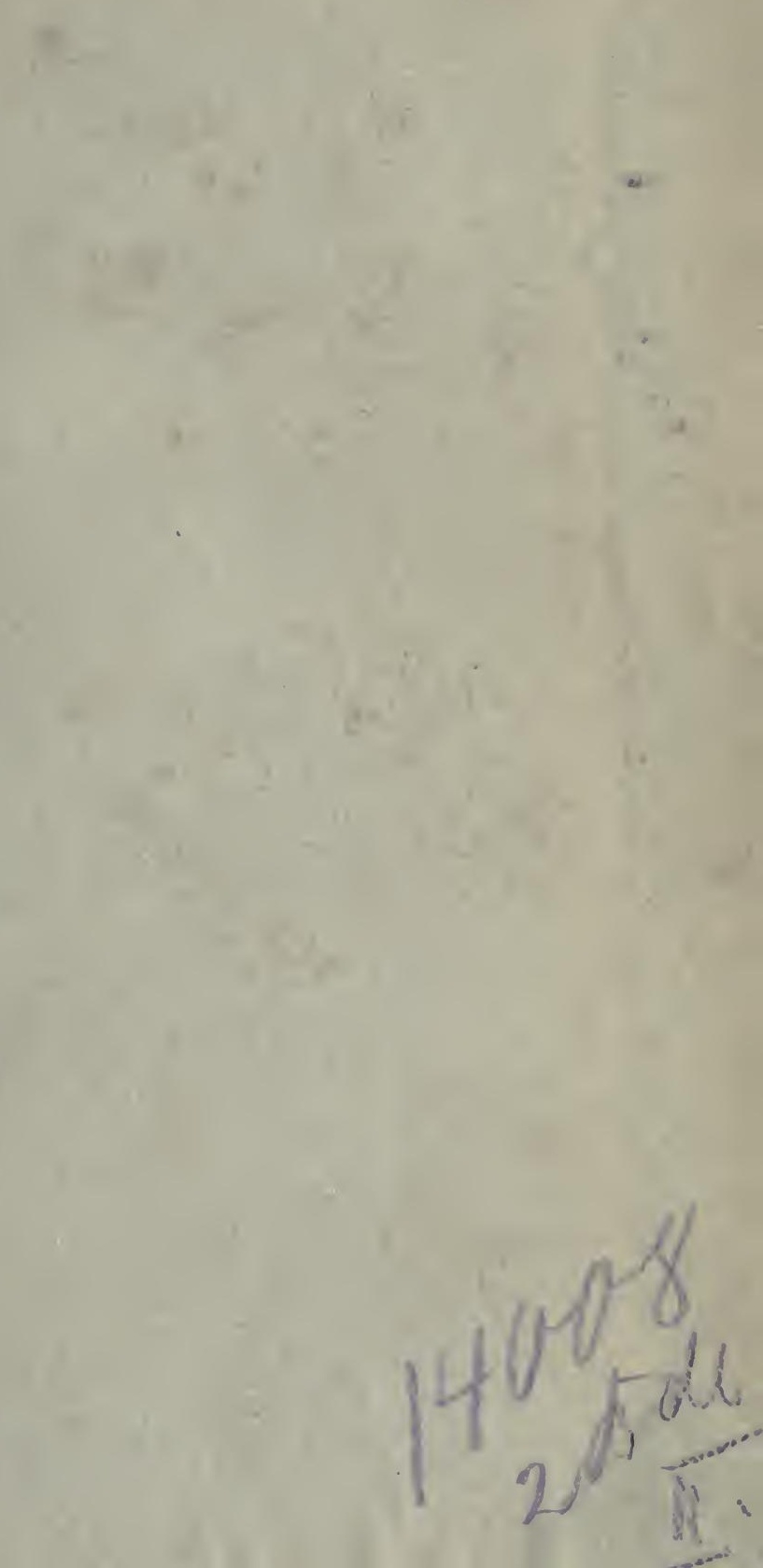
